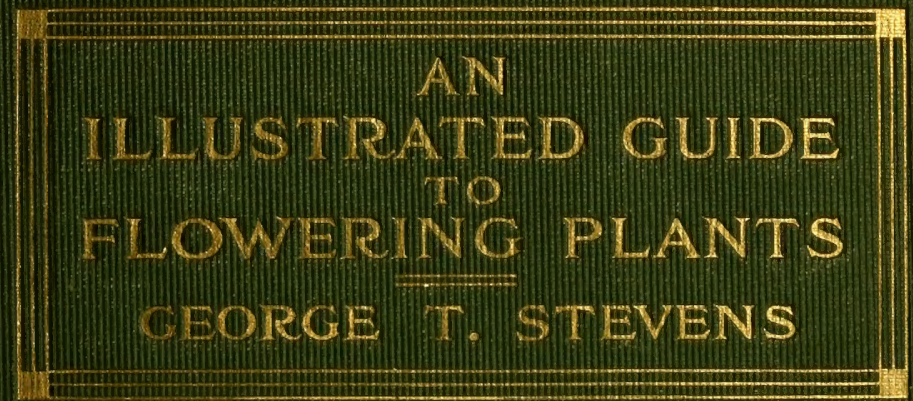



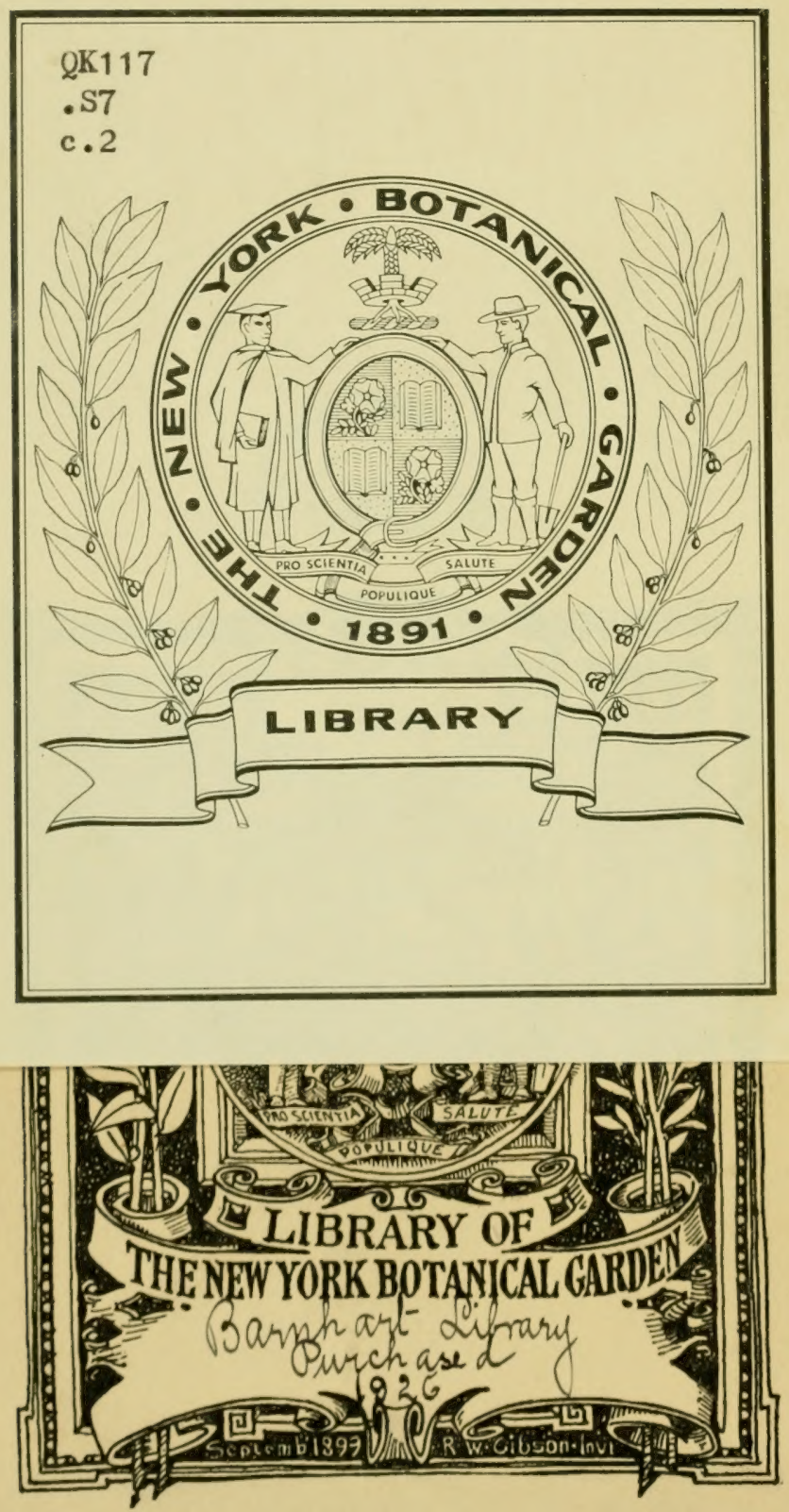

$\overline{Q H}^{\prime}$ 
AN ILLUSTRATED GUIDE TO THE FLOWERING PLANTS 



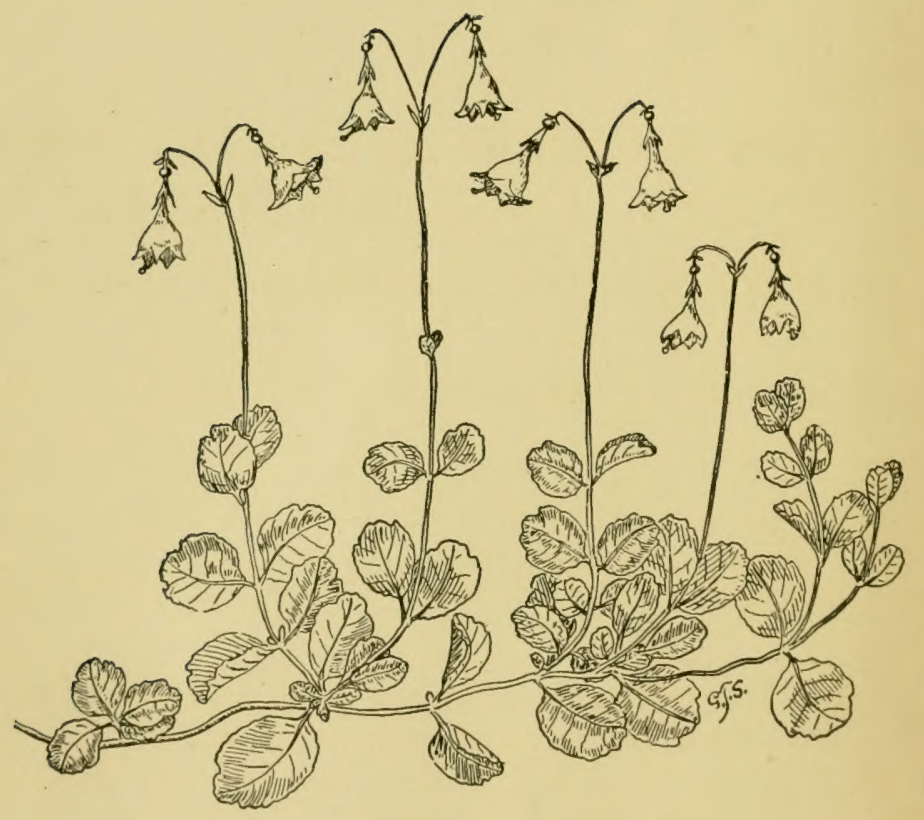

LINNAEA BOREALIS

Natural Size

This interesting and almost universally distributed little plant was selected by the Dutch botanist Gronovius, with the concurrence of Linnaeus, to be named in honor of the great Carl von Linnaeus, father of modern botany and indeed of modern systematic natural history. 


\title{
AN ILLUSTRATED GUIDE
}

\author{
TO THE
}

\section{FLOWERING PLANTS}

OF

\section{THE MIDDLE ATLANTIC AND NEW ENGLAND STATES}

(EXCEPTING THE GRASSES AND SEDGES)

THE DESCRIPTIVE TEXT WRITTEN IN FAMILIAR LANGUAGE

BY

GEORGE T. STEVENS, M.D., Ph.D.

WITH MORE THAN I8OO ILLUSTRATIONS

FROM DRAWINGS BY THE AUTHOR

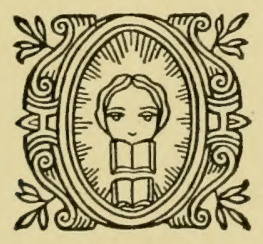

LIERARY

NEW YORA

He:

NEW YORK

DODD, MEAD AND COMPANY 
Copyright, 1910, BY GEORGE T. STEVENS

Published, June, 1910 


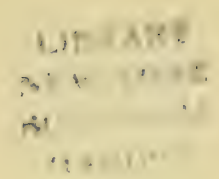

\section{PREFACE}

The purpose of this book is to furnish a practically complete handloook containing descriptions of the native flowering plants of the Northeastern United States, including not only the showy herbs but also the trees, shrubs and weeds growing native in that region and to adapt the work to the convenience and assistance of the very large and ever growing class of educated people who are interested in the study of this most attractive branch of natural history but who, by reason of unfamiliarity with the technical terms which have been in universal use for handbooks of botany, have absolutely no adequate aid in the prosecution of an agreeable and refining pursuit. While aiming to render the work available to the non-technical student, the arrangements and descriptions are intended to conform to the requirements of the technical botanist to the extent of furnishing a convenient handbook.

That there is a distinct and urgent demand for such a work is recognized not only by the cultured general public but also by professional botanists.

In reply to the question recently published in a botanical journal, "Why does not the subject of botany more often create a lasting interest?" a distinguished professor in one of our great universities replies: "All our botanical courses and our text books . . are too technical . . . they are written by technical botanists who have forgotten that they were ever young themselves."

The classification adopted in this work is, in the main, that of Professor Adolph Engler in his Sillabus der Pfanzenfamilien, conceded to be the latest and highest authority on this subject, yet, in a few instances in the interest of a more simplified arrangement, I have followed the classification of Professor Eichler.

By introducing the modern Orders as well as the Families of cplants I have hoped to familiarize the student with their natural c. relations, thus furnishing the observing beginner something of infinitely greater value than the empty linowledge of the names of a ferw plants. By thus giving a correct impression of the developmental or evolutionary relations between the different species, the beginner is soon prepared to recognize as an acquaintance and friend 


\section{PREFACE}

the plant which he or she meets for the first time. Its specific, or, if the term may be used, its baptismal name may hare to be sought in the genealogical record, the handbook, but the student already knows its family and its relations to the family by its general character.

In the preparation of the work I have made use of my very large private herbarium, a collection which has been the work of many years, but I have had constantly before me the works of the latest German, French and English authorities and I have as constantly consulted the American works of Professor Wood, Dr. Asa Gray and that by Messrs. Britton and Brown. Indeed, without the aid of this last named invaluable work the preparation of this book would have been difficult. For numerous data, including locality, season of blooming and other necessary knowledge, I am greatly indebter to this anthority. In the final revision of the manuscript the New Gray Manual has been freely consulted.

The illustrations have been drawn by myself, mostly from the fresh living plants, but a small number of the drawings $I$ have been obliged to make from the dried specimens in my herbarium. These drawings illustrate a very large proportion of our native plants, including nearly every species that the amateur is likely to meet.

The book includes two parts. The first part is an outline of structural botany intended to be sufficient to enable a beginner to use with advantage the second and main part.

'The work has been the oceupation of the hours of recreation from professional labor, a relaxation from the exacting demands of every-day routine of surgical practice and of the writing of professional books and papers, occupations which have filled the larger measuro of the time at my disposal. It has, however, been an agreeable task to turn from the severe tension of professional pursuits to the refreshing attractions of this delightful branch of natural science.

I am indelsted to Prof. Charles II. Peck, the New York State Botanist, for his kinkness in carefully examining the manuseript before it was placed in the hands of the printer and to the pul)lishers for the excellent manner in which the book has been brought out.

New Yonk,

George T. Stevens. 1910. 


\section{CONTENTS}

PAGE

Preface . . . . . . . . . . . . . . . 1

Outline of Strdctural Botany . . . . . . . . 3

Key to Natural Orders . . . . . . . . . . . . . 58

An Artificial Key to tile Families . . . . . . 71

Descriptive Flora . . . . . . . . . . . . 81

Explanation of Abbreviations of Names of Authorities 705

Index of Technical Najes . . . . . . . 707

INdex of CoMimon NaMIES . . . . . . . . . 739 



\section{PAR'T I}

\section{AN OUTLINE OF STRUCTURAL BOTANY}





\section{AN OUTLINE OF STRUCTURAL BOTANY}

IF we consider the characters of a plant from the point of view of its internal and ultimate structure we are oceupied with its Internal Morphology, an important and necessary study, which reveals a great variety of interesting facts all worthy of the attention of the student of nature.

So also if we examine the different phenomena which contribute to the development and growth of the plant, the branch of study known as Vegetable Physiology, we are engaged in inquiries relating to the actions and influences which contribute to the functions of growth and of reproduction and to the form of the plant in its various stages. In this branch of investigation we study the influence of light, of heat, of moisture and of many physical and chemical forces. This branch of botanical sturly is also most interesting and important, and both it and the study of internal morphology are essential to a well rounded knowledge of botany.

Necessary as are these branches of study to one who would acquire a full conception of the science of botany, a familiarity with them is not essential to the student who seeks principally to recognise the various plants which he may encounter in his excursions through fields and forests or along lakes or streams or who desires to form a collection of plants for study or amusement.

In the following pages it is the purpose to present only those facts respecting the External Morphology which will scrve as aids to the student in determining the names and places in elassification of the flowering plants which are found in the region selected.

While space does not admit here of a consideration of the two first mentioned branches of the study of botany and while it admits of only an outline of that branch necessary to aid in the determination of names and of classification of plants, the sturlent should be impressed with the importance of a wider knowledge of the science of vegetable life than that which can be acquired by the superficial acquaintance of plants which one may encounter or collect.

Books treating of both internal and external structural botany and of vegetable physiology are to be found in which the science is treated, some from an elementary standpoint, others from a most technical point of view. 
It is to such works that the student should resort according to the degree to which he would carry his study in order that his acquaintance with the vegetable world may become an intimate one of greatest interest.

\section{ORGANS OF VEGETATION}

The organs of vegetation consist of the root, the stem and the leaves, with those modifications of leaves consisting of the organs destined to reprorluce the species, the spore in non-flowering plants and the flower and fruit of flowering plants.

\section{THE ROOT}

The root is that part of the plant usually growing downward, whose office it is, especially, to absorb from its surrounding medium, most commonly the soil, the moisture and some other materials

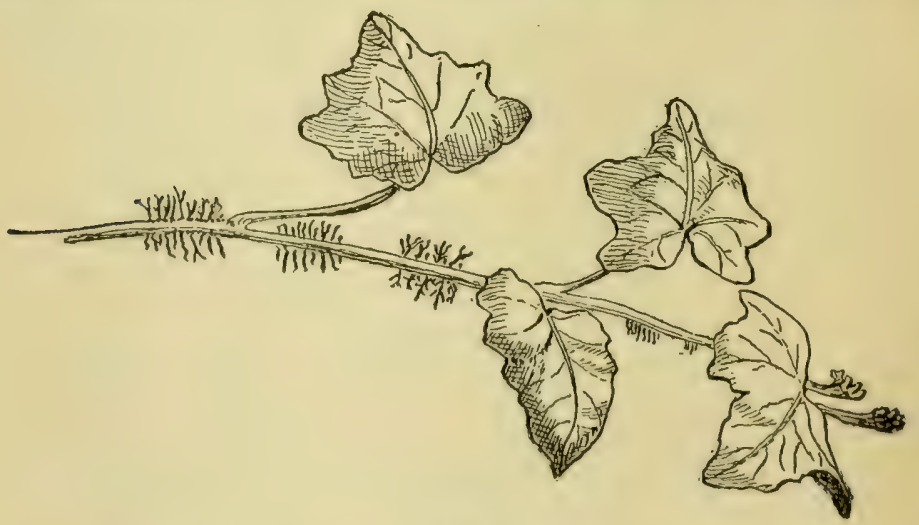

Fig. $x$

from which the plant derives certain elements of its nourishment. The root also, in a great majority of cases, serves to fix the plant in a position favorable to its existence and growth. It differs from the stem in not bearing leaves.

Some plants, notably many species of the orchid group in tropieal and semi-tropical climates and some trees, as for example the mangrove, are supplied with acrial rools. Some of these roots growing in the open air cling to the branches of trees, while other acrial roots hang ats long, more or less fleshy, pendants or cords exposed to the winds. Other acrial roots, arising irregularly in the course of the stem, as for cxample, those from the stem of the ivy (Fig. 1), and which have for their purpose, in general, the support of weak climbing stems, are linown as adventitous roots. Such roots grow- 
ing at regular intervals, as at the leaf axils, are lateral roots (Fig. 2).

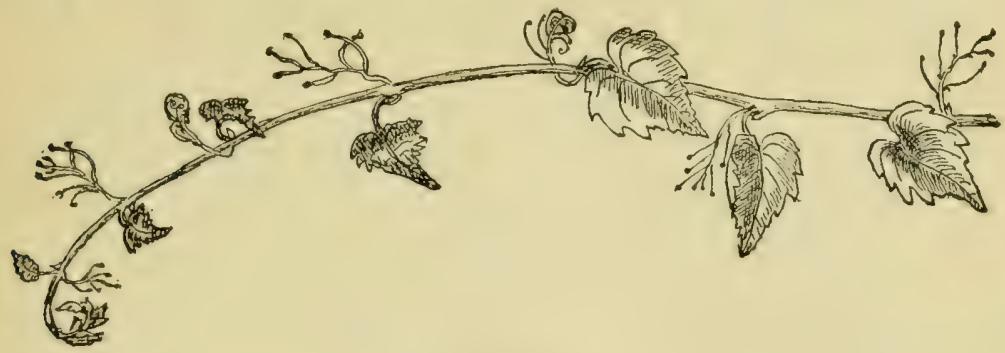

FIG. 2

Still other plants have roots swimming free in water on the surface of which the body of the plant floats.

Many plants of the non-flowering class are devoid of roots, but with rare exceptions, as, for example, the floating grains constitut-

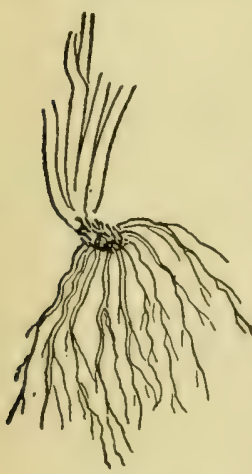
ing the plants of Wolffia, flowering plants are provided with roots, terrestrial, aerial or aquatic.

Although the roots of a plant have their origin in the radicle of the embryo they may exist in large numbers having the appearance of arising from as many distinct origins, but at the very base of the stem. Thus. among the plants of the great grass family, a group of roots seems to spring from the same FIG. 3-Fibrous rootslevel and to proceed downward of grass. with few or no branches. In fact these numerous roots have sprung from the radicle all at nearly the same level and have so far monopolized its structure that they practically, though not theoretically, arise from the base of the stem. Roots of this kind, arising in numbers from apparently the same level are known as compound or fibrous roots, a form common among plants with parallel-veined leaves-(monocotyledonous plants) (Fig. 3). In case of plants with net-veined leaves-dicotyle-

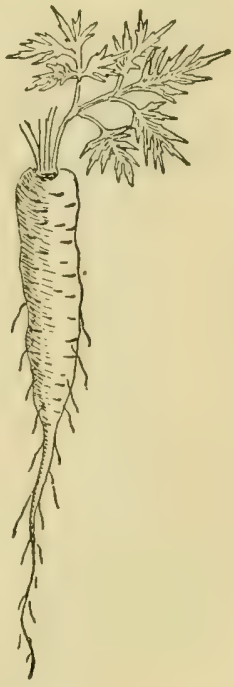

Fig. 4 donous plants) - the axis usually extends downward as a tap root. 
This tap root may continue as the principal axis, taking often the form which we see in the beet or carrot (Figr. 4), in which case it is said to be a fleshy root, or it may maintain a more slender form. In many cases roots become reservoirs of nutrient materials, in which cases they are thickened and fleshy, as in

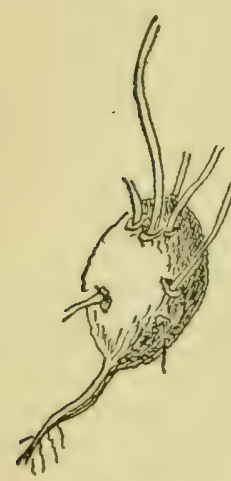

Fig. 5-Tuberous root of Apios. the case of the sweet potato, the peony and others (Fig. 5). These are tuberous roots, which differ from the tubers like the common potato in that this last uniformly bears buds or eyes, and is therefore a part of a modified stem. In the majority of plants whose leaves are net-veined, branches diverge from the tap root which may equal or exceed it in size and importance and the root then divides like the branches of a tree, in it is terminated by a little cap. This cap may be seen prants $6-T w 0$ without the aid of a glass in the little thread hanging Lemnabout

from the body of the duckmeat, Lemna (Fig. 6), which enlarged.

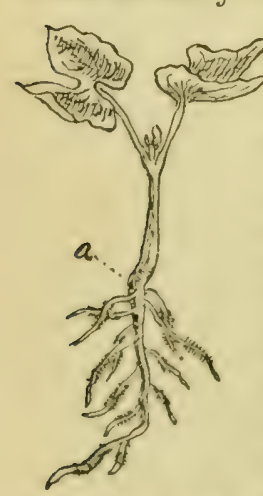

Fic. 7-Young Morning Glory. Between the two cotyleilons or "seed leaves" is scen the expand. ing plumule Along the course of the branching romts the "fiiluse purtion" is shuws. which case it is said to be ramose. This is the form assumed by most shrubs and trees and by a great number of herbs.

If we examine a young root more in detail we find that at its very extremity

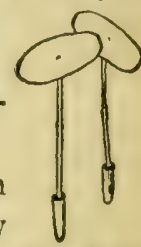
floats at the surface of the water. The of the pencap varies in length and in comparative dulous porthickness, but is always present and is root is seen the the advancing organ in the process of $\mathrm{more}$ nogrowth. Above the cap, with some ex- ticeable in ceptions, appears a more or less ex-plant than tencled in most tended ring of fine hairs, the pilose others. portion of the root (Fig. \%). It is by way of these hairs and not by way of the cap that such nutritive material as is taken from the soil, the water or the air, through the root is introduced into the circulation of the plant. $\Delta \mathrm{s}$ the root extents in length these hairs disalpuralr alsove and new ones appear, maintaining the ring in about a constant distance from the terminal (at]).

Whove the ring of hairs the root assumes a smonth appearanee. In the case of the roots of net-veined leaved plants the young rootlet appears to enter the root hy an opening, as there is 
seen at the point of mion a ring raised more or less above the surface of the root at that point.

'The part just below the stem is known as the caudex ( $a$ Fig. 1\%).

UNDERGROUND STEMS (ROOTSTOCKS, CORMS, BULBS, TUBERS)

There are certain modifications of the stem which by reason of their position, mostly under the soil, the absence of green coloring matter and by their appearance, are, by those who have not considered their nature sufficiently, regarded as roots.

Although these forms are technically morlified stems and not roots, we may consider them in this place as, to some extent, intermediate forms.

If we were to draw from the soft soil a stalk of the common quack grass we would observe at its foot a white cylindrical extension of the size of the stalk and that at intervals there spring fascicles of roots and also, if we have not broken the cylinder, that it is

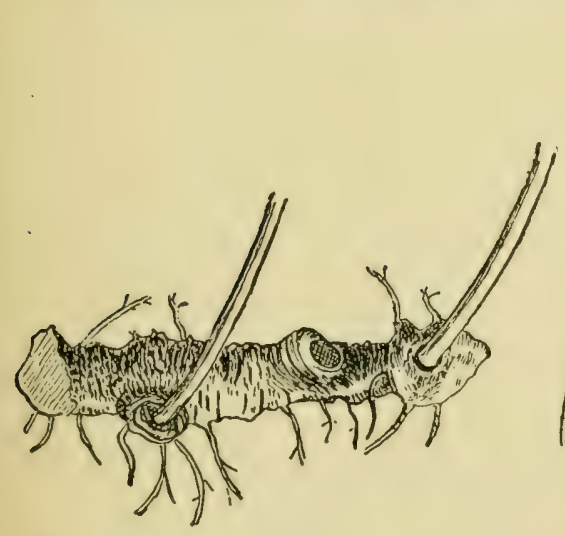

Fig. 8

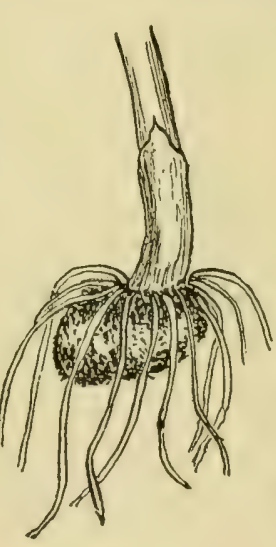

Fig. 9

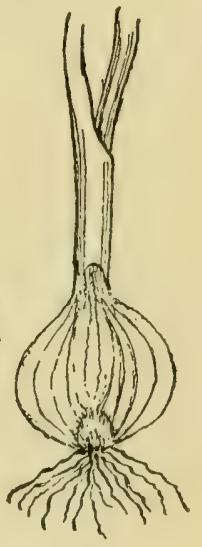

FIG. 10

Fig. 8-Rootstock of Solomon's Seal, showing the "seals" f'rom which arise the branches or aerial stems and the scars marking the point of growth of last year's aerial stems.

FIG. $9-$ Corm of Jack-in-the-Pulpit.

FIG. 1o-Bulb of Wild Onion.

terminated, not by the cap which terminates a root, but by a bud, in which it resembles a stem. Its course is horizontal beneath the soil and it may at intervals send up several stalks. This white cylinder is simply a subterranean stem modified by its position for the performance of its office. It is technically a rhizome, but in familiar language a rootstock. Such rootstocks are found in case of the iris, Solomon's Seal (Fig. 8), wild azalea and a great many other plants. 
Another form of modified stem is the corm (Fig. 9). It is a solid, rounded mass at the foot of the stem, often flattened, as it is in case of the Jack-in-the-pulpit. It resembles a bulb in form, but differs from it in structure.

The bulb, which occupies a position at the foot of the stem similar to that of the corm, consists of a compact mass of scales from the midst of which proceeds a stem (Fig. 10). Both the corm and the bulb give out roots from their base.

A tuber is an expansion of an underground stem in which is stored nutrient material which may be, after the dying down of the aerial part of the plant, supplied to the young buds which have been formed on the surface of the tulber. The common white potatoe is the hest example of such a tuber, its cyes being in fact so many buds which sprout in the spring and.are fed by the starehy material of the tuber.

Other forms of modified stems, runners, stolons and suckers are less underground forms than those above described and will be mentioned in connection with the stem.

\section{THE STEM}

As the root is usually the descending axis of the plant, so the stem is ordinarily the ascending axis, though, as we have seen above, the modified stem, the rootstock, the tuberous root, etc., are buried beneath the soil.

With exceptions of a few minute species all flowering plants are furnished with a stem, although in the case of those improperly sairl to be stemless-acaulescent-the stem is extremely short, consisting only of a narrow ring above the caulex of the root.

Thus the stem may vary in extent from the simple ring above the root to the height of a giant sequoia.

The young stems of most plants bear, at more or less irregular intervals, leaves and buds. If we examine the young twig of a birch we notice that the distance between the leaves diminishes toward the onter extremity until at the end we find a terminal burl which is, in lact, a collection of rurlimentary leares often covered by sales, thrmedres modified leaves, at the point at which the future growth is to take place. At the axil of each leaf and just above we motice a small top-shaped body, a lateral but. It is destined to jut forth as a branch at a future time. The future branches, of which these lateral buds are the promise, will them- 
selves bear leaves and other buds. When a bud is formed not terminal nor at a leaf axil it is an extra axillary bud, or if in irregular order or at intermediate points, it is an adventive bud.

The leares usually arise from the stem in a certain fixed order, depending upon the species of plant, or the order of arrangement governed by a general law. In case of the presence of adventive buds or branches the orderly disposition of the leaves may be materially disturbed.

The points, or more exactly, the transverse planes, marking the insertion of the leaves are called nodes. These nodes are very clearly shown in the stems of grasses. The space comprised between two successive nodes is an internode (Fig. 11).

Upon the relative positions of axillary and terminal buds depend the divisions of the stem. A true bifurcation or forking from exactly opposite buds is rare, especially in case of the higher plants, but a false bifurcation from buds situated in close proximity is much more common.

Naturally the character of the divisions or bifurcations will determine the general form or port of the plant. If the terminal bud con-

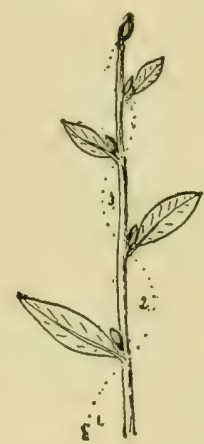

Fic. II - Diagram indicating the rela. tive distances between the buds $-1,2,3$, internodes. tinues to hold a considerable lead, the lateral buds sending out branches in their order the plant will assume a comparatively regular spire-top form such as we observe in case of the fir tree. But if a bud close to the terminal bud sends out a branch about equalling the latter and if the process is repeated indefinitely we have a widely branching stem, the rounded or flat top, such as is shown by the apple tree.

The stem may be cylindric, as it is in many grasses, triangular as in some sedges, fluted, quadrangular or flattened.

From the stem may arise imperfectly developed branches, woody and sharp, which are spines or thorns, these differ from the more superficial prickles, such as are found on the stem of the rose and many other plants, and which arise entirely from the bark. The stem is also modified to form tendrits, as we find them on the vine of the grape, though some tendrils are modified leaf-forms, as we find them in many species of the pea family, as well as in some other plants. 
The stems of flowering plants may be divided into two classes upon which divisions are in large measure founded the two great groups of plants known as Endogenous and Exogenous plants.

In the first of these groups, endogens, including the grasses, palms, liliaceous and many other plants, the accretion of growth is from within the stem. This latter does not become thicker as it extends in height. This statement will not appear correct when one remembers that the stalk of Indian corn is nearly or quite an inch in diameter at maturity, while in its early stage it has only a fraction of that diameter. This is not because the diameter of the first sprout has materially increased, but that successive joints or nodes have arisen from the root, each of greater diameter than the one preceding it. This form of growth may be observed in the grasses, rushes and all of the plants known as monocotylectonous plants. On the other hand, in another great group of plants, the exogens, the growth of the stem is from within outward. The stem of the ordinary tree of temperate climates increases in diameter in proportion to its growth, the accretion being marle externally. This is true of most of the species of herbs growing in the same climate. In the stem of the endogen there is no distinction of bark, wood and pith, but in the stem of the exogen this distinction is clear, at least in the very young plant. The distinction of the bark from the wood is evident throughout the growth of the plant.

Upon the character and size of the stem depend the division of plants into herbs, shrubs and trees.

Plants, the stems of which do not become woody and which die down to the ground at the close of the season, or after flowering, are known as herbs, while those the stems of which become woody or which are persistent from year to year, are, if of small size when of mature growth, shrubs, but if the plant reaches or exceeds about twenty feet when fully grown it is a tree.

While in the greatest number of species of plants the stem rises from the ground, standing erect or nearly so by its own strength,

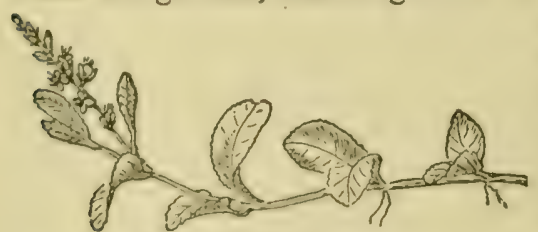

FIG. 12

upright stems, there are others which have too little strength thus to rise independently. Their length is usually out of proportion to their diameter to enable them to stand upright without assistance. Some of these are procumbent stems which creep along the erround like the weak stem of the common blue veronica (Fig. 1\%), its lead 
ascending at length, neither quite erect nor prostrate like its proximate part; or like the strawberry (Fig. 13), which sends out long slender, almost horizontal stems, known as runners, each of which at length puts forth a cluster of leaves and a fasciculus of roots which find their

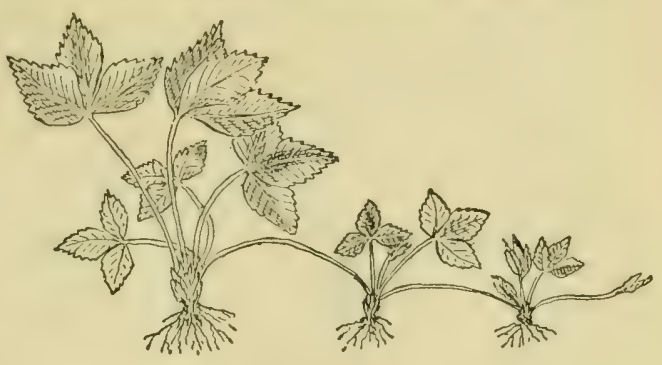

FIG. 13 way beneath the soil and then push out another or several runners from this new station. Runners less slender, such as those

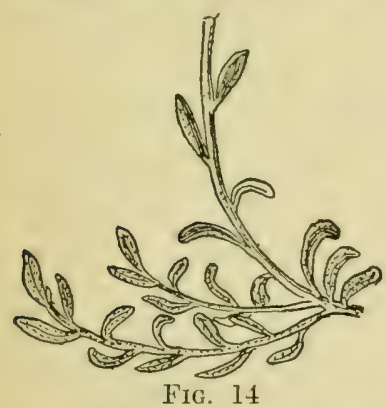
from the common antennaria, are called stolons (Fig. 14). A somewhat different form of prostrate stem is that of the creeping loosestrife (Lysimachia), which lies flat upon the ground and throws out its fascicles of rootlets at the leaf-nodes (Fig. 15).

Some of the stems of many shrubs and even of some trees droop, touching the soil at length and, taking root, give rise to new plants in this manner. The drooping stems of the black raspberry are examples of this form of stem among shrubs, those of the banyan among trees.

But these weak stems do not in all cases run along the ground nor droop to take root like those just mentioned. Some of these weak stems are held in more

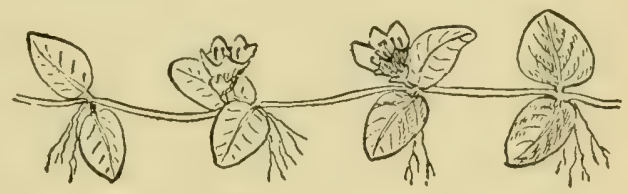

FIg. 15 or less upright positions by means of tendrils, which may proceed directly from the stem as modified branches, as in case of the grape vine, or which are modified leaf stalks, as we find them in case of the clematis, the pea, etc., or the stem may be held by prickers, as in case of galiums. Still other weak stems wind about more erect plants or other bodies, of which the hop, the bindweed, the convolulus and many trailing vines are examples (Fig. 16). 


\section{THE LEAF}

In general the leaf is the digestive organ of the higher plants, for the principal food of plants is carbonic acid which, within the

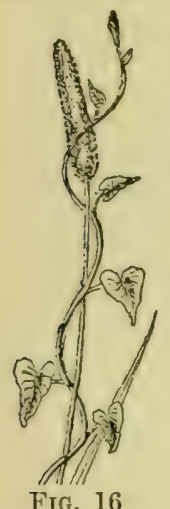

FIG. 16

leaf, is converted into starch with elements which are supplied from the roots. That it contributes to the beauty and interest of the plant is an obvious fact. Of its color and of its physiology we need not here speak, but of the forms which the leaf assumes and of the arrangement of the leaves it is necessary to take note, since on these forms and on these arrangements we must base many of the comparisons between different groups of plants.

In most of the orders of plants usually known as the lower orders leaves are not found, and even in a few of the plants which come under our observation as flowering plants, the leaves may be only rudimentary, yet we may regard the leaf as an essential organ of the class of plants which is to be described in this work.

We may take the leaf of the buttercup as a study of the leaf structure (Fig. 17).

We find then, first, the broad expanse: the blade; second, the slender, yet thicker, somewhat cylindric organ, the petiole, or leaf-stalk, and third, and finally, the base of the petiole, which, in case of the buttercup, nearly or quite surrounds the stem to which it is closely attached.

These three parts constitute the typical leaf, but not all leaves are typical. In the case of many leaves, for example, the broadened base of the leaf stem is wanting and the petiole is attached to the stem by a narrow base, which may or may not be somewhat more expanded than the column of the petiole. Again, the petiole may be almost completely absent and the leaf blade is apparently attached directly to the stem without the intervention of the petiole. 'The leaf is

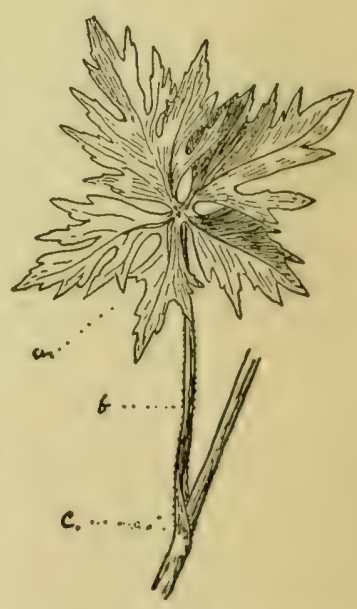

Fig, 17-Leaf of Ranuncu. Jus acris-a, the blade; $\mathrm{b}$, the petiole or leaf-stalk; c, the base. then said to be sessile, as flowers are said to be sessile when there is no pedicle or flower stem. 
So the leaf may consist of the blade and the base without the petiole, as we see it in the long and narrow blade of grass with its base clasping the stem without an intermediate part representing a petiole.

Beyond these three very general forms there are various other modifications such as the formation of a hollow tube by the petiole, as in the Sarracenia, or of the simple awl-like or needle-like forms of the pine leaves or the thread-like leaves of many aquatic plants, and in some plants the form and general structure of the leaf is modified according to the medium in which it exists. Thus some species of Sagittaria have thread-like leaves which are entirely submersed, living wholly below the surface of the water ; broad, rounded blades floating upon the surface of water and sharply angled arrow-like leaves which rise above the water's surface. Many instances of this polymorphism might be mentioned, the modifications being due primarily to the adaptation of the leaf to divers circumstances.

A great, and in classification, a very important, division in the general structure of leaves is that which distinguishes the so-called parallel-veined leaves from the net-veined leaves.

With the former, the parallel-reined leaf, is commonly associated the seed of a single cotyledon or lobe; while with the net-veined leaf is usually associated the two-loberl or dicotyledoned seed and upon these characters are founded the first great division in the class of flowering plants, the monocotyledonous and the dicotyledonous angiosperms, that is, the one-lobed and the two-lobed sub-groups of the class of plants having the ovules within an enclosing ovary.

These striking characteristics in the construction of the leaves permit us, in a great majority of cases, to judge without further consideration whether a given plant belongs to one or the other of these two great groups.

Exceptions, as to most rules, occur here, for there are plants with net-veined leaves belonging to the great group of monocotyledons, for example; the trilliums, which are members of the lily family, have net veins. Then also a few plants belonging to the group of dicotyledons have apparently parallel veins.

Notwithstanding the few exceptions it becomes easy after a little observation to determine with which of the great sub-classes we have to do.

Returning to our buttercup leaf, we find that not only do the veins of the blade diverge and cross among themselves, but that the blade is deeply cut into several segments or lobes and that starting from the point of attachment of the petiole there radiate, 
fan-like, as many strong ribs or veins as there are lobes to the leaf, and that these radiating veins send out a network of smaller veins.

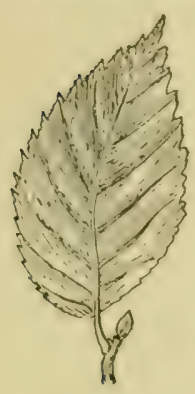

If we compare this with the leaf of the elm (Fig. 18), we see that in the latter a strong rib or vein runs from end to end through the center of the leaf, while other smaller veins diverge on either side and at fairly regular distances, like the barbs of a feather. Because, in case of the ranunculus leaf and others constructed on a similar plan, the veins radiate something like the fingers of the hand when spread out, such leaves are said to be palmately veined, while in the case of the elm leaf and others constructed on the feather plan they are said to be pinnately veined or feather veined.

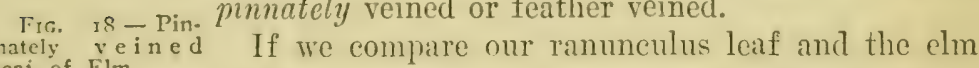
leai of Elm.

leaf with a leaf from the common plantain which grows so freely about country dooryards and in waste places we observe that in case of the elm and the buttercup the borters are not continuous, one being broken by very deep interruptions, the other only by the depth of the sharp teeth. On the other hand, the horders of the plantain leaf are continuous. Such a border is said to be entire, while the others are interrupted. It is somewhat rare to find blarles of the palmate or feather-veined leaves with entire borders, though the entire border is characteristic of the parallelveined leaf.

As it is well known, the leaf blade assumes many forms, most of which liave a resemblance to familiar objects, for example: to the outline of an exgr of an arrow-head; of a spatula, ete, and diagrams representing several of these forms are given in the plate opposite the table which is to follow.

\section{Compound Leaves}

The leaf, as we have thus far examined it, has only the three elemernts which were at first mentioned, namely, the blarle, the fretiole and the base. Such a leaf is known as a simple leaf. But we ofton fincl leaves which are apparently more complex; for example, the leaf of the horse-chestnut is composed of five separate bades radiating from a stout common leaf-stalk or petiole. This 
petiole is not a branch or twig of the tree from which five leaves might arise, for when the leaf is ripe in autumn this common petiole looses its hold upon the stem and it and its five blades fall to the ground together. The petiole and the five blades then constitute a single leaf and the five blarles are not five leaves, but so many leaflets of a compound leaf. Another example of compound leaf is found in that of the locust tree, where the petiole proceeds as a main stem, on each side of which is a series of oval or rounded leaflets, the petiole terminating as the midvein of an odd leaflet. These rounded blarles are no more separate leaves than are the radiating blades of the horse-chestnut, but are elements of the compound leaf. In the case of the radiating leaflets the arrangement is known as a palmately compound leaf ; while in the case where the secondary petioles branch from the main leaf-stalk like the barbs of a feather it is a pinnately compound leaf. Hence it will be seen that similar terms are used both for the simple and compound leaf and this is a fact which the amateur should not fail to comprehend, that while the terms of science may not be familiar the true scientist employs the least number of new terms that it is possible to use in the necessary description and classification of his object.

We find many other examples of compound leaves, as in the clover with its three leaflets, most of the potentillas with their palmate five leaflets and many species of the pea family, with their pinnate double rows of leaflets.

\section{STIPULES}

$\Lambda$ the base of the leaf-stalk or of the blade of many leaves are found leaf-like appendages having often the color and general character of a leaf but differing usually in form and size from the leaf itself. Such appendages are found at the foot of the petiole of a rose leaf, where, starting from the very base of the petiole it extends along its column as a sort of fringed collar.

The stipules constitute a very important feature of the leaf from the point of view of the determination of different species, for a great many leaves are without stipules, while some have very conspicuous ones. About the bud of the magnolia two large brown stipules form a thick protecting cover, which falls as the leaf ex- 
pands. About the stem of the polygons the stipules take the form of tall collars while in the pea family the stipules in some species exceed the leaf in size and among the pondweeds it is often a long grass-like appendage.

Referring to the diagrams on the succeeding page, we find a number of forms which, while each may not precisely represent all the leaves which are classed as belonging to that particular

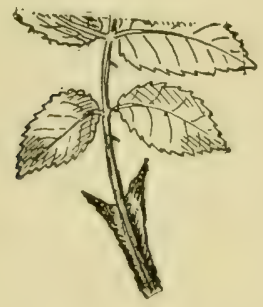

Fig. 19-Stipules of Rose leaf.

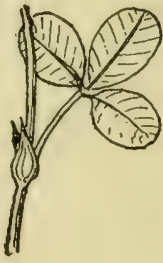

Frg. 20-Stipules of Clover.

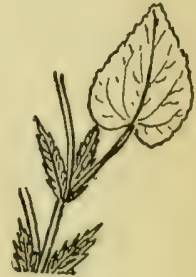

FIG. 21 -Stipules of Viola arenaria.

form, are all sufficiently typical to indicate the class of the leafblade which might be under observation, provided the leaf under consideration is not compound.

We may conveniently arrange them in the following table:

TABLE OF SIMPLE FEATHER VEINED LEAF-FORMS

I

'A single principal vein traverses the main axis of the leaf

The tissues intervening between the veinlets fully or mainly developed . . . Feather Veined Forms. P'innate-Veined

The middle veinlet exceeds the others in length, the veinlets above and below becoming gradually shorter.

The breadth of the widest part is:

About equal to the length of the leaf (Fig. 1) . Orbicular About $\frac{2}{3}$ to $\frac{3}{4}$ the length (Fig. 2) . . . . . . Oval About $\frac{1}{2}$ the length (Fig. 3) . . . . . . . . Elliptic About $\frac{1}{4}$ to $\frac{1}{3}$ the length (Fig. 4) . . . . . Oblong

The veinlets of the lower third exceed the other side veinlets, which become gradually shorter above and below.

The breadth of the widest part is:

Nearly or quite equal to the length (Nig. 6) . . Doltoid About $\frac{2}{3}$ the length, egg-shaped (Fig. 7) . . . Ovate About $\frac{7}{3}$ the length or less, laneeshaped (Fig. s) Lanceolate 

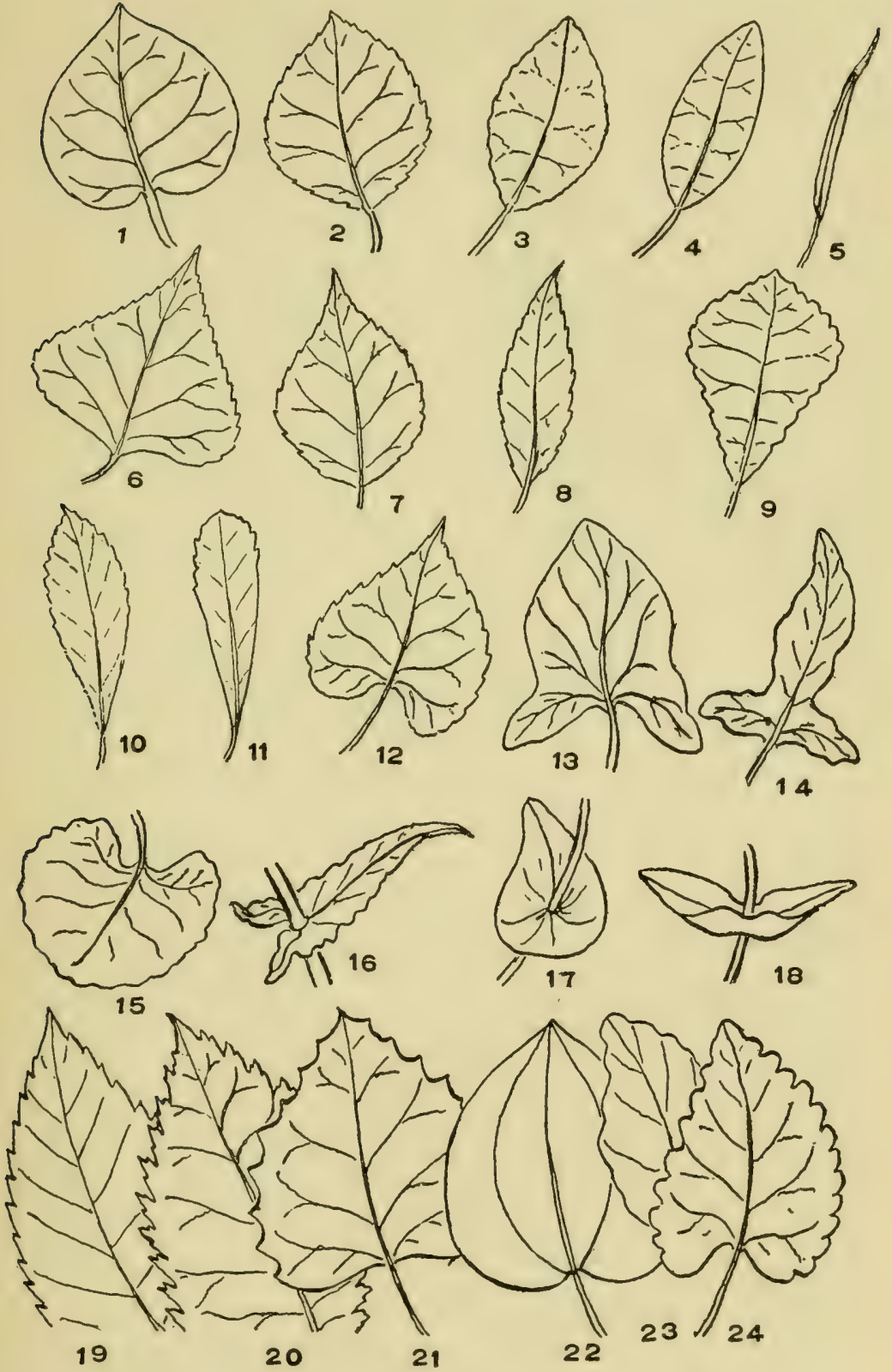
The side veinlets all very short (Fig. 5) . . . . . Linear

The reinlets of the upper third exceed the others, which become gradually shorter above and below.

The widest part is:

About $\frac{1}{2}$ the length, poar-shaped; inversely egg-shaped

(Fig. 9) - . - Obovate

About $\frac{1}{3}$ the length, inversely lance-shaped (Fig. 10)

About $\frac{1}{*}$ that of the length or less spatula-formed

(Fig. 11) . . . . . . . . . Spatulate

The lower veinlets protrude notably outward beyond the general outline or conspicuously backward.

The apex sharp, the two sides of the base rounded. Heartshaped (Fig. 12) . . . . . . . . . Cordate

The apex sharp, the general shape triangular, the two posterior triangular lobes pointing backward, not outward. Arrow-head-shaped (Fig. 13) . . . . . . Sagittate

General form triangular, but the lower part of the leaf suddenly widening into two lateral triangular lobes. Halberdshaped (Fig. 14) . . . . . . . . . . Hastate

The leaf blate of various forms, the posterior lobes protruding backward and inward. Ear-shaped (Fig. 16)

The posterior reinlets directed outward, backward and then inward, the leaf blade enclosing the stem (Fig. 17) Perfoliate The veinlets of each of two opposite leaves projecting backward, the two leaf blades uniting around the stem (Fig. 18) . . . . . . . . . . Connate The midlle veinlet shorter than the width of the leaf blade, the base heart-shaped. Kidney-formed (Fig. 15) . Reniform

There is a single principal vein, hut the intervening tissue between the reinlets may be so irregularly developed as to give to the hade the aflearance of having been deeply ('ut into lobes and sinuses. Such forms are known as pimated leaves.

1. The tissue sharply cut between the veinlets about $\frac{1}{2}$ way to the midvein. Feather-cleft . . . . . . . Pimnatifid

A pinmatifir leat with rounded lobes and sinuses like that of the White Oak (Fig. 29) . . . . . . . . . Sinuate

With its lobes or seconents pointing backwart (Fig. 31) Rumeinale The terminal segment large, broad and rounded. Lyresliaped (Fig. 30) . . . . . . . . . . . . Lyrate

2. Ihe tissues between the winlets cut out nearly to the midrein, the leaf is said to be (Fig. 32) . . . . . Pinnately Parted

\section{III}

Thres or more principal veins radiate from the leaf stem and traverse the leaf hlade.

Palmate veincd 
1. The general outline of the leaf nearly or quite complete.

General form rounded, broader than long, the posterior parts extending into two rounded lobes. Kidney-formed (Fig. 15)

Several principal veins radiating in all directions, the leaf stem inserted in the midst of the blade. Shield-shaped (Fig. 25)

2. General outline cut into deep divisions by deficiency of tissue between the principal veins, forming separate leaflets ( $\mathrm{Fig}$. 35)

Palmate-leaved Principal veins 3 (Fig. 33) . . . . . . . Trilobate Principal reins 5 (Fig. 34) . . . . . . . Five-lobed

In these pinnately cleft leaves the intervening tissue is somewhat or largely wanting but in certain leaves this absence of intervening tissue is carricl to the extent that the segments or lobes appear like quite perfect and independent leaves. An important difference will however be observed between such a group of apparently perfect leaves and a really perfect leaf.

If we separate by force a perfect leaf at the base of the leaf-stalk from the branch, it falls as a single blade as it does also in autumn by ripening. But if we separate the base of the leaf-stalk of one of these groups the whole group falls as did in the other case the single leaf blade.

These groups of leaflets, all attached to a common leaf-stalk or petiole are known as Compound Leaves and a few forms are shown by the following table.

If the number of leaflets is reduced to two the leaf is . . Binate

If there are three leaflets arranged in a palmate form the leaf is

said to be ternate (Fig. 33) Trifoliate

If there are more than three leaflets, all arising at the end of the leaf stem, as in that of the Horse Chestnut, it is Hand-shaped (Fig. 34) . . . . . . . . . . . Palmately Compound

But if the leaflets are arranged along each side of a common leafstalk or petiole the leaf is (Fig. 35) . . Pinnately Compound

If the number of leaflets is exactly the same on each side of the leaf stem and there is not an odd one at the end, the leaf is

But if there is an odd leaf at the end it is . . Odd Pinnate

In the description of plants the point or apex of the leaf often forms an important feature for differentiation. 
When the point ends with an acute angle long drawn out, it is

(Fig. 3(i) . . . . . . . . . . Acuminate If the angle is sharp but not long and tapering it is (Fig. 3i) Acute But if the point is rounded it is (Fig. 38) . . . . . Obtuse If terminated by a nearly straight edge, as though cut off, it is

(Fig. 39) . . . . . . . . . . . . . Truncate $A$ leaf notched at the apex is (Fig. 40) . . . . Emarginate If terminated by a hard bristly point it is (Fig. 41) . Mucronate

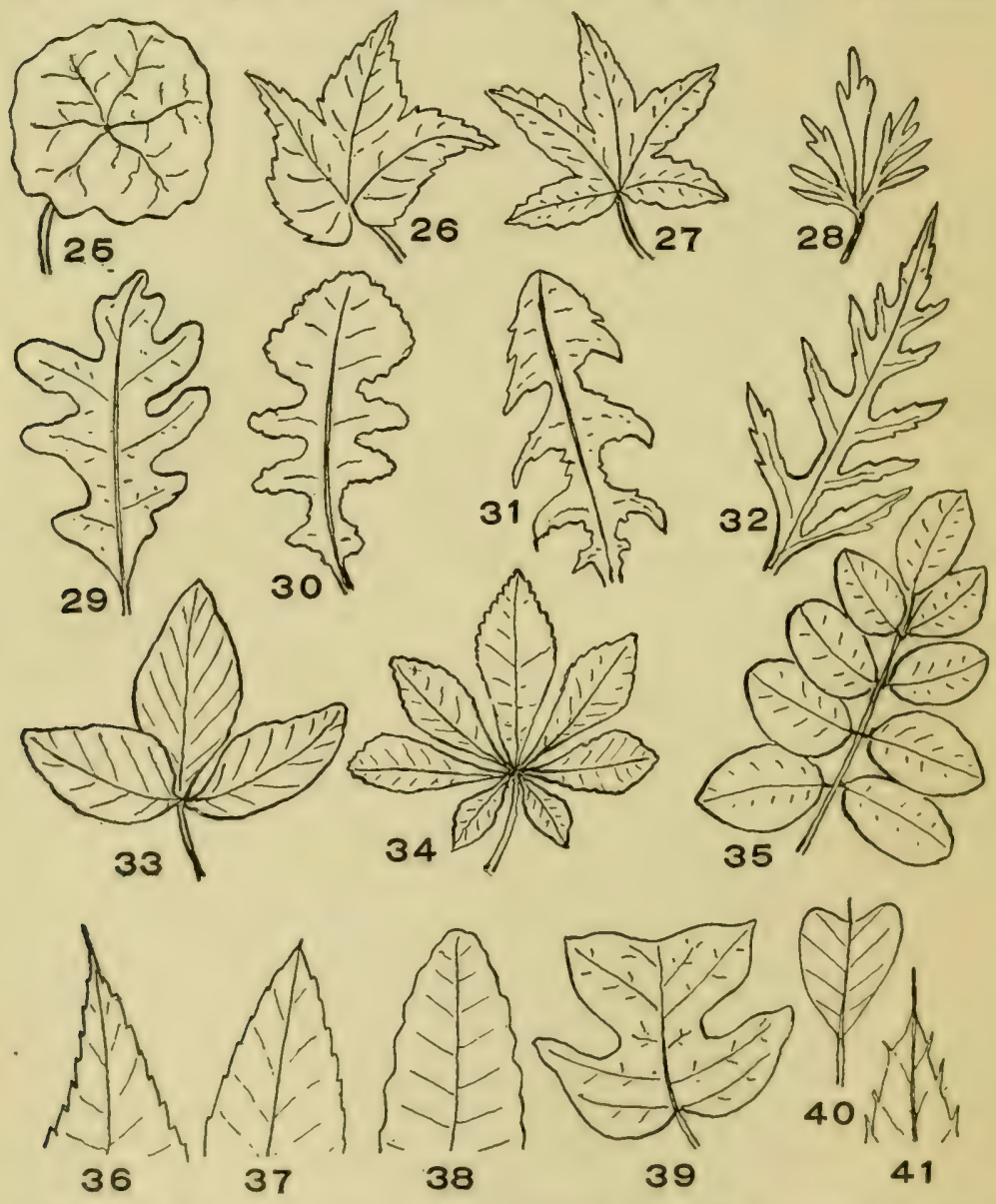

'The leaf margins are also important in differentiation. 'The margin is said to be:

When it is divided into sharp teeth like those of a saw (Fig. 19) 
When these teeth are also serrate the margin is (Fig. 20)

If the margin is formed of teeth with concave outlines as at Fig.

21, it is . . . . . . . . . . . . . . . Dentate

When the margin is complete as at Fig. 22, it is . . . Entire

When the border is formed of rounded teeth with convex outline

it is (Fig. 2t) . . . . . . . . . . . . . Crenate

The diminutive terms anticulate and crenulate are used in place of dentate and crenate when the teeth are very small.

\section{ARRANGEMENT OF LEAVES.}

The disposition of the leaves upon the stem constitutes that part of botanical science technically known as Pliyllotaxy, but to the non-technical it is the Arrangement of Leaves.

Every part of botanical science is of great interest to one who intelligently investigates it and this science of Phyllotaxy is one which richly repays the investigator. But in this place we can only refer to the conspicuous facts of three forms of arrangement. They are:

1st. Alternate, when the leaves are inserted singly at each node of the stem. In each case the insertion may appear to be first on one side of the stem and next on the exact oplosite side. More frequently they appear to be inserted in a spiral line and this, as a matter of fact, is the real insertion, even when the leaves appear first on one then on the opposite side.

2d. They are said to be opposite when they are inserted in pairs, one exactly opposite the other on the stem.

3d. They are in whorls or verticils, whorled or verticillate, when three or more are inserted at the same node, forming a whorl about the stem.

Upon some stems leaves which are in fact alternate are so closely disposed that it is difficult to see their alternate arrangement. In such case the leaves are said to be scattered.

\section{THE FLOWER}

To the ordinary observer a flower is that gracefully formed group of colored petals and stamens surrounded at its base by a rosette of green bracts, which by its vivid hues, attractive shape and pleasant perfume seems to constitute the crowning glory of a plant.

A more exact and perhaps a more useful conception of a flower is that which defines it as an organ essential to the inception and the perfection of the seed and therefore to the perpetuation of the plant species.

In this sense the flower may not consist of gracefully formed 
and brightly colored parts. It may indeed consist of a single stamen lodged against the stem in the axil of a leaf or of a pistil unprotected by any envelope. In such a case the grace and brilliancy of the flower as it is usually thought of, is absent but at least one of the two essential elements necessary to the perpetuation of the species is present and in the view of the botanist this constitutes a flower.

$\Lambda$ flower, then, consists of a more or less complicated apparatus essential to the inception and perfection of the seed.

Two elements are absolutely essential to this process of reproduction of what are known as the higher plants, flowering plants. One is found in the pistil, at the base of which, or constituting the whole of which, is the ovary in which is found the ovule or ovules or, eventually, the developed seed.

The other element is seen in the stamen which furnishes the pollen which must be applied to the pistil in order to fertilize it and without which the ovules can not develop into seeds.

The transference of this pollen from the stamen to the pistil may be aflected by the wind, by water, by insects or by other agencies.

Either of these elements, as we have scen, may be found alone, unacempanied by the other element or by the conspicuous parts usually regarded as the flower. The flexil)le "pussy" of a willow consists of a great number of single flowers, each consisting of a pair of stamens at the base of which there is a single colorless

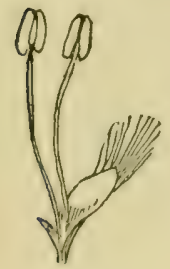

Fig. 22

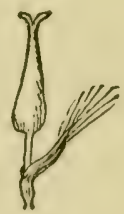

FIG. 23

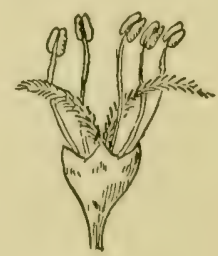

FiG. 24

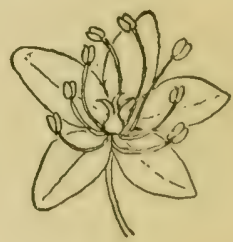

Fig. 25

bract, or if the catkin is made up of pistillate flowers each flower consists of a single pistil with its bract (Figs. 2.2 and 23). But individuals of either kind, pistils or stamens, may unite in a group of conciclerable mumbers or again, pistils and stamens may grow tocrether in the same eroup (Fig. 21). There may be a single stamen and a single pistil or a single pistil with several stamens or there maty be sereral of each in association within the same flower.

Examples in which many staminate flowers are found in one group and many pistillate flowers in another are found in the 
willows and poplars. If the "pussies" of the willows are examined with a little care it will be seen that the soft gray fur of a catkin from one tree covers only staminate flowers while the less smooth catkin from another tree covers exclusively pistillate flowers.

An excellent example of a plant having both staminate and pistillate flowers, each in separate groups is found in the common Maize or Indian Corn. ${ }^{1}$ In this case the tall "tassel" terminates the stalk and spreads into many almost horizontal branches each bearing a great number of staminate flowers. Below, at the side of the stalk, is a husky envelope from which protrudes a bundle of long slender filaments constituting the "silk." Each of these green filaments is the extended portion of a pistillate flower, or more exactly, of two such flowers for in this case two pistils unite as one. When these silky filaments have arrived at the proper stage for fertilization or pollination the wind wafts some of the pollen grains from the tassel of the plant or from a neighboring plant which falls upon the silky filaments and thus each fiber becomes pollinated and the conditions of growth of the individual seeds are supplied when each filament has been subjected to the action of the pollen.

Examples of extremely simple flower's in which both stamens and pistils are found in the same group, ${ }^{2}$ are found in some of the aquatic plants such as the Zanichella (Fig. 26) of the frech ponds where one or two pistils are situated at the axil of a leaf between two stamens. This simple arrangement constitutes the entire flower and indeed all the elements necessary to the development of the seed.

When the flower is thus destitute of any floral envelope, naked, ${ }^{3}$ it is usually the case that the pollination is effected by the agency of the wind or by water.

In the more conspicuous flowers that which gives them their character as blooms, the ornamental part, is the perianth.

${ }^{1}$ Linnaeus called plants having groups of staminate flowers only on one plant and pistillate flowers only on another of the same species Dioeceous (living in two houses), but when such separate groups are found on the same plant he called the plant Monoeceous (one house). Jussieu, a later botanist, called plants having sta. mens in one flower and pistils in another Diclinous and those having the stamens and pistils grouped in the same flower Monoclinous.

When diclinous and monoclinous flowers are found on the same plant the plant is said to be Polygamous. Flowers having both stamens and pistils are Hermaphrodite.

${ }^{2}$ Such flowers are, in the technical sense perfect, because they contain both the elements for the perfection of the seed. They are not, however, complete, because they do not have the appendages of the higher orders of flowers, the calyx and corolla.

${ }^{3}$ Flowers without a calyx or a corolla are apetalous or, more technically achlamyde. ous, words which in the technical works on systematic botany are important and not unfrequently used. 
When this is complete it consists of two circles of organs (Fig. 28). The outer one which is generally, though not always, green called the calyx, is almost always divided, either partly or completely, into several parts known as sepals. These green sepals are well seen in the case of the rose where each becomes more or less sub-divided and thus more ornamental. The inner circle of the perianth is known as the corolla and when this consists of several divisions the parts are called petals.

In many flowers the petals remain distinct from each other ${ }^{4}$ while in other cases the petals are united showing but a single expansion since all the members are blended at their elges as we see the union in the harebell or in the convolvulus.

The petals of a flower are in most cases symmetrical as are other

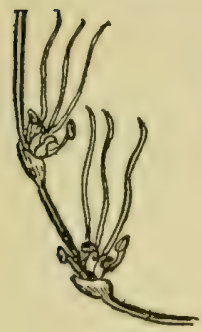

26

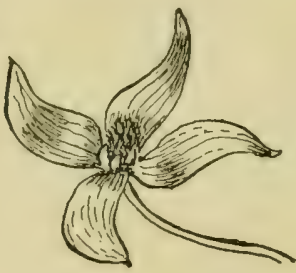

27

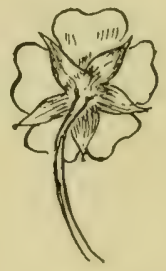

28

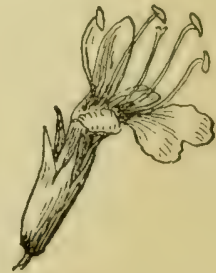

29

Fig. 26-Part of a stem of Zanichella. The naked flowers are seen at the leaf axils.

Fig. 27-An incomplete flower, Clematis. The petals are nearly suppressed while the sepals are large and colored.

lig. 28-A complete flower, Buttercup, with calyx, corolla, stamens and pistils.

Fig. 29-An irregular flower (Salvia).

parts of the same flower. For example, the petals of the buttercup or of the apple blossom are all alike, one as long and as broad as the other and the sepals of the calyx are, in these blooms, similarly symmetrical (Fig. 28). Such flowers are called regular. ${ }^{5}$

But the parts of the flowers are not always thus symmetrieal, for example, the petals of the sweet pea flower differ among themselves in size and shape, so also the parts of the larkspur and of the cypriperlium flowers are not all alike. Such flowers are irregular (Fig. 29.)

Flowers may be perfect in the sense that they include both the stamens and the pistils yet they may not he complete in the sense

1 Flowers, the corolla of which is composed of separate and distinct petals, are known as polypetalous or better, as choripetalous flowers, while flowers, the corollas each of which consists of a single member, made by the union of several petals, are monopetalous or more correctly gamopetalous.

3 When the petals are thus symmetrical the flower is technically homochlamedous or, in tamiliar language, regular. When the parts are unsymmetrical the flower is heterochlamedous, or, irregular. 
that they do not have the envelopes which we have called the perianth, the calyx and the corolla, the organs which, as has been remarked above, are, by the casual observer regarded as the flower. But when all these parts are present, calyx, corolla, stamens and pistils we have not only a perfect but a complete flower.

The calyx or outer circle of the perianth has ordinarily the color of leaves and appears as a little star-shaped circlet or cup-like receptacle at the base of the flower or extending upon the corolla enfolding it to a greater or less extent. (Fig 28.)

In some cases, however, the calyx is not green like the leaves but takes on the vivid colors which we are accustomed to find associated with the petals. In some instances the calyx may resemble the existing petals with which such sepals are generally alternate as in the case of the lily where the sepals are petaloid, alternate with the real petals and resembling them in size, form and color, the three sepals and the three petals uniting in an apparent bell-shaped corolla.

But the calyx may so far usurp the place of the corolla as to

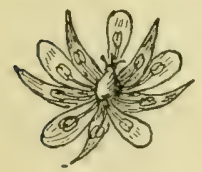

30

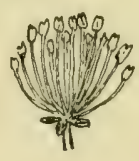

31

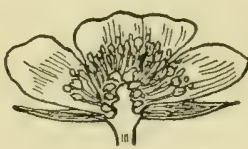

32

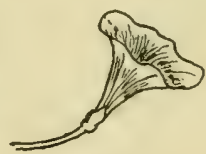

33

30. Polypetalous flower of Chickweed, with 5 sepals, 5 petals and ro stamens. 31. Apetalous flower of Thalictrum, with 5 sepals, no petals and many stamens.

32. Choripetalous flower of Ranunculus.

33. Gamopetalous flower of Convolvulus.

entirely supplant it and assume the color, the delicacy of texture and the brilliancy of hue of the suppressed corolla. In the flower of the clematis (Fig 2\%) we have an instance of this usurpation in which the petals are so nearly suppressed that they appear only as rudimentary bodies while the sepals spread out as a broad white or purple crown. The shining yellow cup of the swamp marigold or american cowslip is another familiar instance for the usurpation of the function of the corolla by the calyx. The calyx is not supplanted by the corolla and when there is but a single envelope in the perianth we know that it is the calyx. In the flower of the columbine we have ten members of the perianth all colored. The five petals resemble little cornucopias while the five sepals have more nearly the ordinary form of petals.

The calyx, like the corolla, may be unsymmetrical and like the petals of the corolla the sepals may be concresently united into a single tube. (Fig. 29.) 
These external organs, corolla and calyx, are largely protective to the essential organs but they have, especially the corolla has, an important function aside from the protective one, that of attracting insects or birds and it is this function which undoubtedly lends to the flower its charm of form, hue and perfume.

When the several petals of a flower are distinct, one from the other to the base as we see them in the buttercup (Fig. 28) the corolla is said to be dialypetalous, $i$. e., separate petaled and the sepals being thus distinct the calyx is dialysepalous; or the corolla is said to be polypetalous, i. e. many petaled, and the calys polysepalous. This arrangement of distinct petals is by no means constant and we see the parts of the corolla more or less united, from those corollas in which there is a faint union at the base to those in which, like the blue bell, the petals are all united to form a single envelope. The corolla of which the petals are thus joined, is said to be gamopetalous or monopetalous. (Fig. 33). In the great family of composite flowers, asters, thistles, etc., the heads are made up of from few to many of these gamopetalous flowers crowded into colonies, the whole having the appearance of a single flower.

The great majority of showy flowers are entomophilous, that is, they are attractive to insects. The primary source of this attraction is a series of small sacs or glands secreting a sweet liquid or semiliquid substance called nectar. These nectar saes may be situated at the base of the pistil, at that of the stamen, in the inner extremity of the pistils or even at the base of the sepals. In the violet it is hidden at the end of the spur. Nectaries are indeed sometimes situated outside the flowers but they are always enticements to the insects which are induced to visit the flower. (Fig. 34.)

It is from the nectar that the perfume of the flower largely proceeds and it is this nectar in which certain insects as well as humming birds delight as an article of food.

It is not always enough that the flower exhales a perfume which is pleasant and enticing to the insect, the wind or other agenciess might prevent the perfume reaching the sensitive organs of smell but there is added a display which is attractive to the sight. IIence the fine colors and even probably the varied and heantiful forms of the corolla are provided as additional attractions to these wingerl visitors.

The instrumentality of these visitors in the fertilization of the flower will be seen as we proceed.

The various elements of the flower are arranged with a certain degree of uniformity even in the must irregrular forms. 
Selecting a well known "regular" flower as an illustration of the typical arrangement we may examine the blossom of the common buttercup when the petals are fully expanded.

In the very center are several greenish bodies, arranged about the receptacle, which represent the pistils. They are attached to this receptacle which is the summit of the axis of the little stem of the flower, the peduncle. (Fig. 32).

When there is but a single pistil in a typically regular flower it springs from the very central point of this axis which is often concave at the summit as we see it at Fig. 35. About this little group of carpels of the buttercup, stand, at regular intervals a row of stamens and beyond this another and still another row. These rows appear to be perfect but if we were to shave them all off at a level just above their origin at the receptacle and should examine this surface by the aid of a magnifying glass of moderate power we would find that there is in fact only a single row of

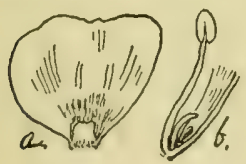

34

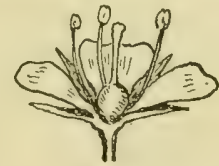

35

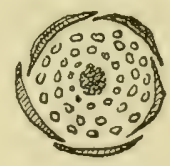

36

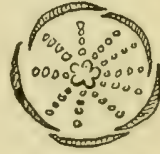

37

Fig. 34-Nectary at base oi a Buttercup . petal-a, view in front; $b$, longitudinal section.

FrG. $35-\Lambda$ typically regular flower.

FIG. 36-Diagram of arrangement of stamens in Ranunculus.

Fig. 37-Diagram of : arrangement of stamens in Columbine.

stamens arranged in a spiral and that this spiral line goes around the carpels three times as we see it in the diagram, Fig. 36 , where the shaded curved lines represent the insertion of the petals and the small points that of the stamens.

This arrangement is not universal nor even always found in the flowers of plants belonging to the same family as the buttercups. For example, the stamens of the columbine, which is a member of the great Ranunculus family, to which the buttercups belong, are arranged in about ten rows radiating from the central group of carpels. (Fig. 3\%). In flowers of other families there may be a single row of fire, six, or more or less stamens or in still others, especially in flowers which are "irregular" the stamens may all be mored to one side or, as in orchids, consolidated and attached, to the pistil.

Returning to our buttercup flower, beyond the spiral row of stamens we find the five petals, their inner borders being attached to the receptacle in a row just outside the ranks of the stamens.

At the base of each of the petals is a little sac, the nectary, which 
is more distinctly shown in the buttercup petal than it is in many flowers. (Fig. 34.)

These five petals appear at first to be arranged in a circular line, each occupying an equal space in the circle, but if we shave the flower as before and examine with care we find that they over ride one another in a broken spiral as seen in the diagram, Fig. 36.

As in the case of the arrangement of the stamens, this disposition of the petals may not hold for other flowers although it is typical of many. In the flowers of the lily, for example, three petals occupy each a portion of a circle while the three other petaloid members of the bell, in fact sepals, occupy a circle beyond these.

As also in case of stamens, in "irregular" flowers the petals may assume positions not at all typical. Thus, in the flower of the sweet pea three of the petals are situated much to one side, while a fourth, which is in fact a union of two, occupies much of the other side.

Leaving the petals and examining our buttercup flower further we find inserted into the base of the receptacle, in a ring outside the petals, the five green sepals. (Figs. 28, 32.) These are arrangerl about the base of the receptacle in much the same order as the petals, one overlapping the other to a certain extent, but alternating with the petals.

Thus we have the four elements of the complete flower arranged in four series from within outward in the order, the pistil, the stamens, the petals and the sepals; the petals forming the corolla, the sepals the calyx.

But while these four sets of organs'are generally in this order they are not always thus disposed, for in certain cases the stamens are inserted, not in a circular group next to the pistil but upon the hase of the petals and again, they may find this insertion upon the calyx. So also the calyx and corolla may seem to arise, not from below the base of the pistil but from above the rounded base.

Such peruliarities are important as characteristies in the classification and description of the flower and should be carefully observed.

When the whorls of stamens and petals are arranged below the pistil and free from it they are technically said to he hypogynous. (Fig. :39), and as this term is much used in botanical works it is a cromel one to remember as is also the term eprigynous (Fig. 40) which is applied when the ealyx, corolla and stamens seem to grow at the summit of the rounder base of the pistil, the ovary, as is the ease with the rose where the ovary forms a gracefully oval base 
to the remainder of the flower. When the petals and the stamens are united with the calyx at its base, appearing to rise from it, whether the calyx adheres or not to the ovary the flower is said to be perigynous (Fig. 39.)

These few technical words are introduced here because they occur so frequently in botanical literature and the characters are so important from the point of view of describing the flower that the student of plants even if he proposes to interest himself only as an amateur should carry these terms in his mind.

Before leaving the description of the flower we must not fail to call attention to some characteristics of the inner whorls, the pistils and the stamens. On a knowledge of these characteristics much depends in the identification of a plant by means of its flower.

\section{THE PISTIL.}

The pistil or pistils occupy, as we have seen, the central portion of the typical flower. (Fig. 42.) At the basal part of each pistil is the distended portion containing the ovules, destined to become the seeds, and this distended portion is known as the ovary. This

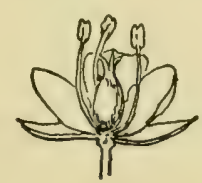

38

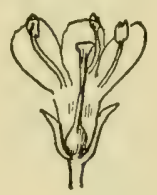

39

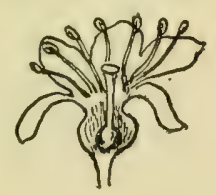

40

Fig. 38-Diagram of a flower in which the corolla and stamens are hypogynous, i. e., situated below the ovary.

FIG. 39-Diagram of a flower in which, although the corolla is inserted below the ovary, the stamens are inserted on the corolla, above the ovary. The stamens are perigynous.

FIG. 40-Corolla and stamens inserted above the ovary, epigynous.

ovary may consist of a single enclosure or carpel or it may be partitioned into several compartments or cells.

The ovules are found in these compartmens or cells as they are called but the part of the cell to which they may be attached differs in different plants. Thus, in our buttercup the single ovule is attached to the side of the single cell of the carpel. (Fig. 41.) In other flowers a colunin rises through the center of the ovary and about this the ovules are arranged. In still others, the ovules are attached to the partitions which divide the ovary into compartments and in still other cases they are attached to the ridges which represent unfinished partitions. The adjoining figures illustrate some of the methods of arrangement of the ovules and the character of the cells or locules of the ovaries. (Figs. 43, 44.) 
The parts of the flower are regarded as modified leaf-forms and the orary is not an exception. If we suppose a leaf folded once with its borders mited we have a conception of an ovary of a single carpel, from the united borders of which may arise a single ovule or several ovules. If two or more such folded leaves are combined to form an orary we have an ovary of several carpels which may be permanently separated by the infoldings of the elemental leaves which will form so many partitions or, should these infoldings not extend to the center or should, in the course of the process of formation, some part of the infolding borders fail of development the partition will be only partially or not at all formed and the compound carpel may show only some partial indications of partitions and when although the original borders may have united, parts of the folds are wanting there may remain

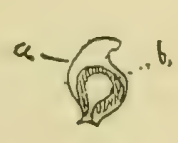

41

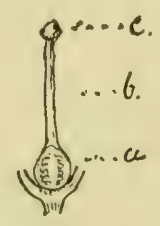

42

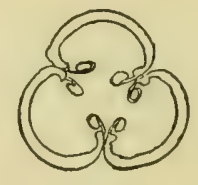

43

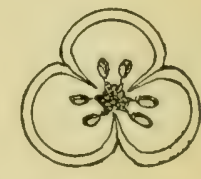

44

Fic. 4I-Carpel of Buttercup- $a$, shell of carpel; $b$, seed.

Fig. $42-\Lambda$ pistil- $a$, ovary: $b$, style; $c$, stigma.

FIG. 43 -Diagram of attachments of ovules to placentas on the wall of the ovary. These placentas are known as parietal placentas.

Fig. 44- - $t$ tachments of the ovule around a central column. The points of at. tachments are central placentas.

a central column in the cavity of the ovary with only the peripheral indications of the typical structure.

Rising from the rounded ovary is found, in a majority of the more typical flowers, a column which, in botany, is known as the style. There may he a single style which may arise from an ovary of a single locule or from one in which several locules are united or there may arise several styles from a number of earpels. 'The style differs in length and in comparative thickness in different flowers as in the aise of the long and slender style of the tiger lily and in the short and thick one of the buttereup. Althomigh, in its typical form it is a rounded and recular column it astumes other forms as in the orchict in which it is flattened ant hears the stamen on its sirle or as we have seen it in the silk of the Indian corn where it is a long drawn out filament. Many other flowers may be found which afford an interesting sturly of this organ for rach lorm of the pistil as a whole is designed so as loset to promote the function of the orean, which is an adjunct to the process of 
perfection of the seed. In some cases the style appears to be wanting as in the case of the poppy in the flower of which the broad capital, the stigma, of which we are presently to speak, rests directly upon the globe-shaped ovary.

Culminating the style as its terminal is a glandular, somewhat spongy appurtenance known as the stigma and which is destined to receive the pollen grains which must fertilize the ovules. This stigma is porous and the style is not as it appears from a superficial glance a solid column, but it encloses a canal or several canals leading to the ovary and through the pores of this stigma and through these canals of the style the pollen grains or the extensions of these grains find their way to the ovules. The stigma to a single style may be divided into several parts, for the style may branch at its summit into two or more divisions and on each of these divisions is found a stigma.

\section{THE STAMENS.}

The stamens, forming a ring outside the pistil and in some measure protective of it are designed as the source of supply of pollen grains. Like the pistil the stamens may assume various
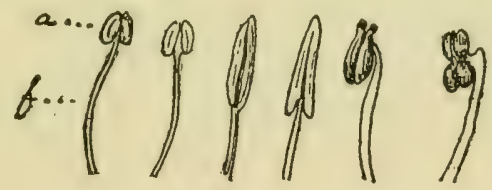

45

Fig. $45^{-\Lambda}$ few forms of stamens- $a$, Anther: $b$, Filament.

forms but the typical stamen arises as a filament terminated by an organ which appears to be differentiated from itself and to be attached to it, sometimes firmly and sometimes very slightly at the end of the filament. This is the anther of which more will be said as we proceed.

These stamen filaments are more or less numerous in different flowers but in one great class of flowering plants, the class in which the leaves are parallel veined or nearly so, (the lily family, the rushes, ete.) they are usually three in number or in multiples of three. In another great class which includes many of those plants with net veined leaves, the stamens are generally five or multiples of five, less frequently four. If we strip the petals from a flower of cranesbill geranium, so common in our woods in early spring: we shall find ten stamens alternately in two rows the filaments of 
the inner row being much longer than those of the outer row. In other flowers the stamens may number twenty or more. ${ }^{1}$ Even when found in these large numbers the arrangement in rows can generally be made out and the multiples of five are also generally to be observed. (Fig. 45.)

Notable exceptions to the general arrangement occur some of which will be mentioned when the architecture of the flower is considered.

The terminal body attached to the stamen is the anther. If we examine one of the anthers which dangle from the long stamens of the tiger lily we shall see that it is an elongated elliptic body along which, from end to end, extends a groove on the side opposite the attachment of the stamen. 'This groove is so deeply cut in some anthers that it almost or completely divides the anther into two which are connected by a narrow band of connective tissue. Again, each of the two divisions has a lesser groove, generally, as in the case of our lily, running longitudinally, and again, the two main divisions of the anther may be divided by a deep transverse groove, making four lobes of a single anther, each with its lesser longitudinal or transverse groove. In instances far less common the anther may be divided into sinuous lobes or into lobes which are transverse to the axis of the filament or it may take other forms which are quite atypical. Whatever form is found in the anther of an individual plant, as for example, that of our lily, it is the common form for that species and no important modification of form is found in the anthers of flowers from the same species of plants.

The anther is the pollen carrier and the secondary grooves form, when the pollen is mature, the openings through which the pollen grains escape. For as the grains enlarge the anther bursts open at these secondary grooves and the pollen lies exposed in such a way that the wind, the foot or the hearl of an insect or some other instrumentality may reach it and carry it to a neighboring pistil.

In the case of our lily the anther is seen to swing lightly from the slender point of the somewhat strong filament hut if we look at a stamen of a water lily we see the anther attached by its hack along the course of the flattened filament and again in some flowers the anther is fixed solidly as a capital at the summit of the filament.

TIIF POLLEN.

We may now examine the pollen which is the essential product

${ }^{2}$ Collectively the stamens are called the androccium, as collectively the carpels and pistils are called the gynoccium. 
of the anther and the substance without the application of which to the pistil the ovules do not become seeds.

The yellow dust constituting the pollen when viewed by the unairled eye appears like other dust with no especial individuality of form. But if we place some grains of it under the lenses of a moderately magnifying microscope we see at once that each grain is a beautiful organized structure, though there are comparative grades of beauty in the grains of pollen from different flowers and it is interesting to note that the forms of greatest beauty are not always from the most attractive flowers. (Fig. 46.)

Generally rounded but sometimes spindle-shaped or cubical its surface may be elegantly facetted, delicately lined, covered with small points or smooth and glistening. Usually the grains are dry with little inclination to cohere to each other but in exceptional cases they are more or less glued together in little masses such as are found in the flowers of the milkweed and orchids so that when any part of the pollen is removed from its bed the whole mass

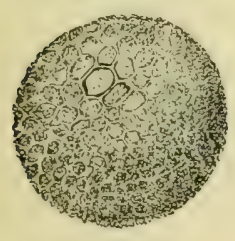

a

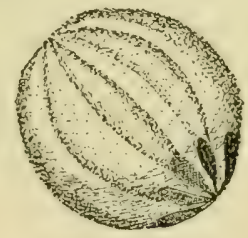

$\mathrm{b}$

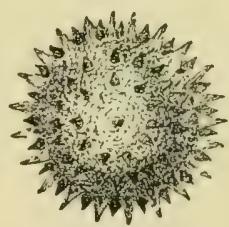

$\mathrm{c}$

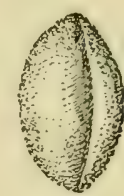

(I)

46

Fig. 46-Some forms of Pollen Grains.-a. Phlox; b. Monarda; $c$. Marigold; $d$. Lily-all magnified about 500 times.

clings to the object which removes it. The grains may also be comparatively heavy or comparatively light. In some of the pines, for example, the pollen grains are supplied with little air vesicles which serve as balloons and enable the grains to float at long distances in the air.

When the pollen grain is brought into immediate relation with the stigma it begins to grow into an elongated fibril which penetrates the spongy substance of the stigma and finds its way down the channeled pistil till it comes in contact with the ovules which at once take on a new form of life and develop into perfect seeds. Naturally the amount of pollen produced by individual plants will depend largely upon the probable waste that must occur in the process of transmission to the stigmas of other flowers than the one which bears the pollen. Hence we find a greater abundance of pollen produced by wind fertilized plants than by those in which the process of fertilization is carried on by the aid of insects. In 
some of these wind fertilized plants the amount of pollen is almost incredible. The cone bearing plants, pines, spruces, etc., must produce such an infinite number of these floating bodies as to insure the falling of great numbers upon distantly removed cones in such a way that they must remain attached to the stigmas.

\section{ARCHITECTURE OF THE FLOWER.}

Notwithstanding the great variety of forms of flowers a close comparison indicates that, in the main, flowers are constituted on a few general and pretty uniform plans and that the variations of form depend, not so much on the adoption of new plans as on the modification of the few general plans.

We have examined the various elements of a flower, pistil, stamens, corolla and calyx and we have found that the first two of this group of organs are essential while the others are protective or useful as auxiliaries.

Botanists have adopted certain diagramatic figures to express in graphic form the relations of these floral organs in the architectural structure of the flower. For example: if we would express the number and relative position of the members of a flower of the Iris family, a diagram something after the manner of that at Fig. 47 would be employed. At the center is found the three-rayed figure enclosed by at thin line. The three rays are lobed at their extremities. This central figure represents the column to which are attached the two rows of orules in each of the three cells of the ovary. The ovary with its closed cells is represented by the heary line just beyond the center. beyond the line representing the ovary is seen a dotted line with three small crosses. The dotted line indicates the circle in which three stitmens would be found were they developed, but since they are undeveloped the crosses indicate the points at which they would have been found had they been developed.

Reyond this is another dotted line in which are three scolloped figures and these figures represent the actual, fully developed, three stitmens of the iris. Beyond the circle for the stamens we find a circle represented by three heary lines and another circle of three parts not shaderl. It is customary to represent the inner of these two cireles by solid lines, the other by shaded lines. They represent, the inmer cirele, the pertals, the outer, the sepals. In this calse both circles repmesent colored organs. Below this circular part of the diagram is seen another heavy curved line which represents a bract at the base of the flower and, as the flower of iris is not always terminal we see at the mpler side of the diagram the line representing another brated and a small circle, which represents the stem.

In expressing the arrangement of a flower with five sepals, five protals, fise stamens and a pistil with a five-celled orary the diagram Fig. 48 would be used.

In each of these cases the diagram is drawn without reference to 
the level of the origin of these members and, as will be seen, in each case the members are not only regularly but typically disposed since we have, in the case of the Iris, three members of each of the four whorls, while at the inner whorl, the fifth, the ovules are shown as two for each cell of the ovary or, for each border of the folded leaf of which the cell is supposed to be formed. In the other case the members are five in each of the whorls and, like the first, the members of one whorl alteruate with those of the adjoining one and are symmetrically placed.

Isut while the general plan may remain, many modifications of it may occur, for example: the five members in the whorl of stamens may be doubled or multiplied several times. On the other hand, some one or more of the members of one or more of these whorls may be suppressed or, as frequently, it is merged with a neighboring member.

Thus, in the case of the lily, there are two rows of stamens of three each, while as we see in our diagram of the iris there is but one row of developed stamens while another row, indicated by the crosses, remains undereloped. Also a single member of one or of sereral of the whorls may be suppressed as it haplens in the gleat mustard family where we have four sepals, four petils, four long and two short stamens and one pistil composed of two united carpels.

Besides the multiplying of the whorls in some cases and the suppression of the whole or a part in other cases we find frequent instances in which the members of some or of several of the whorls have been moved towarl one side of the peduncle and as a result we have a one-sided flower as in case of the pea.

This, like other parts of the delightful study of botany would be
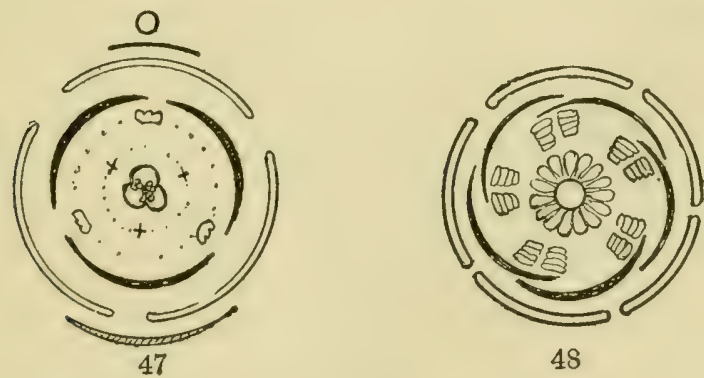

an interesting topic to pursue much more in detail were the space available.

\section{ARRANGEMENT OF FLOWERS.}

The arrangement of flowers on the flower stem constitutes one of the means of identifying the different species of the plant.

When the single flower finds itself the sole occupant of an isolated portion of the stem it is said to be solitary as it is in case of the violet or the tulip but very frequently the flowers are disposed 
in groups which may be simple or quite complicated. Te speak of such a group as the inflorescence.

In the inflorescence of many plants there are found members which do not answer exactly to leaves and are not properly a part of the flower, they are bracts, often found at the base of the immediate flower stem or at the base of the flower itself. We have an example of the first in the fringy collar below the radiating pedicles in the flower cluster of the wild carrot and of the other in the green organs below the head of the china aster. These bracts sometimes take unusual forms, as that at the base of the small cluster of flowers of the linden, and from which the cluster appears to grow. These bracts often fill an important part in the arrangement of clusters of flowers though many clusters are without bracts.

Coming to the most common arrangement of flower clusters we may conveniently arrange them in the form of a table:

I. Flowers arranged along the plant stem without flower stems or with very short ones

II. Arranged along the plant stem on short flower stems, but which are gradually somewhat longer toward the base

III. A similar arrangement, but each flower stem branching into two or more . . . . . A Compound Raceme or Panicle

IV. Flowers on flower stems branching from nearly the same point and reaching about the same level . A simple Corymb

V. Flowers borne on brauched divisions of a corymb

VI. and VII. Flowers on somewhat long flower stems all from the same point and radiating like the rods of an umbrella to a common level or rounded (Figs. VI and VII) $A n$ Umbcl

VIII. The flower stems of an umbel branched to form serondary umbels . . . . . . . . . A Compound Umbel

IX. $\perp$ spike more or less surrounded on at least one side by a spratthe . . . . . . . . . . . 1 śpudir

$\mathrm{X}$. The flowers arranged more or less compactly on a receptacle and surrounded by bracts . . . . . . . 1 Head

$\bar{X}$. Inflorescence on a succession of new axes, the primary, secondary, etc., axes each terminated by a flower . A Cyme

XII. $\Lambda$ cyme in which the inflorescence colls upon itself

Xilf. Arrangement similar to a panicle, but the branches onesided . . . . . . . . . A secund P'unicle 


\section{Arrangemext of Flowers}
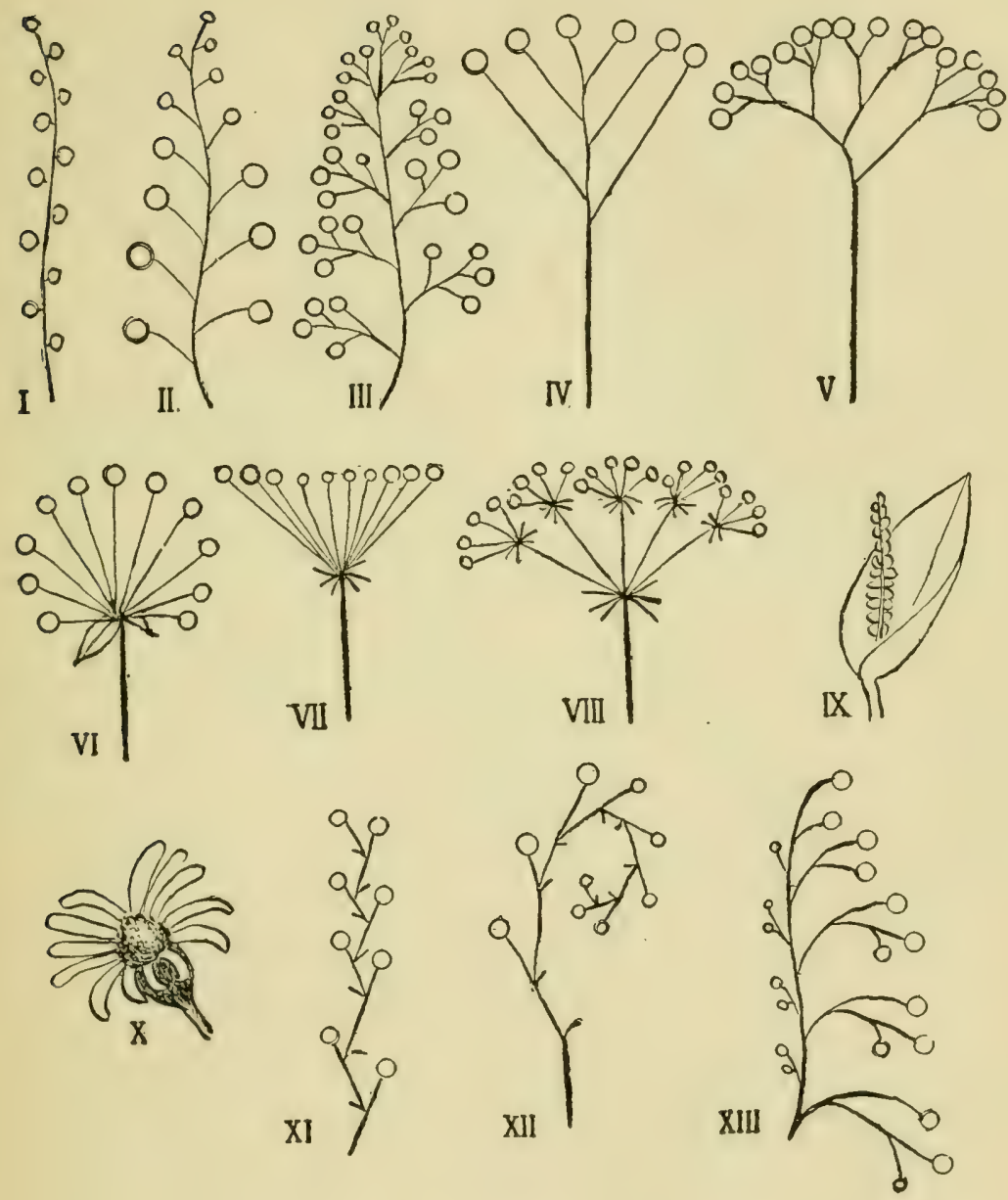

THE FRUIT,

As the ovules, under the fertilizing influence of the pollen advance toward maturity, they and the immediate envelopes which enclose them become modified and are known as the fruit.

While in fact the maturing seed with its immediate protecting membranes is the fruit, popularly the fleshy or pulpy modification of some accessory part is regarded as the fruit. Thus, in the strawberry the little hard shining bodies are the real fruit while 
the delicious pulpy substance which gives value for us to the herry is a modification of the floral receptacle, and the rich sulistance of the apple is another example of the excessive growth of the receptacle on which the seeds first rested and then were enveloped by it.

The forms which the fruit may take during the process of ripening are important elements in the determination of the species of plants and are often employed in the differential descriptions.

The following table will serve to show some, but not all, of the principal forms of fruit.

\section{Simple Fruits}

This dirision includes fruits which have a dry envelope in contrast with the fleshy fruits.

a. Fruits in which the carpels at maturity are burst by the internal pressure of the seed, but which have no regular seam which opens when the seed is ripe.

Pericarp (surrounding of the seeds) not a winged fruit.

Fruit of a single cell and enclosing a single seed. Example: buttercup, anemone, fruit of composite flowers (Fig. 49 anr 50) . . . . . . . . . . . . An Achene

Fruit in which 2, 3, or 4 achenes are united into one is known respectirely as, Diachene, Triachene, etc.

Pericarp developed at the borders into a broad, spreading wing

or wings. Example: maple, ash, etc. (Fig. 51) . . A Samara

b. Fruits in which the carpels, at maturity open at a regular seam or, technically, a dehiscence.

Fruits which consist of a single carpel or of several carpels not joined together, the dehiscence of which is in the direction of the axis of the carpel.

Opening by a single seam. Example: columbine, larkspur (Fig. 52 and 53) . . . . . . . . . A follicle Opening by two seams. Example: the pea (Fig. 54)

Fruit a rompond ovary more or less hird and wooly and which opens at the side or top (Fig. 55 and 56) A Capsule or Casket

An ovary of two demsated arpels which are joimed. sibe by side, and which open from bottom to top leaving a partition between the two valves (Fig. 57) . . . . . . I silique

A silicle is a short silique. These forms are characteristic of the family of crucifers.

An ovary of one or more carpels opening transfersely, a capsule like a little cup with a lid (Fig. 5S) . A l'yxis or Box

\section{Fleshy Fruits}

Frut in which the seed is immediutely surrounded by al strong membraneous or woody wall.

a. The seods anch (usually 5) surrounded hy a tough mombranoous or cartilaginous wall. Lxample: apple, pear, etc. (rig. $60)$ 


\section{Fruit Forms}
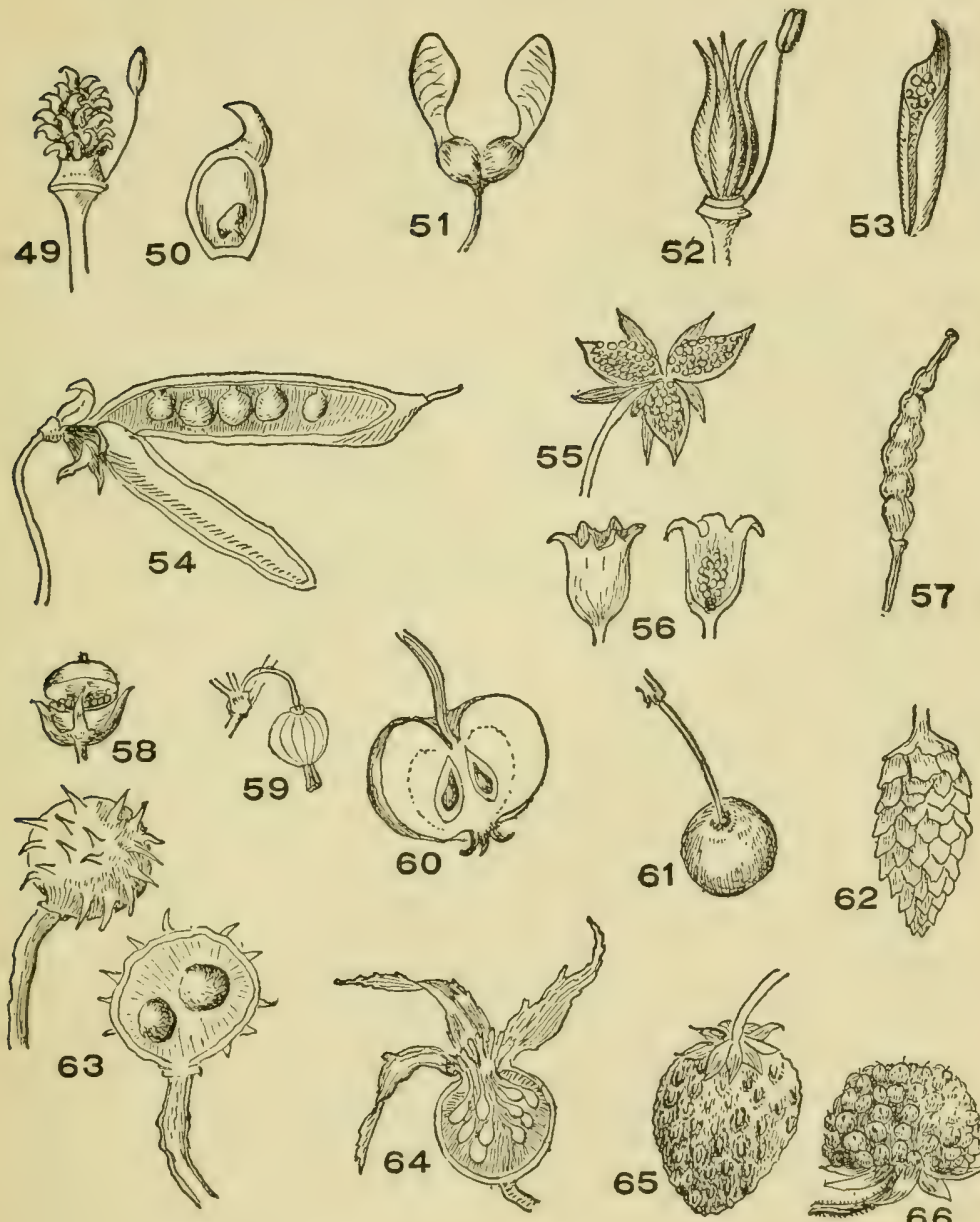

Figures

49. Cluster of achenes of buttercup. 50. A single achene from the group. 51. Samara of maple.

52. Follicles of columbine.

53. A single follicle half open.

54. Pod of pea.

55. Capsule of violet, open,

56. Capsule of silene showing the complete capsule
57. Silique of mustard.
58. Pyxis of "four o'clock."

59. Berry of gooseberry.

6o. Pome.

6r. Drupe.

62. Cone.

63. Husk oi horse chestnut, showing two 64. Hip of rose.

65. Compound fruit of strawberry.

66. Compound fruit of raspberry. 
b. A small fruit with a membraneous covering which includes a soft pulp in which lie the seeds. Example: currant, gooseberry, blueberry (Fig. 59) . . . . . . . . 4 Berry The orange and lemon would come under this group.

c. A compound ovary of carpels with a strong, rather thick envelope containing a pulp in which are distributed the seeds.

Example: melon, cucumber ....... A Gourd or Pcpo

d. A fruit in which the seed is protected by a bard, woody wall, a nut, or stone.

The stone covered hy a fleshy succulent layer. Example: cherry, plum (Fig. (61) . . . . . . . . A Drupe

The stone not covered by a fleshy layer. Example: oik, chestnut (Fig. 63) . . . . . . . . . . A Nut

\section{Aggregated Fruits}

Many small seed bodies included on the surface of a pulpy or dry convex receptacle

The receptacle pulpy. Example: strawbers (Figs. 65, 66).

The receptacle dry. Example: potentillas, roses (Fig. 64).

\section{Compound Fruits}

Include the cones of the Pine family, Fig. 62, and some other forms not common with us.

\section{TIIE SEED.}

The ovule, when it has been fertilized through the influence of the pollen, takes on a new form of growth in which there is the beginning of the prospective plant, the embryo.

In the ovules of plants belonging to the great division to which the grasses, serlges, palms and lilies belong-the monocotylertonsthe embryo is formed at the base of a single lobe or cotyleton of the developing seed (Fig. 70 ), while in the grand division to which most of the plants with net-veined leaves belong-the dicotyledons - the cmbryo is formed between two lobes or entylerlons ( Fig. $6 r$ ).

The presence then of one or of two cotvledons or lobes in the sceds, constitutes the distinguishing feature characterizing the two great types of plants whose seerls are enclosed in an ovary. In the group of cone-bearing trees, pines, spruees and the like, the eotyledtons are not uniform in number, there being from three to several cotyledons in the single seel. Fig. $\% 1$ shows a yound pine with the expanding cotylefons, numbering eleven, in a vorticel. At the summit, still holding the rotylertonous leaves torether at their extremities is seen the terument of the seed, not yet cast off. As the plantlet pushes upward a new whorl of leaves will appear and later other whorls.

Even in the class of monocotyledonous and dientylednnous plants there are oceasional exeeptions in the numbers of entyledons, for the seeds of the pond-weeds, for example, among the first great. 
class may have more than one cotyledon, while exceptions, like the seed of the African Kola tree, in which there may be from one to several cotyledons, occasionally occur in the other class.

These cotyledons with the enveloping tegument and the embryo comprise the essential elements of the seed.

Commencing our examination with the tegument we find that not only does it invest the seed, but that while apparently a single organ it consists, in fact, of several layers of each to which names are given. ${ }^{1}$

To the outer membrane or layer which is commonly smooth, as we see it on the grain of corn or wheat, may occur various modifications which are devices for the dissemination or protection of the seeds. These modifications may be in the form of appendages such as hairs, hooks, bristles or wings.

The ovule is held in relation to the ovary by a little connective organ, the funiculus, and the point at which this little bond of union is attached to the ovule or seed is marked, when the latter separates from the ovary, by a spot known as the chalaza.

The essential part of the seed is, of course, the embryo, which is, in fact, the rudimentary young plant, and it is to this that all other parts of the seed are subsidiary. Thus, the cotyledons store up nutriment which will be required by the embryo during the early stages of its development until it can draw its nourishment from the soil or other environment.

The embryo consists of a radicle which is destined to form the root and of a plumule, the rudiment of the stem and leaves (Fig. 6\%). The cotyledons occupy, as a rule, much the largest portion of the seed and form, in dicotyledonous plants, the first pair of leaves which are often thick and fleshy (Figs. 67 and 68), while the single cotyledon of the

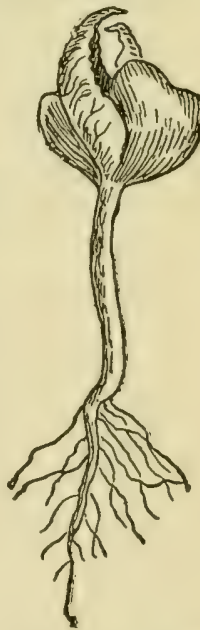

FIG. $67-$ Coty. ledons of common bean, showing em. grain of corn forms, in germination (Fig. 70) a bryo between. storage body which does not rise above the surface of the soil and does not assume a green color, as do the cotyledons of the bean, the maple or the oak.

While the nutrient material is often stored in the cotyledons, a reservoir of nutritious matter is sometimes found in an independent body known as the albumen, which varies in its nature and position.

1 The outer layer of the integument is the testa, the second is the mesosperm and the third the endosperm. 
The embryo, which lies at the base of the single cotyledon of the grain of wheat and almost straight between the lobes of the bean may curve around the albumen mass in the seeds of certain plants and from the fact of the encircling of the albumen by the embryo of such plants, as for example, the Corn Cockle, and many other plants of the pink family, this feature is an important element in the classification of the plants. In still other seeds the albuminous mass completely encloses the embryo.

It is unnecessary here to discuss the processes attending the

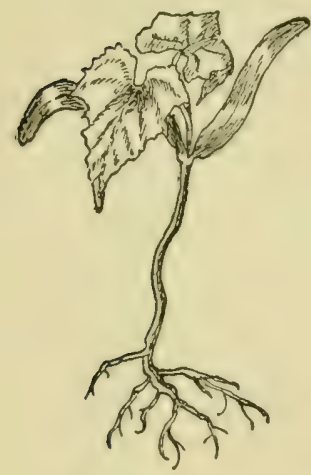

Frg. 68

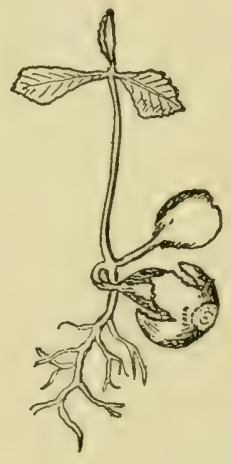

FIG. 69

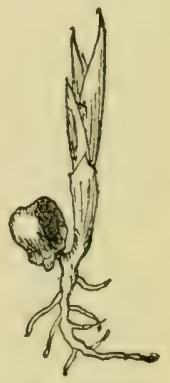

Fig. 70

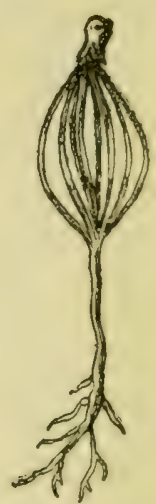

119. 71

germination of the seerl beyond mentioning some of the more obvious phenomena. Under the influence of the air, of moisture and of a certain degree of heat the parts enclosed within the membraneous or woody coverings swell and break through the outer wall by separating its parts at certain seams or joints, or tearing it in an irregular manner. Thus the young plant commences an inclependent existence.

The plumule of a seed which has been buried in the soil pushes toward the light and air while the radicle penetrates even deejer into the soil. At this stage the cotyledon may, as it usually does in case of plants of the dicotylertonous class, cling. one to one side of the little stem, the other to the other side and as the stem pushes upward they appear alove ground as the two first leares as we see them in the fleshy seed leaves of the bean (Fig. 6i). As the expansion of the plumule proceeds the characteristic leaves of the plant appear as we see them in the young maple shown at Fig. fis. At Fig. 69 we see a young oak, one of the cotyledons of which has not yet thrown off the shell of the acorn. 
The single cotylerlon of the monocotyledonous class does not usually rise above the soil as do those of the other great class, but remains hidden where the moisture of the soil can aid it in its nourishment of the new plant. At Fig. 70 is shown the young plant of maize, the shell and cotyledon remaining near the branching and descending radicle.

In the seed of the pines there are several cotyledons, and they rise in a little spindle-shaped structure formed of a number of symmetrically curved ribs, lifting the shell of the seed at their summit like a little cap, as we see it at Fig. \%1. At length the cap is thrown off and from the midst of the group of cotyledon rays arises whorl after whorl of needle-like leaves.

\section{THE NAMES OF PLANTS}

To the amateur the names of plants are a source of difficulty and often of perplexity. The common name of an individual plant usually differs not only in words, but in meaning, so far as it has a meaning, in rlifferent languages. Even in the same language there are often many names for the same plant in different localities and the same name is often applied to plants widely different in character and appearance.

Hence, for an English-speaking person to know the common names of the plants growing in his or her vicinity might be of little advantage, since in another locality these common names might be differently applied or other names might be used for the same species.

This unfortunate state of confusion existed when Linnaeus, the great systematizer, not only of botany, but of other branches of natural science, adopted a system of giving to each plant two names which, in some sense, compare with the names which we apply among ourselves; for example, we say, James Monroe; Monroe referring to a group of persons and James to an individual.

In plant naming we use the two names much in the same way; thus, we say: Viola tricolor: Viola being the name of a group which is called a Genus, while the qualifying or specific name tricolor refers to the three colors found in the flower of this species and is its specific name.

A rule which is now almost universally accepted requires that the Genus or the Species shall bear the name given it by the person first describing the Genus or Species. Thus, although many species of violets were lnown before Linnaeus, he first applied the name in 
the system now current; hence Tiola remains in all countries the name of a group of plants having many common characteristics, while the specific name tricolor, also given by the same great botanist, remains the-name for this particular species.

In writing this name botanists are accustomed to follow it by the name or the initial letter of the authority giving the name; thus, Viola tricolor, L. But another species of Viola described and named by the botanist De Candolle is Viola arenaria, DC.

A plant which has been assigned to a Genus, not the one to which it was originally assigned, retains the specific name given by the first authority whose name follows in brackets and the name of the later authority follows this: thus, Ranunculus Cymbalaria, Pursh, is now Oxygraphis Cymbalaria (Pursh), Prantl.

It must be acknowledged, even by those who do not like to charge their memories with unfamiliar names, that this general system is most important and even necessary, yet it is unfortunate that so many men of learning have, in the naming of the plants which they have described, forgotten that simplicity and euphony should characterize the nomenclature of objects of interest.

It is an interesting and most fortunate fact that the great Linnaeus, who introduced and established the double-name system and who gave their names to a vast number of plants, was a true lover of them and made it a rule to employ the simplest terms that he could find for his specific names; the terms which he used as generic names were, in a great number of cases, those which had already been employed for one or other plant of the group before he introduced his nomenclature, so that he was not always responsible for these generic names, but even here, when he was at liberty to choose, he selected the most euphonic or the most familiar name. Thus the generic name Viola was not originally used by Linnaeus, but was selected by him from several applied to the same group; then, to specify a particular form of Viola he gave the specific name tricolor, an easy name to remember and one in euphony with the generic term. Through all the vast lists of these specific names given by this great man the character of simplicity will be observel and it will be noticed also that these simple terms are repeated over and over. This systematic effort at simplicity, it is unfortumately necessary to add, has not always been imitated by botanists of lesser fame. 


\section{CLASSIFICATION OF PLANTS}

When we observe a considerable number of plants we may find among them striking differences in manner of growth, in comparative size and in the form of leaves and flowers as well as in other details. But on further observation we may find in this diversified collection a number of groups, the individuals of which can only, with difficulty, be distinguished from each other, or which are quite indistinguishable from a slight examination. Observing still further we may see that some of these groups, the inclividuals of which are alike, strongly resemble some other groups, while the individuals of one group differ in some important respects from individuals of the other groups. We may carry these comparisons to several degrees of approximate resemblance and we may find that of the diversified collection, which at first seemed to possess no organization, we may separate the individuals into several more or less approximately related groups.

Taking those first, the individuals of which resemble each other more than they resemble any others in the collection, we would have the first of our series of groups. Selecting next from these first groups the groups which most strongly resemble each other, that is, which have the greatest number of common characteristics, we would have a second grouping which, with perhaps many common features, would still include some differences. Still carefully observing we might still arrange this secondary group into a more general assemblage.

This is what has been done in the classification of plants. In respect to the first group, the group in which the individuals so strongly resemble each other that, given the name of one individual we call all the others by the same name, it has been found that from the seed of one of these individuals we may obtain a plant just like the parent plant and like the other individuals of the original group.

Such a group of individuals, from the seeds of which may be produced succeeding generations of similar plants, is known as a Species.

We need not then further define a Species than by saying that it is a group of individuals resembling each other more than they resemble individuals of any other group and that from the seed or from cuttings may be produced other generations similar to the first.

Our second grouping would include plants which, although hav- 
ing characteristics common to all, would have less resemblances among the individuals than we find in the Species and if the seed of one member of the group were planted it would not produce a plant which would resemble all the members, but only members exactly like that which produced the seed.

This secondary grouping is known as a Genus (meaning race, stock). It is the second step in our classification and the second easiest, for there are usually found between the species of a genus very obvious connecting features.

But on much closer scrutiny we may collect these Genera into other groups with evident general resemblances shown either in general appearance or by the comparative study of one or more classes of organs. It is, in fact, by this latter method principally that this third grouping is determined and the groups are called Families.

Eren these Families may be united into larger groups and we have Orders, and the collection of Orders leads us to Classes, and these Classes finally form Divisions.

Thus, the mushrooms, which are without flowers and without seeds, belong to one Division, while the violet, with its flower and its seed, belongs to another Division; and of the flowering and seeded plants we have the large group of plants with parallel veined leares whose ovules have a single lobe, belonging to one Class, while the plants with net-veined leaves and two-lobed ovules belong to another Class.

We may then arrange our groups of plants, from the most general to the most specific groups, as follows:

Divisions. Classes. Orders. Families. Genera. Species.

It is found convenient in some cases to subdivide some of these groups, when the subdivisions are known as Sub-Classes, SubFamilies, etc., or, in the case of Species, as Varieties.

In treatises and text-books during most of the nineteenth century it was the custom to arrange the sequence of Families according to a prevailing view of the perfection of the development of the plants from highest to lowest; commencing with what were regarded as the most fully developer, the plants of the Ramunculus Fimily, and procecling towards those less completely organized.

This system of arrangement has, within the past few years, given way to the much more natural and more reasonable arrangencent of finding the sequence of the Families in the gratual evolution of the organs of the plants. This system has not simply reversed the order of arrangement with which many of us have become fil- 
miliar; investigation has changed the comparative rank of many Families so that the newer arrangement differs not only in the reversal of the sequences, but in a more or less general rearrangement.

Again, the text-books universally known in this country during the last half century and more, those of Gray and Wood, like others less generally used, employed the term Order for the grouping next higher than that of the Genus. The term Family is now used where Gray and Wood and their contemporaries used the term Order and this latter term is employed for a group of Families.

Thus we have, in the main, returned to the method of classification of Antoine Laurent de Jussieu which was published in 1789, but with modifications such as more recent investigations have suggested.

The arrangement most generally accepted at present is that of Dr. Adolph Engler, ${ }^{1}$ which system, with few modifications, has been followed in this work.

The system is based upon the principle of development from the more simple to the more complex. Yet it is not always practicable to follow in a direct line such an evolutionary principle, since evolution has progressed along different lines. Hence, one line is followed to its highest point of development. For example, along the line of monocotyledonous plants the Orchid Family represents the highest degree of development. It is more highly specialized than many plants of the Class of Dicotyledons, yet because, on the whole, this latter Class contains the most complex organizations, the whole of the Class takes rank above the whole of the Class of Monocotyledons, including the Orchids.

This system of arrangement reveals the beauty of the principle of development in the Plant Kingdom and by the gradual modifications which contribute to the characters of the successive Families the student is presented with a panorama of the history of the plant world which not only charms by the beauty of its symmetry, but enables him with much greater facility to comprehend and remember the relationship of the groups which he studies than was possible by the former system.

\section{SOME OF THE CHARACTERS OF PLANTS USED AS THE BASES OF CLASSIFICATION}

Evidently in order to form a practical system of classification of

\footnotetext{
${ }^{1}$ Dr. Engler is Professor of Botany and Director of the Botanical Gardens and
} Museums of Berlin. 
plants certain characters must be chosen which are common to one group and which are absent from another.

Thus we may commence with the individuals which are most alike and proceed toward those which have the least number of common characteristics or we may commence with those having but few characters in common and proceed to those in which most of the characters are common.

The system which we may adopt may be an artificial one, such, for example, as the tistinction between trees and herbs, water plants and land plants and other such characters. The beautiful system of Tinnaeus which served so long as an almost indispensable aid in the study of plants was an artificial one based, for flowering plants, in great part, unon the number and relations of the stamens and pistils. Even now this system is perhaps the most convenient for the determination of the species.

It has, however, in later times, given way to the system linown as the natural method which has infinitely greater scientific value. It is in fact based, so far as our knowledge extends, upon the theory of genealogical descent, determined by the analogy of characters. To this we have referred in the preceding section.

It would be impracticable in this place to indicate every element in such a great system, but for our present purpose we may consider the first great division in the plant kinglom as that which places all plants propagated by seeds in one class and those which are perpetuated without seeds in another.

The plants included in this work belong to a single Grand Dirision of the Vegetable Kingdom. They are Embryo-bearing Plants (technically) Embryophyta.

This Grand Division is also called the Division of Flower-Bearing Plants. It is characterized by the fact that the succeeding generations are developed from true seeds which contain in themselves an embryo stem which terminates at one extremity in what is known as the plumule, the embryonic first leaf or leaves, and at the other extremity as the radicle or embryonic rootlet.

The seed containing the embryo is always developed while connected with the parent plant.

Ferns, true mosses, mushrooms and other non-flowering plants are propagated by a rifferent form of generation. The non-flowering species of higher development are propagated by spores which differ from seeds in being less specialized and apparently less elevated in the seale of development. In the lowest orders propagation is by simple division of the cell constituting the plant or hy the formation within the parent cell of a group of similar cells 
which are set free by the bursting of the wall of the parent cell. This separating the seed-bearing from the non-seed bearing plants constitutes a natural and to a great extent a definite division.

Taking now the plants which are developed from seeds we find certain very general features which are characteristic of large groups. Thus, in a great class of seed-bearing plants the seeds are borne within a closed cavity; for example, the seeds of the pea-vine are enclosed within the pod, those of the rose within the rounded red fruit and those of the portulaca in a round capsule. On the other hand, if we examine one of the "cones" from a pinc tree we find, on separating the more or less woody scales of which it is composed, the seeds lying between these scales not enclosed in a protecting chamber. This character prevails with all the species of pines, spruces and the like and seems to be an extremely old form of seed growth, for it is frequently found among the fossils of the carboniferous age.

This contrast between plants bearing seeds in an enclosed chamber and those plants bearing seeds not enclosed has been taken by botanists as the first line of division, and we have the First Division of embryo-bearing plants consisting of those with the seeds not enclosed, naked seeded, and a Second Division, including all those whose seeds are enclosed within a chamber and these two great divisions include all the embryo-bearing plants. Hence we have reached the first step in Classification.

Although the Gymnosperms are divided into a number of groups all of the species in our northeastern States belong to a single class, the Coniferae.

A difference in the construction of the seeds leads to two great classes among the Angiosperms or plants whose seeds are protected within an ovary.

If a grain of wheat, or a seed from some other grassy plant, and a garden bean or pea are placed in water for a few hours the outer covering or integument can then be easily removed, when it will be seen that the two kinds of seeds act quite differently, that in case of the bean or pea the seed easily divides into two principal lobes between which lies a small leaf-like object, the embryo, while in the case of the wheat kernel no such division occurs, but the embryo lies curled at the base of the single lobe. The two larger parts in the case of the bean and the one principal mass in the case of the wheat are the lobes, or technically the cotyledons, which are masses of nutriment stored up for the support of the embryo until it can draw its own subsistence from the soil.

The single lobe, with the embryo attached, the single cotyledon 
of the wheat seed represents for the whole class to which the grains, grasses, lilies, etc., belong, as the two lobes or cotyledons of the bean represent the structure of the seeds of the other class.

Upon these facts then we may commence the formation of a table of classification as follows.

\section{First Grand Division.-CRYPTOGams}

This is not the more technical division for, in more recent times that division of the vegetable kingdom which has been long distinguished by this term has been divided into several groups, which include the Green Algae, Diatoms, Stoneworts, Fungi, Mosses, Fern-like plants and others. Since none of these classes are included in this work it is unnecessary to specify these divisions. The character which divides all these so-called lower forms of vegetation from those with which we shall be occupied is the absence of flowers and of seeds. They were called in the Linnean system of classification Cryptogams (cryptos, hidden), because the manner of fertilization was not understood.

\section{Second Grand Division.-PHANEROGAMIA or EMBRTOPIIYTA}

This great division includes all plants having stamens and pistils and bearing seeds. The term Phanerogamia (phaneros, visible), refers to the manifest organs of reproduction, the pistils and stamens, while the term Embryophyta signifies an cmbryo bearer. The division is divided into two subdivisions.

\section{FIRST SUBDIVISION.-GYMNOSPERMS}

Characterized by the naked orules (gymnos, naked), that is, ovules not enclosed in an ovary.

\section{SECOND SUBDIVISION.-ANGIOSPERMS}

The sublivision characterized by the fact that the ovules are protected within an ovary.

The subdivision A NGIOSPErMs is divided into two great classes.

\section{CLASS I.-MONOCOTYLEDONS}

Plants whose seeds have but a single lobe.

CLASS II.-DICOTYLEDONS

Plants whose seeds have two (rarely more) lobes.

These dissers are again dividerl as we have seen in the preceding scretion into orders, these orlers into families and these families into genera and then species.

In the extended table at page $5 \%$ will be found characters genrally sufficient to lead us to the Order in which we maly find a given plant growing native in our region. 


\section{COLLECTING, DRYING AND MOUNTING OF PLANTS}

Many intelligent people believe that they have a genuine love for plants, yet they take a seeming pride in the fact that they know little or nothing of their natural relations or even their names, with few exceptions.

It is impossible to have any true appreciation of any class of objects or beings of which we have only the most superficial knowledge.

The pleasure experienced by one who has gained some acquaintance with a group of plants when such an one encounters a member of the group, which he or she has not met before, and the enjoyment of one who is prepared to make comparisons between the different species which may he encountered in a morning's walk, quite surpasses the indifferent satisfaction of one who is pleased only by the color and form of a flower, while the body of the plant is almost or completely disregarded.

Fortunately something beyond a vague undefined enjoyment of plants is now desired by a much larger class of people than was formerly interested in them.

If the technical names of the common plants met with in our excursions through the fields and groves are?learned, one soon becomes interested in finding that these names express relations between individuals of different aspect, which would otherwise be unsuspected. A knowledge of the common names is quite insufficient to enable the casual observer to detect these relations. An illustration of this statement might be found in the case of two species of Cornus common in our region. The excursionist meets with a little plant two to four inches high with a white flower succeeded by a bunch of red berries. He knows the plant as the "Bunch berry." Extending the walk, a tree twenty or thirty feet high is met with ; it is adorued with hundreds of large white flowers with green centers. The tree is the dogwood. In these names there are no suggestions of any relation between the little dwarf plant and the flower-bedecked tree. Should the excursionist, however, learn that the name of each is Cornus, he would be interested to scarch for the resemblance and he would soon find that the "flower" in each case is a group of flowers arranged in very similar fashion, and that there is in fact a striking resemblance between the little herb and the spreading tree.

Such relations and resemblances are to be olserved on every 
hand and mainly by the use of technical names are these resemblances and relations suggested.

The corollary of this is that in order to enjoy the plants and flowers which we meet we should possess a knowledge of botany at least to the extent of recognizing common plants by their technical names.

To one who would like to have a knowledge of the plants of his or her immediate locality an herbarium is important, not to say essential. One camnot always find a growing specimen which has already been identified with which to compare a newly found specimen. The exercise which will soonest fix the name, character and relations of a plant in mind is the act of preparing it for and preserving it in an herbarium.

An herharium is a collection of dried plants arranged according to a system of classification.

When the beginner thinks of the great number of plants which would constitute a complete herbarium he is in danger of discouragement, but it is to be remembered that no herbarium is complete, even the greatest. A collection of the plants of a certain locality, a county, a town or eren a lesser area is valuable according to its completeness for the giren region and the amateur who will make a thorough collection of the plants growing in his town or even in his school district will be a contributor not only to his own enjoyment and to his own intellectual culture, but to science as well.

Hence the collection should begin in the best way, and the best way is, after all, the easiest way.

First, the botanist or the amateur plant-lover should be provided with a receptacle for the specimens to be taken home from his or her excursions. The most convenient receptacle is a tin box made for the purpose and sold by tealers and known as a raseulum or botanist's box. In absence of tlie conventional botanist's box any closed tin box may serve, such, for example, as those in which certain biscuits are sold at the grocers. Cardboard boxes are scarcely a protection and they absorb the moisture from the plant as blotting paper absorbs ink. People who send flowers by mal in cardboard hoxes usually waste the stamps they use, while the friend to whom the flowers are consigned receives a crushed box with wilterl flowers. A tin box with a fairly dose cover will preserve plants quite fresh during several days, often more than a week.

Plants for preservation or for sturly should be placed at once in the rloser box in order to preserve their freshness. A few specimens of a single species are better than many. Small plants should be taken with the roots. Larger plants should always show characteristic leaves and portions of stem. The heginner should 
always commence with a collection of the commonest plants. If one waits for rare or beautiful specimens the collection will grow slowly and will be imperfect and unsatisfactory.

The specimens which are to be preserved must go into the press. The form and materials for a press should next be considered. The purpose is to dry the specimens in the best manner, and in the least practical time.

A press may be made of two thin boards, a few newspapers and a pair of straps with buckles. Dealers supply much better presses at a low cost, which are made of thin slats fastened to cross-bars, the two sides enclosing the drying papers, straps with buckles being used to produce the pressure which should be sufficient to flatten the specimens, but not enough to crush them. Such presses permit of more rapid drying than those made of boards. A temporary press may be made of a number of layers of newspapers laid upon the floor or a table over which a board is laid upon which is placed a weight. Drying papers are sold by dealers, but by far the most convenient papers are ordinary newspapers, not calendered. While for some purposes they are not equal to prepared dryers they are always at hand. Many persons press small plants between the leaves of illustrated magazines. As these magazines are made up largely of highly calendered paper absorption is prevented and the specimens turn black or the leaves drop off. Experience will soon help the beginniner to know about how much paper should lie between the different specimens, but one rule might be stated. If a very considerable number of plants is to go into the press more layers should lie between the different specimens than would be required for a few.

The plant to be preserved should, after being identified, be laid carefully between the drying papers in such a way as to show the leaves, stem, root, when practical, the flowers and fruit, if the fruit and flower are both on the same plant at the same time. If not there should finally be a specimen each for flower and for fruit. As the specimen is placed between the sheets there should always be placed with it a slip of paper with the name of the plant, the date when collected, the locality and, generally, the kind of soil in which it grew. This slip should be carefully preserved in connection with the specimen until the latter is finally mounted on the herbarium sheet when the record should be transferred to it also.

Ranunculus acris. $\mathrm{L}$.

Englewood, N. J.,

May 15, 1909.

Found in moist meadows, or dryer soil. 
Placing the press in the open air in the sunlight will hasten the drying, or at the seaside or in damp weather the press may be placed near a stove. When the specimen is dried it is ready for the herbarium. The mounting papers should if possible be of the standard size, $10 \frac{1}{2} \times 16 \frac{1}{2}$ inches. If it is inconvenient to have such papers the specimens may be kept in folders of fragments of newspapers or sheets of thin wrapping paper or they may be transferred temporarily to sheets of paper of any size by using fasteners which will permit of the final removal of the specimen to standard size paper, care heing always taken that the record follows it.

When a considerable number of specimens have been properly dried and mounted they should be placed in folders of manilla paper, each folder to receive the plants of a genus, the name of the genus to appear on the lower left hand corner. Should a genus contain many species and these perhaps some varieties, thinner folders may be used within the genus holders to separate the species, especially when it is desirable to preserve several specimens of the same species to illustrate the growth of the plant under different circumstances of soil or climate. It is a mistalie to mount the specimens in a book.

Finally, should the collection become large the genus folders should be arranged in a cabinet according to their families.

It is better to keep specimens gathered in widely different localities, for example, those collected in the Northern States and those from the Southern States in separate collections unless the collection has become so important that it fully represents this broad extent of country. 


\section{PAR'T II}

\section{SPECIAL FLORA OF THE MIDDLE ATLANTIC AND NEW ENGLAND STATES}





\section{FLORA}

\section{GROUPING OF FLOWERING PLANTS}

Among the plants familiar to us are found some which do not produce seeds, that is, seeds in the sense that the grains of wheat or of mustard are seeds, each containing the embryo of a future plant. Such plants as ferns, mosses, mushrooms and a great number of less conspicuous forms do not produce seeds of this kind, and, therefore, since a flower is a collection of organs essential to the evolution of the seed, these plants which are not reproduced from seeds have no occasion for flowers and consequently do not produce them.

Plants producing neither flowers nor seeds constitute a great group by themselves, while those commonly known as "the higher plants" constitute another well defined group.

This latter group, characterized by the production of flowers and seeds is known as the Grand Division of Flowering Plants. Technically the Grand Division is known as Embryophyta, ${ }^{1}$ the word meaning Embryo-plants or Phanerogamia, meaning plants having manifest flowers.

In the introductory part of this work more detailed information regarding the principles of grouping in this Grand Division will be found. This should be carefully studied.

The following table includes the Sub-divisions, Classes and Orders of this primary plant series so far as the orders are represented by native plants in our area.

The word Order as employed in the table and throughout this work is applied to a larger group than that to which it was applied in text-books a few years ago. The groups then known as orders are now known as families and an order, as the term is now used, may include several families.

\section{THE GRAND DIVISION OF FLOWERING PLANTS (EMBRYOPHATA, PHANEROGAMIA)}

Plants which produce seeds. They are provided with fully developed or with rudimentary stamens and pistils which are the essential elements of flowers. They are grouped into two Sub-divisions

This grand or primary division is also known as Phanerogamia, meaning visible flowers, while the primary series, not endowed with such flowers is known as Cryptogamia, or hidden flowers. 


\section{Sub-Division I-GYanospermaE ${ }^{1}$-Naked-Seeded Puats (Page 8t)}

Plants whose seeds are not enclosed in protectice seed ressels. There are several Classes of Gymnosperms, only one of which is represented in our region, though the Ginko tree, which is somewhat extensively planted as an ornamental tree, is a member of one of these classes, not, however, growing as a native tree with us. Our native plants with this peculiarity of naked seeds are all included in a single group.

\section{Class-CONiferae-Cone-Bearing Plants (Page 81)}

The plants of this class are included in the Pine and Tew families. They are trees or shrubs with needle-shaped or scale-like leares and are mostly evergreen. The seeds are borne on the face of a scale, a number of scales forming a cone.

A rast majority of our flowering plants, howerer, have their seeds concealed in some form of closed envelope as is the case with the pea in its pod, the small seeds of the larkspur in their dry follicle or the seeds of the apple, enclosed by the tough parchment-like walls which are themselves surrounded by the pulp, those of the squash corered in by the pulp and the tough thick shell. Plants whose seeds are thus enclosed constitute the second great Sub-division.

\section{Sub-Dirision II-ANGIOSPERMIAE 2-Plants with Ex- CLOSED SEEDS}

\section{(Page 89)}

Plants whose orules or seeds are enclosed in a protective seed vessel, the ovary.

This second Sub-division is divided into two classes, each characterized by the manner of growth of the stem and by the number of lobes constituting the seeds.

Below are seen three figures representing the naked seeds of the Pine family and three examples of enclosed seeds.

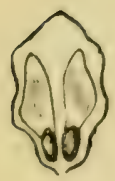

I.

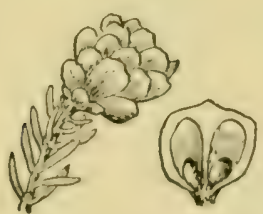

2.

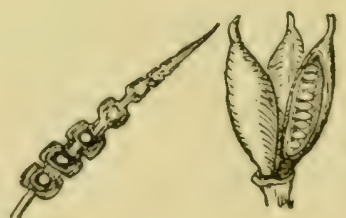

Fig. 1.

4.

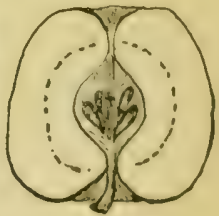

6.

1. A scale from the cone of a pine with two winged seeds lying upon its surface. 2. A cone of hemlock. 3. A single scale from a hemlock cone with its two winged sceds. The protection for the ovules thus lying upon the surface of a scale is from an overlying scale, the ovule resting between the two, 4. A pod of wild mustard, the three lower seeds are exposed by cutting parts of the pod. 5. Three follicles of monks-hood, the seeds of one follicle exposed. 6. Section of an apple, showing the membraneous core, which constitutes the immediate envelope for the seeds.

- Gymnos, naked; sperma, seed.

a Aggeion, a vessel. 


\section{Class I-MONOCOTyledons-Plants with Single Lobed Ovules}

The seeds have a single lobe or cotyledon constituting a rudimentary leaf. The leaves of plants of this class are, in general, parallelveined, and in the stem there is no distinction of pith, wood and bark. The flower of most of the land plants of this class and of the more highly developed of its aquatics, has its parts in 3's (petals 3 or 6 , sepals 3 and stamens 3 or 6 ). In the submersed aquatics and in some other water plants of the class, also in some of the grass-like plants, the parts of the flower are in 2's or 4's or very rarely in 5's.

\section{ORDERS OF MONOCOTYLEDONOUS PLANTS IN OUR AREA}

\section{ORDER I-PANDANALES-CAT-TAIL ORdER (Page 90 )}

Herbs growing in marshes or other wet places. The flowers are arranged on the fleshy terminal of the stem in the form known as a sparix, but without the leaf-like sheath characteristic of the Arum family. The envelope about the floral elements (perianth) is composed of bristles or chaffy scales and the flowers bearing stamens and those bearing pistils are in different groups, one above the other. The flowers are arranged in Iong cylindric groups or in rounded beads.

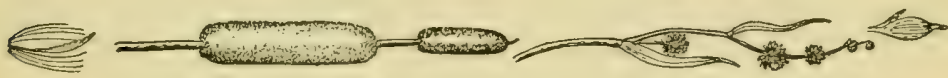

7.

7. Pistillate flower of Cat-tail Bur-reed.

\section{Order II-HelobiaE 1 - Water or Marsh Plants (Page 93)}

Plants wholly or partly submersed in water or partly floating. In some families the perianth (flower envelope) is wanting or incomplete, while in others it is present and conspicuous. The perianth has never more than 4 segments in a single series and it is only in the very inconspicuous flowers that there are so many. The more conspicuous flowers have a calyx of 3 sepals and a corolla of the same number of petals. The stamens number from 1 to many.

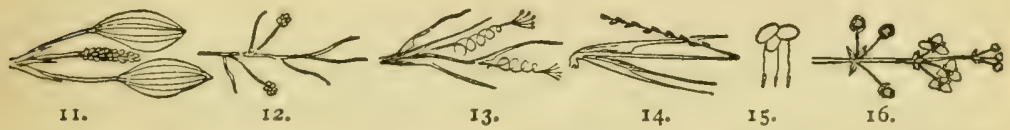

II and I2 Pondweeds. 13. Ruppia. 14. Arrowgrass. 15. Duckweed. 16. Arrowhead.

\section{Order III-GLUMiflorae-Glumaceous Plants (Page rog)}

Flowers bearing glumes of dry husks, which take the place of the ${ }^{1}$ Helos, marsh; bios, life. 
petals of other flowers. The class includes grasses and sedges. These are not included in this work.

\section{Order IV-SPATHifloraE-Spadix-Flowered Plants \\ (Page rog)}

Flowers are borne on a fleshy, club-like receptacle (a spadix), which is usually surrounded by a broad leaf-like sheath, sometimes highly colored (A spathe).

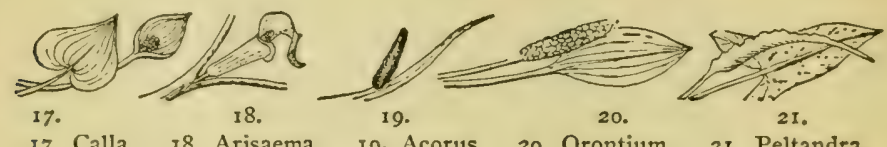

\section{Order V-FArinosae-Plants with Mealy Seeds (Page 112)}

Flowers regular or nearly so (except in Commelina), the sereral carpels united into a single ovary. The flower parts are mostly in 3 's or 6's. Orary situated above the corolla and calyx. Differs structurally from the following order in that the embryo is placed at the end of the seed opposite the point of attachment of the seed to the ovary.

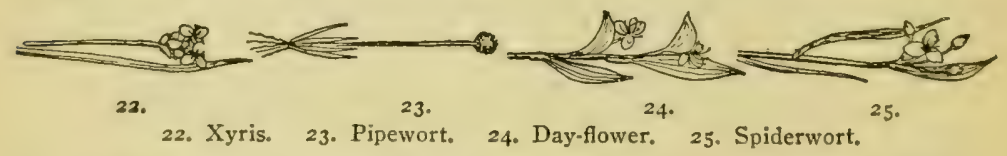

\section{Order VI-LILIFLoraE-Plants with Liliaceous Flowers (Page 117)}

Flowers generally conspicuous and symmetrical. The flower parts always in 3 's; petals 6 , stamens 6 or 3 , pistil 1 with a 3 -celled orary.

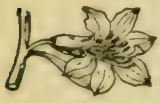

26.

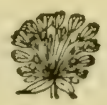

27.

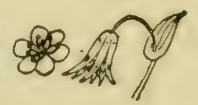

28.

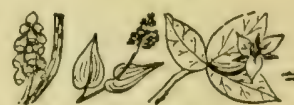

30. 31. 32 .

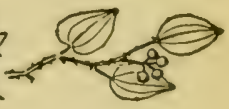

33.

26. Lily. 27. Onion. 28. Veratrum. 29. Bellwort. 30. Hyacinth. 3x. False Lily. of-the-Valley. 32. Trillium. 33. Smilax.

\section{Order vil-ORCIIIDACEAE-Plants witi Ormidaceous Flowers (Page ${ }^{246)}$}

Leaves with parallel veins or veins spreading in elliptical lines. Flowers usually unsymmetrical, stamens growing in union with the pistil within the flower envelope.

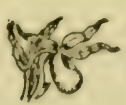

34.

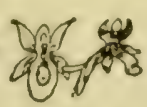

35 .

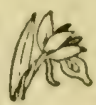

37.

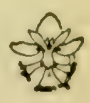

38.

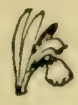

39

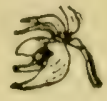

40.

34. Cypripedium. 35. Orchis spectabilis. 36. Orchis orbicularis. 37. White bog orchis. 38. Fringed orchis. 39. Pogonia. 40. Calynso. 


\section{Class II-DICOTYLEDONS-Plants with Twin-loned Ovules (Page 164)}

The seeds have 2 lobes or cotyledons. The leaves are, almost always, net-reined, and the distinction of pith, wood and bark is evident. The flower parts or members are very rarely in 3 's, but usually in 5 's or less frequently in 4's.

\section{SUB-CLASSES, GROUPS AND ORDERS OF DICOTYLEDONOUS} PLANTS IN OUR AREA

\section{SUB-CLASS I-CHORIPETALAE \\ (Page 166)}

Petals separate (examples: Buttercup, Pink, Violet). This natural Sub-Class is here divided into two more or less natural groups, for notwithstanding the sub-class is composed of plants, the flowers of which are assumed technically to have divided petals there is, in fact, a great group in which the petals are undeveloped or in which the floral envelope is of a very rudimentary character. We shall then assume the groups:

1. Flowers without petals . . . . 1st. Group, Apetalat

2. Flowers with several petals or colored sepals. 2d. Group,

\section{GROUP I.-ORDERS OF APETALOUS CHORIPETALAE}

\section{Order I-JULIFLORALES-CatKIN-BEARING Trees and Herbs (Page 166)}

Flowers grouped in large numbers in catkin-like inflorescence or in fascicles. Flowers without corolla and often without calyx. Trees, shrubs and herbs.

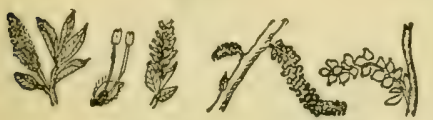

40. 41. 42. 43 .

40. Staminate catkin of Willow. 4r. Single flower. 42. Pistillate catkin of Willow. 43. Staminate catkin of Poplar. 44. Pistillate catkin of Poplar. 45. Pistillate catkin of Hornbeam. 46. Single pistillate flower. 47. Staminate cluster of Elm. 48. Winged seed or Elm. 49. Catkin of Nettle. 50. Catkin of Hop.

\section{Order II-SANTALES-The Mistletoe Order (Page 196)}

Plants, (ours) all parasites; calyx present, sometimes colored, corolla absent, flowers not in catkins. Ovary 1-celled, below the sepals.
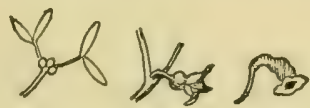


\section{Order III-POLYGONALES-ThE BUCKWHEAT ORder \\ (Page 200)}

Our species, herbs, mostly in wet places. Flowers in general, regular, the parts mostly in $3 \mathrm{~s}$. Orary 1-celled, 1-seeded, the seed arising from the base of the ovars. Leaves alternate, subtended by a collaret or sheathing stipule, technically an ocrea.

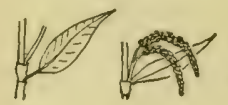

54.

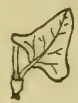

56.

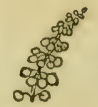

57.

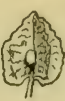

58.

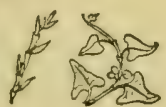

60.

54. Single joint and leaf of Polygonum. 55. Catkin of Polygonum. 56. Leaf of Buckwheat. 57. Spike of flowers of Dock. 58. Winged seed of Dock. 59. Spray of Door Weed. 60. Spray of Bind Weed.

\section{Order IV-CHENOPODIINEAE-PIg WEED ORder}

(Page 210)

Our species always herbs, mostly weeds in cultirated grounds. (The beet and spinach are valuable cultivated species.) Flowers always with the members equal, but these are generally very small and inconspicuous, rarely colored and the corolla is nearly always absent. Orary 1-cellel, 1-seeled. Leaves vithout stipules or collaret.
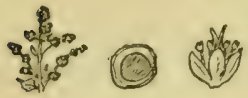

64. 65. 66 .

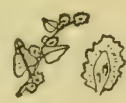

67. 68.

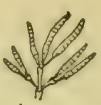

69.

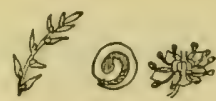

71.72.

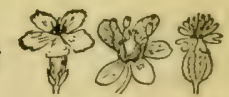

73. 74, 75,

64. Summit of Pig Weed. 65. Transverse section of seed of Pig Weed. 66. Flower of same. 67. Summit of Orache. 68. Seed of Orache. 69. Summit of Slender Glasswort. 70. Spray of Dondia, 71. Section of seed of same. 72 . Flower of Prke Weer. 73. Flower of Pink. 74. Flower of Carpet Weed. 75. Flower of Lychnis.

\section{ORder V-PHYTOLACCINEAE-PoKe Root ORder (Page 221)}

A single, rather coarse plant, in our area, with flowers in a long nearly cylindric cluster. Individual flowers regular, stamens as many or more than the parts of the calyx. Corolla wanting, the calyx white or colored.

\section{GLOUP II-ORDERS OF POLYPETALOUS CIORIPETALAE}

In this group the flowers hare, as a rule, hoth calyx and corolla fully developed, the corolla consisting of several petals distinct and separate from each other. Eximples: Buttercup, Wild Rose, Poppy. In a few species in the Order Caryophyllineae, a few in the Order Lanales, and a very few in other Orders the petals are undeveloped.

\section{Order I-PORTULACINEAE-Order OF PURsLanes \\ (Page 223)}

Flowers with calyx and corolla, the former of 2 (or more) sepals, the latter of 4 or 5 (or more) petals. Stamens as many as the petals and opposite to them or sometimes more or less. Ovary of 1 cell with many orules arising from the base. Fruit a capsule, opening as a lid 
at the top or by 3 teeth at top. Floral receptacle concave and the ovary above the petals and stamens.

\section{ORDER II-CARYOPHYLLINEAE-PINK ORDER \\ (Page 224)}

Flowers generally with both calyx and corolla, the latter of sereral distinct petals, mostly 5. In Paronichia and in certain species of some other genera the corolla is undereloped or only rudimentary. Ovary of 1 cell, above the stamens and corolla, many seeded, the ovules arising from the central column. Leaves always opposite and without teeth or lobes and without stipules.

\section{Order III-RANALES-ORder OF Polycarpes \\ (Page 240)}

Flowers with several petals or in a few exceptional cases without apparent petals, regular or irregular. Stamens usually numerous more than the petals. Stamens and petals below the orury, which consists of 1 or more, frequently sereral, seed vessels (carpels) which, in general, are free from each other (example, those of the Buttercup). The parts of the flower are usually inserted in a spiral line. The Order includes Families differing widely in appearance, but which are united by these general characteristies.

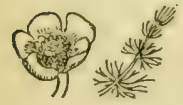

76.

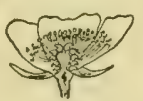

78 .

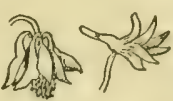

79. 80.

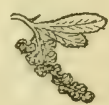

$8 \mathrm{r}$.

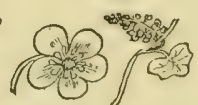

82. 83. 84. 85

76. Flower of Water Lily. 77. Spray of Hornwort. 78. Section of flower of Ranunculus, 79. Flower of Columbine. 80. Flower of Larkspur. 8r. Flower cluster of Barberry. 82. Flower of Mandrake. 83. Menispermum. 84. Leaf and fruit of Sassafras. 85. Flower of Tulip Tree.

\section{Order IV-RHOEADALES-The Poppr Order \\ (Page 268)}

Flowers with double perianth, the netals usually 4 , the sepals 2 or 4 , sometimes 8 . The parts of the perianth are always independent. The receptacle is, with few exceptions, convex; stamens 4 or more. Seed caskets (carpels) 2 or more, which ordinarily grow together, forming a single ovary as in the Poppy.
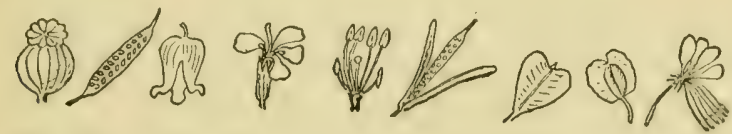

86. 87.88 .89 .

90. $9 \mathrm{I}$.

92.

93. 94 ,

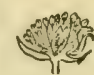

95 ,

86. "Head" of Poppy. 87. Fruit of Celandine. 88. Flower of Bicucula. 89. Flower of Cardimine. 90. Stamens and pistil of Cardimine. 91. Pod (silique), of Tower Mustard, opened. 92. Pod (silicle), of Shepherd's Purse. 93. Pod (silicle), of Penny Cress. 94. Flower of Cleome. 95. Flower of Mignonette.

\section{Order V-SARraceniales-Order of the Pitcher Plants (Page 29r)}

Seed caskets (carpels) 2 or more united into one. Ovaries above the stamens, corolla usually of 5 petals. Leaves all at the base. In Sar- 
racenia the leaf stalk is transformed into a hollow tube. Insectivorous plants growing in swamps, secreting a viscid substance which aids in the capture of insects.

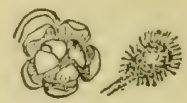

98. 99

98. Flower of Pitcher Plant. 99. Leaf of Droscera.

\section{Order Vi-ROSAles-Order of the Rose Alliance (Page 292)}

Seed casliets (carpels) of rariable number, free from each other or growing together. P'etals and sepals usually 5. Stamens more numerous or of the same number. Flowers symmetrical or not. Receptacle concave. Leaves simple or compound. The stamens are usually inserted on the calyx a short distance from the ovary or at the top of the ovary.
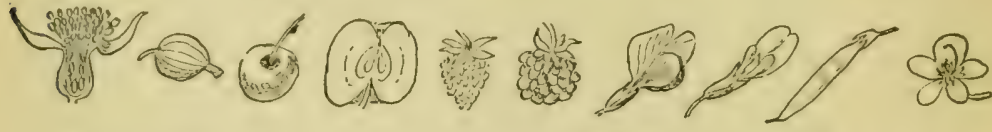

100. 108.

102. 103 104. 105. 106.

108.

Iog.

s00. Schematic section of Rose hip. ror. Fruit of Gooseberry. 102. Fruit of Cherry. 103. Section of Apple. 104. Fruit of Strawberry. 105. Fruit of Blackberry. I06. Flower of Wild Vetch. I07. Flower of Clover. I08. Pod of Wild Vetch. 109. Flower of Sensitive Pea.

Order VII-GERANIALES-ORder OF THE Geraniums

(Page 364)

Ovary superior to and free from the calyx. Stamens fer, as many as the sepals and opposite them or fewer when the corolla is irregular. The ovules are pendulous, the raphe or ridge toward the axis of the ovary.
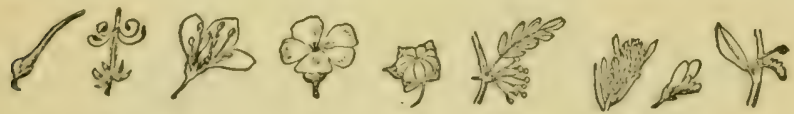

IIO. III. II2.

113.

I14. II 5 .

II 6.217

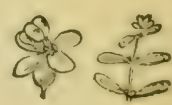

18.

119. 120.

110. Frust of Geranium, 11 . The same aiter the bursting of the ovary. Ixz. Section of flower of Oxalis, II3. Flower of Flax, 1i4. Fruit of Flax. II5. Cluster of fruit of Prickly Ash. II6. Cluster of flowers of I'olygala. II7. Flower of Poly. gala. I18. Flower of Acoylpha. Irg. Flower of Euphorbia. Iro. Summit of Caliiriche.

\section{Order VIII-SAPINDATES-ORder OF THE MAPLeS (Page 380)}

The chararteristics which differentiate this order from the preced. ing is the finet that the ovules are pendulous scith the ridge or raphe turned away from the axis of the ovary.

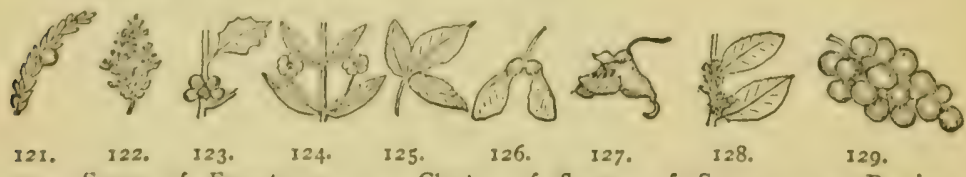

r21. Spray of Empetrum. 122. Cluster of flowers of Sumac. 123. Berries of Ifolly. 124. Ilowers of Euonymus. 125. Leaf of Staphylea. 126. Fruit (key) of Maple. 127. Flower of Jewel WVeed. 128. Flowers of Buckthorn. 129. Grapes. 


\section{ORDER IX-RHAMNALES-ORDER OF THE BUCKTHORN}

\section{(Page 394)}

Shrubs, trees or vines. Ovary superior and free from the calyx. Stamens as many as the divisions of the calyx and alternate with them. When petals are present the stamens are opposite to them. Ovules not pedulous.

\section{Order X-MALVALES-Order of the Mallows (Page 396)}

Trees, shrubs or herbs with distinct petals and, usually, numerous stamens. Carpels united into a compound ovary, which is free from the calyx and above it. Sepals, in the bud, meeting but not overlapping. Orule bearing surface forming a central column within the capsule.

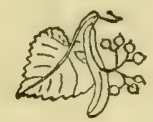

I30.

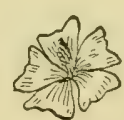

I 31 .

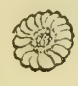

132.

130. Leaf and fruit of Linden. 13r. Flower of Mallow. 132. Fruit of Mallow.

\section{ORDER XI-PARIETALES-ORder OF THE VIOLETS (Page 400)}

Ilerbs, rarely trees or shrubs, ours all small herbs. Sepals overlapping each other in bud or are longitudinally rolled. Orules generally attached to the sides of the capsule or rarely to central axis.

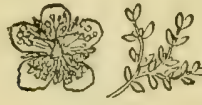

I33. I34.

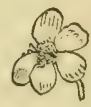

135.

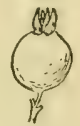

I36.

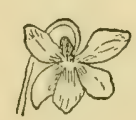

137.

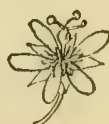

$I_{3} 8$.

133. Flower of Hypericum. 134. Spray of Water-wort, 125. Flower of Frostweed. T36. Fruit of Pin-weed. I37. Flower of Violet. $338^{\circ}$. Flower of Yellow Passion , Flower.

\section{Order XII-OPUNTIALES-ORder of the CaCti (Page 4I7)}

Fleshy and generally, spiny plants. Ovary inferior to the calyx and attached to it. Sepals and petals numerous, indefinite in number.

\section{ORder XIII-THYMELEALES-ORdER OF THE MOOSE WOOD} (Page 4I

In our area, all shrubs, not fleshy or spiny. Calys extending upwards upon the ovary and attached to it. In our species petals are wanting. Ovary of a single cell with a single orule. 


\section{ORdER XIV-MYRTALES-ORdER OF THE MYRTLES \\ (Page 4I8)}

Calyx attached to the ovary or the latter is free. Orules are numerous. Petals present except in one family of aquatic plants.

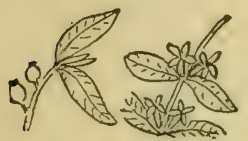

139.

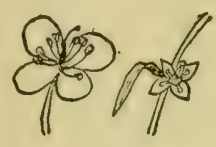

141 .

142.

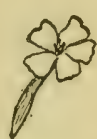

143.

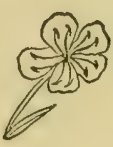

I 44

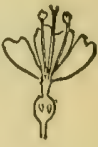

145.

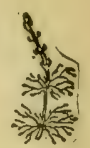

146.

139. Buffalo Berry. 140. Lythrum. 141. Flower of Rhexia. 142. Flower of Ludwigin. I43. Flower of Epilobium. 144. Flower of Evening Primrose. 345. Flower of Enchanters Nightshade. 146. Spray of Myriophyllum.

\section{Order XV-UMBELLALES-Order of The CARrot}

(Page 434)

Herbs, shrubs or trees. Flowers in umbels or umbel-like heads. Orary surrounded by the calyx, each cell of the orary containing a single ovule. Stamens equal in number with the petals and alternate with them.

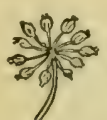

147.

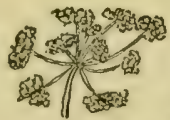

148 .

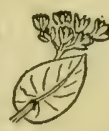

I 49.

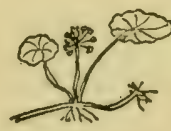

150.

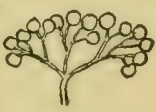

I5 I.

147. Umbel of Aralia. 148. Umbel of Wild Carrot. 149. Umbel of Bupleurum. 150. Hydrocotyle. 14x. Umbel of Cornus.

(For Key to the Orders of Sub-Class II-Sympetalous or Monopetalous Exogens-See Page 456.) 


\section{AN ARTIFICIAL KEY TO THE FAMILIES OF PLAN'TS INCLUDED IN THIS WORK}

cuts.)

(Numerals in parentheses refer to corresponding numbers of the small

1. Ovules lying naked, usually between the scales of a cone or a berry-like body or on a fleshy disk. $(1,2,3)$

Class CONIFERAE. 2

1. Ovules developed in a closed cavity (an ovary). $(4,5)$

CLASS ANGIOSPERMAE 3

2. Seeds (ovules) in a cone-like (1) body or in a 3 -seeded berry

2. Seeds (ovules) on a fleshy disk. (3) . . . TAxaceae. Pg. 82

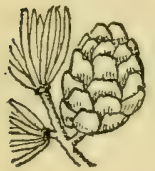

I.

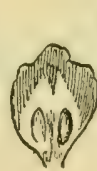

2.

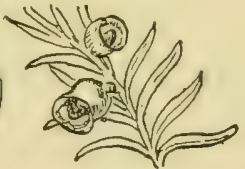

3 .

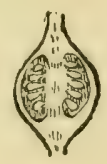

4.

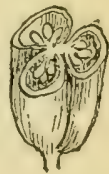

5 ,

3. Leaves mostly parallel-veined; flower parts usually in 3's; stem without pith. $(6,7)$. . . . . . . . 4

3. Leaves net-reined; flower parts mostly in 5's or 4's, not in 3's; stems with pith, at least when young. $(8,9,10) . .25$

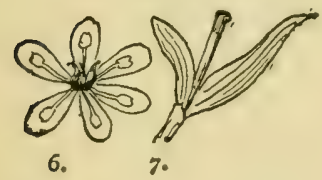

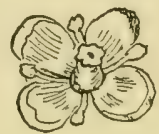

8.

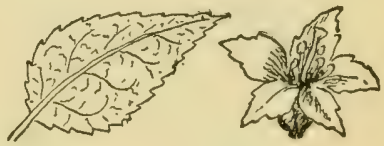

9.

I0.

\section{CLASS I}

\section{MONOCOTYLEDONS}

4. Plants not aquatic

Aquatic Plants

4. Aquatic plants, floating or submersed . . . . . . . . . 5

4. Aquatic plants, not floating nor wholly submersed . . . 8 
5. Small green disks floating on the surface of water, usually with thread-like roots extending downward in the water

5. Plants with true leaves and stem

Lesraceat. Pg. 93

6. Flowers without white or colored perianth, arranged along a fleshy, club-like receptacle or in few flowered umbels. (11, 12)

6. Flowers with white or colored perianth

NAIAdaceae. Pg. 94

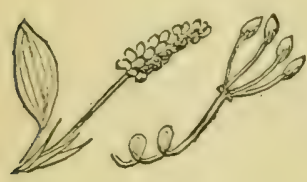

II. I2.

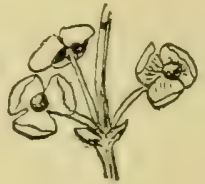

I3.

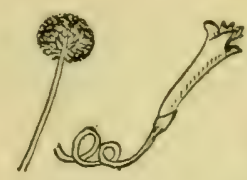

I5,

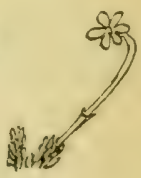

I6.

7. Perianth adherent to the surface of the ovary. $(15,16)$

VAllisiteriaceae. Pg. 108

7. Perianth not adherent to the ovary, flowers subtended by a small leaf-like sheath, one or few in heads

Heteranthera in PoNtederiaceat. Pg. 116

8. Perianth of bristles, hairs or scales . . . . . . . . . 9 9

8. Flowers with minute perianth or none. . . . . . . . 11

8. Perianth of well-developed and conspicuous parts . . . . 12

9. Perianth of bristles or hairs, flowers in compact cylinders. (17)

9. Perianth of scales

TrPHACEAE. Pg. 90 10

10. Perianth of one or more very small scales, flowers in dense heads. (18) . . . . . . . SPArganiaceae. Pg. 92

10. Perimuth of 6 hush-like scales, green or brown, rush-like plants. (22)

JUXCACEAE. Pg. 118

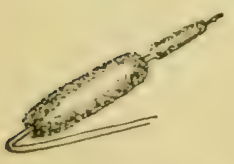

17.

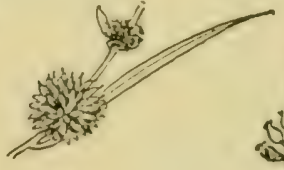

18.

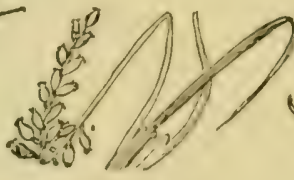

19.

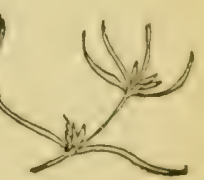

20.

11. Flowers without perianth, on a fleslyy spike (spadix), usually surrounded by or subtended by a leaf-like bract. (21)

Aracese. Pg. 109

11. Plants with ruslelike cylindric leaves and flower stems. Flowers in slender spikes, perianth herbaceous. (19) 
11. Plants with basal leaves, often wholly submersed. Flowers in dense round heads. (14) . . . Eniocaulaceae.. Pg. 113

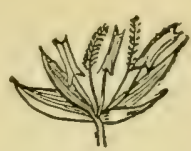

21 .

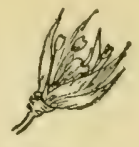

22.

12. Flowers white; petals 3 ; sepals 3 ; flowers usually in succes-

sive whorls on the stem. (13) . . . Alismacene. Pg. 103

12. Flowers blue, in a thick spike which is subtended by a leaf-

like sheath. (23) . . . . Poxtedereacene. Pg. 116

12. Flowers yellow, in elongated heads. (26) . Xrridaceat. Pg. 112

\section{Terrestrial Plants}

13. Flowers without perianth, on an elongated fleshy receptacle subtended by a leaf-like sheath. (27) . . AraceaE. Pg. 109 13. Flowers with perianth of dry scales; grass-like plants.

(21) . . . . . . . ORDER GLUMALES (The Glumales are not included in this work.)

13. Perianth not of scales

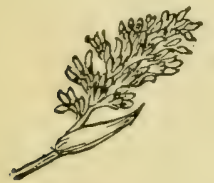

23.

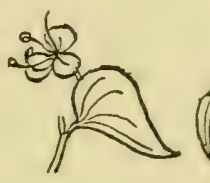

24.

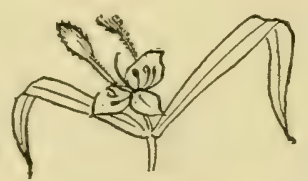

25.

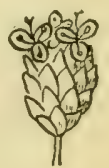

26.

14. Flowers regular or irregular, blue, the flower or cluster sub-

tended by a leaf-like sheath. $(24,25)$ Commelinaceae. Pg. 114

14. Flowers or clusters not subtended by a leaf-like sheath . 15

15. Stamens and pistils free from each other . . . . . . . 16

15. Stamens and pistils united. $(28,29)$. . OrcmidiceaE. Pg. 146

16. Herbs . . . . . . . . . . . . . . . . . 17

16. Woody vines. (30) . . . . . Smilaceae. Pg. 140

17. Stamens 6, petals 6 . . . . . . . . . . . . 19

17. Stamens 3 . . . . . . . . . . . . . . . 18

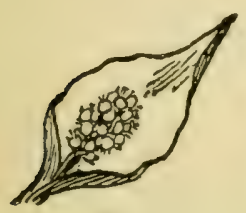

27.

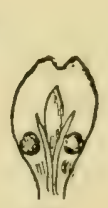

28.

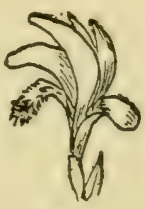

29.

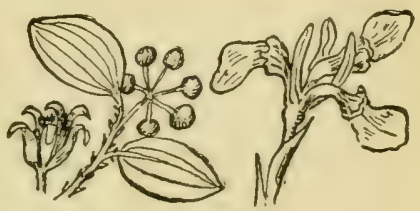

31.

18. Perianth of unequal parts. (31) . . . IRIDACEAE. Pg. 142 18. Perianth of equal parts. (33) . . Haemodoraceae. Pg. 141 
19. Veinlets of leaves in form of a net-work. (32)

. . . . . Trillium, in Convallariaceae. Pg. 138

19. Veinlets not in form of a net-work . . . . . . 20

20. Flowers in umbels, leaves and stem arising from a bulb . . 21

20. Flowers not in umbels . . . . . . . . . . . 22

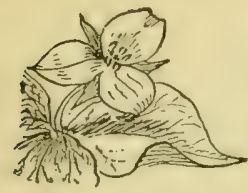

32.

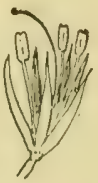

33.

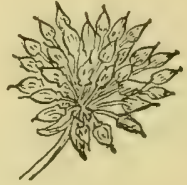

34 .

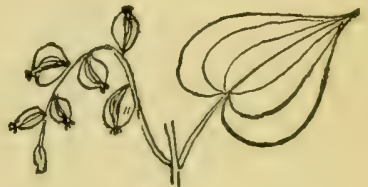

35 .

21. Perianth adherent to the ovary - . A Ararillidaceae. Pg. 141 21. Perianth not adherent to the ovary. (34) - Alliaceae. Pg. 130 22. Climbing vines.

22. Plants not vines.

Dioscoriaceae. Pg. 142

23. Styles 3, distinct.

23

23. Style 1

- Melanthaceae. Pg. 125

24. Fruit a fleshy berry.

(37)

Convallariaceae. Pg. 134

24. Fruit a capsule splitting lengthwise. (38) . Liliacea. Pg. 124

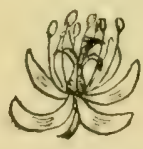

36.

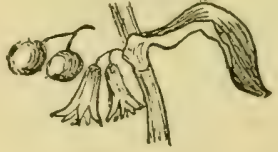

37.

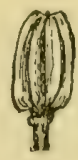

38.

\section{CLASS II}

DICOTYLEDONS, OR EXOGENS

a. Flowers without Petals, 25

b. Flowers witi Severil Pfrars, 54.

c. FlowERS WITH UNITED Petals, 119

25. Trees, shrubs or undershrubs . . . . . . . . . 26

25. Herbs . . . . . . . . . . . . • • . . 39

\section{Trces, shrubs and undershrubs}

26. Flowers in catkins or catkin-like heads. $(39,40)$. . . 27

26. Flowers not in eatkins nor eatkin-like heads . . . . . . 33

27. Leaves compound, feather-formed (pinnate). (41)

27. Teaves simple. $(42)^{\circ} \cdot{ }^{\circ} \cdot *^{*} \cdot *^{*}$ JuglandACEAE. Pg. 178

28. Parasitic shrubs, on other trees; fruit a berry

28. Trees and shrubs, not parasitic . . . . . . . . 29 
29. Sap milky

Moraceae. Pg. 194

29. Sap not milky

30. Calyx not present.

30. Calyx present. (44)

31. Ovary of 1 cell, with 1 seed. (45)

31. Ovary folliculate, many seeded.

32. Both pistillate and staminate flowers in catkins

Mrricaceae. Pg. 177 Salicaceae. Pg. 167

32. Pistillate flowers subtended by an involucre, which becomes a bur or a cup at maturity . . . . FAGACEAE. Pg. 185

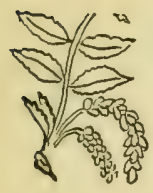

39.

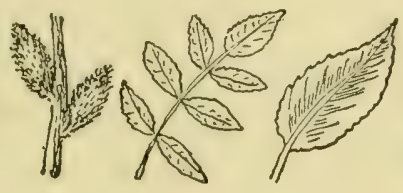

40.

4 I.

42.

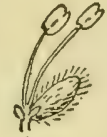

43 ,

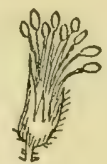

44,

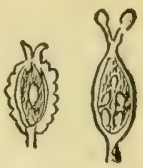

$45,46$.

33. Fruit a key (Samara)

34

33. Fruit a rounded bur-like head

Liquidamber in Hamamelidaceae. Pg。306

33. Fruit a drupe or berry

33. Fruit a single seeded achene with a plumose tail

Clematis in Ranunculaceae. Pg. 248

34. Fruit a double key.

34. Fruit a single key.

Aceraceat。 Pg. 389

35. Leaves simple

35. Leaves of several leaflets . . Fraxinus in OLEACEAE. Pg 485

36. Leaves alternate

37

36. Leaves opposite - . Shepherdia in Elafaganaceae. Pg. 418

37. Calyx 4- or 5-parted . . . . . . Thymeleaceae. Pg. 417

37. Calyx 6-parted . . . . . . . . . . . 38

38. Stamens 4 or 5 . . . . . . . Santalaceae. Pg. 198

38. Stamens 9 . . . . . . . . . . . Lauraceae. Pg. 268

\section{Flowers without Petals, Herbs}

39. Leaves alternate or all from the root.

39. Leaves opposite

40. Plant entirely aquatic, leaves dissected, the segments thread-

$$
\text { like . . . . . . . . . . . . } 41
$$

40. Plants terrestrial, leaves not dissected, not thread-like . . 42

41. Leaves alternate . . . . . . . . Podostemaceae. Pg. 295

41. Leaves in whorls . . . . . Ceratophyllaceae. Pg. 243

42. Stipules present, sheathing the stem above the joints. (49) . . . . . . . . Polygonaceae. Pg. 200

42. Stipules absent 
43. Flowers white or pink, in long slender catkin-like spikes or spikes with small flowers

43. Flowers never white, mostly in rounded masses or clusters or in spikes. . . . . . . . . . . . . 45

43. Flowers neither in close masses nor in spikes . . . . . 46

44. Fruit, 4 fleshy carpels . . . . . . Saururaceae. Pg. 166

44. Fruit a dark purple berry . . . . . Phrtolaccaceae. Pg. 221

45. Calyx green or colored, minute . . C Chenopodeaceae. Pg. 211

45. Calyx of dry scales or husks, and surrounded by dry, often colored bracts . . . . . . Amarantilaceae. Pg. 218

46. Calyx attached to the whole extent of the ovary. (50)

Aristolocimaceae. Pg. 199

46. Calyx not attached to the ovary . . . . . . . . 47

47. Fruit a 3-lobed capsule. (51) . . . . EupHorbiaceas. Pg. 374 47. Fruit an indefinite number of 1-celled carpels.

Some species of Ranunculaceae. Pg. 246

48. Plants entirely aquatic .

48. Plants terrestrial

49. Leaves opposite

49. Leaves in whorls

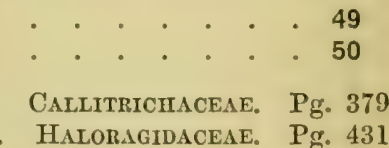

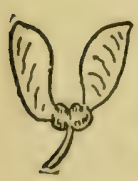

47.

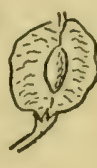

48.

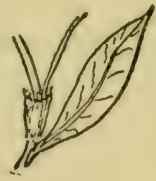

49

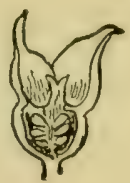

50.

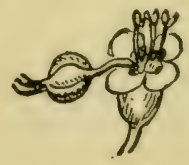

51.

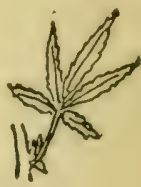

52.

50. Leaves with stipules. (52) . . . . . . . . . 51

50. Leaves without stipules . . . . . . . . . . 52

51. Twining vine or a plant with leaves of 5 leaflets from a common point of insertion . . ParT of Unticaceae Pg. 194

51. Plants not twining and leaves not divided into leaflets

Urticacene. Pg. 194

52. Fruit a 3-celled capsule

52. Fruit usually a 1-celled capsule.

Species in Cartormulaceae. Pg. 225

53. Capsule pendulous.

Eupiorbiaceae. Pg. 374

53. Capsulo not pendulous

AIZOACEAE。 Pg. 221

\section{b. Flowers witil several Petals. Polypetalae}

54. Trees, shrubs, woody vines . . . . . . . . 55 and 60

54. $\mathrm{Herbs}$ 


\section{a. Woody Tines}

55. Fruit a number of single-seeded achenes, each with a plumose tail; sepals 4, resembling petals. (53)

56. Leaves of 3 leaflets . . Rhus radicans in Anicardincene. Pg. 384

56. Leaves never of 3 leaflets . . . . . . . . . . 57

57. Stamens 4 or 5 . . . . . . . . . . . . . 58

57. Stamens 12 or more. (54) . . . Menispermaceat. Pg. 266

58. Throat of calyx crowned with a double or' triple fringe.

(55) . . . . . . . Passifloraceae. Pg. 416

58. Throat of calyx not fringed . . . . . . . . 59

59. Stamens alternate with the petals.

59. Stamens opposite to the petals Colastrus in Cend Pracear. Pg. 395

b. Trees and shrubs

60. Leaves opposite

. . . . . . . . . 61

60. Leaves alternate

Leaves opposite

61. Fruit a capsule.

61. Fruit a berry

61. Fruit a disk-shaped fleshy pod . . . Celastracene. Pg. 386 61. Fruit of 3 inflated carpels . . . . Staphyleaceae. Pg. 388 61. Fruit a double key (samara). (47) . . . Aceracene. Pg. 389

62. Fruit a membraneous 2-celled capsule.

Hydrangea in SAxifragaceaE。 Pg. 302

62. Fruit a globose leathery nut-like capsule. (56)

- Hippocastanaceae. Pg. 390

63. Flowers in elongated clusters . . . . Berueridacene. Pg. 264 63. Flowers in umbel-like clusters. (57) . . . Cornaceat. Pg. 450

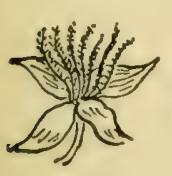

53 .

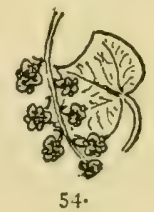

54 .

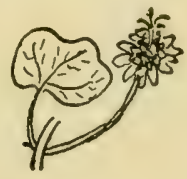

55 .

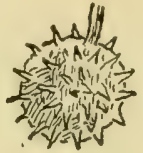

56.

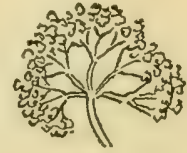

57.

Leaves alternate

64. Teaves compound

64. Leaves simple

65. Juice milky

65. Juice not milky

ANacardiaceae. Pg. 382

66. Leaves compound, fruit a Key (48) or stems armed with large prickles (not thorns) . . . . . . Rutaceae. Pg. 370

66. Fruit not a Key and stems not armed with prickles on the bark 67 
67. Flowers irregular . . . . . . . . . . . . 68

67. Flowers regular . . . . . . . . . . . . . . . 69

68. Flowers yellow . . . . . . . Caesalpixaceae. Pg. 336

68. Flowers white . . . . Robinia in Papillonaceae. Pg. 348

69. Fruit a twisted key . . . . . . Simarubscese. Pg. 371

69. Fruit not a key . . . . . . . . . . Rosicele. Pg. 306

70. Flowers irregular . . . . . . Caesalpivaceae. Pg. 336

70. Flowers regular . . . . . . . . . . . . 71

71. Leaves with mostly permanent stipules . . . . . . . . 72

71. Leaves without stipules or with small ones which fall early . 73

72. Fruit a pendulous head of 'several nutlets. (59)

72. Fruit not a pendulous head of nutlets Rosacese, Po. 306

73. Stamens few . . . . . . . . . . . . 74

73. Stamens usually more than 12 . . . . . . . . . . 77

74. Stamens 2 to 4 , calyx segments $3, \quad(60)$. Empetraceae. Pg. 381

74. Stamens 4 or 5 , calyx segments more than 3 . . . . . . 75

75. Stamens alternate with the petals . . . . . . . 76

75. Stamens opposite to the petals . . . : Rinamaceae. Pg. 394

76. Fruit a 1-celled globular berry . . . Grossularinceae. Pg. 303

76. Fruit a fleshy pod, splitting in the meridians.

76. Fruit a berry-like drupe with several hard nutlets.

Celastraceae. Pg. 386

ILICACE.AE. Pg. 384

76. Fruit a woody 2-beaked capsule . . HajadreldDaceat. Pg. 304

77. Stamens united in 5 sets, flowers from a broad spatulaformed bract . . . . . . TILIACEAE. Pg. 398

77. Stamens distinet . . . . . . . . . . . 78

78. Stamens arising below the base of the ovary . . . . . . 79

78. Stamens arising at or above the base of the ovary . . . . 80

79. Fruit of many carpels borne on an elongated receptacle.

(61) . . . . . . Magmoliaceae, Pg. 244

79. Fruit a large fleshy pod. (62) . . . Anonaceaf. Pg. 244

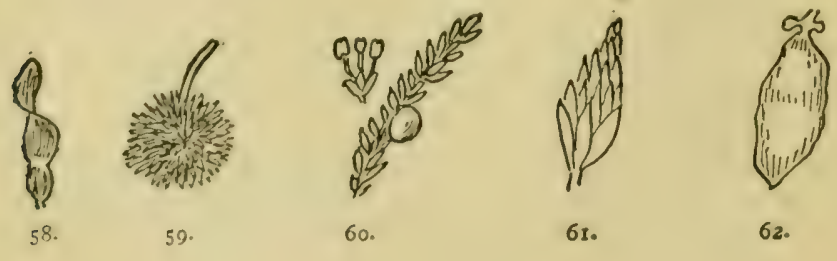


80. Pistil 1, fruit fleshy, enclosing a single hard bony nut, a stone. $(63)$. . . . . . . Drupaceae. Pg. 332 80. Pistils several

81. Fruit of several carpels not pulpy

Rosacene. Pg. $30 b^{3}$

81. Fruit a fleshy pulp enclosing leathery carpels. (64) Pomacene. Pg. 328

82. Leaves alternate or at the base

82. Leaves opposite

\section{Leaves alternate or basal}

83. Flowers regular

83. Flowers irregular

84. Stamens not more than 12 . . . . . . . . . . 85

84. Stamens numerous . . . . . . . . . . . . 98

85. Climbing or trailing vines . . . . Menispermaceat. Pg. 266

85. Not vines . . . . . . . . . . . . . 86

86. Sap milky. (51) . . . . . . . Euphorbiace. . Pg. 374

86. Sap watery : . . . . . . . . . . . 87

87. Petals 3. (65) -. . . . . . Limnanthaceae. Pg. 382

87. Petals 4, rarely 2, . . . . . . . . . . 88

87. Petals more than 4 . . . . . . . . . . . . . 90

88. Plant aquatic.

(66)

88. Plants not aquatic

- Trapacene. Pg. 431

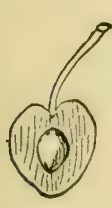

63.

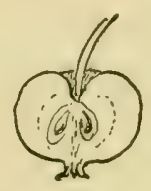

64.

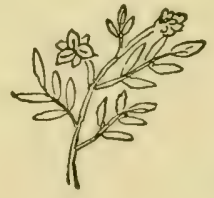

65.

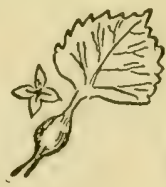

66.
89. Stamens 6 of equal lengths.

89. Stamens 6 of unequal lengths.

89. Stamens 2,4 or 8
(67)

Capparadaceae. Pg. 288 Cruciferae. Pg. 272 Onagraceae. Pg. 422

90. Flowers in umbels . . . . . . . . . . . . . . 91

90. Flowers not in umbels. . . . . . . . . . . . . 92

91. Styles 5, fruit a berry. (70) . . . . Araliaceae. Pg. 434 91. Stỵles 2, fruit 2 dry carpels. (69) . . Umbellifrana. Pg. 436

92. Stamens arising below the ovary and free from it (hypo. gynous). ( 71 )

92. Stamens arising from the ovary, either near its base or from its summit. 
93. Stamens 6 . . . . . . . . Beriberidacene. Pg. 264 93. Stamens 5 . . . . . . . . . . Linaceae. Pg. 368 93. Stamens 10 or 12 . . . . . . . . . . . 95

94. The long capsule splitting from below into 5 carpels, when ripe. (72) . . . . . . . . Geraniaceae. Pg. 364

94. Capsulo oval, round or columnar, not splitting from below,

Oxalidaceae. Pg. 366

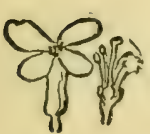

68.

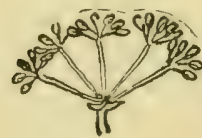

69.

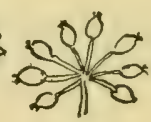

70.

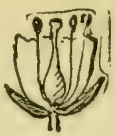

$7 \mathrm{I}$.

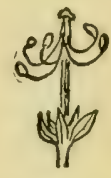

72.

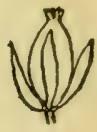

$73 \cdot$

95. Calyx adherent to the ovary. . Lythrum of LrTuraceas. Pg. 421 95. Calyx free from the ovary . . . . . . . . . . 96

96. Leaves all from the root. (74) . . . . Droseracene. Pg. 291 96. Leaves mostly from the stem . . . . . . . . . 97

97. Fleshy herbs : . . . . . . . . . Crassulaceae. Pg. 296 97. Herbs not fleshy . . . . . . Saxifragaceat. Pg. 297

\section{Leaves alternate}

Stamens numerous

98. Leares floating on water, shield-shaped. (75)

- Nrumhaeaceae. Pg. 242

98. Leaves not shield-shaped nor floating . . . . . . . . 99

99. Stems of jointed fleshy masses withcut leaves.

99. Stems not fleshy, leaves present . . . . . . . . 100 100. Plants with milky sap . . . (Part of) PAparerdcene. Pg. 269 100. Plants with watery sap . . . . . . . . . . 101 101. Leaves hollow, pitcher-form. (76) . . SARRaceñaceie. Pg. 291 101. Leaves not hollow or pitcher-formed . . . . . . . 102 102. Stamens united at base forming a central column around the pistil. (77) . . . . . . Malvaceae. Pg. $39 S$ 102. Stamens free, attached to the ovary. (7S) . Rosacese. Pg. 306 102. Stamens free, arising below the ovary . . . . . . 103

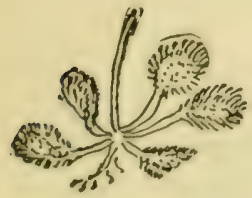

74.

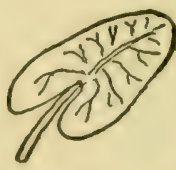

75 .

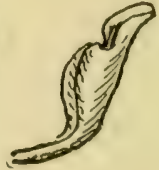

76.

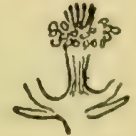

77.

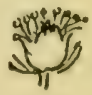

78.

103. Carpels numerous . . . . . Ranunculaceae. Pg. 246 103. Carpel 1....

- Cistacene. Pg. 406 


\section{Leaves opposite}

104. Flowers regular . . . . . . . . . . . 105

104. Flowers irregular. . . . . . . . . . . . 114

105. Aquatic weeds, usually fully submersed Haloragrdaceae. Pg. 431 105. Plants terrestrial or at least not fully submersed . . . 106

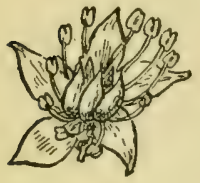

79 .

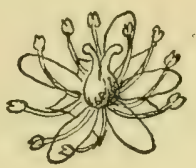

8..

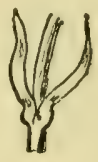

$8 \mathrm{I}$.

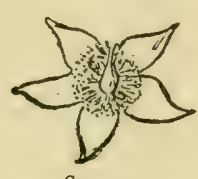

82.

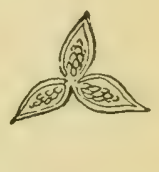

83.

106. Stem and leaves usually fleshy . . Portulacaceae. Pg. 223 106. Stem and leaves not fleshy.

107. Calyx adherent to the ovary . . . . . . . 108

107. Calyx free from the ovary . . . . . . . . . 109

108. Leaves distinctly 3-nerved . . . . . Melastomaceae. Pg. 422 108. Leaves not 3-nerved . . . . . . . . Onagraceae. Pg. 422

109. Stamens and pistils not in the same flower. Plants often with milky juice . . . . . . Euphorbiacene. Pg. 374 109. Stamens and pistils in the same flower . . . . . . 110

110. Fruit a 5-celled berry-like drupe . . . . Araliaceae. Pg. 434 110. Fruit not berry-like . . . . . . . . . . . 111

111. Stems swelling at the nodes. (S1) : Carropirllacene. Pg. 225 111. Stems not swelling at nodes . . . . . . . . 112

112. Stamens numerous. (82) . . .- . Hrpericaceae. Pg. 402 112. Stamens not more than 12 . . . . . . . 113

113. Leaves lobed . . . . . . . . Geraniaceae. Pg. 364 113. Leaves entire . . . . . . . . Lrthracene. Pg. 420

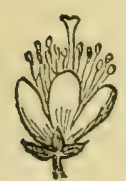

$8+$

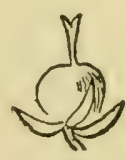

85.

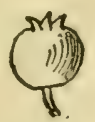

86.

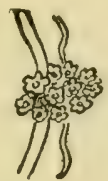

87.

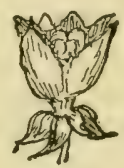

85.

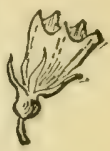

89. 
Flowers with several petals

Irregular

114. Trees . . . . . . . . Hippocastanaceae. Pg. 390 114. Herbs . . . . . . . . . . . . . . . . 115

115. Stamens 20 or more . . . . . Ranunculaceae. Pg. 246

115. Stamens not more than 12 . . . . . . . . . 116

116. Calyx of 2 sepals . . . . . . . Papaveraceae. Pg. 269

116. Calyx of 3 sepals . . . . . . Balsaminaceae. Pg. 392

116. Calyx of more than 3 divisions . . . . . . . 117

117. Fruit a pod (legume, example, Pea)

117. - Caesalpinaceae. Pg. 336, or Papilionaceae. Pg. 339 117. Fruit a capsule . . . . . . . . . . 118

118. Capsule splitting into 3 equal parts. (83) . TIOLACEAE. Pg. 409 118. Capsule splitting at the margin . . . . Polygalaceae. Pg. 371 118. Capsule opening at the top . . . . Resedaceae. Pg. 290

\section{GAMOPETALAE}

119. Herbs

U. Flowers with the petals partly or wholly united.

119. Trees or shrubs

120. Leaves alternate

120. Leaves opposite

121. Lofty tree, stamens more than 10. . . EBenaceae. Pg. 482 121. Shrubs, stamens 10 or less than 10 .

12\%. Petals united only at the base (84). Fruit a capsule

122. Petals distinctly united, fruit a capsule, jrupe Cletracene. Pg. 458

123. Calyz below the ovary. (85) . . . . . . . . 124

i23. Calyx attached to the ovary, its divisions above it. (86)

- Vacciniaceae. Pg. 470

124. Small, moss-like plants . . . . Diapexsidceae. Pg. $\$ 76$ 124. Shrubs . . . . . . . . . . . ERicacene. P. 462

125. Calyx above the ovary . . . . . Caprifoliacene. Pg. 590

125. Calyx below the ovary . . . . . . . . . . 126

126. Stamens 2 or 4 - . Paulownia in Scrofulariacear. Pg. 556

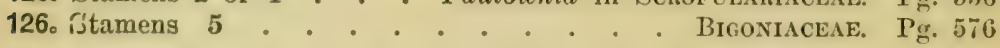

127. Climbing vines with long and juicy stems furnished with tendrils . . . . . . . . Cucumbitacenf. Pg. 604

127. Climbing vines, or more or less erect lerbs, with juicy stems, not furnished with tendrils.

i27. Creeping vine with twin flowers. . Caprifoliaceat. Pg. 590

127. More or less crect herbs. 129

i28. Plants with leaves and bell-shaped flowers.

Convorvutaceae. Pg. 500 
128. Plants without leaves, parasitic vines with small star-like flowers in dense clusters. (87) . . . Cuscutaceae. Pg. 503

129. Herbs with milky juice

129. Herbs with watery juice

130. Styles united, pollen grains not in waxy masses, ovary superior to the calyx . . . . . . Apocynaceat. Pg. 493

130. Styles not united, pollen in waxy masses, ovary superior to the calyx. (88) . . . . . Asclepiadacene. Pg. 494 130. Style 1, ovary inferior to the calyx. (89)

131. Ovary superior to the calyx . . . . . . . . . . 132 131. Ovary inferior to the calyx . . . . . . . . . . 149

132. Stamens twice as many as the lobes of the corolla. (90)

Pyrolacene. Pg. 458

132. Stamens not twice as many as the lobes of the corolla . . 133

133. Parasitic plants without green leaves . . . . . . . 134

133. Plants with green leaves, not parasitic . . . . . . 135

134. Corolla regular. (91) . ‘ . . Monotropacene. Pg. 460

134. Corolla irregular. (92) . . . . . Orobanciraceat. Pg. 574

135. Stamens free from the corolla . . . . . . . . . . 136

135. Stamens borne on the corolla . . . . . . . . . . 137

136. Style 1, fruit a capsule. (93) . . . . Primulaceat. Pg. 477

136. Styles 5, fruit a bladder-like, 1-seeded sac.

Plumbaginaceae; Pg. 482

137. Corolla regular

138

137. Corolla irregular

144

138. Ovary 2, distinet

138. Ovary 1

139. Leaves with stipules, at least a line connecting their bases.

139. Leaves without stipules

Loganiaceae. Pg. 485

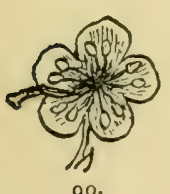

90.

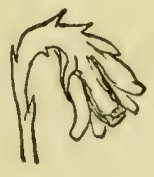

9I.

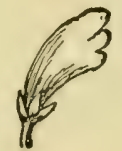

92 .

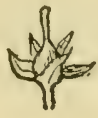

93.

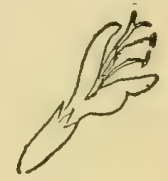

94.

140. Leaves opposite or in whorls 140. Leaves all at the base, aquatic or marsh plants.

Mexyanthaceae, Pg. 493

141. Ovary 1, deeply 4-lobed 141. Ovary 1, not 4-lobed

Boraginacene. Pg. 508 
142. Styles 3

Polemoniaceae. Pg. 504

142. Style 1

143

143. Calyx deeply cleft . . . . . Hydrophyllaceat. Pg. 507

143. Calyx not deeply cleft . . . . . . . Solanaceae. Pg. 545

144. Aquatic plants with dissected leaves. (95)

144. . . . . . . Lentibulariaceae. Pg. 571

144. Terrestrial plants . . . . . . . . . . 145

145. Ovary of 4 cells, a single ovule in each cell . . . . . . 146

145. Ovary of 1 or 2 cells . . . . . . . . . . . 147

146. Ovary not lobed . . . . . . . . Verbenaceae. Pg. 518

146. Ovary 4-lobed. (94) . . . . . . . . Labiatae. Pg. 519

147. Ovary 1-celled, 1-seeded . . . . . . . . . . . . 148

147. Ovary 2.celled, 2-seeded in each cell. (96) Acantinaceae. Pg. 576 147. Ovary 2-celled, many seeded . . . Scrofulariaceat. Pg. 550

148. Leaves all at the base . . . . . Plantaginaceae. Pg. 579 148. Leaves on the stem. (97) . . . . . Phrymaceat. Pg. 578

149. Flowers in heads subtended by an involucre . . . . . 153

149. Flowers not in heads subtended by an involurre . . . 150

150. Ovary 1-seeded . . . . . . . Valerianaceae. Pg. 598

150. Ovary with more than 1 seed . . . . . . . . 151

150. Ovary forming a drupe of several hard nutlets.

151. Ovary with very numerous small seeds Campanulaceae. Pg. 605 151. Ovary with few (1 to 5) seeds . . . . . . . . 152

152. Leaves with stipules . . . . . . . . Rurinceat. Pg. 580 152. Leaves without stipules . . . . . Caprifoliacese. Pg. 590

153. Flowers all expanded into rays. (98) . Crchoriacene. Pg. 610 153. Flowers not all rays . . . . . . . . . 154

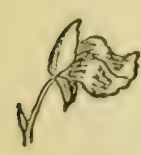

95.

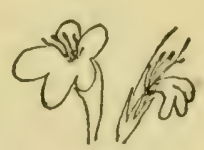

96.

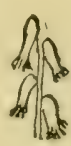

97.

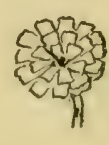

98.

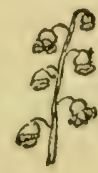

99.

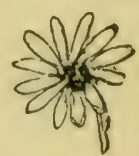

100.

154. Stamens distinct . . . . . . . . . . 155 154. Stamens united into a tube around the style. (100)

155. Stamens 2 to 4 . . . . . . Dipsacacene. Pg. 602 155. Stamens 5. (99) . . . . . . . Ambrosiacene. Pg. 628 


\section{SUB-DIVISION I-EMBRYO BEARING PLANTS}
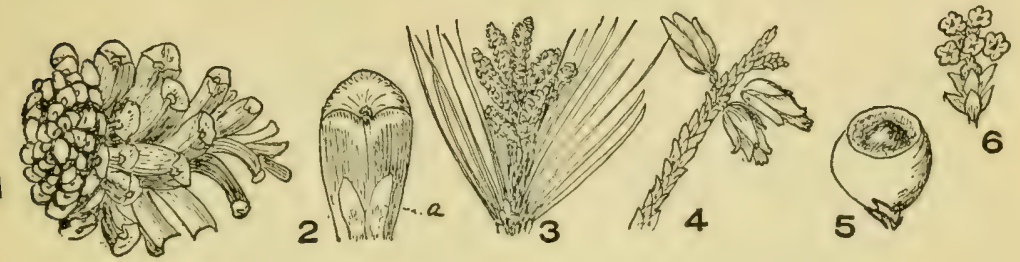

Examples of Flowers of Gymnosperms

I. A Cone of Pinus rigida with the scales separated to permit the escape of the seeds. 2, a single scale from the cone showing at $a$ the thin covers of the seeds, the location of which is shown at the base. 3, staminate flowers of a pine. 4, a spray oi' White Cedar with the small modified cones. 5, a berry of the pistillate flower of Dwarf Yew which is, in fact, a modified cone. 6 , the staminate flower of Yew.

\section{GYMNOSPERMAE. Naked Seeded Plants.}

A principal characteristic is the absence of an ovary or seed casket. The embryo is developed from a thin flat scale which is protected by the woody scales lying on each side of it (1), or within a fleshy fruit resembling a berry (5), but which is in fact a modification of one or more of the scales at the apex of a scaly cone while some of the lower scales may still be seen encircling the base of the drupe. In the first form the group of woody or leathery scales arranged spirally around a long axis forms the cone familiar as the fruit of the family of pines. In the second the berry-like fruit is that characteristic of the yew and the juniper. In either case, whether the fertile flowers are in the form of a cone or of a drupe, the pollen flowers are scaly cones or catkins (3).

The pollen and the ovules are not borne upon the same flowers. In our species the pollen bearing and the ovule bearing cones are found on the same plant (monoecious).

Of this sub-division there is, in our region, but one class.

\section{Class-CONIFERAE. Cone Bearing Trees or Shrubs} All the cone bearers are trees or shrubs and with a single ex- 
ception (the larch) they are evergreens. The leaves are either needle-formed or are flattened, scale-like, which overlap cach other like little tiles (imbricate). The pollen flowers and the fertile flowers are in separate groups. There is no floral envelope and the scale which bears the ovule, like that on which the pollen lies, is naked. There is neither style nor stigma.

The class of cone bearers is, so far as we know, one of the oldest of all the classes of true seed bearing plants. Fossil remains of such trees are found in very ancient geological formations.

In the class of cone bearers there are two families. Fruit a red berry

TAXACEAE Fruit a cone of woody or leathery scales or a brown or blue berry . . . . . . . . . PINACEAE

\section{Family I.- TAXaceae. The Yein Family}

The red, one seeded berry-like fruit (Fig. 5, page 81) is conspicuous among the dark green, flat, needle-shaped leaves which are about an inch in length and arranged in opposite rows, one on each side of the stem. The pollen bearing cones are very small and inconspicuous (Fig. 6, page 81), with numerous (6 to 8) pollen sacs, while the disk-formed or hemispherical fruit is conspicuous and attractive. The juice is not resinous.

\section{TAXUS, L.}

Characters of the Family.

T. baccata, (L.) AMericaN Yew. (T. canadensis, Willd.) A low, spreading shrub with evergreen prickly leaves, which are dark shining green. Berries bright red. In rich shaay zaces.

\section{Family II. PINaceae. The Pine Finily}

Treess and shrubs with resinous juice. The cones bearing pollen and the seerl-bearing cones are on the same tree. Those with pollen consist of an elongated floral axis bearing stamens arranged spirally. T'he fruit bearers are the ordinary cones, more conspicuous and permanent. At the base of each scale of the fruit cone are two or more ovules. 
The leaves are,

1st. Needle-shaped (pine, spruces, balsams and junipers).

2d. Flat, scalc-like leaves overlapping each other (white and

Fruit berry-like, red cedars).

Berry brown or blue . . . . . . . . Juniperus Fruit a cone composed of leathery or woody scales.

Leaves in small bundles or fasciculi.

Falling in autumn . . . . . . . . Larix

Evergreen . . . . . . . . . . . . Pinus

Leaves inserted singly on the stem.

Needle-shaped leaves spreading in all directions.

Leaves prismatic, more or less 4-sided . . . Picea

Leaves flattened, not prismatic . . . . Abies

Needle-shaped leaves spreading on opposite sides Tsuga

Leaves flattened and overlapping each other, not needle-shaped.

Two rows of leaves keeled, stem appearing flattened . . . . . . . . . . . Thuja

Four rows of leaves keeled, stem rounded Chamaecyparis

The family is divided into two tribes, Cupressincae and Abietineae.

\section{Tribe I.- CUpressineaE. The Cypress Tribe}

The leaves are opposite or in whorls, not in bundles, and the scales of the cones are few compared with those in the next tribe.

\section{JUNIPERUS, L.}

Leaves awl-shaped, in our species arranged in whorls of about three leaves each, or scale-like and overlapping. Fruit a false berry containing 1 to 3 hard seeds. Berry embraced below by a few scales. Pollen bearing cones small, oval or globular, in the axils of the leaves near the extremity of the stem and usually on a different plant from the fruit bearer.

1. J. communis, L. (Fig. 8, pl. 1). CoMmon JUNIPER. A small tree or shrub, aromatic, leaves needle-shaped, prickly, $1 / 2$ to $2 / 3$ in. long. Berries turning from greenish the first year to dark brown or bluishbrown the second year. On dry hillsides southeast portion of our region. and southward. Not common in our area.

2. J. nana, Willd. Low JunIPER. (J. communis, var. depressa, Pursh.) A low shrub spreading in a broad circular patch, sometimes 8 or $10 \mathrm{ft}$. in diameter and about $2 \mathrm{ft}$. high. Leaves and fruit resemble those of the erect species, No. 1. Barren hillsides. Common.

3. J. virginiana, L. (Fig. 7, p. 1.) RED CEDAR. A tree, generally, in our region less than $40 \mathrm{ft}$. high. Leaves somewhat flattened, short, 
overlapping, in four ranks. Ends of the leaves sometimes spiny. Berries round or oval, light blue or greenish-blue. Dry hillsides. Common.

4. J. sabina, L. Sirnubby Red Cedar. (J. sabina, var. procumbens, Pursh.) A low trailing shrub, often resembling a vine. Similar to red cedar in leaves and fruit. In northern sections of our region, mostly on sea coast.

\section{THUJA, L.}

Cones leathery or woody with but few (6 to 8 ) scales, ovoid, green or reddish-brown attached to extremities of the twigs. Leaves in four ranks clasping and overlapping each other, the lateral leaf keeled, giving the leaf-enveloped stem a broad flattened appearance.

T. occidentalis, L. (Fig. 5, pl. 1.) White Cedar. Arbor Vitae. A tree often of large dimensions, branching extensively. Growing mostly in swamps. All parts aromatic.

\section{CHAMAECYPARIS, Spach.}

Trees similar to Thuja, with very small leaves in 4 ranks, forming a rounded leaf-encircled stem. Cones globose, with small knobs on the surface of the scales.

C. thyoides, (L.) BSP. (Fig. 4, pl. 1.) Southers White Cedar. A tree, cone-like in form, generally in swamps. Young leaves bluish-green. Cones about $\frac{1}{4}$ in. diameter, bluish, knobby. Swamps, principally in southern part of our area.

\section{Tribe II.- AbIetineaE. The Pine Tribe}

Trees and shrubs with resinous juice. The leaves, all prismatic and needle-shaped, are arranged in spirals around the stem. This arrangement holds whether the leares are grouped in bundles or are inserted separately. In the first instance the groups are arranged spirally, in the second the individual leaves are so arranged.

\section{LARIX, Adams}

Tall tree with spreading branches. Leaves in fascicles of 20 or more, withrut sheath but growing directly from a knobby, woody support (suppressed branch); leaves deciduous.

L. laricina, (J) u Roi) Koch. (Fig. 6, pl. 1.) Larch. TAMaracK. Tree attaining a height of over $50 \mathrm{ft}$. It is our only species of the pine family with dreduous leaves. These grow in thick, diverging clusters, which in the spring are of a light and brilliant green color, $\frac{3}{4}$ in. to $1 \mathrm{in.}$ long. Each leaf of the fascicle starts in the axil of a minute scale. The brown cones ar borme at the base of young branches. In swamps Leaves appear in May.

L. decidua, (Mill), the European species, with longer leaves, often cultivated in our region.

2. PINUS, L.

The young branches have short scaly leaves, in the axils of which spring 


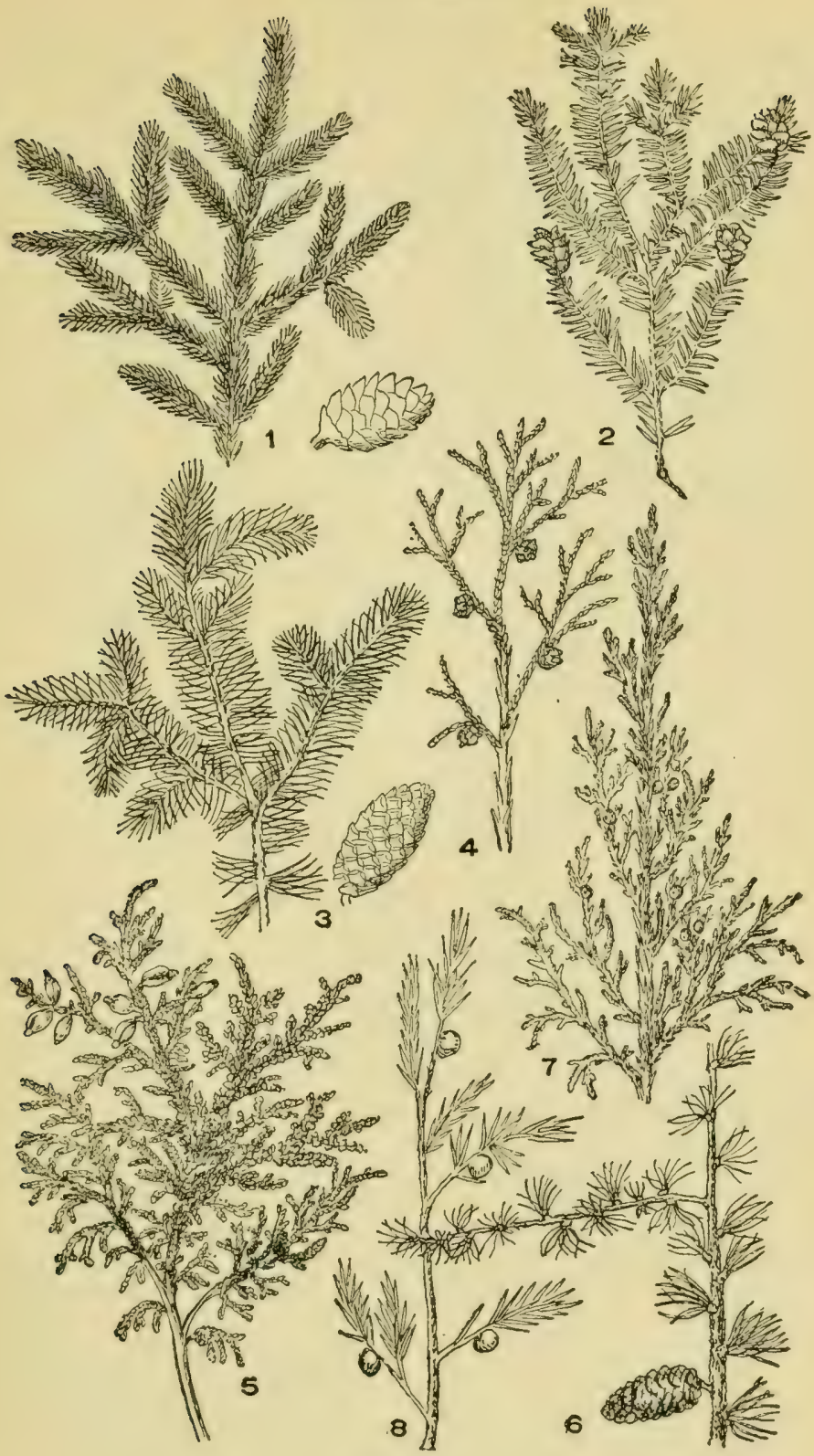

Plate 1

1. Picea mariana. 2. Tsuga canadensis. 3. Abies balsamea. 4. Chamaecyparis thyoides. 5. Thuja occidentalis. 6. Larix laricina. 7. Juniperus virginiana. 8. J. communis. 
the fascicles (bundles) of the more ordinary needle-formed leaves. These last spring from short, woody pedicels (short branchlets) and each group is surrounded at the base by a fibrous sheath. The scale leaves fall as the others attain their growth. The bundles contain each from 2 to 5 leaves, the number depending on the species. Both pollen flowers and ovules in cones, the first smaller than the others and situated more terminally.

The pines are mostly large trees with branches in whorls at regular intervals. The number of leaves in the bundles aids us in determining the species.

Leaves in fascicles of 2 's.

Leaves 4 to 6 in. long . . . . . . . . . . . P. resinosa

Leaves 2 to $2 \frac{1}{2}$ in. long . . . . . . . . . . $P$. virginiana

Leaves about I in. long, stout and thick . . . . P. divaricata

Leaves in fascicles of 2 's or 3 's.

Leaves $2 \frac{1}{2}$ to 4 in. long, stout and rigid . . . . . . P. pungens

Leaves 3 to 5 in. long, slender and flexible.

Cones pyramidal or conic . . . . . . . . . P. echinata

Cones globose or short oval . . . . . . . . P. rigida

Leaves 6 to 8 in. long . . . . . . . . . P. Taedo

Leaves in fascicles of 5 's . . . . . . . . . . P. strobus

1. P. resinosa, Ait. (Fig. 2, pl. 2.) Canadian Pine. Red Pine. A very large tree. Cones oval with a rounded base, $1 \frac{1}{2}$ to $2 \mathrm{in.}$ long, near the ends of the branches. Bark reddish, flaky. Common in the northern half of our area.

2. P. virginiana, Mill. (Fig. 3, pl. 2.) Jersex Pine. Scrub Pine. (P. inops, Ait.) Usually a small tree (20 to $30 \mathrm{ft}$. high), ungraceful in form, bark rough. Pollen cones $I / 3$ in. long, terminal; ovule cones at base of young branches, oval, 1 to $2 \mathrm{in}$. long, curved, scales with slender prickles. Rare north of Long Island. (Wadhams, N. Y., also Jay, N. Y.-G. T. S.)

3. P. divaricata, (Ait.) Gord. (Fig. 4, pl. 2.) LABRAdor Pine. Scrub Pine. Gray Prxe. ( $P$. Banksiana, Lamb.) Sometimes a very tall tree, sometimes a tree of medium height, but often short and scrubby. Bark rough. Leaves may vary from 3 to $2 \mathrm{in}$. long, curved, diverged, with sharp points. Sheaths of fascicles quite short. Cones, long oval, the scales with minute prickles. Sandy soil, forming extensive forests, northern N. Y. and W. New England.

4. P. pungens, Michx. Tame. Mountaix Pixe. Large tree. Leaves mostly in 2's, sle'ath of leaves $5 / 12$ to $8 / 12$ in. long. Cones oval, scales with awl-like spines at extremities which curve dounward. Mountains in southern part of our area and further south.

5. P. echinata, Mill. Yellow Pixe. Very large forest tree. Cones pyramidal, about 2 in. long, extrenities of scales of cone with small, straight spines, which do not curve downwarl. Southern part of our area and southward.

6. P. rigida, Mill. (Fig. 5, pl. 2.) Pitcr Prne. A forest tree 50 to $80 \mathrm{ft}$. high. Ieaves stout and stiff. Cones ovoid to globular, 1 to $2 \mathrm{in}$. long. Scales wedge-shaped, each with a recurved spine. Common, especially in what are known as "Pine Barrens."

7. P. Taeda, L. OLn Field Pine. Large forest tree in the southern states, only rarely in the southern section of our region. Pollen cones 

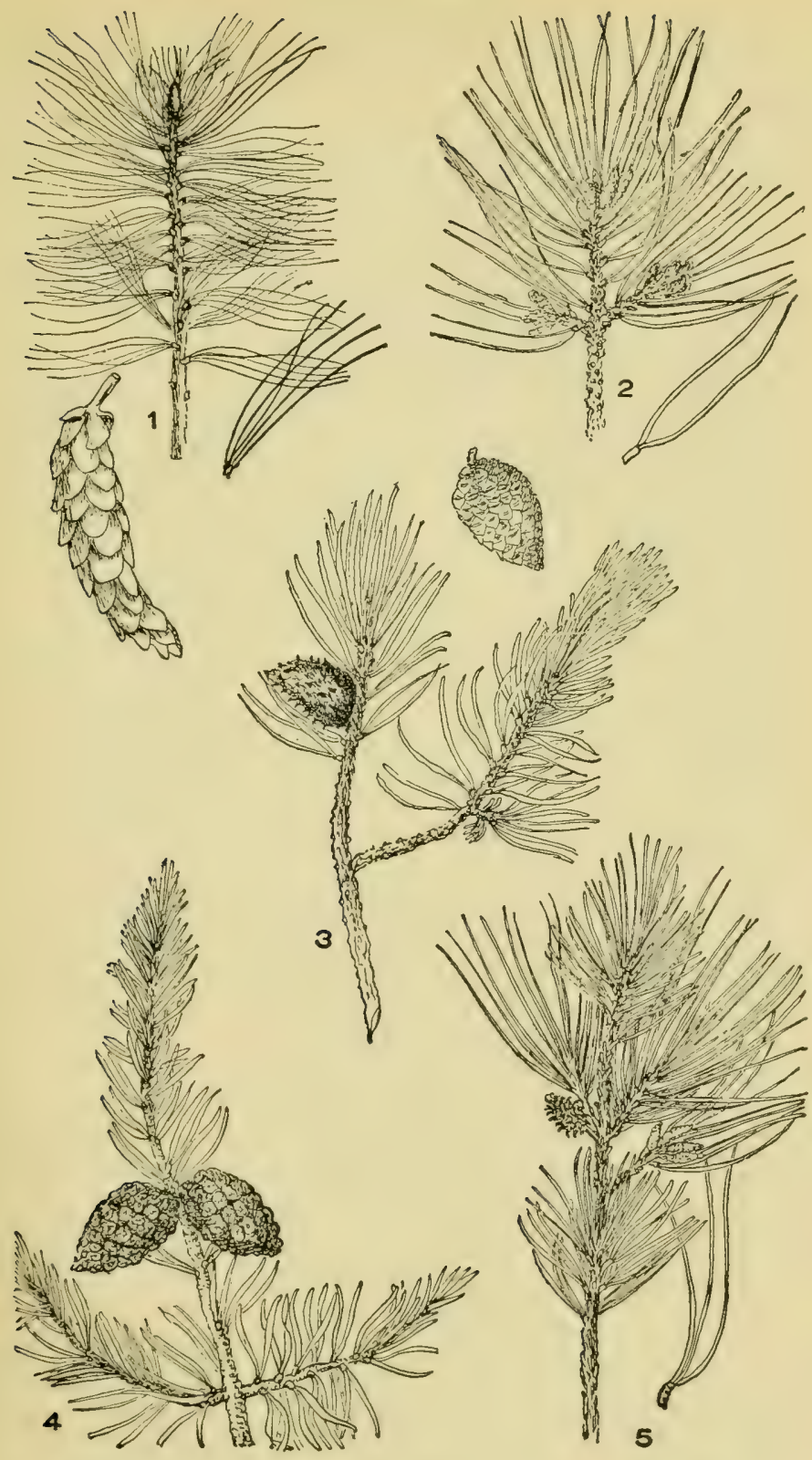

Plate 2

1. Pinus strobus. 2. P. resinosa. 3. P. virginiana. 4. P. divaricata 5. $P$. rigida. 
terminal, long, almost cylindric. Fertile cones 6 to $10 \mathrm{in.}$ long, $2 \mathrm{in}$. thick. Scales large with a ridge running transversely, a recurved point at its center.

S. P. strobus, L. (Fig. 1, pl. 2.) White PrNe. One of the largest of the pines. Formerly very common throughout our region. Young trees still quite common. Leaves more slender than either of the foregoing species, light green, 3 to $5 \mathrm{in}$. long. Cones cylindric, 3 to $5 \mathrm{in.}$ long, without prickles on the scales.

9. P. sylvestris, L. Scotcn Priv. Cultivated species, at some points naturalized in our region. Leaves in 2's.

\section{PICEA, Link.}

Trees with rough bark, leaves all needle-formed, $1 / 3$ to $2 / 3 \mathrm{in}$. long, not included in a sheath but each leaf is separately inserted. The spiral manner of insertion of the leaves gives the appearance of a cylindric brush to the leafy branch, the 4 -angled leaves spreading in all directions. They are borne upon small woody projections which, when the leaves are fallen, give to the branch a rasp-like surface. The cones are oval or cylindric with thin scales, which have none of the ridges or points seen upon the scales of pines. Tree cone-shaped, with spiry summit.

1. P. canadensis, (Mill.) BSP. White Spruce. Cones nodding, cylindric, about 2 in. long, with short foot-stalks. Edges of scales not notched or toothed. Twigs not downy, whitish-green. N. Y. and northward.

2. P. rubra, Link. Red Sprtce. Cones long oval becoming somewhat acute at apex. Scales only slightly toothed and with striations on the surface Leaves very acute, light green, twigs sparingly downy. In our area generally.

3. P. mariana, (Aill.) BSP. (Fig. 1, pl. 1.) Black Srruce. Cones oval or almost spherical, blunt at apex, without foot-stalk, 1 to $2 \mathrm{in.}$ long. Edges of the scales jagged. Twigs downy, brown.

Var. P. mariana brevifolia, Peck, is a slender tree which on high mountains is reduced to a small shrub with leaves $\frac{1}{4}$ to $\frac{1}{2} \mathrm{in}$. long. Scales with irregularly notched tips. Swamps and bogs in the northern part of our area.

\section{TSUGA, Carr.}

Trees with slender, very flexible branches with flat leaves, $\frac{1}{2}$ in. long, which although actually arranged spirally appear as though in two ranks one on each side of the stem. Staminate cones about $1 / 5 \mathrm{in}$. long, in the axils of the leaves. Ovule bearing cones terminal, $\frac{1}{2} \mathrm{in.} \mathrm{long.} \mathrm{Throughout}$ our area.

T. canadensis, (L.) Carr. (Fig. 2, pl. 1.) HemLock. A large forest tree, with flat leaves and reddish-brown cones about $\frac{1}{2}$ in. long. Throughout our area.

\section{ABIES, Juss.}

Trees with smooth bark on which are found "balsam blisters." These trees assume a beautiful pyramidal form and are the most ornamental of the coniferae of our region. The leaves are flat, scattered, longer than those of the spruces and of a rich, dark green color. Fertile cones cylindric.

1. A. balsamea, (L.) Mill. (Fig. 3, pl. 1.) Single Balsam Fir. 
Leaves spreading, but appearing nearly as though in 2 rows on opposite sides of the stem. Dark green above, light bluish-green below. Throughout our area.

\section{SUB-DIVISION II-ANGIOSPERMAE}

The ovules in this great division are concealed in a cavity known as the ovary. (Fig. 1, below.)

The flower consists essentially of a pistil, at the base of which is the ovary containing the ovules and one or two or more stamens bearing anthers on which are developed the pollen grains destined to fertilize the ovules. The pistil and stamens may occupy different flowers. Flower receptacles bearing these two essential elements separately may grow upon the same plant, in which case they are said to be monoecious, or the pistillate flowers may occupy one plant the staminate another, in which case they are said to be dioecious.

When the pistils and stamens are found on the same receptacle the flower is said to be a perfect flower and this is the form prevailing in the great majority of plants of this great division.

Plants of this sub-division are divided into two classes.
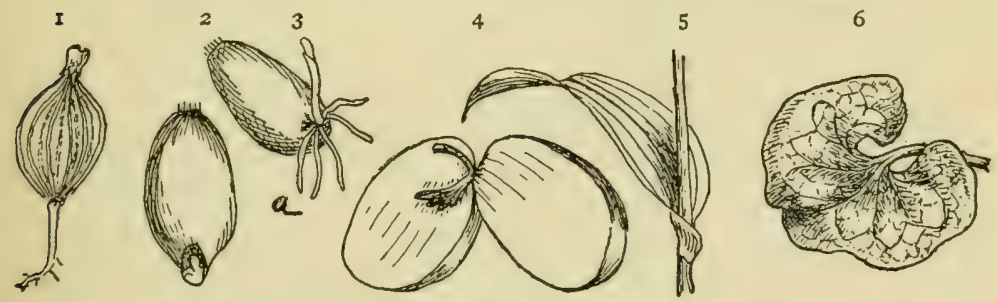

1, showing the numerous cotyledons of pine. 2, a grain of wheat showing the position of the embryo at the base. 3, a grain showing the development of the young plant. 4, the two cotyledons of a garden bean with the embryo between them. 5, a leaf oi grass, showing the parallel veins of the monocotyledons, 6, a leaf of Asarum, showing the net veins of the dicotyledons.

\section{Class I.-MONOCOTYLEDONOUS PLANTS}

\section{Plants with Single-Lobed Ovules}

The embryo has a single seed lobe (cotyledon) (Figs. 2 and 3 , above). Leaves generally parallel-veined (or nerved) (Fig. 5), enfolding one another at the base (sheathing). Rarely the leaves are net-reined. 
Flower, as a rule, 3 parted in its various divisions, thus, the perianth consists of $3+3$ parts, all of which may have the appearance of petals, but which structurally may be regarded as being 3 petals and 3 sepals. There are two rows of stamens, one row of which may not be fully developed. Although there is usually but one pistil, it divides at the base into an ovary of 3 divisions. Most of the plants of the first two orders vary in several respects from the prevailing type.

\section{Order I.-PANDANALES. Naked Flowering Plants}

Flowers without a proper floral envelope. Stamens and pistils in different groups. These groups consist either in dense cylindric spikes or in ball-shaped masses. Instead of a floral envelope each staminate and each pistillate flower composing the dense mass of a spike is surrounded by a few hairs (in Typhaceae) or by small scales (in Sparganiaceae). They are all marsh plants with creeping root-stalks and grow in clusters.

Flowers arranged in dense cylindric masses .

TYPHACEAE Flowers arranged in rounded heads

\section{SPARGANIACEAE}

\section{Fanily I. - typhaceae. Cat Tail Fanily}

Tall marsh plants with very long linear leaves and tall flower stalks bearing at the summit two cylindric flower masses, the more slenter cylinder containing the staminate flowers above, the thicker and more conspicuous, the pistillate flowers, below.

\section{TYPHA, L.}

Cylinder of pistillate flowers 5 to $8 \mathrm{in}$. long, that of the staminate about the sime length. Flowers immensely numerous. The bristles, which alone represent the foral envelope, enclose, in staminate ilowers, groups of 2 to 7 stamens each. One (rarely more) pistil may also be enclosed by a single set of bristles.

1. T. latifolia, J. (Fig. 2, pl. 3.) Broad-leaven Cat Tail. The slender strajglit stems are from 5 to $8 \mathrm{ft}$. high, leaves as high or higher. The flower cylinders become dark velvety brown. The staminate eylinder extends down to and is in contact with the other, but the division may be distinctly seen. Marshes throughout the country.

2. T. angustifolia, L. (Fig. 1, pl. 3.) Narrow-Leaved Cat Tall. 


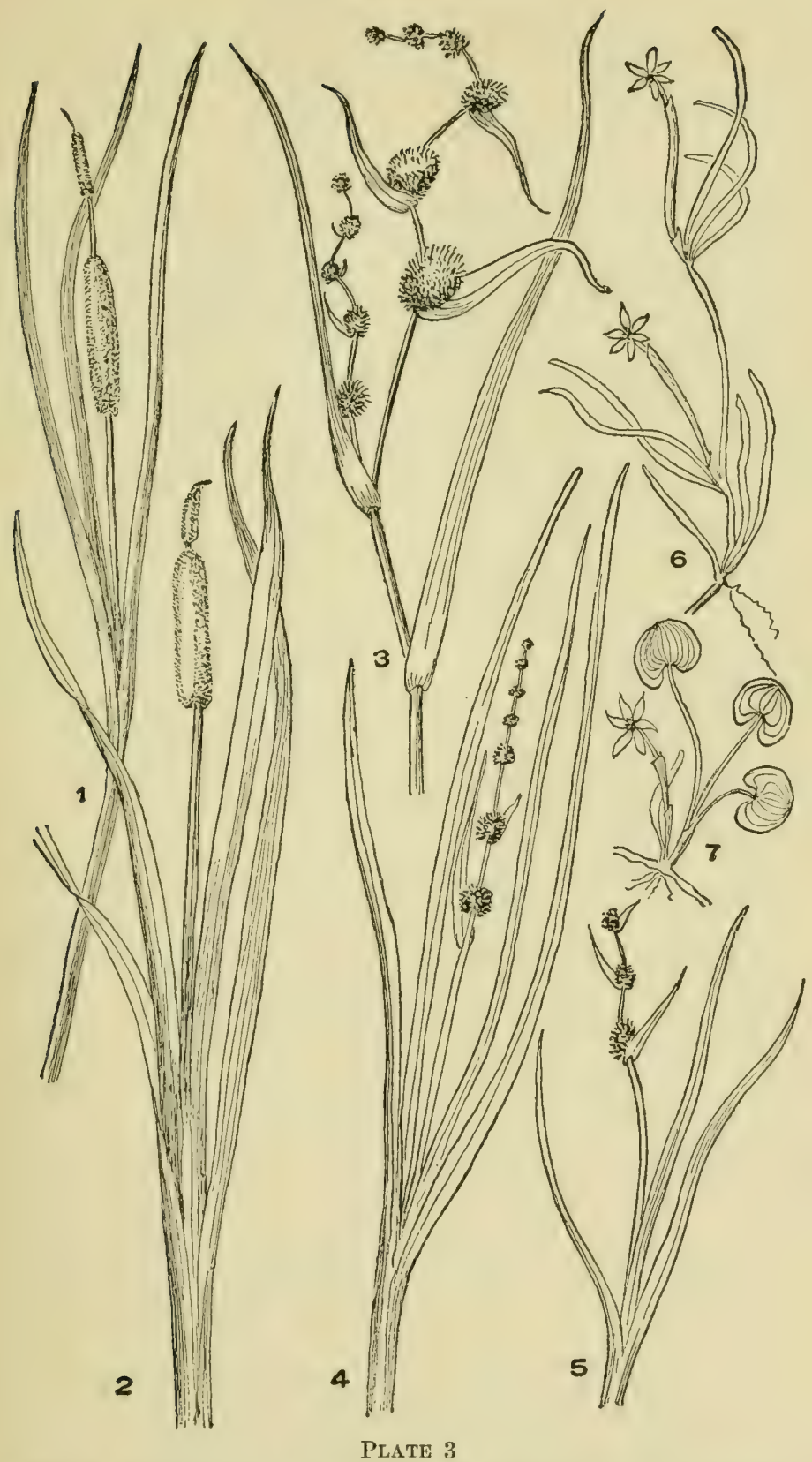

1. Typha angustifolia. 2. T. latifolia. 3. Sparganium eurycarpum. 4. S. simplex. 5. S. minimum, 6. Heteranthera dubia. 7. H. reniformis. 
Stem more slender than the last and generally higher. The cylinder of staminate flowers docs not extend down to the other cylinder. but there is between the two a space of naked stem, of from 1 to 3 inches. Situations similar to No. 1 .

\section{FAMILI II.-SPARGANIACEAE. Bur-REED FAMILY}

Marsh plants with long linear leaves and tall flower stem usually branching near the summit and bearing several globe-formed heads, the heals nearest the summit being much smaller than those beJow. The upper are the staminate flowers, the others the pistillate. Immediately below each of the larger balls a long slender leafy bract starts, which is related to the spathe of the arum family. Each ball of pistillate flowers represents a collection of many seedcarpels.

\section{SPARGANIUM, (Tourn.) L.}

Has the characters described above.

1. S. eurycarpum, Engelm. (Fig. 3, pl. 3.) Broad Frurted BurBEED. Stem 3 to $8 \mathrm{ft}$. high; 2 to 4 pistillate heads on each stem, each usually on a short flower stalk; 5 or more smaller staminate heads above the pistillate. The extremity of the pistil divides in two parts (stigmas).

2. S. androcladum, Engelm. Braxcinsg Bur-ReEd. Pistillate heads 3 to 7 , plant more branching than No. 1 , and smaller, 1 to $2 \mathrm{ft}$. high. Pistil extremity (stigma) single.

3. S. americanum, Nutt. American Bur-reed. Resembles No. 2, but is not branching. The lower flower heads on short stems. Low grounds. Sümmer.

4. S. simplex, Fudson. (Fig. 4, pl. 3.) Simple Stemmed Bur-reed. Stem 2 to 24 in. high, not branching. Pistillate and staminate heads on a straight stem. Generally erect. Lower flower heads without stems.

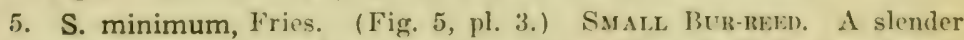
floating species. From a few in. to $2 \mathrm{ft}$. high, with pelueid floating leaves. Generally, one staminate and about two pistillate heads.

6. S. lucidum, Fenalil \& Eames. Plant 30 to $36 \mathrm{in}$. high, the leaves much overtopping the infloreseence. Pistillate flower heads only at the axils and on short stems. Fruit lustrous. Muddy shores, Mass. and south.

7. S. angustifolium, Michx. Slender, 12 to $36 \mathrm{in.} \mathrm{high,} \mathrm{growing} \mathrm{in}$ ponds and slow streams. Leaves very long and narrow. Heads of pistillate flowers somewhat above the axils and lower ones on short stems. New England and west.

8. S. fluctuans, (Morong.) Rolinson. Plant 15 to $40 \mathrm{in}$. high. Leaves narrow and long. Flower heads on branches, each of 2 or 3 branches bearing 3 to 5 heads. Margins of cool lakes, usually at a depth of 20 or 30 inches. 


\section{Order II.-HELOBIAE. Water Plants}

While all the plants of this order are fluvial the order does not by any means include all aquatic plants.

The flowers may be destitute of floral envelopes or may have very imperfect perianths, or have perfectly developed and showy flowers, as in the Sagittaria. The stamens vary from one to many, the pistils also are indefinite in number.

The characteristies of plants included in this order are therefore so varied that they must be found in the characteristics of the different families.

SYNOPSIS OF THE FAMILIES OF THE ORDER HELOBIAE Small rounded green bodies floating on the surface of pools

Plants submersed or floating with very inconspicuous greenish flowers. Submersed plants with upper leaves sometimes floating, lower leaves alternate. Flowers situated on a fleshy cylinder, in a small axillary group or on a grooved receptacle, perianth wanting or consisting of 4 fleshy segments. Leaves sheathing at base. Flowers in axils of leaves, pollen flowers with double perianth

Plants with roots in water, but with aerial stems and more or less conspicuous flowers. Perianth segments 6 ; stamens 6. MIarsh plants with half-rounded, deeply-grooved leaves with membraneous sheaths at the base, not entirely submersed, flowers in long spikes terminally on tall flower stems . . . . . . TRIGLOCHINEAE

Marsh herbs commonly not wholly submersed, but usually growing in water, with sheathing leaves, with flowers on a tall aerial spike and with the perianth (calyx and corolla) in 3 's . . . . . . . . . . ALISMACEAE

Submersed herbs with flowers arising from a spadix (a fleshy cylinder), but not surrounded by or resting upon a spathe (a leaf-like envelope) . . . . VALLISNERIACEAE

Family I.-Lemnaceae. Duckineed Family.

Minute swimming plants, small green scales floating on the surface of still pools. The vegetative apparatus is reduced to a small 
disk less specialized than a leaf' (a thallus). The rootlet is a floating thread extending from the under side of the green disk downward about an inch. From one side of the disk grows the minute flower, or, technically, flowers, for the minute group consists of two stamens and a pistil which, although in close relation are not considered as in the same receptacle. These are surrounded by a green envelope which is regarded as a spathe, hence these plants have been classified as closely related to the Arums.

In the genus Wolffia, minute floating bodies, there is no rootlike appendage.

\section{LEMNA, L.}

Characters included above, with the root-like appendages.

1. L. trisulca, L. (Fig. 3, pl. 6.) Iry-Leaved Duckweed. Fronds in form of a snow shoe, often more than $\frac{1}{2} \mathrm{in}$. long. Ponds, ditches, etc.

2. L. perpusilla, Torr. Minute Duckweed. Scale or frond about $1 / 10$ in. long, pear-shaped, with 3 nerves on the surface, purplish beneath. Ponds, lakes, etc.

3. L. minor, L. (Fig. 4, pl. 6.) Lesser Duckweed. Nearly round, more or less 3 -nerved, about $\frac{1}{2}$ in. diameter, several sticking together. Common in stagnant pools.

4. L. cyclostasa, (Ell.) Chev. Valdria Duckweed. Oval with one extremity pointed, 1/12 in. diameter. No nerves on surface.

5. L. polyrhiza, L. (Fig. 2, pl. 6.) Greater Duckweed. Disk rounded or oblong, 7 to 12 nerved. Rootlets in a cluster of 5 to 11 . (This plant is assigned to a genus Spirodella, S. polyrhiza, by Schleiden.)

\section{WOLFFIA, Horkel.}

In our region, minute flowering plants, the smallest of flowering plants, small grains which can only be distinguished from the lower, non-flowering plants, by the aid of a strong magnifying glass. There is no rootlike thread, the plant is not flattened like Lemna, but more or less globular.

1. W. columbiana, Karst. (Fig. 11, pl. 6.) Plant nearly spherical, about $1 / 50$ in. diameter. Not dotted. Floating near the surficee of stagnant waters.

2. W. punctata, Ciriscb. (W. brasiliensis, Englm.) Plant oblong. about $1 / 50$ in. Iong, with brown dots above and below. Floating in similar situations to No. 1.

\section{Family II.- NaIAdaceaE. Pondwend Fimiy}

Plants of fresh or salt water, entirely immersed exeept that the flowers may appear above water, and the upper leaves may float. Upper leaves usually in pairs, the lower generally altermate, and in 2 rows. Flowers usually small, inconspicuous, in lengthened 
groups, the corolla absent or of various forms. The stamens consist of the anthers only, being without filaments or with only the rudiments of filaments. The stamens and pistil may occupy the same flower or separate flowers.

Flowers on fleshy spikes. Perianth, when present, 4-parted. Found in fresh water . . . . . . Potamogeton

Flowers without perianth, on a long-grooved receptacle which is nearly hidden by the grass-like leaf. Marine plant

Zostera

Flowers few, without perianth, fruit arranged in a false umbel surmounting a tall spiral fruit stalk . . . . Ruppia

Flowers naked, pear-shaped, green, in small radiating groups

in the axils of the leaves . . . . . . Zannichellia

Margins of leaves spiny-toothed. Pistillate and staminate

flowers on different plants. Pistil solitary, naked . Naias

\section{POTAMOGETON, L.}

Aquatic plants mostly in shallow pools or streams of fresh water, with inconspicuous, greenish or sometimes dull reddish masses of flowers arranged on a fleshy pediceled spike, perianth 4-parted, stamens 4; ovaries 4 ; leaves all submersed or, the uppermost spreading into a long narrow or a rounded oval expanse, floating on the surface of the water. Lower leaves alternate, upper generally opposite. Lower leaves quite thin, membraneous; the floating leaves leathery and firm in structure. Stipules thin and generally resembling the membraneous leaves, they are, in some species, several inches in length.

\section{Group 1: Upper leaves floating on the surface of the water and differing from the submersed leaves in form and texture.}

This group is again divided into two sections.

SEc. 1. Fluating leaves more or less heart-shaped at base, sometimes but slightly so.

1. P. natans, L. (Fig. 1, pl. 4.) Common Pondweed. Stem 2 to $4 \mathrm{ft}$. long; floating leaves 2 to 4 in. long, half as wide, on long leaf stems which are as thick as the main stem. Leaves elliptic or ovate, obtuse, tipped with an abrupt point at outer extremity. The nutlet has a deep impression down the middle. Leaf wings (stipules) very long (4 to 6 in.); spike of flowers 1 to 2 in. long, dull green, protruding above the surface of the water. Common in still ponds and borders of lakes and streams.

2. P. Oakesianus, Robbins. (Fig. 1, pl. 5.) OAkes's Pondweed. Stems more slender than those of No. 1. Leaf stems thicker than the main stem. No groove on the side of the nutlet. Leaves elliptic, very 
slightly heart-shaped at base, about $\frac{1}{2}$ as large as those of $P$. natans. Still waters, most of our area.

3. P. pulcher, Tuckerm. Spotted Pondweed. Floating leaves large, 3 to 5 in. long, 1 to 3 in. wide, oval, generally heart-shaped at base. Leaf stalks rather short. Flower stalk longer and spotted. Submersed leaves of two kinds, the upper lance, almost ribbon-shaped, 3 to 8 in. long, thin, pelucid, the lower broader, thicker and on a leaf stalk. Fruit 3 ridged. Lakes and ponds, north to south in our area.

\section{SEc. 2. Floating leaves not heart-shaped.}

\section{A. Submersed leaves expanded to somevhat broad leaf blades.}

4. P. amplifolius, Tuckerm. (Fig. 2, pl. 4.) Large-Leaved PondwEED. Floating leaves (not always present) oval or broadly elliptic, rounded at base 2 to $4 \mathrm{in}$. long. Submersed leaves broader and longer (4 to $\mathrm{S}$ in. long), with short leaf stalks. Stipules very long, grass-like. Lakes, especially in northern half of our area.

5. P. alpinus, Balbis. (Fig. 5, pl. 4.) Northern Pondweed. Floating leaves 2 to $5 \mathrm{in}$. long, often absent, lance-shaped, with apex broadest narrowing to a very short leaf-stalk. Submersed leaves much the same form, but with almost no leaf-stalks. Stipules broad, obtuse at free extremity. Flower stem 2 to $8 \mathrm{in}$. long, spike of flowers 1 to $1 \frac{1}{2} \mathrm{in.}$ long. Fruit reddish. Ponds and borders of streams, our area.

Var. Faxoni, Morong. FAxon's PondweEd. Floating leaves rather shorter and broader than No. 6, and with very blunt points. Submersed leaves broader and with leaf-stalk $\frac{1}{2}$ to 1 in. long. Creeks entering Lake Champlain from the east.

6. P. lonchites, Tuckerm. Long-Leaved Pondweed. ( $P$. americanus, C. \& S.) Floating leaves thin, opposite, elliptic, blunt or somewhat acute at apex, 2 to $6 \mathrm{in}$. long with long leaf stalks. Submersed leaves long, ribbon-like, wavy, acute at each end with leaf stalk 1 to 4 in. long. Stipules acute, 1 to $4 \mathrm{in}$. long. Fruit with 3 distinct ridges on the back. Ponds and streams.

B. Submersed lcaves narrowed to grass-like blades, not thrcad-like.

7. P. heterophyllus, Schreb. Various-teaved Ponnwern. Stems very long and slender. Floating leaves 1 to 2 in. long, broud, elliptic, sometimes approaching to heart-shaped at base, pointed at apex. I eaf stalkis I to $4 \mathrm{in}$. long. Submersed leaves narrow lance-shaped or lincar, acute at loth ends, rather stiff, no leaf stalk. Stipules long, broad at base, olbtuse at onter extremity. A very variable species as the mane indicates. Common.

8. P. spathulaeformis, Morong. Spatriate-ravid Pownwen. Floaling leaves broally elliptic or ovate, with the external extremity broadest, apex sharp pointed. Submersed leaves lanee-shaped broader at outer extremity and tapering to a short leaf stalk, stipules obtuse. Mystic Pond, Medford Poml, Mass. (said to he hybrid of $P$. hetcrophyllus and $l$ ' Zizii).

9. P. Nuttallii, ('ham. \& Seh. (Fig. 3, pl. 4.) Nutrata's Poximbero. (I'. cpriphyelrus, liaf.) Floating leaves oblong, 1 to $4 \mathrm{in}$. long, taperinge 


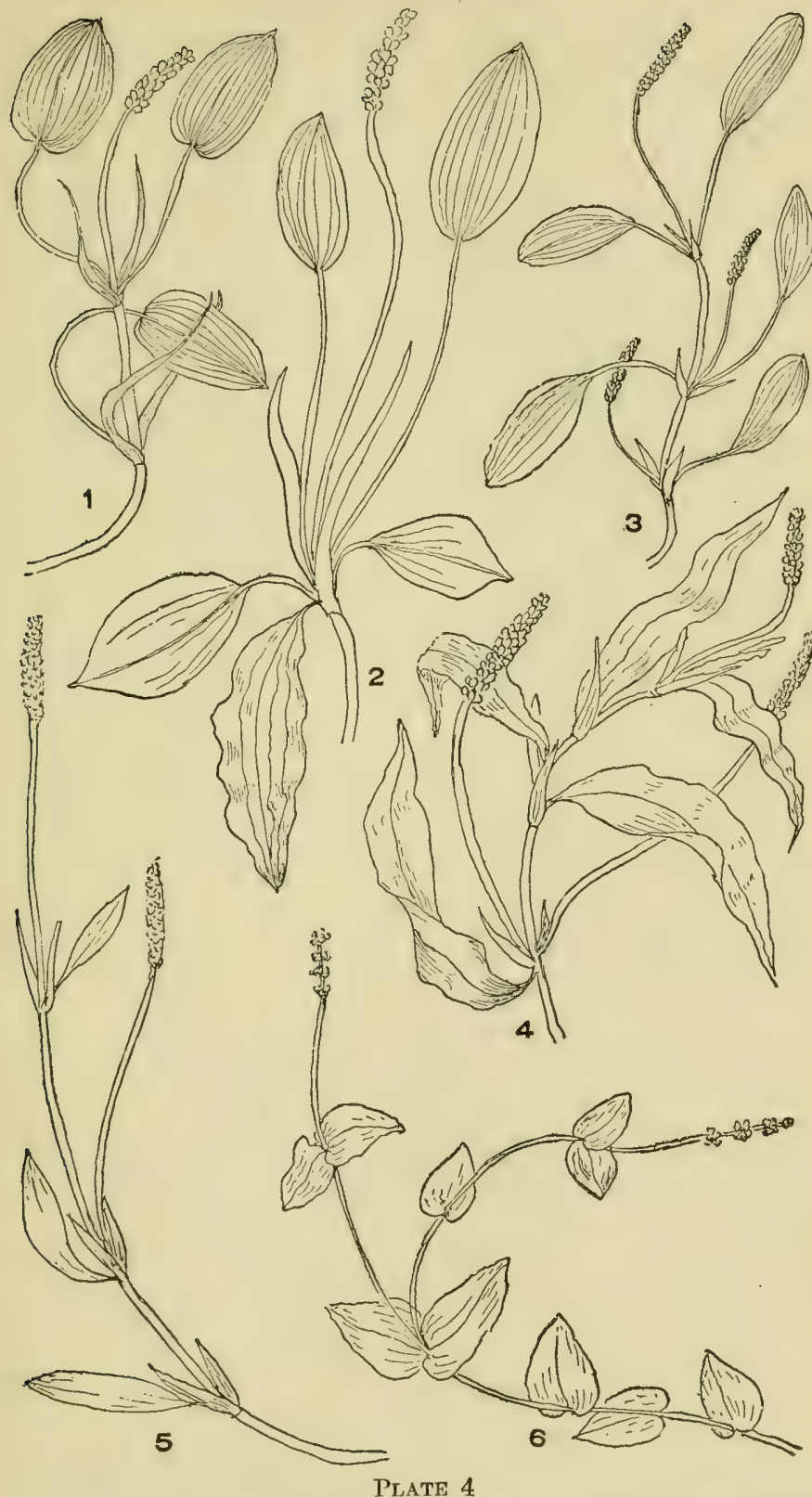

1. Potamogeton natans. 2. P. amplifolıus. 3. P. Nuttallii. 4. P. lucens. 5. P. alpinus. 6. P. perfoliatus 
toward the base and blending into the short leaf stem. Lower floating leaves gradually modified until they pass to the form of the submersed leaves. Submersed leaves pear-shaped or elliptic and generally with nerves diverging from the base. Ponds and streams, through our area.

\section{Upper leaves elliptic, lower leaves thread-like.}

10. P. hybridus, Michx. Rafinesque's Pondweed. ( $P$. diversifolius, Raf.) Floating leaves elliptic, sometimes narrowed to lanceshaped, about 1 in. long, $\frac{1}{2}$ as wide. Submersed leaves 3 or 4 in. long, thread-like, stipules obtuse, less than $\frac{1}{4}$ as long as submersed leaves. Spikes of flowers at surface of water, $\frac{1}{2} \mathrm{in}$. long, those in the axils of submersed leaves with about 4 flowers on a flower stalk $\frac{1}{4}$ in. long, differing in this respect from No. 9. Still waters, throughout our area.

11. P. dimorphus, Raf. (Fig. 8, pl. 5.) Spiral Pondweed. ( $P$. spirillus, Tuckerm.) Stem $6 \mathrm{in}$. to $2 \mathrm{ft}$. long. Floating leaves $2 / 3$ to 1 in. long, $\frac{1}{2}$ as wide. Leaf stalk about as long as leaf. Near the floating leaves are the eylindric flower spikes on stems $\frac{1}{2}$ to $1 \mathrm{in.}$ long, while in the axils of the submersed leaves the small rounded flower masses are without flower stalks. Ponds and ditches, our area.

12. P. Vaseyi, Robbins. VAsey's PondweEd. Floating leaves 1 to 4 pairs, opposite, on fruit-bearing stems, $\frac{1}{4}$ to $\frac{3}{2}$ in. long, more than $\frac{1}{2}$ as wide, stipules long and narrow. Flower spikes only on the stem of floating leaves. Eastern Mass. and westward.

\section{Floating leaves both elliptic and very narrow grass-lite.}

13. P. lateralis, Morong. Opposite-Leavfon Pondween. Stem threadlike, branching, the branches with floating leaves have no flower spikes. Floating leaves elliptic, obtuse, $1 / 3$ in. long, $\frac{1}{2}$ as wide as linear. Submersed branches with very narrow linear leaves beariner flower groups on flower stalks 1 to $2 \mathrm{in.} \mathrm{long,} \mathrm{flower} \mathrm{spike} \mathrm{with} \mathrm{about} 4$ flowers. Lakes and streams, Eastern Mass. and westward.

\section{Grour 2. Leaves all submersed or exceptionally a few floating.}

4. Lcares broat, rounded or heart-shapal at basc, clasping the stem.

14. P. perfoliatus, L. (Fig. 6, pl. 4.) Cuasping-ieaved Pondweed. I.aves broadly oval or rounder, nearly or quite as broad as lond, cordate and clasping the stem, upper leaves opposite, lower alternate. Ponds and streams, our area.

Var. P. lanculatus, with longer lance-shaped leaves. Lake Champlain and northward.

15. P. Richardsonii, (lienn.) Rybd. Leaves long. lance-slatped, hase heart-shaped and clasping the stem, wavy, pale bright green. Quiet waters, New England and N. Y.

\section{B. Lcaves broad lance-shaped not clasping at base.}

16. P. bupleuroides, Fernald. Jeaves nearly orbicular to laneeshapel, olbtuse at apex. flat not erisped. Sitipules ineonspicuous, not usually developed. Fruit rounded, somewhat 3-keeled. Brackish watery. 
17. P. angustifolius, Berchtold \& Prest. Resembles P. Tucens, but is smaller and whereas all the leaves of $P$. lucens are submersed the upper leaves of this form are sometimes floating on the surface. The fruit of this species is 3 -keeled while that of $P$. lucens is roundish and scarcely keeled. Lakes, Vt., Conn., and N. Y.

18. P. lucens, I. (Fig. 4, pl. 4.) Shrning Pondweed. Leaves 3 to $4 \mathrm{in.} \mathrm{long,} 1 \mathrm{in}$. broad, lance-shaped or the uppermost oval, often shining. Leaf stalks short, flower stalk often 4 to $6 \mathrm{in}$. long. Through our area.

Var. P. lucens connecticutensis, Robbins; leaves erisped, not shining. Conn. and N. Y., rare.

19. P. Zizii, Roth. ZIZ's PondweEd. Smaller than P. lucens, but much like it. Branched at base. Floating leaves elliptic, 2 to $4 \mathrm{in}$. long with long leaf-stalks. Submersed leaves long, lance-shaped, wary, the surface shining, on long leaf-stalks. Flowers on stems thicker than the gencral stem. Flower spikes 1 to $2 \mathrm{in.}$ long. Lakes and streams throughout our region.

20. P. praelongus, Wulf. White-stemmed Pondweed. Very long stem, leaves broader at base and half clasping the stem. Stems white. Some leaves 12 to 14 in. long.

21. P. mysticus, Morong. Mrstic Pondween. Plant slender, upper leaves lance-ovate, opposite, 1 to $1 \frac{1}{2} \mathrm{in}$. long, $1 / 12$ to $\frac{1}{4} \mathrm{in}$. wide. Lower leaves alternate, longer than the upper. No leaf stalks. Stipules generally small. Spikes with 4 to 6 flowers. Ponds in Mass.

22. P. crispus, L. (Fig. 4, pl. 5.) Curled-leaved Pondweed. Leaves oblong, rounded at summit, wavy, half clasping at base, 2 to 4 in. long, $1 / 3$ as wide. Spikes with few more or less scattered flowers. Fresh or sometimes brackish water, Mass. and southward.

\section{Leaves very narrow, grass-like or thread-litie.}

23. P. obtusifolius, Mertens \& Koch. Blunt-leaven Pondween. Leaves very narrow grass-like, 3 -veined, 2 to $3 \mathrm{in}$. long, $1 / 20$ to $3 / 20 \mathrm{in}$. wide, very obtuse at extremity. Stipules rather long and also very obtuse. Spike 5 to 8 flowered. Fruit not keeled. Our region, in still waters.

24. P. zosteraefolius, Schum. (Fig. 9, pl. 5.) Eel Grass PondwEED. Leaves similar to No. 23, but often mucl longer and less obtuse at extremity. Indefinitely veined. Fruit keeled. Stipules falling early. Still or running waters, N. J. and northward.

25. P. Hillii, Morong. Hill's Pondweed. Leaves narrow grass-like 1 to 3 in. long, pointed at free extremity. Ponds, Eastern N. Y., westward.

26. P. foliosus, Raf. Leafy Pondweed. Stem thread-like; leaves very narrow 1 to $2 \mathrm{in}$. long, sharp pointed; stipules obtuse; fruit distinctly keeled. Ponds and streams, our region.

27. P. Friesii, Rubrecht. Fries's Pownwefo. Stems 2 to $4 \mathrm{ft}$. long. Plant resembles No. 23 but stipules are acute. Still waters, N. Y. and westward. 
28. P. rutilus, Wolfg. Slender Pondwfed. Stems almost threadlike, 1 to $2 \mathrm{ft}$. long; leaves about $1 \mathrm{in}$. long, very slender grass-like and narrowing all the way to a sharp point. Most northern parts of our area.

29. P. interruptus, Kitaibel. Interrupted PondweEd. Leaves grassy, in clusters sheathed by the stipules. Flowers on interrupted spikes.

30. P. Robbinsii, Oakes. RoBbrn's PondweEd. Stems rigid, much branching; leaves rigid, in 2 opposite rows closely investing the stem, 3 to $5 \mathrm{inl}$ long, acute at outer extremity; stipules sheathing the stem, but at length free, very acute. Flowers very few in interrupted spikes. Lakes and ponds, N. J. and northward.

\section{Leaves all thread-like.}

31. P. pectinatus, L. (Fig. 2, pl. 5.) Fennel-teaved Pondweed. Spikes on long flower stalks with interrupted rounded spikes of flowers. Stem much branching. Stipules in contact with leaves half the length of the former. Some obscure raised lines on the back of the seed. Fresh or salt waters, our area.

32. P. filiformis, Pers. (Fig. 7, pl. 5.) Filiform Pondweed. Stems thread-like, 3 to $20 \mathrm{ft}$. long; leaves 2 to $12 \mathrm{in.} \mathrm{long.} \mathrm{Differing} \mathrm{from} \mathrm{No.}$ 31 by absence of the lines on back of seed. Ponds, western N. Y.

33. P. gemmiparus, Morong. Capillary Pondweed. The stipules are lance-shaped, acute at outer, broad at inner extremity. Ponds, eastern Mass. and R. I.

34. P. pusillus, L. Small Pondweed. Resembles Nos. 31 and 32 but flower groups are small rounded masses, each spike containing from 3 to 8 flowers in a nearly globular mass. Ponds, lakes and streams, our area.

35. P. strictifolius. Leaves much more rigid than those of $P$. pusillus, the edges turned back. In other respects strongly resembles $P$. pusillus.

36. P. confervoides, Reichb. Alga-Like Ponnwerd. Stems very slender, thread-like, 6 to 18 in. high. Leaves thread-like or flat bristleformed, about $1 \mathrm{in}$. long, the point very fine, 1-nerved or nerveless. Stipules nearly or quite $\frac{1}{1}$ in. long, blunt. Flower stem long and erect. Flowers in short spikes or heals, about 1 in. long. In cold mountain ponds throughout most of our region.

\section{ZANNICHELLIA, Mitchell}

Sulumersed water plant with ereeping roots, slender stems and threadlike leaves each broadened to a sheathing base, In the axils of the leaves spring the naked flowers which eonsist each of a single stamen and a group of 4 or less or more pistils, which expand toward the base into oval-shaped ovaries. Fruit directly on the receptacle or on a very short pedicel.

Z. palustris, L. (Fig. 3, pl. 5) Zannicumtru. Stems threat-like; leaves 1 to 3 in. long. Fruits 2 to 5 in a cluster. Fresh water, pools and ditches throughout our area. 


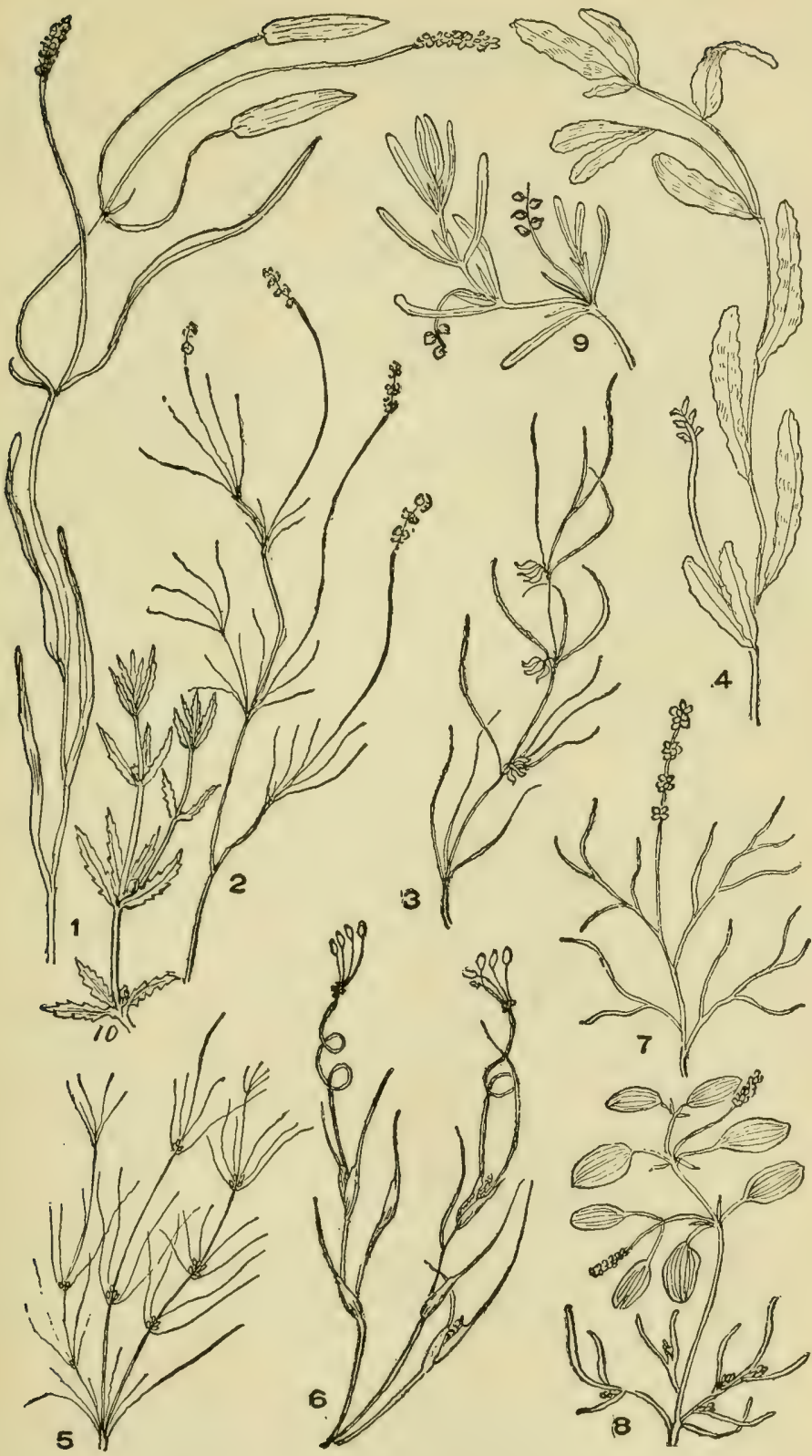

Plate 5

1. Potamogeton Oakesianus. 2. P. pectinatus. 3. Zannichellia palustris. 4. Potamogeton crispus. 5. Naias gracillima. 6. Ruppia maritima. 7. Potamogeton filiformis. 8. P. dimorphus. 9. P. zosteraefolius. 10. Naias marina. 


\section{ZOSTERA, L.}

Submersed water plant in salt water. Stems creeping; leaves narrow linear, often 2 to $3 \mathrm{ft}$. long. The flowers are naked, arranged in 2 rows of about 10 to 20 in ench row, on a long receptacle, which arises at the axil of the sheathing leaf, and which is nearly enclosed by it. Each flower consists of an anther or of a pistil. These alternate in the 2 rows, each being sessile.

Z. marina, L. (Fig. 9, pl. 6.) EeL Grass. Leaves 1 to $6 \mathrm{ft}$. long, less than $\frac{1}{4}$ in. wide, 3 to 7 nerved. Flower mass 1 to $2 \frac{1}{2} \mathrm{in}$. long. Along the Atlantic coast.

\section{RUPPIA, L.}

Submersed plants in salt water with creeping roots and thread-like, much branching. stems. Leaves alternate, thread-like, their bases expanding to a membraneous sheath. From the axil of this sheath arises the flower stalk which, at first, is partly enclosed by the membraneous sheath, but as the fruit matures the flower stalk becomes a long threadlike spirally-wound peduncle bearing an umbel-like cluster of hard seerls. The flower consists of 2 anthers attached directly to the recptacle, each so nearly divided in halves that they appear like 4 anthers. These enclose several (generally 4) pistils, which are also sessile.

R. maritima, L. (Fig. 6, pl. 5.) Ditch Grass. Mariture Ruppia. Stem 2 to $3 \mathrm{ft}$. long; leaves 1 to $3 \mathrm{in}$. long; the slender spiral fruit stalk about $1 \mathrm{ft}$. long. The only species within our limits. Common along the Atlantic coast.

\section{NAIAS, L:}

Slender branching submersed plants with leaves generally in whorls (3 to 5). Margins of the leaves toothed. Pistillate and staminate flowers on different receptacles, sometimes on different plants. Staminate flower with a cylindric calyx, entire or with 4 diverging points. The inner perianth is pelucid, adhering to the single stamen. Capsule 1-seeded.

1. N. marina, L. (Tig. 10, pl. 5.) LarGe NaIAS. Stem stout, with whorls of about 3 leaves, which are about 1 in. long by $1 / 12$ broad, deeply torthed on the marrin with spiny teeth. Several such teeth on the back of the central nerve. Lakes, marshes and salt springs, western N. $Y$. and westward.

2. N. flexilis, Willd. (Fig. 6, pl. 6.) Stender NaIas. Leaves in pairs, narrower than No. 1, acute at outer extremity somewhat sheathing at base. Few teeth on margin. Lakes, ponds and streams, all of our area.

3. N. gracillima, Morong. (Fig. 5, pl. 5.) Tumead-tike Nains. Strm thread-like, branching. Leaves thread-like but minutely notehed on margins, in 2's or in verticles of 3 to 5 . Ponds, pools. Local in Mass., N. Y., N. J., and southward.

\section{FAMILY JI.-TRIGLOCHINEAE. ARROW GRISS FAMIYY}

Plants growing in marshes. Leaves half cylintric, stem naked, with broal nembrancous sheath at base. Flowers small, green or 
yellowish-green, with 4 to 6 segments to the perianth, on a tall, slender, round scape, arranged in spindle-shaped cluster (raceme). Stamens 6 or 4 . Carpels 6 or 3 .

\section{TRIGLOCHIN, L.}

Characters as ahove.

1. T. palustris, L. Marsil Arrow Grass, Leaves linear, 5 to 12 in. long, tapering to sharp point. The naked flower scape 8 to $20 \mathrm{in}$. high. Flowers ereet on the scape, nearly $\frac{1}{4} \mathrm{in}$. long and $1 / 16$ in. wide. Segments of perianth 6. Anthers 6. Fruit of 3 carpels joined, linear club-shaped. In marshes. New York and northward.

2. T. maritima, L. (Fig. 5, pl. 6.) Seaside Arrow Grass. A large species $\frac{1}{2}$ to $2 \mathrm{ft}$. high. Flower stem much longer than leaves. Raceme often $15 \mathrm{in}$. or more in length. Fruit ovate or ovoid, of 6 united carpels. Salt marshes and lake shores. New Jersey and northward.

\section{SCHEUCHZERIA, L.}

Marsh plant with leafy stem. Leaves half round below, grass like above, with broad membraneous sheath at base. Flower stem with long leafy bracts, each flower growing from the axil of a bract. Flowers greenish, perianth of 6 segments. Stamens 6, ovaries 3, radiating.

S. palustris, L. (Fig. 8, pl. 6.) Scheuchzeria. A rush-like plant $8 \mathrm{in}$. to $1 \mathrm{ft}$. high. Leaves 4 to $6 \mathrm{in}$. long. The sheath of the basal leaves is often $4 \mathrm{in}$. long. Bays throughout our area.

\section{Family IV.-Alismaceae. Water Plantain Family}

Marsh or aquatic plants with showy flowers borne in whorls on scape-like stems, which arise at the root, with sheathing leaves, also arising from the root, and with flowers with stamens and pistils on the same flower or on different flowers on the same stem. Petals 3, white, sepals 3, green. Stamens 6 or more. Ovaries numerous. The leaves are found on long leaf-stalks and are strongly marked by the nerves which arise and terminate at the ends of the leaf. The blade of the leaf is in some species reduced to a grass-like or strap-shaped extension of the leaf-stalk.

\section{ALISMA, L.}

Flowers numerous, small, white or rosy, in elongated clusters consisting of several whorls, arranged on the scape which arises from the root. Flowers with both stamens and pistils. Leaves all from the root.

1. A. Plantago-aquatica, L. (Fig. 5, pl. 7.) Water PlantalN. Leaves all at the base, sprealing, broad egg-shaped with 5 to 7 nearly parallel or elliptically arranged nerves. Leaf stalk longer than the leaf. Flowers on a stem 6 to $30 \mathrm{in}$. tall, arranged in a loose pyramidal eluster composed of numerous smaller fan-shaped clusters of whorls, each made up of 3 to 10 flowers on slender individual flower stalks an inch or more in length. Swampy places or shallow water. Common, June-October. 
2. A. tenellum, Mart. Diwarf Water Plantain. (Helianthium tcucllum, Britton. Echinodorus tenncllus, Buchenau.) Leaves lanceshaped, on long leaf-stalks all basal. Flower stem naked, bearing at summit a spreading whorl or umbel of 2 to 8 white flowers on unequal flower stalks. Muddy places. Mass. southward and westward. AprilAugust.

3. A. Geyeri, Torr. Leaves linear-lance-shaped to elliptic, overtopping the shorter flower scapes. Whorls of flowers several, the cluster more diffuse than that of No. 1. Individual flower stems thick, strongly divergent in fruit. Petals rose color at the margins with a yellow spot at base. Locally, N. Y. and westward.

\section{LOPHOTOCARPUS, Durand}

Aquatic herbs with leaves and flowers resembling sagittaria and hardly distinguished from it. In this genus the flowers are all perfect, $i, e_{\text {, }}$, stamens and pistils are on the same receptacle. In sagittaria the stamens and pistils are in different flowers.

1. L. calycinus, J. G. Smith. Lopiotocarpus. Leaves lance-arrow or halberd-shaped. Flower stem decumbent. Plants with habits and appearance of sagittaria. Swamps and muddy bottoms, our area. JulySeptember.

2. L. spongiosus, (Engelm.) J. G. Smith. Spongr Sagrtararia. Submersed aquatic with thick spongy stem-like leaves which are 4 to 12 in. high, sometimes expanding to an arrow-shaped leaf-blade, 2 to $4 \mathrm{in}$. long, with or withont diverging acute lobes half as long as the leaf-stalks, at length decumbent. New Brunswick south to Virginia. July-August.

3. L. spathulatus, J. G. Smith. Spatula-leaved Sagittaria. Small aquatic with stem-like leaves, without leaf-blades. These bladeless leaves 1 to $2 \frac{1}{2} \mathrm{in}$. high. Flower stem usually shorter than the leaves, 1 or 2 flowered. Stamens 6 to 9 . On sandy beaches within influence of the tide. Newburyport, Mass.

\section{SAGITTARIA, L.}

Water plants growing in muddy borders of ponds and streams. Leaves and flowers aerial. Leaves all at base, varying from the extreme arrowliead form to long lanec-shape or even to long loaf stalks without blade. Flowers on a spike in whorls of 3's, each whorl subtended by a whorl of 3 bracts; upper flower whorls consisting of staminate, the lower of pistillate flowers. Corolla of 3 broad white petals, ealyx of 3 green srpals. Carpels on a convex receptacle. The beak at the extremity of the carpel forms an important feature for identification of some variable species.

Leaves arrow-shaped (sagittate), with the posterior lobes at least 1 as long as the blade.

Bracts below the pistillate (lower) flowers as long as the individual flower stems. Beak at extremity of fruit more than $\frac{1}{1}$ the length of the fruit

$$
\text { itself .......... S. longirostra }
$$

Beak less than $f$ length of fruit ....... S. arifolia

Bracts below pistillate flowers shorter than the flower stems.

Leaves broad .
Leaves very narrow, not always arrow-shaped . . . . S. Engclmannia 

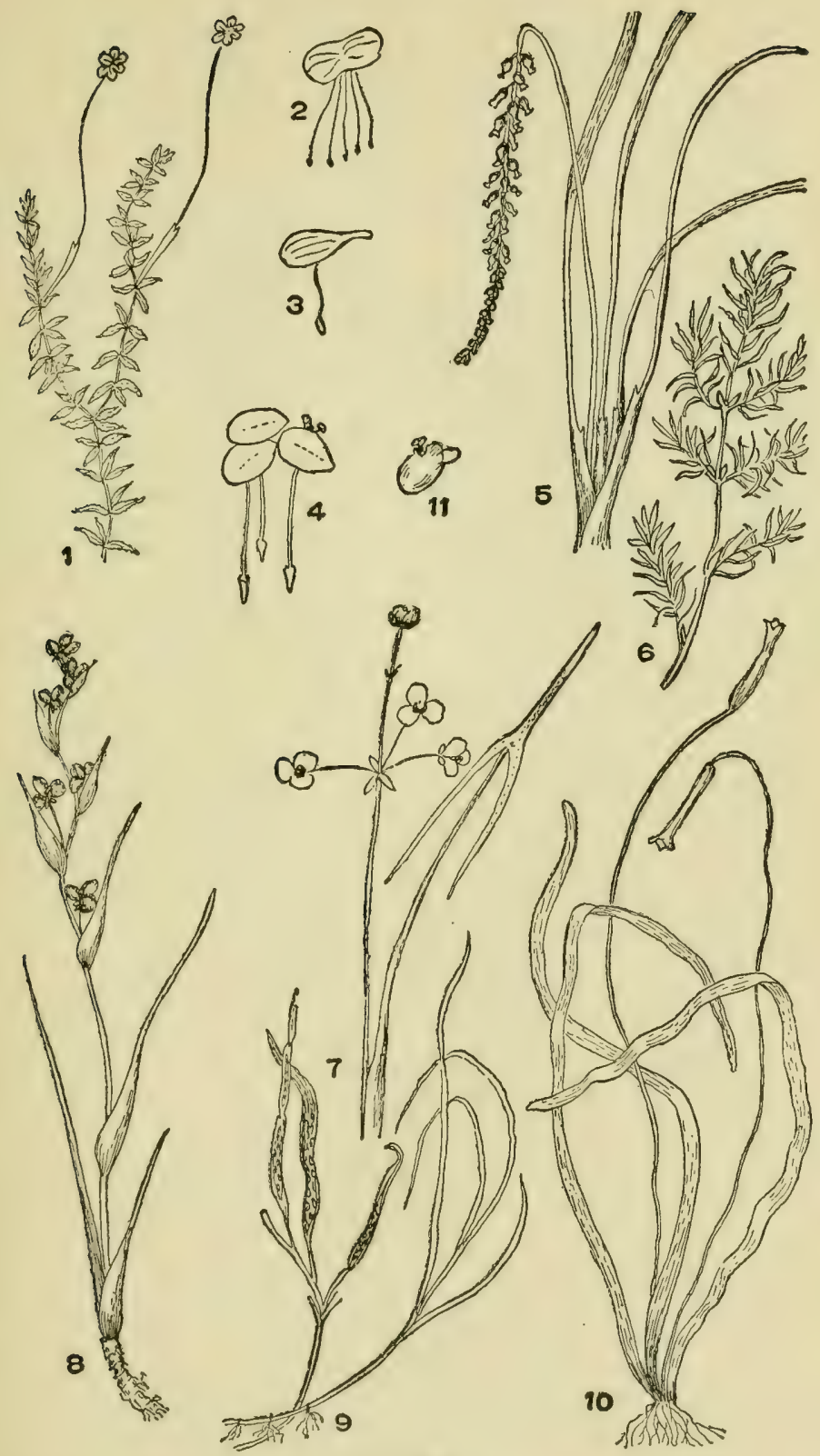

Plate 6

1. Elodea canadensis. 2. Lemna polyrhiza. 3. L. trisulca. 4. L. minor. 5. Triglochin maritima. 6. Naias flexilis. 7. Sagittaria Engelmannia. 8. Scheuchzeria palustris. 9. Zostera marina. 10. Vallisneria spiralis. 11. Wolffia columbiana. 
Leaves not generally arrow-shaped.

Flowers with very short or with no individual flower stems. S. heterophylla Flowers with rather long flower stems.

Leaves reduced to short rounded stems generally without leaf-blade $S$. teres Leaves more or less grass-like.

Leaves lance-shaped

Leaves linear.

Flowers white............. S. subulato

Petals with a rose-colored spot at base .... S. Eatoni

1. S. longirostra, (Micheli.) J. G. Smith. (Fig. 1, pl. 7.) LongBEAKED ARRow-HEAD. Plant 1 to $3 \mathrm{ft}$. tall. Leaves on leaf stalks longer than themselves, often broad, spreading at base to 2 receding lobes, acute at apex and at the ends of the lobes. Flower scape at base 6-angled, longer than leaves, very erect; at upper $1 / 3$ about 2 whorls of pistillate and 2 to 4 whorls of staminate flowers, each subtended by 3 bracts, longer than the flower pedicel. The white petals greater in breadth than length. Fruit with a stout beak, nearly ereet. This is a common species in this country and it is also native in Europe. Its leaves are extremely variable in form and hence the species is known also as S. variabilis. The drawing, Fig. 1, pl. 7, shows the very narrow form of the leaf, the blade is, however, sometimes several inches across. Margins of lakes and ponds and in swamps. July-September.

2. S. arifolia, Nutt. (Fig. 2, pl. 7.) Arum-Leaved Sagittaria. Leaf wings about $\frac{1}{1}$ the length of blade. Flowers arranged as in No. 1. Leaf stalks bend outward. Fruit with a very small bcak less than $1 / 10$ length of fruit. Situations similar to No. 1. August-September.

3. S. Engelmannia, J. G. Smith. (Fig. 7, pl. 6.) Engelarann's ARRow-HEAD. Stem quite slender, leaves very narrow, basal lobes being linear, about $\frac{1}{2}$ as long as the blade. The bracts below the pistillate flowers about $1 / 3$ the length of the flower pedicels. The fruit (achene) is terminated by a beak, nearly $\frac{1}{2}$ its own length, which points dircctly upward. Situations similar to No. 1. August-September.

4. S. latifolia, Willd. (Fig. 3, pl. 7.) Brond-Leaved Arrow-nean. Variable in size and form. Flower scape from $6 \mathrm{in}$. to $2 \mathrm{ft}$. tall. Leaves often very broad, but also sometimes quite narrow. Lobes $1 / 4$ to $1 / 3$ as long as blade. The beak at the summit of the fruit points oblinucly or almost horizontally.

5. S. heterophylla, Pursh. (Fig. 4, pl. 7.) Sessile-fruted ArmowIfEAD. (S. rigida, Pursh.) Plant from $\frac{1}{2}$ to $2 \mathrm{ft}$. high. Leaves variable, from broad linear, alnost grass-like, to lance-shaped or elliptic or ovate, about as high as flower stalk. Pistillate (lower) Howers with very short pediecl (sessile), staminate flowers above, on long pedicels. Fruit with an upright beak 1 length of the fruit itself.

6. S. graminea, Michx. Grass-lisaven Sagittamia. Leavis linear, lance-shaped or elliptic. The pistillate flowers on perlicels as long as or longer than those of the upper staminate llowers. Ponds, our area.

7. S. Eatoni, T. E. Smith. Eatov's Sarittaria. Aquatic with mostly bladeless leaves or rarely with these leaf-stems expanding to a linear lanee-shaped blade. Flower stem 4 to 8 in. high, weak, bearing 1,2 or rarely 3 wlorls of flowers. Lowest whorl with 2 fertile and 1 staminate flower. Pedicels of fertile flowers about \& in, longr. In new edition of 


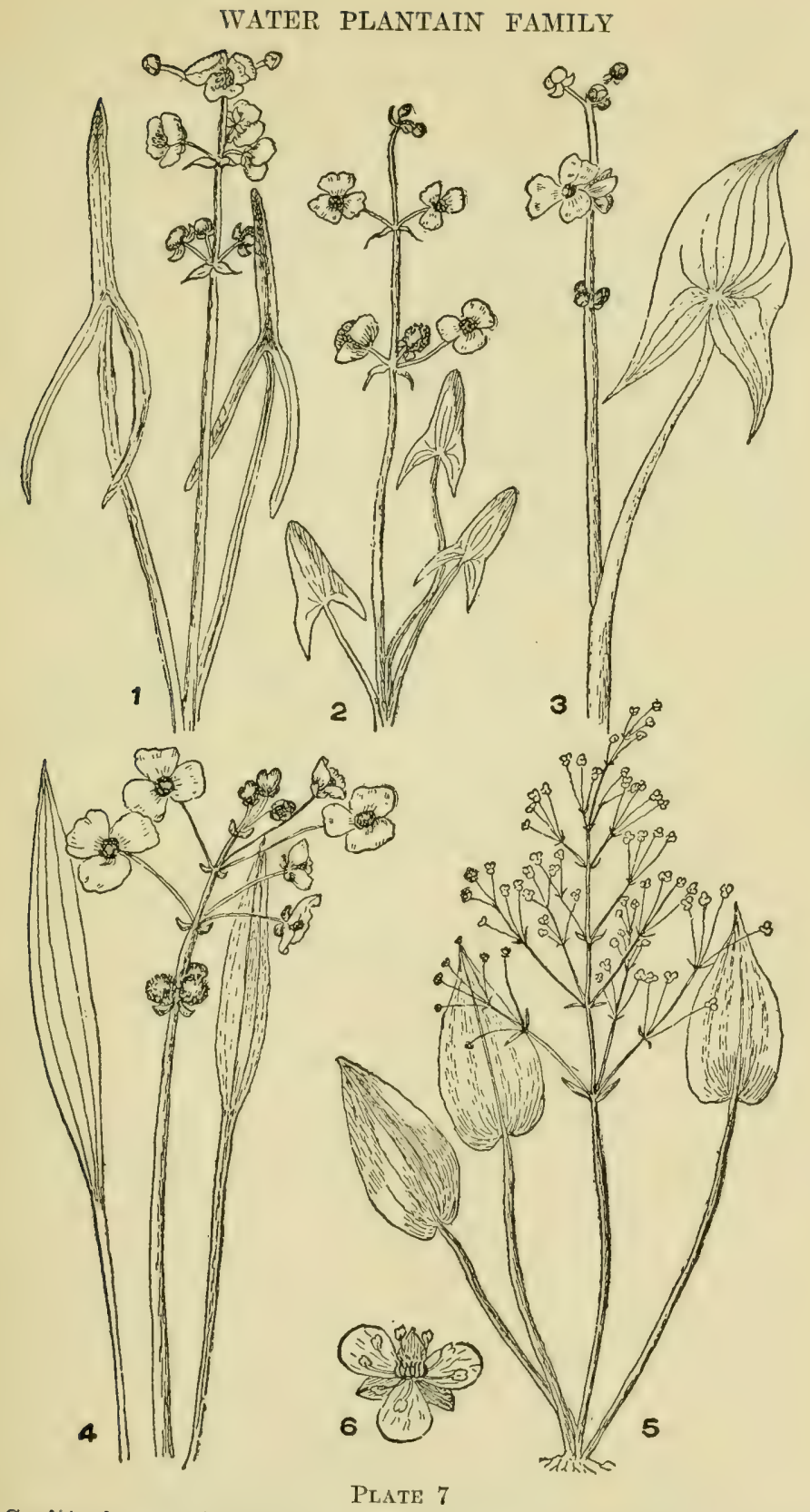

1. Sagittaria longirostra. 2. S. arifolia. 3. S. latifolia. 4. S. heterophylla. 5. Alisma Plantago-aquatica. 6. Enlarged flower of A. Plantagoaquatica. 
Gray regarded as a form of S. graminca. On sandy shores between high and low tide, Newburyport, Mass.

8. S. teres, S. Watts. Slender Sagittaria. Leaves reduced to short rounded leaf stalks without blades or bracts. Flower stalk slender $\frac{1}{2}$ to $1 \frac{1}{2} \mathrm{ft}$. high; few flowered. Ponds, Mass. and southward.

9. S. subulata, (L.) Buchenare. Subulate Sagittaria. Leaves simply leaf stalks or with narrow lanceolate blades. Flower stalk very slender $1 / 6$ to $\frac{1}{2} \mathrm{ft}$. high. Bracts below flower whorls united to their extremities or nearly so. Conn., southward.

\section{Family V.-VALLISNERIAceaE. TApe-grass Famili}

Submersed aquatic herbs, with regular flowers which terminate a long thread-like peduncle, which arises from a spathe or involucre. Flowers tubular, 3- or 6-parted at summit. Pistillate and staminate flowers on the same or on different plants. Stamens 3 to 12 , separate or in union. Fruit ripening under water.

\section{VALLISNERIA, L.}

Submersed. Leaves long, grass-like with 5 parallel nerves including the marginal. Pistillate flowers white, with 3 lobes, on a long thread-like pedicel starting near the root and extending to the surface of the water when expanded. After fertilization the long pedicel becomes spiral and draws the flower below the surface. Fruit much elongated. Staminate flowers on short scape on a conic receptacle.

V. spiralis, L. (Fig. 10, pl. 6.) Lake Grass. Eel Grass. In still waters throughout our region.

\section{ELODEA, Michx. (Philotria, Raf.)}

Submersed plant with many whorls of 3 or 4 short awl-shaped or elliptic leaves. Much branching. Flowers white, 6-parted at summit, on a long white thread-like pedicel ( 6 to 12 in.), which arises from a tubular "spathe" but little thicker than itself and which generally terminates a branch. The tiny white flower floats on the surface of the water, the remainder of the plant submersed. Staminate flowers without the long pedicel, breaking off and rising to surface of water to shed the pollen.

E. canadensis, Michx. (Fig. 1, pl. 6.) Ditcr Moss. In quiet ponds and lakes, throughout our area. May-Aug.

\section{LIMNOBIUM, Richard. (Hydrocharis, Bosc.)}

Water herbs spreading by stolons with broad egg-shaped or heartshaped leaves which arise in fascicled groups at the stolon nodes. Flowers white on flower stalks shorter than the leaves. Pistillate and staminate flowers on same plant. Perianth 6 parted, segments mequal. Staminate flowers in a spathe, 2 to 4 . Fruit berry-like.

L. Spongia, (Bose.) Richard. Frog-13iт. Leaves round or somewhat egre-shaped, 1 to $2 \mathrm{in.} \mathrm{long,} \mathrm{nearly} \mathrm{or} \mathrm{quite} \mathrm{as} \mathrm{wide,} 5$ to 7 nerved. Flowers and leaves arising from the nodes of the runners. In shallow still water, our area. July-Aug. 


\section{Order III.-GLUMIFLORAE. Glumaceous Flowered Plants}

The order Glumiflorae includes the great families of grasses and sedges. The inflorescence is characterized by the dry, scale-like bracts, which are known as glumes. These glumaceous plants number, in our region, more than 400 species. Though of much interest as including some of the most valuable plants, the study of them is, to some extent, a speciality. Owing to the great number of the species and with the view of limiting the extent of this work, these families are omitted.

\section{Order IV.-SPATHIFLORAE. Order of the Arums} The order includes, in our region, only one family, Araceae.

\section{Family I.-ARACEAE. ARum Family}

Herbs bearing a fleshy spike which supports a large number of flowers, which are destitute of a perianth (a spadix). The spadix is enclosed by a sheath-like organ, the spathe. In Acorus the sheath appears like a continuation of the grass-like stem and does not wholly enclose the spadix. When the flowers are perfect, that is, when stamen and pistil are included in the same flower, the fleshy spike is surrounded by flowers which are alike on all parts of the receptacle. When some of the flowers are staminate and others are pistillate the former are on the upper part of the spadix, the latter below. The stamens are without filaments or with very short ones, and the styles are wanting to the pistils or are very short.

Leaves divided into 3 or more segments . . . Arisaema Leaves arrow-head shaped . . . . . . Peltandra

Leaves egg-shaped, heart-shaped at base.

Spathe (flower envelope) white . . . . . Calla

Spathe brown to yellow . . . . . . Symplocarpus Leaves elliptic . . . . . . . . . . Orontium Leaves long, grass-like . . . . . . . . Acorus

I. ARISAEMA, Martius. (Arum, L.)

Stem arising from an acrid, flattened, fleshy, bulb-like mass, a corm. Flower and leaf stems from the same base. Spadix consists of a column, 
the upper part of which bears staminate flowers, the lower, pistillate. The column is enclosed by a sheath, generally striped in green and dark purple (the spathe). Fruit a fleshy oval berry, red when ripe. A number of such berries surround the fleshy, club-like mass.

1. A. triphyllum, Torr. (Fig. 1, pl. 8.) JACK-IN-TIIE-PUlpit. (Arum triphyllum, L.) One or two leaf stems, each bearing 3 leaflets, the stem and leaf $\frac{2}{3}$ to $3 \mathrm{ft}$. high. Flower stem shorter than stems bearing leaves. The green- or purple-striped sheath curves over the spadix. Found commonly in moist woods. April-June.

Var. A. pusillum, Peck. Small Jack-in-tile-Pulpit. Similar to No. 1, but smaller and more slender, $14 \mathrm{in}$. high or less, spathe striped below; hood deep brown or nearly black. Open soggy bogs, New York. May-July.

Var. A. Stewardsonii, Britton. Fluten Spathed Indian Turnip. Similar to No. 1, but spathe is distinctly fluted and leaves are shining on both sides. Spathe about as long as the stem from which it springs. Wet woods, growing among sphagnum, Penn. to Vermont. July.

2. A. Dracontium, (L.) Schott. (Fig. 7, pl, 8.) Green Dragon. Leaf stem bears 5 to 17 leaflets, the stem and leaflets much exceeding the flower scape in height, the leaflets 3 to $10 \mathrm{in.} \mathrm{long.} \mathrm{Sheath} \mathrm{greenish} \mathrm{or}$ whitish, not curving over the spadix, which tapers to a long, slender appendix. Moist shady places, our area. May-June.

\section{PELTANDRA, Raf.}

Large, undivided, arrow-shaped, shining, green leaves on long sheathing stalks, native of bogs. Flower column (spadix) slender and tapering, closely enveloped by the long grcen sheath (spathe). As the fruit is perfected the long flower stems bend toward the ground in goose neek fashion and the extremity of the sheath as well as the column fall off.

P. virginica, (L.) Kunth. (Fig. 1, pl. 9.) Green Arrow Arum. In swamps and bogs throughout our region.

\section{CALLA, L.}

Iow herb with heart-shaped or rounded leaves, in swamps or in borders of sluggish streams. Flower column much shorter than the sheath, which is white within and greenish on the outside. Leaf stem 2 to 6 in. long, leaf blades 2 to 6 in. long and nearly as wide. Berries in a eylindric group around the fleshy spadix, each involuere conic, red, few sceded.

C. palustris, L. (Fig. 6, pl. 8.) Water Arum. Resembles the cultivated calla, but is more or less creeping, and the central colum is much thicker and longer in proportion to the white sheath. Bogs throughout our area.

\section{SYMPLOCARPUS, Salisb. (Spathyema, Raf.)}

Leaves large, heart-shaped or nearly oval. Whole plant fortid. Flower column oval, surrounded by a purplish-brown sheath, 3 to $6 \mathrm{in}$. high and $\frac{1}{2}$ as wide.

S. foetidus, (I.) Nutt. (Fig. 4, pl. 9.) Srunk Cambage. The unattractive flower appears very early in the spring (Feb. to April), preceding the large leaves, these beeme from 1 to $3 \mathrm{ft}$. long and $\frac{1}{2}$ as wide. In swamps and wet soil, our area. Feb-April. 


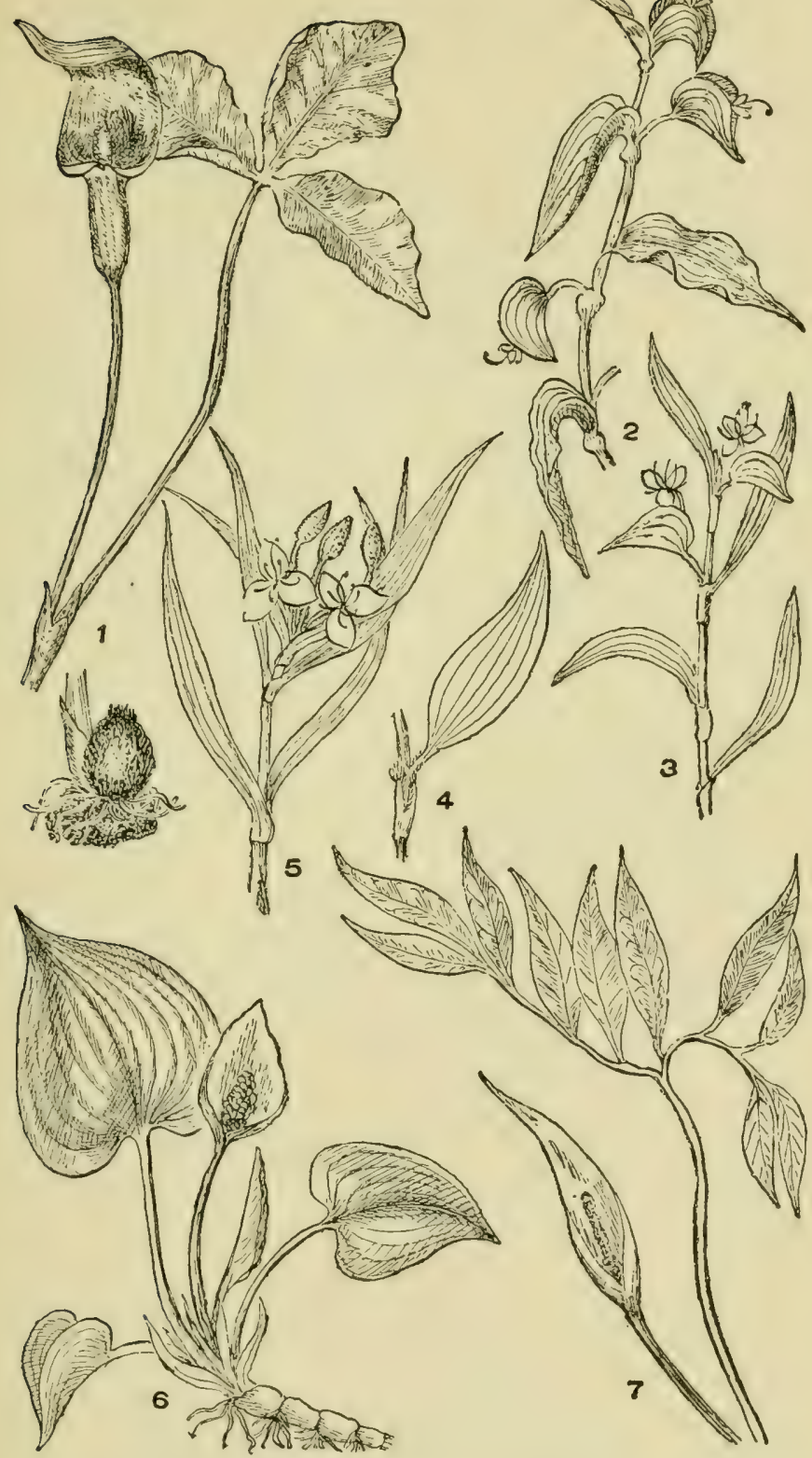

Plate 8

1. Arisaema triphyllum, 1a. Corm of A. triphyllum. 2. Commelina com. munis. 3. C. virginica. 4. C. hirtella (leaf and sheath). 5. Tradescantia virginiana. 6. Calla palustris. 7. Arisaema Dracontium. 


\section{ORONTIUM, L.}

Water plant with elliptic leaves. Flower column (spadix) tall, cylindric. The sheath (spathe) at first covers the column, then recedes, and in many cases falls.

O. aquaticum, L. (Fig. 2, pl. 9.) Golden Club. Leaves often floating in water, 3 to $12 \mathrm{in.}$ long, $\frac{1}{2}$ as wide; entire, with veins nearly parallel. Swamps and ponds, southeast part of our area and southward. AprilMay.

\section{ACORUS, L。}

Long, aromatic, creeping rootstalks and grass- or flag-like leaves; growing in wet places. Flower column appearing to start from the side of a bayonet-like leaf.

A. Calamus, L. (Fig. 3, pl. 9.) Sweet Flag. Calamus Root. Leaves 2 to $6 \mathrm{ft}$. high, 1 in. or less broad. Flower stem triangular or somewhat rounded. Swamps and along streams, common. May-July.

\section{Order V.-FARINOSAE. Order of the Spiderworts}

A small order including herbaceous plants, mostly aquatic, but including the family Commetinaccae, the plants of which are found in rich moist soil. Flowers with 3 or 6 stamens and 1 to 3 ovaries. Petals 3 or rarely 2 ; sepals 3 . Flowers, except Commelinaceae, are nearly or quite regular; the petals and sepals are below the ovary. Flowers generally not individually conspicuous, but in some families forming heads or spikes, which are quite showy.

The order is specially characterized by the technical fact that the embryo arises at the end of the ovule opposite to the point of attachment of the ovule to the ovary.

Flowers yellow, in chaffy heads XYRIDACEAE Flowers white or dull lead color in globose heads

Flowers blue.

Plants not aquatic . . . . . COMMELINACEAE Aquatic plants . . . . . . . PONTEDERIACEAE

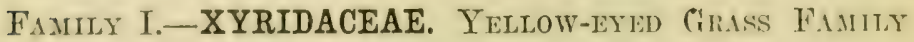

Marsh plants with grass-like tufted leaves and with twisted, angular flower stalks, bearing chafly terminal heads with yellow 
flowers. Petals 5; sepals 3 ; fertile stamens 3 inserted on the corolla (3 aborted stamens), capsule many-seeded.

\section{XYRIS, L.}

Characters, those of the Family.

Scape with a conspicuous bulb at base . . . . . . . . X. arenicole Scape not arising from a conspicuous bulb.

Heads nearly globose.

The two side sepals without wings . . . . . . . . X. Acxuosa

The two side sepals winged.

Scape decidedly flattened . . . . . . . 'X. caroliniana

Scape not distinctly flattened

X. montuna

Heads cylindric or oblong.

Keel of lateral sepals fringed . . . . . . . . X. fimbriata

Keel oi' lateral sepals not fringed . . . . . . X. Simalliana

1. X. flexuosa, Muhl. (Fig. 8, pl. 9.) Slender Yellow-eyed Grass. Heads globose, $\frac{1}{4}$ in. high; leaves narrowly linear. The 2 side sepals without wings. The flower scape only slightly or not at all twisted, 4 to 18 in. high, expanding to a bulb at base. Expanded flower about $\frac{1}{4}$ in. diameter. Swamps and wet places. July-Sept.

2. X. montana, H. Ries. Nortinern Yellow-eyed Grass. Two side sepals with wings, flower scape only slightly twisted, not bulbous at base, heads oblong. Smaller than No. 1, but much resembling it. White Mountains. In cold bogs. July-Aug.

3. X. fimbriata, Ell. (Fig. 6, pl. 9.) Fringed Yellow-eyed Grass. Scape stout, 2 to $4 \mathrm{ft}$. high, angled, heads cylindric, $\frac{1}{2}$ to $1 \mathrm{in.}$ long. Lateral sepals narrow and tuice as long as the subtending chaffy bract and distinctly fringed. Wet pine barrens, New Jersey.

4. X. caroliniana, Walt. Carolina Yellow-ered Grass. Scape decidedly flattened, 6 in. to $2 \mathrm{ft}$. high. Lateral sepals winged, obseurely fringed above, these lateral sepals shorter than the chaffy bract, subtending them. Swamps mostly near the coast.

5. X. arenicola, Small. (Fig. 7, pl. 9.) Twisted Yellow-ered Grass. (T. toria, Kunth.) Scape much twisted, arising from a bulbous base. Leaves also spiral twisted. Heads narrow oblong. Lateral sepals exceeding the bract and slightly fringed. Dry pine barrens, New Jersey. May-Aug.

6. X. Smalliana, Nash. Congdon's Yellow-ered Grass. (X. Congdoni, Small.) Larger than $X$. caroliniana, the stem 16 to $22 \mathrm{in.} \mathrm{high.}$ Leaves about $3 / 8$ in. broad at base, the longer ones as long as the flower stem. Bracts forming the head numerous with irregularly notehed borders. Lateral sepals $\frac{1}{2}$ in. long. Low grounds, Mass. to New Jersey. Aug.-Sept.

\section{Fanily II.-ERIOCAULACEAE. Pipewort Family}

Plants growing in bogs and in water. Leaves tufted, grass-like, springing directly from the root. Flower stem longer than the leaves, sometimes very long, angular and twisted. Flowers in rounded heads, each individual flower subtended by a thin dry bract. Pistillate and staminate flowers in the same head or occa- 
sionally all the staminate flowers on one plant, the pistillate on another. Stamens equal in number or twice the number of the sepals.

\section{ERIOCAULON, L.}

Leaves short. grass-like. Flower stem with a sheathing bract at the hase. Flowers in white or dull lead-colored rounded heads. Flowers bearing stamens nearly tubular, of 2 segments at the summit, united below. Stamens 4 to 6 . The staminate flowers generally exterior to the pistillate. Calyx of 2 or 3 sealy sepals. Corolla tubular, spreading alove and divided at summit into 2 or 3 segments. Stamens twice as many as the segments. Bracts bearded.

1. E. articulatum, (Huds.) Morong. (Fig. 9, pl. 9.) Serex-Axgled PIPEWorT. (E. septangulare, With.). Leaves as long as the sheaths of the flower scapes. Flower scapes twisted, 7 -angled. When growing in water the hearls reach the surface, hence the scape may be 2 to $10 \mathrm{ft}$. long; when on the muddy bank 1 or more inches high. Our area.

2. E. Parkeri, Robinson. Parier's Pipewort. Growing in tufts, smooth, flower stem $2 \frac{1}{2}$ to $5 \mathrm{in}$. high. Leaves linear-lanceolate, about $\frac{1}{4}$ in. wide, $1 \frac{x}{2}$ to $2 \frac{1}{2}$ in. long. Differs from No. 1 in that the head of the latter is said to be "ellipsoid," while this species has heads said to be "campanulate" in fruit and the flowers of the present species are crect while the outer ones of No. 1 are spreading. In tidal mud, near Camden, New Jersey. Sept.-Oct.

3. E. compressum, Lam. Flattened Pipewort. Leaf blades sharppointed, shorke than the sheaths of the flower stem, the latter slender and flattened, 10- to 12-angled, $\frac{3}{2}$ to $3 \mathrm{ft}$. long. Shallow water, south New Jersey and southward.

4. E. decangulare, L. (Fir. 5, pl. 9.) Tex-Axgled Preewort. Leaf biales blunt-pxinted, much longer than the sheath of the flouer scape, rather broad, grass-like, 6 to $20 \mathrm{in.}$ long, often 1 in. wide. Flower stem 1 to $3 \mathrm{ft}$. tall. Swamps, south New Jersey and southward.

\section{FAMIY IIL-COMMELINACEAE. SPIDERoRT FAMILY}

Generally somewhat succulent plants, annual or peremnial by their roots. Idaves alternate, always sheathing the stem at the hase. Flowers lilue, egenerally several, subtended by a leaf-like spathe (Commelina) or leafy bracts (Tradescantia). Sepals 3; petals 3 , unequal; stamens 6 .

\section{COMMELINA, L.}

Weak, semi-prostrate, juicy herbs, with hase of leaves omeireling the strm. Flowers $\frac{1}{2}$ in. hroad, enclosed below by a heart-shaped folded leat or spathe. Sepals or petals unequal. Of the 6 stamens 3 are usually sterile and smaller than the others. Flowers all summer.

1. C. communis, I. (Fig. 2, pl. 8.) Crefering Dax Flower. (C. muliflere, L.?). Leaves and stem light green, semi-prestrate, often rooting 
ARUM AND PIPEWORT FAMILIES
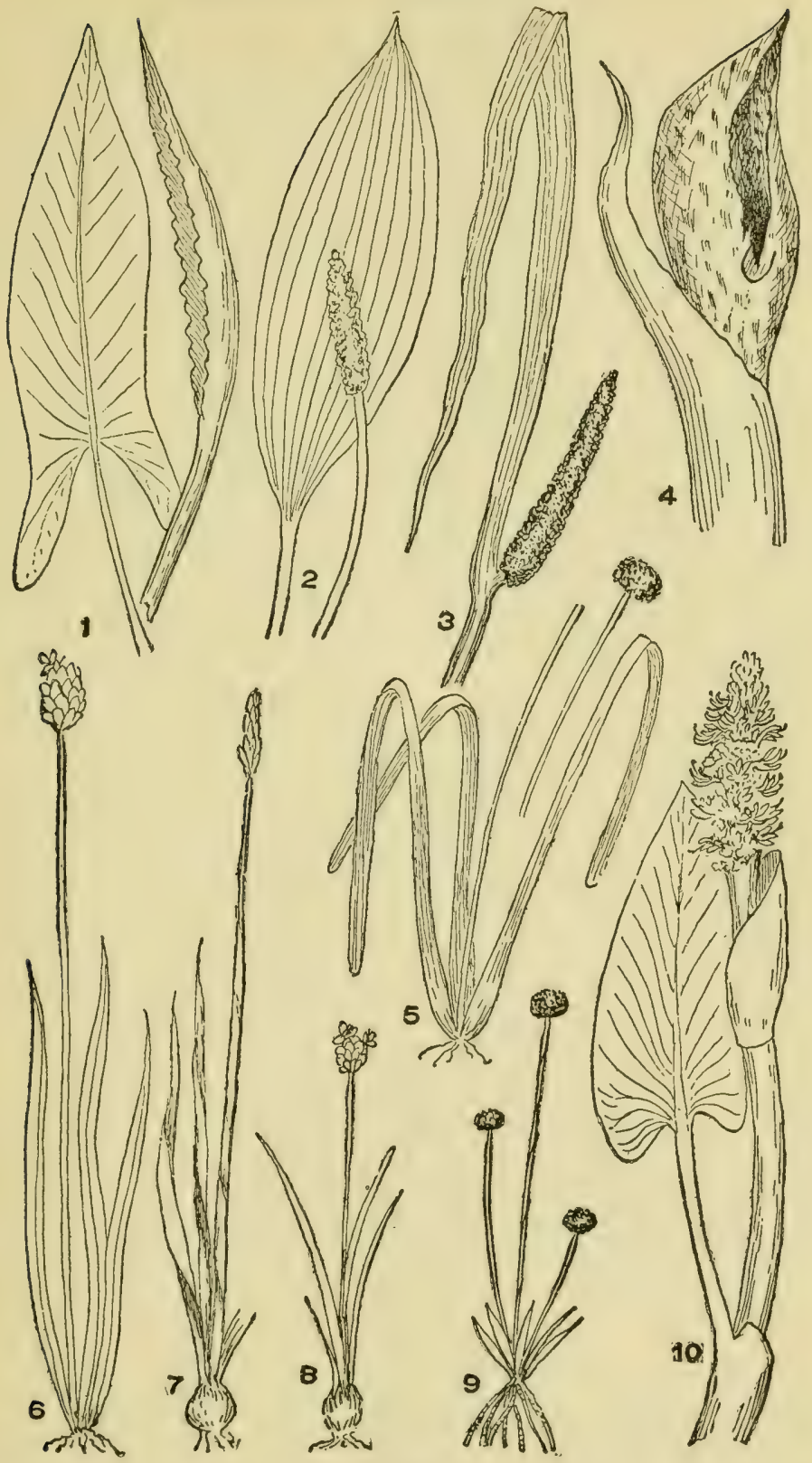

Plate 9

1. Peltandra virginica. 2. Orontium aquaticum. 3. Acorus Calamus. 4. Symplocarpus foetidus. 5. Eriocaulon decangulare. 6. Xyris fimbriata.

7. X, arenicola. 8. X, flexuosa. 9. Eriocaulon articulatum. 10. Pontederia 
at the nodes. Leaves lance-shaped or oval lance-shaped, $\frac{1}{2}$ to $\frac{3}{\mathrm{in}}$. wide, their sheathing bases not fringed with hairs or very slightly ciliate, and of the eolor of the leaf or with whitish veins; the margins of the spathe not united. In moist places, southern part of our area.

2. C. hirtella, Vahl. (Fig. 4, pl. 8.) Bearded Day Flower. Similar to No. 1, leaves broader and sheaths bearded on the edges with a fringe of rather stiff hairs. Penna. and southward.

3. C. virginica, L. (Fig. 3, pl. 8.) Virginia DaY Flower. A larger species, $1 \frac{1}{2}$ to $3 \mathrm{ft}$. high and with flowers $1 \mathrm{in}$, broad. N. I. and southward.

\section{TRADESCANTIA, L.}

Branching herbs with long, narrow leaves, almost grass-like, and regular flowers. Petals blue, 3 in number; sepals 3 , stamens 6 , all alike. The loose cluster of a few flowers is subtended by long leafy bracts.

1. T. virginiana, L. (Fig. 5, pl. 8.) SpIderwort. Stem and leares smooth, light green, stem $\frac{1}{2}$ to $3 \mathrm{ft}$. tall. Leaves linear, channeled. Woods and thickets. Conn., and southward.

2. T. pilosa, Lehm. Zigzag Spiderwort. Resembles No. 1, but the whole plant is more or less hairy. Stem zigzag. Southern Penna, and southward. June-Aug.

\section{Fanily IV.-PONTEDERIACEAE. Pickerel-weed Fanily}

Aquatic plants, herbs with flower-stem bearing clusters of blue irregular flowers subtended by a leaf-like spathe. Leaves broad or linear. Flowers of 6 unequal petals, with 3 or 6 stamens inserted in the tube of the corolla. Pistil 1, the head being 3-lobed. Many flowers forming a nearly cylindric spike . P Pontederia $\Delta$ few flowers in a loose cluster subtended by a spathe Heteranthera

\section{PONTEDERIA, L.}

Perianth tubular with 2 lips of 3 divisions each, the lower lip more spreading than the upper. Leaves thick, heart-shaped. Flower stalk stout.

P. cordata, L. (Fig. 10, pl. 9.) Pickerlit Wren. Leaves lieartarrow-shaped. Flower spike densely flowered, forming a cylindrie spike from 1 to $3 \mathrm{in.} \mathrm{long.} \mathrm{Found} \mathrm{in} \mathrm{shallow} \mathrm{borders} \mathrm{of} \mathrm{ponds} \mathrm{and} \mathrm{streams}$ where the thick creeping rootstalks form a net-work in the mudly bottom. July-Aug.

\section{HETERANTHERA, R. \& P.}

Perianth spreading with 6 nearly equal segments. Flower clusters with few flowers, subtended by a spathe. Stamens 3, inserted in the throat of the perianth. Creeping and floating herbs with various forms of leaves. 
1. H. reniformis, R. \& P. (Fig. 7, pl. 3.) Mud Plantain. Leaves kidney-formed. Flowers 2 to 5 in a cluster, white or pale blue. Mud in shallow borders of ponds and streams. Conn., westward.

2. H. dubia, (Jacq.) MacM. (Fig. 6, pl. 3.) Water Star Grass. Leaves grass-like. One flower only arising from the spathe, yellow. In still water or in the muddy borders of streams. In our whole region.

\section{Order VI.-LILIIFLORAE. Order of Lily-like Flowers}

Perianth (except in Iris and Trillium) of 6 similar parts, usually all colored. In Juncaceae the parts are dry, greenish or brown, scales or glumes, and in Muscari, Aletris and a few others the divisions are more or less united. The divisions are arranged in an outer and an inner row, the outer in fact representing the calyx. In Trillium the segments of the outer row are green sepals. The divisions are, however. in other genera generally structurally similar and all have the appearance of petals. The anthers face toward the inside of the flower.

In the Iris and Bloodwort families 3 stamens are suppressed and in the Iris itself 3 petals are less in size than the other 3 , while the 3 styles are so expanded and colored as to resemble petals. There are, therefore, with the exceptions mentioned, 6 petals, and in all our species, 6 stamens and 1 or 3 pistils, the latter surmounting an ovary divided into 3 cells, the ovary being situated above the stamens and perianth in some families and below in others. In general the leaves are long and narrow with parallel veins. In most of the berry-bearing species the leaves are broadened and in the plants with twining or woody stems the leaves are decidedly broad, often oval or even round. This fact holds also with Trillium.

The order is an extensive one, including Rushes, the onion-like Alliums, the Hyacintlss, Smilax and other tribes besides the true Lilies.

1. Flowers with dry, chaffy perianth (glumes) similar to that of the grasses, sedges, etc., but with the general structure of Liliiflorae . . . . RUSH FAmily JUNCACEAE 
2. Flowers not with chaffy perianth, perianth colored.

Flowers with 6 stamens.

Ovary situated above the perianth.

Fruit a capsule.

Capsule splitting at the partitions.

- Buncii Flower famli melanthaceaE

Capsule splitting between the partitions.

Flowers in loose clusters or solitary.

. . . . . LILY Family IILIIACEAE

Flowers in rounded umbels. Tribe ALLIOIDEAE

Fruit a fleshy berry.

Vines climbing by tendril.

Smilax FaMILY SMILACEAE

Erect herbs with perfect flowers CONVALLARIACEAE Ovary situated below the perianth.

Erect herbs. Amaryllis Family AMARYLIIDACEAE

Herbaceous vine. YAM FAMILY DIOSCOREACEAE Flowers with 3 stamens.

Ovary situated wholly or partly below the perianth.

Stamens opposite the inner corolla segments.

. . Bloodwort Family HaEmodoraceaE

Stamens opposite the outer, segments of the corolla.

Iris Family iRIDACEAE

Fimily I.-JUNCACEAE. 'Tine Riesir F.ming

Grass-like herls, with small dry, greenish flowers much resembling the srases, but having the divisions of the lily order. The perianth is of 6 parts, glume-like, in 2 series, all equal and regular. Stamens 6 (rarely 3 ) ; style 1 ; ovary 1-celled or 3-celled. Inflorescence in spreading or elongated clusters, often one-sidecl.

Capsule many-seeded . . . . . . . . . Juncus

Capsule 3-sceded . . . . . . . . . Luzula

I. JUNCUS, L.

Plants principally inhabiting swamps or wot ground. Leares grasslike. Stamens 6 or 3. Capsule 1- or 3-celled. Seeds many. Flowers usually on a long, cylimbir seape, which to most porple is mistaken for the leaf. 'This long scape forms the rush that is used for various purposes. 


\section{A. Clusters of flowers apparcntly growing from the side of the scape.}

1. J. effusus, L. (Fig. 1, pl. 10.) Common Rusr. Seape straight, $\frac{1}{2}$ to $4 \mathrm{ft}$. high, growing in dense tufts. The cluster of green flowers grows apparently on one side of the scape, which extends above it from 2 to several inches. The cluster is twice compound, the flowers separate, not in heads, the cluster subtended by several bracts. A long leaflike bract sheaths the scape at base. The segments of the perianth are green, lance-shaped, acute. Common in swamps and other wet places.

2. J. filiformis, L. (Fig. 8, pl. 10.) Thread RusH. Scape straight, weak, very slender. The eluster of flowers is nearly simple, not twice compound as in No. 1. The petals are shorter than the scpals, while in No. 1 they are longer.

3. J. setaceus, Rostk. Awl-Leaved Rusir. Scape $1 \frac{1}{2}$ to $3 \mathrm{ft}$. high, plant in dense tufts. The bract. or leaf sheathing the scape at base is extended into a cylindric stem like the seape. Cluster of flowers compound, with conspicuous bracts at the base of the secondary groups. Sepals longer than petals and both narrow lance-shaped and acute at apex. The apparent prolongation of the stem is really the involucral leaf to the flower cluster. Marshes along the sea coast, Delaware, southward.

4. J. Smithii, Coville. Pennsylvania Rush. (J. gymnocarpus, Englm.) Stem 1 to $2 \frac{1}{2} \mathrm{ft}$. high; basal leaves reduced to clasping sheaths. The loose cluster of flowers about an inch high, diffuse, the leaf below the cluster 4 to $10 \mathrm{in}$. long. Parts of the perianth reaching only to the middle of the capsule. The capsule broadly oval with a sharp point or spine at the apex, brown and glistening. Swamps, mountains of Schuylkill and Lebanon Counties, Penna.

5. J. balticus, Willd. Baltic Rusir. Seape 1 to $3 \mathrm{ft}$. high, the plants arising in dense rows from a stout rootstock. Flower cluster brown, 1 to $1 \frac{1}{2}$ in. high, the parts of the perianth lance-shaped, acute, nearly equal. Sandy shores, most of our region.

6. J. trifidus, L. (Fig. 7, pl. 10.) HignLand Rush. A small rush, densely tufted; scape 4 to $12 \mathrm{in}$. high. Basal leaves sheathing the scape, scarcely diverging as leaf blades. At from 1 to 3 in. below the small head of flowers a single-stem leaf arises, which is from 3 to $5 \mathrm{in}$. long; very narrow. Cluster of 1 to 3 flowers in the axil of a bract resembling the leaf-stem, but rarely more than 2 in. long. Flowers dark brown. Stamens 6. On the high mountains of the Adirondack and White Mountain ranges.

7. J. Rœmerianus, Schecle. Rømer's Rusir. A large rush, growing in salt marshes; scape stout, rigid, $1 \frac{1}{2}$ to $4 \mathrm{ft}$. high, arising singly from a horizontal rootstock. Basal leaves short, sheathing, or nearly as long as the stem. Cluster of flowers diffuse, 2 to 6 in. high, with flowers in heads of 5 to 8 , dark brown. Stamens and pistils not always all on same plant. Seeds without tails. Sepals sharp-pointed, the petals shorter. Salt marshes, New Jersey and southward.

8. J. maritimus, Lam. (Fig. 5, pl. 10.) SEA Rusm. Resembles No. 6. Flower green, not dark brown as it is in that species and seeds are tailed. Salt marshes at Coney Island, N. Y. 


\section{B. Clusters of flowers terminal on the scape. \\ Flowers separate, not in heads.}

9. J. bufonius, I. (Fig. 6, pl. 10.) TOAD Rusir. Stem branching, tufted, 3 to 8 in. high. Leaves from root and stem, the latter 1 to 2 in. long. Flowers terminal in forked clusters. Final clusters of 2 or 3 flowers. Parts of the perianth lance-shaped, sharp, the petals much longer than the sepals, not equal among themselves. Common.

10. J. tenuis, Willd. (Fig. 10, pl. 10.) SLender RusH. Stems not branched, wiry, 8 to $30 \mathrm{in}$. high. Leaves flat, thread-like, 晃 the height of stem. Flowers in a diffuse fan-shaped cluster, not in heads, subtended by a braet much longer than the cluster. Parts of the perianth green, spreading; pod globular. Common.

11. J. secundus, Beaur. Secund Rusir. Growing in tufts. Stem 6 to 16 in. high. Flowers in a one-sided cluster. Capsule oblong, 3-sided, equaled by the perianth. Leaf at base of cluster about as long as the cluster. Dry soil.

12. J. Dudleyi, Weigand. Duduer's Rusr. Stems 12 to 40 in. high. Leaves basal, about one-half the length of the scape, narrowly linear, flat. Inflorescence 1 to $2 \mathrm{in}$. high, the subtending leaf or bract exceeding it in length. Cluster few flowered. Capsule ovoid, shorter than the perianth. Me., Washington, Conn.

13. J. dichotomus, Ell. Forked Rusir. Stems not branched, wiry, I to $3 \mathrm{ft}$. high. Leaves thread-like, round, channeled on one side, extending from long sheaths. Flowers in a forked cluster, each flower separate. Pod round, as long as the sepals. This and the preceding species closely resembling each other. Common in dry soil.

14. J. Gerardi, Lois. (Fig. 2, pl, 10.) Black Grass. Stems 8 to 30 in. high, from creeping rootstocks. Basal leaves sheathing then spreading, flat, narrow; stem leaves thread-like. Flowers in a forked cluster, not in heads, each subordinate cluster subtended by a long bract. Pod as long as the sepals, black; parts of the perianth obtuse. Style conspicuous, 3 -branched at summit. Mostly in salt marshes.

15. J. Greenei, Oakes \& Tuckerm. Greexw's Rusir. Scapes wiry, 8 to $30 \mathrm{in.} \mathrm{high.} \mathrm{Leaves} \mathrm{slender,} \mathrm{round,} \mathrm{grooved.} \mathrm{Cluster} \mathrm{forked;} \mathrm{flowers}$ separate; bract at base of cluster very slender and several times longer than the cluster. Flowers straw colored. Sepals shorter than the pod, egg-shaped. Stamens 6. Near the sea coast, Maine, southward.

16. J. Vaseyi, Engelm. (Fig. 3, pl. 10.) VAsEy's Rusir. Resembles No. 12, but sepals are as long as the pod and the bract is usually not much longer than the flower eluster. Dry soil, throughout our area.

\section{Clusters of flowers terminal.}

Flowers in heads. Seeds tailed.

17. J. asper, Engelm. New Jersey Rusir. (J. Cacsaricnsis, Coville.) Strms rigid, 20 to 40 in. high, stout. Joeaves of the stem long, rounded, roughened. Chuster 1 to $4 \mathrm{in}$. high, subordinate clusters (heads), 2- to 3-flowered; parts of the perianth lanee-shaped, sharp pointed, not as long as the 3-sided lance-shaped capsule, which at length becomes 


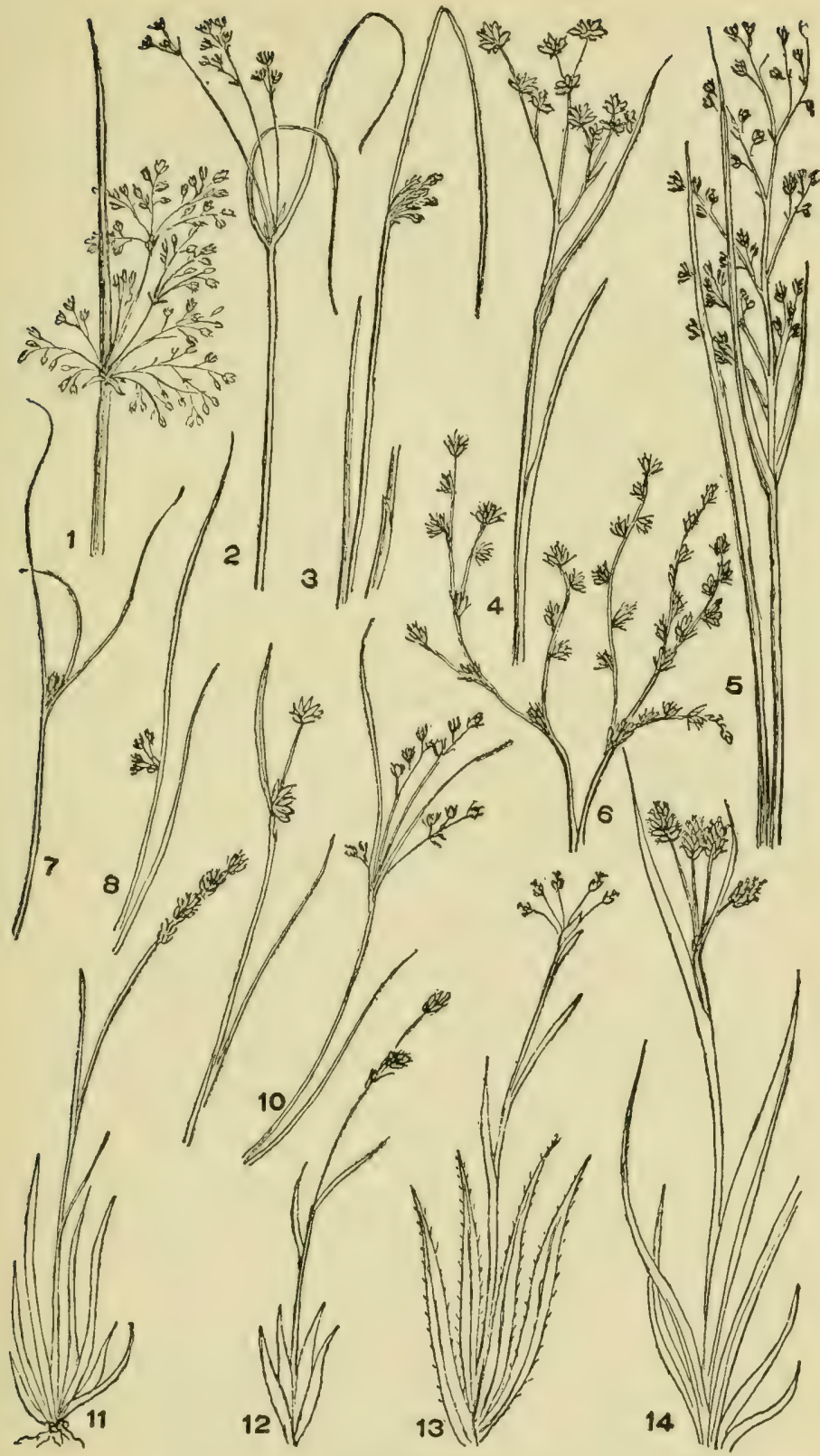

Plate 10

1. Juncus effusus. 2. J. Gerardi. 3. J. Vaseyi. 4. J. canadensis. 5. J. maritimus. 6. J. bufonius. 7. J. trifidus. 8. J. filiformis. 9. J. nodosus. 10. J. tenuis. 11. Luzula spicata. 12. L. confusa. 13. L. pilosa. 14. L. campestris. 
black. Seeds tailed at both ends. Sandy swamps. Southern part of our area. (New Jersey).

18. J. canadensis, Gay. (Fig. 4, pl. 10.) Caxada Rusm. Stems 1 to $4 \mathrm{ft}$. high, stout, with 2 to 4 stem leaves, which are erect and smooth. Flower cluster in whorls, the heads containing from 3 to 40 flowers. Parts of the perianth lance-shaped, acute, the inner row longer than the outer. Stamens 3. Capsule 3-sided, lance-shaped, longer than the perianth. Seeds tailed at each end. Common; quite variable.

19. J. marginatus, Rostk. Grass-Leaved Rusi. Growing in tufts. Scape 6 to $30 \mathrm{in}$. tall, 2- to 4-leaved. Flowers in severai nearly spherical heads on branching stems or one above another. Stamens 3 ; capsule ovoid, as long as the perianth. Grassy places.

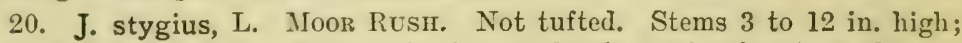
1 to 3 leaves below. Flowers in 1 to 4 heads, each of 1 to 4 flowers. The bract subtending the cluster or clusters, usually exceeding the clusters in length. Capsule spindle-shaped, sharp-pointed, rather longer than the perianth. Maine, northern New York.

\section{Seeds acute, not tailed.}

21. J. pelocarpus, Meyer. Brownish-Fruted Rush. (J. subtilis, Meyer.) Stems slender, 3 to 20 in. high, with 1 to 5 leaves, which are slender and rounded. Flower cluster of whorls of branches bearing very small heads, 1 to 3 flowers, which arē reddish. Pod oblong, pointed, longer than the perianth. Bract subtending the cluster shorter than the cluster. Northern part of our area to southern New Jersey.

22. J. articulatus, L. Jonted Rusi. Stems 8 to 20 in. high, with 1 or 2 leaves, which are rounded and slender. Cluster of several whorls of branches, the branches carrying 1 or more heads each. IIeads of 6 to 12 flowers. Perianth brown, its parts oblong. Pod deep brown exceeding the perianth. Seeds not tailed. Bract of base of cluster shorter than cluster. Throughout our area.

23. J. militaris, Begel. BAYoxer Rusir. Stems stout, 2 to $4 \mathrm{ft}$. high, (ach bearing a single leaf or less frequently 2 rounded leaves, one of which may be 2 to $3 \frac{1}{2} \mathrm{ft}$. high, overtopping the flower cluster. At base are dense fascieles of thread-like laves from the nodes of the rootstock. Cluster branching, with many heads, each containing from 5 to 12 or more brown flowers. Parts of the perianth acute, as long as the cone-shaped capsule. In bogs and streams, northern New York.

24. J. nodosus, J. (Fig. 9, pl. 10.) K.xotTly liusir. Stem slender, $\frac{1}{2}$ to $2 \mathrm{ft}$. high, with 2 or 3 stem leaves, the upper (the bract) overtoppring the eluster. Cluster of few or many heads; the heads nearly spluerieal of is to 20 flowers. Capsule conisal, very slender-pointed, the parts of the involucre also narrow and slender-pointed, $1 / 2$ or $2 / 3$ as long as the capsule. Wet sands.

25. J. Richardsonianus, Silult. Ricusroson's Rusir. In loose tufts. Stems 6 to 20 in. high, 1- to 2 -leaved. Clusters of rounded lwads $2 !$ to 8 in. high, branching, the branches somewhat parallel or spreading. Ieaf below the cluster about 12 as long as the cluster. Heals 3- to 12-lowered. Capsule owid-oblong, slightly exceeding the perianth, straw-colored or brown. Throughout our area. 
26. J. Torreyi, Coville. Torry's Rusm. Stems 8 to $40 \mathrm{in}$. high, not in tufts. Stem leaves 1 to 4 . Heads round, $\frac{1}{2}$ to $\frac{3}{4} \mathrm{in}$. diameter, 1 to 20 in a cluster. Stamens 6. Capsule 3-sided with a long beak, exceeding the perianth. Western New York, extending westward.

27. J. acuminatus, Michx. Sinarp-Fruited Rusi. Stem 1 to $\mathbf{3} \mathbf{f t}$. high, with 2 or 3 stem leaves, the lower 4 to 8 in. long. Cluster long, with remote whorls of flower stems; heads 3 to 15 flowered. Stamens 3. Parts of the perianth narrow, awl-shaped, very sharp pointed, about as long as the brown capsule. Throughout our area.

28. J. scirpoides, Lam. Scirpus-like Rusir. Stem 1 to $3 \mathrm{ft}$. high, slender, rigid, with about 2 rounded stem leaves. Cluster of 2 to 30 spherical pale green heads, the cluster sometimes 6 in. long. Parts of the perianth narrow awl-shaped to bristle-like, nearly as long as the conical capsule. Wet sandy soil, New York, southward.

\section{LUZULA, DC. (Juncoides, Adams')}

Perennial plants with some of the characteristics of the Rushes, but with llat, grass-like leaves which are soft and often hairy, and with flowers in umbels, spikes or diffuse clusters. Flowers, each subtended by a bract. Capsule of 1 cell with 3 seeds; stamens 6 . Plants usually tound in dry grounds.

1. L. pilosa, Coville. (Fig. 13, pl. 10.) Hairy Wood Rusm. ( $L$. saltuensis, Fernald.) Stem erect, 2- to 4-leaved, 6 to $12 \mathrm{in}$. high. Leaf blades grass-like, hairy; stem leaves shorter than those from the basa. Flowers in an umbel subtended by a bract $\frac{1}{2}$ to 1 in. high, the threadlike flower stems bearing each a single flower or rarely 2 . Parts of the perianth 6, triangular, narrowed at apex, longer than the toothed bractlets, brown, with a translucent margin. Capsule longer than the perianth segments, pyramidal, surmounted by the 3 -parted pistil. Found in a considerable part of our area.

2. L. parviflora, (Ehrh.) Coville. Suall-flowered Wood Rusi. Stem 10 to $30 \mathrm{in.} \mathrm{high,} \mathrm{with} 2$ to 5 grass-like leaves, which are smooth. Flowers small, in a cluster composed of 2 or more whorls of flower stems, each of which may be terminated by a sort of umbel, the cluster 1 to 4 in. high, bracted at the base of each whorl and at the branchings. Flowers borne singly on the thread-like branches of the cluster. Parts of the perianth 6, narrowed at the apex, seareely as long as the egg-shaped capsule. Maine, New Hampshire, New York and westward.

3. L. spicata, (L.) Kuntze. (Fig. 11, pl. 10.) SPrked Wood Rusr. Stem 4 to 16 in. high, with 1 to 3 leaves; basal leaves forming a grassy tuft. Flowers brown in a narrow interrupted spike, more or less nodding. Parts of the perianth bristle-pointed; capsule egg-shaped, about as long as the parts of the perianth. Found generally on the high mountains of our area.

4. L. confusa, Lindb. (Fig. 12, pl. 10.) Northers Woon RusiL. (L. hyperborca, (R. Br.) Sheldon.) Plants 4 to 8 in. high. Leaves in a small cluster at base and 1 or 2 on the stem. Flowers in an oblong cluster or two elusters, dense, $\frac{1}{2}$ in. or less in length. Parts of the perianth brown. Higher mountains of our area. 
5. L. campestris, (L.) DC. (Fig. 14, pl, 10.) Common Woon Rusr. Stem 4 to $20 \mathrm{in}$. high, rising from a grassy tuft of leaves and bearing 1 or 2 stem leaves. Flowers in a terminal umbel, straw colored, the parts of the perianth bristle-pointed, longer than the rounded capsule. Common in dry woodlands.

\section{FAMily II.-LILIACEAE. LiLy FAMily}

In our region, herbaceous plants or woody vines with flowers in clusters of various forms. Flowers regular, with 6 segments of the perianth, exceptionally united at base, in 2 rows, an outer and an inner, the outer series in fact representing the calyx. Stamens 6, the anthers mostly with their face inward. Fruit of 3 carpels; style with an entire summit or divided into 3 lobes. Capsule usually splitting at the partitions.
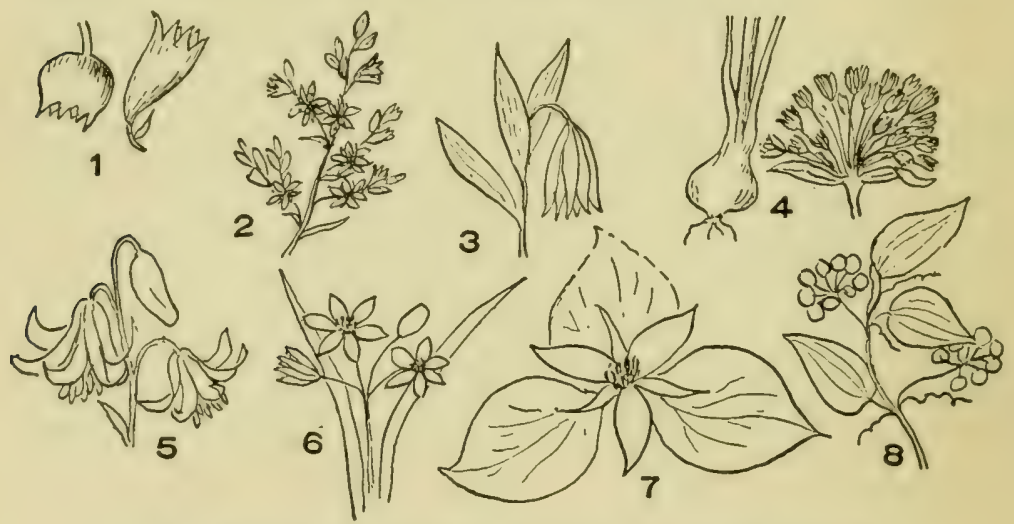

A. Herbs not having twining or woody stems Fruit not a round berry.

Ovary with few exceptions, situated above the perianth.

Flowers with 6 symmetrical petals, all uniformly colored and not united.

Flowers solitary or in loose clusters, pistil not divided in 3 parts . . . Lily T'ribe.

(5) Lilioideae

Flowers few or solitary in more or less dense clusters. Styles divided into 3 spreading lobes.

Flowers solitary. Genus Uvularia (3).

- Buxcil Flower Tribis. (2) Melanthioideae

Flowers in a rounded umbel. Style not divided. Stem springing from a bulb. Onion 'Trums. (4) Allioideae

Flowers with 6 petals all united at the base, forming a 6 tonthed bedl or tube. Hracistir 'T'ziвs: (1) Hyacinthineae 
Ovary situated below the perianth.

Erect herbs. - Convallaria Tribe. (7) Convallariineae

B. Plants with twining stems.

Stems woody . . . Smilax Tribe. (8) Smilacoideae

\section{Tribe I.-MelanthioldeaE. Bunch Flower Tribe}

Herbs springing from a rootstock or less frequently from a bulb. Leaves all from the root or arising from the stem. Perianth of 6 equal parts, separate or slightly connected at the base. Flowers generally in lengthened clusters (spikes, racemes, panicles, I, II, III, p. 36, Part I), in Uvularia solitary. Ovary superior to the stamens and perianth and free from both. Stamens 6 , inserted, not directly on the receptacle, but at the base of the segments of the perianth. Styles 3, sometimes quite short, the 3 divisions of the ovary closely connected, but not completely united as they are in the Lily and other flowers of the Lily family. The divisions are, however, always free at the summit. Fruit a 3-parted eapsule, splitting longitudinally through the partitions.

Flowers in more or less elongated clusters.

Flowers purple . . . . . . . . . . Helonias

Flowers greenish or white.

Leaves narrow, grass-like.

Flowers each with an involucre of 3 bracts . . . Tofieldia

Flowers without an involucre.

Segments of the perianth with 2 glands or protuberances at base.

Segments without a claw . . . . Zygadenus

Segments with a claw . . . . . Melanthium

Segments of corolla without glands.

All the flowers with stamens and pistils.

F'lower stems quite leafy . . Xerophyllum

Flower stems with a few short leaves.

Basal leaves not over $1 / 10$ in. broad

Narthecium

Basal leaves $1 / 6$ in. to more than 1 in. broad

Amianthium

Some of the flowers with only one set of the above organs

Stenanthium

Leaves broad.

Leaves oval or egg-shaped

Veratrum

Ieaves broader at outer extremity than inner (spatulaformed). Flowers mostly either staminate only or pistillate only . . . . . . . Chamaelirium

Flowers solitary, yellow

Uvularia 


\section{r. TOFIELDIA, Huds. (Tofield, an English botanist)}

Perennial plants with narrow flower clusters, each terminal to a long and slender flower-stem (spike, raceme, I, II, p. 36, Part I). Leaves narrow, grass-like and mostly at the base. Flowers with both stamens and pistils, white or green, spreading, each subtended by a small, scale-like 3 parted involucre. At base of each flower stem is a small, green, leaflike bract below the calyx. Segments of the perianth without claws. Stamens bearing anthers which look inward. Capsule 3-angular and separable into 3 parts, each part with many seeds.

1. T. glutinosa, (Michx.) Pers. Glutinous Tofieldia. Stem 6 to 20 in. high, covered with soft, viscid hairs. The flower pedicels very glutinous and clustered in 3's. Seed with a long tail at each end. Capsule oblong.

2. T. racemosa, (Walt.) BSP. (Fig. 5, pl. 11.) VIscid ToFieldia. Stems very viseid, downy, somewhat taller than No. 1. Flowers clustered in 3 's. Seed with a short tail at each end, in an oval capsule. Swamps, southern New Jersey and southward.

\section{NARTHECIUM, (Moehring), Juss. (Abama, Adams)}

Perennial herbs with the general appearance of Toficlitia. Flowers small, greenish-yellow. Segments of perianth 6, linear-lance-shaped. No involucre at base of flower as there is in Tofieldia. Seeds appendaged at end. Capsule oblong-cylindric. Stalk less viscid than that of Tofieldia. Stamens covered with white hairs.

N. americanum, Kier. American Boa Aspiodel. Stem 8 to 20 in. tall, not hairy, wiry. Basal leaves 3 to 8 in. long. Flower cluster 1 to 2 in. long. Rare, swamps in southern New Jersey.

\section{HELONIAS, L.}

Perennial herbs in bogs. Leaves evergreen, broadly spatula-formed or inverscly lanee-shaped, all from the base. Stem surmounted by a somewhat narrow bunch (raceme) of purple flowers. Perianth of 6 parts. Seed with a white tail at each end. Capsule broadly egg-shaped.

H. bullata, L. (Fig. 2, pl. 11.) Swamp Pink. Stem 1 to $2 \mathrm{ft}$. high, with few or no bracts. Southern New York, New Jersey and Penna. Rare.

\section{XEROPHYLLUM, Michx.}

Tall perennial herbs with wooly rootstock, very slender linear leaves and with very numerous showy white llowers in a slender cluster (II, p. 36, Part I). Petals withont glands at base, widely sprealing; sepals white resembling petals, oval. Stamen filaments dilated at middle. Capsule oval, or nearly globular, 3-grooved. The summits of the 3 styles turn outward. Each of the 3 lobes of the capsule with 2 seeds.

X. asphodeloides, (T.) Nutt. Turkwy-1в.ArD. Stem $2 \frac{1}{2}$ to $5 \mathrm{ft}$. high, many leaves below with few above. Leaves from the base $1 \mathrm{ft}$. or more in length and $1 / 12$ of an inch broad. In pine barrens of New Jersey and southward. May-July. 

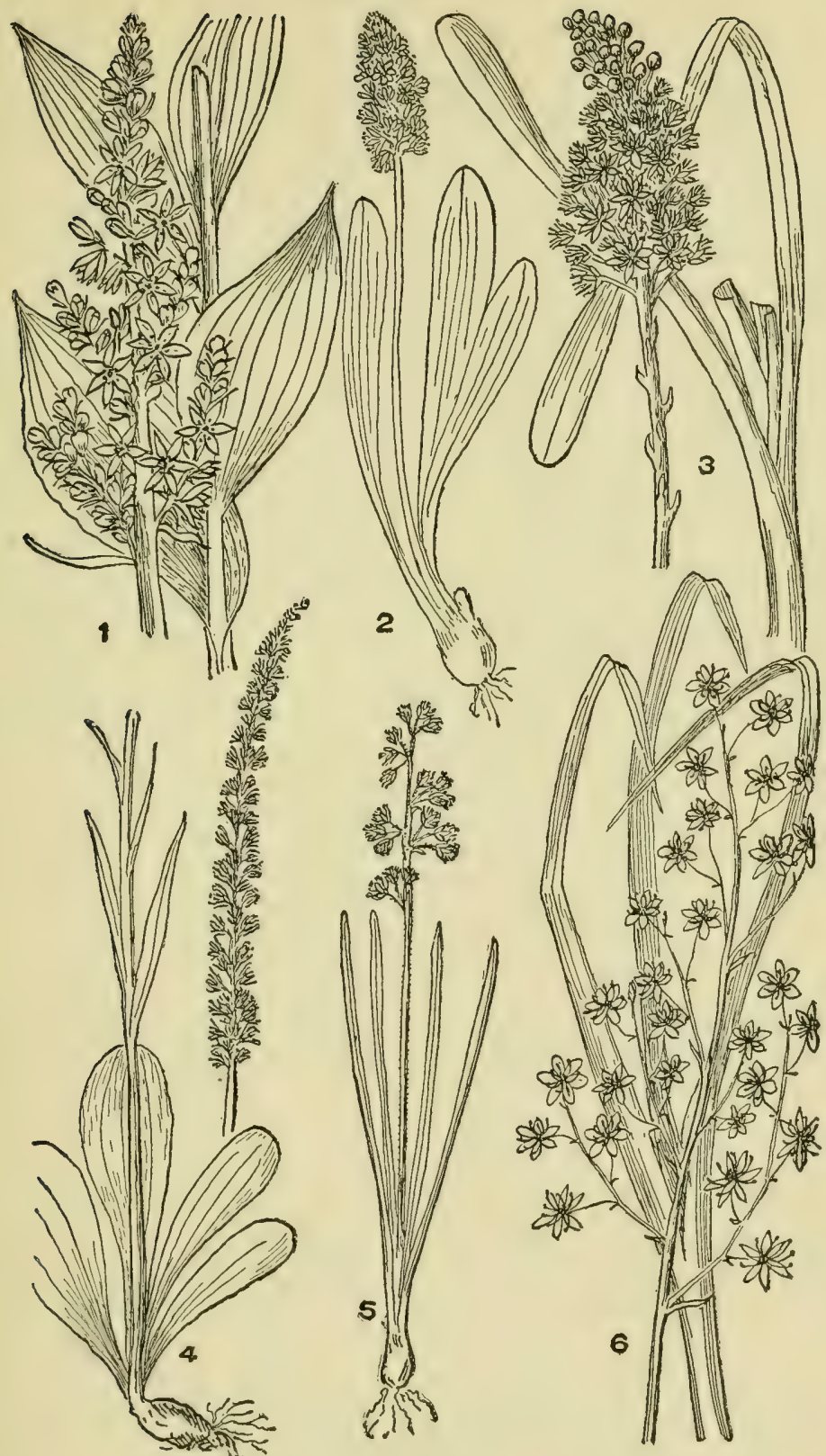

Plate 11

1. Veratrum viride. 2. Helonias bullata, 3. Amianthium muscaetoxicum. 4. Chamaelirium luteum. 5. Tofieldia racemosa. 6. Melanthium virginicum. 


\section{CHAMAELIRIUM, Will.}

Herb, from thick tubrous rootstock. Stem tall and smooth. Staminate and pistillate flowers growing on different plants, each class of flowers in a linear cluster (spike I, p. 36), the petals spatula-formed, white, with a single central nerve. Leaves at the base, spatula-formed (Fig. 11, p. 17, Part I), those of the stem few and lance-shaped. Seeds winged at each end. The plants with pistillate flowers are usually taller than those with staminate flowers.

1. C. luteum, (L.) A. Gray. (Fig. 4, pl. 11.) Blazing Star. Plant $1 \frac{1}{2}$ to $2 \mathrm{ft}$. high, leafy; basal leaves 2 to $8 \mathrm{in}$. long, spatula-formed. Low grounds, New England and south.

2. C. obovale, Small. Similar to No. 1, but the capsule of No. 1 is oblong on a slender pedicel, that of $\mathrm{C}$. obovale is obversely egg-shaped, on a stout pedicel. Mass., northward. Spring.

\section{AMIANTHIUM, Gray (Chrosperma, Raf.)}

Tall smooth herb, starting from a bulb, with many long, linear, blunt pointed leaves from the base and only a few short leaves on the flower stem. Flowers all with stamens and pistils, white, in slender elongated clusters (II, p. 36, Part I). Petals without claws or glands, oval, obtuse and spreading. Ovary 3-lobed, ovoid.

A. muscaetoxicum, (Walt.) Gray. (Fig. 3, pl. 11.) FLr-porson. Stem $1_{2}^{1}$ to $4 \mathrm{ft}$. high. Cluster of flowers dense; seeds fleshy, red. Leaves keeled, grass-like, about $\frac{1}{2}$ in. broad. In southern part of our region.

\section{STENANTHIUM, (Gray) Kunth.}

Plants resembling Amianthium, the terminal cluster of greenish-white flowers less compact and broader below (panicle). Segments of the perianth narrow and long. Leaves grass-like, keeled. Some of the flowers are perfect, bearing both stamens and pistils, others only one set of these organs.

S. robustum, S. Wats. Stout Stenantuium. (S. graminoum, (Ker.) Kunth.). Stem leafy, 3 to $5 \mathrm{ft}$. high. Leaves $1 \mathrm{ft}$. long or more, the upper reduced to bracts. Flower cluster pyramidal, compound (panicle). Moist soil, southern Penna. July-Sept.

\section{ZYGADENUS, Michx.}

Smooth perennial herls, in our species from a bulb, with nearly naked stems and grass-like leaves. Petals each with 1 or 2 glands at base. Seeds angled. Flowers greenish-white, in a loose spike or raceme (I, II, p. 36, Part I) from 6 to 12 in. long. Flowers generally bearing hoth stamens and pistils, greenish, yellowish or white. Capsule 3 lobed, 3-celled.

1. Z. chloranthus, Richards. Guaucus Zyannenus. (Z. elegans, Pursh.?). Plant eovered with a whitened hloom. Bulb about 1 in. long, about $\frac{1}{2}$ in. broad; leaves grass-like. Giland at base of petals distinctly heart-shaped. The flower cluster only moderately spreading (II, P. 36i).

2. Z. leimanthoides, A. (iray. P'inemarren Zrgadenus. Flower 
cluster quite spreading (III, p. 36, Part I). The gland at base of petals only a yellow spot. Flowers about $\frac{1}{2}$ in. broad. Swamps, wet soil.

\section{MELANTHIUM, L.}

Perennial herbs, tall, leafy, with greenish flowers in a long loose terminal pyramidal cluster (panicle, III, p. 24, Part I). Leaves broad-linear. Flowers simply staminate or simply pistillate on the same plant or both classes of organs in the same flower, greenish-white or cream color. Perianth of 6 spreading, oblong or somewhat heart-shaped segments raised on slender claws with or without 2 glands at base. Capsule conical; seeds flat, broadly winged.

1. M. virginicum, L. (Fig. 6, pl. 11.) Bunch-Flower. Stems 2 to $5 \mathrm{ft}$. high. Ieaves somewhat broadly linear-lanceolate. Cluster pyramidal. Petals oblong, the outline not indented. June-Aug.

2. M. latifolium, Desr. Crisped BuncII-Flower. Leaves broader toward the outer extremity. Petals nearly rounded and with undulating outline. June-Aug.

Io. VERATRUM, (Tourn.) L.

Perennial herb with tall leafy stem springing from a thickened rootstock (poisonous). Leaves alternate, mostly broad oval, passing to lanceshaped, marked by strong parallel veins and longitudinal foldings. Flowers in a loose pyramidal cluster (panicle) at the summit of the stem. These are mostly perfect or some may be staminate only and others pistillate only. Stamens not arising from the segments of the perianth, but from the receptacle, nearly erect at first, then spreading.

V. viride, Ait. (Fig. 1, pl. 11.) American White Hellebore. INDIAN POKE. Stem from 2 to $8 \mathrm{ft}$. high; flowers yellowish-green in the axils of bracts, forming a large pyramidal cluster. Wet places throughout our region. May-July.

\section{UVULARIA, L.}

Perennial erect herbs from rootstocks. Stems smooth, forking, leafy above with clasping scales below. Flowers large, drooping, solitary at the extremities of branches or rarely 2 at end of the same branch. Perianth narrow bell-shaped, 1 to $1 \frac{1}{2}$ in. long. Stamen filaments thread-like, the anthers quite long. Ovary 3 angled, ovoid.

Leaves completely surrounding the stem.

Leaves downy beneath . . . . . . . . . U. grandifora

Leaves smooth beneath . . . . . . . . . . . U. perfoliata Leaves not completely surrounding the stem . . . . . U. sessilifolia

1. U. perfoliata, L. (Fig. 5, pl. 12.) Perfoliate Bellwort. Stem and leaves smooth, light green. Stem forked above the middle, 6 to $18 \mathrm{in}$. high, often with a few leaves below the fork. Leaves penetrated by the stem. Flowers pale yellow, an inch or more long, drooping. Ovary with 3 somewhat obtuse angles. Moist woods. May-June.

2. U. grandiflora, J. E. Smith. Large-Flowered Bellwort. Stem penetrating the leaves which are downy beneath and oval or egg-shaped. Flowers larger than in the preceding species. Growing in similar situations. April-June. 
3. U. sessilifolia, I. (Fig. 6, pl. 12.) Sessile-leated Bellwort. (Oakesia sessilifolia, Wats.) Leaves narrowly oval or lance-shaped, not penetrated by the stem but half clasping it, 1 to 3 in. long. Flowers greenish-yellow. Ovary with 3 winged angles. Moist woods. May-June.

\section{Tribe II.-ALLIOIDEAE. ONion Tribe}

\section{Only a single species, Allium, native in our territory.}

\section{ALLIUM, L.}

ITerhs with a characteristic garlicky odor with leaves and flower stem springing from a bulb. Leaves mostly narrow and flat or hollow eylindric tubes. Less frequently broader lance-shaped. Flowers terminal on an erect, generally eylindric, seape, in a rounded umbel which sometimes enntains also small bulblets. Perianth of 6 segments, all colored. Seeds angular, black.

Leaves broad, lanceolate . . . . . . . . . . A. tricoccum Leaves linear, flat.

Heads containing both flowers and bulblets . . . . A. canadense

Heads with flowers only, heads nodding, stamens nearly twice the length of perianth............. A. cernum Leaves hollow tubes.

Stamens, at least the inner 3 , with a prolonged tooth or spine at each side extending above the anther . . . . A vineale

Stamens simple, not furnished with spines . . . A. Schocnoprusum

1. A. tricoccum, Ait. Wild Leek, Lcaves 6 to $12 \mathrm{in.} \mathrm{long,} \mathrm{disap-}$ pearing before the flowers are developed. Flower stalk $\frac{1}{2}$ to $1 \frac{1}{2} \mathrm{ft}$. high. The two bracts subtending the umbel as long or longer than the pedicels of the flowers; falling early. Flowers white, flaments of the stamens flattened, as long as the petals. June-July.

2. A. Schoenoprasum, L. Cinves. Leaves as long as the flower stem, permanent. Bracts of the umbel broad, often partly enelosing the umbel after the opening of the flowers. Flowers forming a dense head, rese-colored, the flower longer than the pediecl. Stamens shorter than the petals. Moist soil, often cultivated. June-Aug.

3. A. cernuum, Roth. Nodning Wirte Onion. Stem 4-angled, 1 to $2 \mathrm{ft}$. high, leaves about as long, flat. Bracts below the umbel small and falling carly. Flower mmbel nodeling. Rather dry localities, New York and westwird. July-Aug.

4. A. vineale, I. Wild Garlic. Stem 1 to $3 \mathrm{ft}$. high, leaves few and shorter than the stem, cylindric, hollow. Umbel containing flowers or bulblets or both. Fields, Connecticut and westward. June-July.

5. A. canadense, L. Meadow GarLic. Stem I to $2 \mathrm{ft}$. high; leaves linear, flat, shorter than flower stem; nmbel bracts conspienous, white, acute at apex. Fluwers pink or white, often replaced by bulblets. Mloist fields, throughout our area. May-June.

\section{T'ribe III.-Lilioideae. 'T'nue Tily 'Trube}

Flowers of the typical construction of the order; 6 petals, 6 stamens, 1 pistil, ovary of 3 cells, above the stamens and free from them; stamens 

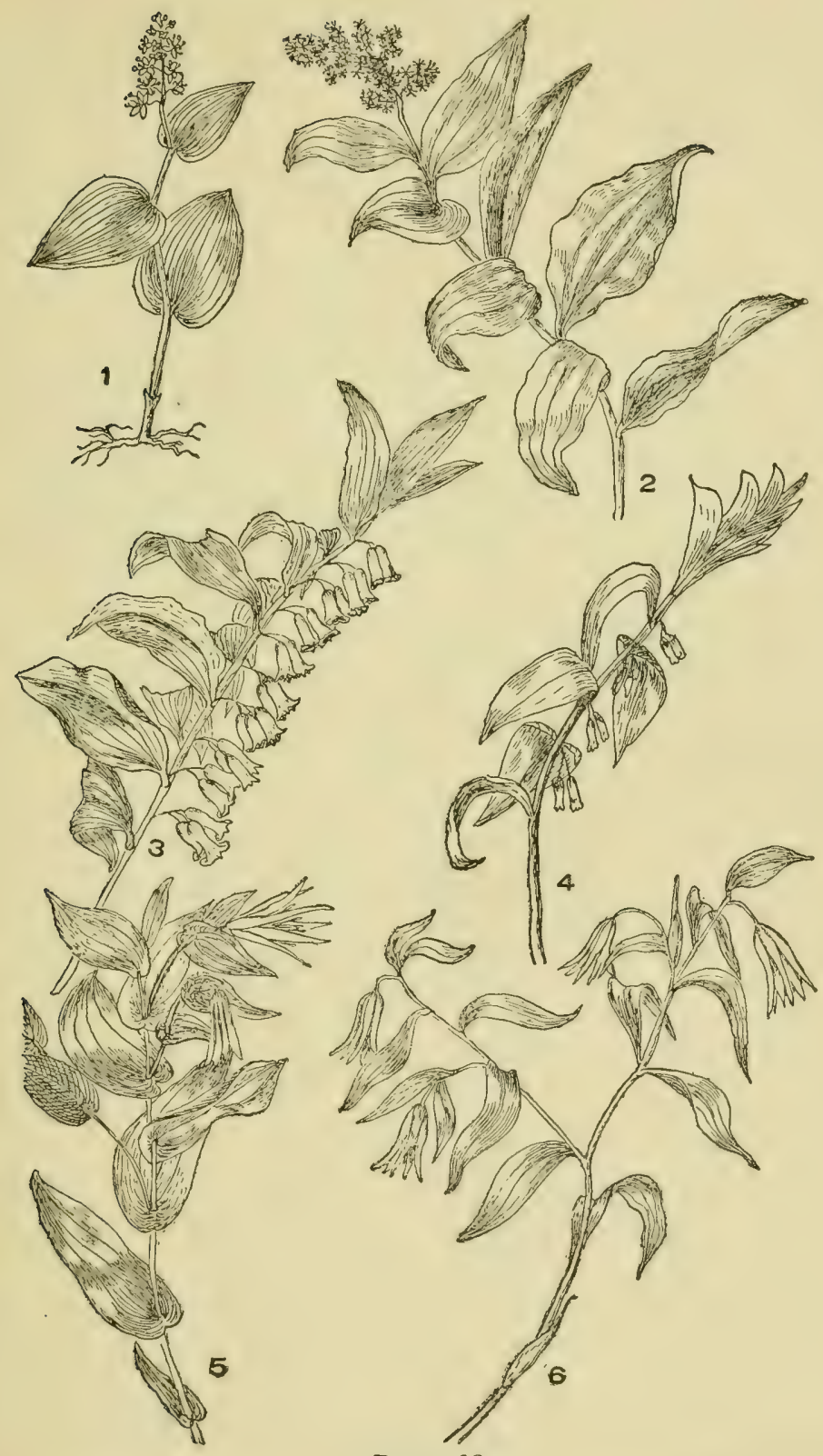

PLATE 12

1. Maianthemum canadense. 2. Smilacina racemosa. 3. Polygonatum biflorum. 4. P. commutatum. 5. Uvularia perfoliata. 6. U. sessilifolia. 
laving anthers which face toward the inside of the flower. Stem springing from a bulb or rootstock bearing one or several flowers in a looso group.

Leaves numerous on the stem

Lilium

Leaves 2 at lower part of stem

Erythronium

Leaves all from the bulb . . . . . . Ornithogalum

\section{LILIUM, L.}

Tall herbs with leafy stems, bearing at or toward the summit one or several large showy bell-shaped flowers of 6 colored, petaloid, segments. Stamens generally shorter than the long, graceful style. Seed capsule sub-triangular.

1. L. philadelphicum, L. (Fig. 2, pl. 13.) RED on WOOD LiLY. Stem very erect, 1 to $3 \mathrm{ft}$. tall, with one or more large deep orange flowers at the summit, erect or nearly so. Leaves lance-shaped, 1 to 4 in. long, in whorls, 3 to 8 leaves in each whorl. Petals with dark purple dots, spreading ahove. A plant of much elegance in dry woods and thickets. June-July.

2. L. canadense, L. (Fig. 3, pl. 13.) Wrld Yellow LrLY. Leaves in whorls; stem much taller than No. 1. ( 2 to $5 \mathrm{ft}$.), and bearing a prramilal cluster of yellow or orange bell-shaped drooping flowers, the petals of which are turned back or spread outward. Leaves lance-shaped with the veins beneath covered with hairs. Edges of leaves also roughened. In moist meadows. Throughout our range. June-July.

3. L. superbum, L. (Fig. 1, pl. 13.) Turk's CaP Lily. Stem 3 to $8 \mathrm{ft}$. high. Leaves in whorls or the upper alternate, the edges and under veins of the leaves smooth. Flowers orange or orange-yellow, purplespotted, notably darker in color than No. 2. Wet meadows and marslies, throughout our region.

4. L. tigrinum, Andr. Trger IrLr. Stem tall, dark purple with dark bulhlets in the axils of the alternate leaves. Flowers similar but larger than those of No. 3. An elegant lily, escaped from cultivation.

\section{ERYTHRONIUM, L.}

Tow horbaceous plants arising from a dilated root base resembling a bull, in form. Ieaves 2, opposite, at the lower half of the stem, broad lanes-form. Flower solitary, nodding, bell-shaped. Perianth of 6 segments; stamens 6 ; ovary 3 celled.

1. E. americanum, Ki'r. (Fig. 4, pl. 13.) Ylitow ADnER's toxgue. Stem 6 to $12 \mathrm{in.} \mathrm{high.} \mathrm{Leaves} 3$ to $8 \mathrm{in.}$ long, $\frac{1}{4}$ to 1 in. wide, dark grem, usually mottlod with brown. Flowers yellow. In wet shady places. Conmon. March-May.

2. E. albidum, Nuft. Wnit: Amers's toxgle. Similar to No. 1, with white or purple flowers. In similar situations. March-May.

\section{ORNITHOGALUM, L:}

Low herls arising from lulls. Leaves all from the bulb; flower stem 


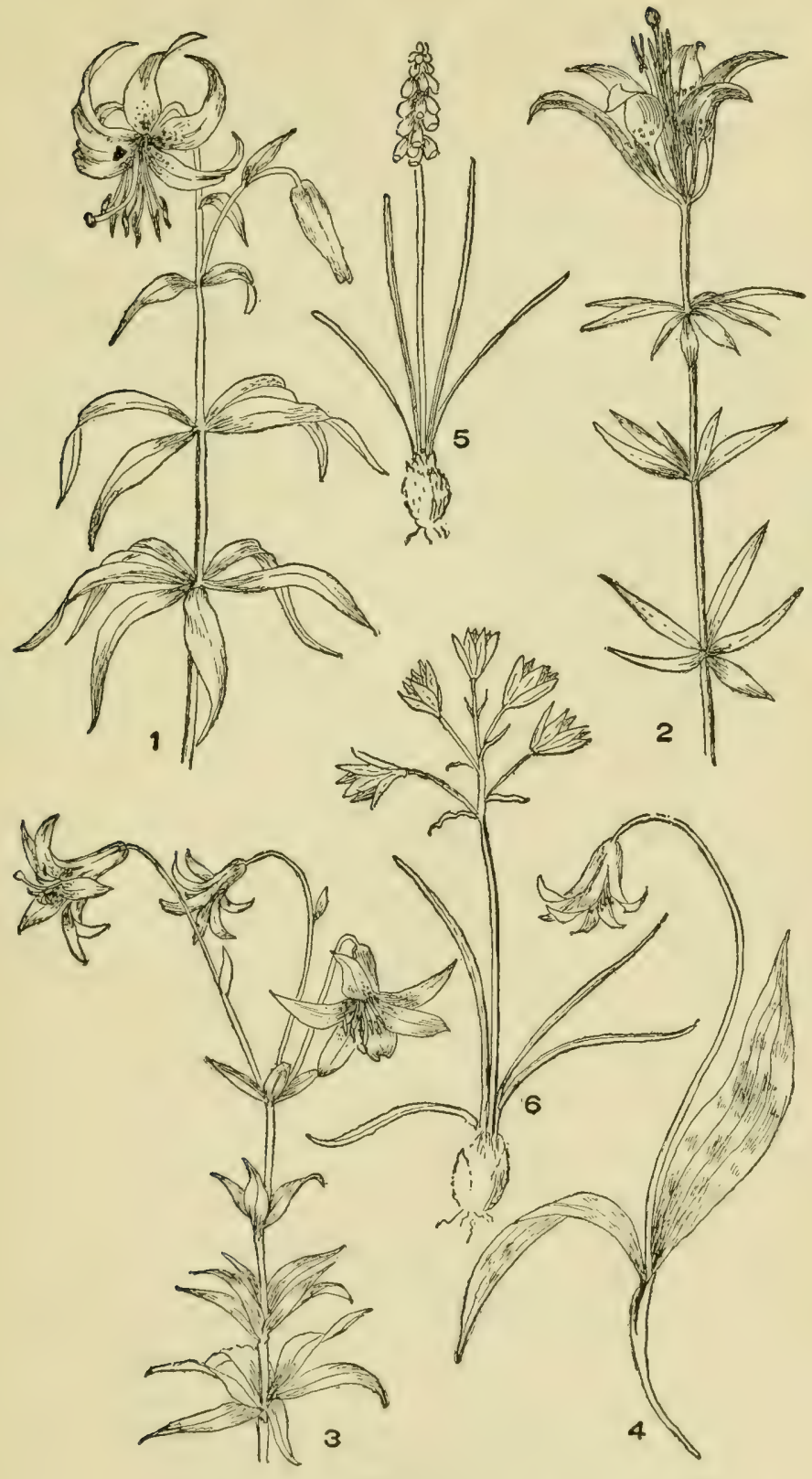

Plate 13

1. Lilium superbum. 2. L. philadelphiøum. 3. L. canadense. 4. Erythronium americanum. 5. Muscari racemosum. 6. Ornithogalum umbellatum. 
lenfless, smooth, bearing a loose broad cluster of white flowers. (VII, p. 36, Part I.)

O. umbellatum, L. (Fig. 6, pl. 13:) Star of Betilenem. Segments of perianth green beneath, spreading, opening in sunshine. Naturalized. In fields and meadows. May-June.

\section{Tribe IV.-HyacinthineaE. The Hracinth Tribe}

Bulbous or fibrous rooted herbs. Flowers with 6 stamens, a single style and a 3-celled ovary. Perianth segments united to form a globose or tubulav bell.

Flowers globose or not spreading at the outer borders . Muscari Flowers tubular, spreading at their outer borders : . Aletris

\section{MUSCARI, Mill.}

Leaves fleshy, arising from the bulb. Flower stem bearing a grape-like cluster of globose or oblong flowers.

1. M. botryoides, (L.) Mill. Grape Hyacintir. Flower stem 4 to $10 \mathrm{in.}$ higl, about equalling the leaves. Flowers dark blue or purple, globose.

2. M. racemosum, (L.) Mill. (Fig. 5, pl. 13.) Starcil Grape HYACINTi. Flowers ovate or oblong. Contracted at outer border. Escaped from gardens.

\section{ALETRIS, L.}

Herbs with slender flower stem and spreading rosette of ycllowishgreen leaves at base. Flowers tubular, spreading at the outer extrenity, each with 6 lobes; arranged in a slender spike, 1 to $3 \mathrm{ft}$. high, the 6 stamens inserted on the segrments of the united perianth, the tall style somewhat derely divided, outer surface of perianth roughened. Ovary 3 celled rounded or ovoid.

1. A. farinosa, L. (Fig. 5, pl. 16.) Star Grass. Colic Root. Flowers white, spike of flowers 3 to $12 \mathrm{in.}$ long, each llower subtended by a bract longer than the llower pedicel. May-July.

2. A. aurea, Walt. Yellow Colic Root. Similar to No. 1 but with yellow flowers. In the southern part of our region. July-Aug.

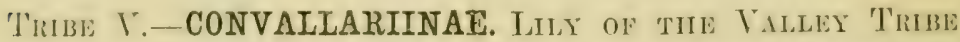

Perennial plants, lrerbs and woody vines arising from rootstocks, leaves all from the root or from the stem. Fruit, exerpte in Trillinm, a roumber flesty bery. Leaves brond with parallel veins. In Trillium and dsparaglus the armanerement of the reins is exerptional, being net-veined in the former and the leaf sate-like or needle-shaped in the latter. Perianth of

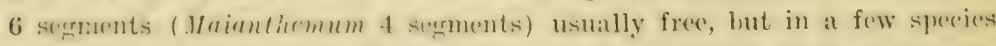
united, forming a tubular flower. Flowers in lengthened clusters, in pairs 
or single. Ovaries, except in Maianticmum, 3-celled above the perianth and free from it.

\section{Herbs without Woody Stems}

Leaves small, needle-formed

Asparagus

Leaves broad, but parallel veined.

Perianth segments 4, stamens 4 . . . . Maianthemum

Perianth of 6 segments free, stamens 6 .

Flowers in an umbel.

Leaves from the root

Clintonia

Leaves in a whorl of more than 3 about the stem . Medeola

Flowers in a lengthened cluster (raceme) . . . Smilacina

Flowers in pairs.

Flower pair terminal . . . . . . . . Disporum

Flowers along the course of the stem (or sometimes single).

Flower segments free. . . . . . . Streptopus

Flower segments united, tubular . . Polygonatum

Leaves broad, ecins not parallel.

Perianth of 3 colored and 3 green segments . . . . Trillium

\section{ASPARAGUS, L.}

Rootstock perennial, stem slender, branching with many short needlelike leaves (or branchlets) arising in groups. The earlier leaves are scale-like with broad insertions and it is in the axils of these scale-like leaves that the needle formed leaves arise. Flowers numerous along the branches of the stem, bell-shaped, segments deeply divided but joined at the base. Berry red when ripe.

A. officinalis, L. Escaped from gardens, naturalized in places in our region.

\section{CLINTONIA, Raf.}

Herbs, growing in shade with spreading roots, few leaves, all from the root and a slender seape or flower stem bearing an umbel-like eluster of bell-shaped flowers. Ovary 2-celled.

1. C. borealis, (Ait.) Raf, (Fig. 5, pl. 14.) Yellow Clintonia. Flower stem covered with fine soft hairs, 6 to 15 in. high. Flowers, 8 to 5 in the umbel, yellow. Common.

2. C. umbellulata, (Michx.) Torr. White Clintonin. Stem more hairy and leaves broader. Flowers 12 to 30 in the umbel, white. Rich woods; New York and southward.

\section{SMILACINA, Desf. (Vagnera, Adams)}

Slender horizontal rootstocks. Leafy stems with loose many fowered 
clusters at the summit. Leaves alternate. Flowers white or greenishwhite.

1. S. racemosa, (L.) Desf. (Fig. 2, pl. 12.) False Spikenard. Flower cluster branching (panicle); leaves oral, strongly veined. Berry red, dotted. Common. May-July.

2. S. stellata, (L.) Desf. Star-Flowered Solomon's Seal. Stem 10 to 18 in. high; flower cluster not branching (raceme). Leaves numerous, oval lance-shaped. Berry red. Moist soil. Common. MayJune.

3. S. trifolia, (L.) Desf. Tirnee-leaved Solomon's Seal. Stem 2 to $15 \mathrm{in.} \mathrm{high.} \mathrm{Flower} \mathrm{cluster} \mathrm{simple,} \mathrm{not} \mathrm{branching.} \mathrm{Leaves} \mathrm{3,} \mathrm{oval}$ lance-shaped. Bogs, in most of our region. May-June.

\section{MAIANTHEMUM, Wiggers (Unifolium, Greene)}

Small plants springing from slender rootstocks with shining alternate leaves $(1,2$ or 3$)$. Flowers in an oval terminal cluster, white, succeeded by berries which, when ripe, are pale red. Petals only 4; ovary of 2 cells; pistil about as long as the ovary.

M. canadense, Desf. (Fig. 1, pl. 12.) Two-Leared Solomox's SEal. Wild LiLY of THE VALEEY. A very frequent little plant in borders of woods, often forming extensive beds. Stem 1 to $6 \mathrm{in}$. high, angular. Leaves heart-shaped, 13 to $2 \mathrm{in}$. long, half as wide, generally blunt at outer extremity. Flower cluster of 20 or more small white flowers.

\section{DISPORUM, Salisb.}

Herbs resembling Uvularia but with hairy stem and leaves and with flowers erect in pairs. Leaves ovate, with long tapering points, without leaf stems, rarely elasping; segments of perianth 6 , slender; stamens 6 , below the ovary and free from it. Flowers greenish-yellow or white. Berry ovoid.

D. lanuginosum, (Michx.) Nichols. IIAIry Disporum. l'lant $1 \frac{1}{2}$ to $2 \mathrm{ft}$. higl, with an abundance of soft hairs. Flowers bell-shaped, nearly erect. In shady places, western New York and westward.

\section{STREPTOPUS, Michx.}

Ilerbs arising from rootstocks. Branching, with alternate leaves which clasp the stem. Flowers solitary or in pairs, from the leaf axils, bellshaped, with 6 slender secrments. Sitamens 6 , opposite the petals and below the ovary. Pistil 1, slender. Berry roundish.

1. S. amplexifolius, (L.) DC: ('LAsping-Leaved Twisted Stalk. Flowers greenish, drooping. Borders of leaves smooth, pale green on the under side, darker above. Leaves 2 to $3 \mathrm{in}$. long, $\frac{1}{2}$ as wide. Plant 1 to $2 \mathrm{ft}$. high. In moist woods throughout our region. May-June.

2. S. roseus, Michx. (Fig. 3, pl. 14.) Rose Twist Foor. Margins of leaves roughened and hairy. Leaves equally green on both sides. Plant about the size of No. 1. Common. May-June.

\section{POLYGONATUM, Adams}

Perianth segments united into a bell-shaped tube, 6 parted at the border. 


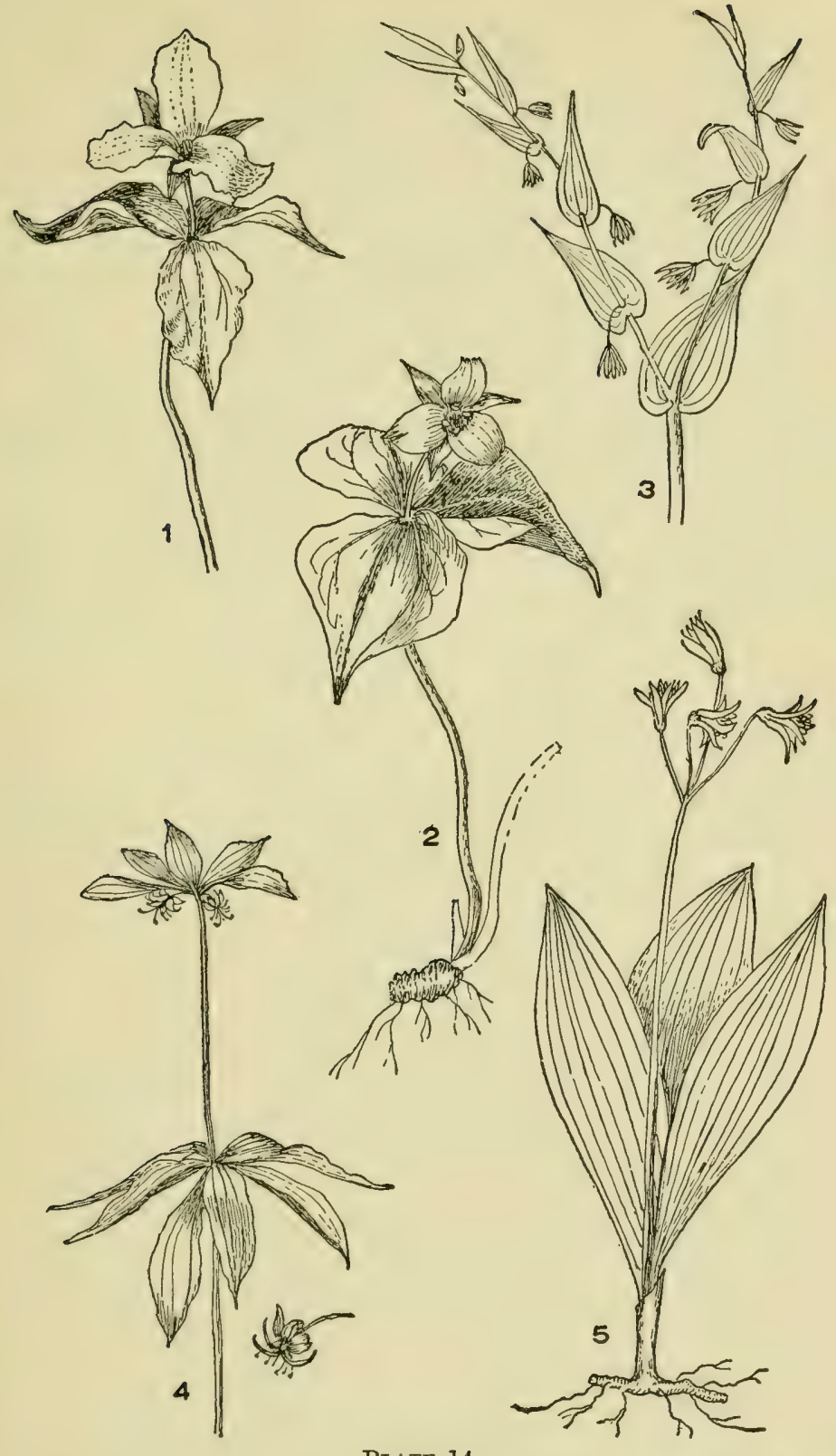

Plate 14

1. Trillium grandiflorum. 2. T. erectum. 3. Streptopus roseus. 4. Medeola virginiana. 5. Clintonia borealis. 
Herbs arising from a horizontal rootstock. Stems not branching, slender. Leaves without leaf stalks, alternate, ovate or lance-shaped, with slender points. Flowers in pairs, or 3 or 4 from a common stalk, the common flower stalks arising at the axils of the leaves. Berry dark blue.

1. P. biflorum, (Walt.) Ell. (Fig. 3, pl. 12.) HaIry Solomon's Seal. Plant hairy, $\frac{1}{2}$ to $3 \mathrm{ft}$. high. Common. In woods and shady places. April-July.

2. P. commutatum, (R. \& S.) Dietr. (Fig. 4, pl. 12.) Sмоoтr Solowon's SeAL. Plant entirely smooth, 1 to $\mathrm{s} \mathrm{ft}$. high. In moist woods, New Hampshire, Rhode Island and southward. May-July.

\section{MEDEOLA, L.}

Slender, erect herb arising from a tubrous root, without branches, stem surrounded, at about the middle, by a whorl of about 6 or more leaves and terminated above by another whorl of 3 to 5 leaves which are sur. rounded by several greenish-yellow flowers. Perianth of 6 re-curving segments; stamens 6 , slender and conspicuous; styles 3 , dark red, much longer than the segments of the perianth and spreading. Berry globose.

M. virginiana, L. (Fig. 4, pl. 14.) Indian Cucumber Root. Plant from 1 to $2 \frac{1}{2} \mathrm{ft}$. high. The 3 or 4 flowers may rise above the upper whorl or droop between its leaves. Moist rich woods. Common. May-June.

\section{TRILLIUM, L.}

Herbs arising from tubrous roots or short rootstocks, with simple stems surmounted by a whorl of 3 broad leaves and a single flower. Flower of 6 segments, 3 green, 3 colored. Stamens 6; ovary 3 -angled and 3 -celled.

Leaves on leaf-stalks.

Plant 2 to 6 in. high ............... . T. nivale

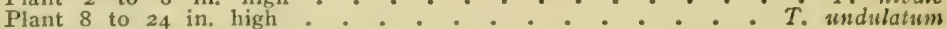

Leaves without leaf stalks or with very short ones.

Petals broadest at outer extremity . . . . . . . T. grandifiorum

Petals broadest at inner extremity.

Pedicel of flower not more than $1 \frac{1}{4}$ in. lomg. . . . . T. cermum Pedicel of flower more than $1 \frac{1}{4}$ in. long $: \div: \therefore:$ T. erectum

1. T. grandiflorum, (Michx.) Salisb. (Fig. 1, pl. 14.) LARGEFLOWEREI WAKE-ROBIN, Petals broadest at outer extremity, white or light rose with greenish veins, and much longer than the green sepals. Flower nearly erect, larger and less spreading than the other species. Stem 8 to 18 in. high. Somewhat common. In moist woods or lowlands. May-June.

2. T. erectum, L. (Fig. 2, pl. 14.) ILL-Scented WAKE-RoBiN. Petals broadest at inner extremity, and scareely exceeding the green sepals in length or even shorter, an inch long and twice as wide as the sepals, spreading to a wheel-formed flower. Flower nodeling on a nearly erect peluncle, dark purple. Stem a foot or more high. Common in moist woods. April-June.

3. T. cernuum, I. NodDing WaKE-Ronin. Leaves more rounded than cither of the other species. Petals white, rather longer than the green scpals, lance-shaped. Flowers spreading with petals rolled back. Stem 10 to $15 \mathrm{in,} \mathrm{high,}$ 

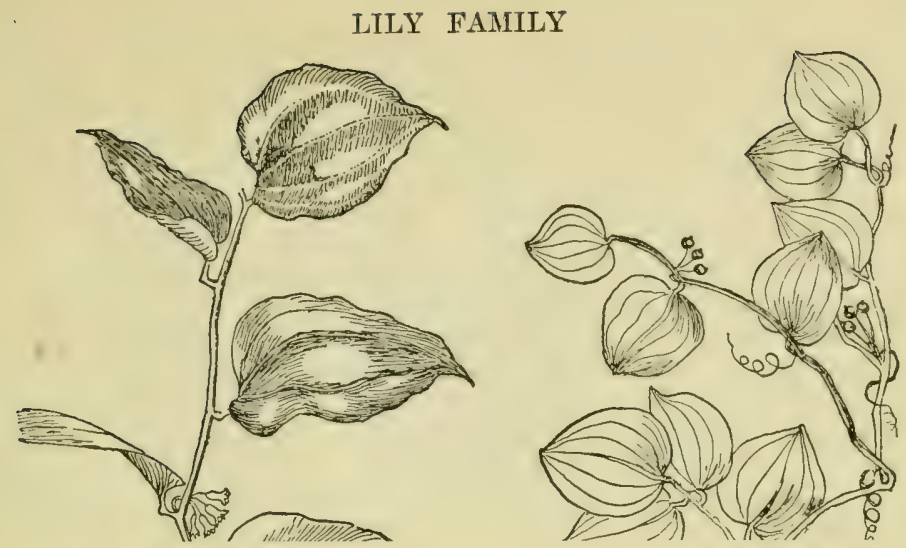

\section{Errata}

Page 138, 15th line

For surrounded read surmounted.

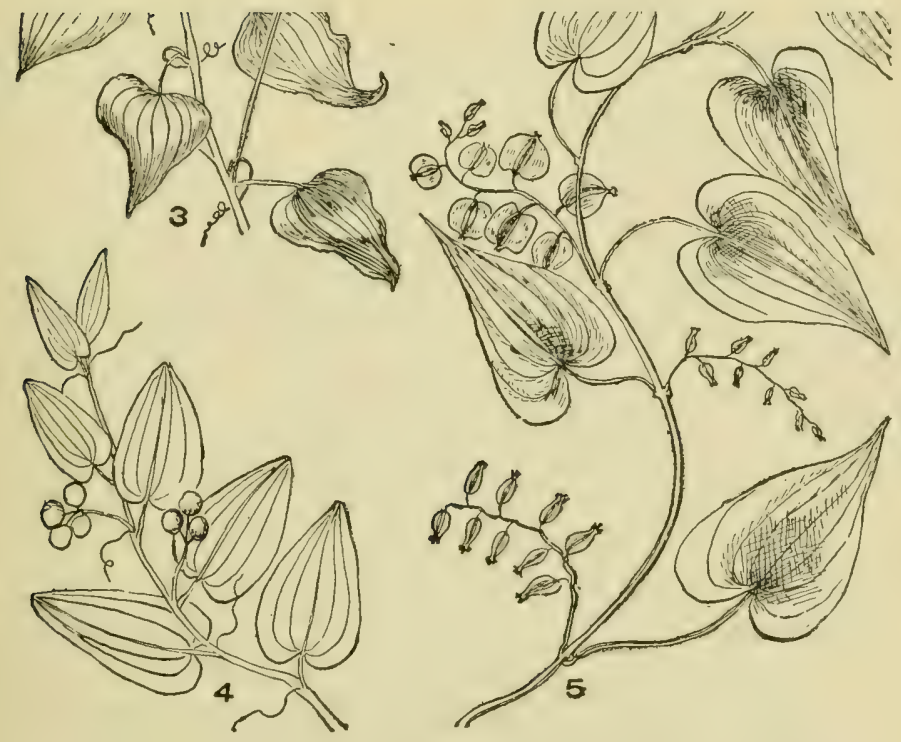

Plate 15

1. Smilax glauca. 2. S. rotundifolia. 3. S. tamnifolia. 4. S. Walteri. 5. Dioscorea villosa. 
Herls arising from a horizontal rootstock. Stems not branching, slender. Leaves without leaf stalks, alternate, ovate or lance-shaped, with slender points. Flowers in pairs, or 3 or 4 from a common stalk, the common flower stalks arising at the axils of the leaves. Berry dark blue.

1. P. biflorum, (Walt.) Ell. (Fig. 3, pl. 12.) HaIry Solomon's Seal. Plant hairy, $\frac{1}{2}$ to $3 \mathrm{ft}$. high. Common. In woods and shady places. April-July.

2. P. commutatum, (R. \& S.) Dietr. (Fig. 4, pl. 12.) SмоотіI Solomon's SEAL. Plant cntirely smooth, 1 to $\mathrm{S}$ ft. high. In moist woods, New Hampshire, Rhode Island and southward. May-July.

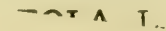

\section{TKILL1U...,}

Herbs arising from tubrous roots or short rootstocks, with simupu surmounted by a whorl of 3 broad leaves and a single flower. Flower of 6 segments, 3 green, 3 colored. Stamens 6; ovary 3-angled and 3-celled.

Leaves on leaf-stalks.

Plant 2 to 6 in. high . . . . . . . . . . . . T nivale Plant 8 to 24 in high $\therefore . \cdots$ T. undulatum

Leaves without leaf stalks or with very short ones.

Petals broadest at outer extremity . . . . . . T. grandifiorum Petals broadest at inner extremity.

Pedicel of flower not more than 17 in. long . . . . T. cernum Pedicel of flower more than $1 \frac{1}{4}$ in. long $: \vdots: \vdots: T$. erectum

1. T. grandiflorum, (Michx.) Salisb. (Fig. 1, pl. 14.) LARGEFLOWERED IVAKE-ROBIN. Petals broadest at outer extremity, white or light rose with greenish veins, and much longer than the green sepals. Flower nearly ereet, larger and less spreading than the other species. Stem 8 to 18 in. high. Somewhat common. In moist woods or lowlands. May-June.

2. T. erectum, L. (Fig. 2, pl. 14.) IlL-ScEnTEd WaKe-RoBin. Potals broadest at inner extremity, and seareely exceeding the green sepals in length or even shorter, an inch long and twice ats wide as the scpals, spreading to a wheel-formed flower. filower nodding on a nearly crect perluncle, dark purple. Stem a foot or more high. Common in moist woods. April-June.

3. T. cernuum, I. Nodning WaKe-robin. Leaves more rounded than either of the other species. Petals white, rather longer than the green scpals, laner-shaped. Flowers spreading with petals rolled back. Stem 10 to $15 \mathrm{in}$, high, 


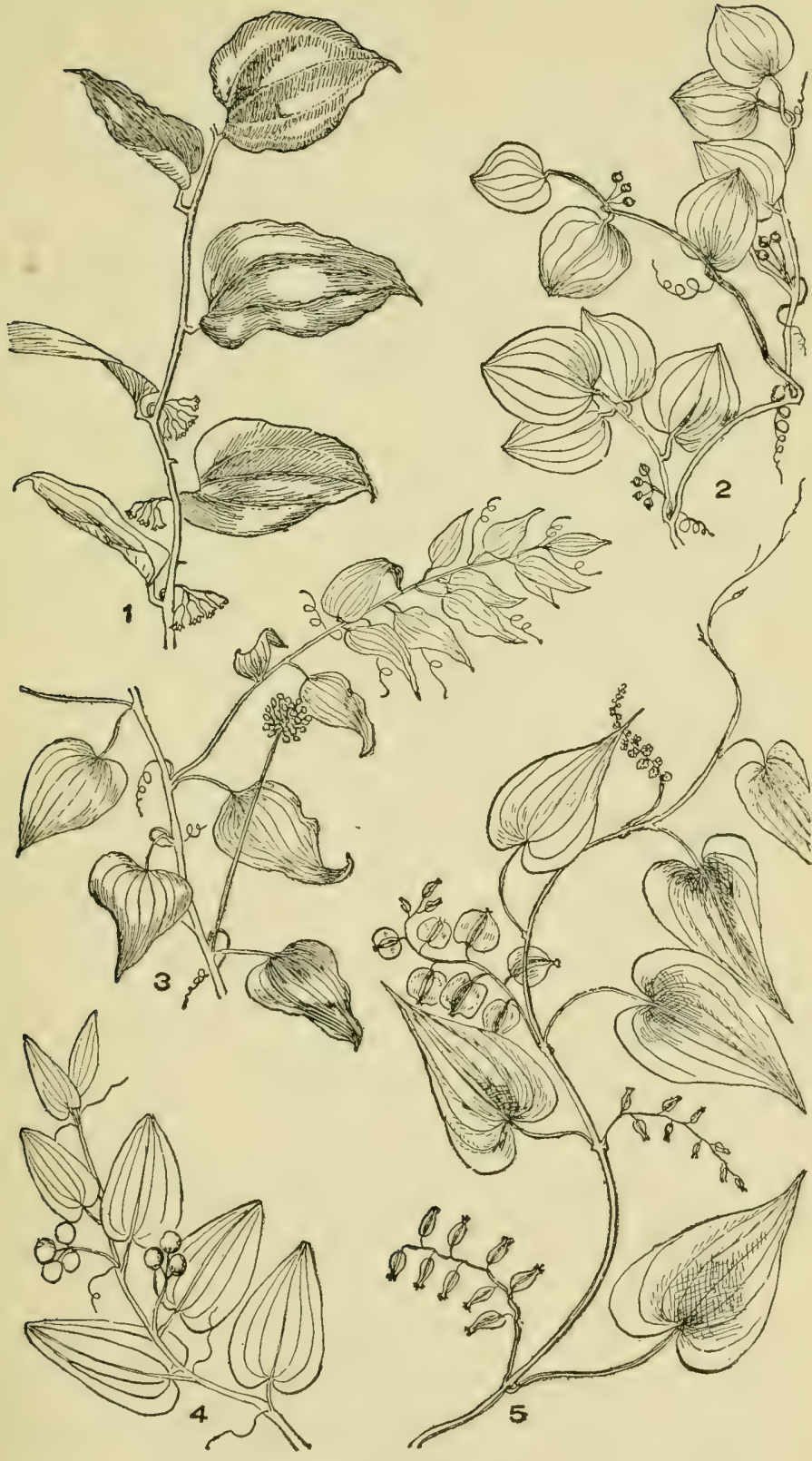

Plate 15

1. Smilax glauca. 2. S. rotundifolia, 3, S. tamnifolia, 4. S. Walteri. 5. Dioscorea villosa. 
4. T. undulatum, Willd. Painted Wake-robin. Leaves with leaf stalks and with long narrow points. Petals lance-shaped or lance ovate, nearly equal at the extremities, edges wavy, longer than the green sepals. Flowers on nearly erect flower stems (pedicels) white, beautifully marked with pink veins which distinctly color the throat. Stem 8 to 12 in. high. Common in woods. April-June.

5. T. nivale, Beck. EARLY WAKE-RoBiN. Plant 2 to 6 in. high. Leaves on leaf-stalks, the blade 1 to 2 in. long, broadly oval. Flower on a flower stem 1 in. long, bent or curved beneath the leaves. Petals white, oblong or oval. Woods, Penna. and southward. March-May.

\section{Tribe VI.-SMilacoideaE. Smilax Tribe}

Woody or, in Nos. 1 and 2 , herbaceous vines, climbing by tendrils, arising from large tubrous rootstocks. Pistillate and staminate flowers on different plants, in rounded umbels, generally on long pedicels. Segments of the perianth 6, small, white; stamens inserted at the base of the perianth segments. Berry globular, 3-celled, with 1 or 2 seeds in each cell.

One family, SirilaCEAE, and only one genus.

\section{SMILAX, L.}

Which has the characters named above.

Herbaceous, annual plants . . . . . . S. herbacea and S. tamnifolio Woody perennial vines.

Stems all armed with prickles - S. glauca, S. rotundifolia and $S$. hispida

Smaller stems without prickles.

Leaves shield-shaped . . . . . . . . S, bona-nox

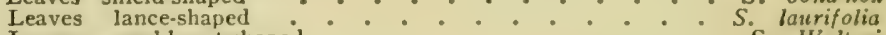

Leaves oval-heart-shaped $\because \because \because \cdots{ }^{\circ}, \quad$ S. Walteri

Leaves egg-shaped..${ }^{\circ} \cdot{ }^{\circ} \cdot{ }^{\circ}$. pseudo-china

\section{Herbaceous Annual Plants}

1. S. herbacea, L. Carrion Flower. Stem round or slightly angled, very smooth, green, bushy, with slender branches. Leaves oblong-eggshaped, 7 -nerved. Flower stems longer than leaf stems. Woods and thickets of our area. April-June.

2. S. tamnifolia, Michx. (Fig. 3, pl. 15.) Halberd-teaved Smilax. Climbing or erect, smooth light green. Leaves heart-shirld-shaped, 5-nerved. Flower stems much longer than leaf stems. Southern New Jersey and Penna., and southward. May-July.

\section{Stems woody, perennial}

Stems armed with many prickles.

3. S. glauca, Walt. (Fig. 1, pl. 15.) Glaucus-leaved Greenrriar. Stem round or the smaller branches slightly 4-angled. Leaves broadly ovate or rarely heart-shaped at base, thick, 3-nerved. Leaf stems bearing tendrils. Flover stems considerably longer than leaf stems. Dry soil, eastern Masss. and southward. May-June, 
4. S. rotundifolia, I. (Fig. 2, pl. 15.) Common Greenbriar. Stem stout, round. Leaves round-egg-shaped, often broader than long. Points of leaves sharp, borders smooth, 5-nerved. Flower stems not longer than leaf stems. Woods and thickets of our area. April-June.

5. S. bona-nox, L. Bristly Greenbriar. Stem round or slightly angular, branchlets angular, with many prickles. Leaves deltoid-heartshaped, 5-nerved, often with prickles along the leaf borders. Flowerstem longer than leaf-stem. Southern two-thirds of our area and southward. April-July.

6. S. hispida, Muhl. Hispid Greenbriar. Stem climbing, covered below by a dense growth of soft bristly prickles, main stem round, the branches somewhat angular. Leaf stems about $\frac{1}{2}$ in. long; leaves thin, egg-shaped, sharply pointed at apex, obtuse or somewhat heart-shaped at base, 7-veined. Stem of flower-cluster from 2 to 5 in. long. Berries bluish-black. Moist thickets, rare. Conn. southward. May-July.

§ Stems without prickles or with prickles only on main stems.

7. S. laurifolia, L. Laurel-Leaved Greenbriar. Stem round, high climbing, prickles only on main stems or rarely on small branchlets. Leaves narrow lance-shaped, broader at outer third than at inner third. Leaves generally 3 -nerved, leaf stems very short. Flower stems $\frac{1}{2}$ to 1 in. long. In southern part of our region. March-Sept.

8. S. Walteri, Pursh. (Fig. 4, pl, 15.) Walter's Greenbriar. Stem angled. Leaves egg-shaped, heart-shaped, obtuse at apex, 3-nerved. New Jersey and southward. Narch-Aug.

9. S. pseudo-china, L. Long-STalefed Greendriar. Rootstock tubrous. Stem climbing, without prickles or with few. Leaves egg-shaped, somewhat heart-shaped at base, 5-veined; leaf stem flattened. Flower stem nearly as long as the leaves. Berries black. Rare. Dry or sandy soil. New Jersey and southward. March-Aug.

\section{FaMily III.-HAEMOdORACEAE. Bloodwort FaMiLy}

General characteristics of the Lily family, but with only 3 stamens, which are opposite the 3 inner segments of the perianth. Perianth situated partly or wholly above the ovary which is 3 celled. Perennial herb with erect stems and narrow, grass-like leaves.

\section{LACHNANTHES, Ell. (Gyrotheca, Salisb.)}

A stout herb with fibrous, perennial roots $1 \frac{1}{2}$ to $2 \mathrm{ft}$. high, woolly or hairy above. Flowers in a head or loose rounded cluster, yellow. Calyx segments long, narrow and pointed, as long as the yellowish petals.

L. tinctoria, (Walt.) Ell. RED Root. Flowers 15 to 20 in a terminal umbel-like eluster, covered with woolly hairs. Found in swamps and wet places, Mass. and southward. July-Sept.

\section{Family IV.-Amaryllidaceae. Amaryllis Family}

Perennial herbs with grass-like leaves. Flowers showy in um- 
bel-like clusters, yellow or white. Perianth segments 6 , atherent to the ovary. Stamens, in our species, 6. Ovary 3-celled, each cell with many seeds.

\section{HYPOXIS, L.}

Low herbs arising from short rootstocks not unlike bulbs. Leaves all from the rootstock, grass-like. Flowers star-shaped, green on the outside, yellow within, the few-flowered cluster terminal to a naked scape. Below the flower cluster are 2 lance-shaped bracts.

1. H. hirsuta, (L.) Coville. (Fig. 4, pl. 16.) Star Grass. Leaves all from the root. Flower stem generally not as long as the grass-like leaves. Whole plant hairy. Flowers 2 to 6 in the group. Stem 3 to 10 in. high. Dry woods throughout our region. May-Oct.

\section{LOPHIOLA, Ker.}

Erect herb arising from a slender rootstock. Leaves grass-like, mostly from the root but found sparingly on the flower stem. The spreading cluster is compound, a dozen to 20 flowers in the group, the flower branch. lets being subtended by 2 lance-shaped bracts. Capsule ovoid.

1. L. americana, (Pursh.) A. Wood. Lopinols. Golden Crest Fower. Perianth segments woolly. Stem 1 to $2 \mathrm{ft}$. high, when young covered with whitish woolly hairs. Root leaves smooth, narrow and long, those from the stem shortor. Flowers yellow within and woolly, greenish on the outside. Bogs, New Jersey and southward. June-Aug.

\section{Fanily V.-DIOSCOREACEAE. YaM FAmLY}

Twining shrubs with alternate heart-shaped leaves. Staminate and pistillate flowers on different plants or the two kinds on the same plant. Perianth of 6 segments, adherent to the ovary. In the staminate flowers the stamens are inserted into the base of the perianth segments. Both kinds of flowers in long slender clusters. Leaves at lower part of stem in whorls of $4 \mathrm{~s}$; above, alternate, each with about 9 conspicuous nerves. Styles 3, ovary 3-celled, winged.

\section{DIOSCOREA, L.}

A twining vine in woods and thickets, mostly elinging to trees. Leaves ergr-shaped, with slender pointed onter extremities, on long slender leaf stalk.

D. villosa, L. (Fig. 5, pl. 15.) Wild Yam-RooT. Mostly in the southern part of our region. June-July.

\section{FAMIIY VT.-IRIDACEAE. TRIS FAMILY}

Perennial herbs, in wet or moist grounds. Leaves limear, erect, in two ranks. Perianth of 6 secments, in fommingia and sisyrinchium alike, in Iris the 3 inner secrments smaller than the 
others. Flowers subtended by conspicuous leaf-like bracts. Stamens 3, opposite the outer segments of the perianth.

Segments of perianth in two unequal series . . . . Iris Segments of perianth equal.

Flowers orange

Flowers blue.

- Gemmingia Sisyrinchium

\section{IRIS, L.}

Three inner segments of the perianth curved outward, narrower than the others. Outer segments more erect but curved inward. The 3 divisions of the style are flattened and colored, resembling petals, the stigmas being on the under (outer) side of the generally 2 lipped style.

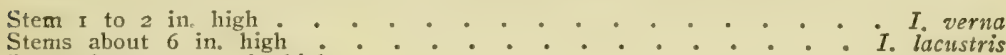

Stems about 6 in. high
Stems from 1 to $2 \mathrm{ft}$. high.

Flowers yellow

Flowers blue.

Leaves sword-shaped

Leaves narrow, grass-like.

Flower pedicel shorter than the bracts subtending it . I. Hookeri

Flower pedicel much longer than the bracts, plant I
$\mathrm{ft}$. or more high . - . . . . . . prismatica

1. I. versicolor, L. (Fig. 3, pl. 16.) LARger Blue Flag. Stems 1 to $3 \mathrm{ft}$. high. Leaves shorter than the stem, $\frac{1}{2}$ to $1 \mathrm{in}$. wide. Bract longer than the flower stem. Flowers blue, with yellow, green and white. The common blue flag along borders of springs and in moist places. MiayJuly.

2. I. pseudacorus, L. Yellow FlaG. Leaves sword-like. Stems $1 \frac{1}{2}$ to $3 \mathrm{ft}$. high. The only native or naturalized species with yellow flowers. Not common. Marshy places. Introduced from Europe. May-July.

3. I. Hookeri, Penny. Hooker's Blue FlaG. (1. setosa, Pall.). Leaves grass-like, mostly from the base. Seed capsules nearly egg-shaped with 3 obtuse lobes. The bracts below the flowers are as long or longer than the pedicel of the flower. Stem 10 to $20 \mathrm{in}$. high. Banks of streams, throughout our area. May-July.

4. I. verna, L. DWARF IRIS. Stem 1 to 3 in. high, usually 1-flowered. Leaves narrowly linear. Flowers violet-blue or rarely white. Shaded hillsides, S. Penna. and southward. April-May.

5. I. prismatica, Pursh. Slender Blue FlaG. Leaves grass-like; plant slender. Flowers solitary or two together, the flower on a long delicate flower pedicel. Capsule acute at each end. Mostly along the eastern coast. May-July.

6. I. lacustris, Nutt. Dwarf Lare Iris. One of the smallest of the genus native in our region. Stem about 5 or 6 in. high. Flowers 1 to $1 \frac{1}{2}$ in. long. Leaves as long or longer than the flower stem. A local species on the shores of Lake Huron and Lake Superior. May.

\section{GEMMINGIA, Fabricius}

An introduced erect herb, perennial, with leaves resembling the Iris 
and with a broad loose terminal cluster of flowers with equal spreading, orange, purple-mottled, flowers, the petals and sepals nearly or quite equal. Stamens 6 , inserted at the base of the perianth segments.

1. G. chinensis, (L.) Kuntze. Blackberry Lily. Stem 1 to $5 \mathrm{ft}$. tall. Fruit many knob-like protrusions, resembling in form and appearance a blackberry. In southern part of our region. June-July.

\section{SISYRINCHIUM, L。}

Herbs arising from rootstocks. The three branches of the style threadlike. Leaves grass-like. Segments of perianth 6, equal, the petals widest at outer extremity; stamens 6. From the midvein of each petal extends a delicate spine-like projection. Flowers wheel-formed. Below the little umbel of flowers are two leaf-like bracts which form a sort of spathe. From this spathe arise by delicate pedicels the two, three, or more starlike flowers.

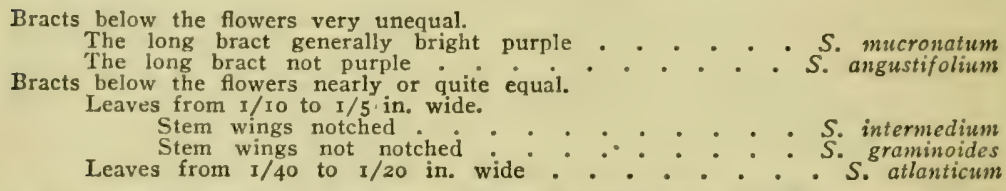

1. S. graminoides, Lamark. Stout Blue-eyed Grass. A common species in damp grassy soil. Flower stem somewhat flattened, branching, one branch shorter than the other. Leaves broad grass-like. Plant 8 to 20 in. high.

2. S. atlanticum, Bicknell. (Fig. 2, pl. 16.) EASTERN Blue-eyed Grass. Iess common than No. 1. Stem and leaves very narrow, whole plant slender. Stem branching, 8 to 24 in. high. Generally growing in tufts. Umbel often many flowered. In moist fields throughout our region, but mostly in the Eastern part. May-June.

3. S. angustifolium, Mill. (Fig. 1, pl. 16.) Pornted Blue-Eyed Grass. Stem flat, two edged. Leaves about $1 / 12$ in. wide and from 3 to 16 in. high. Umbel few flowered, subtended by a long bract which extends considerably above the flowers and a second very inconspicuous bract. In moist meadows. Common. June-Aug.

4. S. mucronatum, Michx. Michaux's Brue-ered Grass. Growing more in tufts than the last; stem and leaves much more delicate and slender, from thread-like to $1 / 15 \mathrm{in}$. widle. Stems with very narrow wings on margins. Leaves often as long as flower stems. The outer long bract at the base of the umbel $\frac{1}{2}$ to $2 \frac{1}{2} \mathrm{in}$. long, often bright purple; the inner bract about $l \mathrm{in}$. or less in length. Flowers deep violet-blue. Meadows and fields, New Jersey and westward. May-June.

5. S. intermedium, Bicknell. Intermediate Buve-eyen Grass. Growing in tufts, stems 4 to $16 \mathrm{in}$. high, slender, simple or branched above into two long flower stems. Leaves nearly $1 / 8 \mathrm{in}$. wide. Stem very llat, the wings very finely notehed. Flower stem usually shorter than the leaf situated just below the branching ( 2 to $3 \frac{1}{2} \mathrm{in}$. long). Outer bract below the little umbel of flowers tapering to a very slender point, 1 to $21 \mathrm{in}$. long, usually purple. Flowers 2 to 6, pale blue. Southern New Jersey and southward. May-June. 


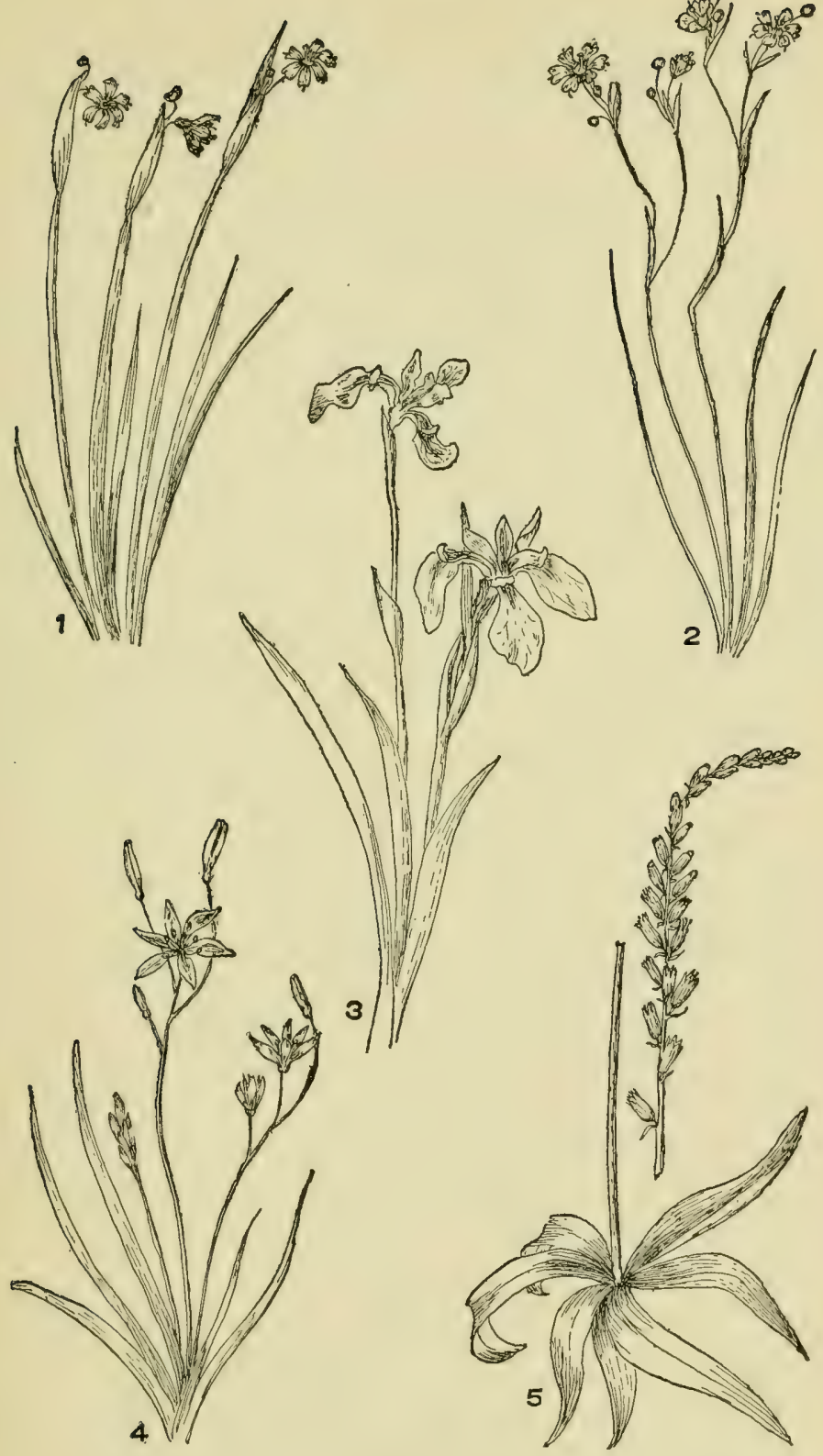

Plate 16

1. Sisyrinchium angustifolium. 2. S. atlanticum. 3. Iris versicolor. 4. Hypoxis hirsuta. 5. Aletris farinosa. 


\section{Order VII.-ORCHIDACEAE. Orchidaceous Plants}

Of this orter there is, in our region, only one family.

\section{ORCHIDACEAE. ORCHID FAMILY}

Among the Nonocotyledonous plants the orchid family is peculiar in being that in which the flowers are always irregular. The perianth is of two rows of flower leaves, an outer, the calyx, of 3 segments which are alike or very nearly so and an inner, the corolla, also of 3 generally very unequal parts. The two side segments are nearly alike, but the midulle or upper one is unlike the others and generally forms a lip, simple or fringed, or a boatlike pouch, and is often extended into a long spur. This upper segment, by the twisting of the ovary or of the flower pecticel may become the lower one. This upper lip difiers from the other segments, not only in form and size but it is often strikingly in contrast in its color. Of the stamens, only one is, as a rule, dereloped, but in cypripedium two are fertile. The stamen or the two stamens grow in union with the pistil, forming what is known as the columm. This arrangement brings the pollen bearing anther directly orer or behind the stigma. The ovary is, contrary to the general rule with monocotyledonous plants, entirely inferior to all the parts of the flower, is elongated and in nearly all cases twisted, the torsion in greneral being $180^{\circ}$, while in some foreign species the rotation is fully $360^{\circ}$.

In Cypripedium the bending of the flower stalk serves the same purpose as does the torsion of the ovary in other genera. The one-celled ovary is divided by three deep partitions to which are attached the very numerous small seeds. Orchidaceous plants are all perennial, the bulh for the suceeding year forming at the site of the bulb of the current year. Leaves generally from the stem and alternate but sometimes all from the root or opposite on the stem or even in whorls on the stem, they are parallel nerved. Flower's in a slemeler spike or loose broadened cluster or, less frequently, solitary.

There are over 5000 known species of orehidaceons plants, the great majority of which are found in tropical climates, the most of these latter being air plants, finding their homes on the branches of trees and deriving their nourishment largely through the long trailing aerial roots. In our region all the species are plants having their roots in the soil or in wet mosses. 
Flowers with two fertile anthers resting each on a lateral projection from the common column, the odd, center stamen (which answers to the fertile stamen of other orchids) spread into a petal-like expansion . . . . Cypripedium

Lip extended into a spur.

Flower with one fertile stamen. Pollen in masses drawn out and forming a little stalk (caudicle) which is connected with a glutinous adhesive substance known as a " gland."

The glands enclosed in a hood or pouch which opens

at the mouth of the spur . . . . . . Orchis

Glands not enclosed in a pouch . . Habenaria

Pollen masses waxy, terminal to the column. Slender

herb arising from a solid bulb. Spur slender, 2 or 3

times as long as the flower. Flowers greenish in a loose lengthened cluster . . . . . Tipularia

Lip not extended into a spur.

Pollen masses not drawn out to form the little stalk, grains more or less powdery, but cohering in 4 or 5 delicate masses and attached to the summit of the anther.

Leaves 2, opposite. The pair of green leaves near middle of stem. Lip of flower split . . Listera

The pair of shining leaves near the base of the stem. Sepals and petals linear . Liparis

Leaves along the stem, mostly below. Flowers in twisted spikes... . . . Spiranthes

Leaves in rosette at base of stem, often blotched with white, not reticulated; lip entire, roundish

Epipactis

Stem very leafy, flowers in a long slender cluster, anther hooded . . . . . Serapias

Leaves mostly reduced to sheaths; flower solitary, purple . . . . . . Arethusa

Leaves broad grass-like; flowers several in a loose cluster, pink purple. Lip crested with long yellow hairs.

Calopogon

Flowers few or solitary. Leaves few, alternate or in a whorl. Anther attached to the back of the column . . . . . . Pogonia 
Leaf single.

Oval, with a single flower having a double, bearded lip . . . . . . . Calypso

Leaf broadly oval clasping the stem with several scales below. Flowers greenish Microstylis Grass-like, with a long cluster of yellow-brown flowers Aplectrum Plants without leaves or with inconspicuous ones. Flowers dull, roots coralloid . . . Corallorrhiza

\section{CYPRIPEDIUM, L.}

Plants with terminal nodding flowers. Two stamens fertile. Stigma in 3 lobes. Lip developed into a large inflated pouch or sac. Leaves from the stem or from the root, large, many nerved.

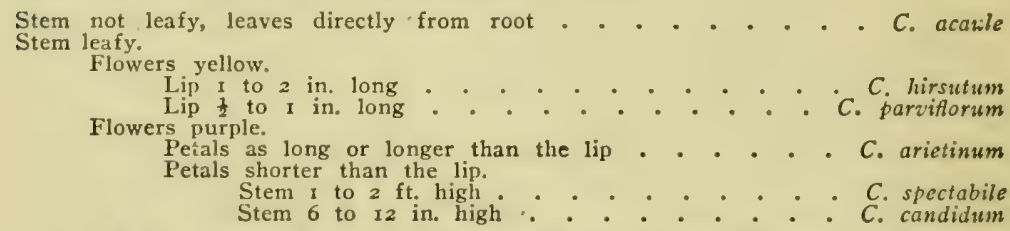

1. C. arietinum, R. Br. (Fig. 4, pl. 17.) Rayis Head. Stems 8 to $12 \mathrm{in.} \mathrm{high,} \mathrm{often} \mathrm{in} \mathrm{clusters.} \mathrm{Leaves} \mathrm{broad} \mathrm{elliptic,} \mathrm{petals} \mathrm{linear,} \mathrm{green-}$ ish-brown; lip red with white veins, somewhat downy, the apex prolonged into a spur. Lateral sepals not united. In damp woods, most of our region. May-Aug.

2. C. acaule, Ait. (Fig. 2, pl. 17.) Mocassin Flower. Flower scape 10 to $14 \mathrm{in}$. high. Leaves from the base of stem, opposite, broad elliptic, strongly nerved. Flower 2 in. long. Petals not as long as the pouch-like lip. Lateral sepals more or less united. An exquisite flower. In damp woods. May-June.

3. C. spectabile, Salisb. (Fig. 3, pl. 17.) Sirowy Tady's Stipper. (C. reginac, Walt.). Stem leafy, $2 \mathrm{ft}$. high; leaves broad lance-ovate, strongly veined. Sepals broad, blunt at end, not as long as the lip. Lip purplish white with many red veins. The most showy of our Cypripediums. In wet meadows and swamps. June-Sept.

4. C. candidum, Willd. Smald White Lady's Slipper. Stem with 3 or 4 broad lanceshaped leaves, 6 to 12 in. high. Sepals and petals longer than the lip. Lip white with purple veins within. Flower rather less than an inch long. Woods and swamps. May-July.

5. C. hirsutum, Mill. (Fig. 1, pl. 17.) Large Yellow Lany's SítipYER. Stem leafy, 1 to $2 \mathrm{ft}$. high, hairy; leaves oval or broad lanceshaped. Flowers large, lip 1 to $2 \mathrm{in}$. long, greenish-yellow with purple stripes. Sepals long, twisted, narrow lance-shaped. Woods and thickets throughout our region. May-July.

6. C. parviflorum, Salisb. Smatl Lady's Stipper. Stems very leafy, about as tall as No. 5, flower smaller; lip 1 to 1$\}$ in. long, bright yellow 


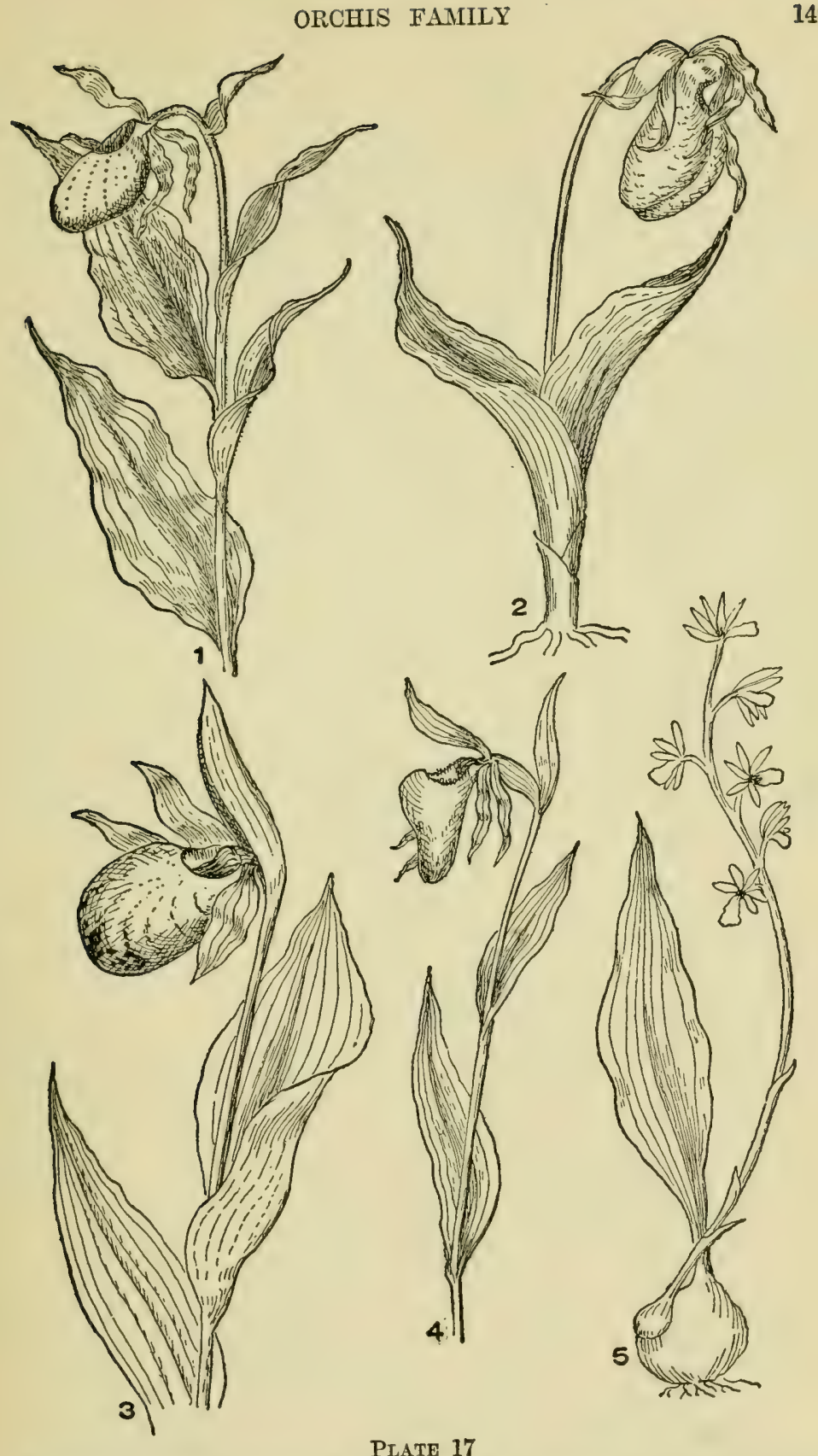

Piate 17

1. Cypripedium hirsutum. 2. C. acaule. 3. C. spectabile. 4. C. arietinum. 5. Aplectrum spicatum. 
with purple spots within. Sepals long egg-shaped to lance-egg-shaped. Woods and thickets. May-July.

\section{ORCHIS, L.}

Perennial, from fleshy roots. Leaves, in our species, 1 or 2 from base of stem. Flower stem leafless with a narrow spike of exquisite purple flowers. Lip spurred. Pollen in two masses, related to each other by the slender elastic threads.

1. O. spectabilis, L. (Fig. 1, pl. 18.) Srowr Orcuis. (Galcorchis spectabilis, (L.) Rydb.). Stem 4 to 12 in. high, but rarely more than 6 in., 4 -angled with 1 or 2 lance-shaped bracts. Leaves 2, opposite, rarely more, broad oval, spreading, about as long as flower stem. Flowers 3 to 6, showy, rose-white or somewhat violet, lip not lobed. Throughout our region in rich, generally piny, woods. April-June.

2. O. rotundifolia, Banks. (Fig. 2, pl. 18.) Sarall Round-Leaved OncHiD. Stem more slender than No. 1, about as high. Leaf single, from base of stem, broadly oval or nearly orbicular. Flower stem with few flowers. Lip white or light purple with purple spots, three lobes, the end one notched. In damp woods mostly in northern part of our area. JulyAugust.

\section{HABENARIA, Willd.}

Plants differing from the orchids only in some, to the amateur, rather obscure features. Mostly with leafy stems. Flowers in long narrow clusters (spikes) or in loose clusters (racemes). Lip entire, 3 lobed or fimbriated. The tuo glands to which are attached the delicate threads (or caudicles) connected with the pollen masses are not cnclosed in a pouch but lie quite naked. The petals are usually smaller than the sepals. Color of flowers, purple, white, green or yellow.

\section{Flowers Grenish-yellow}

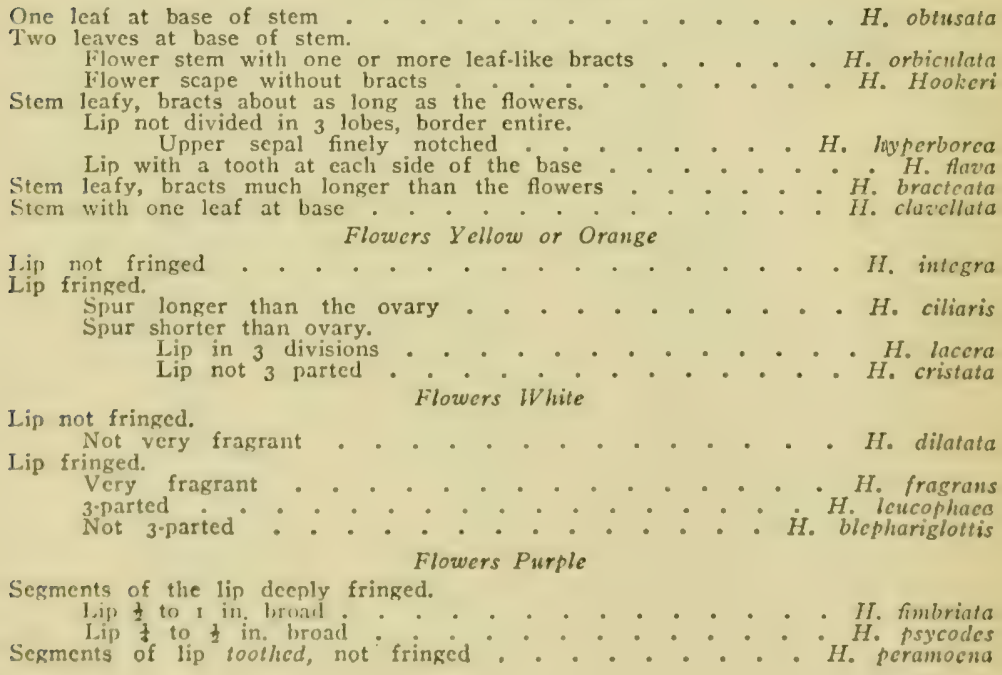




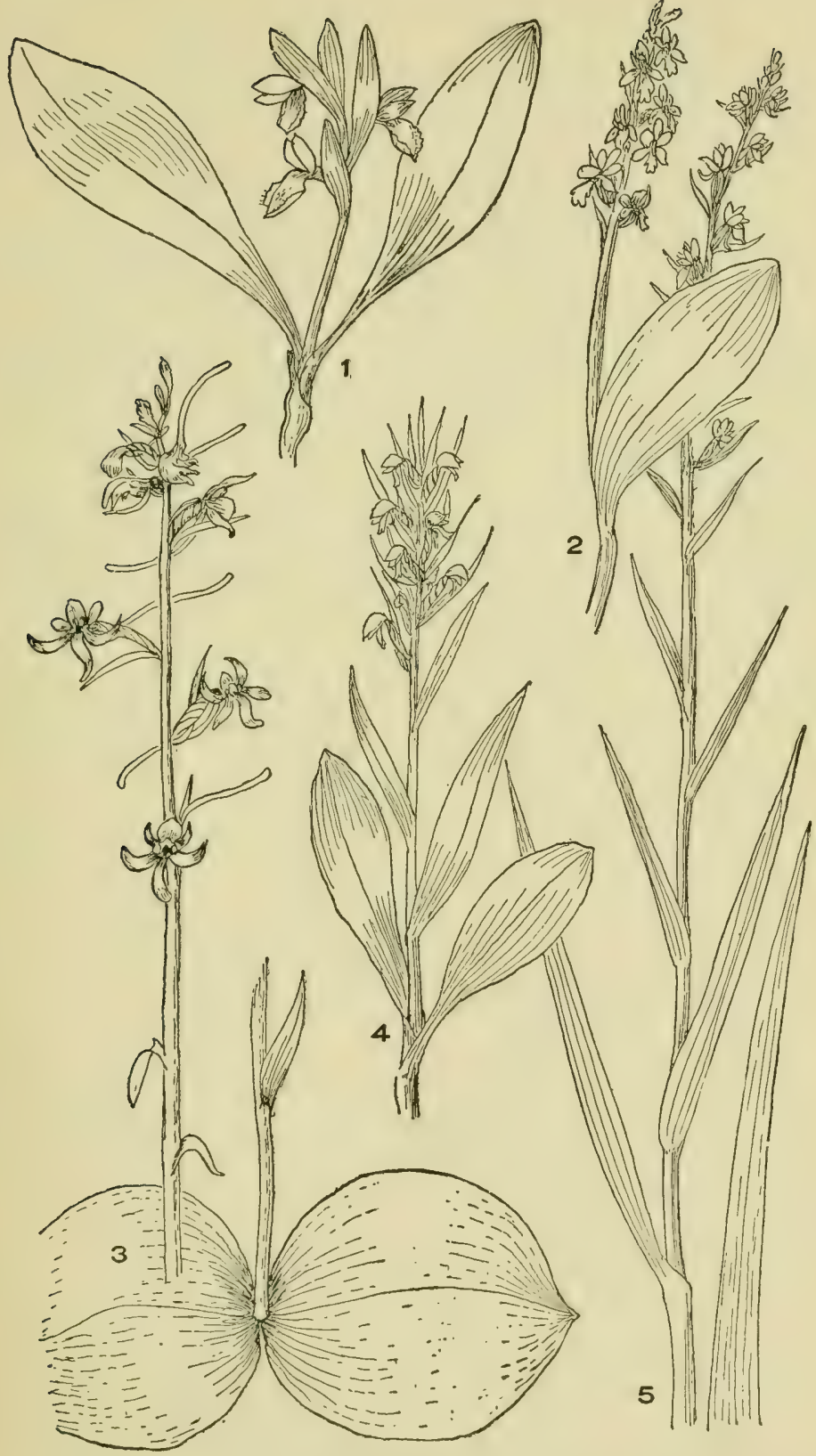

Plate 18

1. Orchis spectabilis. 2. O. rotundifolia. 3. Habenaria orbiculata. 4. H. bracteata. 5. H. dilatata. 
I. H. orbiculata, (Pursh.) Torr. (Fig. 3, pl. 18.) LARge RoundLEAVED ORculs. Stem slender 1 to $2 \mathrm{ft}$. high, bearing a long loose cluster of green flowers and one or more lcafy bracts. Leaves large, shining, 3 to 6 in. long and nearly round, lying flat on the ground. Spur longer than the long twisted ovary. In rich damp woods throughout our area. July-Aug.

2. H. Hookeri, Torr. Hooken's Orcuis. Scape only about half as high as No. 1 and leaves also smaller and less spreading. Flowers yellowish-green, spur 1 in. long. In most respects strongly resembling No. 1 , but the green bracts on the stem are wanting. In situations similar to No. 1. June-Sept.

3. H. obtusata, (Pursh.) Richards. (Fig. 4, pl. 19.) Srall Northers Bog Orcins. Stem 4 to $10 \mathrm{in}$. high, slender, 4 -angled. The single leaf arising from base of stem ovate, widest toward apex. Lip narrow lance-shaped and as long as the spur. Bogs, generally distributed in our area. July-Sept.

4. H. hyperborea, (L.) R. Br. Tall Leafy Green Orchis, (Limnorchis media, Rydb.). Stem 1 to $3 \mathrm{ft}$. high, lcafy. Lance-shaped or broad lance-shaped 2 to 12 in. long. Spike of numerous flowers very narrow; flowers grcenish-yellow, the bracts, one subtending each flower, are longer than the flower. Spur as long as the slightly indented lip. Swamps and damp woods. May-Aug.

5. H. dilatata, (Pursh.) Gray. (Fig. 5, pl. 18.) Tall White Bog Orcuis. Slender stem 8 in. to $2 \mathrm{ft}$. high. Leaves lance-shaped to grasslike. Spike of flowers narrow, long. Bracts below the flowers about as long as or shorter than the white flowers. Lip linear and ending in an obtuse point. Swamps and wet woods. June-Sept.

6. H. fragrans, A. Gray. Fragrant Orchis (Limnorchis fragrans, Rydb.). Resembles No. 5. Lip narrowly linear, dilated at the base, shorter than the spur. Flowers small, white, very fragrant. Bogs, Willoughby mountains, Vermont. July.

7. H. integra, (Nutt.) Spreng. SaAlL Soutuern Orcuis. Stem 1 to $2 \mathrm{ft}$. high; leaves lanceolate to grass-like, about 3 ; spike of flowers short ( 1 to 3 in.), with numerous orange-yellow flowers. Lip ovate, longer than the sepals, spur longer than the sepals. Wet places, New Jersey and southward. July.

8. H. bracteata, (Willd.) R. Br. (Fig. 4, pl. 18.) Lona-Bracted Orcins. Stem to $2 \mathrm{ft}$. high. Leaves oblong, obtuse at apex or somewhat sharp pointed. Lip somewhat 3-toothed at outer end. 3racts below the flowers lance-shaped and three times as long as the grecnish flowers. Petals very narrow, twice as long as the white spur. Woods and meadows. May-Sept.

9. H. clavellata, (Michx.) Spreng. (Fig. 7, pl. 19.) Small Greev Wood Orcurs. Stem $\frac{1}{2}$ to $1 \frac{7}{2} \mathrm{ft}$. high, with only a single leaf, which is noar the base, and with several leaf-like bracts along the stem above. The larger single leaf, willest toward the apex, 2 to 6 in. long. Bracts below the flowers not so long as the ovary. Flower spike $\frac{1}{2}$ to $2 \mathrm{in}$. long, with numerous small grecnish flowers. Moist woods. July-Aug.

10. H. flava, (L.) A. Gray. (Fig. 5, pl. 19.) Small Pale Green Orcins. Stem 1 to $2 \mathrm{ft}$. high. Leaves oblong to lance-shaped, sharp 
ORCHIS FAMILY
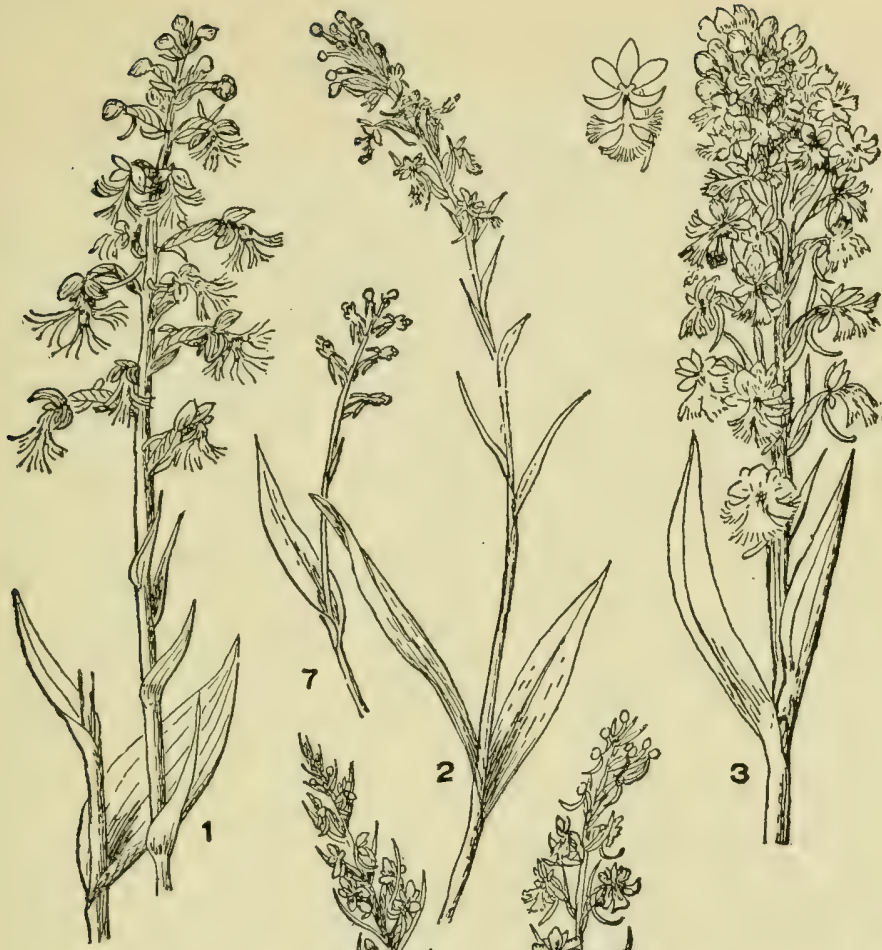

(d) 5 in 5 ?

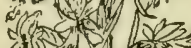
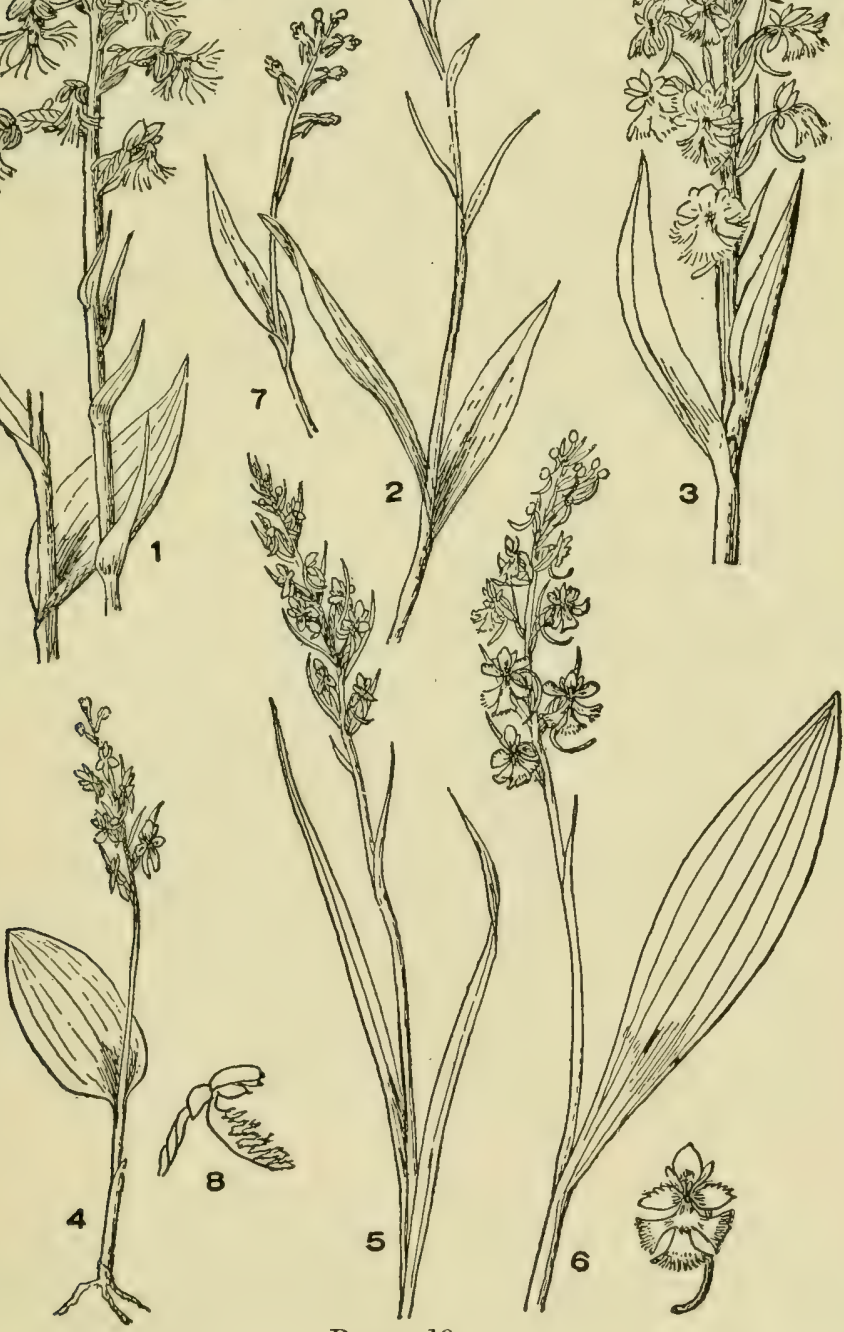

Plate 19

1. Habenaria lacera. 2. H. cristata. 3. H. fimbriata. 4. H. obtusuta 5. H. flava. 6. H. psycodes. 7. H. bracteata. 8. H. ciliaris. 
pointed or obtuse at outer extremity. Bracts below the flowers longer than the yellowish-brown flowers, the lips of which are 3 -toothed, rather longer than the petals and with a tubercle at the base. Moist soil. June-July.

11. H. cristata, (Michx.) R. Br. (Fig. 2, pl. 19.) Crested Yellow Orcuis. Stem 1 to $2 \mathrm{ft}$. high, slender; leaves lance-shaped to grass-like. Flowers in a somewhat dense spike 2 to $4 \mathrm{in.} \mathrm{long.} \mathrm{Lip} \mathrm{rather} \mathrm{longer}$ than the roundish sepals. Spur $\frac{x}{2}$ as long as the ovary. Flowers orange. Swamps, New Jersey and south.

12. H. ciliaris, (L.) R. Br. (Fig. 8, pl. 19.) Yellow Fringed Orciis. Stem about $2 \mathrm{ft}$. high. Leaves lance-shaped, pointed at extremity. Flower spike with many yellow flowers. Sepals rounded, $\frac{1}{6}$ to $\frac{1}{3} \mathrm{in}$. long, petals not as long, toothed. Lip not lobed, oblong, the border profusely fringed. Spur very slender, more than an inch long. IVet meadows. JulyAug.

13. H. blephariglottis, (Willd.) Torr. Wilte Fringed Orciis. Stem 1 to $2 \mathrm{ft}$. high. Leaves lance-shaped. Spikes with many white flowers. Lip long and narrow with copious, sometimes sparse, fringe. Spur 1 in. long. Swamps. July-Aug.

14. H. lacera, (Michx.) R. Br. (Fig. 1, pl. 19.) RagGed Orcirss. Slender stem 1 to $2 \mathrm{ft}$. high. Leaves lance-slaped to linear about $6 \mathrm{in.}$ long, upper smaller. Flower spike with many grecnish-ycllow flouers. Petals obtuse. Spur about as long as the lip. Lip divided into 3 segments, each fringed at the end by long thread-like segments. Wet meadows and woods. June-July.

15. H. leucophaea, (Nutt.) A. Gray. White Prairie Orcirs. Stout angled stem 1 to $2 \frac{1}{2} \mathrm{ft}$. high. Leaves lance-shaped, tapering and sharp pointed. Flower parts much like No. 13 but spur twice as long as the lip and flowers white. Moist fields. June-July.

16. H. fimbriata, A. Gray. (Fig. 3, pl. 19.) Large Purple Fringed Orchis. Fimbriated Orchis. (11. grandiflora, Torr.). Stem $15 \mathrm{in.}$ to $3 \mathrm{ft}$. tall, angled. Leaves oval, broad lance-shaped or narrow, 2 to $6 \mathrm{in}$. long; extremely obtuse. Segments of lip fan-shaped, broader than in Nos. 13 and 14. Ends bordered with thread-like fringes; the petals pointed, notched. Spur as long as or slightly longer than the ovary, curved. Cluster of lilac flowers 3 to $15 \mathrm{in.} \mathrm{long,} \mathrm{forming} \mathrm{an} \mathrm{extremely}$ showy and beautiful floresence. Moist and shady places. June-Aug.

17. H. psycodes, (L.) A. Gray. (Fig. 6, pl. 19.) Sinleer Purpez Frrigits Orenls. Stem more slender than No. 15, not angled, 1 to $3 \mathrm{ft}$. high. Leaves lance-shaped to oval, with sharp points. Spike 2 to $6 \mathrm{in}$. long with many lilac flowers. Lip fringed as in No. 15, but fringe is noticeably shorter and side segments less broad. Petals erect with delicatcly fringed border. Spur $1 \frac{1}{2}$ times as long as the ovary. Wet meadows. July-Aug.

18. H. peramoena, A. Ciray. Fringetess Purite Oreurs. Stem 1 to $2 \frac{1}{2 t}$. high, leafy. Leaves lance-shaped to linear, the longer ones 4 to $8 \mathrm{in}$. in length. Spike of flowers 3 to $7 \mathrm{in.}$ long, of numerous violetfurple showy flowers. Lip segments with very short fringe, or row of finc treth, midelle lobe notehed in center. Spur longer than ovary. Moist meadows. July-Aug. 


\section{POGONIA, Juss.}

Flowers solitary or few, always conspicuous compared to the delicate plant. The segments of the flower distinctly separate. Lip without spur, fringed along the border or deeply notched at outer extremity. Column bearing the stigma and anthers ereet and prolonged.

1. P. ophioglossoides, (L.) Ker. (Fig. 4, pl. 20.) Rose Pogonia. Stem delicate, 8 to $15 \mathrm{in}$. high, with single leaf or rarely 2 or 3 broad lance-shaped leaves, a leaf-like bract also at base of flower. Where single, the leaf is near the middle of the stem, $\frac{1}{2}$ to $3 \mathrm{in.}$ long, without leafstalk. A leaf sometimes also arises by a long leaf-stalk from the base of the stem. Petals and sepals leaning to side, elliptic or oval, $1 / 2$ to $2 / 3$ in. long, beautifully shaded light purple. The lip has a conspicuous fringe about the border, and on the inner surface a crest or beard, it is longer than the petals. One of the prettiest of the orchis family in our region. In wet meadows and swamps. June-July.

2. P. trianthophora, BSP. Nodning Pogonia. (Triphora trianthophora, (Sw.) Rydb.). Stem 3 to $18 \mathrm{in}$. high. Leaves, broad ovate, $\frac{1}{4}$ to $\frac{3}{4}$ in. long without leaf-stalks, 3 to 8 and alternate. Flowers 1 to 5 or more on rather long flower stems. Lip not quite as long as the petals and sepals, broad and somewhat irregularly notehed. Petals elliptic. Flowers, 1 in. long, purple, drooping when expanded. In rich woods. Aug.-Sept.

3. P. divaricata, (L.) R. Br. (Fig. 3, pl. 20.) Spreading Pogonia. Stem 1 to $2 \mathrm{ft}$. high, with one leaf near the middle and a leaf-like bract just below the single flower. Leaf without leaf-stalk, clasping the stem, 2 to 4 in. long and $\frac{1}{4}$ to $\frac{1}{2}$ in. wide, blunt at outer end. Petals and sepals long lance-shaped, the former 1 in. the latter $1 \frac{1}{4} \mathrm{in.} \mathrm{long.} \mathrm{Lip}$ broad with a prolonged middle or two short lateral lobes. Flowers rather dark purple. In swamps. Southern part of our region. Southern New Jersey, southward. July.

4. P. verticillata, (Willd.) Nutt. Wronced Pogonia. (Isotria verticillata, (Willd.) Raf.). Stem about $1 \mathrm{ft}$. high. Leaves 5 in a whorl at summit of stem, broad oval. Single greenish-yellow flower, on a slender flower stem, nodding. Sepals very narrow and more than twice the length of the petals, which are about $\frac{3}{4}$ in. long. The sepals are dark purple, the petals yellowish. Lip with a 3-lobed extremity and a crest of hairs in the inner side. Moist woods. May-June.

5. P. affinis, Austin. Smaller Whorled Pogonia. (Isotria verticillata, (Willd.) Raf.). Stem about $10 \mathrm{in.} \mathrm{high;} \mathrm{leaves} \mathrm{in} \mathrm{a} \mathrm{whorl} \mathrm{at}$ summit, resembling No. 4. Flowers greenish-yellow. Seprals only about cqual in length with the petals. Moist woods, rare. Connecticut, southern New York and New Jersey. June.

\section{ARETHUSA, L.}

Of the two known species ours is an exquisite low herb found usually in bogs. The sheathed stem arises from a small bulb and is terminated by a single or rarely by two, large, richly colored, rose-purple flowers. The solitary leaf is at first concealed by a sheath of the stem but at the time of the opening of the flower it expands and protrudes. Sepals 
and petals are nearly equal, adhering below, in the form of a hood above. The broad lip curves upward, outward and downward, broadest at the summit, crested with hairs down the face. The column is adherent to the lip and becomes petal-like and expanded at the apex. The anther is terminal and lid-shaped. Capsule ellipsoid, erect, angular.

A. bulbosa, L. (liig. 2, pl. 20.) Aretrusa. Plant 5 to 10 in. high; flower solitary or rarely 2 llowers from the same seape. In bogs throughout our region. May-June.

\section{SERAPIAS, L. (Epipactis, R. Br.)}

Tall herbs with leafy stems. Leaves alternate, elasping the stem. Flowers in a long narrow cluster (raceme), with bracts below the individual flowers. Lip with a sac at the base, without a spur, free, broad, the upper portion petal-like. Segments of the perianth all separate.

E. viridiflora, Reichb. Helleborine. Stem 1 to $2 \mathrm{ft}$. high, with soft hairs above. Leaves egg-shaped, clasping the stem, 1 to 3 in. long. Flowers greenish to purple. Petals narrow, lance-shaped. Lip lobed, wavy. Introduced from Europe. July.

\section{SPIRANTHES, Richard (Gyrostachys, Pers.)}

Herbs with slender stems, the flower spike spiral. Leaves few, mostly at the base, generally narrow lance-shaped. The small white flowers are arranged in from 1 to 3 rows which wind, more or less, about the stem. Lip without a spur, broad compared with the other floral segments which are quite narrow, the border wavy. The 3 upper segments of the corolla are often united.

Flowers in 3 ranks which are only slightly twisted.

The 3 upper segments converge and overlie each other forming a sort

of hood; spike dense . . . S. Romanzoffiana

The segments separate, they do not form a hood.

Leaves lance-shaped . . . . . . . . . . S. plantaginea

Leaves linear

Flowers in a single rank, the spike much twisted, not dense.

Stem leafy, leaves grass-like. . S praecox

Stem not leafy, the basal leaves withering before flowering time.

Root a single spindle-shaped tuber.... .5 simplex

Stem not leafy, 2 basal leaves more prominent than those of $\mathrm{S}$.

simplex. Root of several tubers . . . . . . S. gracilis

1. S. Romanzoffiana, Cham. Inoonen LAny's Tressf.s. Stem 6 to $15 \mathrm{in.}$ high, lenfy below, abore, leates reduced to bracts, the larger leaves inlow ranging from rather broad lanceolate to narrow linear, 3 to 8 in. long. Spike of flowers 1 to $4 \mathrm{in}$. long with bracts at the base of and shorter than the flowers. The three upper segments concerge and orerlie carh other, to a greater or less extent, forming a sort of hood. Moist cold soil in all our area. July-Aug.

2. S. plantaginea, liaf. Wunk-leaven Lany's Trassis. (S. lucida, Ames.) Stem 4 to 9 or more in. high, smooth and naked exeept at lower part. Leaves oblong or lanee-shaped 1 to $5 \mathrm{in}$. long, 1 to $3 \mathrm{in}$. wide, all close to the hase and all distinctly 3-nerved. Spike 1 to 3 in. long, narrow. The outer flower segments do not unite with the upper inner segments and are narrow lance-shaped. The upper segment of the outer row somewhat united with the two upper petals. Face of lip pale yellow. Moist soil, common. June-Aug. 


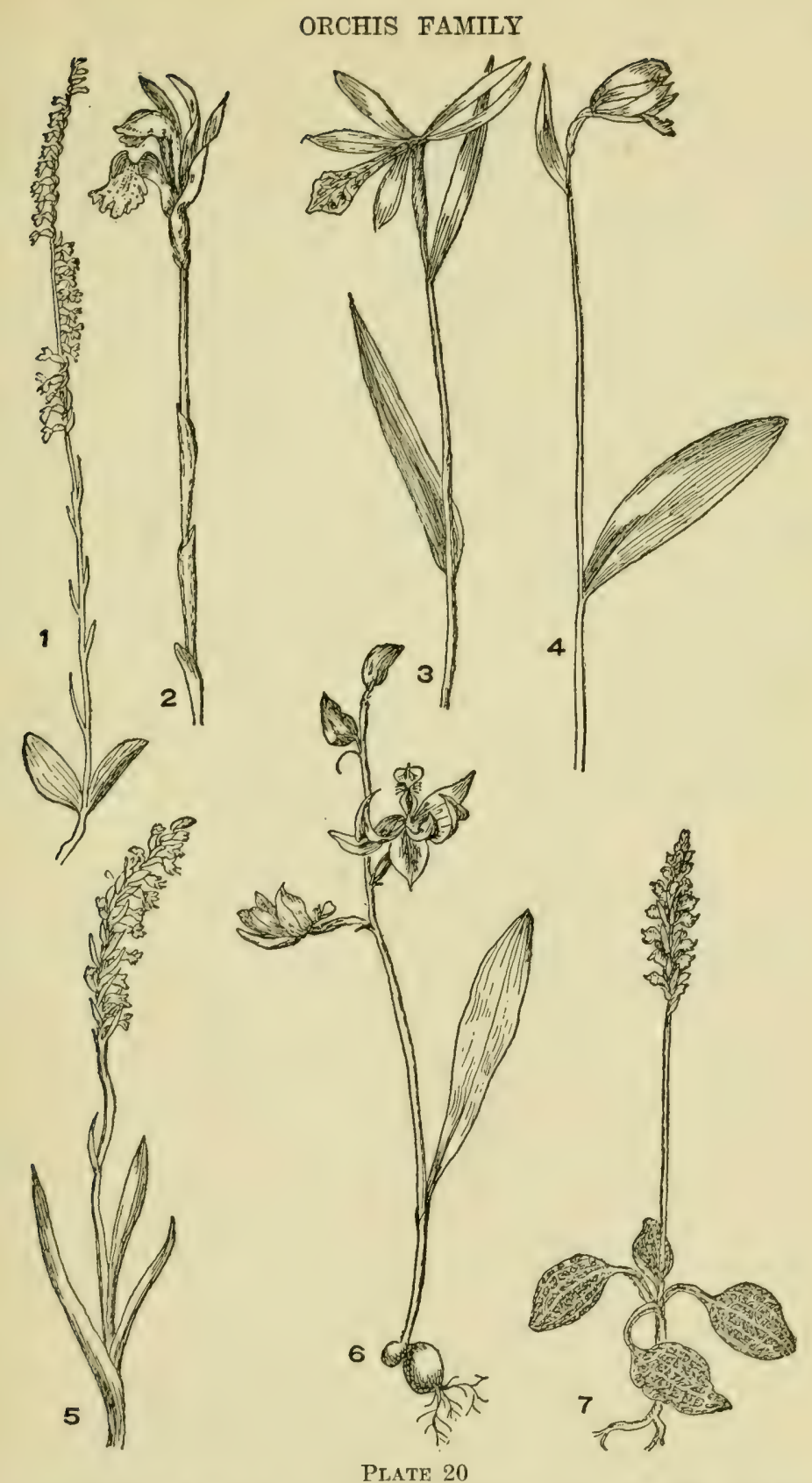

1. Spirantlies gracilis. 2. Arethusa bulbosa. 3. Pogonia divaricata. 4. P. ophioglossoides. 5. Spiranthes cernua. 6. ('alopogon pulchellus. 7. Epipactis pubescens. 
3. S. cernua, (L.) Richard. (Fig. 5, pl. 20.) Nodprivg Ladr's Tresses. Stem leafy at base, bracted above, 6 to $20 \mathrm{in}$. high. Leaves 3 to $14 \mathrm{in.} \mathrm{long,} \mathrm{narrow} \mathrm{lance-shaped,} \mathrm{not} \mathrm{distinctly} \mathrm{3-nerved.} \mathrm{Spike} \mathrm{of}$ flowers 2 to $10 \mathrm{in.}$ long. Flowers sometimes hairy, nodding. Lateral sepals not turned up or connected with the upper petals. Moist soil, common. June-Aug.

4. S. praecox, (Walt.) Wats. and Coulter. Grass-Leaved Ladr's Tresses. Stem 10 to $30 \mathrm{in}$. high, hairy above. Leaves long, grass-like growing from the base and upward. Flowers in a linear spike, somewhat densely crowded. Lip smooth beneath. Moist soil, New Jersey and southward. June-Aug.

5. S. vernalis, Engelm. and Gray. Early Lady's Tresses. Similar to No. 4 but lip downy beneath. Mass., southward.

6. S. gracilis, (Bigel.) Beck. (Fig. 1, pl. 20.) Slender Ladr's Tresses. Stem extremely slender, 5 to $25 \mathrm{in.} \mathrm{high.} \mathrm{Leaves,} \mathrm{oblong} \mathrm{or}$ ovate, the outer and broadest, all in a cluster on the ground, mostly disappearing at flowering time. A few very narrow, acute bracts on the stem. Spike of flowers, about 1 to 3 in. long, slender, the flowers run nearly in a straight row a part of the length of the spike, then twist to another side of the stem, running again in a nearly straight line, then again shifting. Woods and shady places. Common. July-Sept.

7. S. simplex, A. Gray. Little Lady's Tresses. A smaller species, stem 5 to $9 \mathrm{in}$. high. Leaves all at the base, ovate or oblong, disappearing at flowering time; very delicate bracts $(2-3)$ along the stem. Flowers small and nearly in a straight row on one side of the very delicate stem. Dry soil, Mass., southward. Aug.-Sept.

\section{LISTERA, R. Br.}

Small herhs growing in wet places; a pair of opposite leaves near the midlle of the stem. Sepals and petals spreading or turned backward. Lip 2-lolbed, dronping and longer than the other segnents. Flowers small in a slender spike, greenish or purplish.

Leaves oval, base of lip with a triangular tooth at each side at the base

o ${ }^{\circ}$. convallarioide's Leaves heart-shaped at base. Lip twice as long as the petals, linear, not

toothed at base . . . Leaves oval. Lip not lincar but about $1 / 3$ as broad as long, with basal car-

like lubes... . . L. auriculate Leaves kidney-formed; lip broadly 2-lobed at apex $\because \because$. L. Smallii Leaves oval: lip 4 to 8 times as long as petals, split . . . L. australis

1. L. convallarioides, (Sw.) Torr. Imo.u-t.mped Twaymanf. Stem 4 to $10 \mathrm{in.} \mathrm{high,} \mathrm{with} \mathrm{delicate} \mathrm{hairs} \mathrm{on} \mathrm{the} \mathrm{upper} \mathrm{half.} \mathrm{Leaves} \mathrm{oval} \mathrm{or}$ nearly round. Lip twice as long as the petals, broad gencrally, with a tooth at each sills of the base, and at the apex \& lobes separated by a broad notch. Flowers white. Damp woods. June-Aug.

2. L. cordata, (L。) R. Br. (Hig. 1, pl. 21.) IJEart-Leaved TwaYmLADE. Plant murh resmbling No. 1, but leaves heart-shaped at base, and flowers purplish or purple-brown. June-Aug.

3. L. australis, Limll. (Fig. 2., pl. 21.) Solther. Twayrande. Size and general aspect of No. 1. Leaves ovate; lip 3 times as long as the pertals and dephly refl. Flowers white. Swamps. New York, New Jer. sey and southward. June-Aug. 
4. L. Smallii, Weigand. Small's Twayblade. Stem slender, 6 to 8 in. high; leaves at or below the middle of the stem, egg-shaped to kidneyformed, abruptly pointed. The elongated cluster of flowers loose. Sepals and petals lance-shaped, longer than the ovary. Lip large, $\frac{1}{2}$ in. long, wedge-shaped, 2-lobed at the apex and with prominent lateral teeth at the base. Damp woods, mountains of Penna. and southward. June-Aug.

5. L. auriculata, Weigand. Acricled Twayblade. Slender, 4 to 7 in. high. Leaves large $1 \frac{1}{2}$ to 2 in. long, oval or elliptic egg-shaped, borne above the middle of the stem. Cluster many flowered. Lip 2-cleft, $\frac{1}{4}$ to $1 / 3$ as broad as long, slightly hairy. Cedar swamps, New Hampshire and Maine. July.

\section{EPIPACTIS, (Haller) Boehm. (Peramium, Salisb., Goodyera,} R. Br.)

Low herbs with leaves clustered at base of stem and with pointed bracts on the stem. Flowers in narrow spike. Upper sepal and two petals united in sort of hood. Lateral sepals free.

Flowers on one side of the spike . . . . . . . . . . . E. repens

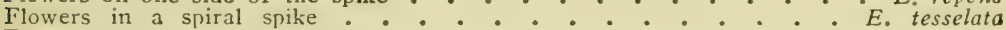
Flowers all around the stem.

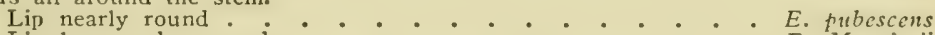
Lip long and grooved . . . . . . . . . . E. Menziesii

1. E. repens, (L.) Crantz. Lesser Rattlesnake Plantain. Stem 6 to 12 in. high. Leaves in a cluster at base, ovate, the upper surface beautifully marked with white reticulations, on dark back ground, reticulations do not follow the main nerves which are nearly parallel. Flowers small, greenish-white. June-July.

Var. $P$. repens ophioides, Fernald, the leaf blotehes are whiter than in $E$. repens. This form represents the species in our area. Woods.

2. E. pubescens, (Willd.) Eaton. (Fig. 7, pl. 20.) Downy RatTleSidare Plantain. Stem 6 to 20 in. high, densely covered with delicate hairs. Leaves oval with leaf-stalks which are nearly or quite wanting in No. 1. Reticulations similar to No. 1. The lip which is nearly round is strongly saccate. Dry woods. Common. July-Aug.

3. E. Menziesii, (Lindl.) Morong. Menzies Rattlessake PlanTAIN. (E. decipiens, (Hook.) Ames.) Stem 9 to 12 in. high. Leaves much like No. 2. Lip long, trough-like, narrowed toward the outer extremity but spreading at the apex. Dry woods, northern part of our area.

4. E. tesselata, (Lodd.) Eaton. Crieckered Rattlesnake PlanTAIN. Leaves dark green with pale blotches or no blotches. Spike of flowers $2 \frac{1}{2}$ to 3 in. long, spiral. Flowers greenish-white; lip forming a sac. Woods, Mass. and northward. July-Aug.

\section{Io. MICROSTYLIS, (Nutt.) Eaton. (Achroanthes, Raf.)}

Low herbs arising from solid bulbs with somewhat the general aspect of Listera but with a single broad elliptic leaf below the middle of the stem. Flowers white or greenish-white in a narrow spike. Lip broad, about as long as the petals. 
1. M. monophyllos, (T.) Lindl. (Fig. 4, pl. 21.) TWirte AdDER's Moutu. Stem slender, 4 to 6 in. high. The single leaf sheathing the stem. The very slender spike of small white flowers about the length of the stem. The flower stalk shorter than the flower, each with a small bract. Lip heart-shaped with the apex contracted to a narrow point. In woods and wet places, throughout our area. July.

2. M. unifolia, (Michx.) BSP. (Fig. 7, pl. 21.) Green AdDER's Movtr. Stem 6 to $10 \mathrm{in.} \mathrm{high,} \mathrm{it} \mathrm{and} \mathrm{the} \mathrm{leaves} \mathrm{much} \mathrm{like} \mathrm{No.} \mathrm{1.} \mathrm{Spike}$ of flowers short, not $1 / 3$ the length of the stem and much broader than that of No. 1. The flower pedicel longer than the flower. Lip broad, almost fan-sliaped, 3-lobed at apex. Cold wet ground, not frequent. July.

\section{LIPARIS, Rich. (Leptorchis, Thouars)}

Low herbs arising from solid bulbs with naked stem and two broad leaves at base. Flowers in rather broad spikes. Sepals and petals narrow and nearly equal; lip broad, often with 2 tubercles near the base.

1. L. liliifolia, (L.) Richard. (Fig. 8, pl. 21.) Large Twarblade. Stem 4 to $10 \mathrm{in.} \mathrm{high;} \mathrm{leaves} \mathrm{broad} \mathrm{elliptic} \mathrm{or} \mathrm{oval.} \mathrm{Spike} \mathrm{of} 5$ to 15 showy flowers, the linear petals and sepals white or greenish-white, the lip purple-brown. Flower stalk nearly an inch long. Lip broad oval, as long as the petals. Woods and thickets. May-July.

2. L. Loeselii, (L.) Richard. (Fig. 9, pl. 21.) Fen Oncris. Stem 2 to 8 in. high; leaves oval. Spike few flowered (3-6). Petals and sepals linear, unequal; lip wedge-shaped, often in 3 lobes at apex, the midlle lobe longest. Sepals and petals greenish-white, lip yellowish. green. Wet places. June.

\section{CALYPSO, Salisb.}

A small herb arising from a solid bulb, with stem 3 to 6 in. high and with a single leaf at the base of the stem and a single flower at its summit. Stem with 2 or more sheathing bracts. The sepals and petals nearly equal, the lip large and inflated.

C. bulbosa, (L.) Oakes. (Fig: 3, pl. 21.) Calypso. Flower showy; leaf nearly round but somewhat pointed at apex. Flower purple, pink and yellow; somewhat resembling the flower of Cypripedium. Rare in our region, but found occasionally in woods. May-June.

\section{CORALLORRHIZA, R. Br.}

Plants mostly without green coloring. Stem and seales brown or purplish. Flowers in loose terminal spike. Lip 1 to 3 ridged, projecting hackward as a spur which grows fast to the ovary or which is entirely suppresied. l'etals and sepals nearly equal. Roots of coralloid branching masseg.

Small spur or little sac or depression of lip at summit of ovary.

Lip egg-shaped with 2 conspicuous lateral teeth near the base $C$. trifida

Lin inversely egg-shaped, wavy or with minute teeth at the borders.

Iin brosdly egeshaped, white with crimson spots: ${ }^{C}$. C. Wontorhiza

Lip in general outline egg-shaped, with a conspicuous rounded lobe

at each side near the base........... C. maculata

No spur or sac to the lip.

Lip egg-shaped, with wavy border . . . . . . C striata 

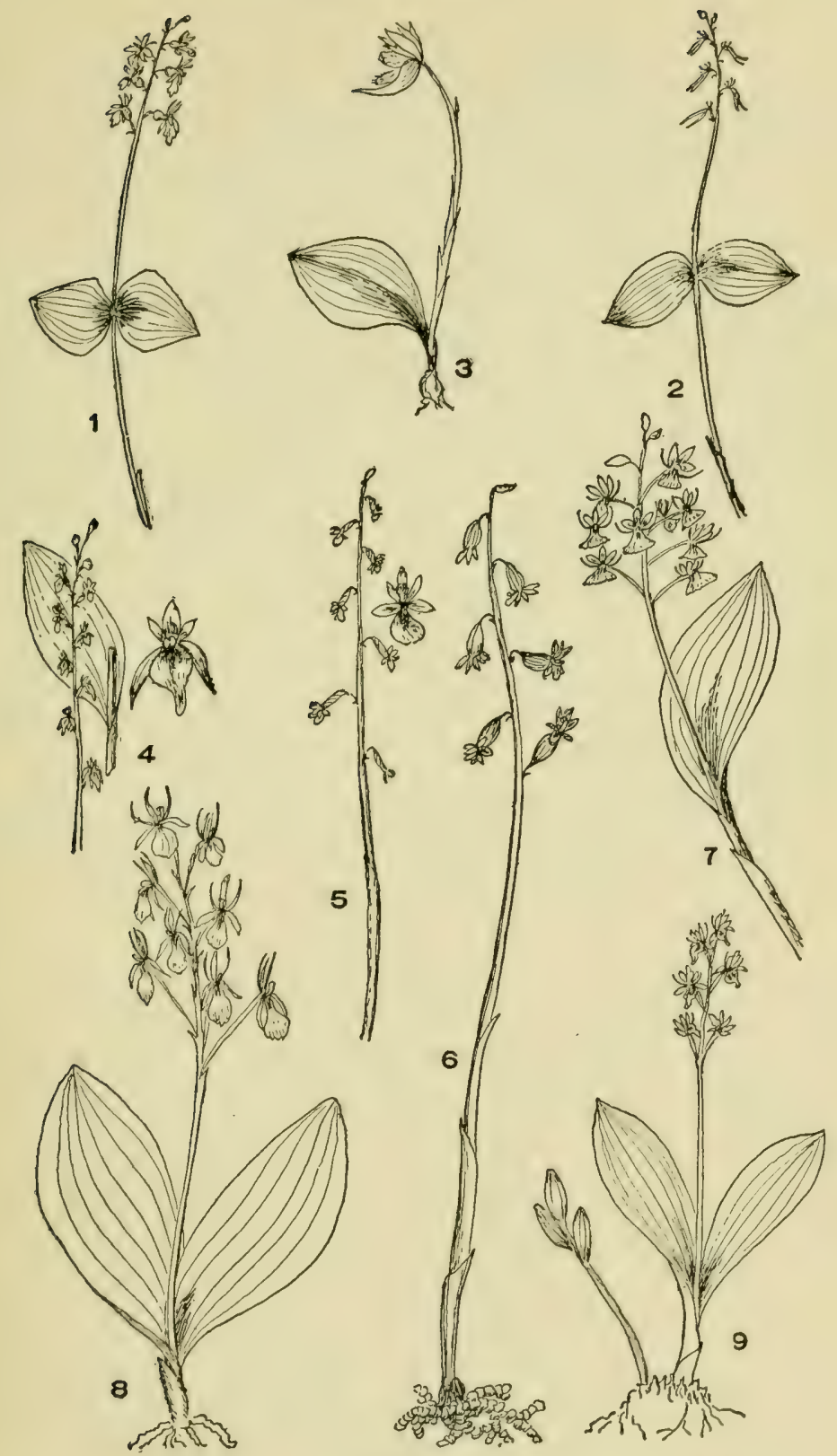

Plate 21

1. Listera cordata. 2. L. australis. 3. Calypso bulbosa. 4. Microstylis monophyllos. 5. Corallorrhiza odontorhiza. 6. C. trifida. 7. Microstylis unifolia, 8. Liparis lilifolia. 9. L. Loeselii. 
1. C. trifida, Chatelain. (Fig. 6, pl. 2l.) Early Coral Root. Stem brown, \pm to $12 \mathrm{in.} \mathrm{high.} \mathrm{Flower} \mathrm{scape} 1$ to $3 \mathrm{in.}$ with few $(5$ to 10) dull purple flowers which are drooping. Petals and sepals nearly equal; lip shorter than the petals, with a tooth on each side near the base and a double noteh at the apex, no spur except a small protuberance. Flower stalk very short or absent. Damp woods. Rare. June.

2. C. odontorhiza, (Willd.) Nutt. (Fig. 5, pl. 21.) SMALL-FLowERED CORAL-Root. Stem 9 to 14 in. high, purplish. Flower scape with 6 to 20 purplish drooping flowers, quite small, on flower stalks about $\frac{1}{4}$ as long as the flowers. Sepals and petals nearly equal, $\frac{1}{4} \mathrm{in}$. long, marked with purplish lines. Lip broadly oval, as long as the petals, wavy but not notched at the apex. Ovary oval, drooping. Spur absent or represented by a small sac connected with the ovary. Woods. July. September.

3. C. Wisteriana. Conrad. Wister's Coral-root. Stem 8 to 16 in. high, not as slender as No. 2. Flower spike with 6 to 18 drooping flowers, each about $\frac{3}{2} \mathrm{in}$. long with slender flower stalks $1 / 6$ as long as the flowers. Petals and sepals about equal. Lip longer than petals, broadly oval witl very slight indentation at apex and with purplish dots on the upper surface. Woods. Feby.-May.

4. C. maculata, Raf. LARGe CoRAL-Root, (C. multiflora, Butt.). Stem 8 to 20 in. high; flower spike 2 to 8 in. long with from 10 to 30 nearly erect brownish-purple flowers. Petals and sepals unequal. Lip much shorter than the lateral sepals, broad, almost quadri-lateral with 3 distinct lobes. Spur present but adherent to the ovary. Woods. JulySeptember.

5. C. striata, Lindl. Striped Coral-root. Stems 6 to 20 in. high; flower spike 2 to 6 in. long. Flowers larger than either of the preceding species, purple. Petals, sepals and lip about the same length. Spur none. Lip oval without lobes or notches, narrowed at the base.

\section{TIPULARIA, Nutt.}

Herb, arising from a large solid bulb, with a single broad leaf on a slender stalk which arises, in autumn, directly from the bulb. Leaf purplish beneath; the flower seape, arising also from the bulb, appears in the following summer, hearing a number of small greenish flowers. Sepals and petals nearly alike, but the latter narrow; lip slightly longer and with 3 lobes. Spur about 3 times as long as the flower and very slender.

T. discolor, (Pursh.) Nutt. Crane-Fry Orcuss. (T. Mnifolia, (Muhl.) ISSP. Flower stem 15 in 20 in. high. Flower spike 5 to 10 in. long. Flowers green, tinged with purple. In woods. July-Augr.

\section{CALOPOGON, R. Br. (Limodorum, L.)}

ITrb arising from a bulb with a long errass-like leaf and a maked flower scape on which are from 3 to 15 showy flowers. The ovary (which is in these orchidaceous plants the flower stalk). does not trist and the lip is therefore on the upper or inner side of the flower. It is conspicuously bearded on its upper side. 
C. pulchellus, (Sw.) R. Br. (Fig. 6, pl. 20.) Grass Pink. CaloPOGON. (Limodorum tuberosum, (?)). Flower scape 12 to $20 \mathrm{in.} \mathrm{high,}$ leaf 8 to $12 \mathrm{in.}$ long, $\frac{1}{4}$ to $\frac{3}{4} \mathrm{in}$. wide. Flowers exquisite pink-purple, $1 \mathrm{in.}$ broad, a small bract below each flower. Petals and sepals nearly alike, lip broad at apex, 2-lobed. The column (combined anther and stigma) is about as long as the lip. Face of the lip light with yellow or rose-colored hairs. In mossy bogs throughout our area. June-July.

\section{I6. APLECTRUM, Nutt.}

Herb arising from a solid bulb-like corm, which is filled with a glutinous substance. In the autumn it sends up a large oval leaf and in the following spring or summer a scape which bears a number of dingy dull yellowish-brown flowers, sprinkled with purple, each about an inch broad.

A. spicatum, BSP. (Fig. 5, pl. 17.) Adam and Eve. Putty Root. (A. hyemale, (Muhl.) Torr.). Stem 12 in. or more high. Flowers in a loose spike. Petals longer than the lip which is somewhat 3-lobed. Rich mould in woods. May-June. 


\section{GROUPS AND ORDERS OF THE SUB-CLASS CHORIPETALS, OF THE CLASS DICOTY- LEDONS, DIVISION OF ANGIOSPERMS.}

\section{Class II.-DICOTYLEDONS}

Embryo with two lobes (see page 50). Leaves generally netreined. In a few cases, by abortion of a cotyledon, there is an apparent condition of monocotyledonism. In a number of instances also the leaves are constructed nearly on the parallelveined plan.

Dicotyledons are divided into two great sub-classes. In the flowers of the first sub-class the petals are separate as in the case of the buttercups, violets, pinks, etc., while in the flowers of the second sub-class the petals are so united that, in general, they appear as a single envelope as in the case of the hare bells, the mints, the huckleberry tribe and others.

Curiously, a large group in which no petals are to be seen, belongs to the first sub-class, since it is assumed that although the petals are little or not at all apparent they are technically present but suppressed.

The first sub-class, Choripetalae, ${ }^{*}$ then, is composed of two groul's, in a certain sense artificial, but convenient for our purpose:

Plants whose flowers have no apparent petals and, generally, only very rudimentary envelopes. 1st Group.

Plants whose flowers have, generally, several petals or colored sepals which are distinctly petaloid. $2 \mathrm{~d}$ Group

POLYPETALAE

In the second sul-erlass Ganopetafas, the petals are united, but in a $f^{\prime} w$ exceptional (ases nearly or quite separated.

- Gr. Clioris, asunder: petalon, a petal. 


\section{ORDERS OF THE GROUP APETALAE}

1. Flowers in catkins or in various groups resembling catkins.

Flowers without corolla and usually without calyx

- Order I. JULIFLORES

Herb with nodding spike resembling a catkin

Sub-Order Piperales

Flowers in true aments or catkins, calyx none

- Sub-Order Amentaceae

Flowers in catkins, a calyx usually present

- Sub-Order Fagales

Flowers in groups of various forms, each flower bearing stamens alone or pistils alone, leaves without stipules . . . . Sub-Order Urticales

2. Flowers not in catkins, calyx present, plants all parasites . . . . . . . ORder II. SANTALALES

3. Flowers not in catkins, calyx present, ovules arranged around a central column of the single celled ovary. (Only a small part of this Order is apetalous.)

\section{Order III. CENTROSPERMAE}

(For the continuation of the Synopsis of the Orders of Churipetalae see the beginning of the Group Polypetalae.)

While the apetalous Orders and Sub-Orders are usually regarded as an artificial group, it is doubtless true that they differ materially from the typical Choripetalae and that the herbs and trees belonging to this group are more primitive in respect to the flower than those belonging to groups with more specialized flowers. The flowers of this group are not only of very simple structure but in most cases the stamens are borne on one tree or plant while the pistils are borne on another. 


\section{Sub-Class I. CHORIPETALAE}

Plants With Free Petals or With no Apparent Petals

\section{Group I. APETALAE. Flowers without petals}

Flowers without a corolla, often with no floral envelope, or with a very simple one. The group includes all the plants of the Order Juliforae, the Order IIysterophytes and all but two Families in the Order Centrospermae. The special characters are shown in the descriptions of the Orders and Families.

\section{Order I.-JULIFLORALES. Catkin-Bearing Trees and Herbs}

Flowers individually quite inconspicuous, wanting the corolla and most frequently the calyx except in a rudimentary form. Flowers grouped in large numbers in catkin-like inflorescence or in fascicles. Stamens opposite to the divisions of the calyx, when a calyx is present.

The Order Juliflorales is divided into three Sub-Orders:

1st. Sub-Order, of which we have but a single species Piperales 2d. Sulb-Order, the true catkin bearers, all trees and shrubs . . . . . . . . . . Amentaceans 3d. Sub-Order, the nettle group, all herbs except Ulmus

\section{Sub-Order I.-PIPERales. Piperales}

Our only species an herb with long nodling spikes of flowers which bear both stamens and pistils, differing in this from catkins. The flowers have neither calyx nor corolla. Truit a berry.

Family I.-SAURURACEAE. Lizard Tail Famlit

The characters of the family are included in the description of those of the Genus Saururus. 
SAURURUS. L.

Flowers without a perianth or with a very rudimentary one. Stamens and pistils in the same flower; stamens 6 or 8 or less, long and white, giving to the spindle-shaped cluster of flowers the appearance of a fully developed spilse of pure white flowers. Pistil of 2 or more ovary cells at base.

S. cernuus, L. (Fig. 1, pl. 22.) Lizard's TAIL. Herb, 2 to 3 ft. high, branching. Leaves egg-shaped, heart-shaped at base, with 5 to 9 distinct, nearly parallel veins; 2 to 6 in. long, 2 to $3 \frac{1}{2}$ in. wide, tapering at apex to a slender point. Spike of white flowers dense, 5 or 6 in. long, on a common flower-stem considerably longer. Swamps and wet borders of ponds or streams, southern half of our area and in central and western New York. June-Aug.

\section{Sub-Order II.-AmentaceaE. Ament or Catikin Bearers *}

Stamens and pistils in different flower groups. Trees and shrubs. Inflorescence of staminate flowers always in catkins; pistillate flowers generally catkin-like. Flowers without a perianth or with a very rudimentary one. Leaves always well developed and always alternate.

Trees with compound leaves . . . . . Juglandaceae Trees with simple leaves.

Pistillate and staminate clusters on different trees Salicaceae Pistillate and staminate clusters on the same tree.

Ovary 1-celled, 1-ovuled and 1-seeded in fruit Myricaceae

\section{Family I.-SALICACEAE. Willow Family}

Flowers all in catkins. Catkins with pistillate flowers not on the same tree with those with staminate flowers. A single flower consists of a cluster of stamens or cluster of pistils in the axil of a bract which is entire, tooth-like, or slit into strips. No perianth except a paddlc-like projection in case of the willows and a somewhat cup-shaped disk at the base in poplars. Stamens, in willows 2 to 5 , in poplars numerous. Some willows have permanent stipules to the leaves, others and the poplars have stipules which fall before the leaf acquires its growth. Fruit a pod (usually several attached to the axis of the catkin) with numerous seeds each furnished with a silky down.

\footnotetext{
* A catkin or ament consists of a group of apetalous flowers, each flower springing from the axil of a scale and all arranged spirally on an undividing stem or axis. The flowers of an individual group or catkin consist, generally, exclusively either of staminate or of pistillate flowers. The axis or stem of the catkin is not, for the staminate group, a complete continuation of the branch from which it grows, but is attached in the manner of a leaf and falls when its purpose is served. The staminate catkins are usually flexible, drooping dangles, while the pistillate aments are frequently erect.
} 


\section{SALIX, (Tourn.) L.}

Trees or shrubs, mostly along streams. Long slender flexible branches with, in most species, long narrow sharp pointed leaves, sharply toothed, or nearly entire. The aments-" pussys" - appear in early spring before the leaves.

1. Catkins on short leafy branches; leaves all lance-shaped

Stamens more than 2 in each axil

Trees from $\mathbf{I} 5$ to 50 or more ft. high.

Leaves very finely and closely notched around the entire border.

Leaves linear lance-shaped

Leaves narrow lance-shaped

Leaves broad lance-shaped

Leaves ovate-lance-shaped

Leaves elliptic lance-shaped

Stamens 2 only in each axil

Tall tree with reddish-green twigs .......... S. fragilis

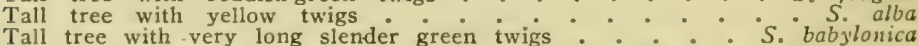

Leaves with distinct teeth ( $1 / 20$ to $1 / 10$ in. apart). Branching shrub, 2 to 10 $\mathrm{ft}$, high.

Leaves narrow lance-shaped . . . . . . . . . S. longifolia

Leaves broad lance-shaped or oblong . . . S. glaucophylla 2. Catkins lateral on the branches or at the terminals

Stamens 2 in each axil

Small trees or shrubs 6 to 18 it. high.

Leaves narrow lance-shaped, broadest near the apex . . . . S. purpurea

Leaves elliptic or lance-ovate.

Hairy above . . . . . . . . . . S. Bebbiana

Smooth green above, nearly white beneath, teeth minute or none $S$. discolor

Leaves oblong, firm, borders distinctly toothed, young branches densely hairy.

Bracts not as long as the individual flower pedicels.?. S, eriocephala

Leaves as above, young branches not hairy, bracts as above. . S. prinoides

Bracts longer than the flower pedicels...$\div$ S. squamata

Leaves rather broad lance-shaped . . . . . . . . . . S. sericea Shrubs 2 to 10 $\mathrm{ft}$. high.

Leaves lance-shaped, scarcely notched.

Twigs not very hairy.

Leaves grayish, hairy beneath . . . . . . . S. humilis

Leaves silvery with silky hairs beneath $\because \because \because$ S. viminalis

Twigs very hairy, leaves oval $: \cdot$ S. adenophylla $^{\circ}$ Leaves narrow egg-shaped . . . . . . $S_{\text {. coactilis }}$

Leaves heart-shaped at base

I.eaves elliptic or broad lance-shaped, tapering at hase . . . So phylicifolia

Leaves ovate or oval, rounded at base . . . . S balsamifcra Shrub 2 to $5 \mathrm{ft}$. high.

Leaves narrow lance-shaped or elliptic, white beneath . . . . S. candida Shrubs 6 in. to $2 \mathrm{ft}$. high.

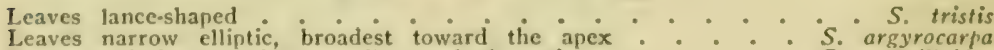

Leaves elliptic, tapering equally at both ends...... S, myrtilloides Shrubs less than I ft. high.

Leaves pear-shaped, broadest toward apex ......... S. Uvu-ursi Leaves orbicular : . . . . . . . . . S herbacea

]. S. nigra, Marsh. (Fig. 1, pl. 23.) Brack Wrrow. Usually a small tree, 15 to $30 \mathrm{ft}$. high, but rarely reaching a much greater height. Jeaves narrow lanee-shaped, tapering sharply at both ends. Branches pale yellow; leaves deep green above, somewhat lighter below; leaf- 


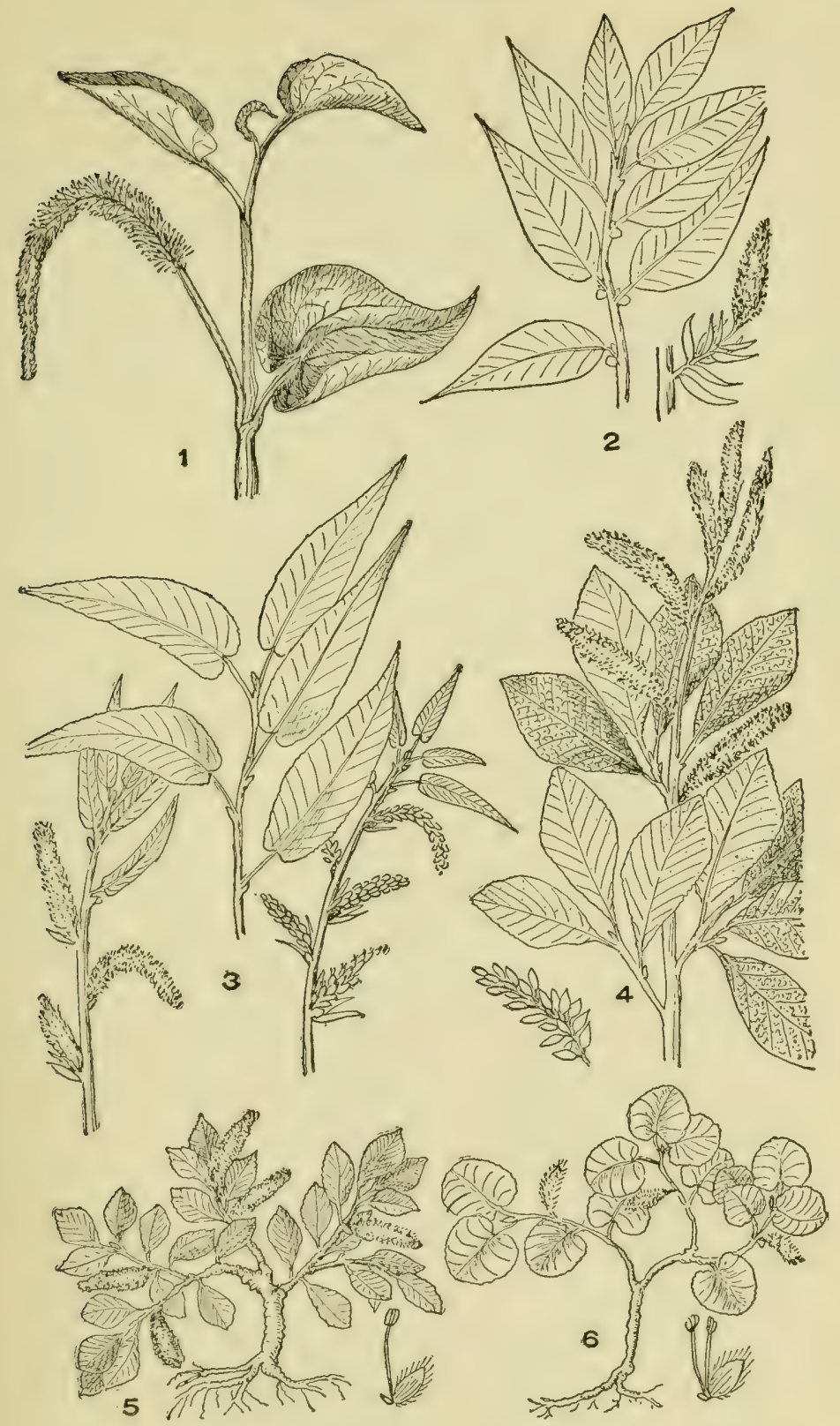

Plate 22

1. Saururus cernums. 2. Salix lucida. 3. S. cordata. 4. S. Bebbiana. 5. S. Uva-ursi 6. 6. herbacea. 
stalk rather short; stipules small and falling early; capsule ovoid, rather longer than its pedicel. Stamens 3 to 7 . Along the banks of streams and lakes. Common.

2. S. amygdaloides, Anders. (Fig. 1, pl. 23a.) Peach-Lenved WiLLow. Tree, usually small but sometimes attaining a height of $70 \mathrm{ft}$. Leaves broad lance-shaped, tapering to a long delicate point at apex and to a more blunt point at base, pale beneath, dark green above, on a long leaf-stalk. Stipules very small and falling early. Capsule egg-shaped. Central and western New York, on banks of lakes and streams.

3. S. lucida, Muhl. (Fig. 2, pl. 22.) Sinning Willow. Shrub, 5 to $15 \mathrm{ft}$. high, rarely higher, with green or yellowish-brown, shining twigs. Leaves smooth and glossy on both sides, egg-shaped to lance-shaped; stipules small, oblong. Basal third of leaf an in. wide, tapering to a long slender point at apex, while at the base the taper is more abrupt. Stamens about 5. Along banks of streams. Common.

4. S. serissima, (Bailey). Fernald. (Fig. 2, pl. 23a.) Late FruitING Willow. Shrub, $13 \mathrm{ft}$., or less, high, with smooth shining brown twigs. Leaves elliptic-lance-shaped or lance-shaped, $\frac{1}{2}$ to $4 \mathrm{in}$. long, $\frac{7}{2}$ to $1 \frac{1}{2} \mathrm{in}$. wide, finely toothed, tapering to a slender point. Leaf-stalks $\frac{1}{2} \mathrm{in}$. long, or less. Catkins borne at ends of short, leafy branches, the catkin stem and scales densely white silky. Staminate catkins nearly an in. long, loosely flowered. Bogs and wet meadows, Mass., New Jersey and New York. May-June.

5. S. Wheeleri, (Bowlee.) Rydb. Wileeler's Willow. A low shrub with silky twigs and linear lanee-shaped leaves $3 \mathrm{in}$. long or more, $\frac{1}{4} \mathrm{in}$. wide, densely white silky on both sides. Catkins borne at ends of short leafy branches. Sandy beaches, New York and northward. June-July.

Stamens 2 only, catkins on short branches (Figs. 1 and 2, pl. 23)

6. S. fragilis, L. (Fig. 3, pl. 23a.) Crack Willow. Brittle WilLow. Tree, 60 to $80 \mathrm{ft}$. high; twigs reddish green. Leaves lance-shaped, broad at basal third, green and shining, tapering to a long slender point at apex. Serrations fine. Capsule conic on a short pedicel. Escaped from cultivation, mostly in the southern section of our region.

7. S. alba, L. (Fig. 2, pl. 23.) White Willow. Large tree with yellow twigs and very narrow lance-shaped, fincly toothed leaves which taper to a slender point at both ends, green above or ashy gray, paler or silky white beneath. Stipules, when present, ovate lance-shaped. Capsule somewhat conic without a pedicel. Branches not drooping. Moist soil, frequent along borders of streams, common.

8. S. babylonica, I. Wefering Willow. A very large tree with lomg dronping and flexible green twigs. An ornamental tree well known and of well marked characteristics.

\section{Stamens 2 in cach axil; borders of leaves remotely notched}

9. S. longifolia, Muhl. (Fig. 3, pl. 23.) Rmer-BaNk Willow. (S. flurintilis, Nutt.). Shrul), 2 to $10 \mathrm{ft}$. high, trunks growing in clumps. Leaves wery narrow, 21 to $4 \mathrm{in}$. long, with remote tecth. Leaf-stalks very short. River banks, common.

10. S. glaucophylla, Bebl. (Fig. 4, pl. 23a.) Brodp-LEaved WiL- 

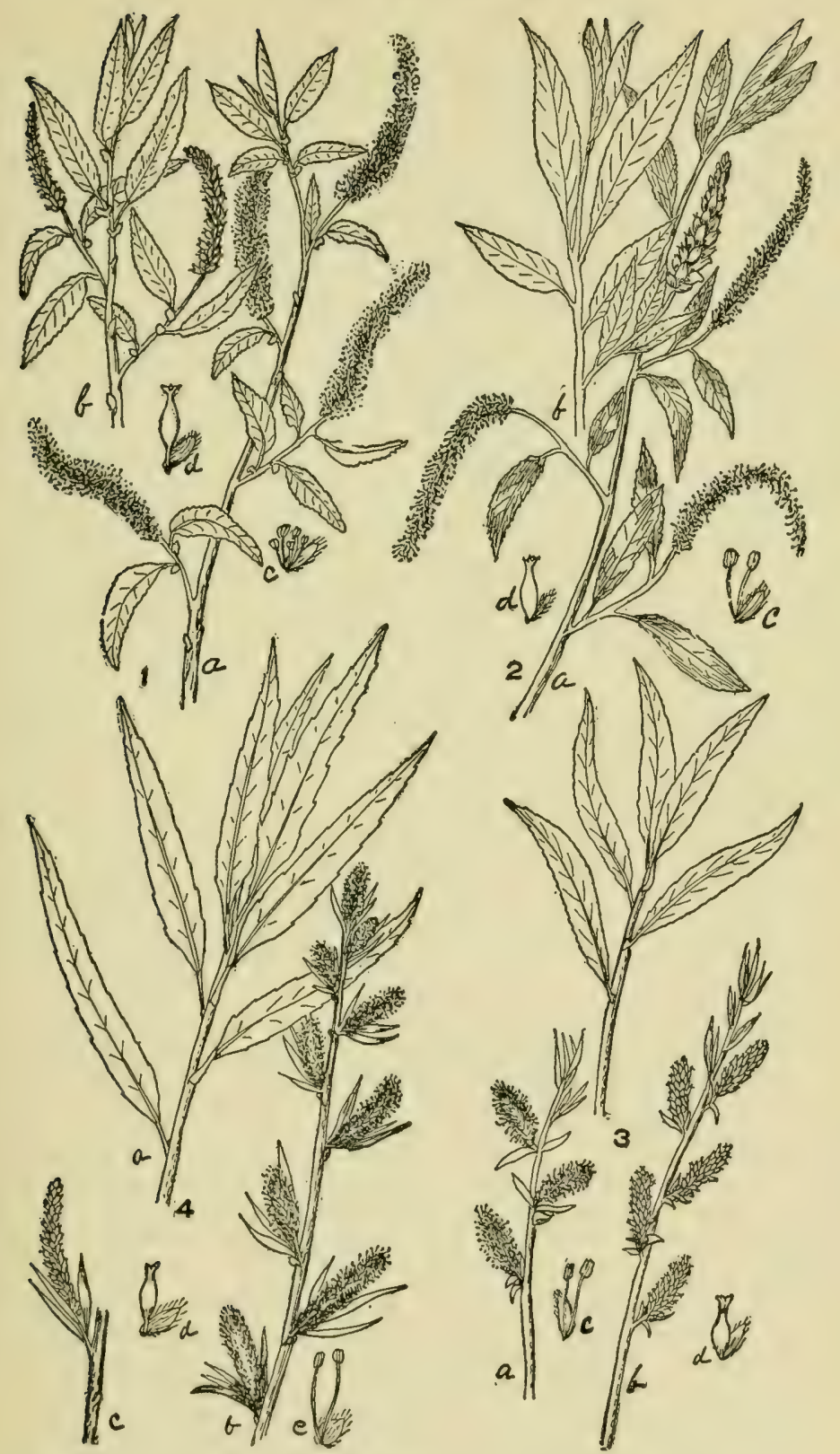

Plate 23
1. Salix nigra. 2, S. alba. 3. S. longifolia, 4. S. sericea. 
Low. Shrub about as high as the last. Leaves dark green, shining above, whitish below, broad lance-shaped, $2 \frac{1}{2}$ in. long, toothed; stipules ear-shaped, rather large, persistent. Catkins leafy at base. Dry soil, Maine and northward.

11. S. purpurea, L. (Fig. 5, pl. 23a.) PURPLE Willow. A small tree, eseaped from cultivation and seen only rarely as a naturalized species. Twigs flexible, long, purple. Leaves lance-shaped but broadest toward the apex. The stamens may be 2 in each axil or their different filaments may be so united as to form a single stamen. The capsules in the pistillate flowers are sessile, $i$. $e$., they have no pedicel or an extremely short one.

12. S. Bebbiana, Sarg. (Fig. 4, pl. 22.) BebB's Willow. (S. rostrata, Richards.) Small tree or shrub, 8 to $15 \mathrm{ft}$. Twigs covered with soft down. Leaves egg-shaped, or generally broadest toward the apex (pear-shaped), 2 to 3 in. long, dull green above, blue or white below; borders scarcely notched but uneven, upper surface rather deeply and irregularly reticulated between the principal veins. Pistillate ilowers, the pedicel of the capsule as long as the capsule itself. Moist or dry soil, common.

13. S. discolor, Muhl. (Fig. 6, pl. 23a.) Graucus Willow. Pussy Willow. Generally a shrub, but sometimes a small tree. Twigs dark reddish purple with silky hairs. Leaves broad lance-shaped or oblong, often broadest toward the apex, 3 to 5 in. long; notches remote; bright green above, smooth and nearly white beneath. Catkins appear much earlier than the leaves. The pedicel of the capsule of pistillate flower about $\frac{1}{4}$ to $\frac{1}{3}$ as long as the capsule and style together. Capsule downy. Borders of streams, common.

14. S. eriocephala, Michx. Pussy Willow. Leaves firm, oblong, the borders distinctly toothed; young branches densely hairy. Catkins short and dense. Wet places, New England to Penna. and westward.

15. S. prinoides, Pursh. Chestnut OAK IVILlow. Resembles the last but young branches are not hairy and catkins are long and loose. New York to Virginia.

16. S. squamata, Rydb. Loxa-Bracted Willow. Resembles S. criocephala but young branches are less hairy, bracts at base of individual flowers are longer than the flower pedicel. New Jersey and Pennsylvania.

17. S. sericea, Marsh. (Fig. 4, pl. 23.) Silky Willow. Shrub, rarely $10 \mathrm{ft}$. high, but sometimes about $12 \mathrm{ft}$. Twigs slender, with fine silky hairs. Leaves 2 to $4 \mathrm{in}$. long, narrow lanee-shaped, tapering at both ends but somewhat broader toward the base than toward the apex. Notches fine and even. Pedicel of eapsule less than $\frac{1}{4}$ as long as eapsule and style. Capsule downy. Wet places, borders of streams.

18. S. humilis, Marsh. (Fig. 7, pl. 23a.) Pr.ırme Willow. Shrub 3 to $8 \mathrm{ft}$. high, with rather broad lance-shaped leaves, the lower even eggshaped, in general broadest toward the apex, 2 to 4 in. long; borders only slightly torthed, upper surface dull green, lower gray with hairs. Pedicel of capsule about $\frac{1}{2}$ as long as eapsule and style. Dry soil.

19. S. viminalis, I. (Fig. 8, pl. 23a.) Osier Writ.ow. Shrub, often cultivated in rows in low grounds for basket work. Introduced and only 


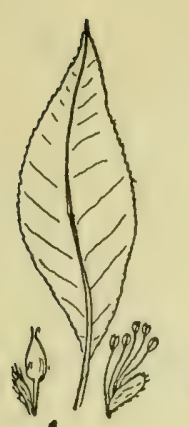

1
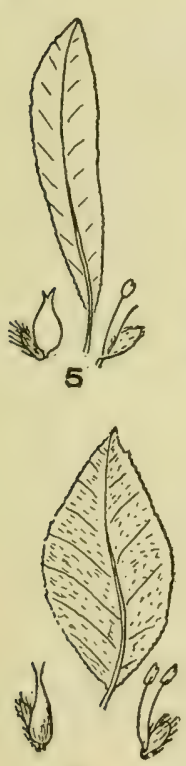

9

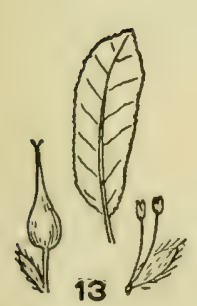

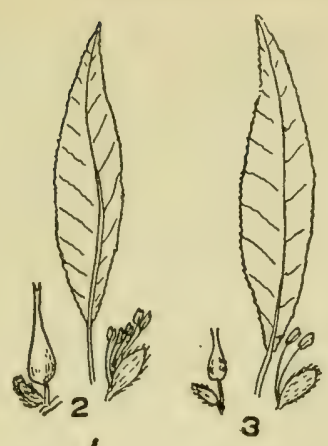
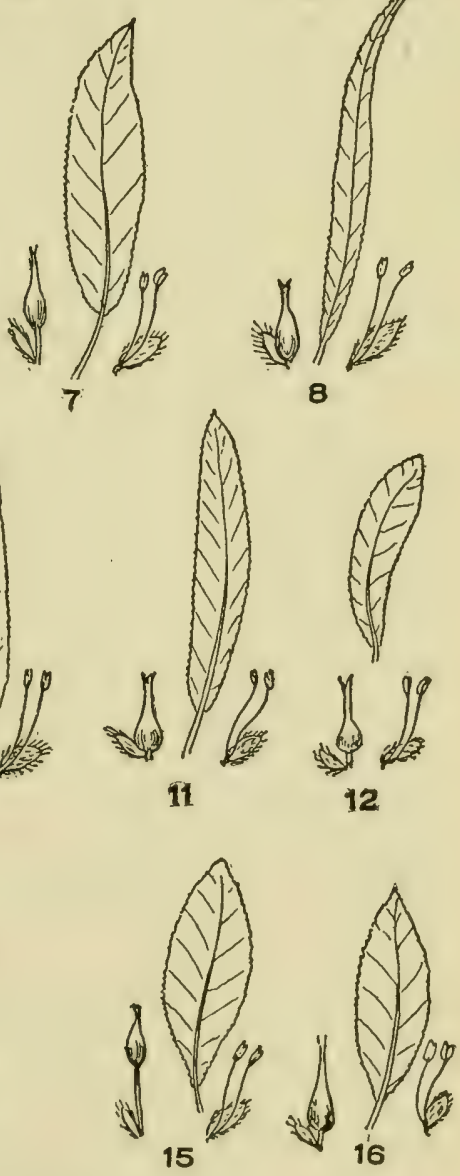

Plate 23a
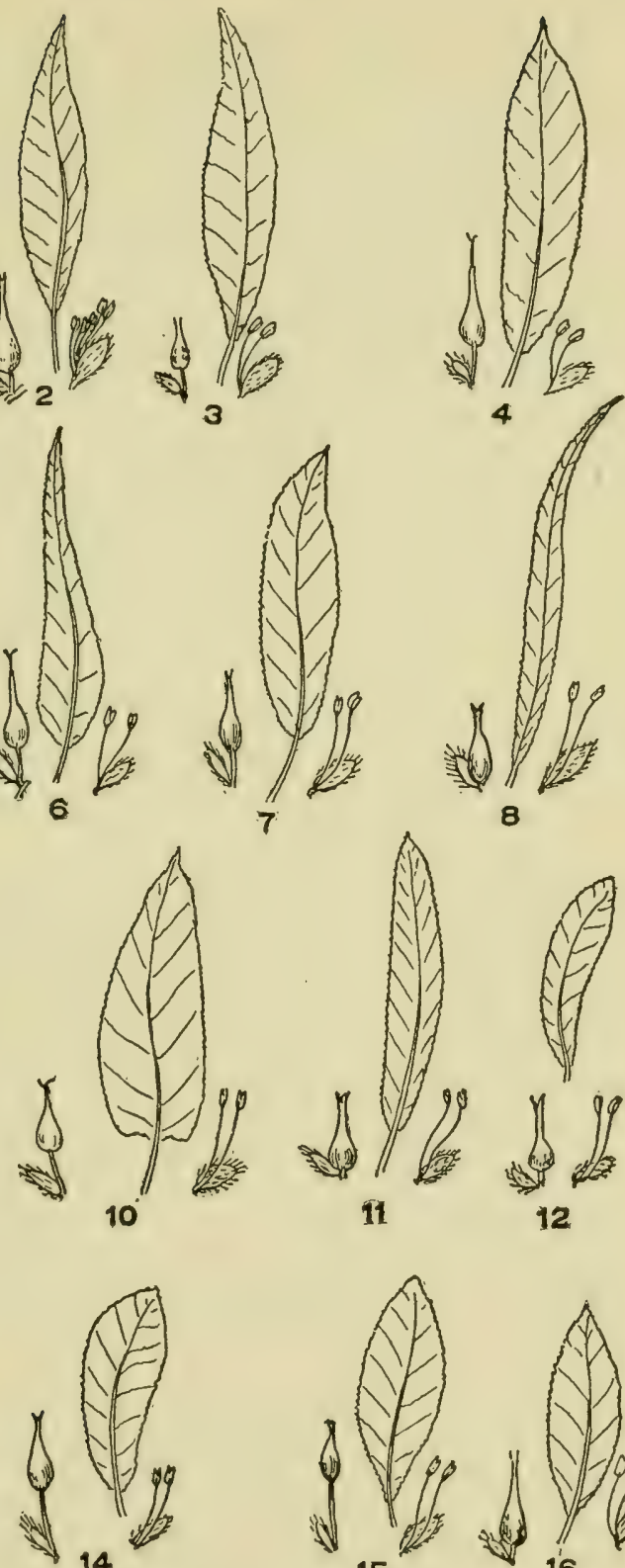

14

1. Salix amygdaloides. 2. S. serissima. 3. S. fragilis. 4. S. glaucophylla. 5. S. purpurea. 6. S. discolor. 7. S. humilis. 8. S. viminalis. 9. S. adenophylla. 10. S. balsamifera. 11. S. candida. 12. S. tristis. 13. S. myrtilloides. 14. S. argyrocarpa. 15. S. coactilis. 16. S. phyllicifolia. 
rarely escapel. Twigs very slender, green, flexible. Leaves linear lanceshaped, tapering about equally toward both ends; 3 to $6 \mathrm{in}$. long; borders scarcely toothed or notched, smooth, dark green above, silver white and silky beneath. Pedicel of capsule wanting or very short.

20. S. adenophylla, Hook. (Fig. 9, pl. 23a.) Furry Willow. Shrub 3 to $9 \mathrm{ft}$. high, with broadly lance-shaped or egg-shaped leaves. The twigs, leaves and stipules clothed, even when the leaves are fully grown, with a dense covering of long silky hairs. Leaves 1 to $2 \mathrm{in.} \mathrm{long,} \mathrm{sharply} \mathrm{pointed}$ at apex, rounded at base, with close and fine serrations at the borders. Stipules heart-shaped at base, conspicuous. Catkins long, densely flowered. Lake and river shores, throughout our region.

21. S. cordata, Muhl. (Fig. 3, pl. 22.) Heart-Leaved Willow. Shrub $5 \mathrm{ft}$. or more high, rarely 10 or $12 \mathrm{ft}$. high. Leaves broad lanceshaped, often heart-shaped at base, $1 \frac{1}{2}$ to $3 \mathrm{in}$. long, sparingly or not at all notched, both upper and lower surface nearly green. Pedicel of capsule less than $\frac{f}{4}$ the length of capsule and style. In wet soil, common.

22. S. phylicifolia, L. (Fig. 16, pl. 23a.) Tea-leaved Willow. Shrub, 1 to $10 \mathrm{ft}$. high; leaves broad lance-shaped or elliptic, tapering nearly alike at both ends; smooth both sides, the lower lighter in color than the upper, $1 \frac{1}{2}$ to 3 in. long. Pedicel of capsule very short. Moist ravines toward the summit of the White Mountains.

23. S. balsamifera, Barratt. (Fig. 10, pl. 23a.) BALsaM Willow. Shrub with egg-shaped leaves rounded or somewhat heart-shaped at base, 2 to 3 in. long. Pedicel of capsule about as long as capsule and style. Swamps in the northern section of our region.

24. S. candida, Fluegge. (Fig. 11, pl. 23a.) Hoary Willow. Small shrub, 2 to $5 \mathrm{ft}$. high. Young twigs white, hairy, later becoming red or purple. Leaves with smooth borders or sparingly toothed, narrow or elliptic-lance-shaped, persistently white and silky beneath, green and somewhat silky above, 2 to 4 in. long. Pedicel of eapsule very short. In swamps, most of our area.

25. S. tristis, Ait. (Fig. 12, pl. 23a.) SAGE Wrllow. Shrub 1 to 2 ft. high. Twiogs hairy. Leaves lance-shaped, broadest toward apex; borders smooth, white silky beneath, light green above, 1 to $2 \mathrm{in.} \mathrm{long.} \mathrm{Cat-}$ kins with few flowers. Pedicel of capsule about $\frac{7}{3}$ the length of eapsule and style. Dry soil, our area.

26. S. coactilis, Fernald. (Fig. 15, pl. 23a.) Large shrub with coarse branchlets, the younger downy. Leaves oblong or narrow engshaped, remotely toothed, with lustrous reddish-white down at first, later velvety. Stipules half-egg-shaped, persistent. Banks of Penobseot river, Maine.

27. S. argyrocarpa, Anders. (Fig. 14, pl. 23a.) Silver Willow. Difluse shrub, to to $2 \mathrm{ft}$. high. Twirg shining. Teitves 1 to $2 \mathrm{in.}$ long, oblong and widest toward the apex, white silky beneath, bright green above. Catkins fow flowerel. Pedicel as long as the silvery eapsule and the style. On the White Mountains.

29. S. myrtilloides, I. (Fig. 13, pl. 23a.) Ron Wrrtow. Shrub 1 to $3 \mathrm{ft}$. high. 'Twigs brown. Ieaves elliptic or erger-shaped, 1 to $2 \mathrm{in.} \mathrm{Iong,}$ tapering nearly equally toward each end. Apex ohtuse or somewhat 

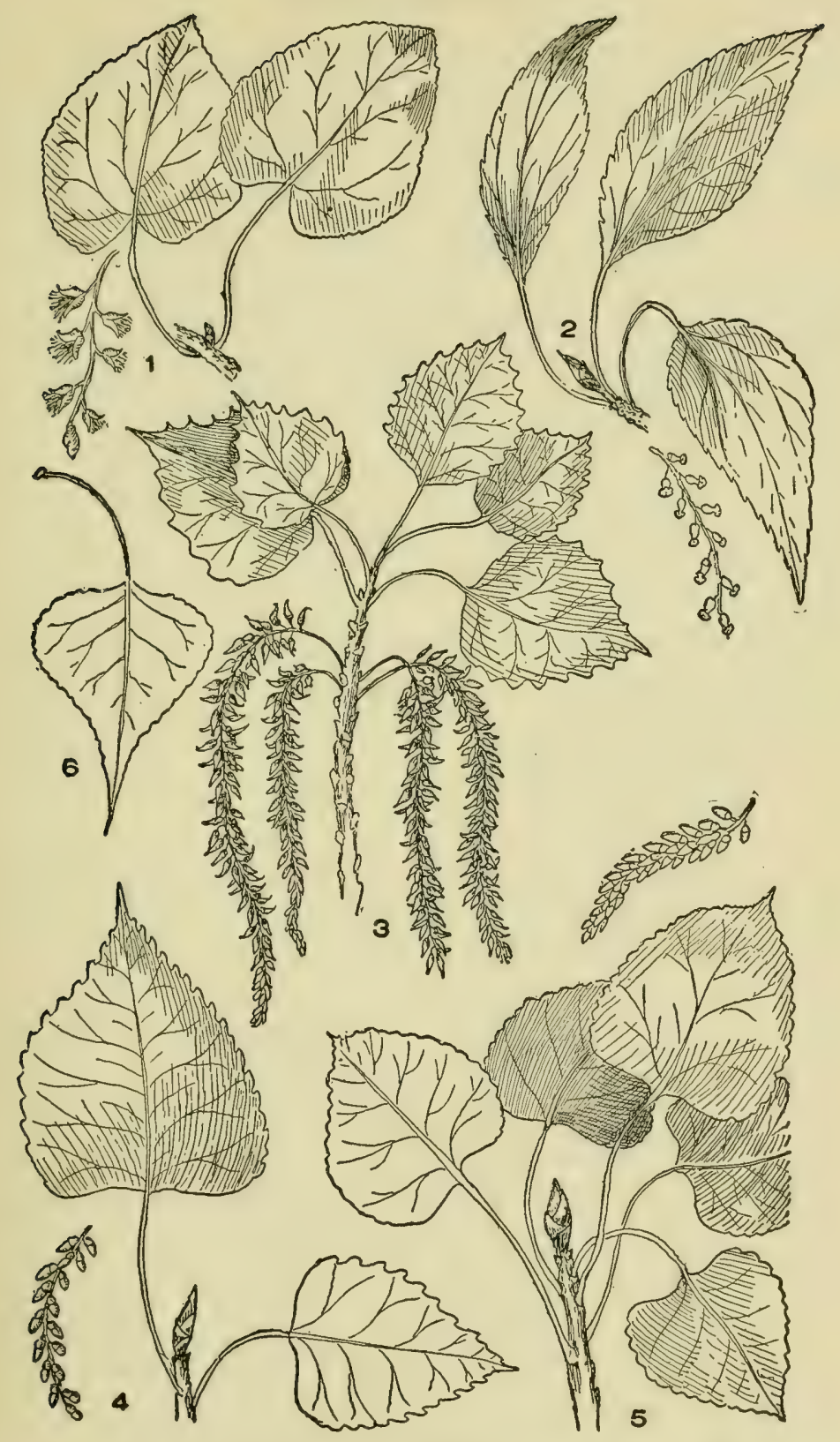

Plate 24

1. Populus heterophylla. 2. P. balsamifera. 3. P. alba. 4. P. grandidentata. 5. P. tremuloides. 6. P. deltoides. 
pointed, border without notches or teeth, bright green above, pale beneath. Pedicel of capsule more than $\frac{1}{2}$ as long as capsule and style. Bogs, throughout our area.

29. S. herbacea, L. (Fig. 6, pl. 22.) DwarF Willow. Prostrate matted shrub with rounded leaves and eatkins with few flowers. Height from 1 to $6 \mathrm{in.}$ On the summits of the White Mountains.

\section{One stamen only in the axil of the bract or rarely two}

30. S. Uva-ursi, Pursh. (Fig. 5, pl. 22.) Bearberry Willow. A prostrate herb-like shrub, generally less than 6 in. high, with crooked stems and egg-shaped or elliptic leaves, which are generally less than $\frac{1}{2}$ in. long and $\frac{1}{2}$ or $1 / 3$ as wide, broalest toward apex, slighitly toothed. Catkins on literal leafy bases, the pistillate heeming quite long. On the summits of the White Mountains and Adirondacks.

\section{POPULUS, L.}

Pistillate and staminate catkins on different trees. Each staminate group containing from 8 to 30 stamens. Bract at base of stamens slit. Buds without hairs, scaly, resinous. Leaves on long slender leaf-stalks, broad, heart-shaped or oval. Catkins long and drooping. Large trees with soft wood.

Leaves permanently covered beneath by a dense, white, silky coat . . $P$. alba Leaves usually only when young covered beneath by a dense silky coat

Ieaves - • • • • • P. hetcrophylla

Leaves narrowly egg-shaped, with rounded leaf-stalks . $P$. balsamifera Leaves broadly egg-shaped, with leaf-stalks flattened laterally. Borders coarsely and deeply toothed ... $P$. grandidentata Borders finely toothed, leaves short-pointed at the apex $P$. tromuloides Leaves with long and slender points. Bases often rounded in . . . . . . . . . P. nigra Bases generally rounded out $: \vdots: \vdots: \vdots: P_{0}$ deltoides

1. P. alba, L. (Fig. 3, pl. 24.) Wimte Poplar. Silver-leaf PopLAr. Large tree. Leaves somewhat obliquely 4-sided (rhombic) with deep sinuous cuttings. Tnder surface of leaves permanently covered by a dense, white, silky coat. March-May.

2. P. heterophylla, L. (Fig. 1, pl. 24.) Swamp or Dowry Poriar. Large tree. Idaves egg-shaped with, usually, a somewhat heart-shaped base. When young the leaves are covered beneath by a white silky coat which usually disappears as the leaf matures. In moist places mostly in the southern half of our area. April-May.

3. P. balsamifera, L. (Fig. 2, pl. 24.) Balsam Porlar. Largo tree. Buds large and varnished, shining, resinous. Leaves broadly egrershaped, finely notehed at borders, smooth, shining above and beneath. Leaf-stalks round.

Var. P. balsmmifore centisans, Fray, is the Balm of fileal tree common in cultivation. I'. Zalsomifera is found throughout our area. April.

4. P. grandidentata, Michx. (Fig. 4, pl. 24.) TAmor Tooturn Aspen. Leaves roumbel-egershaped, sharply tapering at apex, with very eonspienous, irregular teeth. Bark rather smooth, greenish. Leaves at extremities of branches only. Rich woods throughout our region. April.

5. P. tremuloides, Michx. (Fig. 5, pl. 24.) AmErican Aspen. White Porlar. Leaves rounded, heart-shaped at base, sharply tapering 
at apex. Teeth not large. Leaf-stalks longer than the leaves and flattened laterally. A slender tree, very common throughout our area. March-May.

6. P. nigra, L. Black Poplar. Leaves almost triangular (deltoid), tapering to a slender point at the apex. When young the leaves are somewhat silky. Base of leaf bluntly rounded, sometimes rounded in. A large tree, naturalized, found in the Hudson and Delaware Valleys. April-May.

7. P. deltoides, Marsh. (Fig. 6, pl. 24.) Cotrowwoop. Leaves broadly triangular (deltoid), abruptly pointed at apex, generally rounded out at the base. Leaf-stalk about as long as the leaf-blade. Along streams, throughout our region. March-May.

P. pyramidalis, Rosier. Lombandy Poplar, with its broad, deltoid leaves and erect branches, is found wild occasionally.

\section{FAMIILY II.-MYRICACEAE. BAYBERRY FAMILY}

Shrubs with alternate leaves which are aromatic. Catkins, small and erect, both pistillate and staminate flowers found on the same plant or one form only on a single plant. In the aments a single flower only is found at the axil of a bract. Staminate flower consists, usually, of + to 6 stamens, the filaments somewhat united. Fach pistillate flower subtended by 2 to several bractlets. Ovary 1-celled; fruit a small berry-like nut.

\section{MYRICA, L.}

Shrubs with pear-shaped leaves, broadest at the apex, or with linear lance-shaped leaves. After the fall of the catkins the branches of some species bear an abundance of whitish, waxy, berry-like nuts.

1. M. Gale, L. (Fig. 7, pl. 25.) Sweet Gale. Leaves pearshaped, about 4 times as long as broad. Toward the apex the leaves are notched while the basal half of the border is generally smooth. Common at the borders of streams, ponds and swamps. April-May.

2. M. carolinensis, Mill. (Fig. 8, pl. 25.) WAxberry. Shrub, rather larger than the preceding ( 2 to $8 \mathrm{ft}$. high). Leaves similar to No. 1, but without teeth at the borders. Berries very numerous, light grayish-white, waxy to the touch. In early times in this country these berries furnished an important supply of wax to the settlers. In sandy soil, moist or dry. April-May.

3. M. asplenifolia, L. (Fig. 5, pl. 25.) SweEt FERv. (Comptonia perigrina, Coulter.) Shrub, 1 to $2 \mathrm{ft}$. high, very leafy, the leaves and stems decidedly aromatic. Leaves linear-lance-shaped, the borders cut into a number of shallow lobes giving the leaves a fern-like appearance. Stipules half heart-shaped. The pistillate aments at the leaf axils have a bur-like appearance, the staminate aments dangle from the ends of the branches. Dry hillsides and sterile soil, frequent in our region. 


\section{Family III.-JUGLANDACEAE. WALNet FaMili}

Trees, the leares of which are alternate and each consisting of several leaflets (compound leaves). Stipules none. Flowers in simple catkins or, in case of the pistillate flowers, solitary or in a group of several at the end of a shoot of the season. Perianth formed on the typical plan of 4 lobes for the pistillate flowers and 3 to 6 for the staminate ones.

Fruit a hard nut, rounded or egg-shaped, the woody husk or case enclosing a hard nut within which is the oily meat or seed.

Staminate catkins single . . . . . . . . . Juglans
Staminate catkins in $3 \mathrm{~s}$. . . Carya

I. JUGLANS, L.

Compound, pinnate, leares, the leaflets arranged opposite along the main leaf stalk, except the terminal leaflet which is alone. Staminate flowers in long drooping cylindric eatkins, which hang singly. Fertile flowers in small cluster or solitary.

I. J. cinerea, L. (Fig. 3, pl. 25.) Butternut. Leaflets 7 to 16 pairs with an odd one, narrow egg-shaped or oblong lance-shaped; pointed at apex, notched borders, rounded at base; smooth above, soft hairy beneath. Fruit a long egg-shaped nut, the woody ease being roughened by irregular deep ridges, the kernel double and irregular. Nut vecurs singly or in groups of 2 to 4 . A broad tree well known for its oily nuts. Bark light gray, not rough. April-May.

2. J. nigra, L. (Fig. 1, pl. 25.) BLACK WaLNuT. Leaflets 7 to 11 pairs and an odd one, resembling those of former species but more tapering at apex and somewhat heart-shaped at base. Smooth above, somewhat downy beneath. Fruit spherical, outer husk roughly dotted, woody shell corrugated. Bark brown, rough. A large tree. April-May.

\section{CARYA, Nutt. (Hicoria, Raf.)}

Trees, often very large (so to $120 \mathrm{ft}$. high), with pinnately compound leaves, resembling the former grenus. The staminate entlins which, in Juglans are single, are in Carya in clusters of 3 's. liruit spherical to oblong, consisting of a woody husk, a hard shell within this and an irregular kernel or seed within the shell of the nut. The number of leaflets varies in diflerent speeies, being few in Nos. 5 and 6 , and numerous ( 7 to 13$)$ in the other species.

1. C. cordiformis, (Wang.) K. Foch. Bitteis Nut. Swamp IIIckonx. Leallets 7 to !1, 3 to $6 \mathrm{in}$. long. Fruit sub-ghlobose, husk narrouly 6 ridged, splitting tardily into 4 valves. Nut not angled, white, 1 in. long. Iiernel bitter. Mnist woods, swamps, throughout our region.

2. C. ovata, Mill. (Fig. 4, pl, 25.) Sinag-ваRK Irскопу. Bark

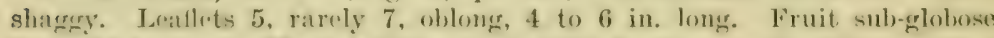
$1\}$ to 22- in. long. Ilusk splitting early into \& valves: nut white, anguler, pointed. Kiernel sweet. New Eingland and westward. 
WALNUT FAMILY
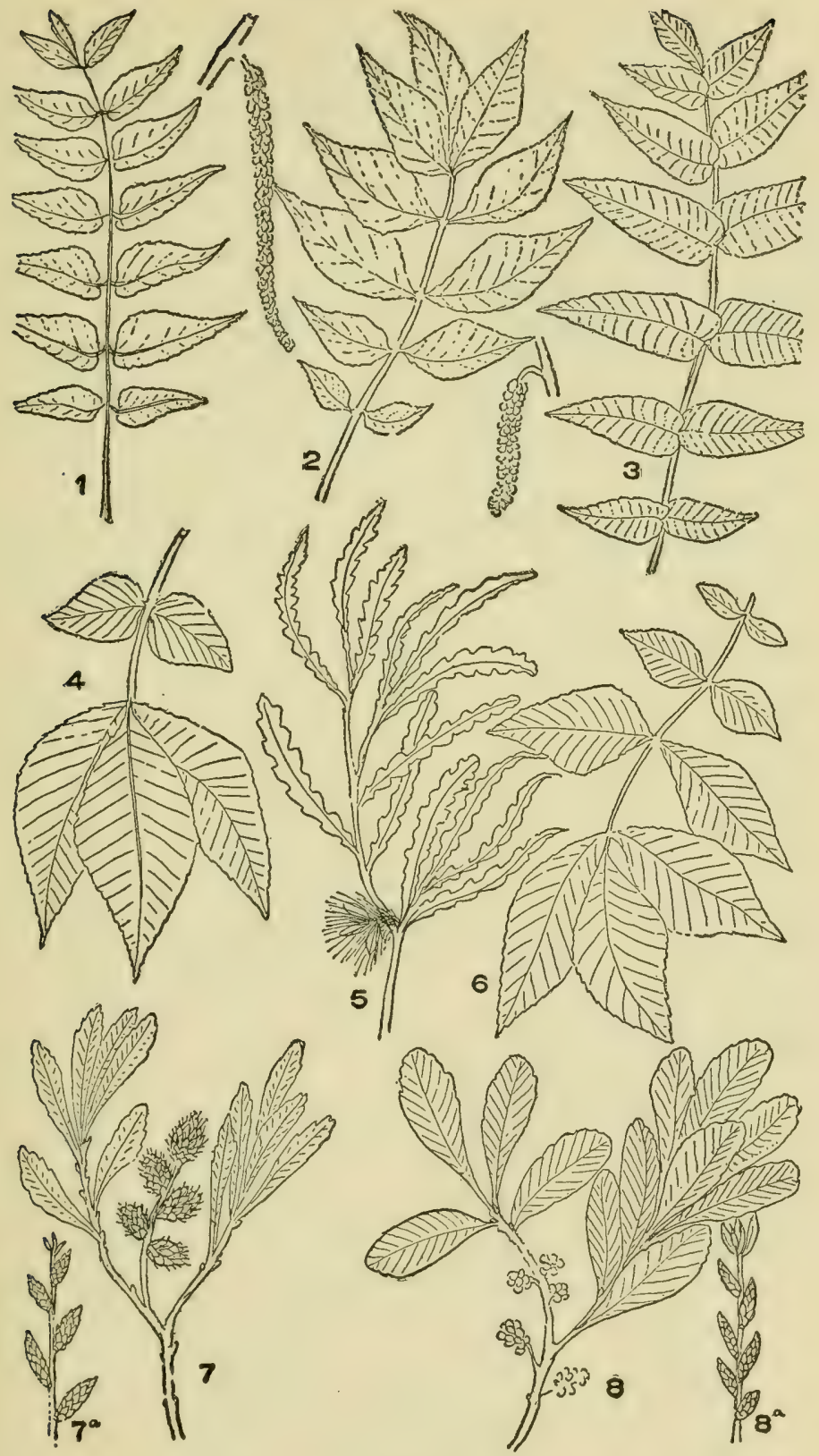

Plate 25

1. Juglans nigra. 2. Carya alba. 3. Juglans cinerea. 4. Carya ovata. 5. Myrica asplenifolia. 6. Carya laciniosa. 7. Myrica Gale, with pistillate eatkins. 7a. Staminate catkins. 8. M. carolinensis. 
3. C. laciniosa, Michx. (Fig. 6, pl. 25.) Big Smag-barE. King Nut. Bark less shaggy. Leaflets, 7 to 9 (rarely 5 ), 8 in. long by 5 in. wide. Fruit 2 to 3 in. long, oblong, splitting early. Nut angular, large (1) to $2 \mathrm{in.}$ long), pointed at both ends, yellowish-white. Kernel sweet. Central New York, Penna., and southward.

4. C. alba, I. (Fig. 2, pl. 25.) Whitte Heart Hickory. Mockeis Nir. Bark not shaggy but rough. Leaflets 7 to 9 , persistently covered with soft hairs. Fruit globose $1_{\frac{1}{2}}^{\frac{1}{2}}$ to $3 \frac{1}{2}$ in. long, husk very thick and hard. Nit globose, not compressed at sides, 4 ridged, angled, pointed at summit. Kernel sweet. East Mass., northward and westward.

5. C. microcarpa, Nutt. Small-fruited HickonY. Bark close but rough. Leaflets 5 to 7 , oblong, $3 \frac{\pi}{2}$ to 5 in. long, not hairy. Fruit small (less than $1 \mathrm{in.} \mathrm{long),} \mathrm{globose,} \mathrm{husk} \mathrm{thin,} \mathrm{splitting} \mathrm{imperfectly} \mathrm{toward} \mathrm{the}$ base. Nut globose, small, slightly compressed, not angular. Kernel sweet. East Mass., and soutbward.

6. C. glabra, Mill. PIG Nut. Brown Hrckorr. Bark elose, not shaggy. Leaflets 5 to 7 , oblong, widest at apex. Fruit top-shaped, the apex pointed. Nut brown, sharp pointed, thick shelled. Fernel bitter. Throughout our area.

\section{Sub-Order III.-FAgales. The Beech Tribe}

Trees or shrubs with simple alternate leaves, the borders of which are generally notched or lobed, with leaf stems. Flowers of two forms almost always on the same tree. The staminate flowers always in catkins, in Castanea and the oaks they are arranged in interrupted clusters on the catkin. In Fagus they are in a single cluster. The stamens are arranged in groups of 1 to 20 in the axil of a bract or attached to the receptacle. The pistillate flowers in catkins in Betulaccae, in small groups in $\mathrm{Fa}$ gaceae. Fruit a nut.

Pistillate flowers in a short more or less creet eatkin or when not in a catkin the involucre at the base of the group without spine:, consisting of leaf-like, gencrally divided, bracts . . . . . . . . . . Betulaceae Pistillate flowers never in catkins, the pistillate involucre forming a small cup containing one or more flowers

\section{Family I.-Betulaceae. 'The Burci Fameily}

The hirehes and alders have the pistillate flowers in short erect atkins. In C'arpinus and Ostrya they are arranged in a leafy 


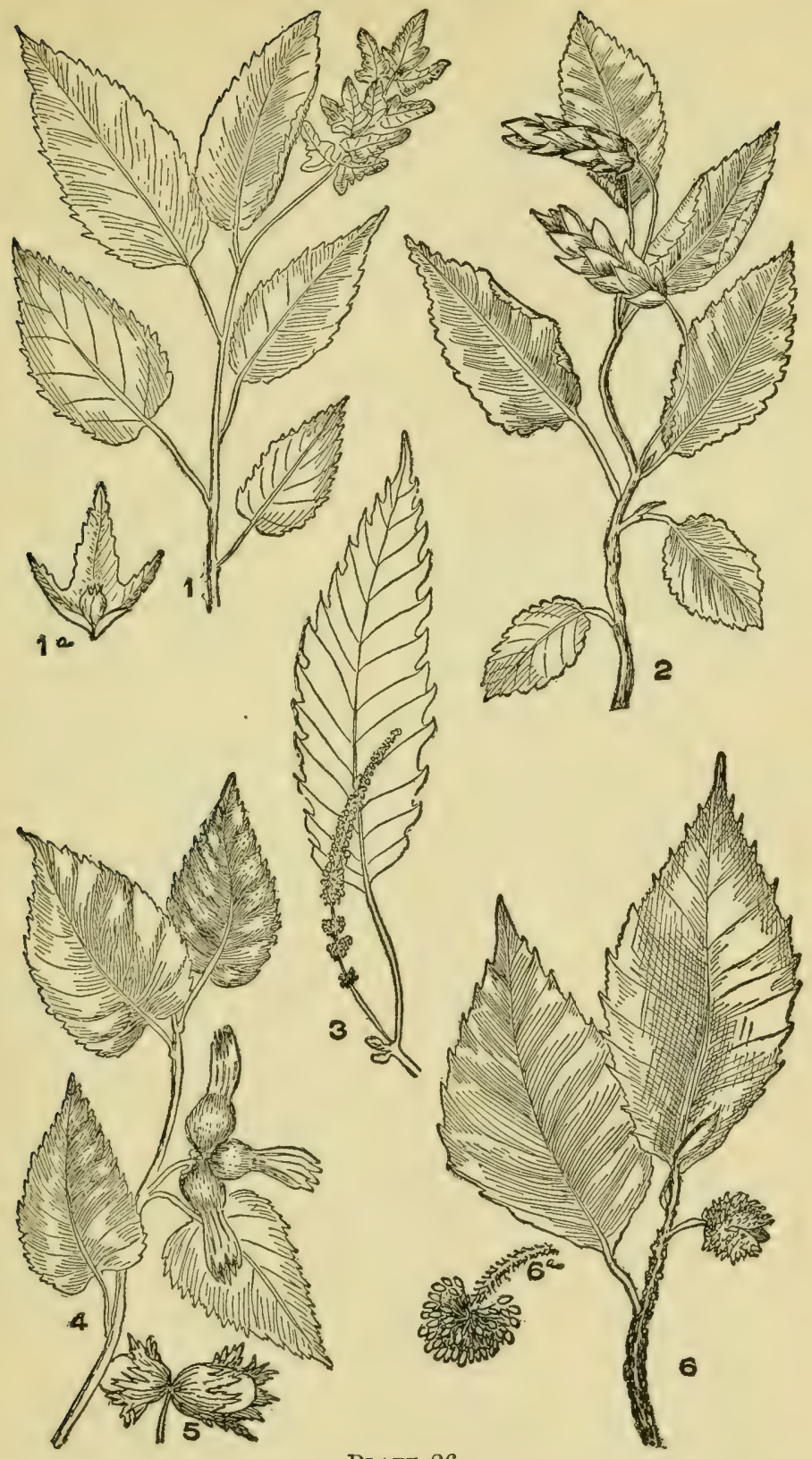

Plati 26

1. Carpinus caroliniana. 1a. Single bract with nut at base. 2. Ostrya virginiana. 3. Castanea dentata. 4. Corylus rostrata. 5. Nut of C. americana. 6. Fagus americana. 6a. Cluster of staminate flowers. 
hop-like group of bracts, while in Corylus the lracts form a much divided fringe-like collar which encloses the oval nut.

Pistillate flowers not in catkins.

Bract of the involucre halberd-shaped . . . Carpinus

Bract of the involucre pointed, oval . . . . Ostrya

Bracts of the involucre much incised . . . . Corylus Pistillate flowers in catkins.

Scales of pistillate flowers falling early . . Betula

Scales persistent . . . . . . . . Alnus

\section{CARPINUS, L.}

Small tree with smooth gray bark and very compact wood. Stems furrowed. Staminate catkins long, drooping and sealy. Pistillate, two flowers to each leaf-like bract, the latter in a spiral around a prolonged stem. Nut small ovoid.

C. caroliniana, Walt. (Fig. 1, pl. 26.) Americay Horxbeas. Blue BеEсн. A small tree, generally growing under the protecting cover of larger trees. Leaves long ovate with sharp notehes, the teeth extending to the spine. Terminal spine very acute. In shady and damp places, throughout our area. April-May.

\section{OSTRYA, Scop.}

Small tree, in general resembling the hornbeam. The leaves are less prolonged and the cluster of fertile flowers and fruit resembles an elongated hop flower.

O. virginiana, (Mills.) Willd. (Fig. 2, pl. 26.) Hop IIorxream. Inoxwoon. Staminate flowers sealy, the seales extending to the branch. Nut oblong ovoid, small. In dryer places than Carpinus.

\section{CORYLUS, L.}

Shrubs with broad leaves, staminate fowers in a sealy eatkin, seales reaching the branch, expanding before the leaves. Pistillate flowers in small groups also appearing before the leates. The involuere surrounding the seed becomes a strong rough envelope to the seed or nut.

1. C. americana, Walt. (Fig. 5, pl. 26.) HazeL Nu'r. Lenves hroad, rounded, with rather fine serrations. The inwolucre large and spreading with deeply lacinated borders. Throughout our area.

2. C. rostrata, Ait. (Fig. 4, pl. 26.) Benked Ifazer Nut. Leaves less round than the previous species, extremity narrowly pointed, serrations coarse. The involucre of the nut contracts to a long narrow neck and is covered with hairs. Throughout our area.

\section{BETULA, L.}

Trees and shrubs, outer hark generally in layers of horizontal fibers. Tark and young twigs aromatie. Both kinds of flowers expand lefore the leaves. Staminate catkins drooping, each seale covering 3 flowers. 


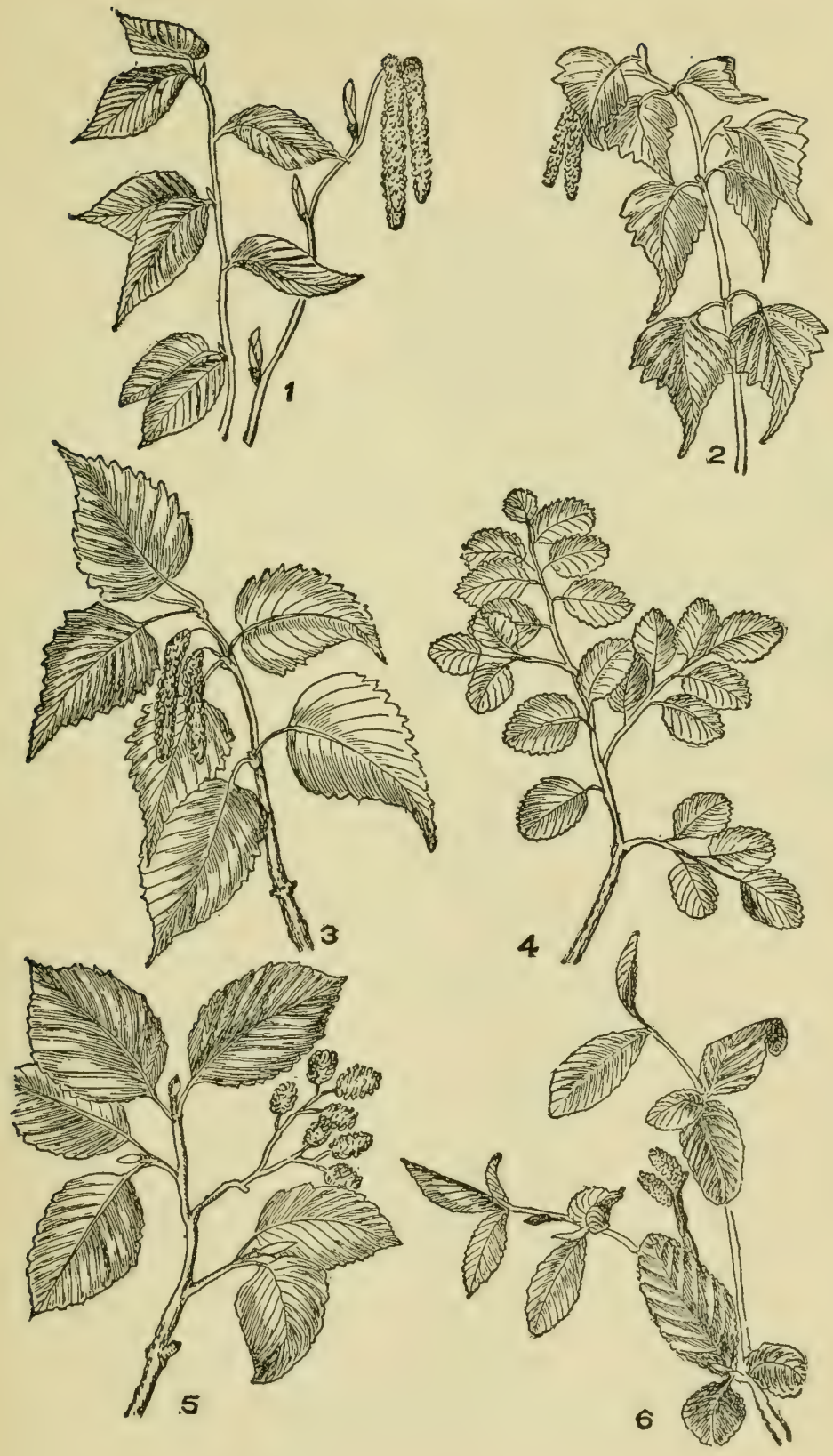

Plate 27

1. Betula lenta. 2. B. populifolia. 3. B, nigra. 4. B. glandulosa. 5. Alnus crispa. 6. A. rugosa. 
Pistillate catkins erect or spreading, scales each covering 3 flowers in the axis.

Trees.

Bark white or yellowish-white.

Leaves deltoid.

Green . . . . . . . . . B. populifolia

$\cdot \cdot \cdot \cdot \cdot$ - B. coerulca

Bark brown or greenish-brown.

Pistillate catkin with a stem . . . . . . . . B. nigra

Pistillate catkin stemless or nearly so.

Bark dark brown Bark yellowish or greenish-brown. - . . . . B. lenta

Twigs not silky - . . . - ${ }^{\circ}$. B. lutea

Shrubs. Twigs quite silky'. . . . 'P. alleghaniensis

Young branchlets dotted with wart-like glands . . . . B. glandulosa

Young branchlets not glandular . . . . . . . . B. pumila

1. B. populifolia, Marsh. (Fig. 2, pl. 27.) American White Bincir. Tree, from 15 to $30 \mathrm{ft}$ high. Bark smooth and white. Twigs brown. Leaves triangular with the free point very slender. Smooth and shining both sides, tremulous. Mostly in damp places but grows in dry soil, most of our area.

2. B. coerulea, Blanchard. BLUE BIRch. Larger than No. 1. Foliage bluish-green; young shoots warty. Leaves egg-shaped to deltoid on long leaf-stalks, irregularly and sharply toothed; base of leaf nearly straight across, apex tapering to a long narrow point, both surfaces smooth. Woods, Vermont. May.

3. B. papyrifera, Marsh. P.yer or Canoe Birci, Tree, 50 to 65 ft. high; bark white, splitting into layers. Leaves egg-shaped to heartshaped, free point less tapering than in No. 1, pale above, somewhat dotted below, doulle serrations with petiole about $1 / 3$ length of leaf. Rich woods and wet places, throughout our range.

4. B. nigra, L. (Fig. 3, pl. 27.) River Bircir. Red Bircr. Tree, 50 to $75 \mathrm{ft}$. high; bark greenish-brown, peeling in very thin layers. Leaves rhombic ovate, tapering at each end, serrations irregular, the larerer serrations including several of the smaller, smooth and deep green above, light below. Banks of streams and lakes, east Mass., southward.

5. B. lenta, L. (Fig. 1, pl. 27.) Crerry Birch. Sweet Birch. Brack Buncr. Tree 50 to $70 \mathrm{ft}$. high; bark dark brown, not separating into layers like No. 3. Twigs very aromatic. Leaves egg-shaped, sometimes heart-shaped; doubly serrate, serrations generally regular, bright green above, veins beneath dull green. Rich woods, our range.

6. B. lutea, Michx. Yellow Brom. Gray Brrer. Tallest of the hirehes. Jark yellowish or gray; not always separable into layers; twigs less aromatic than No. 4; leaves ovate or long-ovate, generally with tapering points, dull green above, downy on the veins beneath. Rich moist woods, our range.

7. B. alleghaniensis, Britton. Sottunn Yercow Burir. Resembles 13. lutea. Youmg twigs downy with long hairs. Jeaves egreshaped, tapering, $5 \mathrm{in}$. long, coarmely and sharply tonthed, heart-shaped at baso or rounded, dark green above, yellow-green and more or less downy beneath, especially on the veins. Jeaff-stalks downy in. long. Stamen bearing catkins about $2 \frac{1}{2}$ in. long. Mass., northward, 
8. B. pumila, L. Low Bircir. Shrub, 2 to $15 \mathrm{ft}$. high. Young twigs and leaves quite downy; leaves pear-shaped, or round, serrations coarse, single and regular. In bogs.

9. B. glandulosa, Michx. (Fig. 4, pl. 27.) Dwarf Bircit. A prostrate or erect shrubby plant, 1 to $2 \mathrm{ft}$. high. On elevations of White Mountains, 4 to 6 inches. Leaves orbicular or somewhat egg-shaped. Smooth and dark green both sides. Branchlets dotted with glands. Found on high mountains in New York, Maine, New Hampshire, etc.

\section{ALNUS, Gaertn.}

Small trees or shrubs. Like the lirches, the catkins of the staminate flowers are long and pendulous, while those of the pistillate flowers are erect, both kinds expand before or with the leaves. The bark is dark brown, in old trees grayish. Leaves alternate, egg-shaped, toothed, dark green.

Flowers appearing with the leaves.

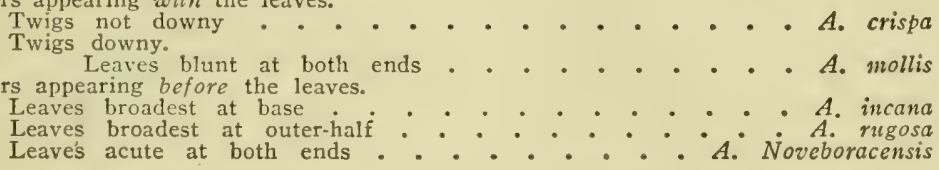

1. A. crispa, Pursh. (Fig. 5, pl. 27.) Green or Mountain Alder. (A. Alnobetula, Koch.?). Low shrub, 2 to $8 \mathrm{ft}$. high. Leaves oval or egr-shaped, when young more or less downy, teeth small and regular, in single series, when older the upper surface dark green and lower light green with pubescence on veins. Leaves and eatkins expand together. On high mountains and along cold streams. New York and New England and southward.

2. A. mollis, Fernald. Hairy Green Alder. More downy than No. 1, the under surface of leaves often densely hairy. Otherwise in general similar to No. 1. New York, westward and northward. May-June.

3. A. incana, Willd. Speckled or HoAry Alder. Shrub, or small tree, 8 to $25 \mathrm{ft}$. high. Leaves more broadly oval than No. 1, dentation generally double, dark green above, whitish beneath. Borders of streams and swamps.

4. A. rugosa, Koch. (Fig. 6, pl. 27.) Sмootr Alder. (A. serrulata, Willd.). Shrub or tree reaching height of $30 \mathrm{ft}$. or more. Leaves tapering at base, broad at upper third and rounded at apex, serrations double, deep green above and below. Forms thick masses of growth along streams or in wet soil.

5. A. Noveboracensis, Britton. New YoRK AldER. Shrub or small tree. Young twigs and leaf-stalks densely downy. Leaves oblong to pear-shaped, acute at both ends, 41 in. long or less, sharply and irregularly toothed, densely downy on the veins beneath. Woods and thickets near the coast, southeastern New York.

\section{Fanily II.-Fagaceae. The Beech Family}

Trees and shrubs with alternate leaves and with small flowers, 
the staminate on drooping catkins or in heads, the pistillate enclosed in a little leafy perianth which finally becomes the bur in Fagnes and Castanea and the cup in Quercus. Fruit, one or more nuts, each enclosed in a woody shell.

Fruit surrounded by a prickly bur.

Nuts triangular . . . . . . . . . . . Fagus

Nuts rounded . . . . . . . . . Castanea

Fruit subtended by a woody cup . . . . . Quercus

I. FAGUS, L.

Trees with smooth light gray bark, widely branching. Leaves alternate. Staminate flowers on a slender peduncle, only the terminal flower being developed. Pistillate flowers, two together, surrounded by an involucre which, at maturity is composed of 4 valves, which open to permit the falling of the fruit.

F. americana, Sweet. (Fig. 6, pl. 26.) American BeEch. ( $F$. grandifolia, Elırh.). A handsome forest tree with rounded aborescence, leaves long egg-shaped with conspicuous and regular serrations. The bur contains two 3-angled nuts which are pleasant to the taste. Throughout our area. April-May.

\section{CASTANEA, Hill}

Tall, profusely branching tree, with long egg-shaped leaves with coarse serrations. Staminate flowers in pendulous interrupted catkins. Pistillate flowers 3 to 5 together in a little cup which becomes at maturity the prickly bur.

1. C. dentata, (Marsh.) Borkh. (Fig. 3, pl. 26.) American Cinestnut. A forest tree, sometimes $100 \mathrm{ft}$. high. Leaves 5 to $12 \mathrm{in.}$ long. Nuts 1 or more in each bur. In most of our region. June-July.

2. C. pumila, (L.) Mill. Cirneuapin. A tree usually not as large as No. 1 , and sometimes a shrub. Leaves 3 to $6 \mathrm{in}$. long, sharply toothed, the teeth narrow, almost spiny. The staminate eatkin is continuous, not interrupted at lower part as is the ease with that of $C$. dentata. Bur smaller than that of No. 1. New Jersey, Penna., and south. June.

\section{QUERCUS, L.}

Trees and shrubs with leaves deeply lobed or entire. The flowers appear before the leaves, the staminate in drooping eathins with interrupted groups of stamens, each group containing from of to ! members (Fig. 8, pl. 28). Pistillate ilowers solitary, each surrounded by an oblong involucre or calyx. The inner bracts of the involucre unite to form a cup in which is developed the oval-shaped nut or acorn.

Trees

Leaves not lobed or conspicuously toothed.

Hairy gray beneath . . . . . . . . . . . . . Q. imbricaria

Not hairy gray beneath $: \vdots \therefore: \cdots: \therefore: \therefore$ Q. phellos

Leaves not lobed, but with deep serrations.
Leaves lance-shaped, about ${ }_{4}$ times as long as broad . . Q. Muhlenbergii 


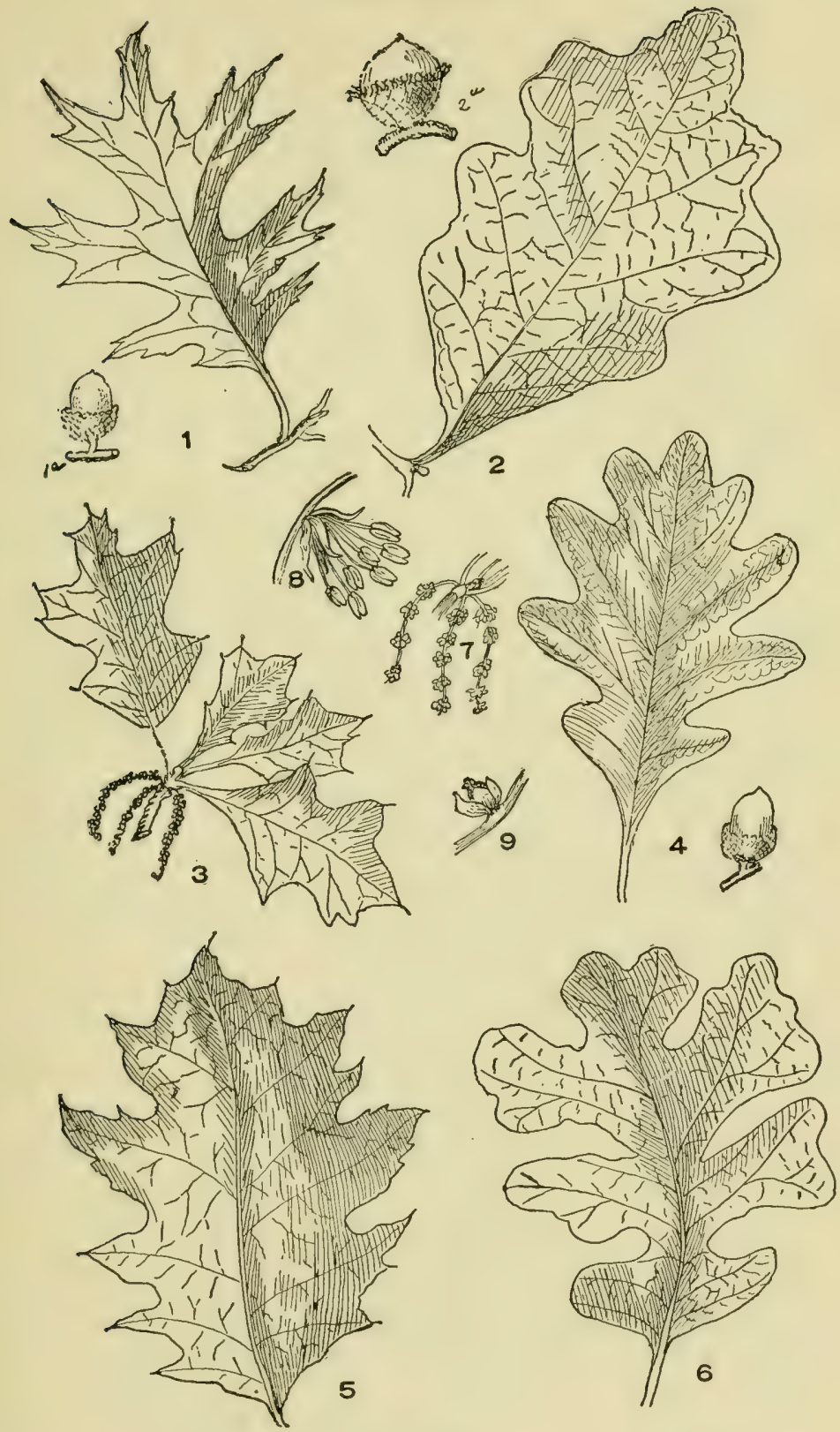

Plate 28

1. Quercus palustris, 2. Q. macnocarpa. 3. Q. ilicifolia. 4. Q. alba. 5. Q. rubra. 6. Q. stellata. 7. Catkin of Quercus. 8. Stamens. 9. A pistillate flower. 
Leaves egg-shaped or pear-shaped.

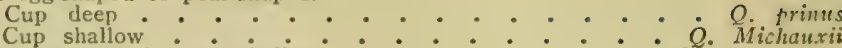

Leaves pear-shaped,

Leaves all deeply lobed.

Leaves tipped, each with a conspicuous bristle.

Dull green above, pale beneath ... . . . . Q. rubra

Shining above, green beneath.

Cup covering the nut . . . . . . Q. palusiris

Cup covering $\frac{1}{2}$ the nut... . . coccinea

Cup covering more than $\frac{1}{2}$ the nut.

Inner bark orange

Inner bark gray or réddish $: \vdots: \vdots$ Q borealis

Leaves green above, grav beneath, lobes lance-shaped . Q. falcata

Leaves green above, grav beneath, lobes triangular $\cdot Q$. ilicifolia

Leaves green above, brown beneath .... $Q_{\text {. marylandica }}$

Leaves not tipped with bristles.

Deep green beneath... . . . . . . . . . Q. alba

Dark brown beneath .......... . Q. stellata

White and silky beneath.

Acorn nearly covered by cup . . . . . . 0 . lyrato

Acorn $2 / 3$ covered, border oi cup fringed $Q$. macrocarpa

Acorn $\frac{1}{2}$ covered by cup, leaves not usually deeply lobed $Q$. bicolor

Shrub

Leaves oval, coarsely toothed . . . . . . . . Q. prinoides

1. Q. rubra, L. (Fig. 5, pl. 28.) RED OAK. Tall forest tree. Leaves in general outline oval but cut into lobes by deep rouniled sinuses, the lobes triangular. Main lobes number about 5. Cup, saucer-shaped, arising from a short stalk, covering about $1 / 3$ of the acorn. Bark dark gray. Common.

Var. borealis, Michx. Gray OAK. Large tree with leaves similar to those of Q. rubra. Cup hemispheric, on a short stem covering $\frac{1}{2}$ the nut, its bracts triangular. Leaves deeply 7 to 13 lobed, lustrous deep green above, dull, paler beneath. Penna., New York and northward.

2. Q. palustris, Muench. (Fig. 1, pl. 28.) Swamp OAK. PrN OAк. Tall forest tree, growing mostly in moist or wet places. Cup shallow satueer-shaped, covering about $\frac{1}{4}$ or less of the mature acorn. Leaves in gencral outline broadest at outer third, with very deep sinuses which are quite broad, main lobes about 5 , each terminated by several sharp points. Bark dark gray. Low grounds, Mass., southward.

3. Q. coccinea, Muench. (Fig. 1, pl. 29.) Scarlet OAK. Tall tree, cup top-shaped and covering more than $\frac{1}{2}$ the somewhat elongated acorn. Laives in outline oval. Simuses very deep and more angular than in the preereling species; lobes sharply angled, about as many as in No. 1 and No. 2. Bark gray, inner bark reddish. Dry soil in our area.

4. Q. velutina, Lam. (Fig. 6, pl. 29.) BuACK OAK. Qulrcitron. Tall forest tree, cup less top-shaped than No. 3 and eovering mly 2 the mature acorm. Le'aves with rounded sinuses, lobes ahout 7 often extending to the middle. Bark dark gray, inner bark reddish or orange.

5. Q. falcata, Michx. (Fig. 2. pl. 29.) SPANisir O.AK. (Q. digitata, (Marsh.) Sudw.). 'Tall tree. Leaves with sharp lobeg and angular sinuses. Lobes about 7 but often reduced to 4 or 3 ; dark green and smonth above, silly gray beneath. Acorn globular, cup nearly half surrounding it. Tark dark brown. New Jersey and southward. Rare in our region.

6. Q. ilicifolia, Wang. (Tig. 3, pl. 28.) Bfar or SCrti OAK. (Q. nana, Sarg.). Slırub or small tree, often growing in dense thickets. 

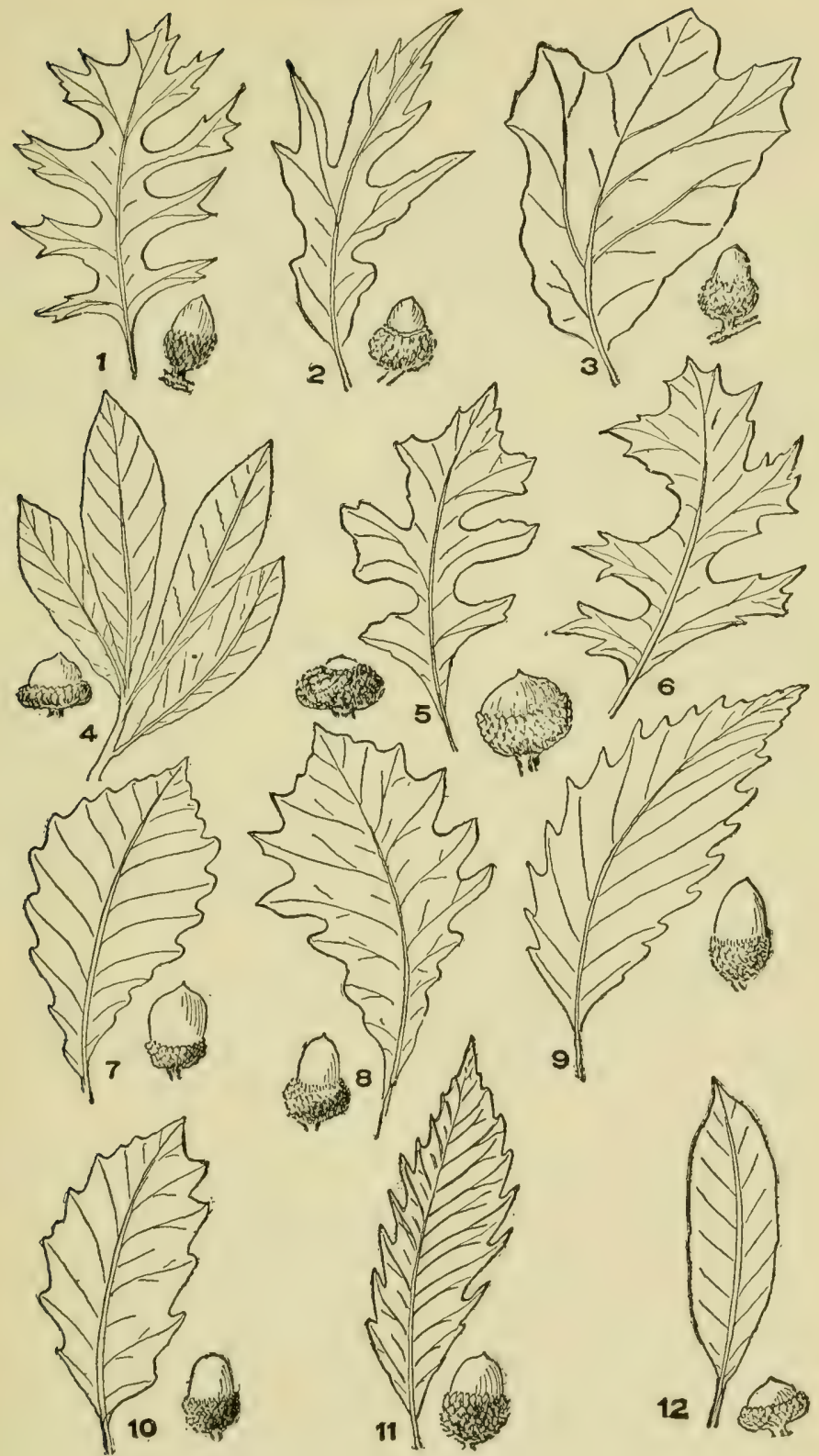

Plate 29

1. Quercus coccinea. 2. Q. falcata. 3. Q. marylandica. 4. Q. phellos. 5. Q. lyrata. 6. Q. velutina. 7. Q. prinus. 8. Q. bicolor. 9. Q. Michauxii. 10. Q. prinoides, II. Q. Auhlenbergii. 12, Q. imbricaria. 
Leaves about 5 lobed, sometimes less, often more. Lobes sharp, sinuses angular, but variable; when mature, dark green above, with silvery silkiness beneath. Bark dark brown, scaly. Maine and westward.

7. Q. marylandica, Muench. (Fig. 3, pl, 29.) BLACK JACK. BARREN OAK. Moderately tall or small tree. Leaves much broadest at the free extremity; lobes rounded shallow and generally 3 , confined to the free extremity. Cup covering $1 / 3$ the acorn. Branches irregular; bark almost black, scaly. Long Island and westward.

8. Q. phellos, L. (Fig. 4, pl. 29.) Wrllow OAK. One of two oaks native in our region whose leaves are neither lobed or serrated. A moderately high tree with long narrow leaves with smooth edges; the basal extremity acute and the free extremity generally so. Surface of leaves above deep shining green, below lighter. Acorns quite small. Long Island and southward.

9. Q. imbricaria, Michx. (Fig. 12, pl. 29.) SHIxgle OAK. A tall tree with lance-shaped leaves with smooth margins and bristle points. The under surface of the leaves gray with silky hairs which are permanent. Central Penna., and southward.

10. Q. alba, L. (Fig. 4, pl. 28.) WHite OAK. One of the largest of the oaks. Leaves deeply cut into narrow but rounded lobes without spines or bristles, the sinuses generally very deep; lobes about 6 , dark green above, rather lighter below. Cup shallow covering about $1 / 5$ the acorn. Bark light gray with shallow fissures. Throughout our area.

11. Q. stellata, Wang. (Fig. 6, pl. 28.) PoST or IroN OAK. (Q. minor, Sar..). Sometimes a shrub, sometimes a moderately tall tree. Leaves deeply divided by rounded sinuses, the lobes, about 5, about as broad as, or even broader at the outer extremities, than at the inner; bristles absent. Dark shining green above, silky brown beneath. Cup covering about $\frac{1}{2}$ the acorn. Mass., southern New York, westward and southward.

12. Q. lyrata, Walt. (Fig. 5, pl. 29.) Swamp OAK. Overcup OAK: Post OAK. Tall tree. Leaves with about 5 lobes, the deep and broad sinuses near the center giving the leaf a peculiar construction there which is elaracteristic. Surface of leaves bright green above, densely silky and white below. Cup covering $2 / 3$ of the nut which is broad and flat. New Jersey and southward.

13. Q. macrocarpa, Michx. (Fig. 2, pl. 28.) Mossy Cup OAK. Bun OAK. Tall tree. Leaves with about 7 rounded lobes with generally shallow sinuses, decp green above, silky gray beneath. (up with coarse scales and with a distinct fringe at its border composed of the bristly tips of the upper layer. Bark grray, in flakes or scales. Throughout most of our area.

14. Q. bicolor, Willd, (Fig. S, pl. 29.) Swamp Winte 0.1к. (O. platanoides, sudw.) Iarge tree. Jeaves, in general form, ovate with free extremity broadest. Lohes rounded, about $7 \mathrm{in}$ number, the sinuses genenerally quite shallow, the stem end decidedly tapering. Bright yellowishgreen above, pale green to white, silky beneath. Bark gray, flaky. Acorn narrow, cup covering the lower half. Generally in our area.

15. Q. Muhlenbergii, Englm. (Fig. 11, pl. 29.) Cnestyux or Yed- 
Low OAK. (Q. acuminata, Sarg.). Tree resembling the chestnut in size and appearance of trunk. Leaves not lobed but with very coarse serrations, lance-shaped or broad lance-shaped. Most of our region.

16. Q. Alexanderi, Britton. Alexander's OAK. Similar to the last; leaves pear-shaped. Cup cup-shaped, short stalked or not stalked. Vermont and westward.

17. Q. prinus, L. (Fig. 7, pl. 29.) Rock Chestnut OAK. ChinQUAPIN. Large tree with ovate leaves broadest at outer third. Serrations coarse. Bark dark brown in broad ridges. Maine.

18. Q. prinoides, Willd. (Fig. 10, pl. 29.) Scrub Chestnut OAK. Shrub, from 2 to $12 \mathrm{ft}$. high; leaves resembling those of No. 14 but smaller (about $2 \frac{1}{2}$ to 5 in. long, 2 to 3 wide), silky gray beneath. Maine and southward.

19. Q. Michauxii, Nutt. (Fig. 9, pl. 29.) BAskeT OAK. Leaves oval with regular dentations, usually more or less silky beneath; acorn with a shallow cup, bordered by a stiff fringe, the acorn twice as high as the cup. Only in the most southern part of our area. (Del.).

\section{Sub-Order IV.-URTICales. The Nettle Alliance}

This section contains plants of widely different general aspect, some being among the highest of our trees, some shrubs, the great majority herbs with inconspicuous greenish flowers. The leaves in all cases have stipules (appendages at the base of the leaf stalk) but in all the trees and shrubs these appendages fall away with the early development of the leaves. In the herbaceous plants they are permanent. The flowers, like those of other plants of the great order of Juliflores are without petals, are small, greenish or yellow-green, with various forms of clusters. Ovary formed of 1 or 2 carpels, one of which is usually sterile, with the calyx-like envelope below.

Trees with watery sap . . . . . . . ULMACEAE Trees with milky sap . . . . . . . MORACEAE Herbs . . . . . . . . . . . URTICACEAE

\section{FAMILY I.-ULMACEAE. ELM FAMILY}

The family of Elms contains some of our loftiest and most beautiful trees. The species of the family are characterized by the inconspicuous flowers, the two forms of which may be upon the same tree or some of the flowers may contain both stamens and pistils. They occur along the course of the twig, not at its extremity, forming little tufts (Fig. 5, pl. 30), or the pistillate (especially in Celtis) may be solitary. Stamens as many as the lobes 
of the envelope. Ovary 1-celled, above the envelope. Fruit a dry nut-like winged body.

Flowers opening before the appearance of leares . . . Ulmus Flowers opening after the appearance of the leaves . Celtis

\section{ULMUS, L.}

Leaves alternate, with oval, sharply notched leaves, which are unequal on the two sides of the midvein. Staminate flowers in tufts of reddishbrown, small, bell-shaped (Fig. 5, pl. 30). Seeds in samaras or dry, flat, ovoid, winged eneasements which float in the wind or drop at the foot of the tree (Fig. 4, pl. 30).

Flowers without pedicels (sessile on the stem) . . . . . . U. fulva Flowers on pedicels.

Bark of twigs smooth
Bark of twigs with corky wings or ridges $\because \because \because U$ U. racemosa

1. U. fulva, Michx. Slippery Elm. Red Elm. A tree 45 to $60 \mathrm{ft}$. high; leaves oval or ovate, one side much shorter than the other, serrations double, the apex slender tapering, upper surface very rough with short papillæ, under surface downy, length 5 to $7 \mathrm{in}$. by 2 to $3 \mathrm{in}$. broad. The roughness of the leaves of this elm is felt whether the hand passes from stem to point or in the opposite direction. Those of No. 2 feel rough only in passing the hand from apex to stcm. New England and westward.

2. U. americana, L. (Figs. 4 and 5, pl. 30.) American Elm. IVirte Elm. The more common species. Leaves similar to No. 1 but on the whole smaller, rough only one way. Common.

3. U. racemosa, Thomas. Cork Elm. Rock Elir. Leaves similar to those of Nos. 1 and 2 but the serrations are finer and the base of the leaf is more rounded. Corky ridges often appear on twigs which are more than a year old. New England and westward.

\section{CELTIS, L.}

While the leaves of the elms hav a single main rein extending through the center from which feather veins run from each side with much regularity, in Celtis the leaves have 3 main veins with lesser veins coursing in various directions. Flowers greenish, the staminate in clusters of several flowers, the pistillate solitary or 2 or 3 together. Calyx of 4 to 6 segments. Iruit a globular berry.

1. C. occidentalis, L. (Fig. 6, pl. 30.) American Nettle Tree. IАсквеRry. Tree resembling an elm with sweet fruit. Leaves eggshaped with reticulate veinings from 3 main veins; serrations single, coarse. Staminate flowers numerous on drooping pedieeds; pistillate usually solitary. Some of the flowers have both stamens and pistils.

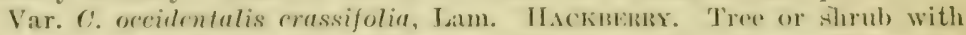
downy twigs and exreshotaped laves which are romgle above. Otherwise much like $O$. occidentalis. New York and southward. 

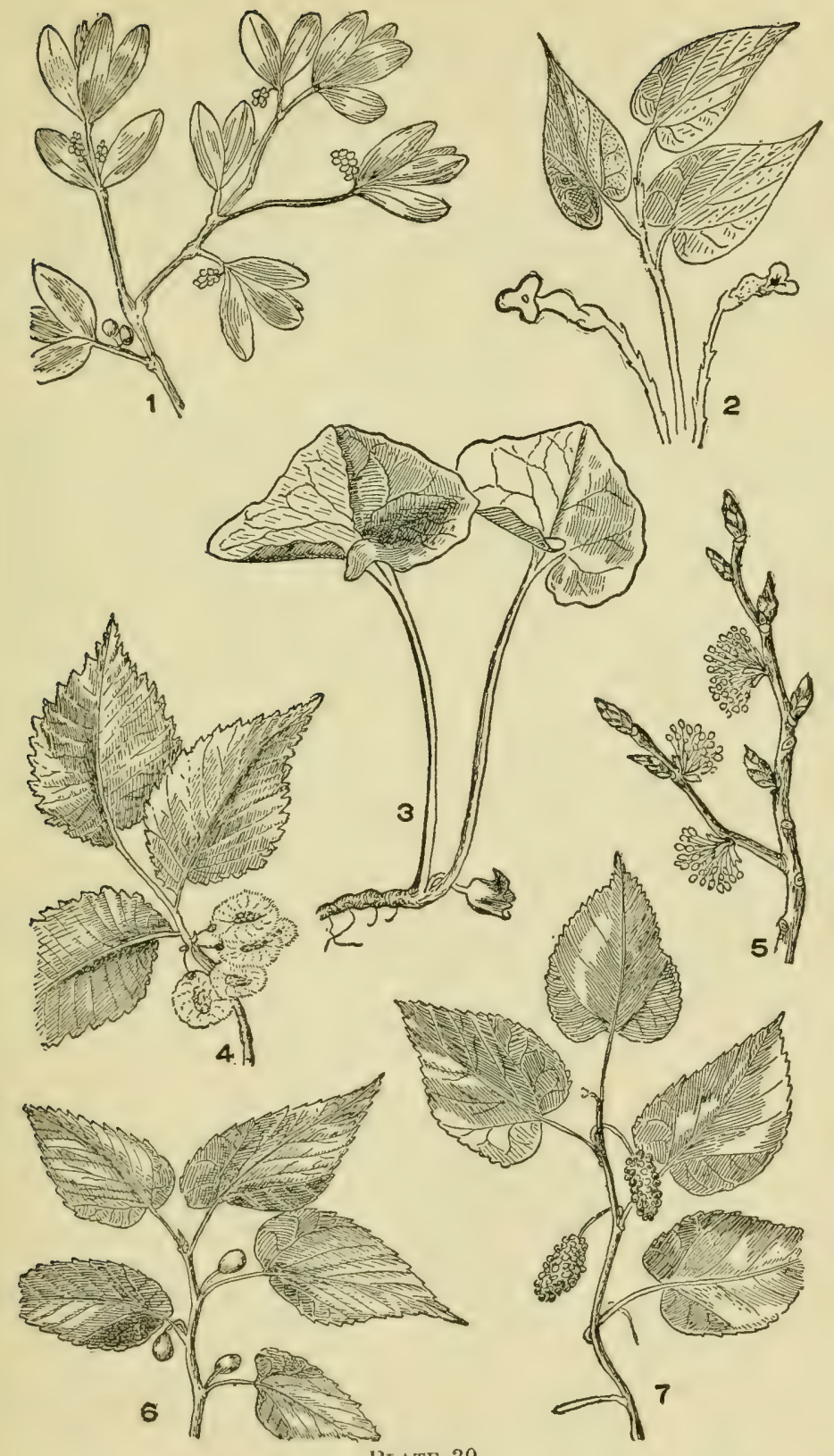

PLATE 30

1. Phoradendron flavescens. 2. Aristolochia Serpentaria. 3. Asarum canadense. 4. Ulmus americana. 5. Staminate flowers of $U$. americana. 6. Celtis occidentalis. 7. Morus alba. 


\section{Family II.-MORACEAE. MULberRy FAMiLy}

Trees and shrubs with alternate, dentate leaves which are often lobed. Stamens and pistils in different flowers, both kinds on the same tree or on different trees. Stamen bearing flowers on a long, pendulous spike arising from the leaf axils, each flower t-parted with $\&$ stamens. Pistillate flowers also in pendulous clusters, the ovary becoming succulent and sweet, the aggregation constituting the berry. Juice milky.

\section{MORUS, L.}

The Genus has the characters of the family.

1. M. rubra, L. Red Mulberry. Leaves broad, egg-shaped, somewhat heart-shaped at base, rough above, silky beneath, with a principal nerve and about 4 secondary nerves with lesser nerves forming reticulations. Fruit an elongated dark purple sweet pleasant berry.

2. M. alba, L. (Fig. 7, pl. 30.) Wirte Mulberry. Leaves similar to No. 1, but smaller and more heart-shaped at base, often lobed, smooth and shining. Fruit drooping, white or pinkish. (Escaped from cultivation. It is the tree the leaves of which are used for feeding silk worms).

\section{BROUSSONETIA, L'Her.}

Tree or shrub with milky juice. Leaves alternate, broad, with conspicuous serrations and generally with deep sinuses dividing the leaf into 3 irregular lobes. Sometimes the sinus is only on one side, in other cases it is absent. Fruit globular.

B. papyrifera, (L.) Vent. PAPER MulberRx. Leaves rough above, silly beneatl, irregularly lobed or without lobes. Fruit red globular berries. Escaped from cultivation.

\section{Finily III.-URTICACEAE. NetTle FaMils}

Herls with permanent stipules and with the stamens and pistils in diflerent flowers, on different plants or on the same plant. Leaves oppocite or alternate, flowers green; the staminate with as many stamens as the lobes of the calyx and vis-atris to them, in loose clusters, inflorescence about a single axis, or more closely rrowted in a catkin-like spike or into an erect fillot. P'istillate flowers with a single orary, in catkins, with leafy bracts or in spikes without bracts.

Twining vine .

Leaves with radiant lobes

Humulus

Leares simple, undivided but toothed.

Cannabis 
Herbs with stinging hairs.

Leares opposite . . . . . . . . . Urtica

Leaves alternate . . . . . . . . Laportea

Herbs without stinging hairs.

Leaves opposite.

Pistillate calyx 3 parted . . . . Pilea

Pistillate calyx 2 to 4 parted . . Boehmeria

Leaves alternate . . . . . . . . Parietaria

I. URTICA, L.

Herbs, 1 to $6 \mathrm{ft}$. tall, with opposite simple leaves, stem and leaves covered with stinging hairs. Flowers minute, green, in long hanging clusters at the axils of the leaves. Staminate flowers (sometimes on same plant with the pistillate and sometimes on same group) with 4 stamens and a 4 parted calyx. The calyx of the pistillate flower also 4 parted but 2 parts are larger than the other pair. Nos. 1 and 2, perennial; No. 3, annual.

1. U. dioica, L. (Fig. 6, pl. 31.) Stinging Nettle. Great Nettle. Leaves ovate with rounded or heart-shaped base, 5 to 7 veined, 1 to $3 \mathrm{in}$. wide, tapering at apex, serrations very deep, very bristly with stinging hairs. Not as common as No. 2. Found in waste places and roadsides.

2. U. gracilis, Ait. (Fig. 4, pl. 31.) Slender Nettle. Leaves slender-ovate to lanceolate. Stinging hairs less profuse than No. 1. Apex tapering, base rounded, rarely heart-shaped, 3 to $6 \mathrm{in}$. long, 1 to $1 \frac{1}{2} \mathrm{in}$. wide. Plant 2 to $6 \mathrm{ft}$. high. Common.

3. U. urens, L. (Fig. 8, pl. 31.) Small Netrle. Leaves elliptic or egg-shaped, very coarsely and deeply serrate, mostly 3 nerved. Stinging hairs more sparingly provided than in No. 1 or No. 2. Two flower clusters in each leaf axil. Plant from $8 \mathrm{in}$. to $18 \mathrm{in.} \mathrm{high.} \mathrm{In} \mathrm{waste} \mathrm{places.}$

4. U. Lyallii, Wats. Lyall's NetTle. Similar to $U$. gracilis, but the leaves broader, the surface somewhat bristly, sometimes quite downy, usually heart-shaped at base. Teeth fewer and coarser than in U. gracilis. Waste places, New Foundland south to Conn., and western New York.

\section{LAPORTEA, Gaud. (Urticastrum, Fabr.)}

Perennial plants with stinging hairs. Flowers small, green, in loose branching and spreading clusters. Staminate flowers, sepals 5; stamens 5. Pistillate flowers, calyx 4-parted, the inner pair of segments larger than the others, surrounding an ovary.

L. canadensis, (L.) Gaud. (Fig. 9, pl. 31.) Wood Netrle. (Urticastrum divaricatum, Kuntze.) Leaves, usually very large (3 to 7 in. long, 2 to $5 \mathrm{in}$. broad), thin, ovate, with spreading feather veins; serrations sharp and conspicuous. Flowers in large loose clusters larger than the leaf steams. Found in rich woods of our area.

3. PILEA, Lindley (Adicea, Raf.)

Herbs without stings, with opposite leaves. Flowers of both kinds on 
a single plant or the two kinds on different plants. Stamens 3 or 4; calyx 3- or 4-parted; pistillate calyx 3-parted. Leaves ovate, pointed at each end, 3 nerved.

P. pumila, (L.) Gray. (Fig. 7, pl. 31.) Clearweed, Richweed. Succulent, half transparent stems $3 \mathrm{in}$. to $2 \mathrm{ft}$. high. Leaves egg-shaped, coarsely and deeply toothed, pointed at base or apex. Flower clusters, two in axil of a leaf, much shorter than leaf stalk. Moist places; frequent.

\section{BOEHMERIA, Jacq.}

Flowers of both kinds or only of one kind on a single plant, collected in spikes of grobular clusters, or, the lower spikes non-continuous. Leaves opposite, 3 nerved. Staminate flowers, stamens 4. Calyx generally 4-parted; calyx of pistillate flowers tubular or 4-toothed.

B. cylindrica, (L.) Sw. (Fig. 10, pl. 31.) Wild False Nettle. A coarse weed in low places, 2 to $3 \mathrm{ft}$. high. Leaves ovate, opposite on long leaf stalks, coarsely dentate. Flower spikes from leaf axils, the upper spikes leafy at top. Moist places; frequent.

\section{PARIETARIA, L.}

Herbs with alternate 3-nerved leaves, with dense axillary clusters of greenish flowers. Staminate and pistillate in the same groups, surrounded by leafy bracts; stamens 4; calyx of both kinds of flowers 4-parted.

P. pennsylvanica, Muhl. (Fig. 5, pl. 31.) Pennsylvania ParieTARI.. Stem weak, delicate, leaves broadly lanceolate, 3-nerved, without indentations, tapering at each end, apex rather blunt; flowers in a rounded group. In dry shady places.

\section{HUMULUS, L.}

A twining vine, often $25 \mathrm{ft}$. or more in length. Leaves opposite, 3 or more loberl, rough; staminate flowers in loose branching elusters, yellowish-grenn; pistillate flowers in catkin-like, rounded or elongated clusters of yellowish-green bracts inclosing each a single ovary.

H. Lupulus, T. (Fis. 1, pl. 31.) IIor. Extensively cultivated, but found wild in thickets, and along streams.

7. CANNABIS, Tourn.

Erect herb with opposite leaves divided in long finger-like lobes. Stipules persistent; clusters of ereenish flowers axillary; the staminate in loose liranching clusters, the pistillate in spikes; pistillate flowers, each surounded by a leafy bract.

C. sativa, L. (Figs. 2 and 3, pl. 31.) HeMr. Very ereet herb, 3 to $6 \mathrm{ft}$. tall, branching; the leaves ennsisting of from 5 to 7 long leatlets joined at the base. In waste places, and cultivated for its fibers.

\section{Order II.-SANTALES}

This small orter, (m)taining two families, each with rery few sperese includes phants whirh are parasitic or hall parasitice Deyond this there are lew common characteristics between the two 


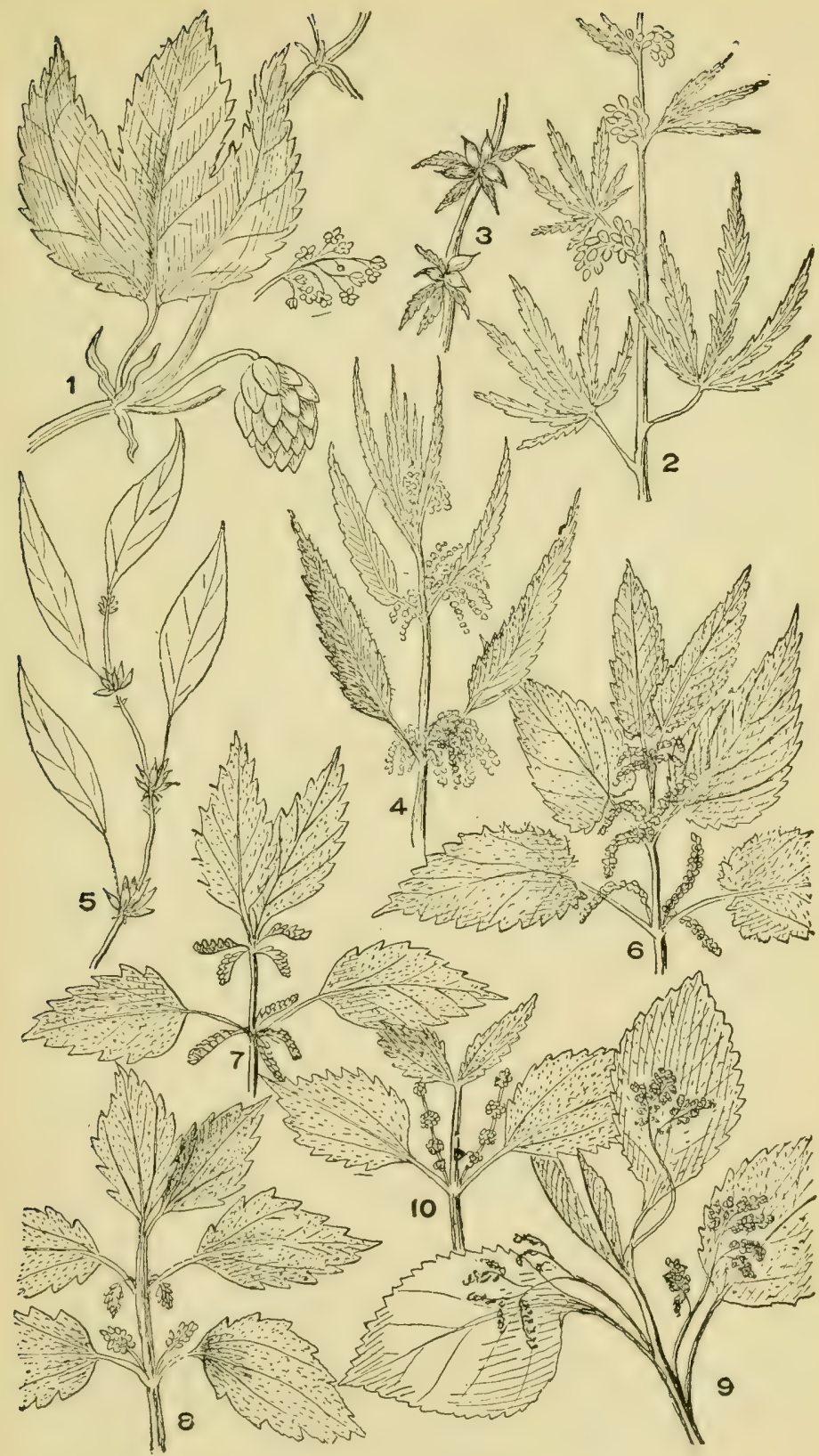

Puate 31

1. Humulus Lupulus. 2. Cannabis sativa. 3. Pistillate flowers of C. sativa. 4. Urtica gracilis. 5. Parietaria pennsylvanica. 6. Urtica dioica. 7. Pilea pumila. 8. Urtica urens. 9. Laportea canadensis. 10. Boehmeria cylindrica. 
families. The flowers in all have a simple and single perianth which closely surrounds the ovary and on which are borne the stamens.

In the Family Loranthaceac all the species are parasitic.

In the Family Lristolochiaceae the species are of plants which find their home at the roots of decaying trees and are in some measure parasitic.

Parasites on trees; fruit a berry. FAMILY I. IORANTHACEAE Plants not parasitic. . . . . FAMILY II. SANTALACEAE Parasites on roots or shrubs; fruit a nut.

FAMILY III. ARISTOLOCHIACEAE

Family I.-loranthaceaE. Mistletoe Family

Plants growing on trees as parasites, nourishing themselves through roots which penetrate the bark of the supporting tree. They have opposite leaves but these in drceuthobium are reluced to thickened scales. Flowers at the end of the branches or in the leaf axils, generally in clusters. They have no colored perianth. Fruit a berry with a single seed.

Leaves foliaceous.

Phoradendron

Leaves scale-like

Arceuthobium

I. ARCEUTHOBIUM, Bieb. (Razoumofskya, Hoffm.')

Small plants, parasitic on the conifers, branches 4 angled, opposite leaves scale-like. Berry globose, fleshy, on a short stem.

A. pusillum, Peck. Sinall Mistletoe. Plant from $\frac{1}{2}$ to 1 in. long, gremish-brown, leaf seales rounded; staminate and pistillate flowers on different plants which may grow from the same tree or from different trees. On twigs of spruce trees. Adirondack region, White Mountain and Pocono regions.

\section{PHORADENDRON, Nutt.}

Leaves leathery, flowers in jointed clusters, staminate and pistillate on dilferent plants. Berry pulpy. Yellowish-green plants growing on other trees.

P. flavescens, (Pursh.) Nutt. (Fig. 1, pl. 30.) AMERicax MistleToE. liregularly branching; leaves oblong, thick and leathery. Berries in clusters. New Jersey, southward and westward.

\section{Famir II.-SANTALACEAE. SANDilwood Family}

ITerbs and shrubs with altermate leaves (opposite in some foreign species) which have entire borders and are without stipules. Flowers in chusters or solitary, terminal or from the leaf axils, each flower with stamens and pistils, or flowers with one of these 
elements only, both kinds of flowers on the same plant or on different plants, mostly greenish. Calyx allierent to the base of the ovary, 3 to 6 lobed; petals none. Stamens as many as the lobes of the calyx. Fruit a drupe or nut; seed one.

\section{COMANDRA, Nutt.}

\section{Characters as above.}

1. C. livida, Richards. Northern Comandra. Stem slender, simple, 4 to $12 \mathrm{in.} \mathrm{high.} \mathrm{Leaves} \mathrm{oval,} \mathrm{rounded} \mathrm{at} \mathrm{apex,} \mathrm{tapering} \mathrm{at} \mathrm{base.} \mathrm{Flowers}$ in small clusters at the leaf axils, from a slender common flower stem about $1 \mathrm{in}$. long, 1 to 5 flowers in the group. Drupe globose. Vermont and northward, June-July.

2. C. umbellata, Nutt. Bastard Toad-Flax. Stem 6 to $18 \mathrm{in.} \mathrm{high,}$ leafy, branched. Leaves oblong or broad lance-shaped, pale green, acute or nearly acute at each end, without leaf-stalks. Flowers in umbel-like clusters, a number of these small clusters arising from as many leaf axils. Calyx greenish-white. Through the extent of our area. AprilJuly.

\section{FAmILY III.-ARISTOLOCHIACEAE. Birtirwort FAMILY}

Low herbs, twining vines and, heyond our area, sometimes shrubs, with leaves from the root or alternate on a stem. Stipules absent; flowers from the axils of the leaves, usually solitary but exceptionally in clusters, greenish or purplish. Petals none, the calyx tube adhering to the ovary and dividing alove the latter into 3 more or less spreading lobes. In some species beyond our limits the lobes are 6 or irregular. Stamens 6 or 12 inserted on the short and fleshy style.

Low herbs, not vines, leaves from the root . . Asarum Twining vines or nearly erect herbs, with irregular flowers; leaves from the stem . . . Aristolochia

\section{ASARUM, L.}

Herbs with, generally, two broad heart-shaped leaves starting from the root and borne on long leaf-stalks, between which springs the single flower. Root branching, aromatic. Calyx bell-shaped, adherent to the ovary, dividing into 3 lobes. Stamens 12, also adherent to the ovary.

1. A. canadense, L. (Fig. 3, pl. 30.) Wild Ginger. Leaves broad kidney-shaped at hase, with fine silky or downy pubescence. Between the two long leaf-stalks arises the slender flower stalk, bearing the brownish-purple, bell-shaped flower, the 3 divisions of the calyx extending into long slender, tapering points. Generally at the base of trees where some, at least, of the wood is decaying. April-May.

Var, reflexum, (Bieknell.) Robinson. Short Lobed Wild Ginger. 
Flowers smaller than the typical form and lobes of the calyx early reflexed. Conn., and southward. April-May.

\section{ARISTOLOCHIA, L.}

Erect herb or twining vines with alternate leaves on leaf-stalks, eggshaped, hase heart-shaped, apex tapering. Flowers irregular. Stamens 6 , style 3 to 6 parted.

1. A. Serpentaria, L. (Fig. 2, pl. 30.) Virginia Snake Root. Leaves egg-shaped or broad lanceolate with heart-shaped base, $1 \frac{3}{2}$ to 5 in. long, alternate. Flowers from a pedicel arising from the root and which bears sealy bracts. The calyx tube elongated and curved like an $\mathrm{S}$, the mouth broadly open. Rare in our region. June-July.

2. A. Clematitis, L. Bintuwort. European species, escaped from cultivation, naturalized near Flushing, Troy, and Utica, N. Y., with straight calyx tube and clustered flowers.

3. A. macrophylla, Lam. Dutchuras's PIPE. A twining vine mostly cultivated. Leaves broad, kidney-shaped, densely downy. Flower in the form of a pipe. Rich woods, southern Penna.

\section{Order III.-POLYGONALES. Order of the Sorrelworts}

Flowers without corollas, the perianth consisting of a regular envelope which is not adherent to the ovary. Stamens generally equal in number to the divisions of the green or colored calyx, rarely double the number or less or more. Ovary one, surmounted hy a pistil which divides into 2 or 3 stigmas. Fruit a dry 3 -angled seed or a compressed one with wings. Stamens and pistils in the same flowers or in different flowers. Only one family.

\section{FAnily. POLYGONACEAE. BuckWHEAT FAגiLY}

TTerlareous plants erect or twining, with alternate leaves. Calyx green, colored or white, divided in 3 to 6 parts; seed cirpels 2 or 3. In our species the joints at the leaf-stalks are always surrommlerl hy a lome sheathing collaret extending on the stem above the insertion of' the leaf stalk. 'T'here is no true stipule. 'These collarets aro known as ocreac. Flowers in elongated terminal clusters or more compressed clusters in the leaf axils.

Calyx in 4 parts, stamens 6 . . . . . . Oxyria Calyx in 6 parts . . . . . . . . . . . Rumex

Calyx in 4 or 5 parts; stamens 5 to 9 .

Perlicels of flowers solitary and closely jointed Polygonella

Pedicels several in a group.

Fruit ordinarily enveloped by the perianth

Fruit larger than the perianth . .

Polygonum

Fagopyrum 


\section{RUMEX, L.}

Erect herbs, annual or perennial. Stems branching, grooved; leaves in some of the species mostly grouped about the root, in others alternate along the stem. Calyx of 6 sepals, the 3 inner ones conspicuously larger than the others in fruit; stamens 6 , opposite the sepals; pistil divided into 3 parts with tufted or stellate summits (stigmas). Flowers in great numbers disposed along the stems in groups, these groups branching, simple or in whorls. The fertile and sterile flowers are found on different plants or in separate groups on the same plant or mingled in the same groups.

Leaves arrow-head- or halberd-shaped; stems and leaves sour to the taste, low herbs.

Sepals of the fruit-hull not longer than the fruit.

Exterior sepals below the fruit, erect . . . . R. Acetosella

Exterior sepals below the fruit, turned down ${ }^{\circ} \cdot R$. Acetosa

Sepals of the fruit-hull several times longer than the fruit $R$. hastatulus Leaves not arrow-head- or halberd-shaped.

Leaves not heart-shaped at base.

Margins of leaves not wavy.

Fruit-hull wings diamond-shaped . . . . R. salicifolius Fruit-hull wings club-shaped ...... R. verticillatus Fruit-hull wings heart-shaped ....... $R$. altissimus

Margins of leaves wavy. Seed wings scarcely toothed . . . . . R. Patientia

Leaves heart-shaped at base.

Flowers in a dense almost uninterrupted spike . . R. persicarioides Flowers in loose interrupted spikes. Seed wings heart-shaped, not toothed. Leai' borders wavy.

${\text { Seed wings spatula-formed } \cdot \cdot \cdot \cdot \cdot \cdot{ }^{\circ} R \text { sanguineus }}^{\circ}$ Seed wings arrow-head-shaped with long spines $R$. obtusifolius

$\S$ Leaves mostly clustercd about base, halberd-shaped; leaves and stcm acid

1. R. Acetosella, L. (Fig. 3, pl. 32.) Field Sorred. Sheep SorREI. Leaves narrow, the base lobes spreading, 1 to 4 in. long, usually broader at or above the middle than elsewhere except the lobes. Upper leaves lance-shaped, not lobed. Flowers crowded in ereet, somewhat branching clusters. Fruit longer than the greenish perianth. Common in dry fields.

2. R. hastatulus, Muhl. Fngelmann's Sorrel. Base lobes of leaves usually less conspicuous than in No. 1 , but sometimes more, leaves 1 to 5 in. long; stem leaves linear; collaret silvery; perianth greenish, as long or longer than the fruit. Sea coasts, southern section of our region. March to August.

3. R. Acetosa, L. (Fig. 11, pl. 32.) Sorrel. Sour Dock. Lobes extending backward almost parallel with the leaf stalk; lower leaves with long leaf-stalks, upper with none. Flower clusters more crowded than in No. 1, or No. 2. Exterior sepals turned backward. Introduced.

$\S \S$ Leaves neither halberd-shaped nor heart-shaped at base. Borders not vavy

4. R. salicifolius, Weinm. (Fig. 5, pl. 32.) PALE Dock. WILlowLEAVED Dock. ( $R$. americanus, Meisn.) Plant erect or spreading, 1 to $3 \mathrm{ft}$. high. Leaves narrow lance-shaped, acute at each end; panicle of flowers interrupted, at least at lower part, clusters dense, of pale green 
flowers. Fruit, smooth, shining, dark red, winged or triangular, not heart-shaped. Swamps. In bloom from May to September.

5. R. verticillatus, L. (Fig. 10, pl. 32.) Swamp Dock. Leaves oblong, lance-shaped, acute at each end, 2 to 12 in. long. Flower cluster a tall spike, densely crowded with whorls of green flowers, 10 to 30 flowers each; and leafless. Leaves with long stalks; wings of fruit, diamond-shaped. Plant 2 to $5 \mathrm{ft}$. high. In swamps. May to July.

6. R. altissimus, Wood. (Fig. 8, pl, 32.) Tal, Dock. PeachLEAVED Dock. Leaves narrow elliptic, acute each end, 2 to 10 in. long. Flower panicles leafless with interrupted dense clusters of light green flowers. Wings of fruit triangular, cordate at base. Plants 3 to $4 \mathrm{ft}$. high. Swamps and moist places. April-June.

\section{+ Leaves as in $\S$, but with wavy borders}

7. R. Patientia, L. (Figs. I and 6, pl. 32.) Patience Dock. Lower leaves broad lance-shaped, 4 to 16 in. long, borders wavy; flower panicle of dense whorls of green flowers. Seed wings broad, nearly orbicular or kidney-shaped, cordate, obscurely toothed at margin. Plant 3 to $5 \mathrm{ft}$. tall.

8. R. britannica, L. (Fig. 13, pl. 32.) Great Water Dock. Ieaves broad lance-shaped, 1 to $2 \mathrm{ft}$. long, somewhat wavy margined. Flower panicle nearly leafless. Fruit wings broadly triangular, cordate, the margins distinctly toothed. Swamps and wet places. July-August.

\section{廿t Leaves cordate at base. Flower panicles more or less interrupted}

๑. R. crispus, L. (Fig. 9, pl. 32.) Curled Dock. Yellow Dock. Leaves lance-shaped, 6 to 12 in. long, margins strongly wavy. Flowers in long wand-like panicles, leafless above; seed wings heart-shaped. Plant 3 to $4 \mathrm{ft}$. high. Fields and waste cultivated grounds.

10. R. sanguineus, L. (Fig. 4, 12, pl. 32.) Bloovy Dock. Red-veined Dock. Leaves lance-shaped or oblong, often fiddle-shaped; 1 to $5 \mathrm{in.} \mathrm{long;}$ panicle of flowers leafless; whorls at some distance from each other. Seed wings club-shaped. Plant 1 to $3 \mathrm{ft}$. high. Waste cultivated grounds. May to August.

11. R. obtusifolius, L. (Figs, 2 and 7, pl. 32.) Findle Dock. Stem somewhat rourh. Leaves broad ovate, heart-shaped at base, blunt at apex, 6 to 14 in. long, wavy margined. Whorls, few flowered and distant, seed wings halberd-shaped with conspicuous spines or awl-shaped teeth. Plant 1 to $3 \mathrm{ft}$. high. In waste places. June to August.

\section{廿 Flowers in a dense uninterrupted panicle}

12. R. persicarioides, L. (Fig. 14, pl. 32.) Golmen Dock. Leaves narrow lance-shaped, blunt or even slightly cordate at base, more or less wavy. Plant erect or prostrate, 1 to $3 \mathrm{ft}$. high. Flowers in a dense uninterrupted spike. Seed wings with 4 or 5 long spine-like bristles. Sandy shores. July to Oct.

\section{FAGOPYRUM, Tourn.}

Annual herl, widely cultivated, most of the plants found wild are from serels eseaper from cultivated fields. Leaves alternate, deltoid or latberd-slatped. Collaret (ocrea) cylindric. The 5 divisions of the calyx 


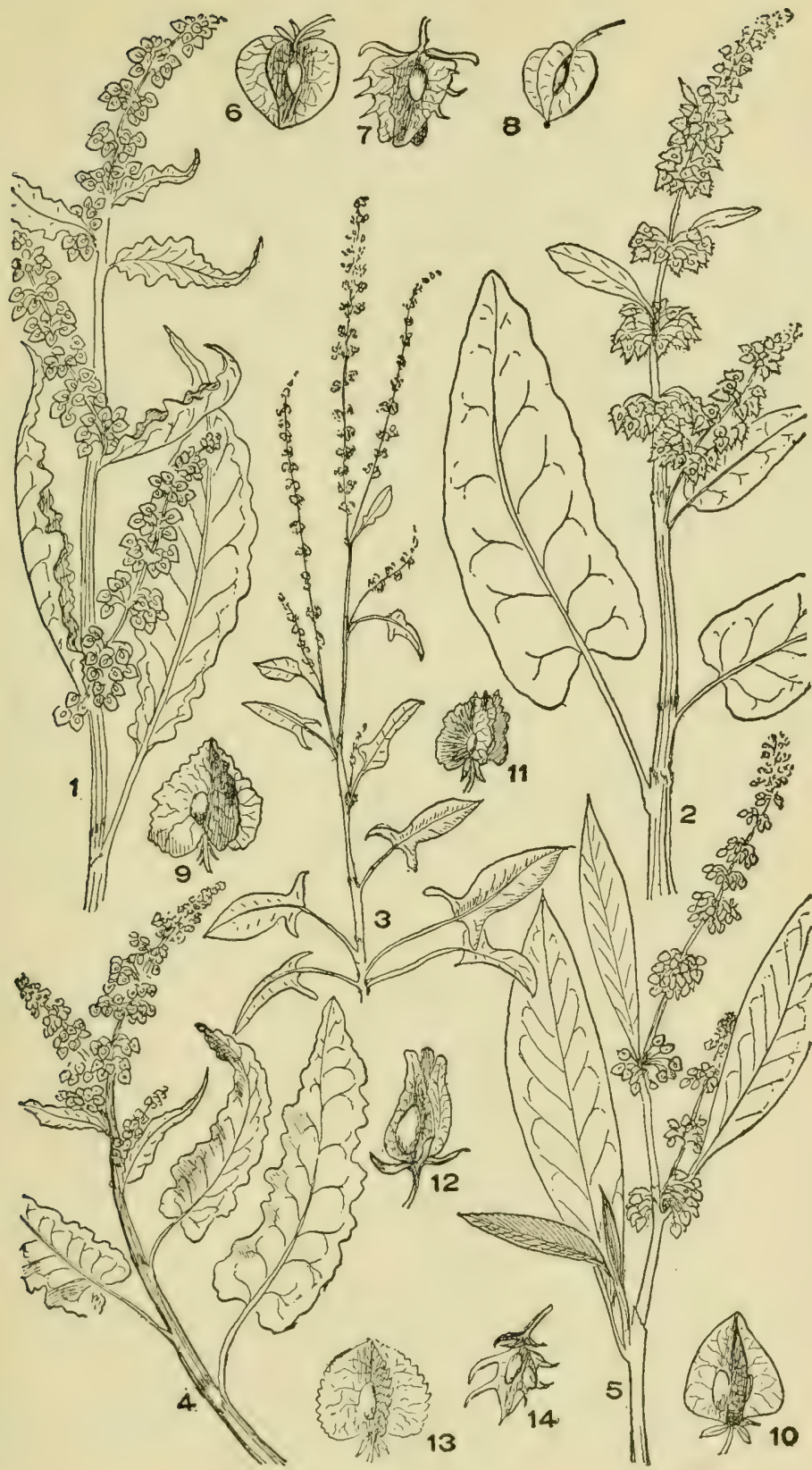

Plate 32

1. Rumex Patientia. 2. R. obtusifolius. 3. R. Acetosella. 4. R. sanguineus. 5. R. salicifolius. 6. Fruit of R. Patientia. 7. Fruit of R. obtusifolius. 8. Fruit of R. altissimus. 9. Fruit of R. crispus. 10. Fruit of $R$. verticillatus. 11. Fruit of R. Acetosa. 12. Fruit of R. sanguineus. 13. Fruit of R. britannica. 14. Fruit of R. persicarioides. 
white or greenish-white or rosy, resembling petals, stamens 8; ovary 1 celled, with a 3-parted style and a stellate stigma.

1. F. esculentum, Moench. Buckwhest. (F. Fagopyrum, Karst.) Flowers in dense clusters, terminal to the branches of the loose inflorescence. Seed much longer than the perianth, its borders not winged.

2. F. tartaricum, (L.) Gaertn. Tartary Buckwneat. Leaves similar to No. 1, but broader and more arrow-shaped. Flowers smaller. Seed winged, the borders of the wings wavy or lobed.

\section{POLYGONUM, L.}

This family includes several somewhat distinct groups of plants, all of which are, in our region, herbs, erect, prostrate or twining. The flowers generally include both stamens and pistils and the corolla is wanting. The divisions of the calyx, generally 5, which are nearly equal, are often colored or white, producing the apparent effect of a corolla. Stamens vary from 5 to 8 . Fruit a dry hard grain, enclosed in some species by the calyx as a seed hull, while in other eases it projects above the hull, the seed being partly uncovered. The ocrea or collaret at the nodes mentioned as characteristic of the Order Polygonales, is in this genus peculiarly conspicuous.

\section{IST. Group.-The Persicariae}

Erect or prostrate herbs, not twining. Flowers in terminal, elongated clusters.

1. Flowers surrounding the axis stem in dense, crowded clusters

Flower clusters single.

Plant found on mountain summits . . . . $P_{0}$ viviparum Flower clusters generally one, sometimes two. Aqquatic plants. Plants smooth. Leaves elliptic . . . . Pmphibium

Leaves egg-shaped, but with long tapering apex $P$. Muhlenbergii
Plant distinctly hairy, generally aquatic - Hartwrightio Flower clusters several. Herbs, generally less than $3 \mathrm{ft}$. high.

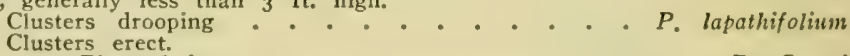

Plant hairy.

Plant not hairy.

Collaret conspicuously fringed . . . P. persicaria

Herb 3 to 8 feet high not fringed $: \div: \div: P^{\circ}$ pennsylvanicum

2. Flowers arranged on the long axis stem in loose interrupted series

The Water Peppers

Collarct long, hairy and fringed with long bristles. Leaves lance-shaped

C. P. hydropiperoides

Collaret long, not hairy, fringed with short bristles.

Stamens 4 to 6 .......... P. Hydropiper

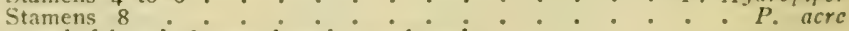

Collaret hairy and fringed, leaves broad egg-shaped.

$\Lambda$ pex of leaves tapering ...... P. virginianum

$\Lambda$ pex of leaves blunt . . . . . . . P. littorale

\section{D. Group}

Prostrate, or, less frequently, erect herbs with flowers all in the axils of the leaves. THE KNotgrasses

Stem leafy to the end; plant prostrate.

Leaves as long as, or usually longer than, the internodes.

Leaves rolled at the margins - . . $P_{\text {. }}$ maritimum

Leaves not rolled at margins ${ }^{\circ}{ }^{\circ} P_{0}$ aviculare

Internodes as long as or longer than the leaves ${ }^{\circ} \cdots{ }^{\circ}$ P. Rayi

Plant erect, leaves broad..$+ \square^{\circ} P^{\circ}$ crsertum 
Leaves at extremity of stem much reduced and transformed to bracts.

Stem round. Plant yellowish-green . . . P. ramoswsimum Stem angular.

Flower and fruit directed upward ........ $P$ tenue Flower and fruit directed downward ... P. Douglasi

3D. Group

Herbs climbing by twining stems or by recurved prickles.

Twining stems, unarmed by prickles.

Seed hull not winged at the angles, or obscurely winged.

Collaret not bristly . . . . . . . P. conrolinulus Collaret bristly

Seed hull conspicuously winged at the angles.

Leaves ovate, cordate at base . . . . . . P. scandens

Leaves narrow, arrow-head shaped . . . . . . P. sagittatum

Leaves triangular, slightly cordate at base . . . P. dumetorum

Leaves egg-shaped, stem prickly. . . . . . P. arifolium

A. Erect or prostrate herbs. Flowers in elongated terminal clusters

1. P. pennsylvanicum, L. (Fig. 5, pl. 33.) Pennsylvanian Persicaria. Plant less erect and less high than No. 5, the elusters of flowers erect or nearly so, bright rose color, spikes often blunt at summit. Leaves long lanee-shaped. Moist soil. July-Sept.

2. P. viviparum, L. (Fig. 6, pl. 33.) ALPINE Bistori. A small plant found on the heights of mountains in New England. Slender, 4 to 8 in. high; collaret conspicuous; flowers crowded, flesh colored, sometimes replaced by small red bulblets (hence the name, viviparum). Lowest leaves oblong with more or less heart-shaped base and blunt apex; upper leaves narrow, lance-shaped.

3. P. amphibium. L. (Fig. 7, pl. 33.) Whter Persicaria. Aquatic; leaves broad, elliptic, thick, rather blunt at each end; generally floating; roots springing from the nodes. Flowers bright pink or rose color. Ponds and lakes, northern New Jersey and northward.

4. P. Hartwrightii, Gray. Hartwrigit's Persicaria. (New Edition, Gray, var. of $P$. amphibium.) Much like No. 2, but-is rough with hairs, at least on the collaret. Grows in mud or floats on water. Swamps and wet places, generally distributed.

5. P. Muhlenbergii, (Meisn.) Wats. Swamp Persicaria. ( $P$. emersum, (Michx.) Britton.) Plant 1 to $3 \mathrm{ft}$. high; leaves long, eggshaped, the apex prolonged and tapering. Swamps and wet places, generally distributed.

6. P. lapathifolium, L. (Fig. 3, pl. 33.) Dock-Leaved Persicaria. Pale Persicaria. Plant larger than most of those of the genus and more ornamental, from 1 to $4 \mathrm{ft}$. high, often in dense masses. Leaves lance-shaped, acute at each end, the apex long and tapering. Clusters of flowers dense, gracefully drooping, white or rose color. Wet places. New England and westward.

Var. incarnatum, Watson, the leaves longer and broader and the spikes long, drooping, linear, several in a cluster. Still another variety, incamum, found in the northern and western sections of our region, is a much smaller plant with smaller leaves and which are covered with a white silkiness beneath, tapering at each end and especially at apex. Ditches and way-side places. Very common.

7. P. persicaria, I. LAdy's Thumb. Plant 6 to 20 in. high; leaves narrow lance-shaped, tapering at each end; the collaret fringed with short bristles. Group of flowers oval or oblong. Leaves conspicuously 
marked with dark spots, often a rather large spot, triangular or other formed, near the central part. Waste places. Common.

8. P. Careyi, Olney. Carey's Persicaria. Plant hairy; clusters of flowers long and curved, less dense than the preceding species. Leaves narrow lance-shaped, tapering at both ends. Shady swamps, mostly in eastern part of our area.

9. P. orientale, L. Prince's Featiner. Plant 3 to $8 \mathrm{ft}$. tall, often grown in gardens but to some extent naturalized in waste places. Leaves 3 to $12 \mathrm{in.} \mathrm{long,} \mathrm{broad} \mathrm{egg-shaped} \mathrm{with} \mathrm{tapering} \mathrm{apex.} \mathrm{Clusters} \mathrm{of} \mathrm{llowers}$ dense, large, bright rose color.

10. P. hydropiperoides, Michx. Wild Water Pepper. Plant 1 to $3 \mathrm{ft}$. high, much branching; leaves narrowly lance-shaped to linear; collarets conspicuously long and hairy with long bristly borders. Flowers arranged on long slender stems in loose series, nearly white. Swamps and wet places. Common.

11. P. Hydropiper, L. (Fig. 2, pl. 33.) Water Pepper. Smart WEeEd. Plant 1 to $2 \mathrm{ft}$. high, smooth. Leaves lance-shaped, sometimes linear, tapering at apex. Flowers arranged as in No. 10. Collarets not hairy and bordered by short bristles. Wet places. Generally distributed.

12. P. acre, HBK. (Fig. 4, pl. 33.) Dotted Water Pepper. Water SMart WeEd. (P. punctatum, Ell.) Plant 2 to $5 \mathrm{ft}$. high, smooth. Leaves narrow lance-shaped, acute at each end. With conspicuous spots on the surface. Flowers greenish-white or tinged with pink. Collaret fringed. IVet places; common.

13. P. virginianum, L. (Fig. 1, pl. 33.) Virginis KNotweed. Plant 3 to $4 \mathrm{ft}$. high, growing mostly in woods and shady places. Leaves broad egg-shaped with tapering apex, the upper often narrow, all on short leafstalks. Sheaths hairy, fringed. Flowers arranged on a long slender stem, sparse. Flower stem usually occupying $\frac{1}{2}$ the height of the plant or more. Rich soil; common.

14. P. aviculare, I. (Fig. 7, pl. 34.) Door WeEd. KNot-grass. Plant very common in neglected door yards, generally prostrate, bluishgreen. Leaves oblong or lance-shaped, mostly acute at each end $1 / 4$ to $2 / 3$ in. long, with very short or no leaf-stalk; interval between the joints rather longer than the leaves. Flowers very small, green, with white borders. Yards and waste places; common.

15. P. littorale, Link. (Fig. 10, pl. 34.) Sirone Kixotween. Similar to No. 13, but leaves mostly blunt and somewhat broaler. Common on shores and in waste places.

16. P. maritimum, I. SEAsine KNotweEn. Leaves fleshy, narrower and shorter than Nos. 13 and 14, the margins gencrally rolled; nodes at very short intervals; sheaths torn by the swelling of the joints. Sands along the seashore.

17. P. Rayi, Ballingt. Ray's KNotween. Plant 3 to 24 in. long, prostrate, hluish-green; leaves longer and hroader than either of the three preceding. Naturalized, found in waste places.

18. P. Fowleri, Robinson. Fowren's KNotweEd. Differs from $P$. Rayi chiclly in the more obtuse leaves, the oblong calyx lobes and the 


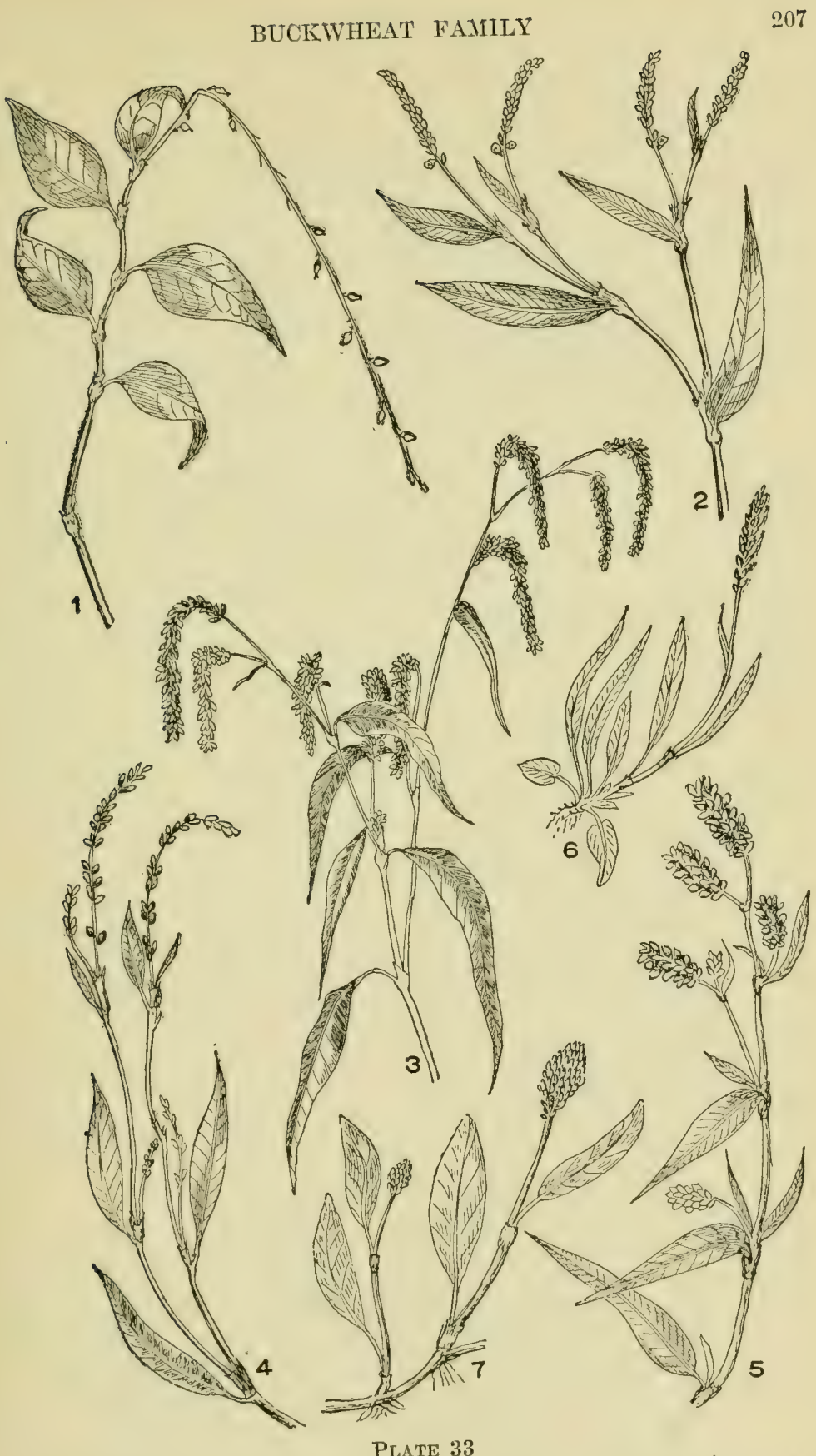

Plate 33

1. Polygonum virginianum. 2. P. Hydropiper. 3. P. lapathifolium. 4. P. acre. 5. P. pennsylvanicum. 6. P. viviparum. 7. P. amphibium. 
smaller more gradually narrowed fruit. Sandy shores, Maine and northward. Aug.-Sept.

19. P. erectum, L. (Fig. 5, pl. 34.) Erect KNotweed. Plant $\frac{1}{2}$ to $2 \mathrm{ft}$. ligh. Leaves oval or oblong, apex acute or somewhat obtuse; joints large with 1 or 2 greenish flowers in the leaf axils. Mostly in rich soil.

20. P. exsertum, Small. (Fig. 4, pl. 34.) Long Fruited Knotweed. Plant about $2 \mathrm{ft}$. Ihigh, slender but ereet; leaves similar to $P$. aviculare, etc. The sheaths at the nodes divided into long silvery points. The 3 -angled seed projects much beyond the hull, hence the name. Brackish marshes, Maine to New York.

B. Leaves of extremity of stem reduced and transformed to bracts. Plants mostly erect

21. P. ramosissimum, Michx. Busny KNotween. Plant erect, often 3 or $4 \mathrm{ft}$. high, yellowish-green. Leaves similar to preceding species, inter-nodes usually shorter than leaves. Collaret fringed in long coarse points which arise from lacerations. Saline soil, coast from Maine to New Jersey.

22. P. tenue, Michx. (Fig. 2, pl. 34.) SLender Krotweed. Stem slender, angled, $\frac{1}{2}$ to $1 \mathrm{ft}$. high, smooth; leaves linear, from $\frac{1}{4}$ to $1 \mathrm{in}$. long with a lateral impression or fold on either side of the mid-vein. Flowers green in axils of leaves, pointing upuarl. Dry soil; generally distributed.

23. P. Douglasii, Green. Douglas's Krotweed. Similar to No. 20, but leaves broader and without the folds. The flowers at the leaf axils point downward. Northern New York and Vermont.

C. Leaves arrow-shaped, egg-shaped or halberd-shaped. All heart-shaped at base. Plants climbers or trailers

24. P. convolvulus, L. (Fig. 8, pl. 34.) BuACK BrxpweEn. Stem somewhat angular; leaves egg-shaped or arrow-head-shaped, upper ones lanee-shaped, tapering at apex. The angles of the seed hull either without wings or very slightly winged. Flowers in pendulous spreading clusters at leaf axils, green. The plant trailing or twining. Common in waste grounds.

25. P. cilinode, Michx. (Fig. 12, pl. 34.) Fringed Buack BindwEED. Leawes broad egg-shaped or spear head-shaped; collarets fringed with depressed bristles, not at border but near the base. Clusters of flowers on stems only slightly spreading or branching. Plant generally twining or trailing over stone fences, etc.

Var. crectum, Peck. Rocky places; generally distributed.

26. P. scandens, T. (Fig. 6, pl. 34.) ('mming False Buckwimat. Vine, sometimes $20 \mathrm{ft}$. high, smonth. Leaves eoreshaperl, heart-shaped at hase, sharp pointed. Feed hull comspieuously winged at the angles, the wings with entire borders. Fruiting calyx about 1 in. long. Woods and thickets. ('ommon. The form I'. dumelorum, L., fruitiner alyx about f in. long, oceasional in our region and very similar to $P$. sermitens.

27. P. dumetorum, L. (Fig. 9, pl. 34.) Cresten Fasse Buckwineat. (I'. eristatum, Engelm, and Gray.) Vine similar to No. 24, 


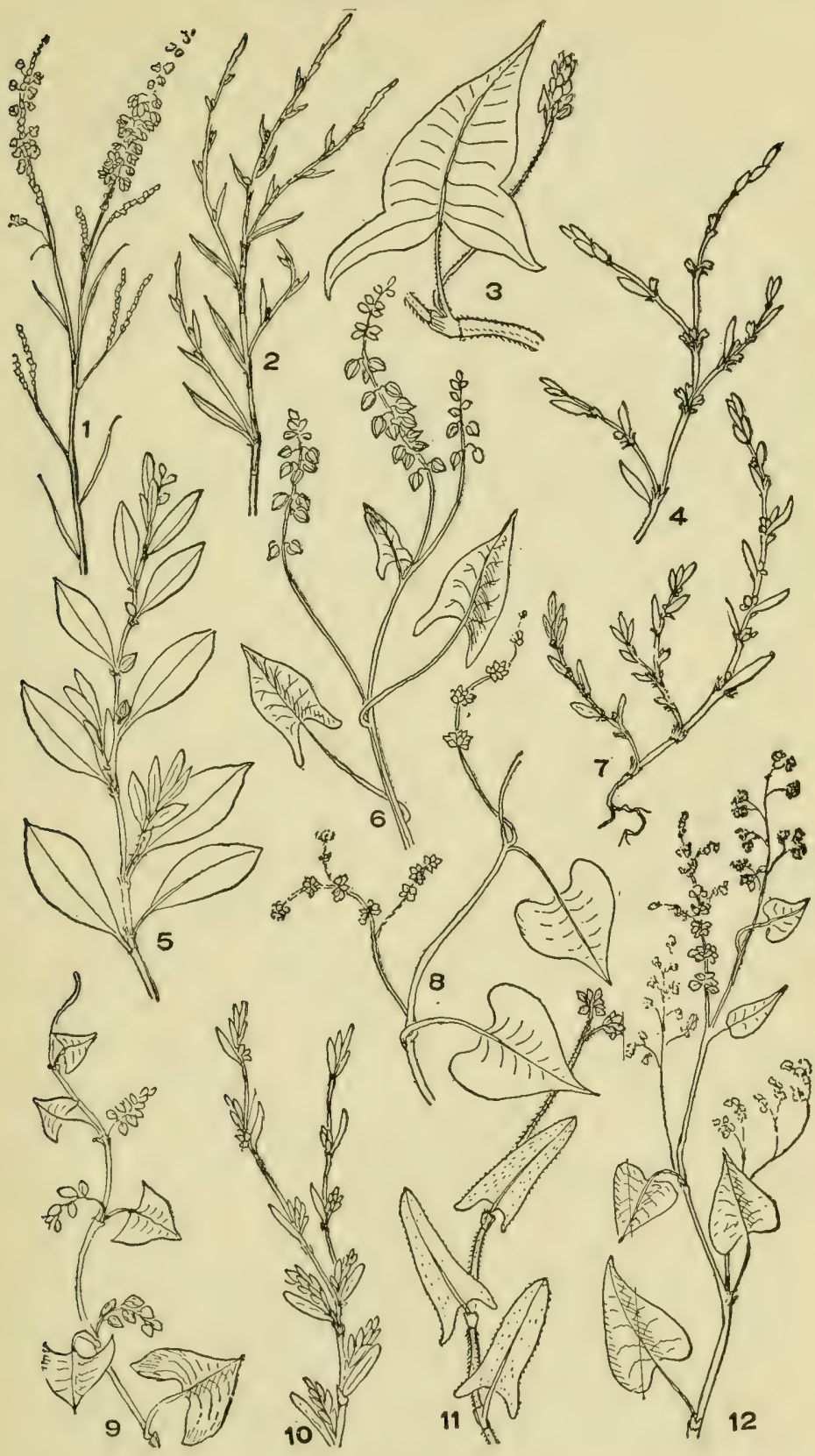

Prate 34

1. Polygonella articulata. 2. Polygonum tenue. 3. P. arifolium. 4. P. exsertum. 5. P. erectum. 6. P. scandens. 7. P. aviculare. 8. P. convolvulus 9. P. dumetorum. 10. P. littorale. 11. P. sagittatum. '12. P. cilinode. 
but leaves broad triangular with depression at hase. Margin of wings of seed hull irregularly notehed. Shady woods, New York and southward.

28. P. sagittatum, L. (Fig. 11, pl. 34.) Arrow-Leaved Tear Trusib. Stem slender, 4-angled, the plant reclining upon other plants and clinging to them by recurved prickles. Leaves narrow arrow-headform, heart-shaped at base; leaf-stalk short. Wet or moist soil; common.

29. P. arifolium, L. (Fig. 3, pl. 34.) Halberd-teaved Tear Tuunb. Stem 4-angled, armed with recurved prickles, climbing by these. Leaves broad egg-shaped with spreading wings at base, on long leafstalks. Flowers few in an elongated eluster. Moist soil. Common.

\section{OXYRIA, Hill.}

A few alpine species with round kidney-form leaves on long leafstalks mostly from the root. Flowers on a scape arising from the base, small, greenish, clustered in a rather loose narrow and elongated group (raceme). Calyx of 4 divisions; stamens 8; fruit a thin, flattened, lensshaped body extending beyond the ealyx and surrounded by a broad wing.

O. digyna, Hill. Mountain Sorrel. High regions of the White Mountains and far north and west. July-Sept.

\section{POLYGONELLA, Michx.}

Herbs with branched conspicuously jointed stems and narrow leaves. Flowers on jointed flower stems. Calyx 5-parted, colored. The 3 inner segments investing the fruit and becoming larger than the others and often developing wings at the angles. Stamens 8; style 3-parted. Fruit a 3-angled dry nut similar to the fruit of Polygonum.

P. articulata, (L.) Meisn. (Fig. 1, pl. 34.) CoAst JorNTweed. Plant 4 to $15 \mathrm{in}$. high; stem wiry, slender, branching. Leaves linear. Flowers in slender diffuse clusters on flower stalls closely jointed. Flowers very small, rose color. Sandy coasts and inland sandy places.

\section{Order IV.-CHENOPODIINEAE. The Order of the Pig- weeds}

TTerhaccous plants, some with fleshy stems and leaves. Teares alternate (except in Salicornia, in our region), smooth or covercel with hairs. The flowers are, in general, small, inconspicuous, sreen, crowiter in glomerate masses or in spilies, but sometimes solitary and moderately conspicuous, while in one instance the flomerate masses are brightly colored. Among the Amaranths some pecies have colored bracts. In some families the flowers are perfect, having the stamens and pistils in the same envelope; in other families the stamens and pistils oceupy different flowers and sometimes different plants. The corolla is always wanting; (alyx generally divided in 5 parts, but in Salicomia and some 
species of Amaranths, 2 or more. The stamens are ordinarily as many as the parts of the calyx and opposite to them. In general there are 2 carpels (divisions of the pistil). The fruit is a small, hard, dry seed (achene) which is persistently enveloped by the perianth. It becomes in many instances an important indicator of the genus by the form which the embryo takes in the seed. If cut longitudinally the embryo may be seen in the form of a horseshoe or in that of a complete ring or as a spiral.

Flowers without membraneous bracts.

CHENOPODIACEAE Flowers with dry membraneous bracts AMARANTHACEAE

\section{Family I.-CHENOPODIACEAE. Goosefoot FAMily}

Flowers without bracts, minute, greenish. Stamens generally as many as the divisions of the calyx and inserted opposite to them or on their base. Calyx persistent and enclosing the fruit.

Flowers in glomerate masses.

Leaves net-veined, spreading.

Stamens and pistils in same flower.

Calyx 5-parted.

Flower groups axillary and terminal

Flower groups only axillary . . Roubieva Calyx in 3 parts . . . . . . . Blitum

Stamens and pistils in different flowers . Atriplex Leaves linear, plant not fleshy . . . . Kochia Leaves aborted or fleshy and linear.

Flowers glomerate, fleshy herbs, leaves reduced to scales . . . . . . . . . Salicornia

Fleshy herbs, leaves linear, rounded . Suaeda Flowers not in glomerate masses.

Fleshy herbs, leaves terminated by prickles Salsola

\section{CHENOPODIUM, L.}

Herbs with alternate leaves on lond leaf stems with small green flowers arranged in glomerate masses, without bracts, the glomerules in the axils of the leaves, and mostly in terminal groups. Calyx generally 5 -parted. Stamens 1 to 5 .

(The leaves used here in differentiating the species are those which are most typical, those from about the middle of the plant and possibly the general appearance of a group and not of an individual leaf.) 
Leaves white, mealy.

Rhomboid . . . . . . . . . . . C. album

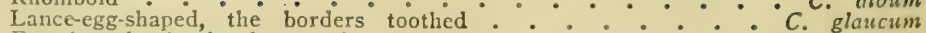

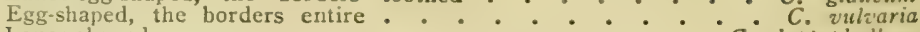
Lance-shaped . . . . . . . . . C. leptophyllum

Leaves green, not mealy.

Varrow, gencrally lance-shaped . . . . . . . . C. Bosciaum

Rhombic . . . . . . . . . . C rubrum

Feather-formed by deep sinuses . . . . . . . C Botrys

Oblong or broad lance-shaped . . . . . . . C ambrosioides Egg-shaped . . . . . . . . . . . . . C. anthelminticum Triangular or nearly so.

Border not toothed or notched . . . . . C. Bonus Henricus Border with I to 4 long teeth : $:$ : $:$ C. hybridum Border with a number of indentations or sharp serrations.

Base of leaf convex, more or less rounded out : C. murale Base of leaf concave, more or less depressed inward $C$. urbicum

\section{All annual except No. 10}

1. C. album, I. (Fig. 3, pl. 35.) Wirte Goosefoot. Pigweed. Plant smooth; 1 to $10 \mathrm{ft}$. high. Whole plant more or less mealy-white. Leaves, rhomboid with sinuate dentations on the two sides; upper leaves narrow to lance-shaped. Stem with alternate green and white or purplish and green stripes. Flowers in compact glomerules which are arranged in loose, leafy, clusters axillary and terminal. Calyx, with keels at the angles, completely enveloping the fruit. Seeds shining black. Embryo completely annular. A common weed in cultivated and waste places.

2. C. glaucum, L. (Fig. 9, pl. 35.) OAK-Leaved Goosefoot. Plant smooth $\frac{1}{2}$ to $1 \frac{1}{2} \mathrm{ft}$. high, prostrate or erect. Plant white, mealy. Leaves oblong to lanee-shaped with deep indentations; teeth rounded, abont 4 on each side; green above, bluish-white beneath. Upper leaves narrow and entire. Seed globose, sharp edged, only partly enveloped by calyx, embryo annular. Like the former species a common weed.

3. C. vulvaria, L. Strnking Goosefoot. Similar to No. 2, but leaves are exg-shaped and the margins are without lobes or teeth. In situations similar to the last.

4. C. leptophyllum, (Moq.) Nutt. (Fig. 5, pl. 35.) NARrowI.EAVE Gooskfoot. Plant densely mealy, erect, $\frac{1}{2}$ to $2 \mathrm{ft}$. high. Leaves narrow lance-shaped with entire borders, $\frac{1}{2}$ to 1 in. long. Glomerules clocely packind about the stem. Sea shore, Connecticut to New Jersey. Shores of Lake Erie.

5. C. polyspermum, I. (Fig. 4, pl. 35.) MANT-SEEnFd GoosEFoot. Plant smooth, low, spreading or sometimes erect. Leaves elliptic or exrg-shaped, green, no mealiness. Clusters of flowers leafy; ealyx partly exposing the fruit. Weed, not very common.

6. C. Boscianum, Moq. (Fig. 1, pl. 35.) Bosc's Goosefoot. Plant slencler, orect (alwut $2 \mathrm{ft}$. high), smooth, mot muly or only slightly so. Jeaves mostly laner-shaped, tapering at, each eme, the borders not indented, errenen on lentle sides. Flowers in lonse leafy elusters on slender branches. Calyx nearly eovering seed. Woods and thiekets, New York, New Jersey and south.

7. C. urbicum, J. Trimsint Goosfroot. City fioosfroot. Plant erect, 1 to $3 \mathrm{ft}$. high. Stem striated, green and white. Teaves triangular with irrenular trianirular teeth. Flower clustere foulless or nearly so, tall and spike-like, the flower groups erowded agranst the stem. Common. 


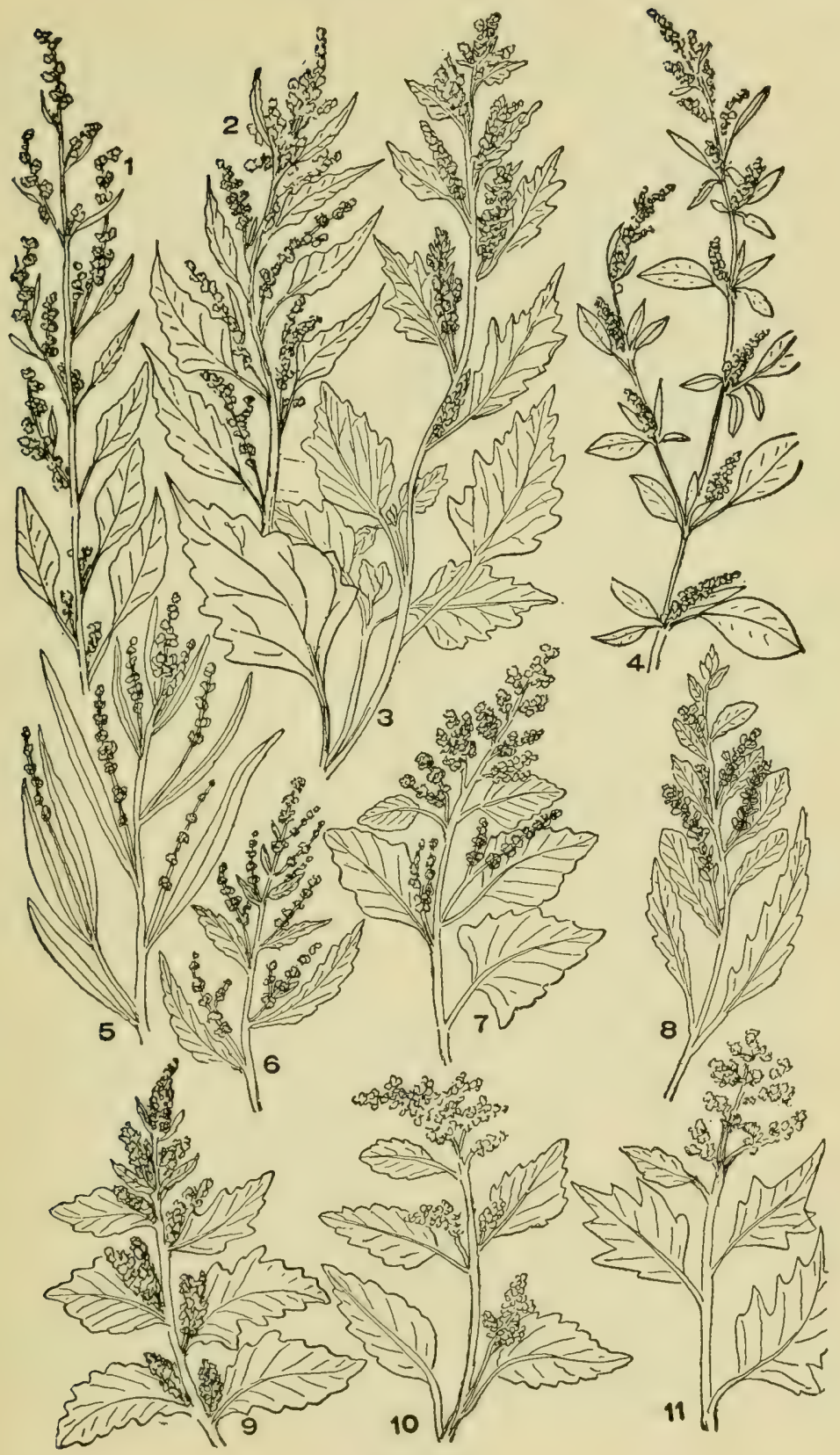

Plate 35

1. Chenopodium Boscianum. 2. C. rubrum. 3. C. album. 4. C. polyspermum. 5. C. leptophyllum. 6. C. anthelminticum. 7. C. Bonus Henricus. 8. C. ambrosioides. 9. C. glaucum. 10. C. murale. 11. C. hybridum. 
S. C. murale, I. (Fig. 10, pl. 35.) Nettle-leaved Goosefoot. Plant with an ollensive odor, leaves thin, shining green, rhombic to eggshaped, apex acute, margins sharply and deeply toothed, clusters of flowers loose and spreading. Seeds not shining, acute at borders. Waste places; common.

9. C. hybridum, L. (Fig. 11, pl. 35.) Maple-Leaved Goosefoot. Plant bright green, 2 to $4 \mathrm{ft}$. high. Leaves triangular with long taper point and 1 to 3 triangular or lance points on margin of each side. (llusters of flowers lealless. Calyx leaving fruit exposed. Woods and thickets. Common.

10. C. rubrum, L. (Fig. 2, pl. 35.) Red Goosefoot. Somewhat fleshy, 1 to $2 \frac{1}{2} \mathrm{ft}$. high, stems becoming mostly red or with red and green stripes. Leaves shining, green or red, rhombic, deeply and sharply toothed, base pointed, apex acute; upper leaves lance-shaped. Flower clusters seattered in axillary and terminal leafy spikes often the whole length of stem. Calyx lobes rather fleshy, and nearly or quite covering the seed. Saline soil; along the sea coasts.

11. C. Bonus Henricus, L. (Fig. 7, pl. 35.) Good Kirg Hexrr. Perenial Goosefoot. Stem ridged 1 to $2 \frac{1}{2} \mathrm{ft}$. high. Leaves large, triangular, margins entire, green or slightly mealy. Flower groups rather dense, crowding closely around the stems, which are not freely branching, clusters leafless. Naturalized. Not very common. In waste places.

12. C. Botrys, L. Featier Geranitur. Jerusalem OAK. Plant $\frac{7}{2}$ to $2 \mathrm{ft}$. high, with a strong odor; stem silky and glandular, somewhat hairy; leaves with long stems, oblong but cut by deep sinuses into a feather-formed leaf, the lobes rounded and toothed. Flowers in small groups looscly arranged in elusters only slightly leafy. Calyx partially enclosing fruit. Waste places throughout our area.

13. C. ambrosioides, L. (Fig. 8, pl. 35.) Mexican TeA. Plant 2 to $3 \mathrm{ft}$. high, strong seented, much branching. Leaves 1 to $31 \mathrm{in}$. long, wilh very short leaf-stalk, ovate, margins sinuous. Glomerules, small axillary masses in long narrow very leafy clusters, these clusters desernding far upon the stem. Calyx completely enclosing the fruit. In wasto places.

14. C. anthelminticum, I. (Fig. 6, pl. 35.) Woraseed. Plant resembling No. 12, lut leaves strongly toothed and clusters of glomerules more clongated, less leafy. Upper leaves very narrow. Waste places. Naturalized from Europe.

\section{ROUBIEVA, Moq.}

$\Lambda$ perennial plant of somewhat offensive odor, prostrate, much branched, with glomerules of very small flowers only in the leaf axils. Flowers with stamens only or pistils only or with both. Calyx 3- to 5-parted, enclosing the fruit; stamens 5, within the calyx.

R. multifida, (L.) Mog. (Fig. 2, pl. 36.) Cut-teaven Goosefont. Inaves small, lance-shaped, deeply cut at margins into linear or laneeshaped lohes, ahont 2 on each side, apex acute. Flowers 1 to 5 in a group, situated at the leaf axils. In waste places. Naturalized. June-Sept. 


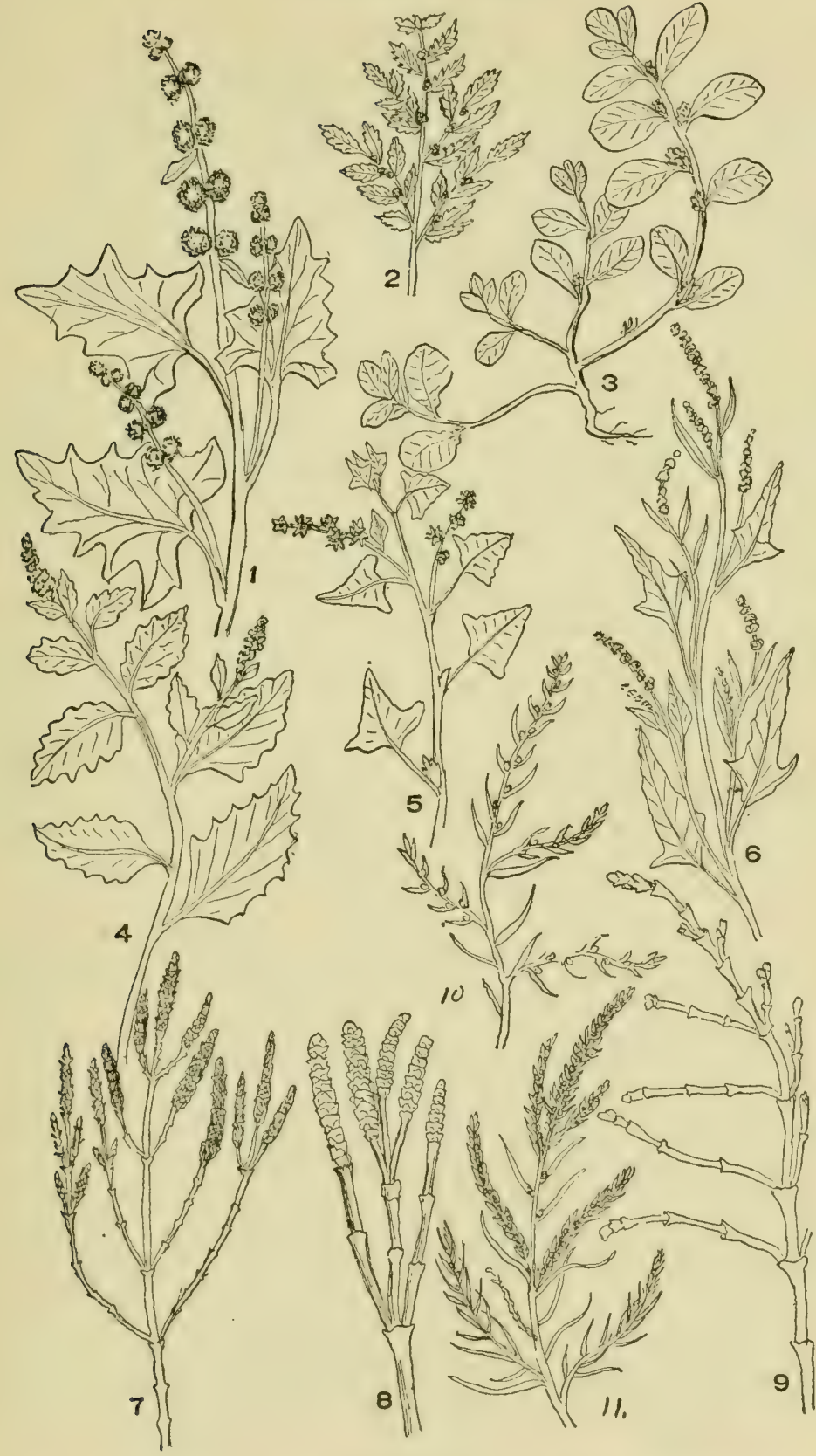

Plate 36

1. Blitum capitatum. 2. Roubieva multifida. 3. Atriplex arenariil. 4. A. rosea. 5. A. hastata. 6. A. patula. 7. Salicornia herbacea. 8. S. mucronata. 9. S. ambigua. 10. Suaeda maritima 11. S, americana, 


\section{BLITUM, L.}

Plant strongly resembling the Chenopodiums with flowers bearing stamens or pistils or both. Calyx fleshy and turning bright red at maturity giving to the rounded flower groups, which are arranged in long, erect, interrupted clusters, the appearance of bright berries attached to the stem. Stamens 1 to 5 .

B. capitatum, L. (Fig. 1, pl. 36.) Strawberry Bltte. Stem leafy helow, but leafless above where the glomerules of flowers appear. Leaves triangular or spear-shaped, the base slightly concave, the other margins wary indented. Leaf stems about as long as the leaves. Mostly in wasto places. June-Aug.

\section{ATRIPLEX, L.}

Plants resembling the Chenopodiums. Flowers bearing stamens or pistils, mostly the two forms on different plants, but often on the same; rarely also flowers with both stamens and pistils. Calyx of staminate flowers 3- to 5-parted, the parts united at the base; that of pistillate flowers of 2 sepals which completely enclose the fruit, and which are more or less united and which are leafy bract-like. Embryo completely annular. Leaves alternate, rarely opposite.

Leaves long, narrow with plane margins or with one conspicuous tooth or more

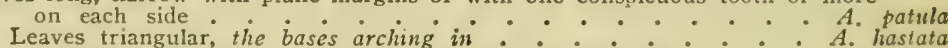

Leaves egg-shaped or triangular, bases arching out . . . A. rosea Leaves oblong, margins plane . . . . :A. arcnaria

1. A. patula, L. (Fig. 6, pl. 36.) Spreading Oracrie. Stems very much branched at base, the lowest branches spreading. Leaves alternate, narrow lance-shaped, with one or more conspicuous teeth on each margin or without teeth, the upper leaves linear. All the leaves tapering at the base, the upper nearly or quite without leaf-stalks, the lower with molerately long stalks. Flowers in glomerules along a branching stem. Waste places. July-Aug.

2. A. hastata, L. (Fig. 5, pl. 36.) Halbern-Leaved Oracie. Stem erect, branching, rigid. Lower branches spreading. Leaves on slender stems, opposite, sometimes alternate, triangular with the bases arching in. The margins somewhat sinuous or toothed. Upper leaves narrow, margins entire. Calyx segments triangular, with or without teeth. Salt marshes and waste places. Aug.-Oct.

3. A. rosea, I. (Fig. 4, pl. 36.) Ren ORAcrie. Stem erect or prostrate, mealy. Leaves erg-shaped or rhomboid with the base arching outurarl, often turning red. T'pper leaves narrow lance-shaped and gen(rally toothed. Ieaf margins sinuate or toothed. Calyx of fruiting flowers rhomboid with conspicuous teeth and with several tubereles on the sides. filomerules arranged as in the preceding species. Waste places, sea coasts, occasionally inland.

4. A. arenaria, Nutt. (Fig. 3, pl. 36.) SeA-Bescm Atmiprex. Mealy, whitish, stem prostrate much branched; leaves oblong, margins without treth. Fruiting flower, calyx triangular, toothed with tubereles on sides. Sandy sea beaches, Mass., southward. 


\section{KOCHIA, Roth.}

Flowers with both stamens and pistils or with staminate and pistillate flowers separate but on the same plant. The herbaceous perianth cupslaped, of 5 divisions. Stamens 5 , pistils 2 , which are united at the base. Fruit dry and hard, covered by the 5-parted calyx.

K. Scoparia, (L.) Roth. KocinA, An herbaceous or shrubby plant, stifi, erect, with linear leaves pointed at the end; branches long, flowers in the leaf axils. Introduced from Europe, where it is sometimes cultivated for making brushes, brooms, etc.

\section{SALICORNIA, L.}

Low fleshy plants growing in salt marshes; leafless or with the leaves reduced to small scales. Stem round; branches opposite. The stem articulated, the inconspicuous flowers partly buried in the nodes. Flowers mostly of 4 toothed, fleshy, sometimes winged divisions. Generally a single stamen, pistils 2. Fruit dry.

\section{Annual}

1. S. herbacea, L. (Fig. 7, pl. 36.) Slender Glasswort. (S. europaca, L.). Stems quite slender, the flower bearing spikes being at most only slightly more than one line in diameter, simple or freely branched. The scales very inconspicuous and rounded at the ends. Stamens of the middle flower protrude beyond the scale higher than do those of the two flowers at its sides. The plant remains green or turns red in autumn. Salt marshy places along the coast.

2. S. mucronata, Bigel. (Fig. 8, pl. 36.) PoINTEd-Scaled GlassWorT. (S. Bigelovii, Torr.). Stems much stouter than those of No. 1. Scales conspicuous and pointed at the extremities. At maturity the whole plant turns red. Plant 3 to 15 in. high. Salt marshes.

\section{Perennial}

3. S. ambigua, Michx. (Fig. 9, pl. 36.) Woody Glasswort. Plant arising from a woody rootstock; erect or reclining; scales pointed, short. Salt marshes along the sea coast.

\section{SUAEDA, Forskal. (Dondia, Adams)}

Flowers without footstalks, in the axils of the thick, almost rounded fleshy leaves, with both stamens and pistils. Perianth consisting of the fleshy calyx, which is in 5 divisions and which surrounds the fruit. Stamens 5, pistils 2 or 3 . Plant of the sea-side.

1. S. americana, (Pers.) Fernald. (Fig. 11, pl. 36.) TALL SEABuigit. Plant 1 to $2 \mathrm{ft}$. high, erect or rarely prostrate, much branched or nearly simple; dark green without whitish bloom. Leaves of the stem linear, sharp pointed, $\frac{1}{2}$ to $1 \frac{1}{2}$ in. long, somewhat 3 -angled. Salt marshes, common.

2. S. maritima, (L.) Dumort. (Fig. 10, pl. 36.) Low SEA-BLigrit. PIant 5 to $12 \mathrm{in.} \mathrm{high,} \mathrm{light} \mathrm{green} \mathrm{and} \mathrm{covered} \mathrm{with} \mathrm{whitish} \mathrm{bloom.}$ Leaves $\frac{1}{2}$ to $1 \mathrm{in}$. long, half round, not as sharp at extremity as those of No. 1. Salt marshes along the coast. 
3. S. Richii, Fernald. Rich's SuAEda. Stems procumbent, forming mats. Leaves dark green, nearly cylindric, obtuse. Salt marshes and wet sand. Maine.

8. SALSOLA, L.

Herbs with branching stems and stiff awl-shaped prickly leaves in the axils of which the solitary flowers appear, directly on the main stems. Flowers with two fleshy bracts, calyx of 5 parts, stamens mostly 5, styles 2.

1. S. Kali, L. (Fig. 6, pl. 37.) Saltwort. A coarse dull green, diflusely branching plant at the seaside. The branches more or less ascending or nearly prostrate. Leaves alternate, prickly; flowers solitary in axils of leaves, the divisions forming a violet colored rosette.

2. S. Tragus, L. (Fig. 5, pl. 37.) Russian Thistle. Stem more slender than No. 1, leaves similar but less fleshy. Grows in cultivated fields. Introduced.

\section{Family II.-AMARANTHACEAE. AmaRantil Family}

Herbaceous plants, weeds, with simple leaves without stipules and with the greenish or white flowers generally in more or less densely crowded terminal heads or in lesser clusters in the axils of the leaves. Flowers with both stamens and pistils or with these organs in separate flowers in the same plant or with stamens on one plant and pistils on another. Petals absent; calyx dry herbaceous with 5 divisions, or absent. Flowers partly or wholly surrounded by dry persistent bracts, commonly 3. These bracts in some cases brightly colored.

Flowers with stamens and pistils, or, if these organs are in different flowers, both kinds on the same plant. Calyx of

5 divisions . . . . . . . . . Amaranthus

Staminate and pistillate flowers not on the same plant; pis-

tillate flowers without calyx . . . . . . Acnida

\section{AMARANTHUS, L.}

Coarse lerbacenus weeds in waste grounds and gardens. Leaves simple, alternate, oval or rhomboid, indented. Stamens 5 or rarely less, either in the same flower with the pistils or in separate flowers gencrally on the same plant. Pistils 2 or 3 . Flowers small, green or purplish, with three bracts.

Flowers in terminal spikes and axillary clusters.

Clusters in thick dense spikes......... . A. retroflezus

Clusters in slender spikes.

Leaves pointed at apex.

Dry spines at base of leaves . . . . . . . A. spinosus

Leaves without spines at base . . . . . . A. hybridus

Leaves rounded and dented at apex ..... A. lividus

Leaves rounded, not dented at apex, flowers in interrupted spikes. 


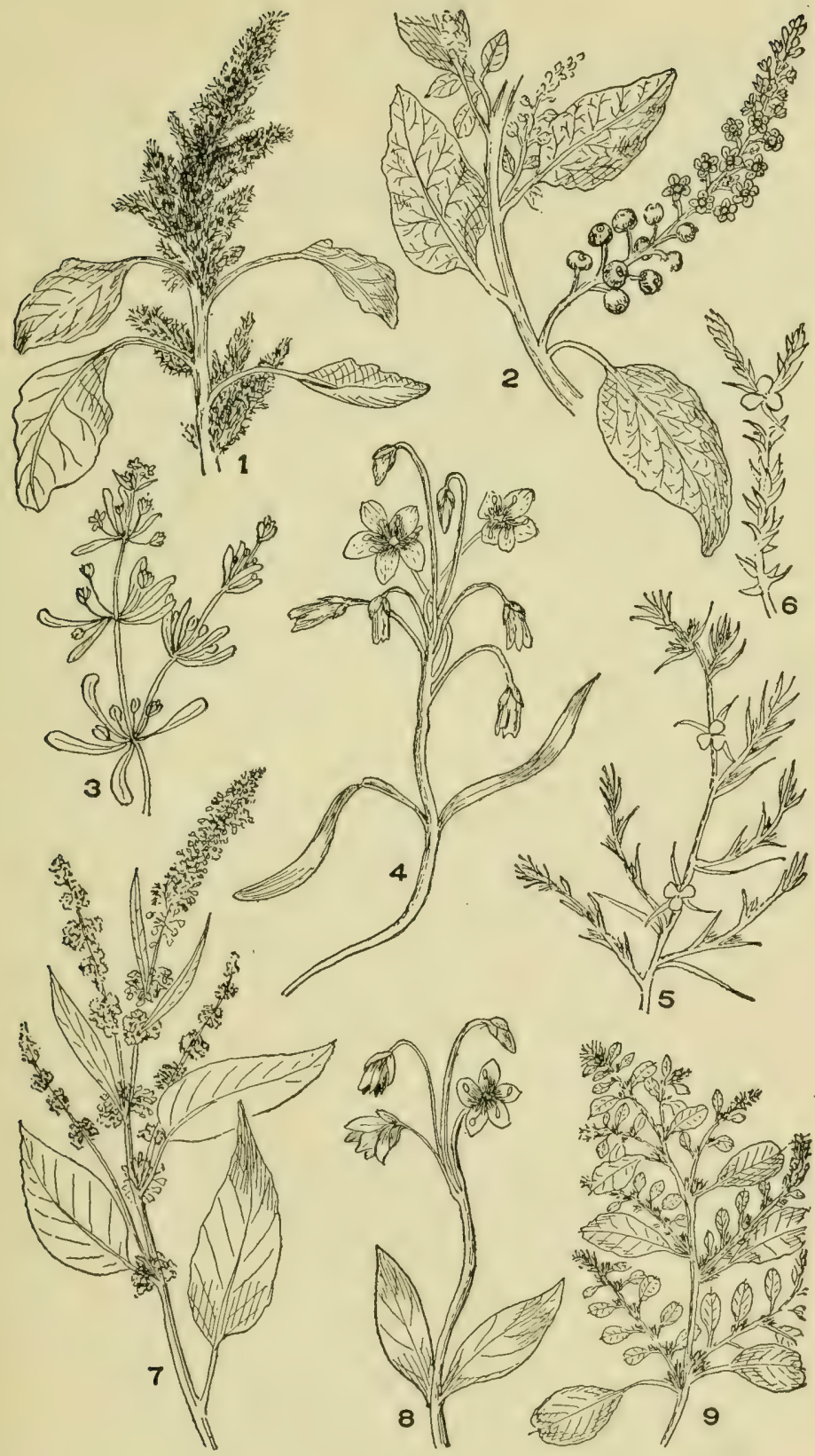

Plate 37

1. Amaranthus retroflexus. 2. Phytolacca decandra. 3. Mollugo verticillata. 4. Claytonia virginica. 5. Salsola Tragus. 6. S. Tali. 7. Acnida cannabina. 8 Claytonia caroliniana. 9. Amaranthus graecizans. 
Flower clusters in the axils of leaves. Leaves broadest at apex, with smooth margins, and a bristle point at apex.
Stem prostrate

Stem erect . . . . . . . . . . . . . A. graecizans

Leaves broadest at base.

Borders indented . . . . . . . . A. crispus

Borders smooth, indentation at apex : $: \therefore$. A. pumilus

1. A. retroflexus, L. (Fig. 1, pl. 37.) Rougir Pigweed. A common coarse weed in gardens with stout branching stem and long slender stalked leaves which are egg-shaped, rhombic or irregular, generally pointed at apex and less pointed at base. The leaf margins are smooth or undulate. Plant more or less covered by soft hairs. Flowers in compact spikes without leaves. Found mostly in cultivated grounds.

2. A. hybridus, L. Slexder Pigweed. Similar to No. 1, but more slender. The flower spikes are longer and less thick, leaves less rough and of a deeper, dull green, or dark purple. Found, like No. 1, in cultivated grounds.

3. A. spinosus, L. SPINy Amarantir. Plant smooth. Leaves eggshaped or ovate-rhombic on long slender leaf stalks. At the base of the leaf stalk and of the small branches start two narrow, dry spines. The upper clusters of flowers form cylindric spikes and are staminate, while the pistillate flowers are in globular clusters below. Flowers inconspicuous, yellowish-green. Waste grounds. Naturalized.

4. A. blitoides, S. Wats. Prostrate Amarantir. Plant prostrate, smooth, pale green. Leaves broadly rounded at apex, narrow and pointed at base. Flowers in leafy clusters in the leaf axils. On railroad ballast in our area.

5. A. graecizans, L. (Fig. 9, pl. 37.) Tumble Weed. Smooth, palo green; stem $\frac{1}{2}$ to $2 \mathrm{ft}$. high, much branched and whitish. Leaves similar to No. 4, $i$. e., obversely egg-shaped or spatulate, with a fine spine at the apex. Flowers surrounded by dry spiny bracts in small axillary groups. Common in waste grounds.

6. A. lividus, T. Perplisir Amarantir. Plant slender, 1 to $2 \mathrm{ft}$. high, with purplish and somewhat sueculent stem. Leaves egrg-shaped or rhomboid-ovate with apex obtuse and eonspieuously indented. Terminal slender spikes of staminate, lower rounded clusters of pistillate llowers. Not very common. Eastern parts.

7. A. deflexus, L. Jow Amarantir. Similar to No. 6, with leaves leis obtuse and not indented at apex. Waste places, eastern parts of our area.

8. A. crispus, (t.) Bram. ('misp-Leavid Amaraxtif. Slender, prostrate, profusely branched, spreading as a mat $\frac{1}{2}$ to $2 \mathrm{ft}$. in diameter over the fround. Leaves oval or rhomboid with umblating borders. Clusters of flowers small in the leaf axils. Stems hairy. Albany, New York City and a few other localities.

9. A. pumilus, Riaf. Const Amainaxir. Low or prostrate, 3 to $\mathrm{S}$ in. high, with fleshy oval leaves or with leaves broader at apex. All distinctly indented at apex. On sea beaches, lihode Island and southward.

2. ACNIDA, I.

Our speceies a tall sueculent herb resembling the Amaranths. The 
flowers, however, occur, the staminate on one and the pistillate on another plant. The pistillate flowers have no floral envelope except the dry bracts. Both forms are grouped in slender cylindric clusters similar to those of the Amaranth.

A. cannabina, L. (Fig. 7, pl. 37.) Salt Marsi Water Hemp. Plant 2 to $6 \mathrm{ft}$. tall, in swampy places. Leaves, lance-shaped to linear with long not very sharp points at apex, narrowed at base. Leaf stalk rather shorter than leaf. Salt marshes, New Hampshire and southward.

\section{Order V.-PHYTOLACCINEAE}

Herbs with simple alternate, opposite or verticillate leaves. In our species all without stipules Flowers regular in form, with both stamens and pistils. Number of stamens variable. Perianth of 5 parted calyx, the sepals white or slightly colored. Ovary of several cells composed of as many carpels, united to form a fleshy berry or a capsule which splits either longitudinally or transversely.

\section{Fruit a fleshy berry . . . . PHYTOLACCACEAE Fruit a capsule . . . . . . . AIZOACEAE}

\section{Family I.-PHYtolaccaceae. Pokeweed Family}

The general characters of the family are those of the order, with, in the family, a calyx which more or less resembles a corolla, with 5 to 15 stamens and with fruit composed of several carpels united.

\section{PHYTOLACCA, (Tourn.) L.}

The divisions of the white or pinkish calyx rounded and equal.

P. decandra, L. (Fig. 2, pl. 37.) Pokeweed. Plant 4 to $12 \mathrm{ft}$. high, stem succulent, branching, the flowers shallow bell-shaped. Flowers arranged along the flower stem as a raceme generally 4 to 6 in. long. Stamens 10 , shorter than the rounded sepals. Ovary of 10 eells which form a ring constituting the fleshy berry which, when ripe, is dark purple in color. The root is an acrid poison. Rich soil throughout our region.

Fanily II.-Aizoaceae. Carpet Weed Family

In our region two species only, these are prostrate, spreading herbs with opposite or verticillate leaves without stipules; flowers 
small, calyx of 5 sepals, petals absent. Fruit a capsule opening by a circular transverse line or by lines up and down.

Capsule opening by a transverse line . . . Sesuvium

Capsule opening by a longitudinal line . . Mollugo

\section{r. SESUVIUM, L.}

Prostrate fleshy herb at sea side with opposite spatula-shaped leaves, broadest at apex, which is rounded and sometimes slightly indented. Flowers without flower stems, springing at the leaf axils, small, pink or purple; stamens 5; capsule 3 to 5 celled with many seeds. The capsule opens hy a circular line by which the eap separates from the cup-like seed basket.

S. maritimum, (Walt.) BSP. (Fig. 5, pl. 38.) Sea Purslaxe. Growing in sands by the sea shore. Long Island and southward.

\section{MOLLUGO, L.}

Herb, profusely branching with leaves inserted in whorls, of about 5 each, spatula-shaped, outer third broadest. Stipules absent. Flowers growing in circles at the leaf vhorls, of 5 sepals, white, small. A prostrate weed in cultivated grounds and waste places.

M. verticillata, L. (Fig. 3, pl. 37.) Carpet Weed. Indian ChickWEED. Prostrate, branching profusely, forming a mat. Flower pedicels several at the axils of the leaves, each bearing a single white flower. Roadsides and cultivated grounds. 


\section{Group II. POLYPETALAE. Flowers with Distinct Petals}

While, among modern botanists the division Choripetalae includes both plants whose flowers have calyx and corolla and plants whose flowers have no corolla, it is most convenient for the purposes of this work to follow the older practice of dividing the class into Apetalous and Polypetalous Exogens. In the preceding orders of Exogens or Dicotyledons the corolla has been absent or only in a rudimentary stage. In the remaining orders of Choripctalae the petals are evident and distinctly separate, with few exceptions.

\section{Order I.-PORTULACINEAE}

The general characters of the order are found in those of the single family.

\section{Family. Portulacaceae. The Purslane Family}

This family is represented in our region by three genera, Claytonia, Montia and Portulaca. They are all small herbs with weak stems and more or less fleshy leaves which are always, in our native species, opposite. The flowers are provided with both calyx and corolla. The divisions of the former are but 2, of the latter 5, which are regular or very nearly so. Stamens 5, opposite the petals (Claytonia) or less in number (Montia) or variable in number (Portulaca). The fruit is a capsule, opening, in Portulaca, like a lid, in Montia and Claytonia splitting at the sides by 3 valves.

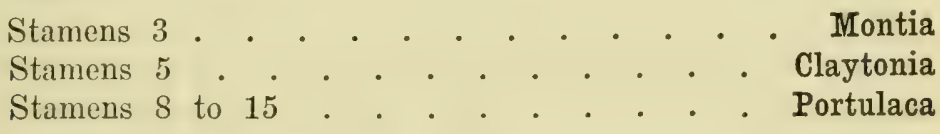

I. MONTIA, L.

Small annual spreading plant with opposite fleshy leaves. Flowers small, fumnel-shaped, white, of 5 petals and 2 sepals; flowers arranged in groups or singly. Stamens 3, style 3-parted, capsule 3 -valved with 3 seeds.

M. fontana, L. (Fig. 2, pl. 38.) Water Chickweed. Blinks. Water Blinis. A densely tufted plant in springs and wet places. 
Light green, spreading, prostrate or partly erect. Flowers mostly terminal.

\section{CLAYTONIA, L.}

Low weak stemmed plants with a pair of opposite leaves, exceptionally 2 or even 3 pairs. Sepals 2, petals 5 , stamens 5 , inserted at the base of the petals, the style 3 parted at apex, capsule 3 to 6 sided. The bellshaped, pretty, purple veined flowers in a loose terminal cluster.

1. C. virginica, L. (Fig. 4, pl. 37.) Sprixg Beautr. The weak stem springing from a tuberous root. Leaves linear lanee-shaped (3 to 7 in. long). Grows in moist open woods. Common. April-May.

2. C. caroliniana, Michx. (Fig. 8, pl. 37.) Carolina Sprixa BeautY. Springing from a tuberous root. Leaves broader than No. 1, ovate-lanceolate or oblong. Principally along the Alleghanies. AprilMay.

\section{PORTULACA, L.}

Prostrate spreading weed with opposite fleshly leaves, smooth, with terminal inconspicuous yellow flowers. Sepals 2 , petals 5 , stamens 7 to 15, petals generally 5 inserted on the calyx. Styles united below, divided above to 2 to 8 . Seed box a capsule which often divides as a lid.

P. oleracea, L. Purslane. Pursley. Prostrate, frecly branching. Leaves fleshy, broad-ovate, clustered at the end of the stems. Flowers without flower stems at the axils of the leaves. In cultivated grounds. A troublesome weed.

(The portulaca of the flower gardens is $P$. grandiflora, Ilook. It is occasionally found escaped from cultivation.)

\section{Order II.-CARYOPHYLLINEAE}

Flowers all regularly symmetrical, with calyx and corolla cxcept in Paronychia, Anychia and Scleranthus, in which genera the corolla is wanting, as it is also in a few species of other genera. Divisions of the calyx 4 or 5 , the petals when present erual in number to the calyx divisions. Sepals free or growing together forming a calyx tube. Petals never growing together. Stamens twice as many as the sepals or less than that number. The stamen filaments sometimes united with each other, more freguently free. Ovary formed of 2 to 5 carpels, at maturity of a single cell. Sityles \& to 5. Seeds several or many, attached to a central column.

IIerls, annual or with perennial roots. Sitems often swollen at the nodes, leaves opposite, without stipules or, in a few species, with membrancous stipulate appendage's to the leaves. 
Famlly. CARYOPHYLLACEAE. Time Pink Family

Sepals united to form a calyx tube - Tribe Silenoideae

Sepals distinct or united only at the base

\section{Tribe SILENOIDEAE}

Calyx segments united, with ribs at the commissures. Stamens and petals situated, each in a circle below the ovary and free from it. Styles distinct from each other.

Calyx ribs between the united sepals at least twice as many as the teeth.

Styles 5, alternate with the calyx teeth . . . . Agrostemma

Styles 5, opposite the calyx teeth.

Capsule with a single cell extending to the base . . Lychnis

Styles 3 or rarely 4 . . . . . . . . . . Silene Calyx ribs only 5 .

Segments of calyx connected by a rather broad intermediary membraneous band . . . . . . . . Gypsophila

Segments of the calyx not united by membraneous intermediary band.

Petals with a lip-like appendage at the base of the spreading blade

Petals without appendage.

Leafy bracts enclosing the base of the calyx . Dianthus

\section{AGROSTEMMA, L.}

Herl with narrow, grass-like leaves which are without leaf-stems. Whole plant hairy. Flowers large, terminal, not grouped. Calyx divided above, the long narrow divisions or teeth exceeding the length of the rounded petals. The blades of the petals without appendages.

A. Githago, L. (Fig. 8, pl. 39.). Corn Cockle. Corn Campton. Plant from 1 to $3 \mathrm{ft}$. high, quite ereet, with few branches. Leaves quite narrow, slightly united at the base with those opposite. Whole plant hairy. Flowers red, from $1 \frac{1}{2}$ to $2 \frac{1}{2} \mathrm{in}$. broad. Found mostly in fields of grain or in waste places. Introduced from Europe. Not common.

\section{SILENE, L.}

Herbs with annual or perennial roots. Leaves opposite or crowded, generally long and narrow, with simple margins. Calyx tubular or much inflated; teeth 5 with twice as many nerves or ridges. Base of the flower without bracts. Petals 5, each with a lip-like appendage at the throat of the flower. Stamens 10. Styles 3 or rarely 4. 
Leaves crowded on the stem in moss-like tufts, plant of high mountains $S$. acculis Leaves in verticils, 4 leaves in a whorl.........$+ S$. stellata Leaves opposite, long and narrow.

Leaves mostly spatula-formed, at least the lower ones and rounded at the apex.

Calyx much inflated.

Flowers numerous . . . . . . . . S. latifolia

Flowers few

Calyx tubular, if inflated, only by the ripening of the pod. Stem. leaves viscidly hairy.

Petals crimson ..... S virginica

Petals pink . . ". Sennsylvanica Stem and leaves smooth or nearly so. Flowers in loose clusters S. Nutans Leaves narrow lance-shaped, pointed at apex.

Stem at the nodes glutinous.

Flowers in loose clusters.... S, antirrhina Flowers in compact clusters . . . . . . S. Armeria

Stems and leaves viscid hairy.

Flowers in loose terminal clusters . . . . . S. noctiflara Flowers in spike-like clusters.

Flowers small, petals not deeply toothed . S. angelica Flowers large, petals deeply toothed . S. dichotoma

1. S. acaulis, L. (Fig. 8, pl. 38.) Moss Campion. A dwarf species growing on the White Mountains. Leaves linear, densely erowded around the branching stems. Flowers without footstalks or with very short ones, solitary at the summit of the stem. Petals purple or whitishpurple. Flowers during the summer.

2. S. stellata, (L.) Ait. (Fig. 9, pl. 38.) Starry Campion. Roots perennial. Stems 2 to $3 \mathrm{ft}$. high. Leaves in whorls of $4 \mathrm{~s}$, broader than in other species, with sharp points. Calyx bell-shaped; petals white, fringed at the borders. Flowers nearly an in. across, in loose clusters. Woods of our region. June-Aug.

3. S. alba, Muhl. (Fig. 1, pl. 39.) Western Wirte Campion. Stem simple or somewhat branching, weak, smooth or nearly so. Leaves lanee-shaped, 3 to $5 \mathrm{in}$. long, $\frac{1}{2} \mathrm{in}$. wide, tapering to a slender point. Flowers few or solitary. white, about 3 in. broad. Calyx inflated, downy. Petals wedge-shaped. Moist places, Penna., and west. June-July.

4. S. latifolia, (Mill.) Britton and Rendle. (Fig. 3, pl. 38.) BuADDE. (AMPIOx. (S. vulgaris, Gareke.) Stem and leaves smooth; joints somewhat swollen, especially the lower ones. Lower leaves somewhat spatula-formed, upper ones lanee-shaped. Calyx nearly globular, muclt inflated, with strongly marked nerves. Petals deeply 2-cleft, the lip inconspicuous, white. Flowers all summer.

5. S. nutans, L. (Fig. 7, pl. 39.) Nodding Catcifly. Root perennial. Sitrm and leaves smooth or nearly so. Plant slender, ereet, with loose clusters of flowers at the summit. Lower leaves sometimes broadest toward the apex, upper ones narrow, lance-shaped, with pointed ends. Flowers white or pink, $1 / 2$ to $2 / 3$ in. broad, the petals deeply 2-cleft. Not common. Sparingly naturalized from Europe. June-Sept.

6. S. virginica, T. Fin: Prok. (Aatenfly. Ront perennial, Stem 12 to 20 in. high. Plant eovered with visciel down. Jower Jeaves spatula-

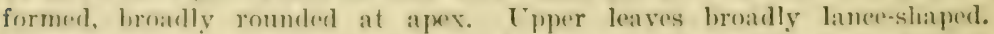
Flowers fow, loosely clusterwe each flower on a foot-stalk about as long as the ealyx. ('alyx erlindrie but with maturity of the capsule beene ing broader at the top. Petals narrow, with two short teeth, color deep crimson. In southern part of our region. June-Aug. 


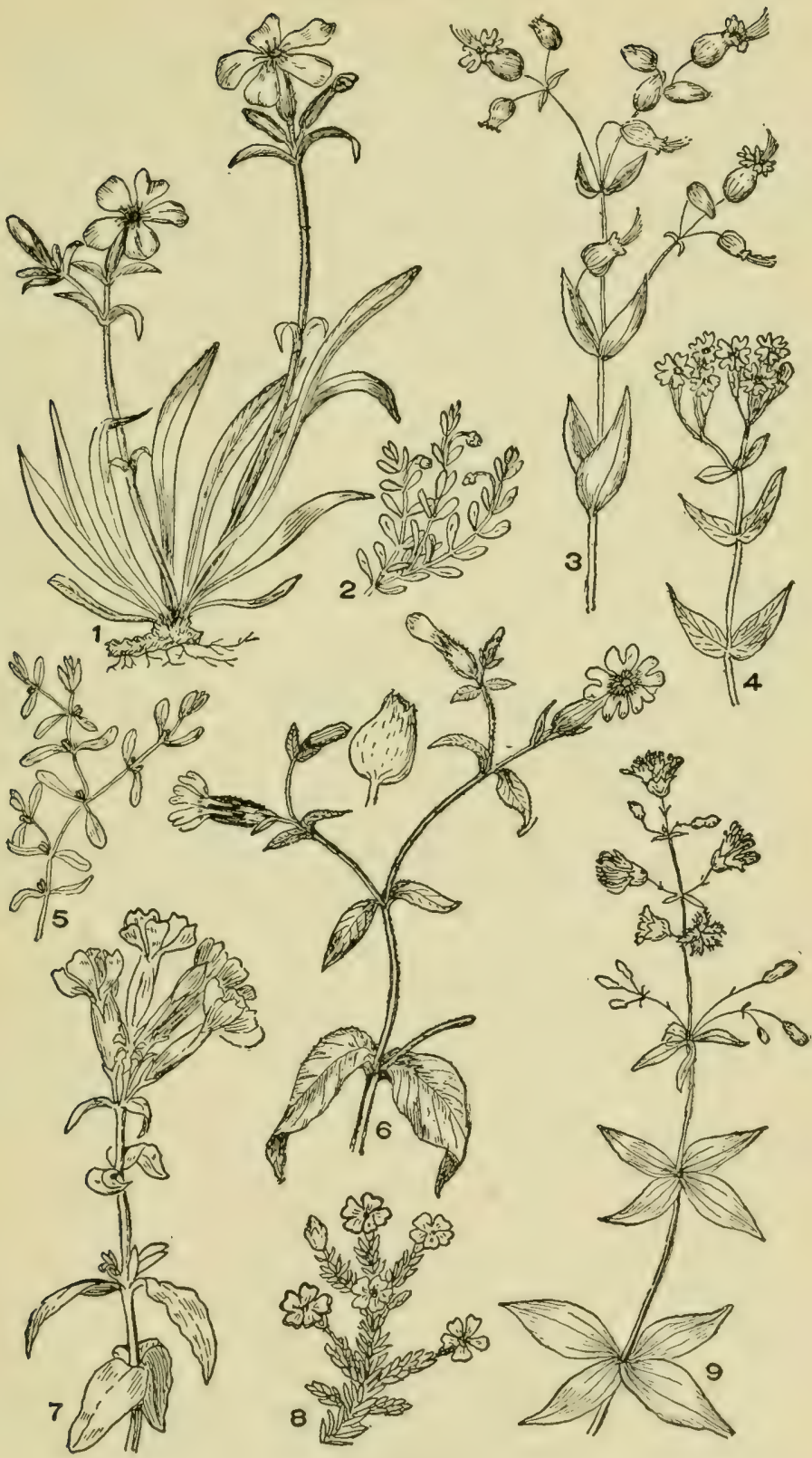

PLATE: 38

1. Silene pennsylvanica. 2. Montia fontana. 3. Silene latifolia. 4. S. Armeria. 5. Sesuvium maritimum. 6. Lychnis alba. 7. Saponaria officinalis. 8 Silene acaulis. 9. S. stellata. 
7. S. pennsylvanica, Michx. (Fig. 1, pl. 3S.) Wild Pixk. (S. caroliniana, Walt.). Root perennial. Stem erect or prostrate, 4 to 16 in. high. Upper parts of the plant viscid, hairy, the lower less viscid or even without that character. Basal leaves narrow and rounded at apex. Stem leaves lance-shaped but not with very sharp points. Calyx tubular, swelling with the ripening of the seeds. Petals wedge-shaped, the outer border slightly notched. Flowers deep pink, conspicuous against the gravelly soil in the early spring. Rocky places, mostly in woods, southern half of our region. April-June.

8. S. antirrhina, L. (Fig. 3, pl. 39.) SLeepr Catcrifly. Root annual. Stem slender and erect, generally smooth, branching above, 8 to $30 \mathrm{in.} \mathrm{high.} \mathrm{Lower} \mathrm{leaves} \mathrm{broader} \mathrm{than} \mathrm{those} \mathrm{above} \mathrm{but} \mathrm{lance-shaped} \mathrm{and}$ with sharp points. Flowers whitish pink, small, in a loose terminal cluster. Calyx ovoid, the small petals each with a single notch at the outer extremity. Fields and woods, most of our area. July-Sept.

9. S. Armeria, L. (Fig. 4, pl. 38.) Sweet William. Lobel's CAtchFly. Root perennial. Stems erect, smooth. Leaves somewhat egg-shaped, the lower with blunt, the upper with sharp points. Flowers in flat crowded, terminal cluster, purple or pink. Calyx tubular. Es. caped from gardens. June-July.

10. S. noctiflora, L. (Fig. 2, pl. 39.) Nigit-flowering Catchfly. Root annual. Stem 1 to $3 \mathrm{ft}$. high, viscid, hairy. Lower leaves blunt, upper ones sharp pointed, all broadly lance-shaped or somewhat eggshaped. Flowers few in a terminal cluster. Petals white or pinkish. Flowers open at dusk and remain open till morning. Waste places, introduced from Europe. July-Sept.

11. S. angelica, L. Exglisif or Sarde-Flowered Catchfly. (S. gallica, I.). Annual. Plant 1 to $2 \mathrm{ft}$. high, the stem rough with rather stiff hairs. Flowers small, white, with short foot-stalks, arranged along the upper part of the stem. Calyx cylindric, hairy. Waste places, introduced from Europe. April-July.

12. S. dichotoma, Ehrh. (Fig. 4, pl. 39.) Forked Catcrifly. Annual. Stem 1 to $2 \mathrm{ft}$. high, branching, hairy. Leaves lanee-shaped or with the broadest part toward the apex, hairy. Petals white, each deeply divided, with only a partially developed lip. Calyx hairy with 5 ribs. Flowers arranged along the upper parts of the much forked stem, each fower with a very short foot-stalk. Fields and waste places, introdueed from Europe. June-Sept.

\section{LYCHNIS, L.}

Plants resembling the Silene. Calyx egr-shaped, tubular or inflated, with commissural nerves. The flowers differ from those of silcne in that in Lyehnis there are 5 styles while in Silene there are but 3 or rarely 4. The plants of this genus have, for the most part, perfect flowers, that is, they have both stamens and pistils, but oceasionally the stamens and pistils orempy dillorent flowers which are not upon the same plant, that is, they are dioccious. All the species in our region have been introduced from Lurope. 


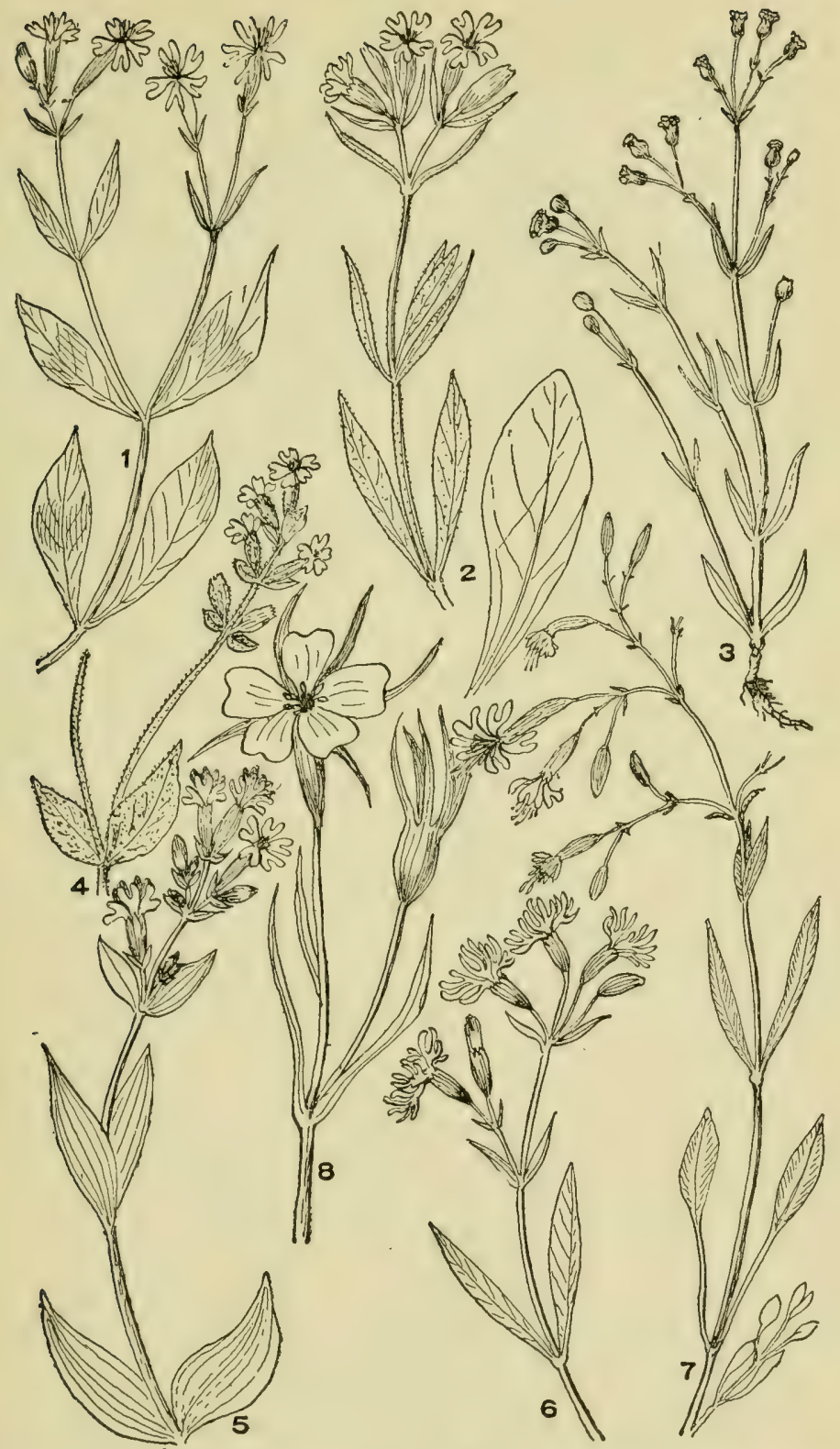

Plate 39

1. Silene alba. 2. S. noctiflora. 3. S. antirrhina. 4. S. dichotoma. 5. Lychnis dioica. 6. L. Flos-cuculi. 7. Silene nutans. 8. Agrostemma Githago. 
Flowers white

Flowers red or purple, rarely white.

Stems very viscid
Stems not viscid or only slightly so.

Petals cut in two lobes.......... L. chalcedonica
Petals cut in four lobes. . . Flos-cuculi

1. L. alba, Mill. (Fig. 6, pl. 38.) Wirte Campion. Evening Lrcmis. Iivots biennial. Stems 1 to $2 \mathrm{ft}$. high, hairy and viscid. Calyx broadly cgro-slaped, hairy. Petals with two lobes and with a conspicuous lip appendage at the throat of the flower. Flowers white or with a tinge of pink, opening toward evening and remaining open until the following morning. Waste places; naturalized. Blooms through the summer.

2. L. dioica, L. (Fig. 5, pl. 39.) RED CAMrion. Root biennial, stem 1 to $2 \mathrm{ft}$. high; viscid, hairy. Lower leaves with long foot-stalks, upper without foot-stalks, broad lanee-shaped or oval. Petals indented, forming two lobes. Flowers red or white. Oalyx with erect narrow teeth. Capsule globose. In waste places, roadside, etc. Blooms during summer.

3. L. chalcedonica, L. Scarlet Lycmisis. Root perennial. Stems with soft hairs, not viscid, 1 to $2 \frac{1}{2} \mathrm{ft}$. high, erect. Leaves egg-shaped. Petals 2 lobed. Flowers red, in hemispheric clusters. Escaped from gardens locally. July-Sept.

4. L. Flos-cuculi, L. (Fig. 6, pl. 39.) Ragged Robin. Cuckoo Flower. Root perennial. Stems 1 to $2 \mathrm{ft}$. high, roughish above. Lower leaves with foot-stalks, points rounded, upper without foot-stalks, apex sharp pointed. Capsule teeth rolling outwards. Flowers rosy, blue or white. Escaped from gardens. June-Sept.

\section{GYPSOPHILA, L.}

Slender annual plant with profusely branching stems and small flowers. Leaves smooth, narrow. Flowers from the leaf axils. Calyx 5-toothed, bell-shaped. Stamens 10. Styles 2.

G. muralis, I. Low Grpsophr.A. Annual. Stems about 6 in. high, much branched, slender. Leaves small and very narrow. Flowers from the leaf axils on long delicate foot-stalks. Flowers purplish. Waste places. Introduced. June-Sept.

\section{SAPONARIA, L.}

Iinot perennial. Stem ereet, with broad lanee-shaped to oval leaves, with 3 conspicuous veins. Flowers rather large in a crowded, or loose conspicuous terminal cluster. Calyx ovoid or tubular with inconspicuous nerves, teoth 5 .

1. S. officinalis, T. (Fig. 7, pl. 38.) Bouncing Bet. Sonpwort. Plant growing in masees at roadsides and waste places. Flowers whitishpink in dense terminal clusters, sometimes double.

2. S. Vaccaria, J. Cow IIsms. (V'accaria Vaccaria, (L.) Britton.) Annual. Stum and leaves very smooth. Flowers in loose clusters, pale red, petals without the lip-like appendage at throat of flower. Waste places; from Europe. June-Aug. 


\section{DIANTHUS, L.}

Perennial or annual herbs with narrow grass-like leaves and generally swollen joints. Calyx cylindric, at its base two leafy bracts sometimes noarly enclosing the calyx. Stamens 10 ; styles 2 . Capsule cylindric opening at the summit dividing it into 4 or 5 teeth.

1. D. Armeria, L. DeptFond PinK. Annual. Flower cluster interspersed with long bract-like leaves which are as long as the calyx tube. Leaves hairy. Flowers small, dark rose colored. Introduced from Europe. July.

2. D. prolifer, L. Proliferous Pisк. Annual. Slender stem and leaves. Flowers small. Calyx surrounded by bracts which are rather broad and less acutely pointed than those of No. 1. Not common.

3. D. deltoides, L. MAIDEN PINk. Lower leaves short and blunt at summit, upper ones narrow and acute, rough at the edges. Striae on the calyx extending its whole length. Flowers almost solitary, pink or whitish. In waste places. Blocms during the summer.

Dianthus barbatus, L. (Sweet William) with flowers in a somewhat crowded head is found occasionally growing wild, escaped from gardens.

\section{Tribe ALSINOIDEAE}

Divisions of the calyx not united at the base. Fruit capsules with as many or with twice as many teeth as there are styles.

\section{Flowers with petals}

Leaves without stipules or stipular appendages.

Petals bifid.

Plant smooth, without hairs, capsule ovoid or oblong Stellaria

Plant more or less hairy, capsule cylindric . . Cerastium

Petals not bifid.

Petals and sepals 4, rarely 5. Styles as many as the sepals and alternate with them

Sagina

Petals 5, styles fewer than the sepals.

Plants not fleshy.

\begin{tabular}{|c|c|c|c|c|c|c|c|c|c|c|c|}
\hline Stamens 10 & 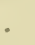 & 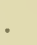 & - & 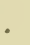 & 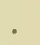 & . & . & . & . & & Arenaria \\
\hline Stamens 8 & . & . & . & - & . & . & - & - & - & . & Moehringia \\
\hline Plants fleshy & . & . & . & - & . & . & . & . & . & . & Amn \\
\hline
\end{tabular}

Leaves with stipules or membraneous appendages.

Leaves in whorls

Spergula

Leaves in pairs 
Flowers without petals

Leaves with membraneous stipules.

Sepals with a terminal prickle . . . . . . Paronychia

Sepals without terminal prickles . . . . . . Anychia

Leaves without membraneous stipules.

Sepals united at base . . . . . . . . . Scleranthus

\section{STELLARIA, L. (Alsine, L.)}

Perennials or annuals, generally tufted delicate herbs rarely more than a few inches in height, erect or recumbent. Flowers single or in a sort of irregular umbel; white; petals white, 4 or 5 , deeply 2 -notehed, or cleft, sometimes wanting. Stamens 10 or less. Styles commonly 3. Capsule 1 celled, globose, dividing by twice as many valves as there are styles.

Styles 5

Styles 3, rarely 4.

Leaves mostly with footstalks . . . . . . . . . S. media Leaves without footstalks or with very short ones at the base.

Leaves broad, breadth at least one-third the length.

Stems hairy, at least in lines.

Leaves generally more than $\frac{1}{2}$ in. long . S. pubcra

Leaves generally less than $\frac{1}{2}$ in. long . S. uliginosa

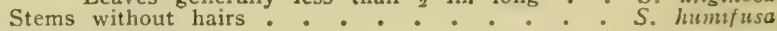
Leaves narrow linear.

Flowers single or rarely several in a group . . . S. longipes Flowers in loose terminal clusters.

Leaves acute at each end. I'etals longer than sepals. Flowers usually less than $\frac{1}{2}$ in. broad $S$. longifolic

Flowers usually more than $\frac{1}{2}$ in. broad $S$. Holostea

Leaves acute at each end. Petals shorter than the sepals . . S. borealis

Leaves acute at apex, broad at base . . S. graminea

1. S. aquatica, (L.) Scop. (Fig. 6, pl. 40.) Water Mouse-Ear CnickWEs. Stems angular, diffuse, 1 to $2 \mathrm{ft}$. long, recumbent or erect. L.eaves egg-shaped to slightly heart-shaped at base, acute at apex. Lower laves an inch or more in length with short footstalks. Flowers in terminal loose clusters, sepals ovate, not as long as the petals. In wet places in our area. Blooms from May to August.

2. S. humifusa, Rottb. Low Crickweed. Stems 2 or 3 in. long, without hairs, spreading, prostrate or partly erect. Leaves fleshy, eggshaped or obleng, $1 / 6$ to $1 / 4$ in. long, rather obtuse or somewhat acute at apex. Petals equal to or longer than the sepals. Wet places, mostly salty marshes. Blooms all the summer.

3. S. uliginosa, Murr. Bog Starwort. Marsin Chickwefd. Stem wak, 6 to 16 in. long, nearly ereet or decumbent, 4-angled; leaves oblong or nearly lance-shajed, the lower with short footstalks, the upper without. Flowers in groups of few flowers with short flower stems. In brooks and springs, common. In bloom all summer.

4. S. media, (T.) ('yrill. (Fig. 1, pl. 40.) Commov Cnickween. Sitrms weak, partly or wholly ereet or decumbent. Along the stem runs a line of hairs, otherwise stem smooth. Leaves broally egg-shaped with footstalks as long or longer than the leaves below, shorter or none above. flowers from the axils of the opposite leaves, small, white, on delicate 
PINK FAMILY

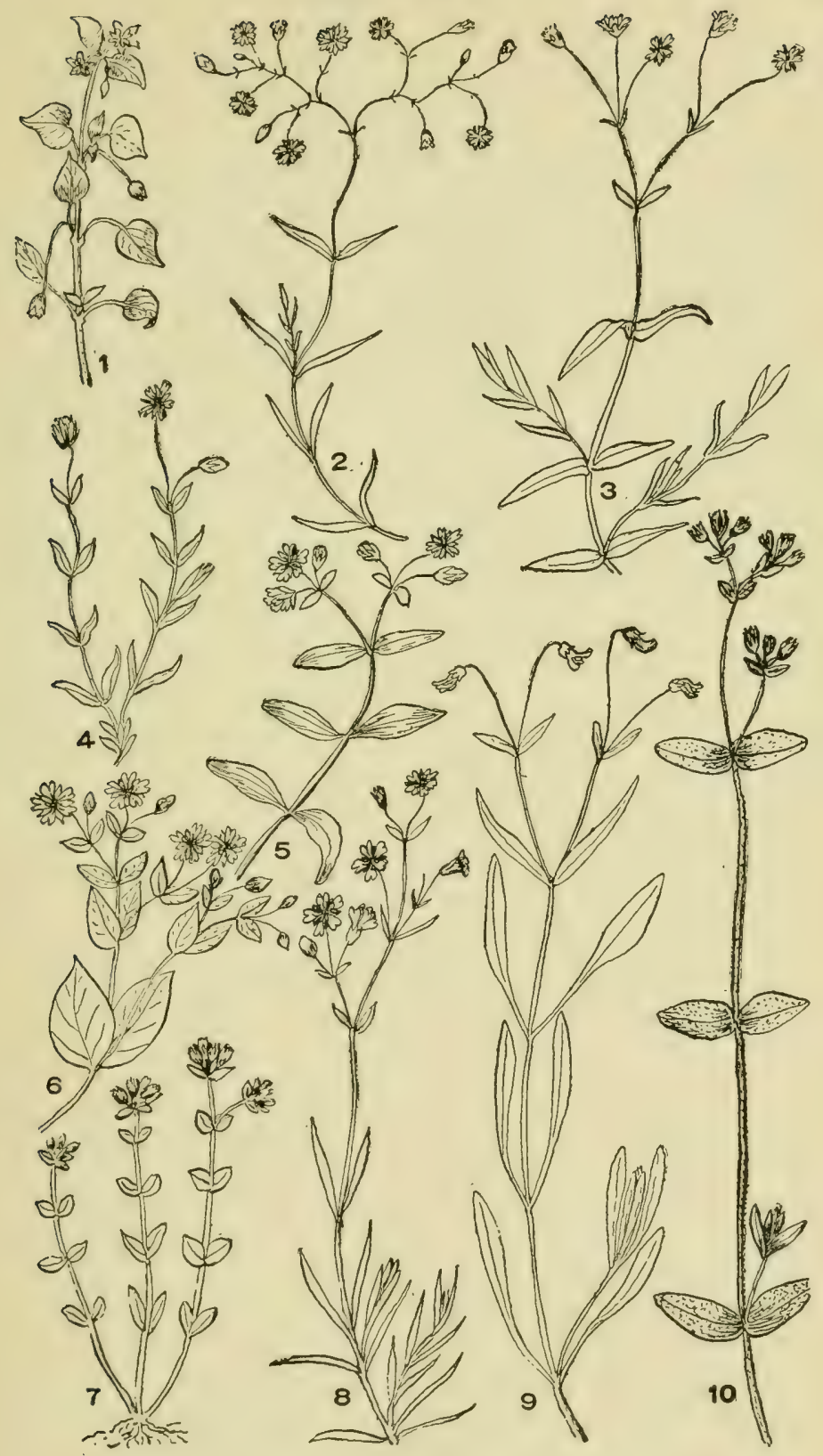

Plate 40

1. Stellaria media. 2. S. longifolia. 3. S. graminea. 4. S. longipes. 5. S. pubera. 6. S. aquatica. 7. Cerastium viscosum. 8. C. arvense. 9. C. nutans. 10. C. vulgatum. 
flower stems, or in terminal elusters; petals 2-parted; sepals acute and longer than petals. Plant 4 to 15 in. high. Waste and cultivated places. Common. Blooms all summer.

5. S. pubera, Michx. (Fig. 5, pl. 40.) Great CHICKweEd. Stems somewhat weak, ereet or decumbent, with two lines of hairs. Leaves oblong, $\frac{1}{2}$ to $1 \frac{1}{2} \mathrm{in}$. long, narrowed at each end, without footstalks except the lower ones. Flowers white, about $\frac{1}{2} \mathrm{in.}$ broad, in terminal leafy groups. Flower stems more or less supplied with soft hairs. Petals 2 parted, longer than the sepals. Moist rocky places in southern part of our region. Blooms May and June.

6. S. Holostea, I. Greater Stitcinwort. Erect; rootstock creeping. Stem 18 to $24 \mathrm{in.} \mathrm{high.} \mathrm{Leaves} \mathrm{without} \mathrm{leaf-stems,} \mathrm{lance-shaped,} \mathrm{tapering}$ to a long slender tip. Flowers showy, $1 / 2$ to $2 / 3$ in. broad, in terminal, leafy, spreading (panicled) clusters. Flower pedicels rather slender. Sepals $\frac{1}{2}$ as long as the 2-cleft petals. Naturalized in a few localities; at Train's Meadow Road, Long Island and at Poland, Maine.

7. S. longifolia, Muhl. (Fig. 2, pl. 40.) Loxg-Leaved Stitcirwort. Stem weak, slender, the plant lying on or ascending by aid of grasses or other plants, 8 to $18 \mathrm{in.} \mathrm{high,} \mathrm{branching} \mathrm{freely,} \mathrm{angles} \mathrm{rough;} \mathrm{leaves}$ linear, acute at each end, 1 to $2 \frac{1}{2} \mathrm{in}$. long and about $1 / 10$ as wide. Flowers in a broadly spreading cluster on slender flower stems. Petals longer than the sepals. Common in damp meadows. May-June.

8. S. graminea, L. (Fig. 3, pl. 40.) Lesser Stitcirwort. Lesser Starwort. Stem similar to last but somewhat stouter. Leaves broader at base or just above it. Flowers also similar to those of No. 7, but larger. May-July.

9. S. longipes, Goldie. (Fig. 4, pl. 40.) Long-stalked Stitcirwort. Stem very slender, smooth and shining. Leaves lance-shaped, narrow, broadest at or near the middle. Flowers few. Plant similar to Nos. 6 and 7. Moist places. Blooms all summer.

10. S. borealis, Bigel. Nontinern Stitcirwort. Stem similar to Nos. 7 and 8. Leaves narrow lance-shape, broadest near the middle. Flowers few in loose terminal eluster. Pctals shorter than sepals. In southern part of our region. Wet places. All summer.

\section{CERASTIUM, L.}

Generally hairy herbs with white flowers in remularly forking terminal groups, Petals all 2-eleft. Stamens nearly always 10. Styles 3 to 5 (generally 5). Seed capsule 1-celled, many seeded.

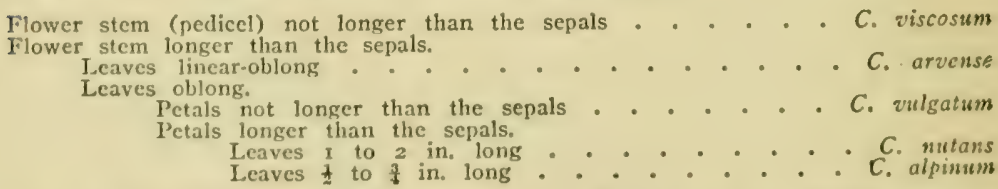

1. C. viscosum, T. (Fig. 7, pl. 40.) Mouse-tar Cutckween. Stems nearly erret, chammy, 4 to $12 \mathrm{in}$. high. Leaves broad ergr-shaped without Inaf strms; apex rounded, base tapering, quite hairy. The sharp pointed hairy sepals longer than the petals or about the same length. Flower 
stem not longer than the scpals. Flowers in terminal groups. In moist grassy places. Not common. May-June.

2. C. vulgatum, L. (Fig. 10, pl. 40.) LARger Mouse-ear ChickWEED. Stems clammy. Leaves oblong, tapering at each end, without leafstems, $\frac{1}{2}$ to $1 \mathrm{in}$. long, half as wide. Flowers in loose terminal groups, the pedicels longer than the sepals, mostly turning downward between flowering and fruiting. Petals equal to or longer than the sepals. Fields and woods, common. May-Sept.

3. C. nutans, Raf. (Fig. 9, pl. 40.) Nodding Chickweed. Powder Hors. (C. longipedunculatum, Muhl.). Stems diffusély branched, clammy or nearly destitute of hairs; 6 to 24 in. long. Leaves 1 to 2 in. long, $\frac{1}{4}$ as wide; the middle and upper ones without leaf-stems, lower with short leaf-stems. Flowers in loose terminal clusters. Petals about twice the length of the sepals. Pods nodding and curved upward. Moist soil; much of our area. May-July.

4. C. arvense, L. (Fig. 8, pl. 40.) Freld Chickweed. Growing in dense tufts, 4 to $10 \mathrm{in.} \mathrm{high.} \mathrm{Stems} \mathrm{and} \mathrm{leaves} \mathrm{downy.} \mathrm{Leaves} \mathrm{linear}$ lance-shape; on the flowering stems the pairs are distant. Petals more than twice the length of the calyx. Flowers terminal in groups of about 4. $\frac{1}{2}$ to $\frac{3}{4}$ in. broad. Dry rocky hills in all of our area. April-July.

Var. oblongifolium, Britt., (Fig. 13, pl. 4l), Taller; leaves broader; pod about twice as long as the calyx. New York and southwest.

5. C. alpinum, L. Alpine Chickweed. Flowering stems erect, 2 to 6 in. high, sterile stems prostrate. Leaves broad lance-shaped, rather obtuse at apex, $\frac{1}{2}$ to $\frac{3}{4} \mathrm{in}$. long and about $\frac{1}{2}$ as broad, hairy. Flowers terminal, about 2 to 4 in cluster. Petals twice as long as sepals. Scarcely found south of Canadian line.

\section{SAGINA, L.}

Small matted herbs with thread-like or awl-like leaves, without stipules and with small white or whitish flowers on very slender flower stems. Petals not divided as in the two preceding genera and sometimes absent. Petals and sepals equal in number when petals are present, sometimes varying in the same species, 4 or 5 . Stamens as many as the sepals. Ovary with a single cell, many seeded. Styles as many as the sepals and opposite to them.

Parts of the flower in 4 's.

Plant depressed . . . . . . . . . . . . S. procumbens

Parts of the flower in $5^{\prime}$ 's.

Petals longer than the sepals . . . . . . . . . . . S. nodosa

Petals shorter than the sepals $: \therefore \therefore . \cdots, S^{\circ}$ decumbens

1. S. procumbens, L. Procumbent Pearlwort. Growing in dense mats, stems 1 to $3 \mathrm{in}$. high, semi-erect or lying on the ground. Leaves thread-like, $1 / 12$ to $1 / 4$ in. long, the pairs joining at the stem. Flowers $1 / 12$ in. broad, terminal or from the axils of the leaves, on thread-like flower stems which are 6 to 8 times longer than the flower. Sepals generally longer than the petals. In moist places, in our area. May-Sept.

2. S. apetala, Ard. Small-flowered Pearlwort. Partly or wholly erect, 1 to 4 in. high, stem very delicate. Leaves $1 / 12$ to $\frac{1}{3}$ in. long, broadened at the stem and at the base sparingly hairy. Flowers on long 
thread-like flower stems, without petals or with very minute ones. Sepals generally 4. Dry soil in Mass., westward. June.

3. S. nodosa, (L.) Fenzl. (Fig. 1l, pl. 4l.) Knotted Pearlwort. Growing in tufts, partly or wholly erect, 2 to $6 \mathrm{in}$. high. Leaves in pairs or mostly, below, in 4's, thread-form. Flowers $\frac{1}{4}$ in. broad, the petals much longer than the calyx, 1 or 2 to each stem. Wet sandy places. Northern part of our area. June-Sept.

4. S. decumbens, (Ell.) T. and G. (Fig. 10, pl. 41.) Decunbent Pearlwort. Tufted annual with stems decumbent or partly erect, 2 to 4 in. long. Leaves narrowly linear, sometimes bristle-tipped, about $\frac{1}{4}$ in. long. Flower stems thread-like $\frac{1}{4}$ to $1 \frac{1}{1} \mathrm{in.}$ long; flowers about $1 / 12$ in. broad. Sepals, petals and styles, each 5 ; stamens 5 or 10 . Petals equal to or shorter than the sepals. Dry soil, eastern Mass., south and west.

\section{ARENARIA, L.}

Small tufted herbs, annual or perennial. Leaves opposite, without leaf stems and flowers in terminal groups. Flowers always white, petals rounded, not divided or notched at apex, or rarely with minute notch. Sepals 5 , styles 3 , stamens 10 .

Leaves egg-shaped, the intervals about equal to or exceeding the length of the

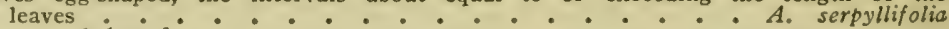
Leaves awl-shaped.

Lower leaves sparingly overlapping . . . . . . . . . A. verna Lower leaves densely overlapping ${ }^{\circ}{ }^{\circ}{ }^{\circ}{ }^{\circ}{ }^{\circ} A^{*}$ caroliniana Lower leaves in distinct whorl-like bundles Intervals between all the leaf pairs exceeding the length of the leaves

1. A. serpyllifolia, L. (Fig. 8, pl. 41.) Tiryme-Leaved Sandwort. Stems 2 to 6 in. high, somewhat hairy, diffusely branched. Leaves eggshaped, without leaf-stems, $1 / 6$ to $1 / 4$ in. long, the intervals between the pairs about equal or sometimes exceeding the length of the leaves. Flowers in terminal loose clusters, small; sepals sharp pointed with 3 to 5 nerves. In waste sandy or rocky places. June-Aug.

2. A. verna, L. Vernal Sandwort. Stems 1 to $3 \mathrm{in.} \mathrm{high,} \mathrm{growing}$ in dense tufts. Leaves narrow awl-shaped, overlapping below but not densely so. Flowers numerous in loose clusters. Sepals sharp pointed with 3 nerves. Petals somewhat exeeeding the sepals in length. Smuggler's Notch, Vermont and northward. June-Sept.

3. A. caroliniana, Walt. (Fig. 6, pl. 4l.) Pinebarren Sandwort. Stems densely tufted, 4 to 6 in. high. Leaves of lower part of stem densely overlapping, the upper portion of the stem without leaves or with 1 or 2 pairs. Flower clusters terminal, about 3 or 4 to a stem, $1 / 2$ to $2 / 3$ in. aeross. Sepals blunt, without nerves. Petals narrow, 3 or 4 times as long as the sepals. In sand, in the southern part of our area. May-July.

4. A. stricta, Michx. (Fig. 4, pl. 41.) Rock Sundwort. Stems slender in donse tufts, 5 to $15 \mathrm{in.} \mathrm{high.} \mathrm{Leaves} \mathrm{bristle-like} \mathrm{with} \mathrm{clusters}$ of 6 to 8 extra leaves in the axils forming a whorl-like fascicle. Flower cluster diffuse, leafless except a few bracts at the divisions of the stems. Petals rounded at apex, twice as long as the narrow and acute sepals.

5. A. groenlandica, (Retz.) Spreng. (Fig. 3, pl. 41.) Mounarix 


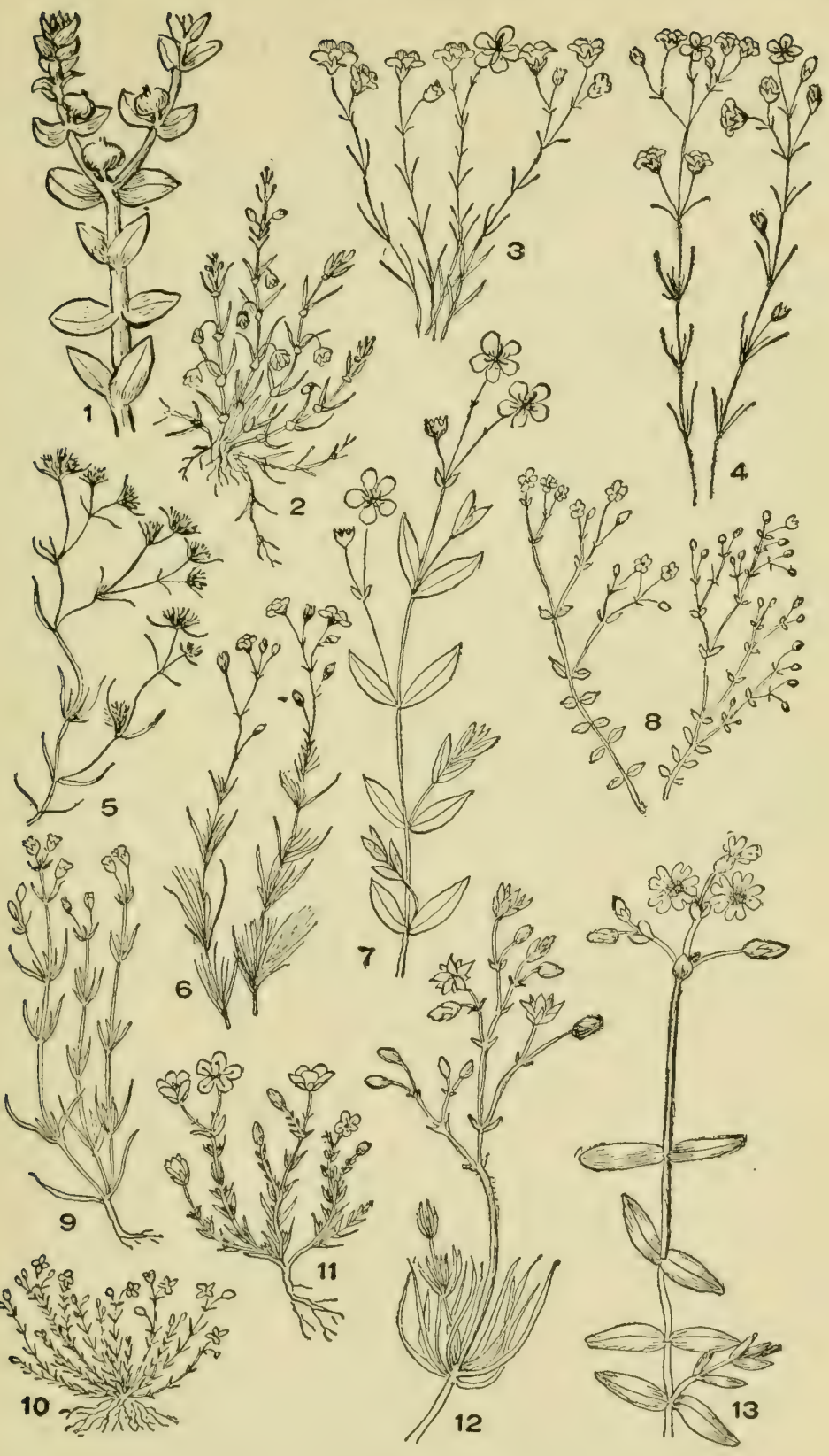

\section{Plate 41}

1. Ammodenia peploides. 2. Spergularia marina. 3. Arenaria groenlandica. 4. A. stricta. 5 Scleranthus annuus. 6. Arenaria caroliniana. 7. Moehringia lateriflora. 8. Arenaria serpyllifolia. 9. Spergularia rubra. 10. Sagina decumbens. 11. S. nodosa. 12. Spergula arvensis. 13. Cerastium arvense var. oblongifolium. 
Saxdwort. Mountain Starwort. Stems in dense tufts 3 to 6 in. high, each dividing into a few (about 3) branches above, each slender branch bearing a somewhat showy, white flower. The tuft presents a gay appearance. Leaves bristle-form, about $1 / 3$ the length of the node between the pairs. Flowers about $\frac{1}{2} \mathrm{in}$. in diameter on thread-like foot stalks. On high mountains, Adirondacks, Catskills and White Mountains. JuneSept.

\section{MOEHRINGIA, L.}

Our species low herbs, perennial, with oblong or oval leaves, with no leaf stalks or with a very short one, with small white flowers in a diffuse lateral or terminal cluster. Sepals and petals 4 or 5. Stamens 8 or 10. Capsule few-seeded, oblong or ellipsoid.

1. M. lateriflora, (L.) Fenzl. (Fig. 7, pl. 41.) Blunt-Leaved SANDwort. Stems covered with a fine down, 4 to $12 \mathrm{in.} \mathrm{high,} \mathrm{erect} \mathrm{or}$ nearly so. Leaves oblong or oval $\frac{1}{2}$ to 1 in. long, blunt at each end. Clusters few flowered, lateral or terminal or flowers solitary, about $\frac{1}{4}$ in. broad, petals and sepals 4 or 5. Stamens 8 to 10. Petals and sepals rounded at apex. Capsule nearly twice as long as the calyx. Moist places, southern and central New York, New Jersey and southward. MayJune.

2. M. macrophylla, Hook. With narrower leaves and with pointed sepals. N. Guildford and Durham, Conn., Vermont and northward.

\section{AMMODENIA, J. G. Gmel.}

Fleshy herbs at seaside. Leaves egg-shaped or oblong. Flowers small, in the axils of the leaves or at the division of the stem. Petals small, inconspicuous, 3 in number, rarely 4. Sepals equal in number to the petals. Stamens 8 to 10 . Styles 3 .

A. peploides, (L.) Rupr. (Fig. 1, pl. 41.) SEA BEACr SANDwort. Stems tufted, 6 to $10 \mathrm{in.} \mathrm{high,} \mathrm{branching} \mathrm{or} \mathrm{simple.} \mathrm{Leaves} \mathrm{egg-shaped,}$ the apex sometimes broadest, clasping the stem at base. Flowers about $\{$ in. broad, in the leaf axils (usually only 1 flower to a pair of leaves), at the branching of the stem or tcrminal. Sands of the sea shore. JuneJuly.

\section{SPERGULA, L.}

Branching herbs with bristle or awl-formed leaves with stipules. Flowers in diffuse clusters, white. Stamens 5 to 10 ; styles 5 ; sepals and petals 5 .

S. arvensis, Id. (Fig. 12, pl. 41.) Spurry. Conn Spurry. Stems 6 to $18 \mathrm{in.}$ high, the whole plant hairy. Leaves with stipules, slenter, rylindric, awl-shaped, elustered in fascicles about the stem (20) or more in a sort of whorl). Flowers white, 1 in. or more in diameter, in diffuse clusters at summit of stem. Petals somewhat pointed at apex. Sepals ahout as long or slightly longer than the petals. Mostly a weed in fields and waste places. Common.

\section{Spergularia, J. \& C. Presl. (Tissa, Adams, Buda, Adams)}

Jow herhs with bristle-like, mostly fleshy, leaves, opposite or in whorllike bundles, stipules at base of leaves. Flowers singly in the axils of 
the leaves or terminal, whitish or pink. Sepals 5; petals 5; stamens 2 to 10 ; styles 3 except No. 1. Found on or near the sea coast, in wet sand.

1. S. rubra, (L.) J. \& C. Presl. (Fig. 9, pl. 41.) Sandy Spurry. Purple Sandwort. Growing in $d r y$ soil, in waste places as a low, slender, spreading weed, stems 2 to 6 in. long. Plant smooth or nearly so. Leaves flattened, scarcely fleshy. Flowers bright pink, small, the petals generally not exceeding the calyx.

2. S. marina, (L.) Griseb. (Fig. 2, pl. 41.) SAlt-marsir Sand SPURRx. Grows in brackish sands, salt marshes along the New England coast, spreading with numerous branches, stems 4 to 8 in. long; smooth or with fine hairs. Leaves not in fascicles, bristle-form, rounded, quite fleshy, with egg-shaped stipules at base. Flowers small, pink, the flower stem about twice as long as the flower. Salt marshes on the coast, also those at Salina, N. Y.

3. S. canadensis, (Pers.) Don. Northern SANd Spurry. Plant similar to No. 2, but with white flowers on flower stems three or four times as long as the flowers. Muddy shores, R. I., Mass., and northward.

\section{PARONYCHIA, Adams}

Tufted herbs, sometimes woody at base, with opposite leaves and mem. braneous, dry, silvery, leaf appendages (stipules). Flowers clustered among dry membraneous bracts, without petals. Calyx of $\mathbf{5}$ divisions, bristle-pointed. Stamens 5; style 2-cleft at summit.

P. argyrocoma, (Michx.) Nutt. (Fig. 7, pl. 43.) Silver WhitLowworT. Growing in tufts in rocky, generally high, situations (White Mits., etc.), stems 3 to 8 in. high, with silvery scale-like hairs. Flowers in very dense clusters surrounded by dry silvery bracts. Rocky places, Maine, White Mountain region and southward.

\section{ANYCHIA, Michx.}

Slender herbs not growing in tufts, with repeatedly forking stems and small inconspicuous greenish flowers without petals in the axils of the leaves. Leaves elliptic, smooth, opposite, with very small dry stipular appendages. Calyx of 5 divisions, greenish without bristle points; stamens 2 to 5 ; styles 2 .

1. A. polygonoides, Raf. (Fig. 6, pl. 43.) Forked Chickweed. (A. dichotoma, Mich.) Stem and leaves downy, mostly prostrate or partly ercet, 3 to 10 in. long. Leaves very narrow, elliptic, rounded at apex, about $1 / 6$ in. long, without foot-stalks. In dry thickets and open places, throughout our area.

2. A. canadensis, (L.) BSP. (Fig. 8, pl. 43.) Slender Forked CHICKwEed. Resembling the last, but stem and leaves mostly without hairs; plant 6 to 12 in. high and usually erect. Leaves $1 / 4$ to $2 / 3$ in. long. Dry woods and open places.

\section{SCLERANTHUS, L.}

Low tufted herbs with forking stems. Leaves without stipulate appendages, narrow awl-shaped. Flowers green, without petals, at axils 
of leaves and in diffuse terminal clusters. Calyx deeply 5-lobed. Stamenz usually 5 opposite to and attached to the divisions of the calyx.

S. annuus, L. (Fig. 5, pl. 41.) Knawel. Geranan Kinot Grass. Stems 3 to 5 in. long, much branched, prostrate or partly erect, smooth or with very soft hairs. Leaves mostly curving backward. Calyx tube 10-angled. Fields and waste places. Common.

\section{Order III.-RANALES. Order of the Buttercups. Polycarpes}

The most characteristic feature of this large order, in which plants of widely different appearance and habits are united, is found in the carpels or fruits, each carpel being regarded as a sort of modified leaf folded so as to contain the ovules. By referring to the figures at the head of the Family Ranunculacer a general idea of these carpels may be obtained. They are most frequently independent, as in the buttercups, and in general they are quite numerous but, e. g., in the barberry the number is reduced to one.

The insertion of the parts of the flower is for the most part spirally around the base of the carpels, but in some instances, as in the case of the common white water lily, the stamens and petals are inserted into the sides of the consolidated group of carpels which form a single globe-like fruit. In the greatest number of genera the flowers are regular, that is, parts of the same kind are alike as in the common buttercup, but in other genera the flowers are quite irregular (Larkspur, Aconite).

Aquatic Plants.

With broad heart-shaped or shield-shaped leaves and conspicuous flowers . . . . . NYMPHAEACEAE

With whorls of dissected leaves and flowers without floral envelope

CERATOPHYILACEAE Trees.

With large conspicuous flowers.

Leaf buds covered by membrancous stipules

Leaf buds naked, leaves without stipules ANONACEAE Trees and shrubs with small, mostly inconspicuous flowers.

With thorny spines below leaf axils. Carpel one 

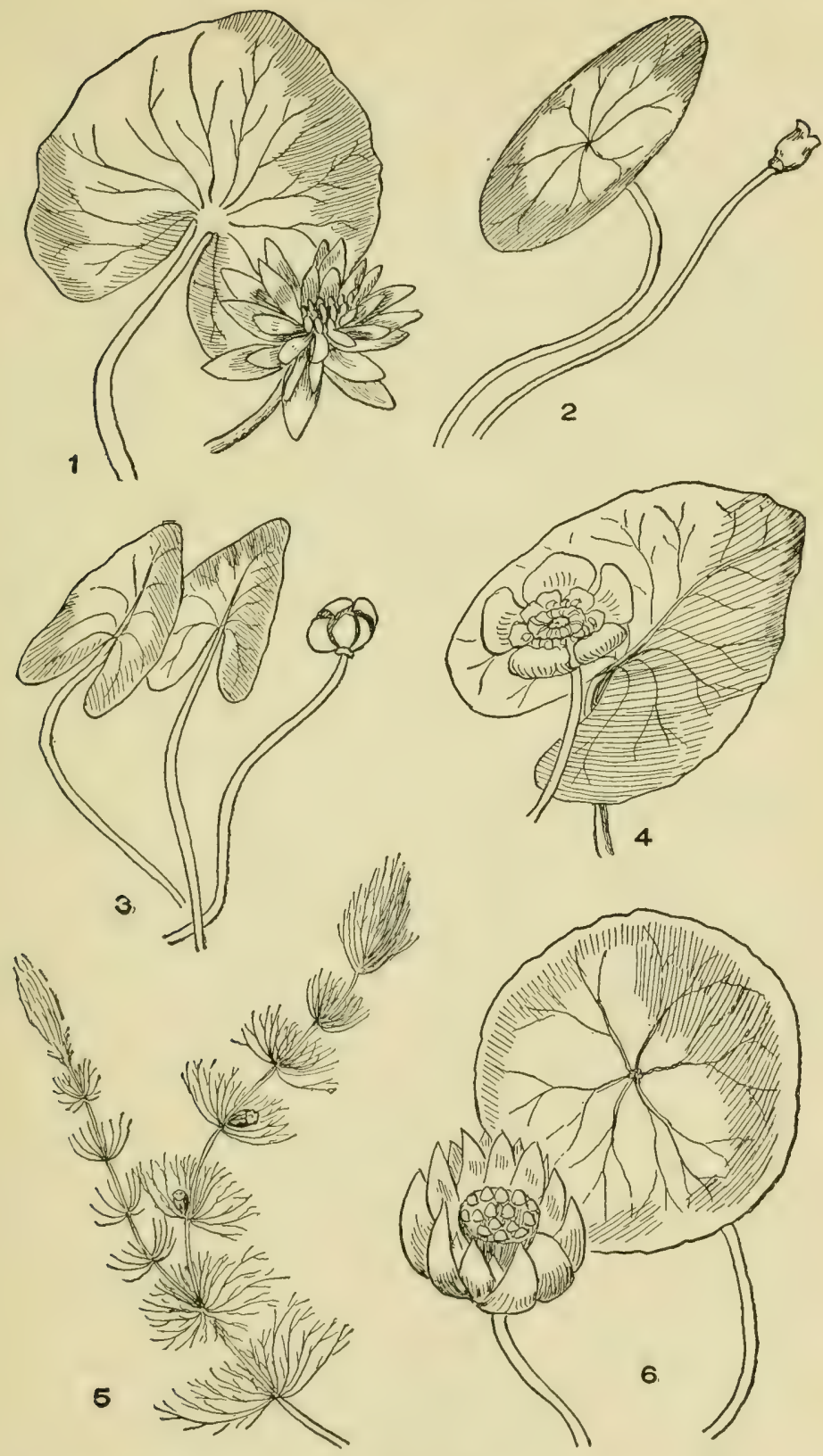

Plate 42

1. Castalia odorata. 2. Bransenia purpurea. 3. Nymphaea microphylla. 4. N. advena. 5. Ceratophyllum demersum. 6. Nelumbo lutea. 
Without thorny spines

IAURACEAE Woody climber, leaves not compound - MENISPERMACEAE Woody climber, leaves compound. Clematis in Ranunculaceae. Herbs.

With several or many independent carpels, stamens mostly more than 12 . . . RANUNCULACEAE

\section{FAMILY I.-NYMPHAEACEAE. Water Lili FAMILI}

Aquatic herbs, the long creeping rootstocks of which are perennial. The shield-shaped or large heart-shaped leaves float on the surface of the water. Flowers solitary, regular, with both stamens and pistils. Divisions of the calyx and corolla in some species variable, passing from one form to the other. Stamens more than 10, also passing by slight gradings into petals.

Leaves all oval, shield form with footstalks near the center

Leaves all heart-shaped, deeply cut at base.

Flowers yellow

Brasenia

Flowers white.

Fruit globose . . . . . . . . Castalia

Fruit an inverted cone... . . Nelumbo

I. BRASENIA, Schreb.

Submersed stems often several feet long, branching. Leaves on long slender foot-stalks, oval, shield-form with the foot-stalks inserted near the center. Floating, borders undivided, 2 to $4 \mathrm{in.} \mathrm{long.}$

B. purpurea, (Michx.) Casp. (Fig. 2, pl. 42.) Water Suield. Witer TArgiet. (B. Schrebcri, Gmel. B. peltata, Pursh.) Flowers dull purple. The oval leaves floating in groups on the surface of ponds and streams. Blooms through the summer.

2. NYMPHAEA, L. (Nuphar, Sibthorn and Smith)

Submersed stems rather stout. Leaves with deep sinus at base. Flowers yellow, sepals 5, colored, petals small, in the cup of the colored calyx, graduating into the stamens. Sepals, petals and stamens surrounding the fort-stalk at base of the ovary. The compound carpels uniting into a single pistil.

1. N. advena, Soland. (Fig. 4, pl. 42.) Large Yeliow Poxp Lilt. Joaves 5 to $12 \mathrm{in.}$ long, $2 / 3$ as wide. Flowers $1 \frac{1}{2}$ to $3 \frac{1}{2} \mathrm{in}$. diameter, decp yellow. Disk at summit of pistil 12 to 25 rayed, yellow or pale red. Common in still water. April-Sept.

2. N. hybrida, Peck. Red Disked PoNd Lily. Similar to No. 1, but smaller and with the disk at summit of pistil bright red or crimson and 
9 to 12 rayed. Intermediate between 1 and 3 . Ponds, northern New York. May-Sept.

3. N. microphylla. Pers. (Fig. 3, pl. 42.) SMall Yellow Pond LiLr. ( $N$. Lialmiana, Sims.) Leaves 2 to 4 in. long, $\frac{2}{3}$ as broad, some leaves submersed. Flowers smaller than No. 1 or 2. Sepals 5. Lakes and ponds in our area.

\section{CASTALIA, Salisb.}

Aquatic herbs with showy white flowers. Sepals 4. Petals many, graduating into stamens. Stamens many. Petals and stamens arising from surface of the rounded seed casket.

1. C. odorata, (Dryand.) Woodv. and Wood. (Fig. 1, pl. 42.) Sweet-gcented White IVAter Lily. (Nymphaca odorata, Ait.) Leaves orbicular with a deep narrow sinus, 4 to 12 in. in diameter. Flowers white or tinged with pink, perfume adundant but pleasing. Ponds and slow streams. June-Sept.

2. C. tuberosa, (Paine.) Greene. Tuberous Winte IVAter Lily. Similar to No. 1, but without, or nearly without perfume. Lake Cham. plain and other northern lakes and ponds.

\section{NELUMBO, (Tourn.) Adams}

Resembling Castalia, but leaves with foot-stalks at or very near the center and with petals and stamens arising below the seed casket, which is in form of an inverted cone. The upper surface shows a number of pits in which the seed carpels are lodged.

1. N. lutea, (Willd.) Pers. (Fjg. 6, pl. 42.) AmericaN Lotus. Leaves prominently ribbed. Plant and flower resembling Castalia, but the petals are less uniform and the knobbed upper surface of the seed casket is conspicuous in the midst of them. In Connecticut River and in lakes in southern New Jersey. Also in Sodus Bay, N. Y.

2. N. nucifera, Gaertn. IndiaN Lotus. ( $N$. Nelumbo, (L.) Karst.) Leaves rounded, standing above the surface of the water or floating, 2 to $3 \mathrm{ft}$. in diameter, the leaf-stalks $3 \mathrm{ft}$. or more in length. Flowers pink or white, 4 to $10 \mathrm{in}$. broad on flower stems 3 to $6 \mathrm{ft}$. high. Introduced into this country by Mr. Edmund D. Sturtevant. Now naturalized at Bordentown, N. J. Cultivated in many parks. July-Aug.

\section{FAMILY II.-CERATOPHYLLACEAE. HoRNTORT FAMILY}

Submersed aquatics with finely dissected leaves in whorls. Staminate and pistillate flowers separate, on the same or on different plants. Staminate flowers with numerous stamens surrounded by an 8 to 12 parted colorless perianth, as is the pistil in the pistillate flower.

\section{CERATOPHYLLUM, L.}

Herbs growing under water in ponds and other quiet waters. Leaves very finely dissected.

C. demersum, L. (Fig. 5, pl. 42.) Horvwort. Stems 2 to $8 \mathrm{ft}$. 
long, depending on the depth of the water. Found commonly throughout our region in still waters.

\section{FaMily III.-MAgNOLIACEAE. MLAgNoli Family}

Trees with alternate undivided leaves which in bud are covered by membraneous stipules which may fall as the leaves spread. Flowers always large and showy on a convex or conical receptacle. Parts of the perianth not united and always regular. Stamens numerous, carpels (seed caskets) several and independent, arranged upon the elongated conical or cylindric receptacle.

\section{MAGNOLIA. L.}

Flowers large, white, or yellowish-green with 3 colored sepals and from 6 to 12 petals in 2 to 4 rows, smaller than the sepals. Fragrant. Seeds fleshy which hang to the elongated receptacle by slender threads which hold them in relation to the thin matrix till they are well ripened.

1. M. virginiana, L. (Fig. 1, pl. 43.) Laurel Magnolia. Street BAY. ( $M$. glauca, L.). Tree 15 to $70 \mathrm{ft}$. high, rarely attaining the height of the latter figure in our region. Leaves thick, broad, oval, tapering at base, obtuse at apex or suddenly acute. Dark, shining green above, light green and slightly hairy beneath. Flowers globe-shaped. In swampy places, in the southern half of our region. May-June.

2. M. acuminata, L. (Fig. 5, pl. 43.) Cucunber Tree. A large tree ( 60 to $90 \mathrm{ft}$. high). Leaves thin, broadly rounded at base, acute at apex. Flowers smaller than No. 1, 2 in. high, bell-shaped, greenishyellow. Cone of fruit a long cylinder from which the common name of the tree is derived. Southern New York, New Jersey and southward. Other species of Magnolia are found in our parks and private grounds which are native further south.

\section{LIRIODENDRON, L.}

Large forest tree with leaves in general form of a heptagon, 4 to 6 loles. Flowers large, sepals 3 , petals 6 , the former turned baekward, the latter erect, seeds suspended by filaments.

L. Tulipifera, L. (Fig. 2, pl. 43.) Tulip Tree. Winte Wood. Leaves hectagronal or nearly orbicular, the apex abruptly terminated with a notch at midvein. Flowers a delicate greenish-yellow, orange within. In woods and along fences.

\section{Family IV.-Anonaceae. Custard apple Fammly}

The characters are sufficiently indicated in those of the genus below.

ASIMINA, Adams

Small tree with alternate leaves which are long and broadest towarl the apex (6 to $12 \mathrm{in}$. long by 2 or $3 \mathrm{in}$. broad). Flowers 1 to 2 in. across; sepals 3 , as broal as long. P'etals 6, arrangert 


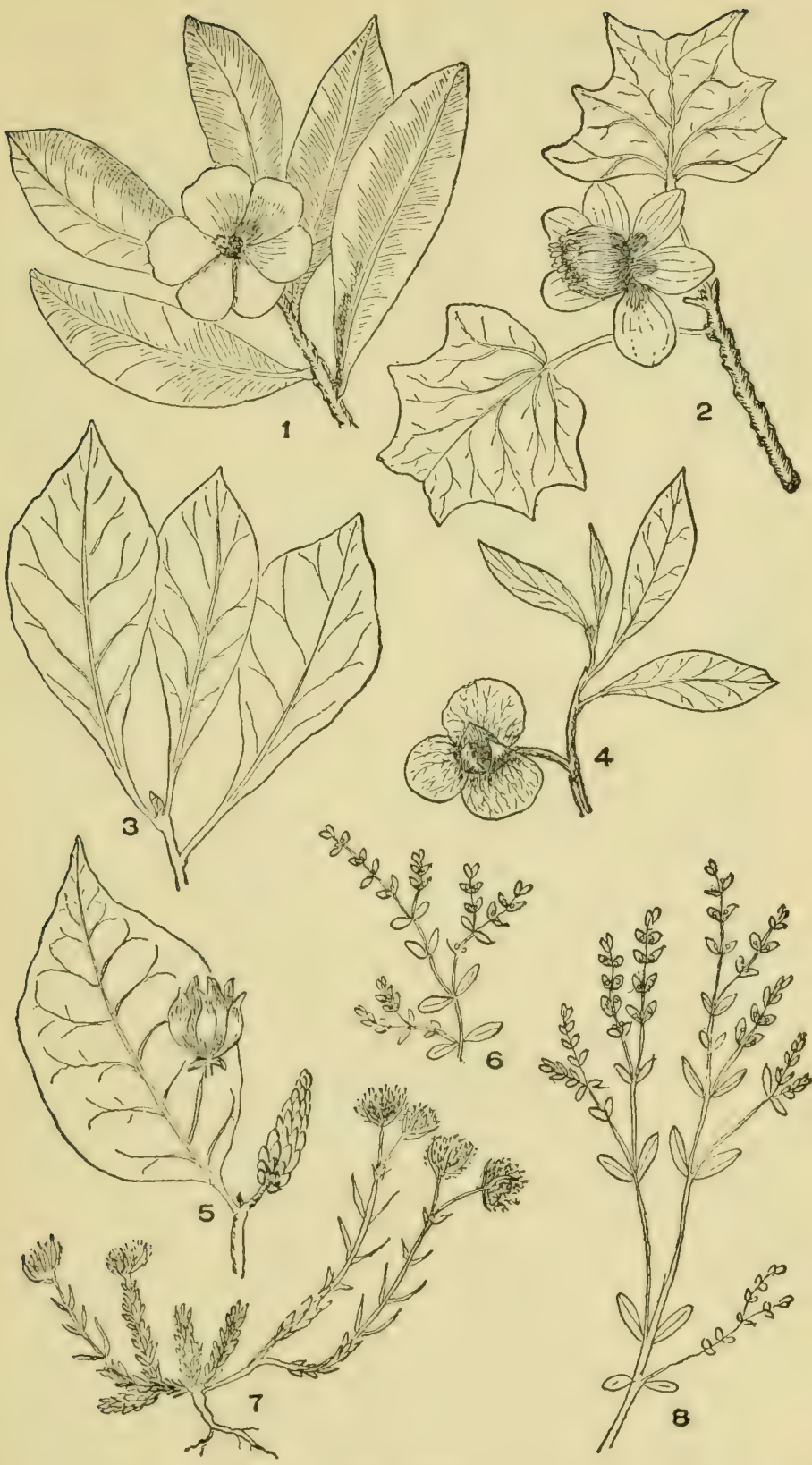

Prate 43

1. Magnolia virginiana. 2. Liriodendron Tulipifera. 3. Asimina triloba (mature leaves). 4. A. triloba (young lenves and flower). 5. Magnolia acuminati. 6. Anychia polygonoides. 7. Paronychia argyrocoma. 8. Anychia canadensis. 
in 2 series. Stamens from 3 to 15 . Carpels also from a few to several. Only a single species in our region.

A. triloba, (L.) Dunal. (Figs. 3 and 4, pl. 43.) Nortil American PAPAW. Tree found only in the southern part of our region. Flowers dull purple, petals 3 or 4 times as long as sepals.
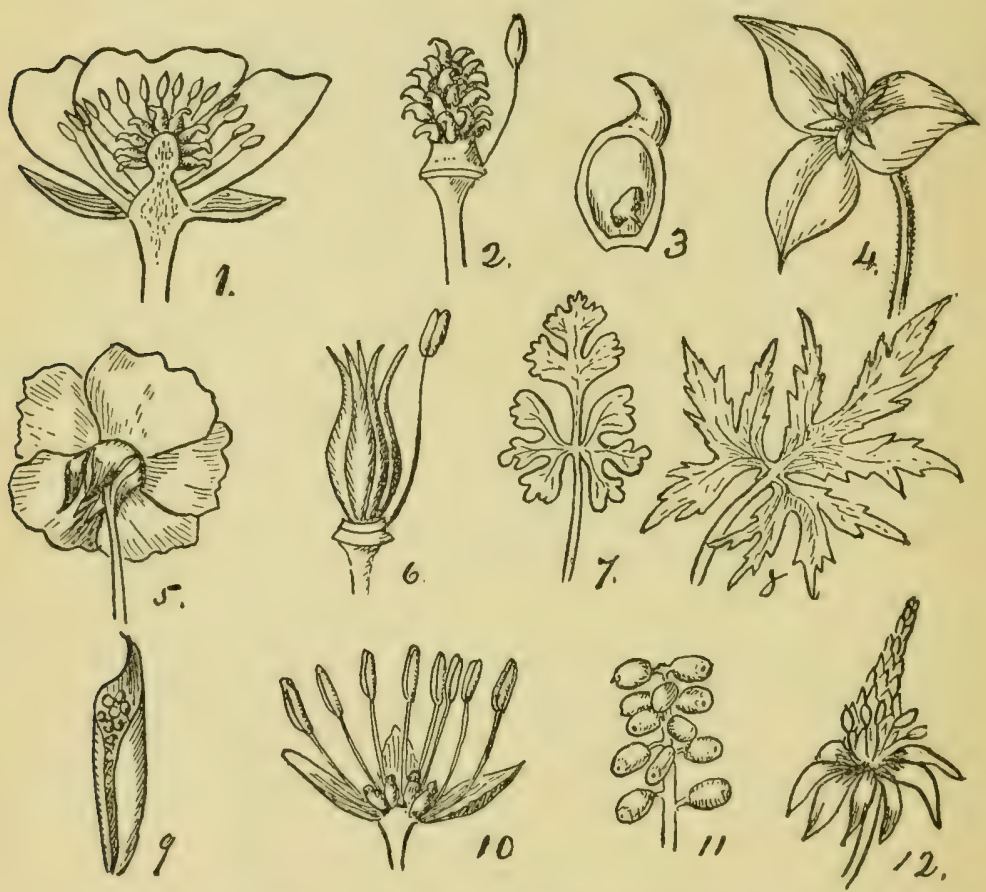

I. Section of a flower of Buttercup showing the arrangement of calyx, petals, stamens and the numerous carpels (achenes), which are arranged about the re. ceptacle. 2. The cluster of achenes on the receptacle witl a single stamen, which is seen to arise from a ring at the foot oi the receptacle. 3. $\Lambda$ single achene cut lengthwise to show the single seed. 4. $\Lambda$ group of achenes of Hepatica above the three bracts of the involucre. 5. Flower of Ranunculus bulbosus, showing the reflected sepals. 6. $\Lambda$ group of follicles with a single stamen arising from the base of the recentacle. 7. Leaf of Ranunculus bulbosus. 8. Leaf of $R$, acris. 9. $A$ follicle nartly opened showing the double row of seeds. 10. Section of a flower oi Thalictrum showing stamens, carpels and small sepals, much cnlarged. Ir. Cluster of berries of Actea. 12. Flower of Myosurus.

\section{Family V.-RANUnCULACEAE. Tine Crowtoot Famis}

(Numerals in brackets refer to figures above.)

A large and important family with a great varicty of forms. All of our species are herlos with the exception of those of $\mathrm{Clcm}$ atis and Atragene, which are climbing vines and Tenthorrhiza 
which is a small shrub. Leaves alternate, except Clematis and Atragene, with the base of the foot-stalk broad and often clasping. In this family are found plants widely differing in appearance, but certain characteristics are common to all. The flowers in most of the species are regular, but in some they are quite irregular, as in the larkspur. So also the flowers of most species are complete in having sepals, petals, stamens and pistils, yet some, as for example, the clematis species, have large colored sepals while the petals are greatly reduced or are absent. In Thalictrum the flower is still further modified, for here not only is the corolla absent $(10)$, but in some of the species the stamens are found in the flowers of one plant and the pistils in those of another. The seeds are contained in carpels which have the form of achenes in which there is but a single seed in the casket; of follicles when there are numerous seeds in the casket, while in a few instances the seeds are enclosed in a fleshy berry (11). Stamens numerous. Pistils numerous, few, or only one.

The carpels or seed caskets form a convenient means of dividing the genera into groups and they should be studied with care. Observe the difference between the entirely closed nut-like achene (3) and the generally longer seed casket, the follicle (6), with its line for splitting when the fruit is ripe (9).

\section{FIRST GROUP}

(References to figures in this Key are to those at the head of Family Ranunculaceae.)

Seeds in achenes (see Fig. 1).

Achenes with long plumose tails . Clematis, Atragene

Achenes grouped around a tall spike (Fig. 12) Myosurus

Achenes in rounded or slightly elongated heads (Fig. 2).

Flowers with only one envelope, but with a short whorl of leaves resembling a calyx near the flower (Fig. 4). Hepatica

Whorl of stem leaves at some distance below the flower. Flowers in an umbel . . . . . Anemonella Flowers not in an umbel . . . . Anemone

Leaves on flower stem not in a whorl.

Flowers numerous

Thalictrum

One-flowered . . . . . . . . Hydrastis

Flowers with two envelopes, calyx and corolla.

Herbs, flowers yellow. 
Head rounded or elongated, achenes (Fig. 2) smooth

Ranunculus

Heads elongated, achenes ridged . . . 0xygraphis Herbs, flowers white . . . . . Batrachium

SECOND GROUP

Seeds in a follicle

(Figs. 6 and 9)

Shrub

Herbs.

Flowers yellow.

Leaves undivided . . . . . . . . Caltha

Leaves dissected . . . . . . . Trollius

Flowers red and yellow . . . . . . Aquilegia Flowers blue.

Upper petal a long spur . . . . . Delphinium

Upper petal a hood . . . . . . Aconitum

Flowers white.

In a spike . . . . . . . . . Cimicifuga

Solitary.

Flower stem naked . . . . . . Coptis

Flower stem leafy . . . . . Isopyrum

THIRD GROUP

Sceds in berries (Fig. 11) . . . . . . . Actaea

\section{FIRST GROUP}

(A.) Carpels one sectcd. Flowers with a single cnvelope, a culyx colored. like a corolla

\section{CLEMATIS, L.}

C'limbing wondy vines and erect herbs. Leaves of the twiners npposite on slender foot-stalks, simple or more frequently compound. Those of No. 3 without foot-stalks. Flower of 4 conspicuous colored sepals, the jetals wanting. Achenes numerous, each with a long plumose tail.

Vines 10 to $20 \mathrm{ft}$. long.

Flowers white . . . . . . . . . . . . C. virginiano

Flowers purple

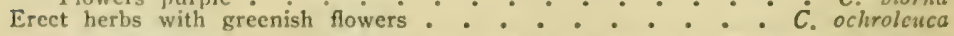

1. C. virginiana, $\mathrm{I}_{\text {. }}$ (Fig. 1, pl. 46.) Vragrn's Bower. A long vine, common, clinging by its leaf stalks to shrubs, trees and fenees and bearing a profusion of white flower elusters. which are borne on long flower stalks springing from the axils of the opposite compoumd leaves. After the fall of the flowers the vine continues to he highly ormamental 


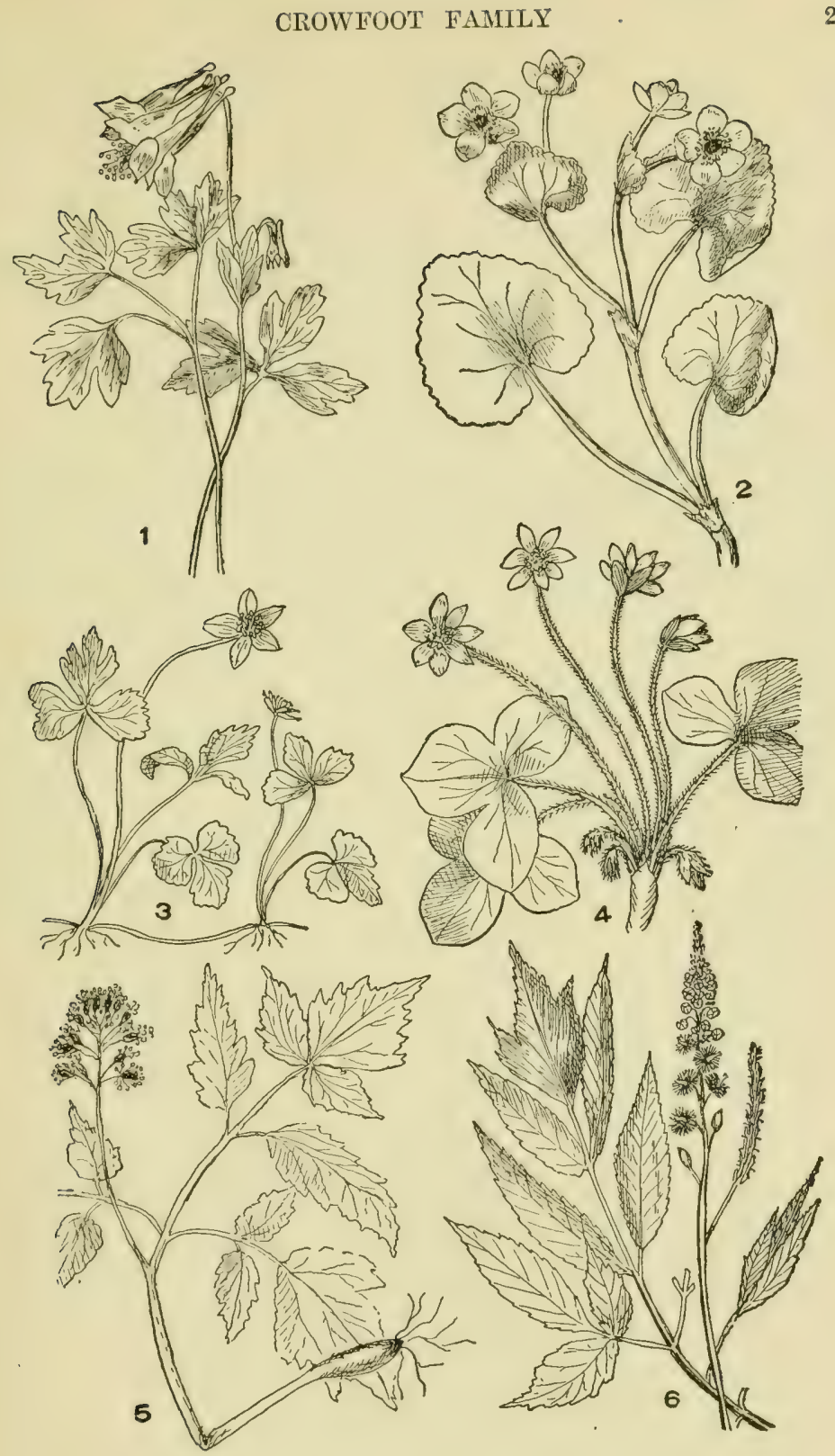

Plate 44

1. Aquilegia canadensis, 2. Caltha palustris. 3. Coptis trifolia. 4. Hepatica triloba. 5. Actaea rubra. 6. Cimicifuga racemosa. 
by virtue of the clusters of plumed seed caskets, which become nearly or quite as conspicuous as the clusters of white flowers. July-Sept.

2. C. viorna, L. Leatier Flower. Flower purple, bell-shaped. Rare, if found at all, in our region.

3. C. ochroleuca, Ait. (Fig. 3, pl. 46.) ERect Silky Crematis. Erect, 1 to $2 \mathrm{ft}$. high. Leaves not compound, broadly egg-shaped and without foot-stalks or with very short ones. Flower nodding, solitary, bell-shaped, about 1 in. long. Color, yellowish-brown. Fields and copses, in our region. May.

\section{ATRAGENE, L.}

Similar to Clematis, but differentiated by the presence of a few small petals. The sepals very large, forming a showy flower.

A. americana. Sims. (Fig. 4, pl. 46.) Purple Virgin's Bower. (Clematis verticillaris, DC.) A climbing vine, 10 to $20 \mathrm{ft}$ high, clinging to shrubs and trees. Leaf stems forming a whorl about the main stem. Leaflets on foot-stalks nearly as long as themselves. Flowers solitary, 2 to $4 \mathrm{in.} \mathrm{broad,} \mathrm{of} 4$ large purple sepals on a long flower stem. One or more flower stems from the same axil. Rocky hills, not common. May-June.

\section{HEPATICA, Hill}

Leaves all from the base (radical) except the three small leaf-liko organs. which are situated just below the flower and resemble a calyx (Fig. 4, p. 396). The true leaves, which are somewhat triangular, or broadly heart-shaped are three-lobed and rather thick and form a brownish or dark green mat which spreads upon the surface of the ground or over the dead leaves of the woods in which the plant best thrives. Several hairy flower-stalks usually arise from the same root, each from 3 to $6 \mathrm{in}$. high, bearing a single blue, purple or whitish-purple flower just above the calyx-like involucre of three stem-leaves. The hepatica is one of the earliest and most attractive flowers of the spring.

1. H. triloba. Chaix. (Fig. 4, pl. 44.) Round-leaved Hepatica. LiverleAf. Liverwort. With the lobes obtuse or rounded.

2. H. acutiloba, DC. Sharp-Lobed Hepatica. With lobes much more acute than in $H$. triloba. In rich moist woods. April-May.

\section{ANEMONE, L.}

Therbs, erect, with leaves arising by a leaf-stalk directly from the base and with leaves also on a separate flower stem. Flowers with 5 to 9 petallike sepals, white, hrownish-white or recklish. Pistil column very short or its capital (stigma) in direct contact with the fruitlet. P'istils and stamens numerous. Fruit, dry one-seeded eells in a cluster. Below the flower, at some distanee, is a whorl of 3 leaves, catch leaf divided (except in A. conculensis), into 3 separate leallets, each of these leallets is derply ent into 3 acute lobes. In 1. canadonsis the leaves are decply divided but not into separate parts. In all our species, except 1. quinduefolia, the flower stem divides at the main whorl of leaves into from 2 to 5 flower stalks, each bearing a single bud or flower and on some of these secondary stalks may occur also a secondary, leaf whorl above which another division of the stem may appear. 


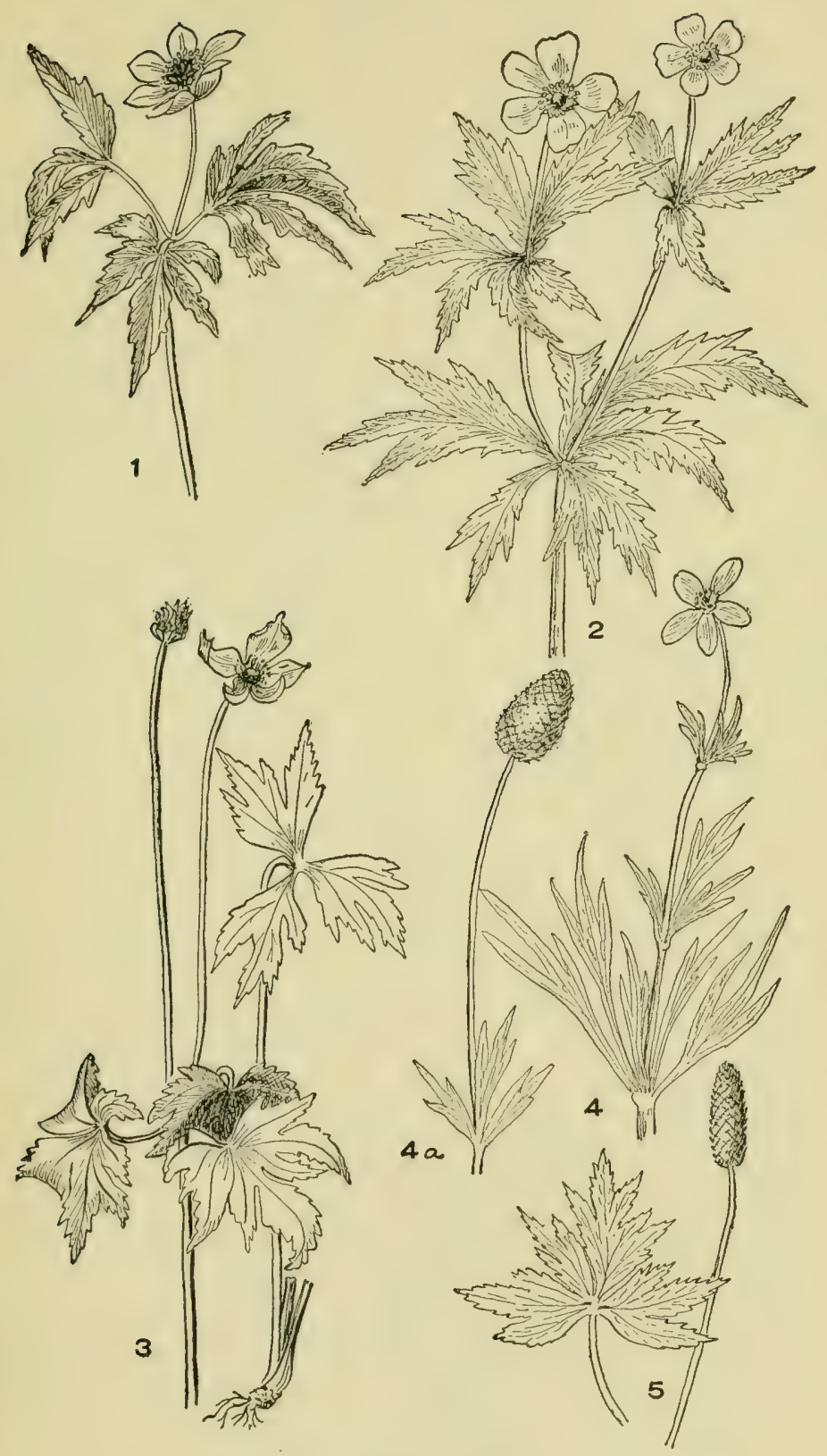

Plate 45

1. Anemone quinquefolia. 2. A. canadensis. 3. A. virginiana. 4. A. multifida. 4a. Head of fruit of $A$ multifida. 5. Leaf and head of fruit of Anemone cylindrica. 
The floral envelope consists of 5 or more petal-like sepals, greenish or yellowish white, about $\frac{3}{3}$ in. across, on naked stalks, 3 to $10 \mathrm{in.}$ long.

Pistils not more than 20.

Flowering stem bearing a single flower.

Leaves 5 parted . . . . . . . . . . A. quinqucfolia

Leaves 3 parted . . . . . . . . . . A. trifolia

Flowering stem bearing more than one flower : $: \dot{*}^{-} \quad$ A. canadensis $^{-}$

Pistils generally more than 20 ( 30 to 50 ).

Flowers red ........... A. mullifida

Flowers white or greenish-white.

Head of fruit oblong . . . . . . . . . . A. virginiana

Head of fruit cylindric.

Leaves of involucre egg-shaped . . . . . A. cylindrica

Leaves of involucre lance-shaped : : : $:$ A. riparia

1. A. quinquefolia, L. (Fig. 1, pl. 45.) Wind Flower. (A. nemorosa, Michx.). Small, delicate plant with the leaf stems about as high as the leaves. Flowering stem 4 to $9 \mathrm{in}$. high. Leaves divided into 5 leaflets, the terminal one being on an independent foot-stalk, the two lateral ones on each side having a common foot-stalk. Borders of all the leaves deeply notched. The flowering stem bears a whorl of 3 leaves an inch or two below the solitary flower. The basal leaves appear later than the flower stem and leaves. Flower about I in. broad, white or, on the outside, somewhat purplish. In woods of our area. April-June.

2. A. trifolia, L. Mountain Anemone. Resembles No. 1, but is usually larger and stouter and the lower leaves are divided into 3 learlets which are broad lance-shaped. Southern Penna., and southward. May.

3. A. canadensis, L. (Fig. 2, pl. 45.) Canada Anemone. Plant 1 to $2 \mathrm{ft}$. high. Leaflets pale beneath, breadth of most of them greater two or more branches which bear each a leaf whorl about which there may spring one or more stems each bearing a flower. Leaves 3-parted by sinuses extending half way or more toward the base. Borders notched. Basal leaves on long foot-stalks. Pistils 12 to 20 . Low grounds. Common. May-June.

4. A. multifida, Poir (Fig. 4, pl. 45.) Cut-leaved Anemone. ( $A$. hudsoniana, Richards.) Plant silky hairy. Flowering stem 6 to 18 in. high. Leaves from the base on long foot-stalks. Foot-stalks of the whorl leaves short. Leaves cut into many linear segments. Flower of 5 to 9 reddish or greenish-red sepals. In the northern part of our region; rare. June.

5. A. virginiana, L. (Fig. 3, pl.45.) Tall Anemone. Flowering stem 2 to $3 \mathrm{ft}$. high. Whole plant hairy. Foot-stalks of the leaves of the whorl nearly as long as the leaves themselves. Leaves 3-lobed, the divisions of the whorl leaves less deep than those of the basal ones. Jireadth greater than length. Sepals generally 5. white or creenishwhite. The fruit head elongated but less eylindric than the next species. Shady places. Common. June-Aug.

6. A. cylindrica, A. Aray. (Fig. 5, pl, 45.) Lovg-teaven Anemone. Flowering stem 1 to $2 \mathrm{ft}$. high. Whole plant covered with silky hairs. Leaves more deeply divided than in the last species. Flowers similar to the last. Fruit head cylindric, often an inch or more long. Open places, common. June-Aug.

7. A. riparia, Fermald. Tesembles A. cylindriea but is less downy, with thinner leaves, those of the flower stem forming the involucre, lance- 

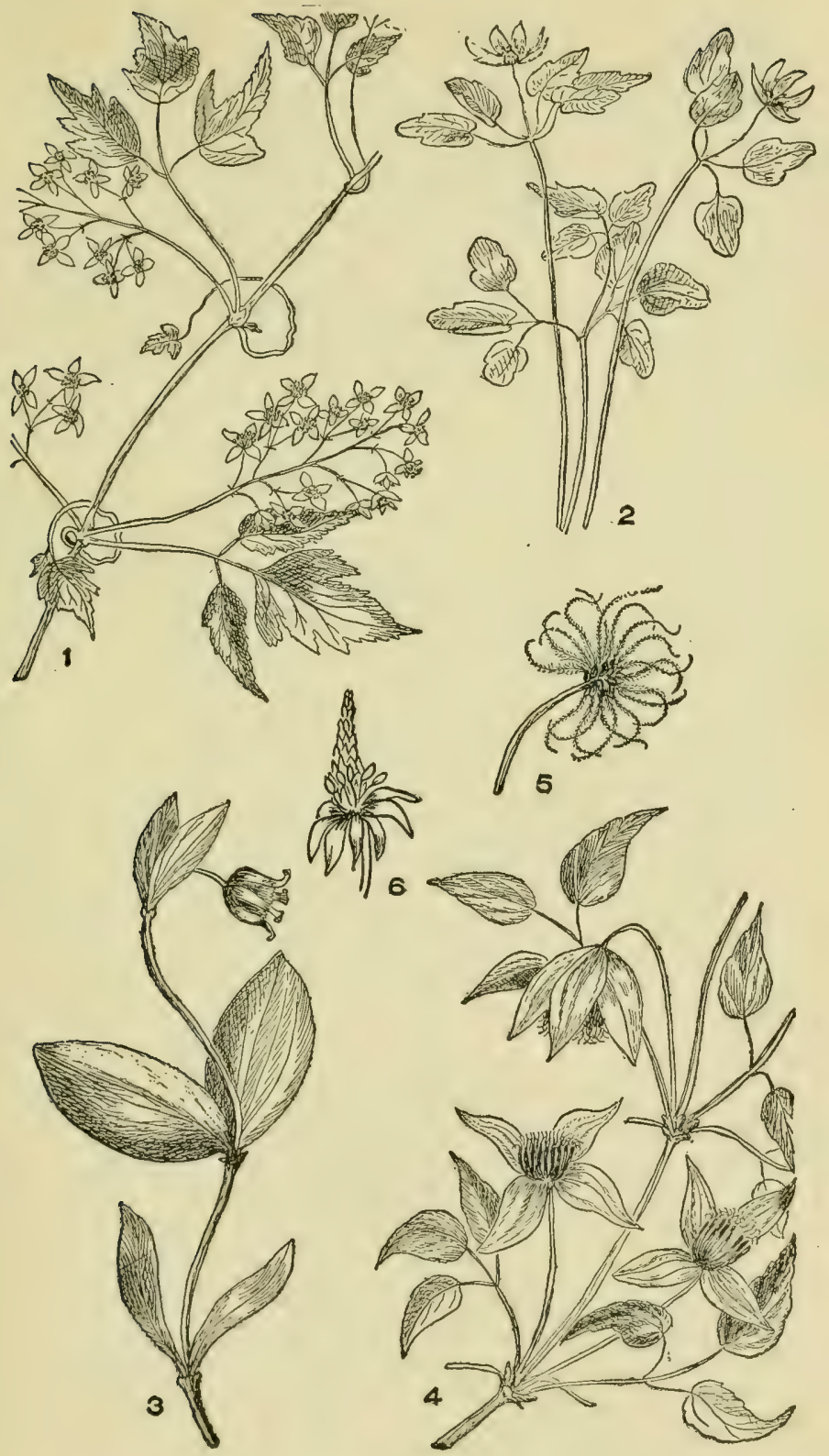

Plate 46

1. Clematis virginiana. 2. Anemonella thalictroides. 3. Clematis ochroleuca. 4. Atragene americana. 5. Head of fruit of C. virginiana. 6. Myosurus minimus. 
shaped. Head of fruit sub-cylindric. Maine, Conn., and southward. June-Aug.

\section{ANEMONELLA, Spach. (Syndesmon, Hoffmg.)}

From a cluster of tubrous roots arises a stem 6 to $10 \mathrm{in.} \mathrm{high} \mathrm{sur-}$ mounted by a whorl of leaves, above which arises a loose umbel of white flowers on long delicate foot-stalks. Later arise the stems of the basal leaves which are ternately compound, the common foot-stalks 1 or 2 in. long dividing into three branches, each bearing a rounded obtusely lobed leaflet.

A. thalictroides, (L.) Hoffmg. (Fig. 2, pl. 46.) Rue Anemone. Flowering stem 4 to 9 in. high, smooth. Sepals white, about 5 or 7 . Flowers from 2 to 6 in the cluster. Common in open woods. Early spring.

\section{THALICTRUM, L.}

Rather tall herbs, flowering from April to June. Stems 1 to $7 \mathrm{ft}$. high. Leaves on the stem bearing the flowers and on one springing from the root and which is flowerless. Leaves of the flowering stem on a main leaf-stalk which divides into 3 branches, each branch again dividing into 3 parts from each of which spring 3 leaflets, each leaflet is also to some extent divided into 3 parts. The tall leaf-stalk which springs from the root has a less regularly divided leaf-stalk. Flowers in conspicuous white or greenish-yellow clusters. Individually the flowers are small (Fig. 10, page 396 ). Petals are absent and the small sepals 5, rarely 4 , in number, are white with a tinge of green. Stamens and pistils may occupy the same flower or different flowers either on the same or different plants. The stamens of the staminate flowers form rather conspicuous little tas. scls of 20 or more stamens. The pistillate flowers are less conspicuous.

1. T. dioicum, L. (Fig. 2, pl. 47.) Early Meadow-Rue. Smooth, 1 to $2 \mathrm{ft}$. high, somewhat hairy. At the first whorl of leaves sending than the length, often heart-shaped at base, 3 or rarely 4 leaflets in a group, each with 3 principal lobes with secondary sinuses or notehes. Flowers, pistillate and staminate on different plants, the latter green or yellowish-green, dangling from the slender foot-stalks, the group forming pretty green tassels. A very early flower in rocky woods. Usually blooms in April.

2. T. revolutum, DC. (Fig. 3, pl. 47.) Purplisn MEanow-Rue. (T. mupuraseens, (iray.) Stem 4 to $7 \mathrm{ft}$. high, purple, branching above. Stem leaves with short or no foot-stalks. Leaflets longer than broad, pear-shaperd or nearly triangular, tapering at base and with about 2 deep notelies at summit or none. Some of the leaflets narrow egreshaped. Flourrs with bolle strmens and pistils. Woods and eopses, Mass., New Jersey, and southward. June-Aug.

3. T. polygamum, Muhl. (Fig. 1, pl. 47.) Tall Meadow-Rue. Stem green, 3 to $11 \mathrm{ft}$. high. Crowing in open swamps or wet places. Leaflets as hroarl as long with 3 lobes at summit, heart-shaped at base. Flowers with both pistils and stamens. Common. June-July.

7. HYDRASTIS, Ellis.

Erect herb with deeply cut, broad, kidney-shaped leaves and solitary 


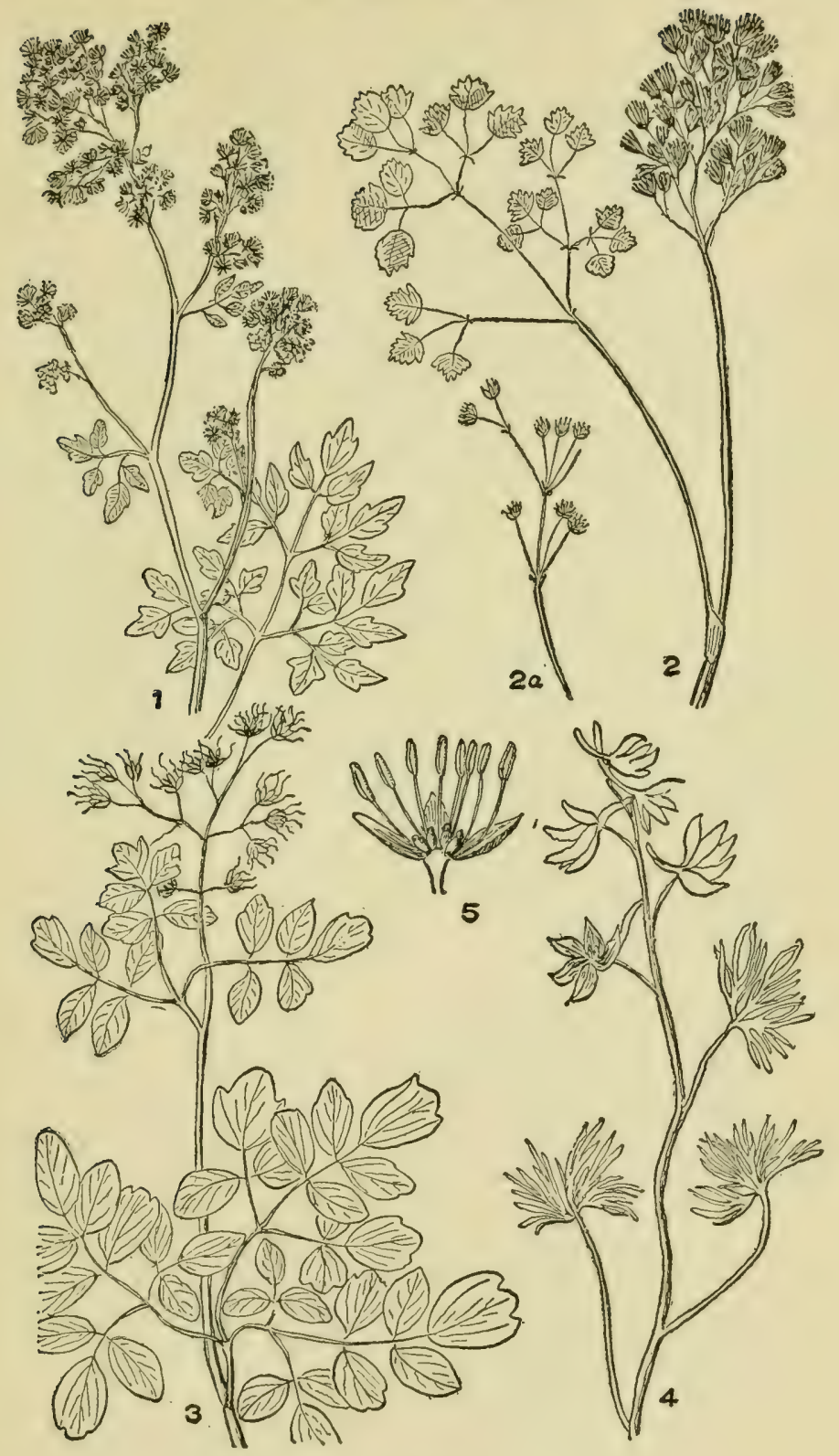

Plate 47

1. Thalictrum polygamum. 2. T. dioicum. 2a. Pistillate flowers. 3. T. revolutum, 4. Delphinium Consolida. 5. Flower of $T$. revolutum, enlarged. 
flower, with 3 sepals which fall as the flower expands. Petals none. Stamens numerous, carpels several, forming a rounded bunch.

H. canadensis, L. Orange Root. Goldex Seal. Basal leaf on stalk separate from flower-bearing stem, 5 to 9 in. broad, heart-shaped at base, at periphery cut by 3 to 5 deep sinuses, the various segments with notched borders. Flowering stem with two smaller leaves similarly cut. Flower greenish-white, the whole plant covered with soft hairs. Woods, most of our area. April.

\section{MYOSURUS, L.}

A small plant found in moist places, its carpels arranged about a spindle-shaped receptacle. Sepals 5 (sometimes none), petals yellowish. Pistils many; stamens 5 to 25 . Leaves linear.

M. minimus, I. (Fig. 6, pl. 46.) Mouse TaIL. Plant 2 to 5 in. high, the elongated seed receptacle occupying nearly or quite $\frac{1}{2}$ the length. Doubtful if found in our area, but has been reported in extreme southern part.

\section{B. Flowers with two envelopes, calyx and corolla}

\section{RANUNCULUS, L.}

Herbs, most of which have the leaves much divided (Figs. 7 and 8, page 396 ). Flowers solitary or in loose clusters. Sepals 5 , or rarely less, falling off as the seeds develop. Petals 5 or more or less, sometimes minute, flattened, with a small pit and a scale at the base (the former to contain nectar). Seed carpels numerous in a rounded or elongated group, smooth. Stem leaves alternate, the foot-stalks broad and clasping. Flowers all yellow, in our region.

Aquatic, with dissected leaves . . . . . R. delphinifolius Terrestrial (Nos. 2 and 3 in ditches and muddy places).

Fruit in cylindric heads.

Plant nearly or quite destitute of hairs....... R. sceleratus Plant very hairy $.0^{\circ} \cdot 0^{\circ}{ }^{\circ}{ }^{\circ}{ }^{\circ}$ pennsylvanicus Fruit in globose heads.

Plants creeping . . . . . R. reptans and $R$. repons Plants not creeping; erect or spreading.

Leaves grass-ike erect or spreading. ..... $R$. laxicaulis

Leaves undivided, egr-shaped or lance-shaped $\cdots R_{\text {. pusillus }}$ Lower leaves broadly rounded and heart-slaped, upper deeply divided . . . . . R. micranthus Summit of fruit armed with a hooked style ${ }^{-} \cdot{ }^{-}$alleghaniensis

Lower leaves egg-shaped but somewhat deeply lobed, upper leaves divided...$R_{0}$ abortivus

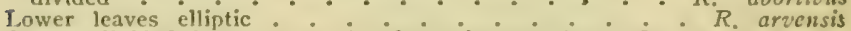

Leaves divided into 3 parts by deep sinuses, the leaflets not on elongated foot-stalks.

Lobes without deep secondary sinuses . . . $R$. recurvatus Lobes cut by deep secondary sinuses.

Plant usually 2 to $3 \mathrm{ft}$, high . . . . . $R$. acris

Plant usually $\sigma$ to $\times 5$ in. high $: \vdots \vdots: \dot{R}$. parvulus

Leaves 3 -divided, one or all of the divisions on elongated foot-

stalks and these divisions $2 \cdot$ or 3 -divided by-deep sinuses.

Sepals reflexed (l'1g. 5, pl. 396$)$.

The terminal leaf division only on a lengthened foot-stalk

Scpls . . . . . . . . R. bulbosus

Each of the leaf divisions on a lengthened foot-stalk

Reptentrionalis Leafiets with segments mostly rounded at apex

Lcafets witi segments mostly ${ }^{\circ} R^{\circ}$. fascicularis 


\section{CROTVFOOT FAMILY}

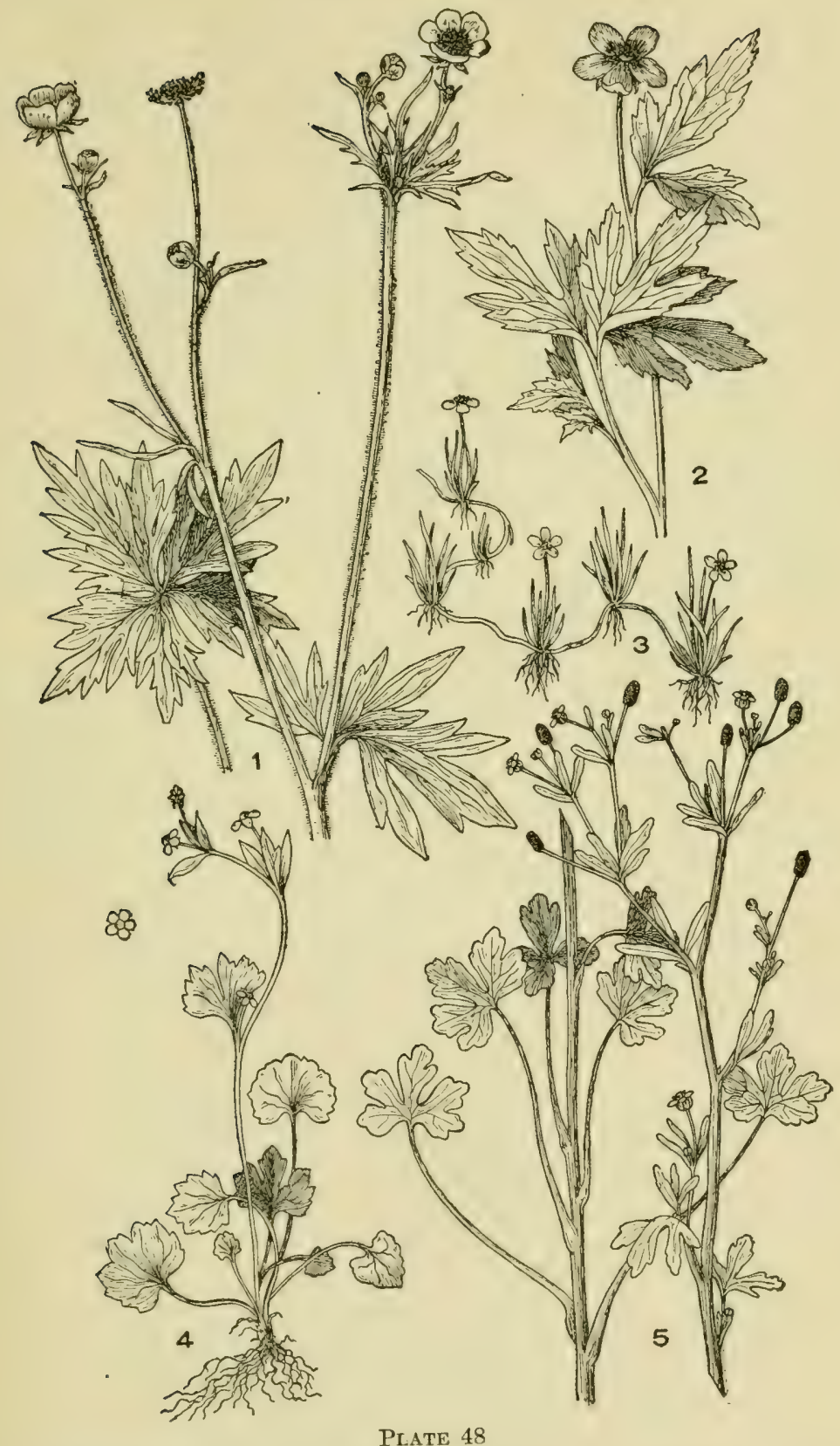

Plate 48

1. Ranunculus acris. 2. R. septentrionalis. 3. R. reptans. 4. R. abortivus. 5. R. sceleratus. 


\section{Aquatic Plants}

1. R. delphinifolius, Torr. Yellow Water Crowfoot. Stem partly or entirely imnersed. J,paves divided into many segments, the submersed ones mostly of thread-like segments, the floating ones somewhat broader and llattened, even rounded or kidney-shaped. Flowers yellow. In ponds througliout our area. May-July.

\section{Terrestrial Plants growing in marshes, ditches and wet places}

2. R. pusillus, Poir. Low Spearwort. A low slender plant, 6 to 12 in, high. Lower leaves egg-shaped, mostly with very shallow dentations, on long foot-stalks. Upper leaves narrow lance-shape on short or no foot-stalks. Flowers small, yellow, usually with few petals or with 5. In marshes, southern New York, New Jersey and south. AprilJuly.

3. R. laxicaulis, (T. and G.) Darby. (Fig. 2, pl. 50.) WATER Plantaln SPEarwort. ( $R$. obtusiusculus, Raf.). Plant ascending or nearly erect, smooth, 1 to $3 \mathrm{ft}$. high. Leaves grass-like, 3 to 6 in. long, about $\frac{1}{2}$ to $\frac{3}{4}$ in. wide, not toothed or with very shallow indentations; on hroad foot-stalks which clasp the stem. Stems throwing out roots at joints. Flowers yellow, rather conspicuous. Marshes and ditehes, our area. June-Aug.

Terrestrial Plants not peculiar to wet places. Heads of fruit cylindric

4. R. sceleratus, L. (Fig. 5, pl. 48.) Celerr-leaved Crotvfoot. Stem $\frac{x}{2}$ to $2 \mathrm{ft}$. high, smooth, sometimes quite thick. Lower leaves on long foot-stalks more or less triangular, the two deep sinuses extending $\frac{1}{2}$ way or more toward the base. Upper leaves without foot-stalks in 3 long narrow divisions. Flowers numerous, yellow, petals small, calyw smeading. Fruit eluster elongated, oblong or cylindric. Swamps and wet places. Common. April-Aug.

5. R. pennsylvanicus, L. f. (Fig. 4, pl. 49.) Bristly Buttercur. Stem similar to No. 4, but bristlong with hairs. Leaves 3-divided and on short foot-stalks. All the segments narrow. Flowers yellow, petals rather small, not exceeding the length of the reflexed scpals. June-Aug.

IIeads of fruit globular. Lower leaves broadly rounded, heart-shaped

6. R. abortivus, I. (Fig. 4. pl. 48.) Kinser-teaved Cromfoot. A smonth plant in londers of woods and in moist places, $\frac{1}{2}$ to $2 \mathrm{ft}$. high. Lower leaves rounded, undivided exeept by wavy undulations, heartshaped at base, on long foot-stalks. Upper leaves without or with very short forol-stalks, divided into 3 narrow serments, each either notehed or acute at apex. Flowers yellow, petals shorter than the divisions of the calyx. Woods and moist grounds. April-June.

7. R. alleghaniensis, Britton. Closely resembles $R$. abortivus, but stem has a whitish bloom and achenes have a recurved beak which is not found in $R$, abortivus. Situations same as $R$. abortivus.

8. R. micranthus, Nutt. Rock Cnowroot. Plant similar to the preceding, but covered with hairs and lower leaves with sinuses extend. 


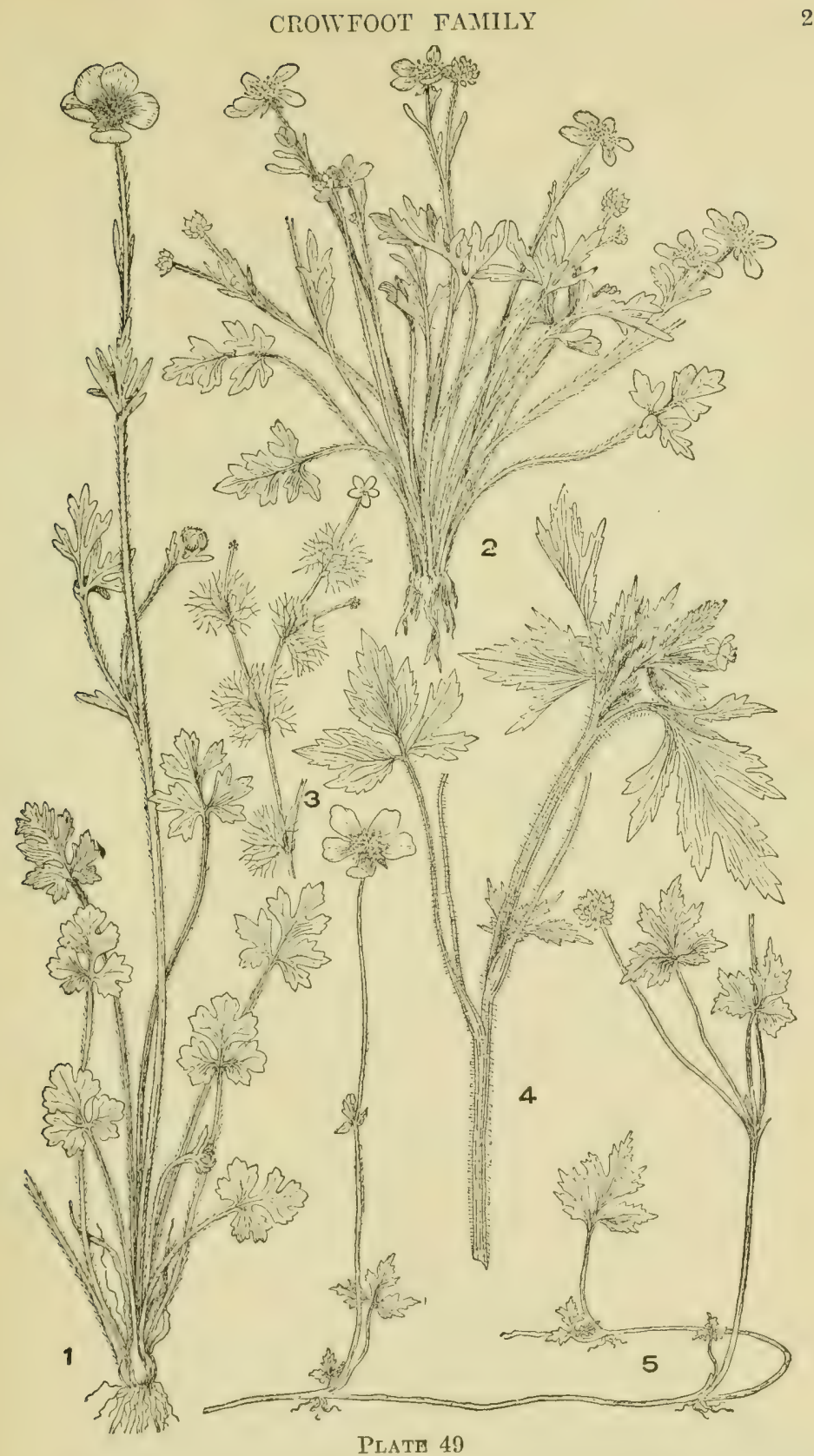

1. Ranunculus bulbosus. 2. R. fascicularis. 3. Batrachium divaricatum. 4 Ranunculus pennsylvanicus, 5. R. repens. 
ing half way to base. Rich woods, rocky places. Throughout our region. April-May.

9. R. arvensis, L. (Fig. 6, pl. 50.) ConN Crowfoot. Plant without hairs or with few hairs; about $1 \mathrm{ft}$. high. Lower leaves on rather long foot-stalks elliptic or more rounded. Upper leaves cut into wedgeshaped or linear segments, these segments entire or notched at the edges. Leaves at middle of stem on foot-stalks, those above without foot-stalks. Flowers about $\frac{1}{2}$ in. broad; segments of calyx not reflexed. Fruit covered with prickles. Waste places, New Jersey and southward. Summer.

\section{Lower leaves 3-parted nearly or quite to the base, divisions not on} elongated foot-stalks

10. R. recurvatus, Poir. (Fig. 4, pl. 50.) Ноокер Cromfoot. Stem $\frac{1}{2}$ to $2 \mathrm{ft}$. high, hairy. Leaves broadly kidney-shaped with two deep simuses extending about half way to base. Lobes indented. Flowers not large. Achenes with a strong hooked beak (Fig. 3, page 396). Common. Mostly in woods.

11. R. acris, L. (Fig. 1, pl. 48.) Tall, or Meadow Buttercur. Stem 2 to $3 \mathrm{ft}$. high, somewhat hairy. Leaves deeply cut into 3 lobes and these lobes again divided. Upper leaves, segments very narrow. Flowers rather large. Sepals spreading. This is the very common buttercup of meadows. Blooms all summer.

12. R. parvulus, L. (Fig. 5, pl. 50.) Hairy Buttercur. Stem 6 to $15 \mathrm{in}$. high. Whole plant hairy. Leaves 3 -divided, the divisions more or less deeply cleft or lobed, the upper leaves linear or divided. Flowers about 1 in. broad; calyx reflexed. Head of fruit oblong. Waste places, New Jersey and southward. All summer.

One leaflet on each of the 3 divisions of the lcaf with an clongated footstalli (Fig. 7, page 246). Only the terminal lcaflet on a foot-stalli

13. R. bulbosus, L. (Fig. 1. pl. 49.) Bulbous Buttrrcup. Stem erect, with few branches, hairy, $\frac{7}{3}$ to $1 \frac{1}{2} \mathrm{ft}$. high. Leaves in 3 parts, the terminal part on a foot-stalk, the other divisions directly on the leaf stem. Each segment deeply indented. Flowers large, calyx reflected. Root bulbous. In grassy fields, mostly in eastern section of our area. May-June.

14. R. fascicularis, Muhl. (Fig. 2, pl. 49.) Farly Buttercur. TuFter) Butrencul. Low, spreading. Stem and leaves hairy. Leaves similar to No. 13, but leaflets less deeply indented. Calyx segments spreading. Flowers rather large. In shady places and lields. New York, New England and southward. May-June.

\section{Each of the three leaflets on a foot-stalk}

15. R. septentrionalis, Poir. (Firr. 2, pl. 48.) Marsir Butrercur. $\Lambda$ bramohing plant, smooth or slightly hairy, 1 to $3 \mathrm{ft}$. high. Lowaflets of 3 distinct leallets, curh on a long foot-stall and each deeply cut into 3 segments. Moist, shady places.

16. R. hispidus, Michx. (Fig. 1, pl. 50.) IIssid Buttercur. Densely hairy, 1 to $2 \mathrm{ft}$. high, spreading. Leaflets, the terminal on a 
long foot-stalk, the lateral ones on quite short ones, each lenflet divided into 2 or 3 segments by sinuses reaching $1 / 3$ the distance to the base. Upper leaves linear. Dry woods and thickets. March-May.

\section{Creeping Plants}

17. R. repens, L. (Fig. 5, pl. 49.) Creeping Buttercur. Plant nearly smooth, spreading by runners. Leaves of 3 leaflets, the terminal one on a foot-stalk.

18. R. reptans, L. (Fig. 3, pl. 48.) Creeping Spearwort. A very small plant, creeping by runners, rooting at the nodes. Leaves grasslike, in a tuft, 1 to 2 in. high. Flowers solitary from the nodes. On sandy shores, somewhat rare but in most of our area. May-Sept.

\section{Io. OXYGRAPHIS, Bunge.}

Small herb resembling Ranumeulus, the achene longitudinally striatcd. Flowers small; leaves mostly from the root.

O. Cymbalaria, (Pursh.) Prantl. (Fig. 3, pl. 50.) Seaside CrowFoot. (Ranunculus Cymbalaria, Pursh.). Low, about 2 to $6 \mathrm{ft}$. high. Spreading by runners. Leaves mostly directly from the root, broadly rounded, heart-shaped at base. Flowers small, singly or in clusters, on a nearly naked flower stem; fruit cluster elongated. On wet sandy shores. May-Aug.

\section{BATRACHIUM, S. F. Gray}

Aquatic herbs with leaves alternate and finely dissected. Flowers white. Achenes not ridged. Sepals and petals usually 5.

1. B. divaricatum, (Schrank.) Wimm. (Fig. 3, pl. 49.) STrFF WATER CRowfoot. (Ranunculus aquatilis, Gray.) Leaves all under water, cut into thread-like divisions which, under water are spreading but which collapse on being drawn from the water. Leaves mostly without foot-stalks.

2. B. tricophyllum, (Chaix.) Bossch. Winte Water Crowfoot. (Ranunculus aquatilis, L.). Similar to No. 1, but the dissected leaves, at least the lower ones, have rather long foot-stalks and the leaves are longer than those of No. 1 .

3. B. longirostris, (Godr.) F. Schultz. Long-Beaked Winte Water Crowfoot. Resembles No. 1, but the dissected leaves are on short leafstems. The fruit (achene) has at its apex a beak nearly $1 / 16 \mathrm{in.}$ long, that of $B$. divaricatum being minute. In ponds and streams, New England and westward. June-Aug.

\section{SECOND GROUP}

Seeds in a follicle (Fig. 9, page 396). Shrub

\section{XANTHORRHIZA, L'Her.}

Low shrub, with once or twice compound leaves each with about 5 leaflets. Terminal leaflet broad and deeply 3-lobed. Side leaflets nearly eggshaped with lobed or nearly continuous border. Bark and long roots deep yellow. Flowers in long drooping clusters (racemes), pistillate and staminate on same sten, Petals small; color, brownish-purple. Stamens 
5 to 10. Carpels, originally follicles with more than one seed. As the follicle matures one seed is suppressed.

X. apiifolia, L'Her. Sinub Yellow Root. Leaves clustered at the top of the stem. Stems in clusters 1 to $2 \mathrm{ft}$. high. Southern section of our region. April-May.

\section{Herbs \\ Flowers yellow. Leaves undivided}

13. CALTHA, L.

Herbs with large kidney-shaped or fan-shaped leaves with somewhat sinuate borders or with prominent teeth. Most of the leaves on footstalks from the root. Leaves of flower stems similar to the basal ones, the upper ones clasping the stem. Follicles numerous or few.

1. C. palustris, L. (Fig. 2, pl. 44.) MArsi Marigold. Stem stout, hollow, more or less furrowed. Flowers without petals but with yellow sepals resembling petals. Leaves rounded, heart-sliaped at base, margins with quite low teeth. Plant found in swampy meadows. Early May.

Var. C. flabellifolia, Pursh. Mountain Marsil Marigold. Plant less stout; leaves fan-shaped with broad sinuses at base. Teeth at margin conspicuous. Pocono plateau, Pa., and northern New Jersey. June-July.

\section{I4. TROLLIUS, L.}

Plant closely resembling Ranuneulus, but usually stouter, 1 to $2 \mathrm{ft}$. high. Leaves divided by several sinuses extending to the stem or only part way to it. Flowers yellow, uswally solitary with 5 sepals resembling petals. Carpels 5 or numerous. Stamens numerous.

T. laxus, Salisb. American Glom'-Flower. Slender, 1 to $2 \mathrm{ft}$. high. Upper leaf without a foot-stalk. Sepals yellowish or purplish, 5 to 6 ; petals minute. Follicles forming a head nearly or quite an inch in diameter, each follicle is tipped with a straight bristle $\frac{1}{d}$ the length of the follicle. Swamps. New Hampshire and New York. May-July.

\section{I5. COPTIS, Salisb.}

Five or six sepals. Petals none or very small. Stamens 15 to 25 . Seeds in follicles, of which there are from 3 to 10 in a stellate group. Small lerbs with long crepping roots from which spring elusters of rout leaves ( 2 to 4 ) each 3 parted, in the midst of which arises the delicate naked flower stem bearing a single flower.

C. trifolia, (L.) Salisb. (Fig. 3, pl.44.) Goldtumead. Three nearly erfually divided kite-shaped leaflets, each slightly lobed at the summit and notehed along the outer $2 / 3$ or $3 / 4$ of the border. Sepals white. A protty star-shaped flower of early spring with shinimer leaves and golden colored thread-like ruming roots. In wools througlout our area. May.

\section{I6. AQUILEGIA, L.}

Petals and sepals colored alike. Flower usually nodding so that the lome tolublar spurs of the petals point upward. The 5 ovate sepals form a 5-printed star, hetwern the division of which the potals aseend. Petals 5, of horn-of-plenty form, each attached to the receptacle ly the short 
lip of the opening. Pistils 5, developing 5 follicles (sce Fig. 7 , page SSS). Ixaf stem divided into 3 secondary stems, each bearing a 3-parted leaf with deeply lobed segments.

A. canadensis, L. (Fig. 1, pl. 44.) Wild Columbine. Plant 1 to $2 \mathrm{ft}$. high, branching. Spur of the petals long, curving in at summit and tipped by a slight rounded extremity. Petals red outside, yellow inside. Sepals red. One of the most interesting of our native spring flowers. Rocky places in woods throughout our region. May.

The garden Columbine, with blue or purple flowers, A. vulgaris, L., is occasionally found in our area as an escape and to some extent naturalized.

\section{I7. ACONITUM, L.}

Tall plants with large radiately lobed leaves and with a tall spike of irregular showy dark blue flowers. Sepals 5. the upper one hooded. Petals 2, under cover of the hooded sepal. Pistils 3 to 5 . Stamens many.

1. A. noveboracense, Gray. New York Monksiood. Plant $2 \mathrm{ft}$. high, flowers on a tall spike, the arched helmet conspicuously beaked. Leaves broad, deeply 5-parted with the segments deeply cut. Southern New York.

2. A. uncinatum, L. (Fig. 7, pl. 50.) WILD MonKsirood. Stem weak, sometimes climbing. Leaves 3 to 5 lobed, each lobe deeply cut. Cluster few flowered. Helmet conic, slightly bealicd. Woods, southern Penna, and south. July-Sept.

\section{DELPHINIUM, L.}

Sepals 5, the upper long-spurred. Petals 4, blue, small, irregular, the two upper ones forming spurs which are enclosed in the long spur of the sepal. Carpels follicular, about 3. Showy plants with rounded deeplydivided leaves and tall clusters of blue flowers.

1. D. exaltatum, Ait. Tall Larkspur. (D. urceolatum, Jaeq.). Two to five ft. high. Flowers dark blue on a tall spike, not large. Pistil 1; leaves 3 -parted, the segments 2 or 3 cleft. In woods. Southern section of our region. July-Aug.

2. D. tricorne, Michx. Dwarf Lakkspur. Plant 1 to $3 \mathrm{ft}$. high. Leaves deeply 3 - to 5-parted, each segment deeply cleft. Cluster of flowers loose, only 4 or 5 in. high. Pistil 1. Western Pennsylvania. April-June.

3. D. Consolida,-L. (Fig. 4, pl. 47.) Field Larkspur. Plant 1 to $21 \mathrm{ft}$. high. Leaves without lcaf-stalks, fincly dissected into linear segments. Flover with 3 pistils. Southern New Jersey and Penna. Naturalized in a few places. Summer.

4. D. Ajacis, L. Flowers more numerous than in No. 3. Pods downy, those of $D$. Consolida are without down. Naturalized in places.

\section{I9. CIMICIFUGA, L.}

Leaf-stalks twice or thrice 3-parted. Flowers white in long slender wand-like clusters (racemes). Pistils 1 to 8 . Stamens many, with white filaments. The 4 or 5 small petals, falling as the flower opens, leave the 
cluster of white stamens as the conspicuous element of the flower. Fruit a dry pod-like follicle.

1. C. racemosa, (L.) Nutt. (Fig. 6, pl. 44.) Black Corrosir. Black Sxakeroot. A tall handsome plant in rich woods, often $5 \mathrm{ft}$. high or more, with very long and slender forked spikes of flowers. Pistil 1, rarely 2 or 3 . Clusters of feathery white stamens. Southern New England and southward. July.

2. C. americana, Michx. AMerican BugBane. Plant generally not so large as No. 1. Pistils 3 to 8 , which develop into several more or less star-like groups of short inflated follicles. Southern Pennsylvania, Watkins, N. Y. Aug.-Sept.

\section{ACTAEA, L.}

Erect branching herbs with 3-parted leaf stalks, each division furnished with 3 to 5 leaflets. Upper leaves without leaf-stalks. Leaflets generally more or less 3-lobed and more or Jess deeply notehed. Flowers in an ovate or oblong white cluster. Petals much shorter than the spreading cluster of numerous stamens. Plants of both species from 1 to $2 \mathrm{ft}$. high.

1. A. rubra, (Ait.) Willd. (Fig. 5, pl. 44.) RED BANEBERrY. Flower cluster egg-shaped or almost rounded. Leaflets egg-shaped, deeply notched at borders. Berries red when ripe. Common. May.

2. A. alba, (L.) Mill. White Baneberry. Flower cluster more elongated, oblong. Leaves also longer and narrower and more deeply incised. Berries white. Rich woods. Common. May.

\section{Family VI.-BERBERIDACEAE. Barberry Family}

Shrubs and herbs. Leaves of the shrubs in rosette-like groups, those of the herbs solitary and springing directly from the root or from the flowering stem. Shrubs with stipulate leaves, herbs without stipules. Stamens equal in number to the petals or double the number. Pistil 1. Fruit a berry.

\section{BERBERIS, L.}

Shrub with spiny leaves and with grape-like pendant clusters of yellow flowers. Tetals and sepals, each 6 , exceptionally sepals exeed 6 . Helow the flower are found 2 or 3 bract-like bodies.

B. vulgaris, L. (Figr. 1, pl. 5l.) Banbenry. Shrub 6 to $8 \mathrm{ft}$. high. Leaves in close groups of about 3 , in a rosette, not in a perfect whorl but condensed. Below each of the groups of leaves are 3 -forled spines which are modified leaves. Leaves pear-shaped, sharply notelied, the serrations each terminated by a soft bristle. linit, an clongated berry, red when ripe. Woods and thickets; naturalized. May-June.

2. CAULOPHYLLUM, Michx.

Herhs with thickened rootstock, the compound leaf arising from the flowering stem. Calyx of 6 sepals, below which are 3 or 4 small sealelike bracts. Stamens 6 . Seeds in berries. 


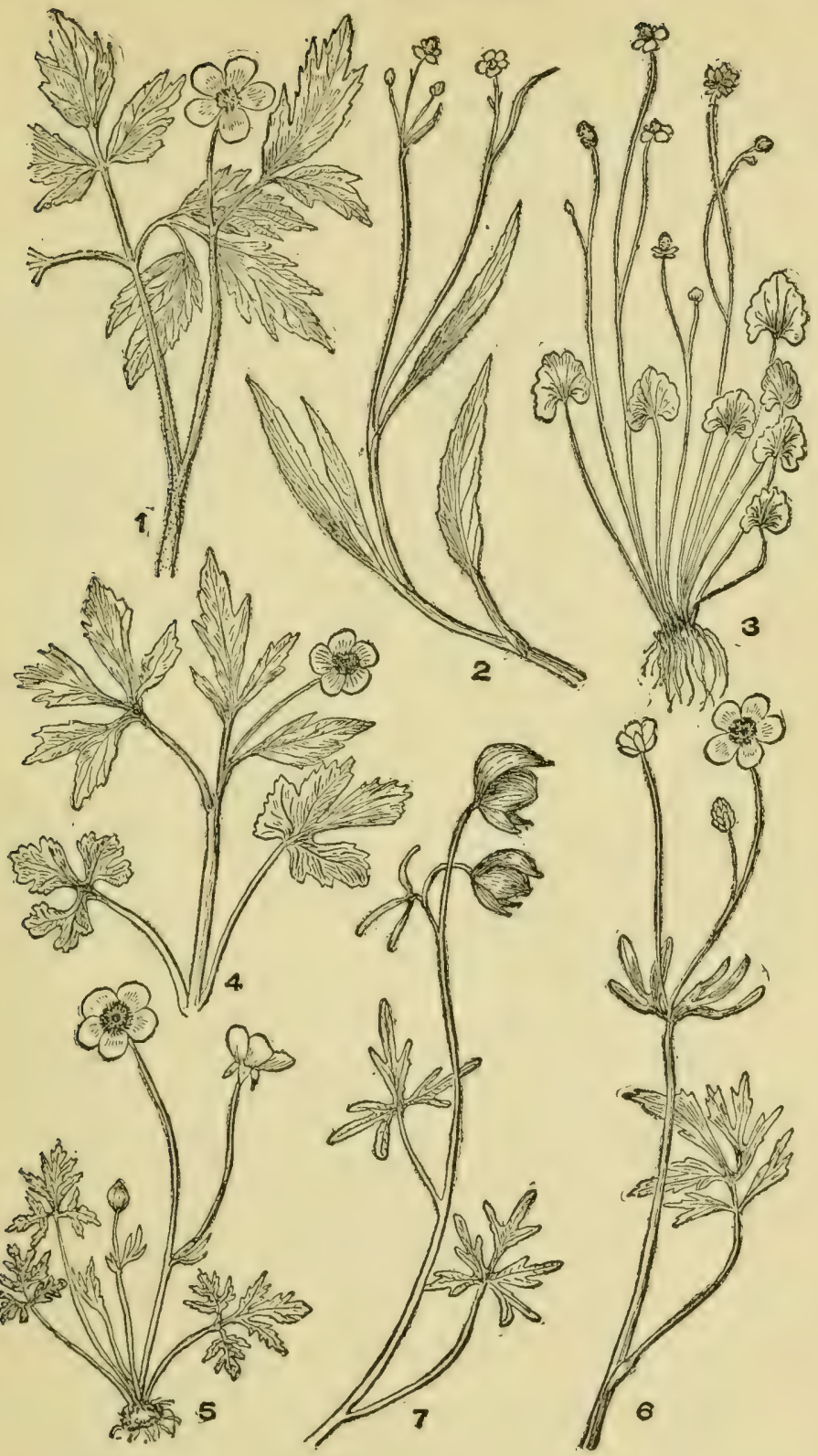

Plate 50

1. Ranunculus hispidus. 2. IR. laxicaulis. 3. Oxygraphis Cymbalaria. 4. Ranunculus recurvatus. 5 R. parvulus. 6. R. arvensis. 7. Aconitum uncinatum. 
C. thalictroides, (L.) Michx. (Fig. 2, pl. 51.) BLuE Corosir. Stem 1 to $3 \mathrm{ft}$. high, with 2 or more sheathing bracts at its origin. Stem otherwise simple, at length giving off a stem for the 3-divided compound leaf, each division of which has 5 leaflets. The flower branch has also a smaller compound leaf of similar composition. Flowers small, in one or two grapelike clusters, greenish-purple, succeded by blue berries. Woods in our area, and southward. April-May.

\section{JEFFERSONIA, Barton}

Smooth herbs with leaf stems directly from root and with a solitary flower also from a slender basal stem. Sepals 4 ; petals 8 ; stamens 8 . Sepals falling early. Seed casket (capsule), a pear-shaped pod opening by a sort of lid near the top, rather less than half the circumference serving as hinge. Capsule many seeded.

J. diphylla, (L.) Pers. Twix Leaf. Plant when in flower 6 to $\&$ in. high, twice that in fruit. Leaves broad (bifid), each divided by a deep sinus at each end. These divide the leaf into two almost completely separated oval parts. Flowers about an inch broad, white. Woods, New York, westward and southward. April-May.

\section{PODOPHYLLUM, L.}

Erect herbs with poisonous rootstocks and with two or three large, deeply sinused leaves and from the flowering stem a solitary flower. Petals 6 to 9 ; sepals 3 ; stamens 12 to 18; pistil an oval-shaped ovary capped by a flat crown.

P. peltatum, L. (Fig. 5, pl. 51.) May Apple. Wild Mandrake. Plant 12 to 20 in. high; leaves nearly a foot in diameter. The flower springs from botween the stems of the large leaves. Flowering stems taller than those without flowers. Flower white, eup-shaped, about an inch in diameter on a stem rather longer than the diameter of the flower. Fruit an oval berry about as large as and resembling in shape an ordinary plum, yellow when ripe. Throughout our region. May.

\section{Family TII.-MENispermaceaE. Moonseed Family}

Our only representative a woody climbing vine with alternate, loherl, leaves without stipules. Flowers in grape-like elusters, staminate and pistillate on dillerent plants. Fruit a fleshy drupe with a stone-like seed.

\section{MENISPERMUM, L.}

Climber 6 to $12 \mathrm{ft}$. high. Leaves 4 to $8 \mathrm{in}$. wide, heart-shaped at base and with several sharp-pointed lobes, or none, at the cireumference. Sepals 4 to 8 , coneraling the shorter petals. Stamens 12 to 24 ; pistils 2 to 4 . Fruit rounded.

M. canadense, L. (Fig. 6, pl. 51.) Caxama Moovseed. Climbing on trees or buslies in borders of woods and along streams. Lower leaves Iroadly oval, upper somewhat lobed or sealloped. New England, westward and southward. June-July. 

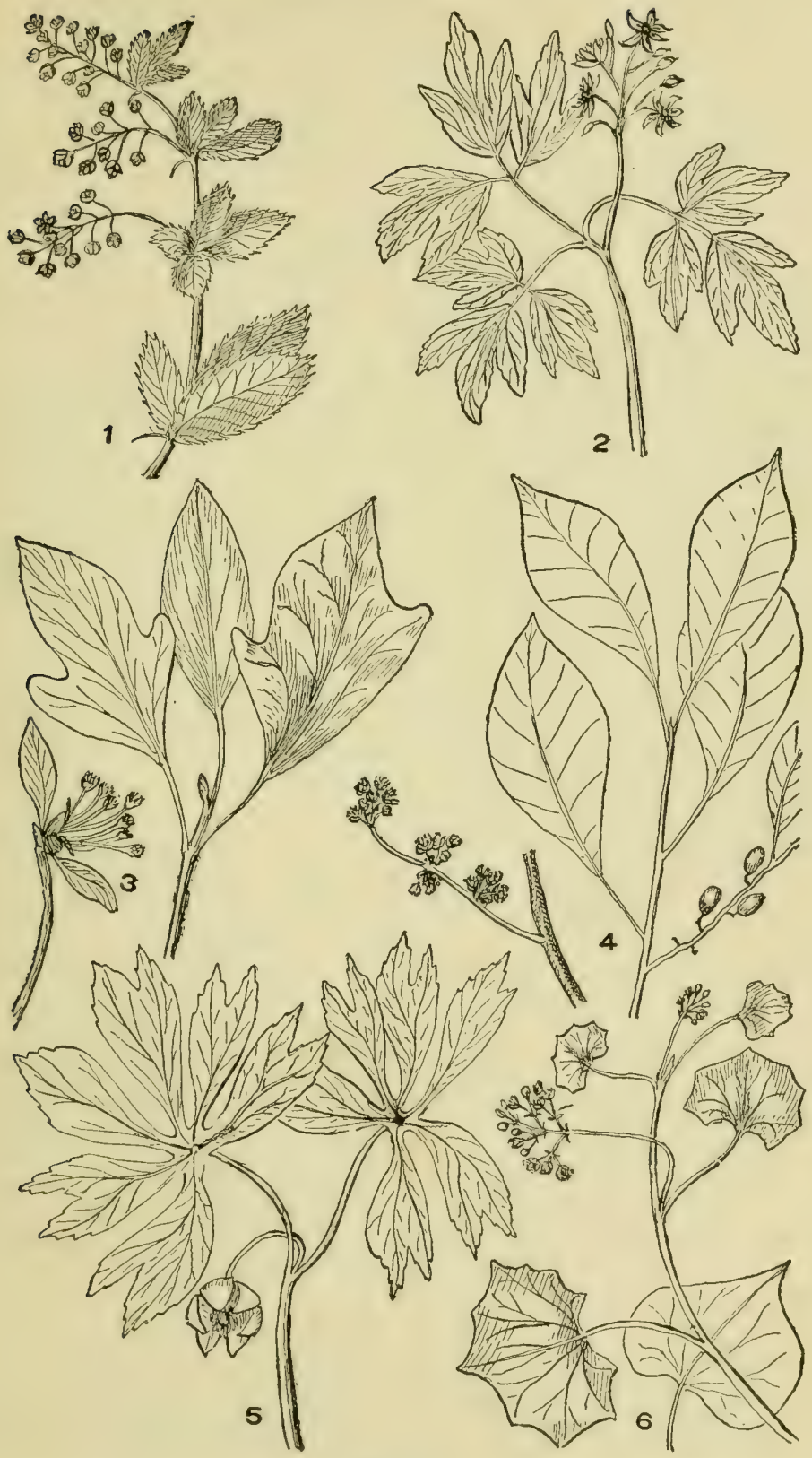

Plate 51

1. Berberis vulgaris. 2. Caulophyllum thalictroides. 3. Sassafras variifolium. 4. Benzoin aestivale. 5. Podophyllum peltatum. 6 Menispermum canadense. 


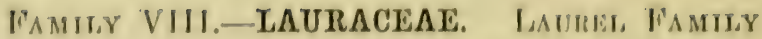

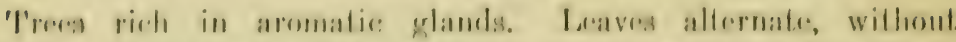

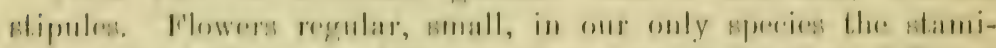

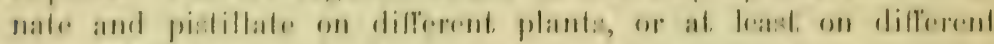

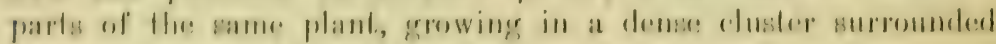
by an involucre of bracts.

\section{SASSAFRAS, L.}

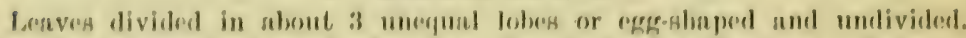

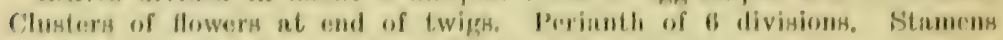
9. The piatillate flowers hive of to a steriles atsmens.

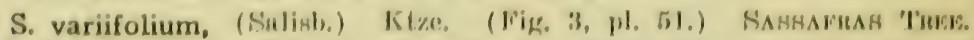

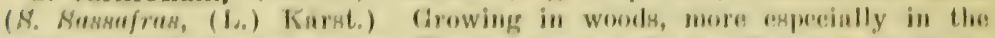
senthern hatf of our section Thes tree is usually small but may attsin to the height of 125 foet. Aprit-Mliy.

\section{BENZOIN, Fiabric.}

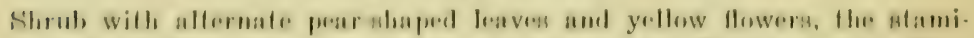

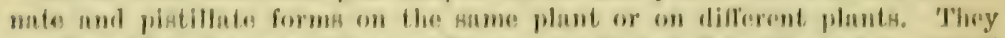

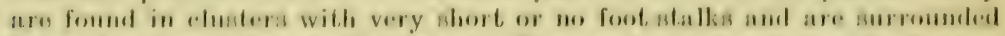

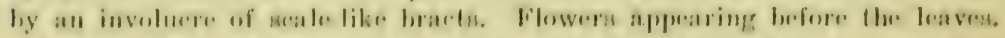

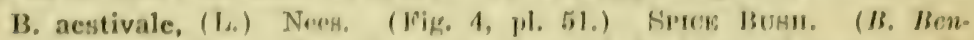
zoin, (I.) (coullor.) Smooth shrub, 1 to $20 \mathrm{ft}$. high, Jaseves suostly

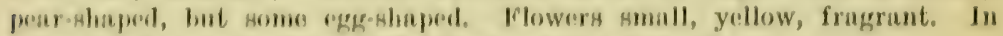
moist woods, northern pert of our urea and westward.

\section{Order IV.-RHOEADALES. Order of the Poppies}

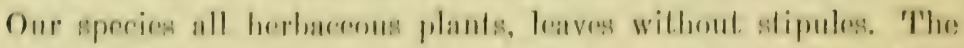

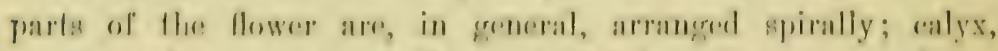

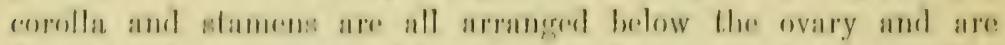

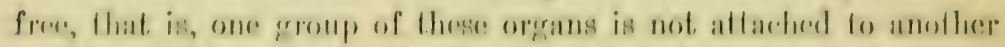

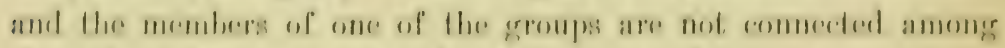

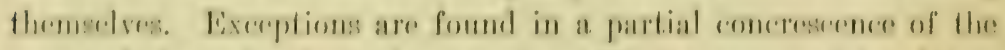

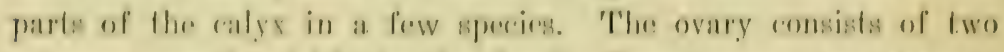

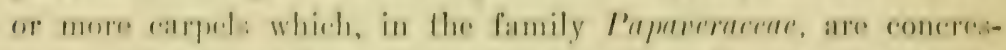

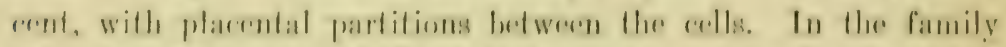

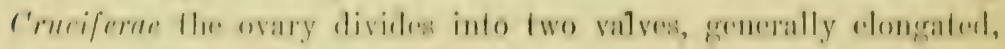
with a strong wall between the valves.

I'nnta with sticky, white or colored juice.

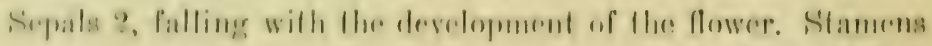
numerous 
Plsnts wilh watery juice.

Sepals 4 or more, equal.

Flowers symmetrical.

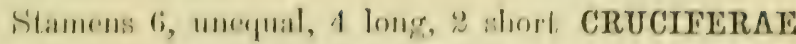

stamen: of to many, equil . CAPPARII)ACEAE

Flowers unsymunetrieal.

Stamens ; to many . . . . RESEDACEAE

\section{FAMH, I. PAPAVERACEAE. 'T'HE POPי FAMH.Y}

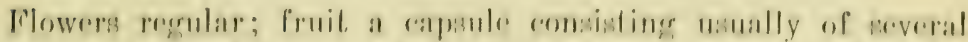

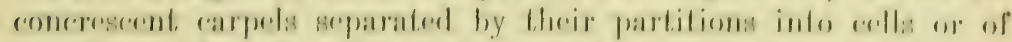
an elongated pod. All the speceses have milky juices lanves alternate of directly from the root, dewply fobed of lincly dis-

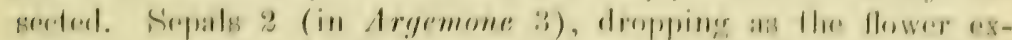
pands. J'etals 4 to 6 , or more. Stamens generally numerous, below, and encircling the ovary.

\section{PAPAVER, I.}

Smonth or hairy herbs with abundant milky sap. Jaseg decply ont

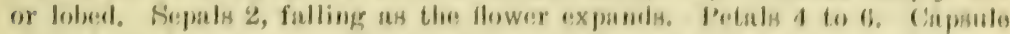

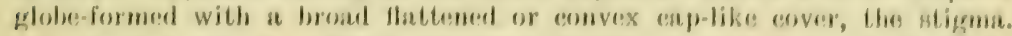

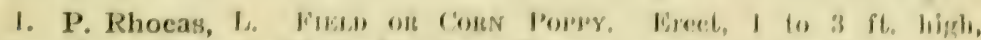

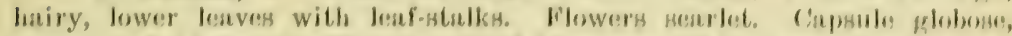

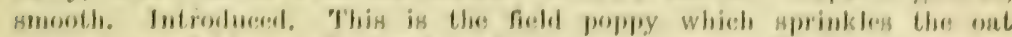

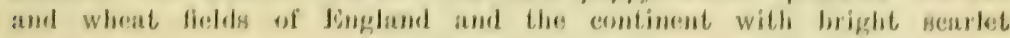
bаяниямн.

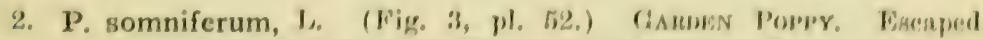

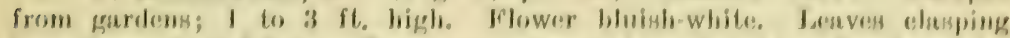

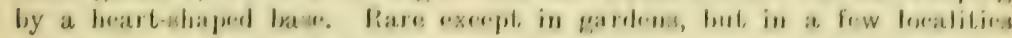
apparently naturalized.

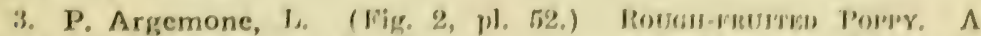

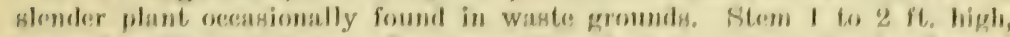

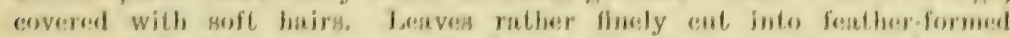
sergments, the lower on stender leaf-atalks, the upuer without leat-ntalks. Flower sed, usually with a dark center. A plant oflen neen in prain flelds in Surope, only sparingly introduced bere.

\section{2. $\triangle R G E M O N E, L$.}

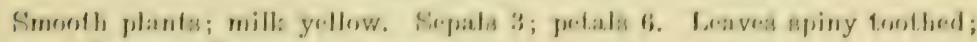
fowers rlowy. Stamens виmerour.

A. mexicana, J. (Fig. 1, pl. 5i.) Mexrean Porers, Strem 1 to 2

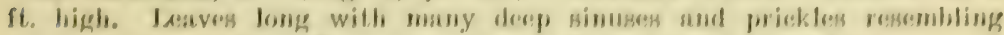
those of the thistle. In waste placess. Introdnesed. June- Supt. 


\section{SANGUINARIA, L.}

Herb with leaf-stalk arising directly from root and flower also on slender basal foot-stalk. Leaves light green, heart-shaped at base, rounded, with a number of shallow seallops.

S. canadensis, I. (Fig. 4. pl. 52.) BLoodroot. Flower scape slender bearing a single white star-like flower. Root-stock bleeds a red juice when broken. Shady places, rich soil. April-May.

\section{CHELIDONIUM, L.}

Branching herbs preferring shady places, with reddish-yellow, sticky milk. Sepals 2; petals 4; stamens numerous. Capsule a lengthened silique or pod dividing to the base.

C. majus, L. (Fig. 5, pl. 52.) CelandrNe. Grows usually in masses in slaady places. Leaves, in general outline oval but deeply lobed and divided in feather-formed leaflets. Flowers bright yellow $\frac{3}{7}$ in. across, in a loose umbel-like eluster surmounting the tall stalk. Seed pod an inch or more long. In cultivated grounds. Common. April-Sept.

\section{SUb-FAMILY FUMARIACEAE}

This sub-division of the family Papaveraceae is differentiated by the modification of the flowers, which, in none of our species are regular. T'he stamens are 4 to 6 and the single style at the top forms a 4-lobed stigma. Leaves alternate without stipules.

Flowers with a spur at base of each division.

Climbing vine . . . . . . . . Adlumia

Erect herbs, leaves all basal . . . . Dicentra

Flowers with only one division spurred.

Pod one seeded . . . . . . . . . Fumaria

Pod several seeded...... . . Corydalis

\section{DICENTRA, Bernh. (Bicuculla, Adams)}

Erect herbs with finely dissected ternately compound leaves. Flower stem becoming taller than the leaves. Flower broadly heart-shaped with a spur on each side. Pods many seeded.

1. D. Cucullaria, (L.) Bernh. (Fig. 1, pl. 53.) Dutchann's Brefcres. Leaf and flower stems arising from somewhat angular tubers of reddish color, 5 to $10 \mathrm{in}$. high. Flowers as broad as long, white, the spurs sprealing, inner petals minutely crested. An interesting plant with dulicately colored, light green, fincly divided leaves and a stem of nodding 2 spurred ftowers. In rich woods, throughout our area. April-May.

2. D. canadensis, (fioldie.) Walp. (Figr. 3, pl. 53.) Squirmer. Cork. Plant with much the same general appearanee as No. 1. The spurs at hase of flower are, however, much hess spreading and more rounded; the inner petals, only slightly crested in No. 1, are in this 


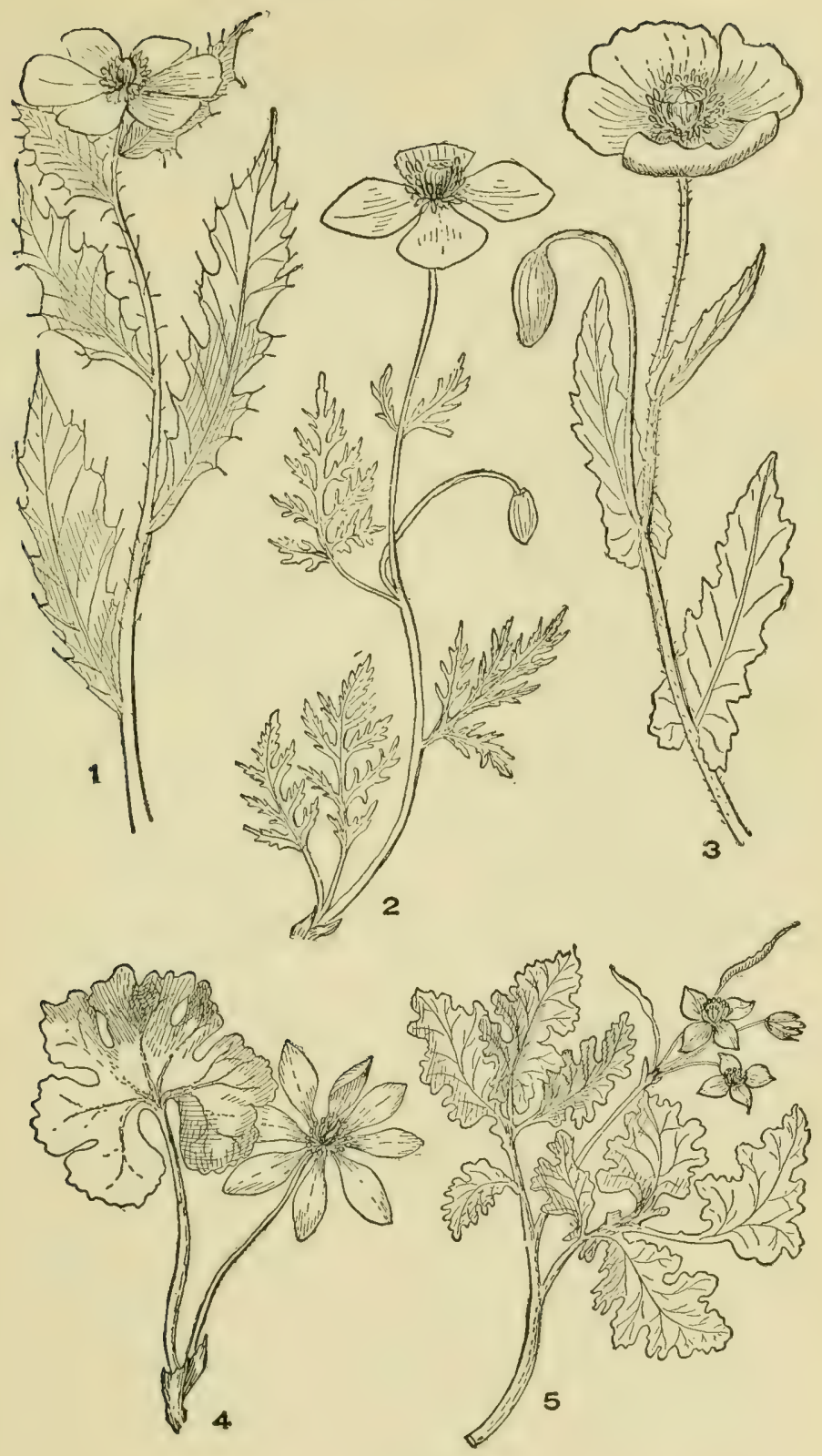

Plate 52

1. Argemone mexicana. 2. Papaver Argemone. 3. P. somniferum. 4. Sanguinaria canadensis. 5. Chelidonium majus. 
species conspicuously crested. Color, greenish-white tinged with purple. In rich woods. Common. May-June.

3. D. eximia, (Ker.) Torr. Wild Bleeding Heart. Plant much larger than the two preceding, and leaves much less divided. 1 to $2 \mathrm{ft}$. high. Corolla oblong resembling that of No. 2, but larger and of a pink color, arranged in clusters more or less compound. Western New York. May-Aug.

\section{ADLUMIA, Raf.}

A delicate vine many feet in length climbing on shrubs, trees, etc. Sepals 2, quite small; petals 4, united into a rather long oval sac with resemblance to the flowers of Dicentra, but with short rounded spurs at base, which is somewhat heart-shaped, while the tips of the petals are only slightly spreading. Leaflets mostly in 3's. Pods few seeded.

A. fungosa, (Ait.) Greene. (Fig. 4, pl, 53.) Mountain Fringe. The vine bears many clusters of pale pink flowers. Many of the leaf stalks are prolonged into winding tendrils. Native in rocky hills. Often cultivated. June-Aug.

\section{CORYDALIS, Vent. (Capnoides, Adams)}

Corolla spurred on one side only. Plants, in our region, erect with compound leaves found on the flower stem. Flowers in terminal clusters or in clusters springing from the stem opposite the nodes of the leaf stalks. Petals 4. Stamens 6. Seed pod linear.

1. C. sempervirens, (L.) Pers. (Fig. 5, pl. 53. Pink Conydalis. (C. glauca, Pursh.). Flowers with delicately alternating shades of red and yellow. Stem light green, 1 to $2 \mathrm{ft}$. high. Leaves of about 5 learlets, (ach leaflet with 3 deep and 3 or more shallow sinuses. Rocky places. April-Sept.

2. C. aurea, Willd. (Fig. 6, pl. 53.) Golden Corydalis. Very smooth, light bluish-green, 6 to 15 in. high. Leaves 3-compound. Flowers with one conspicuously long spur, bright golden-yellow. Woods. AprilMay.

3. C. flavula, (Raf.) DC. Pale Conrdalis. Stem slender, smooth, pale green. 6 to $14 \mathrm{in}$. high. Leaves finely dissected. Flower yellow, with a short spur

4. FUMARIA, L.

Much brancherl herbs, with finely dissected leares and many small flowers in long slender elusters. Calyx of 2 sepals, small seale-like. Petals 4 , both pairs approaching, the inner pair coherent at apex, one of the outer pair spurred. Stamens 6 , in 2 groups.

F. officinalis, L. (Figr. 2, pl. 53.) Fumitory. Stem smooth, very leafy, 6 in. to $3 \mathrm{ft}$. long. Corolla flesh colored or crimson. Waste places, only occasionally; about dwellings. Introduced from Europe.

\section{Family IT.-CRUCIFERAE. Mustard FAMILY}

A lare family of herbs with, generally, quite distinctive characters. While this is true it is not always casy for the amateur to distinguish the individual species. 

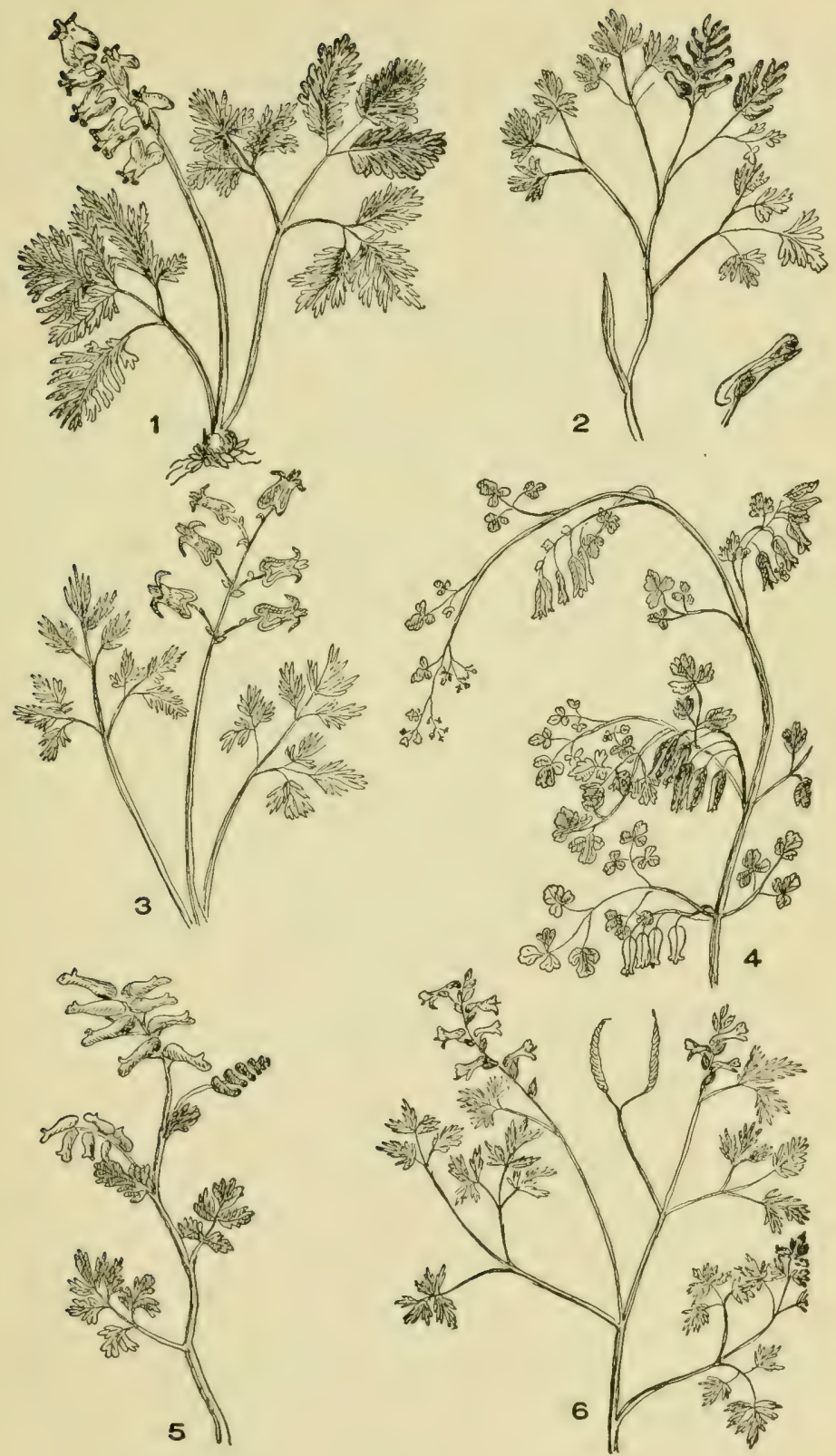

Plate 53

1. Dicentra cucullaria. 2. Fumaria oflicinalis, 3. Dicentra canadensis. 4. Adlumia fungosa. 5. Corydalis sempervirens. 6. C. aurea. 
The corollas are all regular. All have 4 petals, equal and similar, forming a cruciform flower. The sepals are also 4, and equal. The stamens are 6 in number and, unlike the corolla, are unequal, 4 being longer than the remaining 2 ; in some species some of the stamens are suppressed. Pistil 1, of 2 united carpels. The fruit is almost always in a linear por, a turn, or in short more or less triangular, orbicular or oblong pod, a turn.

\section{First Group}

Fruit pod pear-shaped, triangular or oblong, distinctly flattencd contrary to the partition. Flowers white.

Fruit-pod longer than broad.

Pod oval with a notch or with a slender style at the apex, or with both

Lepidium

Pod pear-shaped or triangular; leaves clasping the stem by broad ear-like appendages.

Leaves feather-formed (pinnate), with deep sinuses Capsella

Leaves not feather-formed, sinuses shallow or none Thlaspi

Pod broader than long.

Coronopus

\section{Second Group}

Fruit oval or globular, not flattened or only slightly so. Flowers white or purple.

Fleshy plant growing in sand at sea side

Cakile

Aquatic plant with awl-shaped leaves, all basal

Subularia

Plants not fleshy and leaves not awl-shaped nor all basal.

Leaves mostly in a whorl about the base, plants generally less than a foot high

Draba

Leaves not mostly in whorl at base, plants $1 \mathrm{ft}$. high or

Flowers yellow. more

Berteroa

Leaves clasping stem by a broad base.

Pods marked by distinct reticulations . . . . Neslia

Pods not reticulated . . . . . . . . . Camelina

Leaves not elasping stem by a broad base.

Leaves small, spatula-formed, pod without a conspicuous style

Alyssum

Leaves pinnate (2 species) . . . . . Roripa

\section{Third Group}

Fruit in linear pods (siliques, see page 38, Part I), generally in Ienerth more than 4 times the diameter of the flower. Exeeption, No. 18, about twice the length of the diameter of the flower.

Flowers yellow.

Pods not jointed nor markedly ennstricted between the seeds. Leaves, at least the lower ones, feather-formed. 
Pods not hairy.

Pods 4-angled . . . . . Barbarea

Pods rounded, not 4-angled, term. inated by a long beak . . Brassica

Pods hairy

Sinanis

\section{Errata}

Page 274, lines 6 and 7 , should read:

The fruit is almost always a linear pod, a silique, or a short. more or less triangular, orbicular or oblong pod, a silicle.

Leaves broad, cordate or kidney-formed

Alliaria

Leaves feather-form (pinnate), lobed or ovate Cardamine

Leaves mostly in a whorl or rosette about the base, hairs when present not forked.

Seed pods quite short but generally with several seeds Draba

Seed pods linear, hairs simple . . . . . Arabis

Seed pods linear, hairs forked

Petals white . . . : . . . Stenophragma

Flowers purple . . . . . . Hesperis

The arrangement of these groups is based upon a few of the more general characteristics and does not follow the more technical grouping.

FIRST GROUP

Fruit-pod pear-shaped, triangular or oblong, distinctly flattened contrary to the partition.

\section{Flowers white}

\section{LEPIDIUM, L:}

Erect or diffused plants with pear-shaped, feather-formed or deeply lobed leaves. Pods rounded or pear-shaped, flattened, with two seeds, one in each valve of the pod or with only one seed. Stamens sometimes less than 6. Flowers small or petals sometimes wanting.

\footnotetext{
Stem leaves arrow-formed, clasping with ear-like appendages.

Pods with a somewhat conspicuous slender style . . . . L. Draba Pods without the style..$+L^{-}$. campestre

Stem leaves, pear-shaped, on long leaf stalks $: 0^{\circ} \cdot$ L. virginicum $^{\circ}$ Pods distinctly pear-shaped..$\div \quad$. $:$ L sativum

Iods nval or orbicular.

With wings.........$+-L$. apctalum

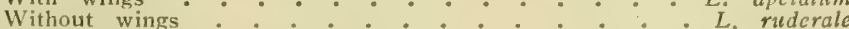

Stem leaves tedther-formed (pinnatifid).
} 
The corollas are all regular. All have 4 petals, equal and similar, forming a cruciform flower. The sepals are also 4, and equal. The stamens are 6 in number and, unlike the corolla, are unequal, . - 1 1 nmen than the remaining 2 ; in some species some of the

Leaves reautr-numen-tr-

Leaves not feather-formed, sinuses shallow or none Thlaspi Pod broader than long

Coronopus

\section{Second Group}

Fruit oval or globular, not flattened or only slightly so. Flowers white or purple.

Fleshy plant growing in sand at sea side . . . . . Cakile Aquatic plant with awl-shaped leaves, all basal . . Subularia Plants not fleshy and leaves not awl-shaped nor all basal.

Leaves mostly in a whorl about the base, plants generally less than a foot high . . . . . . Draba

Leaves not mostly in whorl at base, plants $1 \mathrm{ft}$. high or Flowers yellow. more

Berteroa

Leaves clasping stem by a broad base.

Pods marked by distinet reticulations . . . . Neslia

Pods not reticulated . . . . . . . Camelina

Leaves not clasping stem by a broad base.

Leaves small, spatula-formed, pod without a conspicuous style

Leaves pinnate (2 species)

Alyssum

Roripa

\section{Turmo Group}

Fruit in linear pods (siliques, sec page 38, Part I), generally in leneth more than 4 times the diameter of the flower. Exeeption, No. 18 , about twice the length of the diameter of the flower.

Flowers yellow.

Pods not jninted nor markedly ennstrieted hetween the seeds. Leaves, at least the lower ones, feather-formed. 
Pods not hairy.

Pods 4-angled . . . . . Barbarea

Pods rounded, not 4-angled, terminated by a long beak . . Brassica

Pods hairy

Sinapis

Leaves lance-shaped, not lobed ... . Erysimum

Flowers, yellow white or purple.

Seeds in single row in each valve.

Pods not constricted between the seeds

Sisymbrium

Pods constricted between the seeds

Raphanus

Seeds in two rows in each valve.

Pods generally an in. or more long . . Diplotaxis

Pods less than 1 in. long . . . . . . . Roripa

Flowers white or purple.

Leaves mostly on the stem, not in a whorl at base. Sisymbrium

Leaves in a whorl on the stem.

Leaves divided in 3 to 7 radiating divisions or leaflets

Dentaria

Leaves broad, cordate or kidney-formed . . . Alliaria

Leaves feather-form (pinnate), lobed or ovate Cardamine

Leaves mostly in a whorl or rosette about the base, hairs when present not forked.

Seed pods quite short but generally with several seeds Draba

Seed pods linear, hairs simple

Arabis

Seed pods linear, hairs forked

Petals white

Stenophragma

Flowers purple . . . . . . . . Hesperis

The arrangement of these groups is based upon a few of the more general characteristics and does not follow the more technical grouping.

\section{FIRST GROUP}

Fruit-pod pear-shaped, triangular or oblong, distinctly flattened contrary to the partition.

\section{Flowers white}

\section{LEPIDIUM, L:}

Erect or diffused plants with pear-shaped, feather-formed or deeply lobed leaves. Pods rounded or pear-shaped, flattened, with two seeds, one in each valve of the pod or with only one seed. Stamens sometimes less than 6. Flowers small or petals sometimes wanting.

\footnotetext{
Stem leaves arrow-formed, clasping with ear-like appendages.

Pods with a somewhat conspicuous slender style . . . . . L. Draba

Pods without the style

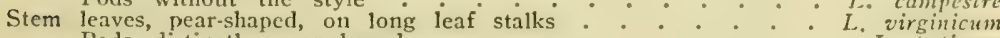

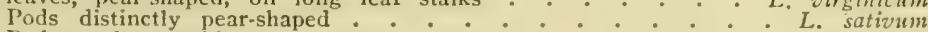

Pods oval or orbicular.

With wings.
}

Stem leaves tedther-formed (pinnatifid). 
1. L. Draba, L. Hoary Cress. Plant 10 to 12 in. high, hairy, stem leaves arrow-formed, basal leaves elliptic. Seed pods oval or rounded, flat, without wing-like appendages but with a distinet style at summit. Fields, waste places; rare. Naturalized. May-July.

2. L. campestre, (L.) R. Br. Field or Crow Cress. Stem leaves similar to No. 1, basal rosette of pear-shaped leaves, rounded at apex. Pod without a style, but thin wing-like appendage at sides and especially at summit. Flowers and fruit pod crowded on fruit bearing stem. A weed in cultivated ground, naturalized. April-June.

3. L. virginicum, L. (Fig. 1, pl. 54.) Wild Peppergrass. Stem leaves elliptic, deeply notched, basal rosette of pear-shaped leaves, rounded at apex, notched at borders, the leaf stalk feather-formed. Seed pod nearly round with a noteh at the summit and a narrow wing-like appendage on either side of it. A weed in cultivated fields and in waste places. May-Nov.

4. L. sativum, L. Garden or Golden Peppergrass. Stem about a foot high, smooth, bright green. Leaves, at least the lower, featherformed, 3-parted, each division feather-formed. Upper leaves more or less linear with deep sinuses cutting into narrow lobes. Seed pod with narrow wing-like border. Waste places. Naturalized. May-Aug.

5. L. apetalum, Willd. Apetalous Peppergrass. Basal rosette of feather-formed leaves, upper nearly linear, more or less distantly notched. Flowers small, petals quite small or wanting. Pods round, notehed at top with narrow wing-like border above. Naturalized. May-Aug.

6. L. ruderale, L. Narrow-Leaved Peppergrass. Similar to last, but seed pod has no wing-like margin.

\section{CAPSELlA, Med. Pfl. Gatt. (Bursa, Weber)}

Stems spreading, one or more erect. Leaves mostly in a basal rosette, those of the upper part of stem narrow, clasping, more or less arrowshaped. Those of the rosette lyrate, feather-formed, somewhat hairy. Pod triangular or pear-shaped, several seeds in each cell.

C. Bursa-Pastoris, Med. Pfl. Gatt. (Fig. 6, pl. 54.) Shepherd's PuRse. Very common in waste places.

\section{THLASPI, L.}

Plant $\frac{1}{2}$ to $1 \frac{1}{\mathrm{ft}}$. high. Lower leaves with leaf stalks, pear-shaped, upper stem leaves arrow-shaped without leaf-stalks, toothed or distantly dentate. Pod round or pear-shaped.

T. arvense, I. Field Penny Cress. Pods nearly round, with a rather deep sinus at apex and with a broad margin of wing-like expansion. Flowers and pods crowded on a long slender stem. In waste places. JuneAug

\section{CORONOPUS, Gaertn.}

Diffuse, 3 to 15 in. high. Leaves crowded, feather-formed. Flowers in crowded clusters quite small. Stamens 2 to 4. Pods with the lateral diameter greater than the longitudinal. Valves of the pod rough, depressed at apex. 
MUSTARD FAMILY

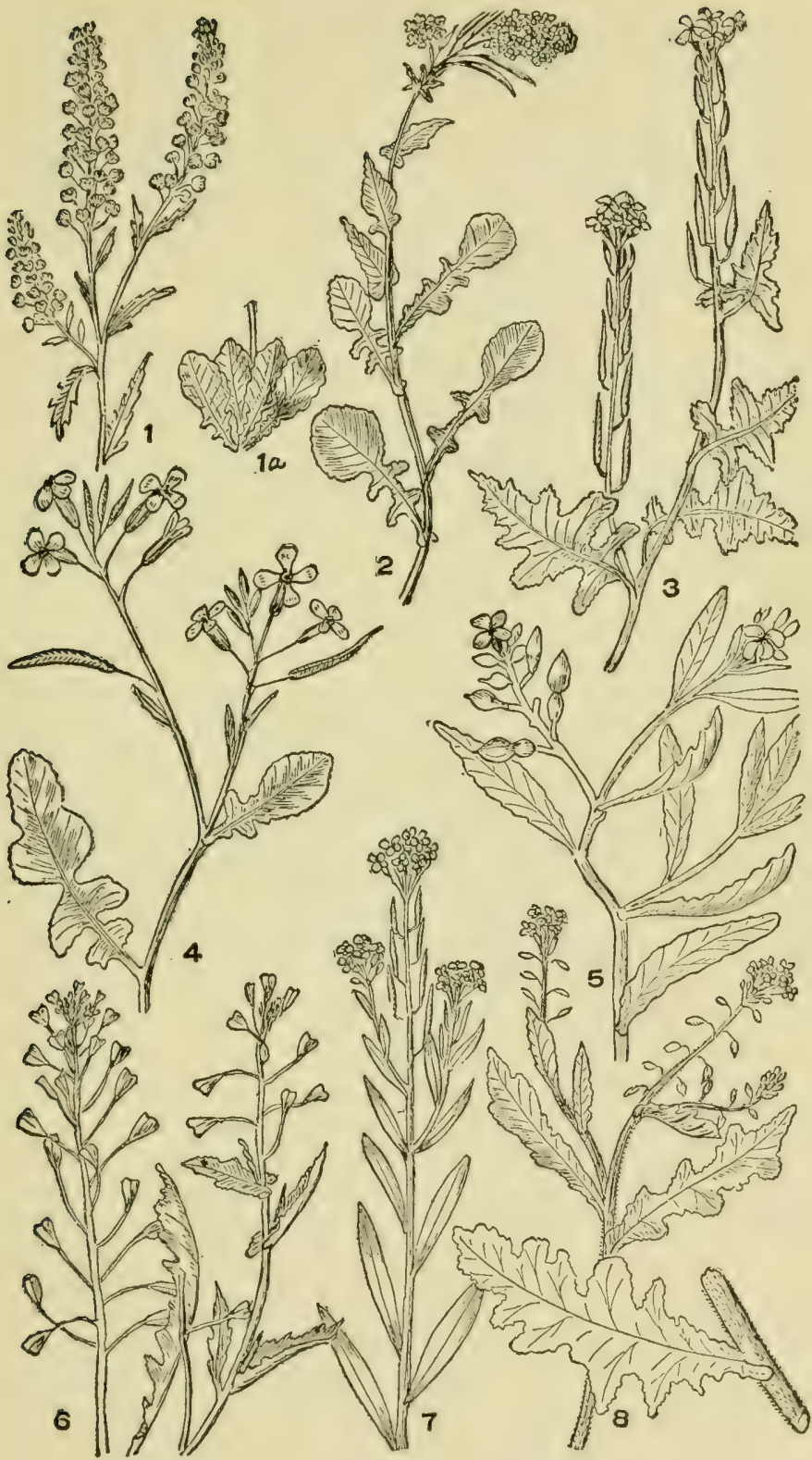

Plate 54

1. Lepidium virginicum. 2. Barbarea vulgaris. 3. Sisymbrium oflicinale 4. Brassica nigra. 5. Cakile edentula. 6. Capsella Bursa-Pastoris. 7. Erysinum cheiranthoides. 8. Roripa hispida. 
1. C. didymus, (L.) J. F. Snith. Lesser Water Cress. Tufted, spreading on the ground, slightly hairy. Flowers quite small. Naturalized; in waste places.

2. C. procumbens, (iilbert. Swine's Cress. (C. coronopus, (L.) Karst.) Similar to No. 1. Pod with an elevated point at apex. Naturalized; in waste places.

\section{SECOND GROUP}

Fruit oval or globular, not flattened or only slightly so Flowers white or purple

\section{CAKILE, Gærtn.}

Difuse, smooth, fleshy, with purple or whitish-purple flowers. Pods two jointed, the upper joint larger.

C. edentula, (Bigel.) Hook. (Fig. 5, pl. 54.) American Sea RockET. Very fleshy and branching. Leaves long and narrow, rounded at apex, border sinuous or notehed. Pod of two joints, each with a single seed. Sands at the sea shore.

\section{SUBULARIA, L.}

Small aquatic plant. Leaves all basal and awl-shaped. Stem few flowered. Pods oval or globose, seeds several.

S. aquatica, L. WATER AWLWORT. P'lants growing in tufts in shallow water. Maine, New Hampshire, and northward.

\section{BERTEROA, DC.}

Herbs 1 to $2 \mathrm{ft}$. high, with forked hairs. Leaves narrow, not notehed or toothed. Flowers in long terminal clusters. Petals deeply 2-cleft. Pod nearly globose or oval with a short style at apex.

B. incana, (L.) DC. (Fig. 1, pl. 55.) Honry Alyssum. Pods very numerous on short stiff spreading pedicels. In waste places. Introduced.

\section{Flowers yellow}

\section{NESLIA, Desv.}

Erert or loranching, velvety, hairs stellate. Leaves of the rosette ob. long, on long foot-stalks. Seed pod without wings.

N. paniculata, (L.) Desv. (Fig. 6, pl, 55.) Nesira. Plant 1 to $2 \mathrm{ft}$. high; stem leaves lance-shapeel with hroad arrow-shated bases and un leaf stalk. Flowers small, yellow. Pods round, distinetly reticulated. Waste places. Introduced.

\section{CAMELINA, Crantz.}

Ereet herb with soft hairs, simple or branched. Lower leaves with leaf statks, upper without. Those of the rosette lance-elliptic, those of the strm lance-shaped, clatsping the stem. Flowers small. Pod globose with a prominent style at apex.

C. sativa, ( $\left.\mathrm{I}_{\text {。. }}\right)$ Crant\% Gold or Pleasune. False Frax. In fields, especially in those in which flax has been grown. Introduced from Europe. June-July. 


\section{ro. ALYSSUM, L.}

Stems branching, low, hairy, with small flowers. Pod orbicular, with a small style at apex.

A. alyssoides, L. (Fig. 2, pl. 55.) Yellow or Siall Alyssum. (1. calycinum, L.). Leaves, mostly on the flowering stems, small pearshaped, without teeth or notches. In waste places and fields. Naturalized.

THIRD GROUP

Fruit in lincar pods, generally in length more than four times the dianieter of the flower.

Flowers yellow

Seeds in a single row in each valve of the pod.

\section{BARBAREA, R. Br.}

Erect branching herbs with angular stems and with leaves with entire margins or with margins deeply lobed, forming distinct segments, or feather-formed. Flowers somewhat conspicuous, petals twice as long as the sepals. Pod long, linear, 4-angled.

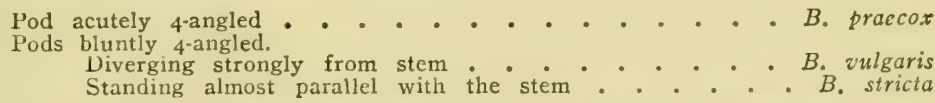

1. B. vulgaris, R. Br. (Fig. 2, pl. 54.) Yellow Rocket or Cress. (B. Barbarea, Mac M.). Stem 1 to $2 \mathrm{ft}$. high. Tufted at base. Lower leaves so deeply lobed as to divide them into about 5 distinct leaflets, the terminal one much larger than the others, ovate with rounded extremity and cordate base, the lateral leaflets also ovate and rounded at apex. Lpper leaves smooth margined or notehed. Lower leaves on slender foot-stalks, upper without foot-stalks. Seed pods diverging from the stem. Naturalized. Common, in fields and waste places. April-July.

2. B. stricta, Andrz. Erect-frutted Minter Cress. Similar to No. 1, but the seed pods follow closely the direction of the stem. Naturalized. In fields and waste places. April-July.

3. B. praecox, (J. E. Smith.) R. Br. Early Winter Cress. Belle IsLE CREss. The segments of lower leaves generally more numerous than in No. 1 or 2, and less rounded. Pods very long and sharply angled. Naturalized. Situations similar to the above.

\section{I2. BRASSICA, L.}

Herbs mostly with basal leaves deeply cut by sinuses (feather-formed), upper leaves toothed or entire. Pods nearly round, terminated by a long beak. Seeds in a single row in each valve.

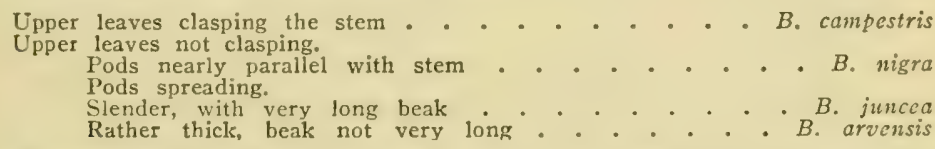

1. B. nigra, (L.) Koch. (Fig. 4, pl. 54.) Black Mustard. Plant somewhat hairy, 2 to $7 \mathrm{ft}$. high. Upper leaves lance-formed, margins 
entire or dentate. Lower leaves on long leaf-stalks, pear-shaped in general outline, but deeply cut by sinuses into more or less feather-form Apex broakly rounded. Flowers rather large, pods eylindric with 4 angles, nearly parallel with the stem. Common in waste places.

2. B. juncea, (L.) Cosson. Indian Mustard. Plant smooth or slightly hairy, 1 to $4 \mathrm{ft}$. high. Upper leaves without leaf-stalks, borders mostly entire. Lower leaves on long foot-stalks, broad and cut by sinuses, but less deeply, as a rule, than those in No. 1. Flowers similar to No. 1. Seed pods slender, the beak being nearly or quite $1 / 3$ as long as the remainder of the pod. Pols more or less spreading. Naturalized. Common in waste places and fields. June-Nov.

3. B. arvensis, (L.) BSP. WiLd Mustard. Similar to last but leaves egg-shaped and much less deeply cut by sinuses. Pods rather thick, somewhat constricted between the seeds. Naturalized. Common. May-Nov.

4. B. campestris, I. Tuknir. The ruta-baga or turnip of the gardens is oecasionally found wild and sometimes persists in grounds in which it has been cultivated.

\section{I3. SINAPIS, L:}

Plant erect, branching, hairy. Lower leaves on long stalks, in general outline pear-shaped, but deeply cut by sinuses, the terminal lobe broad, rounded, toothed, the lateral lobes toothed. Upper leaves without leaf stems but cut and toothed. Pods long, constricted between the seeds, densely hairy.

S. alba, L. Winte Mustard. Plant 1 to $2 \mathrm{ft}$. high, eovered with hairs which turn backward. Naturalized. In waste places.

\section{I4. ERYSIMUM, L.}

Erect herb with narrow lance-shaped leaves, with entire or slightly dentate margins. Pods 4-angled, seeds in one row in each valve of the pod.

E. cheiranthoides, I. (Fig. 7, pl. 54.) Wormseed. Treacle-musTArD. Plant 2 to $2 \mathrm{ft}$. high, branching. Leaves lance-formed, narrow, tapering at base, somewhat blunt at apex. Naturalized. In moist places. June-Aug.

\section{Flowers yellow, white or purple}

Seeds in a single row in each valve of the pod.

\section{I5. SISYMBRIUM, L.}

Tall ereet lerbs, sparingly branched, with feather-formed leaves. Flowers yellow except in $\$$. humile, in which they are white or pink. Pod rather long (in No. 2, very long) and slender.

1. S. officinale, (L.) Seop. (Fig. 3, pl. 54.) Hedge MIUstard. Iiather tall and stiff, branching below, not mueh branched above. The long pods hug the stem, lying in almost their whole length against it. Luaves rather long, in general form more or less triangular or arrowhead-shaped, the lobes toward the inner end extending widely. Flowers small. 
MUSTARD FAMILY

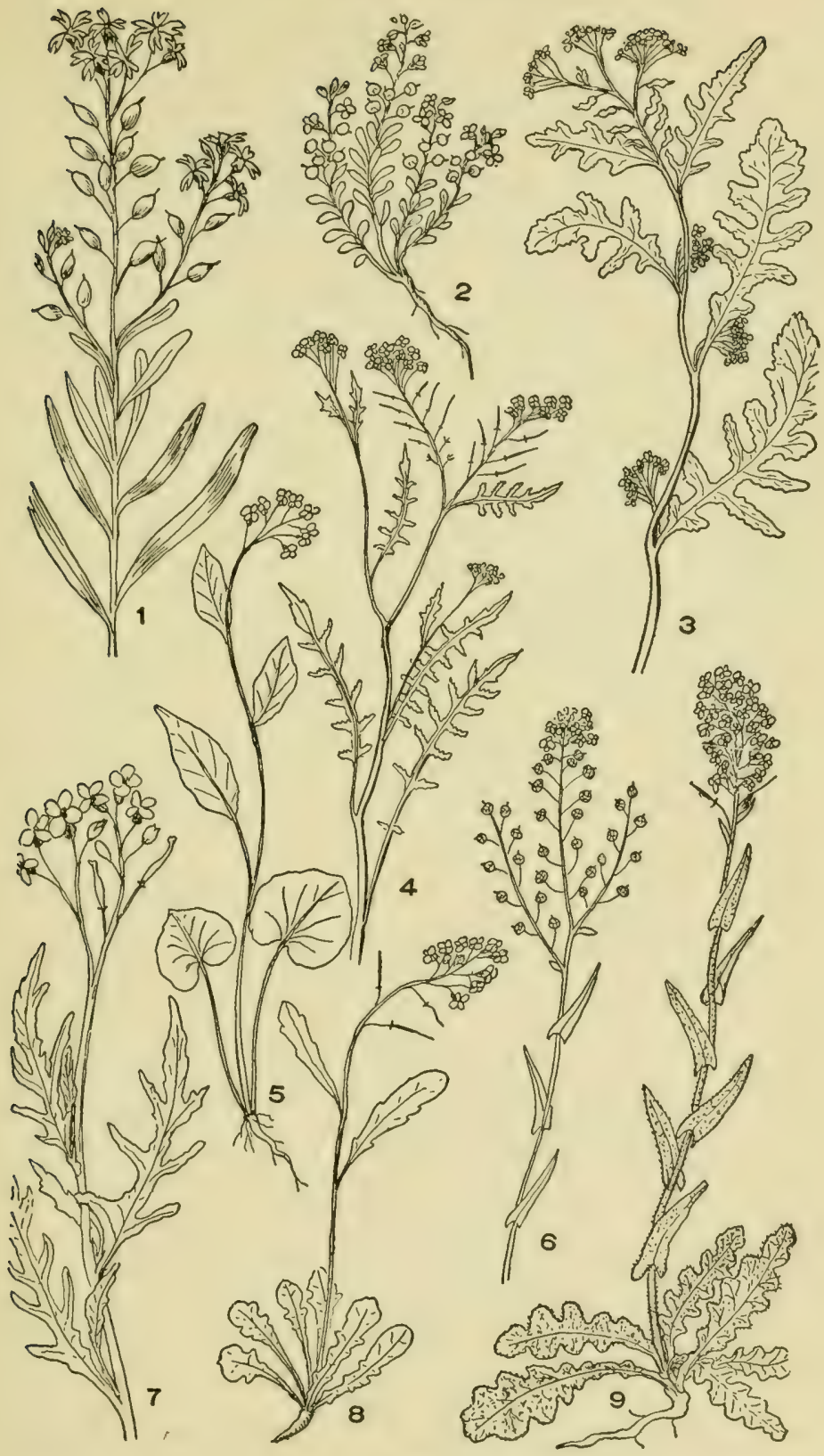

Plate 55

1. Berteroa incana. 2. Alyssum alyssoides. 3. Roripa palustris. 4. Car* damine pennsylvanica. 5. C. bulbosa. 6. Neslia paniculata. 7. Diplotaxis tenuifolia. 8. Arabis lyrata. 9. A. hirsuta. 
2. S. Sophia, I. Flixweed. Herb Sopmia. (Sophia Sophia, Britton.) Herb 1 to $2 \frac{1}{2} \mathrm{ft}$. high, hairy, with forked hairs. Stems slender, branching. Leaves doubly feather-formed. Flowers small. Pods 1 to 2 in. long on slender foot-stalks. Naturalized. Waste places. JuneAugust.

3. S. altissimum, L. Tald Sisyamrium. Stem 2 to $4 \mathrm{ft}$. high, slender, branching, not hairy or with few hairs. Leaves feather-formed. Flowers small. Pods 2 to 4 in. long, very slender, spreading. Waste places. Naturalized.

4. S. humile, Meyer. Low or Nortiner Rock Cress. Stem 4 to $10 \mathrm{in.} \mathrm{high.} \mathrm{Rosette} \mathrm{of} \mathrm{leaves} \mathrm{lance-shaped} \mathrm{with} \mathrm{sinuses} \mathrm{or} \mathrm{dentate} \mathrm{edges.}$ Stem leaves linear. Pod slender. Flowers whitc or pink. Rocky places; mountains of Vermont, rare. July.

\section{I6. RAPHANUS, L.}

Erect, branching. Leaves somewhat hairy, long, eut by deep sinuses. Fruit pods not hairy, constricted between the pods, with a long style.

1. R. Raphanistrum, L. Wild Radisir. Plant 1 to $2.1 \mathrm{ft}$. high, somewhat hairy. Leaves lyre-shaped, rough; pod tapering at apex to a long style, neeklace shaped from the constrictions between the zeeds. Naturalized. Fields.

2. R. sativus, I. Garden Radish. The garden radish with pale purple petal is sometimes found persistent in old fields.

\section{I7. DIPLOTAXIS, DC.}

Plants smooth or nearly so. Leaves long, in general form lance-shaped but cut by sinuses into feather-form. Pod long, somewhat flattened, beak short or absent.

1. D. tenuifolia, (L.) DC. (Fig. 7, pl. 55.) WALL Rocket. A bushy plant 1 to $4 \mathrm{ft}$. high, with leaves cut almost to the mid-vein by the numerous deep sinuses. The lower leaves 3 to 6 in. long, the lobes generally narrow and the sinuses broad. Fruit pods long and slender on slender foot-stalks about $1 / 3$ the length of the pod. Stems leafy up to the loose cluster of flowers. Introduced. Waste places. Summer.

2. D. muralis, (L.) DC. SAND Rocket. Plant resembling No. 1. The leaves of No. 1 are in general outline egg-shaped or long lanceshaped, broadest near the center or at the anterior third. The leaves of this speries are long and narrow the hroadest part being near the apex. The sinuses are much more shallow than those of No. 1, the lobes bring reduced almost to coarse teeth. The stem above is nearly or quite leafless.

\section{x8. RORIPA, Scop.}

Very leafy, branehing herbs with lobed or dissected leaves. Flowers white in two of our species, yellow in all the others. Fruit pods short in most of the spuries, sometimes elongated in a few. Seeds in two rows in each valve of the pod.

Aquatic plants.

\section{Flowers white}

\footnotetext{
Leaves mostly trifoliatc - . . . . . $R_{\text {. Nasturtium }}$ Leaves dissected into thread-like divisions ${ }^{\circ} \cdots^{\circ} R_{R}$ americana Plants not strictly aquatic $. ., \ldots, \ldots, R_{\text {armoracia }}$
} 


\section{Flowers yellow}

Pods elongated.

Slender, not constricted between seeds . . . . . . S. sylvestris

Aboust as long as the pedicel and constricted between seeds $R$. palustris

Pods globose or ovoid

3. R. armoracia, (L.) Rusby. Rusby's Water Cress. Branching plant, floating or spreading and rooting at branches in brouks and ditches. Leaves generally of 3 leaflets, but these may be in greater number, from 5 to 9. Terminal leaflet largest. Brooks and streams. Naturalized. April-Nov.

2. R. americana, (Gray) Britton. Aquatic, upper leaves oblong, not. divided, immersed leaves pinnately divided and finely dissected. Pods ovoid.

1. R. Nasturtium,(L.) Hiteheock. (Fig. 8, pl. 56.) Honse Radisir. Basal leaves feather-formed, oblong, very large, those of stem lance-form. Roots long and large. Eseaped from gardens. Moist grounds, along streams, ete.

4. R. sylvestris, (L.) Bess. Creeping Yellow Water Cress. Stems smooth, angular, from ereeping root-stocks. Leaves variable, 3 to 5 in. long and deeply divided pinnately, the sinuses extending to midvein. Flowers yellow, pod $\frac{1}{3}$ in. long or less. Moist grounds, Naturalized.

5. R. palustris, (L.) Bess. (Fig. 3, pl, 55.) Marsi Water Cress. IIairy plant 1 to $2 \mathrm{ft}$. high, with leaves deeply eut pinnately, the sinuses less completely dividing into leaflets than No. 4. Terminal leaflet larger, sometimes 6 in. long. Flowers $1 / 8$ in. in diameter, yellow. Pods linear oblong, turgid, 2 to 6 times as long as thick. Wet places. Naturalized. May-Aug.

6. R. hispida, (Desv.) Britton. (Fig. 8, pl. 54.) Hispid Yellow Cress. Resembling No. 5, but generally stouter, 1 to $4 \mathrm{ft}$. high. All parts covered with spreading hairs, pods ovoid or round. Naturalized. Waste places. May-June.

\section{Flowers white or purple}

\section{DENTARIA, L.}

Herbs with 3- or 5-divided leaves; slender and rather long and flat seed pod. Seeds in a single row in each valve, the seed stalks alternating on opposite sides of the valves. Stems naked below, bearing above 2- or 3-parted or rarely 5-parted leaves and a cluster of whita or purple flowers. Rootstocks rather fleshy and knotted, mostly horizontal.

1. D. laciniata, Muhl. (Fig. 3, pl. 56.) Cut-Lenved Toothwort. PePper Root. Plant 8 to 15 in. high, root-stock markedly jointed. Stem branching into 3 leaf-stalks and the flower stem. Leaflets each carrving a leaf 2 to $5 \mathrm{in}$. broad, divided into 3 leaflets, these sometimes rather deeply divided; teeth coarse. Other leaves start on long leaf-stalks directly from the root. Flowers numerous, white or rose color. Woods. April-June.

2. D. diphylla, Michx. (Fig. 4, pl. 56.) Two-teaved Toothwort. Plant about as high as No. 1; stem bearing two leaf-stalks, each 3-parted, 
and a flower stalk, the leaflets broad-ovate, with coarse teeth. Root leaves with the single 3-part division. Flowers white. Woods and meadows. May.

3. D. maxima, Nutt. LARge Tootrmort. Similar to No, 2, but larger. Leaves generally 3 but there may be but 2, or there may be as many as 7 , each with 3 leaflets, the leaflets distinctly stalked. Flowers purple.

4. D. incisifolia, Eames. Cut-Leaved Tootuwort. Stem leaves 2, usually opposite. The 3 leaf divisions are vithout stalks. In other respects the plant resembles No. 3. Sherman, Conn.

5. D. heterophylla, Nutt. Slender Tootrwort. Plant 10 to $14 \mathrm{in.}$ high, stem slender and stem leaves, of which there are 2 , of 3 quite narrow lance-shaped leaflets, remotely notched. The leaf from the root has a long slender leaf-stalk and the leaflets are broad-ovate. Woods in the southern part of our region. April-May.

\section{ALLIARIA, Adams}

Branching herb with broad heart-shaped or rounded leaves with the margins cut by deep and broad notches; flowers in a long cluster; seed pods cylindric or nearly so.

A. officinalis, Andrz. Hedge Garlic. (A. Alliaria, (L.) Britton.) Erect branching plant 1 to $3 \mathrm{ft}$. high. Smooth or with few soft hairs; leaves broad, 2 to $7 \mathrm{in}$. wide, with conspicuous notehes in the margin. Flowers white. May-June.

\section{I. CARDAMINE, L.}

Herbs, usually smooth, stems mostly unbranched. Leaves compound (pinnate) or simple. Flowers white or purplish-white, the petals each with a claw at the throat. Pods long and slender, flattened, with the seeds in a single row in each valve.

Leaves pinnately compound (feather-íormed).

Leaflets of lower leaves generally as broad as long.

Plant not hairy.

Flowers from to $\frac{3}{2}$ in broad . . . . C pratensis Plant hairy

Leaflets of lower leaves generally narrow.

Leaflets usually more than 3 pairs in addition to the terminal one

. . . C. arenicola

Leaflets usually not exceeding 3 pairs but more than one.

Seed pods nearly parallel with stem . . . C. parviflora

Seed pods decidedly spreading . . . . . C. fleruosa

Leaves not compound, but often conspicuously lobed.
Plants tufted, 2 to 5 in. high . . . C. bcllidifolia

Plants tufted, 2 to 5 in. high
Plants usually 6 to 15 in. high.

Plants weak, rooting at the joints . . . . C. rotundifolia

Plants erect.

Flowers purple Flowers white $^{\circ} \cdot \bullet^{-} \cdot \bullet^{-} \cdot C^{-} C_{\text {purpurca }}$

1. C. pratensis, L. (Fig. 1, pl. 56.) Meanow Bitter Cress. All the leaves pinnately compound (feather-formed), the lower ones on a somewhat long leaf-stalk, the leaflets orbicular or bruadly angular. The upper leaves on sluorter foot-stalks, the leaflets narrow, in about half a dozen pairs. Flowers in a torminal cluster. white or purple, $1 / 2$ to $3 / 4$ in. broad. Wet meadows and swamps. April-May. 


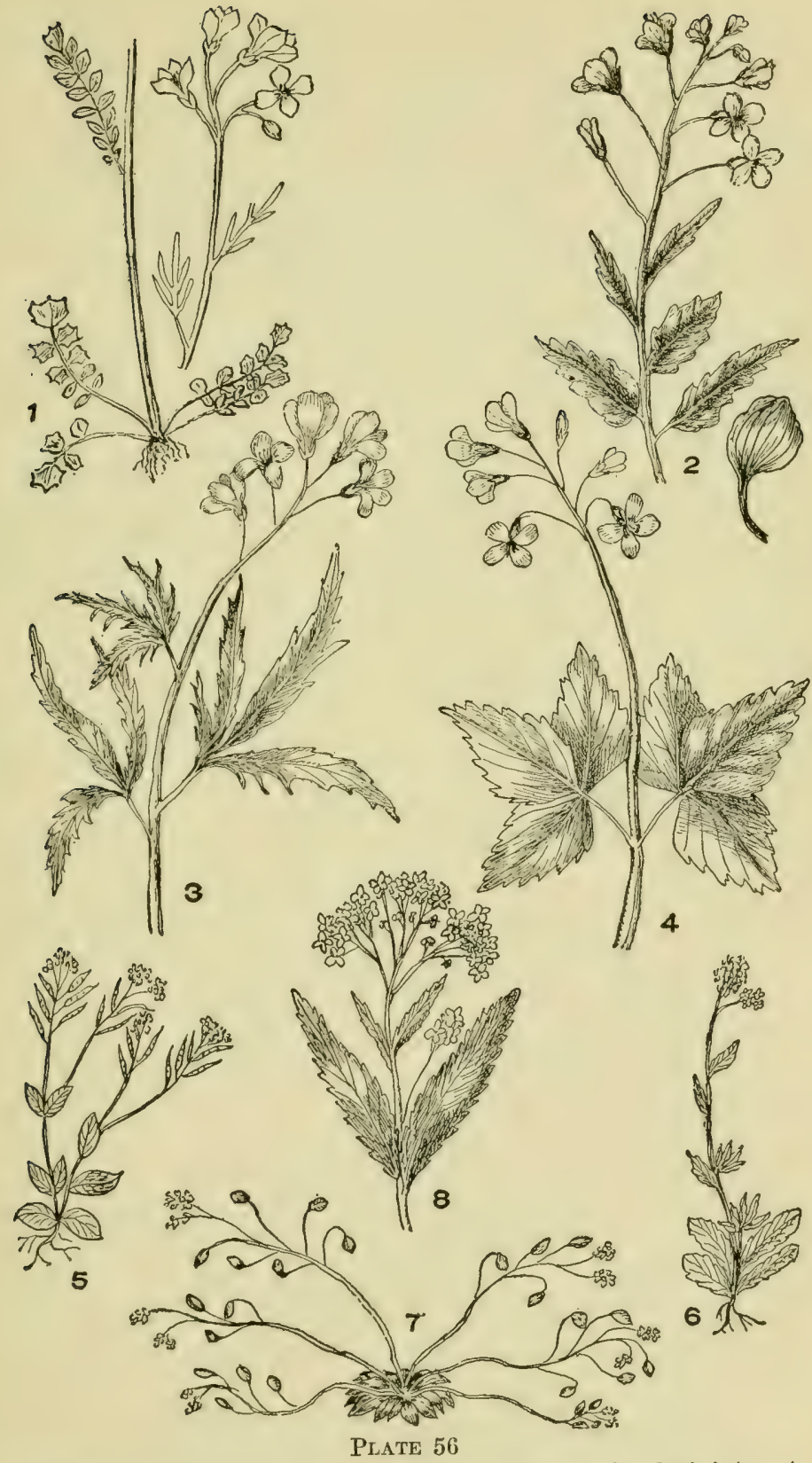

1. Cardamine pratensis. 2. C. purpurea. 3. Dentaria laciniata. 4. D. diphylla. 5. Uraba caroliniana. 6. D. incana. 7. D verna. 8. Roripa armo. racia. 
2. C. hirsuta, L. (Fig. 8, pl. 57.) Hatry Brterer Cress. Whole plant hairy. Leaves nearly all basal, feather-formed, with usually about 5 leaflets, the terminal one orbicular or nearly so, the other more or less oval or oblong. Stem leaves few, their segments linear. Flowers white, pods erect, linear. Moist places, Penna., south and west. March-May.

3. C. pennsylvanica, Muhl. (Fig. 4, pl. 55.) Penssylvania Bitter Cress. Stem $18 \mathrm{in}$. to $3 \mathrm{ft}$. high, leafy up to the clusters of tlowers; leaflets of lower leaves rounded, of upper narrow; terminal leaflet pearshaped with conspicuous notch on each side. Leaflets of all leaves from 4 to 8 pairs. Flowers small, white. Swamps and wet places. April: June.

4. C. arenicola, Britton. SANd BrtTer Cress. Stem usually much branched, $\frac{1}{2}$ to $1 \mathrm{ft}$. high. Leaves compound of 4 or more pairs of linear leaflets, the terminal one long and narrow. Flowers white, about $1 / 6$ in. across. Wet sandy soil. March-April.

5. C. parviflora, I. Sirall-flowered Bitter Cress. Somewhat similar to No. 3, but leaflets less numerous, the stem less branching and flowers smaller. Stem very slender. Dry rocky places. April-May.

6. C. flexuosa, With. Woon Brtter Cress. Stem 6 to 15 in. high, rather stout; lateral leaflets narrow but broadest toward apex, about 3 pairs, the terminal one pear-shaped or orbicular. Wet woods and along streams. May-Aug.

7. C. bellidifolia, L. (Fig. 3, pl. 57.) Alpine Cress. A dwarf species on the White Mountains and other elevations. Jeaves ovate, the lower on long, the upper on short foot-stalks. Flowers few, white. July.

8. C. purpurea, (Torr.) Britton. (Fig. 2, pl. 56.) Purple Cress. Stem not branched, 6 to 15 in. high. Basal leaves orbicular, heartshaped, on long slender foot-stalks; upper, broad, with coarse toothed lorders and without foot-stalks. Flowers purple. Cold wet places. AprilMay.

9. C. bulbosa, (Schreh.) BSP. (Fig. 5, pl. 55.) Bulbous Cress

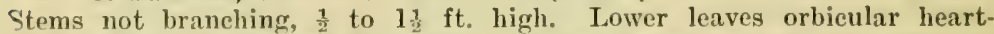
shaped on long slender foot-stalks. Upper, broad and dentate without leaf-stalks. Flowers white. Wet places. April-June.

10. C. rotundifolia, Michx. Round-teaved Water Cress. Stem weak, often rooting at the joints and sending out runners. Jeaves rounded, somewhat angled; sometimes heart-shaped. Flowers white. In cold springs in the southern part of our area.

\section{DRABA, L.}

Small herlos growing mostly in tufts; leaves and stems hairy with forkinl hairs; stums generally with fow or no leaves, the leaves, which may be toothed or not, arranged in a rosette at the base. Flowers in elongated or rounded clusters, small, and in our species, white. Pods oval, or linear, flat, oblong, pointed at the apex, few to many seeded. Seeds arranged in two rows in each valve. 
1. D. verna, L. (Fig. 7, pl. 56.) Vernal Whitlow Grass. A low spreading plant, 1 to 5 in. high, with stems naked from the rosette to the flowers or fruit. Leaves of the basal rosette elliptic, numerous, hairy. Flowers small on foot-stalks $\frac{1}{2}$ to 1 in. long. Fruit an oval or oblong pod. Common in sandy places. Feb.-May.

2. D. caroliniana, Walt. (Fig. 5, pl. 56.) Carolina Whitlow Grass. Plant about the size of the last. One or two pairs of leaves extending upon the flower stem. Pods $1 / 3$ to $2 / 3$ in. long. March-June.

3. D. incana, L. (Fig. 6, pl. 56.) Twisted Whitlow Grass. Leaves long, lance-shaped or with the apex broadest, remotely toothed with rather conspicuous teeth. Small leaves extending up the flower stem arranged alternately. In the Green Mountains and Adirondacks.

\section{ARABIS, L.}

Plants usually rather small; hairy or smooth. Pods long and slender flattened. Flowers white or purple.

Basal leaves not in a rosette

Basal leaves in a rosette.

Leaves of rosette lyre-formed.

Pods erect

Pods drooping . . . . . . . . . canadensis

Leaves of rosette narrow elliptic, deeply or not deeply dentate.

Plant very hairy ............ A. hirsuta

Plant not very hairy ${ }^{\circ} \cdot{ }^{*} \cdot{ }^{*}$ A. brachycarpa

Leaves of rosette long, narrow and deeply toothed or cut by broad and

deep sinuses . . . . . . . . . A. glabra Leaves of rosette egg-shaped, dentate.

Upper stem leaves with entire margins . . . . . . A. laevigata Upper stem leaves markedly dentate....... A. dentata

1. A. lyrata, L. (Fig. 8, pl. 55.) LYre-leaved Rock-cress. Sleniler plants, in tufts, 4 to 12 in. high. Smooth or sometimes somewhat hairy below. Basal leaves feather-formed, upper narrow, with entire margins and blunt apex. Flowers few in a terminal cluster, white. Pods long and very slender. Sandy places and rocky precipices. April. Sept.

2. A. patens, Sulliv. Spreading Rock-cress. Plant downy, 1 to 2 ft. high. Leaves alternate on the stem, without leaf-stalks and to some extent auricled, the margins sharply toothed or nearly smooth. Flowers white; pods an inch or more long. Eastern Penna., westward. Summer.

3. A. canadensis, L. SickLE-POD. Stem not branching, 1 to $3 \mathrm{ft}$. high; smooth or with soft hairs below. Basal leaves deeply dentate or feather-formed, stem leaves, the lower rather broadly lance-shaped with dentate margins, the upper ones narrow lance-shaped with entire margins. Pods long and drooping. Flowers greenish-white. Woods. June-Aug.

4. A. hirsuta, (L.) Scop. (Fig. 9, pl. 55.) Hairy Rock-cress. Stem scarcely branching, 1 to $2 \mathrm{ft}$. high; leaves of rosette deeply dentate or more or less lyrate. Stem leaves narrow lance-shaped, clasping the stem. Whole plant quite hairy. Flower's greenish-white. Pods long and slender. Sandy and rocky places. May-Sept.

5. A. brachycarpa, ( $T$. and G.) Britton. PURPLE Rock-cresss. Stem branched, 1 to $3 \mathrm{ft}$. high, smooth except at lower part. Basal 
leaves narrow, broadest at apex, 1 to $3 \mathrm{in.} \mathrm{long,} \mathrm{margins} \mathrm{notched.} \mathrm{Stem}$ leaves quite narrow, about an inch long, clasping the stem at base. Flowers white or pink, small. June-July.

6. A. glabra, (L.) Bernh. (Fig. 6, pl. 57.) Tower Mustard. Stem erect, rarely branching, smooth and light green above; 2 to $4 \mathrm{ft}$. high. Basal leaves 2 to $10 \mathrm{in}$. long and to $\frac{3}{4} \mathrm{in}$. wide, margins entire or with prominent and unequal dentation. Leaves of the rosette hairy, those of the stem more or less arrow-shaped, clasping the stem and mostly without, hairs. Flowers small yellowish-white in terminal cluster; pods parallel with and close to the stem. Seeds in 2 rows. May-Aug.

7. A. laevigata, (Muhl.) Poir. (Fig. 4, pl. 57.) S^ооти Rock('REss. Whole plant smooth and covered with whitish bloom. Basal leaves broad lance-shaped with deep notches, 2 to $3 \mathrm{in.}$ long. Upper leaves narrow, clasping the stem, notched at the borders. Pods 3 to 4 in. long, spreading and curved downward. Seeds in one row. Flowers greenish-white. Rocky woods. April-May.

8. A. dentata, T. and G. Tootred Rock-Cress. Stem sparingly branching, 1 to $2 \mathrm{ft}$. high, slender, plant hairy. Lower leaves egg-shaped or pear-shaped, with margins coarsely toothed 2 to $4 \mathrm{in}$. long. Stem leaves oblong, dentate, clasping at base. Flowers greenish-white, small. Pods spreading. April-June.

24. STENOPHRAGMA, Celak.

An herb resembling Arabis. Covered with stiff forked hairs. Stem branched, slender.

S. Thaliana, (L.) Celak. (Fig. 1, pl. 57.) Mouse-ear Cress. Plant ranging from an inch to $16 \mathrm{in}$. high, with freely branching stem. Leaves of the rosette spatula- or pear-formed, dentate; those of the stem broad ovate without foot-stalks. Flowers small, white. Southern part of our area. April-May.

\section{HESPERIS, L.}

Erect herhs with simple leaves and large clusters of purple or white flowers. Pods (siliques), slender, linear, cylindric. Petals purple.

H. matronalis, L. (Fig. 2, pl, 57). Rocket. Dame's Violer. Stem 2 to $3 \mathrm{ft}$. high. Leaves lance-shaped, borders wavy. Flowers purple, each nearly an inch broad. The Rocket of the gardens, naturalized in places.

\section{FiMILY III.-CAPPARIDACEAE. CAPER FAMILY}

The characteristies of this family are much the same as those of the Crucifers. So nearly related are these two families that it. is not, in the case of every species, easy to distinguish the one family from the other. An important difference is, however, fouml in the fact that while in the flowers of the Crucifers there are four long and two shorter stamens, in the Caper family the stamens are equal or noarly so. The number of stamens in our species is 6 as in the Crucifers, or more than six . 


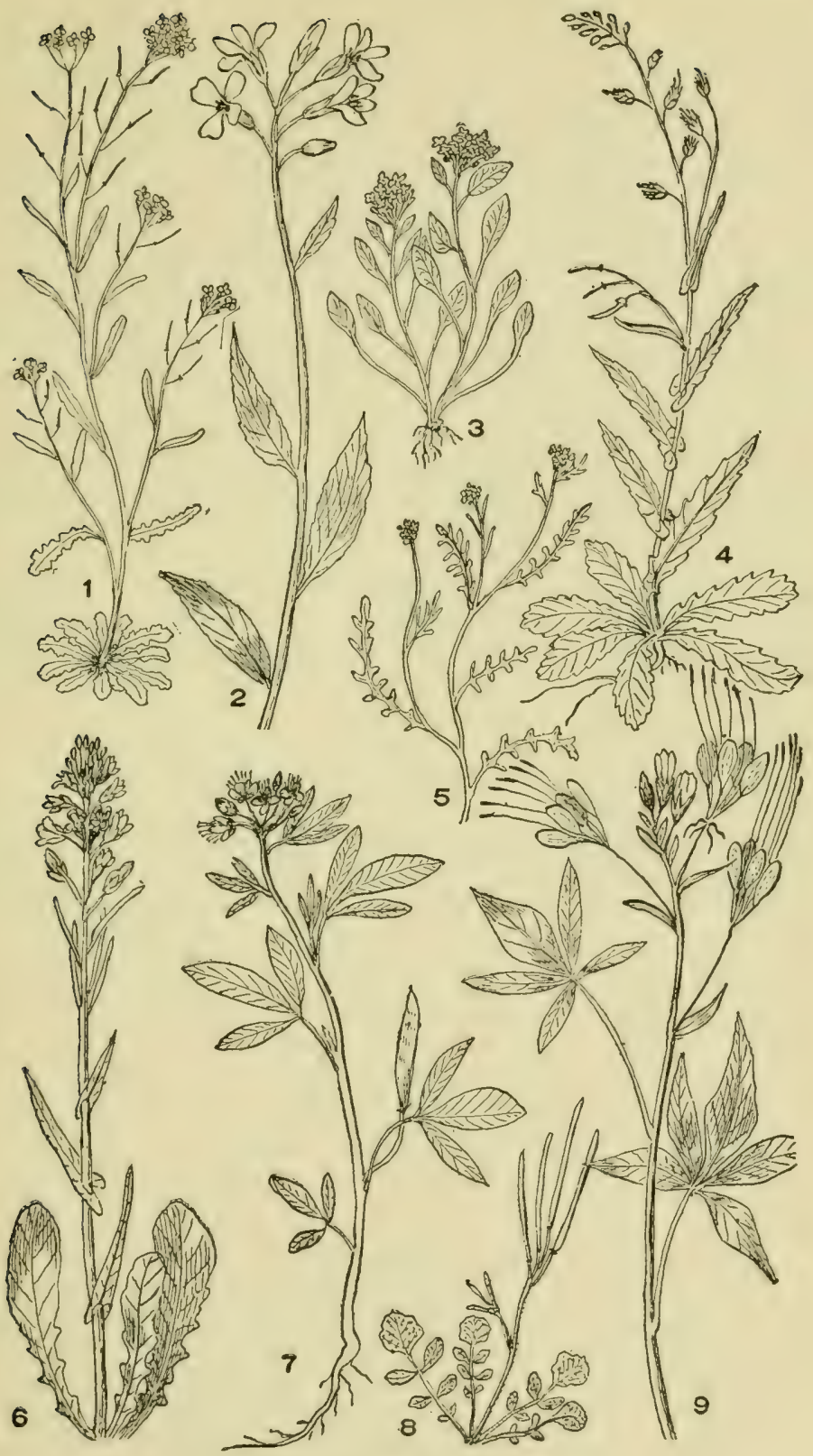

Plate 57

1. Stenophragma Thaliana. 2. Hesperis matronalis. 3. Cardamine bellidifolia. 4 Arabis laevigata. 5. A. virginica. 6. A. glabra. 7. Polanisia graveolens. 8. Cardamine hirsuta. 9. Cleome spinosa. 


\section{CLEOME, L.}

Herbs or shrubs. Ieaves compound, leaflets radiating, 3- or 7-foliate. Calyx of 4 sepals; stamens 6 , equal. Seed-pod elongated, like the silique of mustard, many seeded.

C. spinosa, L. (Fig. 9, pl. 57.) Spider Flower. Plant 2 to $4 \mathrm{ft}$. high, erect. Stem and leaves furnished with soft hairs. Leaves divided into 7 leaflets radiating from the common center. Lower leaves with rather long leaf-stalks, upper with short leaf-stalks or none. Leaflets lance-shaped. Above, the leaves become simple, not divided into leaflets, exg-shaped or heart-shaped at base. Flowers of 4 purple or whitish petals, each with a long, slender claw. The flower is about an in. broad. The stamens are two or three times as long as the petals. Seed-pod 2 to 6 in. long. In the southern part of our area, New York and New Jersey.

\section{POLANISIA, Raf.}

Herbs with a disagreeable odor. Leaves divided into 3 radiating leaflets. Flowers in clusters, small, white or yellowish. Stamens 9 to 12. Pod cylindric.

P. graveolens, Raf. (Fig. 7, pl. 57.) ClammY Weed. Branching, $\frac{7}{2}$ to $1 \frac{1}{2} \mathrm{ft}$. high. Leaves 3 -foliate (clover-formed); leaflets oblong, obtuse, without teeth or notches. Flowers in terminal clusters, yellow. ish-white. Stamens about 11. Pod 1 to 2 in. long. Sandy shores, our area and southward. June-Aug.

\section{Fanily IV.-RESEDACEAE. Mignonette Family}

Annual or perennial herbs with unsymmetrical flowers, introduced from Europe and only found growing wild in our region in certain localities where the species have become naturalized in waste places near sea-ports. Leaves alternate, either simple or compound, feather-formed. Flowers in spikes; calyx of $t$ to 7 parts and corolla of about as many. Stamens, in our species, 3.

\section{RESEDA, L.}

Characters as above.

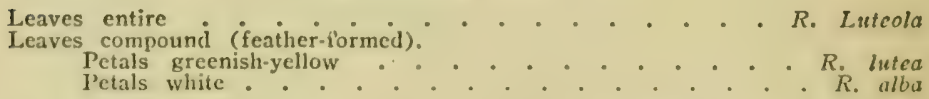

1. R. Luteola, I. (Fig. 7, pl. 58.) Dren's Rocket. Yhitow Wred. Calyx and corolla each of 4 divisions, unequal. Plant 1 to $2 \frac{1}{2} \mathrm{ft}$. high. Leaves longer, laner-shaperl, often with shallow or even rather deep lobes, especially of lower leaves, upper leaves generally with entire odges. Seed rapisule rounded. Introduced. In waste places on Jong Island and elsewhere.

2. R. lutea, T. Yeriow Cut-inaren Mrgnonettr. Plant erect or decumbent. Ifeaves feather-formed, the divisions sometimes rather irregular, 
often secondarily divided. Plant hairy. Calyx and corolla each 6-parted, irregularly divided. Petals quite small, greenish-yellow. Introduced. In waste places, in southern part of our area.

3. R. alba, L. White Cut-leaved Mignonette. Calyx and corolla of 5 divisions each, petals with about 4 teeth, white. Plant smooth, 1 to $3 \mathrm{ft}$. high. Introduced in widely separated localities.

\section{Order V.-SARRACENIALES. Order of Pitcher Plants}

Insectivorous plants which secrete a viscid substance attractive to insects and which aids in their capture. The leaves are all basal and from the midst of this basal cluster of leaves arises a slender flower stem bearing one or several nodding flowers. 'There are 4 or 5 calyx divisions arising below the ovary and 5 petals. Stamens numerous. Fruit a capsule 3- to 5-celled.

\section{Family I.- SARRaceniaceae. Pitciter Plant Family}

Characiers those of the order, but all leaves are hollow, pitcherformed or trumpet-shaped.

\section{SARRACENIA, L.}

Perennial herbs growing in bogs. Leaves all at the base, hollow or pitcher-shaped, with a wing at one side. Flowers solitary on a tall scape, nodding; calyx of 5 sepals with 3 small bracts at base. Petals 5 . The extremity of the pistil spreads out as a broad shield-like plite covering the ovary. Its 5 rays terminate below and constitute as many stigmas. Fruit a capsule of 5 cells.

S. purpurea, L. (Fig. 5, pl. 58.) Pitcher Plant, Side-saddee FLower. This, the only species in our region, is one of the most curious of our plants. It is found in peat bogs where it often grows in considerable beds. The hollow leaves entice insects within their recesses where, owing to the stif hairs pointing downward and the viscid secretions, may of the prisoners die. It is supposed that the juice from the insects contribute toward the nutrition of the plant. The flower stem is from 15 to $20 \mathrm{in.} \mathrm{high.} \mathrm{Flowers} \mathrm{purple} \mathrm{and} \mathrm{yellow.} \mathrm{Blooms} \mathrm{in} \mathrm{June.}$

\section{Family II.-DROSERACEAE. Sundetw Faitlly}

Delicate herlos growing in mossy bogs. Leaves mostly in a basal whorl covered, especially at the edges, with glandular hairs and in the center with a viscid exudation. Flowers on a slender scape, nodding, with 4 or 5 sepals and 5 petals. Stamens 4 to numerous; pistils 3 to 5 ; ovary globose with the calyx attached at base. 
DROSERA, L.

Bog herbs with the characters of the Family as above.

Leaf blades round, fully as broad as long . . . . D. rotundifolia Leaf blades spatula-formed, rounded at apex $\div \cdot{ }^{\circ}$. intermedia

Leaf blades linear, but broader than the leaf-stalk $\cdots \cdots$. longifolia

Leaf blades thread-like, not broader than the leaf-stalk: $D$. filiformis

1. D. rotundifolia, I. (Fig. 1, pl. 58.) Round-Leaved Sundew. Plants 4 to 10 in. high. Leaves nearly orbicular, depressed at center, which is oceupied by a viscid exudation. Leaf-stem and edges of leaves thick set with glandular hairs. Flowers 4 to 12 on a slender seape with quite short flower stems, white, about $1 / 6$ in. broad. In swamps, throughout our area. July-Aug.

2. D. intermedia, Hayne. (Fig. 2, pl. 58.) Spatulate-leaved SunDEw. Similar to No. 1, but leaves are elongated, spatulate, rounded at apex and narrowed at base. The plant is usually smaller than No. 1 and the color of leaves darker. Less common than No. 1, growing in similar situations. July-August.

3. D. longifolia, L. (Fig. 3, pl. 58.) Obloxg-Leaved Sundew. Resembles No. 2, but leaves are still more elongated, and while in Nos. 1 and 2 the leaves lie flat upon the surrounding moss or mud, in this species the leaves are more nearly erect. Whole plant more delicate than either of the preceding species. In bogs, less common than No. 1, blooming at about the same time.

4. D. filiformis, Raf. (Fig. 4, pl. 58.) Trread-leaved Sundew. Leaves narrowly linear, from 5 to $15 \mathrm{in.} \mathrm{long,} \mathrm{covered} \mathrm{throughout} \mathrm{with}$ hairs. Flower scape 8 to 20 in. high with a number of purple flowers which are from $1 / 3$ to 1 in. broad. Sand, near the eastern coast. JulySeptember.

\section{Order VI.-ROSALES. Order of the Rose Alliance}

This large order unites within itself plants of widely divergent habits and appearance. They include trees, shrubs and herhs. Mostly they are land plants, but a few find their homes in swamps and one, in our region, Podostemon, is an entirely submersed aquatic.

The characteristics which join this greatly varied group into an order are:

1st. The presence of both sepals and petals, the latter of which are distinct, that is, they are not united by their edges as they are in such flowers as the hlue-bell or morning glory, but are separate as in the single rose. The sepals of the calyx are to some extent confluent, but always show at least a partial division. 'I'o this general law of characterization there are exceptions: 

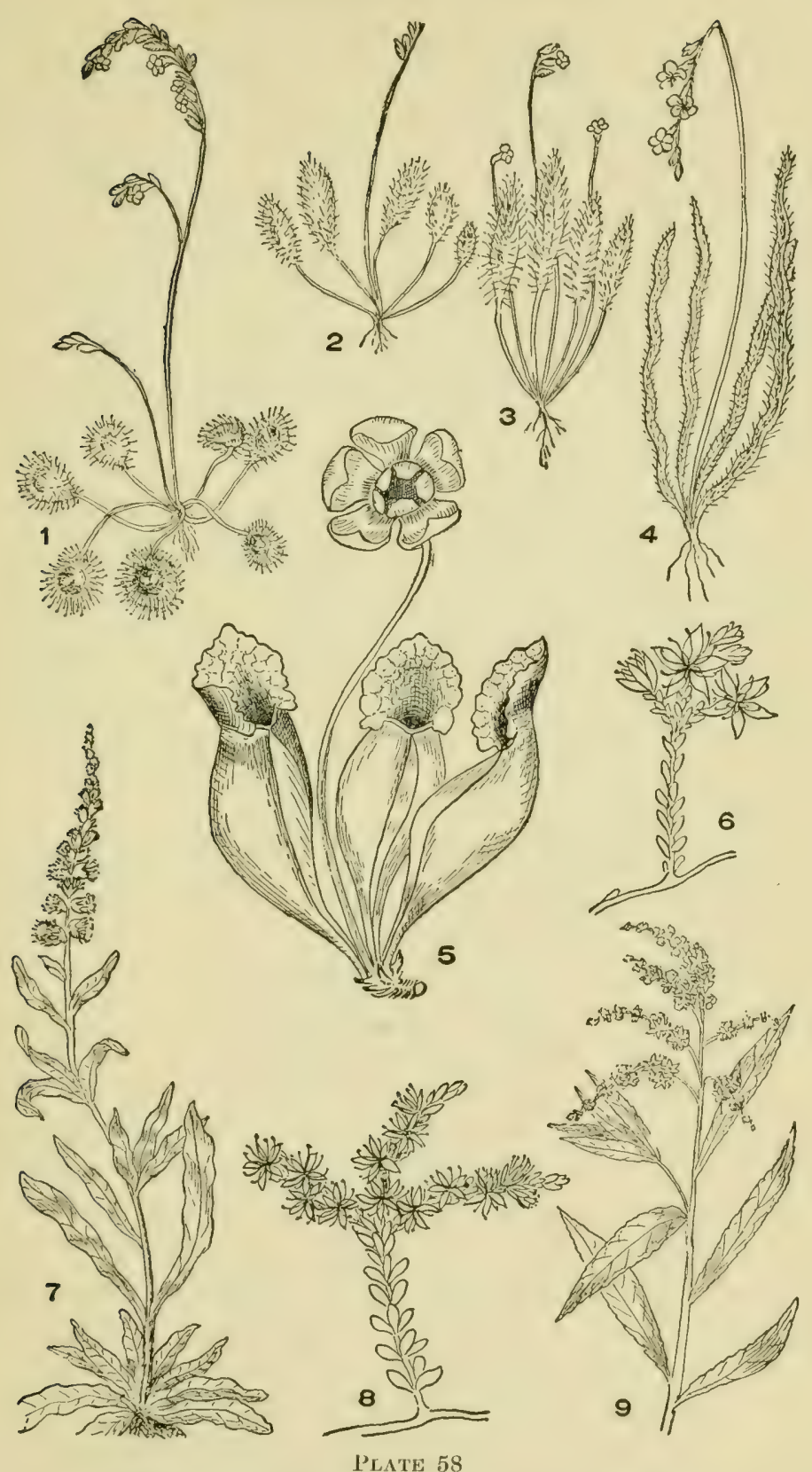

1. Drosera rotundifolia. 2. D. intermedia. 3. D. longifolia. 4. D. filiformis. 5. Sarracenia purpurea, 6. Sedum acre. 7. Reseda Luteola. 8. Sedum ternatum. 9. Penthorum sedoides. 
for example, the Podostemon has neither sepals nor petals, the style and double stamen being partly surrounded at base by a small spathe. In Liquidambar the pistillate flower has a small confluent calyx but no corolla, and from the staminate flower both calyx and corolla are absent. In Sanguisorba the petals, and in Xanthoxylum the sepals are wanting.

2nd. The carpels (seed caskets), are solitary or several may be united in one or collected in a group.

3d. The stamens do not, with very few exceptions, arise from a ring just at the base of the ovary, but spring from the calyx or around the summit of the ovary.

4th. Except Podostemon, which is a submersed aquatic, all are land plants, though a few are found growing in mud or in swamps.

5th. In the great majority of species of this order the stamens and pistils are found in the same flower. In exceptional cases the stamens and pistils occupy different flowers. Examples: Hamamelis, Liquidambar and Platanus.

\section{Families of the Order Rosales}

Submersed aquatic plant . PODOSTEMACEAE Trees, shrubs and herbs, land plants.

Fruit a simple or compound dry capsule.

Stamens less than 20

Fleshy or succulent herbs, leaves without stipules; ovaries as many as the divisions of the calyx. Stamens inserted on the calyx . . CRASSULACEAE

IIerbs or trees, not fleshy, ovaries 2, fewer than the divisions of the calyx. Stamens inserted on the calyx . . . . . . . SAXIFRAGACEAE

Fruit a one-celled globular berry . GROSSULARIACEAE

Fruit contained in a rounded woody capsule.

Shrul, with alternate undivided leaves, with flowers appearing in late summer or in autumn, petals 4 , long, strap-like sepals 1 . . HAMAMELIDACEAE 
Fruit a rounded bur-like head.

Tree with broad leaves and with fruit in globular heads hanging by long peduncles. Stamens and pistils in different flowers. Flowers without sepals or with minute ones . . . . . PLATANACEAE

Fruit a legume, that is, a pod formed like that of a pea. Flowers slightly irregular, but not in form of a peal blossom. Stamen filaments united generally in 2 groups . . . . . . . . CAESALPINACEAE

Flowers quite irregular, papilionaceous-having the general shape of a pea blossom PAPILIONACEAE

Stamens more than 20

Stamens all free.

Fruit, follicles or achenes, $i$. $e$, dry one-celled seed vessels with several seeds, or a dry vessel with a single seed ROSACEAE Fruit a drupe, i. e., like a plum or cherry, with a fleshy exterior and woody stone within . . . . . DRUPACEAE Fruit a pome, $i$. e., a fleshy fruit like the apple or pear

POMACEAE

(In the IIawthorns, Mountain Ash and Shad-berry the fruit is small and less fleshy than the pear and apple.)

Family I.-PODOSTEmaceae. River Weed Family

Only a single species in our region. A fresh water submersed plant with the general appearance of the Naiads. The leaves are thread-formed, much divided. Flowers without perianth except a small spathe-like envelope at base of the very simple flower which consists of the ovary and of a rather long stamen filament dividing toward the top into two stamens.

\section{PODOSTEMON, Michx.}

Characters as above.

1. P. ceratophyllum, Michx. (Fig. 1, pl, 59.) River Weed. Thread Fоот. Plant submersed, dark green with thread-like leaves forming dense fascicles. Flowers very small, inconspicuous, at axils of leaf branches. In shallow streams, northern New York and southward throughout the range. July-Sept. 


\section{Family II.-CRASSULACEAE. ORpine Famil}

Fleshy or succulent herbs with alternate leaves and regular flowers in terminal spreading clusters (cymes). Stipules none. Calyx of \pm or 5 sepals. Petals equalling the number of sepals. Stamens equal in number to petals or double the number, gencrally the latter. Seed caskets (carpels) opposite the petals and of the same number. Fruit, dry seed caskets with several seeds in each casket or follicle.

Minute herbs, stamens equal to number of sepals . . Tillaea

Tery fleshy herbs; twice as many stamens as sepals. Leaves small, scale-like . . . . . . . . . . Sedum

Plant not very fleshy, leaves conspicuous, on leaf stalk. Flowers in forked terminal clusters (cymes). Petals usually wanting . . . . . . . . Penthorum

\section{TILLAEA, L.}

Very small smooth plant growing in mud. Leaves opposite. Flowers very small, one in a leaf axil. Petals 3 to 5 . Calyx of 3 to 5 sepals. Stamens 3 to 5 .

T. aquatica, L. (Fig. 5, pl. 59.) PIgmY Weed. Stem $\frac{1}{2}$ to 3 in. higr. Leaves linear, opposite. In the axes of the leaves appear the small rounded bud or flower, having calyx lobes, petals and carpels, each 4. The petals are greenish. Muddy banks and streams, mostly near sea coast. July-Sept.

\section{SEDUM, L.}

Smooth fleshy plants, generally escapes from gardens. Leaves alternate. Flowers with stamens and pistils. Stamens twice as many as the petals. Flowers generally in 5's, exceptionally 4-parted. Stamens 8 or 10 .

Flowers with 4 petals and 8 stamens.

Stamens and pistils on different plants

Flowers with 5 petals and ro stamens.

Stamens and pistils in the same flower. Petals purple or white.

Leaves broail and flat, $\mathrm{T}$ to 2 in. long . . S. purpureum

Leaves less than an inch long.

Flowers white .......... So ternatum Flowers pink . . . . . . S. telephioides Flowers yellow.

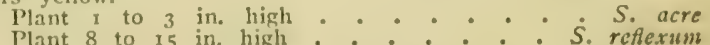

1. S. roseum, (L.) Scop. (Fig. 7, pl. 59.) Rosewort. Stems 5 to $10 \mathrm{in}$. high. Juaves oval without leaf-stalks, toothed, overlying each other. ('luster of leaves terminal, dense, greenish-yellow, turning purple. A northrern species rare in our region, but extending into Maine and further south.

2. S. purpureum, 'Tausch. (Figr. 2, pl. 59. Gamder Live-For-Ever. 
(S. Telcphium, Gray.) Stems 1 to $2 \mathrm{ft}$. high. Leaves broad egg-shaped, without leaf-stalks. Less densely crowded than No. 1. Plant light green. Flowers purple. Escaped from gardens.

3. S. telephioides, Michx. American Orpine. Similar to No. 1, but more slender. Flowers pink; petals twice as Iong as sepals. Southern Penna., and southward.

4. S. acre, L. (Fig. 6, pl. 58.) Mossy Stonecrop. Growing in dense mossy tufts. Plant 1 to 3 in. high, with bright yellow blossoms. Inaves short, thick, egg-shaped, about $1 / 12$ in. long. Eseaped from gardens.

5. S. reflexum, L. (Fig. 6, pl, 59.) Crooked Yellow Stonecrop. Plant 8 to $15 \mathrm{in}$. high. Leaves lance-formed, crowded on the stem, $\frac{1}{4}$ to $\frac{1}{2}$ in. long. Flowers yellow in broadly spreading cluster. Eseaped from gardens. Rare.

6. S. ternatum, Michx. (Fig. 8, pl. 58.) WiLd Stonecrop. Growing in mossy tufts. Stems 3 to $8 \mathrm{in.} \mathrm{high.} \mathrm{Leaves} \mathrm{in} \mathrm{verticles} \mathrm{of} 3$ or opposite in pairs, 1 to 1 in. long. Flower cluster of about 3 spreading branches, thickly studded with purplish or white flowers. Rocky woods in southern part of our region. April-June.

\section{PENTHORUM, L.}

Erect, only slightly succulent. Herbs with alternate leaves with footstalks. Petals generally absent, when present 5. Calyx of 5 sepals, stamens 10, carpels 5, united to the middle. Flowers in spreading clusters, the branches one-sided and drooping (cymose).

P. sedoides, L. (Fig. 9, pl. 58.) Ditci Stonecrop. Leaves lanceshaped, pointed at each end, with foot-stalks $\frac{1}{2}$ to 3 in. long, finely notched at borders. Wet places, borders of ponds, etc. July-October.

\section{FAMILY III.-SAXIFRAGACEAE. SAXIFRAGE FAMILY}

In our region nearly all small herbs; perennial. Leaves mostly alternate or in whorls about the base; less frequently opposite.

Flowers with both stamens and pistils. Sepals 5, generally free, but sometimes adherent to the ovary. Petals 5, rarely wanting. Stamens 10 in all our species. Styles 2, terminating below in a two-celled capsule or a many-seeded casket, opening at the side or, rarely, in a berry.

\section{Herbs}

Flowers in clusters or solitary and purple.

Petals with undivided borders.

Styles 2, ovary of 2 lobes, parted about half way up

Styles 2, ovary of 1 lobe.

- Stamens 10

Saxifraga

Tiarella

Stamens 5

Heuchera 
Petals fringed at borders

Mitella

Petals mostly alosent. Plant aquatic . Chrysosplenium Flowers not in clusters, white; scape bearing a single starshaped flower . . . . . . . . . Parnassia Leaves opposite . . . . . . . . Hydrangea Leaves alternate . . . . . . . . . . Itea

\section{SAXIFRAGA, L.}

IIerbs, peremial; leaves mostly basal, less frequently opposite and scattered along the stem. Stipules none. In all of our species borders of leaves furnished with sharp teeth. Flowers generally in loose, or crowded, terminal clusters. Petals 5, sepals 5, stamens 10, inserted with the petals. Ovary, generally superior to the calyx, 2-lobed above, joining below.

Flowers purple, leaves opposite, over-lapping . . . . . . S. oppositifolia Flowers yellow, or yellowish-green.

Leaves alternate along the stem.

Leaves mostly in a rosette at base.

Leaves mostly less than an in. long . . . . . . S. Aizoon Flowers white.

Leaves more than 3 in. long $: \cdot:: \vdots: \dot{S}$. pennsylvanica

Leaves trilobate . . . . . . . . . . . . S, rivularis

Leaves 5 to 12 in. long, less than as broad $: . \dot{S}$. micranthidifolia

Leaves $\mathrm{I}$ to 3 in, long, about $\frac{\frac{3}{2}}{2}$ as broad ... S. virginiensis

Leaves usually less than an in. long, narrow, with toothed apex $S$, stellaris

1. S. oppositifolia, L. Punile, or Mountain Saxifrage. Stems in tufts, 6 to 8 ill. long, creeping. Leaves crowled, overlapping, opposite, small rather fleshy $1 / 12$ to $1 / 6$ in. long, oval. Flowers solitary, light purple, showy, peials 5-veined. Wet rocks, Mit. Mansfield and Willoughby Mountain, Vt., and further north.

2. S. aizoides, L. (Fig. 4, pl. 59.) Yellow Mountain Saxmrrage. Stems branched, in tufts, 2 to 6 in. high. Leaves seattered along the flowering stem, linear, rather thick and lleshy; $1 / 3$ to $2 / 3 \mathrm{in}$. long, with oceasional stiff hairs along the margin. Flowers yellow, conspicuous. In the same location as No. 1.

3. S. rivularis, L. (Fig. 8, pl. 59.) Alpine Brook Saxifrage. In dense tufts, stems crepping, rooting at leaf nodes. Jower leaves kidneyshaped with 3 to 5 derep lobes, upler leaves oval or lanee-shaped. Flowers few ( 1 to 5 ), white, $\frac{1}{1}$ in. broad. Calyx lobes nearly as long as the petals. Ovary with two widely diverging tips. Summits of White Mountains and north.

4. S. Aizoon, Jacq. (Fig. 3, pl. 59.) Lrvelong Saxifrage. Stems viseid, hairy, 6 to $10 \mathrm{in}$. high; leaves in a dense basal rosette, spatulashaperl, with sharp white firm terth at borders. I fow small leaves along the stem. Flowers in a sprealing cluster, white with yellowish spots, about $f$ in. broad. Petals twice as long as sepals. Dry rocks, Mt. Mansfield, $V t$, and northward.

5. S. virginiensis, Mirhx. (Fig. 2, pl. 60.) Fantx Saxmbage. Stemz viscid, growing in tufts on wot rocks and moist plares. deaves montly at hase in a rather dense rosette, engreshaped with blunt teeth at borders. 


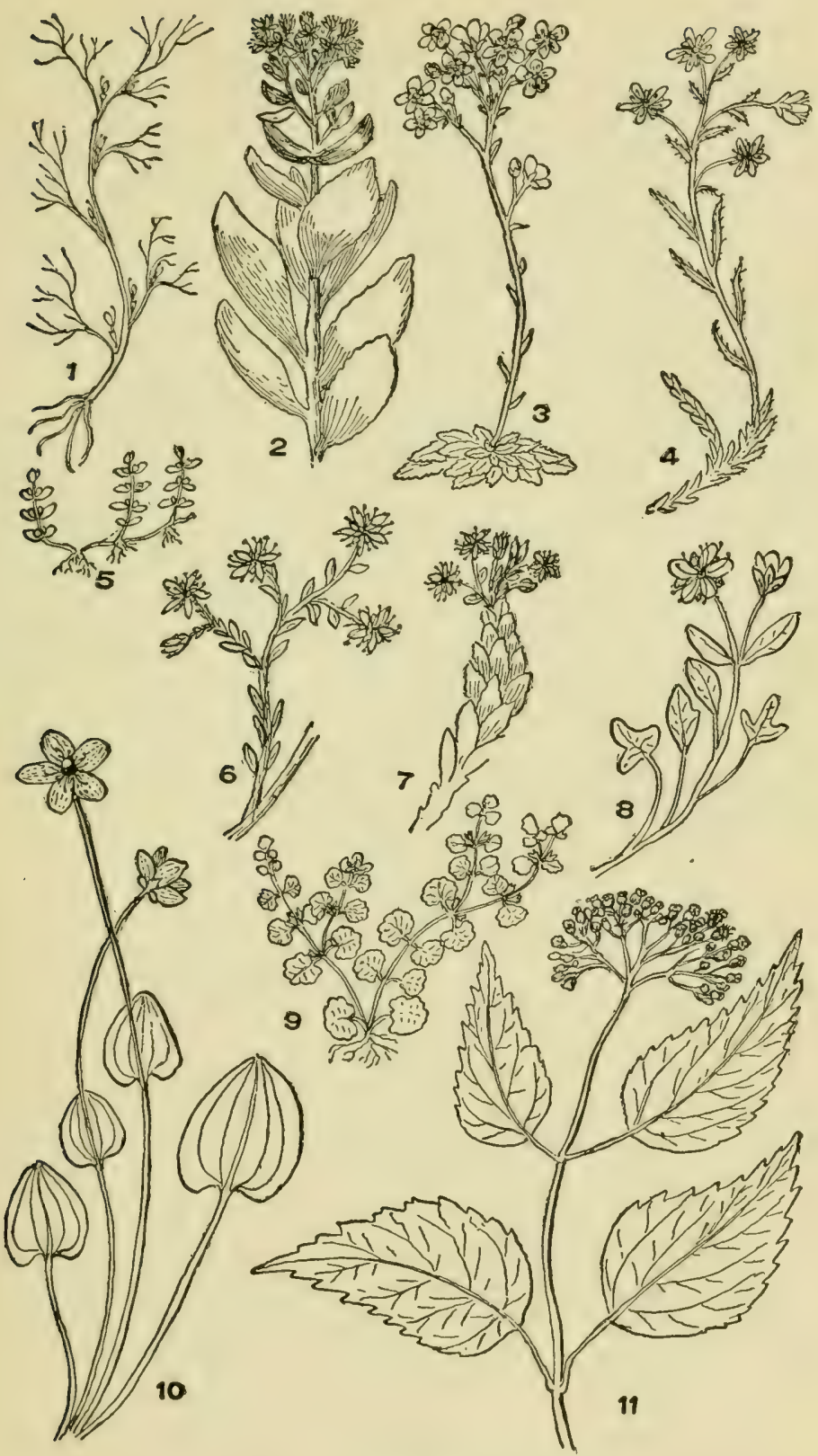

Plate 59

1. Podostemon ceratophyllum. 2. Sedum purpureum. 3. Saxifraga Aizoon. 4. S. aizoides. 5. Tillaea aquatica. 6. Sedum reflexum. 7 S. roseum. 8. Saxifraga rivularis. 9. Chrysosplenium americanum. 10. Parnasia caroliniana. 11. Hydrangea arborescens. in fruit. 
Stem 4 to $12 \mathrm{in.} \mathrm{high.} \mathrm{Leaves} 1$ to $3 \mathrm{in.} \mathrm{long,} \mathrm{tapering} \mathrm{at} \mathrm{base} \mathrm{to} \mathrm{a}$ long leaf-stalk. Flowers white. Early spring, March to May.

6. S. micranthidifolia, (Haw.) BSP. Lettuce Saxifracie. Flower scape somewhat viscid, 1 to $3 \mathrm{ft}$. high. Flowers small, white in a loose pyramidal cluster. Leaves inversely lance-shaped or oval, from a few in. to $1 \mathrm{ft}$. long. Coarsely toothed at margins. Bethlehem, Pa., and southward. May-June.

7. S. pennsylvanica, L. Tall or Swamp Saxifrage. Plant 1 to $3 \frac{1}{2}$ ft. high. Leaves mostly basal, broad lance-shaped, 5 to $\mathrm{S}$ in. long by 1 to 2 in. broad, tapering at base to short leaf stalk, borders toothed. Flowers yellowish-green on tall scape with a few small leaves or none. In wet places in all our range. May.

8. S. stellaris, L. Foliose Saxifrage. (S. comosa, Britton.) Slender plant 2 to 6 in. high, with a rosette of lance-shaped leaves, broadest at apex with about 3 teeth. Flowers few, white, some of them replaced by small tufts of leaves. Mt. Katahdin, Maine, and northward. Summer.

\section{TIARELLA, L.}

Herbs, similar in many respects to Saxifraga. There are, however, at the base of the leaf-stalks, small stipules, and the ovary, which is 2-lobed in Saxifraga, has but a single lobe in Tiarclla which is divided into 2 unequal valves. Leaves nearly all basal on long leaf-stalks, broadly rounded and deeply 3 -lobed to several lobed.

T. cordifolia, L. (Fig. 1, pl. 60.) Coolwort. False Miterwort. Leaves basal, rounded, deeply 3- to 7-lobed. Flower scape 6 to 12 in. ligh, with a long narrow eluster of about a dozen white flowers. Calyx bell-shaped of 5 sepals; petals slightly longer than sepals. In moist woods in early spring, throughout our range.

\section{HEUCHERA, L.}

Perennial herbs with rounded, heart-shaped leaves, principally from the root. When leaves are found on the stem they are alternate. Calyx bell-shaped, 5-cleft, the tuhe alhering to the ovary. Petals small, often shorter than the sepal6. Stamens 5; styles 2, slender; capsule 1-celled.

1. H. americana, L. (Fig. 5, pl. 60.) Alum Root. Stem 2 to 3 ft. high, stout, hairy. Leaves all or nearly all from the base, on long leaf-stalls, round or roundish with 5 to 9 rounded lohes and with blunt teeth; the veinlets radiating from the stem insertion. Calyx broadly lell-shaped; petals very small, greenish. Stamens extending much beyond the calyx and petals. Dry woods, Conn., and southward. MayAugust.

2. H. pubescens, Pursh. Dowry Teucrikns. Plant much like the preceding, more decidedly downy, the lobes of the laves deeper. I'ctals creceling the calyx lobes, purplish. Stamens scarcely longer than the petals. Mountains of Pennsylvania and southward. May-June.

\section{MITELLA, L.}

ITerls with the general character of Saxifrage. Leaves mostly basal but, in our species, the llower seape has, near the eenter, a pair of broad 


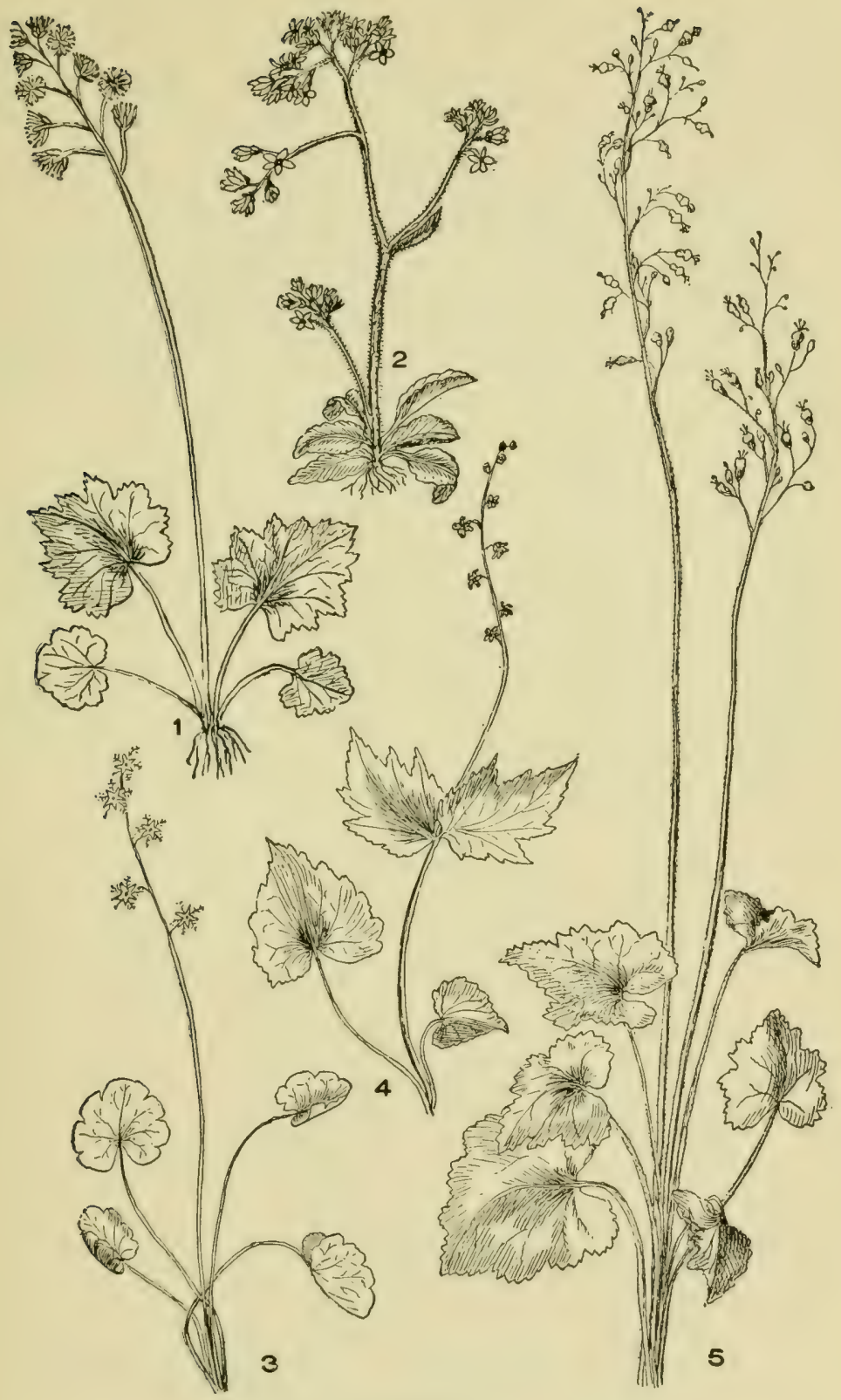

Plate 60

1. Tiarella cordifolia. 2. Saxifraga virginiensis. 3. Mitella nuda. 4. M. diphylla. 5. Heuchera americana. 
leaves (one or even both wanting in .I. muda). Petals fringed. Ovary 1-lobed, 1-valved.

1. M. diphylla, L. (Fig. 4, pl. 60.) Two-Leaved Bisiop's Cap. Miterwort. Basal leaves broadly heart-shaped. Flowering stem 10 to 18 in. high, with a pair of broad leaves less than half way up. Flowers clustered along the upper part of the slender stem. Petals white, two or three times longer than the sepals, beautifully fringed. In rich woods. Early spring. In all our range.

2. M. nuda, L. (Fig. 3, pl. 60.) Nakfd Bisiop's Cap. Miterwort. Flowering stem 3 to $7 \mathrm{in}$. high. Leaves all basal or with one small leaf half way up the stem; rounded, heart-shaped at base, hairy. The hairy flower stem bears about half a dlozen white flowers, the petals being more deeply cut and delicately fringed than No. 1. In similar situations as No. 1. Blooms in early spring and also again in autumn.

\section{CHRYSOSPLENIUM, L.}

Low, creeping, rather fleshy herbs, growing in wet places. Leaves, in our species, opposite, without stipules. Flowers minute, greenish, springing in the axils of the leaves. Petals wanting. Stamens 8 to 10. Ovary of 1 rell, separating above into 2 lobes. Lobes of the calyx, which are the conspicuous elements of the flower, yellowish-green.

C. americanum, Schwein. (Fig. 9, pl, 59.) Water Carpet. Golden Saxifrage. Stems 3 to 8 in. long, creeping, branched, smooth and shining. Lower leaves opposite, round or broadly ovate, with shallow notches in margin. Flowers yellowish or purplish. In wet places, not common. In the central part of our region. From the northern to southern part of our area. Early spring.

\section{PARNASSIA, L.}

Smooth herbs, with basal leaves on long leaf stalks and with slender flower stems bearing a single leaf near the middle. Leaves with 5 endto-end veins. Stem with a single terminal conspicuous white flower. Ovary 1-lobed, 1-celled with short styles or none. Stamens 10 or more, 5 of which are fertile, the others without anthers.

P. caroliniana, Michx. (Fig. 10, pl. 59.) Grass-of-Parnassus. Flowering srape 8 to $24 \mathrm{in}$. high, with a broad heart-shaped leaf clasping below the middle. Basal leaves on long slender leaf-stalks, somewhat heart-shaped at base and decurrent on the leaf-stalk, 1 to $2 \mathrm{in.}$ long, nearly as wide. Flower white with several greenish veins $2 / 3$ to $1 \frac{1}{2}$ in. in diameter; calyx secrments $1 / 3$ as long as petals, light green. In swamps, brook-sides and wet meadows, throughout our area. JuneSeptember.

\section{HYDRANGEA, L.}

Our species a shrub with opposite egg-shaped leaves and terminal clusters of flowers. Leaves without stipules. The exterior flowers of the spreading cluster are often sterile and without petals, but with large and conspicuous calyx lobes. Calyx tube of fertile flowers hemispheric with 8 or 10 ribs. Stamens 8 to 10 . Petals generally 5 , sometimes 4 . Ovary 2- to 1-Jobed with 2 diverging styles. Fxternal to the ovary are 10 to 12 vertical ribs. 
H. arborescens, L. (Fig. 11, pl. 59.) Wild HrDrangea. Shrub 2 to $10 \mathrm{ft}$. high. Leaves smooth, young twigs somewhat hairy. Leaves ovate, sharp pointed with leaf-stalks about $1 / 6$ as long as the leaves. Flowers in a rounded, spreading cluster. Along streams, New York and New Jersey and southward.

\section{ITEA, L.}

Shrub with alternate leaves. Flowers small, white, in narrow elongated cluster. Calyx tube rounded. Sepals 5. Petals 5, much longer than sepals. Stamens 5. Fruit capsule oblong, 2-lobed, spreading above into two slightly diverging styles.

I. virginica, L. (Fig. 1, pl. 61.) Virginia Willow. Shrub 4 to 10 ft. high. Leaves oblong, pointed with small serrations at borders. Wet places in southern part of our area, New Jersey and Pennsylvania. MayJune.

\section{Family IV.-GrossulariaceaE. Gooseberry Family}

This family contains only the single genus, Ribes, gooseberries. The species are all shrubs with alternate leaves which are, however, often in groups or fascicles. The leaves are broad and generally deeply cut by sinuses which divide the blade into 3 or \pm lobes. At the base of the leaf stem are two small stipules. The stems are, in some species, armed with sharp spines just below the leaf axils, in other species the spines or sharp bristles are dispersed along the stem, while in some the stens are entirely destitute of spines or of bristles. The flowers are, in some species, solitary or in groups of 2 to 4 , while in others they are numerous, arranged along a main flower stem in a long slender cluster (raceme). At the base of each small foot-stalk for the flower is a small bract. The calyx has 4 or 5 sepals, sometimes colored; petals 4 or 5, generally 5, inserted into the throat of the calyx; they are small, usually less than the scpals. There are 5 stamens and 3 styles which unite at base into a one-celled ovary. The fruit is a berry containing several seeds.

\section{RIBES, L.}

The only genus. The characters are those of the family.

Flowers few ( $x$ to 4 ), in the leaf axils.

Berries covered with long bristles

Berries smooth or with few bristles.

Spines below the leaf clusters, slender and generally single, sometimes wanting.

Stamens not longer than the lobes of the calyx $R$. oxyacanthoides

Stamens longer than the lobes of the calyx $R$. rotundifolium Spines at leaf axils stout, usually 3 together, branches not bristly

Flowers in long siender pendulous clusters.

Spines below leaf clusters, and bristles dispersed along stem $R$. lacustre Spines absent.

Branches prostrate or spreading . . . . R. prostratum Branches erect. 
1. R. Cynosbati, L. (Fig. 2, pl. 61.) WILD Gooserfrrr. Shrub; branclues with prickles at base of leaf clusters; leaves about 5-lobed; flowers 1 to 3 at the leaf axils, succeeded by rather large ovate berries with many rather long bristle-like prickles. Rocky woods, throughout our area. April-June.

2. R. oxyacanthoides, L. (Fig. 3, pl. 61.) Hawthorn Gooseberry. Nortiner Gooseberrx. Prickles at báse of leaf groups, solitary or none; bristles on stem dispersed or absent. Leaves deeply 5-lobed. Stamens not longer than sepals. Berry smooth, reddish-purple or red. Throughout all but the most southern part of our area.

3. R. rotundifolium, Michx. Eastern WILd Gooseberry. Similar to No. 2, but stamens are distinctly longer than the long segments of the calyx. Berry smooth. Rocky woods, in eastern border of our region. May-July.

4. R. Grossularia, L. Garden Goosenerry. (R. Uva-crispa, L.). Three stout spines at base of leaf cluster. Leaves 3-lobed. Berry large, smooth or with a few weak bristles. Escaped from gardens, along roadsides.

5. R. lacustre, (Pers.) Poir. (Fig. 7, pl. 61.) Swamp Gooseberry. Stem covered with prickles. Spines below leaf clusters several, generally 2 below each leaf cluster. Leaves deeply incised, the lobes angular, toothed. Flowers 10 to 20, arranged in a pendulous cluster along a main flower stalk, green. Fruit covered with long prickles. Disagreeable to taste. In swampy places. May-June.

6. R. prostratum, L'Her. (Fig. 4, pl. 61.) Fetid Cunrant. Branches prostrate or widely spreading. Stems without spines or prickles. Leaf stems long and slender. Leaves 3- to 5-lobed. Flowers 10 to 20, small, green. Fruit red, about the size of the garden currant and resembling it, but covered with bristles. Taste disagreeable. On moun. tains and in wet places. May-June.

7. R. floridum, L'Her. (Fig. 6, pl. 61.) Wild Black Currant. Branches erect, without prickles or spines; leaves 3- to 5-lobed, somewhat dotted below. Flowers numerous, in pendulous clusters, the calyx eylin. drie, bracts exceeding the length of the flower pedicels. Fruit black, smooth, insipid. In woods, rather common. April-May.

8. R. vulgare, Lam. (Fig. 5, pl. 61.) Red Currant. The garden currant, sometimes growing wild. Fruit red, pleasantly acid.

\section{Family V.-hamamelidaceae. Witcri Hazel Family}

In our region, a small tree or shrub, with alternate broad leaves and with clusters of yellow flowers on the newer branches in the late summer or autumn. Calyx small, greenish, of 4 sepals rolled backward, corolla of $t$ elongated strap-shaped yellow petals. Stamens 4 or more. Fruit a 2-celled woody capsule.

I. HAMAMELIS, L.

Tall shrubs or small trees. The genus is sufficiently described under our only species, below. 


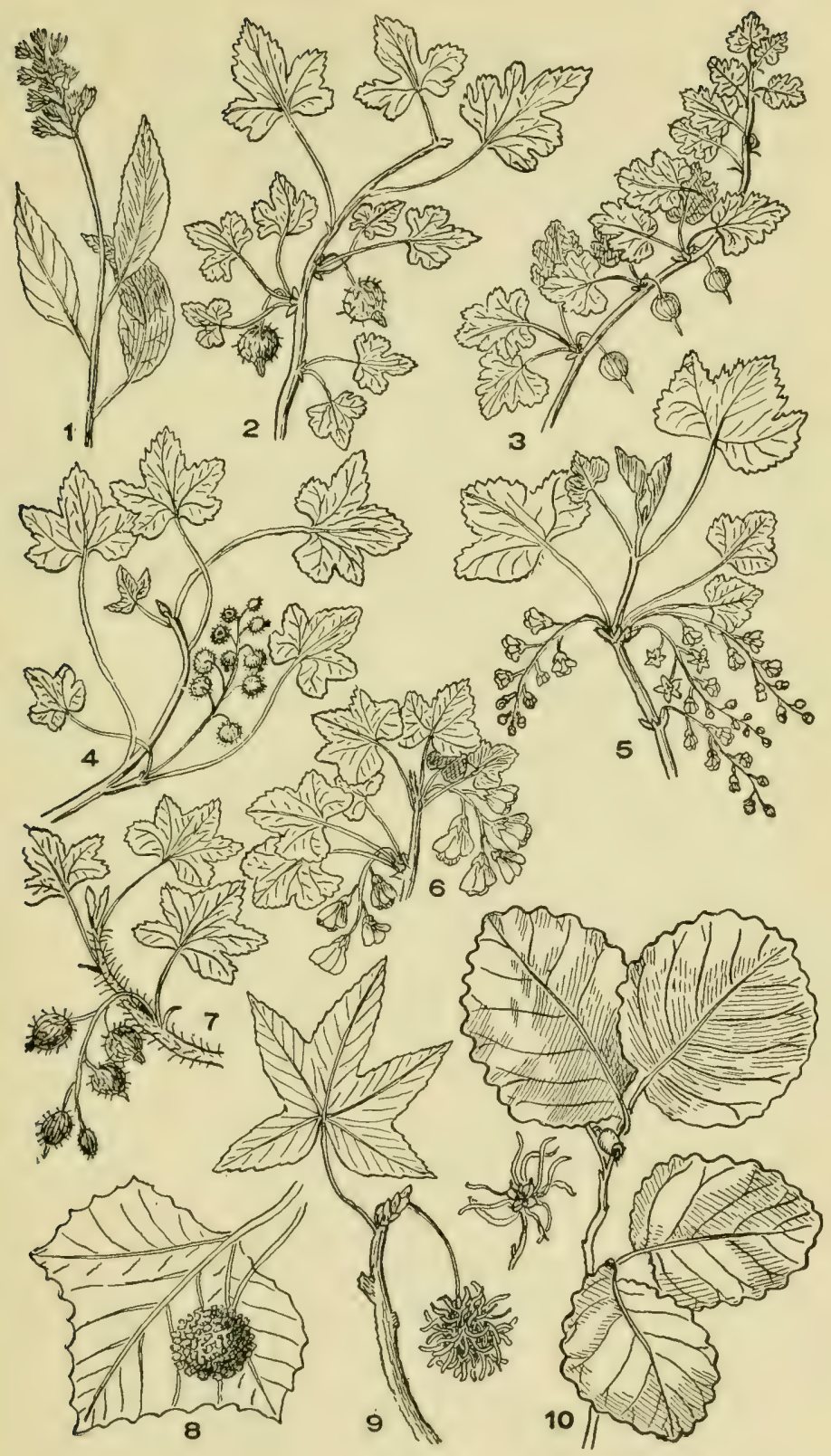

Plate 61

1. Itea virginica. 2. Ribes Cynosbati. 3. R. oxyacanthoides. 4. R. prostratum. 5. R. vulgare. 6 R. floridum. 7. R. lacustre. 8. Platanus occidentalis. 9. Liquidambar Styraciflua. 10. Ilamamelis virginiana. 
H. virginiana, L. (Fig. 10, pl. fil.) Witcil Hazel. Shrub or small tree. Leaves on short leaf-stalks, broadly oval, somewhat heart-shaped and unequal at base, covered, at least when young, with soft hairs; borders with rounded teeth. Flowers in clusters of several, making tufts of yellow, the long narrow petals appearing like threads of yellow in the tuft. They appear, as the leaves fall or earlier, at the axis of the coming leaves. An interesting shrub in damp woods. Blooms Aug.-Dec.

\section{LIQUIDAMBAR, L.}

In our region, a tree with broad 5-fingered or 5-lobed leaves. Stamens and pistils in different flowers which are in different groups on the same tree. Stamens in staminate flowers numerous, calyx and corolla absent. Pistillate flowers have a small calyx the sepals of which are confluent. Petals none.

L. Styraciflua, L. (Fig. 9. pl. 61.) Sweet Gum. Alligator Tree. A forest tree $60 \mathrm{ft}$. or more high. Trunk covered by deeply furrowed bark. Leaves broader than long, divided into 5 deep, sharp pointed, lobes. Fruit in a compact pendulous ball consisting of numerous capsules each with 1 or 2 seeds. Connecticut, southern New York and southward.

\section{Fanily VI.-Platanaceae. Plane Tree Family}

Large tree with broad, lobed leaves and sheathing stipules, bark falling in large scales. Stamens and pistils in difterent groups of flowers on same tree; clusters of fertile flowers forming at length a globose mass of capsules with many bristly projecting points. Sterile flowers also in spherical masses which hang from a thin pendulous stem, the globular masses forming at intervals. The individual flowers have an insignificant calyx and corolla and few stamens. Fruit a nutlet.

\section{PLATANUS, L.}

\section{Characters of the family.}

P. occidentalis, L. (Fig. 8, pl. 61.) Button Woon. Srcamore. Our largest tree, 80 to $130 \mathrm{ft}$. high. Bark falling in thin plates, exposing the grayish-white new bark beneath. Leaves orbicular, angularly lobed, points of lobes sharp. Heads of flowers hanging on long peduncles. Wet woods and along streams. May.

\section{Family VIt.-ROSACEAE. Rose Family}

$\Lambda$ large family consisting of herbs, shrubs and trees. In all our species the leares, which are simple or compound, are alternate and the flowers are all regular and contain both stamens and pistils. In most species the leaves are subtended by stipules, often quite conspicuous. ('alyx of 5 sepals either free or attached to the ovary. Petals 5, or, in a few cases, none. Stamens usually 
numerous (more than 10). Seed carpels one to many, distinct, ripening into one-seeded or several-seeded hard dry fruit.

Stamens numerous.

\section{Shrubs}

Ovaries naked, $i$. e., not completely surrounded by the calyx.

Leaves simple, not deeply lobed . . . . Spiraea

Leaves deeply 3-lobed (rarely 5-lobed). Flowers in dense spherical cluster . . . . Physocarpus

Leaves mostly trifoliate, rarely 5 -foliate; flowers in loose clusters or solitary . . . . . . Rubus

Ovaries enclosed in tube of calyx but free from it.

Leaves pinnate $(i . e$., leaflets arranged in pairs along the central leaf stem except the terminal leaflet) Rosa Stamens only 5 .

Sibbaldia

\section{Herbs}

Flowers green in rather dense heads . . . . Alchemilla Flowers not green, not in dense heads or spikes.

Leaves not basal, nearly orbicular, not lobed, except at base

Leaves all at base.

Flowers yellow

Bracts of calyx shorter than sepals. Waldsteinia

Bracts of calyx longer than the sepals . Duchesnea

Flowers white, plant sending out runners . Fragaria

Leaves along the stem as well as at base.

Flowers arranged in a long slender spike Agrimonia

Flowers in loose clusters or solitary.

Petals nearly as broad as long.

Fruit in a spongy receptacle . . Comarum Fruit dry.

Carpels with tail-like appendages

Petals not more than 5. . Geum

Petals more than 5 . . . . Dryas

Carpels without tail-like appendages

Potentilla

Carpels 2-ovuled; leaves pinnate

Filipendula 
Flowers white in dense elongated heads or spikes; flowers without petals . . . . Sanguisorba

Flowers without petals, in slender spikes forming a compound cluster . . . . . . Aruncus

\section{PHYSOCARPUS, Maxim.}

Branching shrubs with alternate, broad, deeply lobed leaves. Flowers in dense terminal rounded clusters, white. Calyx bell-shaped, with 5 sepals; petals 5, inserted in the throat of the calyx. Fruit 1 to 5 dry, several seeded carpels inflated.

P. opulifolius, Maxim. (Fig. 2, pl. 62.) Ninebark. (Opulaster opulifolius, (L.) Kuntze. Spiraca opulifolia, L.). A rare and beautiful shrub, 3 to $10 \mathrm{ft}$. high. Leaves 1 to $2 \mathrm{in.} \mathrm{long,} \mathrm{roundish} \mathrm{with} 3$ lobes and notehed borders. Bark loose, falling in strips. Stipules falling early. Clusters of white flowers nearly spherical. River banks and rocky hills of our region. June.

\section{SPIRAEA, L.}

Shrubs with alternate simple leaves without lobes. Sepals 5; petals 5 ; stamens 10 to 50 . Fruit dry, several seeded earpels, 3 to 12 . Flowers in terminal elusters, white or rose color, not yellow.

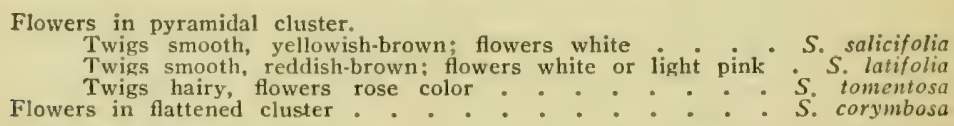

1. S. salicifolia, L. (Fig. 1, pl. 62.) Wrllow-Leaved Mfadow SweEr. Erect shrub with smooth yellowish-brown twigs and elliptic, eggshaped or lance-shaped leaves on short leaf-stalks. Borders of leaves sharply toothed. Flowers in a pyramidal group, individual flowers $1 / 6$ to $1 / 4$ in. broad, white or pinkish-white. In moist grounds and on hillsides in southern section of our range. June-Aug.

2. S. latifolia, Borkh. MeAdow SweET. Similar to No. 1, but twigs are redlish or reddish-brown. Color of flowers as in No. 1. Common in pastures, etc. June-Aug.

3. S. tomentosa. T. (Fig. 3, pl. 62.) Harnuack. Steeple Busir. Erect, slender shrub, generally with few or no branches. Stem covered with soft hairs. Flowers in a tall conical eluster, purple or pink. In old fields and pastures in our area. July-Sept.

4. S. corymbosa, Raf. Commued Sprraea. Juaves broally oval or egg-shaped. Flowers in a spreading flattened cluster (corymb), white. Rocky places, New Jersey and south. May-June.

\section{GILLENIA, Monch. (Porteranthus, Britton)}

Erect herbs from a perennial root. Leaves 3 -foliate with enspicous stipules. Filowers white or pink with 5 long narrow petals inserted into the throat of the calyx. Calyx tubular, of 5 sepals. Stamens 10 


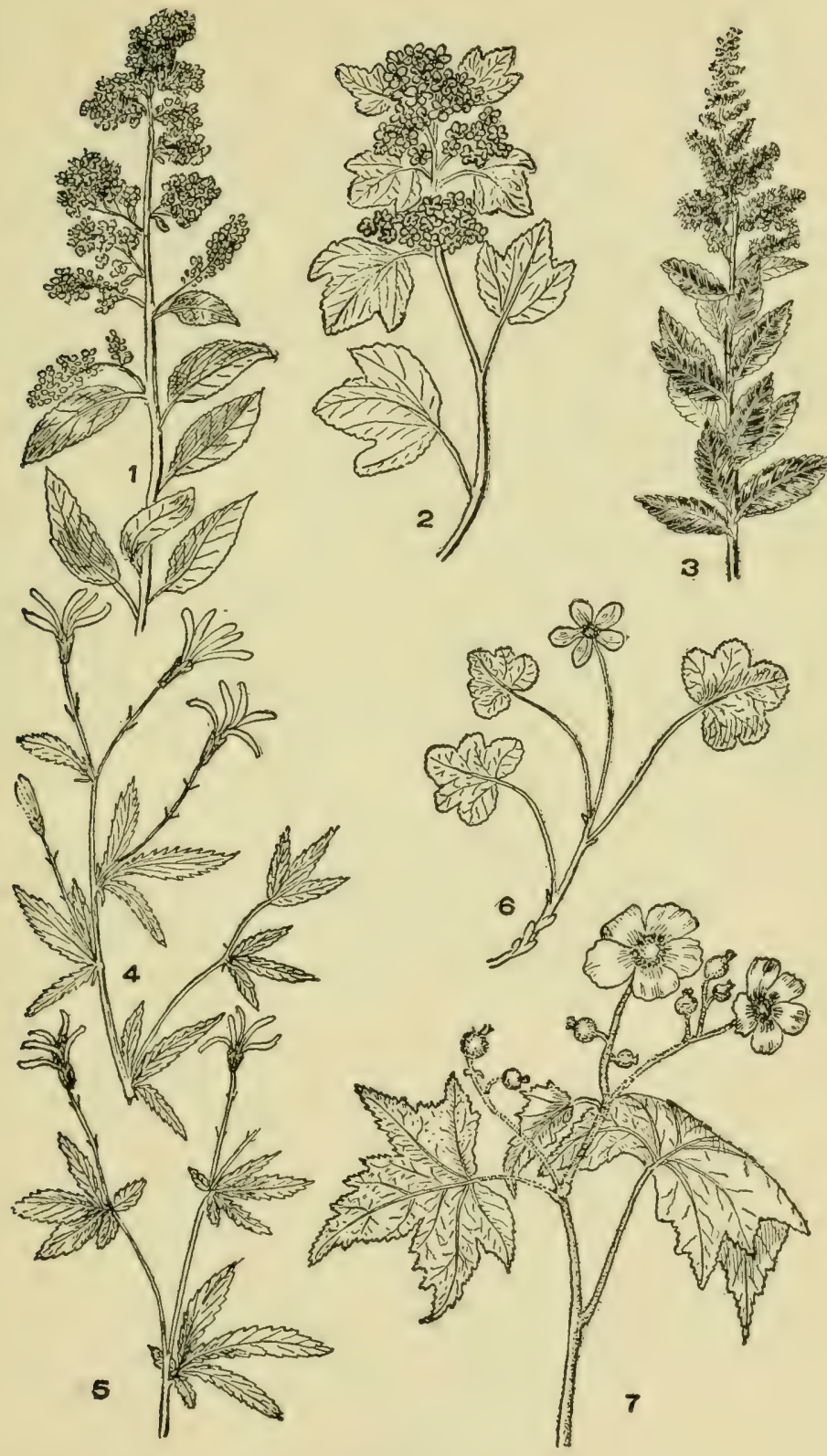

Plate 62

1. Spiraea salicifolia. 2. Physocarpus opulifolius. 3. Spiraea tomentosa. 4. Gillenia trifoliata. 5. G. stipulata. 6. Rubus Chamaemorus. 7. R. odoratus. 
to 20, quite short. Seed carpels 5, united at base, each carpel with 2 to 4 seeds.

Stipules linear, not leaf-like . . . . . . . . . G. trifoliata

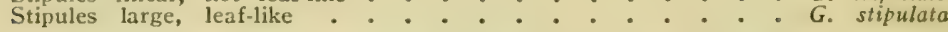

1. G. trifoliata, (L.) Moench. (Fig. 4, pl. 62.) Indian Physic. Bowman's Root. Plint 2 to $4 \mathrm{ft}$. high. Leaves 3 -foliate; at the base; where the leaflets unite at the stem, are 2 narrow lance-shaped stipules without teeth. Flowers in loose terminal clusters, the ovary small, the petals long, slender, spreading, white or pink. Pods reddish. Woodlands, southern part of our region. May-June.

2. G. stipulata, (Muhl.) Trel. (Fig. 5, pl. 62.) American Ipecac. Resembles the last species, but at the base of the 3 leaflets, which have a short leaf-stalk, is a pair of broad leaf-like stipules, giving the leaf the appearance of having 5 leaflets. The stipules are toothed like the leaflets. Flowers similar to No. 1, rose color. In the western part of our region. June-July.

\section{ARUNCUS, Adams}

Herbs with flowers of two kinds, the staminate and pistillate on different plants, perennial. Flowers in long slender elusters (spikes) white, the spikes forming a pyramidal compound eluster. Leaves compound, doubly feather-formed. Stamens numerous; petals as many as the calyx lobes, mostly 5; pistils usually 3 . Seed casket (follicle), usually 2 -seeded.

A. sylvester, Kosteletzky. Goat's-BEARD. Stem erect, branched, 3 to $7 \mathrm{ft}$. high. Leaves doubly compound of 3 to many leaflets. Leaflets eggshaped, toothed, with or without leaf-stalks. Rich woods, mountains of Penna., and south. May-July.

\section{RUBUS, L.}

Perennial shrubs, rarely herbs or trailing vines often armed with prickles. Leaves mostly compound, usually of 3 or 5 leaflets, rarely of more. Calyx 5-parted; corolla of 5 petals; stamens and pistils, each numerous. Fruit a berry with many seeds, or an aggregation of small drupes.

Leaves not consisting of several leaflets.

Flowers purple

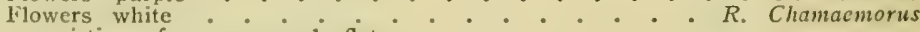
Leaves consisting of 3 or more leaflets.

Fruit concave beneath and when ripe falling away from the dry receptacle.

\section{Raspbcrrics}

Stem armed with prickles.

Firuit dark purple . . . . . . . R. occidcutalis

liruit light red........ $R_{\text {. }}$ strigosus

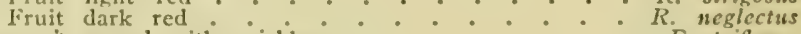

Stem not armed with prickles......... R. triflorus

Fruit not separating from the juicy receptacle.

\section{Blackberrics}

Stems stout, erect or curved.

Stems 2 to $12 \mathrm{ft}$. high.

Lower surface of leaves covered with white down $R$. cuncifolius Lower surface of leaves not white-downy.
Leaflets mostly in 3 's
Leaflets mostly in 5 's.
liruit cylindric
$R$ alleglanicusis

Stems prostrate, mostly trailing. 
Leaves generally of 5 leaflets, plant not trailing.

Hairs tipped with glands . . . . . R. setosus

IIairs not glandular . . . . . . . R. nigricans

Leaves generally of 3 leaflets. Stems trailing.

Stem bristly, scarcely prickly . . . . . . . R. hispidus

Stem prickly.

Leaflets somewhat downy beneath. Rounded or heart-shaped at

base . . . . . Baileyanus

Leaflets smooth, both sides, not rounded or heart-shaped at base

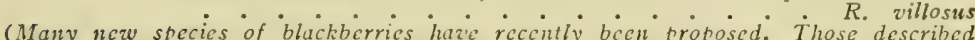
beloze are established and recognized forms. Many of the others may be varieties or hybrids.)

\section{Raspberries}

1. R. odoratus, L. (Fig. 7, pl, 62.) PUrple-flowering Raspberry. An erect shrub, 3 to $5 \mathrm{ft}$. high, with broad 3 - to 5-lobed leaves with small stipules or none, and covered, especially along the veins of the lower side, with hairs. At base the leaf is heart-shaped, often nearly or quite a foot wide. Flowers in loose terminal clusters, each flower 1 to 2 in. broad, purple, showy; calyx with a long slender appendage. Fruit red when ripe, broad, thin and dish-shaped, sometimes called thimble berry because the fruit fits over the end of the finger. Along the borders of woods and in hedges. June-Aug.

2. R. Chamaemorus, L. (Fig. 6, pl. 62.) Mountain Rasprerry. Cloudberry. Herbaceous, 3 to $10 \mathrm{in}$. high. Leaves rounded, 3 - to 5-lobed; borders finely toothed, 1 to 3 in. broad. Flower solitary, white, from $\frac{1}{2}$ to 1 in. broad. Peat bogs and swamps. New England. June-July.

3. R. strigosus, Michx. (Fig. 1, pl. 63.) Wild Red Raspberry. Shrub, 3 to $6 \mathrm{ft}$. high. Stem covered with stiff bristles, older stems armed with prickles. Leaflets 3 (rarely 5), rounded or heart-shaped at base, pointed at apex; borders doubly notehed. Under side of leaflets whitish with fine hairs. Flowers in loose clusters, white. Fruit red. In cultivation varieties with yellow or with white fruit occur. Along fences, and in dry pastures. May-June.

4. R. neglectus, Peck. Purple Wild RAspberry. Stem recurved and rooting at the tip, smooth, but stems sparingly bristly and prickly. Leaflets egg-shaped, sharply toothed. Inflorescence a flattened cluster, rather compact. Flowers nearly $\frac{1}{2}$ in. broad; petals white. Fruit nearly hemispheric, dark red or purple. Dry rocky soil, New England to Penna. June-July.

5. R. occidentalis, L. (Fig. 3, pl, 63.) Black Raspberry. Thim. BLEBERRY. Stems from 5 to $12 \mathrm{ft}$. high, not much branched, recurved and armed with strong hooked prickles. Leaflets 3 , ovate, pointed, covered, as are also the newer stems, with a whitish down. Flowers white, petals shorter than the sepals. Fruit purple-black. Common in pastures.

6. R. triflorus, Richards. (Fig. 5, pl. 63.) DWARF Raspberry. Stems 6 to 12 in. high, generally trailing, without prickles or bristles. Leaflets 3 , broadly and somewhat angularly egg-shaped with double serrations. Flowers few, white, petals recurved. Fruit red-purple, of a few grains. Swamps, most of our region. May-July.

\section{Blackberries}

7. R. frondosus, Bigel. (Fig. 7, pl. 63.) Hign Blackeerry.

$(R$. 
villosus, Gray.) Stems 3 to $10 \mathrm{ft}$. high, erect or recurved, armed with strong curved prickles. Young branches and lower surface of leaves covered with short hairs. Leaflets 3, rarely 5. Stipules at base of common leaf-stem linear; borders of leaves coarsely serrate. Flowers white in terminal conic or pyramidal clusters. Fruit black, sweet and pulpy. Dry soil, New England and southward. May-June.

S. R. alleghaniensis, Porter. (Fig. 8, pl. 63.) Mountain BuackBERRY. Similar to last, but stems more slender and leaflets, often 5, generally narrower, while the fruit is quite narrow, eylindric, less pulpy and of diflerent flavor from the preceding species. Dry soil northeru New York to Penna., and southward. Aug.-Sept.

9. R. canadensis, I. Millspaugh's Blackberry. (R. Millspaughii, Britton.) Stem with few or no prickles. Berry shorter than either of last two species. Adirondack and White Mountains.

10. R. cuneifolius, Pursh. (Fig. 4, pl. 63.) Sand Blackberry. Stems much branched, 1 to $3 \mathrm{ft}$. high, upright with strong straight or recurved prickles. Young branches and under side of leaves whitish downy. Leaflets generally 3, sometimes 5, deeply serrate at borders; rounded at apex, the terminal one broadly wedge-shaped. Fruit black. Sandy woods, in southern part of our area.

11. R. hispidus, L. (Fig. 2, pl. 63.) Running Swamp Blackenrry. Stems trailing, slender with many weak bristles. Branchlets ascending. Leaflets 3, broad at apex, pointed at base. Fruit of a few grains, black. In moist shaded places. June-July.

12. R. setosus, Bigel. (Fig. 9, pl. 63.) Bristly BLAcrвerry. Similar to last, but stems stouter and less trailing. Older branchlets covered with stout reflexed bristles which are tippod with glands. Leaflets generally in 5s, narrower and longer than those of No. 10. Fruit small, sour. Northern New York and eastern Penna. July-Aug.

13. R. nigricans, Rylb. Peck's DewberRx. Stouter than Nos. 10 and 11, and more upright. Stems armed with fine priekles, which are not tipred with glands. Leaves, the lower, at least, in 5s; both surfaces smooth; leaflets on short stalks.

14. R. Baileyanus, Britton. Bamex's Blacknenisy. Stems generally trailing. 3 fo $6 \mathrm{ft}$. long, armed with many prickers. Leaflets generally 3, hroally oval, downy; margins coarsely serrate. Flowers rather large, white; fruit, small. Woods and shady places, Maine to southern New York and southward. May-June.

15. R. villosus, Ait. (Fig. 6, pl. 63.) Low Blackberry. Dewm.sex. (R. procumbens, Mulil.). Stems trailing, 3 to $12 \mathrm{ft}$ long, the ascending branches 4 to $12 \mathrm{in}$. high. Trailing stem and erect branches armed with prickers. Flowers white, rather large. l'ruit black, juicy and of fine llavor. 'Throughout our area.

\section{DALIBARDA, L.}

$\triangle$ low herb of the general appearance of a violet. Stem and leaves downy. Laves nearly orbicular with heart-ihaped bases. Flower solifary, white, with calyx of 5 or 6 parts, generally 3 longer than the others. l'etals 5; stamens numerous. 


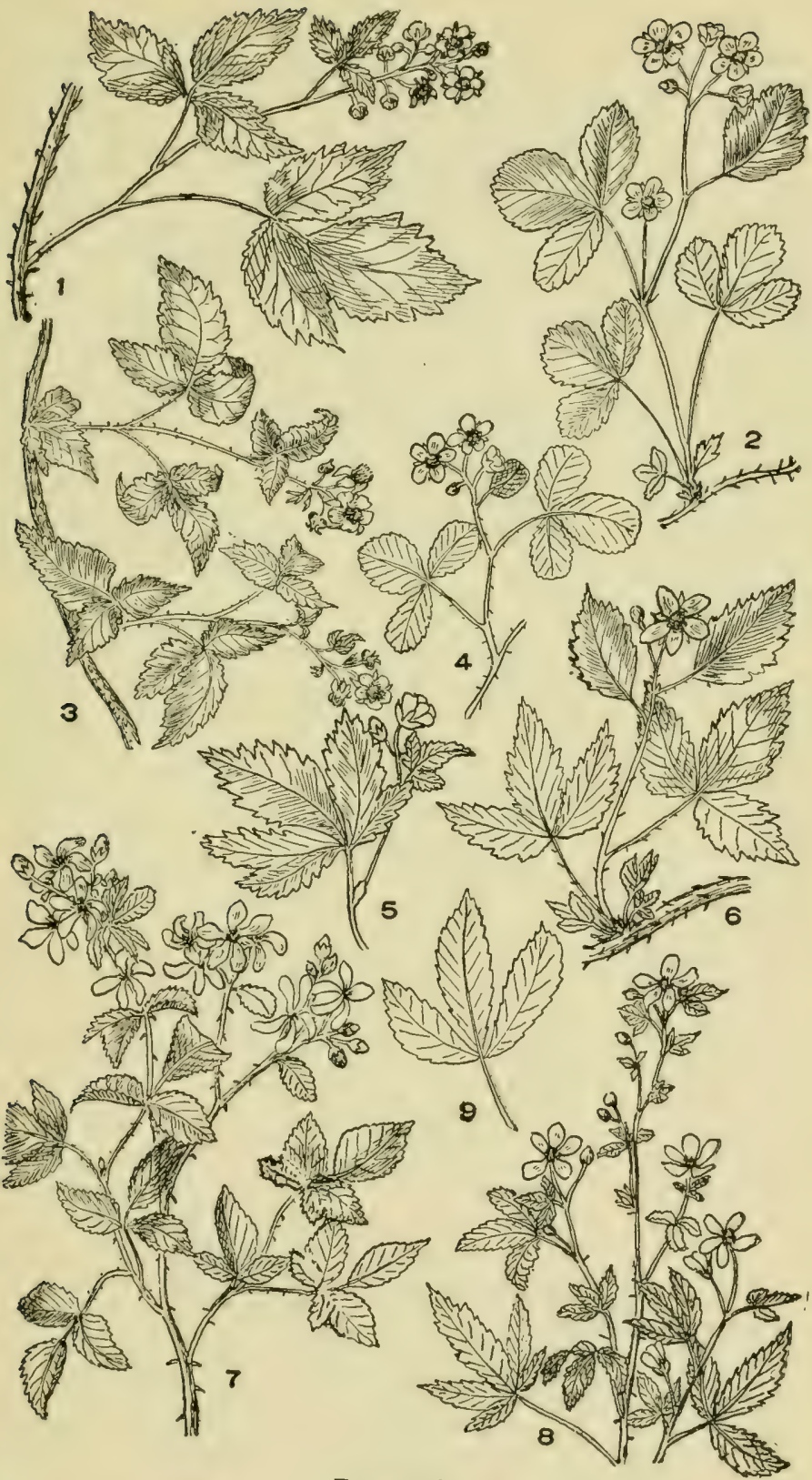

Plate 63

1. Rubus strigosus. 2. R. hispidus. 3. R. occidentalis. 4. R. cuneifolins. 5. R. trillorus, 6. R. villosus. 7 . R. frondosus. 8. R. alleghaniensis. 9. R. setosus. 
D. repens, L. (Fig. 1, pl, 64.) Dalibarda. Stems creeping, sending up tufts of leaves and naked scapes each terminated by a single spreading llower. Borders of leaves serrated. At base of leaf-stalks are found narrow stipules. Found in moist woods; most of our area.

\section{FRAGARIA, L.}

Herbs, with leaves and flower stalks springing from the root, propagating largely by runners. Leaves of 3 leaflets, coarsely serrated, hairy, as are the leaf stems. At base of leaf stems are narrow linear stipules. Flowers white in loose terminal clusters. Stamens numerous. Fruit a pulpy berry on a conical receptacle, red when ripe.

1. F. virginiana, Duchesne. (Fig. 3, pl. 64.) Strawberry. Leaves in tufts; leaf stems hairy, 2 to $6 \mathrm{in.} \mathrm{high.} \mathrm{Fruit} \mathrm{a} \mathrm{juicy} \mathrm{pulp} \mathrm{in} \mathrm{which}$ is imbedded many yellowish achenes or seeds. Form of fruit broad oval or round. In all of our range.

2. F. canadensis, Michx. (Fig. 4, pl. 64.) Nortirerx Striwberry. Plant more slender, less hairy than No. 1, fruit narrow cylindric, and less juicy. Leaflets generally on leaf-stalks.

3. F. Terrae-novae, Rydb. Newfounduaxd Strawberry. Leaflets almost or entirely without leaf-stalks. Otherwise nearly like No. 2.

\section{DUCHESNEA, J. E. Smith}

An herb with general appearance of the strawberries, but with ycllow flowers and with red fruit much resembling the strawberry, but not pulpy.

D. indica, (Andr.) Focke. (Fig. 2, pl. 64.) Yellow or Invian STrAwBerry. Introduced from India and found occasionally in waste places. Southern part of our area.

\section{POTENTILLA, L.}

Herbs, rarely shrubs, generally with perennial roots, rarely annual. Leaves, which are furnished with stipules, are compound of three or more leaflets. Flowers white, yellow or purple, with hoth pistils and stamens, the latter generally numerous, rarely 5 or 10. Calyx double, that is, with 5 sepals and with 4 or 5 bracts below. Corolla of 5 , rarely of 4 petals. The seed carpels grouped upon a dry receptacle.

Shrubs . . . . . . . . . . . . . . P. fruticosa Herbs (a few with woody stems at base).

Flowers white.

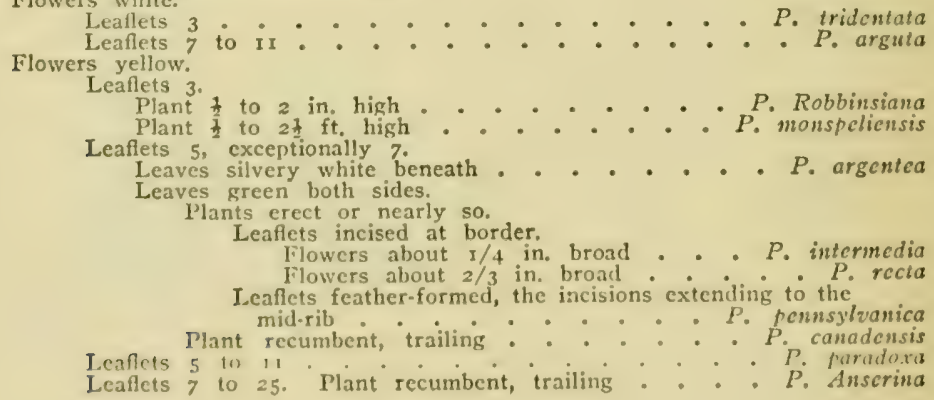



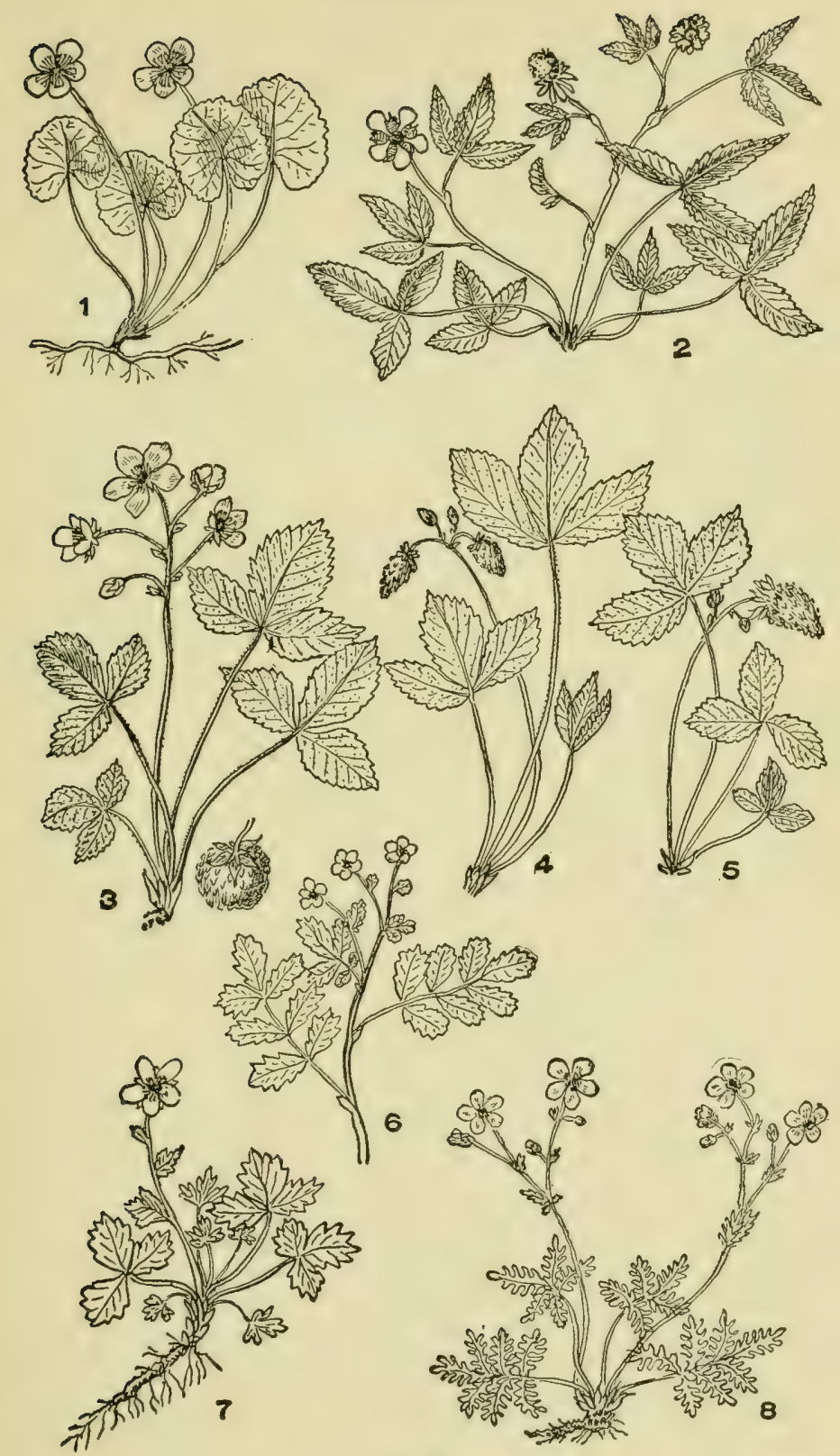

Plate 64

1. Dalibarda repens. 2. Duchesnea indica. 3. Fragaria virginiana. 4. F. canadensis. 5. F. americana. 6. Potentilla paradoxa. 7. P. Robbinsiana. S. P. pennsylvanica. 
1. P. arguta, Pursh. (Fig. 7, pl. 66.) Tal, CrNqueforl. Stems stout, ereet, 1 to $4 \mathrm{ft}$. high, liairy. Leaves compound, of 7 to 11 learlets, borders coarsely serrate, broad oval or rhomboid; stipules membraneous. Flowers in a rather close cluster, creamy-white, about $\frac{1}{2}$ in. diameter. Dry places. Maine to southern New Jersey. June-July.

2. P. argentea, L. (Fig. 4, pl, 65.) Silvery Cinquefoll. Small, tufted, stem branching, 4 to 12 in. long, half prostrate, silvery-white, as is also the under surface of the leaves. Leaflets 5, each deeply cut into alwut 5 narrow segments. Flowers in loose terminal clusters, yellow, $\frac{1}{2}$ to $2 / 3 \mathrm{in}$. diameter. In dry pastures, etc., in our area. May-Sept.

3. P. intermedia, L. (Fig. 3, pl. 66.) Downy Cinqueforl. Stems leafy, much branched, 1 to $2 \frac{1}{2} \mathrm{ft}$. long, partly prostrate, hairy. Leaves of 3 to 5 leallets, which are oblong or pear-shaped, with coarsely serrate borders. Flowers numerous, in loose terminal clusters. Mass., New York and New Jersey.

4. P. recta, L. (Fig. 2, pl. 6f.) Rough-fruited Cinquefoll. Erect, hairy, stems 1 to $2 \mathrm{ft}$. high, branching mostly in $2 \mathrm{~s}$ at the top. Leallets narrow oblong or lance-shaped, 5, less often 7 , spreading from a common center, borders coarsely serrate; stipules rather conspicuous, the lower ones leaf-like. Flowers in loose terminal cluster, each $1 / 3$ to $\frac{1}{2}$ in. broad. In waste places, New York and southward. June-Sept.

5. P. Robbinsiana, Oakes. (Fig. 7, pl. 64.) Robrin's Cinqueforl. (I'. frigida, Ciray.) Dwarf, $\frac{1}{2}$ to 2 in. high, growing in dense tufts; plant silky. Leaves of 3 egg-shaped leaflets, coarsely toothed. Flowers small, generally solitary, the sepals and adjoining bracts equal. White ilountains, N. H.

6. P. monspeliensis, L. (Fig. 1, pl. 66.) Rougri Cinqueforl. ( $P$. norvegica, L.). Stems $\frac{1}{2}$ to $2 \mathrm{ft}$. high, rough-hairy. Leaflets 3 ; stipules leaf-like. lilowers in close leafy terminal clusters. Calyx as large as, sometimes larger, than the corolla. Petals falling quickly. Common in dry soil. June-Sept.

7. P. paradoxa, Nutt. (Fig. 6, pl. 64.) Busmx Crxquerorl. Plant hushy, 1 to :3 ft. ligh, decumbent or ereet, soft downy. Leaves pinnately compound with 6 to 11 leallets, except the very upper ones which are trifoliate; stipules conspicuous, egru-shaped or oval. Flowers seattered, terminal to the branches or branchlets, yellow, $\frac{1}{4}$ to $\frac{1}{2} \mathrm{in}$. broad. New York, shores of Great Lakes and southward. June-Sept.

S. P. pennsylvanica, L. (Fig. 8, pl. 64.) Cosst Cinquefort. $P$. lilloralis, liydlurer.) Stems crect or prostrate, $\frac{z}{2}$ to $2 \mathrm{ft}$. high, slightly latiry or smooth. Leaflets 5 , sometimes 7 , feather-form, incised to the midrib. filowers small, about + in. broad, in terminal clusters. Coast of Maine and New Hampshire. June-July.

9. P. fruticosa, L. ( Fig. 3, pl. 65.) Sirubby Cinqueforl. Low, much loranched shrubs growing in tufted groups. Strms $\frac{1}{2}$ to $4 \mathrm{ft}$. high, with shreddy hark. Ieallets 5 (or 7 ), narrow oblone, without serrations at borders, silky, the margins rolling. Flowers yellow, about an inch hroat, terminal. In moist pastures, Maine to New Jersey. June-Sept.

10. P. tridentata, Suland. (Figr. 2, pl. 65.) THmef-tootued CinqLeFoll. Stems 1 to $10 \mathrm{in}$. high, woody at base. Plants growing in 


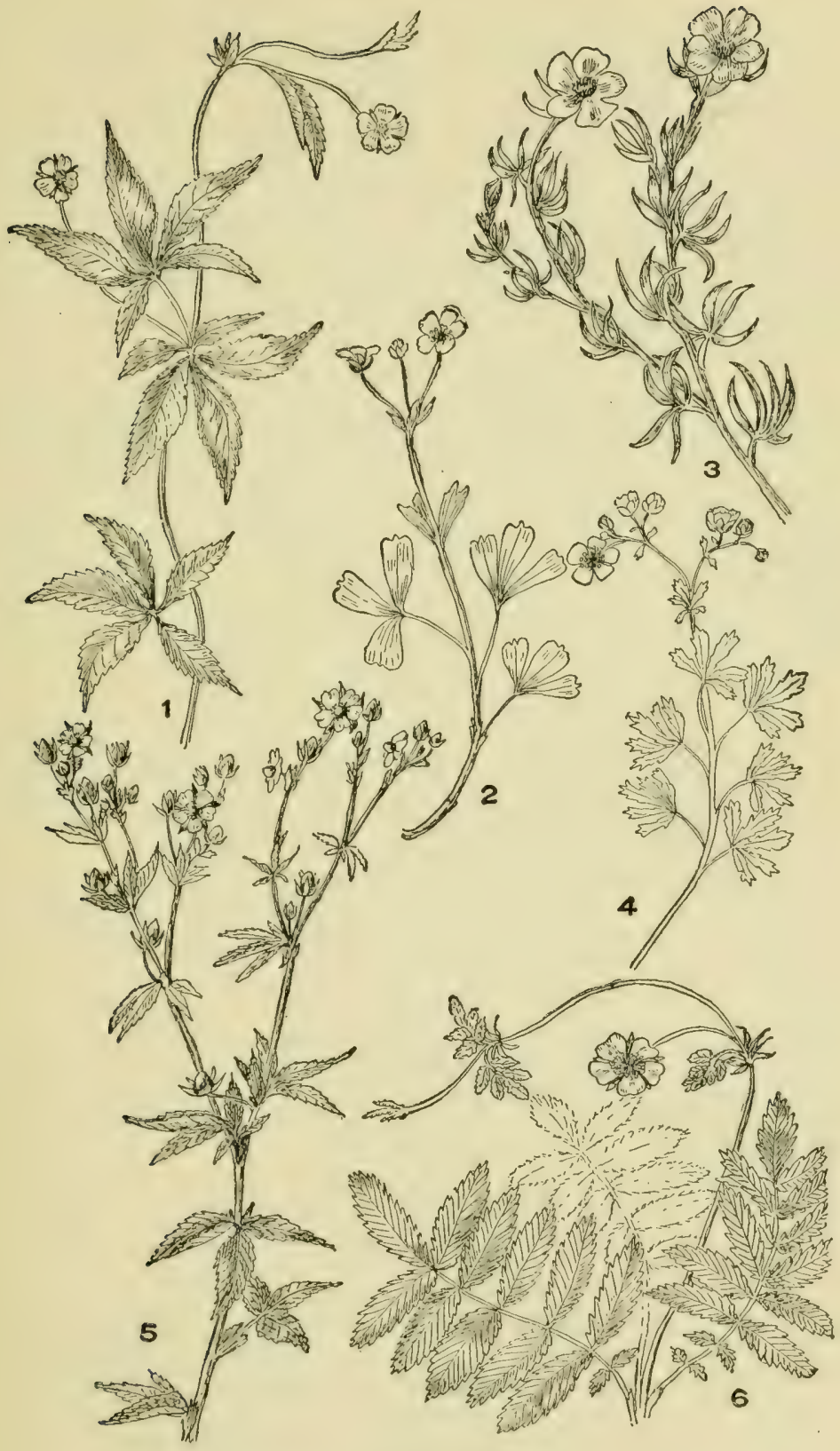

Plate 65

1. Potentilla canadensis. 2. P. tridentata. 3. P. fruticosa. 4. P. argentea. 5. P. monspeliensis. Var. norwegica. 6. P. Anserina. 
tufts. Leaflets 3 , oblong, broad at apex and terminated by 3 conspicuous teeth. Flowers white, about $1 / 3$ in. broad, few, in terminal cluster. Rocky places, especially on high mountains. June-Aug.

11. P. Anserina, L. (Fig. 6, pl, 65.) Silver Weed. Goose Grass. Stem slender, trailing, rooting at nodes. Leaflets many, silky. Flowers yellow, about 1 in. broad, solitary. Moist places, throughout our area. June-Sept.

12. P. canadensis, I. (Fig. 1, pl. 65.) Frve-FInger. CoMmoN Criqueforl. Stems slender, running on ground and spreading by runners which are from a few inches to $2 \mathrm{ft}$. long. Leaflets 5 from a com. mon center, toothed at borders. Common in fields and road-sides. AprilAugust.

\section{COMARUM, L.}

A stout herb, nearly smooth, with purple flowers. General appearance that of a Potentilla ( $P$. palustris of Gray). Stamens and pistils numerous.

C. palustre, L. (Fig. 4, pl. 66.) Purple Cinquefoil. Marsir FiveFinger. (Potcntilla palustris, (L.) Scop.). Prostrate herb with stems $\frac{1}{2}$ to $2 \mathrm{ft}$. long, rooting along the stems. Leaves of 5 , or more frequently 7 leaflets, which are oblong, but broader at apex than at base, sharply toothed at borders, 1 to 3 in. long. Stipules broad, enfolding the leaf stems. Flowers purple inside, about 1 in. broad. In swamps and peat bogs, north to south as far as New Jersey. June-Aug.

\section{SIBBALDIA, L.}

Low, decumbent, shrubby plant found on summit of high mountains. Leaves of 3 leaflets. Flowers with broad ealyx of 5 divisions and with small petals extending only about $\frac{1}{2}$ the length of the ealyx segments. Stamens 5, pistils 5 or 10.

S. procumbens, L. (Fig. 5, pl. 66.) SirbíldiA. Creeping, densely tufted, woody stems. Jeaflets 3, wedge-shaped. Flowers yellow, the calyx much larger than corolla. Summits of White Mountains.

\section{WALDSTEINIA, Willd.}

ITerb with appearance of strawberry. Leaves and flowering stem from the root, 3 leaflets, each broadly wedge-shaped, with lobed and serrated horders. Flowers of 5 yellow petals and 5 sepals, the calyx top-or inverted cone-shajed. Stamens numerous, inserted into the throat of the calyx. Seed cases 2 to 6.

W. fragarioides, (Michx.) Tratt. (Fig. 6, pl. 66.) Bannex StrawmEnx. Plant 4 to $6 \mathrm{in}$. high. The flower scape bearing 3 to 8 yellow flowers Wooded hills, New England and westward. May-June.

\section{GEUM, L.}

Trerbs. Pistils numernus, cach carpel with one ovule; the seed easlet beroming dry fruit when ripe, the styles becoming hairy tails. Calyx of 5 parts with 5 altruating small bracts. Leaves compound, featherformed, $i$. e., of several leaflets arranged along each side of the common leaf stalk, the terminal leaflet being in most instances much larger than 


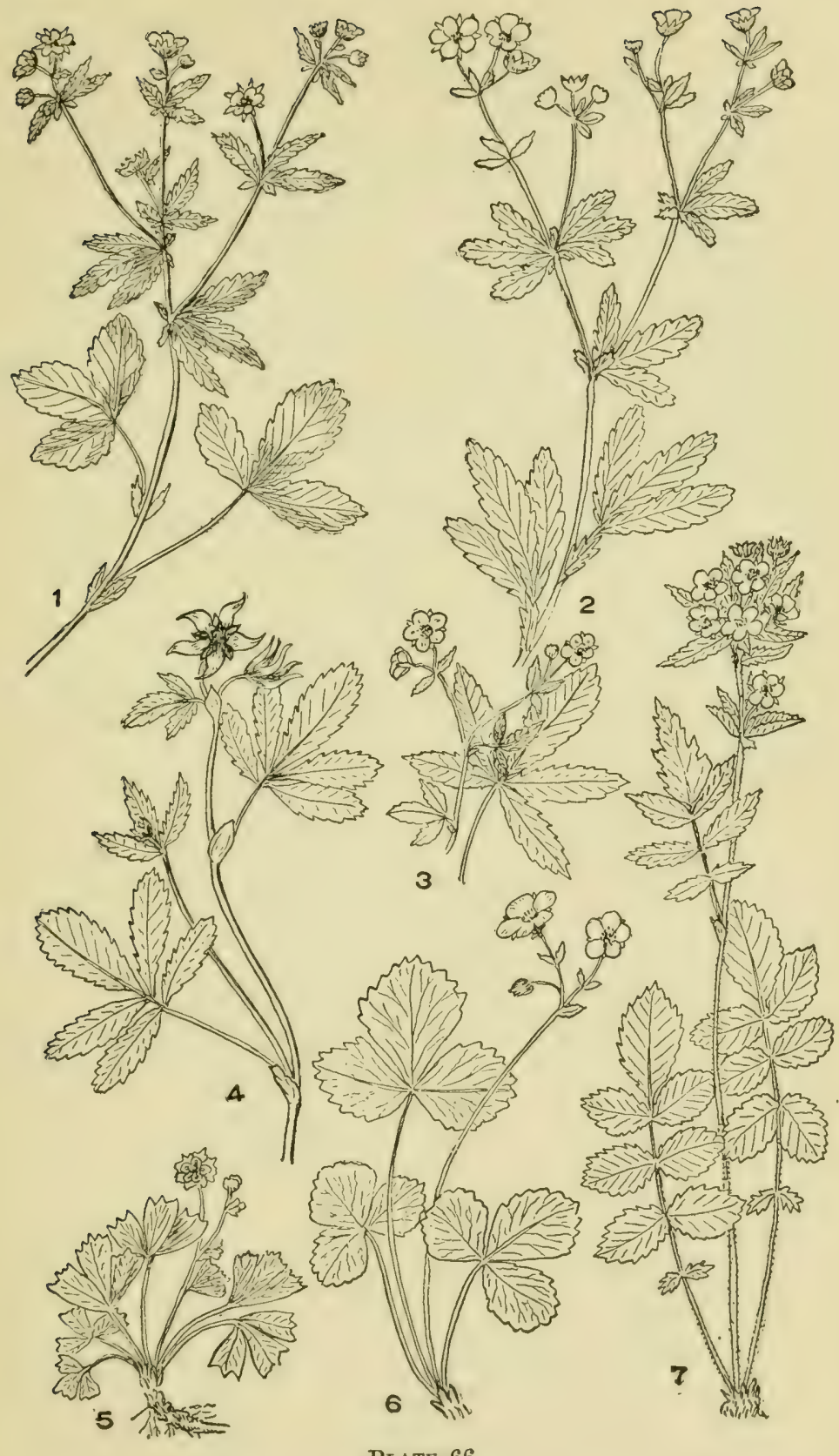

Plate 66

1. Potentilla monspeliensis. 2. P. recta. 3. P. intermedia. 4. Comarum palustre. 5. Sibbaldia procumbens. 6. Waldsteinia fragarioides. 7. Potentilla arguta. 
the lateral ones. Leaves attended by stipules. Stamens many. Petals 5 , rounded, exceeding the divisions of the calyx.

Flowers white.

Plant silky, pubescent

G. canadense

Plant with stiff hairs . . . . . . . . . G. virginianum

Flowers yellow.

Leaflets rarely more than 3 , basal often of an individual leaf . G. vernum

Leaflets 3 to 7 . Terminal one orbicular or kidney-formed $\because \dot{G}$. Peckii Torminal one generally elongated, flowers creamy-yellow : G. flavum

Leaflets numerous, the terminal large, rounded and deeply lobed

Leaflets $\dot{5}$ to $;$ terminal one egg.shaped, about $3 \dot{l o b e d}^{\circ} \mathrm{G}$. macrophyllum Flowers purple.

Flowers nodding.

k. G. rivale, L. (Fig. 1, pl. 68.) Purple Avens. Whater Avens. Plant erect, 1 to $3 \mathrm{ft}$. high, hairy. Basal leaves compound, featherformed with the terminal leaflets much larger than the others. Flowers few, nodding, petals and sepals purple. Seed caskets with plumed tails. Moist grounds, Maine to Pennsylvania. May-July.

2. G. triflorum, Pursh. (Fig. 2, pl. 67.) Long-Plumed Purple Avens. (G. ciliatum, Pursh.). Plant erect, $\frac{1}{2}$ to $1 \frac{1}{2} \mathrm{ft}$. high; basal leaves in tufts much divided, the terminal ones not large. Flowers erect, light purple, plumes of the seed caskets 1 to 2 in. long. Dry soil. Northern New York and New England. May-June.

3. G. Peckii, Pursh. (Fig. 5. pl. 67.) Yfulow Mountarn Avens. (G. radiatum, Michx.). Ereet, to $2 \mathrm{ft}$. high, branching at top, simple below. Basal leaves of several leaflets, the terminal one very large ( 3 to 6 in. broad), nearly round, or kidney-shaped. Flowers yellow. White Mountains and in Maine. July-Aug.

4. G. vernum, (Raf.) T. and G. (Fig. 4, pl. 67.) Spring Avens. Erect, or ascending, $\frac{1}{2}$ to $2 \mathrm{ft}$. high, slender, few leaved. Leaflets 3 to 5 , sometimes the leaf is simple. Leaflets all egr-shaped. Flowers yellow, fow. Calyx reflexed, bracts at base of calyx absent. Fruit head stalked hut not plumed. Shady places. New Jersey and southern New York. April-June.

5. G. canadense, Jacq. (Fig. 1, pl. 67.) White Avens. (G. alzum, (imelin.) Erect, slender, $1 \frac{1}{2}$ to $2 \frac{1}{2} \mathrm{ft}$. high, sparingly covered with soft hairs. Basal leaves of 3 to 5 leaflets or of a simple leaf. Of the compound leaves the terminal leaflet is broadly egg-shaped or pearshaperl. Flowers white, $\frac{3}{4}$ in. broad; calyx lobes reflexed; receptacle bristly. Shaded places. Generally distributed. June-Aug.

6. G. virginianum, T. (Fig. 3, pl. 68.) Rougli Avens. Much stonter than preceding sjecies. Covered with stiff hairs. The reflexed sepals cxceed in length the white petals. Moist grounds, throughout our area. May-July.

7. G. flavum, (Porter.) Bicknoll. (Fig. 6, pl. 67.) Cream Corored Awrs. Eirert, 1 to $3 \mathrm{ft}$. tall. Stem bristly below. Basal leaves sometimes of 3 leaflets, in other cases more. Stem leaves, lower ones often 5-parted, the terminal leaflet often clongated, upper leaflets egre- or lane-shaped. Flowors eream-yellow, petals shorter than the reflexed segrments of the ('alyx. Woods. New York, southward. June-August.

8. G. macrophyllum, Willd. (Fig. 3, pl. 67.) Large-LEAven 


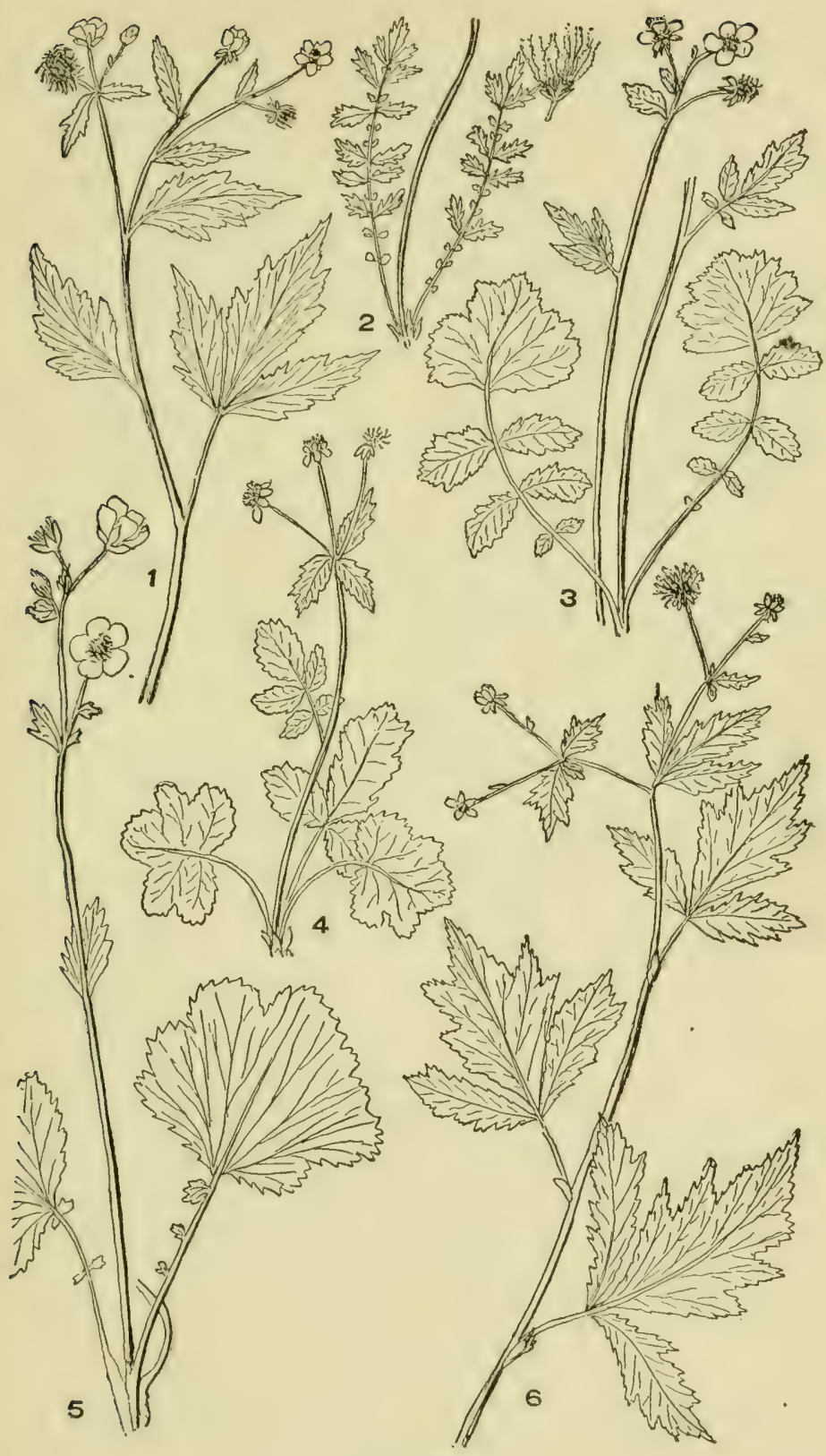

PLATE 67

1. Geum canadense. 2 G. triflorum. 3. G. macrophyllum. 4. G. vernum. 5. G. Peckii. 6. G. flavum. 
Arexs. Erect, 1 to $3 \mathrm{ft}$. high, bristly hairy. Stem simple, branched above. Leaflets of basal leaves numerous, the terminal one very large and heartshaped at base with several lobes at margin. Lateral leaflets quite small. Flowers yellow, petals exceeding the reflexed sepals. Receptacle nearly naked. Low grounds. New England, New York and northward. MayJuly.

9. G. strictum, Ait. (Fig. 2, pl. 68.) Yellow Avens. Erect, 3 to $5 \mathrm{ft}$. high. Somewhat hairy. Leaflets of root leaves 5 to 7 ; terminal one generally of 3 to 5 lohes. Flowers sellow; receptacle covered with soft hairs. Low grounds, Maine to Penna. June-Aug.

I4. DRYAS, L.

Low matted plant, found on the White Mountains by Prof. Peck. Flowers white, rather large, solitary with 8 or 9 petals and many stamens and seed heads, which have plumose tails.

D. integrifolia, Vahl. (Fig. 4, pl. 68.) Entire-leaved Dryas. Summit of White Mountains.

\section{FILIPENDULA, (Tourn.) Hill. (Ulmaria, Hili!)}

Perennial lerbs with compound feather-parted (pinnate) leaves and with flowers in loose inverted pyramidal clusters. Petals 5; calyx 5-lobed; stamens numerous; pistils 5 to 15 ; ovary with 2 ovules.

Leaflets hand-shaped . . . . . . . . . . F. rubra

Leaflets on each side of the leaf stem, not lobed except the terminal one

1. F. rubra, Hill. Queen-of-tire-Prairie. Herb, 2 to $8 \mathrm{ft}$. high, smooth. Leaves sometimes $3 \mathrm{ft}$. long, compound, the leaflets. except the terminal, on each side of the leaf stem, with stipules at the base, the leaflets themselves hand-shaped compound, the borders sharply toothed. Flowers in a loose cluster, pink or purple. Introduced. Escaped from gardens in some parts of our area. June-July.

2. F. Ulmaria, (L.) Barnhart. MEAdow-SwEet. Stem 2 to $4 \mathrm{ft}$. high. Plant resembles No. 1, but, except the terminal leaflet, which is hand-shaped compound, the leaflets are egg-shaped. Flowers yellowishwhite. Also an escape from gardens. June-Aug.

\section{ALCHEMILLA, L.}

Tow herb with rounded and bobed leaves and small greenish flowers in crowded clusters. Stipules conspicunus and leaf-like. Calyx inversely conical of 4 or 5 lobes, petals wanting. Stamens 1 to 4 .

A. vulgaris, L. (Fig. 6, pl. 69.) Lady's Maxtle. Dew-cur. Stems a fow inches long, more or less reclining. Leaves round or kirlney-shaped with 5 or more distinct lobes; stipules toothed. Flowers small, many in the rather crowded cluster. ('alyx usually of 4 lobes. In grassy places, roadsides, cte, mostly in northern part of our area and only occasional. May-Sept.

\section{I7. AGRIMONIA, L.}

Perennial herbs, all of ours 1 to $5 \mathrm{ft}$ high, with compound featherformed leaves, the leaflets arranged on opposite sicles of the leaf-stalk with a terminal leaflet and with several small, apparently partly-developed 


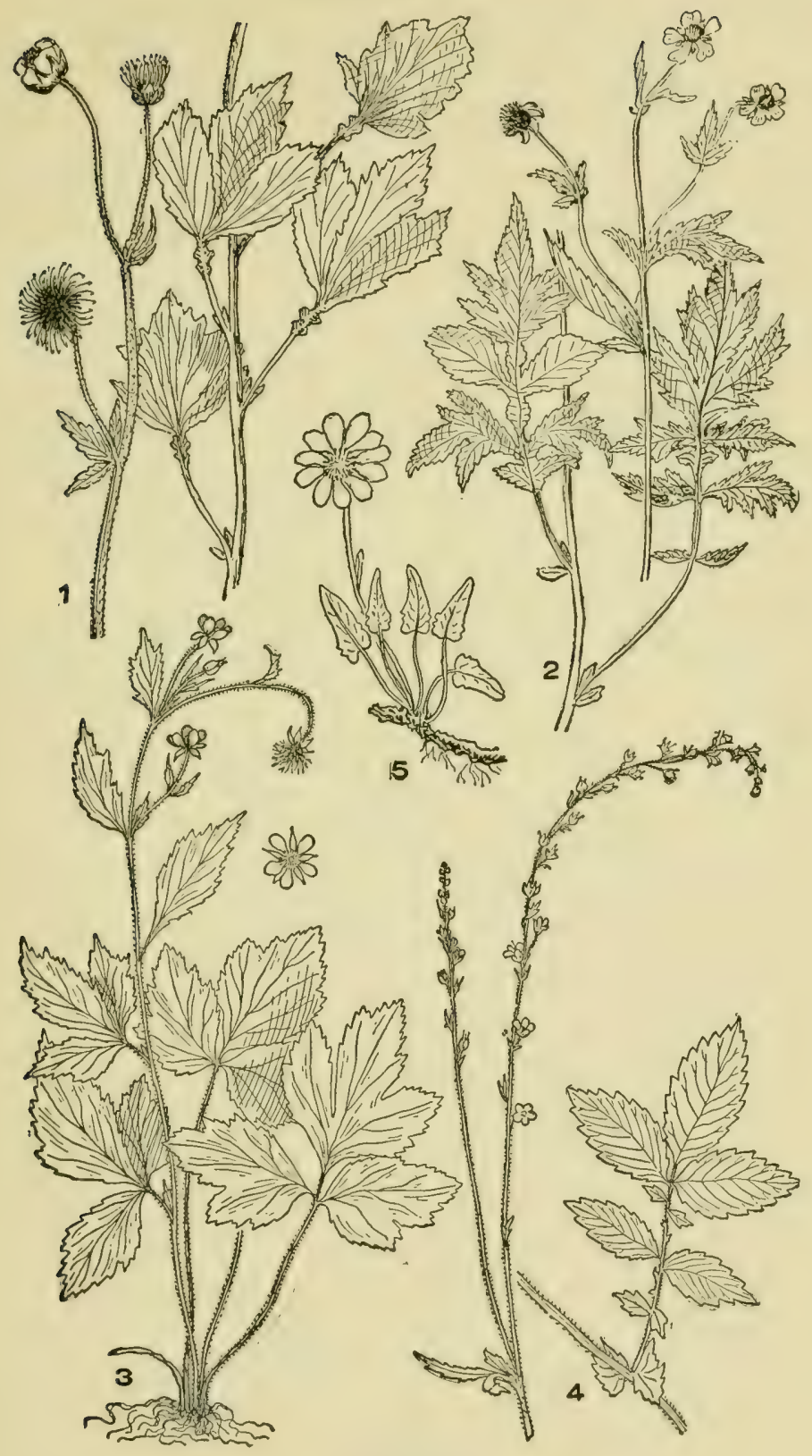

Plate 68

1. Geum rivale. 2. G. strictum. 3. G. virginianum. 4. Dryas integrifolia. 5. Agrimonia gryposepala. 
leaflets interspersed among those fully formed. Stipules at base of leafstalks conspicuous, deeply toothed. Flowers arranged along a slender flower stem, small, yellow. Calyx 5-lobed; petals 5 ; stamens 5 to $\mathbf{1 5}$; seed carpels 1 or 2 , included in the tube of the calyx.

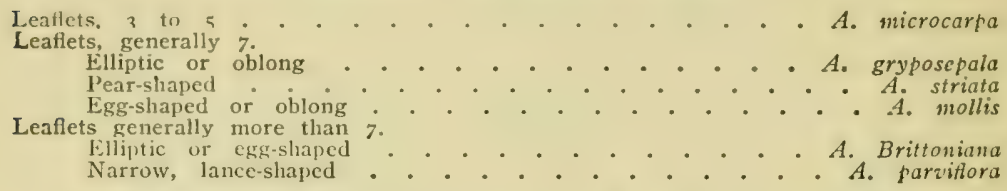

1. A. gryposepala, Wallr. (Fig. 5, pl. 65.) Talt Hairr Agrimony. (A. Eupatoria, Gray's Manual, 6th ed.). Leaflets 5 to 7 , elliptic or oblong, pointed at each end, teeth coarse. Plant hairy with stiff hairs. Petals twice as long as sepals. Roots not tubrous. Flower scape long with many yellow flowers. Woods and thickets, common. July-Sept.

2. A. striata, Michx. (Fig. 1, pl. 69.) Woodland Agrimony. Leaflets 5 to 7 , oblong or pear-shaped. Plant with only a few hairs. Flower seapes short, quite slender, with few small flowers. Roots tubrous. Woods and thickets, Connecticut and southward. July-Sept.

3. A. mollis, (T. and G.) Britton. (Fig. 2, pl. 69.) Soft AgriMONY. Plant with soft hairs. Leaflets narrowly oblong or pear-shaped with a pale pubescence beneath. Roots tubrous. Flowers small on slender spike. Woods and thickets, Connecticut, westward and southward. July-Sept.

4. A. Brittoniana, Bicknell. Britton's Agrisony. Similar to last, but roots are not tubrous, stem and leaves with stifler hairs and leaflets generally 9 to 11 . Thickets and roadsides, northern New York and southward. June-Sept.

5. A. parviflora, Soland. (Fig. 3, pl. 69.) MANy-Flowered AGRIMONY. Stems covered with eoarse brown hairs. Roots not tubrous. Leaflets 11 to 17, narrow lance-shaped. Sonthern New York and southward. July-Oct.

6. A. microcarpa, Wall. Sanil-Fruited Arnimony. (A. pumilla, Muhl.). Plant slender, 1 to $2 \mathrm{ft}$. high, with few branches. Stem hairy. Leaves mostly of 3 leaflets, but often of 5 laflets, small, elliptic, sharply toothed. Flowers few, small. Dry soil, Penna, and southward. Aug.

\section{SANGUISORBA, L.}

Herlos with featler-formed compound leaves. Calyx of 4 lobes, petals wanting, stamens \& to many. Fruit a single nut-like seed enclosed in the dry, angular ealyx.

1. S. minor, Scop. (Fig. 4, pl. 69.) Salad Burnetr. (\$. Sanguisorba, Britton.) Slender, about $1 \mathrm{ft}$. high. Leaflets generally 11 to 13 , arranged along the leaf-stalk, rounded, toothed. Flowers in terminal dense rounded chusters, errenish with a sprinkling of red. Oecasional. Introduced, from gardens. June-Sept.

2. S. canadensis, L. (Fig. 5, pl. 69.) Great american Burnett. Stem 1 to $6 \mathrm{ft}$. high. Smooth or with pubescence toward the base. Leaflets 7 to 15 , erer-shaped, rounded or heart-shaped at base, coarsely 
ROSE FAMILY

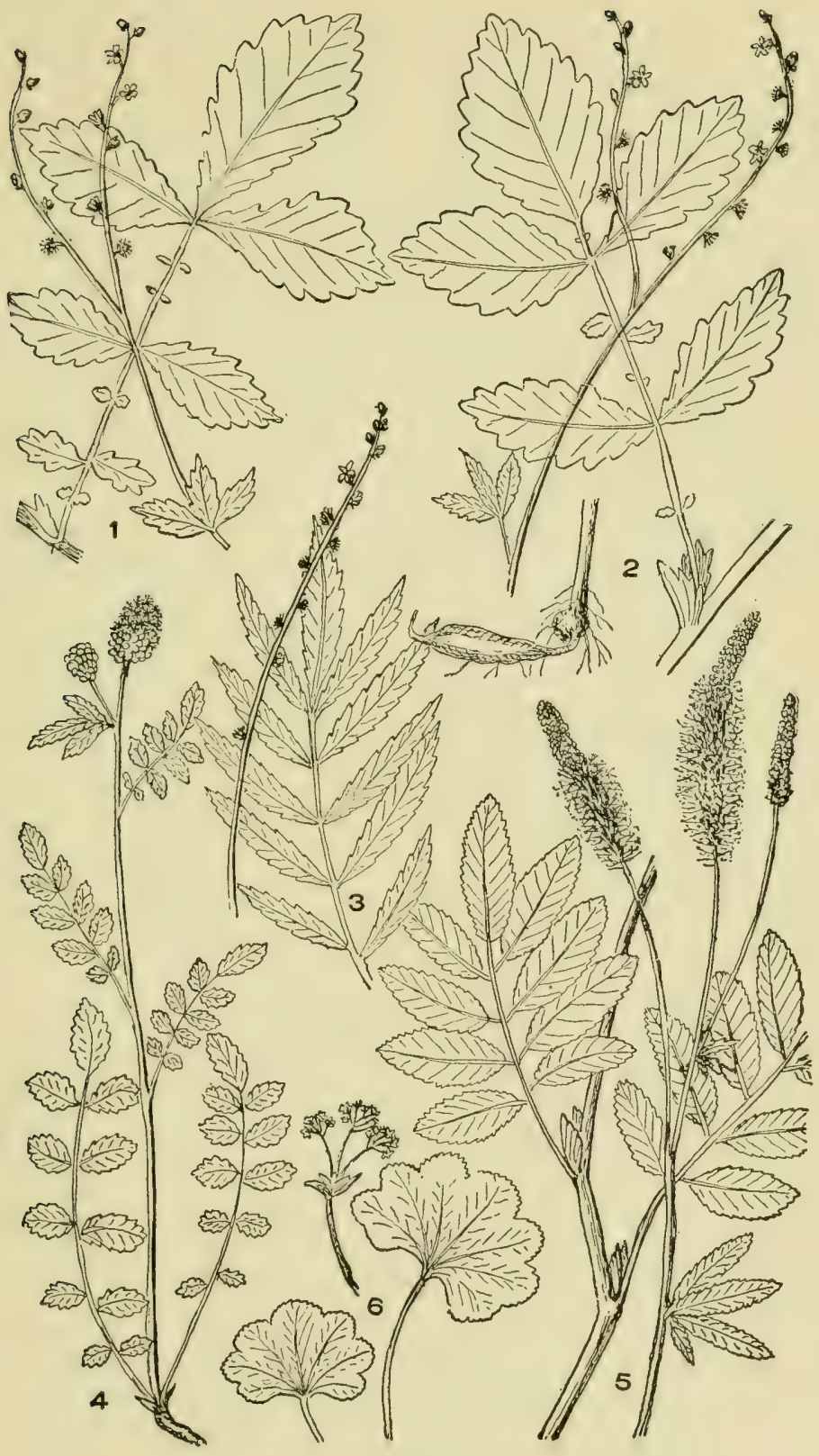

Plate 69

1. Agrimonia striata. 2. A. mollis 3. A. parvillora. 4. Sanguisorba minor. 5. S. canadensis. 6. Alchemilla vulgaris. 
toothed. Flowers in a conspicuous eylindric or pyramidal head, sepals 4, stamens 4, long, white; the long spike taking its color from these exserted filaments. Bogs and wet meadows. July-Oct.

S. officinalis, L., and S. minor, Scop., the former with more dense spikes than No. 1, which are brownish or purplish-red, the latter with globular greenish heads, established in a few places.

\section{I9. ROSA, L.}

Shrubs with, usuany, prickly stems and compound, feather-formed leaves, subtended by stipules, which are united to the sides of the leafstalk. Flowers solitary or, in our species, in loose clusters. Petals 5, spreading, ealyx tube urn-shaped, contracted at the mouth. Stamens numerous, inserted on the ring that lines the calyx tube, within which are the numerous pistils.

\section{Stems without prickles . . . . . . . . . . . R. blanda \\ Stems with both slender and stiff prickles $\because \because \because \cdots$ nitida \\ Stems with stiff prickles only. \\ Prickles straight and slender ......... $R$. humilis \\ Prickles recurved, short and slender, stipules narrow $: \vdots R_{\text {, carolina }}$ \\ Prickles stout, recurved. \\ Leaf borders with single row of teeth ...... $R$ canina \\ Leaf borders with double row of teeth $: !: \vdots \dot{R}$. rubiginosa}

1. R. blanda, Ait. (Fig. 2, pl. 70.) Sмrootr or Mendow Rose. Shrub $l$ to $4 \mathrm{ft}$. high, growing in moist rocky places; stems wholly unarmed or with very few (rarely many) prickles. Stipules broad, extending nearly to the first pair of leaflets, not toothed. Leaflets 5 to 7 , elliptic or narrowly oblong. Serration simple. Flowers pink, 2 to 3 in. broad. Sepals entire. Moist rocky places. June-July.

2. R. carolina, L. (Fig. 1, pl. 70.) Swamp Rose. Shrub often $8 \mathrm{ft}$. high, growing in swamps. Stems usually straight and stout. Prickles, below the stipules generally recurved, short, in pairs. Leaflets 5 to 9 , usually 7 ; narrowly oblong, pointed at the ends; usually silky beneath; serrations of leaves simple. Flowers 2 to 3 in. broad, pink. Calyx lobes simple. Wet grounds; swamps. June-Aug.

3. R. humilis, Marsh. (Fig. 5, pl. 70.) Low or Pasture Rose. Shrub, $\frac{1}{2}$ to $3 \mathrm{ft}$. or more high. Stem slender, armed with strnight, slen. der prickles. Stipules long and narrow; leaflets mostly 7 , narrowly oblong, pointed at ends; horders simply toothed. Flowers few or solitary, 2 to 3 in. broad, the petals dilated above and usually lobed. Sepals with prickles and somewhat lobed. Dry soils.

Var. lucida, Ehrh. Leaves shining above and flowers more numerous. Moist places. (Sometimes deseribed as a species, R. virginiana, Mill.)

4. R. nitida, Willd. (Fig. 3, pl. 70.) Nontueastern Rose. Low hushy shrub. Stems armed thickly with prickles; spines slender. Leaflets 5 to 9 . Stipules rather broad. Flowers few or solitary. Margins of swamps. June-July.

5. R. canina, J. Dos Rose. IVIrd Briar. Shrub, reaching height of $10 \mathrm{ft}$. Sitems armed with stout recurved prickTes. Leaflets 5 to 7 , borders with simple serrations. Sepals, lobed at free extremities. Roadsides and waste places. Naturalized. June-July.

6. R. rubiginosa, I. (Fig. 4, pl. 70.) Eginntrive. Sweet Briar. Shrub, similar to last. Stems wand-like, curving, armed with strong re- 


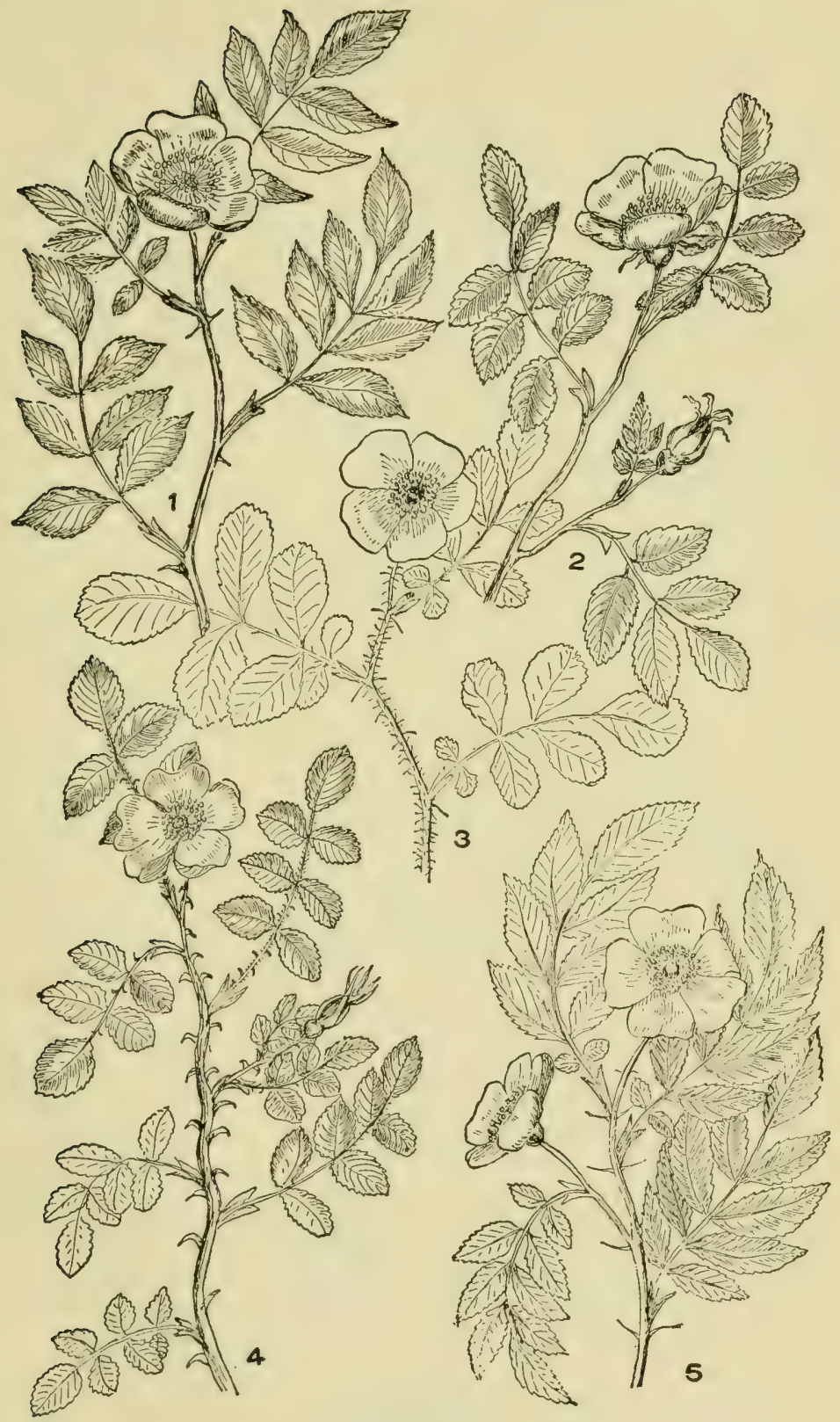

Plate 70

1. Rosa carolina. 2 R. blanda. 3. R. nitida. 4. R. rubiginosa. 5. R. humilis. 
curved prickles. Leaflets with doubly scrratel borders, resinous and very aromatic beneath. Dry pastures. June-July.

\section{Family VIII.-POMACEAE, Apple Family}

Trees or shrubs. Leaves alternate, simple or compound (featherformed). Flowers regular, sepals and petals generally 5 each. Stamens numerous (rarely few). Ovary 1- to 5-celled, most frequently 5. Fruit consists of a wall or walls of stiff parchment-like texture or of a more woorly structure which encloses the seeds and of a fleshy substance which envelopes the 5 or less seed caskets and their contents.

Shrubs and trees armed with thorns . . . . Crataegus

Shrubs and trees without thorns.

Leaves compound (feather-formed) . . . . Sorbus

Leaves simple.

Fruit usually more than an inch in diameter.

Flowers usually white; flesh with gritty cells Pyrus

Flowers mostly pink; flesh without gritty cells

Malus

Fruit small, less than $\frac{1}{2}$ in. in diameter.

Seed cells partially or completely doubled.

Small trees. . . . . Amelanchier

Seed cells not doubled.

Low shrubs . . . . . . . . Aronia

\section{SORBUS, L.}

Trees or shrubs, with compound leaves with about 10 to 16 leaflets arranged on the sides of the leaf-stalk, and with an odd terminal leallet. Flowers in a compact, terminal, nearly flat cluster. Fruit small, berrylike, red.

1. S. americana, Marsh. (Fig. 1, pl. 71.) American Mountain Asrr. (l'yrus amoricena, (Marsh.) DC.). Small trees, reaching a leight of $50 \mathrm{ft}$. Leaflets 11 to 17, narrow, lanee-shaped with tapering points, without hairs, above or below, except when young. Berries as large as pras, red when ripe. Swamps and mountain woods, mostly 111 northern half of our area.

2. S. sambucifolia, (A. Cray.) Roem. Western Movitain Astr. (Pyrus stitchensis, (Roem.) Piker.) Leaflets 7 to 15, oblong or oval, to lanee-shaperl; less tapering at points than those of No. 1, and usually clothed with soft hairs beneath. Fruit larger than that of No. I. Northern New England and northward.

\section{PYRUS, L.}

Trees, sometimes shrubs, with simple leaves. Flowers white or pink, 


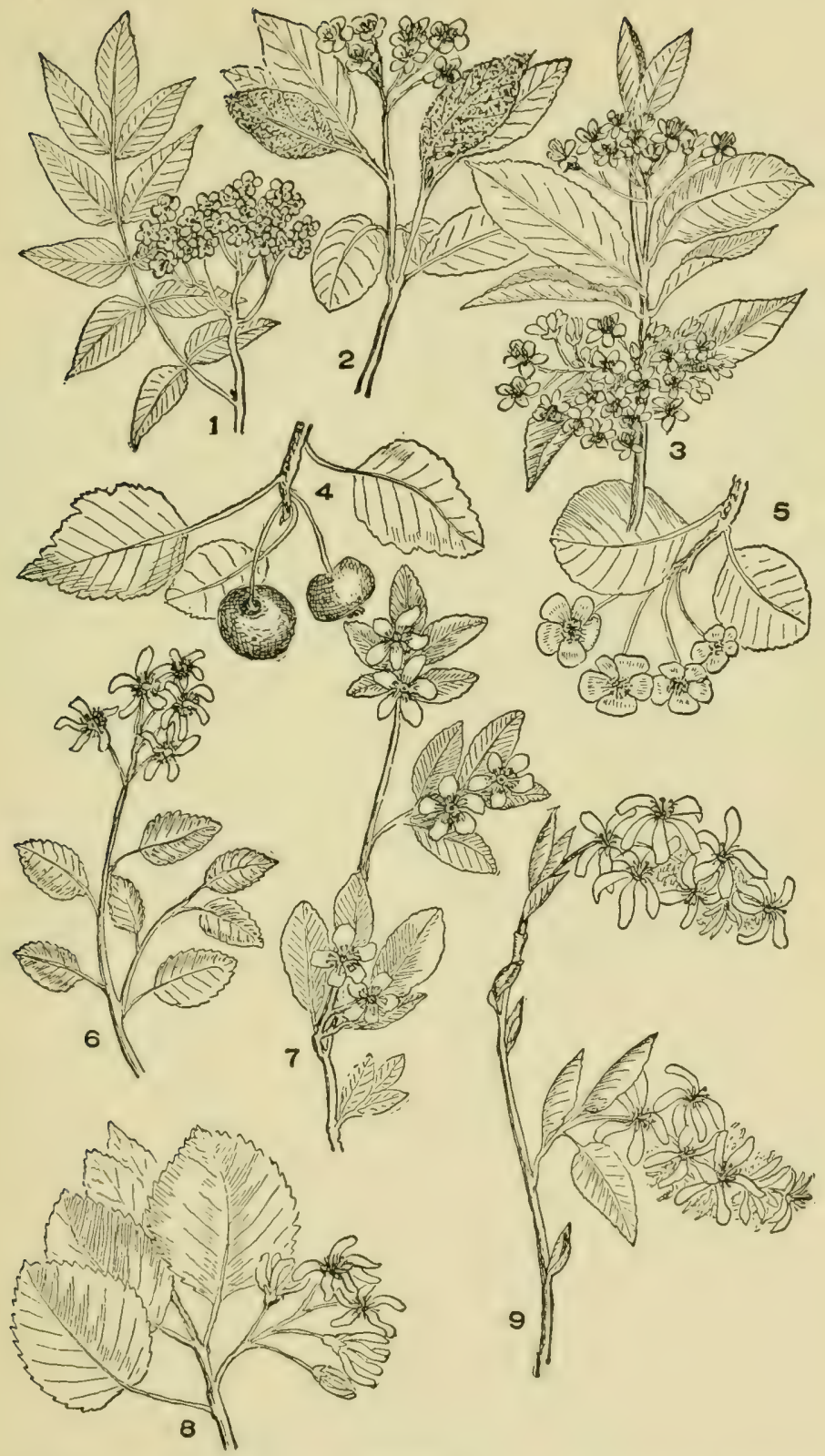

Plate 71

1. Sorbus americana. 2. Aronia arbutifolia. 3. A. nigra. 4. Malus coronaria. 5. Pyrus communis. 6. Amelanchier spicata. 7. A. oligocirpa. 8. A. rotundifolia. 9. A. canadensis. 
showy, in a flat or flattish cluster, the flower stallis of the outer rows being longer than those at the center; the center flowers blooming first. Calyx of 5 acute lobes, urn-shaped. Petals 5, stamens numerous, styles usually 5. Fruit containing many grit-cells; not depressed where attached to stem.

P. communis, L. (Fig. 5, pl. 71.) Pess. Tree well known in cultivation and found also wild, escaped from cultivation.

\section{MALUS, Juss.}

Trees and shrubs, with simple leaves; with umbel-like clusters of flowers; fruit fleshy without grit-cells, depressed at stem attachment.

Leaves often heart-shaped at base . . . . . . . . . . M. sylvestris

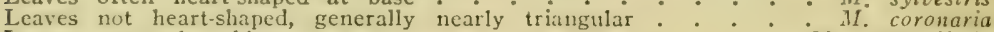
Leaves narrowly oblong -. . . . . . . . angustifolia

1. M. sylvestris, (L.) Mill. Apple. (.I. Malus, (L.), Britton.) Leaves broad egg-shaped, more or less heart-shaped at base, or roanded, point tapering, smooth above, silky hairy beneath. Fruit globose, depressed at insertion of stem. In woods, escaped from cultivation. Southern New York, New Jersey and Pennsylvania.

2. M. coronaria, (L.) Mill. (Fig. 4, pl. 71.) Aderican Crab AprLE. A tree, smaller and more slender than the common apple. Leaves broadly egg-shaped or triangular, with lobes towad the base. Borders deeply serrated. Flowers white or rose color. Fruit $1 \mathrm{in}$. to $1 \frac{1}{2} \mathrm{in}$. diameter, globular, or the stem insertion slightly depressed. In thickets, occasional throughout our area.

3. M. angustifolia, (Ait.) Michx. Narrow-leaved Crab Apple. Small tree resembling No. 2, but leaves are narrow-oblong or lance-form. Fruit rather smaller than No. 2. Oecasional in southern part of our area.

\section{ARONIA, Pers.}

Low shruls with fruit resembling the huckleberry in size and form and with leaves oblong or lanee-shaped. Flowers in terminal compound clusters. Calyx of 5 lobes; petals 5, spreading; stamens numerous; styles 3 to 5 united at base.

Fruit red. Flower cluster hairy ........... . A. arbutifolia Fruit black. Flower cluster not hairy $\therefore \therefore \cdots$ A. nigra

1. A. arbutifolia, (L.) Ell. (Fig. 2, pl. 71.) Tind Choke Berry. Shrub, I to $4 \mathrm{ft}$. high; leaves oblong or inversely lance-shaped, silky beneath. Compound clusters of flowers silky. Flowers white or tinged with red. Fnut $1 / 6$ to $1 / 4 \mathrm{in}$. diameter, astringent. Swamps and damp thickets. March-May.

2. A. nigra, (Willd.) Britton. (Fig. 3, pl, 71.) Вциск Croke BerrY. Leaves similar, but sometimes more and at other times less pointed than those of No. 1. Compound cluster of white or reddish flowers without hairs on the flower stems. Moist shady places. MarehJune.

\section{AMELANCHIER, Medic.}

Shrubs or trees. Leaves simple; stems unarmed; flowers in clusters, white. Calyx of 5 parts; corolla of 5 petals; stamens numerous; pistils 5, joined below. Fruit a berry with 10 seeds, when all mature. 
1. A. canadensis, (L.) Medic. (Fig. 9, pl. 71.) Silnd Bush. ServICE BERrY. Tree, usually small and slender, but sometimes attaining a considerable size. Leaves egg-shaped to oblong, usually heart-shaped at base, borders sharply serrated, 1 to $3 \mathrm{in}$. long, not woolly beneath. Bracts at base of flower stems purplish, silky, falling early. Flowers large, white, in drooping graceful elusters. Fruit about 1 in. diameter, globose; on long stems, crimson or purple, sweet. In dry woodlands. A handsome tree when in bloom in early spring. Woods and swamps. March-May.

2. A. Botryapium, DC. Shad Busir. Tree similar to No. 1, rarely $30 \mathrm{ft}$. high. Leaves densely white-woolly bencath. Swamps. April-May.

3. A. spicata, (Lam.) Dec. (Fig. 6, pl. 71.) Low June Berry. Stems 2 to $9 \mathrm{ft}$. high. Leaves $\frac{3}{4}$ to $\frac{1}{2}$ in. long. Flowers about half as large as those of No. 1 or No. 2. Southern part of our area. Grows among rocks, from long creeping roots. Blooms in May.

4. A. rotundifolia, (Michx.) Roem. (Fig. 8, pl. 71.) Round-LEAvED June Berry. Similar to No. 1, but leaves broad and rounded at both ends, coarsely toothed at borders, sometimes heart-shaped at base, smooth on both surfaces. Fruit similar to that of No. 1, but ripening after that has fallen. Woods and thickets, New York and westward.

5. A. oligocarpa, (Michx.) Roem. (Fig. 7, pl. 71.) Oblong-Fruited JunE BERRY. (A. arguta, Nutt.) Low slırub, 2 to $4 \mathrm{ft}$. high. Leaves oblong, pointed at each end with fine serrations at borders, 1 to $2 \mathrm{in.}$ long. Flowers, only from 1 to 4 , generally 2, in the cluster. Fruit pearshaped, dark purple, $1 / 4$ to $1 / 3$ in. long. Northern borders of our area. May.

\section{CRATAEGUS, L.}

Trees or shrubs armed with woody thorns and with umbel-like clusters of white or pink flowers. Leaves simple or deeply lobed. Calyx of 5 parts, short; petals 5, spreading; stamens numerous; pistils 1 to $\mathbf{5}$. Ovary 1 to 5 celled with a single seed in each cell or when two they are not alike. Fruit small, nearly globular, with thin fleshy parts and rather large nutty seeds.

Leaves pear-shaped or oblong, not deeply lobed or incised.

Flowers in clusters.

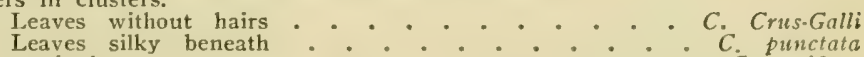

Flowers single

Leaves broad, nearly orbicular or broadly egg-shaped, with deeply incised or

lobed borders.

Leaves abrupt or heart-shaped at base ... . . . . . . . C. coccinea

Leaves acute at base.

Fruit pear-shaped.

Flower stems without hairs . . . . . . C. rotundifolia

Flower stems hairy.

Fruit smooth . . . . . . . . C. tomentosa

Fruit globular hait hairy

Leaves $3^{-}$to 7 -lobed

1. C. Crus-Galli, L. (Fig. 3, pl. 72.) Cockspur Tnorn. Shrub or small tree, with horizontal branches, growing in pastures and thickets. Branches armed with thorns 2 to 4 in. long. Leaves dark shining green above, broadest at apex (pear-shaped) and tapering to a short leaf stalk. Serrations at borders except at basal third. Fruit globular, red, $1 / 3$ in. broad. Common in pastures. Blooms, May or June. 
2. C. punctata, Jacq. (Fig. 6, pl. 72.) Large-Fruited Thorn. Small tree, similar to above, leaves generally broader, and thorns only about $\frac{1}{2}$ as long. Leaves, when young at least, hairy beneath. Fruit about 1 in. diameter, globose, red or yellow.

3. C. uniflora, Muench. (Fig. 4, pl. 72.) Dwarf Thorn. Shrub, 3 to $8 \mathrm{ft}$. high, with slender thorns about 1 to $2 \mathrm{in}$. long. Leaves pearshaped, with serrate borders Fruit globose. Flowers with narrow lanceshaped deeply incised calyx lobes, petals shorter than sepals; flowers not generally in clusters but single or few. In southern part of our section.

4. C. coccinea, L. (Fig. 2, pl. 72.) Scarlet Thorn. Shrub or small tree, with reddish branches and stout spines $1 \frac{1}{2}$ to $2 \mathrm{in}$. long. Leaves on slender leaf-stalks, broad and abrupt at base or somewhat heart-shaped, borders serrate and deeply incised, point acute. Flowers many in a cluster, each about an in. in diameter. Fruit red, globose. Growing in thickets and pastures. Blooms in April or May.

5. C. rotundifolia, (Ehrh.) Borck. (Fig. 1, pl. 72.) Glandular THons. Small tree similar to above, with smaller leaves which are tapering at base and rather smaller than No. 4. Flowers about the size of No. 4. Fruit pear-shaped, red. Often grows with C. coccinea and blooms later.

6. C. tomentosa, L. Pear Thorn. Small tree much like the two preceding. Thorns generally less numerous. Leaves serrated and deeply incised and tapering to base, rather rounded at apex. The leaf-stalks and larger prominent veins of leaves quite douny when young. Fruit oblong. Less common than Nos. 4 and 5 .

7. C. macracantha, Lodd. (Fig. 5, pl. 72.) Lovg-Spined Tirons. Similar to last three. Spines much larger, 2 to 5 in. long. Leaves resemble those of No. 6. Fruit hairy, rather larger than that of No. 4.

8. C. Oxyacantha, L. (Fig. 8, pl. 72.) Hawtilorn. Leaves 3- to 7-lobed. Clusters many flowered. Fruit small. Usually a shrub but sometimes a tall tree. Sparingly escaped from cultivation. May.

9. C. mollis, (T. and G.) Scheele. (Fig. 7, pl, 72.) RED-Fruited Tirors. Resembles $\mathrm{C}$. tomentosa, but fruit is quite hairy. Rarely in northern section of our area. May.

\section{Famir IX.-DRUPACEAE. Plum Family}

Trees and shrubs, bearing fleshy fruit enclosing a hard woody "strone," which is irregularly grooved or smooth. Bark exudiner a clear gum. Teaves simple, alternate, with small stipules which fall early. Flowers in flat or, less frequently, in elongated clusters. Petals 5 ; sepals 5 ; stamens numerous; pistil 1.

\section{PRUNUS. L.}

Shruls and tress with, mostly, edihle fruit. Fruit a fleshy drupe or stone fruit. Flowers white or purplish in clusters of various forms. Petals 5; sepals 5; stamens numerous. 

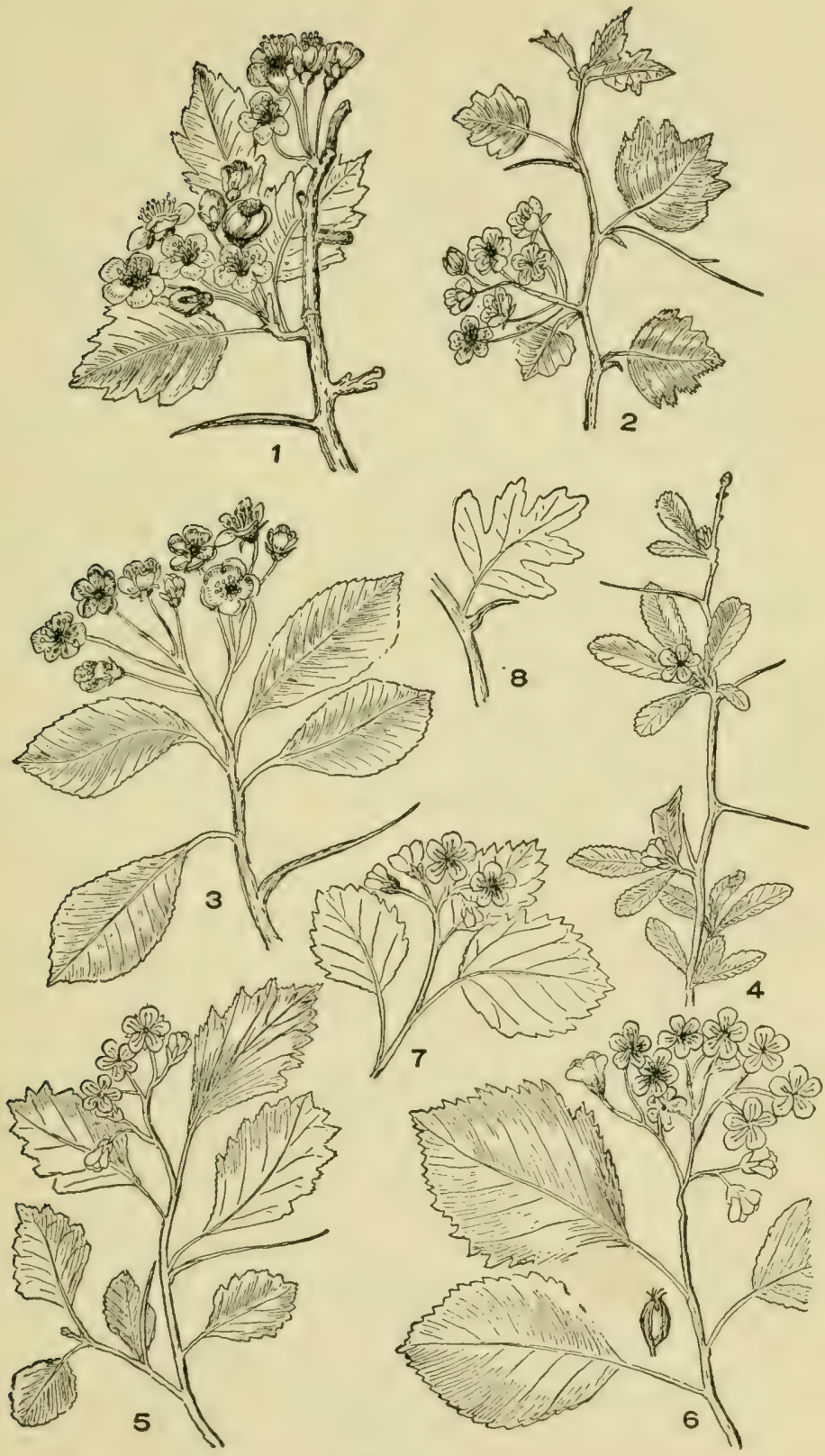

Plate 72

1. Cratregus rotundifolia. 2. C. coccinea. 3. C. Crus-Galli. 4. C. uniflora 5. C. macracantha. 6. C. punctata. 7. C. mollis, 8. C. Oxycantha. 
Drupes smooth, with a bloom on the skin, stone more or less fattened.

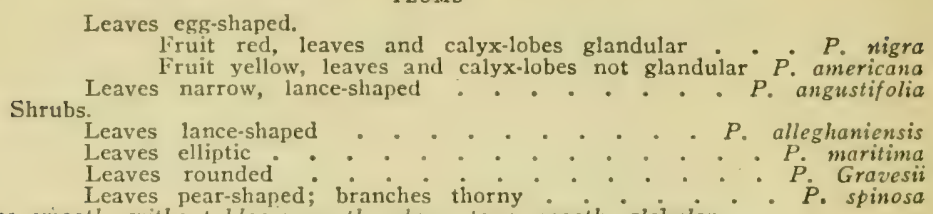

\section{CHERRIES}

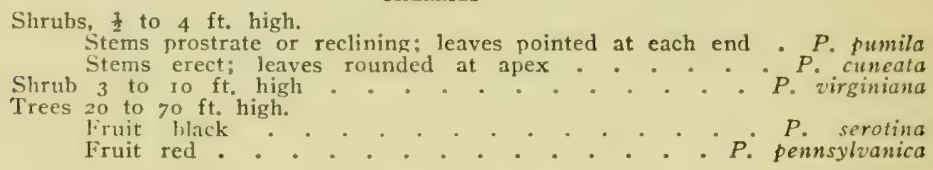

\section{PLUMS}

1. P. nigra, Ait. (Fig. 7, pl. 73.) Horse PuUm. Tree, sometimes $30 \mathrm{ft}$. high. Leaves egg-shaped, rounded at base, tapering in a lengthened point at apex, about 1 in. broad. Fruit egg-shaped, about an in. long, red. Woods and thickets. May.

2. P. americana, Marshall. (Fig. 9, pl. 73.) WILd Yellow or Red Plum. Tree, sometimes $35 \mathrm{ft}$. high, generally, however, about 15 to 20 ft. Branches somewhat thorny. Leaves directly or inversely egg-formed, with the apex conspicuously taper-pointed, and the borders coarsoly or doubly serrate; base rounded. Fruit rounded, $\frac{3}{4}$ to $1 \mathrm{in}$. in diameter, orange or red. Stone flattened. The pulp of the fruit has a pleasant taste, the skin tough and acrid. Woods and river banks. Blooms April to May.

3. P. angustifolia, Michx. Circkasaw Phum. Tree or shrub, 8 to $15 \mathrm{ft}$. high. Branches searcely thorny. Leaves narrow lanee-form with both ends tapering, or less frequently with base somewhat rounded, serrations not coarse. Fruit round, $\frac{1}{2}$ to $\frac{3}{4}$ in. diameter, red. Stone nearly globular. Southern part of our region only.

4. P. alleghaniensis, Porter. Porter's Pudm. Low straggling shrub or small tree, seldom thorny. Leaves egreshaped to lanee-shaped with sharp tecth at the margins; apex slender tapering. Flowers in an r. Inngited eluster. Fruit globose or eggr-shaped. Eastern Conn. Across the Alleghany mountains to $\mathrm{Pa}$. April.

5. P. maritima, Wang. (Fig. 8, pl. 73.) Beacr Plum. Shrub, 1 in $\tau \mathrm{ft}$. high, stragrgling. growing on sandy sea beaches. Leaves eggshaped or pear-shaped. Fruit about $\frac{1}{2}$ in. diameter, purple, sweet.

6. P. Gravesii, Small. (Fig. 10, pl. 73.) Grave's Beach Plum. Leaves round or slightly oval. Fruit smaller than No. 4. Rare. Groton, Conn.

7. P. spinosa, T. (Fig. 4, pl. 73.) Stof, Bucktrons. Although not native is somelimes found along roadsides. Shrub, 2 to $10 \mathrm{ft}$. high. If. has ergeshaped leaves, pointed at each end, branches thorny. Flower clusters consisting of one or two blossoms. Iiruit nearly black. 


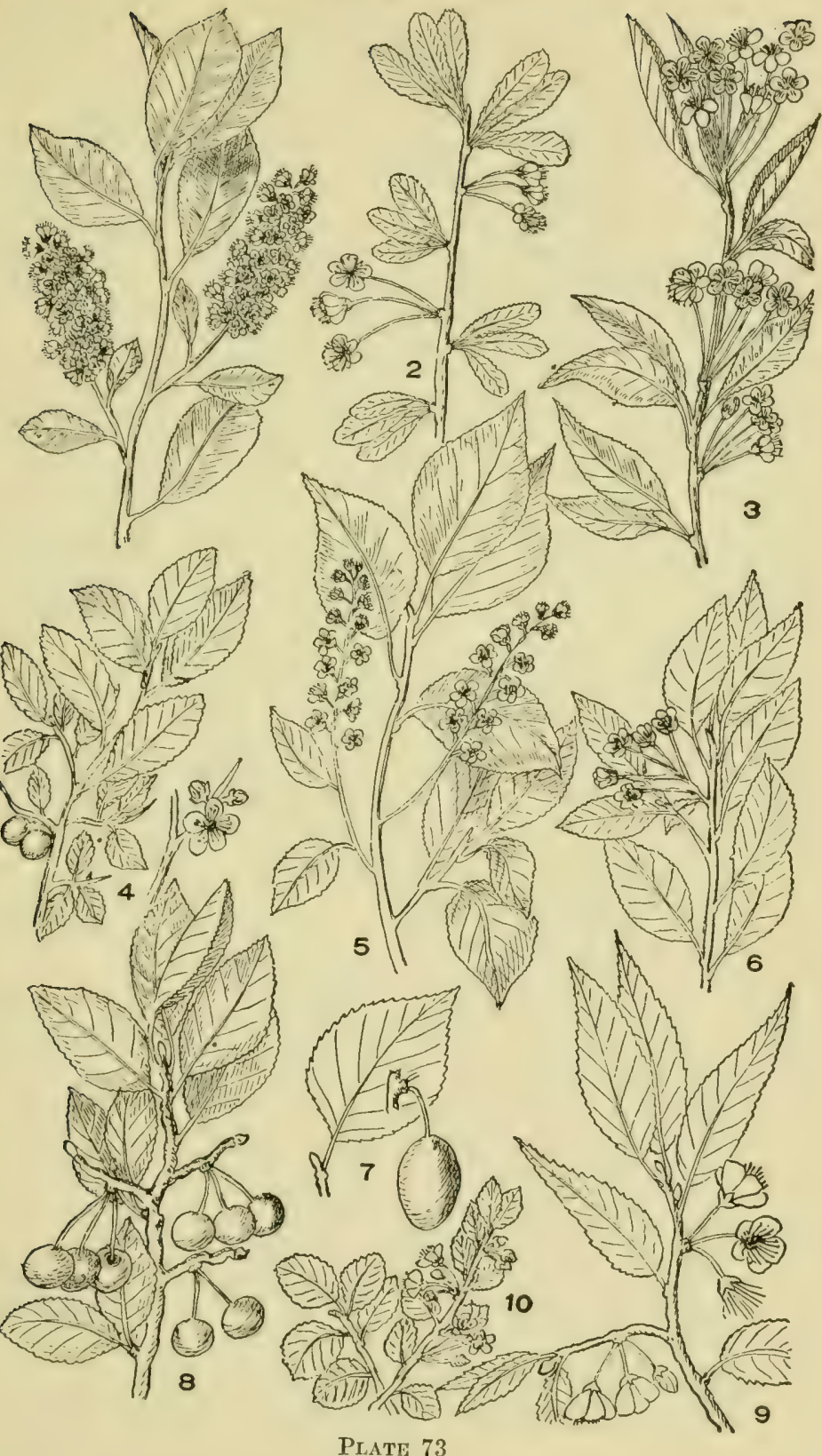

1. Prunus virginiana. 2. P. pumila. 3. P. pennsylvanica. 4. P. spinosa. 5. P. serotina. 6. P. cuneata. 7. P. nigra. S. P'. maritima. 9. P. americana. 10. P. Gravesii. 


\section{CHERRIES}

Fruit small, without bloom on the skin, red or nearly black. Stone rounded or egg-shaped, destitute of margins.

8. P. pumila, L. (Fig. 2, pl. 73.) Dwarf Cinerry. Sand Cherry. A dwarf shrub about $1 \mathrm{ft}$. high, though it may bloom at the height of $6 \mathrm{in}$. or grow to a height of $6 \mathrm{ft}$., the latter very rare. Stems and slender branches smooth and often reclining. Leaves narrow, inversely laneeshaped. but pointed at each end, pale beneath, deep green above; teeth at borders except toward the base. Flowers few ( 2 to 4 in cluster); fruit dark red or nearly black. Banks of streams and wet sandy places. April-May.

9. P. cuneata, Raf. (Fig. 6, pl. 73.) Appalachian Cherry. A small shrub similar to the last, but erect. Leaves rather broader and distinetly rounded at apex. Wet or rocky places. New Hampshire, westward and southward.

10. P. virginiana, L. (Fig. 1, pl. 73.) Choke Cherry. Shrub, growing along fences, in fields or along river banks; generally from 5 to $7 \mathrm{ft}$. high, but more rarely 2 to $10 \mathrm{ft}$. Leaves broadly oval, pointed at each end. Flowers in narrow elongated clusters, pendulous or nearly erect, 20 or more in the cluster. The fruit, which hangs in long elusters is nearly black when ripe, and has an astringent unpleasant taste. Blooms, April-May.

11. P. pennsylvanica, I. (Fig. 3, pl. 73.) Wild Red Cuerry. Pin Cirerry. Tree, 20 to $35 \mathrm{ft}$., rarely shrubby. Bark smooth, reddish-brown. Leaves oblong-egg-shaped or lance-shaped, tapering at each end or rounded at base, shining above and below. Flowers white on long slender flowerstalks in an umbel-liko cluster. Fruit small, red, rather acid. Common at borders of woods and as "second growth" tree. Blooms, April to June. Fruit ripens in August.

12. P. serotina, Ehrh. (Fig. 5, pl. 73.) Wild Black Cherrx. Large tree, sometimes 80 or $90 \mathrm{ft}$. high. Bark black and rough. Leaves oval, tapering at each end and somewhat rounded at base, smooth and shining above, unequally serrate, 3 to 5 in. long. Flowers rather small, numerous, in long cylindric clusters. Fruit in grape-like clusters of nearly black cherries with an agreeable taste. In woods and borders of fields. Common. Blooms, May, Fruit ripe in August.

Besides those above described, a number of species of Prunus are found oceasionally in thickets or woods where they remain in deserted grounds or have found a lodgment as escapes from cultivation.

\section{Famly X.-CAESAlpinaceae. Senna Family}

Herls, shrubs or trees, with flowers of some species closely approaching the typical form of the pea flower, in others nearly symmetrical and regular. Pod resembling the pod of the pea. Leaves alternate, simple or, more generally, compound, featherformed with from 8 to many leaflets arranged along the leaf stem. Trees. 

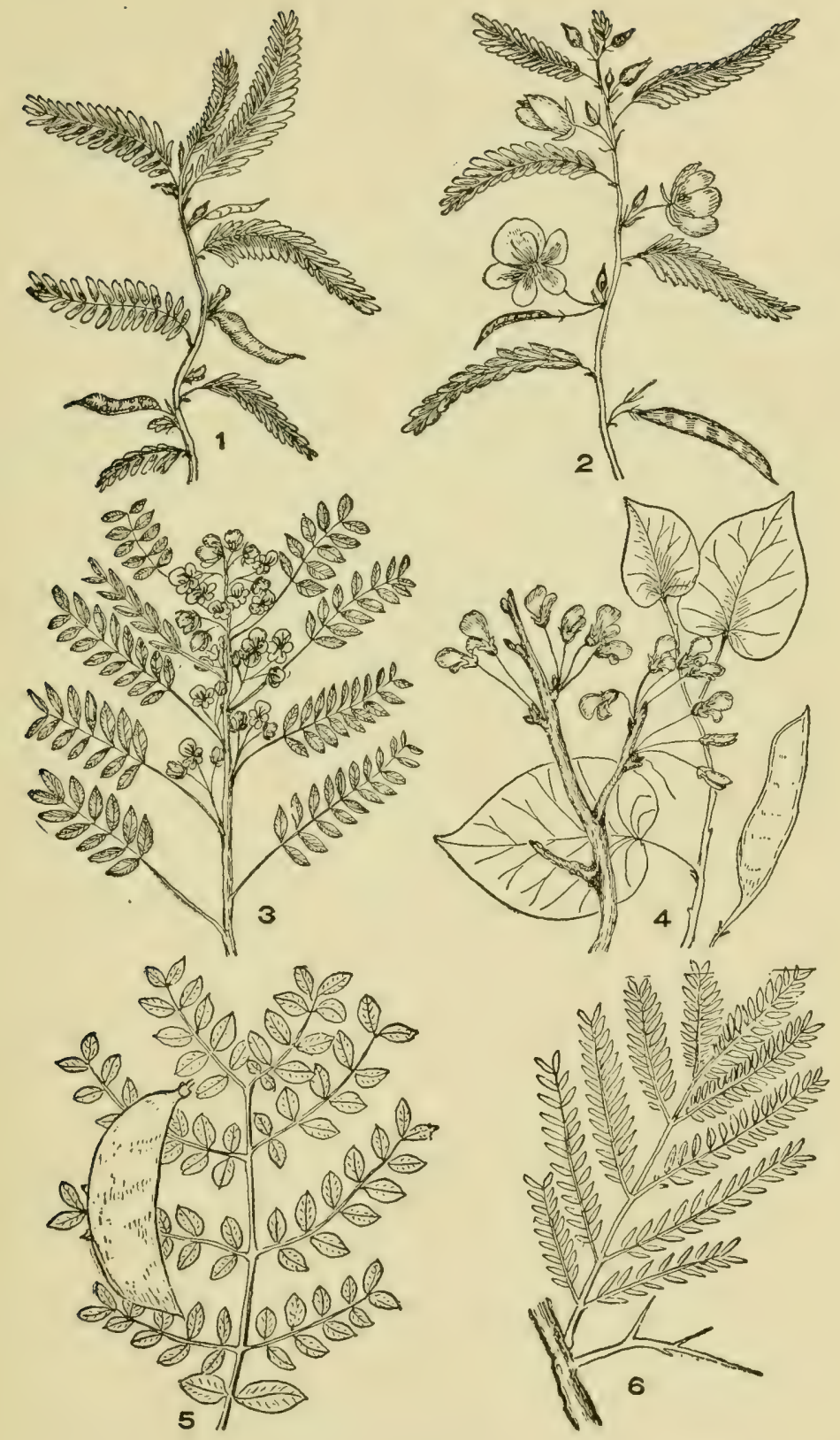

Plate 74

2. Cassia nictitans. 2. C. Chamaecrista. 3. C. marylandica. 4. Cercis canadensis. 5. Gymnocladus dioica. 6. Gleditsia triacanthos. 
With simple leaves

With compound feather-formed leaves.

Flowers greenish . . . . . . . Gleditsia

Flowers, white, showy . . . . . Gymnocladus

Ilerbs

\section{CERCIS, L.}

Small tree, with simple, broad leaves heart-shaped at base, and with clusters of purple flowers which appear before the leaves. Corolla of 5 unequal petals, nearly pea-flower shaped. Stamens 10; pod like that of the pea with several seeds.

C. canadensis, L. (Fig. 4, pl. 74.) RED Bud. AMERTCAN JudAs Trew. Tree, usually 15 to $30 \mathrm{ft}$. high, hut occasionally higher. In early spring the purple blooms cover the tree before the leaves expand. Southern part of our area. April.

\section{CASSIA, L.}

Our species herbs with compound leaves, feather-formed with an equal number of leaflets on each side of the leaf-stalk, no odd terminal leaflet. Flowers yellow. Corolla of 5 petals only slightly pea-blossom-shaped or almost regular. Seeds in an elongated pod, numerous.

1. C. nictitans, L. (Fig. 1, pl. 74.) Sensitive Pea. Wild SensiTIVE Plant. A low annual, somewhat erect or spreading upon the ground, much branching. Stipules long and narrow at base of common leaf-stalk. Leaves sensitive. If a few leaflets are touched by the finger they and those directly opposite close; if the touch is more rude or if repeated, the whole leaf drops at the hinge-like connection with the stem. Traflets about 30, narrow lanee-formed. Flowers solitary, or two or three fogether between the leaf-stalks, but considering the plant as a whole, flowers numerous, $1 / 6$ to $1 / 4$ in. diameter. Pod linear, an inch or more in length. Mostly in dry sandy soil. July-October.

2. C. Chamaecrista, L. (Fig. 2, pl. 74.) Partridge Pea. Largeruowering Sensitue Pes. Resembles No. 1, but is larger and flowers are an inch to $1 \frac{1}{2}$ in. hroad. Petals spotted with purple; pod linear, $1 \frac{1}{2}$ to 21 in. long. Leaves sensitive. Dry sandy soil. July-Sept.

3. C. marylandica, T. (Fig. 3, pl. 74.) Wid.d or Amfrican Senva. IIrrb, 3 to $8 \mathrm{ft}$. high. Leaflets elliptic, 12 to 20, one or two inches long. Flowers generally less than an inch broad, clustering at the base of the leaves at the upper part of the plant. Moist places. July-August.

\section{GLEDITSIA, L.}

Jarge trees with enspicuous thorns, with leaves empound or doubly componde, foather-formed, without the old torminal leaflet. Flowers Errentish, some perfoct, some imperfect, in slender elongated clusters. Pod long, straight or twisted, many seeded.

G. triacanthos, L. (Fig. 6, pl. 74.) Honer Locust. SweEt LocLst. THma-THomed Acacid. $\Lambda$ large tree with rough bark and with 
many stout branching thorns from the trunk. Pods linear, 1 to $1 \frac{1}{2} \mathrm{ft}$. long, twisted. Woods and along fences. May-July.

\section{GYMNOCLADUS, Lam.}

Tree with doubly feather-formed leaves with showy white, perfect or imperfect flowers in clusters. Pods sickle formed.

G. dioica, (L.) Koch. (Fig. 5, pl. 74.) Kentuckr Coffee Tree. Large tree with rough bark. Leaflets broadly egg-shaped, rounded at base, 7 to 12, with or without the odd terminal leaflet. Rich woods. Southern part of our area.

\section{Fanily Xi.-PAPILIONACEAE. Pea Family}

Herbs, shrubs, vines and trees. Flowers perfect (with stamens and pistils), with the petals very unequal, the superior petal (known as the "standard" or "banner") more or less completely enclosing the two lateral ones and the two lower being more or less united (known as the "keel"). Stamens 10, generally in a group of 9, more or less united, with a single one free (diadelphous) but less frequently all united in a single bundle (monodelphous), or still less frequently all the stamens are free or separate. Pistil 1. Fruit a pod similar to that of the pea (a legume) with one, two or many seeds, dividing into two valves.

Leaves generally simple, not divided into leaflets.

Pods flat.

Genista

Pods much inflated... . . . . Crotalaria

Leaflets 3.

The three leaflets springing from a common center. ( $\mathrm{E}_{\mathrm{X}}-$ ample, Clover.)

The two stipules similar to leaflets, giving appearance of 5 leaflets . . . . . . Lotus

The stipules differing from the leaflets.

Stamens 10, all distinct and equal, flowers yellow

Baptisia

Stamens 10, 1 distinct, 9 united in a group.

Porl (legume) sickle-shaped or spiral Medicago

Pod, egg-shaped or globose, not included in the calyx; flowers in terminal, elongated clusters . . . . . . . Melilotus

Pod included in the calyx; flowers in rounded head . . . . . Trifolium

The 3 leaflets arranged as a pair and an odd one. 
Pods (legumes) not jointed.

One-seeded

\section{Lespedeza}

Several-seeded.

Calyx of 4 teeth . . . . Galactia

Calyx of 5 teeth.

Flowers 1 to 4 , pod 4 to 5 inches long

Centrosema

Flowers 1 to 3 , pod about an inch long .

Clitoria

Flowers small, in elongated clusters.

Vines, not hairy . . Phaseolus

Vines, hairy . . Amphicarpa

Flowers in small heads or umbels

Strophostyles

Pods two jointed, one-seeded, flowers yellow Stylosanthes

Pods (loments) of several joints and seeds numerous

Leaflets 3 on the leaf of a single blade. . . . Cytisus The leaflets consisting of stiff spines . . . . . Ulex Leaflets more than 3 ( 5 to 10 ), all arising from a common center.

Lupinus

Leaflets more than 3, arranged symmetrically along both sides of the leaf-stalk.

Number of leaflets equal on both sides, terminating abruptly, or by a tendril.

Wings (side petals) attached to the keel $(i$. e., the united lower petals) . . . . Vicia

Wings nearly free . . . . . . . Lathyrus

Leaflets more than 3 , arranged with an odd one at the extremity.

Trees

Herbs.

Pods jointed.

Flowers purple, in an umbel . . Coronilla

Flowers purple, in an elongated cluster

Hedysarum

Flowers reddish-yellow, few in cluster or solitary . . . . Aeschynomene 
Pods not jointed.

Stem erect, pod linear, flat . . . Cracca

Stem erect or decumbent, pod turgid, oblong . . . . . . . Astragalus

Stem twining . . . . . . . Apios

\section{BAPTISIA, Vent.}

Herbs with leaves of three leaflets, which arise apparently from the same center (or rarely with simple, undivided leaves). Stipules leaflike, small, or none. Calyx of 4 or 5 parts eleft half way. Petals (of our species) yellow and of nearly equal length, somewhat united. Sta mens 10, all distinct. Pods inflated, with generally, many seeds.

1. B. tinctoria, (L.) R. Br. (Fig. 1, pl. 75.) Wild Indigo. Yellow Bвoos. Clusters of flowers numerous, yellow, plant 3 to $4 \mathrm{ft}$. high, much branched. Leaffets pear-shaped, the whole plant more or less covered with a whitish bloom. Stipules very small and falling early. Pods eggshaped or nearly globose. Growing in dry or sandy soil. June-Sept.

2. B. australis, (L.) R. Br. BLUE WILD Indigo. Leaflets less blunt than those of No. 1. Flowers blue. Otherwise much like B. tinctoria. Western Penna., and westward. June-Aug.

\section{CROTALARIA, L.}

Herbs, with simple undivided leaves (in our region), and with yellow flowers in loose, somewhat elongated clusters. Calyx 5-parted, stamens 9 united, 1 free. Pod oblong to globose, much inflated. Seeds several, loose when ripe.

C. sagittalis, L. (Fig. 2, pl. 75.) Rattle Box. Erect, branching, generally less than $1 \mathrm{ft}$. high. Plant covered with silky pubescence. Leaves simple, oval or oblong, 1 to $2 \mathrm{in.}$ long. $1 / 3$ as broad, with very short leaf-stalks. Flowers solitary or 2 to 4 in loose cluster, yellow. Pod oblong about 1 in. long, much inflated. June-Sept.

\section{LUPINUS, L.}

Herbs. Leaves of about 7 to 15 radiating leaflets. Flowers showy in long spikes. Calyx 5-toothed, upper lip of 2 teeth, lower of 3 , sometimes without division. Stamens, 9 united, 1 free. Pod flattened, uneven, constricted between the seeds.

L. perennis, L. (Fig. 4, pl. 75.) Common Lupine. Sometimes erect, more frequently procumbent, spreading. Stems about a foot long, nearly smooth. Leaflets 7 to 9 , soft, downy on long leaf-stalks. Flowers in a long slender spike, blue varying to white. Sandy hillsides and roadsides. May-June.

\section{GENISTA, L.}

Shrubby plants, with simple leaves and clustered yellow flowers. Calyx of 2 lips, the upper one 2-cleft, the lower with 3 teeth. Stamens, 9 united, 1 free. Pods flat with several seeds.

G. tinctoria, L. (Fig. 5, pl. 75.) DYEWEed, WOAD WAXEN. 
Branches round, the flowering ones erect, 1 to $2 \mathrm{ft}$. high. Leaves not compound, lance-shaped, broalest at middle, without leaf-stalks, shining. Flowers numerous, yellow, in loose terminal elusters. Dry hills, eastern part of our region. Summer.

\section{ULEX, L.}

Shrubs with spiny branches, the leaves stiff, linear, spiny. Flowers larere, generally thickly distributed among the spiny leaves. Calyx divided almost eompletely into 2 lips. Stamens united in a single group. Pod egg-shaped or elongated.

U. europaeus, L. (Fig. 3, pl. 75.) Furze. Gonse. Shrub, 2 to 6 ft. high, branching. Leaves spiny. Flowers yellow, appearing among the spiny leaves. Escaped from cultivation in southern part of our area. May-July.

\section{CYTISUS, L.}

Shrubs with 3-foliate leaves or leaves undivided, the stems often spiny. Flowers showy, in elusters. ('alyx divided to base into 2 lips. Stamens in a single group. Pod, flat, oblong to linear, several seeded.

C. scoparius, (L.) Link. (Fig. 6, pl. 75.) Broom. Stiff, wiry shrub, 3 to $5 \mathrm{ft}$. high, stem angular, erect, branching. Leaves trifoliate or of a single blade, small. Flowers bright yellow about 1 in. long. Waste places, introduced sparingly.

\section{MEDICAGO, L.}

Iferbs, with trifoliate lenves, the leaflets arising from a common center. Flowers small, yellow or violet, terminal or from the leaf axils. Leaflets commonly slightly tootherl, the veins terminating in the teeth. Calyx of 5 nearly equal parts. Pods curved or twisted.

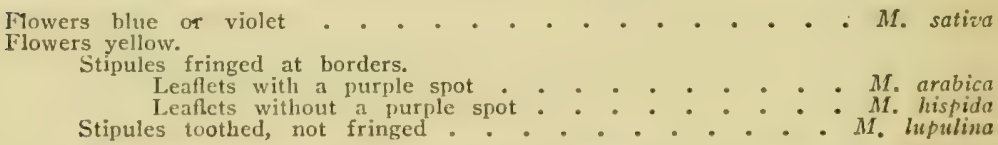

1. M. sativa, I. (Fig. 1, pl. 76.) Alfalfa. Lucerne. Cultivated for fodder in southern and western States. Much branched, erect or decumbent, 1 to $11 \mathrm{ft}$. high. Leaflets inversely lance-shaped or wedgeshaped, the middle one on rather longer leaf-stalk than the others. Flowers bluc, in elongated slender clusters. Fields and waste places. Blooms all summer.

2. M. lupulina, L. (Fig. 7, pl. 75.) BцגCK Medic. Nonesucir. Branclus sprating, decumbent, 1 to $1 ! \mathrm{ft}$. long, downy. Leaflets wedgeshatper or cuss-shaped to nearly orbicular, tonthed at apex. Flowers yellow, small, in dense oblong or cylindric heads. Pods when ripe, black, eurved into a spiral, one-seeded. Fields and waste places. March-Dec.

3. M. hispida, Gaertn. Tootined Menic. (M. denticulata, Willd.). Jeaflets lareer than the last and decidedly wedge-shaped. Stipules large and frimged al brenters. Flowers small, yellow. The spiral pods cleguntly reticulatel, the edges armed with curved prickles. Waste places, etc., mostly near sea-ports. summer. 

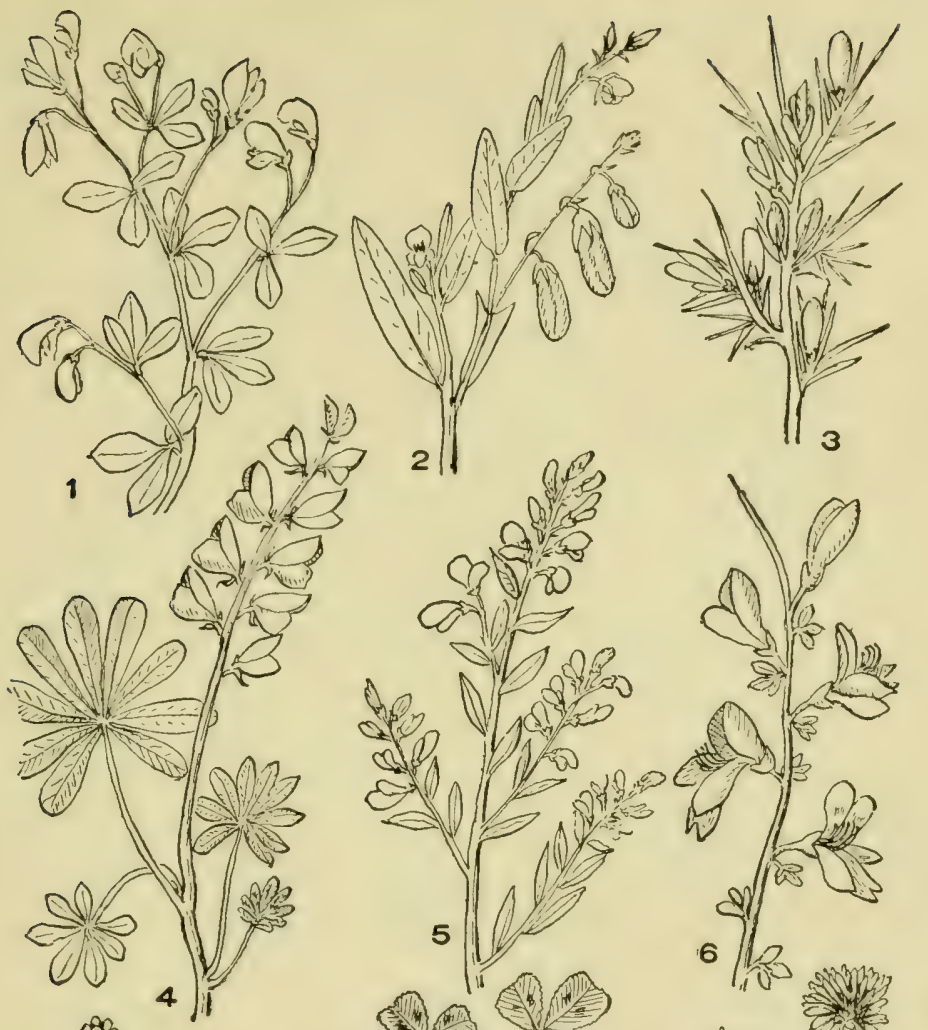

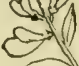
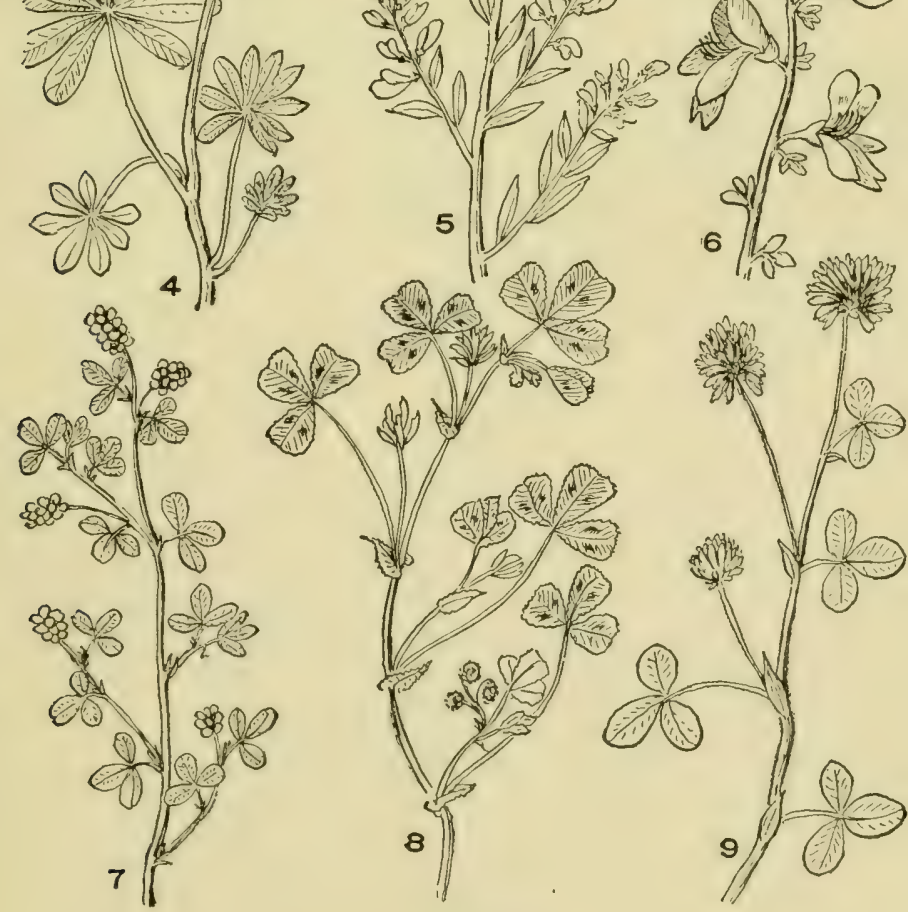

Plate 75

1. Baptisia tinctoria. 2. Crotalaria sagittalis. 3. Ulex europaeus. 4. Lupinus perennis. 5. Genista tinetoria. 6. Cytisus scoparius. 7. Medicago lupulina. S. M. arabica. 9. Trifolum hybridum. 
4. M. arabica, All. (Fig. 8, pl. 75.) SPotted Medic, Leaflets inversely heart-shaped. Stipules similar to those of No. 3. Leaflets with 1 or more purple spots near the eenter. Pol with reticulations and with marginal prickles. Waste places. All summer.

\section{MELILOTUS, (Tourn.) Hill.}

Tall herbs, with trifoliate leaves and with numerous small flowers in long slender spikes. Calyx teeth 5, nearly equal. Pod ovoid with one or more seeds. Plants very fragrant.

Flowers white

Flowers yellow

1. M. alba, Desv. (Fig. 5, pl, 76.) White Sweet Clover. Erect; branching, with slender branches, 3 to $10 \mathrm{ft}$. high. Leaflets oblong or inversely lance-shaped, notehed or rounded at extremity. Flowers white. Along roadsides and waste places. June-Nov.

2. M. officinalis, (L.) Lam. (Fig. 4, pl. 76.) Yeluow SwEeT Clover. Rescmbles No. 1, but leaflets are mostly rather broader and flowers are yellow.

\section{TRIFOLIUM, L.}

Tufted or spreading herbs with (in our species) trifoliate leaves, the leaflets usually toothed. Flowers small, in more or less dense heads. Stamens, 9 united, 1 more or less free. Pod oblong or cylindric, 1 to 6 seeded, often included in the calyx.

Howers yellow.

Stipules long and narrow (length at least 3 times the breadth) T. agrarium

Stipules broad (length not more than twice the breadth).

Flowers in the head usually more than $20 . . . .2 T$, procumbens

Flowers in head few (10 to 12)..... . . T. dubum

Flowers pink and purple.

Leaflets oval, with a pale spot on upper side . . . . . T. pratense

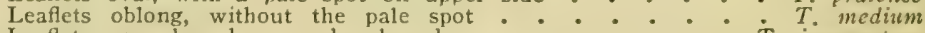

Leaflets pear-shaped or wedge-shaped $: \vdots \vdots \vdots \vdots \vdots \dot{T}$. incarnatum Flowers white.

Calyx teeth long, silky, nearly hiding the small white or slightly pink

corolla........$T$. arvense

Calyx teeth not hiding the corolla.

Plant $I$ to $2 \mathrm{ft}$. high . . . . . . . . . . T. hybridum

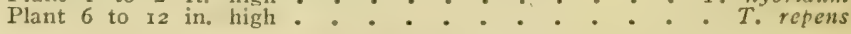

\section{Flowers yellow}

1. T. agrarium, L. (Fig. 6, pl. 76.) Yellow Clover. Hop Clover. Stems bending, ascending. Leaflets inversely ovate, finely notehed at summit. Stipules narrowly lanee-shaped. tapering to a sharp point. Flowers bright yellow in dense heads, the flowers of which are, as they mature, turned bask, calyx teeth not equal, the inferior being twice as long as the superior. Along roadsides, in waste places. All summer.

2. T. procumbens, L. (Fig. 7, pl. 76.) Low or Hor Treforl. Hop Clover. Stems more spreading than No. 1 and more silky, 3 to 6 in. long. Ieaflets wrolge-shaped, rounded and generally notehed at apex. Stipules exgershapel. rather ereater in length than brealth. IIeads of 20) to 40 flowers, turned back when mature. Sandy fields and roadsides. All summer.

3. T. dubium, Sibth. (Fig. 3, pl. 76.) Lenst Iop Crover. Stems similar to Iast. Icaflets decidedly notched at apex. Flowers only 3 to 15 in head. Waste places. Summer. 


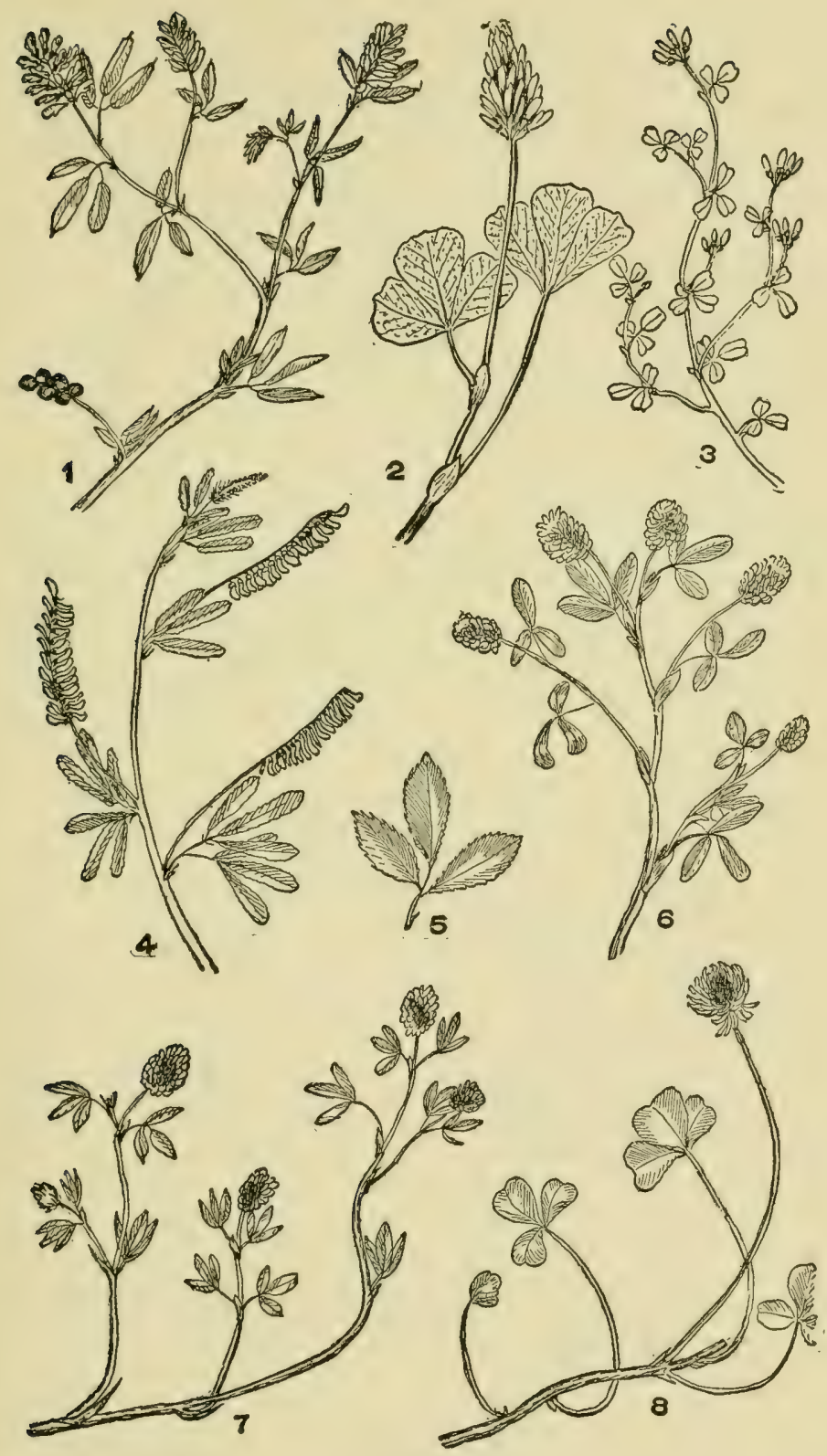

Plate 76

1. Medicago sativa. 2. Trifolium incarnatum. 3. T. dubium. 4. Melilo. tus officinalis. 5. M. alba. 6. Trifolium agrarium. 7. T. procumbens. 8. T. repens. 


\section{Flowers pink or purple}

4. T. incarnatum, L. (Fig. 2, pl. 76.). Crimson Clover. Stems erect, $\frac{1}{2}$ to $3 \mathrm{ft}$. ligh, hairy. Leallets wedge-shaped, hairy. Heads of flowers on rather long stallis, oblong or long egg-shaped. Introduced. Summer.

5. T. pratense, L. RED Clover. Erect or decumbent, stems $\frac{1}{2}$ to $2 \mathrm{ft}$. high, silky. Leaves on long or short leaf-stalks. Leaflets oblong, often notehed at apex, often with a pale spot near base. Stipules broad with bristle points. Heads without much of a flower stalk, round or oblong. Cultivated in fields and growing in rich soils commonly.

6. T. medium, I. Zig-ZaG Clover. Resembles the last. Heads longer and on a flower stem. Flowers of deeper color. Leaves without central spot. Dry fields. Introduced. Summer.

\section{Flowers white}

7. T. arvense, I. (Fig. 1, pl. 83.) Rabit Foot. Stone Clover. Plant velvety, branching, mostly procumbent. Leaflets oblong, narrow, notehed at summit. Flowers small, white or rosy. Nearly hidden by the long silky calyx teeth. Feads cylindric. Fields, waste places. Summer.

S. T. repens, L. (Fig. 8, pl. 76.) Winte Clover. Stems prostrate, rooting. Leaves on long leaf-stalks, leaflets inversely ovate or nearly round, finely notehed at borders and abruptly terminated by one or two teeth at apex. Flowers white, sometimes rose. Common. Summer.

9. T. hybridum, L. (Fig. 9, pl, 75.) Alsatian Clover. A larger plant than the last and more generally erect. Leaves on shorter leafstalks; leallets elliptic, borders notehed; stipules oval with sharp points. Heads globose; flowers white, later rose. Roadsides. Summer.

\section{ro. LOTUS, L. (Hosackia, Douglas)}

ITerls, with (in our species) 3-foliate leaves and small reddish yellow flowers in looso umbellate elusters ( 3 to 12 in cluster). Calyx teeth equal or nearly so. Standard (two upper united petals) orbicular or ovate; stamens, 9 united, 1 free. Pod linear, compressed, 1 to several seeded.

L. corniculatus, L. (Fig. 1, pl. 77.) Burn's-Foot TreforL. Stems slender, decumbent. Leallets 3 , but the two stipules, which are about the size and shape of the leaflets, appear to make 5 leallets. Flowers in an umbel, corollic bright yellow, the standard frequently red or reddish. Introduced. June-Sept.

\section{I1. CRACCA, L. (Tephrosia, Pers.)}

Inairy herls, with compound feather-formed leaves, with an odd number of leaflets; flowers white or purple in terminal or lateral clusters. Leaflets (in our species) about 13 to 25, elliptic. Stamens all united or one free. Pod linear, several seeded.

1. C. virginiana, L. (Fig. 2, pl. 77.) Gosts Rue. Plant silky with whitish hairs. Stem ereet, not branching, 1 to $2 \mathrm{ft}$. high. Flowers in clusters, large and often mumerous, yellowish-white marled with purple. Dry sandy soil. June-July. 

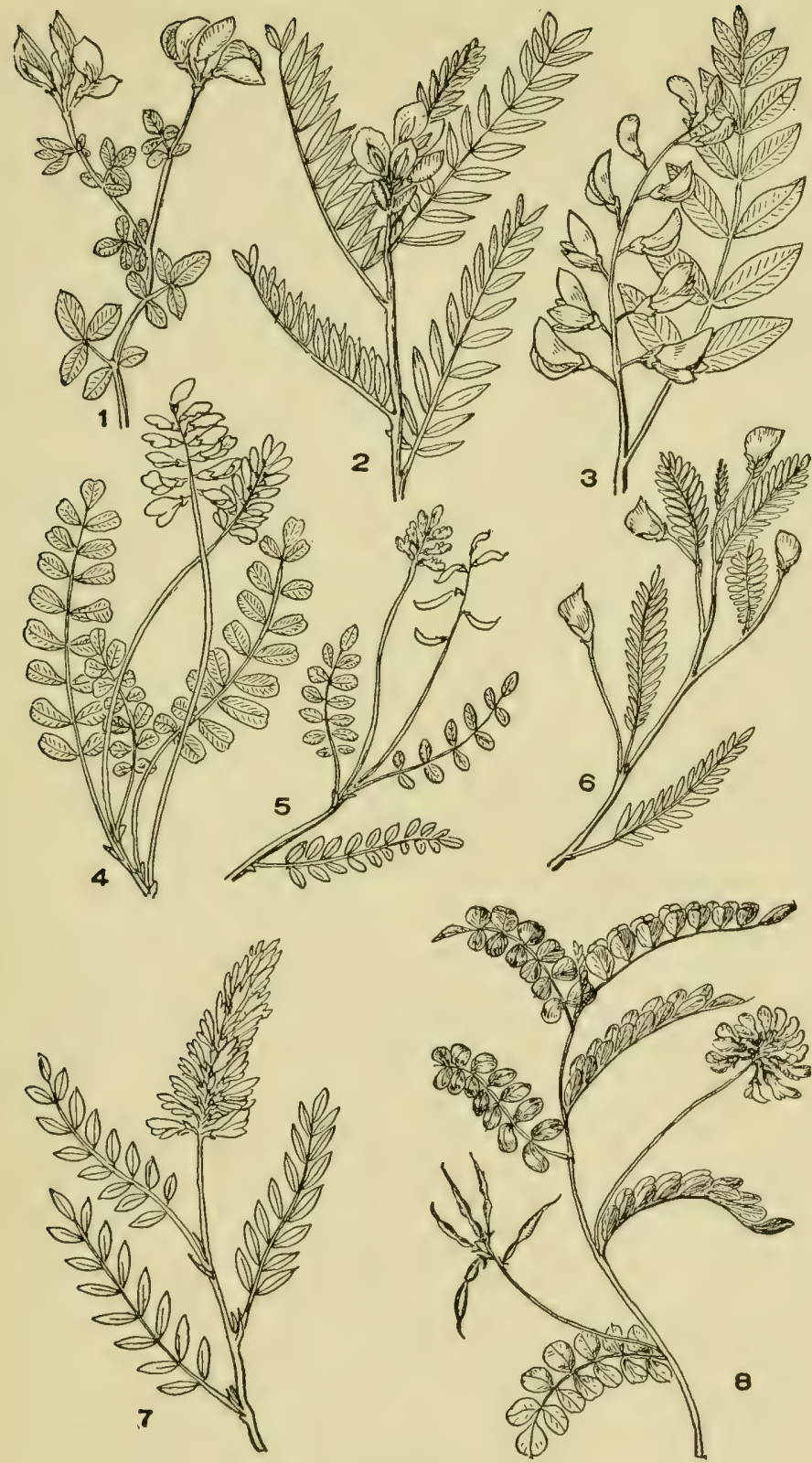

Plate 77

1. Lotus corniculatus. 2. Cracea virginiana. 3. Robinia Pseudacacia. 4. Astragalus alpinus. 5. A. Robbiusii. 6. Aeschynomene virginica. 7. Hedysarum boreale. 8 . Coronilla varia. 
I2. ROBINIA, L.

Our spocies a tree with long pendant elusters of showy white flowers. Leaves feather-formed; stipules small, sometimes spiny. Calyx teeth slightly unequal. Standard large, rounded and turned backward. Pod flat, linear, several seeded.

R. Pseudacacia, L. (Fig. 3, pl. 77.) Common Locust. Our com. mon locust tree has rough bark and grows to height of $80 \mathrm{ft}$., but is usually not more than from 30 to $50 \mathrm{ft}$. high. Pod 2 to 4 in. long. Leaflets 8 to 12 pairs with an odd one at the end. Stipules are often spiny. May-June.

\section{ASTRAGALUS, L.}

Herbs, leaves compound, mostly with an odd number of leaflets; purple, white or yellow flowers in spikes, loose clusters or solitary. Stamens, 9 united, 1 free; calyx of 5 nearly equal teeth. Standard erect, ovate or oblong, usually narrow, koel blunt; pod several seeded, generally turgid.

1. A. Robbinsii, (Oakes.) A. Gray. (Fig. 5, pl. 77.) Robnins's MILK VEтci. Nearly smooth, erect, $\frac{1}{2}$ to $1 \mathrm{ft}$. high. Leaflets 9 to 25. Flowers white or purplish, $\frac{1}{4}$ to $\frac{1}{2} \mathrm{in.}$ long, in loose elongated or short clusters. Rocky places, Maine and northern Vermont. June-July.

Var. A. Robbinsii Jesupi, Eggleston and Sheldon, has larger, darker purple flowers, longer pod, and a flower-stalk longer than the calyx. Localities as above.

2. A. alpinus, L. (Fig. 4, pl. 77.) AlPINe Milk Vetch. Plant branching, decumbent or erect, $\frac{1}{2}$ to $1 \mathrm{ft}$. high, smooth or slightly hairy. Flowers violet-purple. Rocks, northern New England. June.

3. A. canadensis, L. Carolina Milk Vetch. (A. carolinianus, L.). Plant 1 to $4 \mathrm{ft}$. high. Leaflets 15 to 31 . Stipules lance-shaped. Flouers yellowish. Pod without stem, 2-celled. Shores of Lake Cham. plain. (Brainerd.)

\section{I4. CORONILLA, L.}

Herbs with several pairs of leaflets and an odd one. Flowers purple or yellowish, in an umbel. Pod linear, jointed. Calyx teeth nearly equal. Standard nearly orbicular.

C. varia, L. (Fig. 8, pl. 77.) Cononilla. Leaflets 6 to 7 pairs and an odd one. Flower stalks longer than the compound leaves. Flowers light purple (standard pink, wings white or purple). Plant 1 to $2 \mathrm{ft}$. ligh, generally reelining on shrubs or other plants. Connecticut and southern New York. Introduced. June-August.

\section{HEDYSARUM, L.}

IIerlos with several pairs of leaflets and an odd one. Flowers showy in axillary clusters. Calyx of 5 awl-shaped teeth, nearly equal. Stamens, 9 united, 1 free. Pod flattened and distinetly jointed.

H. boreale, Nutt. (Fig. 7, pl. 77.) Inmysarum. (П. americanum, (Mimx.) liriton.) Plant $\frac{1}{2}$ to $21 \mathrm{ft}$. high, ercet or somewhat decumbrnt. Leaflets 13 to 21, oblong to laner-shaped, nearly smonth. Stipules scaly. flowers purple in a many-llowered cluster. Pods of 3 or 4 joints, smooth 
and marked with reticulations. Northern parts of our region. JuneJuly.

\section{I6. AESCHYNOMENE, L.}

Herbs, resembling Hedysarum, with odd pinnate leaves and clusters of yellow flowers. Stamens in two groups of 5 each. P'od on a lengthened stalk, jointed.

A. virginica, (L.) BSP. (Fig. 6, pl. 77.) Sensitive Joint Vetcir. Erect, 2 to $5 \mathrm{ft}$. high, rough hairy. Leaves of 25 to 55 leaflets, which are somewhat sensitive, closing when touched. Flowers few, reddishyellow with veined petals. Pod linear of 5 to 10 nearly square joints. Southern part of our area. Aug.-Sept.

\section{I7. STYLOSANTHES, Swartz.}

Low herbs, branching, with wiry stems and 3 -foliate leaves. Stipules sheathing and uniting with the leaf-stalk. Flowers small, yellow, in terminal clusters. Calyx tube slender, bell-shaped, the 4 upper teeth somewhat united. Standard (upper petal) orbicular. Stamens in two groups, each of 5 . Pod short, strongly reticulated.

S. biflora, (L.) Swartz. (Fig. 3, pl. 83.) Pencil Flower. Growing in tufts, stems $\frac{1}{2}$ to $2 \mathrm{ft}$. long, nearly erect or decumbent. Leaflets lance-shaped. Clusters few flowered, yellow. Pine barrens, L. I. JuneSeptember.

\section{DESMODIUM, DC. (Meibomia, Adams)}

Erect or trailing herbs, with (in our species), 3-foliate leaves, the leaflets of which are arranged as a pair and an odd leaflet. Flowers purple, usually small, in terminal or axillary clusters. Calyx small, its divisions being more or less united as two lips. Lpper petals (standard) round or pear-shaped, side petals (wings) adherent to the keel by means of a small transverse band. Stamens in 1 or 2 groups. Pod (loment) flat, stalked, consisting of one to several joints. These joints roughened by short hairs which aid in their dissemination.

Stamens 10 in a single group. Pods constricted on lower side.

Leaves and flowers on separate stalks ....... D. nxdiflorum

Leaves and flowers on the same stalk.

Flower stalk long, with many flowers . . . D. grandiflorum

Flower stalk bearing but few flowers . . . D. pauciflorum

Stamens 9. united, I more or less free. Pods constricted above and below, though scarcely on the upper margins in Nos, 5, 6 and $I 1$.

Stems trailing or reclining.

Leaflets nearly orbicular . . . . . . . D. rotundifolium

Leaflets egg-shaped.

Plant decidedly hairy, flowers nearly white. D. ochroleucum

Plant nearly smooth, flowers purple . . . D. glabellum

Stems erect, not trailing nor decumbent.

Leaflets narrow, lance-shaped or linear.

Leaf stalk wanting or nearly so . . . . D. sessilifolium

Leaf stalk present.

Flowers in elongated simple cluster
Flowers in a compound cluster - D. strictum Leaflets egg-shaped.

Length more than 3 times the breadth.

Plant quite hairy . . . . . . D. canadense

Plant not hairy
Length less than 3 times the breadth.

Joints of pod decidedly longer than broad, plant decidedly hairy, leaflets abrupt at each end $D$. canescens Joints about as long as broad. 


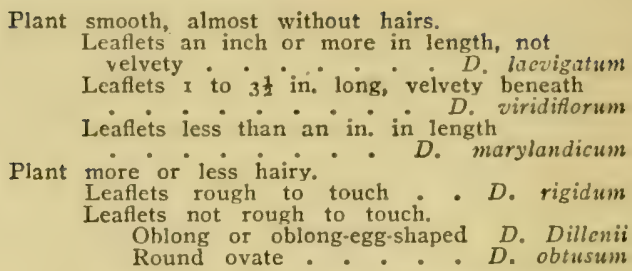

1. D. nudiflorum, (L.) DC. (Fig. 1, pl. 78.) NAKED-FLowered TICK-TREFolL. This plant is easily recognized by its long naked, or almost naked flower stalk springing from the root and the leafy stem at the summit of which all the leaves are crowded. The flower scape often reaches a height of $2 \mathrm{ft}$. or more. Leaves of 3 broadly egg-shaped leaflets. Flowers purple, not very numerous; pod 2 to 3 jointed. Common in dry woods. July-August.

2. D. grandiforum, (Walt.) DC. (Fig. 2, pl. 78.) PointedI.EAVE TICK-TREFoJl. Plant 1 to $5 \mathrm{ft}$. high, erect; leaves crowded at top from which arises the elongated flower stalk. Leaflets round-ovate with long taper points. Flowers Iarge, purple. Pod 2 to 3 jointed. Dry woods. June-Sept.

3. D. pauciforum, (Nutt.) DC. FEW-FLowered Tick-TREFoIL. Plant erect or more or less decumbent, 1 to $3 \mathrm{ft}$. high. Somewhat hairy. Leatlets oval or egg-shaped, the end one rhomboid, silky, pale beneath. Flowers few on a terminal, or axillary naked flower-stalk. Woods. JulyAugust.

4. D. rotundifolium, DC. (Fig. 4, pl. 78.) Prostrate Tick-treFoit. Stems prostrate, 2 to $6 \mathrm{ft}$. long, soft hairy; leaflets orbicular, the odd one less rounded. Flowers purple; pods constricted nearly equally at both margins, 3 to 5 joints. Dry rocky woods. July-Sept.

5. D. ochroleucum, M. A. Curtis. Cream-Flowered Tick-trefoil. Stems with seattered hairs, prostrate; leaflets smooth, egg-shapod, rellowish-green. Flower stalks nuch elongated; flowers whitish. Poils 2 to 4 jointed, twisted. Woods in southern part of our area. Aug.-Sept.

6. D. glabellum, (Michx.) DC. Traming Tick-trefort. Plant procumbent, stems sometimes $8 \mathrm{ft}$. long. smooth or nearly so. I. atlets empshaped or oval, the terminal one somewhat rhomboid. Flower elusters terminai or axillary, flowers purple. Pods 2 to 5 jointed, the joints somewhat rough to the touch. Dry woods. Aug.-Sept.

7. D. sessilifolium, (Torr.) T. and G. (Fig. 6, pl. 78.) SessiueLEAVED 'TiCK-TreFoIL. Stems silky, 2 to $4 \mathrm{ft}$. high. Leallets linear, obtusn at atch rul, almost wilhout leaf-stall. Lpper surface rough, lower silky. Flowers small in long simple or compound clusters. Dry soil in eastern part of our region. July-Sept.

8. D. strictum, (Pursh.) DC. StifF Tick-Treforl. Erect, very straight, 2 to $3 \mathrm{ft}$. high, silky. Leaflets narrow linear, 1 to $2 \mathrm{in.} \mathrm{long,}$ olituse at base, strongly reticulated, not latiry, smooth, on leaf stallis which are $\frac{f}{3}$ to $\frac{1}{2} \mathrm{in}$. long. Joints of pod 1 to 3 (mostly 1). Flowers small on slender seapes. July-Sept. 


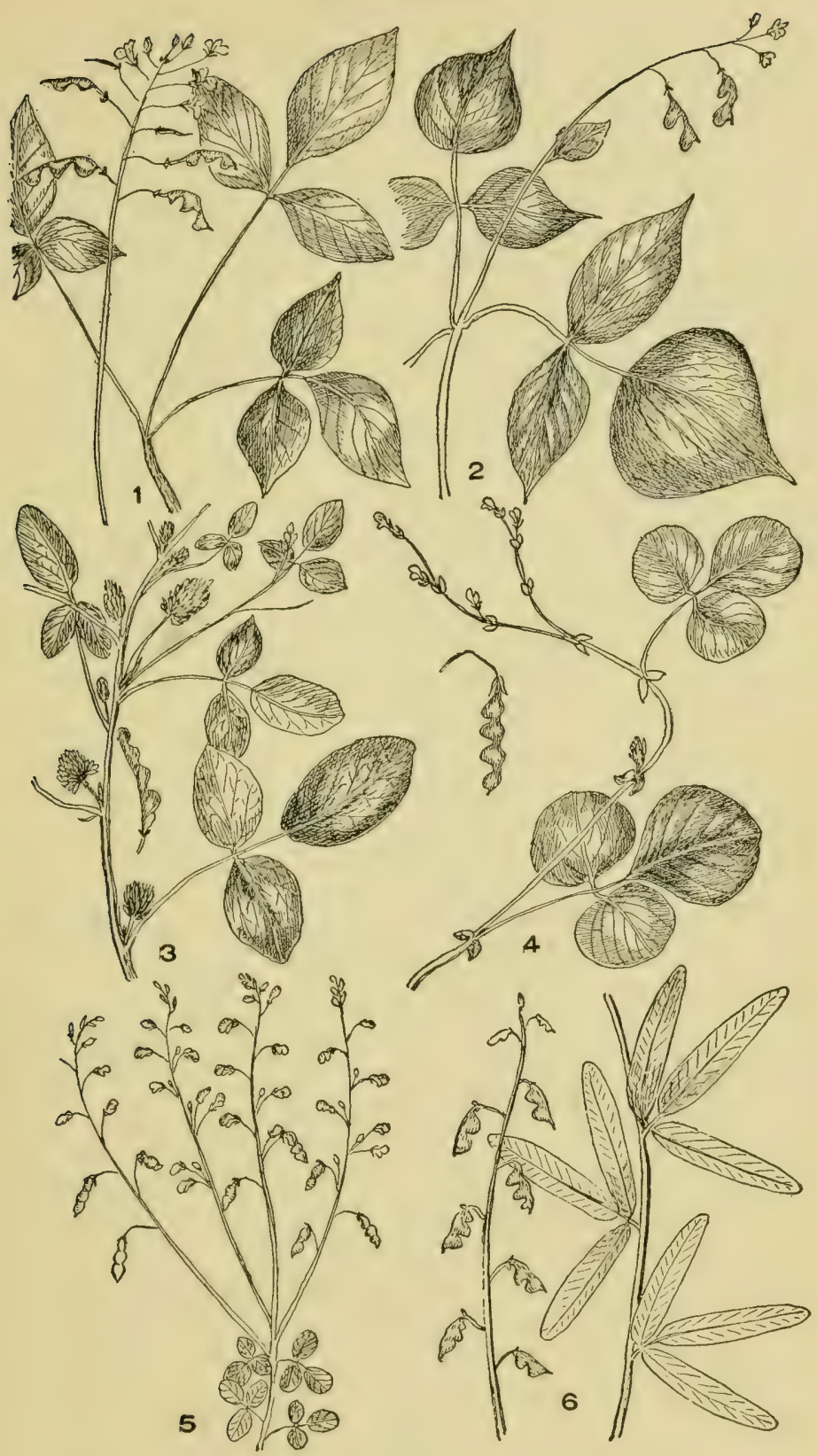

Plate 78

1. Desmodium nudiflorum. 2. D. grandiflorum. 3. D. canescens. 4. D. rotundifolium. 5. D. marylandicum. 6. D. sessilifolium. 
9. D. canescens, (L.) DC. (Fig. 3, pl. 78.) HoARY TICK-Trefoil. Stems branching, densely hairy with soft downy hairs, 3 to $5 \mathrm{ft}$. high. Leaflets egg-shaped, on leaf stalks about as long as the terminal leaflets, rather rough above and below, the under side reticulated and whitish. Flowers small on long hairy scapes. Pods of about 4 joints. Mass., and southward. July-Sept.

10. D. bracteosum, (Michx.) DC. LARge-bracted TicK-Trefoll. Erect, straight, smooth below, somewhat silky on the flower stalk, 3 to $6 \mathrm{ft}$. ligh. Leaflets 2 to 8 in. long, egg-shaped with long slender points. Flowers large, purple. Joints of pod 3 to 5 . Thickets. Common. Aug.Sept.

11. D. paniculatum, (L.) DC. Panicled TiCk-treforl. Slender, eract, 2 to $4 \mathrm{ft}$. high, nearly smooth. Leaflets linear or oblong, blunt at each end, 3 to 5 in. long on short leaf-stalks. Small purple flowers in compound clusters, the branches of the clusters being in many instances at right angles to the main stem. Common. July-Sept.

12. D. laevigatum, (Nutt.) DC. Sмootr TICK-TrefoIL. Stems erect, straight, smooth, 2 to $4 \mathrm{ft}$. high. Leaflets egg-shaped, 2 to $3 \mathrm{in}$. Iong, on long leaf-stalks. Flowers in compound clusters, Joints of pod 4 or more. Aug.-Sept.

13. D. viridiflorum, (L.) Beck. Velver-Leaved Tick-Treforl. Leaves rough above, velvety with long silky hairs beneath. Flowers purple. In form of leaf and general appearance otherwise like $D$. laevigatum. Eastern Penna., southern New York, and westward. Aug..Oct.

14. D. Dillenii, Darl. Dillon's Tick-trefoll. Stem 2 to $3 \mathrm{ft}$. high, erect, silky with hairs scattered. Leaflets oblong or somewhat egg-shaped, blunt at both ends, 2 to $4 \mathrm{in}$. long, on leaf-stalks 1 to $2 \mathrm{in}$. long, pale beneath. Flowers in compound clusters. Pods 2 to 4 jointed, the joints nearly triangular. Common. June-Sept.

15. D. canadense, (L.) DC. (Fig. 11, pl. 79.) SHowr Tick-Trerorl. Stem stout, erect, quite hairy, 2 to $8 \mathrm{ft}$. high. Leaflets oblonglance-shaped, blunt at base, blunt or somewhat sharp at apex. Flowers large, in somewhat dense showy clusters. Common. July-Sept.

16. D. rigidum, (Ell.) DC. (Fig. 10, pl. 79.) Rigid Tick-TrefoiL. Stems rigid, branched, somewhat whitish hairy, as is the lower surface of the leaves. IIeight 2 to $3 \mathrm{ft}$. Leaflets long egg-shaped, blunt at each end, hairy underneath and on edges. Flowers small, purplish, in compound clusters. Pods 1 to 3 jointed. Common. July-Oct.

17. D. marylandicum, (L.) DC. (Fig. 5, pl. 78.) Siootir SMaLLLEAVED 'TíK-TREFoil. Erect, slender, nearly smooth, 2 to $3 \mathrm{ft}$. high. I.caflets hroad exg-shaped with rounded ends $\frac{1}{4}$ to $\frac{1}{2} \mathrm{in}$. long on a leafstalk about the lingth of the lateral ones. Flowers quite small, purplish. P'ods 1 to 3 jounted. Common. July-Sept.

18. D. obtusum, (Muhl.) DC. Hairy SMald-Leaved Tick-trefoll. Much like the last, lut eovered with silky rather rough hairs. Leaves crowderl on short leaf-stalks, leaflets broud egro-shaped or round. Common. July-Oct.

x. LESPEDEZA, Michx.

II rebs, with :-foliate latves, with small stipules or without any. Flowers 


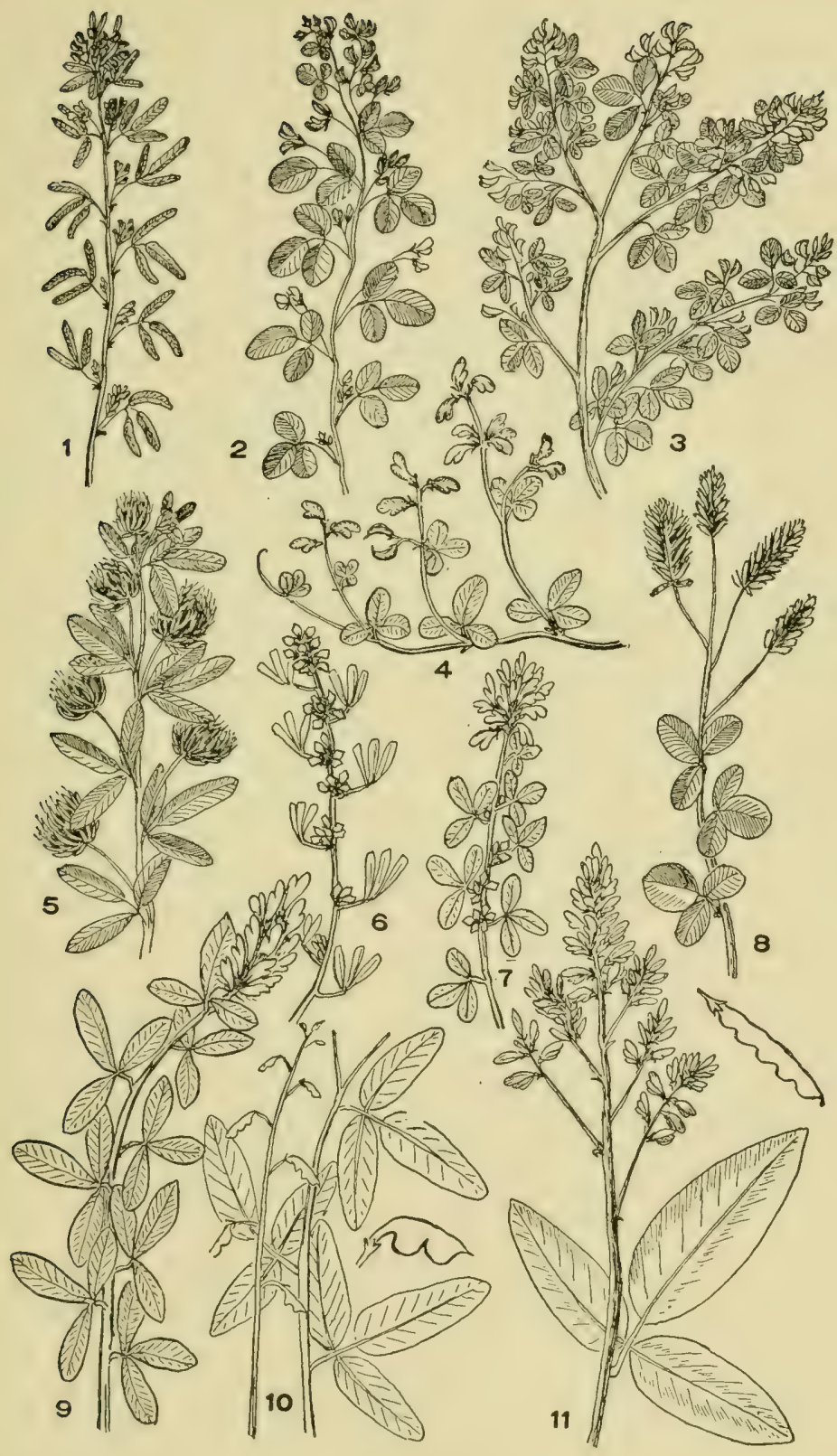

Plate 79

1. Lespedeza angustifolia. 2. L. violacea. 3 L. Stuvei. 4. L, procumbens. 5. L. capitata. 6. L. virginica. 7. L. frutescens. 8. L. hirta. 9. L. Nuttallii 10. Desmodium rigidum. 11. D. canadense. 
often of two kinds (staminate and pistillate, and pistillate only), the former with purplish corolla, the latter without petals or with minute ones. Pods of a single, one-seeded joint, lens-shaped. Keel of the corolla very obtuse.

All the flowers having stamens and pistils, corolla yellowish or whitish, flowers in dense spikes or heads.

Leaflets broadly oval or nearly round . . . . . . . . . . L. hirto

Leaflets oblong or narrowly oblong : . . . . . . L. capitata

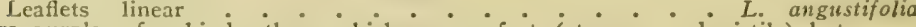
Flowers purple, of 2 kinds, those which are perfect (stamens and pistils) but seldom fertile. The smaller, pistillate only, with very small or no petals.

Plants trailing or procumbent;

Leaves covered with woolly hairs .......... L. repens Leaves not very hairy . . . . . . . L. procumbens

Plants not trailing or procumbent:

Leaves linear

Leaves oblong;

Flower stalks slender, longer than the leaves;

Inflorescence in compact, elongated heads;

Plant not velvety above .... L. Nuttallii

Plant decidedly velvety above . . L. Brittonii Inflorescence loose clusters, few flowered $: L$. violacea Flower stalks shorter than the leaves;

Leaves downy on both sides ...... L. Stuvei Leaves downy only on lower side . . L. frutescens

1. L. hirta, (L.) Ell. (Fig. 8, pl. 79.) HAIRY BusI-clover. Erect, hairy, somewhat shrubby. Stems scarcely branching, 2 to $4 \mathrm{ft}$. high. Leaf stalks not as long as leaves. Leaflets broadly oval or nearly round. Clusters of flowers in elongated cylindric dense heads. All the flowers perfect, reddish-white. Calyx teeth as long or longer than the lens-shaped pod. Dry woods, New Jersey and southward. Aug.-Sept.

2. L. capitata, Michx. (Fig. 5, pl. 79.) Rouxd-heaned Bush-cLover. Erect, hairy, half-shrubby, stems with few or no branches, 2 to $5 \mathrm{ft}$. high. Leaves on short leaf-stalks, leaflets narrow, elliptic, 1 to $1 \frac{1}{2} \mathrm{in}$. long by $f$ as wide, blunt at each end. Flower elusters of dense rounded or oblong heads: flowers yellowish-white with a purple spot on the standard. Dry soils, New England and southward. Aug.-Sept.

3. L. angustifolia, (Pursh.) Ell. (Fig. 1, pl. 79.) N.rrow-Leaved Busu-crover. Erect, simple or somewhat branched above, somewhat downy, 2 to $3 \mathrm{ft}$. high. Leaves on very short leaf-stalks, leaflets narrow, linear, 1 to $1 \frac{1}{2} \mathrm{in}$. long, blunt at each end. Flower stems considerably lunger than the leaves, elusters rounded or somewhat eylindric, flowers whitish. Calyx teeth longer than the pod. Dry sandy soil. Aug.-Sept.

4. L. repens, (L.) Bart. Creering BusH-ćlover. Stem prostrate, spreading, smooth or slightly hairy. Leaflets oval or pear-shaped, rounded at apex, generally narrow at base. Flower stems thead-like, few flowrerrl, the lower flowers being without petals. Petalous flowers purple. Dry soils. Aug.-Sept.

5. L. procumbens, Michx. (Fig. 4, pl. 79.) Traming Bush-clover. sitems procumbent, sprealine, with silky lairs. Isaflets oval or nearly round, upper surface with few or no hairs, lower surface pubescent. Petalous flowers violet. Dry soils. Aug.-Sept.

6. L. Nuttallii, Darl. (F’ig. 9, pl: 79.) Nuttall's Busi-clover. Erect or somewhat reclining, downy, 2 to $3 \mathrm{ft}$. high. Leallets oval to rounded, obtuse at each end or with a noteh and a terminal bristle at apex, smooth above, silky beneath. Flower stems mostly exceeding the 
leaves. Flower clusters in hearls or somewhat cylindric spikes. Petal bearing flowers violet-purple. Calyx teeth shorter than pod. Southern portion of our area. Aug.-Sept.

7. L. Brittonii, Bicknell. Britton's Busn-clover. Stems partly upright, wand-like, 15 to $40 \mathrm{in.}$ long, with short flowering branches. Plant densely velvety above, the upper surface of leaves smooth. Flower branches short; terminal elusters spike-formed on slender stems. Lower clusters few flowered. Corolla pinkish-purple, much longer than the ealyx. Pod egg-shaped to oblong, downy, about twice the length of the ealyx lobes. Bronxville, New York, also eastern Mass. Aug.-Sept.

8. L. violacea, (L.) Pers. (Fig. 2, pl. 79.) BusH-Clover. Erect, usually much branched, with few hairs, 2 to $3 \mathrm{ft}$. high. Leallets elliptie or oval, blunt at each end, $\frac{1}{2}$ to 2 in. long, on short leaf-stalks. Flowers in loose clusters, violet-purple. Calyx teeth shorter than pod. Dry soil, in all of our area. Aug.-Sept.

9. L. Stuvei, Nutt. (Fig. 3, pl. 79.) Stuver's Busi-clover. Stems erect, branching or simple, very velvety, and very leafy, 2 to $4 \mathrm{ft}$. high. Leallets oval to rounded, blunt at each end, silky white beneath and sometimes alrove. Flower stalks short, elusters terminal or axillary, those with petals violet-purple. Calyx teeth shorter than the nearly round pad. Dry soil, Vermont, Massachusetts and south and west. Aug.Sept.

10. L. frutescens, (L.) Britton. (Fig. 7, pl. 79.) WVAND-LIKE Busil-clover. Similar to above, but less hairy and hairs shorter. Leaflets smooth above, somewhat silky beneath. Upper flowers violet-purple. Dry soil, our area. Aug.-Sept.

11. L. virginica, (L.) Britton. (Fig. 6, pl. 79.) SLender BusircLover. Erect, with a simple stem or somewhat branched above. Leaflets linear with or without fine soft hairs. Flower clusters close to main stem without lengthened flower-stalks, violet-purple. Dry soil, New Hampshire, and southward. Aug.-Sept.

\section{VICIA, L.}

Climbing or trailing vines with feather-formed leaves, leaflets of an even number, the leaf terminated by a tendril. Stipules conspicuous. Flowers in axillary clusters, generally conspicuous, mostly blue or violetpurple. Standard egg-shaped or oblong with a depression at the summit; wings oblong, adhering to the curved keel. Stamens, 9 united, 1 free. Style slender, curved, with a ring or tuft of hairs at summit or throughout its extent. Pod 2-valved, 2 to several seeded.

Flowers on elongated flower-stems.

Leaflets about $\frac{1}{2}$ as broad as long;

Stipules broad with conspicuous teeth . . . . V. americana

Leaflets generally less than $\frac{1}{3}$ as broad as long. Ends sharp or rounded.

Flowers in dense clusters, usually more than $20 . V$. Cracca Flowers from 8 to 20 in cluster... Flowers $\mathrm{I}$ to 6 in cluster.

Leaflets rounded or pointed at both ends $V$. tetrasperma Leaflets abrupt at apex
Flowers with very short or with no flower stems.

Leaflets abrupt at apex.

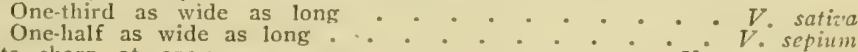

Leaflets sharp at apex.${ }^{\circ} \cdot{ }^{\circ} \cdot{ }^{\circ} V^{\circ}$ angustifolia 
1. V. Cracca, L. (Fig. 1, pl. 80.) Tukted Vetcr. Trailing vine 2 to $4 \mathrm{ft}$. long, with leaves of 9 to 12 pairs of leaflets and with flowers overlapping in a rather dense one-sided cluster ( 20 to 40 flowers). Leaflets linear, pointed at each end or somewhat rounded with a bristlepoint at apex. Flower clusters on long stalks from the axils of the leaves. Stem square, somewhat downy as are also the leaflets. A slender climber or trailer with blue or purple flowers. Dry soil, New Jersey and northward. June-Aug.

2. V. americana, Muhl. (Fig. 1, pl. 81.) American Vetcr. Trailing vine, 1 to $3 \mathrm{ft}$. long, nearly without hairs. Stipules broad with several conspicuous teeth. Leaflets, 4 to 7 pairs, elliptic to egg-shaped ou the one hand or lance-shaped on the other, blunt at each end. Flowers 4 to 8 , bluish-purple, the flower-stem shorter than the leaf-stalk. Pod about an inch long, 4- to 7 -seeded. Moist grounds, New York and southward. May-August.

3. V. caroliniana, Walt. (Fig. 2, pl. 80.) Carolina Vetcir. Slender vine, 4 to $6 \mathrm{ft}$. long, smooth. Leaflets 4 to 6 pairs, oblong or linear. Flowers 8 to 20 in a cluster, the stem of which is generally somewhat shorter than the leaf-stalks. Flowers nearly white or pale blue, the banner tipped with purple. Moist places, our area. May-July.

4. V. tetrasperma, (L.) Moench. (Fig. 4, pl. 80.) Slender Vетсп. Stem slender, clinging, smooth or nearly so. Leaflets 3 to 6 pairs, linear, obtuse or rather sharp at the ends. Stipules simple, narrow, spread at base. Flower stem slender, shorter or about equalling the leaf-stalk, carrying from 1 to 6 pale blue or purple small flowers. Calyx tube of 5 unequal tecth. Pod linear-oblong with 2 or 3 globular seeds. Fields and waste places. May-Sept.

5. V. hirsuta, (L.) Koch. HaIry Veтcr. Vine, somewhat hairy, stem branching. Leaflets 8 to 10 pairs; individual leaflets having the appearance of having been cut off at the end, a small bristle appearing as the termination of the mid-vein. Flowers small, purplish. Pod somewhat velvety, oblong, dark, crimpled, 2-seeded, about $\frac{1}{2}$ in. long. Fields and waste places. May-Sept.

6. V. sepium, L. (Fig. 3, pl. 81.) Bush Vetcr. Wild Tare. Leaflets 10 to 18 , broad egg-shaped very blunt or depresed at apex. Flowers few, without flower-stalks. Waste places, only in northern part of our area. May-July.

7. V. sativa, I. (Fig. 3, pl. 80.) Common Vetcr. Stem flexible, elinging ly the leaf tendrils, more or less hairy, angular. Leaflets 4 to 7 pairs, inversely oval, the base narrowed, the apex rombled with a rather deep noteh at center and with a bristly point to the central vein. Flowers large, bluish-purple, without leaf-stalks, or with very brief ones, g(ncrally 2 flowers at the leaf-axils. Pods solitary or in pairs. broad, strongly veined, dark hrown when ripe. Ficlds. Introdued from Europe where it is cultivated for fodder. May-August.

8. V. angustifolia, Tioth. (Figr. 2, pl. 81.) Smalemer Common Vetror. Strms numerous, hanching, partly crect, 1 to $2 \mathrm{ft}$. Iong. Stipules simple or tontledel. Jacaflets 3 to 8 pairs, narrowly linear, $\frac{1}{2}$ to $1 \frac{1}{2} \mathrm{in.}$ long. Purple flowers without flower-stallis or with very short ones in upper 


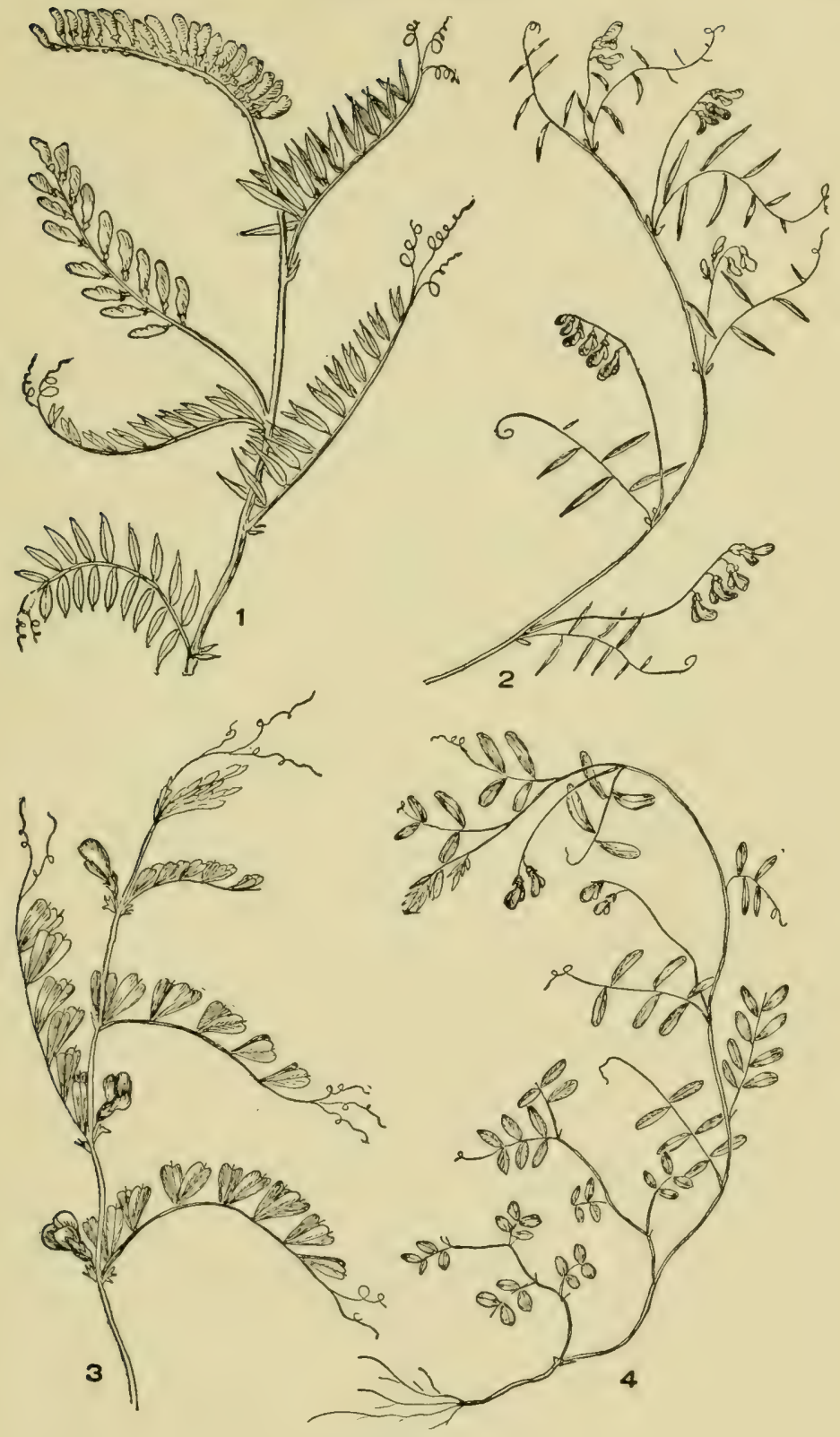

Plate 80

1. Vicia Cracca. 2. V. caroliniana. 3. V. sativa. 4. V. tetrasperma. 
leaf-axils. Pod linear, terminated by a recurved beak, somewhat hairy. Mostly near the coast. April-July.

\section{LATHYRUS, L.}

Vines, mostly trailing, some species partly or wholly erect. Leaves of an even number of leaflets, the leaf-stalk terminating by a tendril. The nerules are usuully nearly parallel with the ecntral nerve. Flowers in clusters or single, nearly like those of Vicia, often large. Stamens, 9 united, 1 free, or 10 united.

Leaflets broadly oval or elliptic.

Flowers purple.

Stipules broad lalberd-shaped, not divided at apex . L. maritimus Stipules deeply divided from apex... . . . . L. venosus Leaflets narrow lance-shaped or somewhat egg-shaped.

Stems with wings at the angles........ . . L. palustris

Stems angled, but not winged. Flowers yellowish.

Stipules narrow, leai-like, lance-shaped . . . . . L. pratensis Stipules broad........ . . . L. ochroleucus

1. L. maritimus, (L.) Bigel. (Fig. 3, pl. 82.) Beacr PEA. Nearly erect, or decumbent, stout, stems about $1 \mathrm{ft}$. high, angled. Stipules very conspicuous, halloerd-shaped and nearly as large as the leaflets. Leallets elliptic or oval, 1 to $2 \mathrm{in}$. long, $1 / 3$ to $1 / 2$ as wide. Flowers showy, purple, in thick clusters on flower-stalks rather shorter than the compound leaves. Pod linear with a beak turned at a sharp angle. Sand at seashores. May-August.

2. L. venosus, Muhl. (Fig. 7, pl. 81.) Veiny PeA. Stem climbing, nearly smooth or covered with soft hairs, 2 to $3 \mathrm{ft}$. high, strongly 4angled. Stipules very small and slender. Leaflets 4 to 6 pairs, broadly elliptic or oval. Flowers purple about as large as those of No. 1, and on a stem about as long as the compound leaf. Pod linear with a beak not much bent. Southern part of our region. May-July.

3. L. palustris, L. (Fig. 4, pl. 82.) MARsh Vetchling. Stems slender, usnally with wings at the angles, smooth or nearly so. Stipules broad, split down the center. Leaflets 2 to 4 pairs, narrow lance-shaped, about 1 to $2 \mathrm{in.}$ long and $1 / 5$ as wide. Flowers in loose clusters ( 2 to 6 in cluster), purple, each about $\frac{1}{2}$ in. long. Pod narrow $1 \frac{1}{2}$ to $2 \frac{1}{2}$ in. long. Moist places, nortliern part of our area. May-August.

4. L. myrtifolius, Muhl. (Fig. 2, pl. 82.) Mrrtle-Leaved Marsir PEA. Stems slender, angled but not winged. Stipules broad and long, resembling leaflets. Leaflets 2 to 4 pairs, oval or oblong, $2 / 3$ to $2 \mathrm{in}$. long. Flowers purple, 2 to 9 in eluster. Pods long, the beak recurved. Moist places, our area. May-July.

5. L. pratensis, I. (Fig. 5, pl. 81.) MEAdow PEA. Climbing or stragerling, 1 to $3 \mathrm{ft}$. long. Leaves of a single pair of leatlets which are linear or broadlinear, $\frac{1}{2}$ to $1 \mathrm{in}$. lone. Stipules of similar form and size so that apparently there are t lcallets, the lower pair attached to the stem. Flowers in a long slender cluster on a long flower stalk, yellow. Maine to New York. June-Aug.

6. L. ochroleucus, Tfook. (Fig. 6, pl. 81.) Crmam-Colonen Vercriuxa. Stem somewhat angled, climbing, 1 to $2: \mathrm{ft}$. high. Stipules broad, 

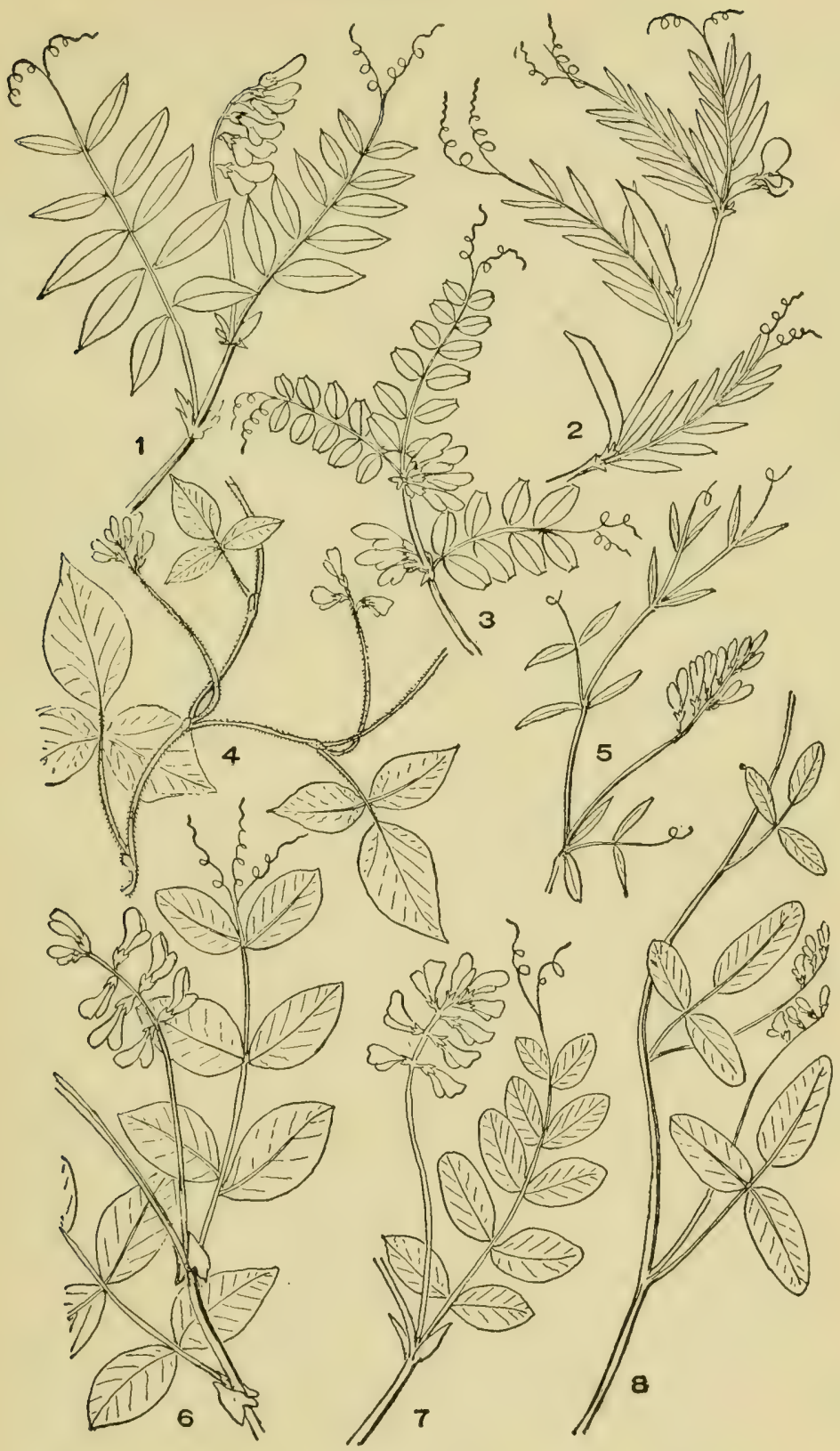

\section{Plate 81}

1. Vicia americana. 2. V. angustifolia. 3. V. sepium. 4. Amphicarpa monoica. 5. Lathyrus pratensis. 6. L. ochroleucus. 7. L. venosus. 8. Galactia regularis. 
leaf-like. Leaflets 3 to 5 pairs, broadly oval or egg-shaped. Flowers yellowish-white in clusters of 5 to 9 , $\frac{3}{4}$ in. long. Pod straight, beak curved. Distributed through most of our area. May-July.

\section{CENTROSEMA, DC. (Bradburya, Raf.)}

Slender twining herb, with 3 -foliate leaves, a pair and an odd one. Both leaves and leaflets stipulate. Flowers in axillary clusters or solitary, showy. Calyx short, bell-shaped, its teeth nearly equal. The large standard erect and rounded with a spur-shaped projection on the back toward the base. Wings pear-shaped, keel broad and curved. Style bearded. Pod long and slender, flat with elongated point. Stamens, 9 united, 1 more or less free.

C. virginianum, (L.) Benth. Spurned Butterfly Pes. Somewhat rough hairy, stem trailing 2 to $4 \mathrm{ft}$. long. Leaflets egg-shaped to oblong or linear, shining. Flower stalks each bearing 1 to 4 showy violet handsome flowers about an inch long. Pods 4 to 5 in. long, very slender, with a long awl-shaped point. Southern part of our area. July-August.

\section{CLITORIA, L.}

Climbing, erect or trailing herbs or more or less woody vines. Leaves 3-foliate, a pair and an odd one. Learlets with stipulate bracts. Calyx tubular, 5-toothed. Flowers large, the standard rounded, ereet with a distinct depression at summit and with no spur at the back. Stamens, 9 united, 1 more or less free. Pod slender, flattened, knotty, severalseeded.

C. mariana, L. (Fig. 6, pl. 83.) Butterfly PeA. Stem 1 to $3 \mathrm{ft}$. high, reclining or partly erect, smooth. Leaflets oblong or very narrow egg-shaped. Stipules awl-shaped. Flower stalk short, with 1 to 3 showy pale blue flowers about $2 \mathrm{in}$. long. Southern part of our area. June-July.

\section{AMPHICARPA, E11. (Falcata, Gmel.)}

Slender herbs, twining, the stem clothed with brown hairs. Leaves 3 -foliate, the leaflets broad. Flowers small, white or violet, in simple slender clusters (in our species). Flowers of two kinds, those of the upper branclies having colored petals, those on lower branches solitary without petals, but producing seed.

1. A. monoica, (L.) Iil. (Fig. 4, pl. 81.) Wild Pea-Nut. Hoc PEA-NUT. Leaflets 3 , to 2 in .long. Flower clusters simple and generally nodding; flowers purplish or white. Bracts at base of flowers egg-shaped. Common. Aug.-Sept.

2. A. Pitcheri, ('T. and G.) Pitchen's Hog PEA-Nut. Leaflets 3, 2 to $4 \mathrm{in}$. long. Bracts below flowers orbicular. Western New York. Aug.-Sept.

\section{APIOS, Moench.}

Twining vines climbing on trees and shrubs with leaves of 3 to 7 leaflots. Flowers in compact, short, often branching clusters, brownishjurple: or red. Calyx bell-shaped, somewhat 2-lipped. Standard very broal and turned backward, the long keel twisted. Stamens, 9 united, 1 free. l'od linear. 

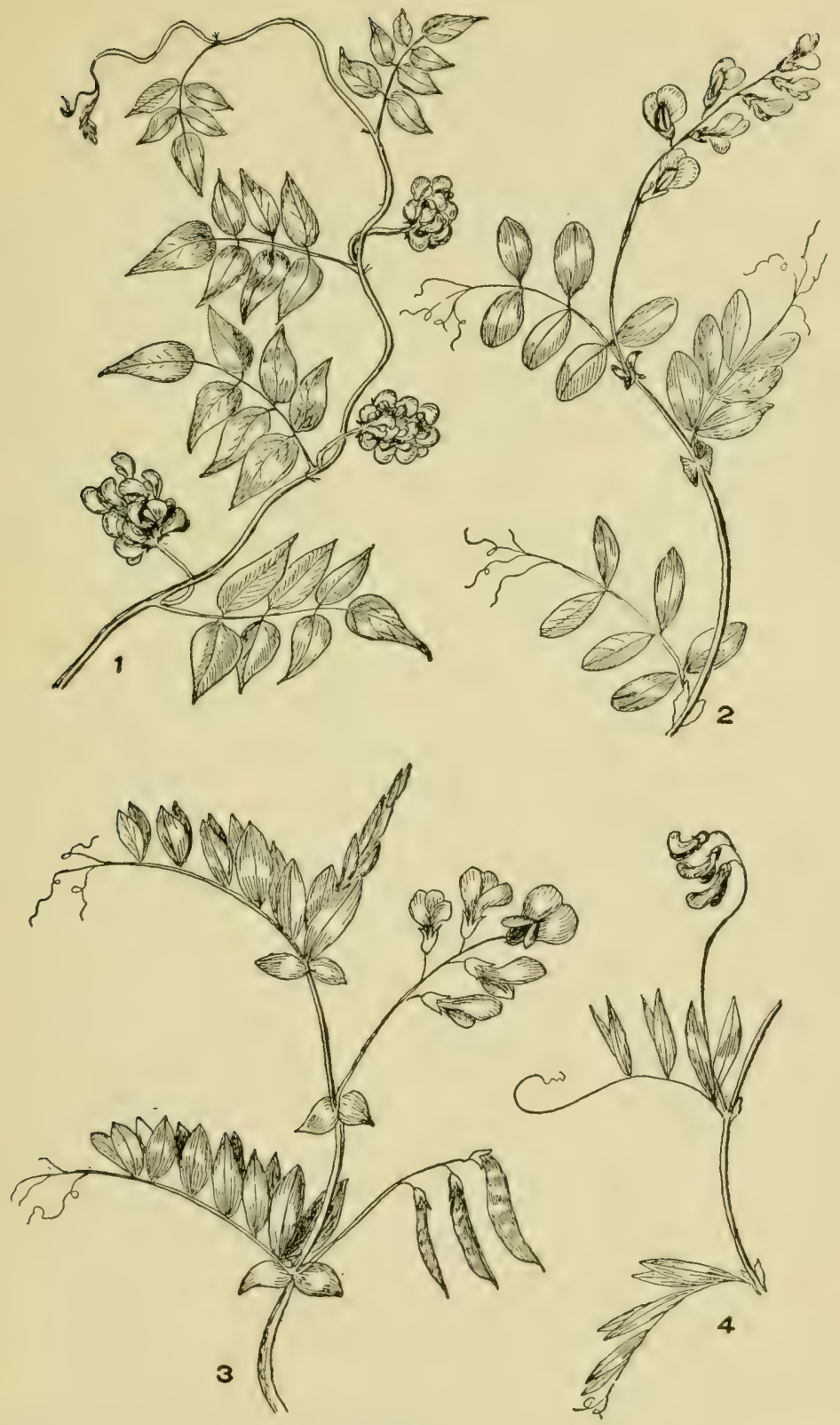

Plate 82

1. Apios tuberosa. 2. Lathyrus myrtifolius. 3. L. maritimus. 4. L. pa- 
A. tuberosa, (L.) Moench. (Fig. 1, pl. 82.) Ground-Nut. A vine, climbing on shrubs and trees often fouml along banks of streams. The underground tubers are said to be edible. Flowers brownish-purple. Moist grounds. July-Sept.

\section{GALACTIA, P. Browne}

Prostrate or twining herbs, with 3-foliate leaves and small stipules, which fall early. Calyx 4-lobed, the lobes narrow and sharp at apex and nearly equal in length. Standard orbicular, keel nearly straight, wings narrow. Stamens, 9 united, 1 free. Pod straight linear, few seeded.

1. G. regularis, (L.) BSP. (Fig. 8, pl. 81.) MilK PeA. Mostly prostrate, smooth. Leaflets elliptic, oblong, obtuse at each end, shining above, somewhat hairy beneath, about 1 to $1 \frac{1}{2}$ in. long. Flower cluster from leaf axils on somewhat lengthened flower-stalks, the cluster about as long as leaves. Flowers purple, greenish on the outside, rather large. Dry soils, near the coast, southern New York, and southward. Aug.-Sept.

2. G. volubilis, (L.) Britton, Downy MILK PEA, Generally twining, stem covered with silky hairs, several feet long. Leaflets similar in form to No. 1. Silky and whitish bencath. Flower cluster generally extending beyond the leaves. Flowers smaller than those of No. 1. Dry soils, southern part of our area. June-Aug.

\section{PHASEOLUS, L.}

Herbaceous twining or trailing plants, with 3 -foliate leaves with stipules which fall early. Flowers in clusters from the leaf axils. Calyx 5toothed or lobed, the upper two somewhat united. Standard orbicular, keel spirally twisted. Pod sickle-shaped or nearly straight.

1. P. polystachyus, (L.) BSP. Fig. 5, pl. 83.) WrLd Bean. BeAN Vine. ( $P$. perennis, Walt.). Vine, often many feet long, climbing and twining on other plants, often forming extensive masses of the light green vine. Leaflets large, broadly egg-shaped, $1 \frac{1}{2}$ to $3 \mathrm{in}$. long, acute at apex, rounded at base. Flower clusters narrow, long, loose flowered. Flowers light purple. Pod about 2 in. long, with compressed dark purple seeds. Common. July-Sept.

2. P. helvolus, L. (Fig. 2, pl. 83.) Trailixg Wild BeaN. (Strophostyles helcola, Britton.) Stem slender, trailing, 2 to $8 \mathrm{ft}$. long, ratlier rough-hairy. Leaflets egrg-shaped, acute or olituse at apex. Flower-stalk much longer than the compound leaves. Flower clusters of few ( 2 to 6) flowers. Corolla greenish-purple. lieel not twisted, but slender and curved. Sandy shores and river banks, eastern section of our area. July-Oct.

28. STROPHOSTYLES, Ell.

Similar to Phaseolus, but lieel of corolla is not spirally coiled, but is strongly incurved.

S. umbellata, (Muhl.) Jritton. (Fig. 4, pl. 83.) PINK Wirn Bes.. Resembles Phascolus helvolus, but the leallets are often narrower and often with one or more shallow lobes at border. Long lsland and southward. July-Sept. 


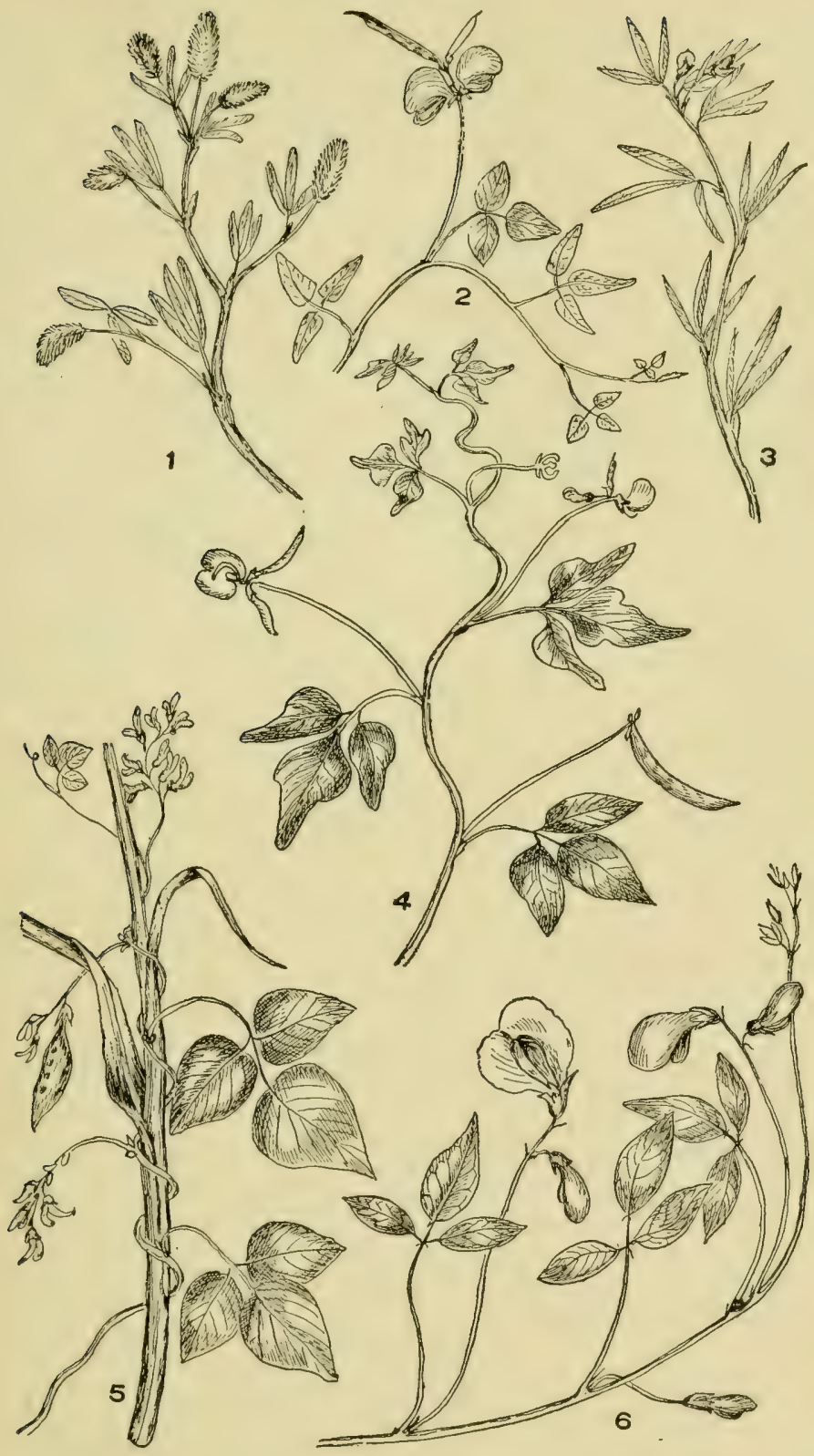

Plate 83

1. Trifolium arvense. 2. Phaseolus helvolus. 3. Stylosanthes biflora. 4. Strophostyles umbellata. 5. Phaseolus polystachyus. 6. Clitoria mariana. 


\section{Order VII.-GERANIALES. Order of the Geraniums}

This order includes families differing so widely that they do not appear related except to the expert. 'There are, however, certain common characteristics. There are present the calyx and corolla except in rare instances. The ovary is superior to and fiee from the calyx and the divisions of the calyx (sepals) are, in nearly all cases distinctly separate from each other to the base or nearly to it. The stamens are few, usually 5 or 10 in flowers in which the petals are all similar (flowers regular), but in flowers in which the petals of the same flower are dissimilar the number is reduced. The carpels (ovule bearing parts of the pistils) 5 or less, are united, retaining, however, their dividing partitions, but in Ceranium these carpels separate when ripe. The ovules are pendulous from the part of the carpel entering into the constitution of the central axis of the combined carpels, and the ridge which connects the two cnds of the ovule (the raphe) lies toward this contral axis.

Herbs.

With colored, showy flowers.

Flowers symmetrical.

Leaves with radiating lobes . . GERANIACEAE

Leaves 3-foliate . . . . OXALIDACEAE

Leaves not lobed or divided . . . LINACEAE

Flowers unsymmetrical . . . POLYGALACEAE

With mostly inconspicuous flowers, plants with millyy juice

. EUPHORBIACEAE

Small aquatic plants with very slender stems, opposite

leaves and minute axillary flowers - CALLITRICHACEAE 'Trees.

Leares of not more than 13 leaflets . . . RUTACEAE

Leaves of from 13 to more than 10 leaflets SIMARUBACEAE

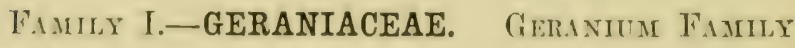

ITerbs, rarely shrubly, the stems of which often divide in pairs. dares usually decply lobed, nearly always with stipules at the 
base of the leaf stalk. Flowers generally regular the calyx and corolla each of 5 divisions. In some foreign species the calyx has less than 5 sepals. Stamens 10 , united at the base, 5 long and 5 short, in Geranium all fertile, in Erodium 5 only fertile. Styles 5 , adherent to a central column, the whole forming a slender beak. Ovary free with 5 cells, the cells each with 2 ovules.

Stamens 10, all bearing anthers . . . . . Geranium

Stamens 10, 5 only bearing anthers . . . Erodium

\section{GERANIUM, L.}

All of our speeies herbs, the stem swollen at the nodes. Leaves opposite or alternate usually cut or lobed, our species all with stipules at foot of leaf stalk. Flowers regular with 5 petals, 5 sepals, 10 stamens, 5 long and 5 short, usually ripening at different times. Ovary 5-celled, terminating in a long beak. Fruit when mature of 5 one-seeded earpels. These at maturity elastically separate from the central column, a thread-like portion of the carpel to which the seed is attached coiling upward. (Fig. 1a, pl. 84.)

Flowers $\mathrm{y}$ in. broad or more . . . . . . . . . . . . G. maculatum Flowers about $\frac{1}{2}$ in. broad.

Leaves divided to the base into 3 compound leaflets, the middle one at

least with a stem ............ Robertianum

Leaves cleft nearly to the base into 3 compound divisions, the middle one not on stem.

Flower stalks exceeding the leaves.

G. columbinum

Flower stalks not exceeding the leaves.

Beak of seed capsule $\mathrm{I}$ in. long . . . . . . G. Bicknellii

Beak of seed capsule about $\frac{1}{2}$ in. long . . . . . G. dissectum

Leaves cleft from $\frac{1}{2}$ to $\frac{3}{2}$ to the base.

Flower stalk with a single flower........ G. sibiricum

Flower stalk with 2 flowers.

Leaves nearly round, sinuses extending not more than half way to

base . . . . . . . . . G. rotundifolium

Sinuses extending more than hall way to base.

Flowers in compact clusters Carpels hairy

Leaves divided into 7 parts

G. carolinianum

G. pusillum

- G. molle

G. pratense

1. G. maculatum, L. (Fig. 1, pl. 84.) Crane's Bilt. Stem 1 to $2 \mathrm{ft}$. high, erect, hairy; leaves about 5 -parted nearly or quite $2 / 3$ to base, the basal ones on long leaf-stalks, more or less rounded, 3 to $6 \mathrm{in}$. wide. Flowers in loose clusters at upper end of stem. Petals light purple; sepals slender pointed. Common in woods. April-July.

2. G. Robertianum, L. (Fig. 3, pl. 84.) IIERB Ronert. Annual or birmial. Extensively branching, the branches prostrate or partly erect, often covered with sticky hairs. Leaves deeply divided into lobes which are distinct to the base, the lobes also deeply incised. Leaf-stalks longer than the leaves. Flowers, 2 on a stalk exceeding the leaves; petals red-purple, sepals velvety, awl-shaped. The plant has a strong and rather unpleasant odor. Common in rocky woods. May-Oct.

3. G. carolinianum, L. (Fig. 2, pl. 84.) Carolina Crane's-bill. Frect, diffusely branched, stems hairy, 6 to $15 \mathrm{in.} \mathrm{high.} \mathrm{Leaves} \mathrm{divided}$ into about 5 to 7 lobes, the sinuses extending rather more than half way 
to base; lobes also cleft into numerous divisions. Flower stalks rather short, branched, each branch with 2 flowers. Sepals as long as the pale purplist petals. Beak about 1 in. long. Barren soil, east Mass., westward and southward. April-Aug.

4. G. Bicknellii, Britton. Bicknell's Crane's-bill. Similar to last, but flower-stalks do not exceed the leaf-stalks. New York, New England and northward. May-Sept.

(The following species, introduced, are more or less naturalized and are found in limited localities in our area.)

5. G. dissectum, I. (Fig. 5, pl. 84.) Cut-Leaved Crane's-bill. Petals not longer than the sepals. Sepals not curved outward. Flowerstalks shorter than leaves, two flowered.

6. G. columbinum, L. (Fig. 8, pl. 84.) Long-stalked Crane's-bill. Slender, mostly prostrate; leaves 1 to $1 \frac{1}{2}$ in. diameter. Sepals and petals of about the same length. Borders of sepals curved outward. Flowerstalks longer than leaves.

7. G. pusillum, I. (Fig. 4, pl. 84.) Sarall-Flowered Crane'sBILL. Stems procumbent, diffusely branching, with soft hairs. Petals longer than sepals. Carpels not wrinkled. Stamens 5.

8. G. molle, L. (Fig. 9, pl. 84.) Dove's-Foot Crane's-bill. Similar to last, but more hairy. Petals about twice as long as sepals. Carpels transversely wrinkled. Stamens 10.

9. G. rotundifolium, L. (Fig. 7, pl. 84.) Round-Leaved Crane'sBILL. Stems decumbent, slightly hairy. Leaves divided nearly to base; lobes linear; general form rounded. Sepals velvety. Fruit and seeds with long silky hairs tipped with purple glands.

10. G. sibiricum, L. (Fig. 6, pl. 84.) Siberian Crane's-bill. Stems decumbent, freely branched, silky. Leaves deeply 3-parted, divisions strongly toothed. Flowers dull white, generally solitary.

11. G. pratense, L. Spreading Crane's-Bill. Leaves mostly 7parted, the narrow lobes deeply cut. Flower stems downy. Corolla deep purple. Maine and locally in Mass.

\section{ERODIUM, L'Her.}

Resembles Geranium, but leaves are, in our'species, pinnate, $i$. $c$, featherformed. Of the stamens 5 are perfect, the others sterile, greatly reduced or wanting.

E. cicutarium, (T.) L'Her. Hemlock Stork's-bill. Heron's-Bill. Growing in tufts. Hairy, low, spreading. Leaves of opposite leallets on an elongated axis, the leaflets deeply cut. Flowers purple, nearly $\frac{1}{2}$ in. broad. The beak very long. Introduced. April-Sept.

\section{Family II.-OXalidaceaE. Wood-sorrel Family}

ITerlss, with 3-foliate leaves, 10 stamens, of which 5 are shorter than the remaining 5 (rarely 15) ; 5 styles, more or less coherent. Sepals 5; petals i); symmetrical. Fruit a capsule with 5 valves. Orules several in each cavity. Leaves basal or alternate. 


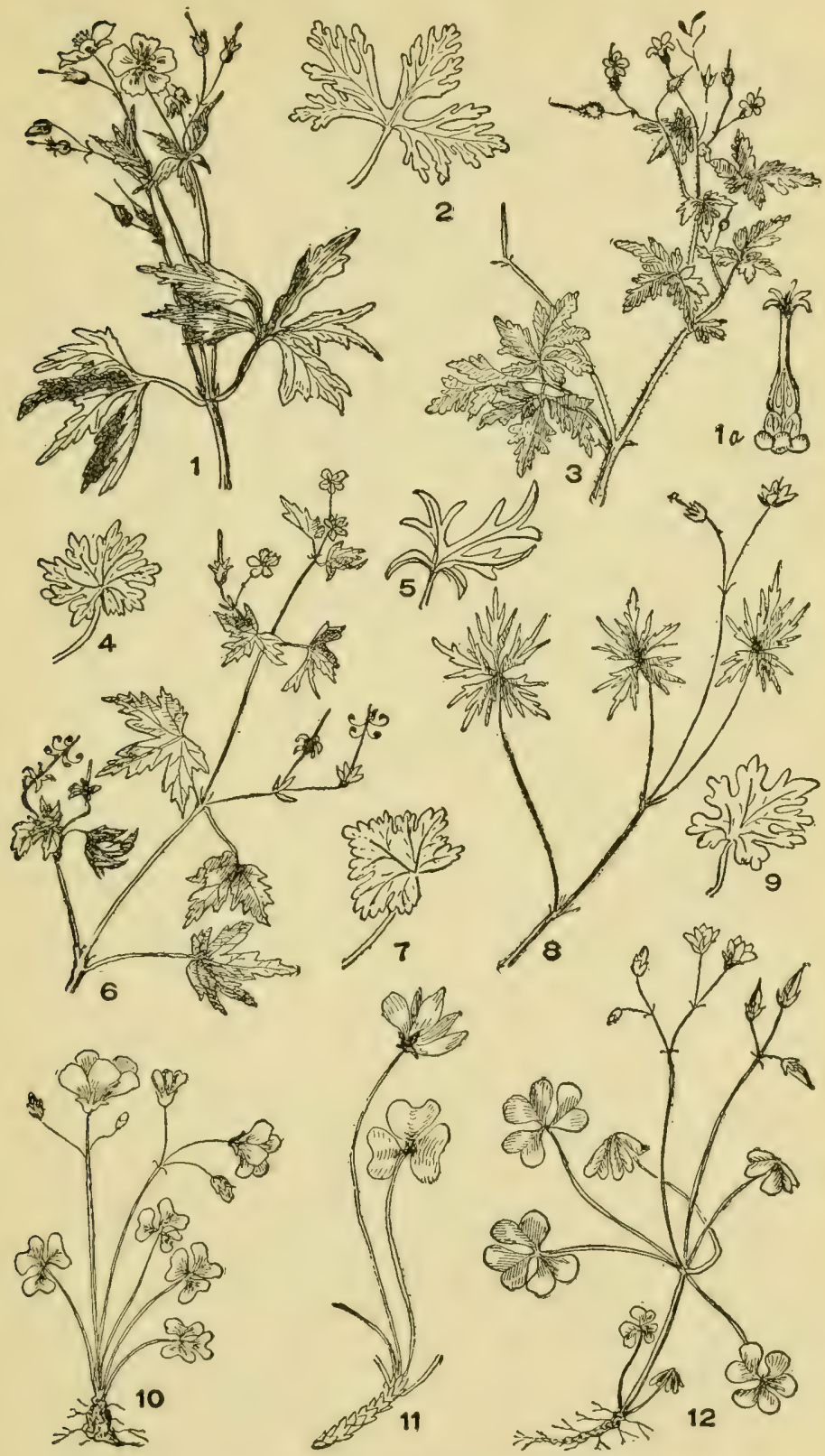

Plate 84

1. Geranium maculatum. 1a. Pistil of G. maculatum. 2. G. carolinianum. 3. G. Robertianum. 4. G. pusillum. 5. G. dissectum. 6. G. sibiricum. 7. G. rotundifolium. 8. G. columbinum, 9. G. molle. 10. Oxalis violacea. 11. O. Acetosella. 12. O. stricta. 


\section{OXALIS, L.}

Characters as above.

Leaves and flower-stems directly from the rootstock.

Flower-stem one-flowered . . . . . . . . o. Acetosella

Flower-stem several-flowered . . . . . . . O. violacea

Leaves and flower-stems not from the rootstock.

Stipules conspicuous ........... O. corniculata

Stipules not conspicuous ........... O. stricta

1. O. Acetosella, I. (Fig. 11, pl. 84.) Witte Woon-sorrei. Herbs, 2 to 6 in. high; leaves all from the base. Rootstock creeping and scaly. Flower stem from the root, one-flowered; petals white with reddish veins. Moist woods. May-July.

2. O. violacea, I. (Fig. 10, pl. 84.) VIOLET WOoD-SORReL. Root bulbous, scaly. Flower stems from root, with from 3 to 12 flowers, which are rose-purple or nearly white. Rocky woods. May-June.

3. O. corniculata, L. Yellow Wood-sonkel. Stems branching, mostly precumbent, 1 tó $6 \mathrm{in}$. long. Flowers yellow, 2 to 6 on a flowerstem. Pods linear. Stipules conspicuous. Less common than No. 4. Summer.

4. O. stricta, L. (Fig. 12, pl. 84.) Upright Wood-sorres. Stems ercet, stipules not conspicuous. Plant without hairs. Flowers yellow. Common in woods and fields. April-Oct.

In addition to the above a considerable number of forms found in our area are reported as species by Dr. Small.

\section{Family III.-IINACEAE. Flax Family}

Ilerbs (always in our area), with alternate or opposite leaves which are simple, with borlers entire, attached directly to the stem (sescile) and without stipules. Flowers recrular, symmetrieal, in our genus of 5 petals; sepals 5 . Stamens 5 fertile, 5 sterile or suppressed, the fertile alternate with the petals. Ovary mostly of 5 cells.

In our area we have only one genus.

\section{LINUM, L.}

Which has the characters of the family, $i$. $e$, sepals 5 , petals 5 , longer than the calyx; stamens 5 ; styles 3 to 5 . Seed capsule globular.

likwers blue

lilowers yellow.

Howers about $\frac{1}{2}$ in. broad, stem striped or angular . . L, virginianum Nowers about $1 / 8$ in. broad, stem not striped... L. medium lilowers alout t in. broad, branclies sharply angled or winged L. striatum Illowers $\frac{1}{2}$ in. broad or more, stem angled with wings . . L. sulcatum

1. L. usitatissimum, L. (Fig. 1, pl. 85.) Flax. Linseed. Stem branching abure. Ermerally simple below, erect, about 12 to $20 \mathrm{in.}$ high. Flowers bell-shaped, large, in loose clusters, each flower on a slender more or len elomgated flower stalk. Sepals oval, sharply pointed. Found occasionally spontaneous. Introduced. Summer.

2. L. virginianum, L. (Fig. 2, pl. 85.) Stender Yellow Flax. 
FLAX FAMILY

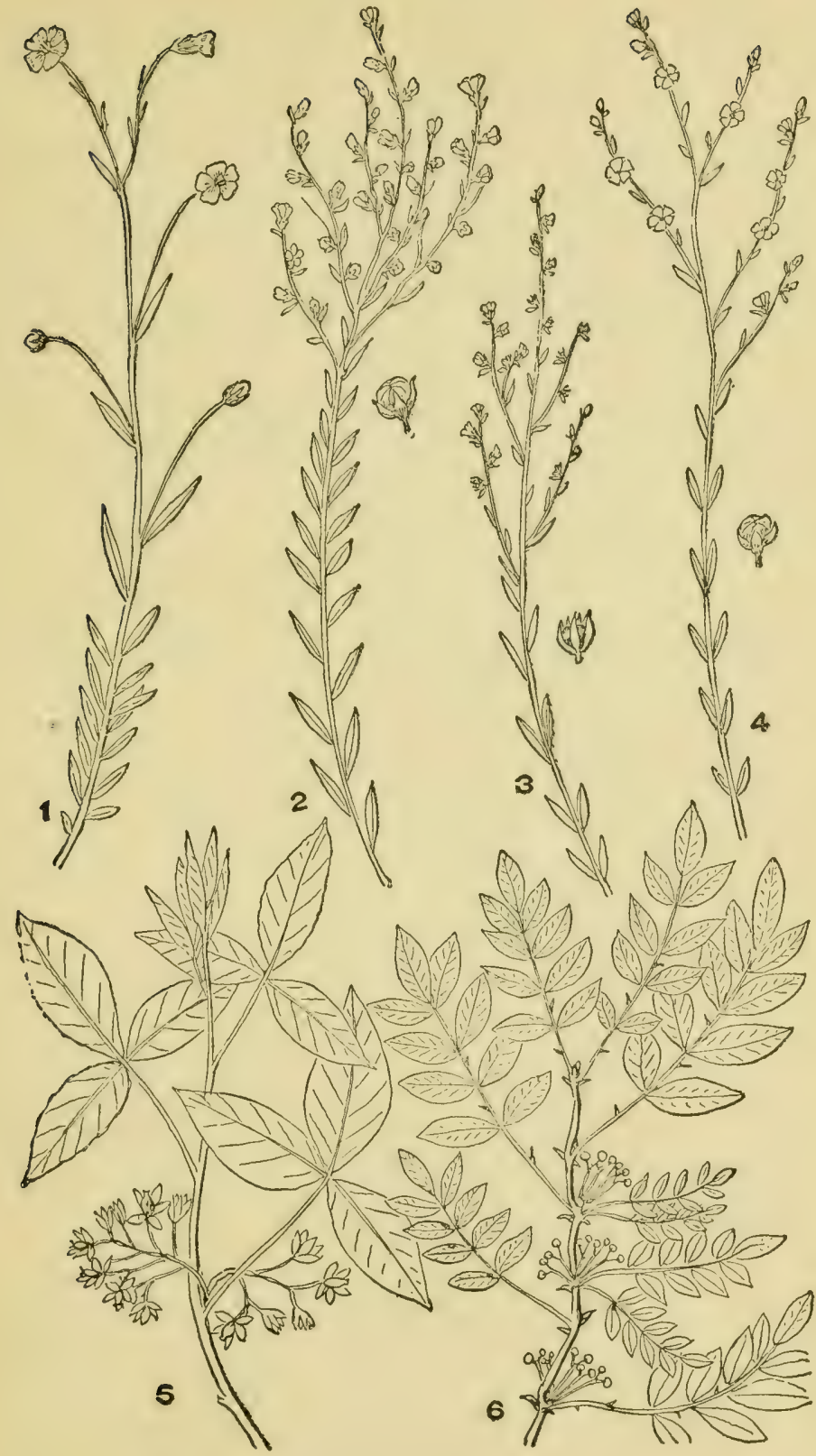

Plate 85

1. Linum usitatissimum. 2. L. virginianum. 3. L. medium. 4 L. striatum. 5. Ptelea trifoliata. 6. Xanthoxylum americanum. 
Erect, 1 to $2 \mathrm{ft}$. high, lower part of stem simple, upper branching, striped or somewhat angular. Branches all reaching nearly the same height. Leaves oblong, without leaf-stalks. Flowering stems spreading or recurred. Flowers small, sepals ovate, pointed. Styles distinet. Dry woods, our area. June-Aug.

3. L. medium, (Planch.) Britton. (Fig. 3, pl. 85.) StifF YeLLow Flax. Similar to No. 2. but branches do not recurve, and stems are never angular. Most of our area.

4. L. striatum, Walt. (Fig. 4, pl. 84.) Ridged Yellow Fuax. Generally numerous stems together, all erect and branched above; leaves generally opposite, lance-shaped. Stem and branches sharply angled with about 4 wing-like angles, somewhat viscid. Wet grounds, Mass, and southward. Summer.

5. L. sulcatum, Riddell. Grooved YelLow Flax. Stem erect, simple, branching only at the upper part. Stem and branches winged or grooved, at least above. Leaves alternate, lance-shaped, the upper ones with glandular hairs along the borders, 3-nerved. In place of stipules are dark glands. Most of our area.

\section{Family IV.-RUtaceae. Rue FaMilu}

The members of this family in our area are trees and shrubs. Flowers bearing stamens on one tree and pistils on another in Tanthoxylum, staminate pistillate and perfect flowers on the same tree in Plelea. Sepals 4 or 5 or more, stamens twice as many as sepals or equal in number. Petals 4 or 5 . Pistils 2 to 5 generally united. Fruit a capsule or a winged fruit (samara). Leaves of our species compound, alternate or opposite and abounding with a pungent or heavy aromatic volatile oil.

\section{XANTHOXYLUM, L.}

Staminate and pistillate flowers on different plants. Sepals 4 or 5 or none, petals 4 or 5 . Pistils 2 to 5 , separate above, but united below. Capsule thick and fleshy.

X. americanum, Mill. (Fig. 6, pl. S5.) Prickiy Asi. Toothacme Tres. A small tree or more frequently a shrub, sometimes $25 \mathrm{ft}$. high, the stems and often the leaf-stalks prickly. Teaves compound of about 4 pairs and an odd leallet. Flowers in umbellate clusters in the axils of tha leaves, greenish, appearing before the leaves. Calyx none, petals 4 or 5. Woods, throughout our area. April-May.

\section{PTELEA, L.}

Fiowers perfect or staminate only or pistillate only. Petals and stamens 3 to 5. (Wary of 2 cells, pistils 2 above. Fruit a 2 -celled, 2-seceded, broad-winger samara. Leaves 3-foliate; flowers greenisl-white in compound clusters.

P. trifoliata, I. (Fig. 5, pl. 85.) TuREE-LEAven IIor-tres. Rather t:ll shrub, with 3 -foliate leaves, the leaflets egg-shaped, pointed, 2 to 5 
in. long, the group on a long leaf-stalk. Flowers in compound cluster. greenish-white. Seeds, 2 in a broad winged fruit, the wings reticulated, nearly round, about ${ }^{3}$ in, in diameter. In southern part of our area. Not common. June.

\section{Family V.-SimarubaCEAE. Ailantimus Family}

Trees or shrubs. Flowers regular, with calyx and corolla, generally 5 sepals, 5 petals and twice as many stamens; staminate and pistillate flowers separate. Carpels generally free or united above. Fruit (in our species) winged. Leaves compound, without stipules.

AILANTHUS, Desf.

A. glandulosa, Desf. The only species in our region, the Ailantluus, planted as a shade tree, grows to a height of from 40 to $90 \mathrm{ft}$. The compound leaves are often 2 or $3 \mathrm{ft}$. long with from 6 to 20 pairs of leaflets and an odd one.

\section{Family VI.-POLYGaLACEAE, Milkwort Familly}

In our area, all herbs, with unsymmetrical flowers; calyx of 5 sepals and corolla usually of 3 petals; two of the sepals resembling petals. Stamens generally 8 , sometimes 6 . Ovary of 2 cells. Style simple. Fruit a capsule.

\section{POLYGALA, Tourn.}

Flowers generally showy, colored, quite irregular, in grape-like clusters. Calyx of 5 sepals, the upper and the two lower small and greenish, the two side sepals large and colored like petals. Three petals only are developed, the anterior of which is much the largest and is covered by the two posterior. The large petal is 3-lobed, the middle lobe being fringed or tufted, the whole petal resembling the keel of a boat or in some species it is spoon-like. Stamens 6 to 8 . Fruit a 2 -seeded pod.

Principal leaves mostly in whorls.

Flower heads in close contact with leaves . . . . P. cruciata

Flower heads removed from leaves by elongated flower stems.

Heads of flowers cylindric or rounded, blunt . . . P. brevifolia

Heads (spikes) slender and spindle-formed..$P^{*}$ verticillata

Lower leaves only in a whorl ......... . . . P. ambigua

Leaves alternate.

Flowers orange-yellow . . . . . . . . . . . P. lutea

Flowers purple to white;

In spindle-shaped spikes or heads.

Leaves linear to narrow lance-shaped, not distant from each other,

flowers greenish or yellowish-purple ..$P$. Nuttallii

Leaves linear, quite distant from each other. Flowers pink $P$. incarnata Fiowers in rounded heads, blunt at top.

Bracts persistent ....... P. sanguinea

Bracts deciduous ....... . P. mariana

Flowers in elongated spikes.

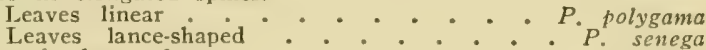

Flowers few, showy, in loose clusters . . . . . P. paucifolia

1. P. cruciata, L. (Fig. 11, pl. 86.) Cross-leaved Milkwort. Marsi Milkwort. Erect, 4 to 16 in. high, branching above, nearly or 
quite simple helow, stem somewhat winged at the angles, or square. Leaves in whorls of 4 , or a few scattered, linear obtuse at apex, $\frac{1}{2}$ to $1 \frac{1}{2}$ in. long, quite narrow ( $1 / 12$ to $1 / 6$ in. wide). Clusters of flowers condensed, oval, quite blunt above, on very short flower stalks, the leaves extending around and above the cluster. Flowers purple, greenish or white. Wet grounds, our area. July-Sept.

2. P. brevifolia, Nutt. (Fig. 8, pl. 86.) Short-Leaved Miliwort. Similar to No. 1; leaves in whorls of $4 \mathrm{~s}$ but shorter; flower stem extending considerably above leaves. Wet sandy places, Rhode Island, Mass., and southward. June-Sept.

3. P. verticillata, L. (Fig. 3, pl. S6.) WHonled Mulkwort. Very slender, 4 to $10 \mathrm{in}$. high, with many branches. Leaves in whorls of 4 , rarely more, narrow, sharp pointed, $\frac{1}{4}$ to $1 \frac{x}{1} \mathrm{in}$. long. Flowers in spindleshaped clusters on long flower-stalks. Flowers greenish-purple. Common in dry or moist fields. June-Nov.

4. P. ambigua, Nutt. (Fig. 4, pl. 86.) Loose-spiked MilkwokT. Resembles No. 3, but leaves, except the lower ones, which may be in one or two whorls, are scattered along the stem. Flower groups more extended, and slender, nearly cylindric. Dry soil, our area. June-Nov.

5. P. lutea, L. (Fig. 10, pl. 86.) Orange Mrкwort. Erect, few branches except at top, leaves alternate, narrow spatulate; flowers in rounded heads, yellow. In southern part of our area. June-Oct.

6. P. Nuttallii, T. G. (Fig. 5, pl. 86.) Nuttall's Milkwont. Stems very slender, 4 to 6 in. high. Simple below, brancling above. Leaves scattered along the stem $\frac{1}{\frac{1}{4}}$ to $\frac{3}{4} \mathrm{in}$. long, very slender linear. Flowers in spindle-shaped heads, greenish-purple. Dry soil. Aug.-Sept.

7. P. incarnata, L. (Fig. 9, pl. 86.) Pink Milkwort. Erect, heads of flowers spindle-shaped or more or less interrupted and cylindric. Leaves narrow linear situated at long distances from each other. Dry soils, southern part of our area. June-Oct.

8. P. polygama, Walt. (Fig. 6, pl. 86.) Bitter Polygala. Erect, not branchiner, leafy, several stems from the same root, 4 to $20 \mathrm{in}$. high. Leaves scattered, lance-shaped or linear, obtuse at end. Flowers in an elongated spike ( 1 to $3 \mathrm{in.}$ ), rather loosely elustored, purple to light rose or even white, with a tinge of rose, showy. Dry soil. June-July.

9. P. sanguinea, I. (Fig. 7, pl. 86.) Purple Milkwort. ( $P$. viridescens, L.). Ereet, branching above, 6 to $15 \mathrm{in}$. high. Leaves linear, alternate, 3 to $13 \mathrm{in}$. long. Heads of flowers roumded, blunt at top, red to purplish-white. Moist meadows, wet grounds. July-Oet.

10. P. mariana, Mill. Maryland Mrizwort. Resembles P. sanguinca. The two littlo bracts at the base of each short flower stem in the cluster of flowers are, in I'. senguinen persistent. In the present species these bracts fall early. Flowers rose-purple. Southern New Jersey and southward. July-Sept.

11. P. senega, L. (Fig. 1, pl. 86.) Senega Snakeroot. Ereet, smorth, scarewy branching, leafy 8 to $14 \mathrm{in.} \mathrm{high.} \mathrm{Leaves} \mathrm{altermate,} \mathrm{lanee-}$ shaped tapering at each end, ajex sharp. Flowers in rather close spike, white. Rocky woods. May-June.

12. P. paucifolia, Willd. (Figg. 2, pl. S6.) Fringed Polygata. 


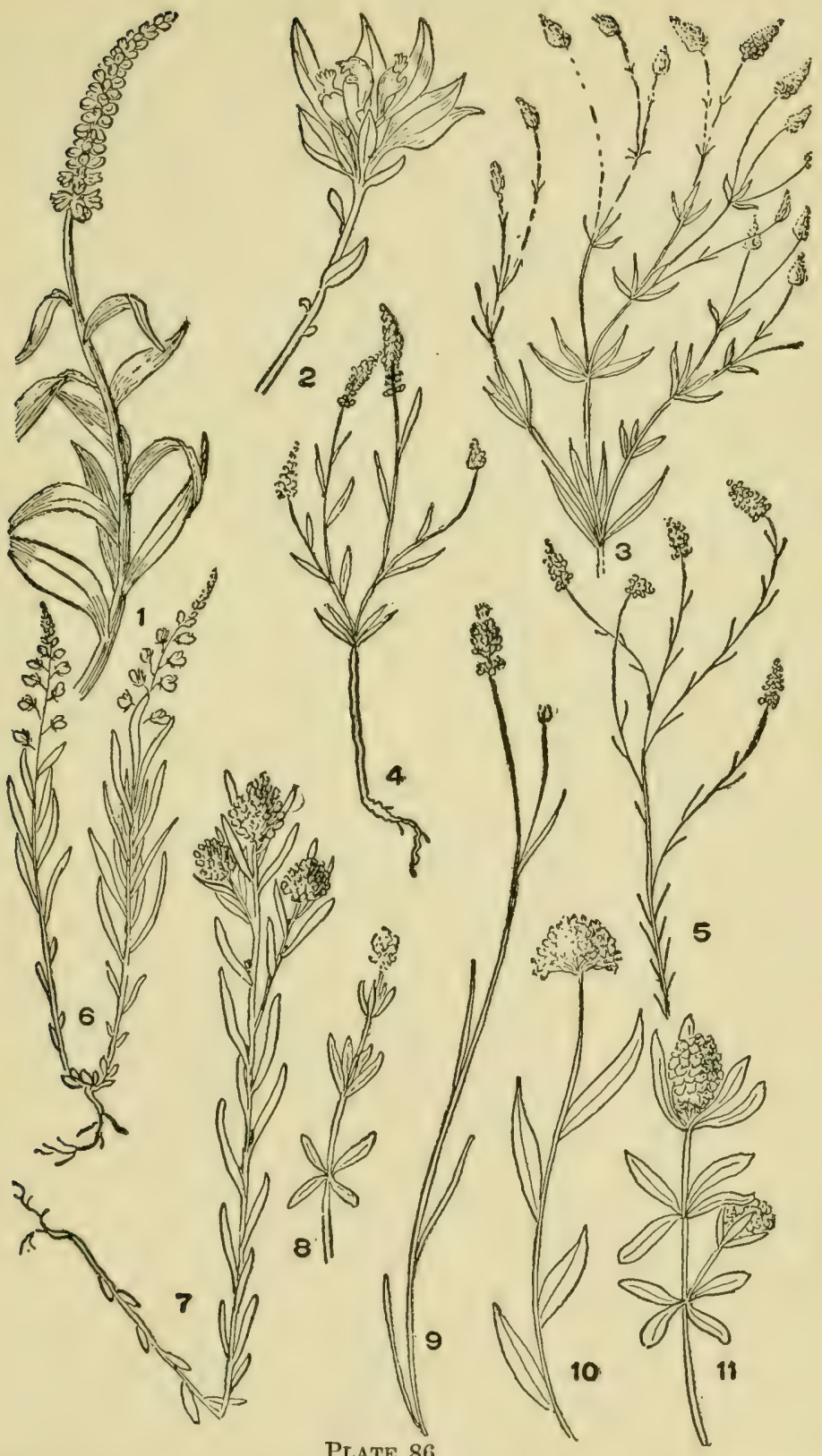

1. Polygala senega. 2. P. paucifolia. 3. P. verticillata. 4. P. ambigua 5. P. Nuttallii. 6. P. polygama. 7. P. sanguinea. 8. P. brevifolia. 9. P. incarnata. 10. P. lutea. 11. P. cruciata. 
Stems simple, half prostrate or erect, 3 to $4 \mathrm{in}$. high. Iseaves crowded, egr-shaped or oblong 1 to $1 \frac{1}{2} \mathrm{in}$. long, $\frac{1}{2}$ as wide, the leaves below the main cluster are reduced to scales or very small leaves. Flowers few, showy rose-purple, the keel beautifully fringed. Another form of flowers small, greenish, are found close to the ground or beneath the surface. In rich grounds, often at foot of rocks. One of the most attractive of our spring flowers. May.

\section{Fanily ViI.-EUphorbiaceae. Spurge Family}

In our region all herbs, with pistils and stamens in different flowers, sometimes on the same plant in other cases on different plants. Whole plant abounds in acrid milky juice. Leaves opposite or alternate. Flowers without petals or with. Stamens few or numerous. In fertile flowers the ovary is composed of from 2 to 9 or more carpels (mostly 3 ) fused to a central prolongation of the axis. An ovule or a pair of ovules may hang from the summit of each cell of the ovary.

Flowers in spikes.

Staminate uppermost . . . . . . . : Croton

Pistillate uppermost . . . . . . Acalypha

Flowers in loose elusters.

Staminate flowers ( 2 or 3 in the loose group) above the pistillate, which is generally solitary . C Crotonopsis

Staminate and pistillate flowers enclosed in the same involuere (leafy bracts resembling a calyx), the ovary generally, toward maturity, becoming exserted and nodding on its little stalk. (Fig. 1. pl. 88.) Euphorbia Flowers solitary, at leaf-axils . . . . . Phyllanthus

\section{PHYLLANTHUS, L.}

Herbs, with wiry stems and alternate, entire leaves. Staminate and pistillate llowers separate, but on the same plant without flower stems. Calyx 4- to b-parted. Stamens ustally 3, the filaments more or less united. Capsule globe-formed.

P. carolinensis, Walt. (Fig. 6, pl. 87.) Carolina Phyllantuts. Slender, 4 to $20 \mathrm{in}$. ligh. Je'aves oblong or pear-shaped, $\neq$ to $3 \mathrm{in}$. long. Calyx lobes 6, linear. Stamens and styles each, 3. Gravelly soil, eastern Penna., west and south. May-Oct.

\section{CROTON, L.}

Inconspicuous weeds. Leaves, in our species, alternate. Flowers of two kinds on the sime flower stalk, the upper bearing stamens, the lower pistils. Calyx of staminate llowers of 5 sepals. Petals usually rudimentary. Stamens 5 or more. Pistillate flowers, ealyx 5 to 10 sepals. Petals wanting. Ovary of 3 cells, each with one seed. 


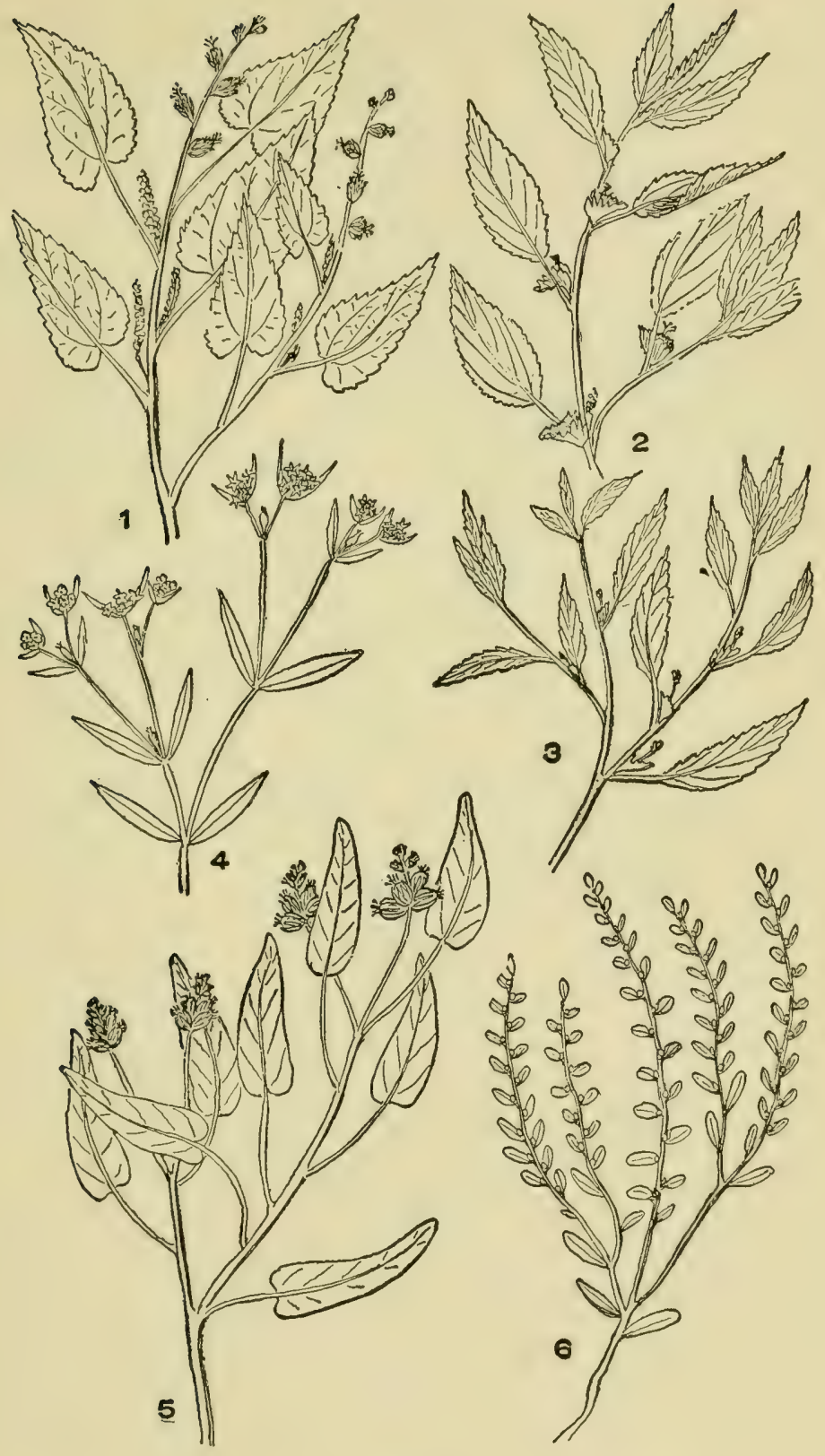

Plate 87

1. Acalypha ostryaefolia. 2. A. virginica. 3. A. gracilens. 4. Crotonopsis linearis. 5. Croton capitatus 6. Phyllanthus carolinensis. 
C. capitatus, Michx. (Fig. 5, pl. 87.) Capitate Croton. Stem densely woolly, leaves woolly on both sides, oblong-lance-shaped with the base rounded or heart-shaped. Clusters of inconspicuous staminate flowers just above the more dilated group of pistillate flowers. 'These staminate flowers have 5 small petals and 10 or more stamens. Pistillate flowers in a rounded group. Only in southern part of our area. MayOetober.

\section{CROTONOPSIS, Michx.}

Herbs, with silky but shining leaves, leaves alternate (opposite in our species). Calyx 5-parted. Petals, none. Stamens 5. Flowers in loose branching clusters, staminate above.

C. linearis, Michx. (Fig. 4, pl. S7.) Crotonopsis. Whole plant silvery from shining seales. Stem erect, branching in regular pairs, 12 to $18 \mathrm{in.} \mathrm{high.} \mathrm{Leaves} 1$ to $1 \frac{1}{3} \mathrm{in}$. long, narrow lance-shaped or broader, to narrow egg-shaped, on short leaf-stalks, opposite. Flowers very small in terminal spikes or masses. Southern part of our area. July-Sept.

\section{ACALYPHA, L.}

Our species herbs, with pistils and stamens occupying different ilowers on the same plant. Stems erect and branching. Leaves alternate. The staminate flowers in axillary spikes bolow the pistillate flowers with ealyx of 4 sepals. Pistillate flowers each subtended by a leafy bract, calyx of 4 or 5 sepals. Ovary 3 -celled, styles 3 ; cells each with one seed.

1. A. ostryaefolia, Ridd. (Fig. 1, pl. s7.) THree-seeded Mrrecrr. Stem branched, hairy, 1 to $2 \mathrm{ft}$. high; leaves on leaf-stalks about 1 length of leaves or more; leaves egg-shaped, sharp pointed at apex, rounded or heart-shaped at base, with toothed borders, 2 to 4 in. long. Staminate flowers very small on somewhat lengthened spikes. Corolla absent. Plant resembles a nettle, hence its name, Acalypha, an ancient name for the nettle.

2. A. virginica, L. (Fig. 2, pl. 87.) Virginia Turee-Seeded Mercerr. Plant 1 to $2 \mathrm{ft}$. high becoming purple. Leaves egre-shaped, not heart-shaped at hase but somewhat tapered. Flowers of both kinds are enclosed within a fringed leafy bract.

3. A. gracilens, A. Gray. (Fig. 3, pl. 87.) Slender Timee-seened Mercury. Leaves linear or lance-shaped. Stems very slender. The staminate spike generally exceeds the fringed bract. Otherwise the plant has characters of No. 2.

\section{EUPHORBIA, L.}

IIerbs, with staminate and pistillate flowers on the same plant and generally surrounded by the same involuere. These involucres are bellshaped, having 4 or 5 segments resembling petals which alternate with as many grand-like teeth (Fier. 1, pl. s.8). The involuceres are subtended by bracts which are often brightly colored. Stamens scattered over the inner surface of the involucre; pistillate tlower solitary, the ovary is situated on a pediend, which inereases until it lifts the ovary in general untside the bell-shaped involuere, where it droops outward and downward. Capsule 3-lobed. 


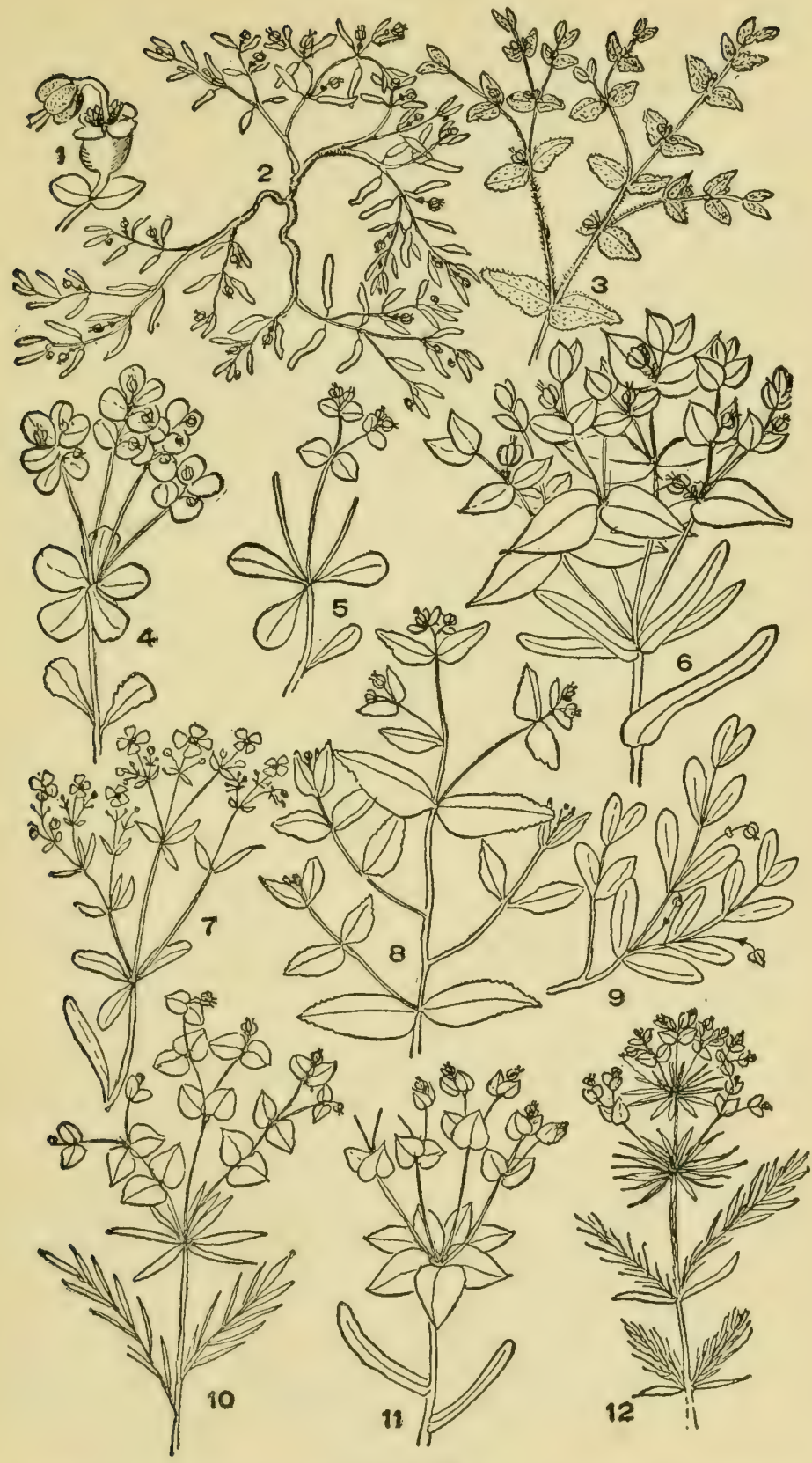

Platé 88

1. A flower of Euphorbia Darlingtonii. 2. Euphorbia polygonifolia. 3. E. maculata. 4. E. helioscopia, 5. E. Peplus. 6. E. Lathyris. 7. E. corollata. 8. E. nutans. 9. E. Ipecacuanhae. 10. E. Esula 11. E. lucida. 12. E. Cyparissias. 
Flowers in axils of the opposite leaves not in umbel-1ike clusters, usually one only.

Plant prostrate.

Borders of leaves without teeth . . . . . E. polygonifolia

Borders of leaves with teetl.

Stem and leaves without hairs . . . . E. glyptosperma

Stem and leaves hairy.

Involucres split on one side . . . . . E. humistrata

Plant erect.

Leaves notched . . . . . . . . . . . E. nutans Leaves entire : $: \div: \dot{E}_{\text {. Ipecacuanhae }}$

Flowers in numbl-like clusters subtended by a whorl of leaves.

Appendages to involucre petal-like . . . . . . . . E, corollata No petal-1ike appendages.

Rays of the umbel 3, rarely more. Stem leaves with leaf stalks . . . . . . . . . E Peplus Rays of the umbel 4 i. . . . . . E. Lathyris Rays of the umbel 5 to 8 .

Floral leaves broad heart-shaped.

Stem leaves elliptic lance-shaped . . E. Darlingtonii

Stem leaves pear-shaped . . E. helioscopia

Stem leaves oblong, blunt at each cnd - E. lucida

Stem leaves linear, sharp at both ends.

Whorl of leaves at base of umbel not repeated

whoris i c - Esula er on

main stem . . . . . E. cyparissias

1. E. polygonifolia, L. (Fig. 2, pl. SS.) SEd-side Sitcrae. Stems spreading, prostrate, 3 to 8 in. long, lying flat upon the sand. Leaves \pm to 3 in. long, opposite, very narrow with blunt ends, fleshy, borders not serrated. Flowers, a single involucre at the axil of one of a pair of leaves, seeds eggr-shaped. Sandy shores. July-Sept.

2. E. glyptosperma, Engelm. Ridge-seenen Spunge. Smooth, prostrate, spreading, stems 2 to 15 in. long. Leaves oblong or narrow, broader at base, and generally very unequal there; blunt at each end, borlers with small serrations toward the blunt apex. Involueres often clustered; seeds 4-angled. June-Oct.

3. E. maculata, L. (Fig. 3, pl. S8.) Mrik Perstaxe. Mainy, both leaves and stem. Stems prostrate, much branched, 2 to $15 \mathrm{in.}$ long. Leaves ahout $\frac{1}{2}$ in. Jong, redelish, usually hlotehed with a brown-red spot near center, oblique at base with small serrations toward the apex. Flowrers in dense leafy axillary clusters. Seculs ovate with 4 sharp angles and 4 shallow grooves. Common, sandy places. June-Nov.

4. E. humistrata, Fugelm. IIAmY Spraning Spurge. Resembles No. 3, but leaves are less hairy beneath and color of leaves and stems light green. Leaves about $1 / 3$ to $1 / 2$ in. long, oblong or oval. Involucres in lateral clusters, split on one side. Aug.-Oct.

5. E. nutans, Lag. (Fig. 8, pl. 88.) LARge or Uprigilt SPotTed Sipcori: Stems upright, simple or more generally branching above $\frac{1}{2}$ to $2 \mathrm{ft}$. high. Jatues opposite, irregularly and unsmumetrically oblong, slightly notehed on the borders. Flowers white or red. Common in sandy soil. May-Oct.

6. E. corollata, J. (Fig. 7, pl. S8.) Flowerivg Spurge. Erect, 1 to :3 ft. higl, hriglit wreen, simple below, branched as an umbel alowe. Jeaves forming the whorl subtending the umbel, narrow, 3 to 6 , thense of the stem narrow lanee-shaped, alternate, those of the umbel also narrow 
lance-shaped or linear. Rays of the umbel 3 or more. Flowers (involucres) terminal with white petal-like divisions. Sandy soil. April-Oct.

7. E. Ipecacuanhae, L. (Fig. 9, pl. 88.) Willd Irecac. Spreading or erect, 4 to $10 \mathrm{in}$. high. Leaves opposite, varying from linear to orbicular, mostly oval. Involuere on a very long slender peduncle. Dry sandy soil, south and east part of our region. May-Oct.

8. E. Lathyris, L. (Fig. 6, pl. 88.) Caper Spurge. Erect, stout, 1 to $3 \mathrm{ft}$. high. Branched as an umbel above. Leaves of the whorl and stem narrow lance-shaped or linear, those of the stem scattered, those of the umbel broadly egg-shaped with sharp points. Introduced. May-Aug.

9. E. Darlingtonii, A. Gray. Darlington's Spurge. Stem stout, erect, 1 to $5 \mathrm{ft}$. high, branching as an umbel at top. Rays of umbel 5 to 8. Leaves of whorl several, lance-shaped, those of stem also lance-shaped tapering at each end, those of umbel broad heart-shaped or kidney-shaped. (For the flower see Fig. 1, pl. 88.)

10. E. helioscopia, I. (Fig. 4, pl. S8.) Sun Spurge. Stem about $1 \mathrm{ft}$. high, often branched at base. Stem leaves spatulate, those of the whorl inversely egr-shaped or nearly round as are those of the umbel. Rays of the umbel 3 to 5, flowers yellowish. Introduced. June-Sept.

11. E. Esula, L. (Fig. 10, pl. 88.) Leafy Spurge. Stems 1 to 2 ft. high, branched above. Tays of umbel 4 to 8 . Leaves of stem and whorl linear, those of umbel broadly heart-shaped. Introduced. May-Oct.

12. E. lucida, Waldsl. and Kit. (Fig. 11, pl. 88.) NicaEar Spurge. (E. nicaeensis, All.). Stem 1 to $1 \frac{1}{2} \mathrm{ft}$. high. Rays of umbel 4 to 7 . Stem leaves linear or oblong, those of the whorl and of the umbel broad heartshaped or kidney-shaped. Flowers (involucres), yellowish. Introduced. July-Sept.

13. E. Cyparissias, L. (Fig. 12, pl. S\$.) Cypress Spurge. Stems mostly erect, about $1 \mathrm{ft}$. high. Plant bright green, the involueres of the umbel showing yellow. Grows in patches, escaped from gardens. Rays of the umbel numerous. Whorls of linear leaves; leaves of the stem thickly scattered, also linear; those of the umbel broadly egg-shaped. Along roadsides where, for the most part, it has been thrown from gardens. May-Sept.

14. E. Peplus, L. (Fig. 5, pl. 88.) Perty Spurge. Plant 4 to 12 in. high: Leaves of the stem pear-shaped, on leaf-stalks. Seeds with 2 grooves on the back and with several pits on the imner face. New Jersey, New York, and southward. June-Sept.

\section{FAMILY VIII.-CALLITRICHACEAE. WATER STARWort FAMILY}

Small aquatic herbs, with opposite leaves which are simple, and with entire (not serrated or notehed) borders. Flowers solitary in the axils of the leaves very minute, without corolla, but in some species, with two colored bracts. Stamens and pistils generally not in the same flowers, but on the same plant. Generally 1 stamen, exceptionally 2. Ovary of \pm cells. Styles 1 . Stems very slender. Leaves spatula-formed or linear. 


\section{CALLITRICHE, L.}

Characters, those of the family.

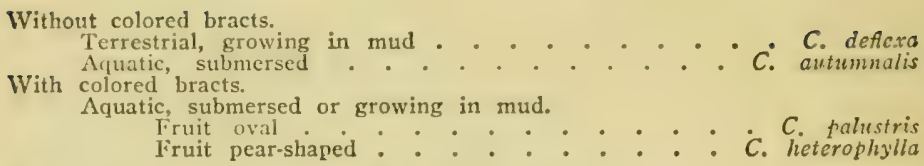

1. C. deflexa, A. Br. (Fig. 5, pl. 89.) Terrestrial Starwort. (C. Austini, Engelm.). Plant forming tufts on moist soil, stem $\frac{1}{2}$ to $2 \mathrm{in}$. high. Jeaves very small (about 1/10 in. long), spatula-formed, 3-nerved, tapering at base. Fruit notehed at each end. In wet soil. Summer.

2. C. palustris, L. (Fig. 6, pl. 89.) Vernal Water Starwort. Growing in mud or in the water. Stems 2 to $10 \mathrm{in.long}$, very slender. Leaves of two sorts, the floating pear-shaped or spatula-formed, about $\frac{1}{3} \mathrm{in}$. long, the submersed, linear of about the same length. Fruit borne in the axils of the higher leaves, enclosed in two small bracts. Common in stagnant waters. July-Sept.

3. C. heterophylla, Pursh. (Fig. 7, pl. 89.) Large Water StarworT. Resembles No. 2. In No. 2 the fruit is higher than broad, thickest at base, without a visible pedicel, its lobes keeled, or acutely angled. In this species the fruit is broader than high, its lobes obtusely angled. In quiet waters. July-Sept.

4. C. autumnalis, L. (Fig. 8, pl. 89.) Nortirers WAter StarwonT. (C. bifida, (L.) Morong.) Stem entirely submersed; leaves all alike, linear or narrow lance-shaped, notehed at the apex, somewhat clasping at the stem. In flowing waters. July-Sept.

\section{Order VIII.-SAPINDALES. Order of the Sapindales or Soapberries}

The plants of this orler have the general characteristics of the last (Geranium Order), except that the ovules are in an opposite position, that is, with the ovules pendulous, but with the ridge connecting the two ends (the raphe) axay from the axis of the ovary, or ascending from the base of the ovary and inverted. On this somewhat obscure and quite technical character the classification of this large group depends. The families of the orter in('lule herlsi, woody heath-like plants (empetraceae), shrubs and trees.

Herlss.

Flowers regular or nearly so

LIMNANTHACEAE

Flowers very irregular

BALSAMINACEAE

Woorly, heath-like, depreseed plants

- EMPETRACEAE 
Shrubs and trees.

Fruit of two long winged samaras; veins of the leaves radiate from the end of the leaf-stem . . ACERACEAE

Fruit a much inflated, bladder-like capsule; veins of the leaves diverging from a mid-rein . STAPHYIEACEAE Fruit a berry-like drupe; veins of leaves diverging from a mid-vein.

Flowers in terminal, generally dense clusters

Flowers in axillary, generally few-flowered clusters; leaves alternate - . . . . . IIICACEAE Fruit in a 2- to 5-celled pod, leaves opposite CEIASTRACEAE Fruit a nut enclosed in a spiny bur-like capsule. Leaflets radiating from the leaf-stem . . HIPPOCASTANACEAE Fruit a 3 -seeded berry, leaves pinnate . . SAPINDACEAE

\section{Fanily I.-EMpetraceat. Crowberry Fanily}

Low spreading plants, with slender woody stems, which are freely branching and covered with small narrow leaves. Flowers inconspicuous, of two kinds, pistillate and staminate, both on the same plant or the two on separate plants. Berry black or red with several hard nutlets within.

\section{EMPETRUM, L.}

Our only species a branching and depressed woody plant with slender stems and thickly seattered, small, linear leaves. Flowers liaving both calyx and corolla or with calyx only; the pistils and stamens in different flowers on the same plant or on diflerent plants. Calyx of 2 or 3, usually 3 , sepals. Stamens of the staminate flowers 3 . Flowers toward the summit of the slender stem in the axils of the leaves. Corolla present.

E. nigrum, L. (Fig. 9, pl. 89.) BLACK Crowberrì. A small prostrate shrub growing on White Mountains and other elevated places and on northern part of our coast.

\section{COREMA, Don.}

Corolla absent, flowers in terminal clusters. Otherwise resembling Empetrum.

C. Conradii, Torr. (Fig. 10, pl. 89.) Conrad's Crowewrry. Low bushy tufted shrub, $1 \mathrm{ft}$. ligh. In pine barrens. 


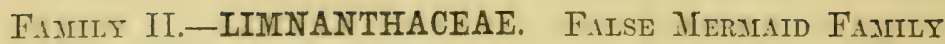

Hcrls, with alternate compound leares, without stipules. Stamens ferw (6 to 10), twice as many as the petals. Sepals and petals equal in number. (arpels equal in number to the stamens, uniting in a single style, which above, is cleft into as many stigmas as there are carpels.

FLOERKEA, Willd.

Small plant with compound feather-formed leaves (about 2 pairs of leaflets and an odd one), growing in marshes and on river and lake banks. Sepals usually 3 , longer than the 3 oblong petals.

F. proserpinacoides, Willd. (Fig. 4, pl. S!.) False Mermatd. A small slender plant growing in marshes and on river banks. Stems about $1 \mathrm{ft}$. long prostrate or partly submersed. Leaves of 5 leaflets, those submersed of three leaflets or divisions. Flowers, in the leaf axils, white. Fruit one or two globular carpels.

\section{F.amily III.-ANACARDIACEAE. Suilic Familly}

Tress or shruls,s, with resinous milky acrid juice, with alternate compount leaves in our species; flowers which may be perfect, but which often contain either stamens only or pistils only. C'alyx, and corolla usually each of 5 members. Stamens usually 10 or twice the number of the sepals, but by suppression the number may be reduced to 1 . Ovary 1 - to t-celled, 1-seeded. Styles 1 to 8 hut, when 1, divided into 3 stigmas at top. Fruit a pulpy berrylike drupe with hard seed-coats. Of the family we have but one genus.

\section{RHUS, L. (Toxicodendron, Mill.)}

Trees, shrubs and woody vines. Leaves mostly compound. Flowers usually snall, in dense elusters. Fruit small with a central strong seed. Seed inverted on a stalk that rises from the base of the ovary.

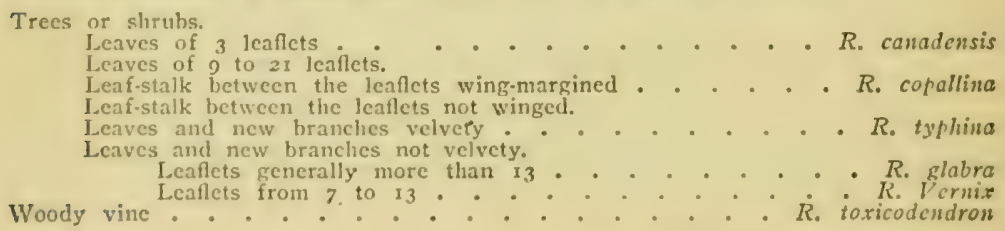

1. R. copallina, I. (Fig. 1, pl. 90.) Difarf Sumac. Mountate Sumac. Small tree or shrub. Branches and leaf-stalks silky. Leaves of 4 to 10 pairs of leaflets with an odd one. The common leaf stalk broadens, butwens the lealfets, into a wing on each side which diflerentiates it from all the other species of likus. It is usually a low shrub or tree, but may rise to a lieight of 20 or even $30 \mathrm{ft}$. The cluster of flowers 


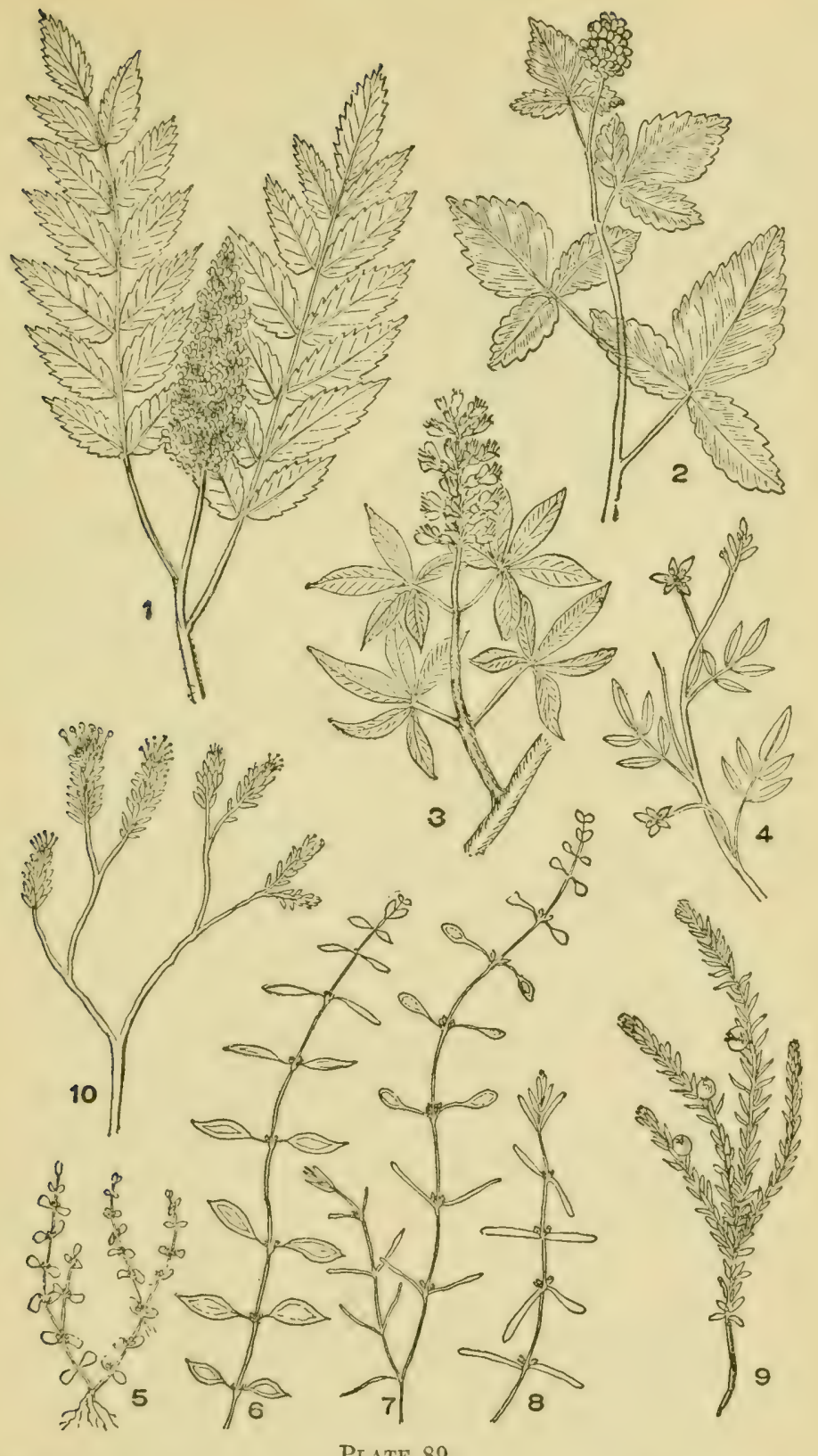

Plate 89

1. Rhus glabra. 2. R. canadensis. 3. Aesculus glabra. 4. Floerkea proserpinacoides. 5. Callitriche deflexa. 6. C. palustris. 7. C. heterophylla. 8. C. autumnalis 9. Empetrum nigrum. 10. Corema Conradii. 
is dense and spindle-shaped of greenish flowers. Found throughout our region on hillsides and in pastures. June-Aug.

2. R. typhina, L. (Fig. 2, pl. 90.) Staghors Sumac. ( $R$. hirta, (I.) Sudw.). Branches and common leaf-stalks densely silky or velvety. Leaves of 11 to 31 leaflets, the compound leaf being from 7 to $30 \mathrm{in}$. long. Leaf-stalks not winged. A small tree generally 15 to $20 \mathrm{ft}$. high, but often reaching a height of more than $30 \mathrm{ft}$. Common. June-Aug.

3. R. glabra, L. (Fig. 1, pl. 89.) Sirootir T'pland Sumac. Shrub or tree, 10 to $30 \mathrm{ft}$. high, with long compound leaves, leaflets from about 11 to about 31. Leaflets and leaf-stems smooth, lanee-shaped, with serrated edges, very acuto at outer extremity, pale beneath. No wings on the main leaf stem. Hillsides. June-August.

4. R. canadensis, Marsh. (Fig. 2, pl. 89.) (R. aromatica, Ait.). Shrub, 3 to $8 \mathrm{ft}$. high. Leaves trifoliate. Leaflets egg-shaped or rhombic, aromatic, with coarse teeth at edges. Flowers yellowish-green in dense rounded or oblong masses. Flowers appearing before the leaves. Woods, not common. March-April.

5. R. Vernix, L. (Fig. 3, pl. 90.) Poisor Susac. A shrub or small graceful tree, very poisonous. Height from 6 to $25 \mathrm{ft}$. Leaflets 7 to 13 , smooth or when young somewhat downy, oval and without teeth. Flowers green, in clusters much less dense than those of the preceding species. Found in swamps. Is more poisonous than the following species.

6. R. toxicodendron, L. (Fig. 4, pl. 90.) PoIson IvY. ( $R$, radicans, L.). Climbing vine, adhering to rocks or trees by rootlets which shoot from the stem. Often erect as a low bushy shrub. Leaves of 3 egg-shaped leaflets which have smooth edges. Flowers greenish. Along fences and thickets or climbing trees.

A pernicious species which is too often permitted to grow to the detriment of the health of many people, even when not poisoned by contact. Many persons living in neighborhoods where this vine is tolerated become ill from obscure nervous troubles, which are often ennsidered as malarial and the value of property is in such places reduced since the localities acquire the reputation of being "malarial." This is especially the case with many interesting localities along the Hudson River.

\section{FAMILY IV.-ILICACEAE. HoLIy FAMILY}

Trees or shrubs, with small white flowers in the leaf axils, generally of 4 or 6 petals, 3 to 6 sepals and 4 to 6 stamens. Fruit a berry-like drupe. Leaves alternate and simple.

Petals oval or oblong . . . . . . . . . . Ilex Petals linear

\section{ILEX, L.}

Shrubs or small trees, with alternate leaves and with flowers, several or solitary, appearing at the leaf-axils. Petals, in our speeies, 4 to 6 ; stamens as many as the petals (No. 5 has from 4 to 8 petals). Calyx minute of 4 or 6 divisions. Fruit a round berry inclosing 4 or 6 small nutlets. The flowers may enclose both stamons and pistils or stamens may be found in one llower and pistils in another. 
P P
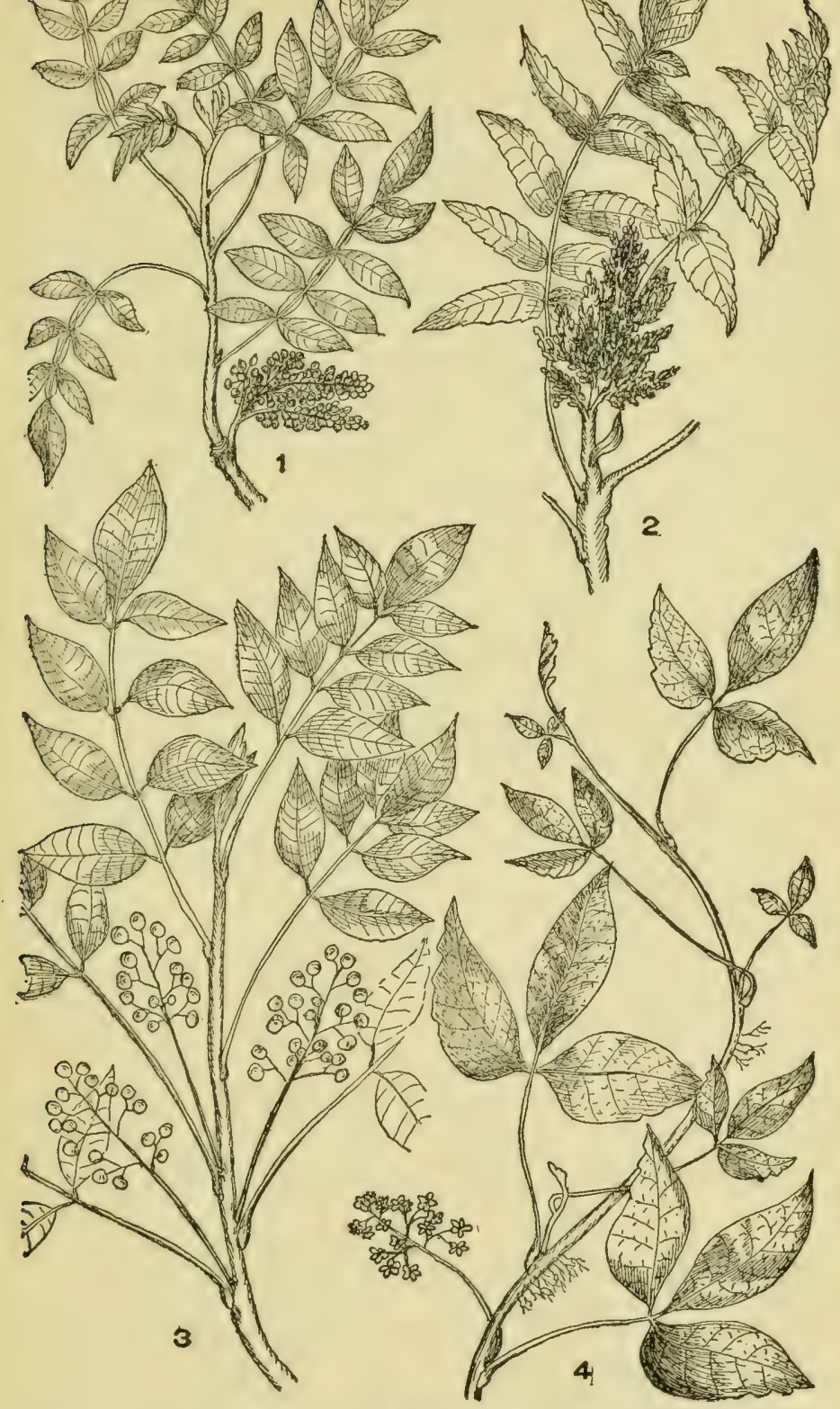

Plate 90

1. Rhus copallina. 2. R. typhina. 3. R. Vernix. 4. $R$. toxicodendron. 
Leaves evcrgreen

With spiny tips at borders................ I. opaca

Without spiny tips ........... I. glabre

Leaves falling in autumn.

Flowers on short flower stalks.

Nutlets ribbed
Nutlets not ribbed.
Twigs not gray
Twigs gray

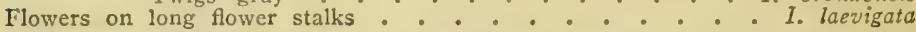

1. I. opaca, Ait. (Fig. 2, pl. 91.) Americax Holly. A tree, 20 to $40 \mathrm{ft}$. high, with evergreen glossy foliage, the loaves having wavy margins with spiny tips. Flowers in axillary clusters of from 3 to 10, white, of 4 petals and 4 stamens. Fruit a round berry turning red when mature. Moist woods, near the seacoast. April-June.

2. I. glabra, (L.) A. Gray. (Fig. 6, pl. 91.) INkBenRy. Shrub, 2 to $3 \mathrm{ft}$. high, with evergreen spincless leaves which are inversely lance. shaped or elliptic. Flowers, the pistillate generally single on rather long perluneles, the staminate in groups of 3 to 6 . Sandy ground, near the coast. June.

3. I. monticola, A. Gray. (Fig. 3, pl. 91.) Large-Leaved Hollr. ¿sually a shrub, but less commonly a tree with falling leaves, which are thin, lance-shaped or oval lance-shaped, from 2 to $6 \mathrm{in.}$ long, with serrated borders and with leaf-stems $1 / 4$ to $1 / 3$ the Iength of the leaves. Flower pedicels very short and bear a single flower, but the staminate flowers may grow in elusters while the pistillate are solitary. Tho nutlcts within the berry are ribbed. Woods. May.

4. I. verticillata, (L.) A. Gray. (Fig. 5, pl. 91.) BцAcK Alder. Shorub, resembling the last. Leaves usually broader, thicker, more shining and of dark green color. Petals and stamens usually 6. Veins on lower side of leaves downy. Flowers on very short pedicels. Nutlets within the berry are not ribbed. In wet grounds. June-July.

5. I. bronxensis, Britton. Bronx Wreter-nerry. Similar to No. 4, but with light gray twigs, pear-shaped leaves and with larger orangered fruit. Swamps, Maine to New Jersey, and west.

6. I. laevigata, (Pursh.) A. Ciray. (Fig. 4, pl. 01.) Sмооті WisTER-menrs. A shrub, usually rather smaller than the last, with similar leaves. Petals and stamens 4 to 8 each. Flowers on long pedicels, usually solitary, but the staminate growing 2 or more together in some cases. Swamps. May-June.

\section{ILICIOIDES, Dumont. (Nemopanthes, Raf.)}

$\Lambda$ smooth shrub with falling leaves, which are without serrations at the borders and which have flowers bearing stamens, others bearing pistils and yot others learing both sets of organs. 1'etals 4 or 5 lincar. I Berries on long stalks deeply grooved.

I. mucronata, (L.) Britton. Mountain Moldx. A branching shrub with gray bark resembling Ilex. Found in damp woods. May.

\section{Fantex V.-Celastraceat. Stafi Them Famili}

S'hrulss or trees. Our species all shrulss, snme of which are climbing. Jeaves simple and ours, cxcept Colustrus, opposite. 

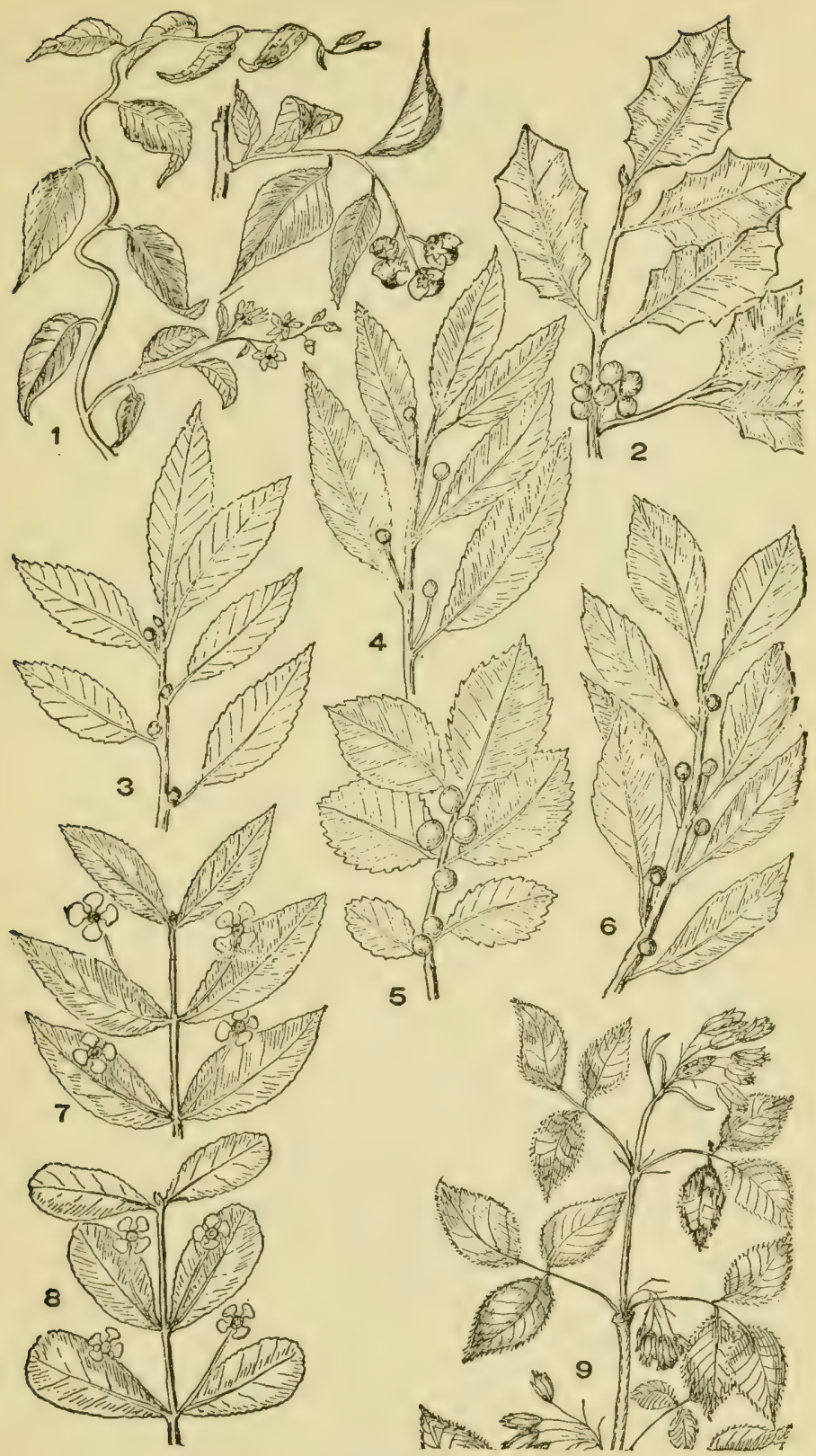

Plate 91

1. Celastrus scandens. 2. Ilex opaca. 3. I. monticola. 4. I. laevigata. 5.

I. verticillata. 6. I. glabra. 7. Euonymus americanus, 8. E obovatus, 9. Staphylea trifolia. 
Petals 4 or 5, stamens as many and alternate with the petals. Flowers usually with petals, sepals, stamens and pistils. Fruit a rounded or more or less angular pod which splits at maturity. The dominant characters are the regularity of the flowers and the equality in numbers of petals and stamens.

\section{EUONYMUS, L.}

Frect shrubs, with opposite leaves and small axillary purple or greenish flowers on rather long pedicels, which spring at the leaf axils. Calyx of 4 or 5 divisions, flat and spreading. The dise on which the 5 stamens are inserted is above the 4 or 5 ( 5 in our 2 species), petals which are rounded and spreading into a flat greenish or purple corolla. The pistil is short as are the stamens. The capsule or pod is more or less lobed or angular and splits from below upward showing the seeds.

1. E. americanus, L. (Fig. 7, pl. 91.) Strawberry Busm. Shrub, 2 to $5 \mathrm{ft}$. high, somewhat simple or branching. Leaves, almost without leaf-stalks, lance-egg-shaped with finely toothed elges, the veins nearly opposite and symmetrical, outer extremity acutely pointed. Flowers 1 or more on a single rather long pedicel, which is solitary in the leaf axil. Petals greenish, generally 5 ; stamens of the same number alternate with petals. Pod or berry rough, warty, bright red when ripe. When the pod splits the seeds are seen adherent to the central column or aril, which is bright scarlet.

2. E. obovatus, Nutt. (Fig. 8, pl. 91.) Running Strawberri Busir. A low trailing bush, rising about a foot from the ground. Leaves pear. shaped. Flowers similar to the last, but smaller, 3 or 4 on the single long pedicel. Low wet places. April-May.

3. E. atropurpureus, Jacq. Burning Busir. Shrub, 6 to $14 \mathrm{ft}$. high, with elliptic or long oval leaves the borders of which are finely serrated, outer extremity sharp pointed. Length of leaf about 2 to $5 \mathrm{in}$. Twigs 4-angled. Flowers purple, several on the single long pedicel arising at the leaf axil. Pods smooth, deeply lobed, crimson, very showy. In copses and borders of woods. June.

\section{CELASTRUS, L.}

Our species a climbing woody vine, bearing an abundance of clusters of orange capsules which remain during the winter and are very ornamental. Leaves alternate with small stipules which fall early. Petals and stamens, each 5, which are inserted at the margin of a flattened disk below which the petals are inserted. Flowers in elongated elusters at the ends of the branches. Pod globose, orange-colored when ripe and splitting into 3 valves which expose the scarlet seeds.

C. scandens, L. (Fig. 1, pl. 91.) Bitterswete. The twining vine which in the autumn adorns many of our tall trees with its clusters of bright berries.

\section{Famix VI.-STAPHYLEACEAE. Bunntr-nut Famis}

In our region only one representative, which is a shrub with 
opposite, 3-foliate leares supplied with small stipules and drooping clusters of whitish flowers from the leaf-axils. Stamens 5; petals 5, alternate with the petals. Ovary of 2 or 3 parts, numerous ovules. Pod a large membraneous inflated capsule of 3 cells, each containing 1 to 4 hard seeds.

\section{STAPHYLEA, L.}

Characters as above.

S. trifolia, L. (Fig. 9, pl. 91.) AMerican Bladder Nut. A shrub, 6 to $12 \mathrm{ft}$. high, with smooth striped bark. Found in thickets. AprilMay.

\section{Family VII.-ACeraceae. Maple Family}

Trees or shrubs, with opposite leaves. Flowers which are generally small in pendulous or spicate clusters may be perfect, having both stamens and pistils or these organs may find their homes in separate flowers, on the same plant or perfect and imperfect flowers may be found on the same tree. There is usually a calyx and a corolla, each of 5 divisions. Stamens 3 to 10 . There are 2 carpels or dry seed capsules which are joined together and to each of which is attached a winged appendage, a samara (see Fig. 51, p. 39), the "Maple Key."

\section{ACER, L:}

\section{Characteristics of the family.}

Leaves simple and generally deeply lobed.

Flowers in lateral pendulous fan-shaped clusters, appearing before the leaves.

Leaves silvery white beneath . . . . . . A. saccharinum

I.eaves dull white beneath . . . . . . . . . . A. rubrum

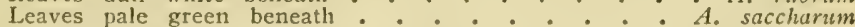

Leaves full green both sides . . . . . . . . A. nigrum

Flowers in elongated, more or less spicate clusters.

Clusters drooping. A. pennsylvanicum

Clusters erect Leaves compound, of 3 to 5 leaflets on a leaf-stem (pinnate) . $^{\circ} \cdot$. $^{*}$. Ncgundo

1. A. saccharinum, L. (Fig. 4, pl. 92.) Silver Maple. White Marle. Tree, 50 to $100 \mathrm{ft}$. high. Leaves deeply 5-lobed, the sinuses acute and the lobes narrow with irregular teeth; at base the leaf is cut almost squarely off or is slightly heart-shaped. Flowers appear before the leaves, corolla absent. The samaras diverge and become nearly or quite 2 in. long each, or often are unequally developed. Found in woods. Flowers open February to April.

2. A. rubrum, L. (Fig. 1, pl. 92.) Red Maple. Swamp Maple. Tree, generally of less height than No. 1. Twigs red or reddish. Leavez 2 to 6 in. long, 3 - to 5 -lobed, length exceeding width; the middle lobe generally longer than the others. The sinuses are acute and the lobes are irregularly and coarsely toothed. Flowers with both calyx and corolla, the latter of 4 or 5 red petals. Stamens scarlet, 5 or 6 in number. The key is scarlet borne on drooping stem 4 or $5 \mathrm{in.} \mathrm{long.} \mathrm{The} \mathrm{wings}$ 
at first incurved but later diverging, forming a key from an inch to 2 inches across. Leaves turn brilliant crimson in early autumn. Found along river banks and in swamps but often grows in dry places. Hlowers, March-April.

3. A. saccharum, Marsh. (Fig. 2, pl. 92.) Sugar Maple. Tree, similar to No. 1. Leaves 3 to 6 in. long, width greater than length, the 5 lobes separated by rounded sinuses. Base of leaf heart-shaped, margin with few or no tecth except the extremities of the secondary lobes. Color dark green above, light green beneath. Flowers appearing with the leaves, greenish-yellow. Perfect or imperfect flowers in separate clusters; corolla wanting. Stamens 7 or 8 . Wings of the "key" diverging, each from $\frac{1}{2}$ to $1 \mathrm{in}$. long. The key hangs pendulous from a long and slender footstalk. Flowers appear in May. Tree found in woody uplands. From it is produced most of the maple sugar of the market. April-May.

4. A. nigrum, Michx. Black Sugar Maple. Tree similar to the last. Leaves darl grecn both sides. Found in similar situations. Flowers appear in May.

5. A. pennsylvanicum, I. (Fig. 3, pl. 92.) Striped MApLe. Whistle Wood. Moose Wood. A small tree, mostly in damp and shady woods. Height generally less than $30 \mathrm{ft}$. Leaves 5 to $8 \mathrm{in.} \mathrm{long}$, rounded or heart-shaped at base, free end of 3 sharp lobes; border sharply tonthed. Flowers yellow in long, narrow, drooping elusters, those bearing stamens usually in different clusters from those bearing pistils. Calyx and corolla present. The bark of this beautiful tree is of a dark green marked with streaks of reddish-brown. When young striped with lighter lines. In woods, most of our area.

6. A. spicatum, Lam. (Fig. 5, pl. 92.) Mountain Maple. A small bushy tree, or more frequently a slirub. Leaves 3 to 5 in. long, rounded or heart-shaped at base, terninated by 3 lobes, the larger of which are often slightly divided into two. Flowers greenish-yellow in slender, ercet clusters 5 to $7 \mathrm{in}$. long. The keys are from $1 \frac{1}{2}$ to $2 \mathrm{in}$. across. Rocky woods, our area. Flowers in May.

7. A. Negundo, I. (Fig. 6, pl. 92.) Box Elder. Small tree, with compound leaves of from 3 to 5 leaflets. These latter are from 2 to $4 \mathrm{in}$. long, oval or egg-shaped, sharply pointed a a pex and generally roumled at base. They are irregularly and coarsely toothed, the terminal one often 3-lobed. The "lieys" are similar to those of other maples, but the wings are less diverging. Occasional in most of our area.

The Jurwax Mares, Acer platinoides, with leaves more rounded than the native sugar maples and with sinuses more shallow and color of darker green, is common as a planted tree in parks and along streets of cities and villages; and the Sycamone MArLe, A. pseudo-platanus, with smaller leaves, with more rounded lobes is also extensively planted as an ornamental tree. Neither are native species.

\section{FAMILX TIII.-HIPPOCASTANACEAE. BuCKEY FAMILY}

Trees and shruls, with opposite compound leaves and conspicuous flowers in large cluster's. Flowers irregular. Stamens 5 to 8. 

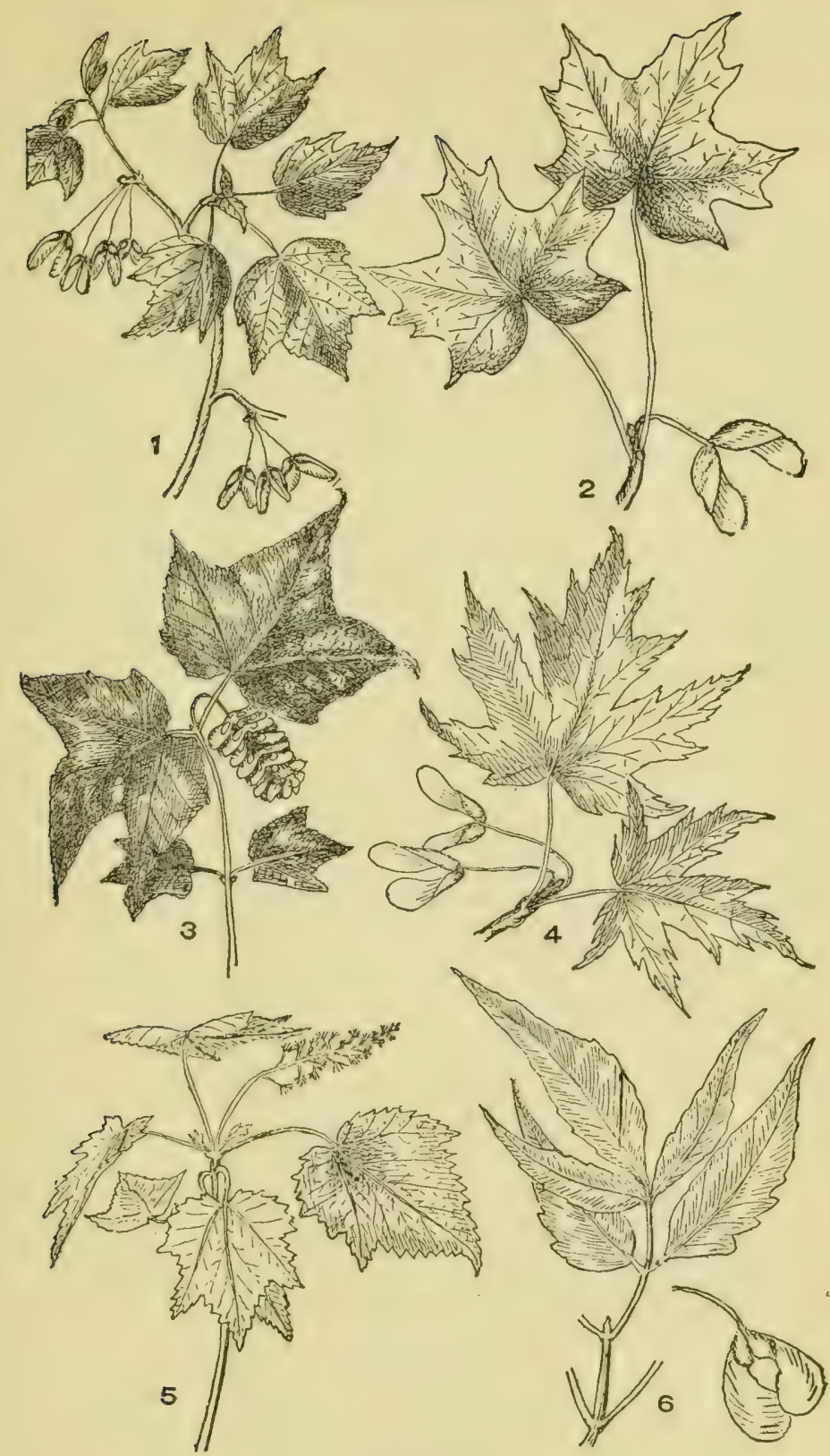

Plate 92

1. Acer rubrum. 2. A. saccharum. 3. A. pennsylvanicum. 4. A. saccharinum. 5. A. spicatum. 6. A. Negundo. 
Orary 3-celled. Fruit a leathery capsule studded with spines enclosing 1 to 3 smooth roundish seeds.

\section{AESCULUS, L.}

Characters as above.

1. A. Hippocastanum, L. Honse Chestnut. A large tree, extensively planted as an ornamental tree. Leaves opposite, compound, of 7 leaflets all springing from a common center. Each leaflet wedge-shaped and notehed along the borders. The two outer leaflets smaller than the others. The showy, erect clusters of white (sometimes purple) Howers are conspicuous in parks and along roadsides in May and June.

2. A. glabra, Willd. (Fig. 3, pl. 89.) OHi BuckeYe. Leaflets 5. Otherwise much resembling No. 1, but with yellow flowers. Found in southern Pennsylvania of our region.

\section{FAMILY IX.-SAPINDACEAE. SoAPBERRY FaAILY}

Trees, shrubs or herbaceous vines, with alternate leares, which are usually compound. Flowers regular or slightly irregular. Calyx division 4 or 5 ; petals 3 to 5 . Stamens 5 to 10 . A single species in our region.

\section{CARDIOSPERMUM, L.}

Description included with the only species in our area.

C. Halicacabum, L. (Fig. 8, pl. 93.) Balloon Vixe. Heart Seed. $\Lambda$ slender vine, climbing on shrubs and trees, 2 to $6 \mathrm{ft}$. long. Leaves alternate and doubly compound, $i$. $c_{\text {., }}$ of 3 divisions, each of 3 wedgeshaped or oval leaflets, these coarsely toothed. Flowers in small clusters, the two lower footstalks of each cluster changed to tendrils. Divisions of calyx 4, of which two are larger than the other two; petals also 4, with similar disproportion between two pairs, white. Stamens 8, unequal. Fruit a much inflated bladder-like capsule 1 in. long. containing black globose seeds. Escaped from cultivation, occasional only.

\section{Fanily X.-BALSAMinaceaE. Jewel Treed Fumix}

Annual lierls, with sueculent stems, with simple alternate leaves and very unsymetrical flowers. Calyx of 3 sepals, uncyual and unlike; stamens 5 ; petals 5 or 3 , two of them divided into unequal and clissimilitr lobes. Ovary compound, of 5 cells ; pistil very short. Fruit in our genus a cylindric capsule which bursts clastically on pressure.

IMPATIENS, L.

Divisions of ealyx colored like the comolla. Tetals apparently 2, the lower being united with the two lateral. Joints of stem swollen.

1. I. biflora, Walt. (Fig. 1, pl. 93.) Spotten Touch-ML-Not. Jewed IVEev, Succulent herb, 2 to $5 \mathrm{ft}$. high, with ovate or elliptic leaves, the 

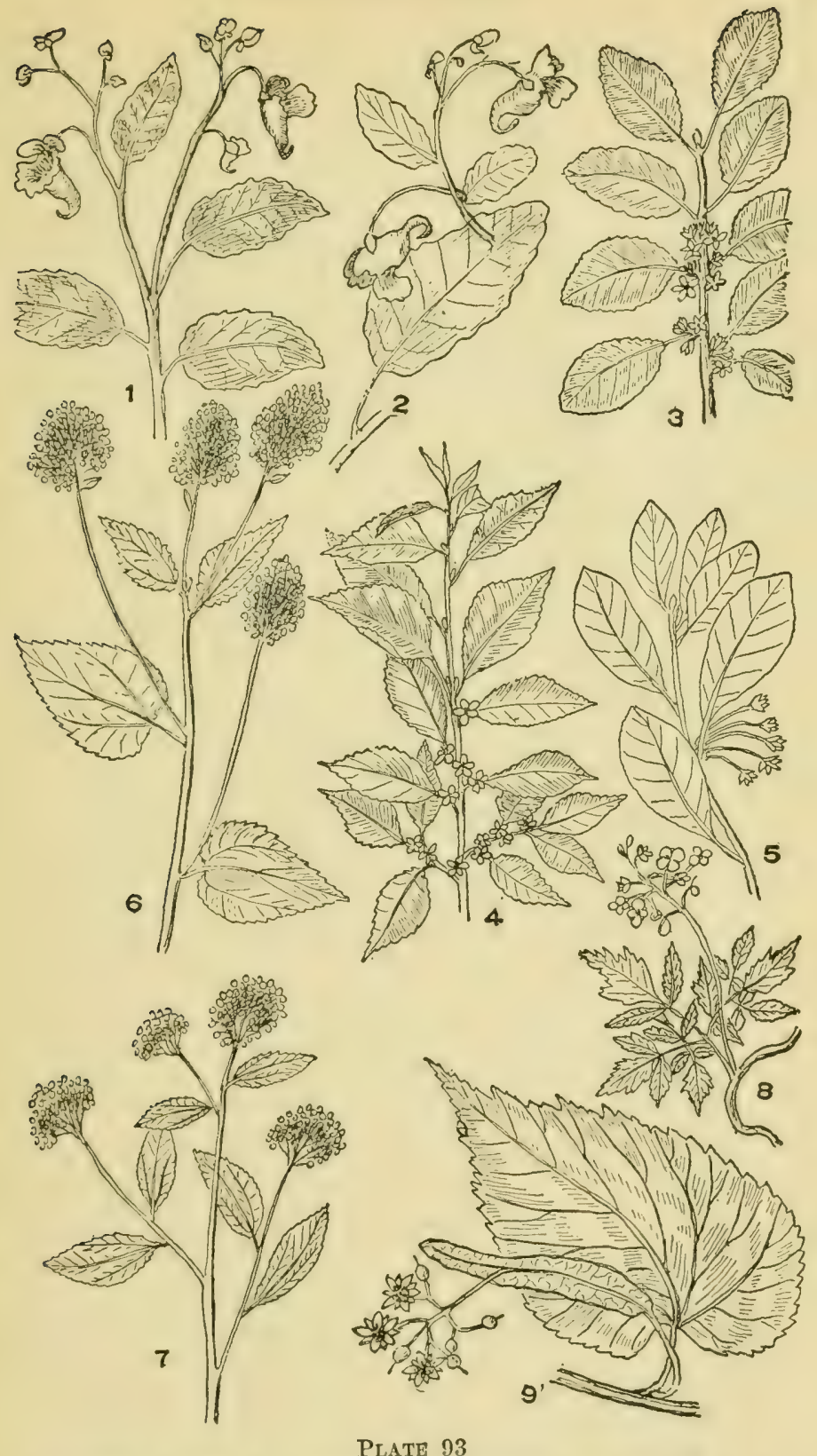

Plate 93

1. Impatiens biflora. 2. I. pallicla. 3. Rhamnus cathartica. 4. R. alni folia. 5. I. Frangula. 6. Ceanothus americanus. 7 C. ovatus. 8. Cardiospermum Halicacabum. 9. Tilia americana. 
edges of which are coarsely toothed. They are thin, pale and smooth. Flowers orange-yellow mottled with brown, in pairs at extremities of branches. The lower sepal forms a conical spur which is elongated and curved. Sac broader than long. In moist places, borders of streams mostly. July-Oct.

2. I. pallida, Nutt. (Fig. 2, pl. 93.) Pale Jewel IVeed. TouchME-Not. (I. aurea, Muhl.). Plant similar to preceding species, but leaves larger and longer. Flowers pale yellow, with a few brown dots. Spur short. Sac longer than broad. In situations similar to last.

\section{Order IX.-RHAMNALES. Order of the Buckthorns}

Shrubs, small trees or climbing vines, with or without thorns. Leaves always simple, not lobed. Stamens as many as the divisions of the caly.x and alternate with them. When petals are present the stamens are opposite them.

\section{Fanily I.-RHAMNACEAE. BucKtionNs}

Leaves opposite or alternate, not lobed or compound. Stipules present but small and falling early. Flowers in clusters either terminal or from the axils, always small, regular of 4 or 5 sepals and when petals are present they are of the same number and inserted on the calyx. Stamens of same number as sepals and alternate with them. Fruit a dry berry-like drupe or a capsule. Seeds solitary in the cells of the drupe or capsule.

Shrubs with axillary clusters of flowers . . . Rhamnus

Shrubs of herbaceous appearance with terminal umbels of flowers

\section{RHAMNUS, L.}

Small shrubs with alternate leaves and clusters of small fowers in the axils. Calyx of 4 or 5 divisions, petals inconspicuous or absent. Fruit a berry-like drupe with from 2 to 4 hard seeds.

Leaves toothed at borders.

Long and narrow

Egg-shaped.

Branches thorny

作

Branclies without thorns $\cdot \cdots \cdot \cdots \cdot{ }^{R}$ alnifolia

Leaves with remote teeth ........... $R$. caroliniana

1. R. cathartica, T. (Fi心. 3, pl. 93.) Buckтиors. Shrub with thorny branches, cultivated for hedges. Leaves egg-shaped or broadly elliptic. Flowers small, greenish, a few clustered in the axils. Calyx divisions 4. Stamens of like number. Berries round, black. Escaped from cultivation. May-June.

2. R. lanceolata, Pursh. Lance-Leaved BucKtions. Tall erect 
shrub. Leaves 1 to $3 \frac{1}{2}$ in. long, about $\frac{1}{1}$ as wide, very finely toothed. Flowers in the leaf-axils, a few in a cluster, greenish, mostly staminate and pistillate on different plants. Moist soil. Penna., and westward. May.

3. R. alnifolia, L'Her. (Fig. 4, pl. 93.) DwarF Alder. AlderLEAVED BUCKTIORN. A low shrub, growing in clumps in swamps or wet grounds, height 2 or $3 \mathrm{ft}$. Leaves oval or rounded at the base, 2 to 4 in. long with fine serrations at borders. Flowers small, yellow, at leaf axils. Fruit black.

4. R. Frangula, L. (Fig. 5, pl. 93.) Alder Buckthorn. Shrub resembling the last, but with larger leaves, which are not serrated at borders. Flowers at the axils borne on foot-stalks $\frac{1}{2}$ in. long. Found in bogs, Long Island and other points in southern part of our area. MayJune.

5. R. caroliniana, Walt. Carolina Buckthorn. Tall shrub or small tree, thornless. Leaves elliptic or oblong, 2 to 6 in. long. Flowers at the leaf-axils on foot-stalks, all with stamens and pistils. Wet grounds, New Jersey, and southward.

\section{CEANOTHUS, L.}

Low shrubby plants resembling herbs. Leaves alternate; flowers in terminal, nearly umbellate, clusters. Calyx of 5 lobes. Corolla of 5 small hooded petals, white or yellowish-white. Fruit dry, 3-lobed.

1. C. americanus, L. (Fig. 6, pl. 93.) New Jersey Tea. Red Root. Stems 1 to $3 \mathrm{ft}$. high, slender, branching at top. Leaves oval with 3 prominent ribs running longitudinally. More or less covered with soft hairs, especially above. Flowers in dense umbel-like clusters at summit of naked flower branches. Dry woods. May-July.

2. C. ovatus, Desf. (Fig. 7, pl. 93.) Smaller Red Root. Similar to No. 1, but leaves smaller, less pointed at apex and less rounded at base and without hairs or nearly so. Oceasional, not common in our area. Máy-July.

\section{Family II.-VitaceaE. Grape Family}

Vines climbing by tendrils. Rarely shrubs, but never in our area. Leaves simple, alternate, broad, with the principal veins starting from a common center at the extremity of the foot-stalk or of 5 leaflets starting from a common center. Flowers small, greenish, in elongated, conical clusters. Stamens 4 or 5, opposite the petals. Stamens and pistils not always in the same flower and sometimes not on the same plant. Fruit a grape berry.

Leaves simple . . . . . . . . . . . . Vitis

Leaves compound, of several leaflets . . . . Cissus 


\section{VI'TIS, L.}

Characters as above.

Leaves decidedly downy beneath.

Generally 3 -lobed with shallow sinuses $\ldots . . . \quad$, labrusca

Generally 5 lobed with deep sinuses $: \therefore \therefore: \therefore \quad V$ : aestivalis Leaves not downy.

Not lobed or only slightly lobed . . . . . . . . V cordifolia 3-lobed toward apex 3. to 5-lobed, lobes extending back $\because \cdots, \cdots$ bicolor

1. V. labrusca, L. (Fig. 2, pl. 94.) Fox Grape. Northern Plum Grape. Leaves broad, generally 3 -lobed at the apex and rounded or heartshaped at base. Deeidedly downy beneath. Berries large, few, brownishpurple. In thickets. This is the original of several varieties of eultivated grapes: Concord, Isabella, Catawba, etc.

2. V. aestivalis, L. (Fig. 1, pl. 94.) Small Grape. Summer Grape. Leaves of about 5 lobes with deep sinuses; downy beneath. Berries small, deep blue. Clusters wanting opposite each third leaf. Thickets and shady banks.

3. V. bicolor, Le Conte. (Fig. 4, pl. 94.) Winter Grape. Similar to No. 2, but leaves not downy or with few hairs. Fruit dark blue, ripen. ing after the frosts. New Hampshire, and southward.

4. V. vulpina, L. (Fig. 3, pl. 94.) Sweet-scented Grape. Leaves smaller than either of the preceding species, heart-shaped at base, slightly 3-lobed at summit. Berries bluish-black, rather sweet. In situations similar to those of other species.

5. V. cordifolia, Michx. (Fig. 5, pl. 94.) Frost Grape. Leaves cordate, not lobed or only slightly so. Smooth and shining on both sides. Berries black, ripening after frosts. In thickets and along streams.

\section{CISSUS, L}

Climbing vines, the tendrils being, in our species, terminated by expanding tips which adhere to supporting surfaces. Flowers much like those of Vitis but in more expanding elusters.

C. Ampelopsis, Pers. (Fig. 6, pl. 94.) Virainia Creeper. (Parthenocissus quinquefolia, Planch. Ampelopsis quinquefolia, Michx.). A slender woody vine climbing upon trees. Leaves of 5 divorging leaflets. Common in woods and thickets.

\section{Order X.-MALVALES. Order of the Mallows}

Leaves net veined, petals distinct, carpels united into a compound ovary. Ovaries free from the calyx and above it. Stamens mumerous. S'epals, in bud, meeting at the exleses, not overlapping. Ovule bearing surface forming a central column within the capsule. 


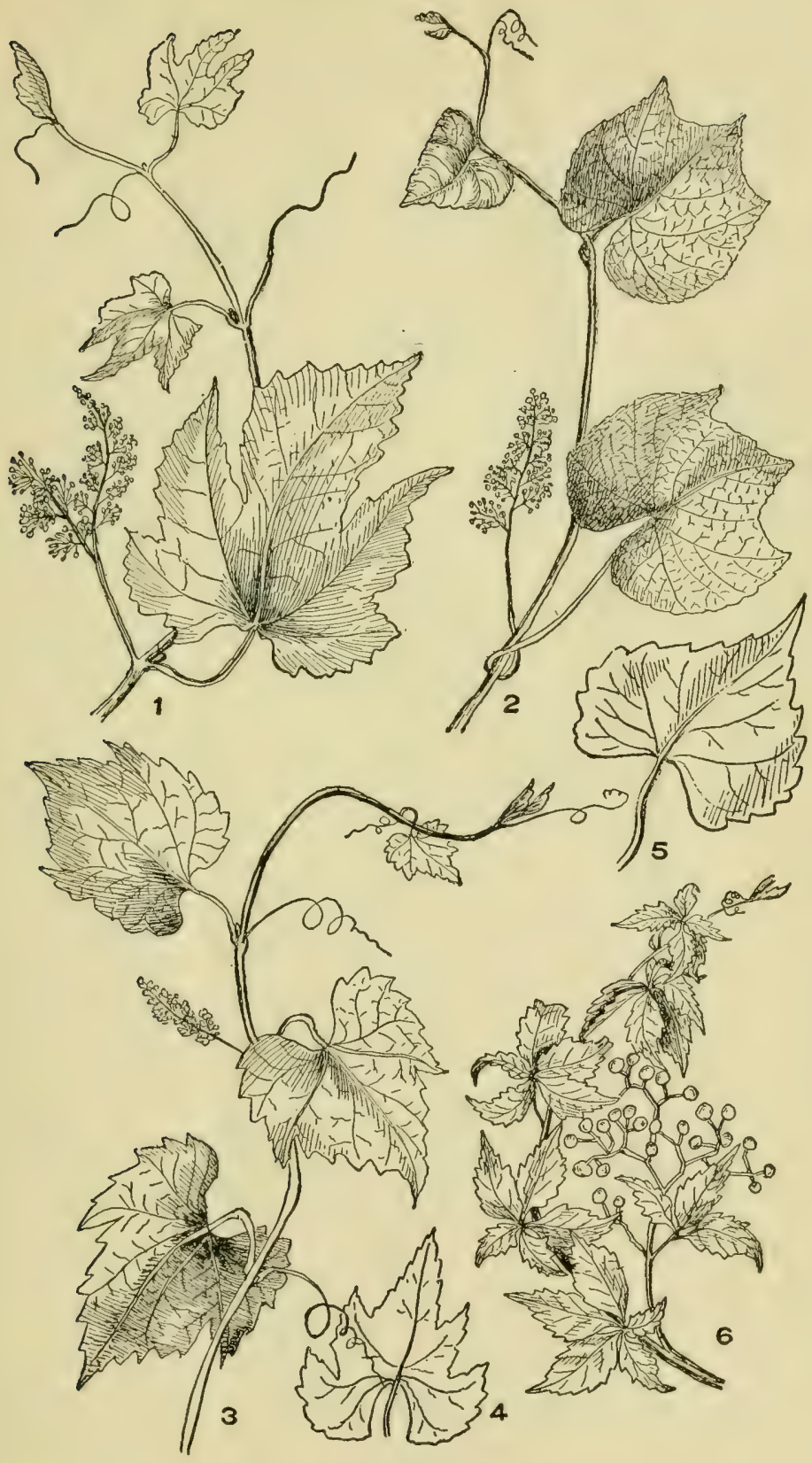

Plate 94

1. Vitis aestivalis. 2. V. labrusca. 3. V. vulpina. 4. V. bicolor. 5. V. cordifolia. 6. Cissus Ampelopsis. 


\section{Famile I.-Tiliaceae. Linden Family}

Trees, shrubs or herbs. In our area trees only. Leaves alternate (rarely opposite) not compound. Stipules present but small and falling early. Divisions of calyx generally 5 , falling; petals of the same number when present. Stamens numerous in several united sets. Fruit a dry rounded berry or nutlet containing 1 or more seeds.

\section{TILIA, L.}

Trees, with simple heart-shaped leaves, one side of which developes larger than the other. Flowers yellowish, in clusters, the foot-stalks of these clusters subtended by a broad bract to which the foot-stalk is also to some extent attached.

1. T. americana, L. (Fig. 9, pl. 93.) Basswood. American LiNDEx. A large tree with comparatively smooth bark. Leaves heart-shaped, one side larger than the other, smooth on both sides or with hairs along the under side of the nerves only. This is our common Basswood growing in woods and fields throughout our area. Blooms May and June.

2. T. pubescens, Ait. Southerv BAsswood. Leaves rather smaller than No. 1, and decidcdly downy or densely woolly beneath. In southern part of our area.

3. T. heterophylla, Vent. Wiite BAsswood. Leaves larger than either of the above. White downy beneath. In New York, southern Pennsylvania and south from there.

4. T. europaea, T. Eunopeax Lindex. Has smaller and more regular leaves. Our native species have scales at the base of the petals. This lias none. Planted extensively as an ornamental tree.

5. T. Michauxii, Nutt. Micmudx's Lindex. Resembles T. heteroflylla, but while in this the floral bract is recurrent along the flowering strm to its base or nearly so, in $T$. Michauxii it extends within $\frac{1}{2}$ in. of the end of the stem. Penna., and westward.

\section{Famili II.-MALVACEAE. MaLLow Family}

ITerls, in our area, elsewhere herlos and trees, with alternate leaves with small filling stipules. Flowers regular, with both stamens and pistils. Stamens mumerous, forming a single set in union which forms a column around the pistil. Ovary often lobed, several seeded.

\section{Columns of stamens bearing anthers only at top}

Involuce of 6 to 9 bractlets.

Althaea

Involucre of 3 distinct bracts.

Summit of pistil (stigma) linear.

Malva 
Bracts of involucre absent. Summit of pistil a flattened cap.

Carpels, each one seeded . . . . . . Sida Carpels, each 3 to 9 seeded . . . . Abutilon

Bracts of involucre incised, each forming 3 teeth Kosteletzkya

Columns of stamens bearing anthers along much of their lengths Bracts of involucre numerous . . . . . . Hibiscus

\section{ALTHAEA, L.}

Below calyx an involucre of 6 to 9 bracts which unite at base. Styles numerous, the stamens forming a column about them. Petals 5; calyx of 5 sepals. Divisions of the ovary several, 1-seeded each.

A. officinalis, L. (Fig. 2, pl. 95.) MARsi MALlow. Leaves large, somewhat 3-lobed, serrated at borders; downy on both sides. Flowers large and showy, in axils of leaves. Pink. Abundant in salt marshes.

\section{MALVA, L.}

Herbs, leaves often deeply divided. Flowers generally conspicuous petals 5 , calyx of 5 sepals with a 3 -leaved involucre at the base. Pistils numerous, the stigma running down the inner side. Fruit a depressed disk-like body ("a cheese"), which, at maturity separates into many 1-seeded divisions.

1. M. sylvestris, L. (Fig. 3, pl. 95.) Higm Mallow. Stem erect, 2 to $3 \mathrm{ft}$. high; leaves rounded but somewhat divided into 7 lobes more or less angular, hairy. Flowers reddish-purple crowded toward the sum. mit of the stem. Frequent along way-sides, blooming through the summer. Sometimes called "pink cheeses."

2. M. rotundifolia, L. (Fig. 5, pl. 95.) DWARF or Common MALLow. CheEses. Stems spreading upon the ground, 4 to $10 \mathrm{in.} \mathrm{long;}$ leaves heart-shaped at base, on very long foot-stalks. Flowers pale blue, or whitish, at the leaf axils. Fruit a flattened, disk-like collection of carpels. Common about cultivated grounds, door yards and way-sides.

3. M. verticillata, L. Whorled Mallow. Flowers elustered in the axils appearing to surround the stem. Rare except as an escape from gardens.

4. M. moschata, L. (Fig. 4, pl. 95.) Musk Mallow. Stem 1 to $2 \mathrm{ft}$. high. Leaves 5-parted, the divisions again once or twice parted into linear segments. Basal leaves round. Flowers 1 to 2 in. broad, rosepink, at the summit of the stem.

\section{SIDA, I.}

Herbs, with alternate leaves. Bracts at the base of the calyx wanting, sepals and petals, each 5. Stigma (summit of pistil) a small head.

S. spinosa, L. (Fig. 8, pl. 95.) Prickly SinA. A weed 10 to 20 in. high. Leaves egg-shaped to oblong, serrate, downy, on leaf-stalks 2 as long as the leaves. Flowers at the axils of the leaves, yellow, small. Waste places. Summer. 


\section{ABUtilon, Gaertn.}

Our only species an herb with broad heart-shaped leaves. Flowers at the axils; the carpels each 2 - to 9 -seeded. Calyx with no bracts at base. In general appearance like Sida.

A. Theophrasti, Medic. (Fig. 6, pl. 95.) Velvet Leaf. Indian Mallow. (A. Abutilon, (L.) Rusby.) Plant 2 to $6 \mathrm{ft}$. high, whole plant downy. Leaves rounded, heart-shaped, acute at apex, 4 to $12 \mathrm{in}$. wide, on long leaf-stalks. Flowers yellow, $\frac{1}{2}$ to 1 in. broad. Fruit about an in. in diameter. In wet places. Aug.-Oct.

\section{KOSTELETZKYA, Presl.}

Our species an herb, downy, with angular leaves. At base of calyx some small bracts, incised, forming linear segments. Stamens, all united about the pistils which are 5 in number, and have eapped summits.

K. virginica, (I.) A. Gray. (Fig. 7, pl. 95.) Virginia KosteLEтzKy . Plant 2 to $4 \mathrm{ft}$. high. Leaves 2 to $5 \mathrm{in}$. long, generally less than $\frac{1}{2}$ as wide. Point of leaves long and narrow, base rounded; at $1 / 3$ distance from base to apex is a rather pronounced angle at each side. Flowers pink, $1 \frac{1}{2}$ to $2 \frac{1}{2}$ in. broad. Southern New York and southwards. In brackish marshes. August.

\section{HIBISCUS, L.}

Shrubs or herbs. In tropical regions sometimes trees. Leaves simple. Flowers large and showy. The column of stamens which surrounds the pistils bears anthers throughout much of its length. Calyx of 5 sepals subtended by a fringe of linear bracts. Fruit a 5-celled pod with several or many seeds in each cell.

1. H. Moscheutos, L. (Fig. 1, pl. 95.) Swamp Rose Maliow. Leaves 3 to $7 \mathrm{in}$. long, egg-shaped or lance-shaped, rounded or heartshaped at base, slender tapered at apex, downy white beneath, smooth, green above. The lower leaves often 3-lobed. Flowers 4 to 7 in. broad, pink or white. Pod smooth. Salt marshes on the eastern coast. Aug.Sept.

2. H. oculiroseus, Britton. Crimson-eye Rose Mallow. Corolla white with a dark crimson center. Growing with $H$. Moscheutos and blooming at the same time.

3. H. Trionum, I. Flower-OF-AN-Hour. Plant, low, branching, rather hairy, annual. Leaves much incised, the middle one of the 3 main divisions much the longest. Flowers pale yellow with a purple center, the edges of the petals also tinged with purple. Flowers open only a fow hours. Porls much inflatcd, 5-winged. Waste places. Introduced. Aug.-Sept.

\section{Order XI.-PARIETALES. Order of the Violets}

Generally herbs, rarely shrubs and still more rarely trees. Leaves opposite, alternate or from the root. Flowers with stamens and pistils, the former numerous or few. Petals 3 to 5, distinct. Sepals or divisions of caly.x overlap each other or are longitudinally rolled. 


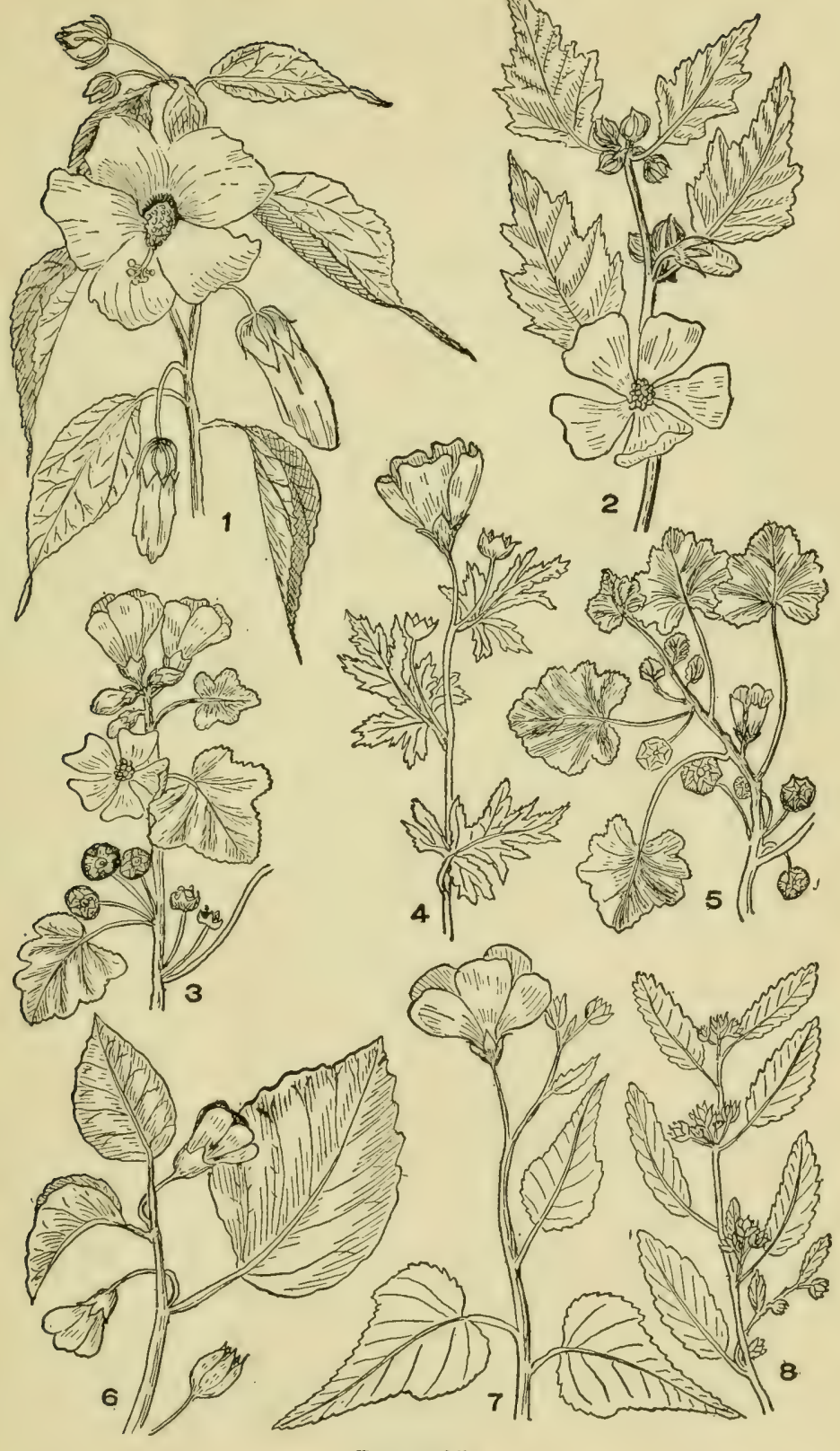

Plate 95

1. Hibiscus Moschentos. 2. Althaea officinalis. 3. Malva sylvestris. 4. M. moschata 5. M. rotundifolia. 6. Abutilon Theophrasti. 7. Kosteletzkya virginica. 8. Sida spinosa. 
The ovules are generally attached, not to a central column as in the preceling order, but to the sides of the capsule, or rarely to a central axis.

Herbs or shrubs with opposite leaves.

Plants from a few to many in. high, without stipules

Minute marsh plants with stipules . . ELATINACEAE Herus (not climbing) with alternate leaves or leaves from the root.

Flowers regular . . . . . . . . CISTACEAE

Flowers irregular . . . . . . . . VIOLACEAE Climbing woody vines . . . . . PASSIFLORACEAE

FAnILY I.—HYPERICACEAE. ST. JoHN'S-Wort FAMILT

IIerlss or shrubs, with opposite leaves, which are neither lobed nor serrated at borders and with no stipules. Flowers regular, ours all yellow. Stamens generally numerous, commonly collected in 3 or more clusters or bundles. Petals in bud mostly rolled longitudinally. Pod 1-celled.

Divisions of calyx 4 , in 2 unequal pairs .

Ascyrum Divisions of calyx 5, all alike.

Stamens numerous

Hypericum

Stamens 10 or less, leaves scaly . . . . Sarothra

Stamens usually 9 or more, leaves not scaly - Elodea

\section{ASCYRUM, L.}

Low, somewhat shrubly, smooth plants, with opposite leaves without serrations at horders. Petals 4, sepals 4, 2 of which are larger than the other pair. Stamens numerous, scarcely collected in clusters.

1. A. stans, Michx. (Fig. 4, pl. 96.) St. Pетег's-wort. Stem simple, 1 to $2 \mathrm{ft}$. high, but with a few branches at top. Jeaves oval without foot-stalks. Flowers about an in. broad, bright yellow, one to three at summit of stem, showy. Dry soils. July-Aug.

2. A. hypericoides, I. (Fig. 6, pl. 96.) ST. Andrew's Cross. Stems much branched and partly decumbent. Jeates narrow oval or rorgshaped. Flowers in the leaf axils along the stem, the potals seareely exceeding the sepals. Dry sandy soil. Eastern coast. July-Aug.

\section{HYPERICUM, L.}

Ifrers or shrubs, with opposite leaves dotterl with hlack points, without sorrations and with no stipules. Flowers regular, yellow, sepals and

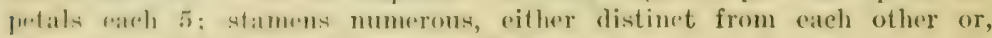
more commonly, collected in 3 to 5 clusters. 
Stamens 25 to 100, more or less united in groups.

Styles five.

Leaves egg-shaped or nearly oval.

Flower an in. or more broad

Leaves oblong-linear, flower nearly an in. broad

Styles three, rarely four.

Plants shrubby, at least at base.

Leaves lance-shaped or oblong.

Flowers an in. broad..... . H. prolificum

Plants not shrubby.

Flowers $\frac{1}{2}$ in. broad ...... II. densiflorum

Creeping at base, stem winged . . . . H. adpressum

Creeping at base, stamens not in phalanxes ${ }^{\circ}$. Bissellii

Erect, not creeping at base.

Leaves elliptic, styles united at base . . H. ellipticum Leaves oblong or linear . . . . H. perforatum

Stamens 5 to 15 . Flowers small.

Leaves egg-shaped, obtuse : $: \dot{*}^{-} \cdot H_{\text {. maculatum }}$

Clusters of flowers with leafy bracts . . . . . . . H. boreale

Clusters of flowers with narrow awl-shaped bracts.

Leaves egg-shaped or oval.

Leaves linear, obtuse at apex

H. mutilum

Leaves lance-shaped, acute at apex "

1. H. Ascyron, L. (Fig. 2, pl, 96.) Giant St. Joinn's-wort. (H. pyramidatum, Ait.) Plant, 2 to $6 \mathrm{ft}$. high. Leaves oblong egg-shaped with rather blunt points, 2 to 5 in. long, clasping at base. Flowers bright yellow about $1 \mathrm{in}$. broad. On dry hills also along banks of streams. July-Aug.

2. H. Kalmianum, L. (Fig. 1, pl. 96.) KaLm's ST. JoHn's-wort. Shrubby, at least at base, 1 to $2 \mathrm{ft}$. high. Leaves narrow-oblong, obtuse but with the mid-vein protruding as a stiff bristle; about 2 in. long, $\frac{1}{4}$ in. wide at apex, narrowed at base; rather numerous. Branches 4 -angled. Clusters of flowers mostly terminal. Individual flowers about $\frac{3}{4} \mathrm{in}$. broad. Fruit capsule 5-celled, tipped with 5 styles.

3. H. prolificum, I. Silruise St. Joins's-wort. Shrubby, 2 to 4 ft. high. Leaves very numerous. oblong, narrow, rounded at tip, narrowed to a short leaf-stalk at base, 1 to $3 \mathrm{in}$. long. Flowers yellow, numerous, $\frac{1}{2}$ to $\frac{3}{4}$ in. broad. Branches 2-edged. Sandy soil. July-Sept.

4. H. densiflorum, Pursh. Bushy St. John's-wort. Similar to No. 3 , but branches, leaves and flowers smaller and crowded. July-Sept.

5. H. adpressum, Bart. Creepixa St. Joirs's-wort. Shrubby at base, 1 to $2 \mathrm{ft}$. high. Leaves oblong-linear, 1 to $2 \mathrm{in}$. long, rounded at tip, branches 2 -winged. Flowers in terminal clusters, without leaves, each about $\frac{1}{2}$ in. broad. Styles 3 to 4 .

6. H. Bissellii, Robinson. Brssell's St. Jonn's-wort. Resembles H. adpressum. Stamens in the latter are separable into phalanxes, in this not. (apsule of $I I$. arlpressum partly divided into 3 or 4 cells, this has only 1 cell. Southington, Conn. July-Aug.

7. H. ellipticum, Hook. (Fig. 5, pl. 96.) Elliptic-teaved St. JoIn's-worT. Smooth with 4 -angled stem, $\frac{1}{2}$ to $2 \mathrm{ft}$. high. Leaves thin, rather broadly elliptic, rounded at tip, without leaf-stalk at base. Flowers few, terminal, pale yellow, $\frac{1}{2}$ in. broad. In marshy grounds and along streams. July-Aug.

8. H. perforatum, L. (Fig. 7, pl. 96.) Common St. Jomn's-wort. Stems 1 to $2 \mathrm{ft}$. high, 2-winged, much branched. Laaves oblong, rounded at tip; attached directly to stem, many shoots commonly springing from 
leaf-axils. Leaves black dotted, generally broader at tip than at base. Clusters of flowers nearly terminal, of many flowers, leafy. Common in pastures, etc. July-Sept.

9. H. maculatum, Walt. (Fig. 9, pl. 96.) Spotted St. Jorn'sworT. (H. punctatum, Lam.). Shrubby at base, 1 to $3 \mathrm{ft}$. high. Leaves ovil, broadest at base, abundantly sprinkled with black dots, 1 to 3 in. long. Flowers small, crowded; petals black dotted, much longer than the sepals. Styles 3. Capsule 3-celled. Moist soil. July-Sept.

10. H. boreale, (Britton) Bicknell. (Fig. 11, pl. 96.) NortirerN ST. Jonn's-wort. Stems rounded or somewhat 4-angled, 1 to $1 \frac{1}{2} \mathrm{ft}$. high. Leives elliptic, f to 1 in. long, $1 / 12$ to $1 / 3 \mathrm{in.}$ wide, commonly 3 -nerved. clusters lenfy, few flowered. Stamens few. Capsule purple, longer than the sepals or petals. Wet soil. July-Sept.

11. H. mutilum, L. (Fig. 10, pl. 96.) DwarF ST. JoHn's-worT. Stems slender, $\frac{1}{2}$ to $2 \mathrm{ft}$. high, abundantly branched, 4-angled. Leaves oblong, clasping at base, somewhat rounded at tip, 5-nerved. Flower clusters not lcafy, but with awl-shaped bracts. Flowers small. A slender species. Low grounds. July-Sept.

12. H. majus, (A. Gray) Britton. Larger Canadian ST. John'swoRT. Stems 1 to $3 \mathrm{ft}$. high, stouter than No. 12, branched above. Leaves lance-shaped, clasping at base, tapering but rounded at tips, 5-nerved. Moist soil. June-Sept.

13. H. canadense, L. (Fig. 8, pl. 96.) Canadian St. John's-wort. Stems $\frac{1}{2}$ to $l_{\frac{1}{2}} \mathrm{ft}$. high, branching. Leaves linear, $\frac{1}{2}$ to $2 \mathrm{in}$. long, rounded at tip. Flower clusters with awl-like bracts. Flowers small. Low grounds. July-Sept.

\section{SAROTHRA, L.}

Small branching herb, with leaves reduced to scales. Flowers small, yellow, along the stem in the axils of some of the scales. Petals 5; sepals 5 , stamens 5 to 10 .

S. gentianoides, I. (Fig. 3, pl. 96.) Orange-grass. (Пуреricum mulicaule, Walt.). Stems wiry, 3 to 9 in. high. In sandy fields. Common. June-Oct.

\section{ELODEA, Pursh. (Triadenum, Raf.)}

Perennial herbs growing in marshes. Leaves opposite and without lobes or tecth. Flowers in terminal clusters also in smaller clusters in the leaf axils. Calyx of 5 divisions; petals 5 ; stamens 9 or more in 3 groups. Alternating with these stamen groups are three large glands resembling petals. The presence of these glands forms the distinetive feature of the flower of ilodea.

1. E. virginica, (T.) Nutt. (Fig. 3, pl. 97.) Marsi St. TonN'swont. Opposite leaves oblong, blunt at earh end and atlached direclly to the stcm without internention of lcaf-stall, dotted with black dots. Flowers reddish-purple each about $\frac{1}{2}$ in. broad. Swamps. July-Aug.

2. E. petiolata, Pursh. Taneer Marsi ST. John's-wort. Plant uswally larger than No. 1, and leaves attached to the stem by a short leaf-stalk. 

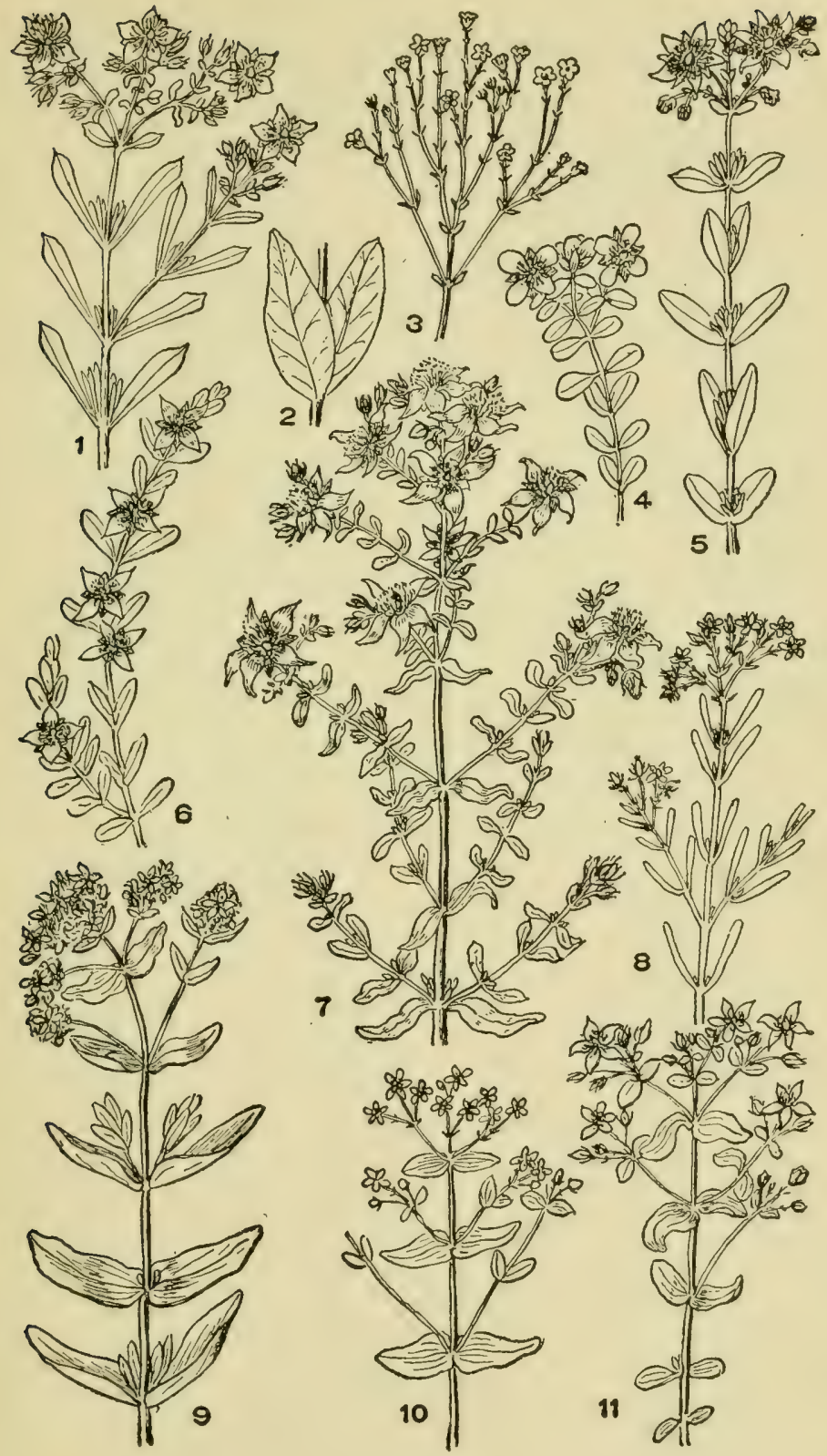

Plate 96

1. Hyṕericum Kalmianum. 2. H. Ascyron (leaves). 3. Sarothra gentian. oides. 4. Ascyrum stans. 5. Hypericum ellipticum. 6. Ascyrum hypericoides. 7. Hypericum perforatum. 8. H. canadense. 9. H. maculatum. 10. H. mutilum. 11. H. boreale. 


\section{Family II.-ElatinaceaE. Water-trort Fanimi}

Low herbs, with opposite leaves; in our species with undivided borders; movided with small nembraneous stipules between the opposite leares. Flowers of our species mainly solitary in the leaf axils. Pod round, 2- to 4-celled.

\section{ELATINE, L.}

Divisions of calyx and of corolla 2 to 4 . Stamens usually as many as petals. Dwarf plants growing in mud or in water, often rooting at the leaf nodes.

E. americana, (Pursh.) Arn. (Fig. 4, pl. 97.) WATEr-Wort. MIUd Punslane. Tufted, spreading, stems 1 to $1 \frac{1}{2} \mathrm{in}$. long; leaves obtuse. Flowers generally solitary in leaf-axils. Margins of ponds and sluggrish streams. Blooms all summer.

\section{Family III.-CISTACEAE. Rock Rose Family}

Low, shrubly plants, mostly of herbaceous aspect with regular flowers, but with the two outer sepals (when 5 sepals are present) smaller than the others, resembling small bracts. Petals 3 to 5, filling carly. Stamens generally numerous, each free from the others. Fruit capsule one-celled with 3 to 5 valves. Leaves simple, not lobed or serrate, upper alternate, lower usually differing in size and form from the stem leaves, usually opposite.

Petals five.

Flowers small yellow.

Style long and slender . . . . . Hudsonia

Flowers large, yellow.

Style very short or none . . . . Helianthemum

Petals three. Flowers small, greenish-purple . . . Lechea

\section{HELIANTHEMUM, Tourn.}

Wonly herhs, with encpicuous yellow flowers, also, in our species, with other llowers withut petals and therefore inconspicuous. Petals of the larese yellow flowers falling on the day following the opening of the flowers. Valves of the eapsule 3. Stamens numerous.

1. H. majus, (L.). BSP. (Fig. 1, pl. 97.) Hoary Frostweed. Stroms 1 to $2 \mathrm{ft}$. high, frosed with grayish-white hairs. Leaves oblong lance-shaped, the main stem leaves alternate $\frac{1}{2}$ to $1 \frac{1}{2}$ in. long. Flowers in a terminal cluster of 5 to 10 , bright yellow about an inch broad. (a) lyx hoary like the stem, the outer sepals nearly as long as the three inner. Later there appear at the leaf axils branches bearing flowers without petals. These apetalous flowers grow dircelly upon the stem or with very short fool-stalks. Dry soils. June-July. 

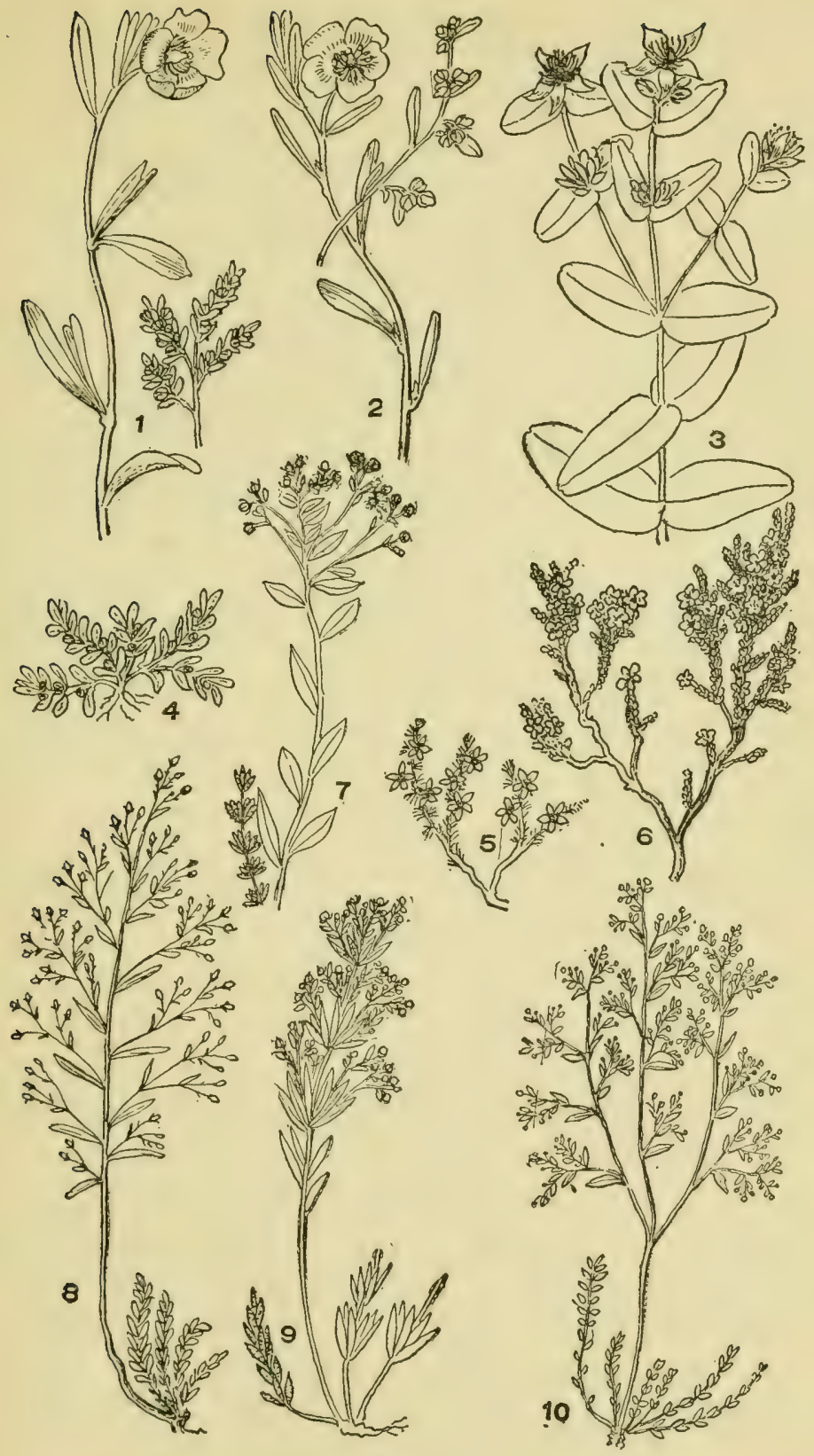

Plate 97

1. Helianthemum majus. 2. II. canadense. 3. Elodea virginica. 4. Elatine americana. 5. Hudsonia ericoides. 6. H. tomentosa. 7. Lechea inter. media. 8. L. minor. 9. L. juniperina. 10. L. racemulosa. 
2. H. canadense, (L.) Michx. (Fig. 2, pl. 97.) Loxg-rrancied Frostweed, Resembles the last, but the apetalous flowers are furnished with foot-stalls longer than those of No. 1, and the branches bearing the apetalous flowers overtop those which have borne the petalous flowers, which is not the case with No. 1. Dry places. May-June.

3. H. corymbosum, Michx. Pine-barren Frost-weed. All the flowers are borne at summit of stem in a rather broad spreading cluster (corymb). Pine barrens, New Jersey, and southward.

\section{HUDSONIA, L.}

Low, heath-like little shrubs, the stems covered with small scale-like or minute awl-shaped, leaves. Flowers small, bright yellow, erowded among the small leaves along the upper part of the branches. Petals 5, sepals 3 subtended by 2 others much smaller. Stamens 9 to 30 .

1. H. tomentosa, Nutt. (Fig. 6, pl. 97.) Wooldy Hudsonia. False Heatier. Low, tufted little shrub with seale-like leaves which are about 1/12 in. long overlapping one another. Flowers mostly toward the summit of the stem; the whole plant downy-grayish. Sands by the sea shore and in pine barrens. May-July.

2. H. ericoides, L. (Fig. 5, pl. 97.) Hentir-Like Hudosonia. Leaves much more slender than No. 1, and more in circling clusters. Flowers scattered along the whole length of stem. Dry sandy soil. May-Jume.

\section{LECHEA, L.}

Ineonspicuous perennial herbs often shrubby at base. Flowers very small, greenish-purple. Petals 5; sepals 5 or 3 , of which when 5 , the outer 2 are very minute. Stamens 3 to 12 .

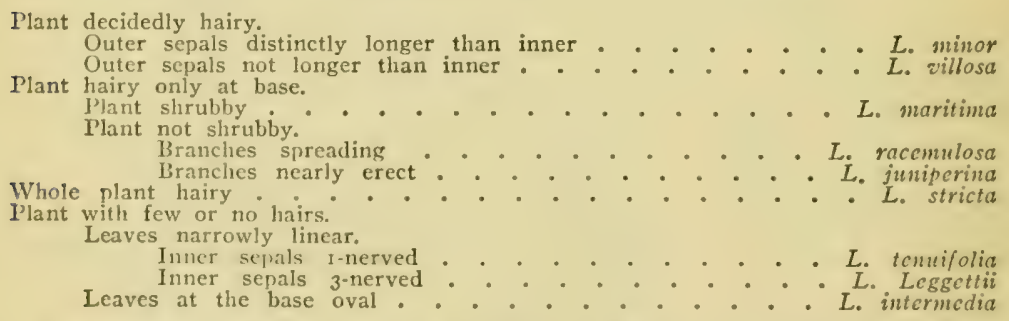

1. L. villosa, Ell. Larger Pin-weed. Plant, erect, hairy, 1 to 2 ft. high. Leaves of the stem elliptic, those from the basal shoots oval or rounded. Flowers small, crowded. The outcr scpals are shorter than the inner or less frequently equal to them.

2. L. minor, I. (Fig. 8, pl. 97.) Tirme-teaved Pin-weed. Less hairy, in most otler respeets similar to No. 1. The outer sepals are longer than the inner.

3. L. racemulosa. Michx. (Fig. 10, pl. 97.) Oblong-rrutted PiNWEED. Stem and stem leaves searcely hairy, but stem and leaves of basal shoots hary. IPuer stem leaves lincar, those of basal shoots oval. filnwering hranches deredolly spreading; outer sepals shorter than inner. Dry sandy soil. July-גug. 
4. L. maritima, Leggett. BeAcrr Pin-weed. Shrubby, especially at base from which spring many hairy shoots with oval leaves. Stem leaves linear, blunt at the ends. Flowers much erowded, petals reddish; the outer sepals shorter than the inner. Sea-shore and pine barrens. JulyAugust.

5. L. tenuifolia, Michx. Narrow-Lenved Pin-weed. Slender, 4 to 10 in. high. Growing in dense tufts. Branches spreading. Leaves linear, as are those of the basal shoots. Outer sepals equalling the inner. Petals red or purple. Dry soil, eastern Mass., and westward. July-Aug.

6. L. Leggettii, Britt. and Hol. Legaets's Pin-ween. Resembles the last but is higher; 1 to $2 \mathrm{ft}$. high. Outer sepals nearly equalling the inner. Long Island, westward and southward. July-Aug.

7. L. intermedia, Leggett. (Fig. 7, pl. 97.) Large-Podded PinweEd. Plant, 1 to $2 \mathrm{ft}$. high. Leaves elliptic, smooth but basal shoots hairy. Basal leaves oval. Outer and inner sepals about equal. Dry places throughout most of our area. Aug.

8. L. juniperina, Bicknell. (Fig. 9. pl. 97.) MaIne Pin-tweed. Growing in tufts, $\frac{1}{2}$ to $2 \mathrm{ft}$. high. Very leafy, the leaves more or less in whorls, the mid-vein with very short hairs which give to the plant a. grayish-hoary appearance. All branches short and so nearly erect that the outline of the plant is slender. Coast of Maine. July-Sept.

9. L. stricta, Leggett. Busmy Pin-weed. Very slender and straight, densely branched, the branches nearly erect, covered with a finc, thin down. Inflorescence spine-like. Open places, western New York, and southward. July-Aug.

\section{Family IV.-Violaceae. Violet Family}

Herbs or shrubs, with mostly irregular flowers often of two kinds, first those which open and are showy, second, those which do not open, but are usually hidden beneath dead leaves or eren by the solt soil. These last are known as cleistogamous. They are not fertilized by insects yet bear an abundance of seeds. The leaves are furnished with stipules, are all basal or, when on a stem, alternate. Petals 5, the lowest the largest; sepals 5, the latter nearly equal. Ovary of 1 cell with many seeds, the capsule splits into 3 wedge-like valves at maturity.

\section{VIOLA, L.}

Small herbs. Leaves all from the base or alternate on a stem, stipulate. Flowers of two kinds. The closed form is known as cleistogamous. These pollinate themselves, being furnished with abundance of pollen. The larger lower petal of the open flower is spurred as are the 2 Jower of the 5 stamens. Sepals not united, each free from the others.

Flowers blue.

§. Leaves and flowers all arising from the rootstock

Leaves heart-shaped or rounded, not deeply incised or parted.

Leaves and stems hairy.

Leaves spreading on the ground . . . . . V. villosa

Leaves erect.......... $V_{0}$ sororia 
Leaves deeply incised.

Leaves and stems without hairs or with very few hairs.

Rootstock short thick and erect.

Capsule not 3-angled . . . . . . V. cucullato Capsule 3 -angled $\because \therefore . \cdot V$. septentrionalis

Rootstock very slender, horizontal.

Spur of flower $1 / 3$ in, long . . . . . V. Selkirkii Spur of flower $1 / 12$ in. long $: V_{0}:$. palustris

The middle lobe broad.

Leaves and stem smooth or with few hairs.

Leaves arrow-shaped . . . . . . $V_{.}$sagittata Leaves egg-shaped in outline..... $V_{\text {. notabilis }}$

Leaves and stem hairy.

Leaves as broad as long....... . V. palmata

All lobes narrow lance-shaped.

Flower scapes higher than the leaves..... $V$. atlantica

Flower scapes about equal to leaves ..... $V$. pedata

Flower scapes shorter than the leaves: $: \dot{V}_{0}$ Mulfordae

Flnwers yellow

Flowers white.

Leaves nearly or quite orbicular.

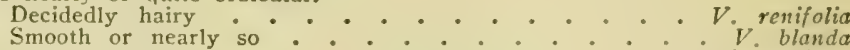

Leaves ovate or oval . . . . . . . . . V primulacfolia

Leaves narrow lance-shaped . . . . . . . . V. lanceolata

†. Leaves and flowers arising from stems above the rootstock

Fiowers blue or whitish.

Stipules not fringed or deeply incised . . . . . . V. canadensis

Stipules fringed.

Spur oi flower shorter than the corolla.

Flowers never creamy-white . . . V. labradorica

Flowers varying to creamy-white . . . . V. striata

Spur as long or longer than corolla.

Spur about as long as corolla, plant hairy . . . . . V arenaria

Flowers yellow.

Spur longer than corolla, plant not hairy: $: \therefore: V$. rostrata

Leaves halberd-shaped . . . . . . . . . . . . V. hastata

Leaves broadly egg-shaped or nearly round.

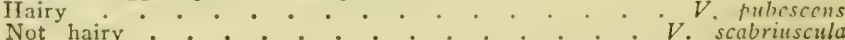

$\S$ Leaves and flowers all from the rootstock

\section{Leaves not incised. Flowers blue}

1. V. cucullata, Ait. (Fig. 4, pl. 98.) Hooded Blue Vrolet. ( $V$. obliqua, Hill.) Stems and leaves smooth or with few hairs. Rootstock thick and short. Early in season of bloom flower scapes are usually shorter than leaves, but later they usually much exeerl the leaves. Leaf blades vary from egreshaped to orbicular, not deeply incised but with coarse teeth at margins. Woods and meadows. April-June.

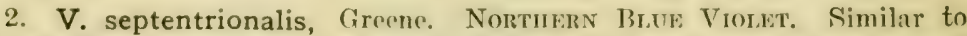
$V$. cucullata, eapsule of $V$. curullata strongly 3-angled, that of the present form not angled and plant extending more northward. Extending from Ontario into northern New England.

3. V. villosa, Walt. Solthers Woon Vrofer. Teaves rounded or less frequently egreshaped; downy, lying flat upon the ground. Petals bearded, blue. Only in the southern part of our area. $\Lambda$ pril-May.

4. V. sororia, Willd. (Fig. 2, pl. 98.) Woolly Bluk Vrolet. Rootstock thick, generally oblique. Jasves heart-shaped, from exreshaped to orbicular, covered, as aro the leaf-stallis and flower seapes, with long soft hairs. Dry soils, mostly in southern part of our area. April-May. 


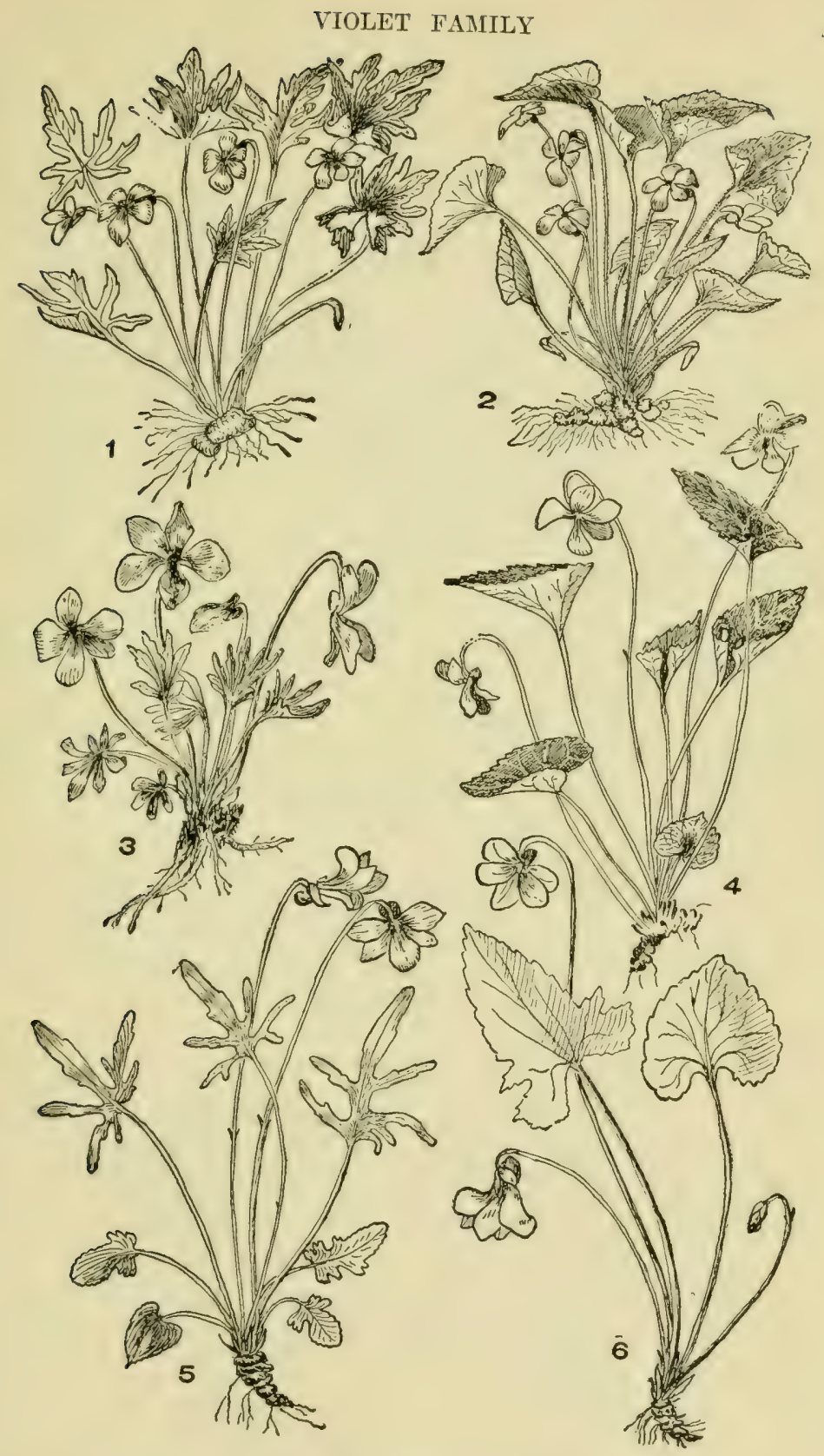

Plate 98

1. Viola palmata. 2. V. sororia. 3. V. pedata. 4. V. cucullata. 5. V. atlantica.6. V. sagittata. 
5. V. palustris, L. (Fig. 3, pl. 99.) MAnsi Vrolet. Leaves kidney-form, round or broadly egg-shaped. Not hairy. Rootstock slender. Flower spur very short; petals slightly bearded. In wet grounds. Mountains of New England and northward. May-July.

6. V. Selkirkii, Pursh. (Fig. 6, pl. 99.) SElkink's Violet. Leaves broadly exg-shaped to round, heart-shaped at base. Flower spur nearly as long as the petals, blunt. Moist soil, woods, throughout our area. April-May.

\section{Leaves incised. Flowers blue}

7. V. palmata, I. (Fig. 1, pl. 98.) Early Blue Vtolet. Downy; rontstock thick, usually oblique. Flower seapes at first shorter than leaves, later generally longer. Leaf-stalks generally much longer than leaf-hlades, the latter as broad or broader at base than the length, it is incised at base, forming from a few to 11 or 13 lobes, the middle lobe remaining broad and egg-shaped, while the lateral ones are narrow, often with only shallow incisions. Division of calyx linear or narrow lanceshaped. Lateral petals bearded. Hidden flowers numerous. In dry woods, throughout our area. April-May.

8. V. Mulfordae, Pollard. Miss Mulfond's Violet. Leaves and flowers from the root-stock. Whole plant somewhat downy. Leaf blades oblong or egg-shaped in general outline but the margin eut into several lobes on each side. The lateral lobes lance-shaped, acute at apex, the terminal lobe much larger, oblong to lanee-oblong, the margins finely toothed. Flower stems shorter than the leaves or at first somewhat longer than the leaves. Flowers violet-purple about $\frac{3}{2}$ in. broad. Dry sandy soil, Hempstead Plains, L. I. May.

9. V. atlantica, Britton. (Fig. 5, pl. 98.) Const Violet. Leaves on long slender leaf-stalks, nearly or quite smooth. Leaves deeply incised but middle lobe rather broadest, the others narrow and diverging. The lourer lates are small, nearly or quite undivided, egg-shaped or clubshruped.* Epper leaves t to 8 in. high, Flower seapes as high or higher. Latiral petals bearded. Somewhat rare. Eastern Mass., and southward. May-June.

10. V. notabilis, Bicknell. Elegant Violet. Flowers and leaves from the root-stock. Leaves in outline broadly egg-shaped or oblong, heart-shaped at base, obtuse or rounded at apex, divided at lower half or third, several oblong obtuse lobes cut half way or less to the mid-rib, the basal lobe lonader and itself toothed or lobed. Flower stems generally exeereling the leaves, hecoming 8 to $10 \mathrm{in.}$ high. Flowers very large, deep purple. Southwestern Long Island, low grounds.

11. V. sagittata, Ait. (Fig, 6, pl. 98.) Arrow-Leaved Violet. Jouves long, halloerd-shaped. generally incised at base, smooth, hollowed but not heart-shaped at hase which is somewhat winged, the wings being more or lesis loled. Petals densely bearded, dark blue. Dry hills, throughout our area. April-Nay.

In the form $V$. cmarginata, Le Conte, the leaves are more nearly triangular.

\footnotetext{
"According to the author's specimens, by others not so specified.
} 


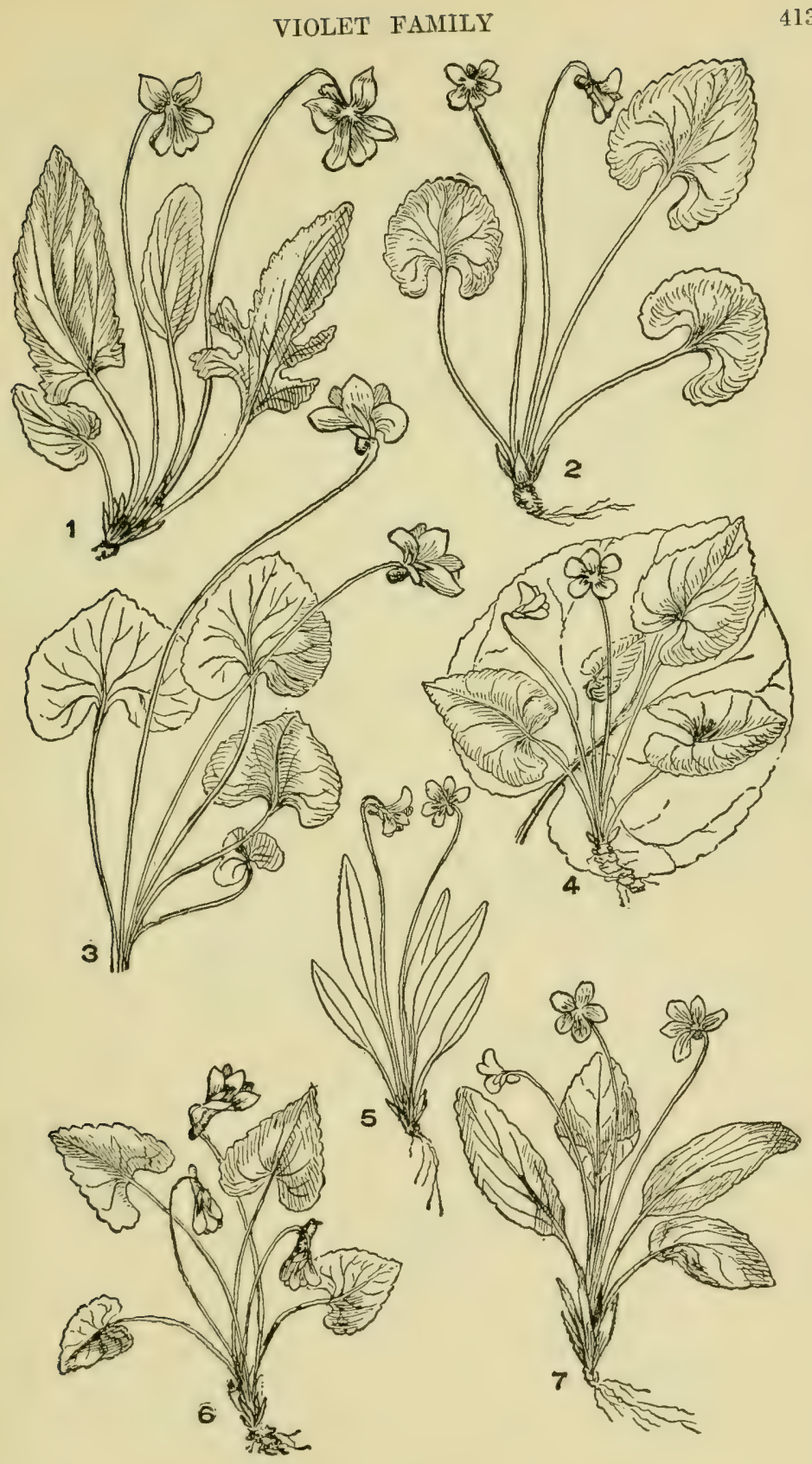

Plate 99

1. Viola ovata. 2. V. blanda. 3. V. palustris. 4. V. rotundifolia. 5. V, lanceolata. 6. V. Selkirkii. 7. V. primulaefolia. 
12. V. ovata, Nutt. (Fig. 1, pl. 99.) Ovata-Leaved Vtolet. Leaves, leaf-stalk and flower scapes hairy; long egg-shaped, rounded at apex, incised, not winged at base. Southern part of our area. April-May.

13. V. pedata, L. (Fig. 3, pl. 98.) Bird's-Foot VIOLET. Rootstock short, thick, erect. Leaves parted nearly to leaf stem into 5 to 9 narrow lobes which are smooth-bordered or somewhat toothed toward apex. All parts smooth. One of our most beautiful violets. Color, lilac to dark blue. Dry fields, somewhat prevalent. April-June.

\section{Flowers yellow}

14. V. rotundifolia, Michx. (Fig. 4, pl. 99.) Round-Leaved Violet. Leaves smooth or slightly downy; broadly egg-shaped when young becoming nearly round at length; heart-shaped at base, the sinus. nearly closed. Flower scapes short ( 2 to $4 \mathrm{in}$. high); flowers yellow. The plant sends out many stolons later in the season as well as many hidden (cleistogamous) flowers. Woods, in rich soil. April-May.

\section{Flowers white}

15. V. blanda, Willd. (Fig. 2, pl. 99.) Sweet White Vrolet. Leaves cordate at base, round, kidney-formed or broadly egg-shaped. All parts except the flower scape usually smooth, the latter generally somewhat hairy. Flowers white, with purple veins. Wet places. April-May.

16. V.primulaefolia, L. (Fig. 7. pl. 99.) Primose-Leaved Violet. Leaves lance-egg-shaped, suddenly contracted at base, the edge of the leaf following along the leaf-stalk. Flowers white, petals beardless. Long stolons late in summer with many hidden (cleistogamous) flowers. Open moist soil, New York. New England, and southward. April-May.

17. V. lanceolata, L. (Fig. 5, pl. 99.) Lance-leaved Violet. Leaves smooth, lance-shaped, tapering at base. Flowers white. Many stolons late in season and many cleistogamous flowers. Moist meadows, prevalent to some extent throughout our area. April-June.

18. V. renifolia, A. Gray. Kidney-Leaved Violet. All parts of plant hairy. Leaves broad, egg-shaped, kidney-shaped or round. More or less heart-shaped at base. Flowers white. Stoloniferous. Woods and fields, New York and westward. April-June.

\section{$\dagger$ Leaves and Flowers all springing from a stem}

\section{Flowers yellow}

19. V. pubescens, Ait. (Fig. 1, pl. 100.) Hairy Yellow Violet. Plant 5 to $20 \mathrm{in}$. high. Leaves broadly egg-shaped to round, toothed, those at the base of stem having leaf-stalks longer than the blades, while of the upper leaves the blades excel the leaf-stalks in length. The lower leaves at blooming timo are usually wanting. Stipules not fringed or divided, egre-shaped or lanee-shaped. Whole plant covered with soft hairs. Flowers bright yellow. Woods, April-May.

20. V. scabriuscula, Schwein. (Fig. 5. pl. 100.) Sмоotil Yellow VIofer. Fiesmbles No. ] (j, but the hairy covering is nearly or quite ahsent and the surface of the stem is rough. Lower leaves generally present at blooming time. Stipules similar to those of No. 16. Flowers yellow. Woods. April-May. 


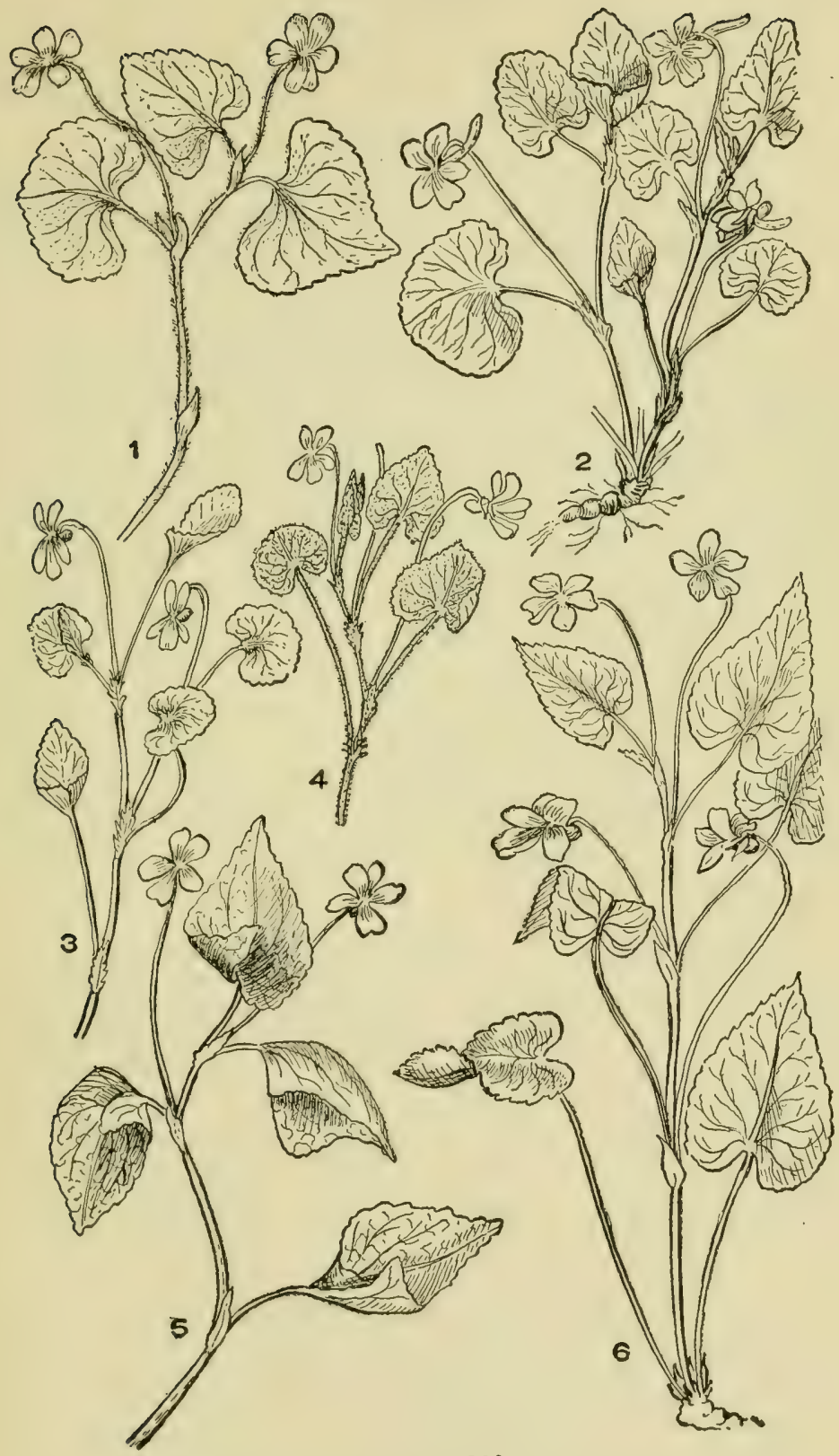

Plate 100

1. Viola pubescens, 2. V. rostrata. 3. V. labradorica. 4. V. arenaria. 5. V. scabriuscula. 6. V. canadensis. 
21. V. hastata, Miclix. HaLberd-Leaved Violet. Leaves halberdshaped or oblong with heart-shaped base, slightly toothed, apex acute, stipules small, egg-shaped. Mountains of Penna. and southward. May.

\section{Flowers blue}

22. V. canadensis, L. (Fig. 6, pl. 100.) Canadian Vrolet. Stems 4 to $14 \mathrm{in}$. high. Leaves egg-shaped, heart-shaped at base, apex sharp pointed. Whole plant smooth or nearly so. Stipules not fringed or divided, egg-shaped.

23. V. striata, Ait. Pale Violet. Striped Violet. Similar in size and general growth to No. 22. Leaves round or egg-shaped, the apex less sharply pointed than No. 22. Stipules long, narrow, with sharp tecth at borders. Flowers on long flower stalks, light blue to white. Spur $\frac{1}{4}$ as long as the corolla. Woods. May-July.

24. V. labradorica, Shrank. (Fig. 3, pl. 100.) Americax Dri TroLet. Stem weak, half reclining. Leaves from broadly egr-shaped to kidney-form or round, finely toothed at borders; plant smooth. Stipules lance-shaped with fringed borders. Flowers on long flower stems. spur half as long as the corolla, obtuse at the end. Color pale purple. Wet places. March-May.

25. V. arenaria, DC. (Fig. 4, pl. 100.) SANd Violet. Resembles No. 24, but plant is covered with soft hairs. Color somewhat darker. sitipules are longer and are deeply incised. Sandy soil, Maine and westward. May-June.

26. V. rostrata, Pursh. (Fig. 2, pl. 100.) Long-spurned Violet. Plant smooth, erect; leaves as in Nos. 24 and 25. Stipules fringed. l'etals bearded. Spur longer than the corolla. Moist woods, generally distributed. June-July.

V. tricolor, L., and V. odorata, L.. are sometimes found in our region as escapes from gardens.

2. HYBANTHUS, Jacq. . (Cubelium, Raf. Solea, Spring')

Our species an ereet leafy plant with rather inconspicuous greenish flowers growing from the leaf axils. Sepals equal, narrow lance-shaped. Petals nearly equal, the lower one 2 -lobed and with a blunt spur. Stamens uniting to form a sort of sheath about the ovary.

H. concolor, (Forst.) Raf. (Fig. 4, pl. 101.) Grees VIolet. Plant slinhtly downy, 1 to $2 \mathrm{ft}$. high. Leaves alternate, lanee-shaped, 3 to $t_{2}$ in. lomg, $1 / 3$ as wide. tips very slender and tapering. Flowers 2 or 3 in the axils, on short flower-stems, greenish. Moist woods, northern New York and southward. May-June.

\section{Faniluy V.-Passifloraceae. Passion Flower Family}

Siepals more or less united, forming a tule from which project 5 points. The throat of the calyx is covered by rows of sterile stamen filaments. Above these is the corolla. Fertile stamens 5 . Our single spereses is a climbing, tendril-bearing, vine. 


\section{PASSIFLORA, L.}

In our species leaves lobed, alternate. Flowers axillary, single or in pairs on rather long flower stems. Petals greenish-yellow, longer than the sepals. Fruit a berry with many seeds.

P. lutea, L. (Fig. 6, pl. 101.) Yellow Passion Flower. Vine, 3 to $10 \mathrm{ft}$. long, trailing or climbing. Leaves much broader than long, 3-lobed. Flowers and tendrils from the axils. Flowers yellow. In southern part of our area. May-July.

\section{Order XII.-OPUNTIALES. The Order of the Cacti}

An order of fleshy, generally spiny plants of which we have but a single species. The ovary is inferior to the calyx and attached to $i t$. The flowers are regular with an indefinite number of petals and stamens. The stems are fleshy and the leaves often rudimentary.

The FAIILY CACTACEAE is the only one of the order and in our North Eastern States we have only a single Genus.

\section{OPUNTIA, Mill.}

With its succulent branching stems and spiny leaves. Flowers upon the sides of the stem, with numerous petals. which are slightly united at base. Stamens also numerous. Fruit a pear-shaped spiny berry.

O. vulgaris, Mill. (Fig. 7, pl. 101.) Eastern Prickly Pear. (O. Opuntia. (L.) Coult.) Is our only species, growing on rocks and in dry soil in the southern and eastern section of our region June-Aug.

\section{Order XIII.-THYMELEALES. Moose Wood Order}

The species of this order are, in our area, all shrubs. The calyx extends upward upon the ovary, covering it and adhering to it. The flowers are without petals. The ovary has but a single ovule. For other characters, see those of the two Families.

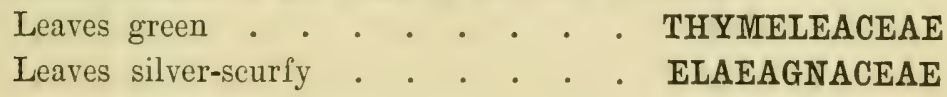

\section{FaMily I.-THYMELEACEAE. Moose Wood FAMILY}

Our only native species a small shrub. Flowers without petals. Ovary with a single ovule. The immer bark is tough and fibrous, the leaves without lobes and with entire horders are alternate. Flowers with colored calyx, stamens and pistils, the calyx of 4 sepals. Fruit a hard, dry, ovoid drupe. Another species, an 
cscape from cultivation, occasionally found is the Daphne or Spurge Laurel, a shrub of small size.

\section{DIRCA, L.}

With the characters above mentioned. The only species is:

D. palustris, L. (Fig. 1, pl. 101.) Leatherwood. Moose Woon. A shrub 2 to $6 \mathrm{ft}$. high, with tough yellow bark, oval leaves and small yellow flowers. Stamens much longer than the yellow sepals. Fruit a small oval red berry. The flowers appear in April, before the leaves. The bark is used for withes and binders. Mostly in wet soil.

\section{DAPHNE, L.}

Small shrubs, with alternate leaves and purple or white flowers in clusters, in our species encircling the stem at the inter-nodes of leaves. The flower is without petals, the 4 spreading lobes of the calyx forming the perianth. Stamens 8 , arising from the calyx, usually included within the tube of the ealyx. Ovary 1-celled; style very short. Fruit an ovoid drupe.

D. Mezereum, L. (Fig. 3, pl. 101.) Spurge Laurel. A fragrant shrub, 1 to $5 \mathrm{ft}$. high, with lance-shaped leaves and purple or white flowers. Escaped from gardens. April-May.

\section{Family II. - elaeagnaceae. Oleaster Family}

Shrub, in our region, with a silvery scurf. Leaves with lobes or teeth, opposite in our species, without stipules. Flower's springing at the leaf axils or at the nodes of the twigs of the preceding season in small clusters. Corolla absent. The calyx divided into 4 sepals. Stamens few. Ovary 1-celled with a singe ovule. Seeds erect. Our only Genus is :

\section{SHEPHERDIA, Nutt. (Lepargyraea, Raf.)}

With opposite leaves and small flowers. Staminate flowers with 8 stamens. Calyx tube investing the ovary but not adhering to it. Fruit berry-like.

S. canadensis, (T.) Nutt. (Fig. 2, pl. 101.) Canadian Buffalo T3Frry. A shrub, 4 to $8 \mathrm{ft}$. high, with elliptic leaves. smooth above, coverel below with hairs and silvery scales. An ornamental shrub growing on banks and along streams. April-June.

\section{Order XIV.-MYRTALES. Order of the Myrtles}

ITerls, shruls or trees. Flowers, with rare exceptions, regular, the calyx rising partly or completely above the ovary and adhering to it or entirely frec. Styles usually fused into one, oviries with many ovules, (arpere 2. Petals present except in the small flowered water plants of the family Haloragidaceae. 


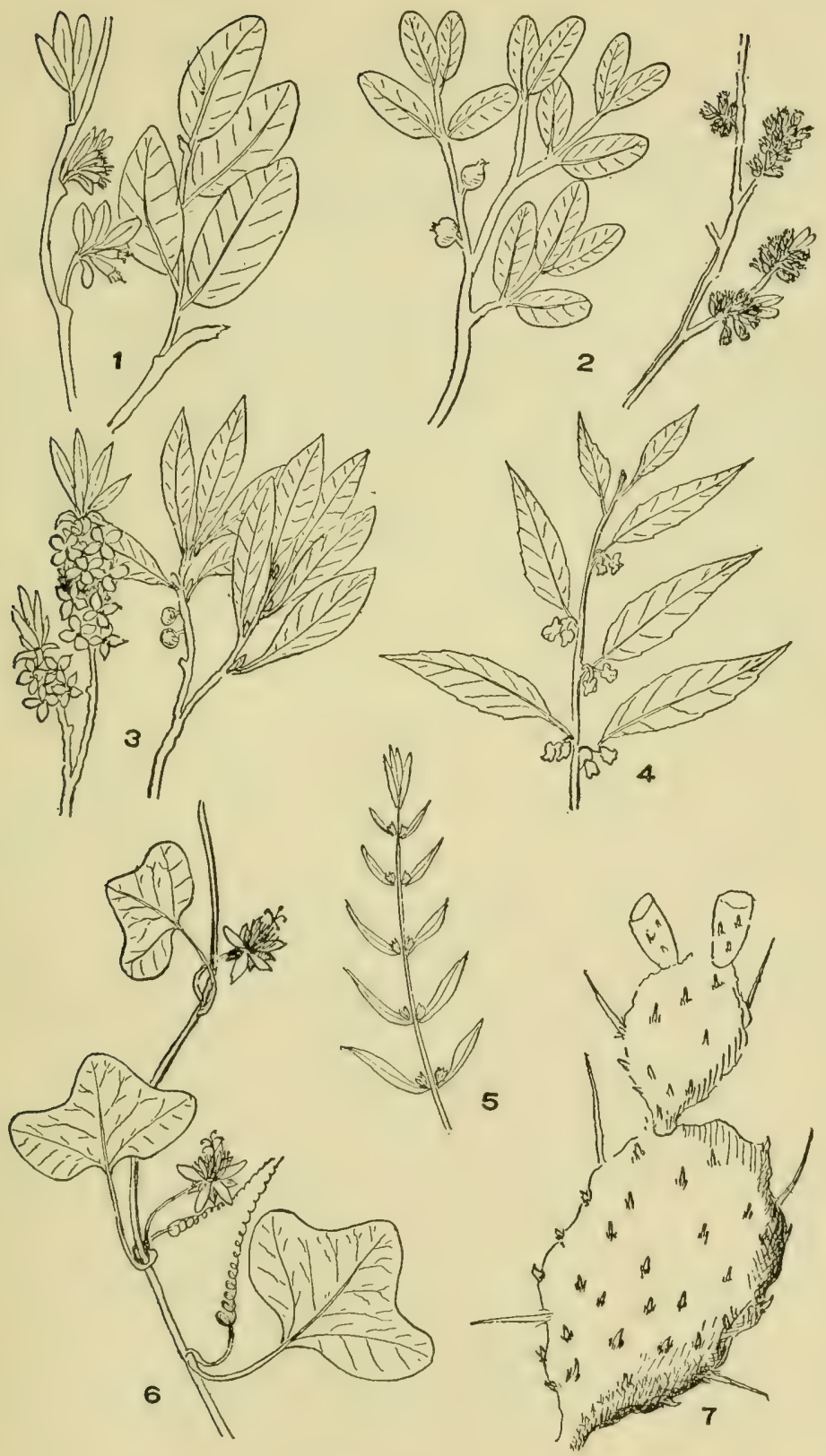

Plate 101

1. Dirca palustris. 2. Shepherdia canadensis. 3. Daphne Mezereum. 4. Iybanthus concolor. 5. Rotala ramosior. 6. Passiflora lutea. 7. Opuntia vulgaris. 
Ovary completely free or only partly inferior.

Anthers opening by a longitudinal split MELASTOMACEAE Anthers opening by a pore at the summit IYTHRACEAE Ovaries inferior to the calyx, the calyx adhering to it.

Water plants with fincly divided leaves HALORAGIDACEAE Water plants with broad floating leaves . .TRAPACEAE Land plants or marsh plants . . . ONAGRACEAE

\section{Family I.-LYThraceaE. Loosestrife Family}

In our region all herlos except Decodon. Leaves opposite, except in Lytlirum. Flowers regular or somewhat irregular. Ovary free or more or less adherent to the calyx, 2- to several-celled. Stipules none. Calyx of 4 or more lobes. Petals as many as the principal lobes of the ealyx, but sometimes alsent. Anthers attached to the filament of the stamen near the middle and opening longitudinally.

Flowers regular.

Flowers large, many . . . . . . . , Decodon Flowers small, few.

Capsule bursting at the partitions between the cells

. . . . . . . . . . Rotala

Capsules bursting irregularly . . . . Ammannia Calyx cylindric . . . . . . . . Lythrum Calyx tubular, swollen below . . . . Cuphea

\section{AMMANNIA, L.}

Our plant an herb, 2 to 6 in. high, with opposite leaves, in the axils of which are 1 to 3 inconspicuous flowers with bell-shaped calyx and 4 small purple petals which fall early. Stamens 4. Low herbs of no special beauty.

1. A. Koehnei, Britton. Koenne's AmMannia. Plant, rather more than $1 \mathrm{ft}$. high, sometimes less; smooth. Leaves mostly lanee- or spatulashaped, with blunt extremities, the base of the upper ones clasping with ear-like lobes at base. Flowers 1 to 3 in each upper axil, quite inconspicuous. In IIackensack marshes, New Jersey, and south. Flowers all summer.

2. A. coccinea, Rotth. Jong-teaved Ammannia. Leaveg sharppointed at extremity, narrow lance-shaped. Swamps and muddy banks. New Jersey, and southward. July-Sept.

\section{ROTALA, L.}

Inw inconspicunus herb, with opposite leaves and small axillary flower, generally solitary. Calyx 4-lobed with as many accessory teeth between the lobes. 
R. ramosior, (L.) Koehn. (Fig. 5, pl. 101.) Rotala. Leaves nar. row, oblong, about an in. long. Flowers 1 in each axil Swamps JulySept.

\section{DECODON, Gmel. (Lythrum, L.)}

Herbaceous shrub, with leaves in whorls and with dense whorl-like clusters of flowers at the axils. Calyx short, broadly bell-shaped with 5 to 7 lobes and as many slender accessory teeth, one at each sinus. Petals 5, stamens 10, inserted on the calyx tube, alternately longer or shorter.

D. verticillatus, ElI. (Fig. 5, pl. 102.) Swamp Loosestrife. WiLLow Herb. Plant, 2 to $8 \mathrm{ft}$. high, growing at edges of streams and in swamps. Stems 4- to 6-angled; leaves opposite or in whorls of about 4, lance-shaped, 2 to 5 in. long and rather less than $\frac{1}{4}$ as wide. In the axils of the upper whorls of leaves are clusters of purple flowers, each nearly an inch broad of lance-shaped petals and with 10 stamens, which considerably exceed the petals in length. July-Sept.

\section{LYTHRUM, L.}

Slender herbs, with 4-angled stems and opposite or alternate leaves and purple or white flowers which are found at the axils or in terminal slender clusters. Petals 4 to 6 , usually 6 . Stamens the same number as the petals or double the number, inserted on the calyx. Capsule 2-celled.

Flowers in tall slender clusters . . . . . . . . . . . L. Salicaria Flowers at the leaf axils.

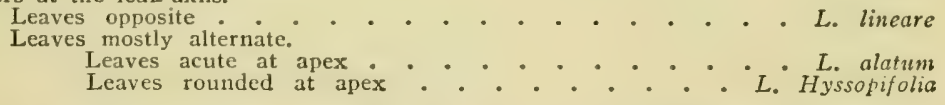

1. L. Hyssopifolia, L. (Fig. 7, pl. 102.) Hrssop Loosestrife. Plant, 6 to $10 \mathrm{in}$. high; leaves oblong-linear, obtuse at apes, without leaf-stalk, longer than the inconspicuous pale purple flowers. Marshes along our coast. June-Sept.

2. L. alatum, Pursh. (Fig. 6, pl. 102.) Wing-ANgLed Loosestrife. Tall, slender, branches with winged edges or simply angled, Stem 1 to $4 \mathrm{ft}$. high. Leaves without leaf-stalks, alternate or the lowest opposite, lance-shaped or oblong, acute or nearly so at the end, rounded at base. Flowers deep purjle, stamens of some of the flowers longer than the petals. Low swampy grounds. June-Aug.

3. L. lineare, L. (Fig. 8, pl. 102.) LINeAR-Leaved Loosestrife. Stem tall, slender ( 2 to $4 \mathrm{ft}$. high). Leaves opposite, very narrowly linear, an inch or less in length. Petals whitish-purple. In some flowers the style is long, stamens short, in others stamens are long, style short. Salt marshes. July-Sept.

4. L. Salicaria, L. (Fig. 4, pl. 102.) Spikfd Loosestrife. Slender, 2 to $4 \mathrm{ft}$. high. Leaves opposite or in whorls of about 3 , lance-shaped, rounded or heart.shaped at base, sharp at apex, 2 to $3 \mathrm{in}$. long. Flowers purple in a long narrow terminal cluster. In respect to the length of stamens and style there are three forms. Swamps, wet meadows. JuneAugust. 


\section{CUPHEA, Jacq. (Parsonsia, P. Br.)}

An herb, with opposite leaves and showy flowers, in clusters or from the axils. Calyx tubular, inflated, 12-ribbed, oblique at the mouth, with 6 teeth and as many secondary ones. Petals 6. unoqual. Stamons 11 or 12, in 2 sets; unequal. Ovary with a curved gland at base. Capsule oblong, few seeded, included in the calyx.

C. petiolata, Rusby. (Fig. 9, pl. 102.) Blue Wax Weed. Cuammy C'upiea. Petals ovate, purple. Leaves lance-shaped on leaf-stalks about $\frac{1}{2}$ as long as the leaves. Dry fields. July-Oct.

\section{Family II.-melastomaceae. Mendow Beautr Family}

Herbaceous plants (or woody), with opposite leaves or leaves in whorls. Leaves without stipules, 3- to 5-nerved. Flower's regular, showy, with stamens and pistils. The anthers open by a pore at the summit. In other respects similar to family Onagraceac.

\section{RHEXIA, L.}

Calyx tube 4-cleft, urn-shaped, adhering to the ovary below. Petals 4, large. Stamens 8 ; style 1. Low perennial herbs with showy flowers.

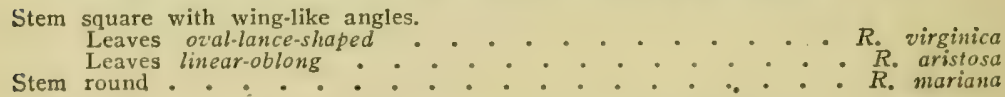

1. R. virginica, L. (Fig. 1, pl. 102.) MEadow BEAUT\}. Flowers bright purple; petals 4 ; stems and leaves downy. Sandy swamps. JuneSept.

2. R. aristosa, Britton. (Fig. 3, pl. 102.) Awn-Petaled Meadow BEAUTY. Stem square; flowers bright purple; petals 4; stem and leaves not downy. Sandy swamps. July-Aug.

3. R. mariana, L. (Fig. 2, pl. 102.) Maryland Meadow Beatty. Leaves narrow, lanee-shaped. Stem round; plant downy or hairy, 1 to $2 \mathrm{ft}$. ligh. Flowers pale purplo of 4 petals. Swamps and pine barrens, New Jersey and southward. June-Sept.

\section{Family iII.-ONagraceae. Evening Primose Family}

Herhs, rarely shrubs, with opposite or alternate leaves without stipules; calyx tube adherent to the ovary and rising above it, 2. to 6 -lobed. Petals usually 4 , but may be more or less, or rarely absent. Stamens usually in 2 rows and twice as many as the petals. Ovary usually 4 -celled, styles united.

Petals and sepals, each 4.

Leaves opposite

Leaves alternate. 


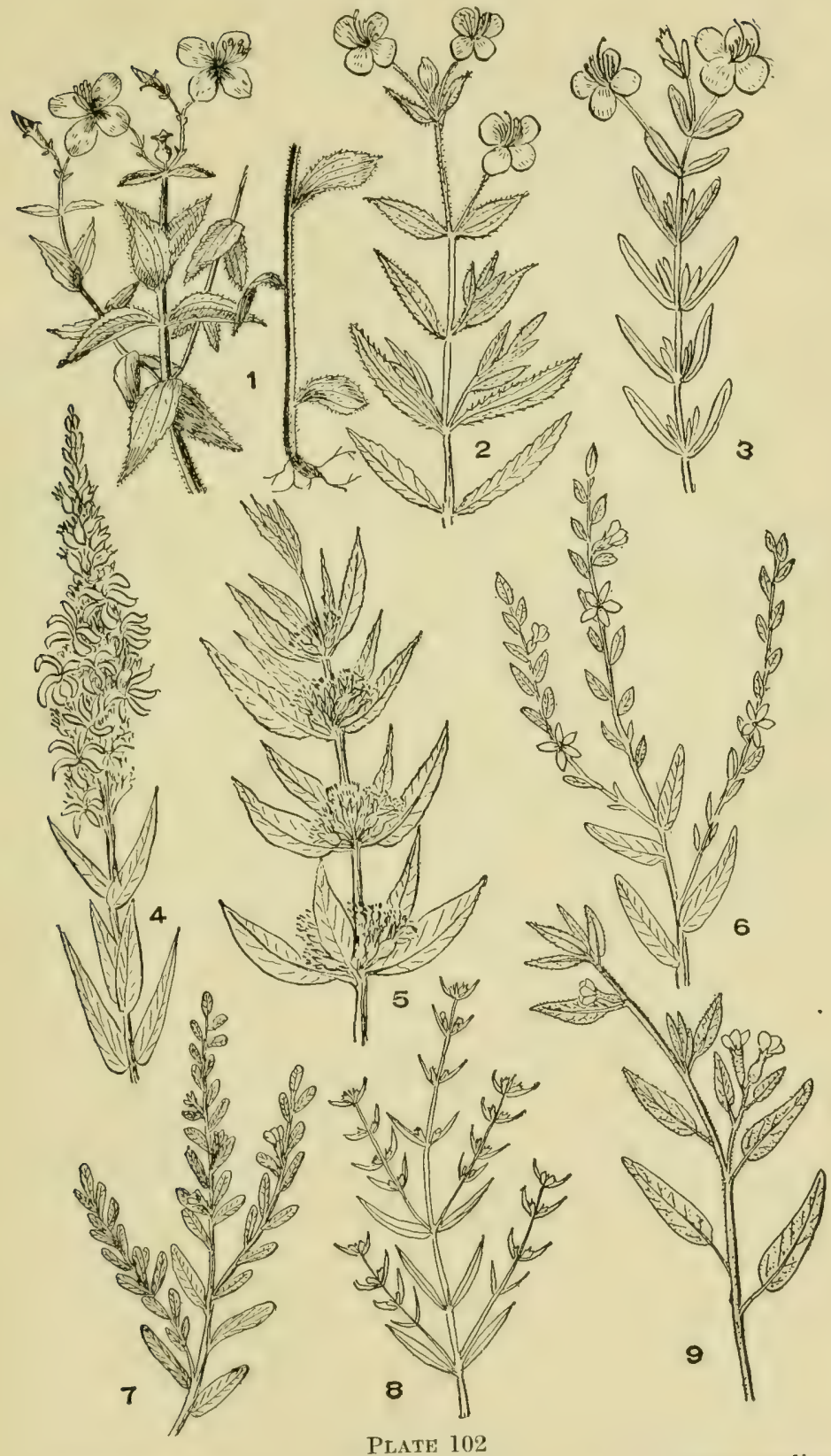

Plate 102

1. Rhexia virginica. 2. R. mariana. 3. R. aristosa. 4. Lythrum salicaria. 5. Decodon verticillatus. 6. Lythrum alatum. 7. L. Hyssopifolia. 8. L. lineare. 9. Cuphea petiolata. 
Calyx tube not longer than the ovary.

Seeds without hairs.

Ludwigia

Sceds with silky hairs . . . Chamaenerion

Calyx tube longer than the ovary.

Seeds with silky hairs.

Epilobium

Seeds without hairs.

Flowers yellow.

Stamens of equal length.

Ovules, 2 rows in each of the 4 divisions of

the ovary lying horizontally and by compression angled in the long axis . Onagra

Ovules in 1 row in each of the 4 divisions, upright and not angular . Oenothera

Stamens of unequal length . . . Kneiffia

Flowers pink . . . . . . . Gaura

Petals and sepals, each 2 . . . . . . . . Circaea

\section{LUDWIGIA, L.}

Merbs, with alternate leaves and with rather inconspicuous axillary flowers. Lobes of the calyx 4, adherent to the ovary but not prolonged beyond it. Petals 4, often wanting; stamens 4 inserted into the petals. Ovary 4- or 5-celled. Capsule short or cylindrical, winged or ribbed. Seeds very small.

Capsules nearly globe-formed.

IJowers small, without flower stalks, in the leaf-axils, with small greenish petals or none.

Bractlets at base of capsule very small or none . . L. sphaerocarpa Bractlets at base of capsule as long as capsule : $:$. Lolycarpa Capsules much longer than broad . . . . . . . . . L. linearis Flowers showy.

Plant hairy . . . . . . . . . . . . . L hirtella
Plant not hairy . . . . . . . . . . L. alternifolia

1. L. sphaerocarpa, Fll. (Fig. 10, pl. 103.) Glone-fruted LudWigis. Plant growing in swampy or wet places, 2 to $3 \mathrm{ft}$. highl. Leaves lanee-shaped or linear, some leaves with very small teeth at borders, alternate, 2 to $4 \mathrm{in}$. long. Whole plant or at least upper part of it finely downy. Bractlets at base of flowers minute or absent. Capsules globular. Petals very minute or none. Calyx 4-parted, generally shorter than the capsule. Swamps, eastern Mass., southern New York and southward. July-Sept.

2. L. polycarpa, Short and Peter. (Fig. 9, pl. 103.) ManY-Frutted Lxinwris. P'lant growing in swamps, 1 to $3 \mathrm{ft}$. high, with runners at hase. Jeaves narrowly lanceolate, borders not toothed, acute at each end, without leaf-stalk, 2 to $4 \mathrm{in.} \mathrm{long.} \mathrm{Laves} \mathrm{of} \mathrm{the} \mathrm{rumers} \mathrm{spatula.}$ formed. Bractlets at lase of flowers linear and conspicuous. Wet places. July:Oct.

3. L. linearis, Walt. Linean-maven Lumbia. Plant, 1 to $2 \mathrm{ft}$. 
high, often with runners at base. Leaves very narrow lance-shaped, tapering at base to a flower stalk, 1 to $2 \mathrm{in.} \mathrm{long,} \mathrm{without} \mathrm{teeth.} \mathrm{Flowers}$ in axils, petals pale yellow. Capsule a reversed 4-sided pyramid, longer than the calyx lobes. Swamps, New York and southward. June-Sept.

4. L. hirtella, Raf. (Fig. S, pl. 103.) Hairy Ludwigia. Plant erect, 1 to $2 \mathrm{ft}$. high, decidedly hairy with stiff hairs. Leaves oblong, more or less egg-shaped, blunt at ends. Flower-stem in leaf-axil with 2 bracts. Petals showy, yellow, longer than the sepals. Pod 4-angled, winged, nearly globular. Swamps, New Jersey and southward. JuneJuly.

5. L. alternifolia, L. (Fig. 7, pl. 103.) SEed Box. Erect, 2 to 3 ft. high, not hairy. Leaves lance-shaped, sharp at each end, 2 to 4 in. long. Flower-stems at the axils, 2 bracted. Petals yellow, longer than the purple scpals. Pod 4-angled, winged. Swamps, Mass., to northern New York.

\section{ISNARDIA, L.}

General characters similar to those of Ludwigia, but leaves are opposite.

I. palustris, L. (Fig. 4, pl. 103.) Marsh Purslane. (Ludvigia palustris, Ell.) Plant, lying flat in the mud, floating or partly erect, branching, 4 to 15 in. long. Leaves oval or spatula-formed, tapering at base to a leaf-stalk $1 / 3$ as long as the leaf. Flowers at the axils, small, solitary, without bracts below the calyx. Pod oblong, 4-angled. Stem and leaves reddish. Muddy ditches and swamps, generally distributed. June-Nov.

\section{CHAMAENERION, Adams. (Epilobium, L.)}

A single species, in our region which has been more generally known as the most conspicuous Epilobium. A showy herb with alternate leaves and perfect irregular flowers in terminal pyramidal clusters. Calyx tube adherent to the ovary, but not exceeding it in length, of 4 segments. Petals 4. Capsule 4-celled, 4-angled.

C. angustifolium, L. (Fig. 5, pl. 103.) WrLlow Herb. Simple, not branching, erect, 2 to $8 \mathrm{ft}$. high. Leaves lance-shaped, 2 to $6 \mathrm{in.}$ long. Flowers purple, in a long pyranidal cluster, a small bract below each flower. Petals 4, unequal, sepals 4, seeds with silky down. In recently burned lands, along fences, a conspicuous herb in mid-summer. JuneSept.

\section{EPILOBIUM, L.}

Our species all herbs, with alternate or opposite leaves and with flowers in terminal clusters. Petals 4, sepals 4, the calyx tube adhering to the ovary and produced beyond the latter. Stamens 8. Ovary of 4 cells, capsules elongated, 4-angled. Seeds small, each with a tuft of silky hairs attached. Flowers purple or less frequently white.

Plant densely hairy.

Flowers about I in. broad . . . . . . . . E. hirsutum

Flowers less than $\frac{1}{ \pm}$ in broad . . . . . . . E molle

Plant not hairy or with few hairs, lower leaves broadly oval and opposite E. alpinum Leaves narrowly linear . . . . . . . . . . E: lineare Leaves lance-shaped.

Without serrations at borders . . . . . E. palustre Borders serrated.

Pods densely hairy ...... . E. adenocaulon

Pods only slightly hairy . . . . . E. coloratum

Pods free from hairs . . . . E. Hornemanni 
1. E. hirsutum, L. (Fig. 6, pl. 103.) Hainy Willow Hers. Plant, stout, branching, 3 to $5 \mathrm{ft}$. high, densely hairy. Some of the leaves opposite, lance-shaped or oblong, sharply toothed, without leaf-stallis. Flowers in terminal clusters or in the axils of the upper leaves, about an inch broad, purple. Waste grounds. June-Sept.

2. E. alpinum, L. Alpine Willow Herb. (E. lacliflorum, Haussk.) Plant, from 6 to 12 in. high, not hairy. Lower leaves opposite, broally elliptic or oval, slightly toothed, obtuse at apex, tapering to a leaf-stalk at base. A few of the upper leaves alternate and lance-shaped. Flowers few from the upper axils, small, white. Adirondack and Whits mountains. June-Sept.

3. E. palustre, L. Swamp IVILLow IIERe. Plant, slender, about 1 ft. high, branched, with fine down; leaves lance-shaped, somewhat pointed at apex, rounded at base, without leaf-stalks, nearly all opposite. Flowers few, in upper axils, pink or whitish. Marshy places. White mountains and north. June-Sept.

4. E. lineare, Muhl. (Fig. 2, pl. 103.) Linear-Leaved Willow Hers. ( $E$. densum, Raf.) Plant, 1 to $2 \mathrm{ft}$. high, slender, usually branched. Leaves alternate or to some extent opposite, very narrow, 1 to $2 \mathrm{in.}$ long by $1 / 12$ as wide, sharply pointed at each end. Flowers pale pink, numerous. Bogs. July-Sept.

5. E. molle, Torr. Downy Willow Herb, (E. strictum, Muhl. $E$. dcnsum, Raf.) Erect, 1 to $2 \mathrm{ft}$. high, somewhat densely covered with soft whitish hairs. Leaves lance-shaped, broader than those of No, 4. Flowers in upper axils, small, pink or whitish. Bogs, generally distributed. July-Sept.

6. E. coloratum, (Muhl.) (Fig. 1, pl. 103.) Purple-Leaved Willow Herb. Tall, branching, 1 to $3 \mathrm{ft}$. high. Leaves rather large, lance-shaped, distinctly toothed at borders, sharp pointed at apex, tapering at base, with leaf-stalk. Above, plant slightly downy. Flowers numerous in leafy clusters from the axils, pale purple. Wet places. July-Sept.

7. E. adenocaulon, Iaussk. (Fig. 3, pl. 103.) Nontiers Willow IIErb. Differs little from No. 6, but leaves are less sharp at apex and the long seed capsules are covered with a dense growth of soft hairs. Wet places. July-Sept.

8. E. Hornemanni, Reichenb. Hornearann's Whilow IIrrib. Plant, not much branched, $\frac{7}{2}$ to $1 \frac{3}{2} \mathrm{ft}$. high; smooth. Leatves egrershaped on short leaf stalks, with few remote teeth. Flowers in the terminal leaf axils, purple. White Mountains. July-Sept.

\section{ONAGRA, Adams}

Hrrbs, with erert stems, alternate leaves and yellow flowers which open in the evening. They are arranged in long slender clusters. The calyx is prolonger freyond the ovary and has 4 lance-shaped lobes. Petals 4. C'apsule long, 4-sided, 4.eelled, the ovules in 2 rows in ench eell, compressed and angular.

Flowers small, petals narrow about $1 / 12$ in. broad . . . . O. cruciata lilowers large, petals broad.

Capsules an inch long. . . . . . . . . . O bicrnis

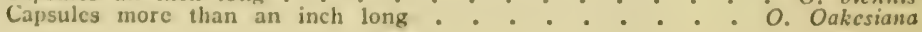



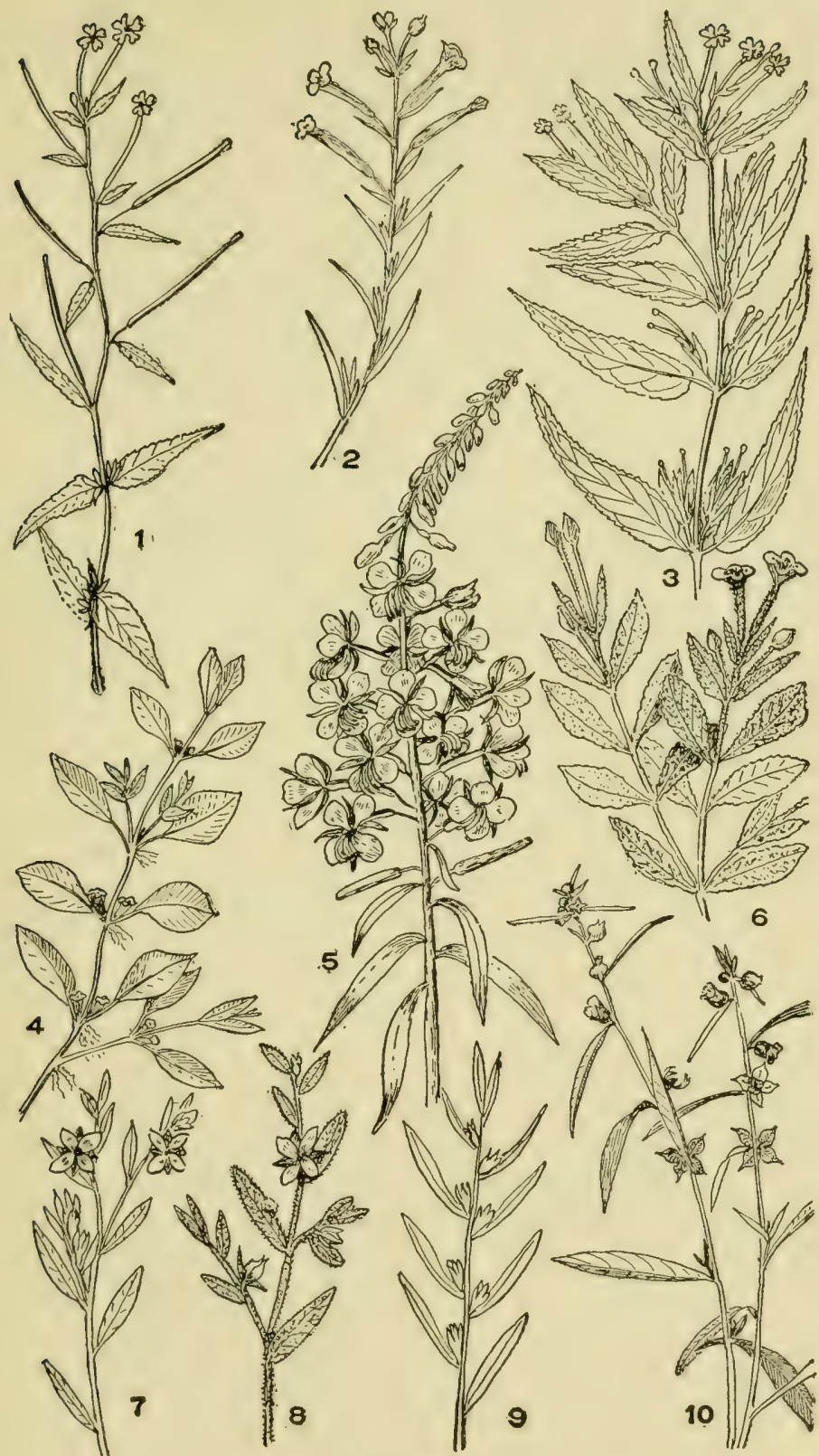

Plate 103

1. Epilobium coloratum. 2. E. lineare. 3. E. adenocaulon. 4. Isnardia palustris. 5. Chamaenerion angustifolium. 6. Epilobium hirsutum. 7. Ludwigia alternifolia. 8. L. hirtella. 9. L. polycarpa. 10. L. sphaerocarpa. 
1. O. biennis, (L.) Scop. (Fig. 5, pl. 104.) Evening Primrose. Stout, erect, 1 to $9 \mathrm{ft}$. high, slightly branching, with a few or many downy hairs. Leaves lance-shaped to oblong, narrowed at base and somewhat clasping, 1 to 6 in. long. Flowers bright yellow, opening in the evening, about "2 in. broad. Calyx adherent to ovary and much longer than the latter. Capsule hairy. In waste places. Common. June-Oct.

2. O. cruciata, (Nutt.) Small. Sarall-rowered Evening PrimRose. Similar to No. 1, but petals are lance-shaped and much smaller than those of $\mathrm{O}$. biennis. June-Oct.

3. O. Oakesiana, (A. Gray) Britton. OAnes's Evening Primrose. Resembles No. 1, but is more slender, leaves generally narrower, and plant not hairy or with few hairs. Flowers about $\frac{1}{2}$ as broad as those of No. 1. Capsule about $1 / 3$ longer than that of No. 1. Dry waste places in northern section of our area. June-Oct.

\section{OENOTHERA, L.}

Similar to Onagra, but seeds not compressed and not angular.

1. O. humifusa, Nutt. (Fig. 4, pl. 104.) Seaside Evening PrimRose. Plant, $\frac{3}{4}$ to $1 \frac{1}{2} \mathrm{ft}$. high, much branched, generally reclining, covered with a silvery down. Leaves narrow with wavy, somewhat toothed, margins $\frac{1}{2}$ to $2 \mathrm{in}$. long. Flowers yellow, from the leaf-axils, not numerous, $1 / 2$ to $2 / 3$ in. across. Sea beaches, New Jersey and southward. June-Sept.

2. O. laciniata, Hill. Sinuate-leaved Evening Primrose. Plant, about the size of the last. Leaves deeply waved, the sinuses reaching nearly to mid-vein. Hairs not silvery and much less dense than in No. 1. Sandy soil, New Jersey, Fennsylvania and westward. May-June.

\section{KNEIFFIA, Spach.}

IIerbs, usually more slender than the species of Onagra. Leaves mostly narrow, without teeth or with low teeth. Flowers yellow in terminal clusters, petals 4, calyx segments 4. Stamens 8 , the alternate ones longer. Ovary 4-angled; pistil 4-cleft at summit. Seeds numerous, not angled.

Plants not covered with coarse hairs.

Leaves without teeth or divisions.

P'ants reclining . . . . Plants crect $:+0_{-} \cdot 0^{-} \cdot{ }^{\circ}$ pumila

Leaves with toothed or wavy borders.

Foot-stalk of the capsule longer than the capsule . $K$. longipedicellata foot-stalk of the capsulc shorter than the capsule.

Leaves broadest toward the apex ...... K. linearis Leaves broadest toward base ..... K. fruticosa Plants covered with coarse hairs............. K. pratensis

1. K. Alleni, Small. Allen's Sunbrors. Plant, reclining, much branclied, stems from $3 \mathrm{in}$. to $2 \mathrm{ft}$. long. Teaves inversely lanee-shaped without, teeth: the whole plant covered with fine down. Flowers yellow $2 / 3$ to 1 in. broad in more or less terminal elusters. Capsule d-angled, winged, nearly glohe- or pear-shaped, on a foot-stalk longer than itself. Sandy places on Long Island. June-Aug.

2. K. longipedicellata, small. (Fig. 3, pl. 104.) Long-STEMMED 


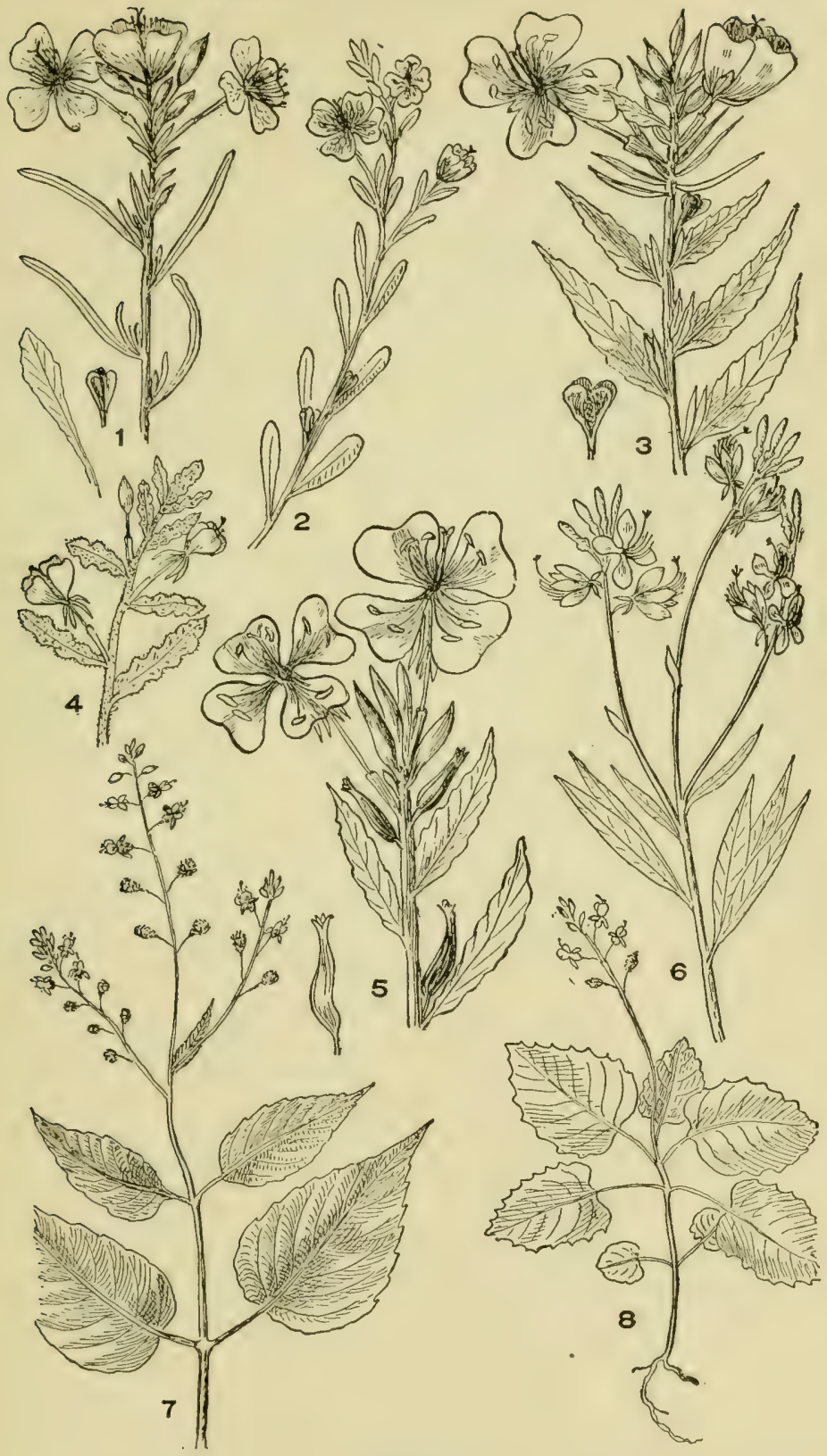

Plate 104

1. Kneiffia linearis. 2. K. pumila. 3. K. longipedicellata. 4. Oenothera humifusa. 5. Onagra biennis. 6. Gaura biennis. 7. Circaea lutetiana. 8. C. 
Suxprors. Slender, 1 to $2 \frac{1}{2} \mathrm{ft}$. high, somewhat downy; stem red, not much branehed. Lower leaves spatula-shaped, upper narrow lance-shaped with wavy borders, without leaf-stalks or with very short ones. Flowers yellow, 1 to $2 \mathrm{in}$. broad in terminal clusters. Calyx hairy, of linear segments. Capsule pear-shaped with 4 wings, hairy, on a foot-stalk longer than itself. Sandy soil. May-Aug.

3. K. linearis, (Michx.) Spach. (Fig. 1, pl. 104.) NArrow-LEaved Sundrops. Plant, $\frac{1}{2}$ to $2 \mathrm{ft}$. high, sometimes much branched above. Leaves inversely lance-shaped, the upper ones quite narrow, with wavy borders. (ienerally with few hairs. Flowers yellow, about 1 in. broad. Capsule pear-shaped or elongated, winged, on foot-stalk not as long as itself. Sandy soil. June-Sept.

4. K. pumila, (L.) Spach. (Fig. 2, pl. 104.) Small Sundrops. Plant, quite slender, generally about 8 to $10 \mathrm{in}$. high, but may reach height of $2 \mathrm{ft}$; covered with soft down. Leaves narrow lance-shaped, blunt at apex, not wavy or toothed at borders. Lower leaves spatulaformed. Flower from $1 / 3$ to 1 in. broad, yellow, in a narrow leafy cluster. Capsule pear-shaped, slightly winged. Dry fields. June-Aug.

5. K. pratensis, Small. Harry Sundrops. Stem 15 to 30 in. high. Whole plant covered with coarse spreading hairs. Leaves oblong-lanceshaped, both sides hairy. Low grounds, Maine to Conn.

6. K. fruticosa, (L.) Raimann. Comson Sundrors. Plant, 1 to $3 \mathrm{ft}$. high, usually much branched, downy. Leaves lance-shaped generally wavy with low teeth. Flowers 1 to $2 \mathrm{in}$. broad in terminal loose cluster. Capsule oblong with conspicuous wings on a very short foot-stalk or without one. Common in dry soil. June-Aug.

\section{GAURA, L.}

Terbs, somewhat woody at base with alternate narrow leaves and rosecolored or white flowers. Calyx tubular, with 4 narrow sepals turned lackward. Stamens 8. Petals 4, unequal, narrow with a long narrow claw cxtending down the calyx tube. Fruit nut-like with prominent ribs or angles.

1. G. biennis, L. (Fig. 6, pl. 104.) Biennial Gaura. Plant slender, slightly downy, branching above; leaves lance-shaped, sharp pointed at each end, wavy with remote teeth. Flowers in terminal clusters, rosecolored or white. Dry soil. July-Sept.

2. G. coccinea, Pursh. Scariet Gaura. Resembling the last, but with scarlet flowers, established about Rochester, N. Y. July-Sept.

\section{CIRCAEA, L.}

Low, rather delieate herbs, ours growing in deep shades. Leaves opprosite on slender leafstalks. Flowers small, white, in long slender clusters. Calyx tubular, ils \& lobes prolonged beyond the ovary. Petals 2, stamens 2, altermate with the petals. Ovary 1-or 2-celled. Fruit small, ovoid, bristly with hoolicd hairs.

1. C. lutetiana, L. (Fig. 7, pl. 104.) Encinanter's Nigutsirade. Plant, from 1 to $2 \mathrm{ft}$. high, very fine hairs. Leaves eggr-shaped, wavy, tonthel, the stem swollen where the opposite leaves join it. Flowers 
white in a tall spike, each on a short foot-stalk. Damp woods. Common. June-Aug.

2. C. alpina, L. (Fig. 8, pl. 104.) Smaller Exchanter's NightSHADE. Plant, 3 to 8 in. high. The leaves heart-shaped at base, teeth more conspicuous than in No 1. Damp woods. July-Sept.

\section{FAMily IV.-TRAPACEAE. WATER-NUT FAMily}

Aquatic herbs, the submersed leaves of which are finely dissected, feather-formed, those which float are rounded and deeply indented. Of these last the leaf-stalks are inflated. Petals and sepals, each 4; stamens 4. Fruit a large spiny nut.

\section{TRAPA, L.}

Characteristics as above.

T. natans, L. (Fig. 11, pl. 105.) SwimMing Water-Nut. A large leaved aquatic, which has been introduced in lakes and parks and which has become naturalized in a few localities. June-July.

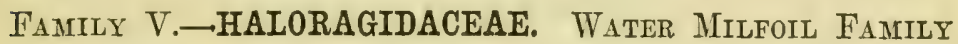

Our species all aquatic herbs. Calyx adherent to the ovary. Leaves in whorls or opposite, or rarely alternate, often finely dissected. Flowers with stamens and pistils or with those having one set of these organs on one plant and those with the other on another plant or with the two kinds of flowers on one plant. Petals small or none, when present 2 to 4 . Stamens 1 to 8 . Ovary oblong or cylindric, ribbed or angled.

Stamen 1, ovary 1-celled .

Hippuris

Stamens 2 to 8 ; ovary 3 - to 4 -celled.

Fruit sharply angled . . . . . Proserpinaca

Fruit splitting into 4 carpels . . . . Myriophyllum

\section{HIPPURIS.}

Stems erect, not branching. Leaves simple, without serrations, arranged in whorls. Flowers greenish, in the leaf axils, having a single stamen on the margin of the calyx and a single style, which is longer than the stamen. Petals absent. Fruit a small 1-celled drupe.

H. vulgaris, L. (Fig. 1, pl, 105.) MARE's TAIL. JorNT WEEd. Plant, 1 to $2 \mathrm{ft}$. high. Leaves narrow linear, sharply pointed at the apex, attached directly to the stem at base where about 6 or more are arranged in a whorl. In borders of ponds and in marshes, in the northern part of our area. Flowers found all summer.

2. PROSERPINACA, L.

Aquatic; stems not generally branching, reclining at base, finally erect. 
Leaves alternate, toothed or finely dissected. Flowers in the leaf axils, small, without petals. Stamens 3; pistils 3. Fruit long, 3 - or 4-celled.

1. P. palustris, L. (Fig. 9, pl. 105.) MIEmaId-weEd. Aquatic. Plant from to $2 \mathrm{ft}$. long. Leaves which float are narrow lance-shaped or elliptic, with sharp serrations. Those submersed are finely featherformed. Common in swamps. June-July.

2. P. pectinata, Lam. (Fig. 10, pl. 105.) Cut-leaved MermaidWEED. Aquatic. Leaves all finely feather-formed. Otherwise much like the former species. Plant 5 to 10 in. long. Rare in our section. Swamps.

\section{MYRIOPHYLLUM, L.}

Aquatic herbs, with creeping roots; leaves in whorls or alternate and with greenish flowers. Leaves, which are wholly under water, are dissected into capillary segnents, those above toothed or with smooth borders. The upper flowers are generally stamen bearers, those below are pistillate. Petals none, calyx 4-toothed. Stamens 4 to 8 . Some of the flowers have both stamens and pistils. Fruit of 4 nut-like hard carpels, which are coherent at their angles.

Flowers in narrow spikes above the submersed leaves.

Leaves of the flower spike very small; flowers in whorls ${ }_{1}$. spicatum.

Leaves of the flower spike longer than the flowers and much dissected; submersed leaves in dense whorls, stamens $8 . .0$. II. rerticillatum

Plant nearly leafless, the leaves being reduced to small bract- or hair-like appendages, stamens 4 . - . M. tenellum Flowers on both submersed and emersed parts of the plant.

Plant with a few scattered leaves, those of the upper part linear, those of the lower part feather-formed, dissected; stamens $4, M$. humile

Leaves of flower bearing portion of stem in whorls of 4 or 5 , not threadlike, with conspicuous teeth; stamens 4.

Flowers alternate

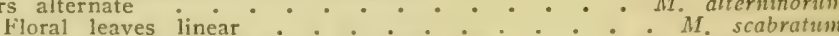
Floral leaves lance-shaped or egg-shaped : : Mr. hictcrophyllum Flowers only on spikes which are submersed.$\cdots \cdots$. Farwellii

1. M. spicatum, L. (Fig. 4, pl. 105.) SPIKen WATER-MILFoIL. Plant, growing in deep water, the submersed leaves finely dissected into capillary segments, in whorls of 4 or 5 leaves. At the summit is a long spike with whorls of inconspicuous greenish flowers which are accompanied or not by leaves reduced to bracts, which are shorter than the small flowers: Stamens 8. In ponds and quiet waters.

2. M. alterniflorum, DC. Loose-FiowerFi WATER-MILFoIL. Submersed leaves finely feather-formed. Flowers alternate. Ponds, lakes and streams, Mass. and Lake Champlain.

3. M. verticillatum, I, (Fig. 5, pl. 105.) TWHORLED WATER-MrLorL. Plant of deep or shallow water. The arrangement of submersed leaves similar to that of No. 1. The floral leaves are conspicuous and like those under water are finely dissected. Stamens 8.

4. M. tenellum, Bigel. (Fig. 2, pl. 105.) Stexden Water-anlffoil. Plant, growing mostly at borders of ponds, 3 to $10 \mathrm{in.} \mathrm{high.} \mathrm{Stems} \mathrm{nearly}$ leafless, or with very small capillary appendages. Flowers in a spike on upper part of stem. Stamens 4.

5. M. humile, (Raf.) Morong. (Fig. 3, $a$ and $b$, pl. 105.) Low WATER-Aituoll. Plant of pomds and ditches. The form growing in mud, out of water, lig. 3 , b., about 1 to $2 \mathrm{in.} \mathrm{high,} \mathrm{with} \mathrm{the} \mathrm{upper} \mathrm{leaves,}$ 

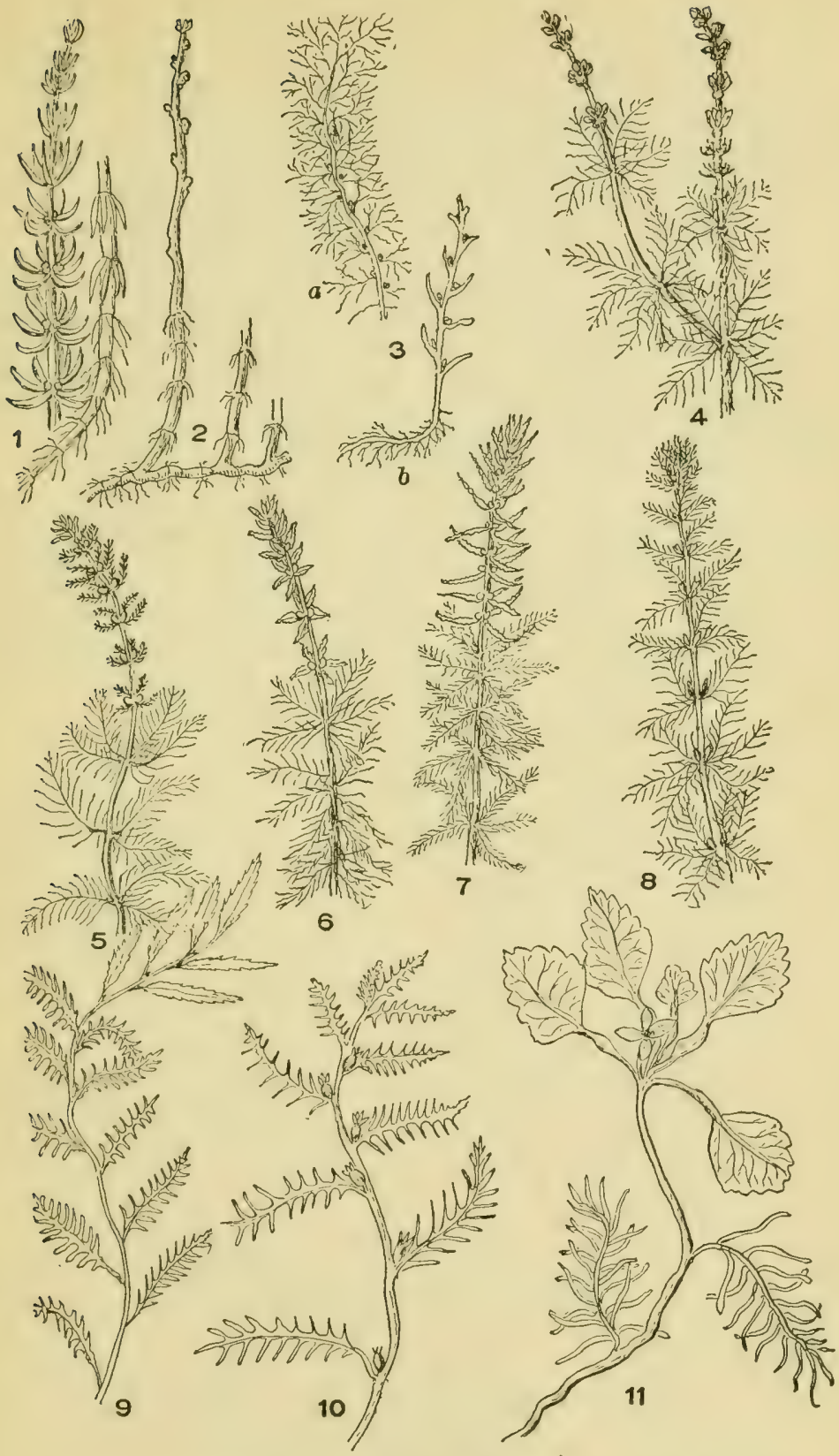

Plate 105

1. Hippuris vulgaris. 2. Myriophyllum tenellum. 3a. M. humile, aquatic form. 3b. M. humile, land form. 4. M. spicatum. 5. M. verticillatum. 6. M. heterophyllum. 7. M. scabratum. S. M. Farwellii. 9. Proserpinaca palustriø. 10. P. pectinata. 11. Trapa natans. 
among which are found the small flowers, narrowly linear. The form growing in water has finely dissected leaves. Fig. 3, a. Stamens 4.

6. M. heterophyllum, Michx. (Fig. 6, pl. 105.) Tarious-Leaved WATER-Mrforl. Plant of ponds and still waters. Stems stout. Lower leaves dissected into fine capillary segments; the upper, floral leaves, eggshaped or lance-shaped with conspicuous teeth. Flowers with 4 stamen.

7. M. scabratum, Michx. (Fig. 7, pl, 105.) Pinxate Water-Mil. FoIL. (Ir. pinnatum, (Walt.) BSP.) Resembles No. 5, but floral leaves are linear, with conspicuous teeth.

8. M. Farwellii, Morong. (Fig. 8, pl. 105.) FArwell's WaterMILForL. Leaves in whorls of $3 \mathrm{~s}$ or $6 \mathrm{~s}$ or scattered, narrow, featherparted, the divisions thread-like, in 5 to 7 opposite pairs with minute black spines at the axils. Petals 4, oblong; styles 4. Still water. Maine, westward.

\section{Order XV.-UMBELLALES. Order of Umbelliferous Plants}

Herbs, shrubs or trees. Flowers in umbels or umbel-like heads. Orary surrounded by the calyx which is superior to it; each cell of the ovary containing a single ovule. Calyx segments little developed or absent. Stamens free from each other and equal in number with the petals, alternate with them.

Stamens 5, flowers in umbels.

Fruit composed of 2 dry carpels, which separate at maturity . . . . . . . UMBELLIFERAE Fruit a fleshy berry . . . . . ARALIACEAE

Stamens 4. Trees and shrubs. Flowers in heads or umbellike groups . . . . . . . . CORNACEAE

\section{Fumily I.-ARALIACEAE. Ginserg Fumily}

ITerhs, shrubs or trees, perennial. Leaves all compound. Flowers small; stamens 5. Fruit a fleshy berry. Calyx tube surrounding and adhering to the ovary, 5-toothed.

Leaves alternate . . . . . . . . Aralia

Leaves in a whorl . . . . . . . . Panax

\section{ARALIA, L.}

Herhs, shrubs or trees, with alternate compound leaves and small white or greenish flowers in umbels or heads. Calyx of 5 divisions; petals 5 ; stamens 5; ovary 5-celled.

Shrub or trec

Herbs.

Umbel compound on a lengthened axis

Umbels of about 3 secondary umbels

Umbel of a single head.

A. spinosa

- A. racemosa A. rudicaulis - A. hispida 

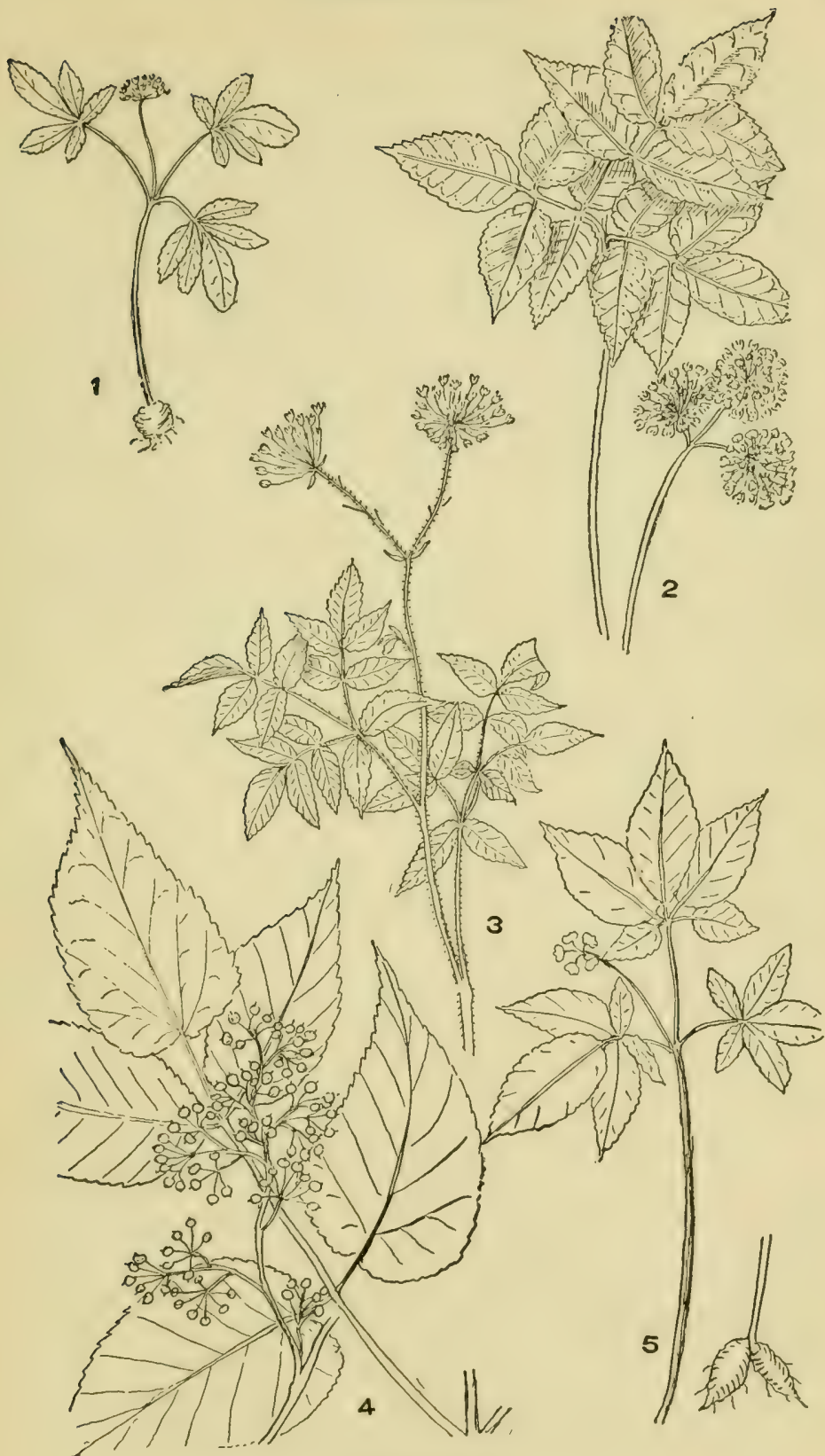

Plate 106

1. Panax trifolium. 2. Aralia nudicaulis. 3. A. hispida. 4. A. racemosa. 5. Panax quinquefolium. 
1. A. spinosa, L. ITercules's Club. Axgeltca Tree. Shrub or low tree, with thick stem, with prickles on the branches. Leaves doubly com. pound, of several pairs of egg-shaped, thick leaflets, with an odd one for each division. liver banks, in southern part of our region. June-Aug.

2. A. racemosa, L. (Fig. 4, pl. 106.) American Spikenard. A large, much branched herb, with egg-shaped leaflets, which are heartshaped at base and slender pointed at apex. Umbel on an extended axis, giving the cluster of flowers a more or less pyramidal shape. Flowers greenish; fruit a dark purple or brown berry. Rich woods. July-Aug.

3. A. nudicaulis, L. (Fig. 2, pl, 106.) Wild Sarsaparilla. Stem divides before or almost immediately after leaving the ground into a leafstem and a flower-stem. The former axis straight and slender about $\mathrm{l} f \mathrm{ft}$. high, when it divides into 3 branches, each bearing 3 or 5 leaflets, which are oval or egg-shaped. The flower-stem is shorter and naked to the summit where a three branched umbel is found, each branch of the umbel bearing a small rounded umbel or head. In woods. Common. May-June.

4. A. hispida, Vent. (Fig. 3, pl. 106.) WiLd Elder. A plant, shrublyy at base, more or less bristly, 1 to $2 \mathrm{ft}$. high. Leaves doubly compound; leaflets egg-shaped, toothed at the edges. Umbels on long slender flower-stems. Common about decaying stumps and rocky places. July-Aug.

\section{PANAX}

Herbs or shrubs. Our species herbs, arising from a globose or spindleshaped root with a slender stem branching into 3 leaf-stalks at the top, each bearing 5 or less leaflets, which are inversely lance-shaped, or inversely egg-shaped, and a single flower-stem bearing a rounded umbel of a few white flowers. Stamens 5. Fruit a somewhat flattened berry.

1. P. trifolium, L. (Fig. 1, pl. 106.) Dwarf Ginseng. Ground Nut. Plant, 3 to 8 in. high, in moist woods. Leaflets 3 to 5 , the lower pair single, the upper ones inversely lance-shaped. Root globular. Woods. common. April-June.

2. P. quinquefolium, L. (Fig. 5, pl. 106.) Ginseng. A large plant, 8 to $15 \mathrm{in.} \mathrm{high.} \mathrm{lioot} \mathrm{spindle-shaped.} \mathrm{Leaves} \mathrm{inversely} \mathrm{egg-shaped.}$ Rich woods, New England. April-May.

\section{Family II.-Umbelliferae. Carrot or Parsley Family}

IIerbs, with usually hollow stems and alternate leaves which, in all but a few species, are compound. Iseaf-stallis expanded, often forming a sheath to the stem. Flowers in mubel, that is, the flower stems of the chuster of flowers all spring from one point and radiate like the rays of an umbrella. In general each primary ray grives ofl a secondary gromp, which is known as an umbellet, on which are borne the flowers. The flowers are small and individually inconspicuous, but the groups or umbels constitute showy heads or dusters, as for example, those of the wild carrot. At the base of the umbel in certain species there is found a whorl of bracts 
which is known as the involucre, this involucre may be simple or divided. In several species in which no involucre is found when the umbel is mature some small bracts may be found at an earlier stage, but these fall as the umbel approaches the mature state. In other species while there is no whorl of bracts, involucre, at the base of the primary umbel, there is an involucel at the base of the umbellet. This involucel may be found also in connection with the involucre. The small corolla has 5 petals; calyx j-toothed, adhering to the ovary; stamens 5 ; pistils 2 . Fruit of 2 dry cohering carpels. The fruit is usually oval or rounded but is sometimes long and spindle-shaped and, in case of the Sanicles, the fruit is covered with hooked spines forming a bur-like body.

Flowers white, or at least not yellow; seeds rounded or oval.

Leaves not compound.

Leaves long, narrow, with spiny teeth .

Eryngium

Leaves round Hydrocotyle

Leaves reduced to hollow leaf-stalks . . . Liliaeopsis Leaves compound.

Involucre to main umbel present.

The bracts dissected or at least divided.

Leaves dissected.

Fruit flattened, ribs bearing bristly hairs . . . . . . . Daucus

Fruit oval, without bristles Ptilimnium

Bracts of the main umbel not finely divided or at most only toothed or ternately cleft.

Leaves of 3 sets of trifoliate leaflets Ligusticum

Leaves of 3 to 5 leaflets radiating from a common center . . . . . Sanicula

Leaves of stem compound, feather-formed, (once pinnate).

Involucre of linear bracts . . . Sium

Involucre of broad leaf-like bracts Berula Leaves compound, doubly feather-formed.

Segments of leaflets narrowly linear Carum Segments somewhat broad.

Stem spotted . . . . Conium

Main umbel without involucre or with few small bracts which fall early. 
Umbellets with involucels.

Segments of leaflets rather broad Conioselinum

Segments narrow linear . . . Aethusa

Leaflets not dissected . . . . Cicuta

Fruit compressed . . Angelica

Umbellets without involucels.

Fruit densely bristly . . Caucalis

Fruit not bristly.

Leaves finely dissected . . . . Apium

Leaves simply or doubly feather-formed compound.

Fruit compressed. Leaves not dissected . . . . Angelica

Leaflets round deeply toothed Pimpinella

Leaflets lance-shaped . . . 0xypolis

Leaflets linear . . . . . Cicuta

Leaves of 3 broad leaflets (ternate).

Flower umbels regular . . Heracleum

Flower umbels irregular . Cryptotaenia Leaves doubly ternate.

Sea coast plant . . . Coelopleurum

Inland plant . . . . Aegopodium

Fruit long spindle-shaped

Fruit less than an in. long.

Long tapering at base

. . . . Chaerophyllum

Blunt at base . . Osmorhiza

Fruit and appendage more than an inch long . . . . . Scandix

Flowers Yellow

Lcaves undivided, the stem appearing to penetrate the leaf plate . . . . . . . . . . . Bupleurum

Leaves feather-formed, of deeply lobed leaflets . . Pastinaca Leaves ternately or bi-ternately divided.

Borders of leaflets notched.

Fruit laterally flattened . . . . . . . Zizia

Fruit not flattened . . . . . Thaspium 
Borders of leaflets not notched

Pimpinella

Leaves of 3 to $\%$ radiating lobes.

Sanicula

\section{Flowers Purple}

Leaves radiating

Leaves ternately divided

Sanicula

Thaspium

Flowers white. Seeds rounded or oval

Leaves not compound

I. ERYNGIUM, L.

Herbs, with spiny toothed elongated leaves. In our two species the leaves are grass-like, with spines along both edges. Flowers are collected in dense heads, below each of which is an involucre of conspicuous bracts both at the base of the individual head and at the base of the group of heads. Calyx lobes somewhat leafy; petals white or bluish.

1. E. aquaticum, L. (Fig. 6, pl. 109.) Button Snake-root. Stem 2 to $6 \mathrm{ft}$. high. Leaves from 1 to $2 \mathrm{ft}$. long, about an in. wide, with parallel veins and with the edges armed with spines. Heads rounded, averaging about ? in. diameter. Low grounds, New Jersey and westward. July-Aug.

2. E. virginianum, Lam. (Fig. 5, pl. 109.) Virginia Eryngo. Stem 1 to $3 \mathrm{ft}$. high; leaves, the upper grass-like with spines at the borders; 2 to 8 in. long. The basal leaves long and narrow on a leafstalk. Heads about $\frac{1}{2}$ in. diameter. Marshes near sea-coast, New Jersey and southward. July-Sept.

By some authorities this is regarded as only a variety of $E$. aquaticum.

\section{HYDROCOTYLE, L.}

Marsh herbs, ours quite small, prostrate and rooting at joints. Leaves of our species round with leaf-stem near the middle; whole plant smooth. Flowers small, white in small heads, either simple or one head above the other on the flower stem.

1. H. umbellata, L. (Fig. 4, pl. 111.) Marsi Pennywort. Stem creeping, several in. long, rooting at joints. Leaf-stem arising from the creeping stem and above the small fasiculus of roots. Leaves round, veins radiating from near the center. Flowers in small round heads or umbels at the summit of the flower stem. Wet places, eastern Mass., and southward. Nearly all summer.

2. H. Canbyi, C. and R. (Fig. 5, pl. 111.) Canny's Pennywort. Resembles No. 1, but flowers are in several small heads, one above the other on the flower stem. Flower stem considerably longer than lcaves. Wet grounds, New Jersey and southward. June-Sept.

3. H. verticillata, Thumb. (Fig. 6, pl. 111.) WhorLed MARSII PENnYwort. Flower heads very small, one above the other; the flower stem shorter than the leaves. Mass., and southward. June-Sept.

4. H. americana, L. (Fig. 7, pl. 111.) American Marsi PennyworT. Stems thread-like; leaf stem affixed near the border of the rounded 
heart-shaped leaves. Flowers on a very short flower stem, only from 1 to 5 very small flowers in the cluster. Wet places, throughout our areat. June-Sept.

\section{LILAEOPSIS, Greene. (Crantzia, Nutt.)}

Small creeping herbs, rooting at the joints, in the mud. Leaves simply hollow eylinclric stems. The few white flowers in small heads, with involucre below the head.

L. lineata, (Michx.) Greene. (Fig. 6, pl. 107.) Litudeorsis. Leaves about 1 to $3 \mathrm{in}$. high, from the creeping root. In salt marshes. JulyAug.

Leaves compound; seeds rounded. Involucre to main stem present. Involucre bracts finely dissected

\section{DAUCUS.}

Herbs, with more or less bristly hairs and with much-divided leaves and with leaf-like bracts of the involucre, which are divided into linear or thread-like segments. Flowers white in compound umbels. Fruit oval with 5 slender ribs which are winged, each rib bearing a single row of barbed hairy prickles.

D. carota, L. Wild CARrot. Our wild carrot, now found too abundant in meadows and fields as well as at roadsides. All summer.

\section{PTILIMNIUM, Raf. (Discopleura, DC.)}

Herbs, smooth, branching, annual. Leares finely dissected. Involuere of leaf-like bracts which are divided into thread-like segments. Flowers white, in secondary umbels each with its involucel. Fruit egg-shaped, ribs without bristles. Calyx teeth small or none.

P. capillaceum, (Michx.) Hollick. (Fig. 1, pl. 111.) Mock BIsnopWEED. Plant 1 to $2 \mathrm{ft}$. high, leaves dissected into thread-like segments. Umbels compound with involueres and involueels. Wet soil. June-Oet.

Flowers white. Fruit rounterl, inroluere bracts not divided or at most only toothed or ternately cleft

\section{LIGUSTICUM, L.}

Plant smooth, with compound leaves. Tmbels subtended by narrow bracts or none. Leaves of our species of 3 divisions each terminated by 3 wedge-shaped, decply notehed leallets, each leatlet from 1 to 4 in. leng.

L. scothicum, L. (Fig. 10, pl. 111.) Sea Parsley. Scotci Lovage. Plant growing at scaside, 1 to $2 \mathrm{ft}$. high. Stem simple, or slightly branched abose. Ifatlets werlge-shaped, mostly 3-lobed and decply notehed. Fruit oblong. July-Aug.

\section{SANICULA, L.}

Plants smooth with alternate leaves, which are divided into 3 to 5 segments, which radiate from the leaf stem. Rays of umbel few, each terminated by from 1 to 3 or more bur-like heads. Involucre leaf-like of 2 or more broad greenish bracts, which in Nos. 1 and 3 are ternately divided. Fruit globular, without ribs but thickly beset by hooked prickles.

1. S. marylandica, L. (Fig. $1, \mathrm{pl}$. 109.) SANicle. Plant, 1 to 4 


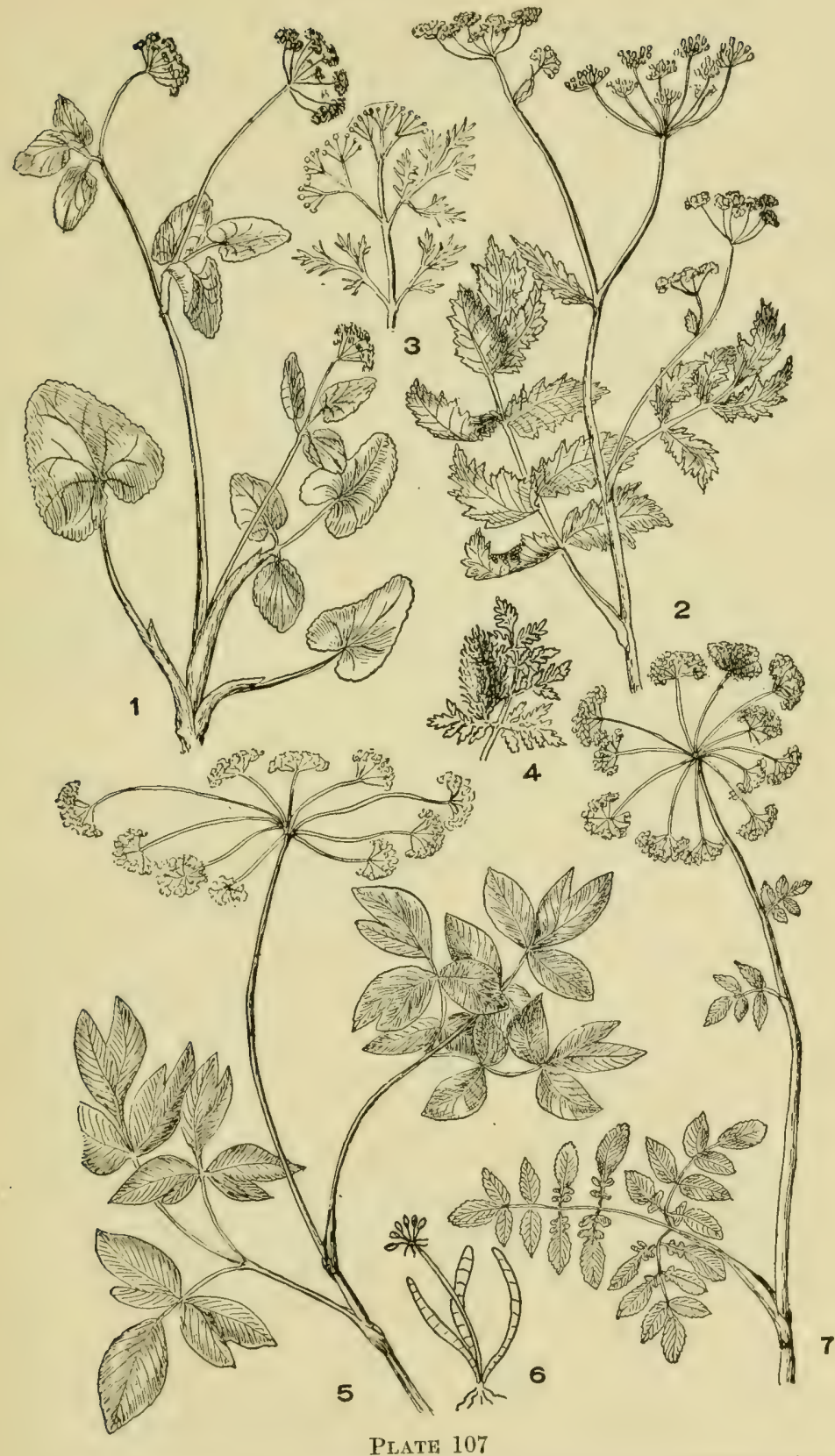

1. Zizia cordata. 2. Z. aurea. 3. Apium leptophyllum. 4. Caucalis anthriscus. 5. Pimpinella integerrima. 6. Lilaeopsis lineata. 7. Angelica villosa. 
ft. high. Leaves of 3 to 7 radiating lohes, the divisions sharply tonthed. Involucre of broad leaf-like bracts often ternately divided. Flowers greenish-white. Several sterile flowers in each group on long pediccls. In rich woods throughout our region. May-July.

2. S. gregaria, Bicknell. (Fig. 2, pl. 109.) Clustered Sanicle. Similar to No. 1, but plants thickly clustered and flouters yellow. WVods and thickets, southern New York and southward. May-June.

3. S. canadensis, L. (Fig. 4, pl. 109.) Short-STried SANicle. Similar to No. 1, but there are few sterile flowers and those on short pedicels. Flowers white. Dry woods, Mass., southward. June-Aug.

4. S. trifoliata, Bicknell. (Fig. 3, pl. 109.) Large-Fruited Sanicles. More slender than either of the other forms. 1 to $2 \frac{1}{2} \mathrm{ft}$. high. Leavez tcmately divided as are the broad bracts of the umbel. Flowers white. Woods, southern New York, Conn., and northward. June-July.

\section{SIUM, L.}

Herbs of wet places, with featler-formed stem leaves, the lower leaves being often dissected, and with compound umbels and umbellets having involucres of narrow bracts. Flowers white. Fruit oval or egg-shaped, compressed, prominently ribbed, not bristly.

S. cicutaefolium, Gmel. (Fig. 4, pl. 108.) Temlock IVAter Parsnip. A stout plant in marshes, 2 to $6 \mathrm{ft}$. high. Leaf-stems sheathing at base, the leaf consisting of from 7 to 17 linear leaflets, these sharply notched at borders. The lowest leaves often finely dissected. In swamps and salt marshes. July-Oct.

Var. S. Carsonii, Durand. Carson's Water Parsnip. More slender than No. 1, 1 to $2 \mathrm{ft}$. high. Leaf of 3 to 7 linear or lance-shaped leallets, sharply toothed. In streams. July-Aug.

\section{BERULA, Hoffm.}

Smooth plant in marshes or in water. Leaves feather-formed, the leaflets, about 15, more or less, often partly divided but all with sharp teeth. Fruit orbicular with smooth slender ribs.

B. erecta, (Huds.) Hofim. (Fig. 9, pl, 111.) Cut-Leaved Water PAnsilp. In swamps and streams, 1 to $2 \mathrm{ft}$. high, stout, branched. Ideaflets 7 to 19, oval, often partly divided, borders sharply notehed. Imbels with rather enspicuous involueres, umbellets with small narrow bracts. Fruit orbicular with inconspicuous ribs. July-Sept.

\section{CARUM, I.}

Our species an herb, escaped from cultivation. Leaves feather-former or doubly feather-formed, the leaflets of thread-like segments. Involuere for the main umbel. Leaf-stem clasping. Seeds aromatic.

C. carui, L. Caraway. Plant, 1 to $2 \mathrm{ft}$. high. Involucre of 1 to 3 narrow bracts. Waste places. May-July.

\section{CONIUM, L.}

Tall smonth lacrb, in waste plares, generally in rich soil. Stems hranching, spotted. Leatves twiee feather-formed, the segments decply incised. 

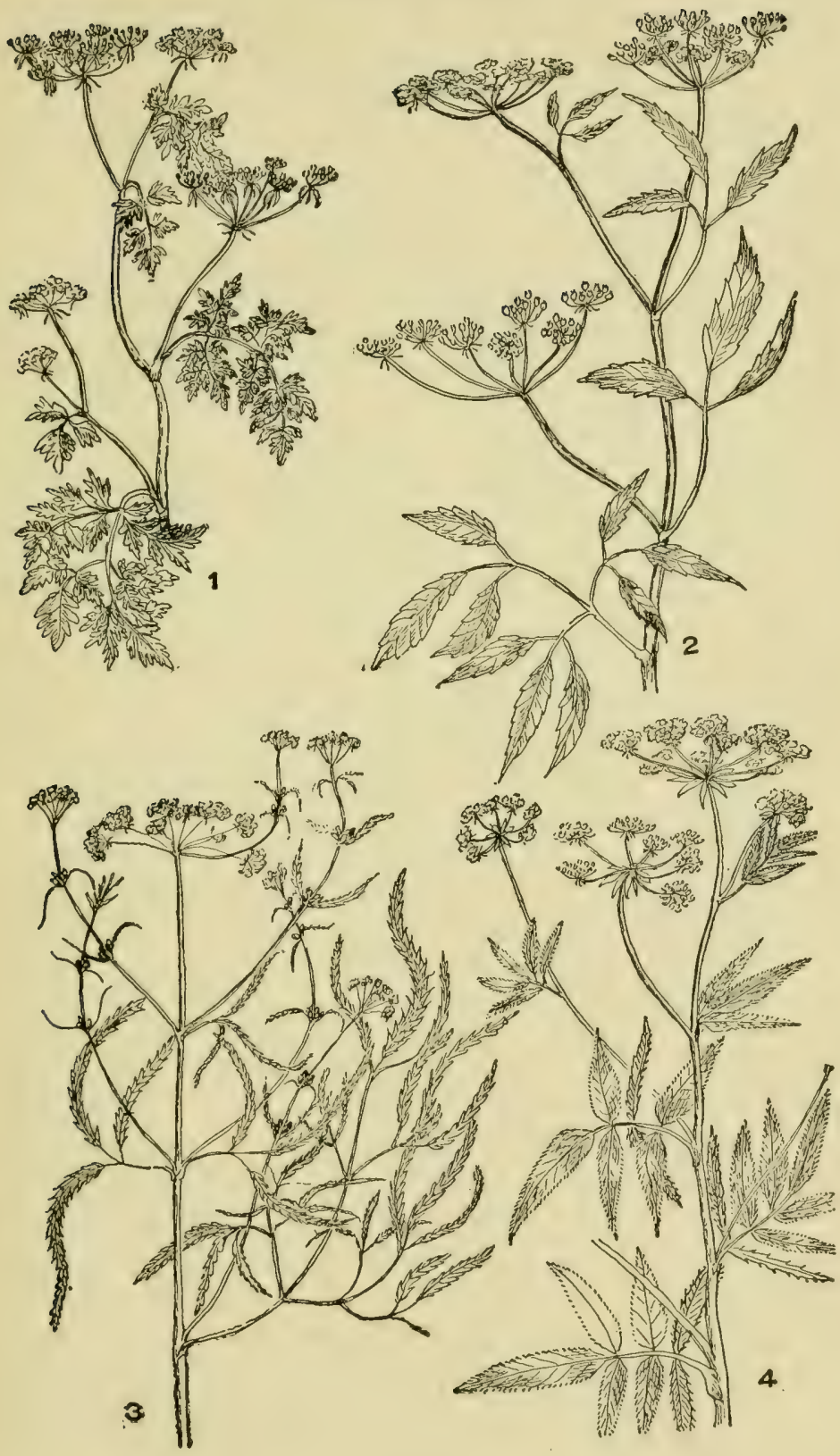

Plate 108

1. Conium maculatum. 2. Cicuta maculata. 3. C. bulbifera. 4. Sium cicutaefolium. 
Flowers small, white in many rayed umbels. The umbels and umbellets supplied with involucrate bracts. Calyx teeth obscure or absent; petals small. Fruit flattened, wavy ribbed.

C. maculatum, L. (Fig. 1, pl. 108.) Poison HemLock. Leaves finely dissceted, the divisions, however, not thread-like, but deeply notehed narrow plates. In waste places throughout our area. June-July.

\section{CAUCALIS, L.}

Plants, in stems and foliage much resembling the carrot. Involucre absent. Flower umbels of our species either in the form of a rather close head or of an umbel with few rays. Calyx teeth 5, prominent. Flowers white or tinged with pink. Fruit with prickles or hooks arranged along the ribs.

1. C. nodosa, (L.) Hudson. Knotted Hedge Parsley. Stem reclining, branched only at base. Leaves dissected into linear segments. Flowers in heads opposite the leaves. Fruit long-oval armed with long stifi hairs or prickles. Waste places. May-Aug.

2. C. anthriscus, (L.) Hudson. (Fig. 4, pl. 107.) Erect Hedge Parsley. Plant, 2 to $3 \mathrm{ft}$. high, erect. Leaflets not so finely dissected as in No. 1. Flowers in few rayed umbels. Fruit long-oval, very bristly. Waste places, Philadelphia, etc. July-Sept.

\section{CONIOSELINUM, Hoffm.}

Tall slender herbs, without hairs, with finely dissected, donbly compound leaves. Involucre to main umbel absent, or of a few bracts which fall early. Involucels of secondary umbels present. Fruit oval, flattened, ribs on the back prominent, those of the sides extended into wings. Calyx teeth absent.

C. chinense, (L.) BSP. (Fig. 3, pl. 111.) Hemlock Paisley. Stem round, 2 to $5 \mathrm{ft}$. high, striped. 'The lower leaves on long leaf-stalks, the upper with short stalks or none. Flower umbels 9 to 16 rayed, the umbellets with a few narrow bracts. Wings of the seed nearly as broad as the seed itself. Cold swamps, southern New York and northward. Aug.-Oct.

\section{AETHUSA, L.}

Poisonous lerbs, with much the appearance of the Carrot in respect to stem and foliage. Umbels not flattened at tip like carrot, but more or less rounded. The two bracts of the umbellet are narrow and long and both turn in the same direction.

A. cynapium, L. (Fig. 11, pl. 109.) Fool's PArsley. Stem 1 to $2 \mathrm{ft}$. high. In waste groumds that have been cultivated. Waste places throughout our area. June-Aug.

\section{I5. CICUTA, L.}

Tall poisomous herls, found in swamps. Leaves doubly compound but leaflets not dissected. Umbels of white flowers, involueres absent or falling varly. Involucels present, of many bracts. liruit smooth, ribs not prominent. 


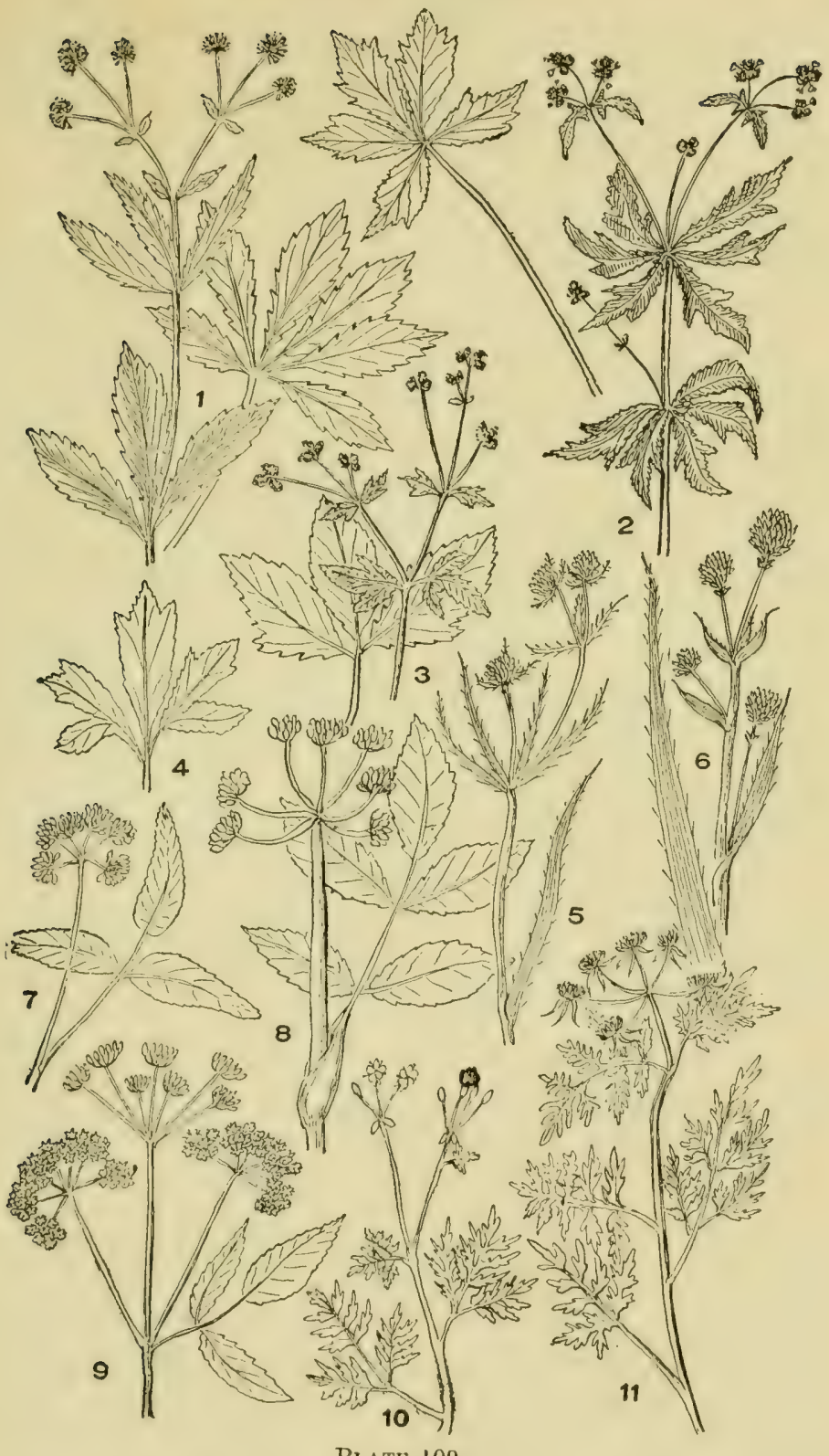

Plate 109

1. Sanicula marylandica. 2. S. gregaria. 3. S. trifoliata. 4. S. canadensis, basal leaf. 5. Eryngium virginianum. 6. E. aquaticum. 7. Thaspium trifoliatum: 8. Coelopletrum Gmelini. 9. Aegopodium Podagraria. 10. Chaerophyllum procumbens. 11. Aethusa cynapium. 
1. C. maculata, L. (Fig. 2, pl. 10S.) Water Hemlock. Spotted Cowbane. Stem stout, 2 to $6 \mathrm{ft}$. high, streaked with purple and arising from lleshy tuberous root-stocks. Leaves, doubly or trebly compound; leatlets lanee-shaped, 1 to $5 \mathrm{in}$. long coarsely toothed at margins. Umbels of many rays, without bracts. Flowers white. Plant very poisonous in all its parts.

2. C. bulbifera, L. (Fig. 3, pl. 108.) Bulb-BEaring Water HemLock. Plant much branched, 1 to $3 \mathrm{ft}$. high. Leaflets linear. The upper leaves bear bulblets at the axis of the leaves. Swamps throughout our area. July-Sept.

\section{I6. ANGELICA, L.}

Stout, erect, lranching herbs, with twice or thrice compound leaves and large umbels of white or greenish flowers. Involucres absent or scanty. Involucels of several small bracts. Umbels compound, of white flowers; many rays. Calyx teeth absent. Fruit strongly flattened, the primary ribs very prominent, the laterals forming distinct wings.

1. A. Curtisii, Buckley. Curtis's Angelica. Erect, 2 to $3 \frac{1}{2} \mathrm{ft}$. tall, smooth; leaves doubly or trebly compound, the leaflets, 5 to 7 , egg-shaped and one sided with sharp irregular teeth at margins. Southern part of our area. Aug;-Sept.

2. A. atropurpurea, L. (Fig. 5, pl. 110.) Purple-stemmed ANGELICA. A very stout plant, from 4 to $6 \mathrm{ft}$. high, with dark purple stem. Leaves compouml, the segments of from 5 to 7 leaflets which are lanceor egg-shaped with sharp teeth at margins. River banks. June-July.

3. A. villosa, (IValt.) BSP. (Fig. 7, pl. 107.) Pubescent ANGELICA. More slender than No. 1 or $2 ; 2$ to $6 \mathrm{ft}$. high. The umbels and upper part of the stem densely downy. Dry soil, Comnecticut and south. ward. July-Aug.

\section{I7. APIUM, L.}

Annual and biennial smooth herbs. Leaves compound, divided in 3 main sergments, which latter may be composed of broad or of narrow linear clements. Limbels rompound with no bracts or with few. Flowers white. Fruit oval, laterally compressed.

A. leptophyllum, (I)(.) F. Muell. (Fig. 3, pl. 107.) Fine-Leaved Marsu Pansier. Plant, 3 to 24 in. high, slender, branched. Leaves divided in 3 parts, each subdivided into fine linear segments. Umbels of inconspicunss white flowers. New Jersey and southward. June-Aug.

\section{PIMPINELLA, L.}

Simooth herlss, with leaves onee or twice compound. Involucres and involucels absent. Flowers white or yellow. Fruit 5-angled.

Hlowers white

Jinwers yelluw

1. P. saxifraga, I. Burnets Saxifrage. Smooth, erect, 1 to $3 \mathrm{ft}$. lighli. Leaves feathereformed, the leaflets, a) to 19), exgr-shaped or nearly romol, with very compound sharp teeth at the margins. Flowers white. Waste places, southern part of our area. June-Oct.

2. P. integerrima, ( $\left.\mathrm{L}_{.}\right)$A. Gray. (Fig. 5, pl. 107.) Yellow Pra- 
Perxell. Smooth with a whitish bloom on stem and leaves; 1 to $3 \mathrm{ft}$. high, branching. Leallets lance- or egg-shaped, not dissected and without marginal teeth. Rays of the umbel numerous. Flowers yellow. Rocky or sandy soil, eastern Pennsylvania and in New Jersey. May-June.

\section{I9. OXYPOLIS, Raf. (Tiedemannia, DC.)}

Erect aquatic herb, without hairs. Leaves simple feather-formed (in our species). Rays of umbel few, compound, ours without involucre. Flowers white. Calyx teeth 5. Fruit without bristles, ribbed, the lateral ribs winged.

O. rigidus, (L.) Britton. (Fig. 6, pl. 110.) Cowbane. Plant growing in swamps, 2 to $5 \mathrm{ft}$. high. Leaves, the lower ones sometimes a foot long of 3 to 9 narrow but thick leaflets, remotely toothed on the margins. New York and southward. Aug.-Sept.

\section{HERACLEUM, L.}

Tall herb, leaves ternate, of broad leaflets each of which is deeply lobed. T'mbels of white flowers, the latter rather larger than those of most species in this family. Petals heart-shaped or 2-lobed. Involucels of several narrow bracts.

H. lanatum, Michx. (Fig. 11, pl. 111.) Cow Parsnip. Plant 4 to $8 \mathrm{ft}$. high, woolly with grooved stem, which is thick and rigid. Leaves, on leaf-stalks, divided into 3 large rounded or egg-shaped lobed leaflets, which beside the deep lobes are sharply toothed at the margins. The flowers, on large umbels are larger and individually more showy than any of the family, bearing white flowers, in our region. Moist grounds, throughout our area. June-July.

\section{I. CRYPTOTAENIA, DC. (Deringa, Adams)}

Erect plant, with 3 -parted leaves and umbels of very unequal rays. Fruit oblong, carpel with 5 ribs, calyx teeth absent. Involucre and involucels absent.

C. canadensis, DC. (Fig. 2, pl. 110.) Hone WorT. Plant smooth, 1 to $2 \mathrm{ft}$. high. Leaves of 3 large ovate leaflets which are toothed at the margins, the center leaflet generally only slightly lobed, the side leaflets commonly deeply lobed. Fruit narrow at both ends. Flowers small, white. Moist woods, throughout our area. June-July.

\section{COELOPLEURUM, Ledeb.}

Stout smooth herb, found at sea-coast with leaves once or twice 3-parted. Leaves on leaf-stalks which are greatly inflated. LTmbels large, involucre absent or falling very early. Involucels of narrow bracts often deciduous, never: conspicuous. Fruit oblong to globose, the lateral ribs slightly broadest. Flowers greenish-white.

C. Gmelini, (DC.) Ledeb. (Fig. 8, pl. 109.) Sea Const Angelica. Plant 1 to $3 \mathrm{ft}$. high. Leaflets egg-shaped, deeply toothed and ofter. lobed at margins. Fruit about $1 / 5$ in. long. Sea coasts, Mass., and northward. Summer. 


\section{AEGOPODIUM, L.}

Coast herb, with leaves once or twice 3-parted. Leaflets egg-shaped, sharply toothed, umbels large; calyx teeth absent. Fruit egroshaped, smooth with thread-like ribs. Seed cylindric.

A. Podagraria, L. (Fig. 9, pl. 109.) Goutweed. Plant 1 to $2 \frac{1}{2}$ ft. high. Found in waste places. June-Aug.

\section{Fruit long, spindle-shaped}

Flowers White

\section{CHAEROPHYLLUM, L.}

Herbs, with leaves twice 3-parter, the leaflets deeply incised, making feather-formed segments Flowers white; calyx teeth absent. Fruit ob. long to linear. L'mbels of few rays, compound, the umbellets also few rayed. Involucres absent, involucels of several small bracts.

C. procumbens, (L.) Crantz. (Fig. 10, pl. 109.) Spreaning Chervil. Plant somewhat downy, $\frac{1}{2}$ to $1 \frac{1}{2} \mathrm{ft}$. high. Leaves on long leafstalks. Flowers few in each umbel. Moist grounds, New York and southward. April-June.

\section{OSMORHIZA, Raf. (Washingtonia, Raf.)}

Ours, downy herbs, with compound leaves and white flowers. Unbels few rayed, involucres absent, involucels of a few bracts. Calyx teeth absent. Fruit lincar with short beak, 5-angled. Roots thick, aromatic.

1. W. Claytoni, (Michx.) Clarke. (Fig. 8, pl. 111.) Woolly Sweet-cicely. Somewhat stout, decidcdly downy. Leaves twice 3-parted, the central leaflet of each division more or less feather-formed, and all the divisions more or less incised. Umbels 2 to 6 rayed. Fruit about $\frac{1}{2}$ in. long. Woods, throughout our area. May-June.

2. W. longistylis, (Torr.) DC. SMrootmer Siveet-cicely. Much less hairy than No. 1. Woods, common. May-June.

\section{SCANDIX}

Herbs, with finely dissected leaves and with few rayed umbels and white flowers. Involuere absent or of a single bract, involucels present. Fruit greatly elongated, the "beak" much longer than the body.

S. Pecten-Veneris, L. (Fig. 4, pl. 110.) Vexus's Comb. Snepmerns' Nrente. Plant $6 \mathrm{in.}$ to $18 \mathrm{in.} \mathrm{high,} \mathrm{much} \mathrm{branched.} \mathrm{Leaves} \mathrm{finely}$ dissected. Fruit with its beak $2 \mathrm{in}$. or more in length. Waste places. Introduced. May-July.

\section{Flowers Yellow}

(Thaspium trifoliatum, Purple),

\section{BUPLEURUM, L.}

IJerh, with elasping leaves or with the stems apparently passing through tho leaves and with compoumd umbels of yellow flowers. Involuere ab. sent, involueds of is comspieuous, rather broid bracts. Calyx teeth absent. Fruit oblong; ribs slender. 


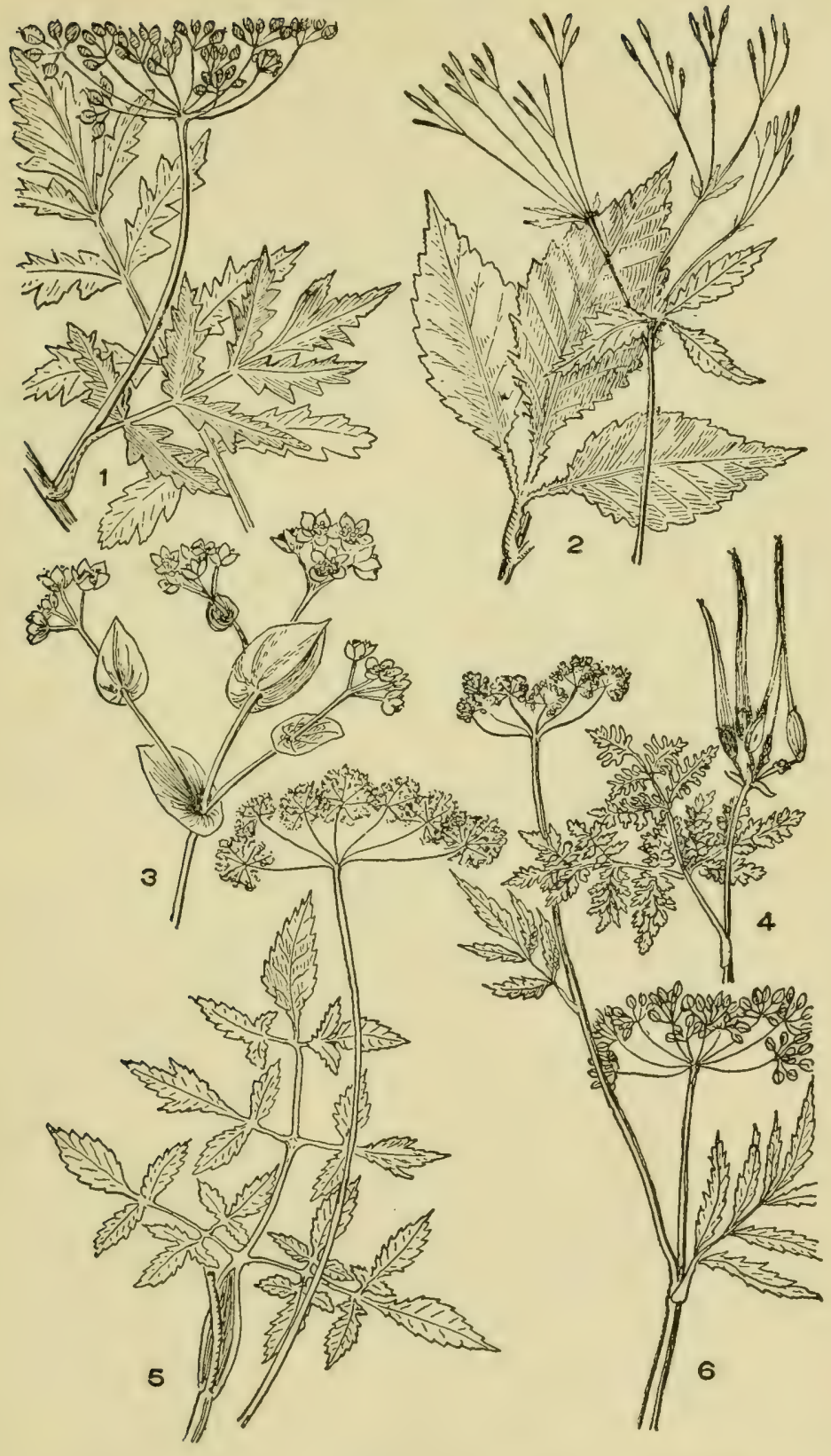

Plate 110

1. Pastinaca sativa. 2. Cryptotaenia canadensis. 3. Bupleurum rotundifolium. 4. Scandix Pecten-Veneris. 5. Angelica atropurpurea. 6. Oxypolis rigidus. 
B. rotundifolium, L. (Fig. 3, pl. 110.) Hare's Ear Modestr. Plant 1 to $2 \mathrm{ft}$. high, common in cultivated grounds. July-Aug.

28. PASTINACA, L.

Tall, stout, smooth herb, with large feather-formed leaves, broad umbels without involucres or involucels and with yellow flowers. Fruit oval, smooth, much flattened. Ribs very slender.

P. sativa, L. (Fig. 1, pl. 110.) Wild Parsnip. Plant 2 to $5 \mathrm{ft}$. high; stem grooved. Leaflets about 3 pairs and an odd one, broadly eggshaped, or lobed; margins with coarse teeth. In waste lands. JuneSept.

\section{ZIZIA, Koch.}

Herbs, smooth with at least the upper leaves once or twice 3-divided or the basal leaves undivided. Tmbels of yellow flowers without involucre, the involucels consisting of a few small bracts. Fruit ovate or oblong.

1. Z. aurea, Foch. (Fig. 2, pl. 107.) Golden Alexanders. Golden Meadow Parsnir. Erect, 1 to $2 \frac{1}{\mathrm{ft}}$. high. Lower leaves on long leafstalks, the very upper ones of three leaflets witlout leaf-stalk, the intermediate on moderately long leaf-stalks twice 3-parted. Leaflets eggshaped, with sharply toothed margins. Rays of the umbel 12 to 25 . Flowers yellow. Wet fields, throughout our area. April-June.

2. Z. cordata, DC. (Fig. 1, pl. 107.) Heart-leaved Alexanders. Branched, 1 to $3 \mathrm{ft}$. high. Lower leaves undivided, margins toothed, on long leaf-stalks. Stem leaves 3 or 5 parted, with egc-shaped or lanceshaped leaflets. Woods and moist places, southern New Jersey, New York, Connecticut, and southward. May-June.

\section{THASPIUM, Nutt.}

Herbs, 2 to $5 \mathrm{ft}$. high, with 3-parted or twice ternate leaves. the leaflots of which are sometimes lobed and always deeply toothed. The basal leaves sometimes without division. Flowers in compound umbels without involucre but with involucels of a few bracts. Color of flowers yellow or purple. Fruit oval, the carpels ribbed and winged.

1. T. trifoliatum, (L.) Britton. (Fig. 7, pl. 109.) Purple Mesnow Parsir. Plant 1 to $2 \mathrm{ft}$. high. Basal leaves sometimes umlivided, upper ones once or twice 3-parted. Leaflets egg-shaped or lanee-shaped, with serrated margins. Petals dark purple. Rare, Rhode Island, New Jersey, and southward. June-July.

2. T. barbinode, (Michx.) Nutt. Mairs Jornted Meanow Parsin. Erect, 2 to 4 feet, lranched. At joints a tuft of hairs. Isaves onee, twice or thrice 3-parted. Ieallets engeshaped to lance-shaped, sometimes lobed, margins toothed. Flowers bright yellow. Banks of streams, throughout our area. May-June.

\section{FAMILY TII.-CORNACEAE. DogWOON FAMILY}

Shrubs or trees; one plant, Cormus canadensis, in our area, small, herbaceous in appearance. Leaves without stipules, opposite 


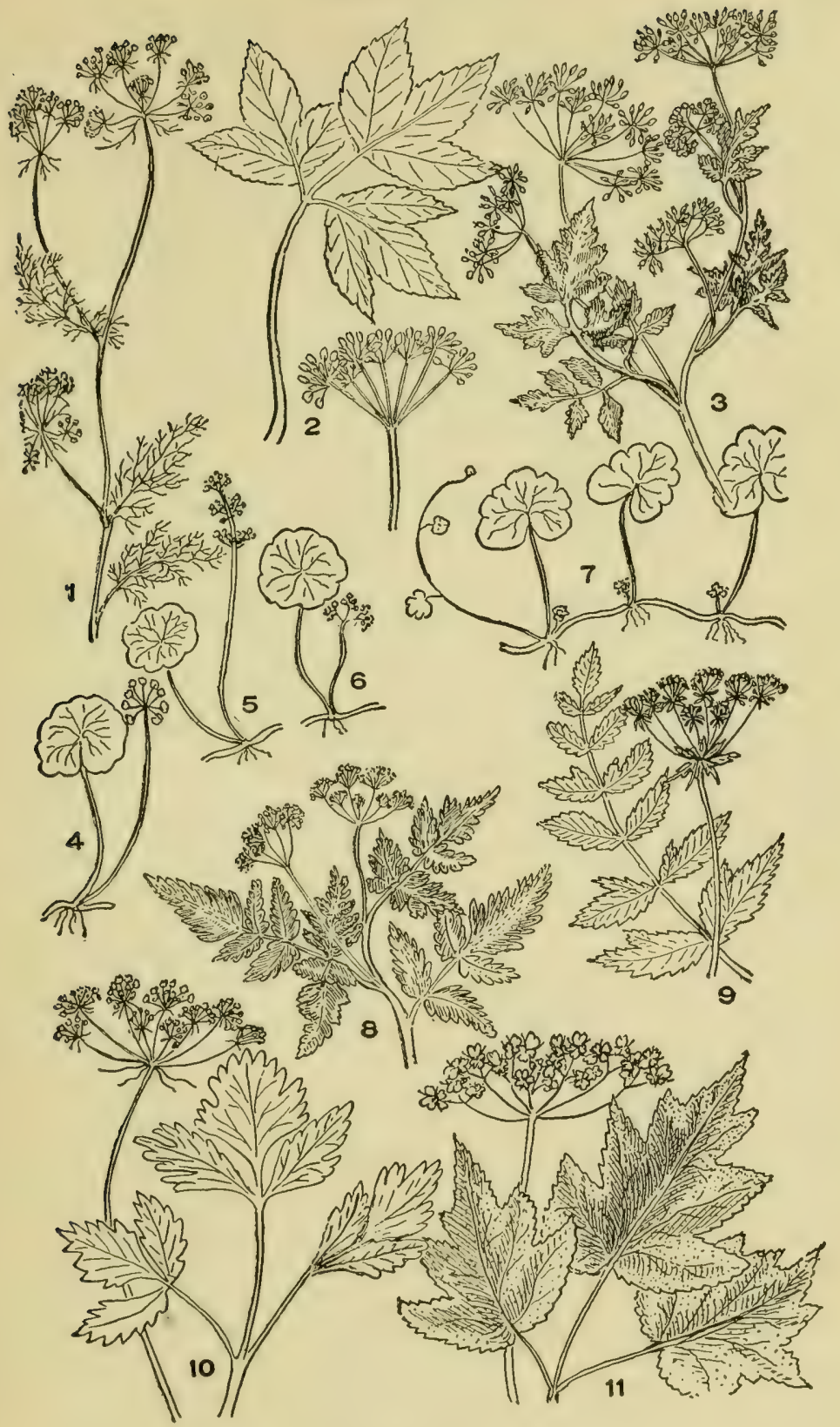

Plate 111

1. Ptilimnium capillaceum. 2. Imperatoria ostruthium. 3. Conioselinum chinense. 4. Hydrocotyle umbellata. 5. H. Canbyi. 6. H. verticillata. 7. H. americana. 8 Osmorhiza Claytoni. 9. Berula erecta. 10. Ligusticum scothicum. 11. Heracleum lanatum. 
or rarely alternate. In all of our species the margins are entire. Flowers in umbel and umbel-like clusters. They have generally 4 or 5 divisions of the calyx, which is joined to the ovary. Petals also 4 or 5 , alternate with the calyx teeth, or they may be absent. Stamens equal in number with the petals when petals are present, and opposite to them. Style 1. Ovary surrounded by the calyx, which adheres to it, of 1 or 2 cells. Fruit a fleshy berry with 1 or 2 hard woody seeds.

\section{CORNUS, L.}

Leaves opposite or in a whorl or, in a single instance in our region, alteruate. Flowers with stamens and pistils, small, in heads or umbels. When in heads the group of flowers is surrounded by an involucre of broad white bracts which simulate petals.

Low herbaceous appearing plants, flowers greenish . . . . . C. canadensis Tree with greenish flowers in a head with 4 large petal-like bracts . C. florida Shrubs with umbel-like clustęrs of flowers, without involucre.

Leaves alternate Leaves opposite.

Under surface of leaves covered with a woolly pubescence.

Leaves nearly round . . . . . C circinato Leaves oval or nearly lance-shaped, fruit blue - C. Amonum Leaves oval, the upper surface and the young branches rough, fruit white. . . . . . . C. asperifolio Under surface of leaves smooth or with fine silky hairs. Young twigs red or bright purple..... C. stolonifero Young twigs gray ......... C. paniculato

1. C. canadensis, L. (Fig. 4, pl. 112.) Bunch Berry. DivarF ConNel. A low herbaceous plant, woody only at the base. Leaves in a whorl toward the summit of the stem with a pair or two pairs of small opposite leaves below. The bracts of the involuere, resembling broad petals are white and 4 in number. The real flowers are in the head, enclused by three bracts and are green. In fruit the plant bears a rounded cluster of bright red berries. In damp woods, common. May-July.

2. C. florida, L. (Fig. 2, pl. 112.) Flowering Dogwood. A slender tree. with spreading branches, with opposite broadly egreshaped loves withmotedh at the margins and with tapering pointed tips. Flowers gremish-yollow in a crowded head which is surrounded by the 4 large and comspicmons white bracts of the involuere. In woods, generally distributed. April-June.

3. C. alternifolia, L. (Fig. 6, pl. 112.) Alternate-Leaved Dogwoon. Small tree or shrub, with alternate leaves which are oval with narrow pointed tips on slender leaf-stalls; the young twigs bright reddish-purple. liranelose warty. Flowers white or cream color in umbellike elusters. Fruit globular, blue when ripe. Woods, common. MayJuly.

4. C. circinata, TiTnel. (Fig. 3. pl. 112.) Round-teaved Dogwood. Shrub, with opposite loases which are hroadly oval, nearly round, the tip narrower to a proint, silky white heneath slightly downy above, 2 to 6 in. Ione. Pranclues warty. Flowers white in dense molsel-like elusters. Fruit glolular, light bluc. Shady places, common. May-June.
5. C. Amonum, Mill.
(Fig. 7, pl. 112.) Silky Dogwood.
(C. 


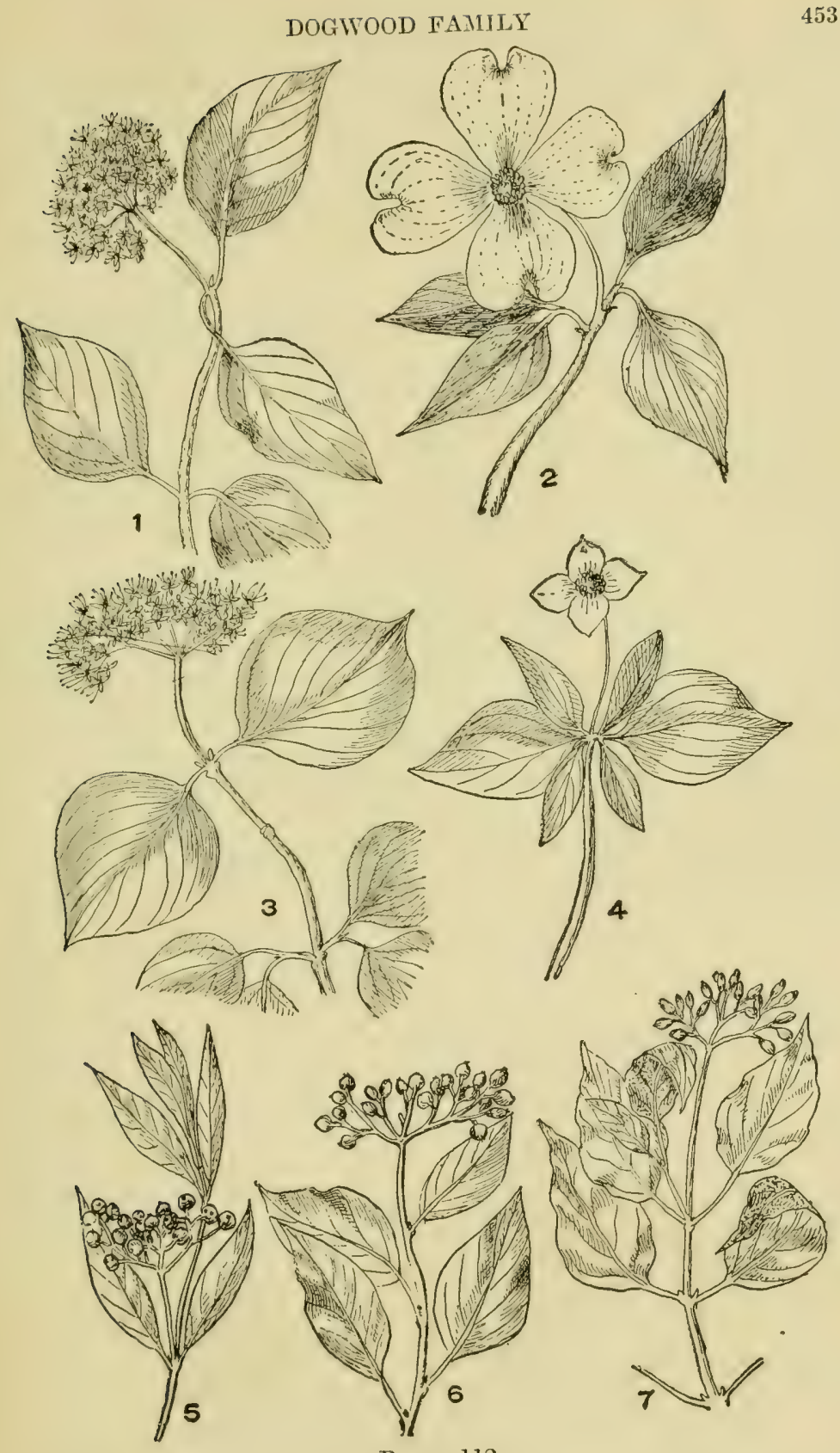

Plate 112

1. Cornus asperifolia. 2. C. florida. 3. C. circinata. 4. C. canadensis. 5. C. paniculata. 6. C. alternifolia. 7. C. Amonum. 
scricea, L.) Branches purple, the smaller woolly. Leaves elliptic or eggshaped, densely silliy witl brownish hairs beneath. Flowers yellowishwhite, the umbellate clusters rather compact. Fruit dark blue. Woods, and along streams. May-July.

6. C. asperifolia, Michx. (Fig. 1, pl. 112.) Rough-LEaved Dogwoop. General appearance of the shrub similar to last. Leaves rough, hairy above, downy beneath. Fruit globular, white. Wet places. MayJune.

7. C. stolonifera, Michx. Red Osier. Shrub, often sending out run. ners, which take root. Branches slender, the younger bright reddishpurple. Leaves egg-shaped on slender leaf-stalks, with few soft hairs above, whitish silky beneath. Berries bluish-white. Moist places. MayJune.

8. C. paniculata, L'Her. (Fig. 5, pl. 112.) Panicled Dogwood. (C. candidissima, Marsh.) Branches gray, smooth. Leaves lance-shaped or somewhat egg-shaped. Pale, silky beneath. Clusters of flowers pyramidal. Berries bluish-white.

\section{NYSSA, L.}

Our species large trees, with rough bark. Leaves alternate without teeth at the margins. Flowers small, greenish, the stamens and pistils on different flowers or different trees or perfect and imperfect ilowers on the same tree. Petals 5, minute and fleshy; stamens 10. Pistillate flowers few in a group, staminate flowers numerous. Berry oval, one-seeded.

1. N. sylvatica, Marsh. Pepperage. Sour Gum. Large tree, with rough bark. Leaves alternate, oval, smooth at margins, pointed at each end. Berry nearly black. Swamps and rich soil. April-June.

2. N. bifiora, Walt. Southern Tupelo. Similar to No. 1. Leaves mostly smaller, oval or pear-shaped, mostly obtuse at apex. Swamps and along ponds. New Jersey and southward. 


\section{Sub-Class II. SYMPETALAE}

\section{Called also Gamopetalac, or Monopetalae}

Plants, the flowers of which nearly always have both a calyx and corolla and which have the petals more or less united at the base, forming a corolla, which seems to be a single, undivided or only partially diviled envelope.

\section{SYMPETALOUS OR MIONOPETALOUS EXOGENS}

Of the groups of plants thus far described we have found cither an absence of petals or when, as in the greater number of groups there has been present a corolla, it has consisted of several petals, as in case of the rose, the buttercups, and the members of the pea family.

In case of the sub-class now to follow, the general rule is that all the petals are so united as to appear as a single member, as in the morning glory and the blue bell. To this complete union there are, however, some exceptions, for the clethra and some of the pyrolas and even some plants of the heath family besides a few others, have corollas divided nearly or quite to the base, thus forming an envelope of several petals. Other characters of these plints hold them in the sub-class to which they really belong, yet to which they form, in respect to the petals, exceptions. Thus, for example, the corolla in some pyrolas is composed of a single member with moderate sinuses between its 5 elementary parts. In case of other pyrolas the sinus is so deep that the corolla is practically divided into 5 distinct petals. Yet these pyrolas are evidently closely allied to each other.

In a few cases, as in Fraxinus and Glaux, the corolla is absent.

In general the calyx has 5 points and, as we observe in the morning glory, the corolla is usually 5 pointed.

There are, in a considerable group, 5 stamens; in another group this number is doubled, while in still another group there may be less than 5 or more than 10 stamens. 


\section{KEY TO THE ORDERS OF SUB-CLASS II}

\section{The Sympetalous or Monopetalous Exogens}

(Characters are for plants within our area only).

\section{Otary Superioli}

(The corolla and calyx form, each a whorl below the ovary to which neither is attached. Exceptions: Family Vacciniaceae, Family Symplocaceae.)

1st. Group. Stamens as many as the lobes of the corolla and alternate with them; or stamens twice as many as the corolla lobes. Stamens free from the corolla or very nearly so.

2nd. Group. Five stamens inserted into the corolla, each opposite to a lobe of the corolla, or twice as many as the lobes, or more. Herbs . . . . . ORDER II. PRIMULALES

Eight to 16 stamens, inserted into the tube of the t-lobed corolla. Shruls and trees. Order III. EBENALES

3rd. Group. Stamens 5 or less, inserted into the corolla tube. When equal in number to the lobes of corolla, alternate with them.

Oraries 2, distinct (except in Gentianaceas and in Menyenthes). Flowers regular; leares mostly opposite; stamens attached to the lower part of the corolla tube

. . . . . . . Order IV. Gentianales

Ovary 1, compound; flowers regular (irregular in Echium). Sitamens mostly joined to corolla tube abore the middle. IIerls twining or erect . O OrDek $V$. TUBIFLOREAE

Ovary 1, mostly deeply 4-lobed, around the style. Flowers irregular (recular in Solunaceae, in Wentha and Lycopus). All irregular corollas 2-lipped. Stamens as many as the lohes of the corollia. IIerls. Capsule 2, rarely 1-seeterl. Leares mostly opposite - OrDER VI. VERBENINALES 
Calyx and corolla each of 4 lobes, the latter dry, membraneous. Stamens 4. Styles 2, one short, one longer and feathery . . . . ORDER VII. PLANTAGINALES

\section{OVART INFerior}

(The calyx and corolla are inserted above the ovary and are attached to it.)

Stamens as many as the corolla lobes and free from each other, not forming a tube about the pistils

Stamens fewer than the lobes of the corolla

. . . . . . . Order IX. VAlERIanales

Stamens at their summit united or leaning toward each other nearly in union .. . . ORDER X. CAMPANULALES

\section{Order I.-ERICALES. Order of the Heaths}

Herbs, shrubs and trees. Corolla with petals united except in a few instances. Stamens as many as the lobes of the corolla and alternate with them, or twice as many, free from the corolla or nearly so, and not forming a tube about the pistils except in Fam. Diapensiaceae. Ovary superior to the calyx and corolla to which these are not attached.

Stamens free from the corolla.

Shrubs, the ovary 3 -celled, the leaves not persistent, the petals divided so nearly to the base as to be practically polypetalous

Perennial herbs, mostly evergreen, ovary 4 - or 5-cellet. Stamens twice as many as the slightly united petals

PYROLACEAE

Herbaceous plants, growing from the roots of other plants and without green leaves, petals more or less separate

Ovary superior; shrubs, often with evergreen leaves; stamens usually twice as many as the corolla lobes; ovary 2- to 5-celled:

ERICACEAE 
Ovary inferior, the calyx adhering to it; the summit of the stamens with two prominences,-_" two horned." Fruit a berry

VACCINIACEAE

Orary superior; low tufted shrubs; stamens 5, arising from the throat of the corolla and alternate with the lobes

\section{Fanily I.-ClethraceaE. White Alder Fadili}

Our only species a shrub. Flowers regular; sepals 5 ; petals 5 . Leaves alternate, with serrate borkers and with leaf-stalks, falling in autumn. Flowers in long slender clusters (II, p. 37), white. Stamens 10. Ovary 3-angled, 3-celled, with numerous ovules.

\section{CLETHRA, L.}

Characters, those of the family.

C. alnifolia, L. (Fig. 3, pl. 115.) White Alder. Shruh, 3 to $10 \mathrm{ft}$. high; leaves pear-shaped, with sharply toothed borders, except toward the base. Wet places, mostly near the coast. July-Aug.

\section{Family il.-Pyrolaceae. Whatergreen Family}

Perennial herbs, low, with long branching root-stocks. Flowers regular, with stamens and pistils; calyx of 4 or 5 divisions, equal to the divisions of the corolla. Stamens twice as many as the lobes of the corolla. The anthers without horns. Style short or long and slender; often bent toward one side. Capsule 4- or 5-celled. seeds numerous, very small.

Flowers in tall slender spikes (I, p. 3\%) . . . . Pyrola Flowers solitary . . . . . . . . Moneses Flowers few in a loose umbel-like cluster . . Chimaphila

\section{PYROLA, L.}

Low herbs, with the leaves crowded at base. Roots branching at base. Flowers on a slender spike. Corolla of 5 lobes or divisions. (alyx of 5 sepals. Flowers nodding (in ease of No. 1, ascending); the pistıl in most eases doubly eurved and the stamens leaning toward the outer side of the corolla. Capsule nearly globular, but compressed, 5-lobed.

\section{Flowers White or Grecnish}

Style with a double curve, stamens leaning to one (the outer) side of the corolla.

Petals lance-shaped and sharply pointed.?.? ? . P. oxy'petala Petals broad, obtuse at apex.

Leaves shining Leaves dull green. Leaf-blades leathery, generally shorter than the leaf-stalk 
Leaf-blades not leathery, generally longer than the leaf-

stalk . . . . . . . P. elliptica Style straight, stamens not leaning to one side.

Leaves rounded

Leaves elliptic

Flowers Pink or Purple

Leaves more or less heart-shaped at base . . . . . . . P. asarifolia Leaves not heart-shaped at base $.+\therefore: \therefore P^{\circ}$ uliginosa

1. P. oxypetala, Austin. Sharp-petaled IVintergreen. Leaves leathery, dull, egg-shaped, on leaf-stalks longer than the blades. Flowers greenish, about 9 on a slender flower-stalk which is about 8 in. high. Petals lance-shaped with sharply tapering points. Rare. Found in Delaware Co., N. Y., by C. F. Austin. June.

2. P. rotundifolia, L. (Fig. 1, pl. 113.) Round-Leaved WinterGREEN. ( $P$. americana, Sweet.) Leaves shining, nearly round or round egg-shaped; leaf-stalk dilated above. Flower scape $\frac{1}{2}$ to $13 \mathrm{ft}$. high with about a dozen nodding white flowers. Style with a double curve; stamens leaning to one side. Common in woods. June-July.

3. P. chlorantha, Swartz. (Fig. 4, pl. 113.) Green-Flowered PyRolA. Leaves round or broadly oval, leathery, dull green, on leaf-stalks longer than the blades. Flowers greenish, nodding. Calyx segments short and obtuse. Leaves much smaller than those of No. 2 or No. 4. Woods. June-July.

4. P. elliptica, Nutt. (Fig. 2, pl. 113.) Pear-leaved Pyrola. ShrnLEAF. Leaf blades dark green, broadly oval, thin, not leathery, about $\frac{1}{2}$ as wide as long. Flower seape 5 to $10 \mathrm{in}$. high, with about a dozen nodding white flowers. Calyx lobe triangular, style with a double curve, stamens leaning to one side. Rich woods. June-Aug.

5. P. minor, L. (Fig. 7, pl. 113.) Smaller Prrola. Lesser WiNTERGREEN. Leaves rounded on leaf-stalks as long as the blades and dilated toward the blade. Flowers nodding, white; style straight and stamens not leaning to one side. On high hills and mountains, northern New England. June-Aug.

6. P. secunda, L. (Fig. 5, pl. 113.) One-sided Prrola. Leaves elliptic, thin, on leaf-stalks generally shorter than leaves. Flower scape 4 to $10 \mathrm{in.} \mathrm{high,} \mathrm{with} \mathrm{the} \mathrm{nodding} \mathrm{white} \mathrm{flowers} \mathrm{all} \mathrm{on} \mathrm{one} \mathrm{side} \mathrm{of} \mathrm{the}$ scape. Style straight, stamens not leaning to one side. Woods and thickets, common.

7. P. asarifolia, Michx. Liver-leaved Pyrola. Leaves round or kidney-shaped, the base heart-shaped, leathery, shorter than the leafstalk. Flowers nodding, purple with curved style and leaning stamens. Wet woods. Mass, northern New York and northward. June-July.

8. P. uliginosa, Torr. Bog Prrola. Resembles $P$. rotundifolia, but flowers are purple. A swamp plant, central New York, New England and northward. June.

2. MONESES, Salisb.

A low, smooth herb, with leaves at the base of the stem, which are nearly round with fine serrations at the borders. Stem leaning at base. From the cluster of leaves a flower stem arises bearing a solitary white 
nodding flower. Stamens 10 ; pistil straight, the stigma 5-lobed. Calyx lobes and petal lobes each 4 or 5 , generally 5 .

M. uniflora, (L.) A. Gray. (Fig. 3, pl. 113.) ONE-FLowered WiNTERGREEN. Stem with a few whorls of leaves at base. Flower stem 2 to 4 in. high. Flower about $\frac{1}{2}$ to $\frac{3}{4}$ in. broad, shallow cup-shaped. Woods, common. June-Aug.

\section{CHIMAPHILA, Pursh.}

Small herbs, with shining, thick leaves, which are coarsely toothed at borders, growing near the ground. Flower stem with a few flowers in a spreading umbel-like cluster. Calyx lobes and lobes of corolla each 5 . Stamens 10. Ovary 5-lobed.

1. C. umbellata, (L.) Nutt. (Fig. 6, pl. 113.) Prince's Pine. Leaves green, shining, long, broader toward apex, the apex blunt. Woods, common. June-Aug.

2. C. maculata, (L.) Pursh. (Fig. 8, pl. 113.) Spotted WinterGREEN. Leaves 2-colored, long and narrow, broader toward the base and tapering toward the apex. Woods, common. June-Aug.

\section{Family ili.-Monotropaceae. Indian Pipe Fanily}

Low herbs, without green foliage, growing mostly as parasites from the roots of trees in dark shady places. Leaves reduced to scale-like bracts. Flowers regular, white; stamens 6 to 12. Petals 3 to 6 ; calyx 3 to 6 parts. Ovary above the calyx and corolla, 4- to 6-lobed.

Corolla egg- or bell-shaped

Corolla of several parts.

Flowers solitary . . . . . . . . Monotropa

Flowers several . . . . . . . Hypopitys

\section{PTEROSPORA, Nutt.}

A redilish or purple leafless plant, woolly, ennsisting of a slender scape, from which hang rounded bells or globose fruit, arising from a rounded mass of roots. Calyx 5-parted; corolla with 5 lobes; stamens 10; capsule 5-lobed.

P. andromedea, Nutt. (Fig. 5, pl. 118.) Pine Drops. Scape 6 to 30 in. high, with from 12 to 50 or more nodding white llowers. In rich woods; rare. June-Aug.

\section{MONOTROPA, L.}

White, suceulent parasitic luerb, without leaves, but with white or yellowish bracts along the stem and with a solitary nodding flower which at length becomes more or less upright. Sepals 2 to 4 ; petals 5 or 6 ; stamens 10 to 12 . Ovary 5-celled.

M. unifora, J. (Fig. 4, pl. 118.) Innran PIPE. Seapes generally in clusters, 4 to $6 \mathrm{in}$. high, surmomnterl by the nodeling white bell-shaped flower about 1 in. long. In rich woods. June-Aug. 


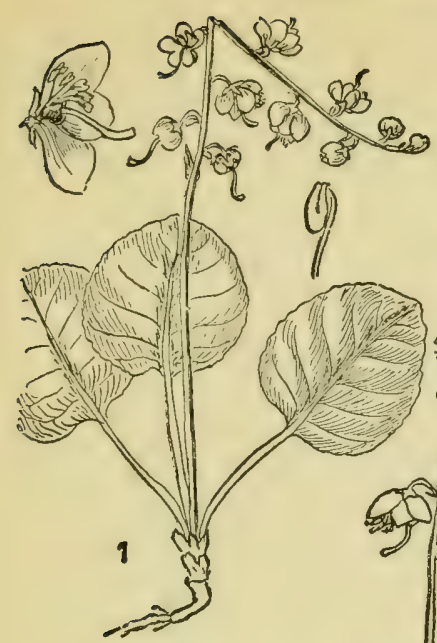

as
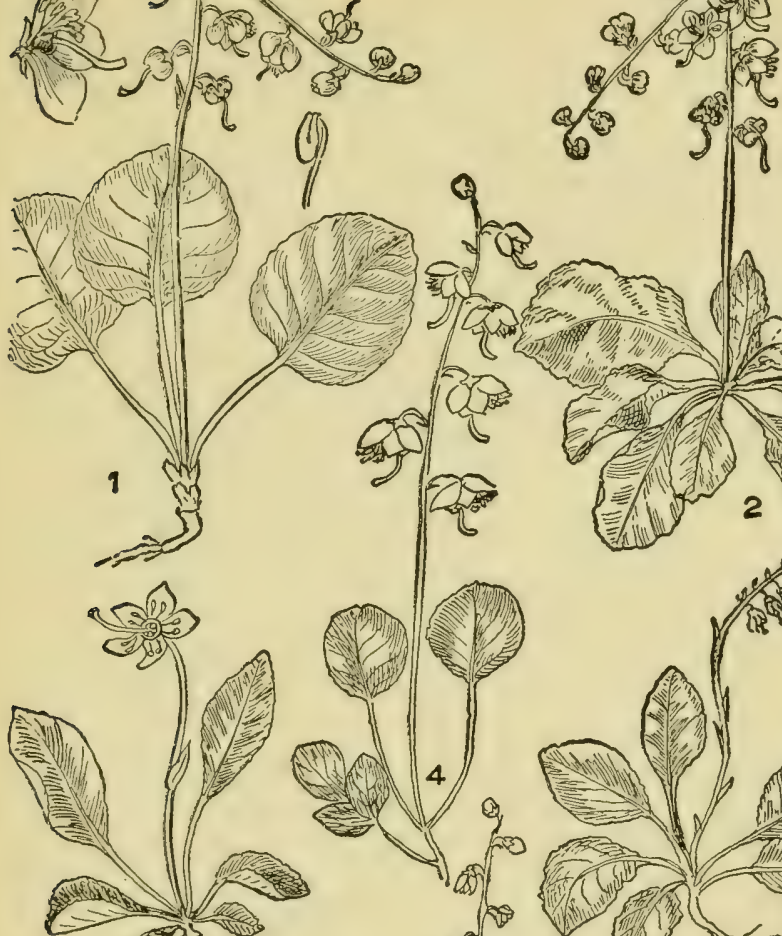

है? 100

a

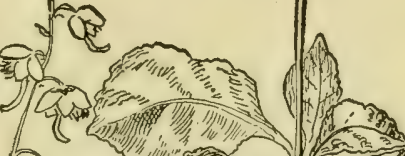

दिए

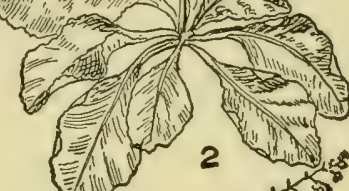

Fo

3

3 3

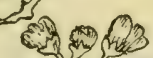

$\rightarrow$
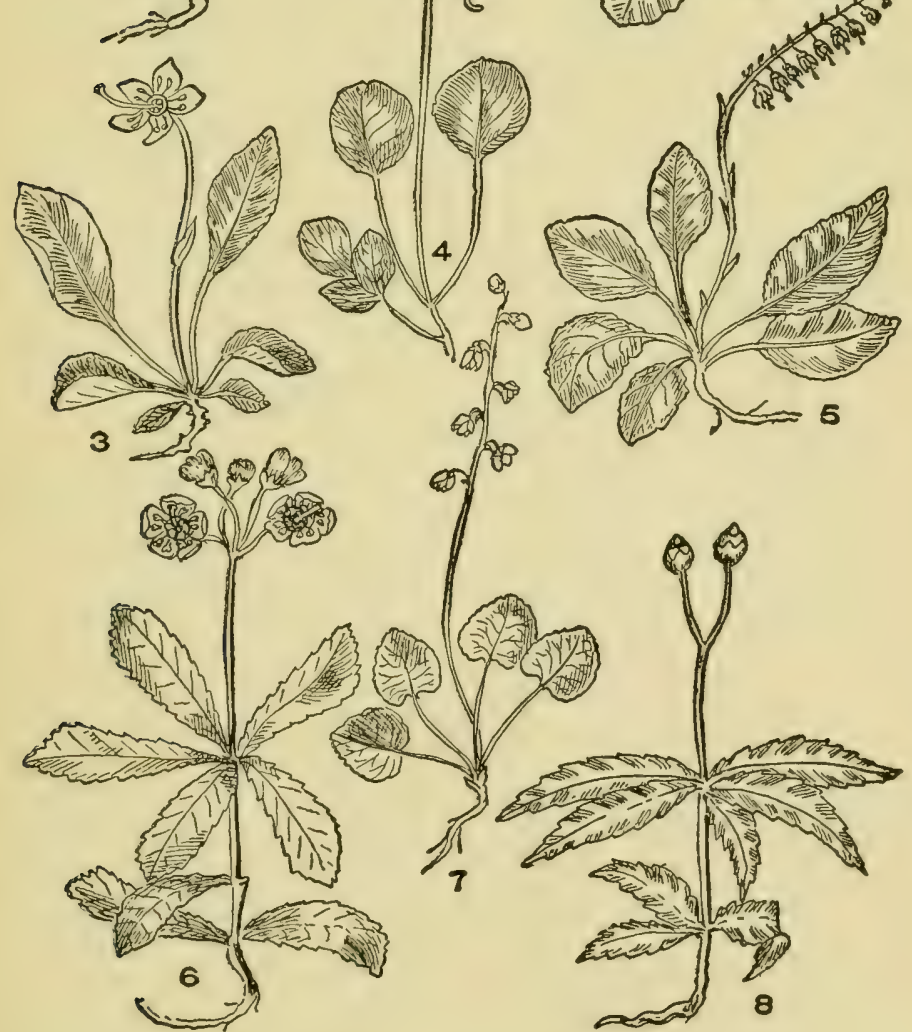

Plate 113

1. Pyrola rotundifolia. 2. P. elliptica. 3. Moneses uniflora. 4. Pyrola chlorantha. 5. P. secunda. 6. Chimaphila umbellata. 7. Pyrola minor. 8. Chimaphila maculata. 


\section{HYPOPITYS, Adams}

White, succulent, parasitic herb. Scape slender, with a number of flowers in a narrow eluster at summit. Lower flowers with 3 or 4 petals, terminal one with 5 ; stamens 8 to 10 ; eapsule 4 - to 5-celled. Root a mass of fibers.

H. americana, Small. (Fig. 3, pl. 118.) Prve SAP. (H. Iypopitys, Small,) Seapes 4 to $12 \mathrm{in.}$ ligh, elustered, more or less hairy. Flowers yellowisli-white. The lateral flowers have 8 stamens and 4 petals; the terminal one 10 stamens and 5 petals. Woods, throughout our area. June-Oct.

\section{Family IV.-ERICACEAE. The Heatil Family}

Mostly shrubs, rarely, in our region, small trees. Leaves often evergreen, not divided or lobed. Flowers regular or slightly irregular; commonly stamens twice as many as lobes of the corolla, free from the petals. Stamen summits (anthers) often sending out on each sile a projection or so-called "horn." Ovary 2- to 5-celled. Fruit a berry.

Low undershrubs mostly with the general aspect of herbs Corolla egg-formed.

Leaves oblong-linear.

Flowers erect

Chamaecistus

Flowers nodding.

Plant heath-like . . . . . . Phyllodoce

Plant moss-like . . . . . . . Cassiope

Leaves spatula-formed or pear-shaped.

Berry red . . . . . . . Arctostaphylos

Berry black . . . . . . . . Mairania

Leaves oval.

Fruit a red berry . . . . . . . . Gaultheria

Fruit a globose capsule . . . . . . Epigaea

Erect shrubs

Corolla of separate petals.

Leaves brown, woolly beneath . . . . . . Ledum

Leaves not woolly beneath . . . . . . . Dendrium

Corolla formed of united petals.

Corolla very irregular, 2-lipped . . . . . . Rhodora

Corolla slightly irregular.

Bell-shaped, stamens 10 . . . . Rhododendron

Funnel-form, stamens 5 . . . . . . Azalea 
Corolla regular.

Saucer-shaped, holding anthers in 10 sacs . . Kalmia Ovoid.

Leaves linear .

Leaves oblong.

Flowers in long, narrow, lateral clusters, not leafy .

Leucothöe

Flowers in lateral clusters attended by leafy bracts

Flowers in long, lateral, leafy clusters

- Pieris

C.. • • • • • • • Chamaedaphne Leaves minute, overlapping each other • Calluna Tree, 15 to $60 \mathrm{ft}$. high

Corolla ovoid .

0xydendron

I. LEDUM, L.

Our species a small evergreen shrub, with alternate leaves which are smooth and green above and brown-woolly beneath and are rolled at the borders. Flowers white, in broad umbel-like elusters. Calyx minute; corolla of 5 spreading petals; stamens generally 10 ; capsule globose.

L. groenlandicum, Oeder. (Fig. 6, pl. 114.) Labrador TeA. Shrub, $\frac{1}{2}$ to $2 \frac{1}{2} \mathrm{ft}$. high; the younger twigs downy. Leaves elliptic, green above and woolly beneath, borders recurved, to $1 \frac{1}{2}$ in. long. Flowers $\frac{1}{4}$ in. broad, about a dozen in a cluster. In bogs and swamps in our area and northward. May-July.

\section{DENDRIUM, Desvaux}

A very small shrub, with leathery evergreen alternate leaves and many small white flowers in terminal clusters. Calyx 5-parted; petals 5; stamens 10, longer than the petals. capsule egg-shaped.

D. buxifolium, Desvaux. (Fig. 9, pl. 117.) Sand Mrrtue. (Leiophyllum buxifolium, Pers.) Shrub, $\frac{1}{2}$ to $1 \frac{1}{2} \mathrm{ft}$. high. Leaves crowded along the stem, oval or oblong, obtuse at apex, shining above, black dotted beneath. Flowers several in broad terminal clusters. Dry sandy places, New Jersey and southward. April-June.

\section{CHAMAECistus, Oeder. (Loiseluria, Desv.)}

A small evergreen plant, with straggling branches, growing in tufts; leaves opposite, leathery, very narrowly elliptic or linear, the margins turned back. Flowers white, small, erect, a few in a terminal cluster. Calyx 5-parted, corolla 5-lobed; capsule egg-shaped, 2-celled.

C. procumbens, L. (Fig. 11, pl. 117.) Alpine Azalia. Found on summits of White Mowntains. July-Aug.

4. PHYLLODOCE, Salisb.

Low, heath-like shrubly plant, with evergreen leaves crowled about 
the stems, which are more or less reclining. Leaves linear with blunt points. Flowers rather large on long slender pedicels. Calyx 5-parted, corolla ergo-shaped with 5 low teeth at the spreading border. Stamens 10 ; ovary 5-celled.

P. coerulea, (L.) Babington. (Fig. 5, pl. 117.) Mountain Heatir. A minute shrub, 4 to $6 \mathrm{in}$. high, on summits of White Mountains. JulyAug.

\section{CASSIOPE, D. Don.}

A minute shrub, with a mossy aspect; evergreen; leaves small, overlapping, stem an inch to $3 \mathrm{in}$. high, terminated by a bell-shaped white or pinkish-white nodding flower. Calyx and corolla 4 - or 5-lobed. Stamens 8 to 10 ; capsule globe-formed, 4 - or 5 -celled.

C. hypnoides, (L.) D. Don. Moss Plant. Cassiope. Found on the summits of the higher Adirondack Mountains and of the White Mountains. ("I have never seen it on the Adirondacks and do not think it is there now, though it was on Mt. Marey many years ago.-C. $\mathbf{H}$. РECK.")

\section{ARCTOSTAPHYLOS, Adams}

Low trailing shrubly plant, with alternate, thick leathery leaves, evergreen. Flowers white or pink, small, in terminal clusters. Calyx 5-parted; corolla egg-shaped; stamens 10 , rarely less. Fruit a red berry.

A. Uva-Ursi, Spreng. (Fig. 6, pl. 117.) Uva-Ursi. Red Bearberry. Trailing and much branched, stems 6 to 24 in. long. Leaves spatulaformed. Found mostly on cold hills or on mountains, our area and northward and westward.

\section{MAIRANIA, Necker.}

Low, trailing shrub, with deciduous leaves and white egg-shaped flowers in scattered or terminal clusters Calyx 4- to 5-parted. Fruit a black berry.

M. alpina, Desvaux. Alpine BlAckberri: (Arctostaphylos alpina, Spreng.) Leaves pear-shaped, notched at margins; flowers mostly in terminal clusters. Found on summits of White Mountains.

\section{GAULTHERIA, L.}

Our species a small plant with alternate, evergreen, shining leaves, with a few flowers at the leaf axils. These are urn-shaped, white or pink. Calyx 5-parted; stamens 10. Fruit an-aromatic red berry.

G. procumbens, I. (Fig. 1, pl. 115.) Wintrimefen. CheckerBErry. Stem 2 to 6 in. high. Leaves clustered toward the ends of branches. Found extensively in woods, especially those in which evergreen trees prevail.

\section{EPIGAEA, L.}

Plant trailing, flat upon the ground; stems woody. Leaves alternate, evergreen, broad, nearly orbicular, hairy leneath, smooth but rusty colored above. Flowers in a terminal cluster, salver-form. Stamens 10; capsule 5-celled.

E. repens, T. (Fig. 8, pl. 115.) Traning Anbutus. Marfower. Stems hairy, 10 to 15 in. long, trailing flat upon the ground; leaves alternate, 1 to 3 in. long, more or less heart-shaped at base and blunt at 

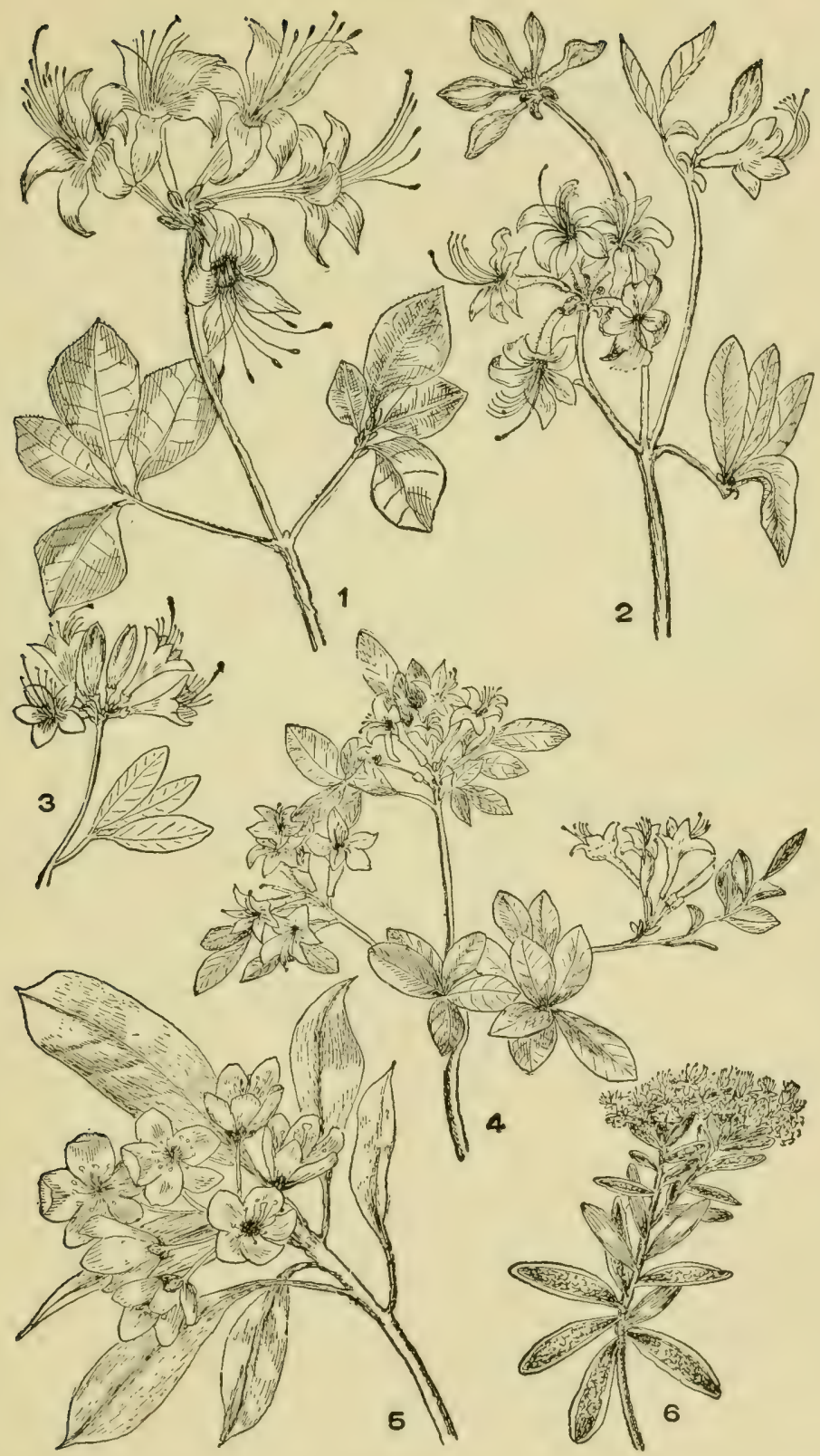

Plate 114

1. Azalea canescens. 2. A. nudiflora. 3. A. Iutea. 4. A. viscosa. 5. Rhododendron maximum. 6. Ledum groenlandicum. 
apex. Tube of the corolla hairy within; flowers with a delicate spicy fragrance. It is one of the earliest plants to bloom in the spring, its charming white blooms often in close proximity to a belated snow drift. March to May.

\section{Io. RHODORA, L.}

A small branching shrub, with alternate leaves (deciduous) and pur. ple flowers which grow in a terminal umbel-like eluster. The corolla is deeply divided into two parts, the upper part or lip composed of 2 , mostly 3 parts, the lower of two Iong narrow segments. Calyx small. Stamens 10. Capsule 5-celled.

R. canadensis, L. (Fig. 8, pl. 117.) RHodora. (Rhododendron canadensis, BSP.) A handsome shrub, 2 to $3 \mathrm{ft}$. high, with terminal elusters of large flowers. Leaves appearing with or later than the flowers, oblong, downy beneath. Bogs and wet hillsides. May.

\section{RHODODENDRON, L.}

Shrubs, with evergreen leaves and large white, pink, or purple flowers. Corolla bell-shaped with rather short tube and rounded spreading lobes, nearly equal. Calyx small, 5-parted; capsule woody, with 5 to 20 cells and numerous seeds.

1. R. lapponicum, (L.) Wahlenberg. (Fig. 7, pl. 117.) LAPLAND Rose Bay. A dwarf shrub, with elliptic leaves and purple flowers in a spreading terminal cluster. The leaves clustered toward the summit of the stems, $\frac{1}{2}$ to $\frac{3}{4} \mathrm{in.}$ long, nearly half as broad, with brownish seales above and below. Flowers purple 3 in. broad. Summits of the higher Adirondacks and White Mountains.

2. R. maximum, L. (Fig. 5, pl. 114.) American Rose Bar. A splendid shrub or small tree, growing in wet places, with evergreen leaves which are from 4 to $7 \mathrm{in}$. long and from 1 to $3 \mathrm{in}$. wide. Shining above and dark green below. Stems crooked and branching, growing in clusters. Flowers in large clusters, white or rose-colored, each $1 \frac{1}{2}$ to $2 \mathrm{in.}$ long and an inch broad at moutli; the lobes rounded and indented. Before the blooms are expanded the cluster is enveloped in a covering of broad sticky bracts, an inch or more in length. It is found in a few localities in New England, but is more abundant in the middle States. In low grounds and along borders of streams. Blooms latter part of June or in July.

\section{AZALEA, L. (Rhododendron, L.)}

Frect shrubs, with conspicuous flowers, mostly in terminal clusters. Leaves deciduous. Cialyx 5-parted; corolla funnel-formed, the lobes spreading, the tube long and viscid. Stamens 5, exserted from the mouth of the flower. Capsule oblong, 5-celled.

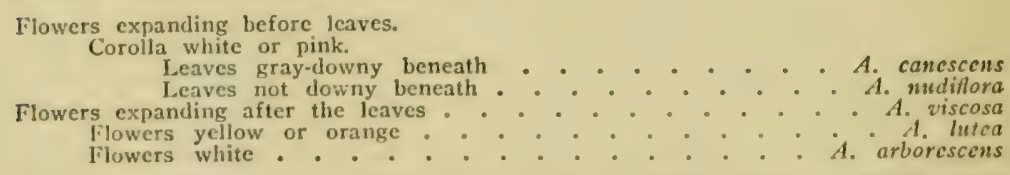

1. A. nudiflora, L. (Fig. 2, pl. 114.) Pink Azatea. P'inkster. IBranching shrub, 2 to $6 \mathrm{ft}$. high. Leaves, alternate, narrowly oblong or 


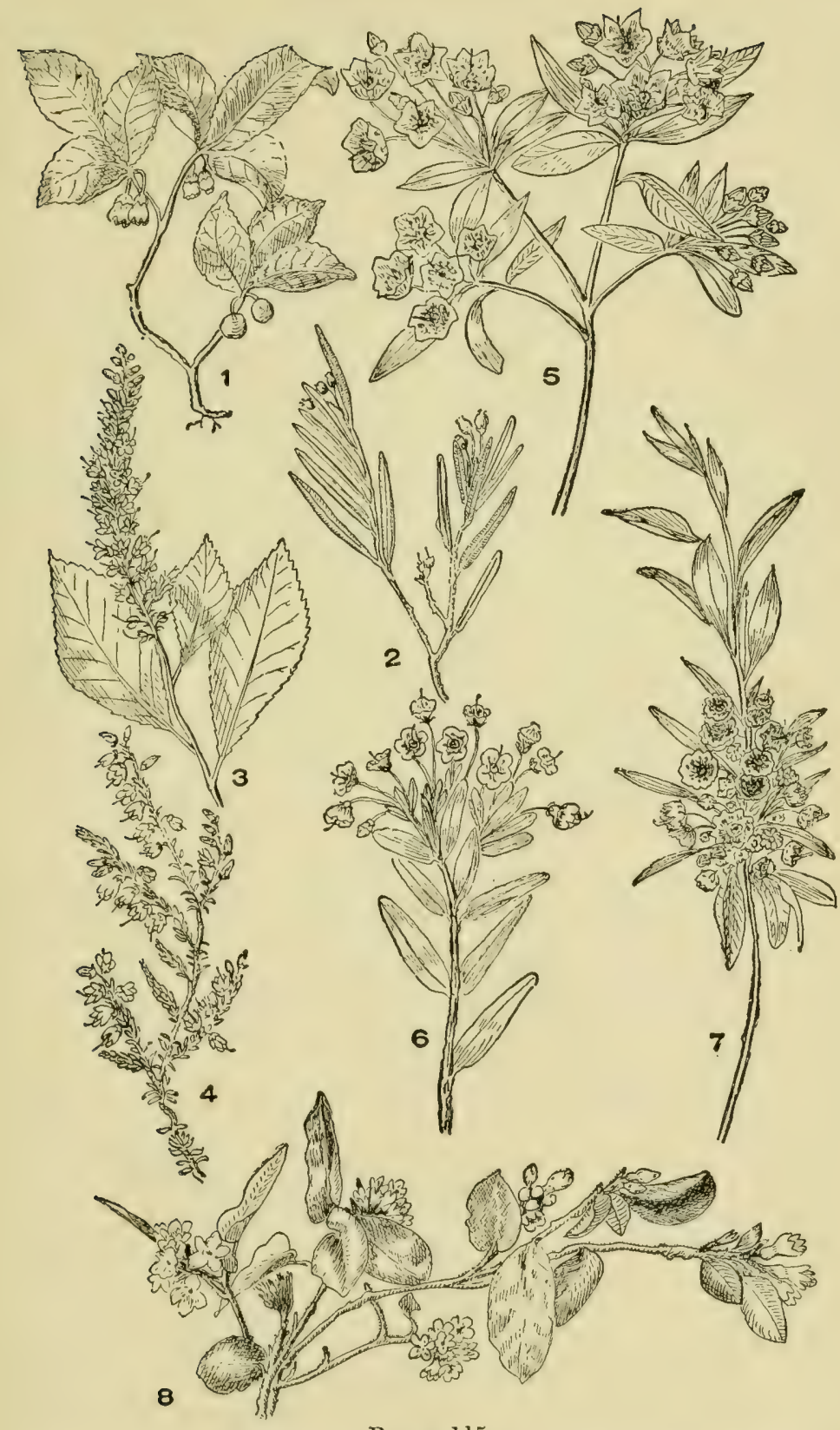

Plate 115

1. Ganltheria procumbens. 2. Andromeda polifolia. 3. Clethra alnifolia. 4. Calluna vulgaris. 5. Kalmia latifolia. 6. K. glauca. 7. K. angustifolia. 8. Epigaea repens. 
oval, tapering at each end, margins with stiff hairs. Flowers large, consisting of a long slender tube which is covered by soft down, and of 5 broad and spreading lobes which are, each, rather shorter than the tube and which are somewhat unequal. Both stamens and pistil are much exserted beyond the tube. Color pink to nearly white. Rocky woods and thichets. April-May.

2. A. canescens, Michx. (Fig. 1, pl. 114.) Mountain Azalea. In general a taller shrub than No. 1; 4 to $15 \mathrm{ft}$. high. Leaves wider and shorter than those of No. 1 and covered beneath by a soft gray down, while along the principal veins grow stiff hairs. Leaves margined with stiff hairs. Flowers rose color to white, very fragrant. Stamens less exserted than in No. 1. Flower at lobes 2 in. broad. Woods; Catskill Mountains; Mass., and southward. April-May.

3. A. viscosa, L. (Fig. 4, pl. 114.) Swamp Pink. White Azalea. Branching shrub, 4 to $8 \mathrm{ft}$. high, the whole plant sticky. Leaves alternate, pear-shaped, 2 to $4 \mathrm{in}$. long, with bristly hairs on the veins beneath. Flovers expanding after the leaves, white or tinged with pink, less broad than No. 1 or No. 2. Stamens exserted. The whole flower viscid. In swamps and at borders of ponds, general in our area. June-July.

4. A. lutea, L. (Fig. 3, pl. 114.) Flame Azalea. (A. calendulacea, Torr.) Shrub, 4 to $15 \mathrm{ft}$. high, with terminal umbellate clusters of yellow or orange flowers. Leaves pear-shaped, with finely toothed margins. Flowers appearing with the leaves, yellow or orange, very showy. Dry woods, southern part of our area. May-June.

5. A. arborescens, Pursh. Tree Azalea. A shrub, 8 to $20 \mathrm{ft}$. high, without hairs on stems or leaves. Leaves oval pear-shaped or inversely lance-shaped. Flowers white or tinged with pink, very fragrant. Woods; southern Penna., and southward. June-July.

\section{I3. KALMIA, L.}

Evergreen shrubs, with flowers in terminal or lateral clusters and with shining leaves; calyx 5-parted; corolla whed-shaped, cupped, with 10 small sacs or depressions for the lodgment of the anthers. Capsule globose, 5-celled. Stamens 10, extending only to the pits in the corolla. In our species the showy flowers are in an unbel-like terminal cluster, or a dense whorl a little below the terminal portion of the branch.

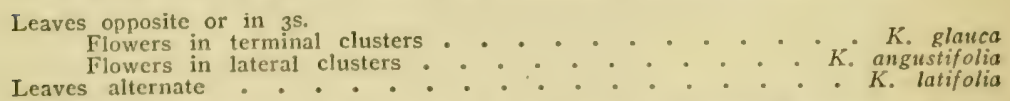

1. K. angustifolia, I. (Fig. 7, pl. 115.) SHeep I Aurf. Shrub, erect, branching, $\frac{1}{2}$ to $3 \mathrm{ft}$. high. Leaves usually opposite, but often in whorls of 3 , whitish beneath, oblong or lanes-shaped, tapering at each (ndl. Flowers numerous in collar-like clusters which enrich the stem beJow the termination of the branch. Found in moist places, cold hillsides and often at borders of bogs. May-June.

2. K. latifolia, T. (Fig. 5, pl. 115.) Mountain Taurel. Shrub, 2 to $15 \mathrm{ft}$. high, with commonly altrornate leaves and with terminal flower rlusters. Jeaves oval or elliptic, tapering at eitch end, bright green on both sides. Flowers numerous in very showy chustrs, rose-color to white. 
This shrub often forms dense thickets and when growing in woods often attains the height of $20 \mathrm{ft}$. or more. May-June.

3. K. glauca, Ait. (Fig. 6, pl. 115.) Pale or Swamp Laurez. ( $K$. polifolia, Wang.) A smooth shrub, $1 \frac{1}{2}$ to $2 \mathrm{ft}$. high, with leaves opposite or in 3s. Leaves long, narrow, tapering at each end, bright green above, whitish beneath, the borders rolled backward. Flowers in loose terminal clusters, purple. In bogs. May-Aug.

\section{I4. LEUCOTHOE, D. Don.}

Shrubs, with alternate leaves and many egg- or eylindric-shaped small flowers in lengthened slender clusters, axillary or terminal. Calyx of 5 sepals; corolla cylindric or egg-shaped; stamens 10; capsule 5-lobed, 5 -celled.

L. racemosa, (L.) A. Gray. (Fig. 2, pl. 118.) Swamp Leucotröe. Shrub, 3 to $10 \mathrm{ft}$. high. Leaves oblong to egg-shaped, tapering at each end, 1 to 3 in. long, $\frac{1}{2}$ as wide. Flowers in long spike-like clusters, each flower with a bract at the flower pedicel, the clusters more or less ascending. Swamps and thickets. April-June.

\section{ANDROMEDA, L.}

A shrub, with globose or egg-shaped white flowers, in a terminal cluster. Leaves evergreen, linear or narrowly oblong, the margins rolled backward, whitish beneath. Calyx 5-parted; corolla globose or eggshaped; stamens 10; capsule nearly globose, 5-celled.

A. polifolia, L. (Fig. 2, pl. 115.) Wild Rosemary. A shrub, 1 to $3 \mathrm{ft}$. high. Leaves narrow with margins rolled back, dark green above, whitish beneath. Umbels of flowers terminal, few-flowered. Bogs, northern New Jersey, Penna., and northward. May-June.

\section{I6. PIERIS, D. Don.}

Our species a shrub, with alternate leaves and cylindric or egg-shaped white or pinkish flowers in lateral clusters, the flower pedicels attended by sharply tapering bracts. Stamens 10; capsule 5-celled.

P. mariana, (L.) Benth. and Hook. (Fig. 1, pl. 118.) STAGger Busf. (Lyonia mariana, D. Don.) Shrub, 2 to $4 \mathrm{ft}$. high; leaves oblong or oval, 1 to $3 \mathrm{in}$. long, $\frac{1}{2}$ as wide. Flowers nodding in lateral clusters, appearing on the nearly leafless stems of the preceling season. Corolla about $\frac{1}{2}$ in. long, pink or pinkish-white. Low wet grounds, southeastern New York and along the eastern coast from Rhode Island southward. May-July.

\section{I7. CHAMAEDAPHNE, Moench. (Cassandra, D. Don.)}

Low, much branched, erect shrub, with alternate, leathery, nearly evergreen leaves and with many white ovoid flowers in one-sided leafy clusters. Calyx of 5 rigid sepals bracted at the base. Corolla 5-toothed, narrowed at the throat. Stamens 10. Capsule globose, depressed, splitting when ripe, into an inner and an outer layer, the immer dividing into 10 , the outer into 5 valves.

C. calyculata, (L.) Moench. (Fig. 7, pl. 118.) Leatmer Leaf. Dwarf CASSANDRa, Shrub, 2 to $4 \mathrm{ft}$. high, branching; Leaves oblong, 
obtuse, $\frac{1}{2}$ to $1 \frac{1}{2} \mathrm{in}$. long, densely covered with scurfy scales, at least when young. Upper leaves redueed to floral bracts. Bogs and swamps through. out most of our area. Also on high mountains. April-June.

\section{XOLISMA, Raf.}

A bushy tree, found in low grounds, with alternate leaves and terminal clusters of small globe-formed flowers. Calyx 4- or 5-parted; stamens 8 to 10 ; capsule 4 - or 5 -celled, globose.

X. ligustrina, (L.) Britton. (Fig. 6, pl. 118.) Privet Andromeda. (Andromeda ligustrina, Muhl.) Shrub, 3 to $15 \mathrm{ft}$. high. Leaves oblong, oval or pear-shaped, with fine serrations at margins, tapering at each end. Corolla globular or nearly so. Swamps and wet soil, New England, New York and southward. May-July.

\section{I9. CALLUNA, Salisb.}

A low shrub, naturalized from Europe. Evergreen, branching; our species with minute overlapping leaves and with long slender clusters of bell-shaped flowers. Calyx of 4 sepals; corolla with 4 lobes; stamens 8; capsule 8-angled, 4-celled.

C. vulgaris, (L.) Hull. (Fig. 4 pl. 115.) Heatirer. Found occasionally in sandy or rocky soil. Flowers pink. July-Sept.

\section{OXYDENDRON, DC.}

Tree, 15 to $60 \mathrm{ft}$. high, with alternate, deciduous leaves which are oblong or broad lance-shaped, sharp pointed at apex and tapering at base, sour to the taste. Flowers numerous, ovoid, white, in long one-sided slender clusters. Stamens 10. Calyx of 5 nearly distinct sepals; corolla 5-toothed; capsule pyramidal, 5-celled, 5-valved.

O. arboreum, (L.) DC. Sour Woov. A tree found in rich woods of Penna., and further south. June-July.

\section{Family V.-VACCINIACEAE. HuCkleberry Family}

Shrubs, with alternate, undivided leaves and small bell- urn- or egg-shaped flowers. 'The calyx is adherent to the ovary through the whole extent of the latter, the 5 (rarely 4 ) sepals expanding above the ovary. The petals are united to form an undivided corolla though in exceptional cases the lobes are somewhat deeply clelt, as in the oxycoceus (cranberry). Stamens twice as many as the petals, arising from the base of the pistil or from the corolla. Fruit a berry.

Corolla bell-cylindric or egg-shaped.

Berries not white.

$$
\begin{aligned}
& \text { Seeds 10 . . . . . . . . . . Gaylussacia } \\
& \text { Seeds small, numerous . . . . . Vaccinium }
\end{aligned}
$$

Berries white . . . . . . . . Chiogenes

Corolla decply clelt, with recurved lobes. . . 0xycoccus 


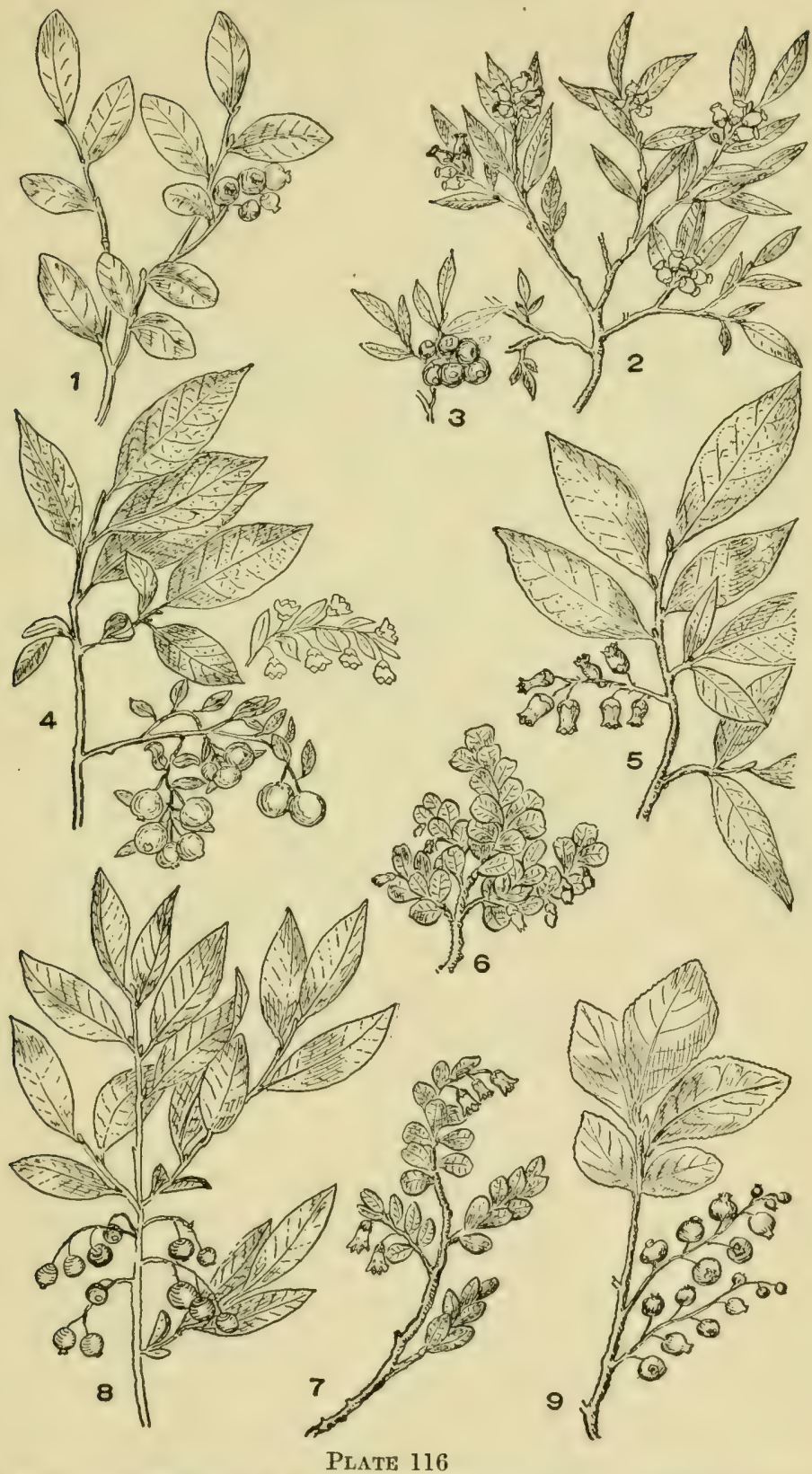

1. Vaccinium vacillans. 2. V. pennsylvanicum. 3. V. pennsylvanıcum, fruit. 4. V. stamineum. 5. V. corymbosum. 6. V. caespitosum. 7. V. VitisIdaea. 8. Gaylussacia resinosa. 9. G. dumosa. 


\section{GAYLUSSACIA, HBK.}

Shrubs, with alternate, undivided leaves and with small white or reddish flowers in lateral clusters. Flower pedicels usually with 2 small bracts. Calyx 5-lobed. Corolla tubular. Fruit a dark blue or black berry with 10 hard seed-nutlets.

Fruit blue, leaves with a whitish bloom beneath . . . . . . . G. frondosa Leaves leathery, without whitish bloom . . . . G. brachycera Fruit black, both sides of leaves green.

Bracts at the flower pedicels leaf-like, oval, persistent . . . G. dumosa Bracts of the pedicels small and falling early . . : G. resinosa

1. G. frondosa, (L.) Torr. and Gray. Dangleberry. Shrub, 3 to $6 \mathrm{ft}$. high, smooth, young shoots green or yellowish; leaves oblong or pearshaped, $1 \frac{1}{2}$ to 2 in. long, blunt at apex tapering at base, pale whitish beneath. Flowers in slender loose lateral clusters; corolla small, bellshaped. Flower pedicel with a small bract at base. Fruit dark blue with a whitish bloom, sweet. Moist woods, New York. New Hampshire and southward. May-June.

2. G. resinosa, (Ait.). Torr, and Gray. (Fig. 8, pl, 116.) BLACK Huckleberry. Higir-busi Huckleberry. (G. baccata, C. Koch.) Shrub, 1 to $3 \mathrm{ft}$. high, branching, the young stems often deep red, leaves oval or oblong, pointed or rather blunt at apex, tapering at base, with a resinous covering when young, studded with resinous dots. Clusters of flowers one-sided, with few reddish-yellow flowers. Bracts at the base of the flower pedicel small and falling early. Fruit black with a bloom. Woods and thickets, extent of our area. May-June.

3. G. dumosa, (Andr.) Torr. and Gray. (Fig. 9, pl. 116.) Busi Huckleberry. Shrub, 1 to $3 \mathrm{ft}$. high, young branches somewhat downy. Leaves pear-shaped or oblong, green on both sides, thick and shining when old. Bracts at the base of flower pedicels large, leaf-like, oval, persistent. Flowers in loose, slender clusters, corolla bell-shaped. Fruit black without a bloom, insipid. The whole plant more or less sprinkled with resinous dots. Sandy swamps, from north to south in our area. May-June.

4. G. brachycera, (Michx.) A. Gray. Box IUckLenerex. Branching shrub, about $1 \mathrm{ft}$. high, with oval, finely toothed leaves, which are thick and leathery and without leaf-stalks or with very short ones. Corolla eylindrie-bell-shaped, white or pink in short close clusters. Wooded hills, Penna., southward. May.

\section{VACCINIUM, L.}

Shrubs, branching, mostly guite low, with scattered leaves and small flowers solitary or in currant-like clusters. Corolla monopetalous with 4 or 5 teeth at free margin or 4 - or 5 -lobed. Stamens twice as many as lobes of corolla and included within it. Fruit a berry with numerous small seeds; smaller and less observable than those of Gatylusacia.

Corolla rather deeply cleft, lobes expanding.

Lobes 4 . . . . . . . . . . . . V Vitis-Idaen

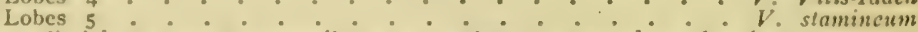

Corolla cylindric or ovate, generally more or less contracted at the throat.

filowers solitary or only a to 4 together; alpine dwarf species.

Corolla mostly 4 -toothed. . . . . . . . V. uliginosum Corolla 5 tuothed . . . . . . . . V. caespitosum 
Flowers in slender currant-like clusters.

Flower 2 or 3 times as long as broad. Leaves not usually toothed.

Leaves smooth or only slightly downy . - . $V$. corymbosum Leaves, under surface, densely downy, especially on veins

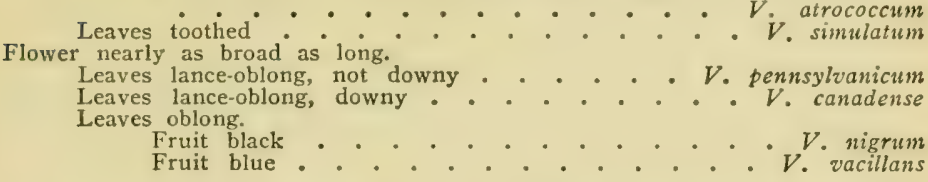

1. V. Vitis-Idaea, L. (Fig. $7, \mathrm{pl}$. 116.) Mountain Cranberry. A little evergreen shrub, found where cold winds sweep the northern consts of our region and on the summits of the White Mountains. Its stems are creeping with erect branches rising from 3 to 8 in. in height. Its broadly oval or pear-shaped leaves, leathery, green and shining above and black dotted beneath, curve backward at their margins and are crowded near the summit of the slender stems. Flowers in a small cluster at the extremity of the stem, the corolla bell-shaped, rather thickly cleft into 4 lobes which expand from the throat. They are white or pinkish and nodding. Fruit a globular dark red berry about $1 / 3$ in. in diameter. August-Sept.

2. V. stamineum, L. (Fig. 4, pl. 116.) DeErberry. A branching shrub, with deciduous leaves and large numbers of bell-shaped flowers dangling in leafy bracted lengthened clusters. Stems 2 to $5 \mathrm{ft}$. high. Leaves oval, oblong or rarely broader toward base than at center, 1 to 4 in. long, on rather short leaf-stems, light green above, paler beneath. Corolla rather deeply eleft into 5 lobes, which expand into a bell-shaped flower of purplish tinge. The stamens project somewhat beyond the bell of the corolla. Berry greenish-white, yellowish or dull red. Woods and thickets, frequent, especially in the southern half of our area. AprilJune.

3. V. uliginosum, L. BoG Wortleberry. A dwarf shrub, found on the summits of the Adirondack and White Mountains. Stems $\frac{1}{2}$ to $2 \mathrm{ft}$. high, much branched. Leaves pear-shaped, or oblong, $\frac{1}{2}$ to 1 in. long, thick, dark green above, lighter beneath. Flowers solitary or in elusters of 3 or 4 , about $\frac{1}{2}$ as long as the leaves. Fruit a large blue berry. JuneJuly.

4. V. caespitosum, Michx. (Fig. 6, pl. 116.) Dwarf Billberry. Dwarf, much branching shrub, growing in dense tufts, stems 3 to 6 in. high, found on summits of White Mountains and Adirondacks. Leaves broad at apex, narrow at base, $\frac{x}{2}$ to 1 in. long, with blunt teeth at margins. Calyx 5-toothed; corolla egg-shaped, 5-toothed, contracted at throat. Stamens 10. Berry blue, with a bloom. June-July.

5. V. corymbosum, Michx. (Fig. 5, pl. 116.) High-Busir BlueBERrY. A tall shrub ( 6 to $10 \mathrm{ft}$. high), with oval or oblong leaves and clusters of white flowers and sweet blue berries with a bloom. Leaves on short leaf-stems, 1 to $3 \mathrm{in}$. long, smooth above, very slightly downy, if at all, beneath. Corolla $\frac{x}{4}$ to $\frac{1}{2}$ in. long, cylindric or constricted at throat, white or pink. Fruit a blue berry with a bloom. Swamps and moist woods. May-June. 
6. V. atrococcum, (A. Gray) Heller. Black BluenerRy, Differs from $Y$. corymbosum in the absence of bloom on the berry, in the down on the under side of the leaf, which is dense, and in the form of the flower, which is smaller and more round. Leaf borders entire. Swamps and wet woods, throughout our area. May-June.

7. V. simulatum, Small. Serrulate-leaved Blueberry. Shrub, resembling the last two. Leaves elliptic to oblong-lance-shaped, acute at apex and usually at base, smooth, bright green above, somewhat downy beneath at least on the veins; margins notched with fine tecth. Berry with a bloom. New York and southward.

8. V. pennsylvanicum, Lam. (Figs. 2 and 3, pl. 116.) Jow-rusy. BLteberry. A nearly prostrate shrub, with stems $\frac{1}{2}$ to $2 \mathrm{ft}$. long, found in dry rocky soil, mostly on high hills. Stem branching, the newer shoots light green, warty, the older stems reddish. Leaves elliptic-lanceshaped, green and smooth on both sides, the apex tapering to a hard tip. Flower bell-shaped, white, in few flowered, short clusters. Calyx 5-toothed. Fruit a round berry $3 / 8$ in. in diameter, blue with a thick white bloom. The sweetest and earliest of the blueberries. May-June. Fruit ripe June-July.

9. V. canadense, Richards. Canadian Blueberry. Similar to last, but leaves somewhat broader and somewhat downy. The fruit ripens later and is the latest of the blueberries to appear in market. May-June. Fruit ripe July-Sept.

10. V. nigrum, Britton. Low Black Bluenerry. Similar to No. 8 , often growing with it, but has a broader leaf, which is commonly more rounded at base, and rounder bell than the latter and the black berry has no bloom on its surface.

11. V. vacillans, Kalm. (Fig. 1, pl. 116.) BLUE HuckLeberry. A branching shrub, $\frac{1}{2}$ to $4 \mathrm{ft}$. high, with oval leaves or with leaves sometimes broadest toward apex, 1 to $2 \frac{1}{2} \mathrm{in}$. long. Margins entire or finely serrated, sharp points at apex, terminated by a sharp bristle. Flowers pink or greenish-white, bells $\frac{1}{4} \mathrm{in.}$ long, eylindric, constricted at throat. Fruit a round blue berry with a bloom. A fine fruit. Dry, sandy soil. May-June. Fruit ripe July to Sept.

\section{CHIOGENES, Salisb.}

Our species a trailing evergreen, with delicate stem, scarcely woody, with small roundish oval, alternate leaves. Calyx adherent to the ovary except at the summit, 4-lobed; corolla bell-shiaped rather broad at the throat. Fruit a white berry with many seeds.

C. hispidula, L. (Fig. 4, pl. 117.) Creeping Snowberry. Leaves $1 / 4$ to $1 / 3$ in. long; flowers small, at the leaf-axils. Found in shady woods and on mountains, throughout our area. May-June.

\section{OXYCOCCUS, Hill}

Our species delinate crerpers found in hogs. Stem extremely slender; leaves small, alternate, oval or ovite, with margins rolled lack. Calyx adherent to the ovary to its summit, its border 4- or 5-cleft. Corolla deeply cleft, nearly divided into 1 petals, these turning outward and 

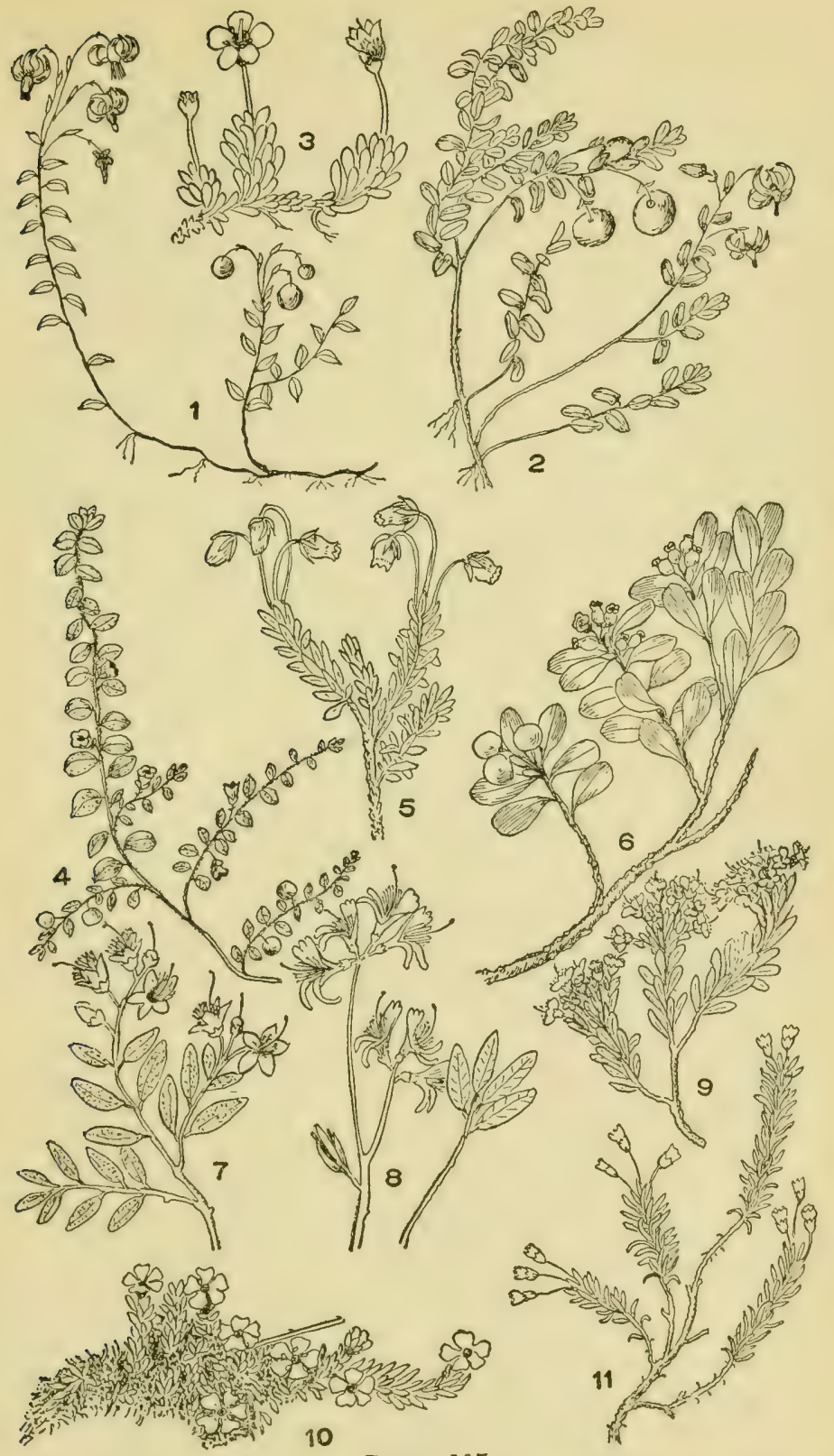

Plate 117

1. Oxycoccus palustris. 2. O. macrocarpus. 3. Diapensia lapponica. 4. Chiogenes inispidula. 5. Phyllodoce coerulea. 6. Arctostaphylos Uva-Ursi. 7. Rhododendron lapponicum. 8. Rhodora canadensis. 9. Dendrium buxifolium. 10. Pyxidanthera barbulata. 11. Chamaceistus procumbens. 
backward. Stamens 10 , the anthers in contact forming a cone about the pistil. Fruit a red acid berry.

1. O. palustris, Pers. (Fig. 1, pl, 117.) SMall Cranberry. $(O$. Oxycoccus, (L.) Mc. M.) Stem 6 to 18 in. long. Leaves egg-shaped, 1/6 to $1 / 3 \mathrm{in.}$ long, acute at apex, margins strongly rolled back. Floucrs all terminal. Berries red, $1 / 3$ in. in diameter. May-July.

2. O. macrocarpus, (Ait.) Pers. (Fig. 2, pl. 117.) Large AmeriCan Cranberiy. Leaves oval, $1 / 4$ to $2 / 3 \mathrm{in.}$ long, margins slightly rolled back, points blunt. Flowers not generally terminal. Berries red $1 / 3 \mathrm{in}$. in diameter. June-Aug.

\section{Fhally TI.-DIAPENSIACEAE. Diapexsia Family}

In our region only two species which are very small, moss-like, tufted, evergreen plants of herbaccous appearance but with woody stems, small crowiled leares without stipules and with perfect bellformed or whecl-shaped flowers. Calyx deeply 5-parted; corolla 5 -loleed; stamens, 5 pollen bearers and 5 rudimentary. Ovary free from the calyx and superior to it; capsule 3-celled, many seeded.

\section{DIAPENSIA, L.}

Calyx partly invested by 2 to 4 bracts below its base; corolla bellshaped. Small Alpine mossy plant growing in dense tufts. Leaves opposite, overlapping, small, spatula-shaped. Stem 1 to $3 \mathrm{in.} \mathrm{high,} \mathrm{termi-}$ nated by a single white bell-shaped flower.

D. lapponica, L. (Fig. 3, pl. 117.) Drapensia. Found on summits of the Adirondack and White Mountains. June-July.

\section{PYXIDANTHERA, Michx.}

Mnss-like plant, resembling Diapensin, the stems longer, prostrate, creping, corolla wheel-shaped. Flowers solitary, white or rose-color, numerous.

P. barbulata, Michx. (Fig. 10, pl. 117.) Prxie. This little plant blooms early in April or even in March and is welcomed as the first flower of Spring. Cirows in rounded tufts, in the pine barrens of New Jersey and farther south.

\section{Order II.-PRIMULALES. Order of the Primroses}

Flower's regular; corolla of united petals. Stamens borne on the corollat, as many as the lobes of the corolla and opposite to them or twire at many or more. Ovary superior to the calyx and corolla or in cxerptional instances these are more or less aftached to it. Orules arising from a central placatat. Slyle single; fruit a capsule. 


\section{Fanilly I.-PRIMiUlaceaE. Primrose Fammy}

Herbs, with mostly undivided leaves and regular flowers, with both stamens and pistils. Corolla of united petals (absent in Glaux) ; stamens as many as the lobes of the corolla and inserted opposite them. Orary of 1 cell with a free column in the interior supporting the ovules.

Leaves all at the base of the stem.

Aquatic, leaves feather-formed . . . . Hottonia

Terrestrial . . . . . . . . . . . Primula Leaves alternate . . . . . . . . Samolus Leaves in whorls of more than 4 . . . . . Trientalis Leaves opposite or in whorls of not more than 4 .

Flowers white . . . . . . . . Glaux

Flowers red . . . . . . . . . Anagallis

Flowers yèllow.

In axillary dense clusters . . . . . Naumburgia Solitary in the axils or in loose axillary clusters.

Stamens 5 and rudiments 5 . . . Steironema

Stamens 5 to $\%$, no rudiments . . Lysimachia

\section{HOTTONIA, L.}

Aquatic plant, with feather-formed, composite leaves and hollow flower stems fringed with hands of whitish llowers. Calyx 5-parted, its divisions linear and longer than the corolla which is tubular with 5 lobes. Stamens 5; capsule 5-valved, many seeded.

H. inflata, Ell. Americax Featuenfoll. In stagnant pools and ditches, Mass., central New York and south. June-Aug.

\section{PRIMULA, L.}

Herb, with a radicle rosette of leaves at the base and a spike surmounted by an umbel of a few flowers, below which is a whorl of bracts, an involuere. Calyx bell-formed or tubular with 5 lobes. Corolla nearly tubular, expanding at the throat into a wheel-shaped 5 -lobed border. Stamens 5 inserted on the tube.

1. P. farinosa, L. (Fig. 1, pl. 119.) Bird's Ere Primrose. Plant, 4 to $18 \mathrm{in}$. high; leaves long, narrow, broadest above the center, tapering to the leaf-stalk which is about $\frac{1}{2}$ as long as the blade. Leaves and involucre covered with a white mealiness. Flowers pink or lilac with a yellowish eye. Moist places, northern part of our area.

2. P. mistassinica, Michx. Caxadan Primrose. Smaller than No. 1,1 to 6 in. high. Leaves oval, not broadest above the center. Leaves not covered with mealiness. Northern part of our area. 


\section{SAMOLUS}

A smooth herb of wet places, with alternate, undivided, leaves and small flowers in elongated terminal clusters. Calyx adhering to the ovary below, 5-cleft. Corolla bell-shaped, 5-lobed. Stamens 5 fertile, and commonly 5 sterile. Capsule globose, many seeded.

S. floribundus, HBK. (Fig. 6, pl. 119.) Water Piaperxell. Brook Treen. Plant, 6 to $18 \mathrm{in}$. high, branching. Leaves 1 to $3 \mathrm{in.} \mathrm{long,} \mathrm{rounded}$ at apex, narrowed at base. Growing in wet places. June-Sept.

\section{TRIENTALIS, L.}

Inw, smonth perennial, with simple erect stem surmounted by a whorl of thin lance-shaped leaves and by one or more white star-like flowers borne on, long, very slender pedicels. The stem also bears a few minute scale-like bracts or leaves alternately arranged. Calyx of about 7 linear segments, corolla spreading, flat and star-like with about 6 or 7 rays.

T. americana, Pursh. (Fig. 5, pl. 119.) Star Flower. Stem 3 to 9 in. high; leaves $1 \stackrel{1}{2}$ to $4 \mathrm{in}$. long, tapering at both ends. Flower about $\frac{1}{2}$ in. broad. In moist woods. May-June.

\section{GLAUX, L.}

A low, fleshy perennial, with many opposite fleshy leaves, which are oblong and undivided and without teeth. Flowers in the axils of the l'aves, solitary but opposite Calyx 5-parted, the lobes colored like petals, the latter wanting. Stamens 5, at the base of the calys, opposite the corolla lobes. Capsule 5-valved, few seeded.

G. maritima, L. (Fig. 4, pl. 119.) SeA MiLrwort. Plant, 2 to 8 in. high, leaves $\frac{1}{4}$ to $\frac{1}{2} \mathrm{in.}$ long, oblong, oval or linear. Growing in salt marshes and on sea beaches. June-Aug.

\section{ANAGALLIS, L.}

Our species a low spreading herb found in moist pastures and waste places, with opposite leaves and solitary scarlet or whitish flowers. Calyx of 5 narrow tapering lobes; corollat wheel-shaped of 5 rather derply-parted lobes; ovary globose, the top separating like a lid to allow the escape of the minuto seeds.

A. arvensis, L. (Fig. 7, pl. 119.) Scarlet Pimpernell. Poor Min's Weatier Glass. Plant procumbent, stems 4 to 12 in. long, 4-sided. Leaves broadly egg-shaped without leaf stems. Flowers in leafaxils, on slender pediecels generally opposite; petals rounded, somewhat deeply separated. Moist places. Naturalized. June-Aug.

\section{NAUMBURGIA, Moench.}

A plant of cold swamps. Frect. leaves opposite, the lower renlued to scales, smooth; flowers in dense rounded tufts from the leaf-axils, yellow, the calyx and corolla each 5- to 7-parted, sepals and petals linear; stamens 5 to 7 , extending beyond the corolla. Ovary globose.

N. thyrsiflora, (L.) Duby. (Fig. 5, pl. 120.) Turtud Loosestrife. 


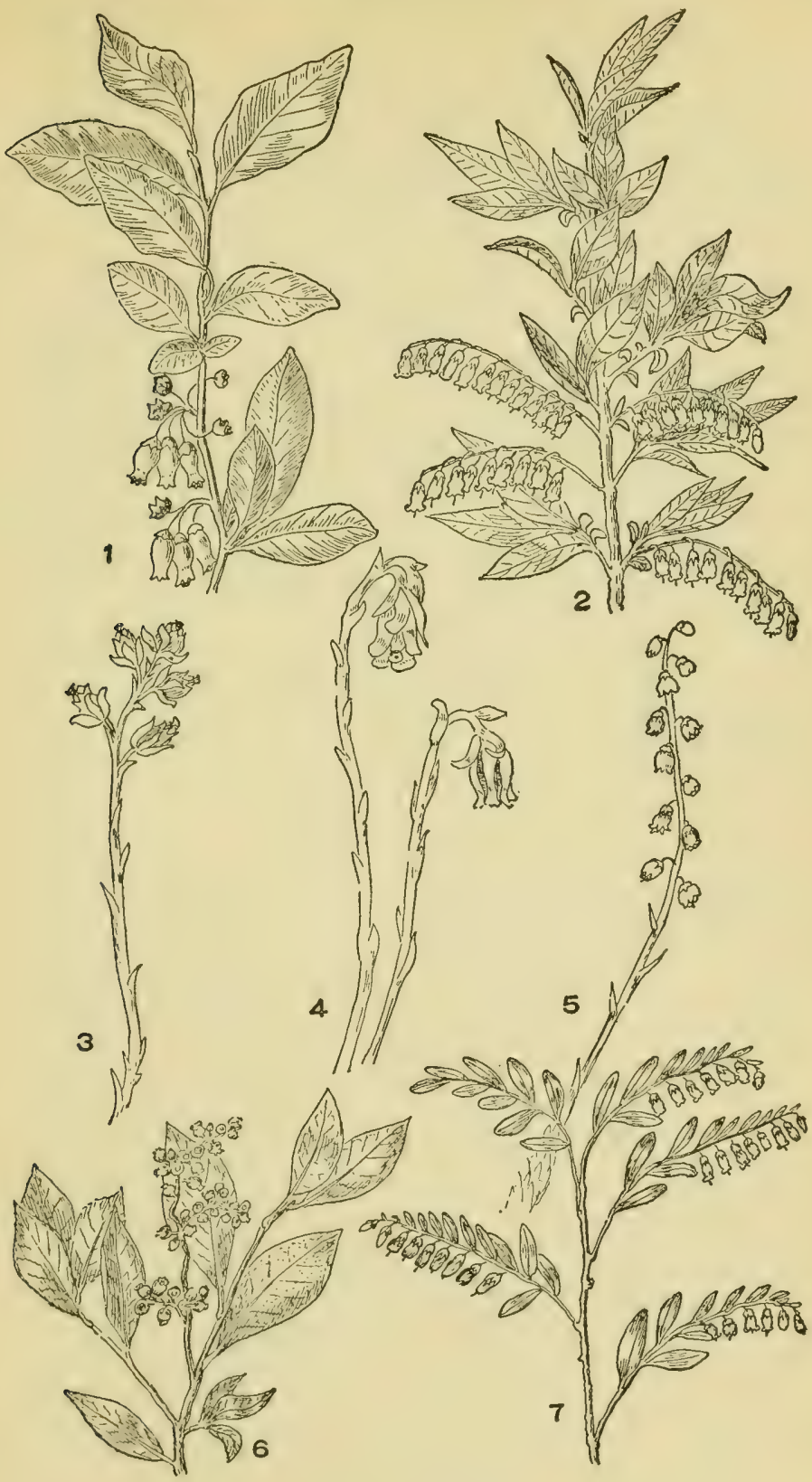

Plate 118

1. Pieris mariana. 2. Leucothoe racemosa. 3. Hypopitys americana. 4. Monotropa uniflora. 5. Pterospora andromedea. 6. Xolisma ligustrina. 7. Chamaedaphne ealyculata. 
Stem 1 to $2 \mathrm{ft}$. high; leaves lance-shaped tapering at each end. May. July.

\section{STEIRONEMA, Raf.}

Perennial smooth herbs, with opposite leaves, or leaves in whorls on the flowering branches. Flowers yellow, spreading or nodding; calyx 5-parted; corolla wheel-formed, lobes rounded each with a tooth at apex, the base of each folding on a stamen. Fertile stamens 5, sterile as many. Capsule 10- to 20-seeded.

Leaves egg-shaped, the leaí-stalk hairy . . . . . . . . . S. ciliatum Leaves lance-shaped, tapering at each end . . . . . S. lanceolatum Leaves linear .............. S. quadriforum

1. S. ciliatum, (L.) Raf. (Fig. 4, pl. 120.) Fringed Loosestrife. Erect; stems 1 to $4 \mathrm{ft}$. high. Leaves egg-shaped, broadly or narrowly, the leaf stems hairy, the blade 2 to 6 in. long. Flowers on thread-like pedicels arising at the leaf-axils; calyx 5-parted, the lobes sharp; corolla wheel-formed, the petals rounded, fringed, at outer margin. Capsule extending beyond the calyx. Moist thickets throughout our region. JuneAug.

2. S. lanceolatum, (Walt.) A Gray. (Fig. 2, pl. 120.) LANCELEAVED Loosestrife. Similar to the last, but leaves are narrow and tapering at each end and petals are not fringed at border, but have a tooth at outer extremity. Moist soil, throughout the area. June-Aug.

3. S. quadriflorum, (Sims.) Hitche. Prainie Monerwort. Stem stiff, erect, 4 -angled, 1 to $3 \mathrm{ft}$. high. Stem leaves narrowly linear, 2 to $4 \mathrm{in}$. long, smooth and shining. Corolla $\frac{3}{4}$ to $1 \mathrm{in.}$ broad. Along streams, western New York and southward. June-July.

\section{LYSIMACHIA, L.}

Perennial herbs, with leafy stems, the leaves opposite or in whorls of 3 or 4 , or more. Leaves without divisions or teeth, commonly dotted. Flowers wheel-shaped, yellow. Calyx 5-or 7-parted, free from the ovary; corolla 5-to 7-parted; the petals without teeth at border. Stamens 5 to 7 , inserted in the throat of the corolla. Capsule globose; seeds few or many.

Prostrate, creeping herb . . . . . . . . . . . L. Nummularia Erect herbs.

Leaves arranged in whorls of $4 \mathrm{~s}$, corolla lobes dark streaked . L. quadrifolia Leaves in whorls of 3 or more, corolla pure yellow.

Flowers in terminal leafy clusters... . . . . . L. vulgaris

Flowers from the leaf axils . . . . . . . L. punclata

Leaves opposite, flowers in pyramidal cluster . . . . . L. terrestris

1. L. vulgaris, L. (Fig. 2, pl, 119.) GoLDEN Loosestime. Erect, branching, 2 to $3 \frac{1}{2} \mathrm{ft}$. high, densely covered with soft hairs. I.eaves, opposite or in whorls of $3 \mathrm{~s}$ or $4 \mathrm{~s}$, on short leaf-stallis, oval or broadly lanceshaped, tapering at each end, 2 to 4 in. long. Yellow flowers an inch, more or less, in diameter, in terminal leafy clusters. A naturalized speeies, not very common. June-Aug.

2. L. punctata, I. Spotren Loosestrise. Another naturalized species, not eommon. liesembles the last, hut flowers arise in the leaf-axils down the stem. Waste places. June-July.

3. L. quadrifolia, L. (Fig. 2, pl. 120.) Cnosswort. Whonlid 


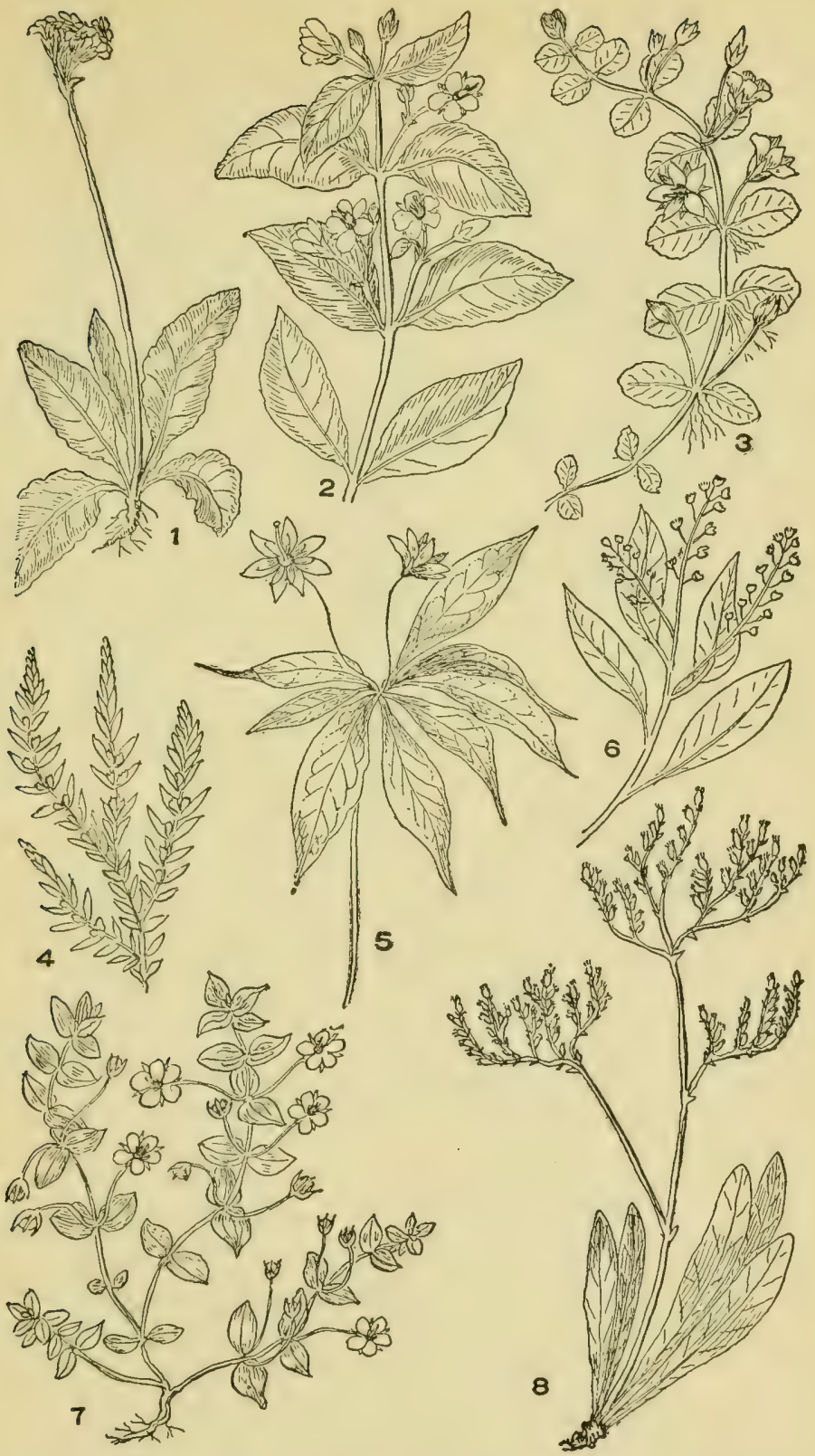

Plate 119

1. Primula farinosa, 2. Lysimachia vulgaris. 3. L. Nummularia. 4. Glaux maritima. 5. Trientalis americana. 6. Samolus floribundus. 7. Anagallis arvensis. 8. Limonium carolinianum. 
Loosestrire. Plant slightly downy or smooth, 1 to $2 \mathrm{ft}$. high; leaves in whorls of $4 \mathrm{~s}$, sumetimes of $5 \mathrm{~s}$, or more or less than 4 , without leaf-stalks, lance-shaped or oblong, 1 to $4 \mathrm{in}$. long. Flowers in whorls at the leafaxils, on long thread-like pedicels. Corolla wheel-shaped, the petals oblong-egg-shaped. Moist soils. Common. June-Aug.

4. L. terrestris, (L.) Ait. (Fig. 1, pl. 120.) Bulb-bearing LoosestRIFE. (L. stricta, Ait.) Stems 1 to $2 \mathrm{ft}$. high, often bearing small globular bulbs at the axils. Leaves opposite or rarely some of them alternate, lance-shaped, tapering at each end with short leaf-stalks or none, 1 to $3 \mathrm{in}$. long, often dotted with black points. Flowers yellow with purple streaks, about $\frac{1}{4}$ in. broad, in terminal pyramidal cluster, each on a thread-like pedicel. Swampy places. July-Sept.

5. L. Nummularia, L. (Fig. 3, pl. 119.) Creeping Loosestrife. An introdneed speciss, from Europe, eseaped from gardens, not common. Stems ereeping, extending 1 to $2 \mathrm{ft}$. Leaves roundish, opposite on short leaf-stalks, $\frac{1}{2}$ to 1 in. long. Flowers yellow about an in. broad. JulySept.

\section{Family II.-PLUMBaginaceaE. Plumidao Family}

INerlos, ours with the leaves all radicle. Flowers perfect but small, in clusters at the summit of a flower stem. Calyx not adherent to ovary, its parts more or less united, tubular, with 5 points. Corolla of 5 lobes; stamens 5 opposite the petals; styles 5. Fruit a dry one-seeded pod. A single species in our region.

\section{LIMONIUM, Adams. (Statice, Tour.)}

II rb growing at the sea-side, with thick perennial leaves arising at the base and with naked, branching flowering stem bearing large numbers of lavender-colored flowers. Flowers one-sided on the branches; calyx 5 -lobed; the lobes linear; corolla bell-formed, tubular, 5-parted. Stamens 5 , usually attached to the lobes of the corolla.

L. carolinianum, (Walt.) Britton. (Fig. 8, pl. 119.) SEA L.IVENDER. Marsi liosicanir. Leaves narrow, broalest toward the apex, tapering into long laf-stems, one conspicuons rib tipped with a bristly point. Sitrms with flower cluster 1 to $2 \mathrm{ft}$. high. Salt meadows, all along our coast. July=Oct.

\section{Order III.-EBENALES. Order of the Ebonys}

Shlumbs or trees, with hard wood. Flowers with stamens as many as the corolla lohes or twice as many; with hoth stamens and pistils or staminate and pistillate flowers separate. Iruit a berry.

\section{FAMILY I.-EBENACEAE. EB̉ony FAMILY}

Calyx well dereloped, 5- to r-parted, but its parts united below the fruit. Orary liee from calyx; in the staninate flowers it is 
PRIMROSE FAMILY
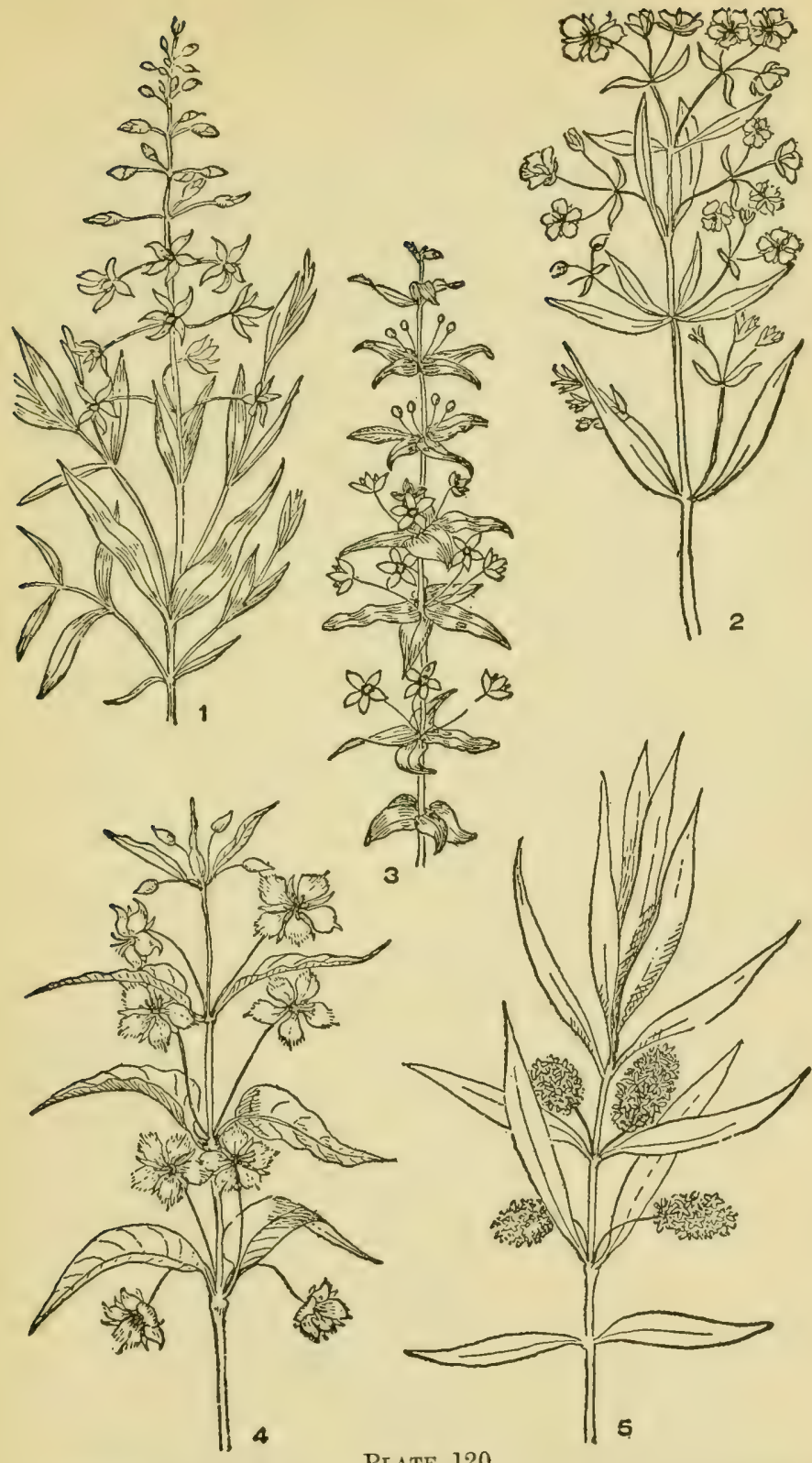

Plate 120

1. Lysimachia terrestris. 2. Steironema lanceolata. 3. Lysimachia quadrifolia. 4. Steironema lanceolata. 5. Naumburgia thyrsiflora. 
only partially or not at all dereloped. Fruit a berry containing one or more seeds.

\section{DIOSPYROS, L.}

A tree of considerable size in southern part of our area, common further south. Bark furrowed, dark; leaves broad egg-shaped or oval, 2 to 5 in. long, about $\frac{7}{2}$ as wide, dark green above, light beneath. Corollas with petals united but parted 졸 way into 4 lobes or more. Stamens 8 to 20 ; styles 2 to 6 . In the sterile flowers stamens reach the highest number, in the fertile flowers very few or no stamens. Berry pulpy. The berry has an extremely astringent taste before ripening, but when ripe is sweet and palatable.

D. virginiana, L. (Fig. 11, pl. 121.) Persimmon. Is occasionally found in the south eastern part of our area. Blooms May-June. Fruit ripe Sept. to Nov.

\section{Order IV._GENTIANALES (Contortae, Engler). Order of the Gentians}

An order including herbs and trees. Stamens borne on the corolla, when this is present, as many as the corolla lobes or fewer. The corolla is not dry and chaffy, in contrast with that of the Plantains. Flowers regular, stamens attached to the lower part of the corolla only. Leaves in our species opposite except in Menyanthcs, in which they are from the root. Ovary superior to calys. Trees

Herbs. With water juice.

Leaves from the stem.

With stipules . . . . . IOGANIACEAE

Without stipules . . . . . GENTIANACEAE

Leaves from the rootstock - . MENYANTHACEAE

Herbs. With milky juice.

Stamens distinct, styles united . . APOCYNACEAE

Stamens grouped, styles distinct . ASCLEPIADACEAE

\section{Family I.-OLEaceae. Olive Family}

Trees or shrubs; leaves opposite, mostly compound featherformed with an odd leaflet. Flowers of our speries of 4 divisions of the corolla when it is present, and 1 divisions of the calyx in all cases. Stamens mostly 2, sometimes 1. Fruit a capsule, a winged samara, a berry or drupe. 


\section{FRAXINUS, L.}

Trees, with opposite compound leaves, which are feather-formed, with several pairs and an odd leaflet. Flowers small, green, rarely with both stamens and pistils in the same flower and generally with staminate and pistillate flowers on different trees, in compound crowded clusters, which appear with the leaves, or before them in the axils of the leaves of the preceding year. Petals none or 2 or 4 , small; calyx small with 4 points or the points may be wanting or irregular. Fruit a flat winged samara, or "key," usually 1-seeded.

Leaflets stalked.

Wing extending along the sides of the samara. Under side of leaf not velvety........ F. lanceolata Under side of leaf velvety.

Leaf margins with very fine teeth . . . . F. pennsylvanica Leaf margins entire ....... . . F. Michauxii Wing only at the outer end of the samara: $:$. . . F americana Leaflets not stalked........... . . . . F nigra

1. F. americana, L. (Fig. 7, pl. 121.) Whiтe Ası. Large forest tree. Leaflets 5 to 9 , egg-shaped or narrow-egg-shaped. The twigs smooth, leaves without teeth or with very fine dentations. Fruit a rounded body appended to which is a wing 2 or 3 times as long as itself and extending only from the outer extremity, in form elliptic lance-shaped. April-May.

2. F. lanceolata, Borkh. (Fig. 10, pl. 121.) Green Asr. Forest tree, not as large usually as No. 1. Leaflets 5 to 9, egg-shaped or oblong, tapering at each end, sometimes with small serrations toward the outer extremity. Samara 1 to $3 \mathrm{in.}$ long, the wing extending along the sides, blunt at the apex. April-May.

3. F. pennsylvanica, Marsh. (Fig. 9, pl. 121.) Ted Asir. Large tree. Leatlets 5 to 9, egg-shaped or narrow-egg-shaped. The twigs, leafstalks and the lower surface of the leaves downy or velvety. Pistillate and staminate flowers on different trees. Body of the samara surrounded by the wing on all sides and which extends beyond it to a length equal to the body, the whole being elliptic or spatula-formed.

4. F. Michauxii, Britton. Michaux's Asir. Leaf margins entire; leaves thick, either velvety or smooth; samaras broadly spatula-formed. Swanips, New York and southward.

5. F. nigra, Marsh. (Fig. 8, pl. 121.) Black Asн. Hoop Asн. Large forest tree. Leaflets without stalks, 7 to 11, lance-shaped, tapering at each end, sharply indented at borders. Samara 1 to $2 \mathrm{in.} \mathrm{long,} \mathrm{the}$ wing extending all around, broad at apex, usually with an indentation. Swamps and other wet places. April-May.

\section{Family II.-LOGANIACEAE. Logania FaMily}

Herbs, shrubs or trees. Leaves opposite or in whorls, with stipules or with a membrane between the opposite leaf-stalks. Flowers regular, ours with calyx and corolla each 5-parted; the calyx below the ovary. 


\section{SPIGELIA, L.}

Herb, with opposite leaves with entire magins. Flowers in long narrow one-sided clusters. Stamens 5 ; style 1 , slender; capsule short.

S. marylandica, L. Marylaxd Pixқ-root. Stem simple, 4-angled, erect, 1 to $2 \mathrm{ft}$. high. Leaves without leaf-stalks, a membrane passing from one to its opposite, egg-shaped or lance-shaped. Corolla tubular with 5 narrow segments above, scarlet outside, yellow within. Flowers in one-sided cluster. Woods, New Jersey, and south.

\section{POLYPREMUM, L.}

Smooth, diffusely branched annual herb, with narrowly linear or awlshaped opposite leaves with their bases connected by a membrane representing stipules. Flowers small, white, in terminal bracted clusters. Corolla not longer than the calyx, almost wheel-shaped with 4 lobes. Stamens 4, short; style 1, short. Capsule ovoid, notched at apex.

P. procumbens, L. Polypremum. Flowers in the forks at the ends of the branches. Dry sandy fields, New York, Pennsylvania, and southward. June-Oct.

\section{Family III.-GENTIANACEAE. Gentian FAMILY}

Smooth herbs, with opposite (rarely whorled) leaves and conspicuous flowers, the corolla of which is tubular, bell-shaped or wheel-shaped, and which, in the bud is twisted. The divisions of the calyx are 4 to 10 which are united at base. The corolla lobes are as many as the divisions of the ealyx and the stamens number as many as the corolla lobes and are inserted alternately with them into the throat. Styles united into one, but sometimes wanting. Ovary 1-celled; capsule many seeded.

Leares reduced to scales, whole extent of stem . . Bartonia Lower leaves reduced to scales . . . . . . Obolaria Leaves fully developed.

Often in whorls . . . . . . . . Frasera Opposite.

Corolla with horns

Halenia

Corolla without horns or spurs.

Wheel- or bell-shaped, deeply cleft . 'I'ubular.

Sabbatia

Style short or none.

Gentiana

Style long, slender . . . . Erythraea

\section{ERYTHRAEA, Rencalm}

Irorbs: Ionves npunite without leaf-stalks, somotimes clasping the stem; flowers numerous, vather small; corolla a long slender tube with 4 or 5 


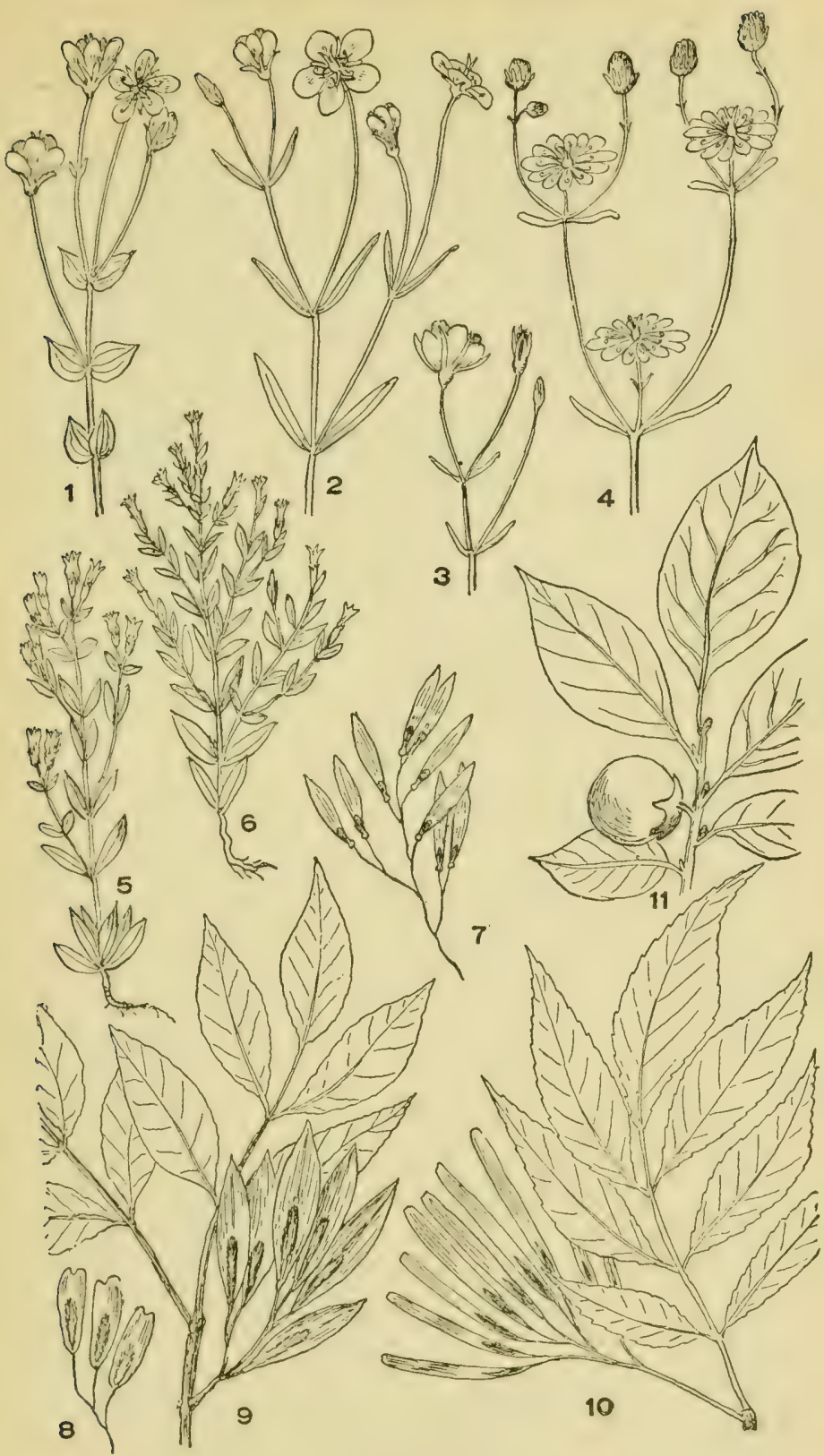

Plate 121

1. Sabbatia angularis. 2. S. stellaris. 3. S. gracilis. 4. S. dodecandra. 5. Erythraea centaurium, 6. E. pulchella. 7. Fraxinus americana. 8. F. nigra. 9. F. peunsylvanica. 10. F. lanceolata. 11. Diospyros virginiana. 
short lobes; calyx 4- or 5-parted. Anthers twisting spirally and extending beyond the throat of the tube. Low branching annuals with purple, white or yellow flowers.

1. E. centaurium, (L.) Pers. (Fig. 5, pl. 121.) Centaury. (Ccntaurium umbellatum, Gilib.) Stem upright, branching, 6 to 12 in. high; leaves oblong, obtuse at apex, narrowed at base, at the base of the stem the leaves form a rosette. Clusters of flowers form a nearly flat-toppea compound cluster of purple flowers which liave very short flower stems. Waste grounds. June-Sept.

2. E. spicata, (L.) Pers. SPIKed Centuury. (Centauria spicata, Fernald.) Resembles No. 1, but flowers are arranged in slender spikes. Coast of Nantucket. May-Sept.

3. E. pulchella, Fries. (Fig. 6, pl. 121.) Branching Centaury. (E. ramossissima, Pers. Centauria, Druce.) Low, much branched, 2 to 6 in. high; leaves mostly oval, not in a rosette at base; stem widely forking above, the flowers forming a diffuse cluster, all the flowers on flower stems. Fields and wet places. Southern part of our area. JuneSept.

\section{SABBATIA, Adams}

Slender stemmed anmual or biennial herbs, with diffusely clustered, showy flowers and with opposite or whorled leaves. Corolla 4 - to 12-parted, as is also the calyx; stamens 4 to 12 , inserted in the tube of the corolla, which is shallow, the lobes expanding to a wheel-shaped flower. Ovary 1-celled; style slender, 2-cleft.

Calyx and corolla, each 8- to 12-parted . . . . . . . S. dodecandra Calyx and corolla $4^{-}$to 5 -parted.

Branches opposite.

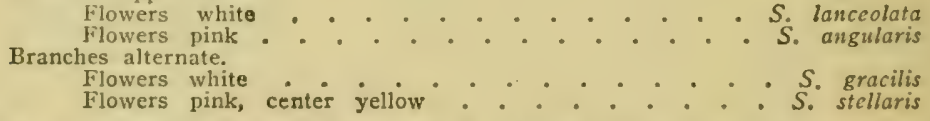

1. S. lanceolata, (Walt.) T. and G. Lance-Lenyed SAbbatia. Stem simple, slender, 2 to $3 \mathrm{ft}$. high, with opposite branches at top bearing diffuse cluster of white 5-rayed flowers. Leaves 3-nerved, egg-shaped, the upper sharp-pointed. Wet pine barrens, southern part of our area. MiaySept.

2. S. angularis, (T.) Pursh. (Fig. 1, pl. 121.) Rose PINk. Stems 1 to $2 \frac{1}{\mathrm{ft}}$. high, somewhat 4 -winged; leaves opprosite, broadly egg-shaped, somewhat heart-shaped at base, apex tapering, 5-nerved. Flowers in loose clusters above, corolla of 5 radiating lobes which are rounded at apex and are twice as long as the linear calyx lobes. Flowers pink, with a greenish or yellowish star in the center, on long slender flower stems. Thickets. Rich soil. Southern part of our area. July-Aug.

3. S. stellaris, Pursh. (Fig. 2, pl. 121.) Mansir Prink. Stem to $2 \mathrm{ft}$. high, slightly angular or round; branches alternate; leaves opposite, lanee-shaped or linear. Flowers pink or white with a yellowish starry center. Calyx 5-pointed, the points linear, half as long as the lobes of the corolla. Corolla 5-lobed, the lobes spreading and rounded at apex. Salt marshes. July-Sept.

4. S. gracilis, (Miclıx.) Salisb. (Fig. 3, pl. 121.) Stexder Marsm 


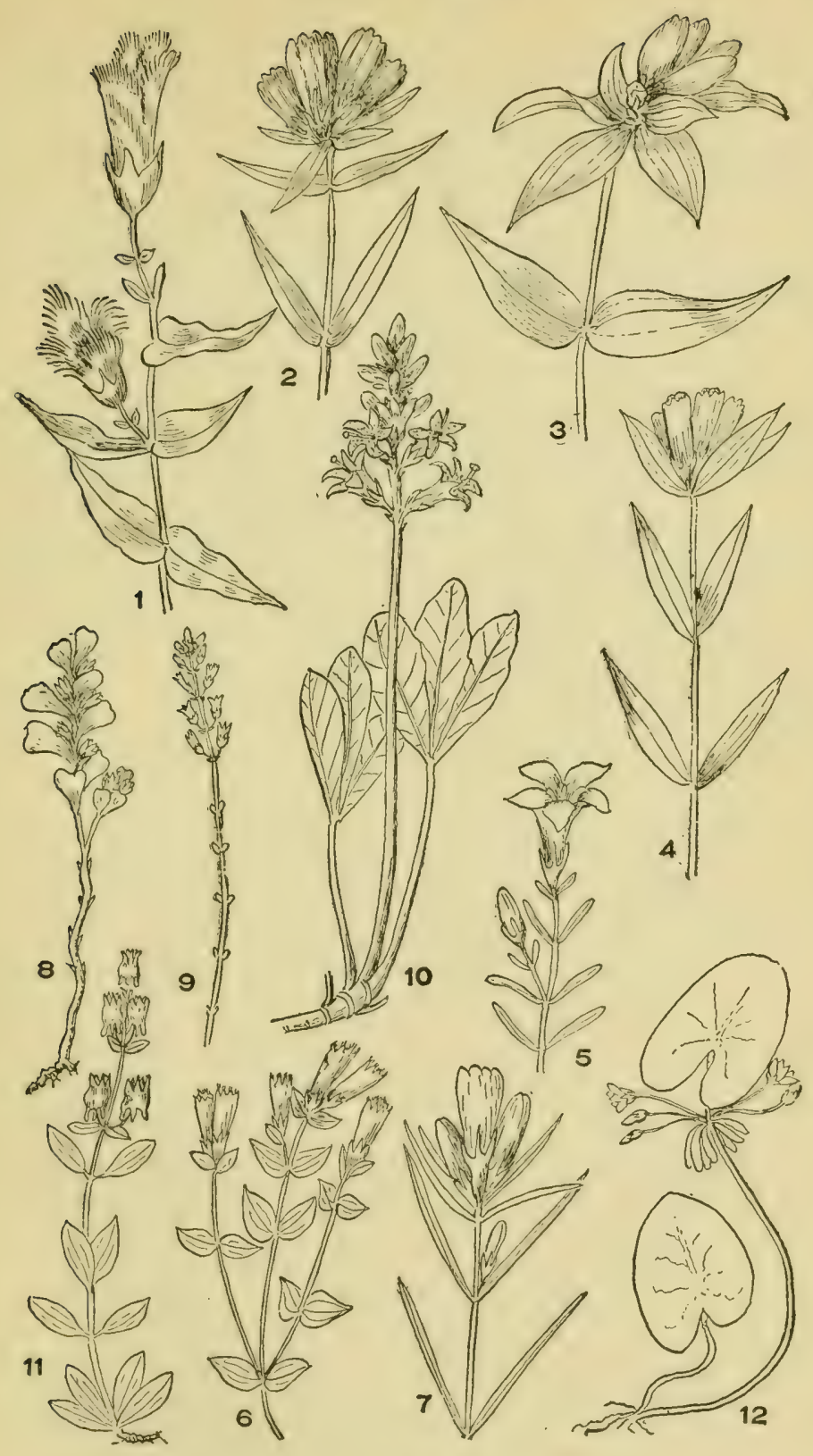

Plate 122

1. Gentiana crinita. 2. G. saponaria. 3. G. Andrewsii. 4. G. rubricaulis. 5. G. Porphyrio, 6. G. quinquefolia. 7. G. linearis. 8. Obolaria virginica: 9. Bartonia virginiea. 10. Menyanthes trifoliata. 11. Halenia deflexa. 12. Limnanthemum lacunosum. 
Pink. (S. campanulata, (L.) Torr.) Stem very slender, 1 to $2 \mathrm{ft}$. high, diffusely branched above, the branches alternate. Leaves opposite, the lowest oral, those along the stem linear, redueed to narrow thread-like bracts. Flowers in diffuse clusters, pink with a yellow eye, the calyx points as long as the 5 lobes of the corolla and thread-like. Salt marshes, rare, in fresh water swamps. May-Aug.

5. S. dodecandra, (L.) BSP. (Fig. 4, pl. 121.) LARge Marsir PrNk. Stem 1 to $2 \mathrm{ft}$. high, branching above, branches alternate; leaves opposite, those at base spatula-formed, those above linear. Calyx lobes 8 to 12 , linear; corolla 8 to 12 lobes, radiating, rose-colored or nearly white. Sandy borders of brackish ponds. July-Sept.

\section{GENTIANA, L.}

Herbs, with opposite or rarely whorled leaves which have entire, or in some cases, hairy margins, and with flowers in terminal and axillary groups or solitary at the end of the stem. Flowers blue, purple, yellow or white. Calyx mostly 4-parted, but may have 5 to 7 lobes; corolla also of 4 lobes, but less frequently 5 to 7 , often with intermediate folds or plaits at the sinuses. Stamens equal in number to the lobes of the corolla, inserted at the throat and alternate with the lobes. Styles short or none. Capsule 2-valved.

\section{Corolla without folds or tecth at the sinuses}

Borders of corolla fringed, leaves egg-shaped or lance-shaped . . G. crinita Borders of corolla lobes fringed, leaves linear . . . . . . . G. procera Borders of lobes not fringed. . . . . . . . . . G. quinquefolia

\section{Corolla with teeth or folds in the sinuses}

Flowers blue or bluish-white.

Corolla closed, club-shaped, margin of leaf rough.

Corolla lobes distinct, longer than, or as long, as the inter mediate plaits......... G. Saponario Corolla lobes obscure or absent, the plaits very broad $G_{\text {. Andrcwsib }}$ Corolla open, margins of leaves smooth. llowers in terminal clusters.

Leaves narrow lance-shaped . . . . . . G. lincaris

Leaves broad at base, tapering toward apex: $\quad$ G. rubricaulis

Flowers solitary.?. G. Porplyrio

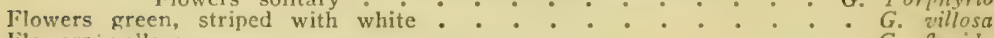

Flowers yellow ................. . . . . flavida

1. G. crinita, Froel. (Fig. 1, pl. 122.) Fringed Gentran. Stem 1 to $2 \mathrm{ft}$. high, branching above; leaves lance-shaped or egreshaped with the base heart-shaped or romded. Calyx foles 4, mequal and extending the length of the corolla tube. Corolia 4-lobed, the lobes rounded and strongly fringed at the borders. Ovary tall, conical. Found in wet places and flowering in autumn.

2. G. procera, Holm. Smalcer Fringed Gentian. (G. detonsa, Rottb.) Similar to G. erinita, but smaller, with linear leaves, the base not rounded or heart-shaped. Western New lork and westward. JulySept.

3. G. quinquefolia, L. (Fig. 6, pl, 122.) StrfF Gentian. Stem slender, stiff, wsually branched, I to $2 \mathrm{ft}$. high. Teawes exer-shaped, partly clasping the stem, generally 5-nerved (or 3- or 7-nerved), tipped by a sharp point. Flowers in clusters at the end of the stem or at the axils; calyx about $1 / 3$ as long as the corollat. Corollat pale blue, its lobes tri- 
angular, tipped with bristle points. Capsule spindle-shaped. Flowers smaller than those of the Fringed Gentian and nearly cylindric. Moist places, southern Maine and southward. Aug.-Oct.

4. G. saponaria, L. (Fig. 2, pl. 122.) SoApwort Gentran. Stem erect, without or with a few short branches above, 1 to $2 \mathrm{ft}$. high. Leaves oval-lance-shaped, tapering at each end, the borders rough with short stiff hairs. Flowers in close branches at top of stem and often a single or a few flowers at each of several leaf axils, large, bright blue, closed at top. Calyx of 5 egg-shaped segments. Corolla lobes evident, as long as or longer than the intermediate plaits. In wet soil and usually in sliady places. Aug.-Oct.

5. G. Andrewsii, Griseb. (Fig. 3, pl. 122.) Closed Gex̃tian. Very similar to the last, 1 to $2 \mathrm{ft}$. high; corolla lobes scarcely evident, the intermediate plaits being broad and somewhat fringed, nearly obseuring the narrow lobes (Fig. 5, pl. 122). Stamens gatlered into an adhering ring. Moist, shady places. Aug.-Oct.

6. G. linearis, Froel. (Fig. 7, pl. 122.) Narrow-teaved Gentian. Stem mostly without branches, $\frac{1}{2}$ to $2 \mathrm{ft}$. high; leaves very narrow lanceshaped, $1 \frac{1}{2}$ to $3 \mathrm{in}$. long, $1 / 6$ to $1 / 3$ in. wide, smooth at borders. Flower branches at top of stem and one or more at each of several leaf-axils. Corolla funnel-shaped, open at top, about $1 \frac{1}{2}$ in. long. Lobes 5, inter. mediate plaits much narrower than lobes. Calyx tube funnel-shaped, the 5 linear lobes as long as the tube. In bogs and other wet places. Aug.-Sept.

7. G. rubricaulis, Schwein. (Fig. 4, pl. 122.) Red-stemared GeNTIAN. Stem 1 to $2 \mathrm{ft}$. high; leaves $1 \frac{1}{2}$ to $2 \frac{1}{2} \mathrm{in.} \mathrm{long,} \mathrm{oval,} \mathrm{narrow,} \mathrm{or}$ broadened at base and tapering to a sharp point at apex, 3-nerved, mar. gins somewhat rough. Stem tinged with red, leaves brown or reddish. Flowers bunched at top of stem, the bunch being subtended by 2 broad leaf-like bracts. Corolla open at top, the 5 lobes conspicuously longer than the 5 intermediate plaits, bright blue or greenish-blue. The whole plant has a somewhat marked appearance of rigid regularity. Wet soil, central New York and northward. Aug.-Sept.

A form with leaves broad at the base was regarded by Dr. Gray as a variety of $G$. linearis, (var. latifolia).

8. G. Porphyrio, J. F. Gmel. (Fig. 5, pl. 122.) ONe-Flowered GeNTIAN. Stem simple or branched, slender, $\frac{1}{2}$ to $1 \frac{1}{2} \mathrm{ft}$. high. Leaves linear. Flowers terminal, solitary; corolla 5 lobes, the lobes spreading, much longer than the plaits. Calyx loles thread-like. Color of flower bright blue, sometimes whitish or greenish. Pine barrens, southern part of our area. Aug.-Oct.

9. G. villosa, L. Striped Gentian. Stem $\frac{1}{2}$ to $1 \frac{1}{2} \mathrm{ft}$. high. Leaves broadly ovite, widest toward apex, narrowed at base. Flower branches at top of stem and one or more at some of the leaf-axils. Calyx tube funnel-shaped, the lobes thread-like, longer than the tube; corolla open at top, greenish-white striped on the inside with green veins and purple stripes; lobes much longer than the appendages. Shady places, southern part of our area. Sept.-Nov.

10. G. flavida, A. Gray. Yellowisil Gentias. Stout, I to $3 \mathrm{ft}$. 
high. Leaves 2 to $5 \mathrm{in}$. long, broad at the rounded base, tapering to a sharp point, smooth at margins. Flowers bunched at top of stem with one or more in upper axils. Calyx tubular, the lobes short, triangular. Corolla fummel-formed, 5 lobes and 5 appendages. Color, yellow or greenish-white. Moist soil, occasional in most of our area. Aug.-Oct.

\section{FRASERA, Walt.}

Tall showy herbs, bearing opposite or whorled leaves. Stem mostly simple; llowers in terminal spreading elusters. Calyx, a shallow tube and 4 narrow sepals. Corolla 4-lobed, spreading; stamens 4, inserted at base of the corolla tube. Capsule oval, flattened, few seeded.

F. caroliniensis, Walt. Americax Columbo. Stem stout, 3 to $\mathrm{s} \mathrm{ft}$. high; leaves mostly in whorls of 4, oblong or lance-shaped, the lower spratula-formed, 3 to 6 in. long. Flower cluster pyramidal; corolla about 1 in. broad, greenish-yellow with brown purple dots. Rich soil, western section of our area. June-Aug.

\section{HALENIA, Borkh. (Tetragonanthus, Kuntze)}

Small herbs, usually growing in tufts; leaves opposite; flowers terminal and in the upper leaf-axils. Tube of calyx shallow, lobes narrow and long; corolla of 4 lobes, each lobe with a hollow spur projecting below; stamens 4 or 5; ovary 1-celled, many seeded.

H. deflexa, (J. F. Smith) Griseb. (Fig. 11, pl. 122.) Spurred GenTIAX. Stem simple or branched above, $\frac{1}{2}$ to $1 \frac{1}{2} \mathrm{ft}$. high; leaves oval or egrg-shaped, sharp pointed at apex, 3- to 5-nerved, 1 to 2 in. long. Flowers purplish or white, bell-shaped, the spurs cylindric, $\frac{1}{4}$ to $\frac{1}{2}$ as long as the 4-lobed corolla. Damp woods, most of our area. July-Aug.

\section{OBOLARIA, L.}

A low perennial plant, purplish-green with a simple or branched stem and npposite fleshy scales which occupy the place of leaves. Flowers axillary and terminal, the 2 divisions of the calyx leaf-like. Corolla 4-cleft; stamens 4, inserted at the sinuses of the corolla. Capsule ovoid; seeds numerous.

O. virginica, L. (Fig. 8, pl. 122.) PExwrwont. Root and stem fleshy, stem 3 to 6 in. high. Stem leaves scale-like, those among the flowers about $\frac{3}{2} \mathrm{in.}$ long, purplish, triangular, broad at the apex, narrowed and extending down the stem at base. Flowers about $\frac{f}{2} \mathrm{in}$. long, pale purple or whitish, longer than the 4 stamens. Southern part of our area. April-May.

\section{BARTONIA, Muhl.}

Small slender herhs, with simple stems or with few branches, and with oppusite leaves, which are reduced to awl-shaped scales; some of these srales may be alternately arranged. Flowers small, white or yellow, arrangerl in strmeler upright clusters. (alyx 4 -parted; corolla d-lobed, bellshaped; stamens 4 , short. ('apsule oval or oblong, flattened and pointed with the persistent style. Seeds numerous.

1. B. virginica, (L.) BSP. (Fig. 9, pl. 122.) Yellow Bartoria. Stem thread-like, 4 to $12 \mathrm{in.} \mathrm{high,} \mathrm{5-angled;} \mathrm{seales} \mathrm{about} 1 / 10 \mathrm{in.} \mathrm{long}$; 
flowers opposite, yellow, from 2 to several pairs, less than $\frac{x}{4}$ in. Iong. Moist soil, most of our area. July-Sept.

2. B. iodandra, Robinson. Purplisil Bartonia. Stem 2 to 8 in. high, simple or alternately branched. Scales alternate. Corolla distinctly purplish, about twice as long as the calyx. In sphagnum, New Jersey, northward.

3. B. paniculata, (Michx.) Robinson. Panicled Bartonia. Slender, 8 to $16 \mathrm{in}$. high. Stem beset by scales in place of leaves, these often alternate. Flowers yellowish or greenish-white. Wet woods and swamps, Mass., southward. Aug.-Oet.

\section{FAMily IV.-MENYANTHACEAE. BuckBein FAMILY}

Perennial herbs, growing in marshes. Root-stock stem-lilie. An acrial stem absent, the long leaf-stalks arising from the rootstock as does also the flower-bearing scape. Flowers in clusters, regular, bearing both stamens and pistils. Calyx 5-cleft; corolla 5 -lobed; stamens 5, arising between the lobes of the corolla. Fruit a capsule.

\section{MENYANTHES, L.}

Leaves 3 -foliate on long leaf-stalks arising from the root-stock; leaflets oval or pear-shaped, each about 1 to 2 in. long. Flowers borne on a tall seape forming a cylindric cluster consisting of from 10 to 20 tubular purple flowers, the corolla lobes triangular, spreading, the tube and lobes bearded with white hairs. Stamens shorter than the corolla; capsule egg-shaped, tipped by the permanent style.

M. trifoliata, L. (Fig. 10, pl. 122.) BuckbeaN. A beautiful plant found in sphagnous bogs. May-June.

\section{LIMNANTHEMUM, S. G. Gmelin. (Nymphoides, (Tourn.)} Hill

Leaves floating, the leaf-stalks arising from the root-stock which is buried in mud. The leaf is broadly oblong or nearly orbicular, with a deep sinus and with leaf-stalk from 1 to $10 \mathrm{ft}$. long, from the summit of which arise, the leaf, which is small in proportion to the length of the leaf-stalk ( 1 to 2 in. long), an umbel of small white flowers and a cluster of narrow tubers each of which may produce a new plant. Primary leaves submersed, without flowers or tubers.

1. L. lacunosum, (Vent.) Griseb. (Fig. 12, pl. 122.) Froativa IIEArT. Found in ponds. Flowers white, leaves 1 to 2 in. Iong. JulyAug.

2. L. aquaticum, (WaIt.) Britton. Large Froating Heart. The plant is stouter, the sinus shallow and leaves 2 to $6 \mathrm{in}$. long. Southern part of our area. May-Aug.

\section{Family V.-Apocynaceae. Dogbane Family}

Plants, all of which in our region, have acrid milky juice. Leaves sometimes alternate but generally opposite. Flowers regular; 
calyx deeply 5-cleft (rarely 4-cleft); corolla 5-lobed; stamens 5 (lobes of corolla sometimes 4 and stamens 4 , but not in our species). Stamens not united, inserted on the corolla. Ovaries (in our species) 2, free from the calyx; styles united into 1.

Leaves opposite.

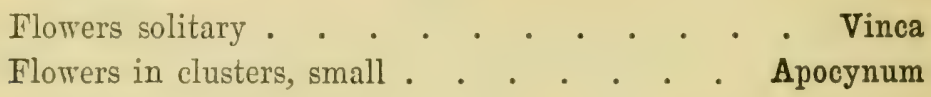

I. VINCA, L.

Ilerbs, with opposite Ieaves and solitary blue or whitish flowers arising from leaf-axils. Our species a trailing herb which has escaped from cultivation. The leaves smooth at the edges, firm, dark green on both sides, egg-shaped, with short leaf-stalks. Flowers solitary, generally blue, with a short eylindric tube and 5 broad spreading lobes. Ovaries of 2 long cylindric follicles.

V. minor, L. Myrtle. Periwinkle. In borders of woods and at roadsides. Blooms nearly all summer.

\section{APOCYNUM, L.}

Perennial herbs, with opposite leaves and white or pink flowers in spreading clusters, generally terminal. Calyx small, deeply 5-cleft; corolla bell-shaped, bearing at the throat 5 small triangular appendages. Stamens 5, inserted at base of corolla. Seeds in two long cylindrie carpels.

Branches spreading

Branches erect or nearly so.

Base of leaves tapering . . . . . . . . . . A. cannabinum

Base of leaves rounded $\because{ }^{\circ}{ }^{\circ} \cdot{ }^{\circ} \cdot{ }^{\circ}$ A. hypericifolium

1. A. androsaemifolium, L. (Fig. 1, pl. 123.) Spreading Dog. rA.X. Stem 1 to $4 \mathrm{ft}$. liph; branches spreading. Leaves broally elliptic or oval, sharply pointed or blunt at apex, generally rounded at base. corolla pink, the lobes shorter than the tube. Fields and roadsides, throughout our area. June-July.

2. A. cannabinum, I. (Fig. 3, pl. 123.) Ixpian Ifemr. Resembles No. 1, but branches more erect; base of leaves narrowed or somewhat rounderl. Lobes of rorolla as long as or longer than the tube. Fields and thickets. June-Aug.

3. A. hypericifolium, Ait. (Fig. 2, pl. 123.) Claspriv-Leaven DogBANE. l'lant smooth with a whitened bloom, 1 to $2 \mathrm{ft}$. high. Leaves oblong to oval, obtuse at apex, heart-shaped or clasping the stem at base. Central New York, Maine and northward.

(Sereral forms, found in our area and differing in some respeets from these have been described as species by some, as varieties by others.)

\section{Family Vi.-Asclepiadaceae. Murketi Mamily}

I'lants, with milky juice, with leaves opposite or in whorls or less freguently alternate, without lobes or teeth. Flowers in termi- 

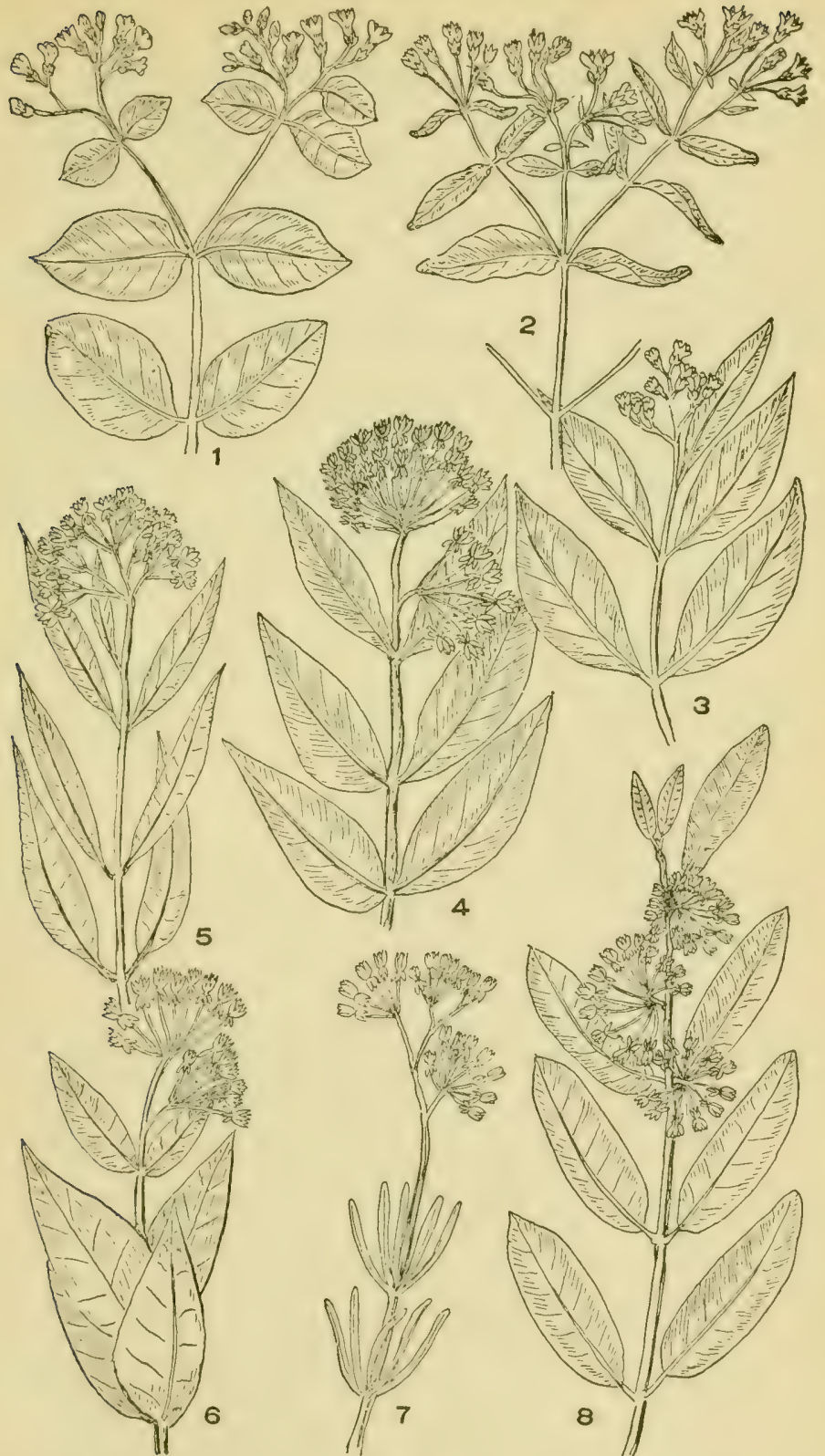

3
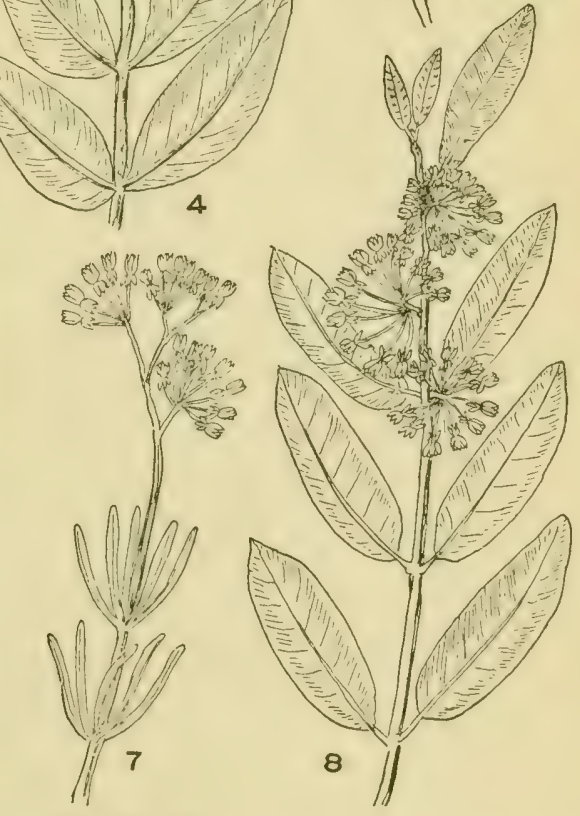

Plate 123

1. Apocynum androsaemifolium. 2. A. hypericifolium. 3 A. cannibinum. 4. Asclepias purpurascens. 5. A. lanceolata. 6. A. rubra. 7. A. verticillata. 8. Acerates viridillora. 
nal or axillary clusters; calyx 5-parted, the sepals turned back; corolla bell-shaped, urn-shaped or wheel-shaped. Between the corolla and the stamens is a 5-lobed crown attached either to the corolla or to the stamens. Stamens 5 , the anthers in close connection with the summit of the pistil. The pollen grains cohere in masses. Ovary of two long pods.

Crown of 5 hooded bodies, each with an incurved horn. Leaves opposite

Asclepias

Crown without the incurved horns, leaves alternate.

Erect plant .

Trailing vine.

\section{r. ASCLEPIAS}

Our species have opposite, whorled or scattered leaves, a milky juice, and small flowers in terminal or axillary umbels. Crown of 5 hood-like bodies each bearing an incurved horn.

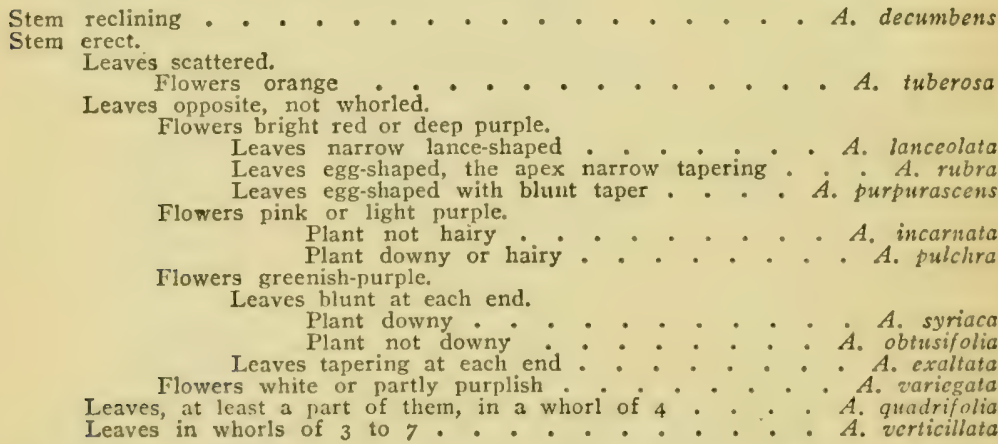

1. A. tuberosa, L. (Fig. 3 , pl. 124.) Butrerfer Weed. Precrisy Rоoт. Stems rather stout, 1 to $2 \mathrm{ft}$. high, hairy, rough, bearing at the summit a number of umbels of orange-colored flowers. Leaves linear to lance-shaped, attached directly to the stem or by a short leaf-stalk. Pods erect on pedicels which first dip downward then curve upward. Dry fields. June-Sept.

2. A. decumbens, L. Decumbext Butterfer-weed. Plant hairy; stems decumbent; leaves oblong or elliptic. Flowers dark orange. Dry fields, Conn., not common in our area. June-Aug.

3. A. lanceolata, Walt. (Fig. 5, pl. 123.) (A. paupercula, Miclıx.) Stem slender, few if any hranches, 2 to $4 \mathrm{ft}$. high, smooth, without hairs, as are the leaves. Leaves opposite, 4 to $10 \mathrm{in.} \mathrm{long,} \mathrm{linear} \mathrm{or} \mathrm{narrowly}$ lance-shapel, rough on the edges, tapering at each end, but broactest toward the hase, generally on very short leaf-stalks. Flowers in terminal umbels, one or more, each with from 5 to 12 llowers; corolla sements red, hoods derp orange. Pod erect, about 4 in. long. Wet places, mostly near the coast, southern part of our area. June-Aug. 

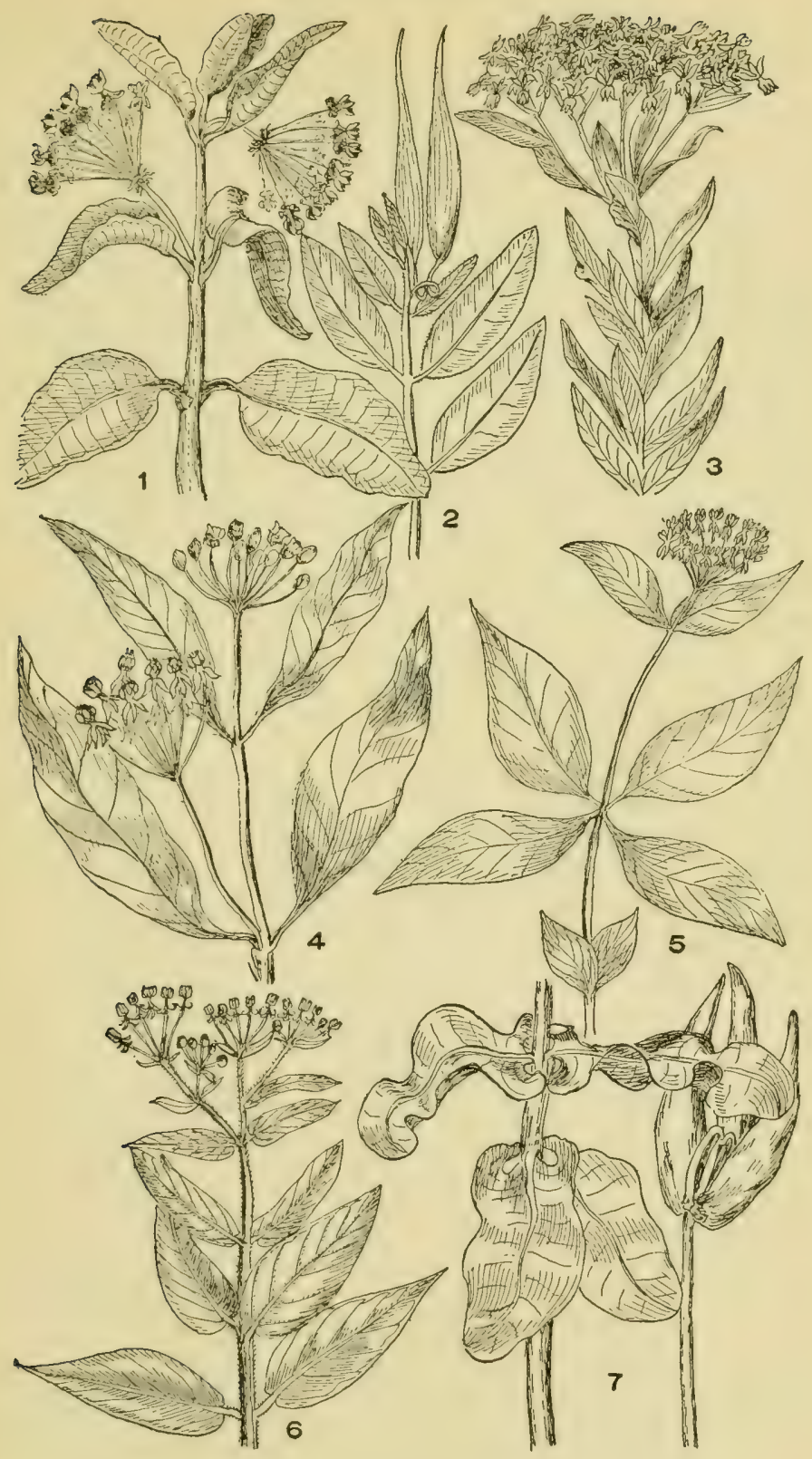

Plate 124

1. Asclepias syriaca. 2. A. variegata. 3. A. tuberosa. 4. A. exaltata. 5. A. quadrifolia. 6. A. pulchra. 7. A. obtusifolia. 
4. A. rubra, L. (Fig. 6, pl. 123.) Red Milmweed. Plant with few if any hairs, stem 1 to $4 \mathrm{ft}$. high, few if any branches. Leaves opposite, 2 to $6 \mathrm{in.}$ long, egg-shaped to lance-shaped, the base rounded, apex tapering to a very sharp point, on very short leaf-stalks or none, bright green. Lmbels terminal of many purplish-red flowers, the incurved horns long and slender. Pods slender, spindle-shaped, about 4 in. long. Moist soil, southern part of our area. June-July.

5. A. purpurascens, L. (Fig. 4, pl. 123.) Purple Miliweed. Stem rather stout, with few if any branches, slightly downy or free from hairs, 2 to $4 \mathrm{ft}$. high. Leaves opposite, elliptic or oblong, the upper ones taper pointed, base of all rounded or narrowed, the under side downy, upper smooth, on short leaf-stalks, 3 to 8 in. long. Flowers in terminal umbels, color deep purple. Pods 4 to 5 in. long, downy, nearly erect. Dry grounds, New Hampshire and northward. June-Aug.

6. A. incarnata, L. SwAMP Mrixweed. Stem 2 to $3 \mathrm{ft}$. high, smonth or slightly downy, very leafy, branching or rarely without branches. Leaves opposite, lance-shaped, sharply tapering at each end or somewhat rounded at base, 3 to $6 \mathrm{in}$. long. Flowers light purple or rarely white, horns of the crown longer than the hoods, slender, needle-pointed. Pod 2 to $3 \frac{1}{2}$ in. long, slender. Common in swamps.

7. A. pulchra, Ehrh. (Fig. 6, pl. 124.) Hairy Minkweed. Similar to No. 5, but leaves are broader and more rounded or slightly heart. shaped at base and the under surface of leaves is decidedly velvety. Flowers light red, pink or white. Moist fields throughout our area. July. Sept.

8. A. obtusifolia, Michx. (Fig. 7, pl. 124.) Blunt-Leaved MilKWEED. (A. amplexicaulis, Sm.) Stem 2 to $3 \mathrm{ft}$. high. Leaves oblong, usually wavy, very blunt at apex and base, on very short leaf-stalks or clasping at base, $2 \frac{1}{2}$ to 5 in. long. Flowers green-purple, in a manyflowered terminal umbel. Dry fields throughout our area. May-Aug.

9. A. exaltata, Muhl. (Fig. 4, pl. 124.) Tall Milkweed. Poke Milemeed. (A. phytolaccoides, Pursh.) Stem 3 to $6 \mathrm{ft}$. high, with 2 downy lines. Leaves opposite, oval or egg-shaped, thin, tapering at each end, 4 to $9 \mathrm{in}$. long, $1 \frac{1}{2}$ to $4 \mathrm{in}$. wide, the lower sometimes broadest toward the apex, sometimes downy beneath. Umbels terminal and from the leaf-axils. Flowers greenish with white crown. Horns each with a long projecting slender point. Moist thickets and woods. June-Aug.

10. A. variegata, L. (Fig. 2, pl. 124.) White MrLkweed. Stem 1 to $2 \mathrm{ft}$. high, somewhat downy above when young. Jeaves opposite, thick, eng-shajed, oval, or pear-shaped, sometimes about the middle of the stem whorled, rather blunt at each end, the margins wavy or toothed, 3 to 6 in. long, on leaf-stalks ahout 4 in. long. Flowers in 1 to 4 compact terminal umbels or rarely also in one or two lateral umbels, white with purplo or purplish crown. Dry woods, southern part of our area. June-July.

11. A. quadrifolia, Tacq. (Tig. 5, pl. 124.) Folr-Litied Miskweld). Stem slender, 1 to $2 \mathrm{ft}$. high, mostly leafless below or with a pair of erershaped leaves at lower third, with one or two whorls of +5 or 5 leaves about the midfle and sometimes one or two pairs of leaves immediately below or above these whorls. Leaves of the whorls more or less broadly lanee- 
shaped, tapering at each end, thin, 2 to 6 in. long, $\frac{1}{2}$ to $2 \frac{1}{2}$ in. wide, on short leaf-stalks. Flowers in 1 to 4 terminal umbels (rarely some small umbels in upper axils), pink or white. Woods and thickets. May-July.

12. A. syriaca, L. (Fig. 1, pl, 124.) CoMmon MuLntweed. Stem stout, branching little, if any, slightly downy above, 3 to $5 \mathrm{ft}$. high. Leaves opposite, oblong or oval, blunt at each end, densely downy beneath, 4 to $9 \mathrm{in}$. long. Flowers dull green-purple to whitish, in numerous umbels. Fields, rich grounds. June-Aug.

13. A. verticillata, L. (Fig. 7, pl. 123.) Whorled Mrlkweed. Stem slender, sometimes branched, leafy, 1 to $2 \frac{1}{2} \mathrm{ft}$. high. Leaves linear in whorls of 3 to 7 or more. Flowers in terminal umbels, greenish-white. Dry hills, New York and southward. July-Sept.

\section{ACERATES, Ell.}

Herbs similar to Asclepias, but the hoods compassing the erown are without the horn which is characteristic of Asclepias.

A. viridiflora, Eaton. (Fig. S, pl. 123.) Greer Milkweed. Stem whitish, downy, at least when young, without branches, reclining or nearly erect, 1 to $3 \mathrm{ft}$. high. Leaves opposite, or, less frequently alternate, eggshaped, on short leaf-stalks, thick, 1 to 3 in. long, 1 as wide, slightly rough, base rounded, upper blunt. Flowers in axillary umbels, green. Pod long and slender. Dry sandy soil. June-Sept.

\section{CYNANCHUM, L. (Vincetoxicum, Moench)}

A trailing vine, with opposite or whorled leaves and umbels of small flowers which resemble those of Asclepias. Calyx and corolla wheelformed; crown cup-like, not divided into 5 distinct parts as in Asclepias, but has 5 lobes.

C. nigrum, Pers. Black Swallow-wont. Twining vine, 2 to $5 \mathrm{ft}$. long, with lance egg-shaped leaves, rounded at base, tapering at apex. Flowers dark purple. Pod slender, resembles that of Asclepias. Escaped from gardens. June-Sept.

\section{Order V.-TUBIFLORALES. Order of Tubular Flowers}

Flowers almost always regular, the corolla of a single envelope more or less parted into 5 lobes at the border. Stamens 5 inserted with the corolla and alternating with its lobes. Seed pods (carpels) 2 to 5 , always above and free from the calyx. Style nearly always simple.

Ovary deeply 4-lobed.

Corolla regular (except in Genus Echium), pods (carpels) separating as nutlets. Herbs, not trailing or twining vines

BORAGINACEAE

Ovary not 4-lobed. 
Corolla regular; twining vines.

Yellowish-white leafless vines, parasites CUSCUTACEAE

Vines with normal leaves, not parasitic

Herbs, not vines.

CONVOLVULACEAE

Ovary 3-celled. Flowers in umbel-like, spreading clusters, rarely solitary, or in a loose irregular compound cluster, stamens not plumose . POLEMONIACEAE

Ovary 1-celled, stamen filaments plumed with rather long hairs HYDROPHYLLACEAE

\section{Family I.-CONVOLVUlaceaE. Morning-glory Family}

Herbs, mostly with twining vines. Leaves alternate, without stipules. Flowers regular, corolla of a single petal (by concrescence of 5) ; calyx 5-parted; margin of corolla in 5 lobes; stamens 5 , inserted at the very base of the corolla or with it. Ovary superior to the calyx and not connected directly with it; styles 1 to 3. Fruit a capsule or 2 to 4 pods, distinct.

Styles 2, or one deeply 2-parted .

Breweria Style 1.

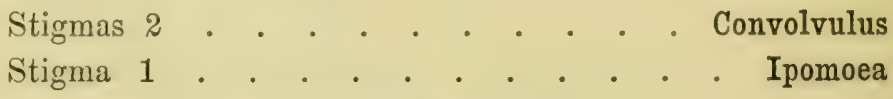

\section{BREWERIA, R. Br.}

Ours a slender species, nearly or quite prostrate, with long narrow leaves and axillary betl-shaped flowers resembling those of Convolvulus. Caysule globose, 2-celled.

B. Pickeringii, (M. A. Curtis) A. Gray. (Fig. 4, pl. 125.) Prckrkixci's Bricweria. Stem 1 to $2 \mathrm{ft}$. long, downy. Leaves very narmowly linear, tapering at base. Flower stems spring at axils, bearing from I to 3 flowers. Southern part of our area. June-Aug.

\section{IPOMOEA, L.}

Twining or trailing vines. Corolla fumel-form to bell-form, the margin only slightly lobed. Calyx without braets at the base. Style undividel, terminated by a single cap or 2 or 3 globose nearly united caps. Capsule globular.

Flowers white.

Corolla 2 to 3 in. long . . . I. pandurata

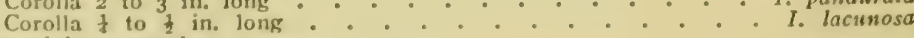
Flowers pink or purple.

Leaves decply lobed ............ I. hederacce Leaves not decply lobed........... i. purpurea 


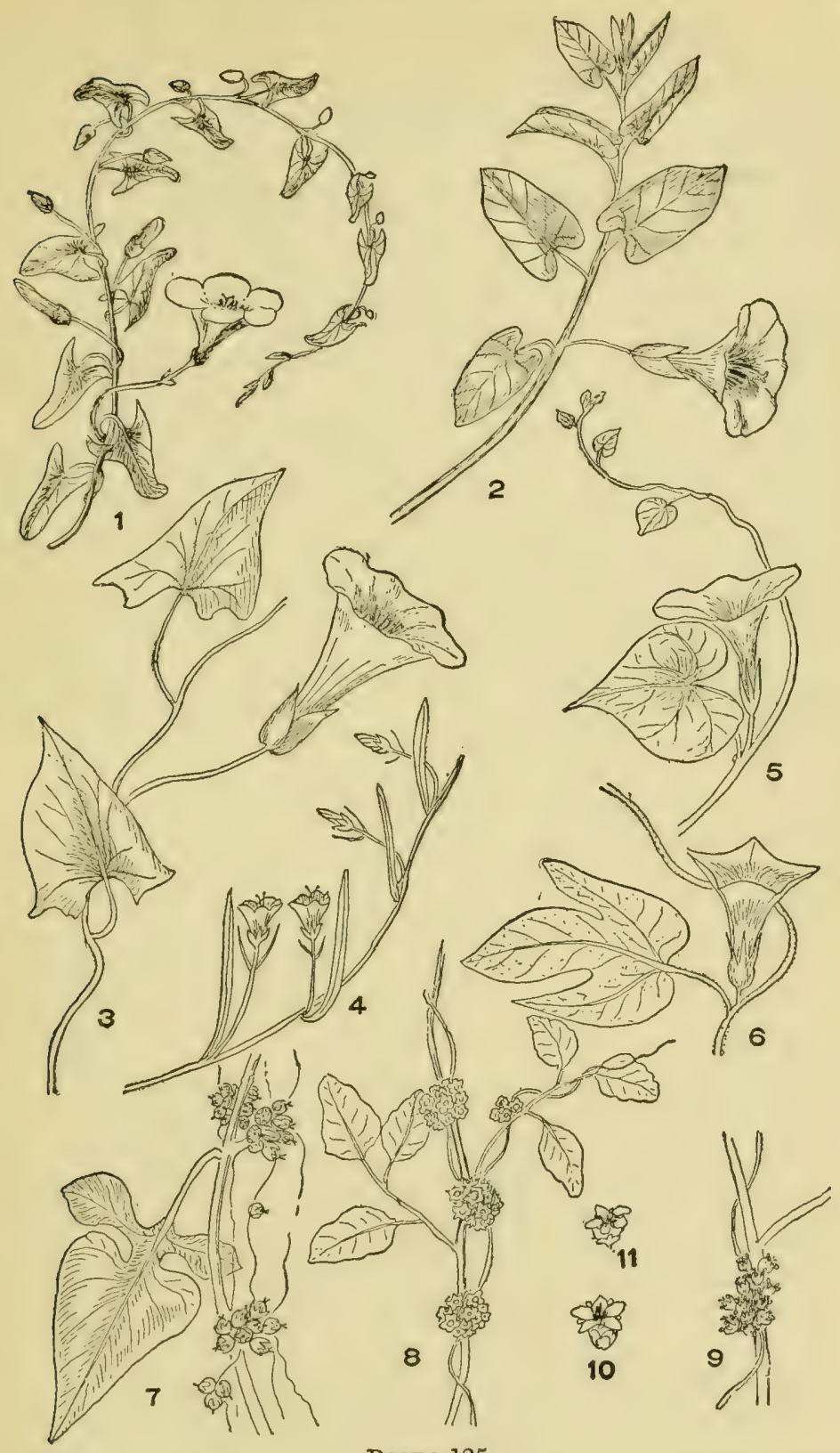

Plate 125

1. Convolvulus arvensis. 2. C. spithamaeus. 3. C. sepium. 4. Breweria Pickeringii. 5. Ipomea pandurata. 6. I. hederacea. 7. Cuscuta arvensis, growing on Nightshade. 8. C. Gronovii, on Jewel weed. 9. C. Coryli. 10. C. compacta, single flower. 11. C. cephalanthi, single flower. 
1. I. pandurata, (L.) Meyer. (Fig. 5, pl. 125.) Wird Ротато ViNe. Perennial vine from a very large root, smooth or slightly downy, stems 2 to $12 \mathrm{ft}$. long. Leaves alternate, broadly egg-shaped, heart-shaped at base, sharp pointed at apex, without teeth at margins and generally without lobes, but sometimes contracted at middle, giving leaf a fiddle-shaped outline or some of the later ones angular. Flower stem usually longer than the leaf-stalk, with from 1 to 5 white, funnel-form flowers with pink or purple stripes in the throat, the corolla about $3 \mathrm{in.}$ long and as broad. Dry soils. Connecticut and southward. May-Sept.

2. I. lacunosa L. Small-flowered White Moring-glory. Stem trailing, 2 to $8 \mathrm{ft}$. Iong, downy or hairy. Leaves on slender leaf-stalks, lieart-shaped at base, egg-shaped or 3-lobed. Flower stem shorter than the leaves; flower white, $\frac{1}{2}$ to $\frac{3}{4}$ in. long. Penna., and southward. JulySept.

3. I. purpurea, (L.) Roth. CoMmox Morring-glorr. Climbing vine, escaped from gardens. Stem 4 to $10 \mathrm{ft}$. long, hairy. Leaves broadly ovate, heart-shaped at base, sharp pointed at apex, sometimes more or less lohed, hairy. Flower stems slender, 1- to 5-flowered. Flowers funnelformed, purple, blue, pink, etc. Ovary 3 , rarely 2 -celled, capsule globose. Waste places, mostly from gardens. July-Oct.

4. I. hederacea, Jacq. (Fig. 6, pl. 125.) Ivr-Leaved MorningGronx. Stem 2 to $5 \mathrm{ft}$. long, hairy. Leaves deeply 3 -lobed, lobes acute, heart-shaped at base, hairy. Flower stem bearing 1 to 3 funnel-shaped flowers nearly white, the rim light blue or purple, I to 5 in. long. Ovary 3-celled, capsule globose. Southern part of our area. July-Oct.

\section{CONVOLVULUS, L.}

Herbs, with trailing or climbing vines or erect stems. Leaves in our species without teeth at margins and without stipules; the vines with leart-shaped, or arrow-shaped leaves, the ereet plant with oval leaves; corolla funnel-shaped, pink, purple or white, the border 5-angled, plaited, or continuous. Calyx with or without bracts at its base. Pistil dividing into 2 near the top. Stamens 5, inserted at the base of the corolla. Capsule globose.

Stems climbing or trailing, leaves heart-shaped at base.

Stems 3 to ro $\mathrm{ft}$. long..................... sepium

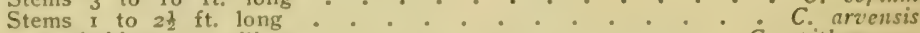

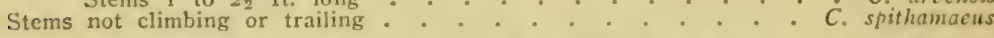

1. C. sepium, T. (Fig. 3, pl. 125.) Retraxn Beauty. Irenge Bixnwred. Stems trailing or twining, 3 to $10 \mathrm{ft}$. long. smooth or slightly hairy. Leaves triangular spear-shaped on slender leaf-stalks, acute at apex, dorply depresod at base. Flowers, one on an elongated flower stem, arising from a leaf-axil; corolla white or pink, about $2 \mathrm{in.} \mathrm{long} \mathrm{and} \mathrm{as}$ broad across the border. Bracts at the base of the corolla large, eggshaped, heart-shaped at base. On stone walls and in thickets. JuneAug.

2. C. arvensis, T. (Fig. 1, pl, 125.) Siratr, Brnnweed. Trailing on the gromul, strms 1 to $2 \frac{1}{2}$ ft. long. Tdives triangular, arrow-slatped, 1 to $2 \frac{1}{2}$ in. long, the basal lobes spreading. Flowers 1 to 4 on a flower stem, which is shorter than the leaves, with 1 to 3 bracts at the summit. 
Corolla about an in. long and as broad, pink or white. Calyx without bracts at base. Waste places. May-Sept.

3. C. spithamaeus, L. (Fig. 2, pl. 125.) Upright Bindweed. Stems erect or curving upward, smooth or mostly downy, not twining or the summit slightly twining, $\frac{3}{2}$ to $1 \mathrm{ft}$. high. Leaves alternate oblong, with or without a heart-shaped base, round at apex. Corolla 2 in. long, white, a single flower on the flower stem. Calyx enclosed by 2 large bracts. Dry sandy soil. May-Aug.

\section{Fanily II.-CUSCUTACEAE. Dodder FAMILY}

Long thread-like white, yellowish or reddish vines with leaves recluced to small scales, rising from the ground, but becoming entirely parasitic, lying upon or twining about herbs or shrubs to which they adhere by means of suckers. Flowers in more or less densely compact rounded or irregular clusters, white or yellowish. Flowers with calyx and corolla, pistil and stamens. Calyx below the ovary and not adherent to it, of 5 lobes or divisions; corolla bell-shaped, urn-shaped or egg-shaped, in the tube of which are, alternating with the corolla lobes, 5 scales which are finely toothed or fringed. At the sinuses of the corolla lobes and above the scales arise the 5 short filamented stamens. Pistils 2. Capsule globose.

\section{CUSCUTA, L.}

Characters as above.

The scales within the corolla bordered with small rounded teeth. Summit of pistil elongated.

The scales not incurved . . . . . . . C. Epilinum

The scales strongly incurved $\because \cdots C^{C}$. Epithymum The scales within the corolla bordered by a fringe." Sumit of pistil rounded.

Flowers without flower stems .......... C. arvensis Flowers with short flower stems.

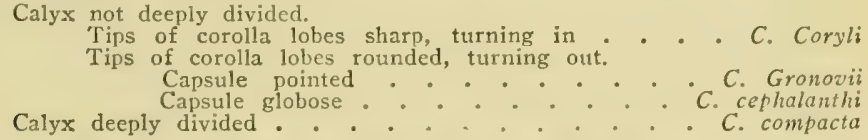

1. C. Epilinum, Weihe. FuAx Donner. Stem yellow or reldish, very slender. Flowers globular, in dense heads, flowers elosely connected with the stem without flower stem. Corolla with 5 lobes, scarcely exceeding the divisions of the calyx; seales within the corolla rounded, the upper border with rounded teeth which do not curve invard. The lobes of the corolla spreading outward. Growing on flax, hence its name. June.

2. C. Epithymum, Murr. Thyme Donder. Clover Donder. Sten reddish, thread-like. Flowers in small dense rounded clusters, without flower-stems, the clusters pinkish. Corolla tube longer than the ealyx; scales within the tube toothed, and strongly eurved inward. Found on clover and alfalfa in this country. In Europe on thyme, hence its name. July-Sept. 
3. C. arvensis, Beyrich. (Fig. 7, pl. 125.) Fieln Dodder. Stems pale yellow, slender. Flowers small, each on a very short flower-stcm, clusters few flowered. Corolla bell-shaped, with 5 shallow lobes, the scales within being fringed around the whole margin. The acute tips of the lobes of the corolla are strongly turned in. Found on various plants on rather dry soil. July-Aug.

4. C. Coryli, Engelm. (Fig. 9, pl. 125.) HAzeL DodDER. Stem coarse, twining about stems of shrubs, etc. Flowers with distinct flowerstems in dense elongated clusters. Calyx of 5 lobes, not deeply divided, triangular; corolla bell-shaped, 4- or 5-lobed. Scales inside the corolla small, obtuse with a scant fringe or the scale reduced to a few fringe elements. Corolla lobes angular, deflected inward at apex. Grows on hazels and other shrubs or on coarse herbs.

5. C. Gronovii, Willd. (Fig. 8, pl. 125.) Gronovius's Dodder. Love VINE. The most common of the dodders. Stems coarse, sometimes climbing high. Corolla lobes rounded, the tips turning out. Scales within deeply fringed; pistils with rounded heads (stigmas). Wet shady places. July-Aug.

6. C. compacta, Juss. (Fig. 10, pl. 125.) Compact Dodder. Stem coarse, flowers in densely compact clusters, each without flower-stem. Calyx of 5 parts, dceply divided from each other, subtended by 3 to 5 bracts resembling the calyx lobes. Corolla salver-form, the 5 lobes spreading, obtuse at tip, scales narrow, fringed. On slirubs in damp woods. July-Sept.

7. C. cephalanthi, Engelm. (Fig. 11, pL 125.) ButroN-Busir DoDDER. Stems yellow, coarse, high climbing. Flowers in compact masses, the lobes of the corolla rounded, spreading or rolling outwarl. Tall herbs and shrubs, Pennsylvania, south and westward. July-Aug.

\section{Family III.-POLEMoniaceae. Phlox FaMily}

IIerbs with alternate or opposite leaves and with regular and perfect flowers; a 3-celled ovary superior to the calyx; the pistil 3-parted ahove; stamens 5, inserted on the corolla tube and alternate with the corolla lobes; calyx tubular or bell-shaped, 5-parted; corolla funnel-formed, bell-shaped, wheel- or saucer-shaped. Capsule splitting at the sides, 3 -valved.

Leaves simple, opposite . . . . . . . . Phlox

Leaves compound (feather-formed), alternate Polemonium

\section{PHLOX, L.}

Ornamental herhs, with opposite leaves and terminal clusters of flowers. Calyx tubular with o narrow divisions, 5-ribled. Corolla a long slender tube abruptly expanding into a flat whecl-like expanse, the border 5-lobed. Stamens 5, inserted into the tube of the corolla at about its middle, pistil 


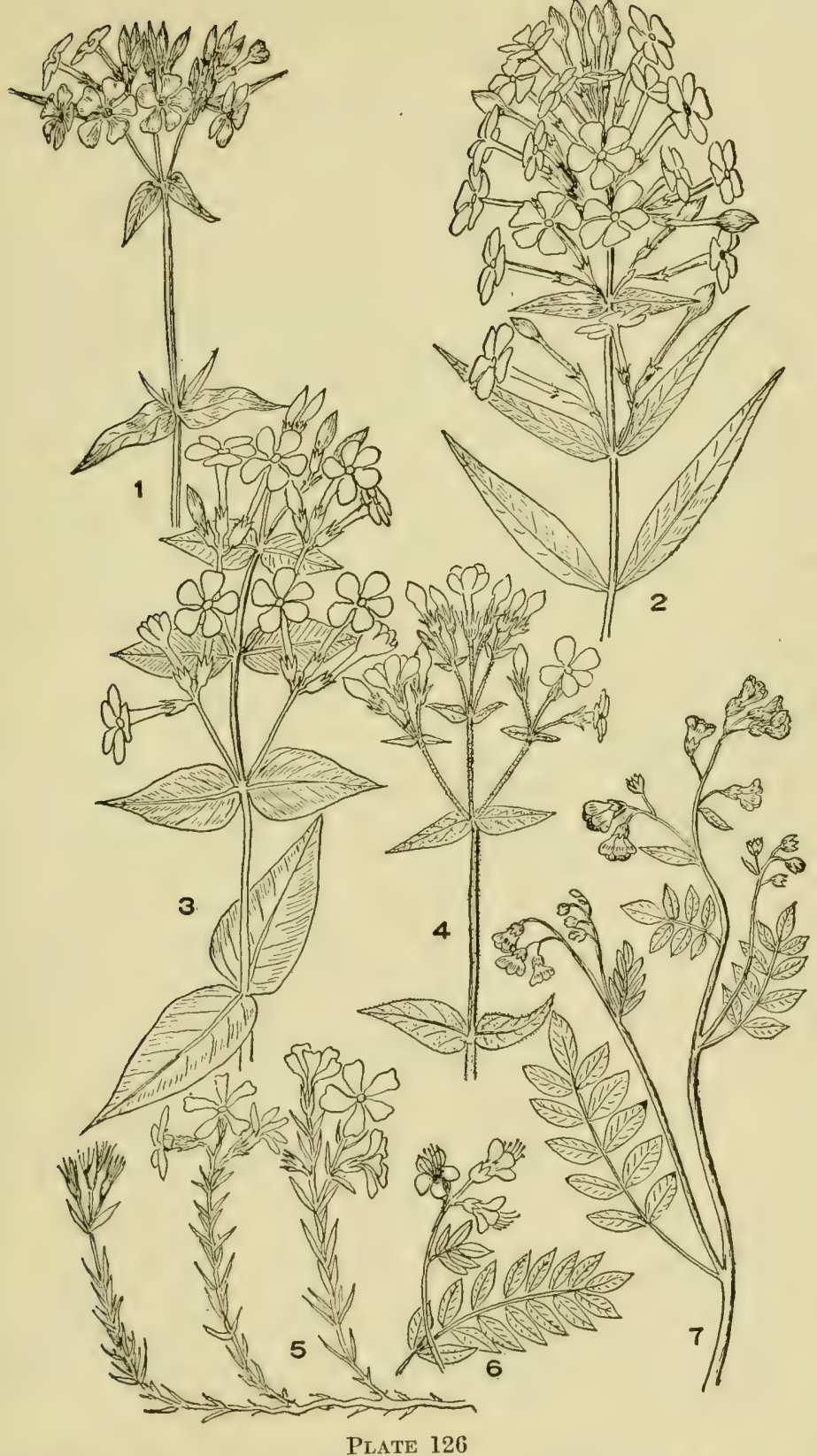

1. Phlox divaricata. 2. P. paniculata. 3. P. maculata. 4. P. pilosa. 5. P. subulata. 6. Polemonium coeruleum. 7. P. reptans. 
1, divided near summit into 3 branches. Capsule 3 -celled, each cell 1-seeded.

Leaves flat, opposite.

Stems strictly erect.

Stem with purple spots . . . . . . . . P. maculato

Stem without purple spots.. .9 . paniculata

Stem more or less decumbent, at least at the base.

Calyx not hairy ......... . . . P. ovata

Calyx hairy.

Flowers blue or lilac . . . . . . P. divaricate

Flowers purple, pink or white $\because \cdots, P$. pilosa

Leaves awh-shaped, in whorls... . . . . . . . . . P. subulata

1. P. maculata, L. (Fig. 3, pl. 126.) Wild Sweet-william. Stem erect, $1 \frac{1}{2}$ to $3 \mathrm{ft}$. high, generally flecked with purple spots; leaves opposite, lance-shaped, rounded or more or less heart-shaped at base, tapering to an acute point at apex, not hairy. Flowers in an elongated rather compact cluster. Calyx teeth triangular, lance-shaped, without hairs. Corolla purple, pink or rarely white. Moist woods, southern and central part of our area. June-Aug.

2. P. paniculata, L. (Fig. 2, pl. 126.) Garden Pillox. An escape from gardens which has becomo naturalized in the very southern part of our area. Stem erect, 2 to $6 \mathrm{ft}$. high. Leaves opposite, lance-shaped, tapering at both ends, the upper sometimes heart-shaped at base. Flowers in a large pyramidal cluster; calyx teeth awl-shaped. Corolla pink to white. Not found wild except in southern section of our area. Common in gardens. Established in a few localities. June-July.

3. P. ovata, L. Mountain Phlox. Stems leaning at base, 1 to 2 ft. high, whole plant without or with very few hairs. Leaves opposite, more or less leathery, the upper egg-shaped, or somewhat lanee-shaped, the base broad and rounded or even heart-shaped, 1 to $2 \mathrm{in}$. long, tapering to a point at apex, the lower leaves pear-shaped. Calyx teeth lanceshaped, not hairy or viscid, nearly $\frac{1}{2}$ as long as the corolla tube. Corolla pink or red. Woods in the very southern part of our area. May-Aug.

4. P. pilosa, L. (Fig. 4, pl. 126.) Downy Prilox. Stem slender, mostly more or less decumbent at base, the upper part of stem ereet or nearly so. Whole plant soft downy. Leaves opposite, linear or narrow lance-shaped, tapering at each end, 1 to $4 \mathrm{in.} \mathrm{long.} \mathrm{Flowers} \mathrm{in} \mathrm{rather}$ flat clustrors. Calyx viseid, hairy. Corolla pink-purple or red, rarely purplish-white. Dry woods, New Jersey and south. April-June.

5. P. divaricata, L. (Fig. 1, pl. 126.) WhLd BLue PHLox. Stems decumbent at base, 3 to $1 \frac{1}{2} \mathrm{ft}$. high, viseid downy. Leaves opposite, lanceshaped, rounded or lheart-shaped at base, pointed at apex. Cluster of flowers broad, rather flat, loosely flowered; lobes of corolla notched at the end, rarely entire, blue or pale lilac. Rocky damp woods. AprilJune.

6. P. subulata, L. (Fig. 5, pl. 126.) Moss PINא. Common in gardons in New Engrand and New York. In southern part of our area found often in extensive patches forming in spring a large expanse of bright pink or purple color. Strms decumbent, 1 to $\frac{1}{2} \mathrm{fi}$. long; leaves linear, awl-shaped, in whorls about the stem. lilowers in terminal flat clusters. Corollat lobes noteherl at the end. Dry hills, New York, southward and westward. April-June. 


\section{POLEMONIUM, L.}

Perennial (rarely annual) herbs, with alternate compound (featherformed) leaves and with clusters of blue, white or yellow flowers. Calyx bell-shaped. Corolla fummel-formed; stamens 5, inserted at the summit of the short tube of the corolla. Capsule ovoid, few to several seeded.

1. P. coeruleum, A. Gray. (Fig. 6, pl. 126.) American Jacor's LAdDer. (P. Van Bruntiac, Britton.) Stem 1 to $3 \mathrm{ft}$. high, erect, smooth or slightly hairy above. Compound leaves alternate, the lower ones consisting of from 9 to 21 leaflets, the upper mostly of 3 leaflets, eggshaped, pointed at each end, $\frac{1}{2}$ to $1 \frac{1}{2} \mathrm{in}$. long. Flowers in a loose terminal cluster; divisions of the calyx longer than its tube; the 5 lobes of corolla rolled outward; stamens and pistil extending considerably beyond the corolla. Flowers blue. Swamps and wet places and on mountains, Vermont, northern New York and southward. May-July.

2. P. reptans, L. (Fig. 7, pl. 126.) Greer Valerian. Stems more or less reclining, about $1 \mathrm{ft}$. high or less, smooth or slightly downy. Leaflets 5 to $15^{\circ}$; oblong, pointed at each end, the upper leaves of 3 leaflets. Calyx lobes obtuse; stamens not extending beyond the corolla. Color light blue. Woods, New York, southward and westward. May-June.

\section{FAMily IV.-HYDROPHYLlaCEAE. WATER-LeAf FAMily}

Herbs, mostly with alternate, large, deep-lobed leaves, generally hairy, with regular flowers, blue, purple or white. Calyx inferior to and free from the ovary, 5-cleft, often with an appendage at the cleft. Corolla tubular bell-shaped, 5-lobed, often with 10 horny scales near the base. Stamens 5, inserted into the corolla. Style deeply bifid. Capsule 1- to 2-celled, ovoid.

Stamens extending beyond the corolla.

Anthers linear or oblong .

Hydrophyllum

Anthers egg-shaped.

Phacelia

Stamens not extending beyond the corolla . . . . . Ellisia

\section{HYDROPHYLLUM, L.}

Herbs, with large, lobed or somewhat feather-formed, leaves and with floweres in clusters. Other characters as above.

Calyx with a reflexed appendage between the sepals at base . . $H_{\text {, appendiculatum }}$ Calyx without appendages between the sepals.

Plant sparingly if at all downy . . . . . . . H. virginianum Leaves downy at least beneath.$\cdots^{*} \cdot \cup^{\circ}$ H. canadense

1. H. appendiculatum, Michx. Appendaged Water Leaf. Stems usually branched, 1 to $2 \mathrm{ft}$. high, usually covered with viscid hairs above. Leaves deeply 5 -lobed, the lobes with acute tips; margins coarsely toothed, leaves on long leat-stalks. Appendages between the sepals deflexed. Corolla violet, blue or purple. Woods. May-June.

2. H. virginianum, L. (Fig. 1, pl. 127.) Virginia Water Leaf. 
Stems slender, 1 to $3 \mathrm{ft}$. high. Not hairy or with very few hairs. Leaves deeply 5-lobed, the lobes sharp pointed and with coarse sharp teeth, the lower leaves with 5- to 7 -lobes, feather-formed. Calyx without appondages between the sepals. Flowers white or palo purple. Woods. May-Aug.

3. H. canadense, L. (Fig. 2, pl. 127.) Broan-leayed Water Leaf. Stem slender, 1 to $2 \mathrm{ft}$. high. Leaves nearly round with 5 to 7 acute lobes and with coarse teeth. Appendages between the sepals absent. Lower side of leaves somewhat downy or hairy. Woods. June-Aug.

\section{ELLISIA, L. (Macrocalyx, Trew.)}

Our species a hairy branching, slender herb, with alternate featherlobed leaves and solitary star-shaped flowers. Calyx equally 5-parted, large; the bell-shaped corolla much enlarged in fruit. Appcudages between sepals absent. Stamens 5, inserted at base of corolla and included within it. Capsulo 2- to 4-seeded.

E. Nyctelea, Kuntze. Nycteces. Stem much branched; leaves pinnately divided. Flowers white, solitary; calyx, in flower about $1 / 6$ to $1 / 4$ in. broad, in fruit about 1 in. or more broad. Capsule globose. Moist soil, southern part of our area. April-July.

\section{PHACELIA, Juss.}

Small annual herbs, usually with stifl hairs. Leaves alternate, sometimes entire, but more frequently deeply eut or lobed. Flowers in coiled elusters (cymes). Calyx 5-lobed. Corolla open bell-shaped, tubular or funnel-formed. Styles united below, stamens included in the corolla or exserted.

1. P. dubia, (L.) Small. Sanll-floweren Phacelia. Small branching plant, 5 to $12 \mathrm{in}$. ligh. Leaves divided into 3 to 5 oblong segments, opposite and terminal. Flowers in narrow clusters, the clusters not much coiled, blue or white, 5 to 15 in a cluster. Capsule globular, 6- to 12 seeded. Moist shady places, New York, and southward. April-June.

2. P. Purshii, Buckl. (Fig. 3, pl. 127.) Puisu's Puacelia. Branching, 6 to is in. high. Lower leaves on leaf-stalks, narrow, much lobed; up|er without leaf-stalks less lobed; cluster partly one sided, scareely coiled, with 10 to 20 blue or white open bell flowers with exserted stamens. Calyx lobes linear. Penna, southward, locally further north. April-June.

\section{Fanily V.-Boraginaceae. Borage Family}

Terbs, anmual, biennial or perennial. Teaves alternate or rarely opposite. Flowers, mostly blue, generally in one-sided, curved or roiled clusters. Flowers mostly regular, with both stamens and pistils, the corolla of one piece forming a tube and a spreading lismerler, which is clivided into 5 lobes. At the throat of the corolla often a slight (rest. Stamens 5, alternate with corolla loles and inserted at the throat of the corolla or deeper. Pistil 1, simple or divided at top. Ovary superior, of 2 rounded pods each 


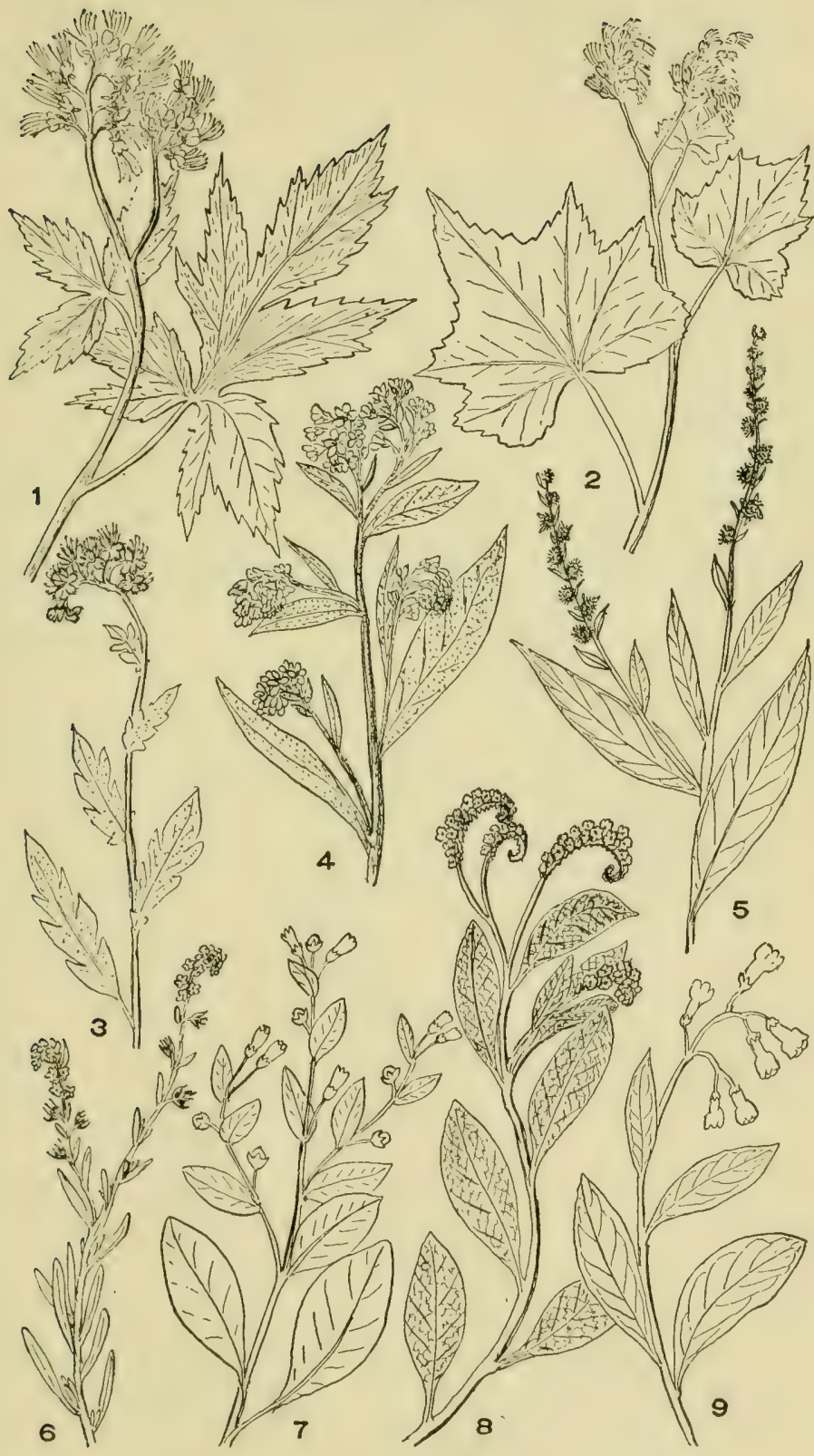

Plate 127

1. Hydrophyllum virginianum 2. H. canadense. 3. Phacelia Purshii。 4. Cynoglossum officinale. 5. Lappula virginiana. 6. L. echinata. 7. Pneumaria maritima. 8. Heliotropium europaeum. 9. Mertensia virginica. 
2-sceded, the base of the ovary being 4-lobed except in Helictropium. Fruit mostly 4 one-seeded nutlets.

Ovary not lobed . . . . . . . . . . Heliotropium Ovary 4-lobed.

Corolla borders regular, tube not bent

Nutlets (the 4 divisions of the ovary) armed with barbed prickles.

Corolla funnel-form, the nutlets spreading - Cynoglossum Corolla salver-form, the nutlets incurved . . . Lappula Nutlets not armed with prickles.

Corolla throat closed by scales.

Fleshy herb . . . . . . . . . Pneumaria

Herbs not fleshy.

Corolla star-shaped, the lobes sharp pointed, no tube

Borago

Corolla with a long tube. . .

Symphytum

Corolla throat not closed by scales.

Lobes of the corolla erect, tube cylindric

Lobes of the corolla spreading, rounded, the tube tapering . . . . . . . Myosotis

Lobes of corolla forming a bell-shaped body.

Flowers white or yellow . . Lithospermum

Flowers blue or purple . . . Mertensia

Corolla border irregular, tube not bent

Flowers blue, lobes of the corolla unequal . . . . Echium

\section{Tube of corolla bent}

Flowers blue

\section{HELIOTROPIUM, L.}

Terbs, some of which have more or less wooly stems, rarely shrubs, our only speceses purely herbacens. Leaves alternate, rarely lobed or notrlard at margin. Flowers in slemder one-sided clusters which coil nearly to the extent of forming a ring. Corolla small, funnel-form or salver-form, the 5 lobes romderl, ealyx with 5 lanee-shaped lobes. Ovary, although of 2 cells, each containing 2 seeds, is not deeply lobed as is the case with other genera of this family. 
H. europaeum, L. (Fig. 8, pl. 127.) Eunopean Heliotrope. Much branched, $\frac{1}{2}$ to $1 \frac{1}{2} \mathrm{ft}$. high. Leaves oval, apex obtuse; the whole plant rough hairy. Flowers white in terminal curved spikes. Naturalized from Europe. In southern part of our area. June-Oct.

\section{CYNOGLOSSUM, L.}

Mostly rough hairy tall herbs. Leaves alternate, with smooth margins, the lower with long leaf-stalks. Flowers in curved clusters; corolla funnel- or salver-form with short tube, throat closed by 5 scales. Calyx 5-parted. Ovary deeply 4-lobed, the lobes spreading and covered with short barbed prickles.

1. C. officinale, L. (Fig. 4, pl. 127.) Hound's Tongue. GiPsY Flower. Stem $1 \frac{3}{3}$ to $3 \mathrm{ft}$. high, usually branched, downy, leafy to the top. Lower leaves narrow-oblong, $\frac{1}{2}$ to $1 \mathrm{in}$. long, upper lance-shaped without leaf-stalks. Flowers in terminal curved clusters in which there are ro leafy bracts. Corolla dull purple. Plant with an unpleasant odor. In fields and waste places. May-Sept.

2. C. virginianum, I. Wild ComfreY. Plant much larger than No. $1,1 \frac{1}{2}$ to $2 \frac{1}{2} \mathrm{ft}$. high, and leaves broader and longer, 4 to $12 \mathrm{in}$. long, obtuse at apex. Leafless above, leaves below oblong. Flowers blue. Woods. April-May.

\section{LAPPULA, Moench. (Echinospermum, Sw.)}

Herbs, mostly rough hairy. Leaves alternate, margins entire. Flowers in long, somewhat curved and more or less one-sided spikes, with leafy bracts among the flowers. Nutlets erect or curving with barbed prickles on the bank.

1. L. echinata, Gilibert. (Fig. 6, pl. 127.) European Stickseed. (L. Lappula, Karst.) Whole plant hairy, branching, 1 to $2 \mathrm{ft}$. high. Leaves lance-slaped to linear, without leaf-stalks. Flowers in long and slender spike, scattered, with a bract below each flower. Nutlets with prickles in 2 rows. Waste places. May-Sept.

2. L. virginiana, (L.) Greene. (Fig. 5, pl. 127.) Viraivia Stick. SEED. Plant downy, 2 to $4 \mathrm{ft}$. high. Leaves broadly oval, the lower, 3 to 8 in. long and sometimes nearly round. Flowers in slender spikes, several from the main stem, bracted only at the base of the spikes. Flowers white or purplish-white. Dry woods and thickets, Maine and southward. June-Sept.

\section{PNEUMARIA, Hill. (Pulmonaria, L. Mertensia, S. F. Gray)}

A fleshy, smooth, diffusely-branching herb, with alternate leaves, entire at margins and with small blue-purple or pinkish flower in loose terminal, leafy clusters. Corolla tubular, crested in throat, 5-lobed. Ovary 4-lobed, rounded; style 1. Nutlets fleshy not armed with prickles.

P. maritima, (L.) Hill. (Fig. 7, pl. 127.) SeA Lungwort. Orster Plant. Branches spreading 3 to 15 in. long, pale green. Leaves thick, fleshy, egg-shaped, oblong or pear-shaped, obtuse at apex. Flowers blue or purple. Sandy sea shores, rare, Long Island, Mass., and northward. May-Sept. 


\section{MERTENSIA, Roth.}

Perennial herbs, stem and leaves usually smooth. Leaves alternate, sometimes dotted with pelucid dots. Flowers in slender or spreading clusters. Corolla tubular, spreading above, 5-lobed, without scales at the throat. Stamens 5, inserted at the top of the tube. Nutlets smooth; ovary 4-lobed.

M. virginica, (L.) Link. (Fig. 9, pl. 127.) Virginia Cowslir. Stem somewhat decumbent or erect, very smooth, branched, 1 to $2 \mathrm{ft}$. high. Leaves, the lower large, 2 to 5 in. long, obversely or directly egg-shaped, lower on leaf-stems, the upper without. Flowers in terminal cluster not one-sided; corolla trumpet-shaped, blue to lilac, handsome, about 1 in. long, erect or pendant. Nutlets rounded, not prickly. Moist places, most of our area. March-May.

\section{MYOSOTIS, L.}

Low herbs, branching, somewhat decumbent or erect, hairy or downy. Flowers in slender curved clusters, spikes not bracted, or with a few small bracts at base of cluster. Calyx 5-cleft; corolla funnel- or salver-form, border of 5 lobes, throat closed by scales. Stamens 5 , inserted into lower part of corolla tube. Nutlets egg-shaped, smooth.

Hairs on the calyx minute and straight.

Lobes of calyx shorter than calyx tube .. . . . . M. scorpioides Lobes as long as tube . . . . . . . . M. laxa

Hairs on calyx stift and bent backward at end.
Fruit-stems longer than calyx . . . . . . M. arvensis Fruit-stems shorter than calyx. Corolla yellow, changing to bluish . . . . . M. versicolor Corolla white ............. M. virginica

1. M. scorpioides, J. (Fig. 1, pl. 128.) Forget-Me-Not. (H. palustris, (L.) Lam.) Plant downy or nearly smooth, leaves lance-shaped or oblong, blunt at apex. Flowers in one-sided curved spikes (XII, p. 38) ; corolla blue with a yellow eye. Escaped from gardens. In brooks and marshes, more especially in the northern half of our area. May-July.

2. M. laxa, Lehm. (Fig. 2, pl. 128.) Smalder Forget-Me-Not. Leaves long and narrow, blunt at apex. Flowers in very loose curved spikes, the fruit stem much longer than the ealyx which has short soft hairs. Corolla blue with yellow center. In muddy places and in water throughout our range. May-July.

3. M. arvensis, (I.) Hill. Lam. Field Sconpion Grass. Very hairy, leaves long and narrow; the hairs on the calyx stiff and turned back at end. Stem of fruit much longer than calyx. Corolla blue. Moist fields, northern part of our area. June-Aug.

4. M. versicolor, (Persh.) Reichenb. (Fig. 3, pl. 128.) Yellow avd Bive Sconplon Grass. Stem slender, leaves long and narrow. Plant very hairy; slender flower spikes without bracts; calyx 5 -parted; corolla pale yellow, changing to violet; stem of fruit not as long as calyx. Fields and roadsides, southern part of our area. May-July.

5. M. virginica, (T.) I3SP. (Fig. 4, pl. 128.) Srring Scorrion firass. Very hairy; lower leaves spatula-form. Calyx longer than the fruit stem. Flowers white. Dry hills, northern part of our area. AprilJune. 

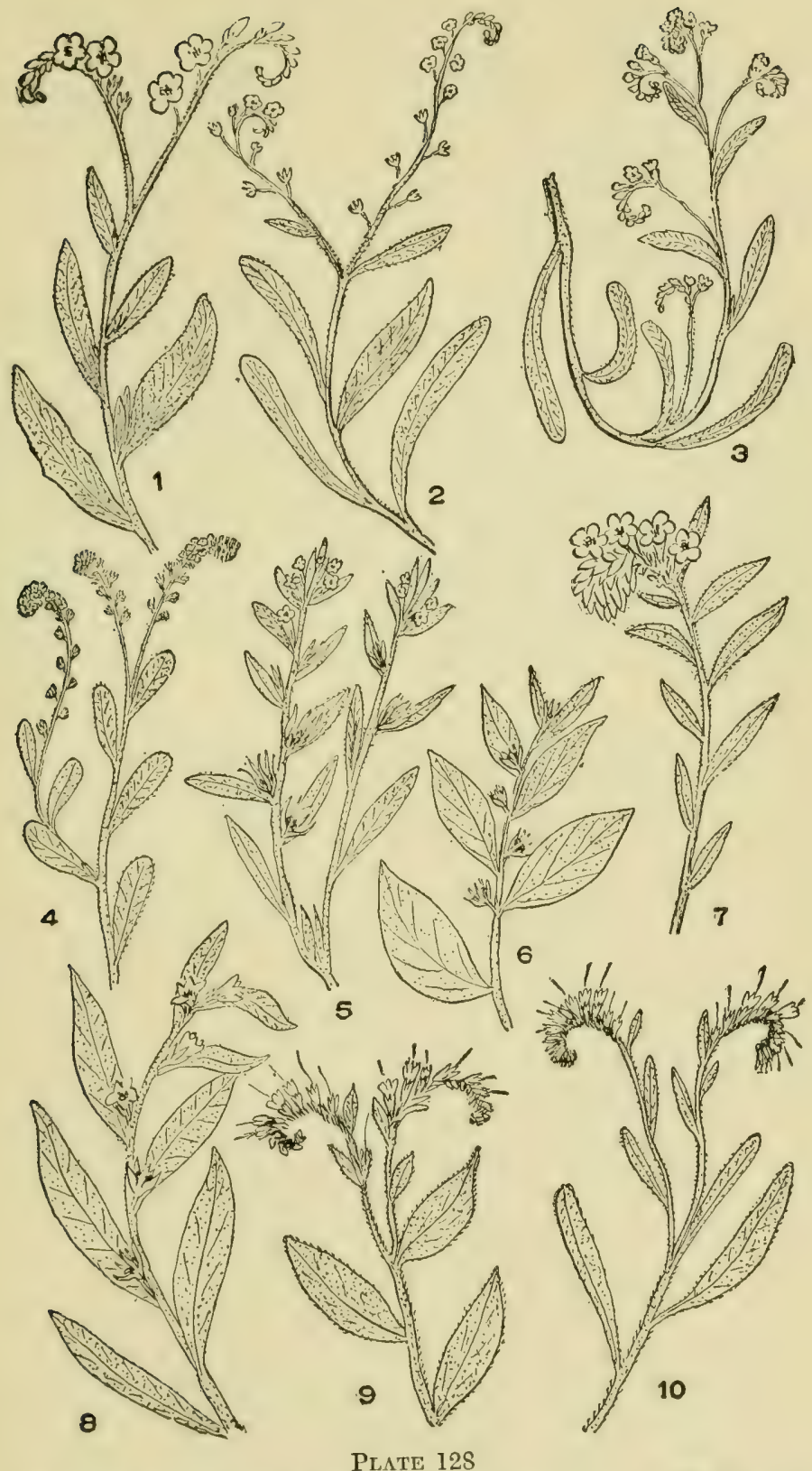

1. Myosotis scorpioides. 2. M. laxa. 3. M. versicolor. 4. M. virginica. 5. Lithospermum arvense, 6. L. latifolium. 7. L. canescens. 8. L. officinale. 9. Onosmodium hispidissimum. 10. O. virginianum. 


\section{LITHOSPERMUM, L.}

Hairy herbs, the hairs soft or rigid. Stems from a thick reddish root. Flowers white, yellow or blue, in leafy spikes or terminal spreading clusters. Calyx 5-parted; corolla funnel- or salver-form, border 5-lobed. Stamens 5, included in the corolla; head of pistil bifid; nutlets 4, horny, rough or smooth.

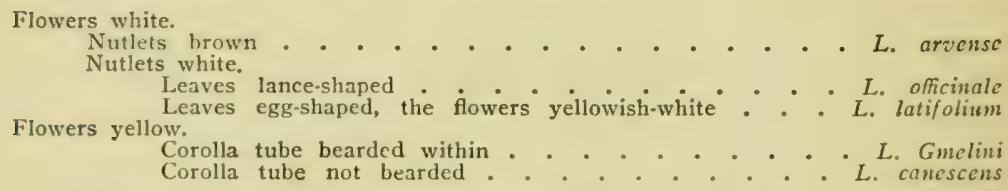

1. L. arvense, L. (Fig. 5, pl. 128.) CoRN GromwelL. Stem erect, usually branched, 12 to $15 \mathrm{in.} \mathrm{high.} \mathrm{Whole} \mathrm{plant} \mathrm{hairy,} \mathrm{the} \mathrm{stems} \mathrm{rough}$ hairy, leaves downy. Leaves alternate, narrow lance-shaped, 1 to 2 in. long, obtuse at apex, without leaf-stems. Flowers small, white in the axils of the upper leaves. Nutlets brown, hard, shining. A weed, in waste places, May-Aug.

2. L. officinale, L. (Fig. 8, pl. 128.) Officinale Gromwell. Stem very branching, 1 to $2 \mathrm{ft}$. high; leaves lance-shaped, sharp pointed at apex. Flowers small, white in leaf-axils. Whole plant hairy, rough; leaves gray-green. Nutlets white. Waste places, in most of our range. June-July.

3. L. latifolium, Michx. (Fig. 6, pl. 128.) Broad-Leaved GronW'EL.L. Stems erect not much branched. Leaves round egg-shaped, tapering at each end. Flowers at leaf-axils, yellowish-white or white. Corolla crested at throat of tube. Nutlets shining white dotted with small points. Dry woods and thickets, New York and northward and westward. May. June.

4. L. Gmelini, (Michx.) Hitcheock. HaIn Gromwelt. Stems ereet, usually clustered, 1 to $2 \mathrm{ft}$. high, hairy. ILeaves lance-slaped sharp pointed at apex, no leaf-stem. Flowers nearly an inch long in terminal spreading clusters; corolla yellow; calyx segments about $\frac{1}{2}$ as long as corolla tube. Dry woods, New York and westward. April-June.

5. L. canescens, (Michx.) Lehm. (Fig. 7, pl. 128.) Hолrx PuCcoox. Stems in clusters 6 to 18 in. high, hairy with soft hairs. Leaves lance-shaped rather sharp at apex, without leaf-stem. Flowers handsome, yellow, crowled near the top of the stem. Corolla not bearded at throat; intlets white, shining. Dry places, throughout most of our range. AprilJune.

\section{ONOSMODIUM, Michx.}

('oarse hairy herbs, with alternate, stromgly veined leaves, without leaf-stems. Flowers in one-sided, more or less coiled spikes or loose onesided clusters. ('alyx 5-parted, the divisions linear; eorolla tubular, or funnel-form, without crest at throat. Stamens 5, inserted in the tube or at the throat of the corolla, not extending leyoud the eorolla. Nutlets brny, white, smooth, 4, of which generally inly one is perfected.

1. O. hispidissimum, Mackenzie. (Fig. 9, pl, 12s.) SHafir Fasse (imombirlo (U. curolinianum, I)C.) Plant, 1 to $3 \mathrm{ft}$. high, the whole 
plant shaggy with long, spreading, loose hairs. Leaves broad lanceshaped, acute at apex; corolla tubular, 5-lobed, the lobes sharp pointed the points hairy outside. Flowers yellowish-white. Dry fields, woods and thickets, Mass., and southward. May.July.

2. O. virginianum, (L.) DC. (Fig. 10, pl. 128.) Virginia False Gromwell. Similar to No. 1, but leaves blunt at apex, and lobes of corolla narrow, awl-shaped, very sparingly hairy on outside. Flowers yellowish-white. New York, New England and southward. May-July.

\section{SYMPHYTUM, L.}

Coarse hairy perennial herbs, with thick bitter mucilaginous roots, the clusters of flowers somewhat one-sided and nodding. Corolla tubular, inflated above, the border more or less spreading, the throat closed with the 5 very narrow, awl-like scales. Calyx, 5-cleft, the segments narrow. Flowers yellow, blue or purple. Stamens 5, inserted on corolla tube, not extending beyond tube. Style 1, thread-form. Nutlets 4, smooth.

S. officinale, L. (Fig. 8, pl. 129.) Comfrey. Whole plant very hairy, stem 2 to $3 \mathrm{ft}$. high. Leaves broad lance-shaped, the lower nearly a foot long on narrow leaf-stalk, the upper shorter without leaf-stalk, the insertion extending down the stem, forming wings. Flowers in rather spreading clusters, yellowish or purplish. Moist places, escaped from gardens. June-Aug.

\section{Io. BORAGO, L.}

Hairy herbs, with alternate leaves and star-shaped, showy blue flowers in loose terminal elusters. Calyx 5-parted, deeply cleft, hairy; corolla wheel-shaped, with the 5 acute lobes forming a star, the tube shallow. Stamens 5, inserted into tube of corolla, the 5 anthers cohering about the pistil. Nutlets 4, smooth.

B. officinalis, L. (Fig. 1, pl, 129.) Borage. Stem 1 to $2 \mathrm{ft}$. ligh; leaves oblong to egg-shaped, 2 to 5 in. long without leaf-stalks, mostly clasping the stem. Flowers bright blue. Escaped from gardens. June. Sept.

\section{LYCOPSIS, L.}

Bristly herbs, with alternate leaves and small blue flowers. Calyx 5-parted; corolla somewhat irregular, tubular, the tube curved, the border 5-lobed; throat closed with scales, Nutlets 4, wrinkled.

L. arvensis, L. (Fig. 2, pl. 129.) Small Bugloss. Stem branched, 1 to $2 \mathrm{ft}$. high, covered with stiff hairs. Leaves alternate with stilf hairs, lance-shaped or narrowly oblong, obtuse at apex, without leaf-stalks. Flowers in a narrow crowded, one-sided coiled spike. Fields and waste places, generally in our area. June-Sept.

\section{I2. ECHIUM, L.}

Plants covered with bristly hairs, with alternate leaves and with rather large, blue or rarely white, flowers in leafy, more or less one-sided clusters. Calyx 5-parted, corolla tubular, spreading at border, 5-toothed or lobed, the lobes unequal. Stamens 5, inserted low in corolla tube, unequal in 
length, the longer ones extending beyond the corolla tube. Nutlets 4, rough.

E. vulgare, L. (Fig. 3, pl. 129.) Blue ITeed. Virer's Bugloss. Somewhat branching, 1 to $2 \mathrm{ft}$. high. Flowers showy, blue, varying to reddish-purple; corolla about an inch long, lobes unequal. Leaves lanceshaped, pointed at apex. A weed in fields and waste places. June-July-

\section{Order VI.-VERBENINALES. Order of the Vervanes}

Flowers mostly irregular. Carpel or nutlet usually containing 2 seeds or rarely 1 seed. Leaves mostly opposite or in whorls. Fruit mostly dry carpels. Flowers not in one-sided spilies. In other respects the characters of this order are similar to the preceding (of which this is a sub-order, according to Engler, but here advanced to an order in the interest of simplicity and convenience).

Nutlets 1- to 2-seeded.

Corolla 2-lipped.

Ovary not lobed, 2 - to 4 -celled

VERBENACEAE

Ovary 4-lobed around the style, the lobes ripening into 1 -seeded nutlets.

LABIATAE

Nutlets several seeded.

Flowers regular, stamens 5; ovary 2-celled SOLANACEAE

Flowers more or less irregular, mostly 2-lipped; stamens 2 or 4 . . . . . . SCHROPHULARIACEAE

Flowers 2-lipped. Marsh or water plants without leaves or with leaves, mostly thread-like at the root

\section{LENTIBULARIACEAE}

Flowers 2-lipped, plants nearly destitute of green, parasites

OROBANCHACEAE

Flowers trmmet-shaperl, somewhat irregular; vines and trees

BIGONIACEAE

Corolla r-tobed, nearly regular, 2-lippert, stamens 4, 2 long, 2 short; ovary 2 -celled, the cells several seeded

ACANTHACEAE

Corolla nearly eylindric, 2-lipped; ovary 1-celled, 1seeded. Calyx in fruiting season reflexed to side of stem 


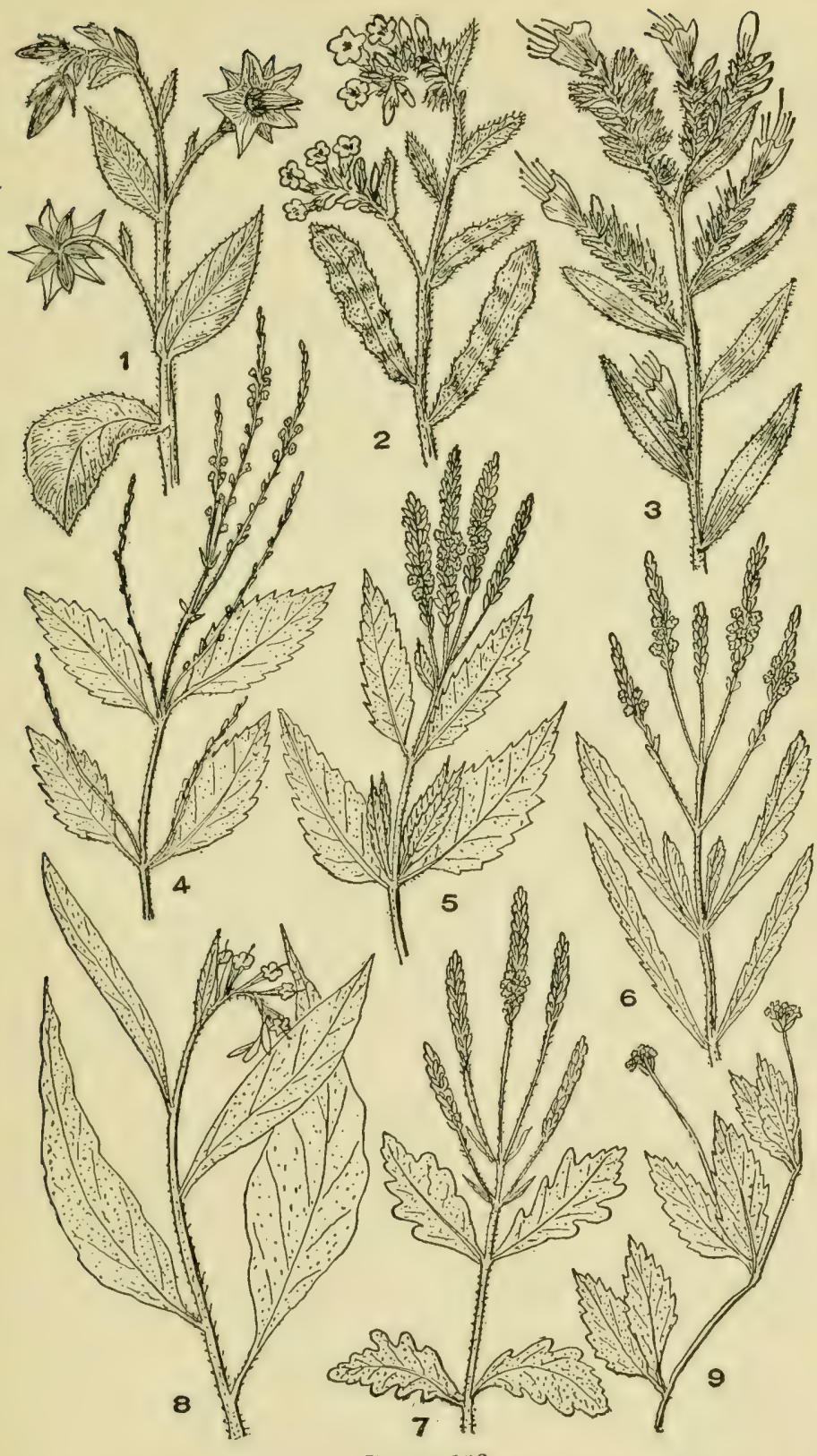

Prate 129

1. Borago officinalis. 2. Lycopsis arvinsis. 3. Echium vulgare. 4. Verbena urticifolia. 5. V. hastata. 6. V. angustifolia. $7 \mathrm{~V}$. oflicinalis 8. Symphytum oflicinale. 9. Lippa lanceolata. 


\section{Fanilit I.-Verbenaceae. Virvain Family}

American species, herbs, rarely shrubs, with opposite or whorled leaves. Corolla of our species 4- or 5-lobed, generally regular or more or less :2-lipped, generally with a cylindric tube and spreading 4 - or 5-lobed border. Stamens attached to corolla tube gencrally not the same number as the corolla lobes, often 4,2 of which are longer than the other 2. Sometimes there are 2 stamens and in other cases 5, alternate with the corolla lobes. Pistil simple with one or two caps (stigmas). Ovary superior to the calyx and corolla; the fruit composed of 2 nutlets (carpels) which at maturity split into 4 .

\section{VERBENA, L.}

American species, herbs. Leaves opposite or in whorls, with notehed or deeply incised borders. Flowers in slender spikes; corolla usually slightly 2-lipped, 5-lobed border and with a curved or straight tube. Stamens 4; 2 long, 2 shorter, rarely 2 only. Ovary 4-celled with a single ovule in each cell. Fruit at first a single nutlet, which at length divides into 4, each 1 -seeded.

Flowers blue or purple.

Margins of leaves deeply incised . . . . . . . V. officinalis Margins of leaves notched.

Flowers white

Leaves egg-shaped . . . . . . . $V$. hastata

1. V. hastata, L. (Fig. 5, pl. 129.) Blue Vervain. Perennial, rather rough; stems erect, slightly branching; leaves opposite, broad lance-shaped or egg-shaped with coarse teeth at margins. Flowers dark blue in slender spikes, several of which at summit of stem form a more or less pyramidal outline. Low wet grounds, throughout our region. June-Sept.

2. V. officinalis, I. (Fig. 7, pl. 129.) Eunopean Vervaix. Flowers on slender spikes similar to those of No. 1, but spikes few. Leaves deeply incised. Otherwise quite similar to No. 1. Moist grounds, generally distributed. June-Sept.

3. V. angustifolia, Michx. (Fig. 6, pl. 129.) NArrow-LeAved VerVArN. Spike of purple flowers usually solitary. Leaves narrow, linear, broadest toward apex, the margin toward apex, notelied. Dry fields, Mass., southward. June-Aug.

4. V. urticifolia, L. (Fig. 4, pl. 129.) Winte Vervais. General aspect of plant similar to No. 1, but flowers white. Waste places, throughout our region. June-Sept.

\section{LIPPIA, L.}

Irrbs and shrubs. Ifaves opposite or in whorls, rarely alternate. Flowers smatl, each attemded by a bratet, in compact heads or spikes. fit!yx small, membranesus, 20- to A-eleft; corolla 2 -lipped with 4 lobes, the lower one often partly divided. Stamens 4 , of diferent lengths. 
Ovary 2-celled with a single ovule in each cell. Style short. Fruit at length separating into 4 nutlets.

L. lanceolata, Michx. (Fig. 9, pl. 129.) Fog Fruit. Stem procumbent, rooting at the nodes, the erect part little if at all branched. Smooth or with a few hairs. Leaves opposite, lance-shaped, notehed at margins. Flowers blue, in rounded heads. Moist soil, New Jersey, westward and southward. June-Aug.

\section{Family II.-LabiataE. Mint Familly}

In our region all the labiates are herbs, with opposite leaves without stipules, generally the stem is 4-sided. Many of these herbs are aromatic. Flowers are, in general, irregular. The calyx, 5 -parted, is regular or irregular, in the latter case the divisions are more or less 2-lipped, the upper being of 3 , the lower of 2 teeth. Corolla tubular, expanding above into 2 lips, the upper of 2 lobes which often coalesce to the extent of appearing as one; the lower of 3 distinct lobes. Stamens borne on the tube of the corolla, mostly 4, two of which are longer than the other two (didynamous). Sometimes the anterior (lower) pair is longer than the upper and less frequently the posterior (upper) pair is longest. In a certain number of species one pair of stamens is sterile or absent. The pollen sac's are usually double, lying parallel with each other along the filament or diverging from each other, forming with the filament a sort of cross. The ovary is always above and free from the alyx; it is 4-lobed or deeply divided into 4 parts. Fruit 4 one-seeded nutlets.

\section{The Mint Tribe}

Corolla of 4 nearly equal lobes, one of which is concave or plane at top. Stamens 4, 2 longer than the other pair.

Stamens all fertile

Mentila

Two stamens fertile, two rudimentary

Lycopus

\section{The Thyme Tribe}

Corolla clearly 2-lipped; the upper lip plane or feebly concave; stamens 4, straight or divergent, the anterior or lower pair the longest.

Creeping herb, leaves very small ......... THrmus Erect herbs.

Calyx tubular, with 5 equal teeth, 15-nerved. Longest stamens extending much beyond the corolla. Leaf margin not incised or toothed . . . . . . Hrssopus

Calyx oval bell-shaped with 5 nearly equal teeth, 10- to 13-nerved.

Anther sacs divergent

ORIGANUM

Anther sacs parallel .

Pycnanthealum 


\section{Balm Tribe}

Corolla clearly 2-lipped; upper lip plane or only slightly concave. Stamens 4, diverging at base, converging above, the anterior (lower) pair longest.

Calyx with 5 equal teeth, bell-shaped, naked at the throat, 10-nerved; corolla tube straight ......... SATUreia

Calyx tubular (not bell-shaped), 2-lipped, mostly 13-nerved; corolla tube much longer than calyx, naked or hairy at throat; anther sacs divergent............ . . Clinopodium

Calyx somewhat bell-shaped, 2-lipped; corolla tube curved. Stamens scarcely extending beyond tube. Anther sacs divergent . Melissa

\section{The Sage Tribe}

Corolla clearly 2-lipped; fertile stamens ? only, the other pair when existent reduced to rudimentary organs.

The two sacs of the anthers divergent.

Between the two saes of the anther is a bridge of connection as broad as the anther sac. At one extremity is a fertile sac, at the other a sterile one . . . . Salvia

The connection between the two anther sics is not broad or well developed, the two sacs coalescing at their extremities.

Superior lip of the corolla erect or arched. Calyx tubular, 15-nerved, the teeth equal.

MONARDA

Calyx 13-nerved, the teeth unequal. Throat of corolla tube not hairy, the two stamens extending beyond the upper lip . . . . . . . . . . . . BlepHILIA

Stamens not extending beyond the upper lip. Throat of corolla hairy . . . . . . . . . Hedeoma

The two anther sacs parallel; calyx equally 5-toothed, corolla

tube hairy . . . . . . . . . . . . Cunila

\section{The Hedge-Nettle Tribe}

Corolla plainly 2-lipped; the upper lip concave. Stamens 4; the anterior (lower) pair longest. Stamens approaching above under the upper lip of the corolla.

Calyx not distinctly 2 -lipped, teeth 3 to 10 .

Calyx nearly equally 5 -toothed, the teeth membraneous; anther cells parallel to the filaments...... Prirsostegra

Anterior branch of the style longer than the posterior . Pulouis Branches of the style nearly equal.

Anthers with 2 equal sacs which are divergent.

Teeth of the calyx spiny . . . . . . . Leoncrus

Teeth of the calyx not spiny . . . . . Lamium

Anthers with divergent saes each of which is transversely

2-valved . . . . . . Galeopsis

Anther saes divergent, but not transversely 2-valved.

Calyx funnel-form, the 5 teeth spreading into a fringe;

anther saes divergent . . . . . . BALlota

Corolla tube mol. lomerer than the calyx, anther saes divergent; filaments lean outward ...... STACHYS 
Calyx tube 5- to 10-nerved, corolla tube longer than the calyx. Anther sacs parallel. Lower leaf-stalks very long . .

\section{The Skullcap Tribe}

Corolla 2-lipped. Stamens 4, shorter than the upper lip of the corolla and ascending under it. The upper lip arched over stamens.

Calyx deeply 2-lipped, 10-nerved, upper lip of 3 short teeth, lower of 2 lance-shaped teeth . . . . . . Prunella Calyx with a protuberance on the upper side . . . Scutellaria Calyx without a protuberance.

Calyx spiny-pointed . . . . . . . . . Marrubium Calyx not spiny-pointed . . . . . . . . Meemania

\section{\%. The Catmint Tribe}

Corolla 2-lipped; stamens 4, the posterior (upper) longest. Anther cells divergent or parallel. Stamens shorter or scarcely Ionger than the upper lip of the corolla.

Calyx tubular with 5 sharp teeth, not 2-lipped, but the upper 2 teeth longer than the 3 lower, 15-nerved, erect plant . NEPETA

Anther sacs diverging and at right angles to the connecting bridge. Cresping herb . . . . . . . . . GLEComa

Calyx with 5 sharp teeth, the upper largest, the whole calyx covered with long hairs. Calyx tubular, 15-nerved Dracocepialua

Anther cells parallel or nearly so. Very tall herbs, with long cylindric clusters of flowers . . . . . . . Agastache

\section{Horse Balm Tribe}

Of the 5 lobes of the corolla 4 are nearly equal, while the 5 th is very long and dependent, its border fringed . . . . Collinsonia

\section{Wood Sage Tribe}

Corolla border very irregular, stamens 4 , extending beyond the tube of the corolla, the anterior longer. Calyx 5- to 10-nerved.

Corolla border very irregular; tube straight; the upper lip very short

AJUGA

Corolla border very irregular, the tube and parts of the border hairy, stamens longer than corolla . . . . . . TEuCriuM

Corolla small, with spreading lobes; calyx short; stamens very much longer than corolla

Trichostema

Calyx tubular, corolla small, the lobes distinct and rounded, stamens shorter than corolla

ISANTHUS

¥Corolla of 4 nearly equal divisions, one of which is concave at the summit. Stamens 4, in Mentha all fertile, in Lycopus 2 fertile

\section{MENTHA, L.}

Aromatic herbs, with 4-angled stems and dentate bordered leaves. Flowers white, pink or purple, in axillary clusters or in dense terminal 
spikes. Calyx bell-shaped or tubular with 5 equal or nearly equal teeth. Corolla tube short, nearly or quite included in the ealyx, the border spreading, of 4 nearly or quite equal lobes or the upper lobe broadest. Stamens 4, all. equal or nearly so and all fértile. Ovary 4-parted.

Flower spikes narrow, leafless, the flowers densely crowded; leaves without leafstalks.

P'lants not hairy.

Spikes long, narrow, interrupted below . . . . M. spicata

Spikes thick, mostly dense.

Leaves lance-shaped . . . . . . . . . . M. piperita

Leaves broad, egg-shaped . $\because . . . M$. citrata

Plants more or less hairy.

Spikes slender, dense or interrupted.

Leaves lance-shaped . . . Mt. longifolia

Leaves broad, elliptic or egg-siaped ${ }^{\circ}{ }^{\circ} \cdot{ }^{\circ}$. rotundifolia

Spikes not s!ender, dense.

Leaves without leaf-stems . . . . M. alopecuroides Leaves with leaf-stems, some of which are quite short.

Leaves with simple teeth at margin ?. M. aquatica Leaves deeply incised . . . . . M. crispa

Flowers not in spikes, but in axillary whorls.

Leaf margins with rounded teeth . . . . . . . . M. arvensis

Leaf margins with sharp teeth.

Lower leaves egg-shaped, sharp pointed at apex, more or less

rounded at base . . . . . . M. cardiaca

Leaves narrow, tapering at both ends.

Calyx hairy all over.... . . . . M. canadensis

Calyx hairy at border . . . . . . . M. gentilis

1. M. spicata, L. (Fig. 2, pl. 130.) Spenrmint. Plant nearly or quite smooth; leaves oblong or nearly egg-shaped, coarsely toothed, without leaf-stems or with very short ones. Flowers in long slender spikes, tapering at end, interrupted, the central one much the longest. Flowers pale purple. Wet places, throughout our range. July-Sept.

2. M. piperita, L. (Fig. 1, pl. 130.) Peprenmint. Plant smooth or with a few hairs; branching, pungent to taste, 1 to $3 \mathrm{ft}$. high; leaves oblong-lance-shaped or lance-shaped, coarsely toothed and tapering at each end. Flowers in terminal spikes of many closely related dense whorls, the ends of which are blunt. Wet places, throughout our range. July-Sept.

3. M. citrata, Ehrh. (Fig. 3, pl. 130.) Berganot Mint. Stem 1 to $2 \mathrm{ft}$. Iong, nearly erect or decumbent; whole plant smooth. Leaves eggshaped, rounded at base, the lower rather blunt, upper sharp pointed at apex, on rather long leaf-stems, larger leaf blades 2 in. long, nearly as wide. Flowers in dense terminal whorls and also in the upper axils. Wet soil. Not common. July-Sept.

4. M. longifolia, Ifuls. (Fig. 7, pl. 130.) IIonsemixt. This plant bears a strong resmblance to M. spicata (No. 1), but is covered with hatirs, while the latter is smooth. Found in southern part of our region. July-Oet.

5. M. rotundifolia, IIuds. (Fig. 12, pl. 130.) Rouvin-LEaved Mint. Plant eovered with long hairs; stem 11 to $21 \mathrm{ft}$. high; leaves round-ergshaped or broad alliptic, without leaf-stalks, somewhat elasping the stem at base; upper surface dark gren, lower whitish-silly. Borders reith rounded tecth; flowers in termint slender interrupted spikes; corolla slightly downy. Waste places in all of our area. July-Sept.

6. M. alopecuroides, Hull. (Fig. 9, pl. l:30.) Wool.r. Mixt. Plant demerly hairy, stem $1 !$ to $3 \mathrm{ft}$. high. Leaves with shorp tecth at the mar. 

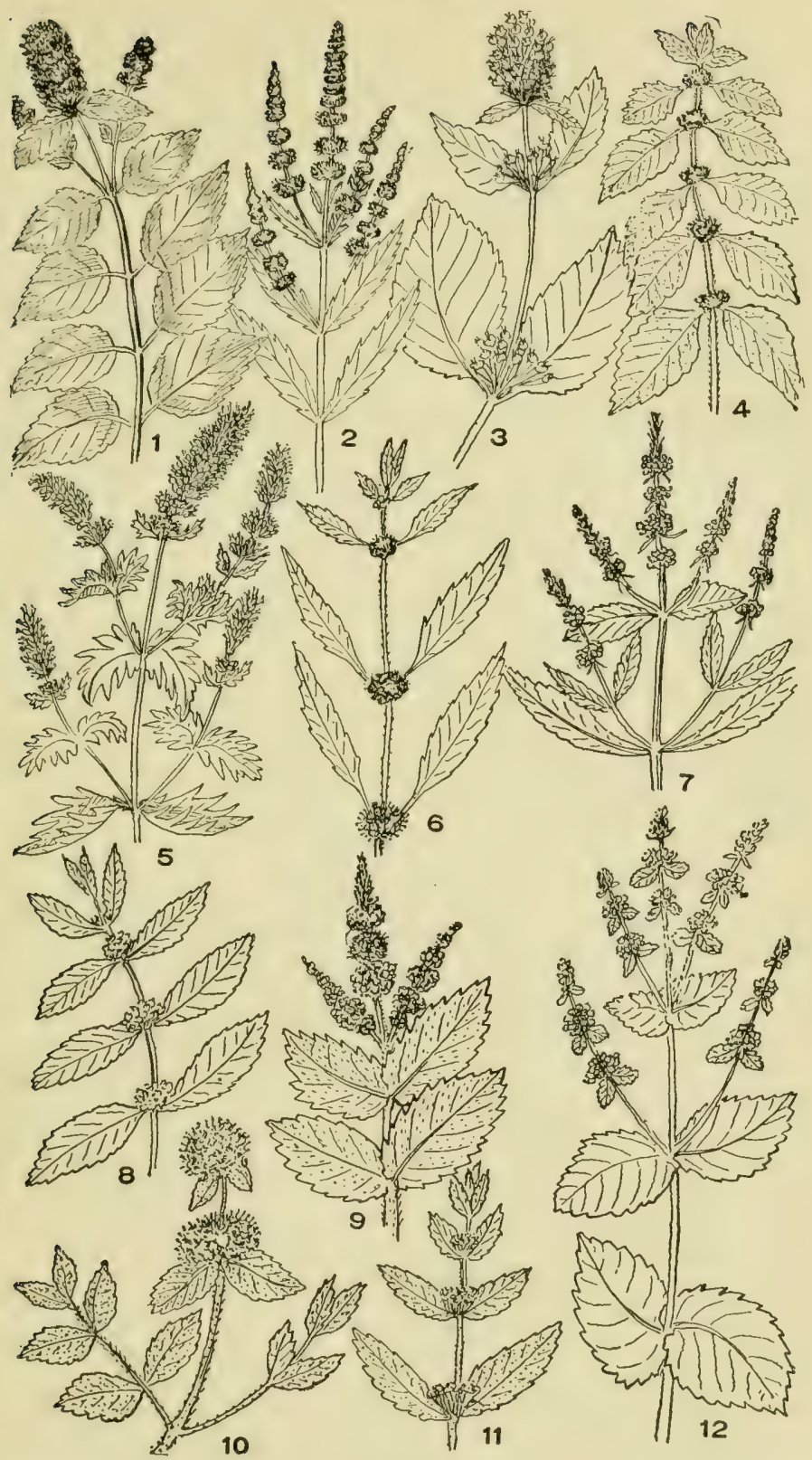

Pr.ate 130

1. Mentha piperita. 2. M. spicata. 3 M. citrata 4. M. arvensis. 5. M. crispa. 6. M. canadensis. 7. M. longifolia. 8. M. gentilis. 9 M. alopecu. roides. 10. M. aquatica. 11. M. cardiaca. 12. M. rotundifolia. 
gins. Otherwise resembles No. 5. Roadsides and waste places. July. Oet.

7. M. aquatica, L. (Fig. 10, pl. 130.) WAter Mint. Plant dewny, rarely smooth; stem usually branched, $1 \frac{1}{2}$ to $21 \mathrm{ft}$. high. Leaves broadly egg-shaped; flowers in terminal, interrupted whorls, on short flower stems and often with one or more clusters in the upper axils; hairs of the stem point downward. Wet places, ditches, ete. Aug.-Oct.

8. M. crispa, L. (Fig. 5, pl. 130.) Curlen Mint. Plant smooth or nearly so, stem $1 \frac{1}{3}$ to $3 \mathrm{ft}$. high; leaves, at least the lower, on short leafstalks deeply ineised, wavy, or the upper simply deeply toothed. Flowers in terminal more or less interrupted spikes. Swamps and ditches, southern part of our area. Aug.-Oct.

9. M. arvensis, L. (Fig. 4, pl. 130.) Corn Mint. Plant generally hairy; stem branching or simple, 冞 to $2 \mathrm{ft}$. high; leaves oblong lanceshaped, the marginal teeth rounded. Flowers all in axillary whorls; calyx downy, the teeth triangular. Stamens extending beyond the corolla. Dry places in most of our range. July-Sept.

10. M. gentilis, L. (Fig. 8, pl. 130.) Creeping Whorled MrNT. Plant more or less decumbent, branched, soft downy, 1 to $2 \mathrm{ft}$. high; leaves oral on short leaf-stems; flowers in axillary whorls, on short flower stems, the marginal teeth sharp. Calyx hairy only at the upper border, between or on the calyx teeth. Waste places, many localities in our range.

11. M. cardiaca, Gerarde. (Fig. 11, pl. 130i) MARSH WHORLED MiNT. (MI. sativa, L.?) More hairy than No. 10, and ealyx is covered through its whole extent with hairs. Waste places. Escaped from cultivation. Aug.-Sept.

12. M. canadensis, L. (Fig. 6, pl. 130.) American Wild Mint. Stem more or less downy, 절 to $2 \frac{1}{2} \mathrm{ft}$. high. Leaves from lance-shaped to oblong egg-shaped, tapering at each end on slender leaf-stalks, margins toothed with sharp teeth, blade of larger leaves 2 to $3 \mathrm{in}$. long. Flowers all in axillary whorls, the whorl not usually covering the flower stem. Calyx densely hairy. Wet places throughout our area. July-Oct.

\section{LYCOPUS, L.}

Perennial herbs, with stolons or suekers, with erect or diffuse stems and opposite leaves; flowers in dense whorls at the leaf-axils, white or purple. Calyx tuhular nearly regular, 4- or 5-toothed, the teeth spinous; corolla nearly equally 4-lobed, not distinctly 2-lipped. Fertile stamens 2 ; ovary deeply 4-parted. Slender style, 2-parted at summit.

Calyx teeth usually 4 , the mature nutlets exceeding them in height . $L$. virginicus Calyx teeth 5 , very sharp, exceeding the mature nutlets in height.

Corolla twice as long as the calyx.

Leaves without leaf-stalks ......... Lo sessilifolius

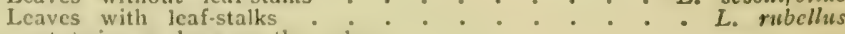

Corolla not twice as long as the calyx.

Leaves deeply incised . . . . . . L. americanus

Leaves with coarse teeth at margins, not decply incised, oblong or egg-shaped . . . . curopacus

1. L. virginicus, L. (Fig. 3, pl. 131.) BUGLE WeEn. Stem acutely 4-angled, $\frac{1}{2}$ to '2 $\mathrm{ft}$. ligh; smooth or slightly downy; leaves oblong to 
lance-shaped, rather coarsely toothed, the teeth sharp, toward the base the border plane, $1 \frac{1}{2}$ to 3 in. long, tapering at each end, on short leafstalks. Shady moist grounds. July-Sept.

2. L. sessilifolius, Gray. Sessile-leaved Water Hoariound. Stem stout, 4-angled, smooth or slightly downy above; leaves without leafstalks, coarsely dentate, lance-shaped or narrowly egg-shaped, 1 to 2 in. long; calyx teeth awl-shaped, rigid. Moist soil. Aug.-Oct.

3. L. rubellus, Moench. (Fig. 2, pl. 131.) Stalked Water HoarIIOUND. Stem 4-angled, angles not acute, smooth or nearly so; leaves lance-shaped, coarsely toothed at margins, except toward the base, on lcafstalls. Calyx teeth less acute than in No. 2. Southern part of our region. Aug。-Oct.

4. L. americanus, Muhl. (Fig. 1, pl. 131.) Cut-Leaved Water Hoariound. (L. sinuatus, Ell.) Stem acutely 4 -angled, 1 to $2 \mathrm{ft}$. high; leaves on leaf-stalks, lance-shaped or oblong, the margins decply incised, the teeth sharp, tapering at each end. Calyx teeth awl-shaped. Wet soil. June-Oet.

5. L. europaeus, L. (Fig. 4, pl. 131.) Water Honriound. More or less downy, stems branching, 1 to $2 \frac{1}{2} \mathrm{ft}$. high; leaves egg-shaped on short leaf-stalks, margins with very coarse teeth; calyx teeth narrow lance-shaped. Found naturalized in a few places, southern part of our area. July-Sept.

‡Corolla 2-lipped, upper lip plane or concave; stamens 4 straight or divergent, anterior (lower) pair longest

\section{THYMUS, L.}

Perennial herbs, or creeping shrubby plants, with opposite smoothmargined leaves and with flowers in dense terminal clusters, or sometimes in the upper leaf-axils. Corolla distinctly 2-lipped, the upper one flat and nearly straight, slightly notehed at apex; calyx egg-shaped, with 3 long, lance-shaped teeth and 2 short ones, 13-nerved; stamens 4, lower pair longest, the 2 longer extending beyond the upper lip of the corolla.

T. serpyllum, L. (Fig. 5, pl. 131.) WiLd Tiryı. Stems creeping, slender, much branched, 4 to 12 in. high, usually forming dense mats. Leaves oblong rounded at apex, somewhat tapering at base, edges entire. Flowers in terminal clusters and sometimes in axillary whorls. Natu. ralized in places, in woods, thickets and roadsides. June-Sept.

\section{HYSSOPUS, L.}

Ereot herb, with erect, scarcely branching stem and with linear leaves, entire at borders, and blue or purple flowers in dense clusters in the upper axils. Calyx tubular, 15-nerved, equally 5-toothed; corolla short, 2-lipped, upper lip flat, erect, notehed, lower 3-lobed, the middle one much the longer and 2-cleft. Stamens 4, diverging, all extending beyond the corolla.

H. officinalis, L. (Fig. 7, pl. 131.) Hyssor. Naturalized, roadsides and waste places. June-Oct. 


\section{ORIGANUM, L.}

Herbs, sometimes shrubby plants, with opposite, nearly or quite entire leaves and with pink or purple flowers in dense spreading terminal clusters. Calyx bell-shaped, hairy in the throat, 5-toothed, 13-nerved; corolla 2-lipped, the upper lip erect, notched at apex, lower of 3 lobes. Stamens 4, the upper 2 extending above the upper lip, the shorter pair exserted from the corolla tube.

O. vulgare, I. (Fig. 8, pl. 131.) WILD MARJoraM. Erect, hairy, the flower clusters spreading into broad nearly umbel-like groups. Leaves round egg-shaped. Roadsides. June-Oct.

\section{PYCNANTHEMUM, Michx. (Koellia, Moench)}

Lpright herbs, with the odor of mint, with short spreading branches; leaves among the flower clusters often whitened; flowers small, white or dotted with purple. Calyx ovate or tubular, about 13-nerved, the 5 teeth being equal or the 3 upper teeth being more or less united, not hairy at the throat; corolla 2-lipped, the upper lip plane or noteled at apex, the lower 3-cleft. Stamens 4, nearly equal, the lower pair somewhat the longer, the two sacs of the anther parallel. Ovary deeply 4-parted, the nutlets smooth or rough.

Leaves linear or narrow lance-shaped.

Plant not hairy or with few hairs.

Calyx teeth bristle-tipped, rigid, $I / 3$ as long as the corolla tube

Cal P. flexusum Calyx teeth triangular, ${ }^{\circ}$ as long as tube oi corolia". $P$. virginianum

Plant decidedly hairy.

Calyx teeth bristle-tipped.

Not hairy between teeth . . . . . P. verticillatum Long hairs between teeth $\cdots, P^{\circ}$ clinopodioides Leaves not linear or narrow lance-shaped.

Calyx teeth bristle-tipped.

Leaves with a minute hoary down, flowers in a dense head $P$. aristatum Leaves whitish downy above, with white wool beneath. $P$. incanum Calyx teeth not bristle-tipped........ . . P. muticum

1. P. flexuosum, (Walt.) B. S. P. (Fig. 7, pl. 132.) NarrowLeaved Mouvtain Mint. (P. linifolium, Pursh.) Stem erect, stiff, slender, smooth, $1 \frac{1}{2}$ to $2 \frac{1}{2} \mathrm{ft}$. high. Leaves linear, tapering at both ends, 1 to $3 \mathrm{ft}$. high. Leaves lance-shaped, rounded at base, tapering at apex. Calyx teeth triangular, hairy. Flowers in dense heads in spreading terminal clusters. Fields and thickets, Maine, southward and westward. JulySept.

2. P. virginianum, (T.) D. and J. (Fig. 1, pl. 132.) Vimernu Mountarx Mrý. (I'. lanceolalum, Pursh.) Stem ereet, stifi, not hairy, 1 to 2 in. Jong. Flowers in compact terminal heads in spreading clusters. Calyx tubular, the 5 teeth egual, triangular, but each tipped with a short bristle grint. Fields and thickets, Mass., and southward. July-Sept.

3. P. verticillatum, (Michx.) Pers. (Fig. 8, pl. 132.) 'Tonn's Morixtan Mixt. (J'. Torryi, Benth.) Slightly dorny, stem 1 to $2 \frac{1}{2} \mathrm{ft}$. hiofl, erecet, stifr, slender. Latves lance-shaped, tapering at each cond, withrout dentations at margins. Calyx teeth white-downy with bristleshapeed tips. Corolla downy, the tube somewhat exeeding the calyx. Dry hills, Vermont, southward and westward. July-Sept. 


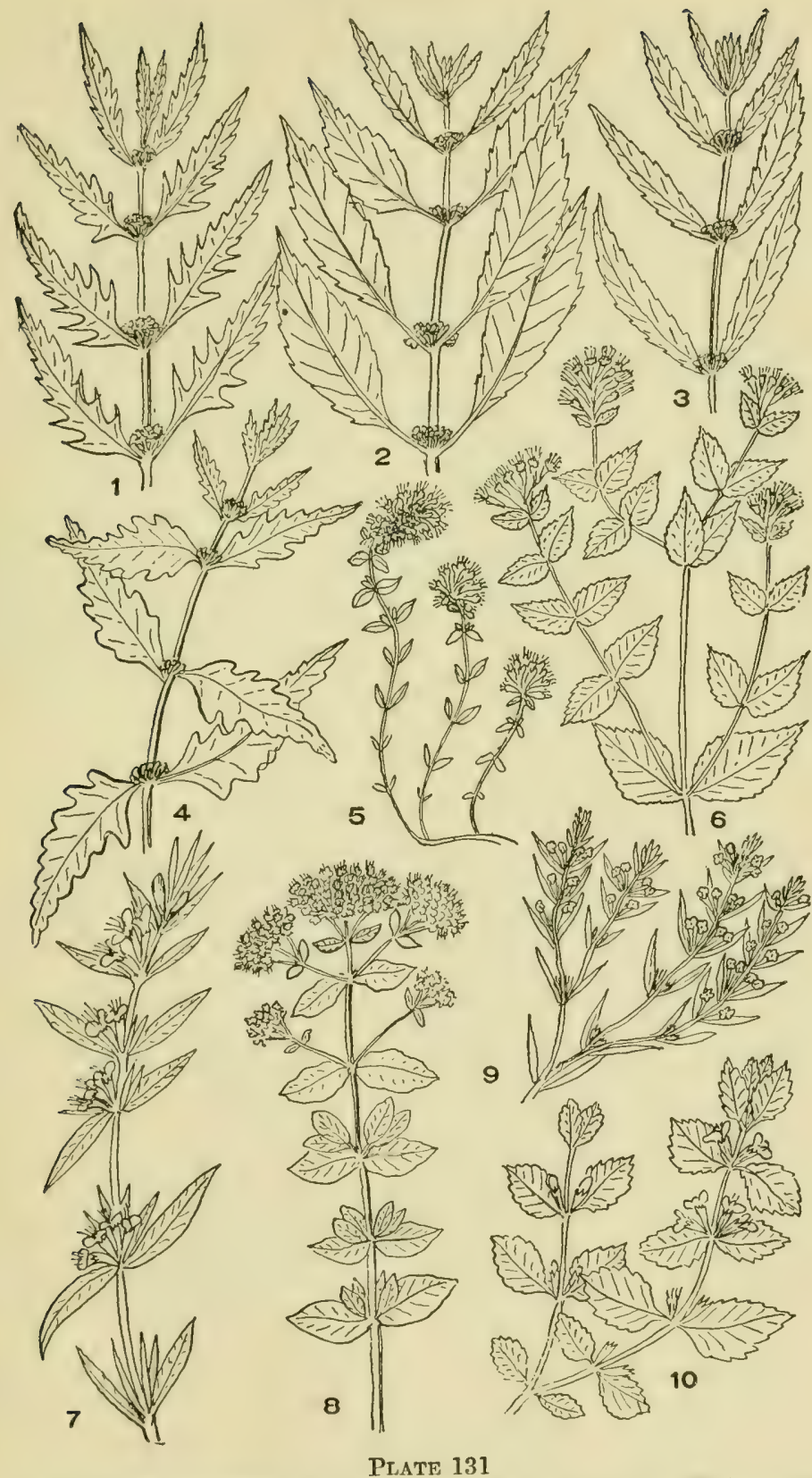

1. Lүсopus americanus. 2. T. rubellus. 3. L. virginicus. 4. L. europaeus. 5. Thymus serpyllum. 6. Cunila mariana. 7. Hyssopus officinalis. 8. Origanum vulgare. 9 Satureia hortensis. 10. Melissa officinalis. 
4. P. clinopodioides, T. and G. (Fig. 3, pl. 132.) Basil Mountain Mrst. Downy, stems 1 to $2 \frac{1}{2} \mathrm{ft}$. high. Leaves broadly lance-shaped on short leaf-stalks, with sharp teeth at margins. Heads larger than in the previous forms and fewer. Calyx with long hairs in the sinuses between the teeth. Dry soil, New York and Penna., and southward. Aug.-Sept.

5. P. aristatum, (Michx.) (Figs, 4 and 5, pl. 132.) AwNED Mountain Mint. Minutely downy, hairy. Stem 1 to $2 \mathrm{ft}$. high. Leaves egg-shaped, tapering at apex rounded at base, margins sharply dentate. The bracts at base of flowers long awned. (Fig. 4, pl. 132.) Calyx teeth with long bristle points. Pine barrens, New Jersey and southward. July. Sept.

6. P. incanum, (L.) Michx. (Fig. 2, pl, 132.) Hoary Mountaix Mint. Stem downy, $1 \frac{1}{2}$ to $3 \mathrm{ft}$. high. Leaves egg-shaped, sharply dentate, downy above and white with long woolly hairs beneath, the upper leaves white on both sides. Calyx teeth unequal, somewhat bristle pointed. Dry thickets and hillsides. Aug.-Oct.

7. P. muticum, (Michx.) Pers. (Figs, 4 and 6, pl. 132.) Sноrт. toothed Mountain Mint. Nearly smooth or somewhat hoary, stem 1 to $2 \frac{1}{2} \mathrm{ft}$. high, much branched; leaves egg-shaped, dentate, tapering at apex, rounded at base or slightly heart-shaped at base, mostly without leafstalks. Calyx tecth vohite downy, triangular. (Fig. 6, pl. 132.) In general aspect No.'s 5 and 7 are so similar that either is fairly represented by Fig. 4, but the brarts at base of flowers are shown at Figs. 5 and 6 of the plate. Sandy soil. July-Sept.

‡Corolla 2-lipped; upper lip plane or concave; stamens 4, divergent at base, convergent above, the anterior (lower) pair longest

\section{SATUREIA, L.}

Aromatic herb, with small undivided leaves with smooth margins and with purple flowers in somewhat spiked clusters. Calyx bell-shaped, 10-nerved, 5-toothed; corolla 2-lipped, the upper lip flat, erect, notched or plane at apex, the lower 3-parted. Stamens 4, converging under the upper lip, the lower pair longest

S. hortensis, L. (Fig. 9, pl. 131.) Summer Savory. Downy; stem 6 to 1 is in. high; leaves linear, flowers few in the axillary clusters. Calyx teeth unequal, hairy. Escaped from gardens. July-Sept.

\section{CLINOPODIUM, L. (Calamintha, Moench. Satureia, (Tourn.)} Lee.

In our area all herbs, with somewhat dentate or smooth margined leaves and with purplish or white flowers. Calyx tubular, 13-nerved, hairy (mostly), 3 -lipued. Stamens 4, ascending under the upper lip of the corolla. Nutlets smooth.

Leaves egg-shaped.

Leaves 1 to 2 in. long . . . . . . . . . . C. vulgare

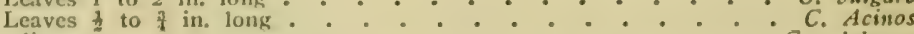
Leaves linear . . . . . . . . . . . C glabrum

1. C. vulgare, L. (Fig. 10, pl. 132.) Wild Basid. (Calamintha Clinopolium, Benth.) Ereet, 1 to $2 \mathrm{ft}$. high, quite hairy; leaves egg- 

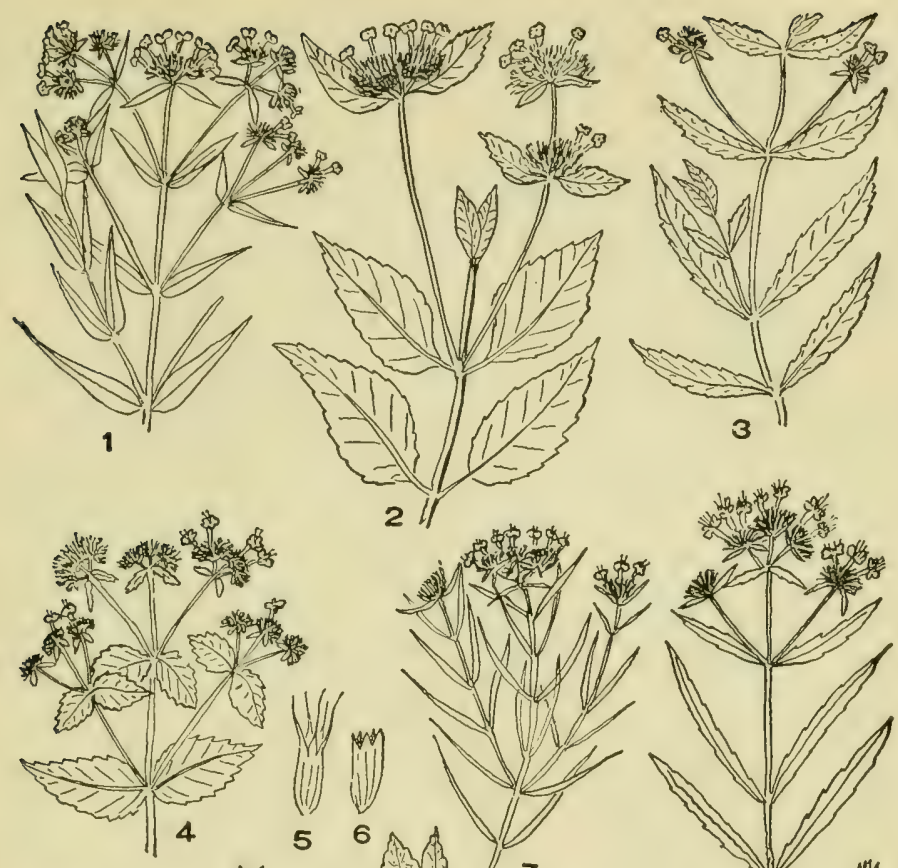

II
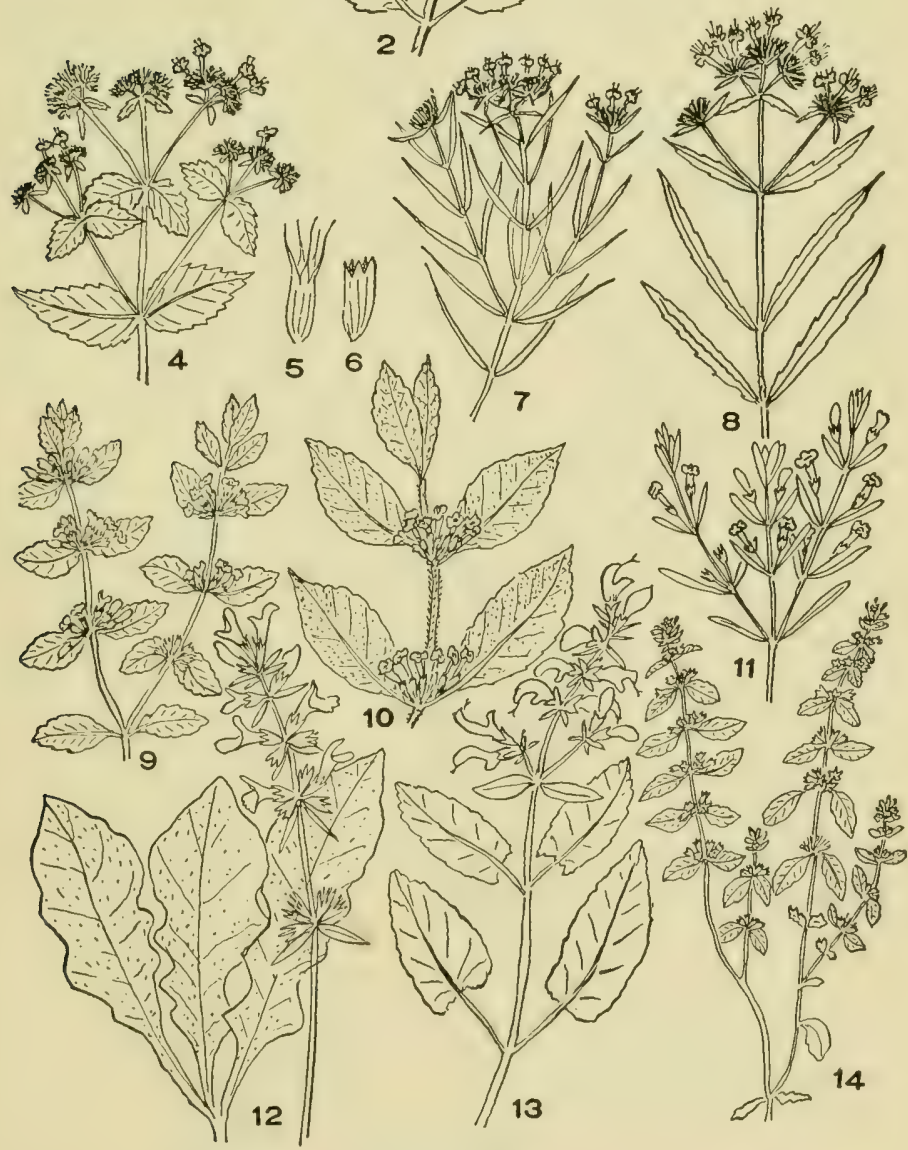

Plate 132

1. Pyenanthemum virginianum. 2. P. incanum. 3. P. clinopodioirles. 4. P. aristatum. 5. Calyx of $P$. aristatum. 6. Calyx of P. muticum. 7. P. flexuosum. 8. P. verticillatum. 9. Clinopodium Acinos. 10. C. vulgare. 11. C. glabrum. 12. Salvia lyrata. 13. S. pratensis. 14. Hedeoma pulegioides. 
shaped, rounded at base, tapering at apex, dentate. Flowers in dense axillary and terminal groups. Woods and thickets throughout our range. June-Oct.

2. C. Acinos, (L.) Kuntze. (Fig. 9, pl. 132.) Basil Balm. (Saturcia acinos, Scheele.) Stems slender, branched from the base, 6 to 8 in. high. Leaves oblong, more acute at base than at apex, a few notches toward apex. Flowers purplish, in loose axillary and terminal elusters; calyx very hairy, teeth bristle-formed, unequal. Waste places. Naturalized. May-Aug.

3. C. glabrum, (Nutt.) Kuntze. (Fig. 11, pl. 132.) Low CaL.AMrvт. (S'atureia glabra, Fernald.) Smooth, stems very slender, much branched, 4 to 12 in. high. Leaves linear, the margins slightly curled backward. Flowers, 1 to 4 in the axils. Runners from base of stem have short egg-shaped leaves. Damp soil, western New York and westward. May-Aug.

\section{MELISSA, L.}

Ours an herb, with broad dentate leaves and rather small flowers in axillary clusters. Calyx bell-shaped, 13-nerved. Corolla tube bent, border 2-lipped. Stamens 4, ascending under the upper lip. Ovary deeply 4-parted.

M. officinalis, L. (Fig. 10, pl. 131.) Lemon BaLM. Upright, branching, leaves broadly egg-shaped, with coarse teeth. Flowers a few in tho axillary clusters, white. Escaped from gardens. June-Aug.

$¥$ Corolla 2-lipped; fertile stamens 2 , the 2 sacs of the anther divergent

Io. SALVIA, L.

Northern U'nited States species, herbs, mostly with rather large showy flowers in spikes. The single species in our region with lyre-shaped leaves below, egg-shaped leaves above. Calyx 2-lipped, the upper lip 3-toothed or entire. Corolla deeply 2-lipped, upper lip straight, sometimes arched. Fertile stamens 2 , on short filaments. Ovary deeply 4-parted. Nutlets smooth.

1. S. lyrata, L. (Fig. 12, pl. 132.) Lree-LeAved SAGE. Stem 12 to 30 in. high, somewhat hairy. Basal leaves tufted, lyrate, upper eggshaped or narrow without leaf-stalks. Flowers in loose whorls, bluepurple; corollia downy, about an inch long, straight. Southern part of our area. May-July.

2. S. pratensis, L. (Fig. 13, pl. 132.) Meanow SagE. Leaves eggshaped, the lower heart-shaped at base, borders with rounded-teeth. Atlantic Co., N. J., locally introduced.

\section{MONARDA, L.}

Frect aromatic herhs, with opposite, rounded or sharply serrate-toothed leaves, and enuspicuous heads of scarlet, purple, white or yellowish flowers, the elusters usnally terminal, but oecasionally also axillary. Calyx tube narrow, 15-nerved, feeth nearly equal, each terminated by a bristle- or awl-like point or simply triamenlar without the bristle point. Corolla always conspicuous, markelly 2-lipped, the upper lip linear and some- 


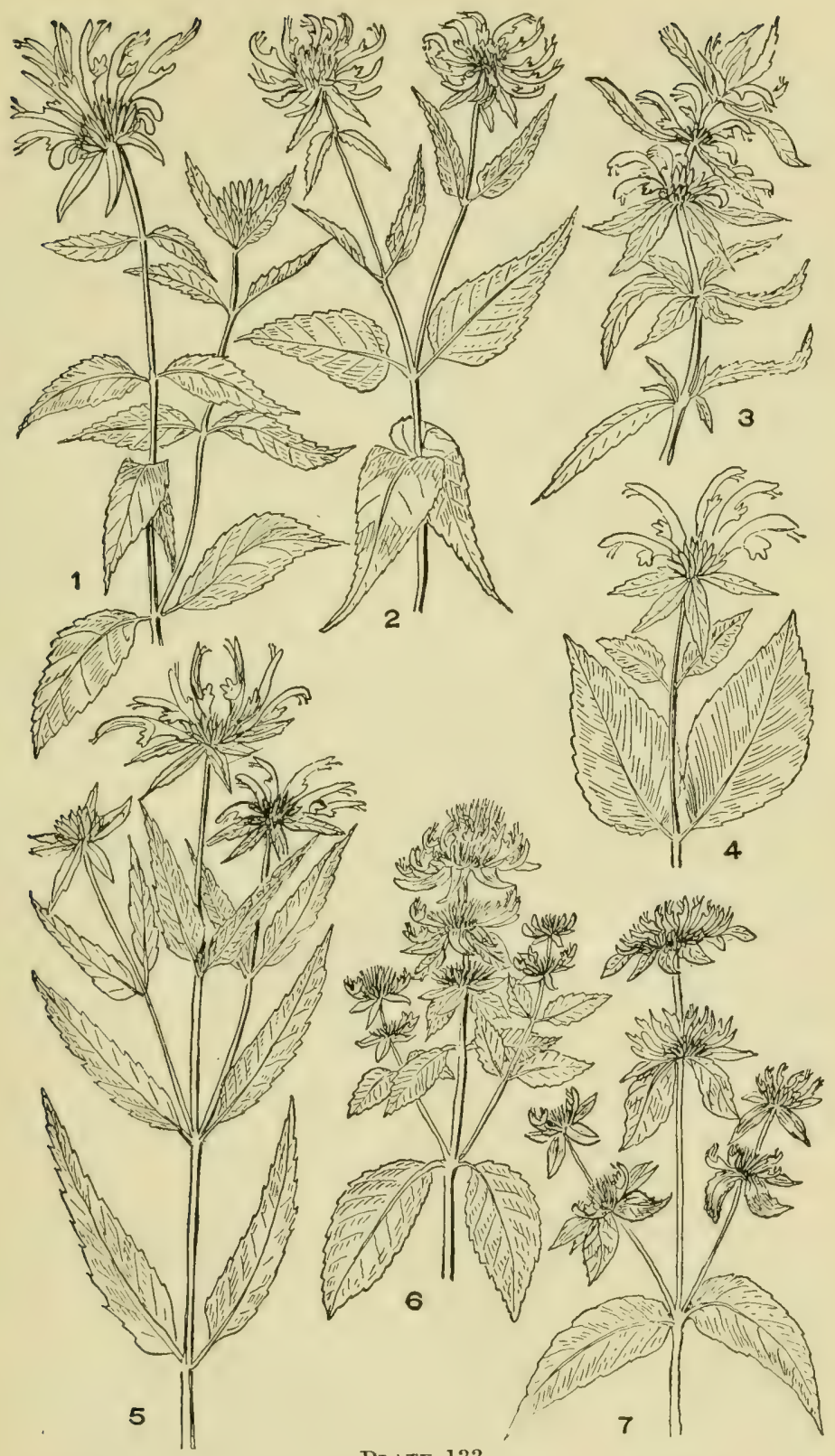

Plate 133

1. Monarda didyma. 2. M fistulosa. 3. M. punctata. 4. MI media. 5. M. clinopodia. 6. Blephilia hirsuta. 7. B. ciliata. 
what arching, the lower lip 3 -lobed, the middle one much the longest. Fortile stamens 2, usually extending somewhat beyond the upper lip. Ovary deeply 4-parted.

Leaves broad, more or less egg-shaped.

Flower whorls mostly terminal and sometimes with a smaller secondary whorl above the main whorl.

Corolla bright scarlet . . . . . . . . . . M. didyma

Corolla yellowish-pink, leaves with leaf-stalks, membraneous

C. M. clinopodia

Corolla yellowish-pink or purple, leaves not membraneous $M$. fistulosa

Corolla deep purple or purple-red . . . . . . M. media Leaves narrow, lance-shaped ............. Munctata (These species, except $M$. punctata, are found in nearly all parts of our region.)

1. M. didyma, L. (Fig. 1, pl. 133.) Mountain Mint. Bee Balm. Stem branching, 2 to $4 \mathrm{ft}$. high, acutely 4 -angled; leaves egrg-shaped or broad lanee-shaped, tapering at each end, sharply toothed at margins. Flowers in terminal and perhaps sub-terminal heads; corolla brilliant searlet. Moist soil. Often cultivated. July-Sept.

2. M. clinopodia, L. (Fig. 5, pl. 133.) Basil BaLM. Stem slender, not much branched, I to $3 \mathrm{ft}$. high. Leaves egg-shaped or broad lanceshaped, slender tapering at apex, somewhat rounded at base. Flowers in terminal whorls or heads. Bracts among the flowers pale or white. Calyx searcely hairy; corolla yellowish-pink. Woods and thichets. JuneAug.

3. M. fistulosa, L. (Fig. 2, pl. 133.) Wild Bergamot. Stem 2 to $3 \mathrm{ft}$. high, slender. Leaves egg-shaped to broad lance-shaped, slender pointed, base rounded, on leaf-stalks. Flowers in large terminal heads, corolla pale lilac or yellowish-pink. Dry hills and thickets. June-Sept.

4. M. media, Willd. (Fig. 4, pl. 133.) Purple Bergamot. Stem 2 to $3 \frac{1}{2} \mathrm{ft}$. high. Leaves thin, not membraneous, broadly egg-shaped, slender tapering at apex, rounded at base, on short leaf-stalks. Flowers in large terminal heads. Corolla deep purple or red. Mroist thickets. June-Aug.

5. M. punctata, L. (Fig. 3, pl. 133.) Horse Mint. Stem 2 to 3 ft. high, usually much branched; the whole plant commonly hairy or downy. Leaves narrow, lane-shaped to linear. Heads of flowers terminal and axillary, usually several. Corolla yellowish with brown or purple spots. 1)ry fields, southern part of our area. (New York, and southward.) July-Oct.

\section{I2. BLEPHILIA, Raf.}

Ceneral aspect similar to Monarda, but lower whorls usually several. Flowers rather small; calyx unequally 5-toothed, 13-veined. Corolla tube short, border 2-lipped. Stamens 2.

1. B. ciliata, Raf. (Fig. 7, pl. 133.) Downx BLepuIlis. Stem 1 to $2 \mathrm{ft}$. high, uswally not lranehing. Whole plant downy. Leaves opposite, the pars distant, lanereshapeel, rommed at base, acute at apex. Flowers in 2 or more whorls; corollit purple, downy. J)ry woods and thickets, southern New England and southward. June-Aug.

2. B. hirsuta, 'Iorr. (Fig. 6, pl. 133.) Harry Blepirila. Stem $1 \frac{1}{2}$ to $3 \mathrm{ft}$. high, usually branched; whole plant hairy. Leaves broal egrrshaped on long leaf-stalks, margins sharply toolloeil. Flowers in several whorls. Corrolla pale purple. Damp wouls, lermont and southward. June-Sept. 


\section{HEDEOMA, Pers.}

Low, odorous, branching plants, with small opposite leaves and loose clusters of small blue or purple flowers at the axils. Calyx egg-shaped or tubular, 13-nerved, bearded in the throat, somewhat 2-lipped or the 5 teeth nearly equal. Corolla 2-lipped, the upper lip ereet, entire, notched at apex, lower, 3-lobed. Fertile stamens 2. Ovary deeply 4-parted.

H. pulegioides, (L.) Pers. (Fig. 14, pl. 132.) American PennxRoyal. Low, branching from the base, hairy. Leaves oblong, few toothed, narrow at each end. Whorls axillary, about 6-flowered; corolla equalling the calyx, bluish. Aroma very pungent. Dry hillsides and fields. JulySept.

\section{I4. CUNILA, L.}

Herbs or shrubs, with small white or purplish flowers and opposite leaves. Calyx ovoid-tubular, equally 5-toothed. Corolla longer than tho calyx, 2-lipped, upper lip erect, flat, mostly notehed, lower lip spreading, 3-lobed. Stamens 2, extending beyond the corolla.

C. mariana, L. (Fig. 6, pl. 131.) DitTANy. (C. origanoides, (L.) Britton.) Stems stir, branched, plant tufted, 1 ft. high. Leaves eggshaped, without leaf-stalks, toothed at margins, rounded at base. Flowers in loose spreading terminal clusters. Corolla purplish-pink. Plant aromatic. Dry woods. Aug.-Sept.

‡ Corolla 2-lipped, upper concave; stamens 4, the anterior (lower) pair longest. Stamens approaching under upper lip of corolla

\section{I5. PHYSOSTEGIA, Benth.}

Erect herbs, mostly smooth with wand-like stems and oblong or lanceshaped leaves without leaf-stalks, margins usually toothed. Calyx nearly equally 5-toothed, about 10-nerved, short-tubular. Corolla funnel-formed, the throat much dilated, the border 2-lipped, the upper lip erect or somewhat arched, the lower 3-lobed. Stamens 4, ascending under the upper lip, the lower pair the longer.

P. virginiana, (J.) Benth. (Fig. 1, pl. 134.) False Dragon Head. Stem rather stout, erect, not branched or only above, terminated by one or more spikes of purple or rose-colored flowers. Leaves opposite, obversely lance-shaped, coarsely toothed at margins without leaf-stalks. Calyx tubular bell-shaped, its teeth about the length of the tube. Corolla about 1 in. long. Wet grounds. July-Sept.

\section{PHLOMIS, Tourn.}

Tall herbs or shrubs. Calyx tubular, nearly equally 5-toothed. Corolla 2-lipped, the upper lip arched, the lower spreading, 3-lobed. Within the mouth of the corolla tube is a ring of woolly hairs. Stamens 4 , ascending under the upper lip of the corolla, the anterior pair longest.

P. tuberosa, L. Jerusalear Sage. Plant 3 to $6 \mathrm{ft}$. high, smooth, with large egg-shaped leaves, heart-shaped at base, blunt at apex, with coarse rounded teeth at margins, on leaf-stalks. Flowers pale purple to white in clusters terminal and in the upper axils. Waste places, naturalized in places. June-Sept. 


\section{LEONURUS, L.}

Tpright herbs, with deeply incised opposite leaves and whorls of small white or pink flowers in the leaf-axils. Calyx tube bell-shaped, 5-toothed, 5 -nerved, hairy, the teeth rigid. Corolla 2-lipped, the tube slightly exceeding the calyx. Stamens 4, the anterior pair longer, ascending under the upper lip of the corolla. Nutlets 3 -angled.

1. L. cardiaca, L. (Fig. 3, pl. 134.) Motmenwort. Stem 2 to $5 \mathrm{ft}$. high, commonly branched; plant hairy, leaves on long leaf-stalks, spreading into 3 principal, more or less triangular lobes, these plane or toothed at the margins. Flowers in whorls at the axils. Corolla purple, bearded within. Roadsides and waste places. June-Sept.

2. L. Marrubiastrum, L. (Fig. 4, pl. 134.) Hoarhound MotherworT. Stem 2 to $5 \mathrm{ft}$. tall. branelied; plant hairy; leaves on rather long leaf-stalks, egg-shajed, rounded or tapering at base, blunt at apex, the borders deeply divided by rounded teeth. Corolla shorter than the calyx, whitish, the tube not bearded within. Waste places. June-Sept.

3. L. sibiricus, L. (Fig. 2, pl. 134.) Siberian Motherwort. Resembles No. 1, but leaves are more deeply 3-parted, the lobes, especially of lower leaves, incised. Waste grounds, Penna., and southward. May. Sept.

\section{I8. LAMIUM, L.}

Tpright herbs, with rounded cut-lobed leaves and whorls of small flowers in avillary whorls. Calyx tubular, bell-shaped, 5-nerved and with 5 nearly equal awl-pointed teeth. Corolla tube longer than the ealyx, 2-lipped, the upper arched, the lateral lobes of the lower lip quite small, the middle lohe notehed or divided. Stamens 4, under the upper lip of the corolla.

1. L. amplexicaule, L. (Fig. 7, pl. 134.) Hensit. Plant 6 to 20 in. high; stems weak, slender, partly decumbent or ereet. Leaves rounded and deeply incised or toothed, the lower small, on very short leaf-stalks, the upper $\frac{1}{2}$ to $1 \mathrm{in}$. broad, clasping or partly clasping the stem. Flowers few, in axillary clusters, purple or red, corolla about $\frac{1}{2} \mathrm{in}$. long. Cultivated grounds and waste places. April-Oct.

2. L. maculatum, I. Spotted Dean Netrle. Stems weak, partly decumbent or erect, branching. Leaves rounded, somewliat pointed at apex, leart-shaped at base; on leaf-stalks, marked usually with a white spot on the upper face. Flowers few, in the axil, purple. Escaped from gardens. May-Oct.

3. L. album, I. Wirte Dean Nerte. Stem ráther stout and more or less decumbent, branched, 1 to $1 \frac{1}{2} \mathrm{ft}$. long. Leaves egg-sliaped on short leaf-stallis, decply sut into large teeth at the margins. Flowers few, axillary, white. Waste places. Naturalized. April-Oct.

4. L. purpureum, I. (Fig. 8, pl. 134.) Red Dead Nettle. Similar to No. 1, lut all the leares have leaf-stalks and the plant is more or less downy. Waste grounds and cultivated soil. From Europe. April-May.

\section{I9. GALEOPSIS, L.}

Irribs, with opposite leates and small flowers in the upper axils or forming dense torminal leats or spikes. Calyx bell-sliaped, 5-toothed, 


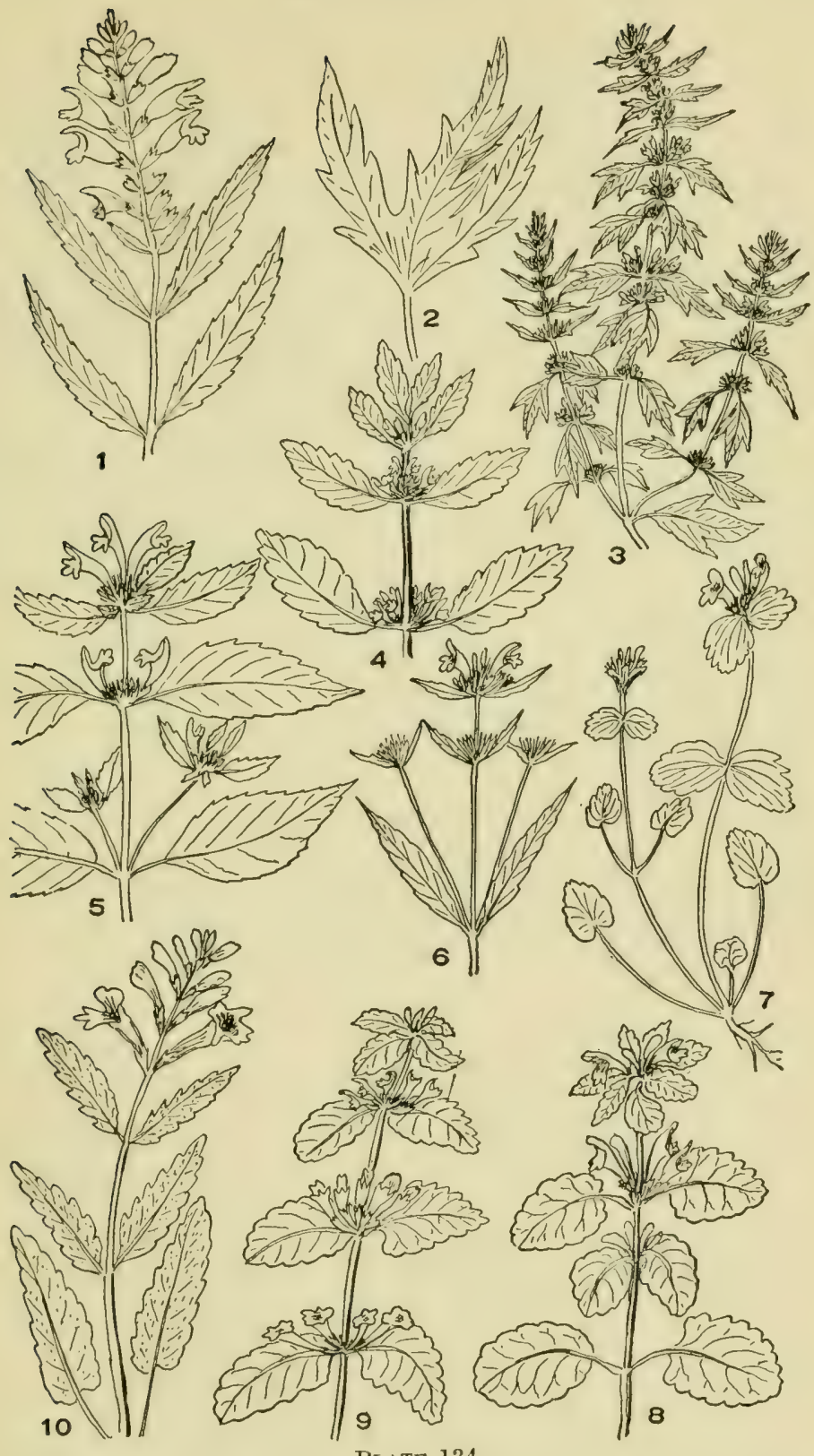

Plate 134

1. Physostegia virginiana. 2. Leonurus sibiricus (leaf). 3. L. cardiaca. 4. L. Marrubiastrum. 5. Galeopsis Tetrahit. 6. G. Ladanum. 7. Lamium amplexicaule. 8. L. purpureum. 9. Ballota nigra. 10. Betonica officinalis. 
the teeth nearly equal, spiny, 5- to 10-nerved; corolla with a narrow tube, 2-lipped, dilated at throat, upper lip arched, entire, lower spreading, 3-eleft. Stamens 4, ascending under the upper lip, the anterior pair the longest. Style 2-cleft at the summit.

1. G. Ladanum, L. (Fig. 6, pl. 134.) Red Hemp Nettle. Stem downy, 6 to 18 in. long, erect. Leaves oblong lance-shaped, tapering at each end, downy; corolla red or rose color, frequently spotted with yellow, much longer than the calyx. Waste places. Rare. July-Oct.

2. G. Tetrahit, L. (Fig. 5, pl. 134.) Common Hemp Nettle. Stem 1 to $3 \mathrm{ft}$. high, erect, the whole plant rough hairy. Leaves egg-shaped, on leaf-stalks, coarsely toothed. Corolla purple varied with white, twice as long as the calyx. Waste places. Naturalized. June-Sept.

\section{BALLOTA, L.}

Downy or woolly herbs, sometimes shrubs. With opposite dentate leaves and axillary whorls of small flowers. Calyx fumel-form, 10-nerved, expanding into a border of from 5 to 10 teeth. Corolla 2-lipped, the upper erect, concave or notched, lower 3-lobed, tube about as long as the calyx; the throat hairy. Stamens 4, ascending under the upper lip of the corolla, the anterior pair longer. Style 2-cleft at summit.

B. nigra, L. (Fig. 9, pl, 134.) Black Hoarhound. Stem $1 \frac{1}{2}$ to 3 ft. high; the whole plant hairy but green. Leaves egg-shaped on slender foot-stalks, borders with coarse rounded teeth. Axillary whorls of flowers dense. Calyx teeth 5, longer than the tube of the purple corolla. Waste places. Naturalized. June-Oet.

\section{I. STACHYS, L.}

Iferbs, with opposite leaves and with flowers in axillary whorls. Calyx bell-shaped, 5- to 10-nerved, equally 5-toothed. Corollia 2-lipped, all of ours purple, the tube not exceeding the calyx, narrow, not dilated at the throat. Stamens 4, the anterior pair longer, ascending under the upper lip of the corolla.

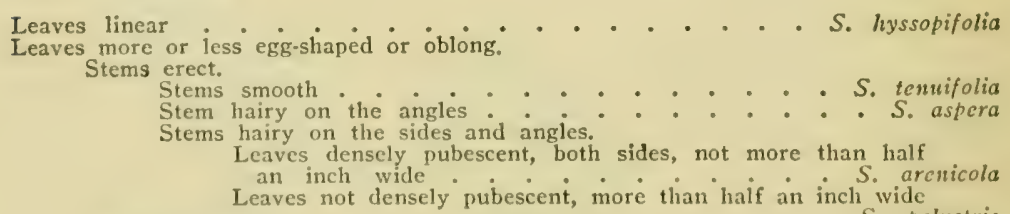
Stems decumbent ${ }^{\circ} \cdot{ }^{\circ} \cdot{ }^{\circ} \cdot{ }^{\circ} \cdot{ }^{\circ}$ S. palustris

1. S. hyssopifolia, Michr. (Fig. 1, pl. 135.) Stem about $1 \mathrm{ft}$. high, smooth or slightly hairy at the nodes. Jeaves linear, entire, tapening at both ends, without laf-stalks. Flowers light purple in a kind of terminal spike consisting of a few whorls of 4 to 6 flowers each. Moist fields, Mass., and southward. July-Sept.

Var. ambigua, A. Gray. (Fig. 2, pl. 135.) Stouter. Leaves with low tecth, plant somewhat hairy. Fastern Penna., sonthward and westward.

2. S. tenuifolia, Willi. (Fig. 3, pl. 135.) Sмootu IIsnge Nratew. Stem 1 to $2 \mathrm{ft}$. ligh, smooth or rough with minute bristly hairs on the 


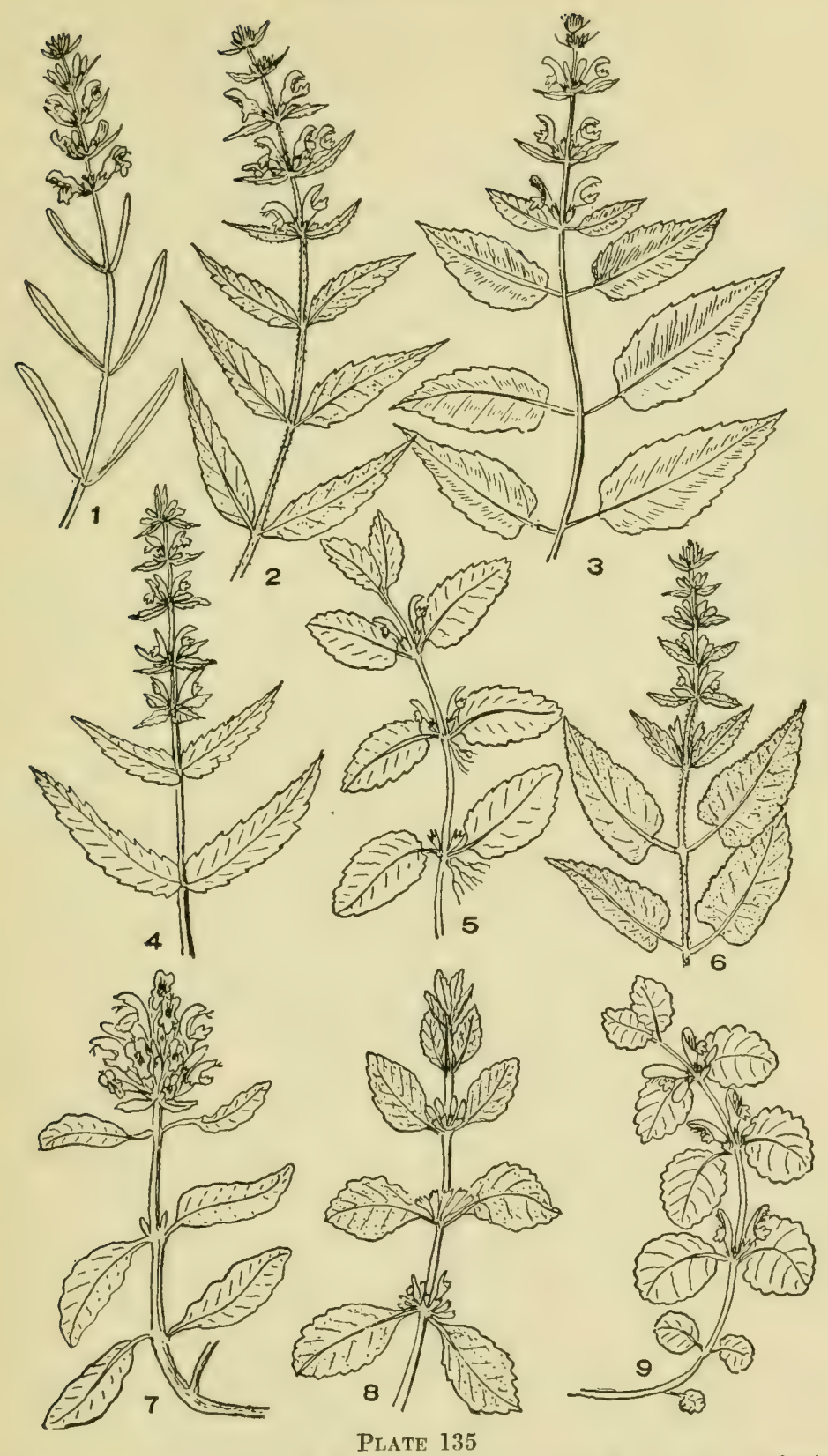

T. Stachys hyssopifolia. 2. S. ambigua. 3. S. tenuifolia. 4. S. palustris. 5. S. arvensis 6. S. aspera. 7. Prunella vulgaris. 8. Marrubium vulgare. 9. Glecoma hederacea. 
angles, usually branched; leaves ollong, lance-shaped, rounded at base, narrow fapering at apex, the borders toothed, on leaf-stalks. Flowers in a terminal spike of several whorls of pale red or purple flowers. Moist fields. June-Aug.

3. S. arvensis, L. (Fig. 5, pl. 135.) FIELd Woundwort. Stem decumbent, branched, hairy, $\frac{1}{4}$ to $1 \mathrm{ft}$. long. Leaves egrg-shaped, rather blunt at apex, heart-shaped at base. Flowers in the axils, whorls few flowered. Corolla purple. Waste places; naturalized in places about eastern seaports. (Regarded by Fernald as a Var. of S. tenuifolia.) July-Oct.

4. S. arenicola, Britton. HaIry Hedge Nettle. Stem 12 to 24 in. high, very hairy. Leaves lance-shaped or linear, very hairy on both sides. Flowers in a dense, partly interrupted spike. Corolla inconspicuous. Sandy soil, New York, westward.

5. S. palustris, L. (Fig. 4, pl. 135.) Hedge NetTle. Stem erect, 1 to $4 \mathrm{ft}$. high, the whole plant hairy. Leaves lance-shaped, rounded at hase, without leaf-stalks, tapering toward the apex. Flowers in a spike, of whorls of purple or pale red flowers. Moist soil, western New York, westward and southward. June-Sept.

6. S. aspera, Michx. (Fig. 6, pl. 135.) Rougir Hedge Nettle. Stem 2 to $4 \mathrm{ft}$. high, the angles beset with stif hairs which turn downward. Leaves egg-shaped, mostly heart-shaped at base, on short leafstalks, smooth or hairy. Flowers in terminal spikes of whorls of redpurple blooms. Stamens hairy. Wet grounds. Common.

\section{BETONICA, L.}

IIerbs, resembling Stachys, the corolla beardless. Lower leaves in a cluster on long leaf-stalks, egre-shaped, heart-shaped at base, upper leaves eger-shaped or lance-shaped, with no leaf-stalks or short ones. Whole plant hairy. Flowers purple in terminal spike.

B. officinalis, I. (Fig. 10, pl. 134.) BETTONY. Escaped from gardens. Flowers purple in a terminal spike. Waste places. July-Sept.

FCorolla 2-lipped; stamens 4, shorter than the upper lip of the corolla, lower longest, the upper lip arching over the stamens.

Calyx decply ?-lipped

\section{PRUNELLA, L.}

Our only species a low, often prostrate herb, with opposite egg-shaped leaves on long leaf-stallis and with a eylindric head of purple flowers, plentifully interspersed with green bracts. Calyx deeply 2-lipped, the lower lip of a very acute lance-slaped teeth, the upper of 3 triangular or blunt teeth. Corolla arching over the stamens.

P. vulgaris, J. (Fig. 7, pl. 135.) SELF-11EAL. A common weed about door yards and in waste places. May-Oct.

\section{SCUTELLARIA, L.}

Ilerbs, with opposite leaves and with flowers at the leaf-axils, or terminal forming spikes. Calyx 2-lipped, the upper one with a crest or pro. tulurance "upon its batck. Corolla 2-lipped, "pper lip valulted, the lower 
dilated, the tube much exceeding the calyx. Stamens 4, ascending beneath the upper lip. Style usually 2-cleft.

Flowers solitary in the axils (opposite).

Leaves with leaf-stalks.

Not white hoary.$+\cdots \cdot S_{\text {s. serrata }}$

White hoary.

Leaves without leaf-stalks.

Borders deeply dentate.

Nutlets not winged ........ S. neriosa

Nutlets winged . . . . . . . . S. galericulata

Flowers not solitary or some of them in terminal groups.

In long narrow spikes from the axils, more or less one-sided . S. lateriflora Flowers few, largely terminal.

Leaves on leaf-stems, borders toothed ...... S. pilosa

Leaves not on leaf-stems; borders entire. Leaves linear $S$. integrifolia

1. S. lateriflora, L. (Fig. 1, pl. 136.) MAD-dog SKullcar. Leaves opposite, on leaf-stalks, egg-shaped, rounded at base, tapering toward apex, borders coarsely toothed. Flowers in opposite narrow spikes from the axils, the flowers turning mostly to one side, numerous, small, blue varying to nearly white. Waste places. Common. July-Sept.

2. S. serrata, Andr. (Fig. 3, pl. 136.) Srowy Skulccap. Stem 1 to $2 \mathrm{ft}$. high, ereet. Leaves large, egg-shaped, on leaf-stalks, notehed at margins, the upper reduced to floral bracts without leaf-stalks. Flowers in the terminal axils, opposite; corolla blue. Woods, southern New York, Penna., and southward. May-June.

3. S. pilosa, Michx. (Fig. 6, pl. 136.) Hairy Skullcap. Stem slender, 1 to $21 \mathrm{ft}$. high. Leaves opposite on leaf-stalks, oval or egg-shaped, notehed at margins; the whole plant hairy or downy. Flowers in terminal pairs, the cluster short, corolla blue. Dry woods, southern New York and Penna., southward and westward. May-July.

4. S. integrifolia, L. (Fig. 7, pl. 136.) Hrssop Srullcap. Stem $\frac{1}{2}$ to $2 \mathrm{ft}$. high, downy. Leaves opposite linear to oblong, 1 to $2 \mathrm{in.} \mathrm{long,}$ or with very short leaf-stalks. Flowers in a loose terminal cluster; corolla blue at summit varying to nearly white at base. Sandy woods, New England and southward. May-July.

5. S. parvula, Michx. (Fig. 5, pl. 136.) Small Sirullcap. Stem 3 to 12 in. high, somewhat branched, smoothed or slightly downy. Leaves opposite, broadly egr-shaped, rounded at base, attached directly to stem, blunt at apex, t to $1 \mathrm{in}$. long, nearly as wide as long. Flowers solitary in the axils, opposite, blue to violet. Moist sandy soil, eastern part of our area. April-July.

6. S. galericulata, L. (Fig. 2, pl. 136.) Hooded Skullcap. Stem 1 to $3 \mathrm{ft}$. high, simple or branched. Leaves opposite, lance-shaped with heart-shaped base dentate at margins, without leaf-stalk or the lower with short leaf-stalks. Flowers in the axils, few; corolla blue. Swamps and wet places, Maine to New Jersey. June-Sept.

7. S. nervosa, Pursh. (Fig. 4, pl. 136.) Veined Skullcap. Stem $\frac{1}{2}$ to $2 \mathrm{ft}$. high. Leaves opposite, egg-shaped, the lower on short leafstalks, the upper directly attached to stem, coarsely toothed. Flowers in the axils only, opposite, blue. Moist woods. May-Aug.

8. S. incana, Muhl. (Fig. 8, pl, 136.) Downy Skcllcap. Leaves 
exrg-shaped or oval, on rather long leaf-stalks, the lower surface of the leaves and the flowers covered with a whitish down. Southern Penna, and southward. June-Aug.

\section{MARRUBIUM, L.}

Peremial herbs, branching, more or less covered with whitish, woolly hairs, of bitter aromatic taste, with axillary clusters of flowers of white or purplish color. Calyx nearly equally 5- to 10-toothed, the teeth somewhit spiny-pointed; corolla 2-lipped, the upper lip erect, lower spreading, 3-lobed. Stamens 4, included in the tube of the corolla, the anterior (lower) pair longest. Style 2-cleft.

M. vulgare, L. (Fig. 8, pl. 135.) Common Honriound. Stem I to $3 \mathrm{ft}$. high, woolly. Leaves opposite, round egg-shaped with coarse rounded teeth at the margins, on rather long leaf-stalks. Flowers axillary, in dense rounded clusters; corolla small, white. Common in waste places.

\section{MEEHANIA, Britton}

Low herb, sprealing. Leaves on long leaf-stalks, opposite, heart-shaped at base. Calyx only slightly 2-lipped, 5-toothed, the teeth long and sharp, rather unequal, 15-nerved. ('orolla rather large, swollen at throat, 2-lobed, the lower lobe 3-cleft. Stamens 4, two long and two short, included in the upper lip. Cells of the anthers parallel.

M. cordata, (Nutt.) Britton. MeErrania. A low plant, 3 to 8 in. high, with hairy rumbers. Leaves broadly eggr-shaped or nearly orbicular, luart-shaped, on loner leaf-stalks, rounded teeth at margin. Flowers blue, showy, in whorls of a few flowers each, the leaves at the whorls shorter than the calyx, the erolla hairy inside. Moist woods and thickets, southwest Penna., and soutliward and westward. May-July.

‡Corolla :-tipped; stamens 4, the posterior (upper) pair longest, shorter than or scarcely longer than the upper lip of the corolla

\section{NEPETA, L.}

Perennial herbs, with opposite, dentate leaves and with terminal and axillary clusters of purplish flowers. Calyx obliquely 5-toothed; corolla dilated at the throat, 2-lipped, upper lip ereet, lower 3-lobed, the middle lobe much the larerst. Stamens 4, ascending under the upper lip, the anterior pair shortest.

N. Cataria, L。 (Fig. 10, pl. 136.) Catmint. Catnip. Whole plant downy; stem branched, 1 to $3 \mathrm{ft}$. ligh. Leaves heart-shaped, on leafstalks, sharply tapering at apex, the upper bract-like, small, all with rounded coarse texth at margins. Flowers mostly in terminal spikes, corolla whitish-purple. About dwellings. Common. July-Sept.

\section{GLECOMA, L.}

A prostrate herb, resembline Nepeta in many respects; the upper leaves not small and hract-like, and the apex of leaf is rounded. Flowers not numerous, in axillary loose clusters.

G. hederacea, L. (Fig. 9, pl. 135.) Gill-oven-tile-ground. (Vcpeta 

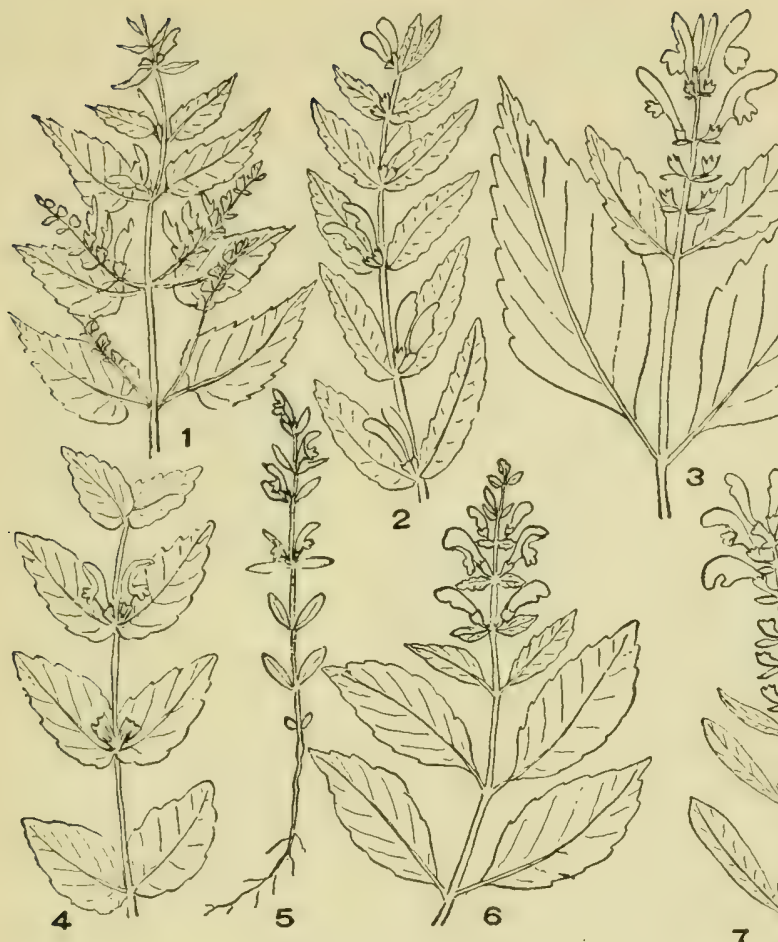

Lin
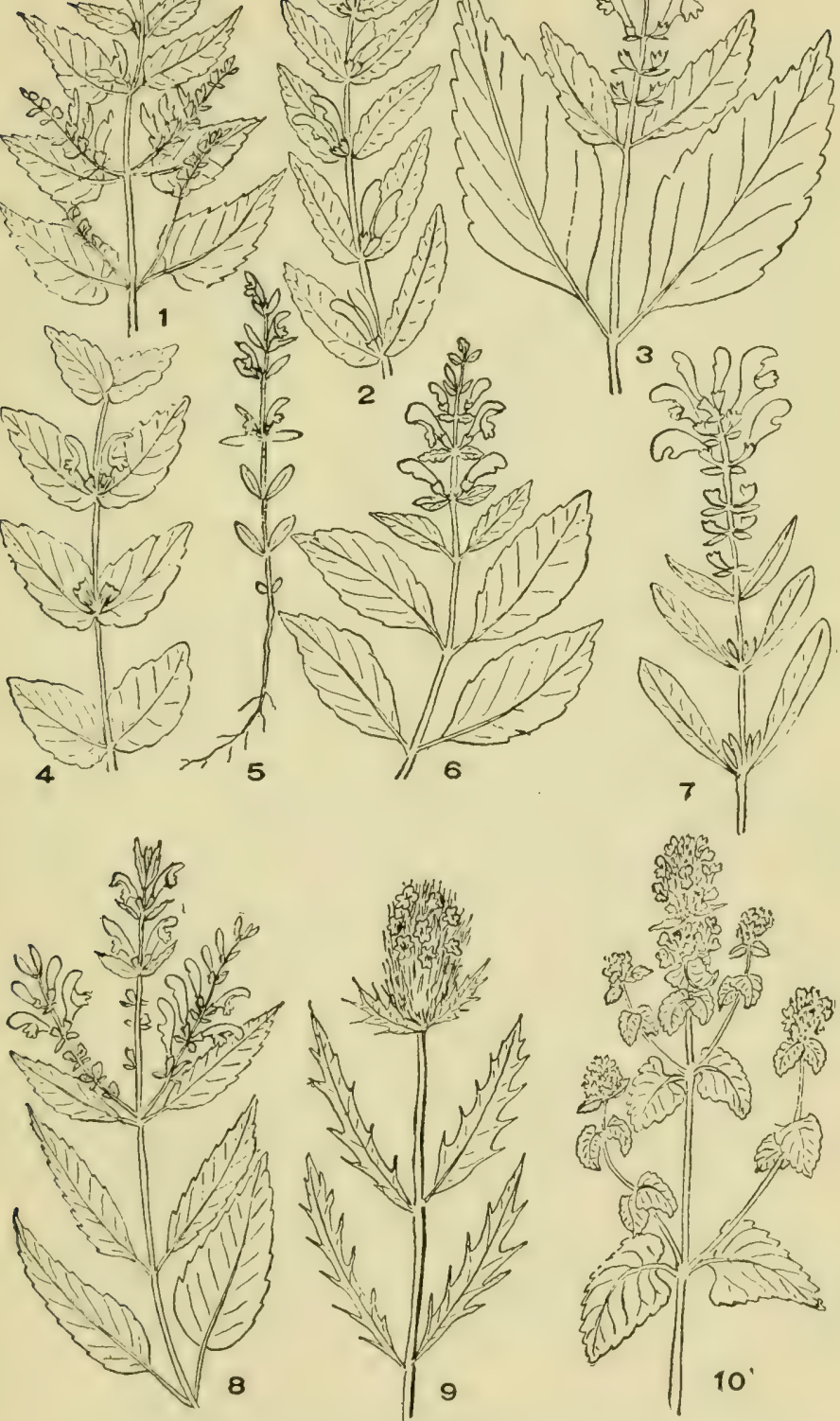

Plate 136

1. Scutellaria lateriflora. 2. S. galericulata. 3. S. serrata. 4. S. nervosa. 5. S parvula. 6. S. pilosa. 7. S. integrifolia. S. S. incana. 9. Dracocephalum parviflorum. 10. Nepeta Cataria. 
hederacca, Trevisan.) Stems creeping and trailing. Leaves rounded or kidney-shaped. Corolla light blue. Damp places, mostly about dwellings. March-May.

\section{DRACOCEPHALUM, L.}

Perennial herbs, with opposite leaves and with blue or purple flowers in terminal or axillary clusters. Calyx tubular, very hairy, 5-toothed, the upper tooth usually much longer than the others. Corolla 2-lipped, the upper arehed, lower 3-lobed. Stamens 4, ascending under the upper lip, the upper pair longest.

D. parviforum, Nutt. (Fig. 9, pl. 136.) American Dragon-mead. Leaves egg-shaped to lance-shaped, very deeply cut at margins, the teeth very sharp. Clusters of flowers dense, crowded in terminal spikes. Dry soil, northern New York and westward. May-Aug.

\section{AGASTACHE, Clayt. (Lophanthus, Benth.)}

Tall herbs, with opposite leaves on rather long leaf-stalks, margins coarsely toothed with rounded teeth. Calyx bell-shaped, 5-toothed, the upper teeth longest. Corolla 2-lipped, the tube scarcely exceeding the calyx. Stamens 4, the upper pair longest. Anther sacs nearly parallel.

1. A. nepetoides, (L.) Kuntze. (Fig. 1, pl. 137.) Catnip GiantIrssor. Stem 2 to $5 \mathrm{ft}$. high, sharply 4 -angled, smooth. Leaves eggshaped, pointed at aper, rounded or somewhat tapering at base, coarsely toothed with rounded teeth, 2 to $4 \mathrm{in.} \mathrm{long.} \mathrm{Flowers} \mathrm{in} \mathrm{terminal} \mathrm{spike}$ 5 or 6 in. ligh. Calyx teeth stightly shorter than corolla tube. Corolla greenish-yellow. Woods, Vermont and southward and westward. JulySept.

2. A. scrophulariaefolia, (Tilld.) Kuntze. (Fig. 2, pl. 137.) Frgwort (incis-Irssor. Strm ohtusely 4-angled, plant doumy. Calyx teeth very sharp, deciledly shorter than calyx tube, Woods, Connecticut and westward and southward. July-Oct.

\# Corolla 5-lobed, one lobe much longer than the others, which are nearly equal; border of the longer lobe fringed

\section{COLLINSONIA, L.}

Tall horhs, with opposite leaves on long leaf-stalks and with loose terminal clusters of yollowish flowers. Calyx bell-shaped, 2-lipped. 2 of the teeth much lonerer than the other 3. Corollat much longer than calyx, 5-loberl, 4 of the lobes nearly equal, the 5 th much longer and dependinge, bordered with a fringe.

C. canadensis, I. (Fig. 5, pl. 137.) Iorse-Balm. Stem 2 to $5 \mathrm{ft}$. high, smonth: loaves rers-shaped or obloner. hordered hy coarse rounded teeth, 6 to $10 \mathrm{in.}$ long, the upper on short leaf-stalks. Flowers in loose spreading, pyramidal clusters, aromatic, eorolla yellow. Moist woods. July-Oct.

\# rerolla beriter rery irregular. Stamens 4, restending beyond the tube of the corolla, the anterior longer. Calyx 5. to 10-nerved 


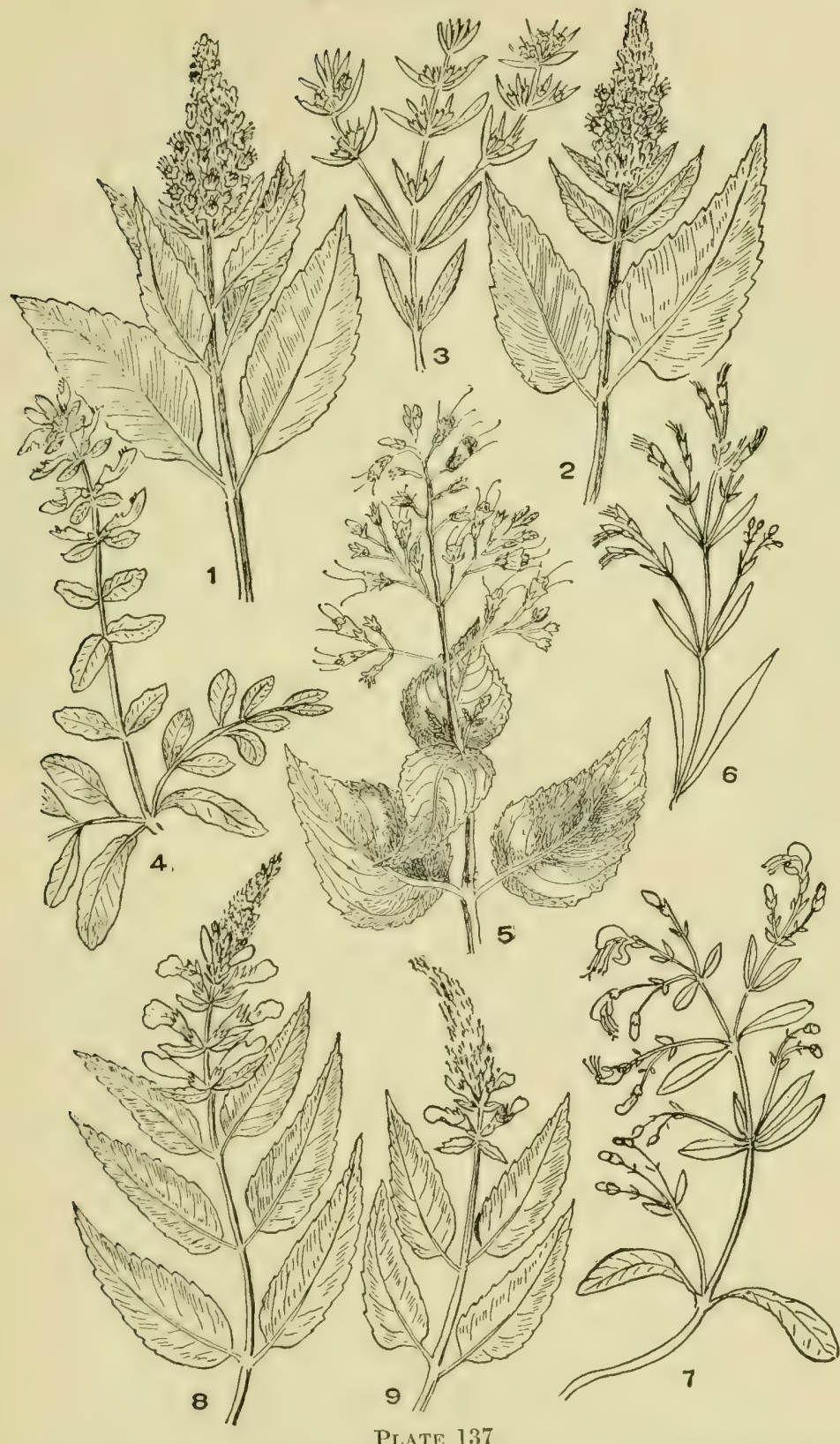

Plate 137

1. Agastache nepetoides. 2. A. scrophulariaefolia. 3. Isanthus brachiatus. 4. Ajuga reptans. 5. Collinsonia canadensis. 6 Trichostema lineare. 7. T. dichotomum. S. Teucrium canadense. 9. T. occidentale. 


\section{AJUGA, L.}

Herbs, with opposite leaves and with flowers in axillary clusters. Calyx egg-shaped or bell-shaped, nearly equally 5-toothed. Corolla border 2-lipped the upper small, the lower much larger, the middle lobe largely exceeding the side lobes.

A. reptans, I. (Fig. 4, pl. 137.) Bugle. Stem $\frac{1}{2}$ to $1 \frac{1}{2} \mathrm{ft}$. high, nearly smooth. From the base extend runners (stolons), which reach out from the stem. Leaves at the base in a tuft, stem leaves rounded or egg-shaped, without leaf-stalks. Flowers few in the leaf-axils, corolla blue, much exceding the calyx. Naturalized. Fields, Maine to southern New York. May-June.

\section{TEUCRIUM, L.}

Herhs, with opposite leaves and purple flowers in a narrow terminal spike. Calyx bell-shaped, nearly equally or somewhat unequally 5-pointed. Stamens 4, extending beyond the corolla. Corolla border irregularly 5-lobed.

1. T. canadense, L. (Fig. 8, pl. 137.) Woon SAgE. Stem 1 to 2 ft. tall. Leaves lance-shaped on short leaf-stalks, sharply toothed, rounded at base, tapering toward the apex, downy. Flowers nearly an in. long, blue; calyx covered with short grayish hairs. Waste thickets. JuneSept.

2. T. occidentale, Gray. (Fig. 9, pl. 137.) Hairy Germander. Calyx covered with long loose hairs. Somewhat rare. Moist soil, eastern Penna., and southward. July-Sept.

(Bicknell describes several other forms found in our area as new species.)

\section{TRICHOSTEMA, L.}

IIerbs, anmual or perennial, with branched stems and opposite leaves with entire borders, and with small flowers in terminal loose-spreading clusters. ('alyx bell-shaped, with 5 very unequal teeth, the 3 upper much the longest and partly united, the 2 lower short. Corolla 5-lobed, the lobes nearly ryual in longth, the tube in our speeses extending notably beyond the ealyx and somewhat curved. Stamens 4, the anterior pair longer, extending beyond the corolla.

1. T. dichotomum, L. (Fig. 7, pl. 137.) BluE CUrLs. Stem slender, much hranched, $\frac{1}{2}$ to $2 \mathrm{ft}$. high. Leaves oblong or lance-shaped, on leaf-stalks, 1 to $3 \mathrm{in.}$ long, $1 / 3$ to 1 in. wide, the whole plant somewhat viscid. Flowers loosely clustered, 2 or, less frequently, 3 borne together. Corolla blue, pink or rarely white. Dry fields, Maine to Florida. July-Oct.

2. T. lineare, Nutt. (Fig. 6, pl. 137.) Narrow-Leaved Blue Curls. Iraves linear, in other respects much like No. 1. Dry fields, Maine to Florida. July-Aug.

\section{ISANTHUS, Michx.}

Low herl, viseid, much branehing, with narrow lanee-shaped leaves, with entire margins and with small blue flowers in loose axillary clusters. Catlyx bell-shaped, 5-lohed, the teeth equal; corolla somewhat longex than 
the calyx, the border somewhat unequally 5-lobed, the lobes rounded and spreading. Stamens 4, not longer than the corolla, anterior pair longer than the others.

I. brachiatus, (L.) BSP. (Fig. 3, pl. 137.) False Pennyroyal. Stem much branched, $\frac{1}{2}$ to $1 \frac{1}{2} \mathrm{ft}$. high. Leaves lance-shaped, tapering at each end, without teeth or with a few sharp ones. Flowers at the axils, 1 to 3 in a cluster, blue. Sandy soil, Maine, southward. July-Sept.

\section{Family III.-SOLANACEAE. Potito Family}

Herbs, vines, rarely shrubs (none in our area), with alternate leaves and regular flowers with 5 divisions of the calyx, 5 lobes of the corolla and 5 stamens. Fruit a capsule of 2 cells or a berry. Style single. Stamens alternate with the lobes of the corolla, and inserted in the tube. Calyx below the ovary. Seeds numerous. Fruit a pulpy berry.

Calyx, in fruit forming a large colored, inflated sac about the berry . . . . . . . . Physalis

Calyx 5-lobed, fitting closely about the berry Leucophysalis Calyx 5-lobed, not investing the berry . . . Solanum Fruit a capsule.

Calyx enclosing the fruit, not covered with spines

Calyx covered with spines . . . . Datura
Calyx only partly covering the fruit . . Nicotiana

\section{PHYSALIS, L.}

Herbs with, in our species, wavy bordered leaves and yellow or white flowers. Calyx 5-parted, inereasing as fruit develops, forming an inflated enclosure for the large berry. Corolla open-bell-shaped, the 5 stamens inserted near the base of the corolla tube.

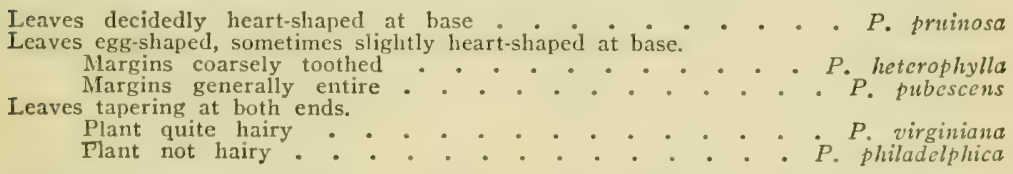

1. P. pruinosa, L. (Fig. 5, pl. 138.) Tall Hairy Ground Cherry. Annual, much branched, erect or decumbent; leaves ega-shaped, heartshaped at base, margins wavy or with some sharp tecth, whole plant very hairy. Flowers yellow, tinged with purple or spotted with brown. Low grounds, Mass., and southern part of our area. July-Sept.

2. P. pubescens, L. (Fig. 1, pl. 138.) Low IIAiry Ground Cherry. A very diffuse annual, when mature decumbent. Leaves 1 to $2 \frac{1}{2} \mathrm{in.}$ long, egg-shaped, at base oblique, one side usually longer than the other, the border entire or with distant angular teeth. Stem and leaves downy, but 
leaves becoming in some cases smooth, except along the veins. Calyx lobes narrow; corolla yellow spotted with purple in the center. Anthers violet. Pennsylvania and southward. July-Sept.

3. P. philadelphica, Lam. (Fig. 2, pl. 138.) Pinladelphia Ground Culerry. Leaves lance-shaped or egg-shaped, tapering at each end, on rather long leaf-stalks. Plant sometimes 4 or $5 \mathrm{ft}$. high, smooth or with few hairs. Calyx closely investing the large red or purple fruit. Corolla yellow, with purple in throat. In cultivated soils, Rhode Island, and southward. July-Sept.

4. P. virginiana, Mill. (Fig. 3, pl. 138.) Virginia Ground Cherro. Stem 1 to $3 \mathrm{ft}$. high, diffusely branched; erect or decumbent. Leaves oblong or egg-shaped, tapering at each end, wavy or sharp toothed at margins; the whole plant hairy. Corolla about an in. broad, yellow. Cultivated grounds, New York, westward and southward. July-Sept.

5. P. heterophylla, Nees, (Fig. 4, pl. 138) Clammy Ground Ciernt. Peremial, decidedly downy or hairy with jointed hairs; stem at first erect, later decumbent, spreading, 1 to $3 \mathrm{ft}$. long. Leaves egg-shaped to oval, hades generally 2 in. or more in length, somewhat heart-shaped at base or bluntly tapering, borders with coarse teeth. Corolla greenish. yellow with a dark eye at center. Fruit a large yellow berry. Rich soil, somewhat common.

\section{LEUCOPHYSALIS, Rydberg.}

Tall, viscid hairy annual. Leaves not toothed, egg-shaped or lanceshaped, tapering at each end. Calyx bell-shaped, 5-toothed, fitting closely around the large berry. Corolla open-bell-shaped, yellow.

L. grandiflora, (Hook) Rydberg. (Fig. 6, pl, 138.) LARge White Fiowered Ground Cherry. (Physalis grandiflora, Hook.) Plant erect. 1 to $3 \mathrm{ft}$. high. Flower about $1 \frac{1}{2} \mathrm{~m}$. broad, white, resembling the Morningglory flower, but with short tube. In valley of Lake Champlain. MayJuly.

\section{SOLANUM, Tourn.}

Therhs and vines, with alternatr leaves, the larger of which are often accompanied by smaller lateral ones. Flowers in clusters, white, blue, dark purple or yellow. ('alyx 5-cleft, wheel-shaped; corolla wheel-shaped, the 5 lobes often extending nearly to the base. Stamens inserted in throat of corolla, the anthers converging around the style. Berry 2-celled, globose.

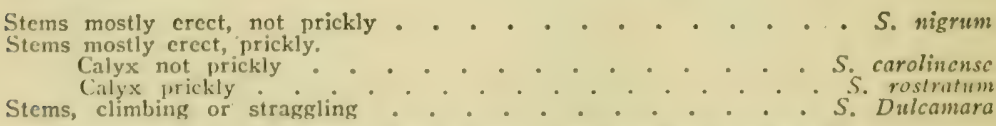

1. S. nigrum, L. (Fig. 3. pl. 139.) Common or Brack Nigitsinad\%. Jow, much hranehing, generally without hairs, 1 to $2 ! \mathrm{ft}$. high. Teaves coge-shaped, tapering at, rach end, on leaf-stalks, a small leaf often springing from the side of the leaf-stalk. Flowers in small umbel-like clusters, dirented laterally from the stem; corollat star-shaped, the eonverging anthers form a shiarp (one in the eenter. Berries globular, black. In rich shaded grounds. July-Oct. 


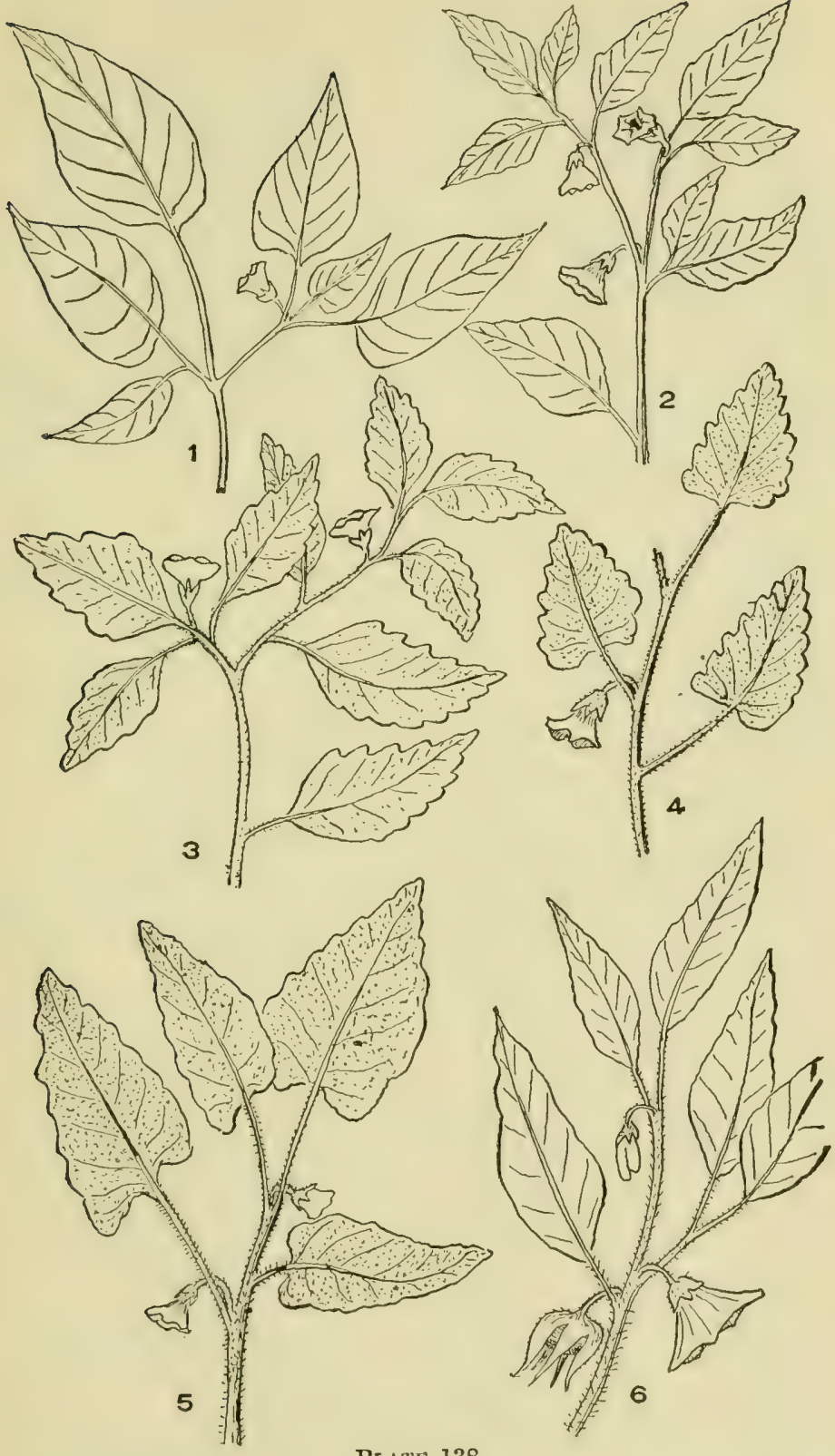

Plate 138

1. Physalis pubescens. 2. P. philadelphica. 3. P. virginiana. 4. P. heterophylla. 5. P. pruinosa. 6. Leucophysalls grandiflora. 
2. S. carolinense, I. (Fig. 1, pl. 139.) Horse Nettle. Stem much branching, 1 to $4 \mathrm{ft}$. high, armed with long slender prickles. Leaves in general outline egroshaped, but deeply sinuate, the sinuses extending some. times nearly to the midvein. Flowers in a terminal cluster; corolla starshaped, the lobes extenling half way to the base; anthers forming a pyramidal cone. Fruit a yellow berry.

3. S. rostratum, Dunal. (Fig. 2, pl. 139.) SANd Bur. Very prickly, 1 to $2 \frac{1}{\mathrm{ft}}$. high. Leaves sinuate lobed, some of the sinuses extending to the midvein, all lobes rounded; surface of leaves covered with a copious yellowish down. Calyx covered with long slender prickles. Fruit a large globular berry. Sandy waste places. May-Sept.

4. S. Dulcamara, L. (Fig. 4, pl. 139.) Bittensweet. Nigitsilade. Perenial climbing or trailing vine, more or less downy. Leaves, the upper halberd-shaped, the lower egr-shaped, heart-shaped at base. Flowers in side clusters, eorolla blue or dark purple. Calyx not enclosing fruit. Fruit an oval, red berry. Moist shady places, mostly about dwellings. JuneSept.

\section{HYOSCYAMUS, L.}

Coarse, fetid weeds, with alternate deeply lobed leaves and large regular flowers from the leaf-axils. Calyx bell- or urn-shaped, 5-lobed, striped; corolla funnel-form with a 5-lobed, more or less unequally spreading border. Stamens spreading. Fruit a capsule enclosed in the calyx.

H. niger, L. (Fig. 5, pl. 139.) Black Hendane. Stem stout, 1 to $21 \mathrm{ft}$. high. Leaves clasping the stem, deeply sinuate. Flowers on very short flower stems; corolla greenish-yellow with purple markings. Capsule oblong. Escaped from gardens. June-Sept.

\section{DATURA, L.}

Coarse weeds, with unpleasant odor, poisonous. Leaves with sinuate borders, the lohes irregular and often deep. Flowers large, showy in the forks of the stem. ('alyx 5-lobed, prismatic, covered with hooklets; corolla large, funnel-form.

1. D. Stramonium, T. (Fig. 6, pl. 139.) Strasioxium. Whole plant very dark green, 1 to $5 \mathrm{ft}$. high, branching. Leaves 3 to $8 \mathrm{in.} \mathrm{long,} \mathrm{irregu-}$ larly sinuate. Flower large, about $3 \frac{1}{2} \mathrm{in.}$ long, $2 \mathrm{in}$. broad. White. In rich waste grounds. Summer.

2. D. Tatula, I. Purple Stramonium. Taller than No. 1, and flowers pale violet-purple. Fields and waste places. May-Sept.

3. D. Metel, L. Entire-Leaven Thonn-Apple. Leaves broadly egg. shaped, unequal on the two sides, rounded at base or heart-shaped. Flowers white. Waste places, Rhode Island, southward. July-Sept.

\section{NICOTIANA, L.}

C'oarse, rank herlss, wilh large entire leaves and terminal elusters of larige flowers. Calyx tubular, 5-eleft; corolla funmel-form. Stamens 5, inserted in tube of corolla. Capsule 2-celled.

N. rustica, I. WIrn 'lonscco. Leaves egreshaped, borders entire, 2 to 8 in. long. Calyx teeth low triangular; corolla cylindric fumel-form, 

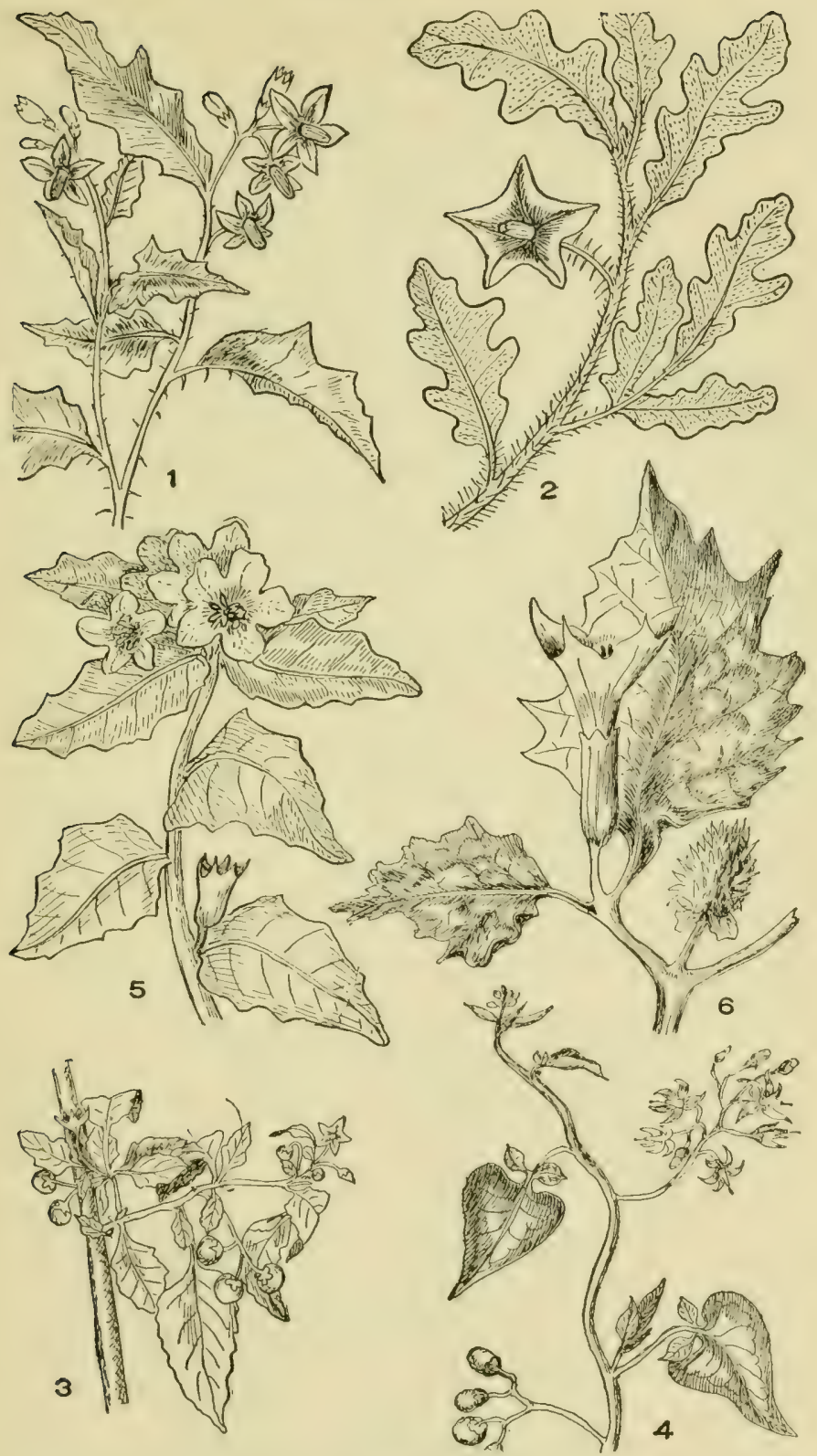

Plate 139

1. Solanum carolinense. 2. S. rostratum. 3. S. nigrum. 4. S. Dulcamara. 5. Hyoscyamus niger, 6 Datura Stramonium. 
greenish-yellow. Southern part of our area. Relic of Indian culture. June-Sept.

\section{FAMILY IV.-SCROPHULARIACEAE. Figwort FAMILY}

In our area nearly all the species are herbs, a single species, Paulownia, is a tree. Elsewhere shrubs and trees are found within the family. 'The leaves may be opposite or alternate, always simple, lut the borders may be entire or more or less indented. The flowers may be solitary or in variously formed clusters. Flowers alway's more or less irregular, though in the first tribe the irregularity is slight. Calyx persistent 5- or t-toothed or demply divided. Corolla with a mited petal more or less 2-lipped with a tube of greater or less extent. Stamens free from each other, inserted in the tube of the corolla, 5 or mostly 4 when 2 are longer than the other 2 , or in some cases only 2 fertile stamens. Pistil 1; fruit sometimes a berry more frequently a capsule. Seeds numerous.

\section{The Mullen Tribe}

Corolla nearly regular, wheel-form, generally with 5 fertile stamens

Verbascui

\section{The Snapdragon Tribe}

Corolla decidedly irregular, 2-lipped, the upper lip, in bud, covering the lower; in bloom the lower lip approaches the upper so as nearly to close the throat (personate). Stamens (fertile) 4. Leaves usually opposite, at least below.

Herbs.

Corolla tube prolonged into a spur or forming a sac or swelling anteriorly.

Tube with a spur.

Leaves with veins diverging from mid-vein.

Flowers solitary

Elatinoides

Flowers in elusters . . . . . . . Linamia

'T'ube saccate

ANTIRRHINUM

Corolla not spurred or saccate.

Stamens 4.

Tube of corolla inflated the 5 th stamen represented by a scale, attached to the upper side of the eorrlla . . . . . . . . Scropilularia

Tube not inflated, elearly 2-lipped, the 5th stamen present, but shorter than the others and sterile; seeds winged

Chelone

The 5th stamen about as long as the other, sterile;

seeds without wings . . . . . Pextstemon

Tube of corolla 2-cleft nearly to base . CoLrinsia 


\section{The Monkey Flower Tribe}

Corolla clearly irregular, 2-lipped, not saccate or spurred, the posterior lobes covered, in bud, by the lateral lobes. Fertike stamens 2 or 4 , when 4, 2 long and 2 short. Capsule splitting at maturity in the seams running from below upward.

$$
\text { Herbs }
$$

\section{Stamens 4. Corolla 2-lipped}

Stamens included within the tube of the corolla.

Stamens not ascending under its upper lip.

Throat of the corolla closed.

Leaves opposite in pairs.

Leaves coarsely toothed.

Mimulus

Leaves entire

BACOPA

Throat of corolla not closed.

Collinsia

Stamens ascending under the upper lip.

Leaves opposite in pairs.

Flowers in narrow spikes.

Corolla not hairy . . . . . . . Ruinanturus

Corolla hairy . . . . . . . . . Odontites

Flowers solitary.

Leaves rounded.

EUPHRASIA

Leaves lance-shaped

MELA MPYRUM

Leaves in whorls

LEPTANDRA

Leaves all from the root

LIMIOSELLA

Leaves

alternate

Castilleja

Corolla not 2-lipped, but sub-equally 5-lobed

Leaves opposite.

Flowers purple.

Leaves linear, entire . . . . . . . Gerardia

Leaves egg-shaped or lance-shaped, borders toothed

Flowers yellow

BUCIINERA

Leaves alternate, flowers yellow.

Leaves deeply lobed, the borders toothed

Leaves simple (not lobed), the borders not toothed, corolla decidedly 2-lipped

DASYSTOMA

Pedicularis

SCHWALBEA

Corolla 2-lipped.

\section{Stamens 2}

Calyx 5-parted.

Sterile filaments absent or minute..... . GRatiola

Sterile filaments evident and forked . . . . . Imrsantries

Calyx 4-parted . . . . . . . . . . Micrantuemum

Corolla not 2-lipped, but sub-equaily 4-parted . . . . . Veronica

Tree . . . . . . . . Paulowisa

I. VERBASCUM, L.

Herbs, with alternate leaves, biennial or rarely peremial. Flowers in 
terminal spikes; corolla wheel-form with the 5 lobes unequal. Stamens 5, leaning outward, all fertile. Calyx 5-parted or 5-cleft.

1. V. Thapsus, L. Great Mullen. Velvet Plant. Stem erect, sometimes with one or two branches above, 2 to $7 \mathrm{ft}$. high. Leaves large (4 to $12 \mathrm{in.}$ long); with small teeth or none, the base of the leaf rumning down the stem each side, making winged angles to the stem; whole plant rough, with dense wool. Flowers in long club-shaped spikes, yellow; stamens unequal. In dry fields and waste places. June-Sept.

2. V. phlomoides, L. (Fig. 3, pl. 140.) Clasping-leaved Mullen. Similar to the last, but usually less high and less stout. The leaves, which in V. Thapsus, extend along the stem below the insertion, in this species are scarcely or not at all decurrent. Introduced in parts of New England from Europe. Also on Long Island. June-Aug.

3. V. Lychnitis, L. (Fig. 2, pl. 140.) White Mullen. Stem angled, considerably branched, 2 to $5 \mathrm{ft}$. high; the whole plant white with short soft hairs except the upper surface of the leaves. Leaves oblong to oblong-lance-shaped, with rounded tceth at borders, tapering at each end, 2 to $7 \mathrm{in}$. long. Flowers white or cream-color, in a pyramidal cluster of many flowered spikes. Mostly in southern or western part of our area, in dry waste places. June-Sept.

4. V. Blattaria, L. (Fig. 1, pl. 140.) Mотн Mullen. Stem erect, branching above, 1 to $3 \mathrm{ft}$. high, without hairs or only slightly downy. Leaves oblong. egg-shaped or lanee-shaped, broad and clasping the stem at base, tapering toward the apex, with coarse rounded teeth at margins. Flowers in a terminal slender spike, yellow or white, marked with brown at the back; spike 2 to $12 \mathrm{in.} \mathrm{long,} \mathrm{with} \mathrm{narrow} \mathrm{bracts} \mathrm{at} \mathrm{the} \mathrm{base} \mathrm{of} \mathrm{the}$ flowers. Stamens purplish, unequal. Dry fields, waste grounds. JuneSept.

\section{ELATINOIDES, Wetts}

Spreading or ereeping herbs, with veins sprealing from mid-vein. Flowers 2-lipped with a conspicuous spur at base of tube. Throat of corolla closed hy a sort of palate. Stamens 4, inclosed within the corolla. Flowers solitary from the leaf-axils.

1. E. spuria, (L.) Wetts. (Fig. 9, pl. 140.) Round-Leaved 'I'oad FLAx. (Linariu spuria, (1.) Mill.) Leaves nearly round, blunt at apex, heart-shaped at base, without leaf-stalks. Flowers yellowish-purple. Waste places. From Europe. June-Sept.

2. E. Elatine, (L.) Wotts. (Fig. 10, pl, 140.) SHarr-ponted Tosd Fux. (Linaria clatine, (I.) Mill.) Leaves arrow-shaped on short leafstalks, downy. Corolla yellowish-purple. From Europe. Waste places. June-Sept.

\section{LINARIA, Juss.}

Iferlos, with altermate leaves (at least the upper ones) with simple margins and with flowers axillary or in terminal clusters, ours spikes. Corolla 2-lipped, the throat nearly closed; a eonspienous spur extending batkwarl from the tuhe of the corollat. Calyx 5-parted, the parts nearly equal. Capsule oval or globose. 

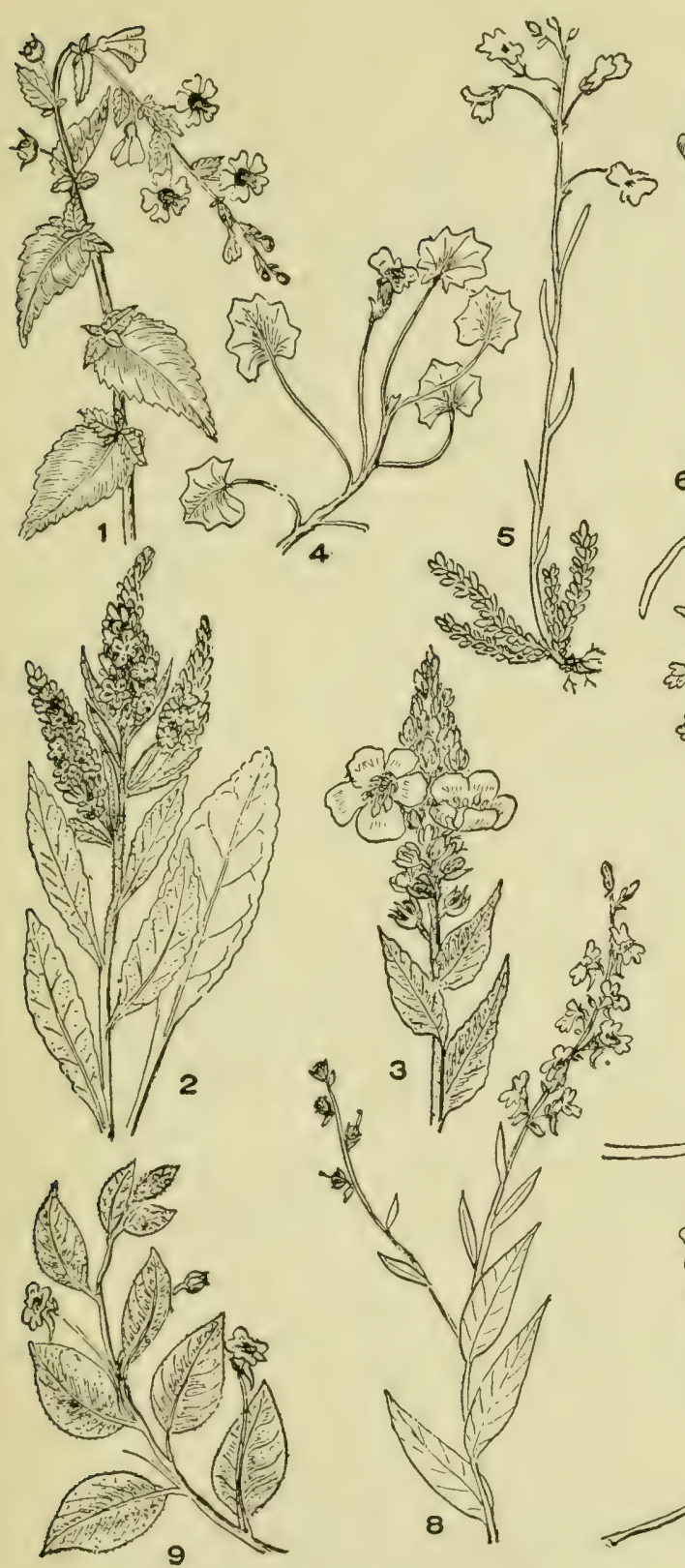
Flowers axillary

Flowers in spikes.

Flowers yellow.

Leaves linear . . . . . . . . . . . . . L. vulgaris Leaves lance-shaped . . . . . . . . . . L. genistacfolia Flowers blue or bluish.

Corolla spur long . . . . . . . . . . . . . L. canadensis

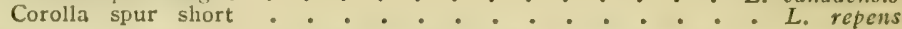

1. L. vulgaris, Mill. (Fig. 6, pl. 140.) Butter and Eggs. Yellow Toad Flax. Stem erect, smooth, 1 to $3 \mathrm{ft}$. high. Leaves very numerous, linear, alternate. Flower cluster narrow, densely flowered; the corolla about an ineh long, or ineluding the slender spur, longer, light yellow. Seeds winged. Common, fields and roadsides. June-Oct.

2. L. genistaefolia, (L.) Mill. (Fig. 8, pl. 140.) Broom-LEAved Toad Flax. Leaves broader, lance-shaped, and flowers smaller and seeds not winged. Flowers yellow. Sparingly naturalized. June-Aug.

3. L. canadensis, (L.) Dumont. (Fig. 5, pl. 140.) Blue ToAD Flax. Stem smooth, slender, simple or somewhat branched, $\frac{1}{2}$ to $2 \frac{1}{2} \mathrm{ft}$. high. Leaves linear, blunt at apex, the basal leaves forming a dense rosette. Flowers blue. Sandy soil, common in southern part of our area. May-Sept.

4. L. repens, (L.) Mill. (Fig. 7, pl. 140.) Pale-blue Toad Flax. Stem more or less decumbent, $\frac{1}{2}$ to $2 \frac{1}{2} \mathrm{ft}$. long. Leaves linear to lanceshaped. Flowers nearly white with a bluish tint. In waste places. From Europe; sparingly naturalized. June-Oct.

5. L. cymbalaria, (L.) Mill. (Fig. 4, pl. 140.) KenILwortil Ivr. Smooth, trailing, rooting at nodes, 2 to 12 in. long. Leaves round, radiate veined, leaf-stalks about $2 \mathrm{in}$. long. Flowers blue or lilac on long flower stems. Capsule globose, scveral seeded. Waste places, from Europe. JuneAug.

\section{ANTIRRHINUM, L.}

Herbs, with alternate leaves and flowers in terminal elusters or with flowers solitary in the axils. Calyx 5-parted, nearly regular; corolla decidedly 2-lipped, the throat nearly closed, the tube not spurred, but somewhat inflated. Stamens 4, included in the corolla. Capsule ovoid or globose. Seeds numerous, not winged.

1. A. Orontium, L. Lesser Snaporagon. Stem about $1 \mathrm{ft}$. high, nearly smooth; leaves narrowly linear, seattered. Flowers in the leafaxils, solitary. Calyx segments as long as or longer than the corolla. Corolla white. Waste places, a European speeies. June-Aug.

2. A. majus, L. Great Snaporagon. Stem 1 to $3 \mathrm{ft}$. high. Leaves lance-shaped or linear, 1 to $3 \mathrm{in.}$ long. Flowers large, corolla about $1 \frac{1}{2}$ in. long, purple or red. Calyx segments shorter than corolla. Waste places, eseaped from gardens. June-Sept.

\section{SCROPHULARIA, L.}

Rank hrrlss, usually with opposite leares and with small, purple-greenish flowers in loose clusters (panicles). Calyx 5-parted, the segments obtuse. Corolla tubular or more or lres globular without a spur, the border of 5 very unepual lokes, the 2 upper much longer than the 3 lower. Stamens 
4, unequal, bent to one side, a fifth stamen rudimentary. Capsule many seeded.

1. S. marylandica, L. (Fig. 1, pl. 141.) Maryland Figwort. A coarse herb, 3 to $10 \mathrm{ft}$. high, with opposite leaves, which are egg-shaped, 3 to $12 \mathrm{in.} \mathrm{long,} \mathrm{on} \mathrm{long} \mathrm{leaf-stalks,} \mathrm{the} \mathrm{borders} \mathrm{serrate,} \mathrm{apex} \mathrm{sharp,} \mathrm{base}$ tapering, rounded or even heart-shaped. Flowers in a large, more or less pyramidal, terminal cluster, composed of a number of umbel-like groups. Flowers greenish-purple. In woods and meadows, New York and southward. July-Sept.

2. S. leporella, Bicknell. (Fig. 2, pl. 141.) HARE Figwort. Leaves on short leaf-stalks, narrower than those of No. 1. IVoods and waysides, in stations the same as No. 1. June-Sept.

\section{CHELONE, L.}

Herbs, with opposite leaves and large flowers in dense spikes or axillary clusters, growing in mud by side of streams or in swampy places. Calyx 5-parted, the segments nearly equal. Corolla 2-lipped, the superior lip ereet, the lower of 3 lobes, spreading; tube enlarged above, the throat not closed, woolly within. Stamens 5, 4 only fertile, enclosed in the corolla. Capsule ovoid.

C. glabra, L. (Fig. 3, pl. 141.) Turtle-head. SNake-inead. Stem erect, 4 -sided, 1 to $3 \mathrm{ft}$. high. Leaves lance-shaped, sharp pointed at apex, narrowed at base on very short leaf-stalks, borders sharply toothed. Flowers large, in a dense terminal cluster, white or tinged with pink. Along the borders of streams or in other wet places. Throughout our area. July-Sept.

\section{PENTSTEMON, Soland}

Perennial herbs, with opposite leaves and terminal clusters of showy flowers. Calyx short, 5-parted. Corolla tubular, enlarged at the outer half of the tube, the border somewhat 2-lipped. Stamens, 4 fertile and 1 sterile, included in the corolla. Style slender. Capsule ovoid or globose.

1. P. hirsutus, (L.) Willd. (Fig. 6, pl. 141.) HaIry Beard-Tongue. Stem 1 to $3 \mathrm{ft}$. high, erect, slender. Leaves opposite, viscid hairy, oblong to lance-shaped, the upper clasping the stem by a broad rounded base, the lower tapering at the base to a broad or slender leaf-stalk, the upper leaves serrate at borders, the lower wavy. Corolla purple or violet, inflated toward the throat, which later is densely bearded, the border 5 -lobed; flower about an in. long. Dry grounds, Maine, southward to Florida. May-July.

2. P. laevigatus, Ait. (Fig. 5, pl. 141.) Foxglove Benrd-tongue. Stem 2 to $5 \mathrm{ft}$. high. Lower leaves oval or oblong, with entire or somewhat wary borders, the upper egg-shaped, heart-shaped and clasping the stem, usually sharp toothed. Whole plant, except in the flowering part, smooth. Corolla $\frac{3}{4}$ to 1 in. long, white. Fields, Maine, New York, and westward. May-July.

Var. 1'. Digitalis, Gray. Corolla larger, about 1 1 in. long, and its tube expands suddenly above the calyx.

Var. P. Pentstemon, (L.) Britton. Sirootir Beard-tongue. Resembles No. 2, but with purple corolla. Eseape from gardens. 


\section{COLLINSIA, Nutt.}

Slender branching herbs, with opposite leaves or leaves in whorls, and showy flowers in umbel-like clusters. Calyx 5-cleft. Corolla tipped to one side, the 2 lips divided nearly to the base, the upper lip 2-eleft, lower 3-cleft, larger. Stamens 4, enclosed in the 3-parted lower lip. Capsule 4- to many-seeded.

C. verna, Nutt. (Fig. 4, pl. 141.) INNocence. Stem weak, $\frac{1}{2}$ to 2 ft. high. Leaves thin, opposite, rounded or egg-shaped, the upper elasping by the heart-shaped base, the lower on leaf-stalks, all coarsely toothed at margins. Flowers in a terminal umbel-like eluster of 4 to 6 flowers, the lower lip blue, the upper purple or nearly white. Moist woods, western part of our area. May-June.

\section{PAULOWNIA, Sieb.}

A large spreading tree, with broad opposite leaves and large purple flowers in terminal loose elusters. Calyx deeply 5-eleft. Corolla a long tube with an irregular 5-lobed border. Stamens 4, included in the tube. Style slender. Capsule woody, egg-shaped, many seeded.

P. tomentosa, (Thunb.) Baill. (Fig. 7, pl. 141.) Paulownia. A very large tree, branching freely. Leaves broadly egg-shaped, 6 to $15 \mathrm{in}$. long, on long leaf-stalks. Flowers deep purple about $2 \frac{1}{2}$ in. long. In southern part of our area. Escaped from cultivation. May-July.

\section{г. MIMULUS, L.}

Herbs, with opposite leaves and handsome irregular flowers. Flowers from the axils, tube eylindric, the lips broad and reflexed or erect, rounded; the throat closed. Stamens 4, inserted in the corolla. Style 2-purted at top.

Flowers violet.

Leaves without leaf-stalks . . . . . . . . . . MI ringcns
Leaves with leai-stalks Flowers yellow.

Stem smootri.

Leaves egg-shaped or pear-shaped ......... M. guttatus

Leaves round or broadly egg-shaped $:$. $:$ Mamesii

Stem hairy..$\div \div$ M. moschatus

1. M. ringens, L. (Fig. 1, pl. 142.) Square-stemmed MonkeYFLower. Stem 1 to $3 \mathrm{ft}$. high, smooth, 4-angled. Leaves oblong or lanceshaped, coarsely toothed, clasping the stem at bese, tapering to the apex. Flowers, one in each of the upper leaf-axils, on flower stems longer than the flower. (olor violet-blue, varying sometimes to bluish-white. Along the wet borders of streams, and in swamps. June-Sept.

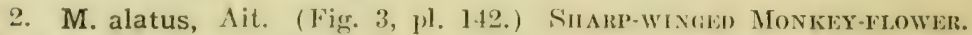
Plant about as large as No. 1, the stem very sharply 4-angled. Leaves oblong, egre-shaped, the upper tapering at each end, the lower somewhat rommded, on lonf-stallis. Corolla violet. Along borders of streams and in swamps. Connecticut and northward. June-Sept.

3. M. guttatus, DC. (Nig. 2, pl. 142.) Yellow MonkeY-FLower. (.M. Itangsdorbii, Don.) Leaves pear-shaped, the lower on leaf-stalks, (")atrsely toothed. Flowers yellow. In fields. Norfolk, Conn. June-Sept. 


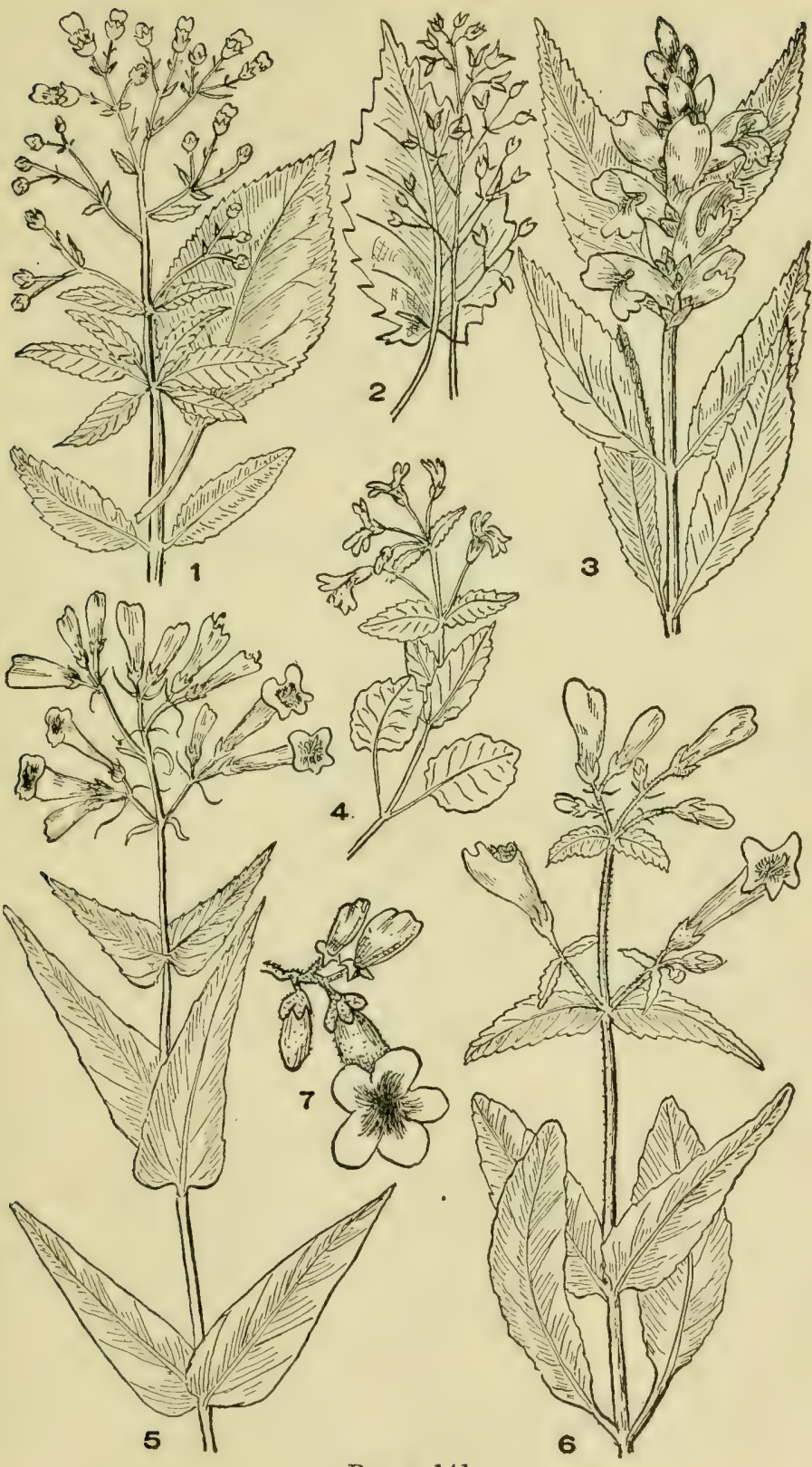

Plate 141

1. Scrophularia marylandica. 2. S. leporella. 3. Chelone glabra. 4. Collinsia verna. 5. Penstemon laevigatus. 6. P. hirsutus. 7. Paulownia tomentosa. 
4. M. Jamesii, T. and Gray. (Fig. 4, pl. 142.) James's Mrarulus. Creeping at hase and rooting at nodes. Smooth, 6 to $18 \mathrm{in.} \mathrm{long.} \mathrm{Leaves}$ rounded or kidney-shaped, the lower with short leaf-stalks, the upper sessile, mostly heart-slaped at base. Veins radiating from the stems insertion. Flowers yellow. Pocono, Pa. (G. T. S.), and westward. June-Sept.

5. M. moschatus, Dougl. Musk-FLower. Stems creeping; leaves eggshaped, on very short leaf-stalks. Whole plant hairy and viscid. Flowers an in. long, yellow. Rare, Locust Valley, Long Island; Middle Grove, Saratoga Co., N. Y. June-Sept.

\section{BACOPA, Aublet. (Monniera, Michx. Herpestris, Gartn.)}

Low herhs, with opposite leaves and flowers solitary in the leaf-axils. Calyx 5-toothed, 5-angled, nearly uniform in size from end to end. Corolla tubular with a spreading 5-lobed, more or less 2 -lipped, border. Stamens 4, unequal, included within the corolla. Style slender, dilated or 2-parted at top.

B. caroliniana, (Walt.) Kuntze. (Fig. 11, pl. 142.) BLUE Hedge IIrssor. Stems creeping at base, rooting at lower nodes, hairy, $\frac{1}{2}$ to $2 \mathrm{ft}$. long. Ieaves broadly oval or egg-shaped, blunt at apex, clasping the stem at base, the leaf borders entire. Flowers on stems shorter than the leaves, generally shorter than the calyx. Corolla blue. Margins of ponds. Pine barrens, N. J.

\section{GRATIOLA, L.}

Jow herbs, with opposite leaves without leaf-stalks and with Jellow or white 2-lipped flowers, which spring mostly singly from the upper axils. Calyx 5-parted, the divisions narrow and nearly equal, below the calyx in our speeies, are two bracts. The upper lip of the corolla entire, or more or less 2-cleft, tube cylindric. Fertile stamens 2. Style slender, the cap slightly 2-lobed. Fruit a capsule with numerous seeds.

1. G. virginiana, L. (Fig. 8, pl. 142.) Clammy Hedge Hyssop. Stem ereet, toward the top widely branched, 3 to $12 \mathrm{in.} \mathrm{high,} \mathrm{hairy,}$ clammy. Leaves lance-shaped, with a few teeth at margins or without teeth, acute at apex, narrow at base, without leaf-stalks. Flowers yellow on flower strms as long or nearly as long as the leares. Common in wet places. May-Oct.

2. G. sphaerocarpa, Ell. (Fig. 5, pl. 142.) Round-Fuuted HedeE Ifrssor. Stem 5 to $10 \mathrm{in.} \mathrm{high,} \mathrm{stout,} \mathrm{smonth.} \mathrm{Leaves} \mathrm{oval} \mathrm{or} \mathrm{oblong,}$ with sharp teeth. Flowers on flower stems scarcely longer than the calyx, yollow. Pol glolular, about $1 \mathrm{in}$. in diameter. Wet places, southern part of our area. June-Sept.

3. G. aurea, Muhl. (Fig. 7, pl. 142.) Golden Mrene IIrssop. Small plint, stem slender, leaning, 21 to $12 \mathrm{in}$. high. Leaves lance-shaped, not toothed at margins. Flower stem nearly as long as the leaves. Corolla Jrollow or white, yellow within. Swamps, most of our area. June-Sept.

4. G. pilosa, Michx. (Fig. 6, pl. 142.) IIARY IImne Hrssor. Leaves bratly "ros-shaped or oblong. C'asping the stem at hase, romded at apex, with fow terth, the whole plant, which is from 1 to $2 \mathrm{ft}$. high, covered with coarse hairs. Flowers with very short flower stems or none. Corolla purplish or white. Wet grounds, most of our area. May-Aug. 


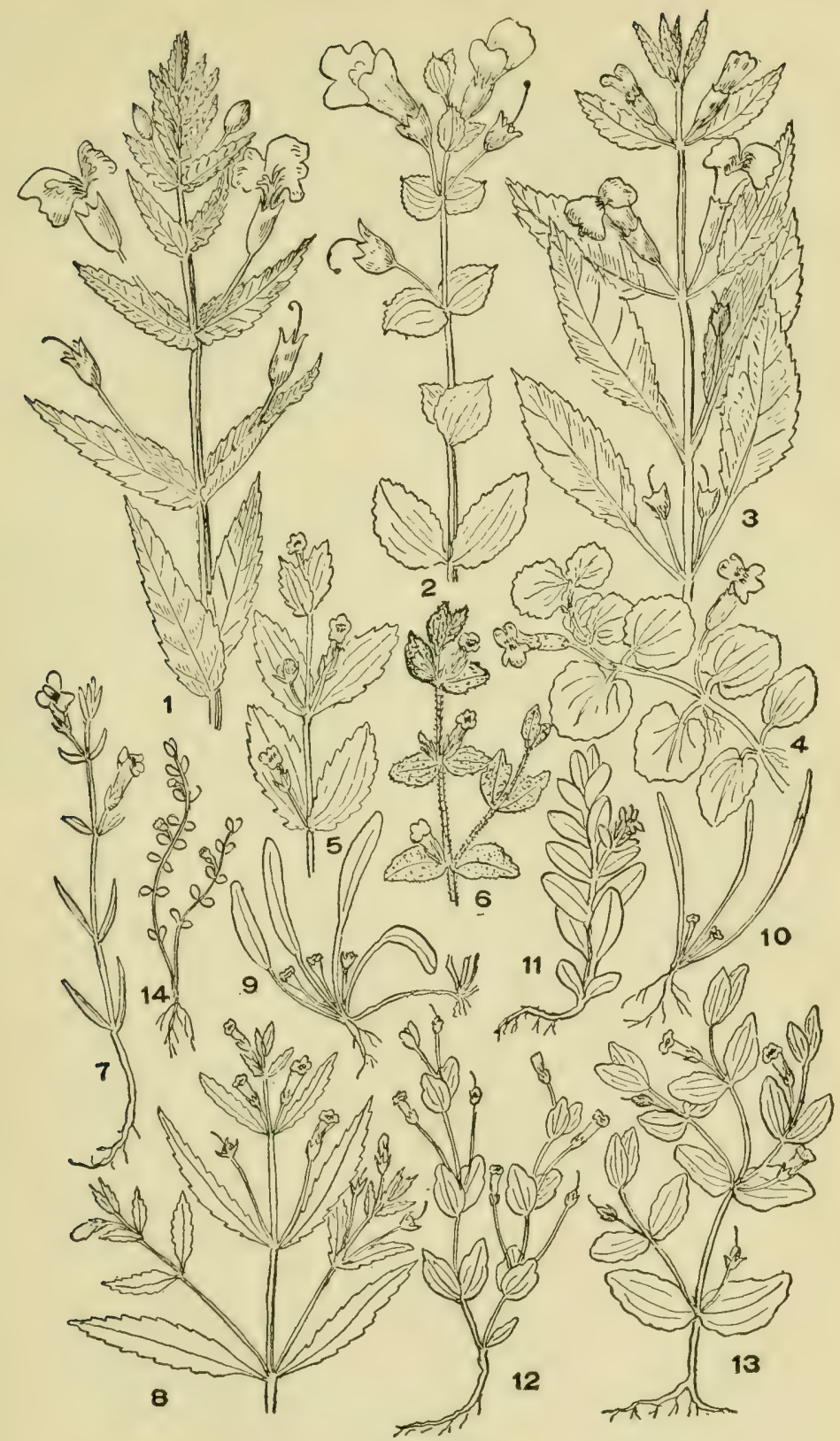

Plate 142

1. Mimulus ringens. 2 M. guttatus. 3. M. alatus. 4. M. Jamesii. 5. Gratiola sphaerocarpa. 6. G. pilosa. 7. G. aurea. 8. G. virginiana. 9. Limosella aquatica. 10. L. tenuifolia. 11. Bacopa caroliniana. 12. Ilysan. thes ratioloides. 13. I. attenuata. 14. Nicranthemum micranthemoides. 


\section{I3. ILYSANTHES, Raf.}

Branching herbs, with opposite leaves and small 2-lipped, purple flowers singly in the leaf-axils, the flower stems without bracts. Fertile stamens 2, sterile stamens 2. Fruit a rounded, many-seeded capsule.

1. I. gratioloides, (L.) Benth. (Fig. 12, pl. 142.) LoNG-STALKED False Pimpernel. Stem slender, much branched, 2 to $8 \mathrm{in.} \mathrm{high.} \mathrm{Leaves}$ egr-shaped, clasping the stem by the heart-shaped bases, somewhat acute at apex, a few teeth at margins. Flowers single in the axils on flower stems much exceeding the leaves in length. Corolla purple. Wet places, New, England, southward. July-Sept.

2. I. attenuata, (Muhl.) Small. (Fig. 13, pl. 142.) SriorT-STalKed False Pimpernel. Plant generally rather larger than No. 1, and flowers on flower stems shorter than the leaves. Wet places, Maine, southward and westward. May-Oct.

\section{I4. MICRANTHEMUM, Michx.}

Very small herbs, smooth, creeping or nearly erect, tufted, growing in mud or shallow water. Leaves opposite, calyx 4- or 5-parted; corolla very irregular, 2-lipped, the upper considerably shorter than the lower or absent. Stamens 2. Style short, many-seeded capsule globose.

M. micranthemoides, Wettst. (Fig. 14, pl. 142.) NutTall's MI('Rastremum. ( 1 . Nuttallii, Gray.) Stem 1 to 2 in. high. Leaves oval or ecrg-shaped, $1 / 12$ to $1 / 6$ in. long. Calyx 4-toothed, bell-shaped. Corolla very irregular, upper lip nearly or quite wanting, the middle lobe of lower lip much longer than the lateral lobes. Appendages at base of stamens about as long as stamens. Tidal mud. Aug.-Oct.

\section{I5. LIMOSELLA, L.}

Small plants growing in mud, usually by the sea shore, creeping by slender rumers, with long-linear or spatulate leaves and small, white or pink flowers on flower stems directly from the base of the plant. Calyx 5-lobed; corolla nearly regular, the border 5-eleft. Stamens 4; style clubslaped; the many-seeded capsule globular.

L. aquatica, L. (Fig. 9, pl. 142.) Narrow-Lenved Munwort. Stems only in the form of rimners, no upright stem. Leaves linear or threadlike, 1 to $5 \mathrm{in.} \mathrm{long,} \mathrm{in} \mathrm{a} \mathrm{group} \mathrm{arising} \mathrm{from} \mathrm{a} \mathrm{notehed} \mathrm{node.} \mathrm{Flowers} \mathrm{also}$ arising by a flower stem shorter than the leaves from the root node, single. Muddy shores of tidal streams. June-Sept.

Var. tenuifolia, Wolf. (Fig. 10, pl. 142.) Leaves linear, thread-like.

\section{I6. VERONICA, L.}

Irros (some exotic species trees and shrubs), with opposite or, less frequently, alternate leaves and small flowers, terminal or in the axils. Calyx 4-parted, rarely 5-parted; corolla flat, rounded, border generally 4-parted, the lower lobe usually narrow, the upper broader. Stamens 2, rxtending beyoul the corolla. Style entire. Capsule compressed, flattened or turgid, many seeded. 
Clusters of flowers narrow or somewhat spreading, springing from the leaf-axils.

Plants essentially without hairs.

Leaves broad, more or less egg-shaped.

Leaves with leaf-stalks . . . . . $V$. Anagallis-aquatica

Leaves without leaf-stalk . . . . . V. americana

Leaves linear ................ . V. scutcllata

Plants decidedly hairy.

Leaves oval on leaf-stalks . . . . . . . . $V$. officinalis

Leaves egg-shaped, with large teetli, leaf-stalks wanting $V$. Chamaedrys

Clusters of flowers in narrow terminal spikes.

Flower-stem shorter than the calyx.

Leaves broadly oval or elliptic . . . . . . . . V. alpina

Leaves narrowly oval, linear or oblong . . . . $V$. peregrina

Flower stem as long or longer than the calyx.$\cdots \cdots$. serpyllifolia

Flowers singly in the axils.

Leaves broadly obtuse or heart-shaped at base . . . . $V$. hederaefolia

Leaves narrowed at base.

Flower stems mucli longer than the leaves..... . $V$, arvensis

Flower stem much longer than the leaf ...... $V$. agrestis

Flower stem about as long as the leaf ..... V. Byzantina

1. V. Anagallis-aquatica, J. (Fig. 3, pl. 143.) W ITFR SpeEdWell. Plant smooth or slightly downy above, decumbent, rooting at the lower nodes, then erect. Leaves opposite, egg-shaped to lance-shaped, toothed at margins, clasping the stem at base. Flowers in slender elongated clusters, arising in the leaf-axils. Corolla pale blue, striped with purple. Capsule nearly orbicular, somewhat compressed. Brooks and swamps, throughout our area. May-Sept.

2. V. americana, Schwein. (Fig. 6, pl. 143.) AMEricaN BrookLIME. Smooth, decumbent at base, rooting at the lower nodes, then ereet, stem 8 in. to $3 \mathrm{ft}$. long. Leaves opposite, oblong or egg-shaped, coarsely toothed at margins, gencrally on lenf-stalks. Flowers in loose, rather slender clusters, small, very light blue, purple striped. Capsule nearly orbicular, compressed. Brooksides and swamps, throughout our area. AprilSept.

3. V. scutellata, L. (Fig. 1, pl. 143.) Marsir Speenwel. Stem slender, decumbent and rooting at base, to $2 \mathrm{ft}$. high, generally smooth. Leaves opposite, linear or narrow lance-shaped. Flowers in slender clusters from the leaf-axils, small, blue. Capsule much flattened, depressed at top. Swamps, southern New Yorw, and northward. May-Sept.

4. V. officinalis, L. (Fig. 11, pl. 143.) Common Speedweld. Stem decumbent, rooting at base, then partly erect; whole plant hairy. Leaves opposite, oval, toothed. Flowers in slender spikes, many flowered, the flower stem shorter than the calyx; corolla blue. Capsule somewhat triangular, notehed at summit. Dry fields, borders of woods. May-Aug.

5. V. Chamaedrys, L. (Fig. 10, pl. 143.) Germander Speedwell. Stem ereeping at base, then ascending, more or less hairy. Leaves op. posite, broadly eggr-shaped, generally heart-shaped at base, with coarse teeth at margins, without leaf-stalks or with very short ones. Flowers in slender spikes. Flower stems longer than the calyx. Capsule, heartshaped above. Fields and waste places, introduced. May-July.

6. V. alpina, L. (Fig. 2, pl. 143.) Alprne Speedweld. Stem erect, branched from the base, 2 to $12 \mathrm{in.} \mathrm{high,} \mathrm{hairy.} \mathrm{Leaves} \mathrm{opposite,} \mathrm{broadly}$ elliptie, attached directly to the stem. Flowers in a short narrow terminal cluster, light blue. Capsule tall, notched at top. High mountains of New England, etc. 
7. V. serpyllifolia, L. (Fig. $7, p l .143$.$) Tir 7$ Me-teated Speedrell. Stem somewhat ereeping at base, 2 to $4 \mathrm{in}$. high, much branched, smooth or nearly so. Leaves opposite broadly oblong or egg-shaped, rounded at both ends, obscurely notched at margins. Flowers in the upper axils forming a narrow terminal spike. Corolla pale blue or white with stripes. Capsule broader than long, notehed above.

8. V. peregrina, L. (Fig. 9, pl. 143.) Purslane Speedwell. Stem 4 to 9 in. high, branched at base, somewhat downy or smooth. Lowest leaves opposite, oblong or oval, sometimes on short leaf-stalks, the upper leaves alternate, narrow, elliptic or oblong without leaf-stalks. Flowers in the axils forming a rather loose spike of bluish, nearly white flowers. Capsule nearly orbicular, slightly notched at top. Waste places and as a weed in cultivated grounds. April-June.

9. V. arvensis, L. (Fig. 8, pl. 143.) CorN Speedwell. Stem 3 to 8 in. high, branched or simple, hairy. Lower leaves opposite, egg-shaped, on leaf-stalks, upper alternate, egg-shaped, without leaf-stalks. Flowers solitary in the leaf-axils, small, blue to white. Fields and waste places. March-Sept.

10. V. agrestis, I. FrELd Speedwell. Stem 3 to 8 in. high, branched or simple, hairy. Lower leaves opposite on leaf-stalks, toothed, upper alternate without leaf-stalks, egg-shaped. Flowers solitary in most of the axils, on flower stems much ionger than the leaves. Corolla small, blue. Capsule round, sharply notched. Waste places, naturalized. May* Sept.

11. V. Byzantina, BSP. (Fig. 5, pl. 143.) Byzantine Speedwell. Stem 1 to $1 \mathrm{ft}$. high, branched, whole plant hairy. Lower leaves opposite, upper alternate, egg-shaped, borders toothed. Flowers solitary in the leaf-axils on flower stems as long as the leaves, corolla blue. Capsule twice as broad as high, broadly notched. Waste places, naturalized. MaySept.

12. V. hederaefolia, L. (Fig. 4, pl. 143.) Try-Leaven SPEedwell. Sitem slender, branched, 3 to 18 in. long, hairy. Leaves round or heartshaped at base with a few deep notehes at margins. Flowers solitary in the leaf-axils on flower stems rather shorter than the leaves. Fields and thickets, southern New York and southward. April-Oct.

\section{LEPTANDRA, Nutt.}

Tall rect herbs, with whorled, or sometimes opposite, leaves and with dense terminal spikes of white or blue flowers. Corolla tube much longer than the calyx and longer than the border. Stamens 2, extending beyond the throat of the corolla; style as long as the stamens. Capsule higher than broad, many seeded.

L. virginica, J. (Fig. 1, pl. 144.) CULver's Root. (Veronica virginica, L.) Erect, smooth or somewhat downy, 2 to $3 \mathrm{ft}$. high. Leaves in whorls of 3 to 9, mostly 4, on short leaf-stalks, lance-shaped, with sharp teeth at margins, 3 to 6 in. long. Flowers small, nearly white in spilies, nsually 3 or more, int less frequently one, the middle one first developed. Rich fields and woods. July-Aug. 


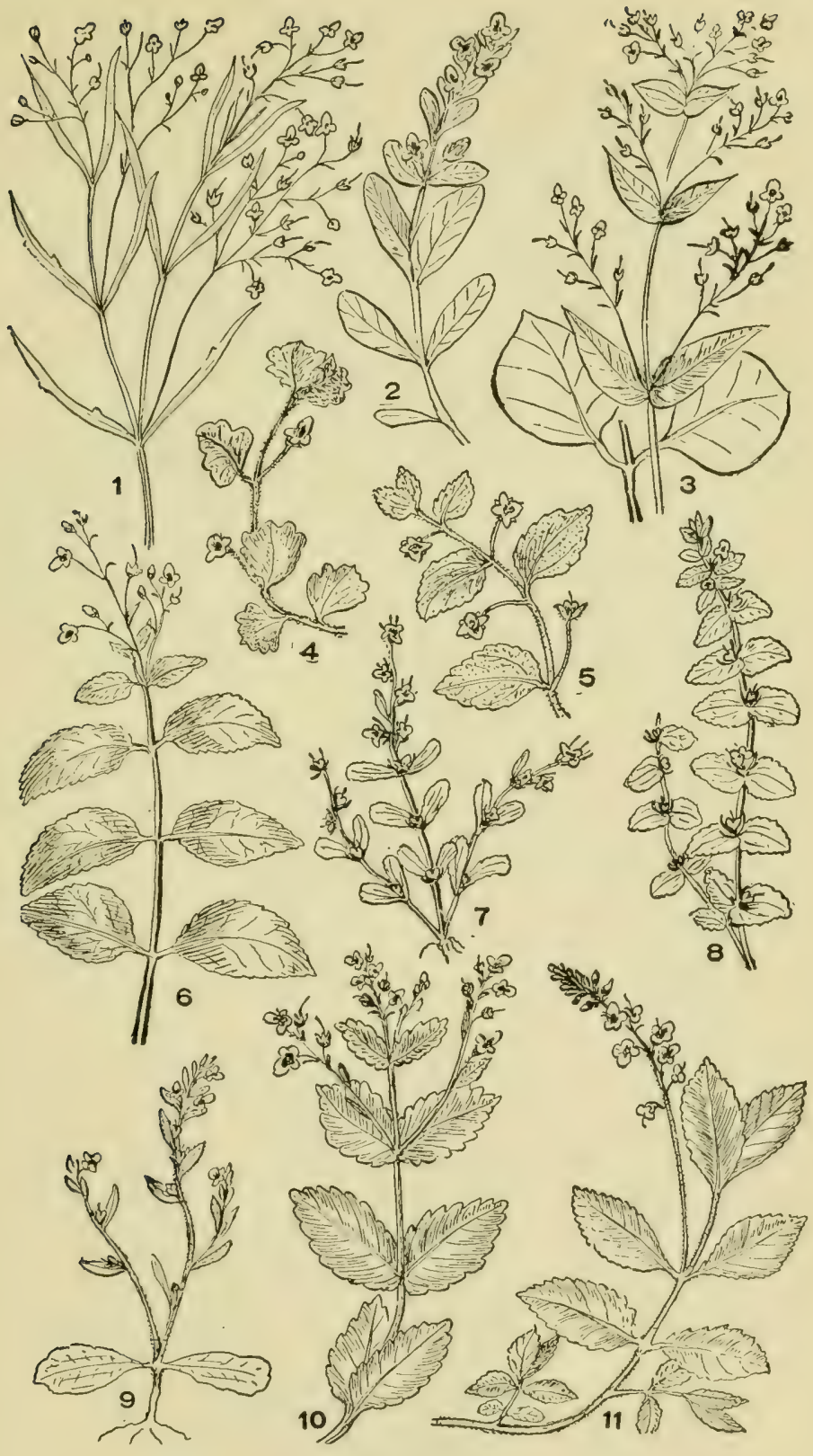

Plate 143

1. Veronica scutellata. 2. V. alpina. 3. V. Anagalis-aquatica. 4. V. hederaefolia. 5. V. Byzantina. 6. V. americana. 7. V. serpyllifolia. 8. V. arvensis. 9. V. peregrina. 10. V. Chamaedrys. 11. V. oflicinalis. 


\section{I8. BUCHNERA, L.}

Rough, hairy herbs, which turn black in drying. Leaves opposite or the upper alternate. Flowers white, blue or purple, opposite in a terminal narrow cluster, rather large. Calyx tubular with 5 equal teeth; corolla tube erlindric, the border of 5 radiating lobes, nearly regular. Stamens 4 , not extending beyond the throat of corolla.

B. americana, L. (Fig. 2, pl. 144.) BluE Hearts. Rough hairy, stem 1 to $2 \mathrm{ft}$. high, slender. Leaves oblong to lance-shaped, with deep indentations at margins. Corolla deep purple. Western New York, New Jersey. Sandy soils. June-Aug.

\section{I9. DASYSTOMA, Raf. (Gerardia, L.)}

Erect, branching herbs, with opposite leaves, usually deeply lobed, or upper leaves sometimes alternate and with yellow trumpet-shaped showy flowers in leafy elusters. Calyx 5-lobed; corolla lobes slightly unequal, yellow, the tube lined with hairs. Stamens 4, not extending beyond the throat of the corolla, quite unequal. Capsule spindle-shaped.

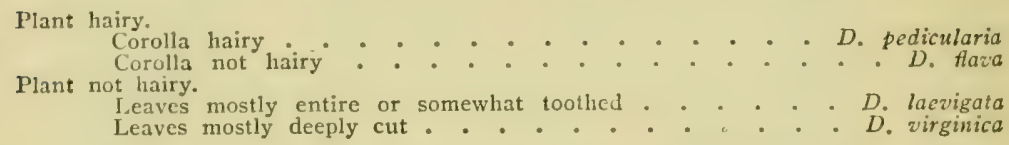

1. D. pedicularia, L. (Fig. 5, pl. 144.) Fern-Leaved False FoxGLove. Stem branched above, 1 to $4 \mathrm{ft}$. high, plant more or less covered with sticky hairs. Leaves opposite or a few upper ones alternate, fornlilie, with the margins of the lobes finely toothed. Corolla 1 to $2 \mathrm{in.} \mathrm{long}$, downy outside and inside. Dry woods, throughout our area. Aug.-Sept.

2. D. flava, (L.) Wood. (Fig. 6, pl. 144.) Downy False FoxGLove. Grayish downy, stem 2 to $4 \mathrm{ft}$. high, with few branches, often more. Leaves oblong or lance-shaped, obtuse at apex, the upper with plane margins, the lower with margins lobed. Corolla $1 \frac{1}{2}$ to $2 \mathrm{in.} \mathrm{long,}$ smooth on outside, hairy within. Dry woods, southern New York, eastern Mass., and northward. July-Aug.

3. D. virginica, (L.) Britton. (Fig. 4, pl. 144.) Sмootr False Foxilove. Smooth, stem sparingly or not at all branched. Leaves long and narrow, deeply incised with double incisions of margins. Corolla $1 \frac{1}{2}$ to $2 \mathrm{in}$. Iong, smonth on the ontside, hairy within. Stem 3 to $6 \mathrm{ft}$. high. Rich woods, throughout our region. July-Sept.

4. D. laevigata, Raf. (Fig. 3, pl. 144.) Entire-tenven Foxigove. Stem simple or sparingly branched, 1 to $3 \mathrm{ft}$. high. Plant not hairy or only slightly so. Ienves usually with leaf-stalks, lance-shaped or somewhat eereshaped. the marerins without teeth or lohes, or the lower leaves toothed or incised. Flower stem shorter than the ealyx. Corolla 1 to $1 \frac{1}{2}$ in. lons. 1)ry woods and thickets, Penna., and southward. July-Aug.

20. GERARDIA, L.

Plants, in our region, all slender herbs, with opposite linear leaves and larege showy trumpetshaped flowers, usually purple. (alyx 5-toothed, the 


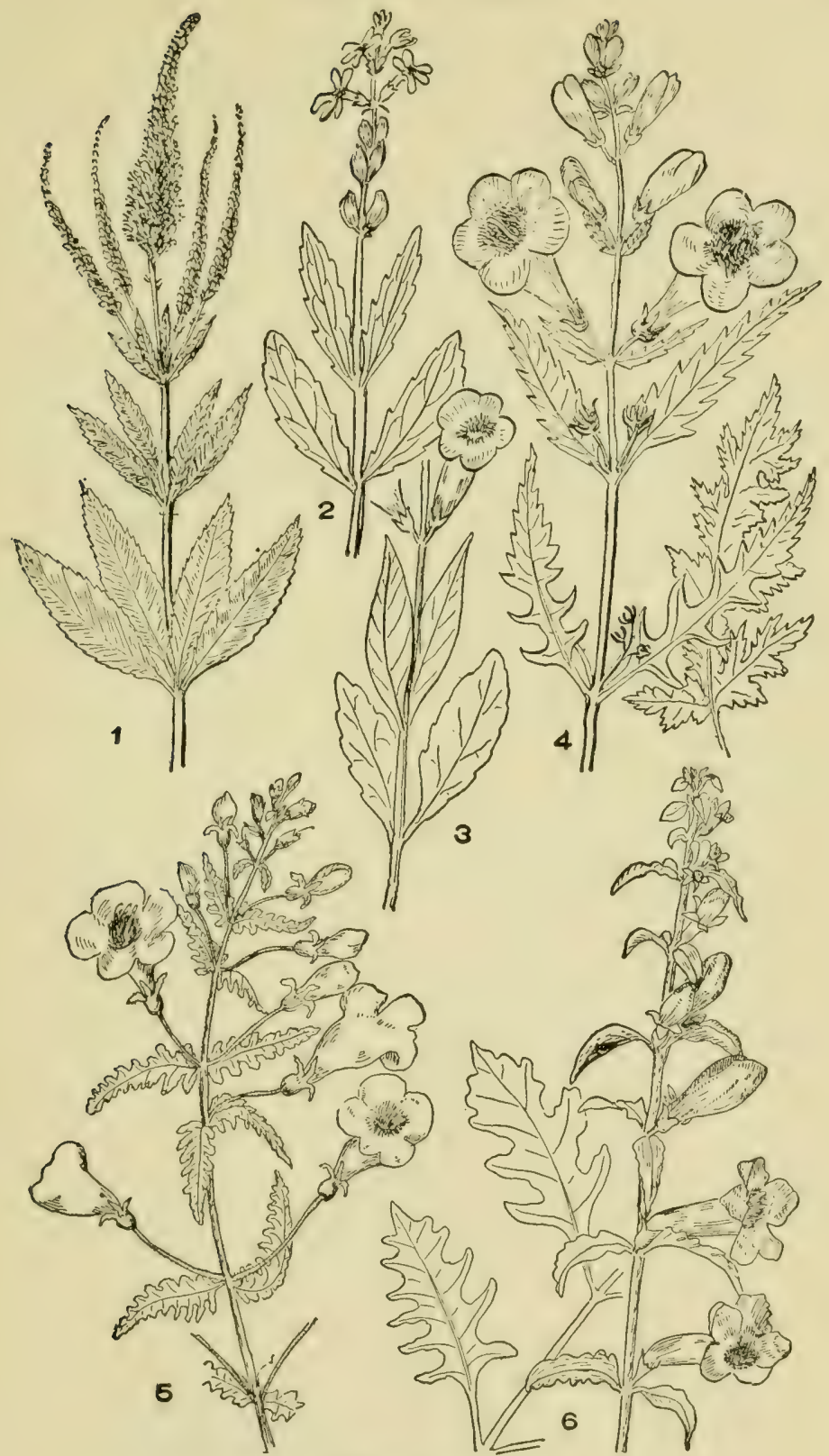

Plate 144

1. Leptandra virginica. 2. Buchnera americama. 3. Dasystoma laevigata. 4. D. virginica. 5. D. pedicularia. 6. D. flava。 
teeth sharp, short. Corolla with a long tube expanding toward the border, border of 5 spreading lobes. Stamens 4, unequal, not extending beyond the throat of the corolla, the filament hairy. Capsule egg-shaped or globose. Flowers opposite, in the axils of the upper leaves, the tube generally dotted with red or yellow.

Flower stems shorter than the calyx.

Corolla about $I$ in, long.

$\cdot \cdot \cdot \cdot$ G. purpurea

Flower stems as long as or longer than the calyx, rarely twice as long Ganpercula

Flower stems more than three times as long as the calyx and longer than the

flower . . . . . . . . . . . G. tenuifolia Flower stems longer than the calyx, about as long as the flower. Plant rough

1. G. purpurea, L. (Fig. 4, pl. 145.) Large Purple Gerardia. Stem 1 to $3 \mathrm{ft}$. high, smooth, slender, branched, the branches spreading. Leaves opposite, broadly or narrowly linear, 1 to $1 \frac{1}{2} \mathrm{in}$. long. Flowers forming a diffuse cluster at the summit of the branches; corolla purple or rarely purplish-white, 1 in. long. Calyx teeth triangular. Capsule globose. Moist grounds, mostly near the coast, north and south in our area. Aug.-Oct.

2. G. paupercula, (A. Gray) Britton. (Fig. 2, pl. 145.) SmalLFLowered GERARDia. Stem to $1 \frac{1}{2} \mathrm{ft}$. high, smooth, slender, branching with nearly erect branches. Leaves narrowly linear, opposite. Flowers in a diffuse cluster at summit of branches. Corolla $\frac{1}{2}$ to nearly 1 in. long, purple, borders as broad as the length of corolla, hairy in the throat. Stamens fringed with long hairs. Bogs and low marshes, New Jersey, northward. July-Sept.

3. G. maritima, Raf. (Fig. 1, pl. 145.) Sea-side Gerardia. Stem smooth, 8 to $16 \mathrm{in}$. high, with a sort of rosette of leafy branches at the base. Leaves fleshy, linear, obtuse at apex, the upper short and remote. Flowers purple, $\frac{1}{2}$ to $3 \mathrm{in}$. long, on flower stems as long or nearly as long as the calyx, longer in fruit. Capsule globose. Salt marshes, extent of our area. July-Aug.

4. G. tenuifolia, Vahl. (Fiø. 5, pl. 145.) Slender Gerardi. Stem 1 to $1 \frac{1}{2} \mathrm{ft}$. high, much branched, smooth. Leaves narrowly linear, the margins smooth or more frequently rough, 1 to 13 in. long. Flowers purple, spotted, rarely white, uswally more than $\frac{1}{2}$ in. long on flower stems as long as the flower. C'apsule globose. Light soil, thronghout our area. Aug.-Oet.

5. G. Skinneriana, Wood. (Fig. 3, pl. 145.) Skinner's Geranda. Stom rough, striped, 1 to $1 \stackrel{1}{\mathrm{gt}} \mathrm{f}$. high, branched, with nearly ereet branches. Leaves grenerally opposite, linear, very rough, generally less than 1 in. long. Flowers pale purple, $\frac{1}{2} \mathrm{in}$. lone, on flower stems hardly as long as the flowers. Eastern Mass., and southward.

\section{CASTILLEJA, Mutis.}

Hrors, parasitic on roots of other plants, with alteruate leaves, those among the flowers being dilated and more highly eolored than the yellow or purplish flowers thenselves. Flowers in spikes; ealyx tubular, compressed, on the upper side cleft, the opposite side eleft or entire. Corollat very irregular, its tulse included within the ealyx, its upper lip long, nar- 

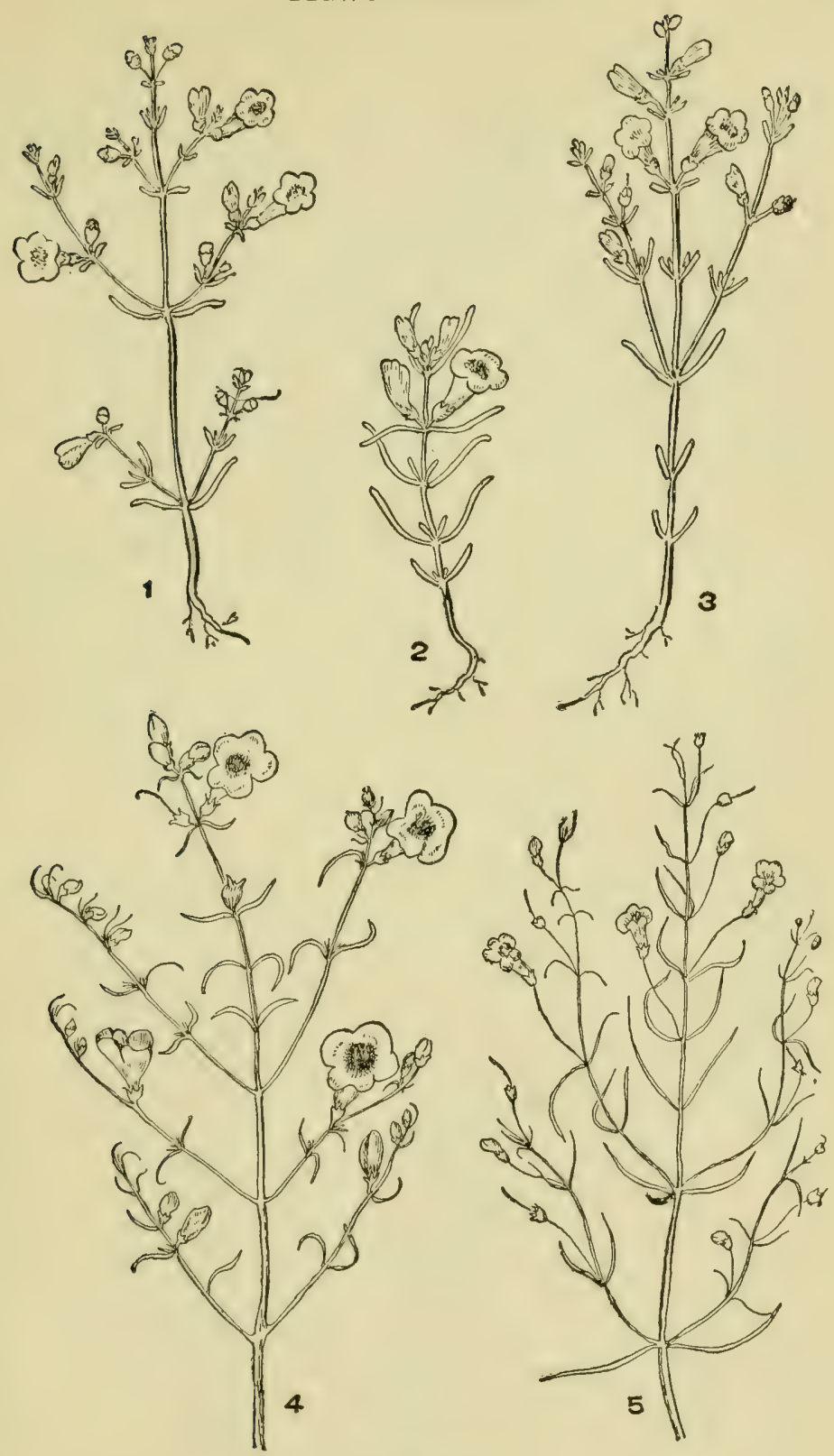

Plate 145

1. Gerardia maritima. 2. G. paupercula. 3. G. Skinneriana. 4. G. purpurea. 5, G, tenuifolia. 
row and arched, flattened laterally. Lower lip short, 3-lobed. Stamens 4, unequal.

1. C. coccinea, (L.) Spreng. (Fig. 4, pl. 146.) Scarlet Paintedcup. Annual, stem angular, erect, not branched or with few branches, 1 to $2 \mathrm{ft}$. high, whole plant hairy. Lower leaves clustered, margins mostly entire, upper leaves deeply about 3 - to 5 -lobed, the segments nearly linear. Flowers dull yellow, inconspicuous by reason of the bright scarlet bracts which exceed the flowers in length and brilliancy, one flower in the axil of each of the colored bracts. A showy and beautiful plant. In wet meadows, Not common. May-June.

2. C. pallida, (L.) Spreng. (Fig. 5, pl. 146.) LANCE-LEAved Parned-cup. (Var. septentrionalis, Gray.) Leaves all entire at borders, alternate, lance-shaped, without leaf-stalks. Flower bracts large, obtuse at apex and generally dentate, ycllowish or greenish-uhite, as long as the flowers, corolla yellowish. Higher regions of the White Mountains. JuneAug.

\section{SCHWALBEA, L.}

Perennial herb, with alternate leaves and large purple flowers in a bracted spike. Calsx tubular, the 5 teeth quite unequal, at the base of the calyx 2 narrow bracts. Corolla very irregular, the tube long, slender, the upper lip entire, arched, lower lip 3-lobed. Stamens 4, unequal, in the upper lip of the corolla. Capsule oblong, many seeded, seeds chaffy.

S. americana, L. CHAFF-SEed. Stem 1 to $2 \mathrm{ft}$. high, erect, downy. Leaves oblong or egg-shaped, the upper small, narrow. passing into bracts of the flower spike. Flowers 1 to $1 \frac{1}{2}$ in. long, without flower stems; corolla yellowish-purple. Wet soil, eastern Miss., and southward. MayJuly.

\section{EUPHRASIA, L.}

Small herbs, generally branching, parasitic on the roots of other plants. Leaves opposite, dentate or incised. Flowers small, white, blue or yellow in leafy bracted spikes. Calyx tubular, 4-cleft. Upper lip of corolla 2-lobed, erect, the sides turned back. Lower lip 3-oleft, spreading. Stamens 4, unequal, under the upper lip. Capsule oblong, flattened, seeds numerous.

1. E: americana, Wettst. (Fig. 8, pl. 146.) HAIRY EyebrigirT. Stem is to 10 in. high; whole plant hairy or mostly smooth. Leaves without leaf-stalks, opposite, rounded, large teeth at margin. Flowers in a terminal rouncled chuster or a slightly elongaterl spike, purple, varying to white, the cluster with leafy bratets, the bracts sharply toothed. Fields and hills, Maine. All summer.

2. E. Oakesii, Wettst. (Fig. 7, pl, 146.) O.niss's Errmigit. Stem 1 to $2 \mathrm{in}$. high. Stem leaves 1 or 2 pairs. Flower eluster round, the bracts bluntly toothed. Summits of the White Mountains.

Several speedes and varieties of Euphresin, resembling the species above described but dlilering in some slinht particulars, are reported as found locally by Robinson and others.

24. ODONTITES, Gmel.

Inerhs, with opposite leaves and slemeler spikes of red or yellow flowers. 


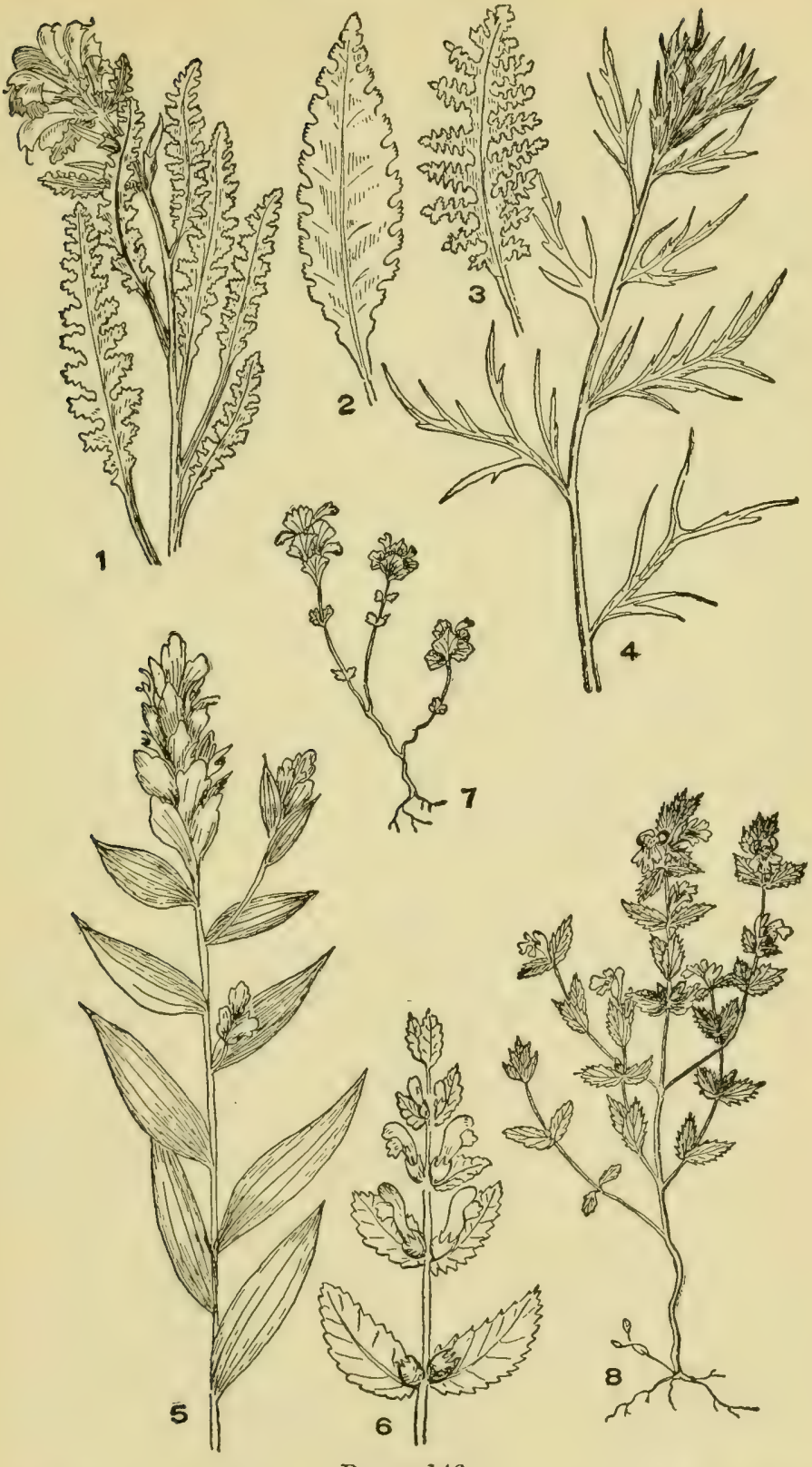

Plate 146

1. Pedicularis canadensis. 2. P. lanceolate (leaf). 3. P. Furbishiae (leaf). 4. Castilleja coccinea. 5. C. pallida. 6. Rhinanthus Crista-galli. 7. Euphrasia Oakesii. 8. E. americana. 
Calyx equally 4-cleft. Corolla tube narrow, upper lip entire, the sides not foldcd back. Stamens 4, unequal. Capsule nearly globose, seeds few.

O. rubra, (L.) Gilib. Red Eyebrignt. Annual, stem roughish, 6 to $15 \mathrm{in}$. high, branching, somewhat hairy. Leaves opposite, without leafstalks, narrow lance-shaped, with remote teeth. Flowers in slender spikes, loosely flowered, corolla red or pink. Fields and waste places. Naturalized. June-Sept.

\section{PEDICULARIS, L.}

Perennial herbs, with leaves alternate, opposite or rarely in whorls and with very irregular flowers in leafy spikes. Calyx tubular, 2- to 5-lobed. Corolla strongly 2-lipped, the upper flattened laterally and strongly arehed, the lower 3-lobed. Stamens 4, unequal, within the upper lip. Anthers transverse.

1. P. lanceolata, Michx. (Fig. 2, pl. 146.) Swamp Lousewort. Plant smooth or nearly so throughout; stem upright, 1 to $3 \mathrm{ft}$. high, with few if any branches. Leaves 2 to $5 \mathrm{in}$. long, partly opposite, in general outline oblong-lance-shaped, the margins lobed nearly half way to the mid-vein, the margins of the lobes with rounded teeth. Flower spikes with lance-shaped, toothed leaves at the base of the flowers. Corolla yellow, about an inch long with a short abrupt beak at the apex. Swamps, Connecticut and northward and westward. Aug.-Oct.

2. P. canadensis, L. (Fig. 1, pl. 146.) Wood Betony. Stems in clusters, half prostrate, hairy. Leaves seattered or some of them opposite, in general outline rather broadly lance-shaped, lobed on each side half way to the mid-vein, margins of the lobes toothed. Spikes of flowers leafy, short and dense. Calyx split on the lower side; corolla yellow, hooded, 2-toothed, under the apex. In woods and dry thickets, rather common. April-June.

3. P. Furbishiae, Tatson. (Fig. 3, pl. 146.) Miss Furbisin's PEDicularis. Stem ereet, 2 to $3 \mathrm{ft}$. high, downy or smooth. Leaves lobed on cach side to the mid-vein (pinnate), the lobes conssely toothed and the teeth themselves dentate. Corolla yellow. In swamps and along streams. Maine. July-Sept.

\section{RHINANTHUS, L.}

IIerbs, with opposite leaves and flowers in one-sided leafy spikes, or solitary in the upper axils. Calyx 4-toothed, much inflated. Corolla very irregular, 2-lipped, the upper arched, laterally compressed, minutely 2-toothed at the apex, lower lip 3-lobed, spreading. Stamens 4, unequal, under the upper lip. Anthers fringed, seeds winged.

1. R. Crista-galli, I. (Fig. 6, pl, 146.) Rattle Box. Stem slender, branching at the axils, the branches shorter than the principal stem, usually streaked with black lines, 6 to $18 \mathrm{in}$. high. Leaves lance-shaped, coarsely toothed, without leaf-stalks. Flowers yillow, 3 in. long, often with a purple spot on one or both lips. Along parts of the coast and on the White Mountains. June-Aug.

2. R. oblongifolius, Fernald. Usually a smaller plant than No. 1, 5 to $16 \mathrm{in.} \mathrm{high.} \mathrm{Few} \mathrm{or} \mathrm{no} \mathrm{branches} \mathrm{from} \mathrm{the} \mathrm{axils} \mathrm{and} \mathrm{the} \mathrm{stem} \mathrm{with"}$ 
out black lines. Corolla yellow without the purple or dark spots on the lips. Mountains of Maine and New Hampshire and Adirondack Mountains.

\section{MELAMPYRUM, L.}

Erect herbs, annual, branching, with opposite leaves and flowers solitary in the axils. Calyx 4-toothed, the 2 upper longer. Corolla irregular, 2-lipped with narrow tube, which is gradually enlarged toward the throat. Upper lip arched and flattened laterally. Stamens 4, unequal, under the upper lip.

M. lineare, Lam. (Fig. 14, pl. 147.) Nanrotv-leaved Cow-twhent. Downy, stem slender, obscurely 4 -sided, $\frac{1}{2}$ to $1 \frac{1}{2} \mathrm{ft}$. high. Leaves opposite, lance-shaped to linear, tapering at each end, on short leaf-stalks. The leaves among the flowers with 4 to 6 conspicuous bristle-point teeth. Corolla yellowish-white on short flower stems. Dry woods, north and south in our area.

\section{FAMily V.-IENTIBULARIACEAE. BladdertTort FaMilly}

Flowers 2-lipped. Marsh or water plants without leaves or with mostly thread-like leaves at the root or the root leaves sometimes broad. Flower seapes erect. Flowers solitary or in fewflowered clusters, terminal, on short flower stems, at the foot of each being a small bract. Calyx below the ovary, 2- to 5-parted. Corolla 2-lipped, the throat closed. Stamens 2. Ovary 1-celled.

Aquatic or bog plants . . . . . . . Utricularia Terrestrial plants . . . . . . . . Pinguicula

\section{UTRICULARIA, L.}

Mostly aquatic herbs, floating free in the water or rooting in mud. The floating species with branching spreading stems with finely dissected leaves and a scape, leaflets or with scale-like leaves, bearing at the summit a few or several irregular flowers. In some species the thread-like leaves are bladder bearing, in others the bladders are borne on leafless stems. Also in certain species there are two kinds of flowers, the open flowers on tho seape and a closed flower like a bulblet growing among the leaves. Calyx 2-lobed; corolla 2-lipped, quite irregular, closed at throat, a spur or sac protruding from the corolla tube.

Plants rooting in the mud, without dissected leaves and with or no air bladders.

Flower scape very straight, leaves reduced to scales, flowers open.

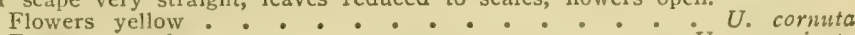
Flowers purple . . . . . . . . . . U. resupinata

Flower scape zigrzag

Flower scape hair-like, flowers without spur, closed, bulb-like U. cleistogama Plants floating or creeping in mud, the branches and finely dissected leaves floating. Air bladders numerous.

Flowers purple yellow on leafless scapes.

Whorl of dissected leaves on cylinclric and inflated leni-stalks $U$. inflata

Stems and stem leaves spreading, the lattet dissected and thread-

like. 
Bladders and closed flowers, borne among the thread-like leaves a. clandestino Bladders but not closed fowers borne among the threadlike leaves.

Spur of corolla about as long as the lip. Flowers I to 3 . U. biflora Spur of corolla usually obtuse, shorter than the lip of the corolla.

Flowers I or $2 . . . . . . \quad U$. gibba Flowers 2 to 8 . $U$. minor Flowers 5 to i2, the thread-like leaves feather-form to - . Uulgaris Leaf segments flat . . . . U. intermedia Leaf segments round $: \cdots, U$. fibrosa

1. U. cornuta, Michx. (Fig. 5, pl. 147.) Horned Bladderwort. Flower seape 9 to $12 \mathrm{in}$. high, rooting in the mud, branches, when present, root-like, leaves reduced to scales, or none. Flowers 1 to 6 , yellow, large, spur long and acute, corolla lips widely parted. Soft mud and shallow pools, northern to southern limits of our area. June-Aug.

2. U. resupinata, Green. (Fig. 9, pl. 147.) Reversed Blanderwort. Scape arising from rooting shoots, 2 to $7 \mathrm{in}$. high, with a solitary purple flower; the spur directed nearly horizontally. Muddy shores, bogs, Maine to Florida. July-Aug.

3. U. subulata, L. (Fig. 8, pl. 147.) ZIG-ZAG Bladderwort. Flower scape thread-like, zig-zag from flower to flower, leares few, linear, or none. Flowers yellow, lower lip 3-lobed, spur conic. Springs, wet sandy soil, Nantucket and southward. March-Aug.

4. U. cleistogama, (Gray) Britton. (Fig. 4, pl. 147.) Closed Bladderwort. Scape 1 to 3 in. high, bearing 1 or 2 closed purplish flowers not larger than a pin's head. Wet soil, eastern Mass., and New Jersey. August.

5. U. inflata, Walt. (Fig. 6, pl. 147.) Strollex Bladperwort. Flower scape 3 to 20 in. high; about its middle a whorl of leaves with inflated leaf-stalks, the leaves themselves finely divided. Lower leaves dissected, without inflated leaf-stalks. Among both sets of leaves are muny air bladelers. Corolla yellow. Ponds, througliout our area. March-Aurr.

6. U. purpurea, Walt. (Fig. 7, pl. 147.) PuRple Bladderwort. Flower seape 1 to $6 \mathrm{in.} \mathrm{high.} \mathrm{without} \mathrm{leaves} \mathrm{or} \mathrm{with} \mathrm{seale-like} \mathrm{leaves,} \mathrm{bear-}$ ing 1 to 4 flowrers. Branches long, floating, the dissected leaves bearing numerous air bladders. Corolla purple. Ponds, mostly near the coast. May-Aug.

7. U. vulgaris, L. (Fig. 1, pl. 147.) Common BLadderwort. Flower seape with a few seales or mone, stout, 3 to $1.4 \mathrm{ins}$ high, bearing from 3 to 20) rather large yellow flowers. Branches floating, sometimess a font lenge, feaves in thread-like divisions, the segments round, bearing bladders. Brooks and ponds, our area. June-Aug.

8. U. clandestina, Nutt. (Fig. 12, pl. 147.) Himkx-Frumten BuanDERwort. Seape slender, 2 to $5 \mathrm{in}$. high, benring from 3 to 5 yellow flowers. Tranches floating, spreadinge, with many fonely divided leaves with bladlers and with closed bulblets (cheistogamic llowers), on rather long flower stems arising from the branches among the leaves. Shallow ponds, mostly near the coast. July. 


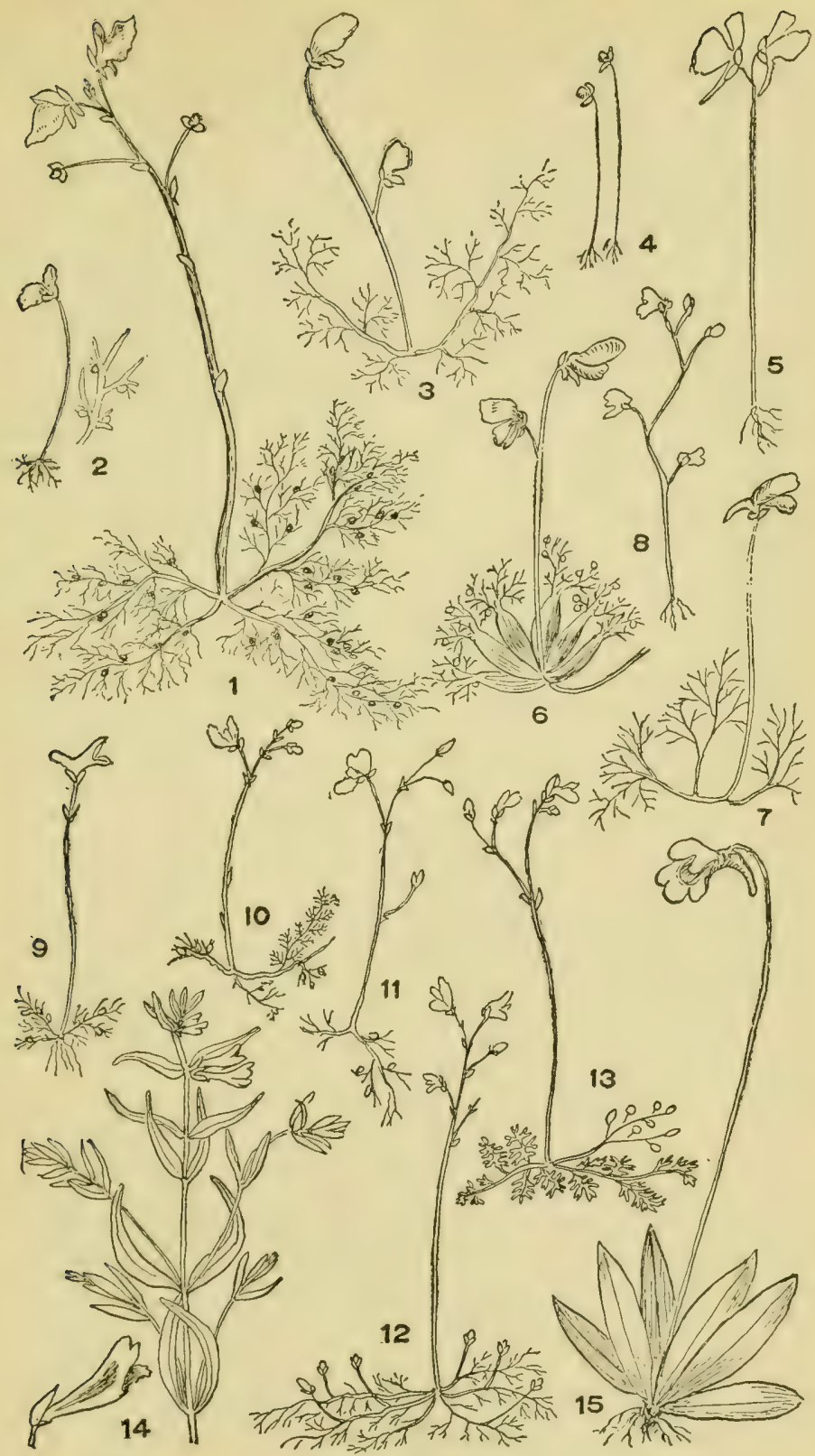

Plate 147

1. Utricularia vulgaris, 2. U. gibba. 3. U. biflora. 4. U. cleistogama. 5. U. cornuta. 6. U. inflata. 7. U. purpurea. 8. U. subulata. 9. U. resupinata. 10. U. minor. 11. U. fibrosa. 12. U. clandestina 13. U. intermedia. 14. Melampyrum lineare. 15. Pinguicula vulgaris. 
9. U. intermedia, Harne. (Fig. 13, pl. 147.) Flat-leaved BladderwonT. Flower seape with a few scales 2 to $10 \mathrm{in}$. high, bearing 2 to 5 yellow flowers. Branches floating. Leaves with 2 ranks of flattened, compound lineur leaflets. Separate stems bear numerous large air bladders. Pools, our area. June-Aug.

10. U. fibrosa, Walt. (Fig. 11, pl. 147.) Finnous Bladnerwort. Flower scape 5 to $12 \mathrm{in}$. high, with a few small scales, bearing 1 to 6 yellow flowers, the middle lobe striped with red. Branches floating. Leaves with few thread-like divisions, bearing bladders or not; bladders sometimes on separate branches. Shallow pools, Long Island and southward. June-July.

11. U. minor, L. (Fig. 10, pl. 147.) Lesser Bladdertront. Scape 2 to $7 \mathrm{in}$. high, bearing 1 to 10 yellow flowers. Branches floating; leaves in 2 ranks, the leaflets short, thread-like. Bladders among the leaves, ferw or absent. Upper lip of corolla shorter than lower. Spur reduced to a broad flat protuberance. Shallow pools and ponds, our area. JuneJuly.

12. U. gibba, L. (Fig. 2, pl. 147.) Humped Bladderwort. Scape 1 to $5 \mathrm{in}$. high, bearing 1 or 2 yellow flowers. Branches floating with very few thread-like leaves, and few air bladders. The leaves root-like, buried in mud or rising above it. Corolla spur blunt and short. Shallow pools and ponds, throughout our area. July-Aug.

13. U. biflora, Lam. (Fig. 3. pl, 147.) Two-flowered Blanderwort. Scape 2 to $5 \mathrm{in}$. high. Branches long, floating. Leaf divisions few, hairlike, often bearing many bladders. Flowers 1 to 3 on the scape, yellow, the lips ncarly equal. Shallow pools and ponds, eastern New England.

\section{PINGUICULA, L}

Herhs, with leaves arising from the root and with slender, naked, oneflowered seape. Upper surface of leaves viseid. Corolla 2-lipped, the upper 2-cleft, lower 3-cleft; from the tube extends a long spur, extending, generally, upward. Calyx 4- to 5-parted.

P. vulgaris, L. (Fig. 15. pl. "147.) Marsir VIolet, Leaves in a basal rosette, lance-shaped or approaching egg-shaped, blunt at apex, 1 to $2 \mathrm{in}$. long. Seape 2 to $6 \mathrm{in}$. high, smooth, bearing a single violet-purple nockding flower, the long spur pointing upward. Wet places, Vermont and northern New York. July-Aug.

\section{Fanix TI.-OROBANCHACEAE. Broourape FaAILY}

Parasitic herbs growing from roots of other plants. Fleshy, leafless, white, yellow or purplish-brown, with perfect 2-lipped flowers, solitary or severil on the spike. Calyx 4 - to 5-toothed, inferior to the oviry, nearly or quite equally divided. Corolla long tubular, the tulue generally bencling, lips 5-lobed. Stamens 4, unequal, insorted in the tube and alternate with its lobes (a rudimentary sth stamen (ompleting the alternations). Ovary 1-celled, free from the ealyx, seeds numerous. 
Flower solitary, terminating the stem

Thalesia

Flowers in a single dense spike, a row of stiff hairs running up the upper lip of the corolla . . . . . Orobanche Flowers in a dense spike, anthers of the stamens fringed

Flowers on several spikes branching from main stem Conopholis Epifagus

\section{THALESIA, Raf. (Orobanche, (Tourn.) L. Aphyllon, (Mitchel) Gray)}

Single or several stemmed, more or less viscid herbs, with solitary flowers terninating a naked seape. Calyx 5-cleft, corolla slightly 2-lipped, the tube long and curved, upper lip 2-lobed, lower 3-lobed. Stamens 4, unequal.

T. uniflora, (L.) Britton. (Fig. 1, pl. 148.) ONE-FLowered BroouRAPE. Stem, mostly buried in the ground, very short, with a few seales. Scapes 2 or more, 3 to 8 in. high, somewhat downy, each with a single flower about $\frac{1}{2} \mathrm{in.}$ long, with a decided curve to the tube. Rich: woods and thickets, throughout our area. April-June.

\section{OROBANCHE, L.}

Flowers in a dense spike, without flower-stems. Calyx split before and behind nearly to the base, both lips 2 -lobed. Stamens 4, unequal, included within the corolla. Parasites on roots of other plants.

O. minor, Smith. (Fig. 2, pl. 148.) Clover Broomrape. Spike 4 to 12 in. high, terminating in a narrow, dense cluster of purplish flowers generally parasitic on the roots of clover. Introduced from Europe. MayJuly.

\section{CONOPHOLIS, Wallr.}

Parasitic herb, with stout, umbranching stem densely sealy terminating in a thick scaly spike of yellow flowers. Calyx irregular, 4- to 5-toothed, at its base 2 bracts. Corolla tubular, swollen at base, strongly 2 -lipped. Stamens 4, unequal, extending beyond the throat of the corolla.

C. americana, Wallr. (Fig. 4, pl. 148.) SQUaw RooT. Plants brown, usually elustered, from thick bases. Flowers about $\frac{1}{2} \mathrm{in}$. long, the upper lip strongly arched, the lower drooping, 3-cleft. In woods, mostly oak, growing in the midst of the fallen leaves. Our area. May-June.

\section{EPIFAGUS, Nutt. (Leptamnium, Raf.)}

Branching parasitic herb, with purplish or yellowish stems, which carry a few scales, but no leaves. Flowers in slender spilies, the upper flowers sterile, the tube long and curved, the lower closed (Cleistogamic) but fertile. Calyx 5-toothed, oblique. Corolla 4-lobed, the upper larger than the 3 lower.

E. virginiana, (J.) Raf. (Fig. 3, pl. 148.) BeEcit Drops. Plant $\frac{1}{2}$ to $2 \mathrm{ft}$. high, with several flowering branches, flowers whitish and purplish, about $\frac{1}{2}$ in. long. Growing from the roots of beech trees. Our area. Aug.-Oct. 


\section{Family ViI.-Bigontaceae. Trumpet Tine Family}

Woody plants; vines, shrubs, trees with, in our naturalized species, opposite leaves and large showy trumpet-shaped flowers in large clusters. Calyx 2-lipped, 5-toothed or not toothed. Corolla of a long tube expanding toward the throat and with a 5-lobed, somewhat 2-lipped border. Stamens, inserted in the corolla tube, 4 or 2 fertile. Ovary bearing a long style.

Woody vine.

Large tree

I. TECOMA, Juss.

Climbing vines, with compound leaves and aerial rootlets. Calyx 5-toothed, bell-shaped; corolla tube long, lobes 5, nearly equal. Stamens 4, unequal. Capsule 2-celled.

T. radicans, DC. (Fig. 5, pl. 148.) TRUMPET Flower. The ordinary Trumpet Flower of lawns which in places has been naturalized.

\section{CATALPA, Scop.}

Trees, with large, opposite, ovate leaves and large clusters of white or mottled flowers. Calyx deeply 2-lipped. Corolla decidedly 2-lipped, in general form trumpet-shaped, the 5 lobes quite unequal. Fertile stamens 2. Fruit capsule a long and slender pod; seeds winged on each side, the wings fringed.

C. speciosa, Warder. Catalpa. Tree, with thick flaky bark. Leaves large, egg-shaped, heart-shaped at base. Flowers numerous, white; corolla 1 to $1 \frac{1}{2}$ in. long. Pod 4 or 5 in. long. Escaped from cultivation in some localities. June-July.

\section{Fanily VIII.-ACANThaceae. Acantiscs Family}

Chiefly herbs with opposite leaves and without stipules, and with rather large flowers, which are usually much bracted, more or less 2-lipped. Stamens 2 or 4 , inserted in the tube of the 5-lobed corolla.

Lobes of the corolla sub-equal, star-shaped

Ruellia Corolla conspicuously 2-lipped . . . . . Dianthera

\section{RUELLIA, L.}

Perennials. Leaves entire, opposite. Flowers large and showy, blue or purple, white or yellow, in lonse clusters. Calyx 5-toothed. Corolla more or less trumpet-form, somewhat 2-lipped, the 5 lobes radiating. Stamens 4, unequal, extending beyond the throat of the corolla. Fruit an oblong capsule.

1. R. ciliosa, Pursh. (Fig. 7, pl. 148.) IIsiry Rueldia. Stem 1 to $2 \frac{1}{\mathrm{ft}}$. high, ereet. Whole plant very hairy with soft whitish hairs. Leaves 
BROOMRAPE AND ACANTHUS FAMILIES
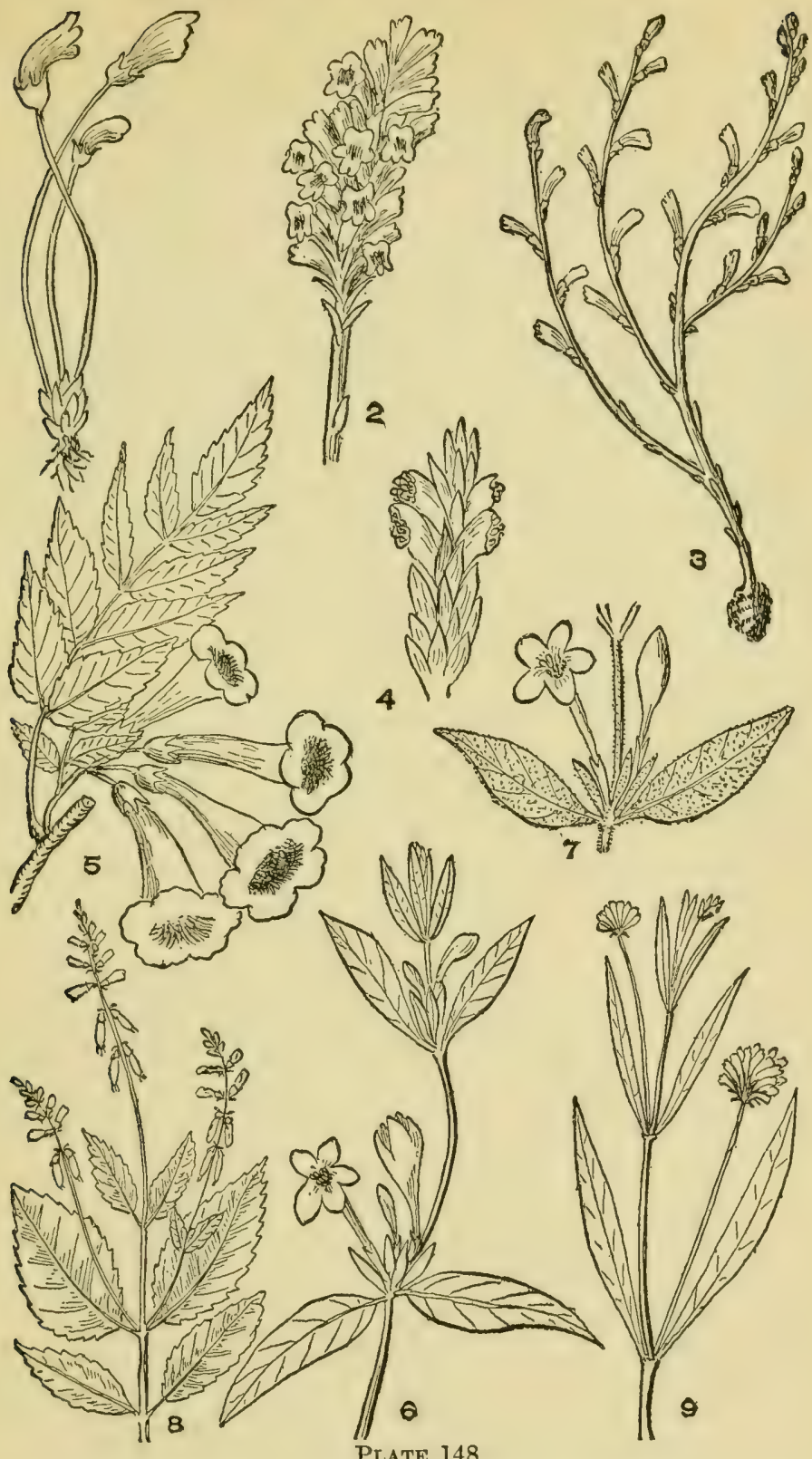

1. Thalesia uniflora. 2. Orobanche minor. 3. Epifagus virginiana. 4. Conopholis americana. 5. Tecoma radicans. 6. Ruellia strepens. 7. R. ciliosa. 8. Phryma Leptostachya. 9. Dianthera americana. 
oblong, oval or egg-shaped, tapering at each end, without leaf-stalks or with short ones. Calyx lobes narrow, tapering into long bristle-like points, the whole calyx hairy. Corolla tube twice as long as the calyx, narrower; lobes spreading into a star-shaped flower an inch in diameter. Corolla blue. Dry ground, southern part of our area. June-Sept.

2. R. strepens, L. (Fig. 6, pl. 148.) Smootir Ruellia. Similar to preceding species, but not downy or hairy. Penna., and southward. MayJuly.

\section{DIANTHERA. L.}

Mainly perennial herbs, our only species growing in shallow water at the edge of streams or ponds. Leaves opposite, entire. Calyx 5-parted. Corolla deeply 2-lipped, the tube slender, the upper lip erect, notched, the lower lip 3-parted. spreading. Stamens 2, inserted in the throat of the corolla, not extending beyond the upper lip. Capsule flattened, 4-seeded.

D. americana, L. (Fig. 9, pl, 148.) WATER Willow. Stem angled, grooved, 1 to $3 \mathrm{ft}$. high, scarcely branching. Leaves opposite, lanceshaped, 3 to 6 in. long by about $\frac{1}{2}$ in. wide. Flowers in dense terminal clusters on very long naked stems. Corolla about $\frac{1}{2}$ in. longr, purple. Shallow water, not common. July-Sept.

\section{FAMILY IX.-PHRYMACEAE. LoPSEED FAMILY}

A perennial herb with branching stems, opposite egr-shaped leares and narrow spikes of small, irregular, purplish flowers. Calyx cylindric, 2-lipped, the upper lip of 3 bristle-like teeth, the lower shorter, 2-parted. Stamens 4, unequal, not cxtending beyond the throat of the corolla. Ovary 1-celled with a single ovule In fruit the capsule lops downward. Corolla purple.

\section{PHRYMA, L.}

Characters as ahove.

P. Leptostachya, I. (Fig. 8. pl. 148.) Lopsfr. Plant 2 to $3 \mathrm{ft}$. high, downy, stem somewhat 4-sided. Jeaves broad, coarsely toothed, spikes of flowers very narrow, flowers mostly opposite, at first ereet, then strongly reflexed against the stem. The narrow tecth of the calyx, in fruit, lock over the capsule. Woods, in most of our area. June-Aug.

\section{Order VII.-PLANTAGINALES. The Plantain Order}

ITerbs with inconspicuous flowers with nerveless, dry, thin, membranaceous corollas, the flowers arranged in long slenter dense grecenish spikes or, in a head or solitary (the last two conditions rare and of these only one species with solitary flowers in our regrion). Calyx below the ovary, the segments equal or two of them loncer. Corolla a spreading t-pointed star on a short tube. Stamens 2 or 4 . Fruit a capsule which opens by a lid. 


\section{Family-PLantaginaceae. Plantain Family}

Characters as above.

\section{PLANTAGO, L.}

Herbs, with leaves all basal and with flowers on a leafless scape in a slender, dense flowered spike (exceptionally leaves on the stem and flowers in a head, but not in our species). Calyx 4-parted, corolla 4-lobed. Stamens usually 4. Fruit a capsule opening by a lid.

Leaves all basal, egg-shaped, tapering at each end.

Plant not hairy.

Flowers densely crowded in a narrow cylindric spike . . P. major

Flowers not densely crowiler, the spike more or less interrupted

Plant very hairy.

Leaves heart-shaped at base

Leaves lance-shaped, not linear.

Plant very hairy . . . . . . . . . . . . . P. virginica

Plant not very hairy.

Margins of leaves more or less lobed . . . . . P. heterophylla

Margins of leaves not lobed.

Bracts between flowers much longer than flowers . P. arisiata Bracts not exceeding flowers.

Flower scape usually much longer than the leaves Flower scape usuilly about equalling the leaves lanceolata

Leaves linear . . . . . . . . . P. maritima

1. P. major, L. (Fig. 3, pl. 149.) Common Plantain. Leaves eggshaped, tapering at each end, the margins smooth or wavy, not hairy or only slightly so, from 1 to $10 \mathrm{in.} \mathrm{long.} \mathrm{Scape} 6 \mathrm{in}$, to $2 \mathrm{ft}$. high, spike very narrow and flowers densely crowded. Door yards and waste places, common. May-Sept.

2. P. Rugelii, Dec. (Fig. 7, pl. 149.) Rugrl's Plantain. Similar to $P$. major, but there are many interruptions in the spike of flowers. Fields, woods and waste places. June-Sept.

3. P. lanceolata, L. (Fig. 4, pl. 149.) Ribwort. Leaves lanceshaped, pointed at each end, with 3 to 5 ribs, 2 to 12 in. long. Flower seape angular, longer than the leaves, from to $2 \mathrm{ft}$. high, the spike dense, rather short, blunt. Meadows and roadsides. Common. AprilNov.

4. P. media, L. (Fig. 10, pl, 149.) Hoary Plantain, Leaves rather narrower than those of $\mathrm{P}$. major, but somewhat similar in form. Leaves and seape covered with brown hairs. Scapes slender, 1 to $2 \mathrm{ft}$. high. Waste places. May-Sept.

5. P. cordata, Lam. (Fig. 6, pl, 149.) Heart-leaved Plantain. Leaves broadly egg-shaped, heart-shaped at base, 4 to $10 \mathrm{in}$. long. Scape $\frac{1}{2}$ to $2 \mathrm{ft}$. high, the flower spike interrupted, from a few in. to a $\mathrm{ft}$. long. Swamps and along streams, New York and southward. March-July.

6. P. maritima, L. (Fig. 5, pl. 149.) Sea-sme Plantain. Leaves narrow, grass-like, fleshy. Scapes about as long as leaves. Spike of flowers loose. Salt marshes and along coast. June-Sëpt.

7. P. aristata, Michx. (Fig. 1, pl. 149.) Large-bracted Plañain. Leaves grass-like, smooth, scipe 6 to 18 in, tall, flower spike 1 to 6 in. 
long. The bracts, linear, extending much beyond the flowers. Waste places, introduced from Western States. May-Oct.

S. P. virginica, L. (Fig. 2. pl. 149.) White Dwarf Plantain. Leaves spatula-formed or pear-shaped, the whole plant covered with hairs. Scape 1 to $19 \mathrm{in}$. high; flowers in a dense eylindric spike or the lower flowers somewhat seattered. Dry soil, Connecticut and southward. MarchJuly.

9. P. elongata, Pursh. (Fig. 8, pl. 149.) Slender Plantain. Leaves thread-like. Spikes very slender. Stamens not extending beyond the flowers. Dry sandy soil, New York and southward. April-Aug.

10. P. heterophylla, Nutt. (Fig. 9, pl. 149.) Many-Seeded PlanTAIN. Leaves lance-shaped, grass-like, but horders more or less lobed (like those of dandelion) or with low teeth. Spike of flowers more or less interrupted. Capsule 10- to 24 -seeded. Wet places, New Jersey and southward. April-July.

\section{LITTORELLA, L.}

A low, succulent herb, with linear leaves, all from the base and solitary, membraneous flowers terminal to seapes shorter than the leaves. Flowers of 2 kinds, those bearing stamens and those with pistils. In the former the stamens extend conspicuously beyond the throat of the flower. Calys 4-toothed; corolla 4-lobed.

L. uniflora, L. (Fig. 13, pl. 149.) SHore Grass. Growing in tufts, leaves linear 1 to $3 \mathrm{in.} \mathrm{long.} \mathrm{Seape} \mathrm{half} \mathrm{as} \mathrm{long} \mathrm{as} \mathrm{leaves.} \mathrm{Borders} \mathrm{of}$ lakes and ponds, Maine and Vermont. July-Aug.

\section{Order VIII.-RUBIALES. The Madder Order}

Corolla of united petals; leaves opposite. Calyx adherent to the ovary, the calyx borders of lobes or teeth partly or completely above the ovary. Stamens fixed upon the corolla, as many as its lobes and alternate with them (in Linnea 1 less than the lobes) or stamens double the number of the lobes. Anthers separate; ovary more than one-celled with usually more than one seed in each cell. The order includes 2 families in our area. They are, Rubiaceae and Caprifoliaceae.

\section{FaMily I.-RUBIACEAE. MIADder FAMILY}

Herbs, shruls, trees; but in our area, with the exception of a single shrub, all small and slender herbs. All have opposite leaves which are sail to be stipulate, yet in many cases the stipules are not easy to detect. Flowers perfect and nearly symmetrical. Calyx tuhe adherent to the ovary, its teeth or lobes varring. ('orolla of united petals of various shapes. Stamens as many as the lobes of the corolla and alternate with them. Anthers free from 


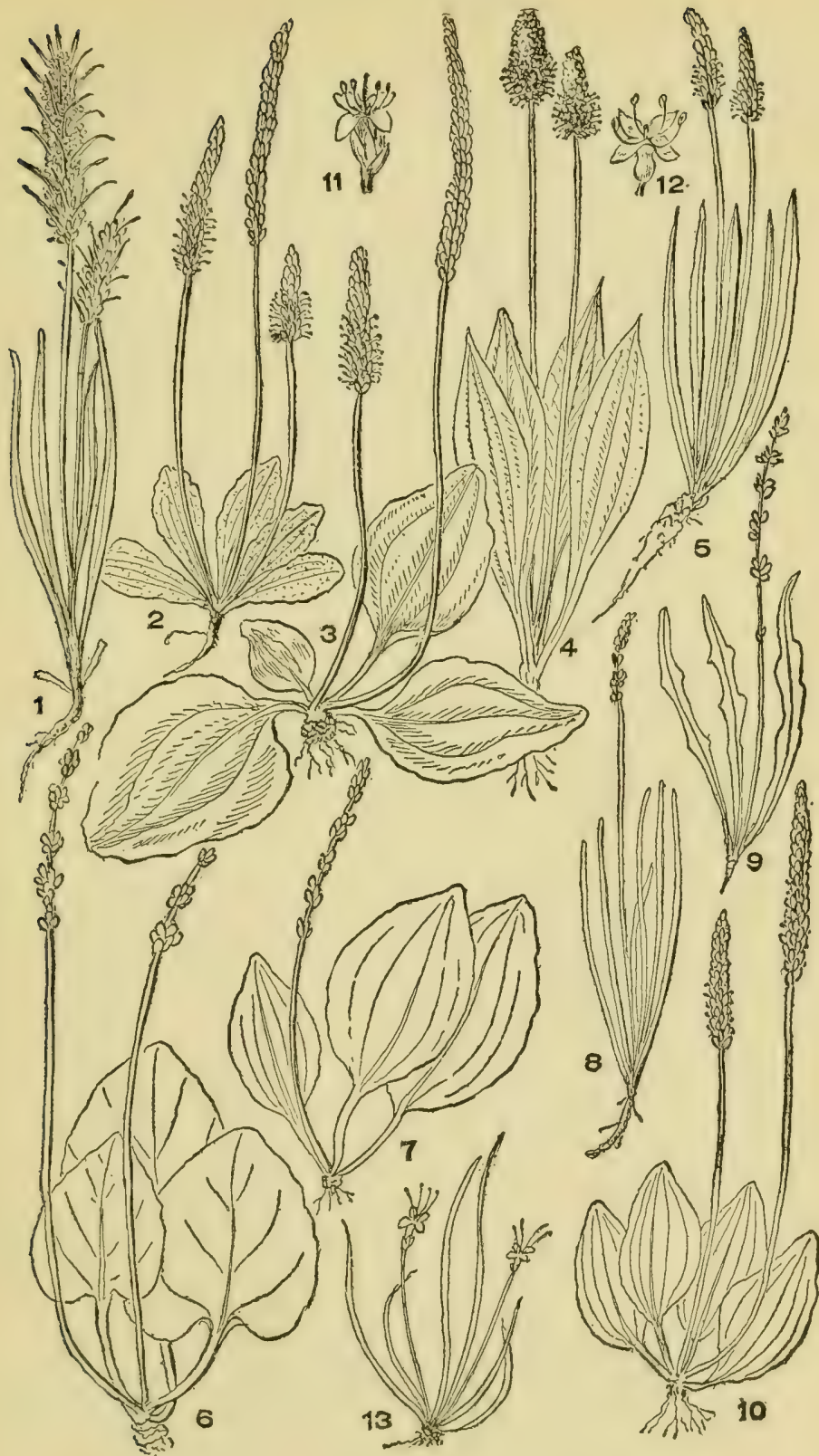

Plate 149

1. Plantago aristata. 2. P. virginica. 3. P. major. 4. P. lanceolata. 5. P. maritima. 6. P. cordata. 7. P. Rugelii. 8. P. elongata. 9. P. heterophylla. 10. P. mellia. 11. Flower of P. major. 12. Flower of P. lanceolata, deprived of its calyx. 13. Littorella uniflora. 
each other. Orary 1- to 10 -celled, the cells containing from 1 to several seeds. Fruit a capsule, a berry or a drupe.

Shrub with flowers in a lense round heal . . Cephalanthus Herls, with onpoite leares or leaves in whorls of 3.

Flowers in pairs, fruit a red berry . . . Mitchella

Flowers separate.

2 carpels each one-seeded . . . . . Diodia

2 carpels each many seeded.

Corolla funnel-form . . . . . Houstonia

Corolla wheel-shaped . . . . Oldenlandia

Herbs with leares in whorls of 4 or more.

Corolla commonly t-lobed, flat, round . . Galium

Corolla funnel-form.

Flowers in heads surrounded by inrolucre leares or bracts

Flowers in loose clusters . . . .

Sherardia

Asperula

\section{HOUSTONIA, L.}

Small. delicate lerbs (with us). with opposite leares and often with a rowtte of loves at the base. Sipules unitcl with the lcaf-stem. Calyx tuhe fg-shapmi, 1-partud. Corolla tube slender, the 4 lobes spreading. Stamens 4, enual, inserted in the tube of the corolla. Orarg 2-celled, seeds numerous.

1. H. coerulea, L. (Fig. 4, pl. 150).) Blters. Irxocerce. Small harb. growing in tuits; stem 3 to 6 in. high. sparingly branched. Leaves obling. sputula-jorm. opposite, forming a resette at base, about $1 / 3$ in. lung. Cornlla light blu. lilac or nearly white with a velluwioh center. Tube longer than the lobes. Grassy places, our area. April-July.

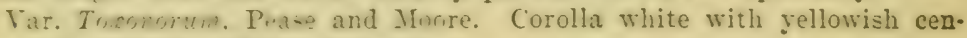
ter, tube shorter. White Mountains.

2. H. longifolia, Gaertn. (Fig. 5, pl. 150.) Lorg-Ledved Mors. Insis. Tuitul. stems $5 \mathrm{t}, 10 \mathrm{in}$. high. Basal luves spatula-form. stem lare linent. Fliwer s ple blue. furple to nearly white. Open dry places, throughout our region. May-Sept.

2. H. ciliolata, Torr. (Fig. 6. pl. 150.) Frisgen IInestovis. Plant 4 in i in. hich. Rem leaves -patula-formed. lower leaves in a rosette, rival or rear-hajmil. their margins fringed with hairs. Western New York, and southward. May-Sept.

\section{OLDENLANDIA, L.}

slenter lorbs, rest or litfuse with oprisite leaves, the small stipules united to the leaf stums and (in our area) small axillary flowers, white w pink. Calyx and corolla. each 4-parted. Stamens 4. equal, inserted in tise thrcat of tie corclla. Ovary 2-celled, orules numerous in each carity. 

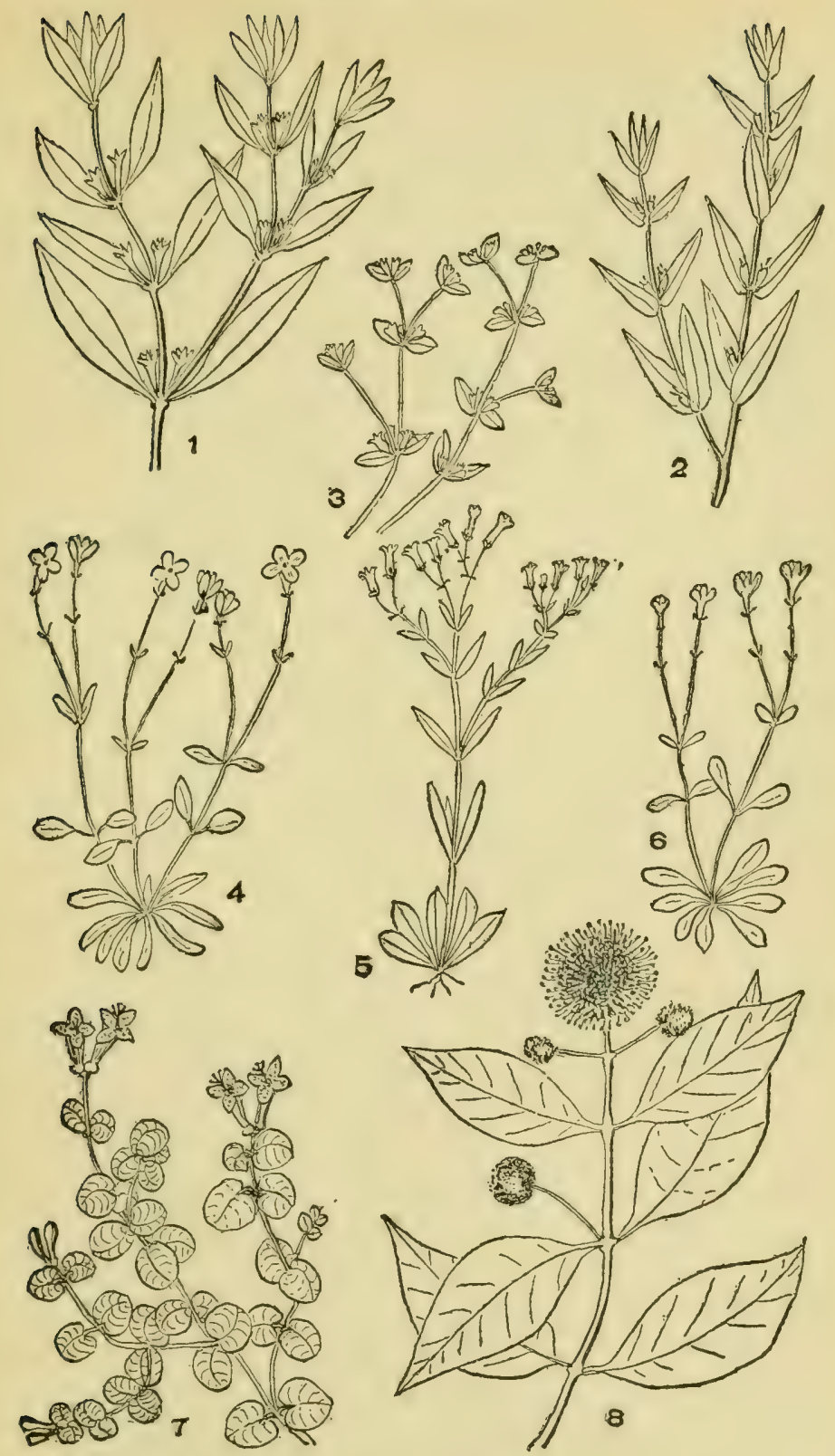

Plate 150

1. Diodia virginiana. 2. D. teres. 3. Oldenlandia uniflora. 4. Houstonia coerulea. 5. H. longifolia. 6. H. ciliolata. 7. Aitchella repens. 8. Cephalanthus occidentalis. 
O. uniflora, L. (Fig. 3, pl. 150.) Crustered Bluets. Stem weak, half prostrate, branched, spreading, 1 to $15 \mathrm{in}$. long. Leaves egg-shaped to oblong. Corolla inconspicuous, white, shorter than the calyx. Wet places, southern New York, and southward. June-Sept.

\section{CEPHALANTHUS, L.}

Shrub, with the white flowers in a dense round head, hanging by a long flower stem. Calyx tube 4-toothed; corolla tubular, wider at top and 4-lobed. Style 1, long, slender; stamens 4, inserted in the throat oi the corolla. Fruit small, dry and hard.

C. occidentalis, L. (Fig. 8, pl. 150.) Button Busr. Shrub, 3 to $10 \mathrm{ft}$. high, with large opposite or whorled egg-shaped leaves on long leaf-stems and with ball-like clusters of white flowers. Wet grounds, borders of streams. June-Sept.

\section{MITCHELLA, L.}

Small, trailing herb, with opposite, dark shining evergreen leaves and white flowers in pairs. Stipules minute. Calyx 3- to 6-lobed. Corolla of a long slender tube and 4 or more recurving lobes, bearded in the throat. Stamens 4 or more. Pistil in some flowers extending much beyond the throat of the corolla, while the stamens are included within the corolla. In other flowers the exact opposite condition prevails, namely, the stamens extend beyond the corolla and the pistil is hidden in the tube. Fruit a red berry.

M. repens, L. (Fig. 7, pl. 150.) Partridge Berry. Stems 3 to 12 in. long. Leaves nearly round. Flowers growing as twins from the single flower stem and both sometimes appearing as if enclosed at the base by the same calyx. Fruit red, rarely white, edible but rather tasteless. Rich woods, our area. April-June.

\section{DIODIA, I.}

Iferbs, with opposite, stipulate leaves and small flowers in the leafaxils. Stems more or less decumbent or quite erect. Calyx ovoid, in our species 4-parted. Corolla tubular, spreading toward the border, which is usually 4-lobed. Stamens 4, inserted in the throat of the corolla and extending beyond the corolla. Ovary 2-celled with a single ovule in each cell.

1. D. virginiana, I. (Fig. 1, pl. 150.) Larger Buttow-ween. Plant decumbent or nearly erect, hairy or smooth, bearded. Leaves lanee-shaped to linear, without leaf-stems. Flowers white, 1 to 3 in the leaf-axils, tube of corolla slender, expanding suddenly into a 4 -lobed, wheel-like border. Style 2-parted. Fruit at first fleshy, beeoming dry. Low grounds, New Jersey, and southward. June-Aug.

2. D. teres, Walt. (Fig. 2, pl. 150.) Rougu Buttox-weso. Usually rough hairy, sprealing, stoms more or less prostrate or nearly ereet. Leaves opposite, without leaf-stems, narrow lance-shape or linear. Corolle does not sudelenly crpond, as in No. 1, lilae, light purple or white. Style not divided as in No. 1. Fruit pear-slaped, hairy. Dry soil, southern New York, Connecticut, and southward. July-Sept. 


\section{GALIUM, L.}

Slender herbs, with 4-angled stems, generally branching and often leaning on other herbs, with leaves in whorls and with small flowers mostly in terminal or axillary more or less umbel-like elusters. Calyx teeth absent. Corolla mostly 4-parted, star-shaped, with a short tube. Stamens usually 4, exceptionally 3, short. Styles 2. Fruit double from the same pedicel.

Flowers yellow

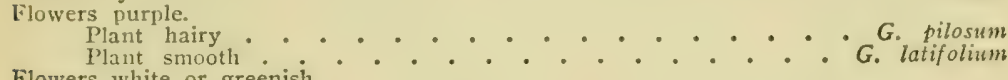
Flowers white or greenish.

Leaves in $4 \mathrm{~S}$.

Fruit a dry, smooth, double berry . . . . . . G. tinctorium

Fruit a smooth, double berry, fleshy $:{ }^{\circ} \cdot$ G. hispidulum $^{\circ}$ Fruit covered with hooked hairs.

Leaves lance-shaped.

Flowers few . . . . . . G. lanceolatum Flowers very numerous ........ G. Goreale

Leaves oval or nearly round.

Corolla hairy not hairy . . . . . G. Gamischaticum

Leaves in 45 or $6 \mathrm{~s}$.

Fruit covered with hooked hairs . . . . . . G. asprellum

Fruit smooth.

Corolla 3-parted.

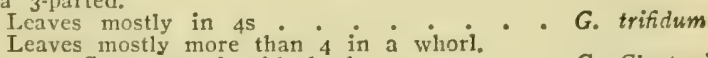

Stem armed with hooks..... G. Claytoni

Stem smooth........ G. concinnum

Leaves in $6 \mathrm{~s}$ to $8 \mathrm{~s}$.

Fruit smooth.

Branches and pedicels widely spreading . . . G. Mollugo

Branches and pedicels ascending : : $:$ G. erectum

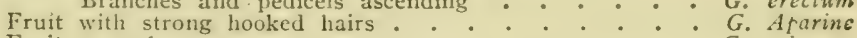

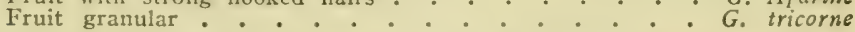

1. G. verum, L. (Fig. 1, pl. 151.) Yellow Bedstraw. Erect, stem $\frac{1}{2}$ to $2 \frac{1}{2} \mathrm{ft}$. high, smooth. Leaves in $6 \mathrm{~s}$ or $8 \mathrm{~s}$, narrow linear. Flowers Yllow in dense clusters at upper part of stem. Naturalized. In waste places and fields. May-Sept.

2. G. Mollugo, L. (Fig. 2, pl. 151.) WiLd Madder. Plant with. out hairs or nearly so. Stem 1 to $3 \mathrm{ft}$. long. Leaves in $6 \mathrm{~s}$ or $8 \mathrm{~s}$, narrow, linear, with a bristle point at apex. Flowers white, small, numerous. Fruit smooth. Fields and waste places. Naturalized. May-Sept.

3. G. erectum, Huds. Frect Bedstraw. Similar to No. 2, but more generally erect, the stems numerous. Flowers fewer and generally larger than those of the preceding species, the branches ascending. Connecticut, Vermont, and northward.

4. G. tricorne, Stokes. (Fig. 4, pl. 151.) Rough-frutted CoRs BedSTR.Iw. Stout, partly prostrate or erect, whole plant rough with hooked hairs. Leaves linear lance-shaped, in $6 \mathrm{~s}$ or $8 \mathrm{~s}$, rough on the margins. Flower stems arising in the leaf axils and shorter than the leaves and ustlally about 1- to 3-flowered. Fruit rather rough from granular elevations. Waste places. Naturalized. May-Aug.

5. G. Aparine, L. (Fig. 3, pl. 151.) Cleavers. Plant armed with strong, hooked hairs, stem 2 to $5 \mathrm{ft}$. Iong, weak, procumbent. Leaves in

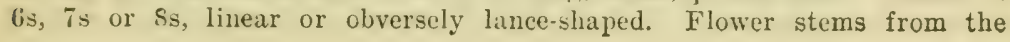


axils, each 1- to 3-flowered, the fruit covered with hooked hairs. Wet thickets and various localities. Our area. May-Sept.

6. G. pilosum, Ait. (Fig. 5, pl. 151.) Hairy Bedstraw. Stem 1 to $2 \frac{1}{2} \mathrm{ft}$. long, whole plant hairy. Leaves in $4 \mathrm{~s}$, oval, about 1 in. long. Flowers axillary and terminal, dull purple to yellowish purple. Dry sandy soil, eastern Mass., and southward and westward. June-Aug.

7. G. lanceolatum, Torr. (Fig. 9, pl. 151.) Torrx's Wild LiquoRICE. Plant smooth or nearly so, 1 to $2 \mathrm{ft}$. high. Leaves in $4 \mathrm{~s}$, lanceshaped, tapering to the apex, $2 \mathrm{in}$. long, $1 / 4$ to $1 / 3$ as wide. Flowers not hairy, yellowish to dull purple. Flower stems rather long with few llowers. Dry woods. Our region. June-Aug.

S. G. circaezans, Miehx. (Fig. 11, pl. 151.) Cross Cleavers. Stem 1 to $2 \mathrm{ft}$. high, smooth or slightly downy. Leaves in $4 \mathrm{~s}$, broadly oval to lance-shaped, 1 to $1 \frac{1}{2} \mathrm{in}$. long, usually obtuse at apex, 3-nerved. Flowers in axillary and terminal diffuse clusters, the common flower stem much longer than the leaves, dividing into 2 or 3 lesser stems, each bearing usually, 2 flowers which are greenish white, the corolla hairy outsidc. Woods, our region. May-July.

9. G. kamtschaticum, Steller. (Fig. 3, pl. 152.) NontIERN W'ILD LIQUonice. Stem weak, 4 to $15 \mathrm{in}$. long. Leaves in $4 \mathrm{~s}$, nearly round or broadly oval, the lower $1 \frac{1}{2} \mathrm{in}$. long, smooth or slightly downy. Flowers on long slender common flower stems which divide into 3 branches, each of which is usually once forked. Corolla yellowish white, not hairy. Mountains, New England and New York. June-Sept.

10. G. boreale, L. (Fig. 6, pl. 151.) Northern Bedstraw. Erect, smooth, 1 to $2 \mathrm{ft}$. high, scarcely branching. Leaves in $4 \mathrm{~s}$, smooth, linear, lance-shaped, 3-nerved, obtuse at apex, or less frequently acute, 1 to $1 \frac{1}{2}$ in. long. Flowers in dense, many-flowered terminal pyramidal clusters, white. Fruit covered with hooked hairs. Along streams, rocky places. May-Aug.

11. G. triflorum, Michx. (Fig. 7, pl. 151.) Fragrant Bedstraw. Stem 1 to $3 \mathrm{ft}$. high, weak, smooth or bristly on angles. Leaves in $6 \mathrm{~s}$, narrowly oval or elliptic-lanceolate, bristle-pointed, 1 to $2 \mathrm{in.}$ long, 1-veined. Flowers not numerous, on long common leaf-stems, each 3-flowered. Fruit covered with hooked hairs. Rich woods. Our area. June-Aug.

12. G. latifolium, Michx. (Fig. 8, pl. 151.) Purple Benstraw. Stem smooth, 1 to $2 \mathrm{ft}$. high, erect, branched. Leaves in $4 \mathrm{~s}$, lanee-shaped, 3-nerved, very sharp pointed at apex, rounded at base, 1 to $2 \mathrm{in.}$ long, common flower stems visually shorter than the leaves, usually more than once forked. Flowers purple. Dry woods in southern part of our area. May-Aug.

13. G. tinctorium, I. (Fig. 10, pl. 15l.) Wild MADDER. Stem erect, stiff, 6 to 15 in. high, branching, several times forkerl. Loeaves in 4s, linear, $\frac{7}{2}$ to $1 \mathrm{in.} \mathrm{long,} \mathrm{1-norved.} \mathrm{Flowers} \mathrm{terminal} \mathrm{in} \mathrm{dilfuse} \mathrm{clusters,}$ 2 or 3 in a lesser group. Corolla rather large, white. Fruit smooth. Damp shady places, throughout our area. May-July.

14. G. trifidum, T. (Fig. 1, pl. 152.) Smal, Benstraw. Stems weak, $\frac{1}{2}$ to $1 \frac{1}{2} \mathrm{ft}$. high, branching, mostly rough on the angrles. Leaves in whorls of $4 \mathrm{~s}$, rarely in $6 \mathrm{~s}$, linear, $t$ in, longe. Flowers in terminal very 

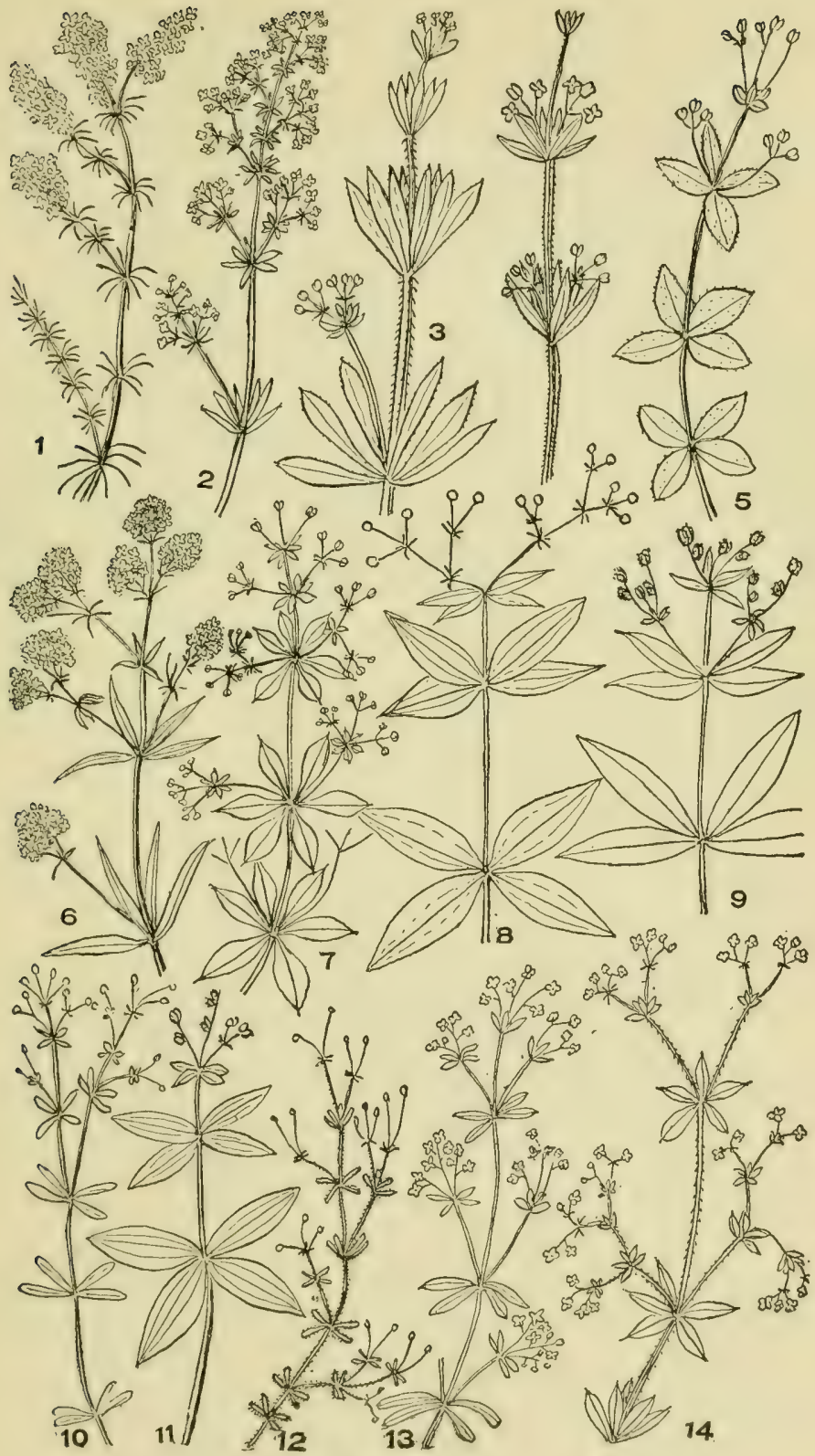

PLATE 151

1. Galium verum. 2. G. Mollugo. 3. G. Aparine. 4. G. tricorne. 5. G. pilosum. 6. G. boreale. 7. G. triflorum. 8. G. latifolium. 9. G. lanceolatum. 10. G. tinctorium. 11. G. circaezans. 12. G. asprellum. 13. G. palustre. 14. G. Claytoni. 
dilfuse clusters, each flower on a long, very slender pedicel. Corolla lobes usually 3; stamens 3, Fruit smooth. Sphagnous swamps and cold wet places, Maine to southern New York. All summer.

15. G. Claytoni, Michx. (Fig. 14, pl. 151.) Crayton's Bedstraw. Stem $\frac{1}{2}$ to $2 \mathrm{ft}$. high, slender, 4-angled, the angles rough with hooked hairs, branching in $2 \mathrm{~s}$ or $3 \mathrm{~s}$. Leaves commonly in $5 \mathrm{~s}$ or $6 \mathrm{~s}$, spatula-form, with a stiff bristle point at apex, which otherwise is rounded, margin rather rough. Flowers in very diffuse clusters at top of plant, the ultimate groups being of 1 or 2 white flowers. Corolla very small, 3-lobed. Fruit smooth. Swamps and wet meadows, generally distributed. May-July.

16. G. palustre, L. (Fig. 13, pl. 15l.) Minsh Bedstraw. Plant nearly or quite smooth, stem about 15 in. high, ereet, slender, long between the nodes, branches quite short. Leaves small, in $2 \mathrm{~s}$ to $6 \mathrm{~s}$, narrow linear, rounded at apex. Flowers in terminal scattered clusters, white. Fruit smooth. Moist shady places, roadsides, etc. May-July.

17. G. concinnum, Torr. and Gray. (Fig. 2, pl. 152.) Surning BEDstraw. Stem weak, decumbent, diffusely branched. Whole plant shining. Leaves in $6 \mathrm{~s}$, linear, $\frac{1}{4} \mathrm{in}$. long. Flowers in 3 -forked terminal clusters, white, minute. Fruit small, smooth. Dry woods, New Jersey and southward. June-Aug.

18. G. asprellum, Michx. (Fig. 12, pl. 151.) Rough Bedstraw. Stems decumbent, very branching, rough with stiff hooked laairs, 2 to 6 ft. long. Leaves in $6 \mathrm{~s}$ or $5 \mathrm{~s}$, very rough at margins, narrowly oval $1 / 3$ to $2 / 3$ in. long, bristle-pointed. Flowers white, small, in terminal clusters. Fruit smooth. In wet places, ditches, etc., leaning on other plants. JuneAug.

19. G. hispidulum, Michx. (Fig. 4, pl. 152.) Coast Bedstraw. Stem branching, nearly smooth or hairy, 1 to $2 \mathrm{ft}$. high. Leaves in $4 \mathrm{~s}$. Flowers few. Fruit a double fleshy berry. Southern part of our area. May-Aug.

\section{SHERARDIA, L.}

Resembles Galium, but flowers are funnel-form with a decided tube and leaves are spiny pointed. Calyx tube 4- to 6-parted. Corolla 4-to 5-lobed. Stamens 4 or 5 .

S. arvensis, L. (Fig. 6, pl. 152.) Blue Field Madder. Stems growing in tufts 3 to $10 \mathrm{in.}$ long, weak. Leaves in $4 \mathrm{~s}$, $5 \mathrm{~s}$ or $6 \mathrm{~s}$, lanceshaped, sharp at apex. Flowers in terminal elusters, each subtended by an involucre, which is as long as the flowers. Corolla pink or blue. Naturalized in many places. June-July.

\section{ASPERULA, L.}

Another Galium-like plant with white or pinkish flowers. Leaves 6 to 9 in a whorl, rough at the margins. Corolla funnel-shaped. Fruit in pairs. Flowers in terminal nearly llat clusters.

A. odorata, I. (Fig. 5, pl. 152.) Swert Woonouff. Stem slender, ercet, smooth. Leaves usually in $8 \mathrm{~s}$ (less or more), lance-shaped, bristlepointed. Flowers pink or white, Fruit hairy. Naturalized, in waste places. May-July. 


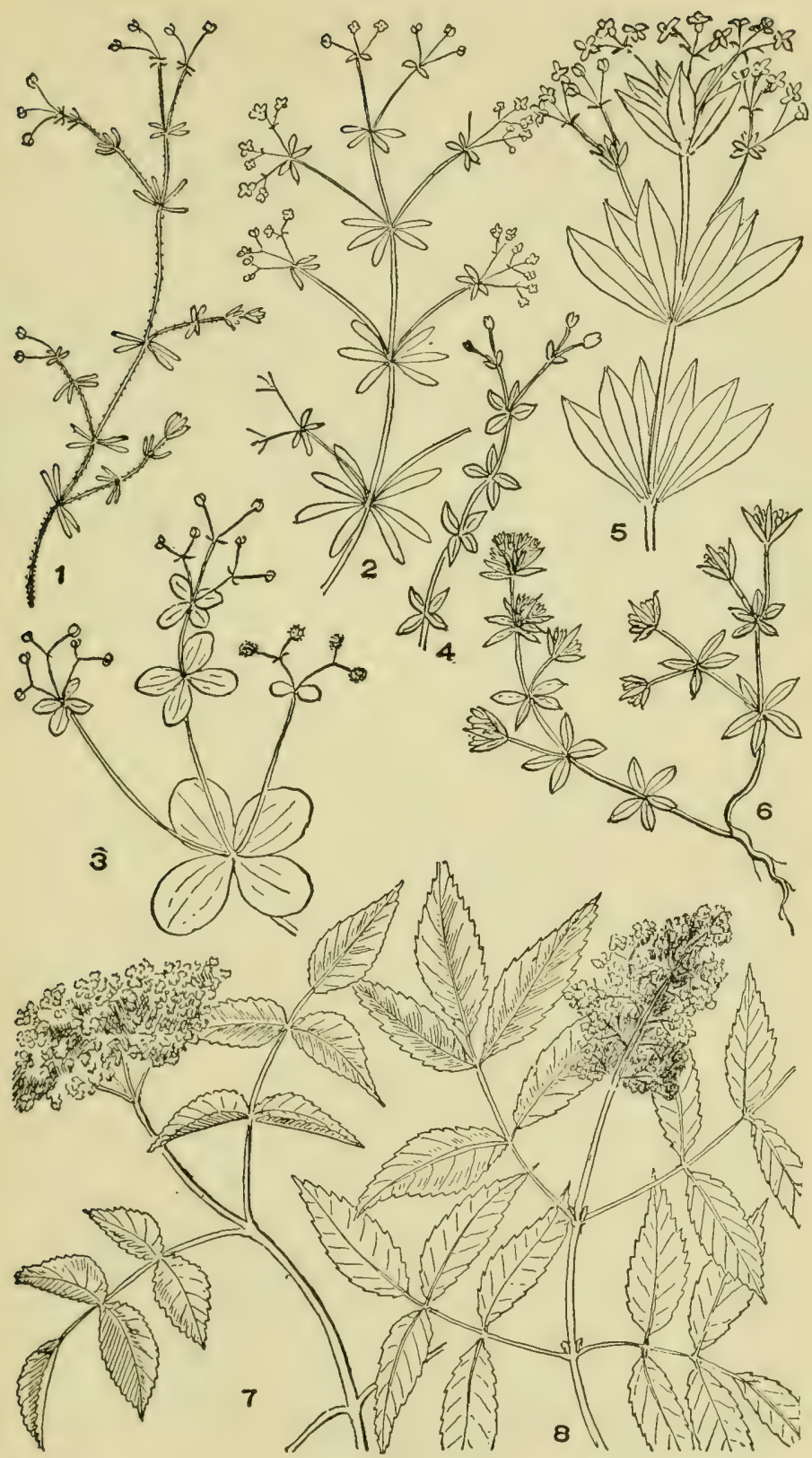

Plate 152

1. Galium trifidum. 2. G. concinnum. 3. G. kamtschaticum. 4. G. hispidulum. 5. Asperula odorata. 6. Sherardia arvensis. 7. Sambucus canadensis. 8. S. racemosa. 


\section{FAMIILT II.-CAPRIFOLIACEAE. ПONEYSCCKLE FAMILT}

Plants very closely related to the Family Rubiaceae, the leaves in this last being usually accompanied by minute stipules or by leaf-like stipules, the IIoneysuckle family nearly always destitute of stipules. These plants are nearly always woody. In our area there are but two exceptions, one of which is the extremcly interesting creeper, the Linnaea, the other, Triosteum. The leares are opposite. Flowers have both stamens and pistils and are regular or quite irregular in form. The corolla is composed of united petals and takes different forms, but the border is always 5-lobed. The stamens are 5, or rarely 4 , inserted in the tube of the corolla. The ovary is, in part at least, enveloped in the calyx, which is adherent to it, and has from 1 to 5 cells, each with 1 or more ovules suspended from the central column. The fruit is a berry, a drupe, a nutty fruit or rarely a capsule.

Leaves composed of leaflets ranged each side of the leaf-stalk with an odd leaflet . . . . . . . . Sambucus

Leaves not compound.

Flowers regular or only slightly irregular.

Shrubs or trees.

Corolla flat, circular; fruit a one-seeded drupe . . . . . . . Viburnum

Corolla tubular or bell-shaped; fruit a oneseeded berry . . . Symphoricarpos

Herbs with regular or slightly 2-lipped corollas.

Erect plant, leaves without leaf-stalks

Creeping vine, somewhat woody, leaves with leaf-stalks . . . . . L Linnaea

Flowers irregular.

Woody vines . . . . . . . . Lonicera

Small shrub . . . . . . . . Diervilla

\section{SAMBUCUS, L.}

Shruhs, with opposite cumpound leaves, the leaflets arranged on each sides of the leaf stem in pairs, with an odd one at each end and with comfund elusters of small white flowers. Calyx ovoid, the lobes small or absent. Corolla round, flat, 3- to 5-lobed. Stamens 5, inserted at the hase of tlir corolla. Drupe, berry-like, juicy, containing 3 to 5 oneseeded nutlets.

Flower cluster flat, umbel-like . . . . . . . . . S. canadensis lilower cluster pyramidal $\because \because \because \cdots, \cdots$ S racmosa 
1. S. canadensis, L. (Fig. 7, pl. 152.) Comson Elner. Shrub. 5 to $10 \mathrm{ft}$. high. Leaflets 5 to 11 , margins sharply toothed. Flower clusters flat. Berries black-purple. Rich moist or wet soil, throughout our range. June-July.

2. S. racemosa, L. (Fig. 8, pl. 152.) Red-Berried Elder. Shrub, 5 to $10 \mathrm{ft}$. high. Leaflets 5 to 7 , margins sharply toothed. Flower clusters pyramidal. Berries bright red. Rocky woods, in all of our area.

\section{VIBURNUM, L.}

Shrubs or trees, with entire, toothed or lobed leaves, sometimes with stipules, and with white flowers in flat clusters. Calyx 5-toothed, corolla deeply 5-lobed. Stamens 5, inserted in the tube of the corolla or, in tho outer flowers of some species, stamenes none. Fruit a one-seeded drupe.

Flower cluster flat, the marginal flowers neutral, flat, showy, much larger than the more central fertile flowers.

Leaves round or nearly so . . . . . . . . . V. alnifolium

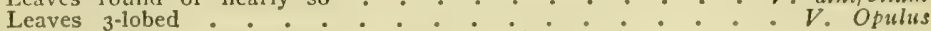

Flower clusters with all the flowers of the same kind.

Leaves with 3 prominent radiating ribs and 3 conspicuous lobes.

Berries (drupes) light red .....$V^{\circ}$ pauciflorum Leaves not 3 -lobed.

Margins very coarsely toothed.

Leaves with few or no hairs . . . . . $V$. dentatum

Leaves decidedly downy on the under side.

Not pubescent above ...... $V$. venosum

Somewhat pubescent above . . . V. pubescens Margins with fine teeth or none.

Flower cluster from a single elongated stem.

Leaves more or less toothed . . . V. cassinoides Leaves not toothed.$: \vdots$ V. nudum

Flower cluster not from an elongated single stem.

Leaves egg-shaped, with very acute points $V$. Lentago Leaves oval, with rounded points . . $\dot{V}$. prunifolium

1. V. alnifolium, Marsh. (Fig. 4, pl. 154.) Hobrle Bush. (V. lantanoides, Michx.) A straggling shrub, rarely more than 5 or $6 \mathrm{ft}$. high, with broad, round, heart-shaped leaves, which are from 4 to 8 in. across, fincly toothed at margins, somewhat downy; youngest branches rusty. Row of marginal flowers large, white, showy. In moist woods, throughout our range. May-June.

2. V. opulus, L. (Fig. 4, pl. 153.) Hign Busm Cranberry. Shrub, 4 to $12 \mathrm{ft}$. high, with erect, smooth branches. Leaves 3-lobed, 3-ribled, with large teeth, the lobes sharp-pointed. Leaf broader than long. Clus. ter of white flowers borne on a single lengthened stem. Fruit bright red, rather pleasantly acid. Low grounds, throughout our range except in the most southern part. June-July.

3. V. pauciflorum, Pylaie. (Fig. 6, pl. 154.) Few-Flowered CranBERry-tree, Straggling shrub, 2 to $6 \mathrm{ft}$. high, with 3-lobed, 3-radiating ribs, lobes acutely angled, teeth large. Flowers few; drupe light red. Dry rocky woods, mostly on New York, New England and Pennsylvania mountains. May-June.

4. V. acerifolium, L. (Fig. I, pl. 153.) Maple-Leaved Viburnuar. Slender shrub, 3 to $5 \mathrm{ft}$. high. Leaves broad, 3-lobed, the lobes sharp, 3 -ribhed, marginal teeth coarse. Flowers in a flat cluster; drupes nearly black. Dry woods, throughout our area. May-June. 
5. V. pubescens, (Ait.) Pursh. (Fig. 1, pl. 154.) Double-Leaved ArRow-Wood. A small shrub, much resembling the last, but the leaves are egg-shaped, not 3-lobed, with very short leaf-stalls if any, and the under surface of the leaf densely velvety. Rocky woods. May-June.

6. V. dentatum, L. (Fig. 2, pl. 153.) ARRow-Wood. Shrub, 5 to $15 \mathrm{ft}$. high, with smooth, slender gray branches. Leaves egg-shaped, with very coarse teeth, not hairy. Flowers numerous in a flat cluster. Fruit dark blue. Wet places, throughout our area. May-June.

7. V. venosum, Britton. (Fig. 7, pl. 154.) Cosst ARrow-woon. Similar to $V$. dentatum. The twigs and lower surfaces of the leaves densely downy. Eastern Massachusetts to New Jersey.

8. V. cassinoides, L. (Fig. 3, pl. 154.) Wrtne-Rod. Shrub, 2 to 12 ft. higb. Leaves oval or egg-shaped, with very small teeth. Flowers numerous in a broad, flat or convex cluster, which spreads from an elongated, slender flower-stem which is, however, shorter than the brealth of the cluster. Fruit becoming dark blue. Sivamps, wet places, Maine to New Jersey. June-July.

9. V. nudum, L. (Fig. 5, pl. 154.) LARger Witne-RoD. Similar to the last, but borders of leaves nearly or quite without teeth and leaves smaller. The flower stem is as long as or longer than the brealth of the cluster. Swamps, Long Island and southward. June-July.

10. V. Lentago, L. (Fig. 2, pl. 154.) Sweet Viburvus. Shrub or small tree. Leaves oval or egg-shaped, tapering to a long slender point, 2 to $4 \mathrm{in}$. long, smooth, with fine teeth at the margins. Flowers in a large convex cluster, the cluster branching from the base without the kingle flower stem. Rich soil, Maine to New Jersey. May.

11. V. prunifolium, L. (Fig. 3, pl. 153.) BLACK Haw. Shrub or small tree. Leaves shining, oval or egg-shaped, with finely serrate margins, blunt at apex. Flowers in a convex cluster without a common flower stem or with a short one. Dry soil, Connecticut and westward and southward. April-June.

\section{TRIOSTEUM, L.}

Coarse herhs, with opposite leaves which unite about the stem or which, at least, have no leaf-stalks. Flowers from the axils of the leaves. The 5 calyx lobes linear or lance-shaped. Corolla tubular, enlarging toward the throat, 5-lobed. Stamens 5. Ovary 3- to 5-celled with a single ovule in each cell, forming a drupe containing 3 to 5 hard seeds or nutlets.

1. T. angustifolium, L. (Fig. 1, pl. 155.) Yellow Ilonse Gentras. Stem 1 to $3 \mathrm{ft}$. high, leafy toward the top. Leaves lance-shaped, tapering to the base into an apparent leaf-stalk. Flowers clustered in the axils or single, greenish-cream-color. Iich soil, Long Island, Comn., and southward. May-Aug.

2. T. perfoliatum, I. Honse Grestax. Figwont. Plant 2 to $4 \mathrm{ft}$. high. Leaves broadly oval or excreshaped, 4 to $9 \mathrm{in.} \mathrm{long,} \mathrm{the} \mathrm{borders}$ extrnding along the leaf-stalk as a broad wing on each side, which partly or wholly clasp the stem. Flowers at the axils, the bracts linear. Corolla purplish brown. Not common, found in rich woods, Mass., and westward. Aug.-Sept. 


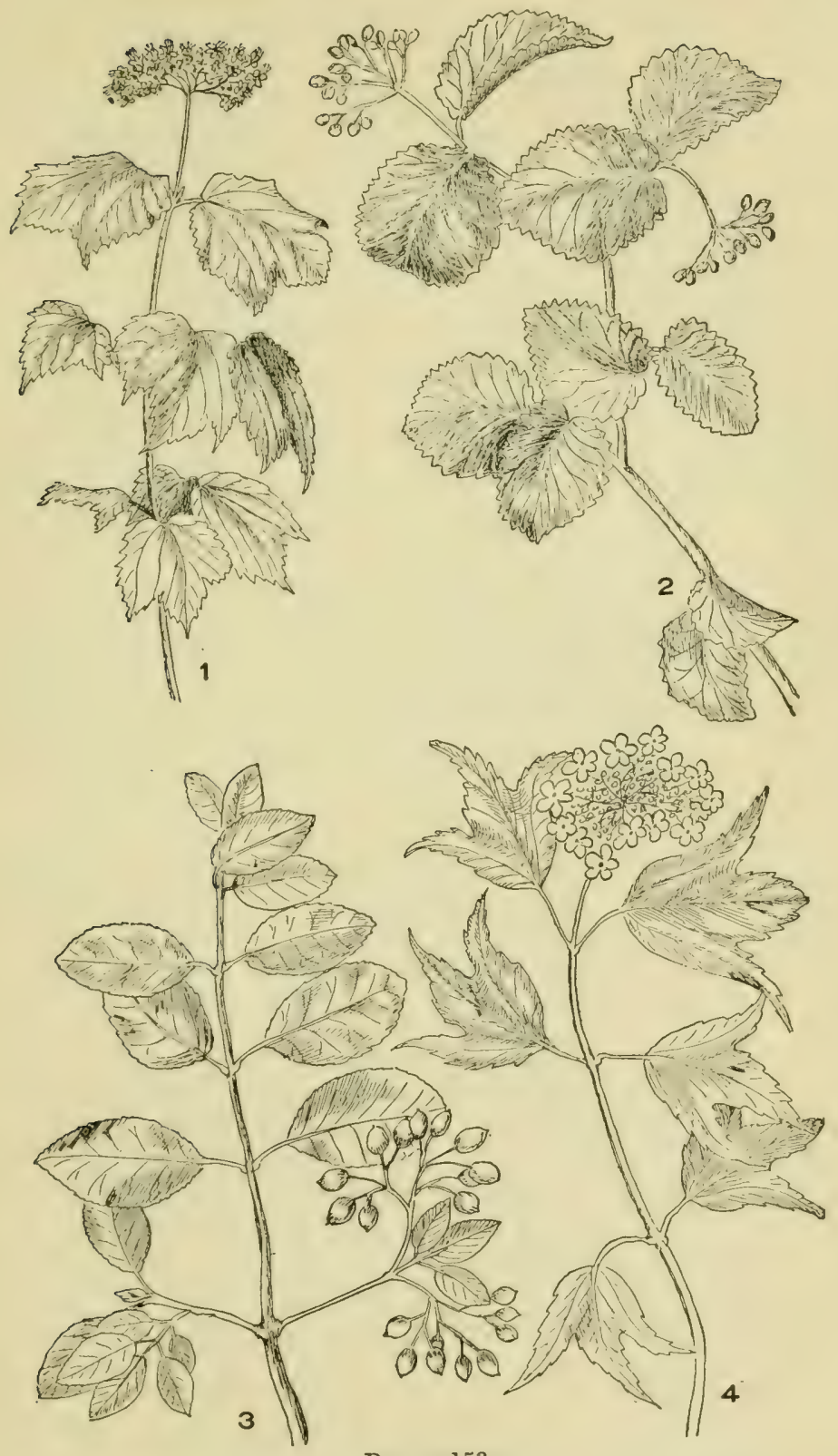

Plate 153

1. Viburnum acerifolium. 2. V. dentatum. 3. V. prunifolium. 4. V. opulus. 


\section{LINNAEA, L.}

A slender creeper, somewhat woody, with opposite rounded leaves on slort leat-stalkis, evergreen. Flowers on thread-like flower-stems, which rise from the horizontal stem and fork into 2 secondary stems, each supporting 1 nodding, fragrant purple flower. Calyx teeth 5, slender. Corollir hell-slaped or fumnel-formed, 5-lobed, the lobes equal or nearly so. Stamens 4, unequal. Ovary 3-celled, the fruit a dry pod with a single seed. Rarely there may be 4 or more secondary stems, with as many flowers.

L. borealis, L. (See Frontispicec.) Twis Fuower. Found in moist woods, or under pine trees. June-Aug.

This little plant was a favorite with the great Linnacus and it was dedieaterl to and named after him by Gronovius, a distinguished Dutch botanist and friend of Linnaeus. The flower of the European form of this little plant is more bell-shaped than that of the American form and the calyx of the former is longer. Hence the American form is regarded as a variety; var. Americana.

\section{SYMPHORICARPOS, Juss.}

Low shrubs, branching, with opposite oval leaves on short leaf-stalks, downy on under surface. Flowers small, white tinged with pink, in clusters in the leaf-axils or terminal. Calyx tube nearly globular. Border of 5 teeth. Corolla tubular, expanding toward the throat, with 4 or 5 more or less spreading lobes. Throat hairy or smooth. Ovary of 4 cells, two of which have single ovules, the other undeveloped. Fruit a globose fleshy berry.

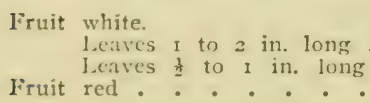

1. S. racemosus, Michx.

$\therefore \therefore \therefore \therefore: \therefore \quad$ S. paccmosus
(Fig. 4, pl. 155.) SNowberRy. Erect shruh, about $4 \mathrm{ft}$. ligh, with smooth slender branches. Leares ova, hairy in the throat. Berry white. Rocky places, river banks, ete. Northern New England and Penna. June-Sept.

2. S. pauciforus, (Tobhins) Britton. (Fig. 2, pl. 155.) Low SNow-

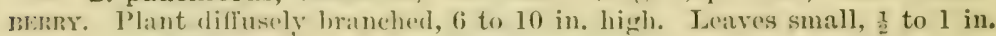
long, oval. Flowers usually 1 in the axils and 2 or 3 in the terminal clustry. Corollat hairy within. Fruit white. Rocky places, Vermont, Western New York and Penna. June-July.

3. S. orbiculatus, Mocneh. (Fig. 3, pl. 155.) Ixdun Cumaxt. ('ons, lisks. (К. vulguris, Michx.) Shrub, 2 to $5 \mathrm{ft}$. high, pmplish. Flowers in the axils of nearly all the leaves. Leaves 1 to $1 \frac{1}{2} \mathrm{in.}$ long. fruit jurplish red. liocky places, along rivers. Southern part of our area. July.

\section{LONICERA, L.}

(limbing or erect shrubs, with opposite leaves, mostly with entire mareins and with flowers in clusters of several or of two only. Calyx tube ovoicl, teeth very short. Corolla tubular or fumnel-form, irregularly 


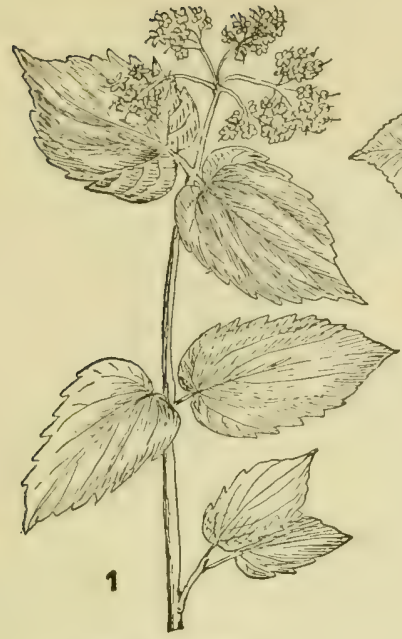

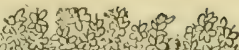
a i is

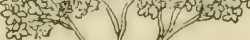
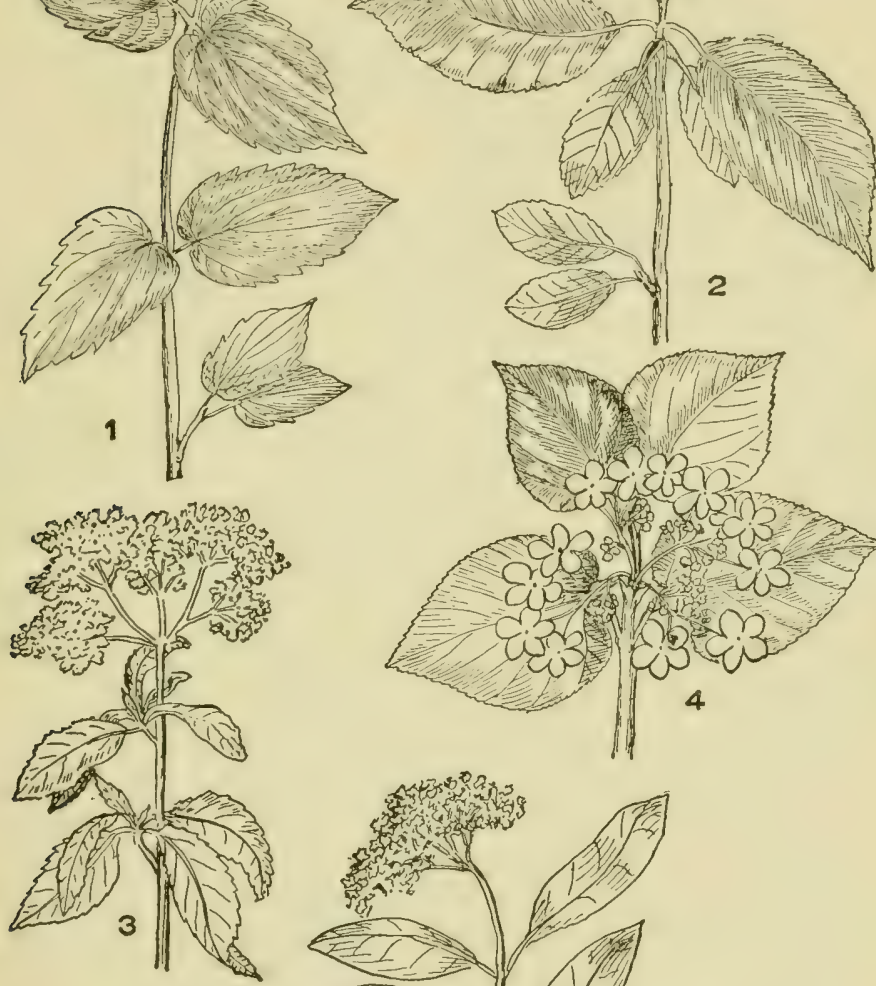

2
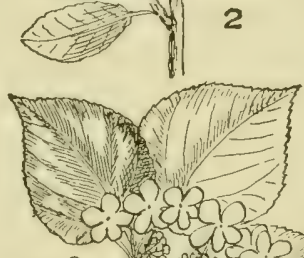

83 \& 3 . din
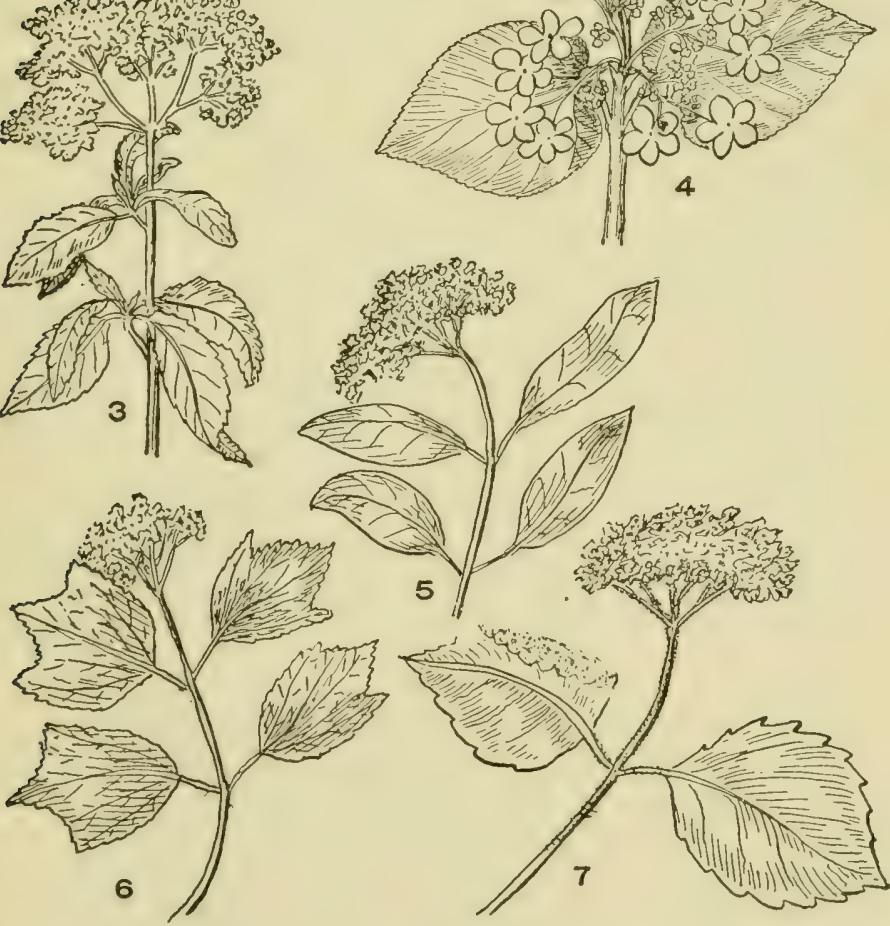

Prate 154

I. Viburnum pubescens. 2. V. Lentago. 3. V. cassinoides. 4. V. alnifolium. 5. V. nudum. 6. V. pauciflorum. 7. V. venosum. 
5 -lobed or almost regularly so. Stamens 5, inserted in the tube of the corolla. Ovary 2 to 3 cells. Berry several seeded.

Climbers. Flowers in clusters of several

Corolla decidedly 2-lipped.

Corolla without hairs in the tube........ L. Caprifolium

Corolla with hairs in the tube.

Leaves downy, both sides . . . . . . . L. hirsuta

Leaves downy on lower side only ... L. glaucescens

Leaves not downy, either side ....... L. dioica

Corolla not 2 -lipped . . . . . . . . . . . L. sempervirens

Shrubs. Flowers in pairs only.

Flowers subtended by slender bracts.

Berries blue . . . . . . . . . . L. coerulca

Berries red.

Leaves with a bluish or whitish bloom . . . L. oblongifolia

Leaves without a bluish bloom.

Base not heart-shaped . . . . . . L. canadensis

Base heart-shaped $+.0^{-} \cdot{ }^{-}$L tartarica

Flowers subtended by broad leaf-like bracts . . . . L involucrata

\section{Climbing Vines}

1. L. caprifolium, L. (Fig. 5, pl. 155.) AMerican Woonbrne. ( $L$. grata, Ait.) A smooth climber, the upper 1 to 3 pairs of leaves united around the stem so as to form apparently a single leaf. Flowers in a terminal cluster without a common flower-stem. Corolla markedly 2-lipped, the upper lip of 4 narrow lobes, the lower of 1. The tube is not hairy. Flowers purple fading into yellowish without, white within. Thickets, southern part of our area. May-June.

2. L. hirsuta, Eaton. (Fig. 6, pl. 155.) Hairy Honersuckle. Similar to ahove, but leares decidedly downy below and somewhat so above. Corolla tube hairy within. Woods, Maine to Penna. June-July.

3. L. glaucescens, Rydb. (Fig. 3, pl. 156.) Douglass's Honeysuckle. Similar to No. 1, but leaves downy on lower side, at least along the veins. Corolla hairy within, yellow, changing to reddish. Thickets, most of our area. May-June.

4. L. dioica, L. (Fig. 2, pl. 156.) Smrootn-Lenved Honersuckie. Similar to No. 1, but tube of corolla hairy inside, and leaves smooth on both sides. Corolla greenish-yellow or purplish. Rocky grounds, especially on mountains, our range.

5. L. sempervirens, I. (Fig. 1, pl. 156.) Coral IIoNerstekLE. High elimbing, all the leaves smooth or somewhat downy beneath. Flowers on a cammon flouer stem. Corolla 5-Iobed, the lobes ncarly or quite equal. Flowers scarlet, fading to yellow, the tube usually an inch or more long. Low grounds, Connecticut and southward. April-Sept.

\section{Erect Shrubs}

6. L. coerulea, J. (Fig. 4, pl. 156.) Mountain Fly-honeysuckle. Erect, 1 to $2 \mathrm{ft}$. high. Leaves oval, downy when young, very blunt at apex, pale beneath. Flowers in pairs, yellow, on very short flouer stems, from tho leaf-axils. Flowers 2-lipped. Berries blue. Rocky woods. MayJune.

7. L. oblongifolia, (Goldie) IIonk. (Fig. 5, pl. 156.) Swamp FiYmoNerscekis, Flowers on long flower stems. Corolla hairy, 2-lipped, yellow. Berries red. Northern New England and New York. 

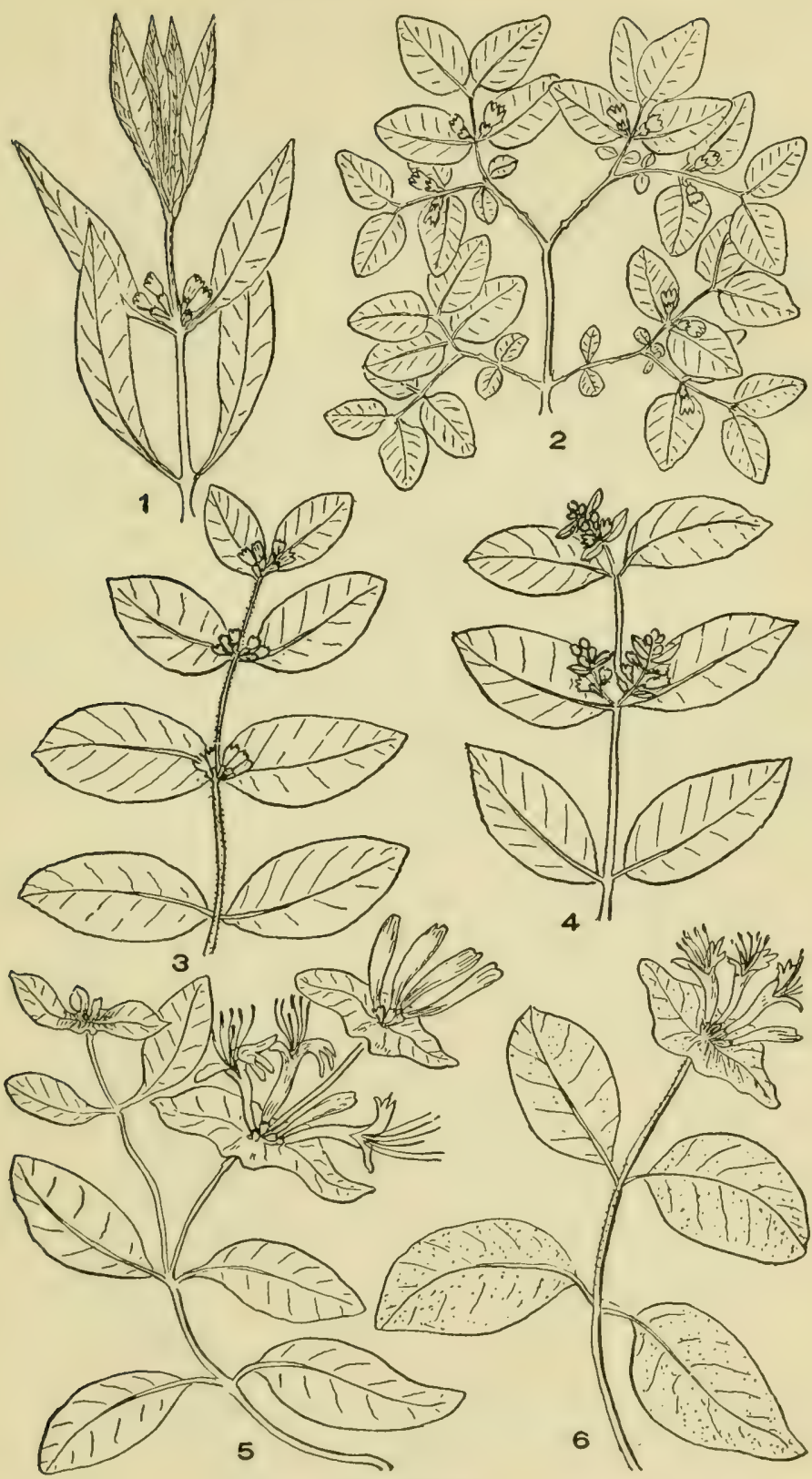

Plate 155

1. Triosteum angustifolium. 2. Symphoricarpos pauciflorus. 3. S. orbiculatus. 4. S. racemosus. 5. Lonicera caprifolium. 6. L. hirsuta. 
8. L. canadensis, Marsh. (Fig. 1, pl. 157.) American Fly-hoxeysuckle. (L. ciliata, Muhl.) Shrub, 2 to $3 \mathrm{ft}$. high. Leaves oval or eggshaped, sharp pointed at apex, somewhat downy on under side, when young. Flowers in pairs, greeenish yellow, not 2 -lipped, the 5 rounded lobes nearly or quite equal. Moist woods, most of our range. May.

9. L. tartarica, L. (Fig. 6, pl. 156.) TARTARIAN Busir-HonersuckLe. Is larger shrub than $L$. conalensis; 5 to $10 \mathrm{ft}$. high, the leaves egg-shaped, but more heart-shaped at base than the former, 1 to $3 \mathrm{in}$. long. Margins of leaves not hairy. Flowers pink or white, 5-lobed, somewhat 2-lipped. Escaped from cultivation locally. May.

10. L. involucrata, (Richards) Banks. Involucred Fly-HonexstCKLE. Shrub, 3 to $10 \mathrm{ft}$. high. Leaves oval or egg-shaped, sharp pointed at apex. Flowers in pairs, yellow, tube cylindric, lobes 5, equal, spreading, the whole corolla somewhat downy. Berries nearly black. Below the flower are leaf-like, oval or ovate bracts. Woods, northern part of our range. June-July.

A few other species, introduced from Asia or Europe, have escaped from cultivation and are found locally growing wild.

7. DIERVILLA, Moench.

Our species a small shrub, resembling the Loniceras, with opposite leaves, 2 to $4 \mathrm{ft}$. high. Flowers yellow, in groups of 3 or more. Calyx slender, elongated, contracted toward the throat, border of 5 linear lobes. Corolla 5-lobed, regular or nearly so. Stamens $\mathbf{5}$.

D. Lonicera, Mill. (Fig. 2, pl. 157.) Busir Honexsuckle. (D. Diervilla, (L.) Mas M.) Flowers yellow. Capsule long, slender and terminated by the persistent calyx-lobes. Dry rocks and rocky woods, throughout our range. Nay-June.

\section{Order IX-VALERIANALES. The Valerian Order}

Differs from the preceling order in that while among the Rubiales the stamens are mostly as many as the lobes of the corolla, or twice as many, in Talerianales the stamens are most feuce than the corolla lobes. The ovary is 1-celled with a single pendulous ovule, or 3-cellerl, but still with only 1 ovule. The order contians luerlos mostly with opposite leaves and perfect flowers, the anthers being separale as in the precerling order, and the caly.x above and more or less adherent to the ovary.

Ovary of 1 cell only

Ovary of 3 cells, 2 of which are empty . VALERIANACEAE

\section{FiMIty I.- VALERIANACEAE. TAITRTAN FAMILY}

T"smally tall, stromes smelling herlss. Stem leaves always opposite, the principal leaves being basil, usually more or less lobed. 

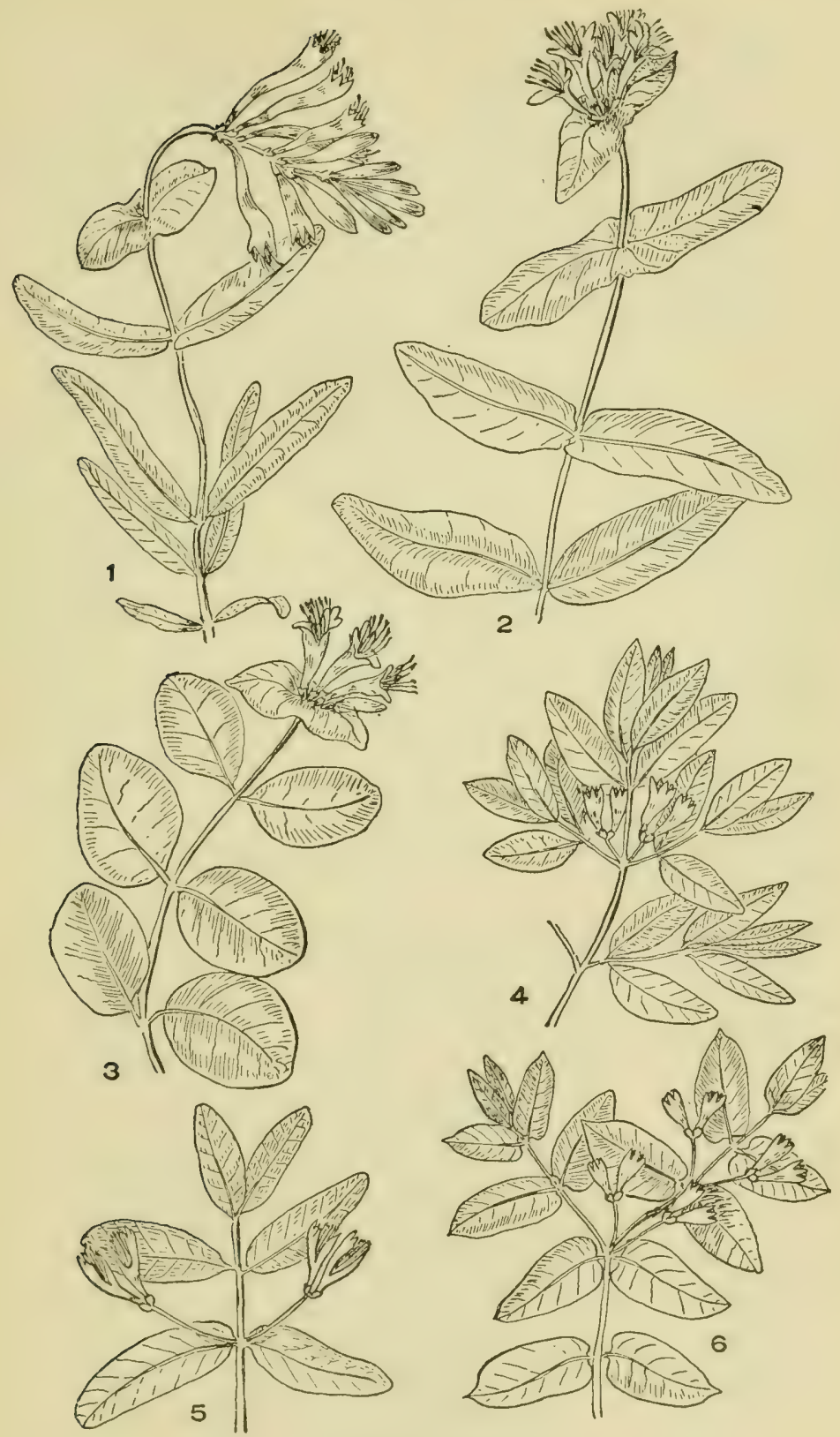

Plate 156

1. Lonicera sempervirens, 2. L. dioica. 3. L. glaucescens. 4. L. coerulea. 5. L. oblongifolia. 6. L. tartarica. 
Flowers in terminal spreading elusters or contracted into rather dense heads. Calyx tube adherent to the ovary, its divisions being superior to it, these divisions consisting of 5 to 15 bristle-like tecth which, inconspicuous in the flower, in fruit are rolled outward. Corolla tubular or funnel-form, usually gibbous at base, the border consisting of 5 equal teeth. Stamens 1 to 4 , mostly 3 , inserted in the corolla and alternate with its lobes, usually extending beyond the corolla. Ovary of 1 to 3 cells, only one cell containing a developed ovule. Fruit dry, one-seeded.

\section{VALERIANA, L.}

Characters those of the Family, the fruit being only one-colled.

1. V. uliginosa, (T. \& B.) Rydb. (Fig. 5, pl. 157.) Swamp VAleriax. (T. sylvatica, Banks.) Plant smooth, erect, $\frac{1}{2}$ to $2 \frac{1}{2} \mathrm{ft}$. high. Basal leaves on long leaf-stalks, spatula-formed, often with one or more pairs of opposite narrow lobes at the base of the blade. Stem leaves of 3 to 13 leaflets arranged on each side of the long leaf-stalk, 2 to 6 pairs and an odd leaflet. Flower cluster loosely pyramidal. Flowers pink or nearly white; the corolla tube short. Vermont, New York and westward.

2. B. officinalis, L. (Fig. 4, pl. 157.) Garden Valerian. A larger plant than No. 1, and all the learcs are divided like the stem leaves of V. uliginosa. Escaped from gardens, occasional.

3. V. pauciflora, Michx. (Fig. 3, pl. 157.) Large-flowered VALERIAx. Stem smooth, erect or ascending, slender, 1 to $3 \mathrm{ft}$. high. Root leaves egg-shaped, heart-shaped at base, toothed at borders. Stem leaves compound feather-formed, of 3 to 7 leaflets. Flower cluster terminal; flowers fewer than in the other species, the tube of the corolla from $\frac{1}{2}$ to nearly 1 in. long. Penna., and southward. May-June.

\section{VALERIANELLA, Poll.}

Characters as above, but the ovary is 3-celled, with only 1 cell ovule bearing: Flowers in dense terminal clusters.

Flowers pale blue

Flowers white.

Fruit triangular

Fruit 4 -angled

Firuit round.

1. V. Locusta, (L.) Bettke. (Fig. 1, pl. 158.) European CorN S.anad. Plant 6 to 12 in. high, smooth, repeatedly forked. Balsal leaves spatula-form, rounded at apex, 1 to $2 \mathrm{in}$. long. Flower clusters dense, rounded, about $\frac{1}{2}$ in. diameter. Corolla blue. Fruit somewhat orbicular in general outline. Waste places. Naturalized in places. April-July.

2. V. chenopodifolia, (Pursh.) DC. (Fig. 2, pl. 158.) Gooss-FooT Cons SAlad). Stem 1 to $2 \mathrm{ft}$. high, smooth. Ieaves all spatula-formed, without tecth at margins. Flowers white. Fruit 3-angled, pyramidal, to of an inch high. Mroist soil, New York and southward. May-July.

3. V. radiata, ( $\mathrm{L}_{.}$) Dufr. (Fig. 3, pl. 158.) Beaked Cors Salad. Plant, $\frac{1}{2}$ to $1 \frac{1}{2} \mathrm{ft}$. high, smooth or with few hairs. Lower leaves spatula- 


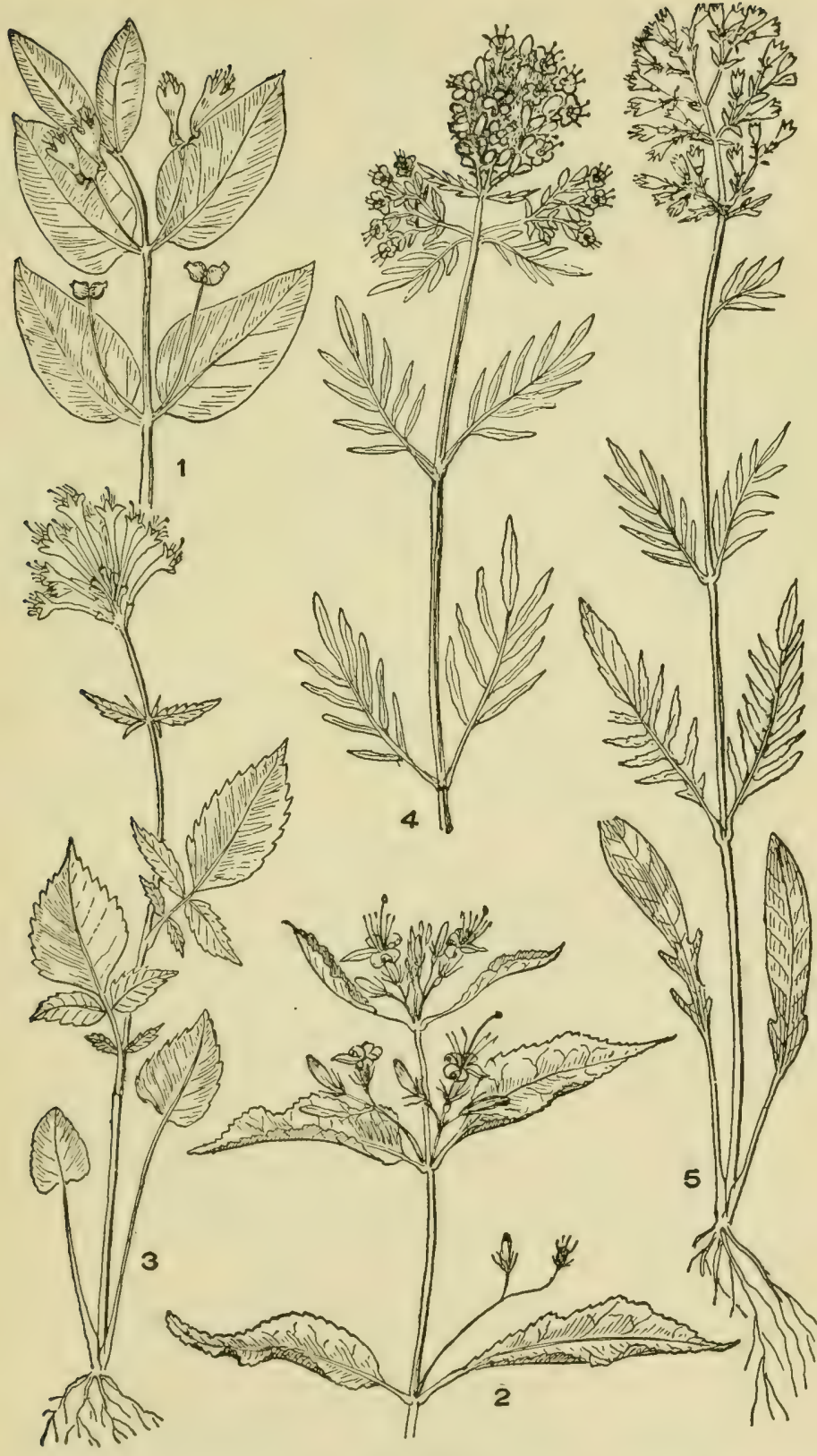

Plate 157

1. Lonicera canadensis. 2. Diervilla Lonicera. 3. Valeriana pauciflora 4. V. officinalis. 5. V. uliginosa. 
form, upper lance-shaped, toothed at margins, the pairs of leaves on upper part of stem often joined around it. Flower clusters small, $\frac{1}{3}$ to $\frac{1}{4}$ in. in diameter. Flowers white. Fruit narrowly ovate with 4 angles. Moist soil, New York, southward and westward. May-July.

4. V. Woodsiana, (T. and G.) Walp. (Fig. 4, pl. 158.) Wood's CoRs SALAD. Plant sometimes $3 \mathrm{ft}$. high, smooth. Lower leaves spatulaformed, upper lance-shaped or narrowly oblong, usually toothed at margins. Flower heads $\frac{1}{2}$ in. broad. Fruit nearly globular. Moist soil. Southern part of our area. May-July.

\section{Family II.-DipsacaceaE. Teasel Family.}

Herbs with opposite or sometimes whorled leaves, without stipules. Flowers in dense elongated heads from an elongated receptacle, the heads subtended by bracts, very conspicuous in Dipsacus, but resembling calyx segments in Scabiosa. Calyx adherent to the ovary, its border cup-shaped or divided into spreading bristles. Corolla tube enlarged at throat, the border 2 to 5 lobed. Stamens 4, alternate with the corolla lobes. Ovary below the calyx border, 1-celled, 1-ovuled. Fruit a dry hard shell including 1 seed.

Bracts below the flower head as long as or longer than the flower head . . . . . . . . . . . Dipsacus

Bracts below the flower head shorter than the flower head.

Receptacle not chaffy ....... Knautia Receptacle chaffy . . . . . . . . . Succisa

\section{DIPSACUS, L.}

Herbs, stout, tall, prickly. Leaves opposite, large, dentate or lobed. Flowers in heads about the size and shape of a hen's egg, the head arising above an involucre of long linear prickly bracts which rise around the head nearly to the level of its summit. Flowers lilac, each surrounded at its base by a prickly scale (an involucel). Stamens 4 . The two species found in our area have been introduced from Europe, largely originating about woolen mills. The ripe teasel heads are, in Europe, used in the process of "carding" wool.

1. D. sylvestris, Iluds. (Fig. 7, pl. 158.) Wind Teıser. Stem (rect, stifl, 3 to $6 \mathrm{ft}$. high, with many prickles. Teaves without leafstalks, the lower oblong, sometimes lobed, 8 to $12 \mathrm{in.} \mathrm{long,} \mathrm{the} \mathrm{upper} \mathrm{lance-}$ shaped, united about the stem. Bracts longer than the flower heads. Waste places. July-Sept.

2. D. lacinatus, I. (CT-LEAved TEaser. Leaves once or twice feather-compound. Established at Allsany, N. Y. (C. II. Peck.)

\section{KNAUTIA, L.}

Ilerbs with opposite leaves and flowers in dense heads, subtended by a several-bracted involucre, the flowers arising from a flattened receptacle 
TEASEL FAMILY

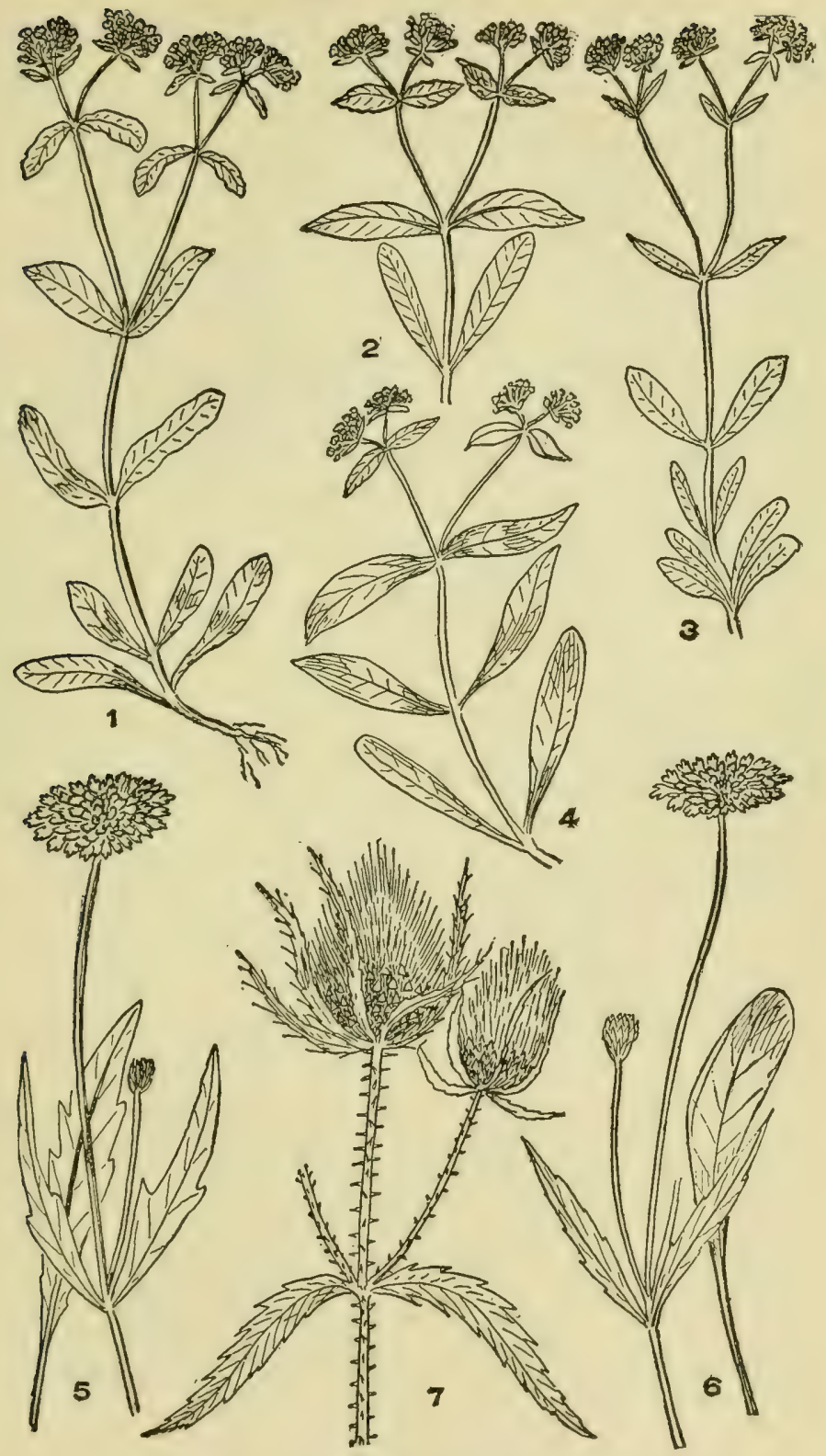

Plate 158

1. Valerianella Locusta. 2. V. chenopodifolia. 3. V. radiata. 4. V. Woodsiana. 5. Knautia arvensis. 6. Succisa australis. 7. Dipsacus sylves. tris, 
without chaff. Calyx border consisting of 8 bristle points. Corolla 4- or 5-lobed. Stamens 4. (rarely 2). Naturalized from Europe.

K. arvensis, (L.) T. Coulter. (Fig. 5, pl. 158.) Field Scabious. Stem 1 to $3 \mathrm{ft}$. high, erect, slender, little branched. Lower leaves lanceshaped, on long leaf-stalks, often lobed on each side. Upper leaves without leaf-stalks, deeply lobed on each side. Flowers lilac purple.

\section{SUCCISA, (Rupp.) Neck.}

Rather tall herbs, resembling Knautia, but the flattened receptacle is decidedly chaffy, the chaff about equalling the flowers.

S. australis, (Wulf.) Reichenb. (Fig. 6, pl. 158.) Soutrers ScabIous. Stem usually dividing into $3 \mathrm{~s}, 1$ to $3 \mathrm{ft}$. high, rather hairy with short or stiff reflexed hairs. Leaves lance-shaped, borders not lobed or notehed. Heads of flowers about $\frac{1}{2}$ in. in diameter. Calyx with 5 teeth, not bristled. Corolla light blue. Meadows and cultivated fields. Introduced. Occasional.

\section{Order X.-CAMPANULALES. Order of Aggregated Flowers}

The calyx or the plumous hairs representing it, always above the ovary. Stamens usually 5. When a corolla is present (as it is in the non-aggregated flowers) it is 5-lobed and the calyx is 5 -lobed, the 5 stamens alternating with the 5 lobes of the corolla. The stamens are not, as in the former order, attached to the tube of the corolla, but arise from the summit of the ovary. In the Campanulaceae and Cucurbitaccae the corolla and calyx are each fully developed, in the other families one or both may be reduced to an aigrette of hairs or scales.

Flowers not aggregate on a common receptacle.

Vines

CUCURBITACEAE

Erect herbs

Flowers aggregate on a common receptacle subtended by an involucre.

Flowers all ray flowers.

CICHORIACEAF

Flowers all tubular or the outer row ray flowers.

Stamens distinct or nearly so

AMBROSIACEAE

Stamens united by their anthers (except in

Kuhnia) . . . . . . COMPOSITAE

Famry I.-CUCURbitaceae. Gorrd Famluy

ITerbacens climbing vines, usually climbing by tenòrils. Lcaves 
alternate, radiately lobed or dissected. Flowers solitary or in lengthened clusters, the stamens and pistils occupying separate flowers of the same plant (monoecious) or separate flowers on different plants (dioecious). Calyx cohering with the 1- to 3-celled ovary, the 5 to 3 stamens united by their anthers. In certain cases there is but a single stamen. Ovary 1- to 3-celled. Fruit fleshy or sometimes membranous. (In cultivation we have the cucumber, the squash, muskmelon and pumpkin as representatives of this family.)

I. MICRAMPELIS, Raf. (Echinocystis, T. \& G.)

Climbing herbs with branched tendrils, lobed or angled leaves and small flowers, the staminate and the pistillate separate on the same plant. Calyx and corolla each 5- or 6-lobed. Stamens 3 in the staminate flowers. Fruit fleshy, dry later, spiny, usually with 2 seeds.

M. lobata, (Michx.) Greene. (Fig. 7, pl. 159.) Wild Balsam Apple. Stem climbing, 15 to $25 \mathrm{ft}$. long. Leaves 5- to 7-lobed on leaf stems 1 to 3 in. long. The pistillate flower solitary or occasionally 2 together. Fruit 2 in. long. Along river banks in our area. July-Sept.

\section{SICYOS, L.}

Climbing vine with branched tendrils and small green flowers of 2 kinds, the staminate and pistillate on the same plant. Calyx and corolla, each 5-parted. Stamens 3, the filaments united into a column. Pistillate flowers several in a group. Fruit prickly.

S. angulatus, L. (Fig. 6, pl. 159.) Bur Cucumber. Stem angled, 15 to $25 \mathrm{ft}$. long. Leaves nearly round, with 5 angles and heart-shaped base. Fruit 1-seeded. River banks, throughout our range. June-Sept.

\section{Family II.CAMpanulaceae. Bellflower Family}

ITerbs with alternate or basal leaves, without stipules. Flowers with stamens and pistils and with the corolla of one petal composed of the union of several; regularly 5-lobed or irregular; inserted between the calyx and ovary, the ovary being inferior to the calyx. Stamens 5, inserted into the summit of the ovary. Anthers separate or united into a ring or tube. Style simple. Fruit usually a capsule, sometimes a berry.

Flowers regular.

Corolla bell-shaped . . . . . . . . . Campanula

Corolla wheel-shaped . . . . . . . . Specularia Flowers 2-lipped

\section{CAMPANULA, L.}

Herbs with alternate or basal leaves. Flowers scattered. Calyx adherent to the ovary, of 5 slender divisions (or rarely 3 or 4). Corolla 
regular, bell-shaped, 5-lobed. Stamens 5, not combined. Style 1. Capsule 2 to several cells, usually crowned with the persistent calyx-lobes. Flowers usually showy, blue.

Stems smooth or without stiff hooked hairs.

Flowers in a loose cluster, basal leaves round .... C. rotundifolia

Flowers in one-sided spikes, not leafy ...... C. rapunculoides

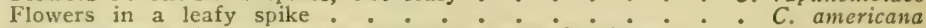

Flowers mostly in a glomerate cluster at summit of stem $\because \dot{C}$. glomerata Stems rough with stiff hooked hairs......... C. aparinoides

1. C. rotundifolia, L. (Fig. 2, pl. 159.) Hare Bell. Blue Belis of Scotiand. Stem very slender, $\frac{1}{2}$ to $2 \mathrm{ft}$. high. Lower leaves round, with rounded teeth at the margins. These leaves are usually absent at flowering time. Stem leaves linear or oblong, more or less indented. Flowers generally several, nodding, bell-shaped, blue. Moist rocky places, throughout our range. June-Sept.

2. C. rapunculoides, L. ( Fig, 1, pl. 159.) Creeping Bellfower. Stem 1 to $3 \mathrm{ft}$. high, branching or simple. Leaves egg-siaped, hairy. Flowers bell-shaped, blue, in a one-sided spike, the flowers crowded. Roadsides. Naturalized in many places. July-Sept.

3. C. glomerata, L. Clustered Bellflower. Stem 1 to $2 \mathrm{ft}$. high, usually simple. Leaves and stem hairy, the lower oblong, elliptic or less frequently egg-shaped, generally on long, sometimes on very long ( 3 to 5 in.) leaf-stalks. The upper leaves lance-shaped. Flowers mostly in a terminal rather dense flattened cluster, blue. Naturalized, found along roadsides, eastern Mass. June-Aug.

4. C. aparinoides, Pursh. (Fig. 3, pl. 159.) Marsi Bellflower. Stem very weak, almost vine-like, $\frac{1}{2}$ to $2 \mathrm{ft}$. high, clinging by its hooked hairs to grasses and weeds, branching above, triangular. Leaves lanceshaped or linear. Flowers in a diffuse terminal eluster, small, bell-shaped, blue or nearly white. In wet meadows, leaning on grasses or water plants. June-Aug.

5. C. americana, L. (Fig. 4, pl. 159.) TAll Bellflower. Erect, tall, 2 to $6 \mathrm{ft}$. high. Leaves broad lanee-shaped, 3 to $6 \mathrm{in}$. long. Flowers in a leafy spike. Copses or woods. July-Sept.

\section{SPECULARIA, Heister. (Legouzia, Durand)}

Annual herbs, with slender stem and branchess, alternate leaves and blue or purplish flowers arising from the leaf-axils. In some species the earlier flowers are fertilized without the opening of the flower, the later ones are wheel-shaped. Calyx 5- (or 3- or 4-) lobed, the tube narrow. From a short, narrow tube the 5 conspicuous lobes of the corolla spread wheelshaped. Nitamons 5, not united at the top; the style bearing 3 stigmas. Capsule 3-celled, prismatic or oblong.

S. perfoliata, I)(: (Figr. 5, pl. 159.) Vraus's Looking-giass. Plant hairy, 3 to 20 in. high, densely leafy. Leaves round or broadly eggshaped, motched at margins, clasping the stem by the heart-sluaped base, or the fowest not elasping. Flowers arising in the leaf-axils and partly anclosent by the leaves, 1 to 3 in a group, the blue star-shaped corollat to to $\$$ in. broad. Dry open ground or in woods. May-Aug. 


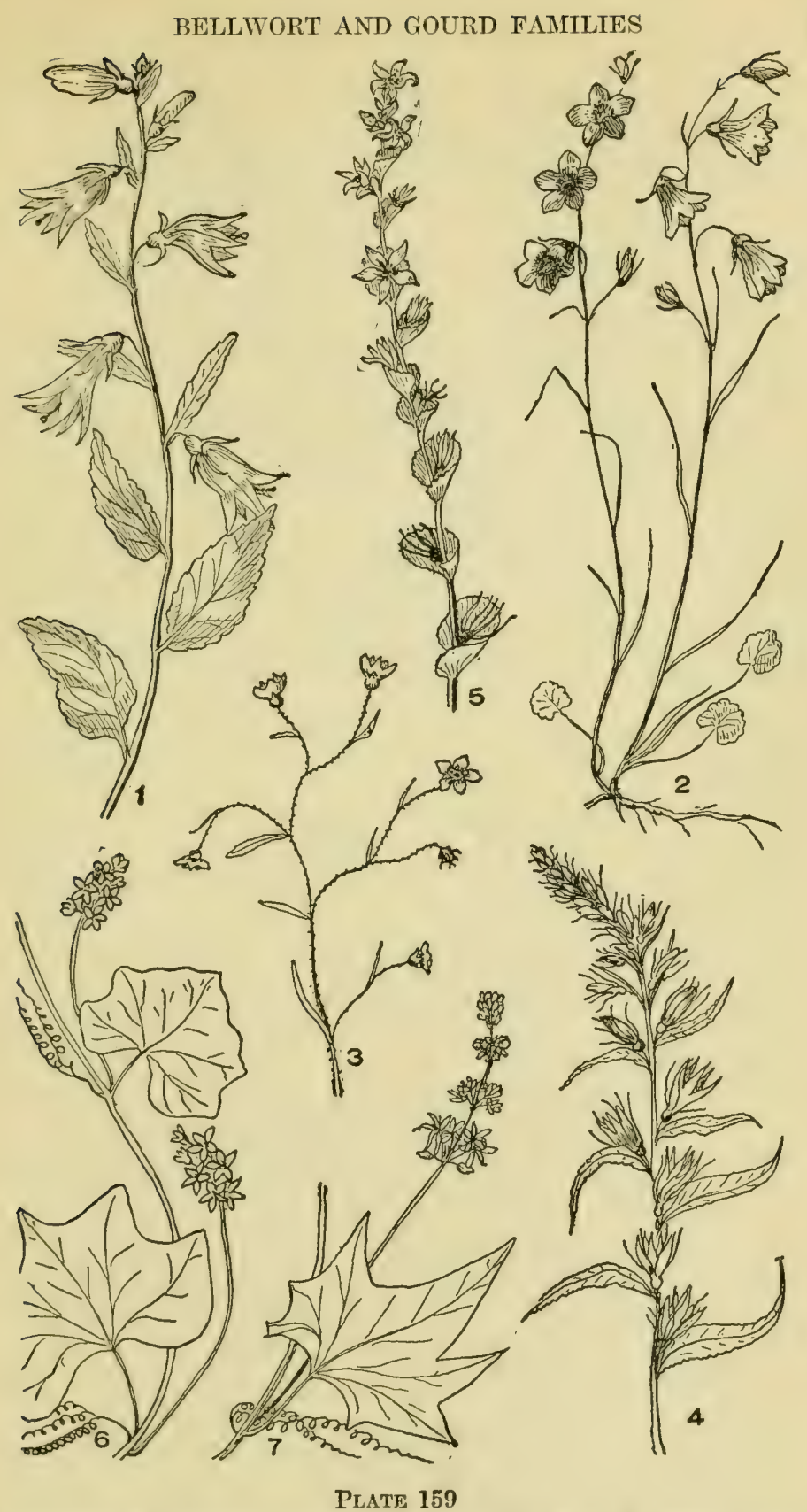

1. Campanula rapunculoides. 2. C. rotundifolia. 3. C. aparinoides. 4. C. americana. 5. Specularia perfoliata. 6. Sicyos angulatus. 7. Micrampelis lobata. 


\section{LOBELIA, L.}

Herbs, with alternate or basal leaves and scattered flowers. Corolla irregular, 5-lobed, 2-lipped. Calyx tube adhering to the ovary. Stamens not attached to the corolla, the anthers of 2 of them (or all of them) bearded at the top.

Leaves all basal, hollow tubes . . . . . . . . . . . L. Dortmanna Leaves flat, alternate along the stem.

Flowers bright scarlet............... L. cardinalis Flowers blue to white.

Stem leaves pear-shaped or oval blunt at the apex.

Flowers less than $\frac{1}{2}$ in. long... . . . L. puberula Flowers more than $\frac{1}{2}$ in. long . . . . . L. spicata

Stem leaves egg-shaped, ends acute.

Calyx lobes downy . . . . . . . . . L. syphilitica Calyx lobes not downy . . . . . L inflata

Stem leaves narrow lance-shaped or linear. Flower stem longer than the flower....... L. Kalmii Flower stem shorter than the flower.

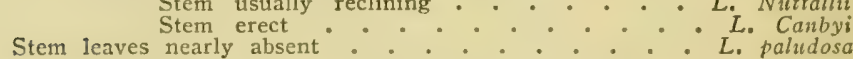

1. L. Dortmanna, L. (Fig. 4, pl. 160.) WATER Lobetia. Leaves all basal, linear, fleshy, tufted. Flower scape 6 to 18 in. high, smooth or with a few scales. Flowers scattered along the upper $\frac{1}{3}$, blue, on slender flower stems. Borders of ponds, sometimes wholly under water.

2. L. cardinalis, L. (Fig. 1, pl. 160.) Cardinal Flower. Stem leafy, tall, 2 to $4 \mathrm{ft}$. high. Leaves broad lance-shaped or oval, 2 to $6 \mathrm{in}$. long, slightly toothed. Flowers in an elongated terminal cluster, bright scarlet. Low grounds, throughout our range. July-Sept.

3. L. syphilitica, L. (Fig. 3, pl. 160.) Blue Cardinal Flower. Stem rather stout, somewhat hairy. Leaves lanee-shaped, slightly toothed. Flowers in a dense narrow spike, somewhat leafy. Corolla blue. In moist soil, throughout our range. July-Oct.

4. L. puberula, Michx. (Fig. 8, pl. 166.) Downy Lobelia. Plant somewhat downy throughout. Stem slender, rarely branched, 1 to $3 \mathrm{ft}$. high. Leaves oval 1 to $2 \mathrm{in.}$ long, with small teeth. Flower spike rather one-siderl, flowers blue. Moist grounds, southern New Jersey and southward. Aug.-Oet.

5. L. spicata, Lam. (Fig. 10, pl. 160.) Pale Sriked Lonelia. Stem slender, not branched, leafy, 1 to $4 \mathrm{ft}$. high. Leaves broadly oblong, oval or inversely ecge-shaped, the margins harely notehed, apex blunt, the upper ones narrower and less roumled at apex. Flowers pale blue in a dense or somewhat loose spike. Dry soil, throughout our area. June-Aug.

6. L. inflata, L. (Fig. 5, pl. 160.) Indan Toвacco. Stem much bratucheol, downy, 1 to $2 \mathrm{ft}$. high. Leaves egrer-shaped, oval to lance-shaped, fincly dentate at margins, eradually beeming smaller until anong the flowors they become bracts. Flowers blue, seattered along the stem. The fruit is round and much inflated. In dry fields, a poisonous weed, throughout our area. July-Nov.

7. L. Kalmii, I. (Fig. 7, pl. 160.) Ввоок Lobria. Stem 4 to 18 in. high, leafy, erect, smooth, branehing above. Lower leaves spatulaformed, rounded at apex, upper leaves linear. Flowers blue in somewhat 
BELLFLOWER FAWILY

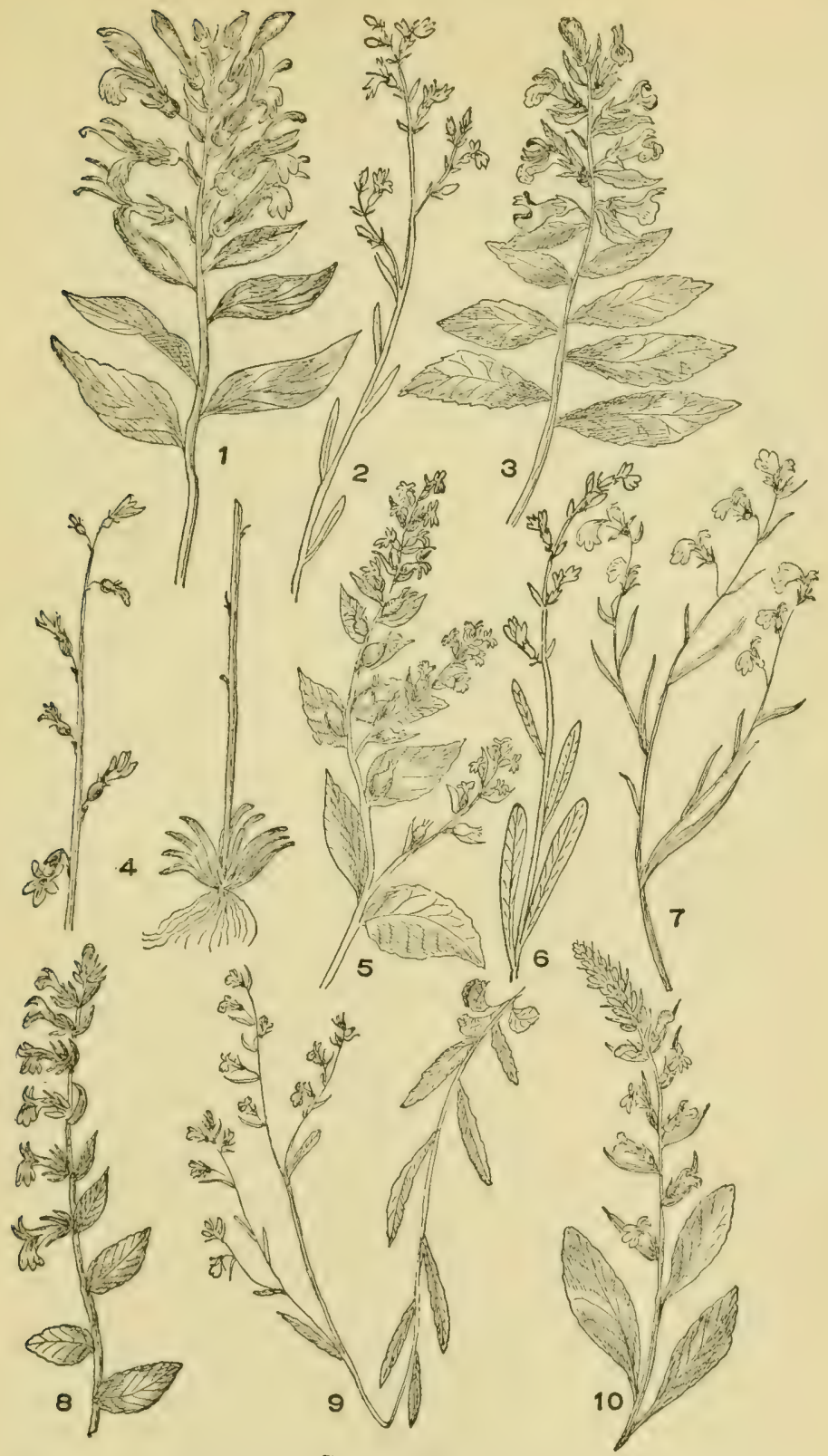

Plate 160

1. Lobelia cardinalis. 2. L. Canbyi. 3. L. syphilitica. 4. L. Dortmanna, 5. L. inflata. 6. L. paludosa. 7. L. KaImii. 8. L. puberula. 9. L. Nuttallii. 10. L. spicata. 
diffuse clusters, following the slender branches, on very slender flower stems, which are not as long as the linear leaf-bract at the base of the flower-stem but as long as the flower. Wet places, Maine to New Jersey and westward. July-Sept.

8. L. Nuttallii, Roem and Schult. (Fig. 9, pl. 160.) NutTAl.'s Loperis. Stem 1 to $2 \mathrm{ft}$. high, weak, often reclining. Leaves spatulaformed to oval, blunt at apex, the upper linear. Flowers blue, in diffuse clusters, on flower-stems shorter than the flowers. Swamps, New Jersey and westward. June-Sept.

9. L. Canbyi, Gray. (Fig. 2, pl. 160.) Canbx's Lobelia. Stem slender, simple or branched above, 2 to $3 \mathrm{ft}$. high. Leaves all linear. Flowers in slender spikes on flower-stems shorter than the flowers. Corolla blue, $\frac{1}{2}$ in. long, bearded in the throat. Wet places, New Jersey and southward: July-Sept.

10. L. paludosa, Nutt. (Fig. 6, pl. 160.) Swamp Lobelia. Aquatic, with few leaves on the stem. Root leaves spatula-form, stem leaves linear. Stem 1 to $4 \mathrm{ft}$. high. Flowers pale blue. Delaware and south. May-July.

\section{Fanilly III.-CICHORIACEAE. Chicory FaMily}

This family includes a part of that large group of plants whose flowers are known as Composite. They are grouped in heads upon a receptacte, which is the expanded end of the stem, upon which they are more or less densely crowded. The individual flowers are never possessed of all the details which we are accustomed to associate with a typical flower, yet each of the elements of the flower may in fact be present. In the case of the present family the receptacle is flat or nearly so, its surface naked or scaly or studded with stiff hairs or marked with small pits. The separate flowers are always perfect, i. e., each has stamens and pistils, and further, cach has a corolla consisting of a tube and a ray upon one side only, the ray being 5-toothed. Owing to the shape of this ray it is sairl to be ligulate or strap-like. 177 the flowers in the head are ligulate. The calyx for the individual flowers is less uniform. It may consist of an aigrette of stiff hairs, which may be plumed or not, it may consist of low scales or even these scales may be alsent. The plants are herbs (in our country) usually with a milky or acrid juice, with leaves all basal or scattered on the stem. Underlying and partly surrounding the head of flowers is a circle of leafy luracts, in a single row or in more than one row, called the involucre. In this family the rows of bracts are nisually sereral, but there may be but one. The fruit is a small, dry 1-erelled, achene, from the apex of which arise the hairy or scale-like calyx and the corolla as well as the stamens and pistil. Example, the seed and plume of the dandelion. 
Calyx formed by a little crown of scales.

Receptacle not chaffy.

Flowers blue

Flowers yellow .

Calyx none or a simple inconspicuous ring.

Receptacle not chaffy.

Flowers yellow.

Flower scape enlarging toward (below) the flower head, leaves basal . . . . Arnoseris

Flower scape not thickening or enlarging below the flower head, leaves mostly on the stem. Fruit 20 to 30 ribbed

Lapsana

Calyx of 1 row of plumose bristles.

Leaves all basal.

Receptacle chaffy . . . . . .

Hypochaeris

Receptacle not chaffy . . . . . Leontodon

Leaves, at least some of them, growing from the stem.

Plant hairy, flowers yellow . . . . . Picris

Plant not hairy, flowers purple or yellow Tragopogon

Calyx of an aigrette of hairs which are not plumose, but toothed.

Fruit (achene) surmounted by a column from the summit of which the hairs radiate, the achene hairy or with many little spines . . . . . . . Taraxacum

Fruit similar to above, but achene not spiny or hairy, though possibly rough.

Fruit (achene) flattened . . . . . . . Lactuca

Fruit blunt at top, without a column.

Fruit flattened and roughened . . . . . . Sonchus

Fruit cylindric.

Flowers yellow.

Involucre of 1 long and 1 short row of bracts Crepis

Involucre of several rows of bracts of irregular length

Hieracium

Flowers cream, white or purple . . Prenanthes

\section{CICHORIUM, L.}

Branching peremial herbs, with stem leaves grass-like, clasping and with a rosette of basal leaves. Flowers blue, purple or pink, the heads among the branches with short pedicels or none, usually 2 or more in a 
group. The involucre is double, the internal row of 8 bracts, the external of 5 , much shorter. Flower rays 5 -toothed, all the teeth in the same plane. Calyx represented by 2 or 3 series of short blunt scales.

C. Intybus, L. (Fig. 1, pl. 161.) CuIconx. Stems stiff, branched, 1 to $3 \mathrm{ft}$. high. Basal leaves incised, or lobed, 3 to 6 in. long; upper leaves lance-shaped. Flowers in clusters on very short stems or none, blue, rarely white. Roadsides and waste places. July-Oct.

\section{KRIGIA, Schreb. (Adopogon, Neck.)}

Herbs, nearly smooth, the stem bearing a single head or more than one head. Leaves mostly basal, in our species one or more stem leaves or none. Leaves entire, wavy or lobed. Involucre of 6 to 15 bracts in 1 or 2 series, all of about the same length. Receptacle flat, without scales. Rays 5-toothed, abrupt at apex. Calyx represented by 1 or 2 series of bristles (pappus).

1. K. virginica, (L.) Willd. (Fig. 6, pl. 161.) Virgrnia GoatsBEARD. Smooth. Lower leaves tufted on long leaf-stalks, which broaden into lance-shaped or rounded leaf-blades, which at the margins are wavy, or more or less incised, 2 to 7 in. long. Toward the summit of the scape is a single oblong leaf which clasps the stem. Above this leaf one or more branches may arise each of which, as well as the main stem, may be terminated by a flower head. Flowers yellow. Scape about $1 \mathrm{ft}$. high. Dry sandy soil, Maine to Mass. May-Oct.

2. K. caroliniana, Britton. (Fig. 2, pl. 161.) Carolina Dwarf DaNDELIOx. Basal leaves more lobed than those of No. 1, and the stem leaf is rarely present. Calyx represented by a series of fine bristles outside of which is a series of scales. Sandy soil, Maine to Southern Penna. April-Aug.

\section{ARNOSERIS, Gaertn.}

A low herb, smooth or nearly so, with tufted basal leaves and no stem leaves. The flower scape is branched and from the forks each stem enlarges gradually toward the head being, just below the head, quite thickened. The involuere is composed of a number of bracts in one series, which turn inward enveloping the head after the flowering period. Fruit without pappus, the only representative of a calyx being a narrow low band.

A. minima, (L.) Dumort. (Fig. 4, pl. 161.) Lamb Succory. Leaves lance-shaped, 1 to $3 \mathrm{in.} \mathrm{long.} \mathrm{Seape} \mathrm{branching,} 3$ to $12 \mathrm{in.} \mathrm{high.} \mathrm{Flowers}$ yellow, Mt, Desert lsland, Maine. Summer.

\section{HYPOCHAERIS, L.}

Herbs, with basal leaves and naked flower scapes more or less branching. Involuce of many bracts in several series. Receptacle ehaffy. Fruit contractul into a short or long column from which arises the aigrette of plumose bristles.

H. radicata, I. Gosmoms. liasal leaves lobed, the lobes turned backward, hairy. Scape branched or simple. Flower head large, 1 in. in diameter, flowers yellow. Wasto places, southern New Jersey. May-Oct. 

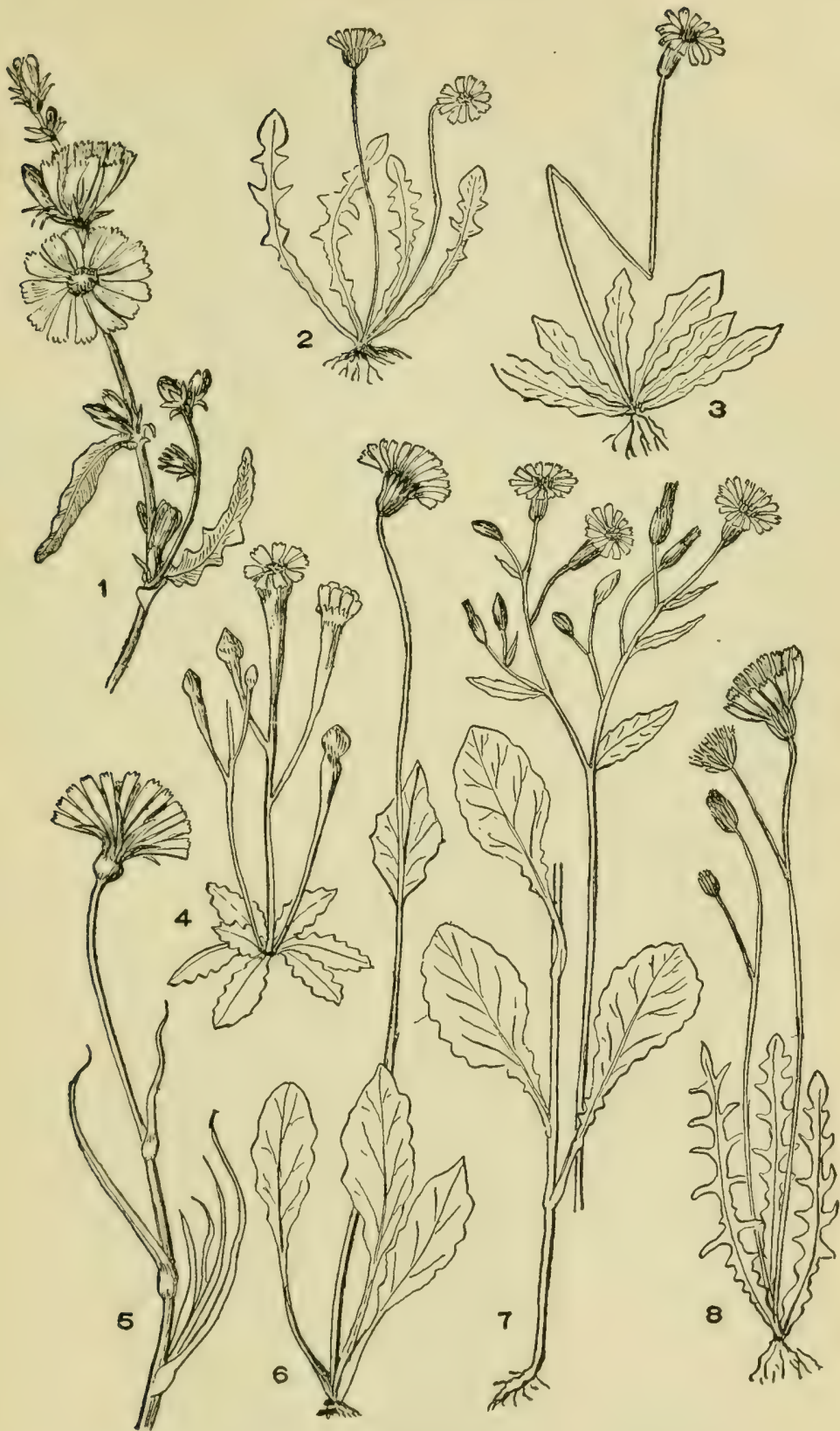

\section{Plate 161}

1. Cichorium Intybus. 2. Krigia caroliniana. 3. Leontodon nudicaule. 4. Arnoseris minima. 5. Tragopogon pratensis. 6. Krigia virginica. 7. Lapsana communis. 8. Leontodon autumnale. 


\section{LAPSANA, L.}

Annual herb, with alternate leaves which are long, egr-shaped and thinly hairy. Margins with large angular or rounded teeth, the lower leaves somewhat feather-formed and the leaf-stalks of the larger leaves with large angular teeth near the leaf. Heads of flowers yellow in a loose irregular cluster. Involucre nearly cylindric, its bracts in a single series.

L. communis, L. (Fig. 7, pl. 161.) Succorx Dock-cress. Stem 1 to $33 \mathrm{ft}$. high, sonewhat hairy below, smooth above. Apex of leaves obtuse, the upper lenves without leaf-stalks, lance-shaped. Heads numerous, about 1 in. broad. Waste places in most of our area. June-Sept.

\section{LEONTODON, L.}

Herbs, with deeply lobed basal leaves and flower scapes naked except for a few small seales. Involucre of a number of bracts, the principal being in 1 or 2 series with a few or no short ones in an outer series. Fruit contracting into a short column or none. Pappus plumose, arising directly from the fruit in our species.

1. L. autumnale, L. (Fig. 8, pl. 161.) Autunn Hawkbit. TalL DAxDeliox. Plant smooth. Leaves lance-shaped, lobed. Involucre nearly cylindric. Scape 6 to 24 in. high. Heads one or several from the same scape. Flowers yellow. Fields and roadsides, our area. June-Nov.

2. L. nudicaule, (L.) Porter. (Fig. 3, pl. 161.) Rougr Hawnвiт. Leaves not deeply lobed, often nearly entire, quite hairy. One head only on the seape. Flowers yellow. Waste places, eastern seaports and occasional in Penna. June-Oct.

\section{PICRIS, L.}

Coarse, leafy branching herbs, covered with stiff hairs. Leaves on the stem alternate with a cluster of leaves at base. Flowers in diffuse clusters at top of stem, yellow. Involuere of a row of bracts and one or two outer rows which may be shorter than the inner row or much larger and longer. Fruit cylindric with plumose pappus.

1. P. hieracioides, L. (Fig. 7, pl. 164.) HAwkweEd PicRis. Branched, I to $3 \mathrm{ft}$. high, with many rather lare yellow flowers. Leaves lance-shaped or broad, the upper clasping the stem, margins wavy or irregularly toothed. Outer bracts of the involuere linear. Fruit oblong cylindric with the aigrette arising directly or nearly so from the summit. Waste places, southern section of our area. June-Sept.

2. P. echioides, L. (Fig. 8, pl. 164.) Bristly Ox-tongue. Stem and lates very hairy with stiff hairs. Plant about $2 ? \mathrm{ft}$. high. Lower fores spatula-formed, irregularly toothed. Heads numerous. Inner bracts of the involuere linenr, the outer 4 or 5, broad, leaf-like, hairy. Aigrrette arising from a column above the fruit. Waste places, eastern seaports. July-Sept.

\section{TRAGOPOGON, L.}

Ilerhs, biennial or perennial, branching herbs, with alternate linear, entire, leaves which elasp the stem at the base. Heads of purple or yellow 

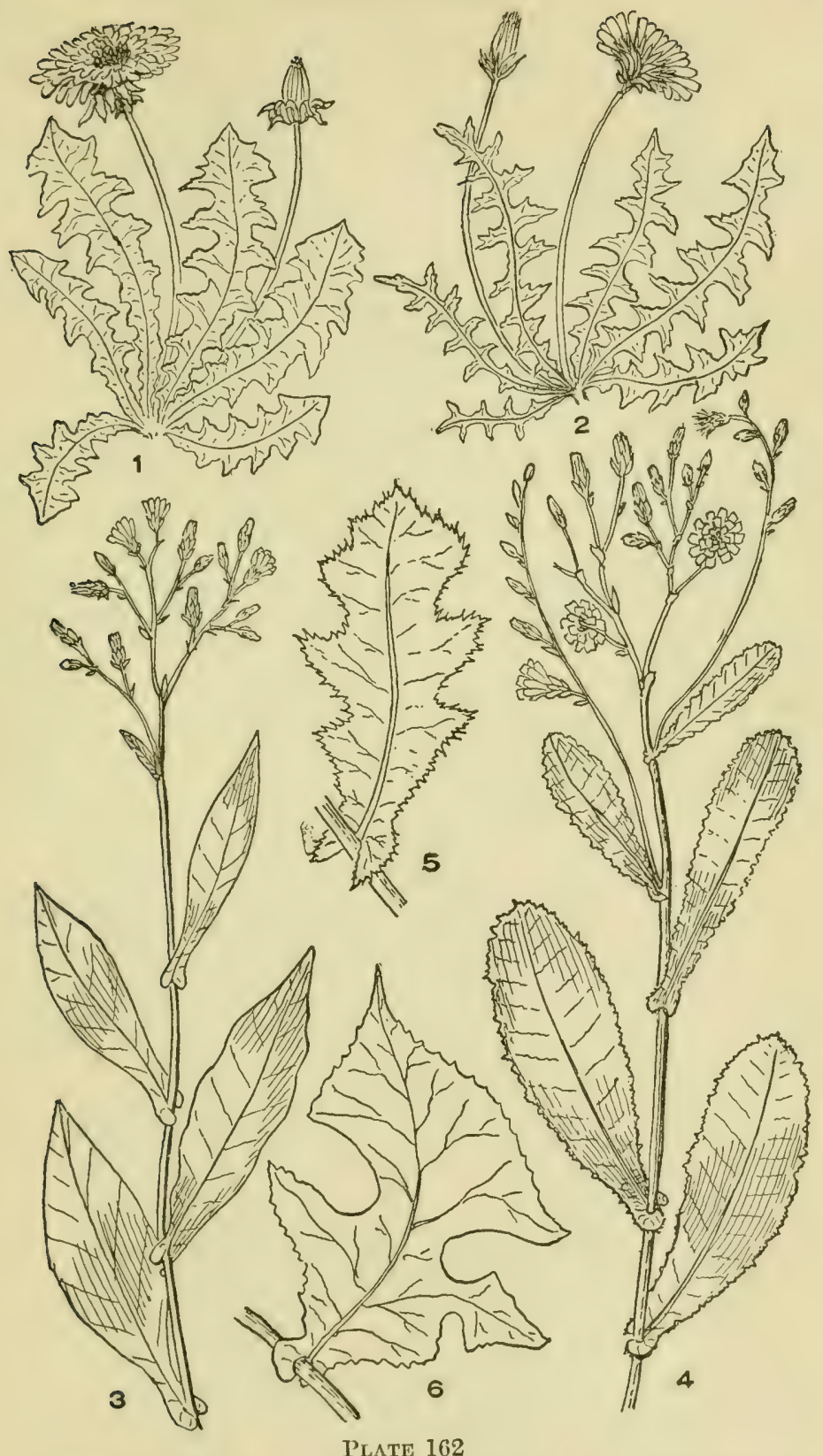

1. Taraxacum officinale. 2. T. erythrospermum. 3. Lactuca sagittifolia. 4. I. virosa. 5. L. Scariola. 6. L. floridana. 
flowers on long flower-stems. Involucre a singlo row of bracts which open in tho morning and close toward noon. Plumose aigrette radiating from a "beak" or column.

1. T. pratensis, L. (Fig. 5, pl. 161.) Yellow Gonts-Benrd. Mendow SALSIFY. Outer rays longer than the bracts of the involuere. Stem $1 \frac{1}{2}$ to $3 \mathrm{ft}$. high. Fields and meadows, New Jersey and northward. JuneOct.

2. T. porrifolius, L. Oyster Plant. Purple Salsify. Rays of the purple flowers much shorter than the slender, tapering bracts of the involucre. Leaves linear, broader toward base. Stem 2 to $4 \mathrm{ft}$. high. Fields and meadows, escaped from gardens. June-Oct.

\section{TARAXACUM, Hall.}

Perennial herb, the leaves all basal, lance-shaped, deeply lobed. Flower scape hollow, bearing a single head of many yellow flowers. Involuere double, an inner series nearly equal and an outer of many unequal but shorter bracts. Receptacle flat, naked. Fruit nearly linear, rough, suddenly terminating in a long beak or column from which radiates the aigrette of thread-like bristles.

1. T. officinale, Weber. (Fig. 1, pl. 162.) DANdelion. (T. Taraxacum, (L.) Karst.) Found in fields, lawns and waste places. After the blooming the greenish-brown fruits with their aigrettes of pappus expand into a delicate white globe, which is broken and distributed by the wind when not eaten by birds. Blooms from early spring to late autumn.

2. T. erythrospermum, Andrz. (Fig. 2, pl. 162.) Red-SEEDED DaNDELION. Resembles the last, but leaves narrower and lobes extend to midrib. Fruit bright red or red brown. Locations similar to those of No. 1.

\section{ro. SONCHUS, L.}

Coarse weeds with leafy stems and diffuse clusters of yellow flowers. Leaves alternate, mostly clasping the stem by broad ear-like appendages at base, lobed, margins prickly. Involucre egg-shaped or bell-shaped, its bracts of several overlapping series. Receptacle, flat, naked. Fruit oblong, oval or linear, ribbed, rough. The aigrette of soft white silky threads without a beak or column.

1. S. arvensis, L. (Fig. 4, pl. 163.) ConN Sow-tuistle. Plant 2 to $4 \mathrm{ft}$. high. Lower leaves often a ft. long, narrowed into short leafstalks. Flower stcms and involucre hairy. Low grounds, roadsides, etc. July-Oct.

2. S. oleraceus, L. (Figs. 1 and 2, pl. 163.) ANNuAr Sow-tiristle. Stem 1 to $10 \mathrm{ft}$. high. Basal leaves on long leaf-stalks, expanding into a derply-lobed blade terminated by a broal triangular segment. The earlike appendages with sharp angles. Involucre not hairy. Fields and waste places. May-Nov.

3. S. asper, (L.) All. (Fig. 3, pl. 163.) Sirarp-fringed SowTIISTIE. Leaves spiny toothed; ear-like appendages at base of leaves rounded. Involucre not hairy. Waste places, most of our area. MayNov. 


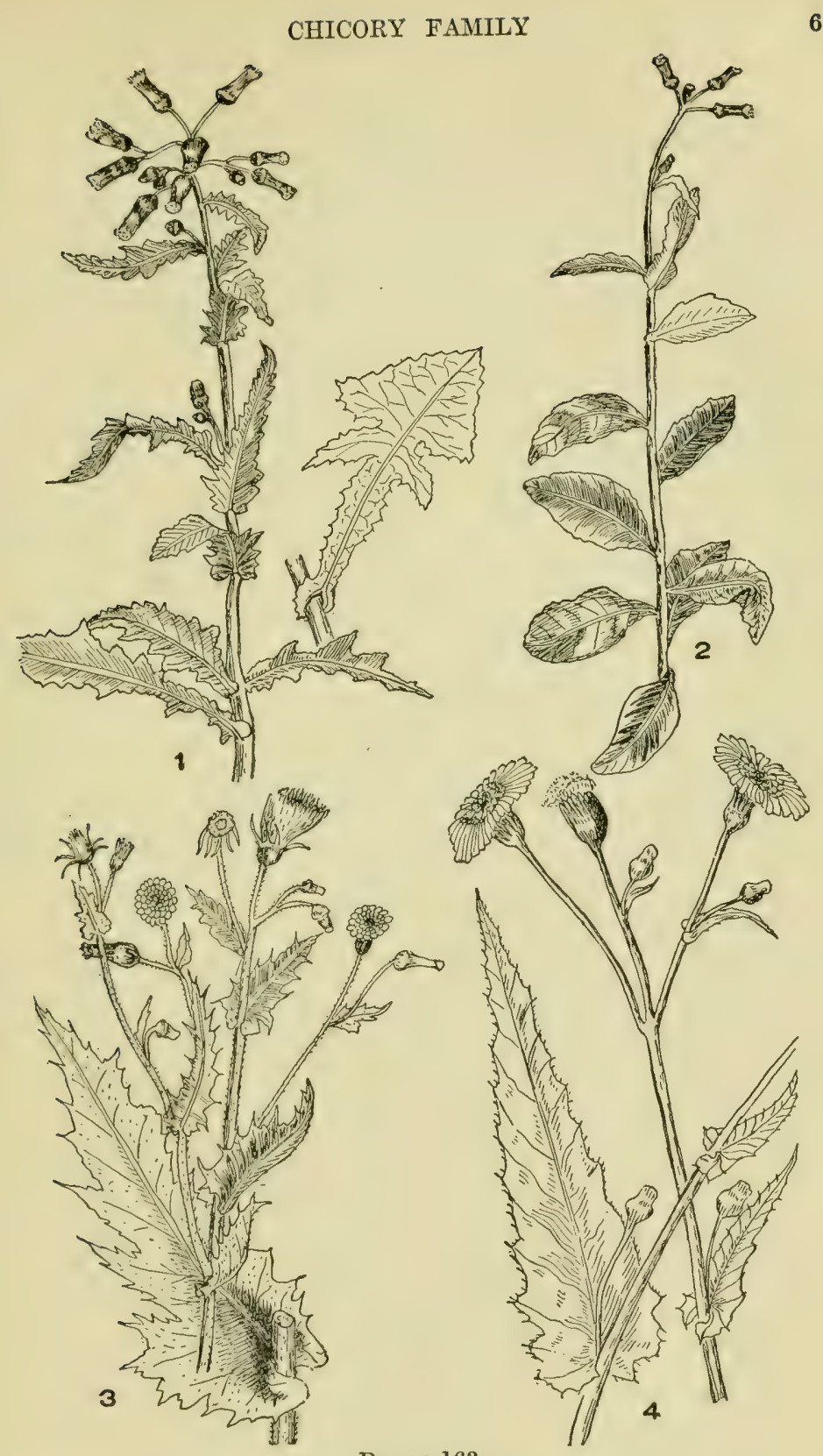

Plate 163

1. Sonchus oleraceus. 2. Another form of the same, 3. S. asper. 4. S. arvensis. 


\section{LACTUCA, L.}

Leafy herbs, with diffuse clusters of yellow, blue or white flowers, and alternate narrow leaves, which are lobed or not, the margins spiny, wavy or toothed. Heads several or many flowered, the involucre cylindric, of overlapping scales in 2 or more series. Receptacle flat, naked. Fruit flattencd, oval to linear, with 1 to 5 ribs on each face, contracted into a column from the somewhat expanded summit of which spring the nearly simple soft hairs of the white or brown pappus.

Flowers Yellow

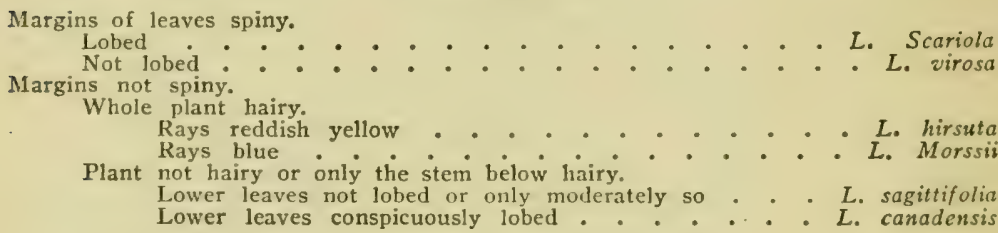

\section{Flowers Blue}

Leaves egg-shaped to broad lance-shaped.

Not deeply lobed

Deeply lobed.

Margins with low teeth . . . . . . . . . L foridana

Margins with high pointed teeth ......... L. spicata

1. L. Scariola, L. (Fig. 5, pl. 162.) Prickly Lettuce. Biennial. Stem stiff, 2 to $7 \mathrm{ft}$. high, smooth above and smooth or hairy below. Leaves oblong or lance-shaped, the lower deeply lobed, the margins spiny, the base with an angular auricle each side of stem; upper leaves entire, clasping the stem. Heads numerous, 6- to 12-flowered. Waste grounds, New York, Penna. Aug.-Sept.

2. L. virosa, L. (Fig. 4, pl. 162.) Strong-Scented Lettuce. ( $L$. scariola, var. integrata, Gren. and Gedr.) Plant erect, 2 to $7 \mathrm{ft}$. high, smooth. Leaves long pear-shaped, 2 to $10 \mathrm{in.} \mathrm{Iong,} \frac{1}{2}$ to $3 \mathrm{in}$. broad, clasping the stem, margins finely and irregularly toothed, the longer teeth somewhat prickly. Under surface of mid-vein prickly, the prickles turning backward. Heads of flowers pale yellow, several on a single slender stem, the whole forming a lonse pyramidal cluster. Fruit black, ribbed. Juice foetid, said to be an acrid narcotic. Waste places, our area and westward.

3. L. canadensis, L. (Fig. 1, pl. 165.) Wild LetTuce. Stem 3 to $10 \mathrm{ft}$. high, leafy, branching above into the diffuse flower cluster. Whole plant smooth. Leaves, the lower on leaf stems, 6 to $12 \mathrm{in}$. long, decply lobed, margins wavy or with low teeth, covered with a whitish bloom. Heads about 20-flowered. Damp soil, in most of our area. June-Nov.

4. L. hirsuta, Muhl. (Fig. 2, pl. 164.) Hairr Wood Lettuce. Plant hairy, 2 to $3 \mathrm{ft}$. ligh. Leaves lobed. Ileads numerous. Flowers yellow-purple to whitish. Dry soil, most of our area. July-Sept.

5. L. Morssii, Robinson. Monse's Wild Lettuce. Similar to No. 3; involuce slorter and rays blue, Along salt meadows, Maine and eastern Mass, to New York. 


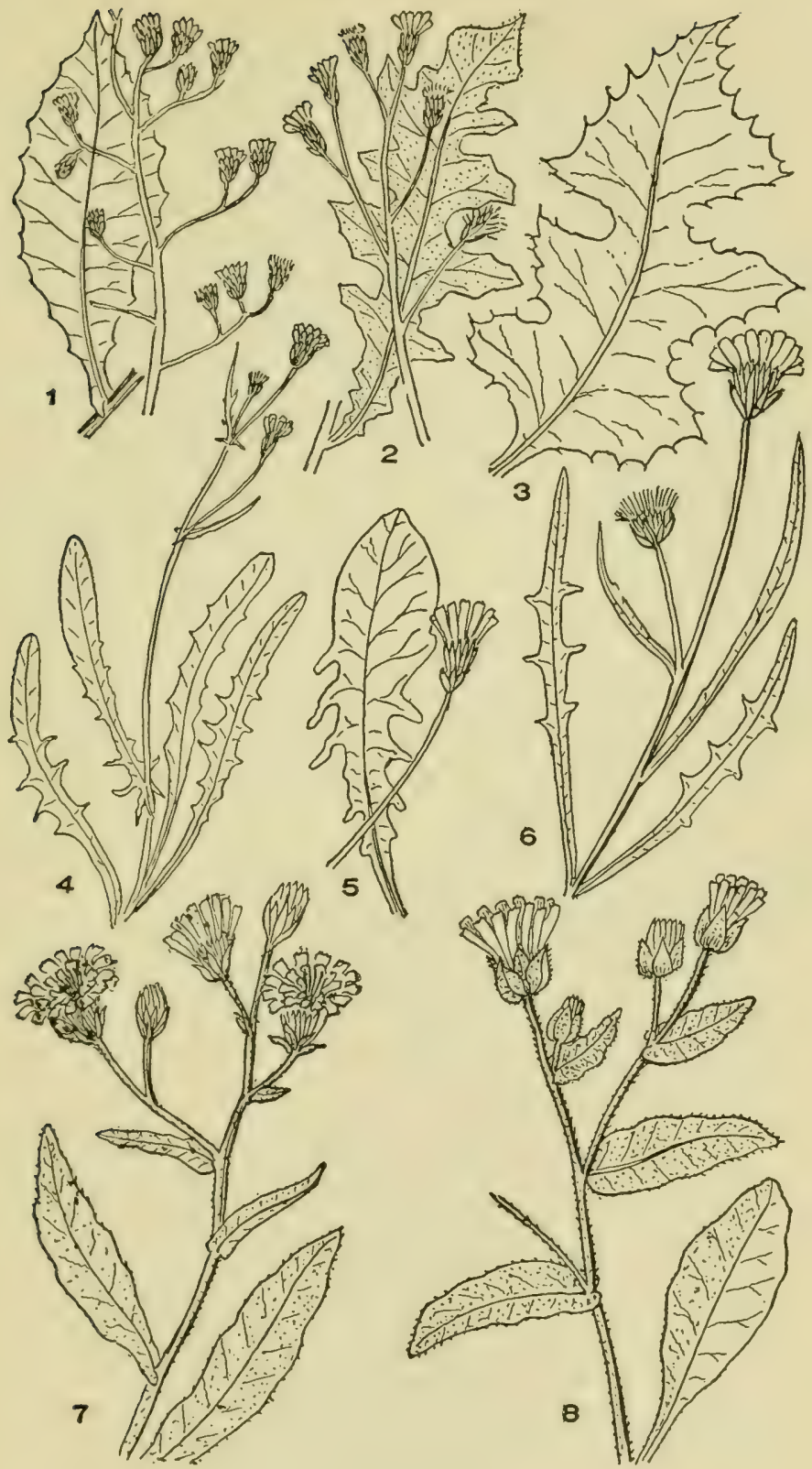

Plate 164

1. Lactuca villosa. 2. L. hirsuta. 3. L. spicata. 4. Crepis virens. 5. C. biennis. 6. C. tectorum. 7. Picris hieracioides, 8. P. echioides. 
6. L. sagittifolia, Ell. (Fig. 3, pl. 162.) Arrow-Lenved LetTuCE. Biennial. Plant smooth throughout, 3 to $5 \mathrm{ft}$. high, not very leafy. Leaves not divided into lobes, oblong lance-shaped, the upper lance-shaped, the lower clasping with angular projections each side of the stem. Flowers yellow or purplish. Dry soil, our area. July-Sept.

7. L. villosa, Jacq. (Fig. 1, pl. 164.) Hairy-veined Blue Lettuce. Stem 2 to $6 \mathrm{ft}$. high, the whole plant smooth. Leaves egg-shaped to oblong-lance-shaped, 4 to 6 in. long, not lobed, the margins irregularly toothed, the lower on leaf-stalks. Flowers numerous in a diffuse cluster, rays blue. Borders of woods, New York, westward and southward. JulySept.

8. L. floridana, (L.) Gaertn. (Fig. 6, pl. 162.) Florida LetTuce. Stem 3 to $7 \mathrm{ft}$. high; plant smooth. Lower leaves triangular, deeply lobed, the margins toothed, 4 to 12 in. long. Heads numerous, with blue flowers. Moist places. July-Sept.

9. L. spicata, (Lam.) Hitehe. (Fig. 3, pl. 164.) Tall Blue LeTTUCE. Plant smooth, 3 to $12 \mathrm{ft}$. high. Lower leaves 5 to $12 \mathrm{in.}$ long, deeply lobed, sharply toothed, with or without leaf-stalks. Flower heads numerous, rays blue. Moist places, throughout our range. July-Oct.

\section{CREPIS, L.}

Herbs, annual or perennial, the leaves mostly basal. Heads of yellow or orange flowers, small or medium in diffuse, more or less flattened clusters. Involucro cylindric or bell-shaped, the principal series of bracts equal, tho exterior bracts small and irregular. Receptacle naked. $\mathbf{A i}$ grette of many soft white bristles.

1. C. tectorum, L. (Fig. 6, pl. 164.) Narrow-Leaved Hawksbeard. Annual herbs, with basal and stem leaves, the former narrow, lanceshaped, 4 to 6 in. long, indented or deeply lobed, the lobes or margins rolled backward, the upper leaves narrow with plane margins which, in case of the larger are rolled back at the margins. Stem 1 to $2 \mathrm{ft}$. high, the whole plant somewhat downy. Flower heads numerous, $\frac{1}{2}$ to 1 in. broad, the involuere about $\frac{1}{2}$ in. high. Fruit spindle-shaped, the ribs rough, the aigrette arising directly from the apex. Waste places, southern part of our area. June-July.

2. C. virens, L. (Fig. 4, pl. 164.) Smootir Hawrsbeard, ( $C$. capillaris, Wallr.) Plant smooth, not downy. Stem 1 to $2 \frac{1}{2} \mathrm{ft}$. high. Leaves mostly basal, lance-shaped or spatula-shaped, clasping at base, 5 to $8 \mathrm{in.}$ loner, decply lobed or indented, not rolled back at the margins. Ipper leaves linear. Flower heads numerous, involuere + in. high, eylindric. Rays yellow. Fruit smooth, 10-ribbed. Waste places, southern section. July-Sept.

3. C. biennis, I. (Fig. 5, pl. 164.) Rougir IIAwismeard. Whole plant usually rough hairy. Stem 2 to $3 \mathrm{ft}$. high. Basal leaves about 6 in, long, spatula-formed or oblong on leaf-stallss, lobed or prominently tonthed, the margins not rolled back. Heads numerous, 1 to $1_{2}^{1} \mathrm{in}$. broad, the involuere $\frac{1}{2} \mathrm{in}$. high. Fruit somewhat eonical with 13 ribs. Bristles very slender. Waste places, New York, New Jersey and Penna. JumeAug. 


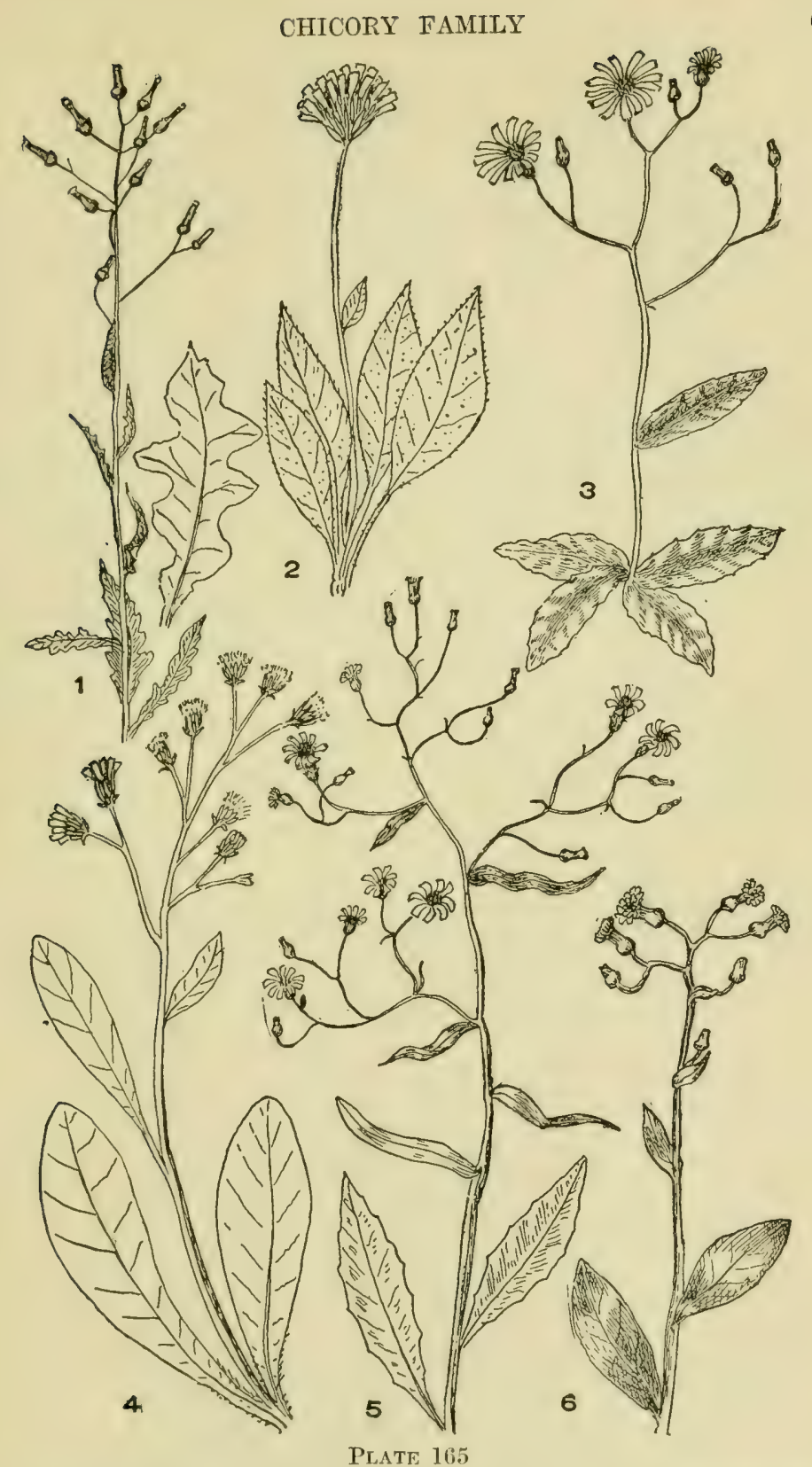

Plate 165

1. Lactuca canadensis. 2. Hieracium Pilosella. 3. H. venosum. 4. H. marianum. 5. H. paniculatum. 6. H. scabrum. 


\section{HIERACIUM, L.}

Herbs, mostly hairy but exceptionally without hairs, with basal or alternate leaves and small or not very large heads of flowers, mostly yellow or orange. Leaves entire or less frequently toothed. Involucre with the bracts more or less overlapping, the outer gradually diminishing. Receptacle flat, naked. Fruit not prolonged to a column or beak, aigrette one row of fine rough bristles.

Flower stems leafless or with one (rarcly more) lcaf and possibly a few bracts

Stem leafless, bearing a single head . . . . . . . . . H. Pilosella

Stem bearing several heads.

Leaves with very prominent teeth.

Rounded or heart-shaped at base . . . . . . . H. murorum

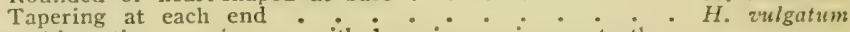

Leaves with entire margins, or with low, inconspicuous teeth.

Flowers orange-red . . . . . H. aurantiacum Flowers yellow.

Stem smooth or only slightly downy.

Leaves purple veined . . . . . H. venosum

Leaves not purple veined.

Leaves lance-shaped . . . . H. florentimum Leaves oblong or inversely egg-shaped.

The flower stem not hairy. H. marianum

Stem very hairy The flower stem hairy.. H. Greenii

Flower stem decidedly leafy

Leaves conspicuously toothed . . . . . . . . . H. canadense

Leaves with low teeth or none.

Piant not hairy or only slightly downy below . . H. paniculatum

Plant decidedly hairy.

Plant with tuft of lower leaves ...... H. Gronorii

Plant without a tuft of lower leaves: $:{ }^{\circ}$. scabrum

1. H. Pilosella, L. (Fig. 2, pl. I65.) Mouse-ear Hawkweed. Plant propagated largely by rumers which are leafy. Flowering scape slender, naked, not hairy, 4 to $10 \mathrm{in}$. high, bearing a single head of yellow flowers 1 in. broad. Leaves oblong or lance-shaped, very liairy, often whitish silky beneath. Dooryards and fields, an European plant. Naturalized in places. May-Sept.

2. H. murorum, L. WaL, HawrweEd. Basal leaves egg-shaped, apex obtuse or sharp, base heart-shaped or nearly so, margins decply toothed toward the base, veins purple. Flower stem 1 to $2 \frac{1}{2} \mathrm{ft}$. high, with 2 or more flower heads, downy or smooth. On the flower branches are found a few linear bracts. Naturalized in a few places. European. June-Aug.

3. H. vulgatum, Fries. (Fig. 4, pl. 166.) IIwкweEd. Basal leaves broad lance-shaped with sharp, remote teeth at margins, tapering at each (nd, 2 to $5 \mathrm{in.} \mathrm{Jong.} \mathrm{Sitem} \mathrm{smooth} \mathrm{or} \mathrm{downy,} 1$ to $3 \mathrm{ft}$. high, with inumerous flower heads. Naturalized. July-Sept.

4. H. aurantiacum, I. (Fig. 1. pl. l6i.) ORange Hawkweid. Paxw 3ntsir. linsetto of hasal leaves, each spatulatormed or oblonge ohtuse at apex, the whole plant very hairy; height of flowering stem 6 to $20 \mathrm{in}$. high. (In the stem a small leaf or two leaves is sometimes found. Flower liands several in a rather compact clustor, the individual flower stems lwing sloort, the locad about $1 \mathrm{in.}$ broal. Flowers dark orange. Along roadsides, in fields and woods, most of our range. June-Sept. 


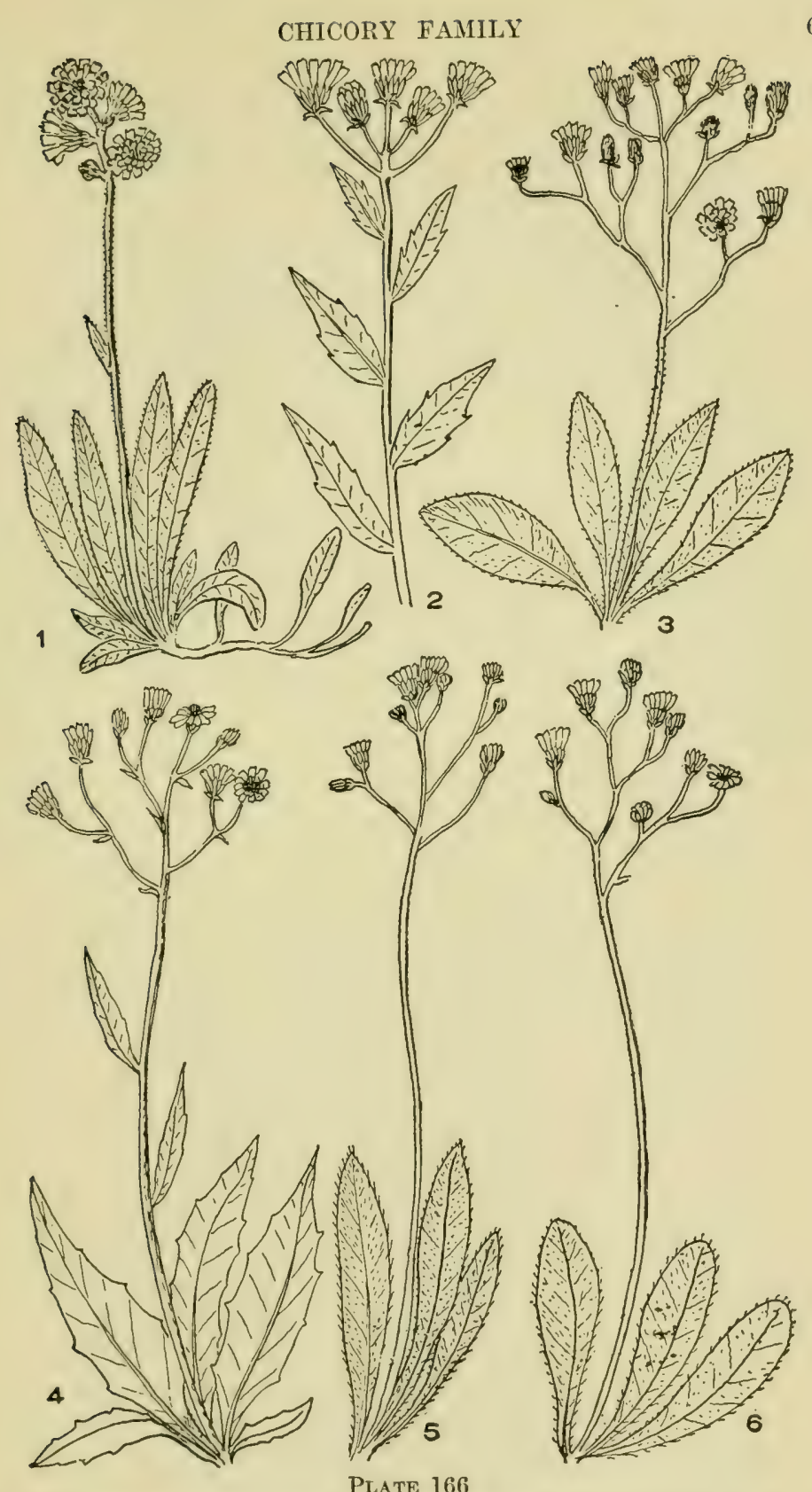

1. Hieracium aurantiacum. 2. H. canadense, 3. H. Gronovii. 4. H. vulgatum. 5. H. florentinum, 6. H. Greenii. 
5. H. florentinum, All. (Fig. 5, pl. 166.) King Devil. (II. pracaltum, Vill.) Flowering stem $1 \frac{1}{2}$ to $3 \mathrm{ft}$. high, not hairs, 1 to 3 small stem leaves at base. Basal leaves tufted, narrowly oblong or lance-shaped, very hairy, 2 to $4 \mathrm{in.}$ long. Heads several, each about $\frac{1}{2} \mathrm{in}$. broad. Flowers jellow. Fields, roadsides, a weed, north central New York. June-Sept.

6. H. pratense, Tausch. Field HAwKwEEd. Stem 1 to $2 \mathrm{ft}$. high, with 1 or 2 spatula-formed leaves toward base. Tuft of basal leaves of numerous spatula-formed leaves 2 to $5 \mathrm{in}$. long, the whole plant very hairy. Flowers yellow, in heads $\frac{3}{4}$ in. broad. Naturalized on Staten Island.

7. H. venosum, L. (Fig. 3, pl. 165.) Rattlesnake-Weed. Stem 1 to $3 \mathrm{ft}$. high, slender, not hairy, generally without leaves, but oceasionally with 1 or more small leaves. The basal leares nearly always conspicuously marked with purple borders to the veins. Cluster manyflowered, heads $\frac{1}{2}$ in. broad. Dry woods and old fields. Common.

8. H. marianum, Willd. (Fig. 4, pl. 165.) MARYLAND HAWkweEd. Flowering stem 2 to $3 \mathrm{ft}$. high, with several leaves. Basal leaves oblong, 2 to 8 in. long, with purple at the veins. Heads numerous, flower-stem moderately long. Dry woods, southern section of our area. May-July.

9. H. canadense, Michx. (Fig. 2, pl. 166) CAxadin HAwhweed. Stem firm, erect, 1 to $5 \mathrm{ft}$. high, leafy, the leaves on the upper part of the stem clasping at base, all leaves conspicuously and remotely toothed at margins. Basal tuft not present. Flowers yellow. Woods and thickets. July-Sept.

10. H. paniculatum, L. (Fig. 5, pl. 165.) PAxicled H.WKWEed. Whole plant smooth, basal tuft not present. Stem 1 to $3 \mathrm{ft}$. high, leafy, the leaves narrow lance-shaped, not prominently toothed, the small teeth may appear at margins. Flower heads numerous in a loose cluster, the flower stems standing nearly at right angles to the main stem. Flowers yellow. Dry woods. July-Sept.

11. H. scabrum, Michx. (Fig. 6, pl. 165.) RougI HAwKweEd. Leaves all on the flowering stem, which is slender, 1 to $4 \mathrm{ft}$. high. Whole plant rough hairy, inversely egg-shaped or spatula-shaped, 2 to $4 \mathrm{in.} \mathrm{Iong.}$ Heads numerous, $\frac{1}{2}$ in. broad. Flowers yellow. Dry woods. July-Sept.

12. H. Gronovii, L. (Fig. 3, pl. 166.) Hairy Hawkweed. Stem with or without stem leaves. Basal leaves spatula-formed, 2 to $6 \mathrm{in.}$ long, quite hairy. Heads numerous. Flowers yellow. Dry soil. JulySept.

13. H. Greenii, Porter and Britton. (Fig. 6, pl, 166.) Green's HAWKWEED. Stem $1 \frac{1}{2}$ to $2 \mathrm{ft}$. high, without hairs up to the branchings. Leavers in a tuft at base, spatula-formed or pear-shaped, with low teeth at borders or nome, hairy. Ileads in a spreading eluster on slender fowerstems. Bracts of the involuere in 1 series. Mountains of Penna. MayJune.

\section{I9. PRENANTHES, Vaill. (Nabalus, Cass.)}

Perennial herbs, with upright stems with many leaves, varialole in form, with margins toothed or deeply lobed and with diffuse terminal clusters of greenish or yollowish, generally drooping, hell-shaped locads of flowers, each head composed of from 5 to 30 flowers. Involuere eylindric of linear bracts, generally in a single row with a few short ones at 


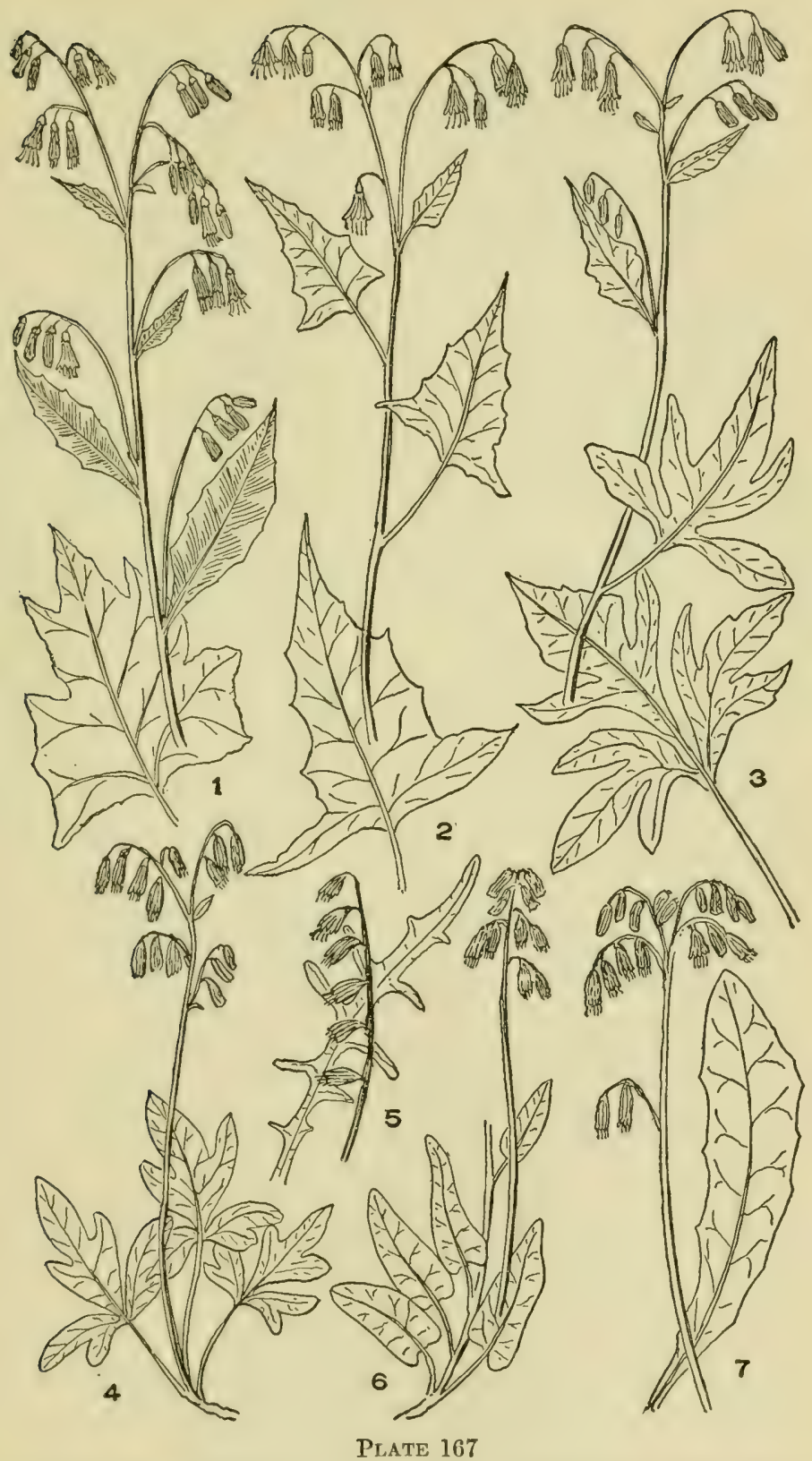

1. Prenanthes altissima. 2. P. alba. 3. P. trifoliolata. 4. P. nana. 5. P. virgata. 6. P. Boottii. 7. P. racemosa. 
the base. Rars terminated by a nearly straight edge with 5 rather low teeth. Fruit striated with an aigrette (pappus) of simple bristles varying from deep brown to nearly white.

plants more than $I \frac{1}{2}$ it. high.

Flower clusters diffuse.

Heads with 5 to 6 flowers . . . . . . . P. altissima

Heads with 8 to 12 flowers.

Aigrette deep brown. . . . . . . . . P. alba

Aigrette straw-color.

Involucre bracts with stiff hairs . . $P$. serpentaria

Flower cluster spicate.

Involucre bracts not hairy : . . P. trifoliolata

Leaves lobed nearly to midvein . . . . . . . $P$. virgata

Leaves not deeply lobed.$\div$..$P^{\circ}$ racemosa Heads with 20 to 25 flowers . . . . P. crepidinea

Plants not exceeding $\mathrm{I}_{\frac{1}{2}} \mathrm{ft}$. high.

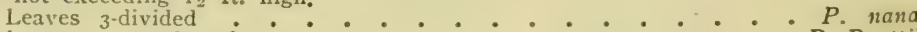

Leaves arrow-shaped .

1. P. altissima, L. (Fig. 1, pl. 167.) Tall White Lettuce. Stem straight, rigid, 3 to $7 \mathrm{ft}$. high, smooth, green or purplish, lower part quite leafy, upper with remote leaves. Leaves of various shapes, the lower broad, usually deeply lobed, on long leaf-stalks. Heads numerous in a terminal diffuse, rather narrow cluster, of subordinate clusters, each containing about half a dozen heads which are pendulous. Involuere cylindric, $\frac{1}{2}$ in long, smooth, green. Flowers greenish or yellowish white, about 5 to 7 flowers in each head. Aigrette light straw color. Rich woods, New England and southward and westward. July-Aug.

2. P. alba, L. (Fig. 2, pl. 167.) Rattlesiane Root. White LeTTLCE. Stem 2 to $5 \mathrm{ft}$. high, smooth, purple. Leaves on lower part of stem broad halberd-shaped, or varying, 3 to 8 in. long, nearly or quite as wide at hase. Ileads pendulous, each 8 - to 15 -flowered, in broad diffuse cluster of subordinate clusters of 2 to 5 heads. Involuere smooth, of about 8 purplish bracts and a few smaller ones at the base. Flowers greenish or yellowish white. Aigrette deep brown. Woods, common. Aug.-Sept.

3. P. serpentaria, Pursh. Lıox's Foot. I.ess tall than No. 2; leaves similat, hut the involucre quite hairy with stiff hairs. Fields and woods, New lingland and southward. July-Oct.

4. P. trifoliolata, (Cass.) Fernald. (Fig. 3, pl. 167.) Tall RattLesNake Root. Whole plant smooth. Stem 3 to $9 \mathrm{ft}$. high. Leaves usually 3-divided with the divisions stalked. Ileads 8 - to 12-flowered. Fowers white to vellowish. Woods, Maine, Vermont, New York, Penna., and southward. Aug.-Oet.

5. P. nana, DC. (Fig. 4, pl. 167.) Liox's Foot. Plant smooth throughout, stem ereet, from 4 to 15 in. high. Lower leaves 3 -parted, the divisions gremerally 3-lobed. Flower heads numerous. Summits of White and Adirondack Mountains. Augr.-Sept.

6. P. virgata, 1)(. (Fig. 5, pl. 167.) Sirxple R.tтlessake Root. Simentl. stem simple, straight, 2 to $4 \mathrm{ft}$. highl. Jeives in general outline lanes-shaped, often lo in. Jong, loberl nearly to the mid-vein on each side. Flower leads in a slonder spike often all on one side. Flowers white. Sandy soil. New Jersey, southward. Sept.-Oct.
7. P. Boottii,
(DC.)
Gray.
(Fig. 6, pl. 167.)
BOoTT'S RATTLE- 


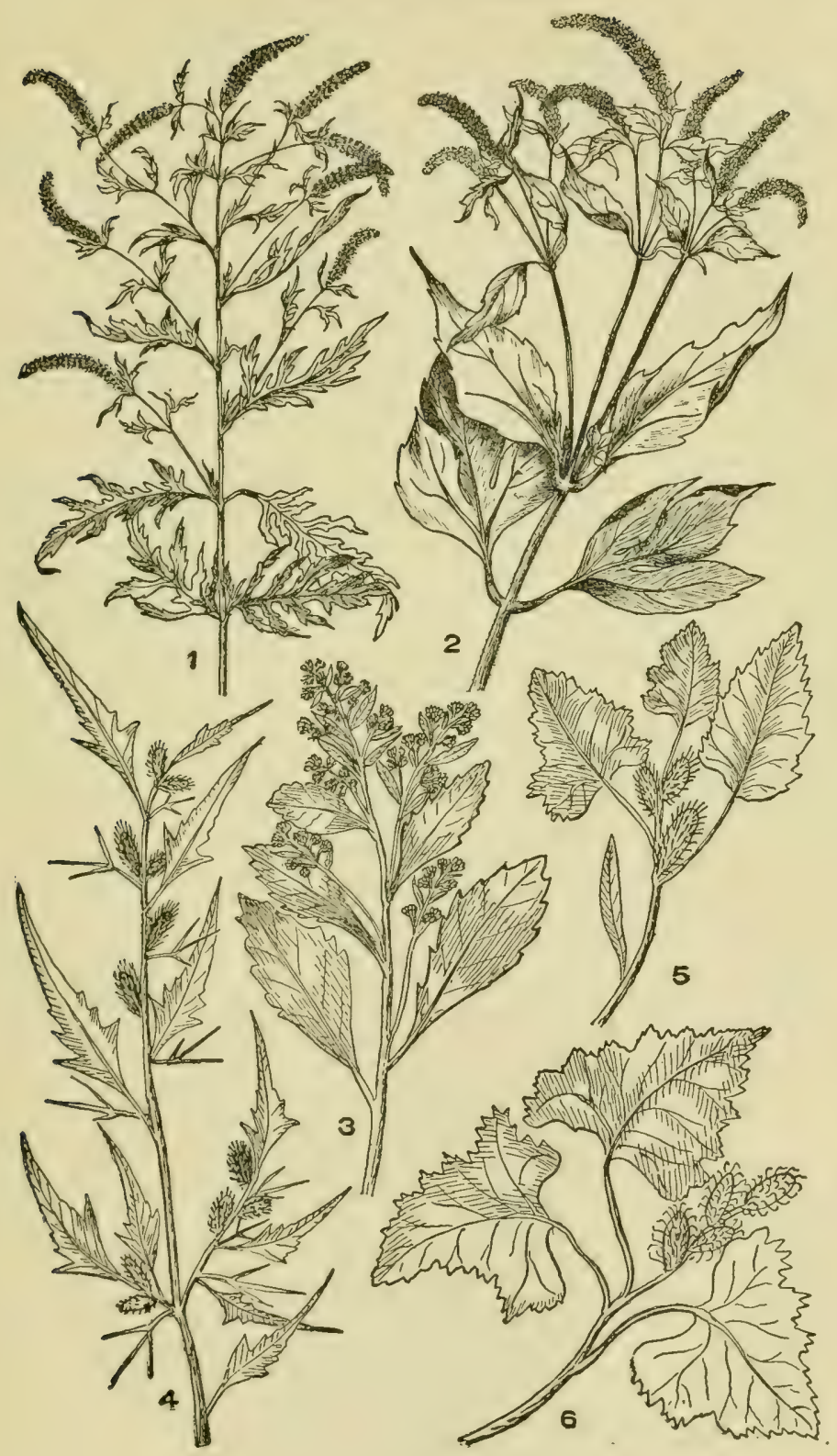

Plate 168

1. Ambrosia artemisiaefolia. 2. A. trifida. 3. Iva ovaria. 4. Xanthium spinosum. 5. X. strumarium. 6. X. canadense. 
sxake Root. A dwarf species, $\frac{7}{3}$ to $1 \mathrm{ft}$. high, the leaves halberd-shaped, upper ones lance-shaped. Summits of Adirondacks and White Mountains. July-Aug.

8. P. racemosa, Michx. (Fig. 7, pl. 167.) Wmite Lettuce. Smooth, stem often with a whitish bloom, 2 to $6 \mathrm{ft}$. high. Leaves lance-shaped to oval or egg-shaped, with low teeth at margins. Flower heads in a dense spike, mostly ercet, I- to 16-flowered. Moist soil, Maine and southward to New York and New Jersey. Aug.-Sept.

9. P. crepidinea, Michx. Corymbed Rattlesnake Root. Stem smooth, 5 to $9 \mathrm{ft}$. high. Leaves halberd-shaped. Flower hearls numerous, the involuere hairy, each head containing 20 to 25 flowers. Fields, woods, Penna. and New York, Aug.-Oct.

\section{Family IV.-AMBRosiaceaE. RagiveEd FAMily}

Herba, mostly weerls, with alternate leaves or the lower leaves sometimes opposite. Flowers in small heals of greenish or white flowers subtended by an involucre of a few bracts; usually the staminate and pistillate flowers are in different heads on the same plant or in the same head-but often the two kinds are on different plants. The aigrette or pappus representing the calyx is absent or reduced to a little rim at the summit of the fruit. The staminate flowers have a narrow tubular corolla which is small and membraneous. The anthers are free from each other or only slightly coherent.

Staminate and pistillate flowers in the same heads . . . Iva Staminate and pistillate flowers in separate heards, the heads

with stamens mostly above.

Involucre of the pistillate heads bur-like.

Xanthium

Involucre not bur-like

Ambrosia

\section{IVA, L.}

Large coarse herbs, with fleshy leaves, opposite or alternate, and with small heads of greenish flowers arranged in spikes, in the axils or solitary. There are within the head, about half a dozen or less pistillate flowers which oceupy the outer cirele, while within are several flowers with buth pistils and stamens. Involucre of a few rounded bracts. Receptacle small, chaffy. Aigrette none.

I. ovaria, Bartlett. (Fig. 3, pl. 168.) MAnsir Elber. (I. frutesecns, Man.) A coarse plant, apparently shrubly, with stems from 3 to $12 \mathrm{ft}$. high, growing in salt marsless. Leaves somewhat fleshy, oval to lanceshaped, the lower with coarse teeth. Heads in the upper axils. Reepp. tacle small, with chall among the flowers. Sea-side, Mass., New York and southward. July-Sept.

\section{AMBROSIA, L.}

Coarse weeds, branching, with alternate or opposite leaves, which are 
usually lobed or deeply divided and with inconspicuous greenish heads of flowers, the stamens and pistils occupying different heals. The staminate heads have an involucre of several scales, united to form a cup in which are from 5 to 20 staminate flowers on a chaffy receptacle. The pistillate heads have each a single flower, consisting only of a pistil, surrounded by an involucre of one piece. There is no aigrette or other indication of a calyx.

1. A. trifida, L. (Fig. 2, pl. 168.) Great Ragweed. Tall herb, 3 to $17 \mathrm{ft}$. high, hairy or nearly smooth. Leaves opposite, 3-lobed, the lobes oval-lance-shaped. Moist soil. July-Oct.

2. A. artemisiaefolia, L. (Fig. 1, pl. 168.) RAGweED. Leaves lobed on each side of the midvein (pinnate). Stem 1 to $6 \mathrm{ft}$. high. A common and troublesome weed in waste places. July-Oct.

\section{XANTHIUM, L.}

Coarse, rough and spiny herbs, with alternate, lobed or conspicuously dentate leaves and small flowers, the pistillate in bur-like heads with hooked prickles, the staminate in rounded heads with a short involucre.

1. X. spinosum, L. (Fig. 4, pl. 168.) Spiny Clotweed. Leaves lance-shaped, deeply lobed on each side of the midvein, under surface and veins above white, at the base of the leaf about three long stiff prickles. Staminate heads above at extremity of branches, fertile heads prickly, in the axils below. Waste grounds. Aug.-Nov.

2. X. strumarium, L. (Fig. 5, pl. 168.) Burweed. Branching, 1 to $6 \mathrm{ft}$. high, not armed with prickles at the leaves. Leaves in general outlino rounded and somewhat triangular, with deep lobes, the borders toothed, heart-shaped at base. Fruit elliptic, armed with stiff prickles and ending with two straight or slightly curved horns. Waste places. (Is perhaps only a variety of $X$. canadense.) Aug.-Oct.

3. X. canadense, Mill. (Fig. 6, pl. 168.) Hedgerog Burweed. Resembles above, but bur much longer and the two horns are curved in and the cxtremity is not divided. Waste places, river banks, etc. Aug.-Oct.

4. X. commune, Britton. Common Clotweed. Leaves broadly eggshaped, more or less lobed. Burs commonly solitary in the axils; prickles slender, hooked at tip and hispid. Northern New York, and westward.

\section{Family V.-COMPOSITAE. Thistle Family}

This is by far the largest family of flowering plants. In the North Eastern United States the plants are nearly all herbs; but in tropical climates some members of the family are trees. The flowers are associated in heads which have the appearance of a single flower, as, for example, the daisy or the aster, in which many small yellowish flowers-florets-are gathered at the center of a group while in nearly all cases a single row of white or colored flowers of a different kind are arranged in a single row about the margin. The groups are subtended by an involucre of bracts which 
resemble a calyx and the florets rest upon a base, the receptacle, which may be flat, convex or concave, and which, when the florets are removed may present a naked surface or may be occupied by bristles or scales or filled with small pits. The individual florets are of two kinds, those which occupy the center of the group and which in some tribes constitute the whole group, are tubular like little blue-bells, the corolla of one piece, with 5 lobes enclosing a style in the center and usually 5 stamens in a ring about it. Below the corolla and stamens is the ovary of a single cell, which produces a single seed. The calyx is not always present, but when present is represented not by the green sepals common in many flowers, but by an aigrette of hairs or bristles, by teeth, awns or scales. The flowers of the periphery, in most of the genera, differ from the central florets in that the corolla is prolonged on one side forming a ray or strap-like nrgan which is conspicuously white or colored. Of this important family not less than 10,000 species are known.

\section{Synopsis of Tribes \\ Receptacle not chaffy}

Florets all of one kind, tubular, the corolla of one piece, regular, 5-pointex. Flowers purple, heads in spreading clusters. Branches of the style long, slender, bristly all over . . . . . . . Tribe 1, Vernoniene Florets all of one kind, with stamens and pistils, the style thickened above, hlunt, not bristly . Tribe 2, Eupatorieate Heads without ray florets (except Inula, which has large ray flowers) Anthers arrow-formed, the basal lobes ertended into tails

Florets mostly of two linds, but in some species all alike, when not all alike the outer, ray, flowers are pistillate. Anthers not tailed, obtuse at base; receptacle naked. Branches of the style flat, prolonged into a lance-shaped appendage. Bracts of the involuere decirledly overlapping . . . . . . . . . . T'ribe 3, Astereae

Florets as in Tribe 4, hut hranches of style either with hairy tips or the tips terminate bluntly. Bracts of involucre overlapping ......... T'. Tribe 6, Helenteate

Florets of the disk with style the hranches of which are provided with a tuft of hairs. Aigrotte of soft bristles. Tracts of the involucre only slightly, if at all, overlapping . . . . . . . . Tribe 8, Senecioneate 


\section{Receptacle usually chaffy}

Branches of the style provided with a fascicle of soft bristles. Bracts of the involucre herbaceous or leaf-like

- • • • • • • • Tribe 5, II LLIANTIIEAE

Similar to last, but bracts of the involucre dry, scaly and overlapping, in several ranks. Heads with white rays

• • • • • • • • • . Tribe 7, Anthemidene

Florets all tubular and perfect (i. e. with both stamens and pistils). Anthers prolonged above into long appendages at the tips and below into tails. . . Tribe 9, Crnareat

\section{Artificial Table of Genera According to Tribes}

\section{Tribe 1, Vernonieae}

Leaves alternate. Flowers all alike, purple; style with long hairy branches; aigrette double.

Flower heads not surrounded by a sub-involuere . Vernonia

Flower heads surrounded by a sub-involucre . . Elephantopus

\section{TRIBE 2, Eupatorieae}

Leaves opposite or alternate. Branches of style obtuse, fruit 3 - to 5-angled.

Leaves opposite.

Erect plants

Eupatorium

Climbing vine

Mikania

Leaves alternate.

Flowers in diffuse clusters. . . . . . . . Kuhnia

Flowers in narrow spikes . . . . . . . . Liatris

Leaves in whorls of 4 . . . . . . . Sclerolepis

\section{Tribe 3, Astereae}

Florets all of one kind

Chondrophora

Flowers all of one kind in individual heads, but pistillate heads on one plant and staminate on another, shrub

Ray flowers yellow (in Solidago bicolor, white).

Heads large, many flowered; aigrette double

Baccharis

Heads small, few flowered; aigrette simple . . . . Solidago

Rays not usually more numerous than the disk flowers.

Rays more numerous than the disk flowers

Erethamia.

Ray flowers white, blue, purple, never yellow, leaves on the stem.

Pappus (aigrette) a single series of bristles (sometimes a few short ones outside the series). 
Bracts of the involucre in 2 to several series.

Rays white, about $\mathbf{5}$

Rays many (6 to 100 )

Aster

Bracts of the involucre in 1 or 2 series only.

Rays longer than the diameter of the disk . . Erigeron

Rays not as long as the disk . . . . . . Leptilon

Pappus (aigrette) distinctly double, one series of long bristles, another, outer, of short ones.

Rays white, leaves lance-shaped

Doellingeria

Rays violet, leaves linear . . . . . . . Ionactis

Pappus a few scales and about 4 hairs, fruit flattened and winged

Boltonia

\section{TrIBE 4, Inuleae}

Heads without ray florets except Inula. Anthers arrow-formed, the basal lobes prolonged into tails.

Heads of flowers large with yellow rays . . . . . . . Inula

Heads of flowers rayless.

Receptacle chaffy

Gifola

Receptacle not chafiy.

Plant not woolly

Pluchea

Plants woolly.

Staminate flowers on one plant, pistillate on another (dioecious).

Bristles of the aigrette of staminate flowers 'enlarged and thickened above, leaves in a cluster at base, stem leaves inconspicuous

Antennaria

Bristles of the staminate flowers not thickened above, leaves of stem linear . . . Anaphalis

Stamens and pistils in same flower, leaves of stem not linear

Gnaphalium

\section{Tribe 5, Heliantheae}

Flower heads with ray flowers. Inwolucre leaf-like or herbaceous. Receptacle chaffy. Aigrette not hair-like, sometimes none. Anther not tailed at base.

Ray flowers with pistils only, but producing fruit. Disk flowers with stamens and pistils, but with no fruit.

Ray flowers in a single series . . . . . . . . Polymnia

Ray flowers in 2 or more series . . . . . . . . Silphium

Both ray and disk flowers with fruit.

Ray flowers remaining on the fruit when mature . Heliopsis

Ray flowers falling when mature.

Aigrette represented by a number of scales.

Airrette absent or of one or two seales. Tays very short Eclipta

Ray flowers not fruit producing, reeptacle high, conical or columnar. 
Fruit of disk flowers 4-sided, without margins . Rudbeckia

Fruit of disk flowers flat, with margins . . . . Ratibida

Ray flowers not fruit-producing, receptacle flat or convex, not high.

Leaves opposite . . . . . . . . . . . Helianthus

Leaves (in our species) alternate . . . . . . Verbesina

Aigrette of 2 or more scales, barbed upward . . Coreopsis

Aigrette of 2 or more scales, or teeth barbed downward Bidens

\section{Tribe 6, Helenieae}

Similar to Tribe 5, but receptacle is not chaffy

Helenium

\section{TRIBE 7, Anthemideae}

The scales of the involucre more or less dry, membraneous.

Heads with ray flowers which are white, or without ray flowers. Leaves alternate.

Heads with white ray flowers.

Receptacle chaffy.

Heads bell-shaped, small . . . . . . Achillea

Heads half-round, rather large . . . . . Anthemis

Receptacle not chafry.

Receptacle flat or nearly so . . . . Chrysanthemum

Receptacle conical . . . . . . . . Matricaria

Heads without ray flowers.

Heads in broad diffuse flattened clusters . . Tanacetum

Heads in narrow elongated clusters. . . . Artemisia

\section{Tribe 8, Senecioneae}

Heads with or without ray flowers. Bracts of the involucre scarcely overlapping. Aigrette of soft bristles. Receptacle naked. Anthers without tails.

Leaves all basal.

Heads solitary . . . . . . . . . . . Tussilago

Heads in clusters. . . . . . . . . . Petasites

Leaves opposite.

Margins of leaves wavy . . . . . . . . . . Arnica

Miargins of leaves with prominent teeth . . . Erechtites

Leaves alternate,

Leaves broad, rounded or kidney-shaped . . . Mesadenia

Leaves triangular . . . . . . . . . . . Synosma

Leaves spatula-formed, with or without deep lobes, or eggshaped . . . . . . . . . . . Senecio

\section{Tribe 9, Cynareae}

Flower heads large, showy, but without ray flowers; bracts of involuere overlapping. Anthers with long appendages both at tip and base. Leaved alternate. Aigrette bristly. 
Leaves very large, broad with smooth margins

Arctium

Leaves armed with prickles.

Receptacle not bristly nor chaffy . . . . Onopordum

Receptacle bristly.

Flowers purple . . . . . . . . Carduus

Flowers yellow . . . . . . . . Cnicus

Leaves lance-shaped or deeply lobed, not armed with prickles

I. VERNONIA, Schreb.

Coarse erect herbs, with leafy stems and flower heads in diffuse clusters. Leaves alternate. Heads with tubular flowers only (no rays); purple, pink or white. Bracts of the involucre overlapping in several series. Receptacle naked, flat. Corolla tubular, 5-lobed, regular. Anthers narrow-formed at the base, without tails. Aigrette of 2 series, the inner series of soft hairy bristles, the outer of scales or stout bristles.

Some or all of the involucre bracts with bristle-like tips . . . V. noveboraccnsis None of the bracts with bristle-like tips.

Lower leaves egg. or pear-shaped . . . . . . . . . $V$. glanca Lower leaves lance-shaped..$\div \div$. $\div$ V. altissima

1. V. noveboracensis, (L.) Willd. (Fig. 1, pl. 169.) Iron W'Een. Plant rather rough, tall (3 to $9 \mathrm{ft}$. high), with alternate lance-shaped leaves with quite low teeth at margins, tapering to a short leaf-stalk. Heads numerous, on stems, with overlapping seales and 20 to 30 purple tubular (rarely white) flowers. Low grounds, Mass., westward and southward. July-Sept.

2. V. glauca, (L.) Britton. (Fig. 2, pl. 169.) Brond-Leaved IroxWEED. Plant slender, 2 to $5 \mathrm{ft}$. high, not hairy or only slightly so. Leaves thin, the lower broadly egg-shaped, sharply toothed, acute at apex, 4 to 7 in. long; the upper leaves narrower and finely toothed. Flower heads in a broad loose cluster. Woods, Pennsylvinia and southward. Aug.Sept.

3. V. altissima, Nutt. (Fig. 3, pl. 169.) Tald IroN-Weed. ( $\nabla . g i$ gantca, (Walt.) Britton.) Plant slender, 5 to $10 \mathrm{ft}$. high, not hairy or only slightly so. Leaves thin, lanee-shaped, 4 to $12 \mathrm{in.}$ long, fincly tootherl. Flower heids in a broad nearly flat cluster. Moist soil, Pennsylvania and southward. July-Sept.

\section{ELEPHANTOPUS, L.}

liough herbs, with alternate or basal leaves and heals of flowers sul)tended by large leaf-like bracts. The lieads containing fow (2 to 5) flowers, which are tubular, 5-cleft, with no ray flowers. Aigrette of stout bristles.

1. E. carolinianus, Willd. (Fig. 4, pl. 169.) Ermpinant's Foot. Ereet, 1 to $3 \mathrm{ft}$. high, somewhat hairy. Stem leafy. Leaves oval to inversely egreshaped, thin, narrowing to a leaf-stalk. Flowers purple, bracts large. Southern part of our area. Aug.-Sept.

2. E. nudatus, A. Gray. (Fig. 5, pl. 169.) Smootmisir Elemant'spoot. Strm with one or two small leaves or more. I3asal leaves oblong or inversely lance-shaped. Delaware and southward. Aug.-Sept. 

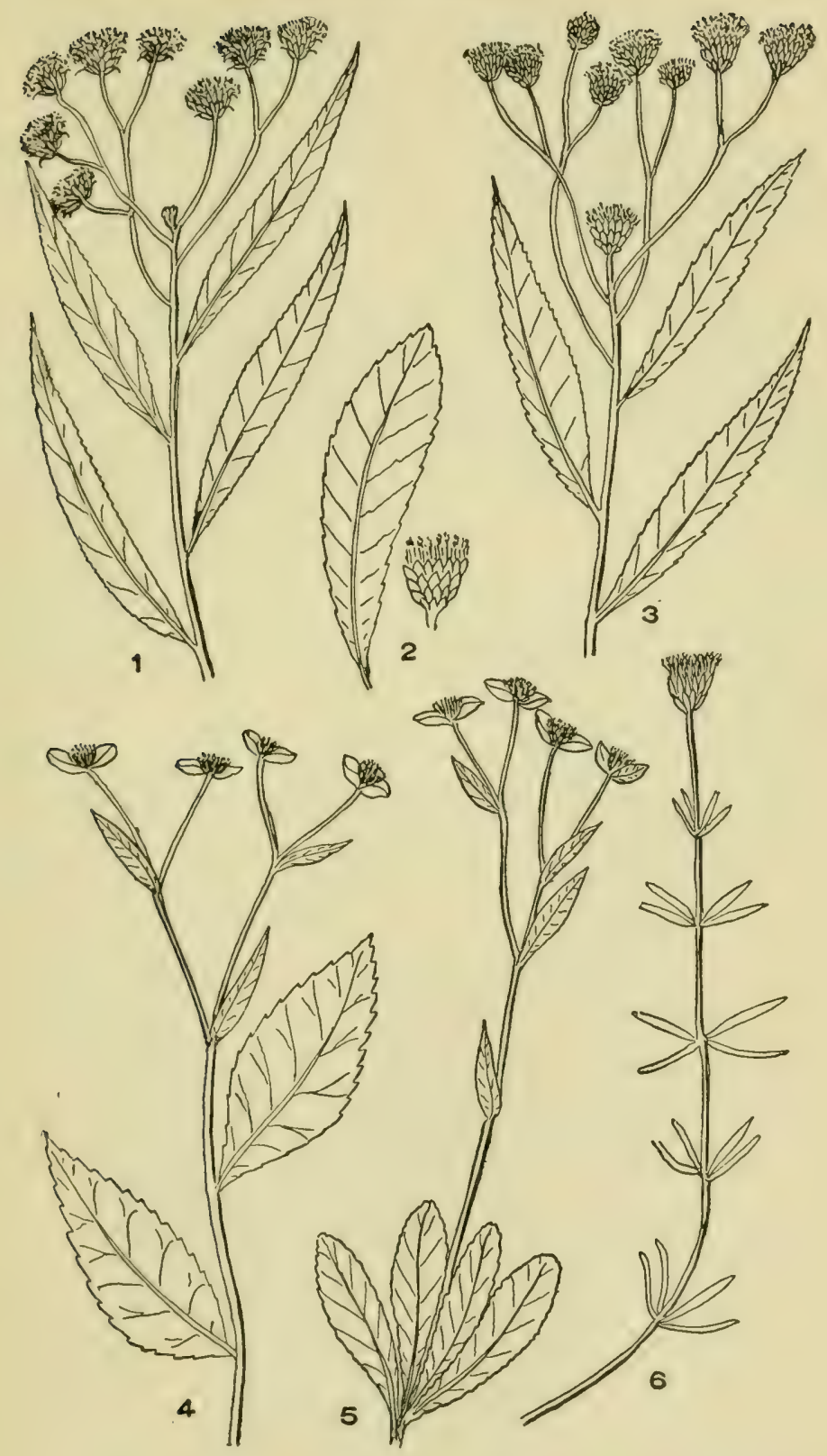

Plate 169

1. Vernonia noveboracensis. 2. V. glauea. 3. V. altissima. 4. Elephantopus carolinianus. 5. E. nudatus. 6. Sclerolepis uniflora. 


\section{SCLEROLEPIS, Cass.}

Slender herbs, growing in water with linear leaves in whorls of 4 to 6 and with terminal heads of small purplish flowers, all tubular.

S. uniflora, (Walt.) Porter. (Fig. 6, pl. 169.) Scleroleris. Stem simple, 1 to $2 \mathrm{ft}$. long, reclining at base. Leaves linear, 1 to $1 \mathrm{in}$. long, in whorls of $4 \mathrm{~s}$ or $6 \mathrm{~s}$. Growing in shallow pools in southern part of our area. July-Sept.

\section{EUPATORIUM, L.}

Erect branching herbs, sometimes sprinkled with resinous dots, with opposite or whorled leaves (rarely alternate) and with flower heads in diffuse clusters. Flowers of the head all tubular, white, blue or purple. Involucre of overlapping bracts in several series. Beyond the tube of the corolla the style extends generally to a considerable extent, equal to the length of the tube or more or less. Aigrette of many soft bristles in a single row.

Leaves in whorls of 3 to 6 .

Plant rough hairy .......... E. maculatum

Plant smooth, scarcely hairy . . . . . . . . . . E. purpureum Leaves opposite.

The opposite leaves clasping the stem.

Stem apparently passing through the united leaves . E. perfoliatum

The leaves not completely united at base . . . . . E. resinosum

The opposite leaves not clasping the stem.

Leaves on distinct leaf-stalks.

Flowers white.

Leaves 3 to 6 in. long . . E. ageratoides

Leaves I to $2 \frac{1}{2} \mathrm{in}$. long : . : . . : E. aromaticum Flowers blue .......... E. coclestinum

Leaves without distinct leaf-stalks (sessile); flowers all white.

Leaves lance-shaped, borders toothed.

Tapering at base, . . . . . . . . E. leucolepis

Rounded or heart-shaped at base . . ' E. scssilifolium

Leaves lance-shaped, toothed at the apex $\because .{ }^{\circ}$. altissimum

Leaves egg-shaped.

Twice as long as wide . . . . . . . . E. pubescens

Not twice as long as wide.

Plant somewhat downy . . . . . . . E. album

Leaves Plant densely hairy . . . . . . E. verbenacfolium

Leaves linear . . * * * . . . E. hyssopifolitm

Leaves nearly round, about as broad as long : E. rotundifolium

1. E. maculatum, I. (Fig. 12, pl. 171.) Spotted Joe-pre WEed. Sitem simple or hanelyed, 2 to $6 \mathrm{ft}$. high, often spotted with purple, rough. Leaves in whorls of 4 to 6 , egres-shaped to lanee-shaped with eoarse teeth at marerins. Flowers pink or purple. Moist places, New lork and southward. Aug.-Sept.

2. E. purpureum, J. (Fig. 2, pl. 170.) Joe-pye Wred. Trumpet WiEd. fitem :3 to $10 \mathrm{ft}$. high, green or purple, usually smooth. L.eaves in whorls, resembling No. 1, but tecth coarser. Flowers purple, pink or oceasionally nearly white. Moist soil, throughout our range. Augr.sept.

3. E. Ieucolepis, Torry and Firay. (Fig. 2. pl. 171.) Winte-nR.icted 'I'norovghwort. Stem little or not at all branched, 1 to $2 \mathrm{ft}$. high. Jeaves olposite, narrow lance-shaperl, tapering at each end, margins entire or with quite low teeth, without leaf-stalks. Flower heads in a broad umbel-like cluster; flowers white. Moist places in southern part of our area. Sept.-Nov, 

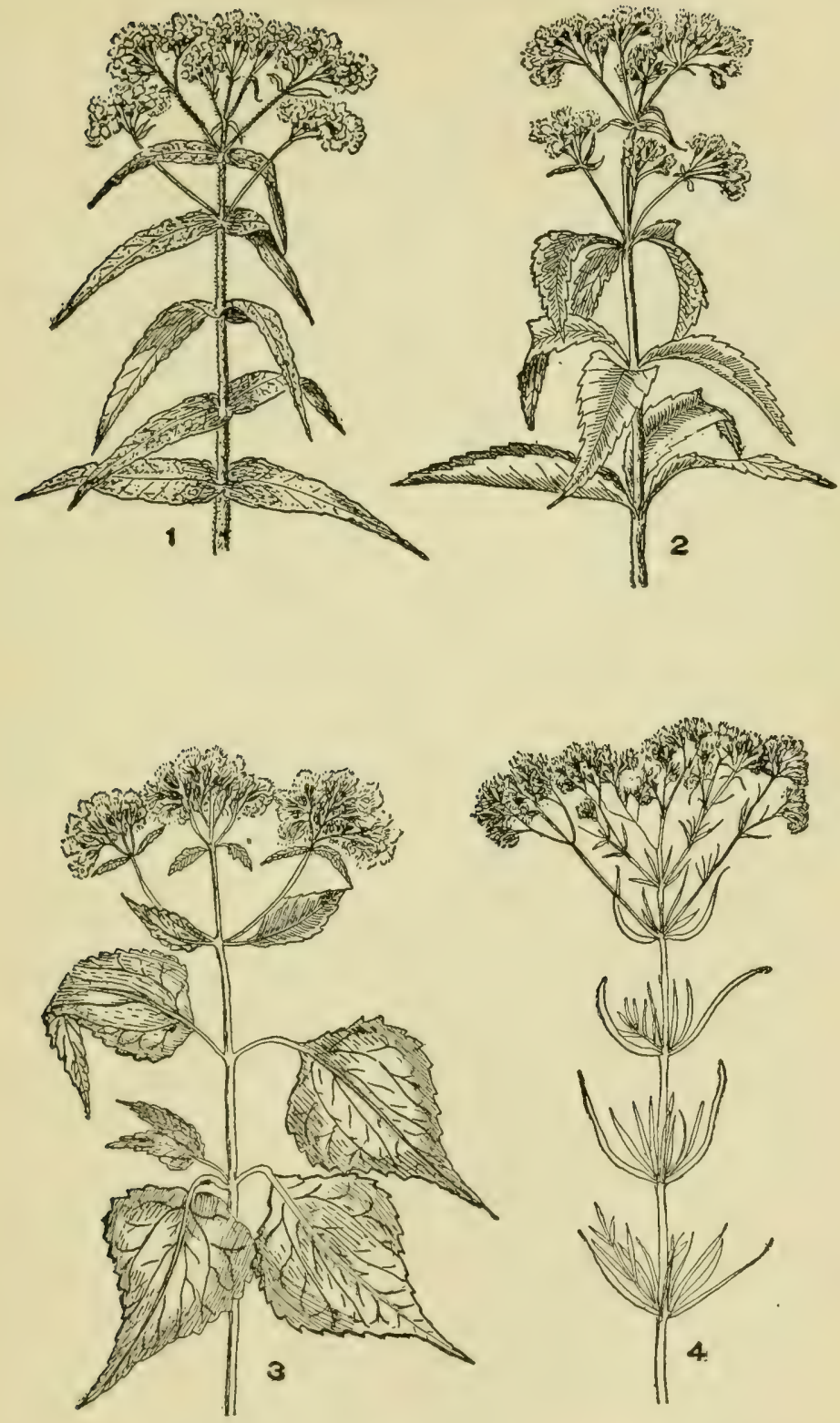

Plate 170

1. Eupatorium perfoliatum. 2. E. purpureum. 3. E. ageratoides. 4. E. hyssopifolium. 
4. E. album, L. (Fig. 1, pl. 171.) White Trrorougnwort. Stem simple below, branched above, 1 to $3 \mathrm{ft}$. high. Leaves opposite, eggshaped or oblong, without leaf-stalks, coarsely toothed. Whole plant somewhat rough hairy. Flowers white. Southern part of our area. Aug.Sept.

5. E. hyssopifolium, L. (Fig. 4, pl. 170.) Hrssop-Leaved Trorovanwort. Stem simple below, branched above. Leaves narrowly linear, opposite, the upper perhaps alternate, other leafy branches starting at the axils give appearance of whorls of leaves. Plant rather rough hairy. Flowers white. Dry fields, Mass., and southward. Aug.-Sept.

6. E. altissimum, L. (Fig. 4, pl 171.) TAl, Thorougnwort. Stem 3 to $6 \mathrm{ft}$. high, with fine down, much branched above. Leaves lanceshaped, tapering at each cnd, conspicuously 3-nerved, the borders toothed above the middle, or the upper leaves without teeth, 2 to $5 \mathrm{in}$. long, $\frac{1}{2} \mathrm{in}$. or more broad. Flowers in a broad umbel-like cluster, white. Pennsylvania and southward. Sept.-Oct.

7. E. sessilifolium, L. (Fig. 5, pl. 171.) Upland Boneset. Plant smooth, 2 to $6 \mathrm{ft}$. high, nearly smooth. Leaves opposite, lance-shaped, sharply toothed at borders, rounded or heart-shaped at base, nearly clasping the stem, 3 to 6 in. long. Flower heads numerous in a broad umbellike cluster, flowers white. Dry woods, eastern part of our area. Aug.Oct.

8. E. verbenaefolium, Michx. (Fig. 6, pl. 171.) Rougir TmonougirworT. Stem 3 to $8 \mathrm{ft}$. high, branched above. Leaves opposite, without leaf-stalks, egg-shaped, margins toothed; the whole plant very rough hairy. Flower heads in a broad nearly flat cluster, flowers white. Moist soil, Mass., and southward. July-Sept.

9. E. rotundifolium, L. (Fig. 11, pl. 171.) ROUND-LEAvED Trorougnwort. Stem 1 to $3 \mathrm{ft}$. high; leaves opposite without leaf-stalks, roundish, about as broad as long; margins toothed; the whole plant rough hairy. Flowers white. Southern part of our area. July-Sept.

10. E. pubescens, Muhl. (Fig. 7, pl. 171.) Hairy Tronougrmont. Plant about $2 \mathrm{ft}$. high, downy or hairy. Leaves opposite, without leafstalks, egro-shaped or lance-shaped, rounded at base and tapering to a slender point at apex. Teeth prominent. Flowers white. Dry soil, New England and southward. July-Sept.

11. E. perfoliatum, J. (Fig. 1, pl. 170.) Bonfeset. TironougirworT. Stem simple below, branched above, 2 to $5 \mathrm{ft}$. hichl, downy. Leaves opposite and secmingly continuous, the stem appearing to penetrate the double-pointed leaf (perfoliate). Flower heals in a broad flat cluster, the whole plant usually with a whitish appearance. Flowers white. In wet places, throughout our area. July-Sept.

12. E. resinosum, 'Torry. (Fig. 8, pl. 171.) RESIN TBONEseT. silnder, 2 to $3 \mathrm{ft}$. high, velvety downy. Leaves opposite, narrow lanceshaperl, tapering at each end, without leaf-stalks. Flowers white. Wet places. Southern part of our area. Aug.-Sept.

13. E. ageratoides, L. (Fig. 3, pl. 170.) Wurte S.xicle. Stem 

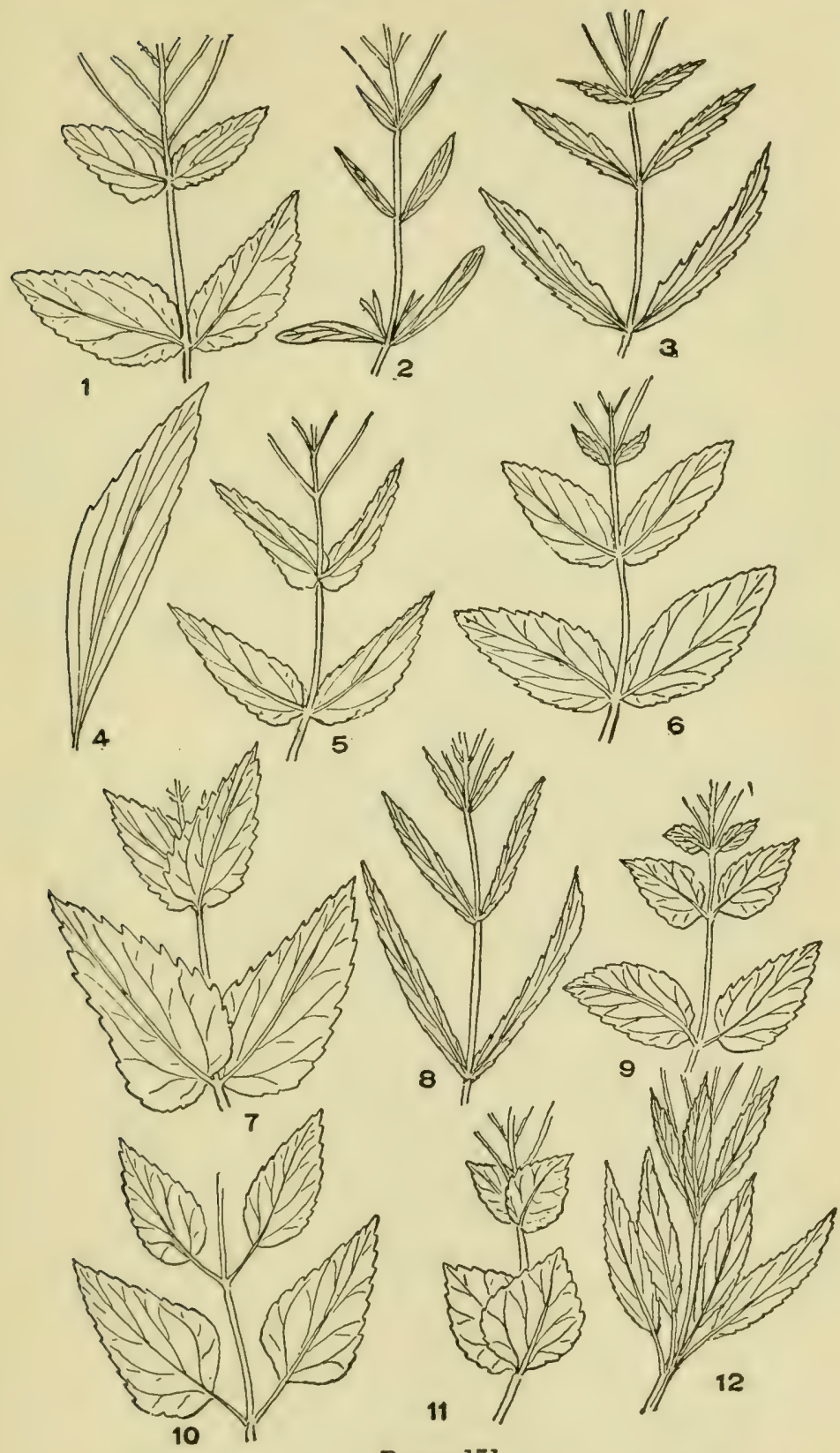

Plate 171

Leaf forms of Eupatorium. 1. E. album. 2. E. leucolepis. 3. E. Torreyanum. 4. E. altissimum. 5. E. sessilifolium. 6. E. verbenaefolium. 7. E. pubescens. 8. E. resinosum. 9. E. aromaticum. 10. E. coelestinum. 11. E. rotundifolium. 12. E. maculatum. 
I to $4 \mathrm{ft}$. high, smooth, branched. Leaves opposite on long, slender leafstalks, egg-shaped, toothed. Flowers conspicuously white. Rich woods, throughout our range. July-Nov.

14. E. aromaticum, L. (Fig. 9, pl. 171.) Wirte Sлакевоот. Stem simple below, branched above, 1 to $2 \mathrm{ft}$. high. Leaves opposite, on very short leaf-stalks, egg-shaped, toothed at margins. Flowers white. Plant not aromatic. Dry soil, Mass., and southward. Aug.-Oct.

15. E. coelestinum, L. (Fig. 10, pl. 171.) Mist Flower. Stem 1 to $3 \mathrm{ft}$. high, branched above, downy. Leaves opposite, egg-shaped to nearly triangular on short leaf-stalks. Flowers blue. Moist soil, southern part of our area. Aug.-Oct.

\section{MIKANIA, Willd. (Willughbaeya, Neck.)}

Our only species a twining vine with opposite leaves and flowers in heads, all tubular, resembling Eupatorium. Heads 4-flowered, flowers white. Receptacle naked. Anthers not tailed. Involuere of 4 narrow bracts. Style branches about as long as the tubular flower. Aigrette of numerous hair-like bristles.

M. scandens, Willd. (Fig. 1, pl. 172.) Climbixg Boneset. Smooth, twining over bushes, 5 to $15 \mathrm{ft}$. long. Leaves opposite, broad heart-shaped at base, tapering to slender point at apex, on leaf-stem half as long as the blade. Swamps, moist soil. July-Sept.

\section{KUHNIA, L.}

Resembles Eupatorium, but leaves are alternate. Heads of flowers with out ray flowers, all flowers being tubular, white or purplish, the heads in diffuse clusters. Involucre of several series of bracts, overlapping. Anthers not tailed; style branches slender, not hairy. Aigrette a single row of plumose bristles.

K. eupatorioides, L. (Fig. 2, pl. 172.) FALSE Boxeset. Stem erect, branching above, 1 to $3 \mathrm{ft}$. high. Leaves narrowly lance-shaped with low notches at margins. Teads of flowers numerous, eylindric, the flowrs white. Dry soil, southern section of our area. Aug.-Sept.

\section{LIATRIS, Schreb. (Lacinaria, Hill.)}

Perennial herbs, arising from a rounded tuber, with narrow, lanceshaped, alternate leaves and with heads of flowers (in our species) in narrow spikes. Flowers all tubular, purple, in rounded heads. Seales of the involucre overlapping, in several series. Receptacle flat or concave, naked. Aigrette of numerous bristles which are feathery or simple.

1. L. scariosa, (L.) Hill. (Fig. 4, pl. 172.) Button SNakeroot. liesembles No. 1, but seales of involuere are romded at apex in several overlapping series. Flower heads with many purple flowers. Dry soil, throughout our area. Aug.-Sept.

2. L. spicata, (L.) Kuntze. (Fig. 3, pl. 172.) Dense Button S.Akвmot. Stem 2 to $6 \mathrm{ft}$. hight, simple. Teaves narrow, linear. Filowers densely crowded on the spike, each head having from 5 to lis hlue purple llowers. Moist soil, Mass, westward and southward. Aug.-Oct. 
THISTLE FAMILY

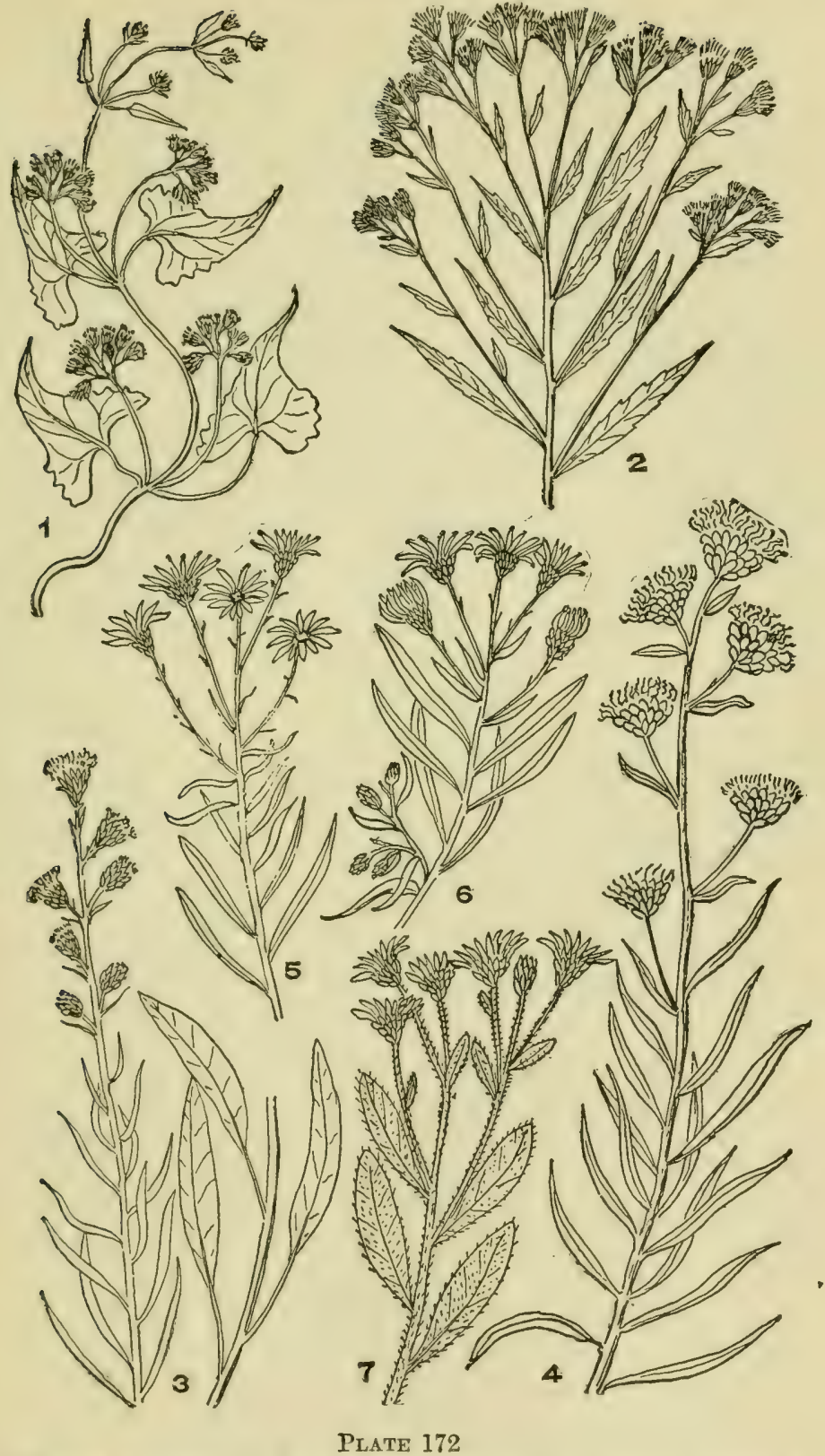

1. Mikania scandens. 2. Iuhnia eupatorioides. 3. Liatris spicata. 4. L. seariosa. 5. Chrysopsis graminifolia. 6. C. falcata. 7. C. Mariana. 


\section{CHRYSOPSIS, Nutt.}

Perennial herbs, with alternate leaves and clusters of heads with yellow tubular and ray tlowers. Involucre of several overlapping series of scales. Receptacle flat. liay flowers with pistils, no stamens; the flowers of the disk generally with both stamens and pistils. Aigrette double, the inner series of rough bristles, the outer of scales or short bristles.

Leaves linear, smooth, or hairy . . . . . . . . . . . C. falcata

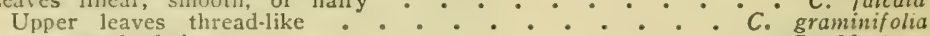

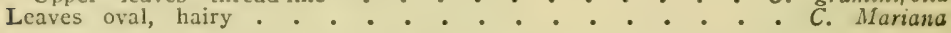

1. C. falcata, Ell. (Fig. 6, pl. 172.) Sickle-Leaved Goldex Aster. Stem branched above, 4 to $12 \mathrm{in}$. high, when young woolly above. Leaves narrowly linear with entire margins. Flower heads nearly $\frac{1}{2} \mathrm{in}$. broad, in a diffuse cluster. Sandy soil, eastern section of our area. July-Aug.

2. C. graminifolia, (Michx.) Nutt. (Fig. 5, pl. 172.) GrassLEAved Goldex Aster. Resembles $C$. fulcata, but the down (pubescence) of this species is silvery, while that of $C$. falcata is woolly. Stem 1 to $3 \mathrm{ft}$. high, slender, branching; leaves linear, the basal ones 3 to $4 \mathrm{in.}$ long. Heads several or many. Delaware, and south. Aug.-Oct.

3. C. Mariana, Nutt. (Fig. 7, pl. 172.) Marrland Golden Aster. Stem branched ahove, 4 to $12 \mathrm{in.} \mathrm{high,} \mathrm{when} \mathrm{young} \mathrm{woolly} \mathrm{above.} \mathrm{Leaves}$ oval, without leaf-stalks, 1 to 2 in. long. Dry soil, southern part of our area. Aug.-Sept.

\section{CHONDROPHORA, Raf. (Bigelowia, DC.)}

Stiff herbs, mostly western, with alternate leaves withont lobes or teeth and with yellow tubular flowers in heads of 3 or 4 , in diffuse terminal clusters. Bracts of the involucre yellowish, in closely overlapping series. Receptacle small, flat, naked. Anthers obtuse at the base. Aigrette of a single row of hair-like unequal bristles.

C. nudata, (Michx.) Britton. RAYless Goldexrod. Stem 1 to $2 \frac{1}{2}$ ft. high, simple below, branching above. Lower leaves clustered, lance- or spatula-shaped; upper leaves remote, small, leaving the stem nearly naked. Heads of flowers small in a flat-topped cluster. Southern part of our area. Aug.-Oct.

\section{I0. SOLIDAGO, L.}

Perennial herhs, with mostly sleuder simple stems and alternate leaves and with numerous or few small heads of flowers, hoth ray and tubular, mostly yellow, rarely white, in terminal clusters of various forms. liay flowers 1 to many, all pistillate. Jisk flowers tubular, nearly all with both stamens and pistils. Involuere of several series of overlapping bracts. Riceptacle small, not chafly. Aigrette of numerous rough bristles, in 1 or 2 series.

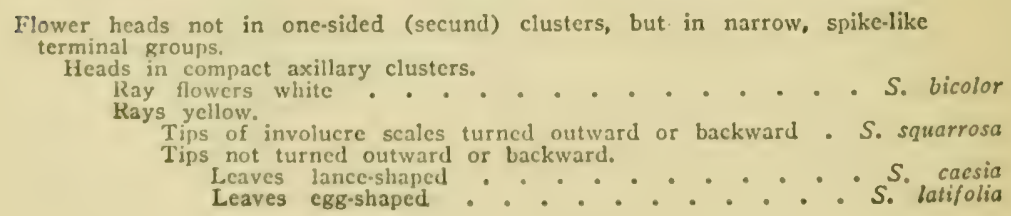



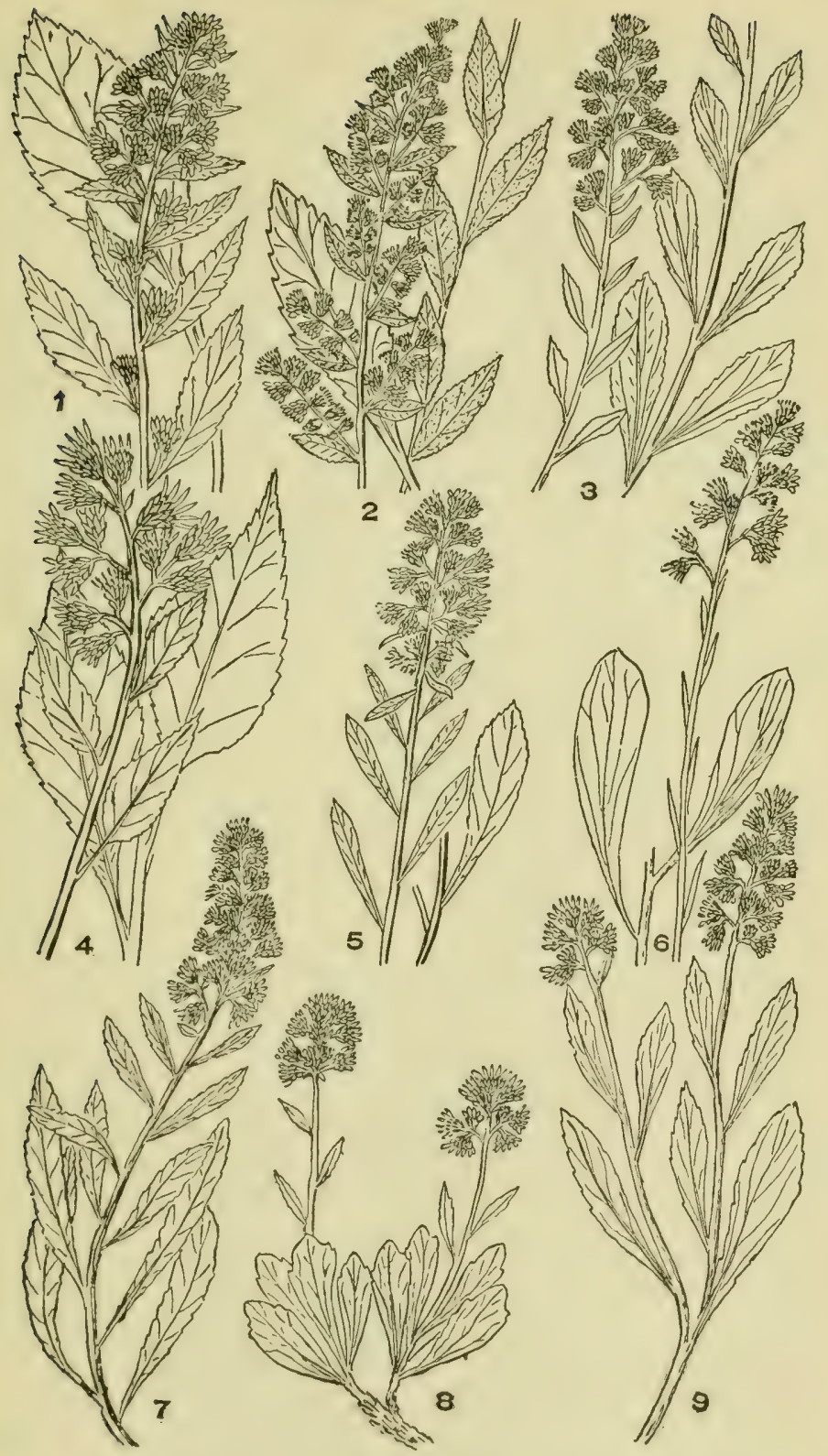

Plate 173

1. Solidago squarrosa. 2. S. hispicla. 3. S. erecta. 4. S. macrophylla, Var. thyrsoides. 5. S. puberula. 6. S. stricta. 7. S. Purshii. 8. S. alpestris. 9. S. Virgaurea. 
Heads in more or less dense spike-like clusters, but not compact groups in the axils.

Whole plant densely hairy .

S. lispida

Plant smooth or slightly downy.

Basal leaves spatula-formed, stem leaves lance-shaped.

Heads numerous, crowded.

Stem leaves sharply toothed . . . . . . S. puberula

Stem leaves lance-shaped, nearly entire .... S. erecta

IIeads iew, not crowded.......... S. Purshii

Basal leaves oblong, stem leaves very small, linear . S. stricta

Leaves all egg-shaped .......... S. macrophylla

Leaves all lance-shaped.

Clusters of heads crowded, numerous.

The branches of the cluster pressed toward the main

axis stem..... S. uliginosa

The branches of the cluster spreading . . . S. speciosa Clusters of few heads.

Plant I to $2 \mathrm{ft}$. high. . . . . . . S. Virgaurea

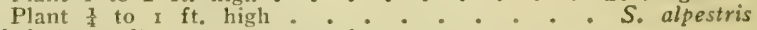

Heads in one-sided (secund), usually large clusters.

Plant with thick fleshy leaves, growing at sea-side . S. sempervirens Leaves not fleshy.

Leaves not 3 -veined.

Leaf margins entire

Leaf margins toothed.

Leaves broad or narrow, lance-shaped, the lower taper-

S. odora ing to a long leaf-stalk. Whole plant rough hairy $S$. rugosa

Leaves lance-shaped, rounded at base, no leaf-stalk. Stem hairy . . . . . S. fistulosa Stem smooth : : - . - : : S. Elliottii

Basal leaves oval to elliptic, tapering to a long leaf-stalk. Leaves rough above . . . . . . . S. patula Leaves smooth.

Coarsely dentate . . . . . . S. ulmifolia Finely dentate........ S. neglecta

Leaves all lance-shaped, clusters of few heads, and heads

with about 3 rays....... S. uniligulata

Leaves all lance-shaped, heads many, rays numerous,

lower leaves toothed, upper entire... . . S. juncea

As above, but all leaves toothed . : : : S. arguta

Leaves 3-veined.

Leaves lance-shaped.

Stem smooth above.......... S. serotina

Stem rough above, smooth below . . . . S. canadensis

Heads in large nearly flat clusters.

Lower leaves broad lance-shaped, upper egg-shaped, without leaf stalks

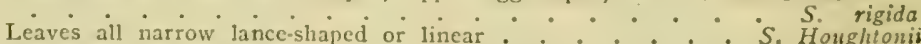

1. S. squarrosa, Muhl. (Fig. 1, pl. 173.) Stout Ragaed GoldeNrob). Stem simple, 2 to $5 \mathrm{ft}$. high. Leaves large, the upper oblong, coarsely touthed, tapering to moderatcly long leaf-stalls; the leaves inversely ecrgshapred to oval, narrowed to a marginal leaf-stalk. II ads numerous, in compact axillary clusters, each head 15- to 25-flowered, seales of the involucre recurved. Rocky soil, our whole range. Aug,-Oct.

2. S. caesia, L. (Fig. 5, pl. 174.) Blue-Stemmed Goldexrod. Wristi (iondixnon). Stem 1 to $3 \mathrm{ft}$. high, smooth, round, usually bluish or purple, branching above. Leatves narrow lance-shaped, sharply toothed, tilperingr at ach ond, without leaf-stalks. Heads in short axillary elusters. Woods and thickets, throughout our range. Aug.-Oct.

3. S. latifolia, J. (Fig. 4, pl. 174.) Brodn-l.eaves Goldenrod. Stem

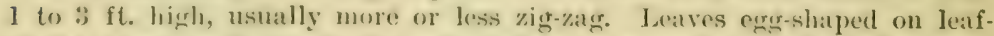
stalks, tapering to a slemeler point at apex, sharply tootherd. Heads in axillary chusters; rays bright yellow. Lich woods, throughout our area. July-Sept. 
4. S. bicolor, I. (Fig. 3, pl. 174.) White Goldexrod. Stem $\frac{1}{2}$ to $4 \mathrm{ft}$. high, usually gray with soft hairs as are the leaves. Basal leaves elliptic to inversely egg-shaped on long leaf-stalks, with low teeth at margins, upper elliptic, small. Flowers axillary in crowded clusters, white. Dry soil, common. July-Sept.

5. S. hispida, Muhl. (Fig. 2, pl. 173.) Hairy Goldenrod. Resembles No. 4, but rays are yellow. Diy soil, somewhat common. Aug.Oct.

6. S. erecta, Pursh. (Fig. 3, pl. 173.) Slender Goldenrod. Closely resembles the two preceding species, but is nearly destitute of hairs, while the others aro very hairy. Rays yellow. Dry soil, southern part of our area.

7. S. macrophylla, Pursh. (Fig. 4, pl. 173.) Large-leaved GordennoD. Stem $\frac{1}{2}$ to $4 \mathrm{ft}$. high, striped, with few or no hairs. Leaves eggshaped, tapering at each end, 3 to 5 in. long, on rather long leaf-stalks, margins sharply toothed; the upper leaves smaller and changing to lanceshaped. Flower heads large ( $\frac{1}{2} \mathrm{in.} \mathrm{high)} \mathrm{in} \mathrm{a} \mathrm{loose} \mathrm{spike.} \mathrm{Rays} \mathrm{yellow,}$ conspicuous. Woods, Catskill Mountains, and northward. July-Sept.

8. S. puberula, Nutt. (Fig. 5, pl. 173.) Dowry Goldexrod. Stem slender, 1 to $3 \mathrm{ft}$. high, with a thin down or none. Lower leaves spatulaformed, tapering to a long leaf-stalk, sharply toothed. Heads many in a narrow spike-like cluster; rays yellow. Sandy soil, northern New York, and southward. Aug.-Sept.

9. S. stricta, Ait. (Fig. 6, pl. 173.) Wand-Like Goldenrod. Stem slender, erect, 2 to $8 \mathrm{ft}$. high; the whole plant smooth. Stem leaves are reduced almost to scales, which are lance-shaped to oval, applied close to the stem. Lower leaves oblong or elliptic, without teeth or notches at margins, 3 to 8 in. long and on long leaf-stalks. Flower heads crowded in a narrow spike-like terminal cluster. Pine barrens, New Jersey, and southward. Aug.-Oct.

10. S. uliginosa, Nutt. (Fig. 1, pl. 175.) Bog Goldenron. Stem simple, erect, smooth, 2 to $3 \mathrm{ft}$. high. Lower leaves broad lance-shaped on long leaf-stalks, upper narrow lanee-shaped without leaf-stalks, margins with low teeth. Flower heads in a dense narrow cluster, the short stems of the heads tending in toward the stem. Swamps, throughout most of our area. Aug.-Sept.

11. S. speciosa, Nutt. (Fig. 3, pl. 175.) Sirowr Goldenrod. Stem stout, 3 to $7 \mathrm{ft}$. high, smooth. Leaves smooth with low toothed margins, oval or egg-shaped, the lower tapering to long leaf-stalks, the blade 4 to 10 in. long. Upper leaves lance-shaped, without leaf-stalks. Flower heads in a broad pyramidal eluster, the branches bearing the heads divering from the stem. Rays yellow. A tall and conspicuous species. Rich soil, throughout our range. Aug.-Oct.

12. S. Purshii, Porter. (Fig. 7, pl. 173.) River-bank Goldenrod. Stem $\frac{1}{2}$ to $1 \frac{1}{2} \mathrm{ft}$. high, simple, smooth. Leaves lanee-shaped, the lower toothed, 2 to 6 in. long, the upper entire. Heads few in a simple rather elongated cluster. River banks, most of our area. July-Sept.

13. S. alpestris, Wald and Kit. (Fig. 8, pl. 173.) AlPine GoldewROD. Stems simple, often in tufts; 3 to 12 in. high. Basal leaves spatula- 
formed, sparingly toothed, a principal tooth on each side at the upper fourth, on leaf-stalks, the upper lance-shaped toothed, without leaf-stalks, remote. Heads rather large, few in a terminal cluster or one or more in tho upper axils. Summits of White and Adirondack Mountains. Aug.Sept.

14. S. Virgaurea, L. (Fig. 9, p1. 173.) European Goldexrod. Similar to No. 13, but taller, stouter and with more heads. Leaves less sparingly toothed. On high mounatins of the Adirondack and White Mountain groups. Aug.-Sept.

15. S. sempervirens, L. (Fig. 2, pl. 176.) Sel-side Goldexrod. Stem stout, usually simple, 2 to $8 \mathrm{ft}$. high. Leaves thick, lance-shaped, without teeth at margins, 3 -veined, crowded along the stem. Heads in a dense, somewhat one-sided, elongated eluster, each head containing from 25 to 30 flowers, about $\frac{1}{3}$ of which are ray flowers. Found along sea beaches. Aug.-Nov.

16. S. odora, Ait. (Fig. 5, pl. 175.) SwEET Goldenrod. Stem round, not ridged, slender, smooth or nearly so, 2 to $4 \mathrm{ft}$. high. Leaves very narrowly lance-shaped, without teeth somewhat abrupt at base, slender tapering at apex, sweet scented when bruised. Ileads numerous, small, in a one-sided cluster. Dry soil, Mass., New York, and south. JulySept.

17. S. rugosa, Mill. (Fig. 1, pl. 176.) Tall Mairy Goldenrod. Stem very leafy, rough hairy, 1 to $7 \mathrm{ft}$. high. Leaves oblong lance-shaped to oval or elliptic, very rough, 1 to $4 \mathrm{in}$. long. Heads in a rather dense one-sided cluster Dry soil, western part of our area. July-Nov.

18. S. fistulosa, Mill. Pixe-barnex Goldenrod. Stem 3 to $7 \mathrm{ft}$. high, branched or simple, rough hairy. Leaves without leaf-stalls, oblong-eggshaped to lance-shaped, rough on margins, which are rather remotely toothed. Upper leaves blunt at apex, without teeth at margins. Cluster of heads one-sided, the heads about $\frac{T}{6}$ in. high, with 5 to 10 yellow rays. Pine barrens, New Jersey and southward. Aug.-Oct.

19. S. patula, Muhl. (Fig. 9, pl. 175.) Rougir-Ledved Gordexrod. Stem strongly angled, smooth, 2 to $7 \mathrm{ft}$. high. Leaves ecrir-shaped, the lower on long latestalks, 3 to $16 \mathrm{in}$. long, smooth and veiny beneath and very rongh alowe. Heats rather large, numerous in one-sided cluster. Swamps. Aug.-Oct.

20. S. ulmifolia, Muhl. (Fig. 5, pl. 177.) Tha-taned Gombiriod. sitem smonth, its upper branches lairy, 2 to $4 \mathrm{ft}$. high. Latoves thin, egershitperl, elliptic. shanply pointed at apex, eoarsely toothed, the lower on loner leaf-stallis. Heatis on rather long branches of the eluster of few hranches; rays bright yellow, about 4 in each head. Woods and copses, common. July-Sept.

21. S. Elliottii, Torr. and Gray. (Fig. 7, pl. 175.) EllootT's Goldesmin. Sitem stout, smooth, very leafy, 3 to $6 \mathrm{ft}$. high. Leaves elliptic, oblong or lanee-shaped, firm, 1 to 5 in long, the margins with very low torth, shining abowe. Heads densely erowded on short recurving branches of the onc-sided clustor, which is more or less pyramidal in form. liays 8 to 12 . Swamps near the coast. July-Sept.

22. S. neglecta, T. and 6 : (Fig. 6, pl. 175.) Swam Golmwrod. 
4.

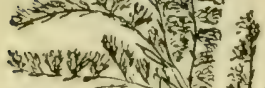
- n
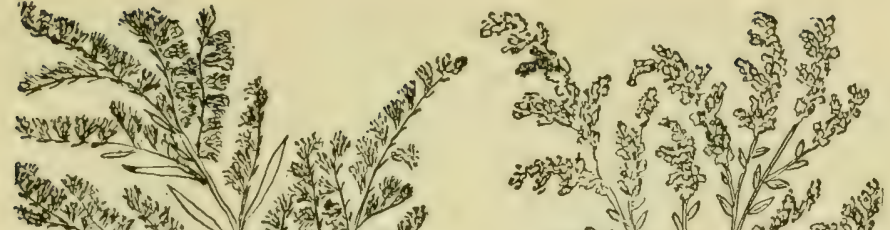
( 1.7) (450)

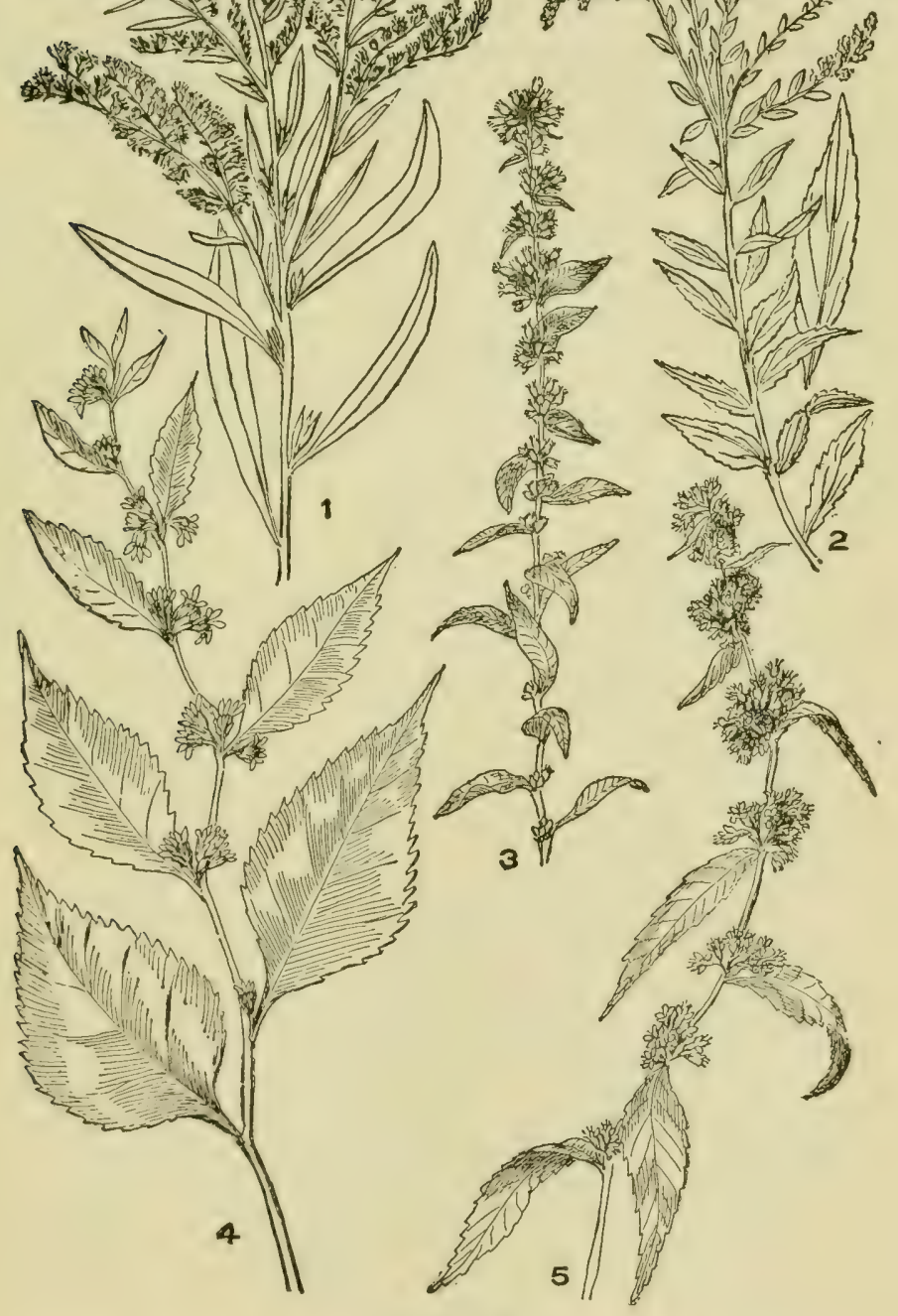

Plate 174

1. Solidago juncea. 2. S. canadensis. 3. S. bicolor. 4. S. latifolia. 5. S. caesia. 
Stem rather stout, 2 to $4 \mathrm{ft}$. high, smooth or somewhat rough above. Basal leaves long, sometimes 12 in., lance-shaped, tapering to a margined leafstalk. Upper leaves smaller, lance-shaped, without leaf-stalks. Heads $\frac{1}{b}$ to + in. high, somewhat in one-sided clusters, rays small, 3 to 8 to a head. Swamps, much of our area. Aug.-Sept.

23. S. uniligulata, (DC.) Porter. (Fig. 4, pl. 175.) FEw-RAYED Goldenrod. Stem stout, smooth, not as leafy as the last three, 2 to $3 \mathrm{ft}$. high. Leaves lance-shaped or oblong-lance-shaped, finely and sharply toothed, the lower tapering to a long leaf-stalk, the upper quite small and narrowly linear or lance-shaped. Cluster of heads short, densely crowded in an elongated somewhat pyramidal but one-sided group. Rays in each head few, 1 to 4. Swamps, Maine to New York, and New Jersey. Aug.-Sept.

24. S. juncea, Ait. (Fig. 1, pl. 174.) EArLy Goldenrod. Stem smooth, 1 to $4 \mathrm{ft}$. high. Leaves smooth, the lower lance-shaped to oval, sharply toothed on long leaf-stalks, the blade 4 to $12 \mathrm{in.} \mathrm{long.} \mathrm{Upper}$ leaves lance-shaped, the uppermost without teetin. Clusters of heads large, one-sided, becoming flattened or drooping. Rays small, 7 to 12 to each head. Dry soil, our area. June-Nov.

25. S. arguta, Ait. (Fig. 8, pl. 175.) Cut-Leaved Goldexrod. Stem angled, smooth, 2 to $4 \mathrm{ft}$. high. Leaves large, thin, coarsely toothed, the basal ones broadly egg-shaped, tapering to long leaf-stalks, the upper lance-shaped, the very highest not toothed. Heads in a spreading onesided cluster. Rays large, 5 to 7 to a head. Rich woods. July-Oct.

26. S. nemoralis, Ait. (Fig. 2, pl. 175.) Gray Goldexrod. Slender, $\frac{1}{2}$ to $2 \mathrm{ft}$. high. Leaves and stem finely and densely downy, giving to the plant an ashy-gray color. Basal and lower leaves spatula-formed or inversely lance-shaped. Upper leaves gradually smaller of similar shape or more lanee-shaped. Heads $\frac{1}{6}$ to $\frac{1}{3}$ in. high, rays 5 to 9. Dry soil, our area. July-Nov.

27. S. serotina, Ait. (Fig. 3, pl. 176.) Lıte Goldenrod. Stem 3 to $8 \mathrm{ft}$. high, stout. Leaves lanec-shaped, three-nerved, sharply toothed, without leaf-stalks, taper pointed at apex, narrowed to base. Ileads in a more or less one-sided cluster, to to in. high, rays 7 to 15 . Our area. Aug.-Oct.

28. S. canadensis, I. (Fig. 2, pl. 174.) CANADA Goldenrol). Stem rough hairy, stout, 2 to $8 \mathrm{ft}$. high. Ieaves lanee-shaped, tapering to a sharp point at apex, and less sharply at base, eoarsely toothed at margins, distinctly 3-veined, 3 to 6 in. long. Ileads small, rays very short in onesided cluster of recurved hranches. Borders of woods and thickets and in fields, very common, known as Yellow Weed. Aug.-Nov.

29. S. rigida, I. (Fig. 4, pl. 177.) Hari)-Leaved Goldexrod. Stem rough and somewhat whitish hoary, 1 to $5 \mathrm{ft}$. high. Leaves thick, rigid, oval or oblong, the lower taperingr to a long leaf-stalk, the upper attached to stem by a broad base. Ileads very numerous in a flattened cluster sometimes slightly one-sided or often spreading on all sides ahout alike. Jeads large, over 30 -flowered; rays 6 to 10 , showy. Dry sandy soil. Auch.Oet.

30. S. ohioensis, Ridkell. (Fig. 6, pl. 177.) Onio Golvexion. 


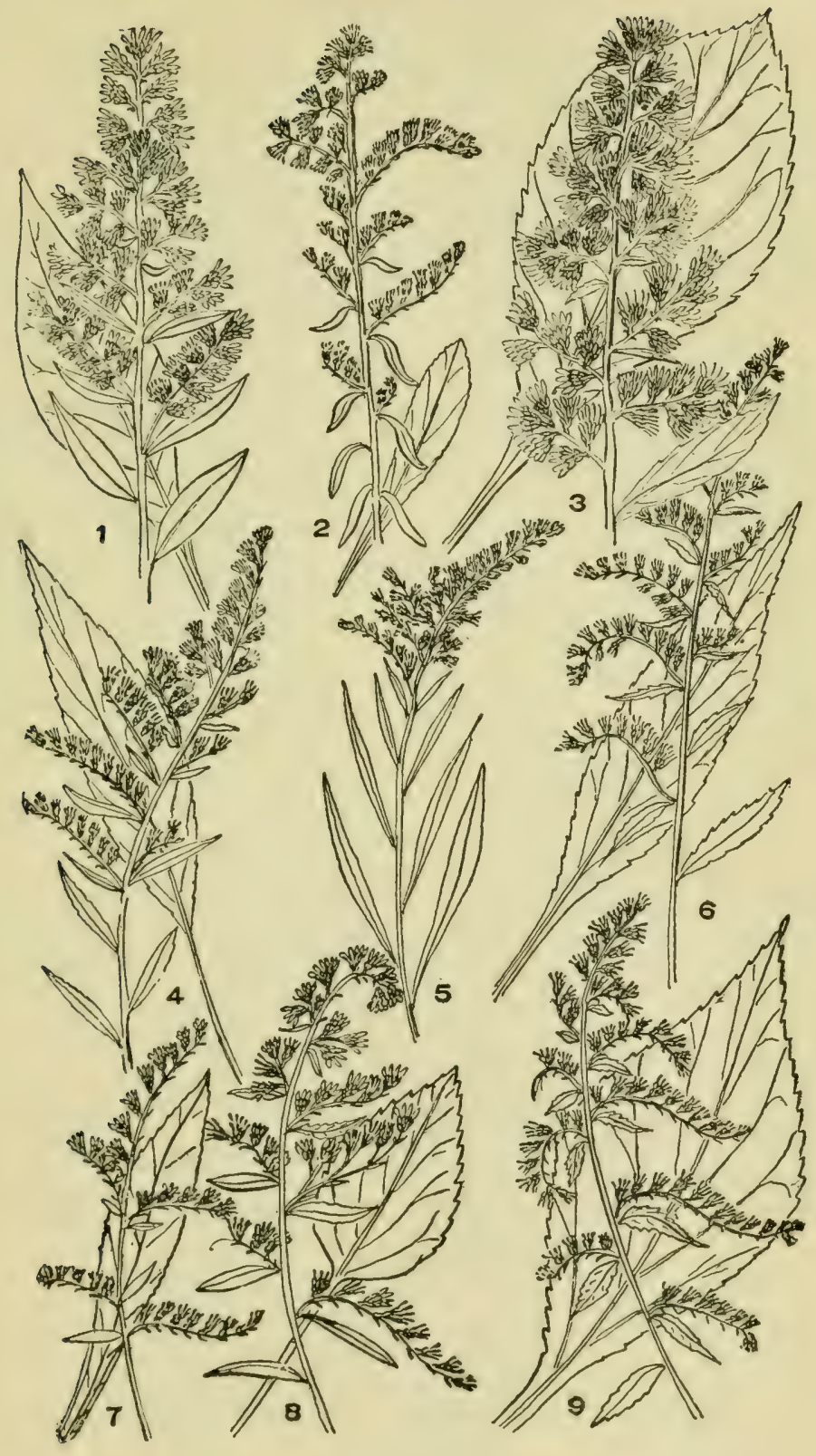

Prate 175

1. Solidago uliginosa. 2. S. nemoralis. 3. S. speciosa. 4. S. uniligulata. 5. S. odora. 6. S. neglecta. 7. S. Elliottii. 8. S. arguta. 9. S. patula. 
Whole plant very smooth. Stem slender, wand-like, 2 to $3 \mathrm{ft}$. high. Lotrer leaves oblong lanee-shaped, often $1 \mathrm{ft}$. long, titpering to a long slender leaf-stalk, apex rounded, margins nearly smooth nearly to the apex, then somewhat dentate. Heads in a broad flat densely crowded cluster, not one-sided. Flowers 15 to 25 to the head; riys 6 to 9. Moist soil, Western New York. Aug.-Sept.

31. S. Houghtonii, Torry and Gray. (Fig. 3, pl. 177.) Hougiton's Goldexrod. Stem smooth, slender, 1 to $2 \mathrm{ft}$. high, simple. Leaves linear, the upper small and remote. Flower heads in a small, terminal, flat cluster of very few heads; rays 7 to 9. Swamps. Genesee Co., N. Y. Autumn.

\section{EUTHAMIA, Nutt. (Solidago, L:)}

Erect herbs, with spreading branches above and with linear or lanceshaped leaves, without teeth and with great numbers of small flower heads in broad flat clusters. Receptaclu nearly llat. Involucre bracts in 2 or 3 series; ray flowers with pistils only, numerous, yellow.

1. E. graminifolia, Nutt. (Fig. 1, pl. 177.) Busiry Goldenrod. Stem much branched, branches slender, 2 to $4 \mathrm{ft}$. high. Leaves numerous, linear lanee-shaped, 3- to 5-nerved. Flower heads yellow, in broad flat clusters. Heads small, with 12 to 20 rays and half as many disk flowers. Fields and roadsides. Common. July-Sept.

2. E. caroliniana, (L.) Greene. (Fig. 2, pl. 177.) SLender FraRANT Goldezinod. liesembles No. 1, but leaves are very narrowly linear and plant is usually smiller. Ileads small, very numerous. Dry soil, Mass., and southward. Aug.-Oet.

\section{I2. BOLTONIA, L'Her.}

Smooth branching herbs, with alternate linee-shaped leaves and with numerous rather large heads of llower's in loosely spreading clusters. Heads at the chls of the branches, with tubular and ray flowers, the latter purplish white, the disk flowers yellow. lieceptacle conic or convex, with small pits in the surface. Involucre of 2 or more series of bracts the margins of which are dry and membraneous. Iruit very flat inversely exreshatped or heart-shaped, its margins winged. Aigrette of several minute seales, or one or two elongated to bristles.

B. asteroides, L'Her. (Fig. 1, pl. 178.) Aster-Lme BoltoniA. Sitem stent, branching ahove, 2 to \& ft. high. Leaves lance-shaped, 2 to 5 in. long. Ieads, including the disk and rays, about $i$ in. in diameter; rays pink, purple or white. Strongly resembles the asters. Moist soil, southern part of our area. July-Sept.

\section{SERICOCARPUS, Nees.}

T'ufted herbs, with altemate 3-nerved leaves and heads of flowers with both tubular and ray florets. Jusoluere nearly cylindric, its bracts membraneous, in several series, often with green tips. Receptacle small. Fruit inversely pyramidal. Aigrette of numerous fine bristles. Ray flowers white with pistils only; disk flowers yellow with both stamens and pistils.

1. S. linifolius, (T.) T3SP. (Fig. 2, pl. 178.) NARrow-LEAVED Whit-Toprin Astik. Sinooth, 1 to $2 \frac{1}{2 t}$. hight, slender. Leaves linear, 


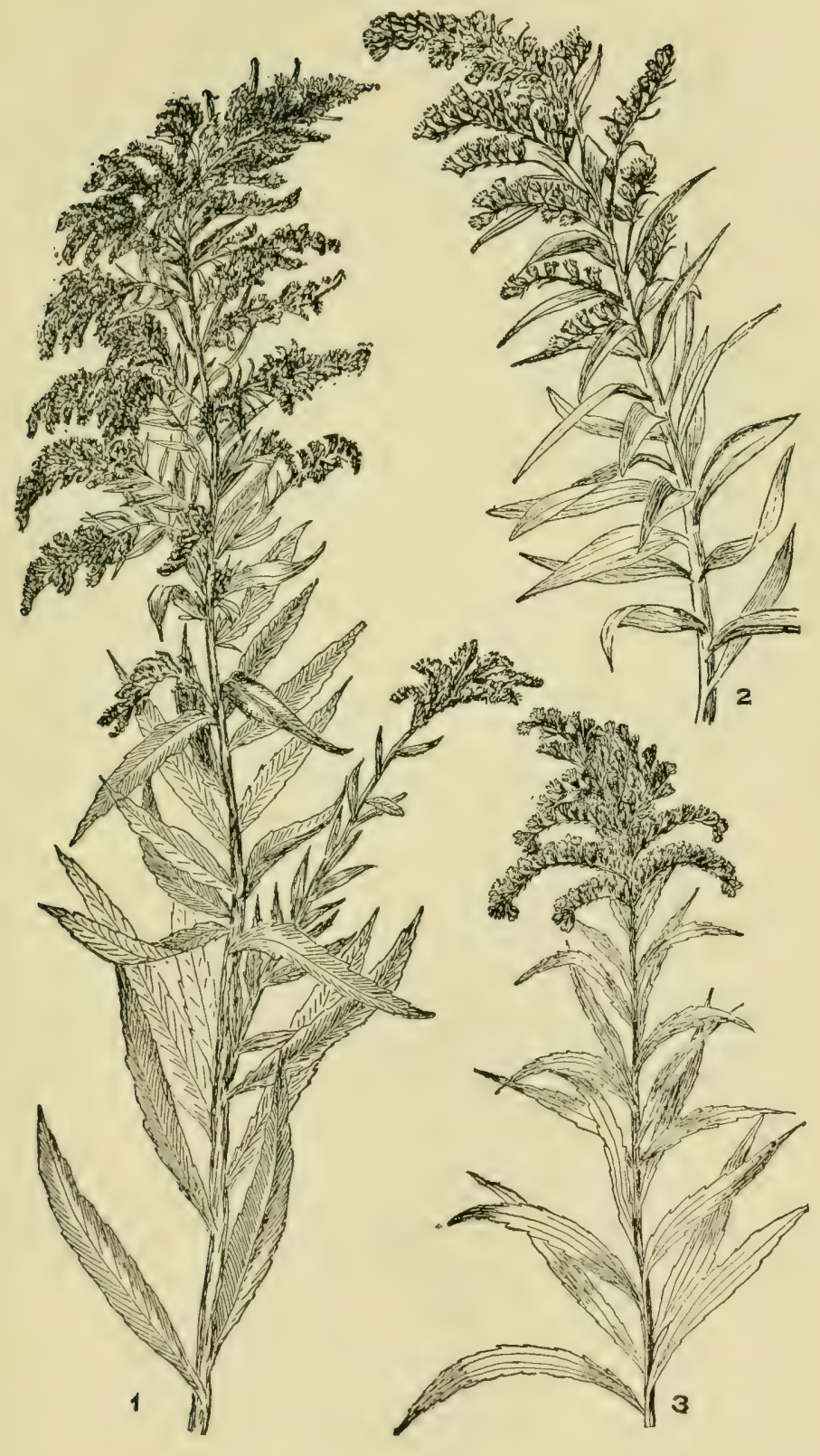

Plate 176

1. Solidago rugosa. 2. S. sempervirens. 3. S. serotina. 
faintly 3-nerved. Heads with about 4 white rays and few tubular disk flowers, the heads in a spreading flat cluster. Dry soil, northern part of our range. June-Sept.

2. S. asteroides, (L.) JSSP. (Fig. 3, pl. 178.) Tоотнed WinteTopped Aster. Stem 1 to $2 \mathrm{ft}$. high, angled. Basal and lower leaves inversely egrg-shaped, toothed at margins, narrowed to long leaf-stalks, the upper leaves lance-shaped, seareely toothed. Ray flowers about 4, white. Dry woods, throughout our range. July-Sept.

\section{ASTER, L.}

Herbs, with alternate leaves and with flower heads in broad, flat or more or less elongated clusters, the heads including both tubular (disk) and ray flowers, the latter in a single row. Involuere seales more or less overlapping, usually with green tips. Receptacle flat or convex, with eircular depressions (alveolate). Disk flowers tubular, with stamens and pistils, usually yellow. Ray flowers with pistils ouly, white, purple, blue, never yellow. Fruit mostly flattened with an aigrette of hair-like bristles, rarely double.

A genus of very numerous species, more abundant in this country than in Europe. Professor Fdward S. Burgess, who has for many years made special study of the asters of our region, has added many new species and many sub-species. It has not been thought neessary to include the latter nor even all of the former in this work.

\section{t. Inflorescence not Unilateral}

Lower lcaves broad, egg-shaped, heart-shaped at base, on slender leaf-stalks

a. None of the leat-stalks clasping the stem.

Ray Flowers White or nearly White

Leaves thin, smooth or nearly so,

Flower stem not as long as the head . . . . . . A. carmesinus

Flower stem as long as or longer than the head.

L.eaves of the branches egg-shaped ....... A. divaricatus Leaves of the branches lance-shaped ...... A. tcnebrosus

Leaves thick and rough.

Inflorescence round or dome topped.

Upper stem leaves egg-shaped . . . . . . . A. glomcratus

Upper stem leaves lance-shaped . . . . . A. curzescens

Inflorescence nearly flat, spreading. . . . . . . . . A. Schreberi

Intlorescence irregularly diffuse . . . . . . . A. Claytoni

\section{Ray Flowers Violet}

Middle stem leaves not sharply and conspicuously toothed.

Upper and middle leaves nearly round ........ A. roscidus Upper and middle leaves ege-slaped A ianthinus

Middle stem leaves very sharply and conspicuously toothed. Inflorescence nearly flat; broader leaves kidney-shaped . . A. violaris Broader leaves egg-shaped . . . . . . . A. multiformis Inflorescence quite irregular ................ A. nobilis

\section{Ray Flowers Bluc}

I.eaf-stalks without winged margins, or with very narrow margins.

Scales of the conical involucre lying close and flat, with green tips

A. cordifolius Scales of the oblong involucre spreading, not lying flat . A. sagiltifolius Leaf-stalks conspicuously margined.

Inflorescence cunical

A. Lozuricanus Inflorescence pyramidal. 


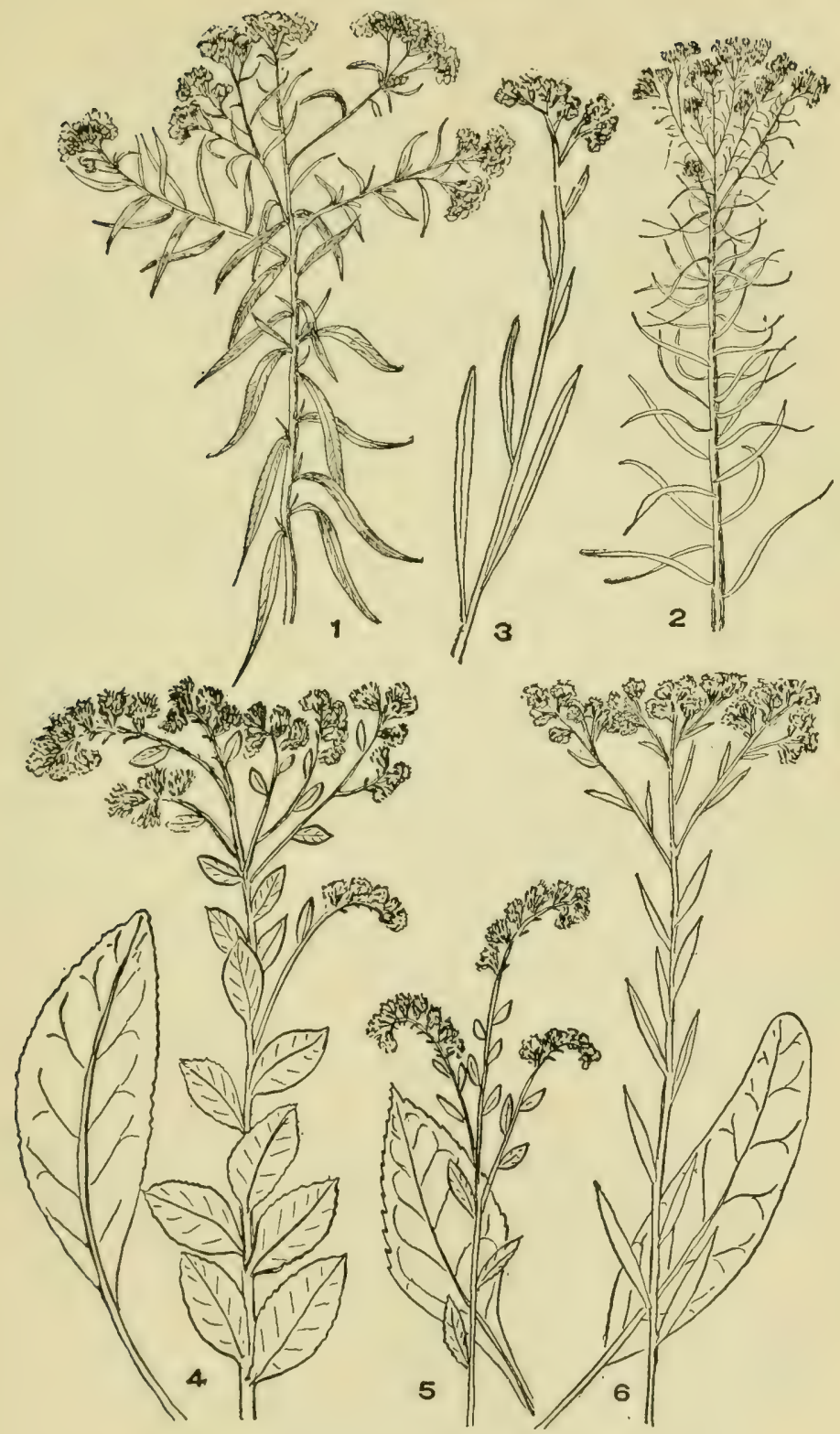

Prate 177

1. Futhamia graminifolia. 2. E. caroliniana. 3. Solidag̨o IIoughtonii. 4. S. rigida. 5. S. ulmifolia. 6. S. ohioensis. 
b. Lower Leaves Heart-shaped with Notched or Entire Margins, the Leaf-stalks, at least some of them, Clasping the Stcm

All the leaves clasping the stem. Margins of the leaves entire

(Nos. 22 and 23 sometimes notched.)

Leaves broadly egg-shaped.

With margined leaf-stalks . . . . . . . . . . A. undulatus

IVithout leaf-stalks . . . . . . . . . A. patens

Leaves lance-shaped, linear or narrow spatula-shaped.

Plant smooth, not downy or hairy.

Heads usually about 2 in. broad . . . . . A. phlogifolius

Heads I in. broad or less.

Leaves almost or quite linear.

Lower leaves spatula-formed . . . . A. concinnus

Lower leaves linear . . . . . . . A. junceus

Plant somewhat downy.

Leaves linear-lance-shaped . . . . . A. longifolius

Leaves rather broad lance-shaped ......... A. laevis

Plant not smooth, decidedly hairy or downy.

Heads I to 2 in. broad, violet-purple . . . . A. Novac-Angliae

Heads I in, broad or less, blue-purple....$A$. ametliystinus

\section{Leaves Clasping. the Stem. Margins Conspicuously Toothed}

Leaves clasping by a very broad base . . . . . . . A. prenanthoides Leaves clasping by a narrow base.

Plant very hairy.

Leaves lance-shaped . . . . . . . . . A, puniceus

Leaves egg-shaped . . . . . . . . . . A. patulus

Plant smooth or nearly so . . . . . . . . . A. tardifloris

c. Leaves not Clasping the Stem, not Heart-shaped at Base and with Entire Margins, or with very Remote Teeth

\section{Plants not Fleshy}

Leaves broad egg-shaped, rather blunt; flowers in a long narrow cluster A. concolor Leaves lance-shaped or linear.

Flower heads in a spreading, almost flat cluster . . . . A. ptarmicoides

Flower heads in a pyramidal cluster. . . . . . . A. dumosus

Flower heads in an irregular spreading cluster... . . A. polyphyllus

\section{Plants Fleshy}

Heads 7 in. to 1 in, broad . . . . . . . . . . . A. teruifolius Heads less than $\frac{1}{2}$ in. broad . . . . . . . . . . . . A. subulatus

d. Lcaves not Clasping the Stem, not Heart-shaped; though in Nos, 37 and 38 there is slight clasping. Leaf Margins Toothed or Entire

Flowers violet.

Lower leaves spatula-formed . . . . . . . . . A. spectabilis

Lower leaves egg-shaped . . . . . . . . A. Herveyi

l.ower leaves oval.

Upper leaves linear . . . . . . . A. gracilis

Upper leaves oblong to broad lance-shaped . : $:$ A. Radula

Lower leaves lance-shaped.

Plant somewhat hairy . . . . . . . . . . A. nemoralis

l'ant smooth or witl few hairs.

Flower clusters very leafy . . . . . A. salicifolius

lilower clusters with few small leaves... A. novi-belgii

lilowers white.

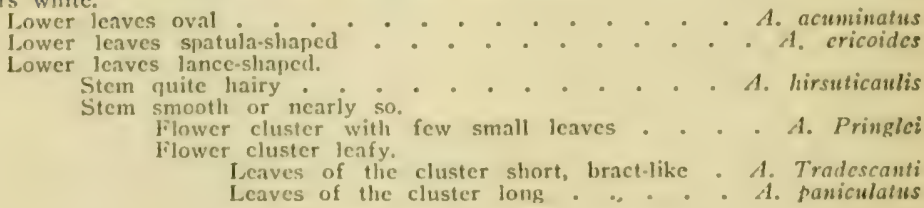




\section{Inflorescence largely Unilateral (secund)}

Lower leaves egg-shaped, upper leaves lance-shaped . . . . . A. lateriflorus All leaves linear.

P'lant smooth

l'lant rough

\section{Inflorescence not unilateral}

Lower leaves broad, egg-shapal, hart-shaped at base, on slender leafstalks. None of the leaves clasping the stem

1. A. divaricatus, L. (Fig. 1, pl. 179.) Winte Wood Aster. (A. corymbosus, Ait.) Stem slender, somewhat zig-zag, tufted, round, 1 to 2 ft. high. Leaves thin, scarcely hairy, the lower egg-shaped to somewhat lance-shaped, the base heart-shaped; borders coarsely toothed, teeth sharp; leaf-stem slender, not hairy; apex of leaf narrow tapering. Heads of flowers in an irregular, broad, flattish, repeatedly forked cluster. Heads about an inch broad, including the rays. Bracts of the involucre broad, rounded at the tip, regularly overlapping, closely hugging each other, the tips scantily herbaceous. Central disk yellow, turning brown. Rays white, linear, about 6 to 9 to a head. Found in the open borders of woods and thickets, very common. Sept.-Oct.

The following 4 are among the forms strongly resembling $A$, divaricatus which Prof. Burgess regards as separate species

2. A. carmesinus, Burgess. CRIMSON-DISK ASTER, Resembles $A$. divaricatus, but the disk turns purplish crimson, the rays rather shorter, the stem for the head shorter and the heads on somewhat short stems, in about 5 rounded groups. Near Yonkers, N. Y.

3. A. tenebrosus, Burgess. Long-Leaved Wood Aster. Similar to No, I, but stems usually not tufted, about $3 \mathrm{ft}$. high, the upper stem leaves more lance-shaped, the disk becoming purplish brown, rays from 9 to 12, narrower than those of No. I. New York and southward.

4. A. Claytoni, Burgess. (Fig. 4, pl. 180.) Clayton's Aster. Similar to No. I. Stem red, main cluster of heads on longer stems and the subordinate clusters distinct. Rays about 6; disk turning brown. New York and southward.

5. A. curvescens, Burgess. DOME-TOPPED Aster. Stem green; basal leaves tufted, heads of flowers in a rather loose somewhat cylindric cluster. Disk becoming purple-brown. New England, New York and southward.

6. A. glomeratus, Bernh. (Fig. 4, pl. 179.) Berninard's Aster. The cluster of heads rounded, the whole plant hairy, the bracts of the involuere green. Otherwise similar to No. 1. In ravines, thickets or swamps, New York and Penna.

7. A. Schreberi, Nees. Scmrerer's Aster. Stem stouter than No. 1; 2 to $3 \mathrm{ft}$. high. Inwer leaves many, broad heart-shaped at base, tapering at apex, rough above with stiff hairs; leaf-stalks conspicuously hairy witli soft hairs when young. Upper leaves lanee-shaped. Heads in broad flat clusters. Bracts obtuse, greenish. Rays about 10. New York and westward.

8. A. macrophyllus, I. (Fig. 5, pl. 179.) LARge-Leaved Aster. Plant rough with long root-stncks and stout, rigid, reddish stems, which are angular, 2 to $3 \mathrm{ft}$. high. Lower leaves numerous, rather thick, elosely and sharply toothed, on long and slender leaf-stalks; blade 4 to $10 \mathrm{in}$. lonks, more than $\frac{x}{2}$ as wide, heart-shaped at base, abruptly pointed at apex; the upper leaves oblong on short margined leaf-stalks, the uppermost without leaf-stalks. Heads in large difuse rigirl flattened clusters. Iays white 
or more frequently bluish-lavender to violet, 10 to $16 \frac{1}{2}$ in. long. Seales of the involucre conspicuously green tipped. Disk turning from yellow to reddisin brown. Dry soil. Common. August.

The following 5 forms, regarded as varietics of $A$. macrophyllus by Robinson and Fernald, are considered species by Burgess

9. A. roscidus, Burgess, DEWY-LEAvED ASTER. In general appearance similar to No. 8. Leaves and stem clammy, with glandular hairs, which are odorous. Rays I4 to 16 , violet. Disk golden yellow, turning red. Maine to Pennsylvania.

I0. A. ianthinus, Burgess. Violer Wood Aster. Rays 12 to 15 , deep violet or pale, Lower leaves broader than those of No, 8, and leaves in the inflorescence cluster and below less conspicuous. Maine and westward.

II. A. violaris, Burgess. VIOLET-LEAF Aster, Lower leaves kidney-shaped, teeth large and sharp, sinus at base shallow, leaf-stalk sometimes 6 or 8 in. long. Leaves conspicuous in Mie inflorescence. Flower cluster nearly flat-topped. Shady places, New York, Sept.-Oct.

12. A. multiformis, Burgess. Various-LEAved Aster. Basal leaves usually 2, large, heart-shaped. Stem leaves rough above. Rays 13, type of No. 8. Maine to Western New York, Pennsylvania and southward.

13. A. nobilis, Burgess. Stately ASter. Stem bright green, shining, 4 to 5 ft. high. Leaves as in No. 8 , smooth above, minutely downy beneatl. Basal leaves sometimes as much as 9 in. long, $2 / 3$ as wide. Rays $1_{3}$ to 15 , violet blue. Lake Champlain and westward.

14. A. cordifolius, L. (Fig. 2, pl. 179.) Common BLve ITOOd Aster. Stem 1 to $5 \mathrm{ft}$. high, much branched above, the spreading branches bearing very numerous heads in pyramidal sub-clusters, the main cluster occupying the whole of the upper part of the plant. Lower leaves all egrshiped, heart-shaped at base, on long leaf-stalks, tapering to a slender point at apex, conspicuously and sharply toothed at margins. Upper leaves on short leaf-stalks or none, egg-shaped or lance-shaped. Flower lowels rather small, $\frac{2}{3}$ in. loroad, the rays $(10$ to 20$)$ violet or blue, rarely white. Bracts of the involucre green tipped, not spreading, oblong-linear, olituse, the janks closely appressed. Woodlands, very common. Sept.Dec.

15. A. Lowrieanus, Porter. (Fig. 5, pl. 178.) Lomrie's Aster. Resembles No. 14, leaves rather thicker, and somewhat succulent; loafstallis ringed. Ileads not very numerous. Rays light blue. Conn., southern New York, and southward.

16. A. Lindleyanus, 'l'orr. and Gray. (Fig. 6, pl. 178.) LindeEr's AstrR. Stout, I to $2 \mathrm{ft}$. high, smooth or slightly downy. Lower leaves egg-shaped, somewhat heart-shaped, on slender leaf-stalks, the upper leaves without leaf-stalks, tapering at each end. Flower heads larger than A. eordifolins, usually not very numerous. Bracts of involuere linear, rather loosely overlappialg, tips green. Rays pale violet. Open places, northern part of our area. Aug.-Oct.

17. A. sagittifolius, Willd. (Fig. 4, pl. 17S.) ARrow-Leaved Astre. Stom slender, erect, rigril, smooth, 2 to $5 \mathrm{ft}$. high. Lower leaves ecrershated or latner-shaped, with heart- or arrow-shaped base on winged leafstalks; upper leaves lanee-shaped or linear without leaf-stalks, tapering at. each end; mearly all leaves with tonthed margins. Ifrads in an clon. gatud clusters; rays 10 to 15 , light hlue; white in var. urophyllus, invo. luere brarts linrat taproin! into awl-shaped loose tips. Open grounds, most of our range. Aug.-Oct. 

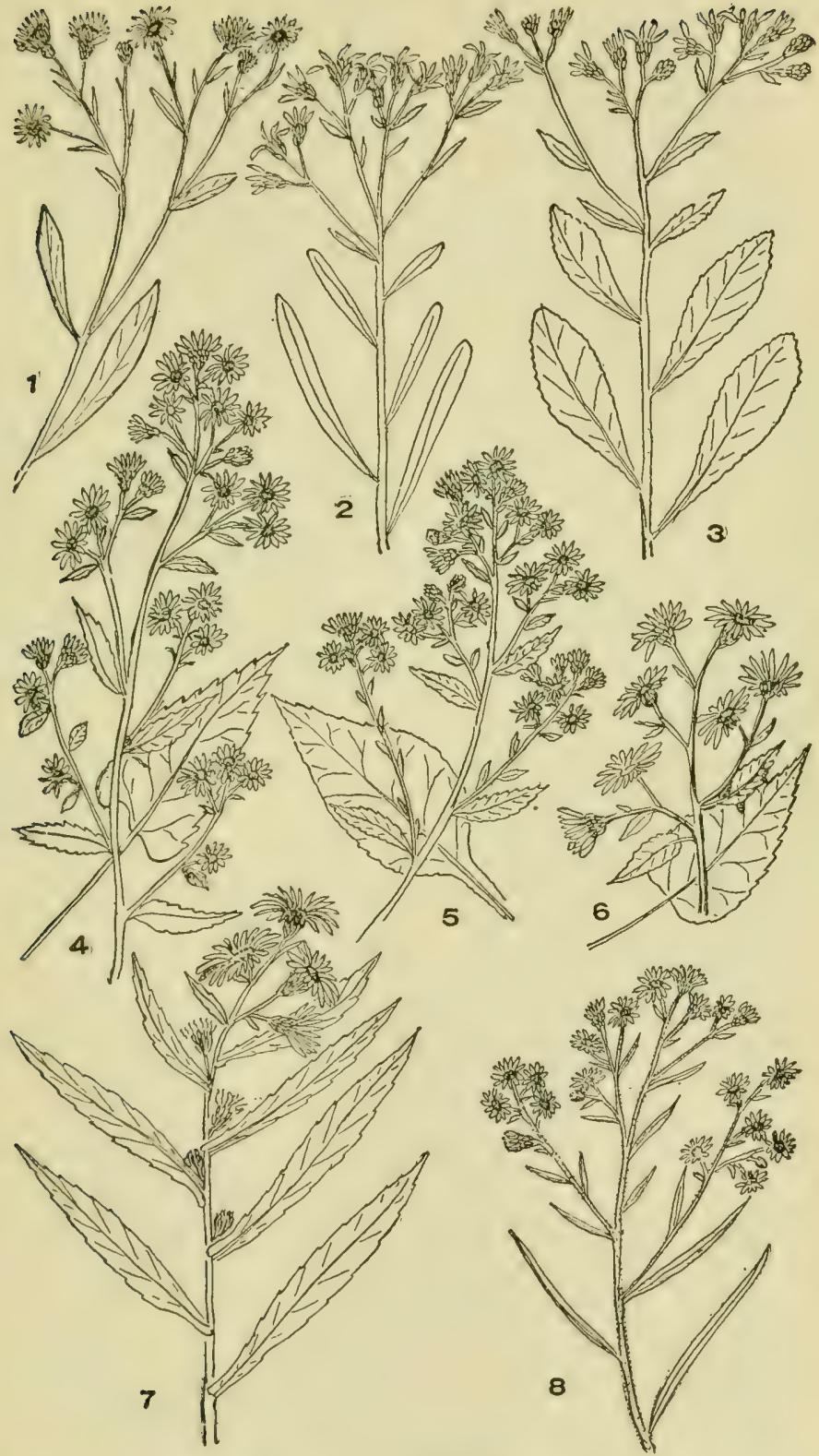

Plate 178

1. Boltonia asteroides. 2. Sericocarpus linifolius. 3. S. asteroides. 4. Aster sagittifolius. 5. A. Lowrieanus. 6. A. Lindleyanus. 7. A. puniceus. 8. A. amethystinus. 


\section{Lower lcaves heart-shaped, the leaf-stallis clasping the stem}

18. A. undulatus, I. (Fig. 3, pl. 179.) Whvi-Lenved Astrer. Stem stiff, rough, somewhat hoary, branched above, with numerous heads in loose, rather elongated clusters. Leaves egg-shaped or broad lanee-shaped, with wavy or slightly toothed margins, the lower leaves heart-shaped at base, the winged leaf-stalks clasping the stem, the upper stem leaves broadened at base, nearly or quite heart-shaped attached directly to stem, nearly clasping. Dry soil. Common. Sept.-Oct.

All the leaves clasping the stem, margins of the leaves entire. (Nos. 23 and 24 sometimes toothed)

19. A. patens, Ait. (Fig. 1, pl. 180.) Late Purple Aster. Stem 1 to $3 \mathrm{ft}$. high, slender, rough, loosely branched above. Leaves oblong egrshaped, to oblong lance-shaped, not toothed at margins, often contracted below the middle, strongly heart-shaped at base, clasping the stem, none with leaf-stalks; thick, rigid, rough. Heads mostly solitary on the branches; rays 20 to 30, purplish blue to deep violet. Scales of the involuere with spreading pointed tips. Dry open places, northern New York, Mass., and southward. Aug.-Oct.

20. A. phlogifolius, Muhl. Thin-leaved Purple Aster. (A. patens, var. phlogifolius, Nees.) Leaves larger than No. 19, thin, not rough, much contracted below the middle. Otherwise similar to A. patens; rays deep purple. Woods and thickets, New York and westward. Aug.-Sept.

21. A. novae-angliae, L. (Fig. 3, pl. 180.) New England Ąster. Stem hairy, stout, 2 to $8 \mathrm{ft}$. high, with broad irregularly flat or elongated clusters of heads with pink, red or whitish rays. Leaves lance-shaped, without leaf-stalks, clasping the stem, very numerous, covered with a soft down, 2 to 5 in. long. liays 40 to 50, linear; heads large. Moist grounds. Common. Aug。-Oct.

22. A. amethystinus, Nutt. (Fig. 8, pl. 178.) Ametrist Aster. Stem 2 to $5 \mathrm{ft}$. tall, much branched. Leaves of the stem small, linear, without teeth at margin, hairy on both sides, partly clasping by the scarecly-enitracted base. IIeals numerous, small, in broad diffuse clusters. Bracts of the involuere linear, hairy, green at the tips, which are sprealing. Rays 20 to 30 , elear blue. Moist grounds, Mass., sonthern New York, Penn. Sept.-Oct.

23. A. laevis, I. (Fig. 2, pl. 1S0.) Smootri Aster. Whole plant very smonth. Stem $2 \mathrm{to} 4 \mathrm{ft}$. high, the branchlets usually quite short, terminated by a showy flower head. Leaves shining, oblong, rounded at apex, clasping at base, the lowest sometimes with a few tecth at the margrins, 1 to $4 \mathrm{in.}$ long, about $\downarrow$ as wide. Heals large; rays 15 to 30 , rich blue or violet. Dry soil, Maine to Penna. Sept.-Oet.

24. A. concinnus, Will. (Figr. 3, pl. 181.) NARrow-Leaven SMootir Astrer. Stem branched ahove, 1 to $3 \mathrm{ft}$. high, smooth or slightly downy. Leaves narrow laner-shaped, 1 to 3 in. long, about $\frac{1}{3}$ in. wide, somelimes toolhed at the mareins. Ifeads numerous, rather large: rays rich blue or violet. Southern part of our area.

25. A. junceus, Ait. (Fig. 5, pl. 181.) Rusi Aster. Stem very 

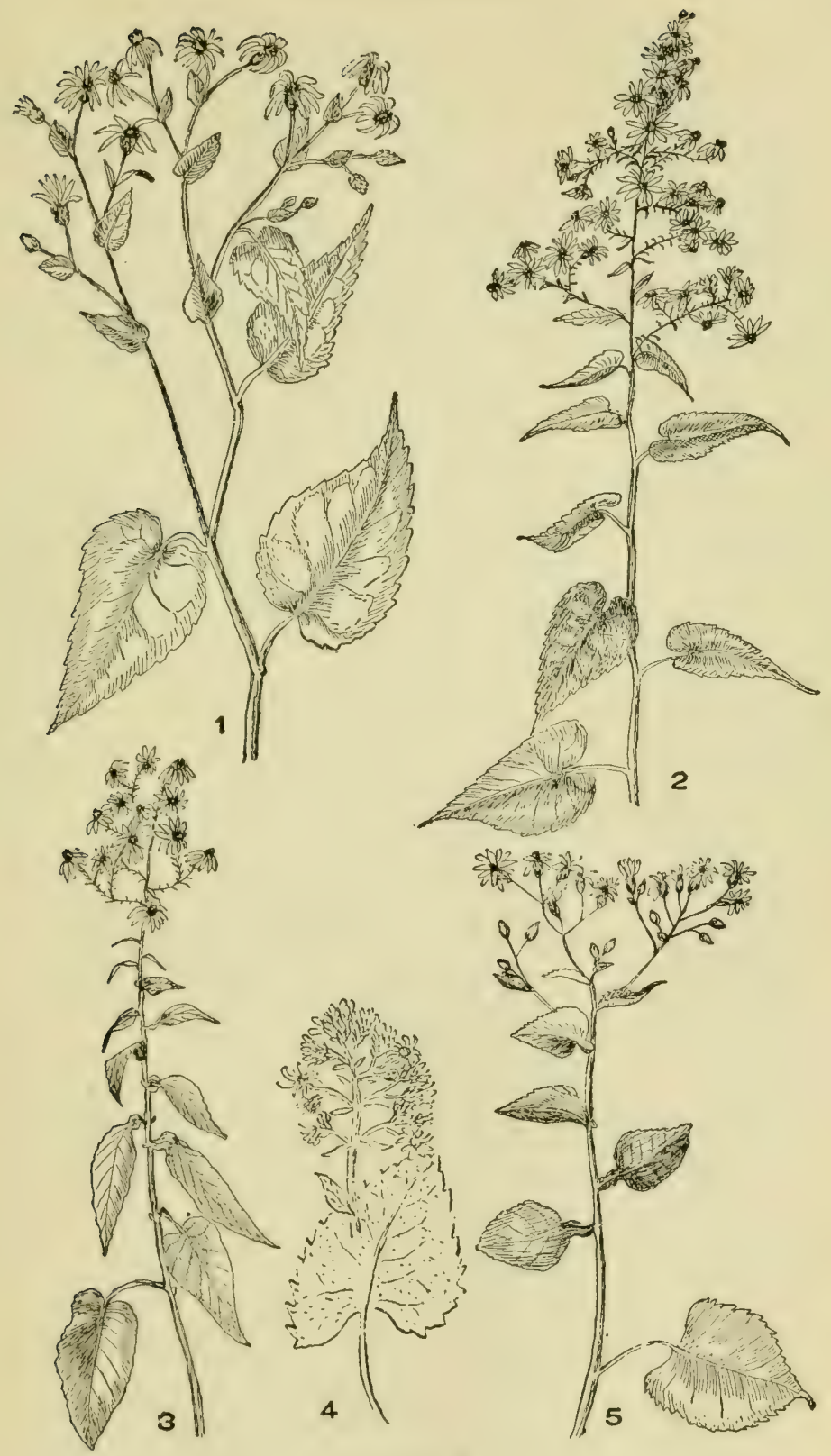

Plate 179

1. Aster divaricatus. 2. A. cordifolius. 3. A. undulatus. 4. A. glomer。 atus. 5. A. macrophyllus. 
slender, 1 to $3 \mathrm{ft}$. high, loosely branching above. Leaves linear, $\mathbf{3}$ to $\mathbf{5}$ in. long, without tecth or with a few remote teeth at margins, slightly clusping or only attached to stem by broad hase. Ileads not numerous, small ( 1 in. broad) ; rays light purple. Bracts in several series, linear, acute, the outer shortest. Swamps and bogs, Maine to New Jersey. July. Sept.

26. A. longifolius, Lam. (Fig. 6, pl. 181.) LoNg-Leaved Aster. Stem smooth or somewhat downy, slender, 1 to $3 \mathrm{ft}$. high. Leaves linear to narrow lance-shaped, 3 to $8 \mathrm{in}$. long, the base clasping the stem, tapering to the margin. Heads about 1 in. broad, numerous. Rays numerous, violet or pale purple, rarely nearly white. Scales not much overlapping, spreading. Swamps and wet grounds, in most of New England. JulyOct.

\section{Leaves clasping the stem, margins conspicuously toothed}

27. A. puniceus, L. (Fig. 7, pl 178.) Purple-Stem Aster. Stem stout, 3 to $\mathrm{S} \mathrm{ft}$. high, reddish, covered with rigid hairs. Leaves laneeshaped, 3 to 6 in. long, not narrowed at base, which clasps the stem, margins somewhat remotely toothed, rough above, downy on the midvein below, sharp pointed. Heads rather large in a diffuse elongated cluster. Scales of involucre narrowly linear in about 2 rows, loosely overlapping. Iiay's 20 to 40 , dark purple or blue. Swamps, most of our area. July-Nov.

28. A. tardiflorus, L. (Fig. 1, pl. 181.) Nortifenstern Aster. Stem smooth or somewhat downy above, 1 to $4 \mathrm{ft}$. high, branched near the summit. Leaves lanee-shaped to egg-shaped, sharply toothed, tapering to a slender point at apex and to a rather narrow clasping base 3 to 6 in. long. If ats usually not mumerous; rays 20 to 30 , violet; braets of the involuere noirly rqual in length, the outer leaf-like. Eastern part of our area. Aug.-Oet.

29. A. patulus, Lam. Sprending Aster. Closely related to A. tardiporus. Smooth or downy; stem 1 to $4 \mathrm{ft}$. high. Leaves oblong lance. shaped to eger-shaped, the lower 3 to $6 \mathrm{in.}$ long, sharply toothed, apex somewhat blunt, the hase tapering to rather long winged leaf-stalks, which morly clasp the stem. Upper leaves without leaf-stalks, tapering at each end. Heads numerous in a loose broad cluster; rays 12 to 15 , violet to white; bracts of the involuere linear, acute, green and spreading. Moist soil, Maine to New IIampshire. Aug,-Oct.

30. A. prenanthoides, Muhl. (Fig. 2, pl. 181.) C'Rooked-stem Aster.

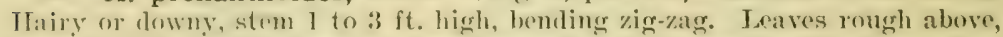
smocith helow, regreshaped to lanee-shaped, with sharp teeth at margins, silmeler taper-pointed at apex. abruptly dilated at the base which elasps the stem. Heals numerous, 1 in. broad; rays 20 to 30 , violet; seales of the involuere linear, spreading, green. Moist soil, Mass., and westward and southward. Aug. Oet.

Leares not rlaspin! the stem, nol herevt-shaped at luse and with entire margins or with very few remote tecth

\section{Plants not fleshy}

31. A. concolor, I. (Fig. 7, pl. 181.) Easters Sulvery Aster. Situm slemer, straight, seatrenly branched, smooth or slightly downy above. 


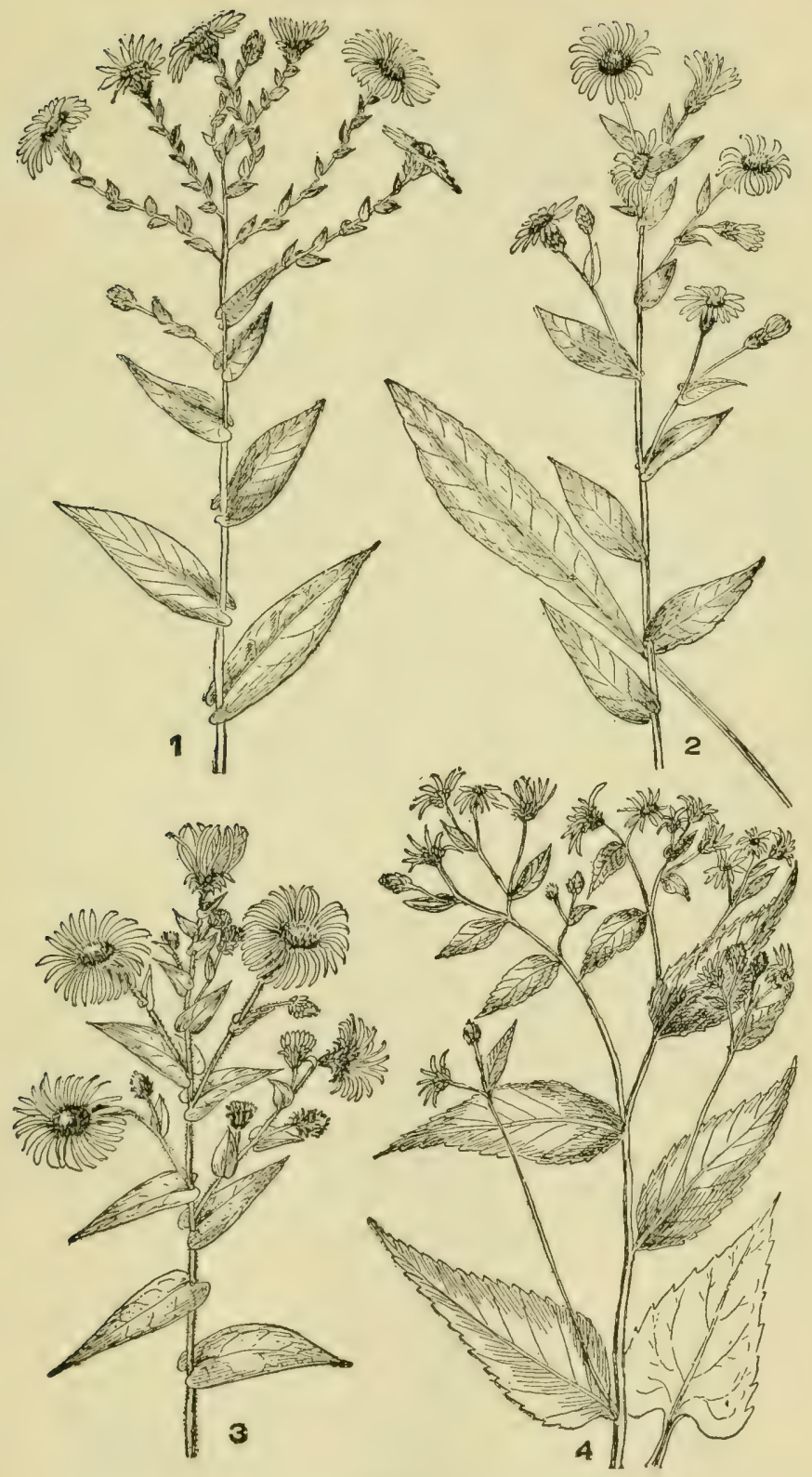

Plate 180

1. Aster patens. 2. A. laevis. 3. A. novae-angliae. 4. A. Claytoni. 
Leaves crowded, oblong or broad lanee-shaped, the upper reduced to bracts, the lower $1 \stackrel{1}{2}$ to $2 \mathrm{in}$. long, half as broad, the apex rather blunt, both sides of the leaf covered with a dense whitish silky bloom. Heads arranged in a narrow spike-like eluster; rays 10 to 15 , lilac. Scales of the involuere overlapping in several rows, lanee-shaped or linear, silky, the tips acute, green. Dry sandy soil near the sea coast. One of our most pleasing asters. Aug.-Oct.

32. A. ptarmicoides, T. and G. (Fig. 4, pl. 186.) Upland White Aster. Stems 6 to 20 in. high, growing in clusters or tufts, smooth or roughish. Leaves linear lance-shaped, rigid, acute at apex tapering to the base, somewhat 3 -nerved, the margins rough with, in some eases, a few remote teeth. Heads small, in a broad flat eluster. Rays white, about $\frac{1}{4}$ in. long; scales of the involuere in several overlapping series. Dry rocky soil, Mass., Vermont, and Eastern New York. July-Sept.

33. A. dumosus, L. (Fig. 2, pl. 183.) Busir Aster. Stems smonth, branched above, 1 to $3 \mathrm{ft}$. high. Leaves of the stem linear, the upper ones quite small, the lower stem-leaves 1 to $3 \mathrm{in}$. long, $\frac{1}{6}$ to $\frac{1}{4}$ in. broad. Basal leaves spatula-formed, with a few teeth at margins. Rays, pale purple to white; seales linear in about 4 series. Sandy soil, southern half of our area and southward. Aug.-Oet.

34. A. polyphyllus, Willd. (Fig. 3, pl. 184.) Faxon's Aster. (A. Faxoni, Porter.) Smooth in all parts. Stem 2 to $5 \mathrm{ft}$. high, branched above. Stem leaves linear-lanee-shaped, 2 to $5 \mathrm{in}$. long, about 1 in. wide, margins entire. liasal leaves oblong, much shorter than the others, with a few remote teeth. Ileads in a dilluse cluster; rays bright white, $\frac{1}{4}$ in. long. Seales linear, acute, green tipped. Moist rocky places, Vermont, Mass., and southward. Aug.-Sept.

\section{Leaves not clasping or heart-shaped; margins not toothed}

Plants fleshy

35. A. tenuifolius, L. (Fig, 6, pl. 184.) Perennial Salt-marsi Aster. Whole plant fleshy; perennial; stem zig-zag, branched, 1 to $2 \mathrm{ft}$. high; stem Feaves grass-like, 2 to 6 in. long, the lowest lanee-shaped. Irads few, torminating the branches. Rays white or pale purple. Seales numerous, spreading. Salt marshes, Mass., and southward. Aug.-Oet.

36. A. subulatus, Michx. (Fig. 7, pl. 184.) Annuat SAlt-Minsir Astrk. Anmual; fleshy; stem ziog-zag, 1 to $6 \mathrm{ft}$. hight. Stem leaves linear, 2 to 10 in. loner; lower leaves lance-slatperl. Hoads in a loose branching cluster, small; rays short, purple or purplish. Seales of the involuere overlappine in 3 or 4 series. Silt marshes, New IIamphire, and southward. Aug.-Nov.

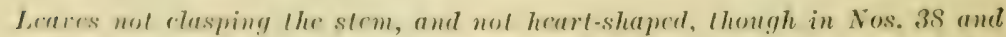
39 there is slight clasping. Margins of some or all the lcaves toothed

:7. A. spectabilis, lit. (Fig. 1, pl. 182.) SEA-sine Purpre Aster. Strm 1 to $2 \mathrm{ft}$. high, simple, but branclied above. Jaraves of the stem linear, entime at matrins; hasal leaves oval on lomgr leaf-stallss, remotely tomtluel. Ileads not very mumerous, 1 in. broad, showy; rays 15 to 30 , bright violet. Sandy soil, mostly near the coast. Aug.-Oct. 


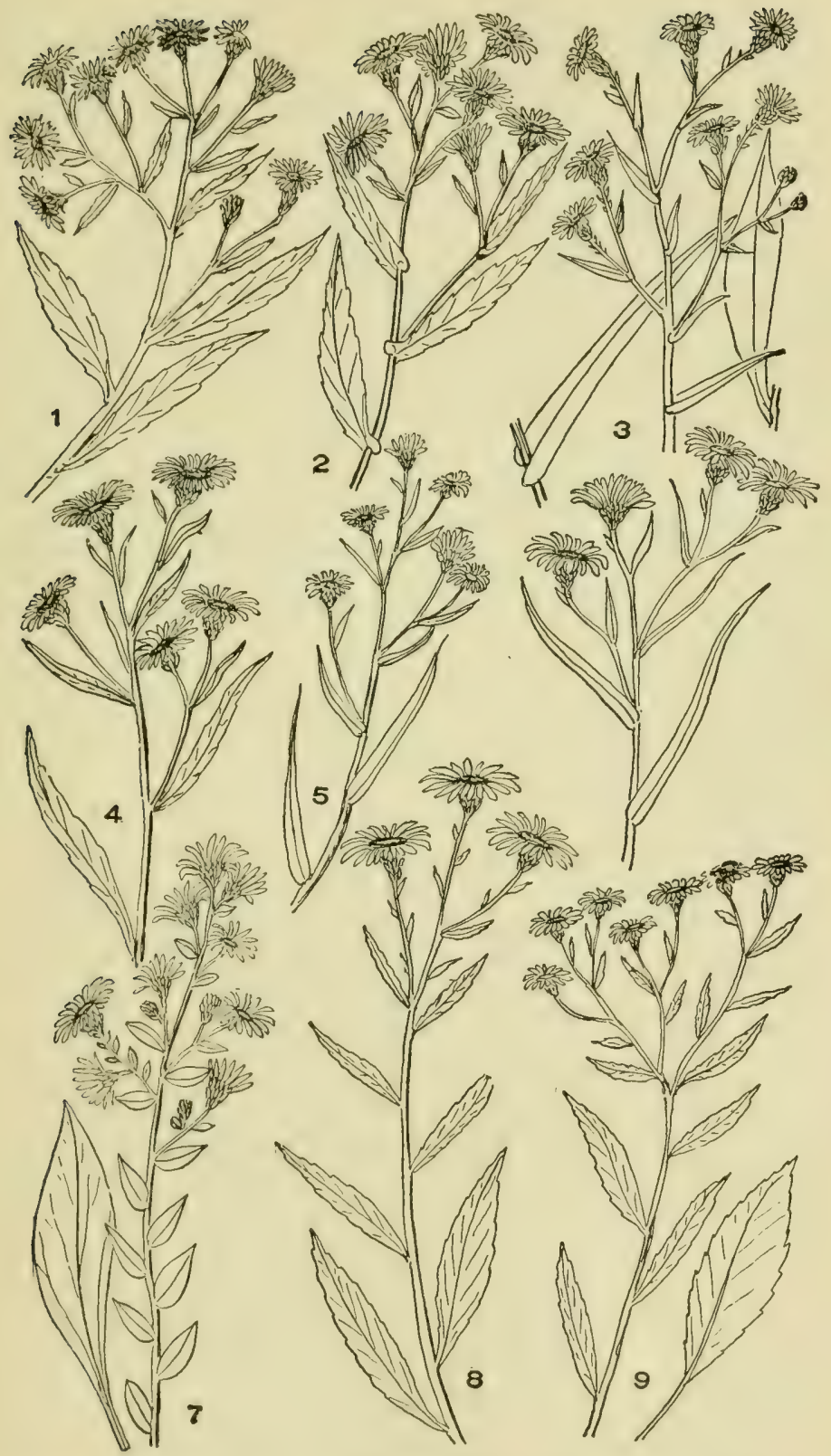

Plate 181

1. Aster tardiflorus. 2. A. prenanthoides. 3. A. concinnus. 4. A. novibelgii. 5. A. juncens, 6. A. longifolius. 7. A. coneolor. 8. A. nemoralis. 9. A. gracilis, 
3S. A. novi-belgii, L. (Fig. 4, pl. 181.) New York Aster. Stem usually much branched, slender, smooth or slightly downy above. Leaves oblong to linear lance-shaped; margins entire or more gencrally toothed, at least remotely, tapering at each end, to a slender point at apex and base, or at base slightly clasping, 2 to $5 \mathrm{in}$. long, the lowest on leaf stems. Ileads in a spreading flattish cluster, numerous, 1 to $1 \frac{1}{2} \mathrm{in}$. broad; rays 15 to 25, violet; bracts linear, acute, green, spreading, in 3 to 5 series. Swamps, Common, Aug.-Oct.

39). A. gracilis, Nutt. (Fig. 9, pl, 181.) Slender Aster. From the occasional thickening of the root-stock sometimes known as Tuber Aster. Stem slender, about $1 \mathrm{ft}$. high. Leares somewhat rough, oblong lanceshaped, the lower broad lance-shaped on long leaf-stallis. Heatds mumerous, $\frac{3}{4}$ in. broad; rays 9 to 15 , violet. Scales of the involuere leathery, whitish, with green tips, in several series. Dry sindy soil, New Jersey, and southward. July-Sept.

40. A. radula, Ait. (Fig. 3, pl. 182.) Low RougI Aster. FileBL.ADL Astra. Stem simple, branching above, 1 to $2 \mathrm{ft}$. high; leaves somewhat crowded, oblong lance-shaped, tapering to a slender point at apex, the upper rather broad, rounded at base, the lower tapering at each end; both sides of the leaf rough. Heads about $1 \frac{1}{2}$ in. broad; rays 20 to 30 , violet. Scales leathery, oblong with green obtuse tips Swamps and low grounds, most of our area. July-Sept.

41. A. Herveyi, A. Gray. (Fig. 2, pl. 184.) Henver's Aster. Stem rough, I to $2 \mathrm{ft}$. high, above downy. Leaves rather rough, margins dentate with low teeth, the upper ones narrowly egg-shaped without leafstalks, the lower broadly egg-shaped on long leaf-stalks. Heads not numerous, an inch or more broad; rays 15 to 25 , violet. Involucre seales oblong, elosely overlapping. Dry soil, Eastern Mass., and Rhode Island. Aug.-Oct.

4.2. A. nemoralis, Ait. (Fig. S, pl. 181.) Bug Aster. Stem downy, to $2 \mathrm{ft}$. high. Jeaves lanee-shaped, acute at each end, the lower tapering to a short leaf-stalk, toothed at margins. IIeads several usually rather more than an inch broud; rays light purple to pink; involuere saucershaped, the scales linear, acute. Simbly bogr, northern half of our area. Aug.-Sept.

4:3. A. acuminatus, Michx. (Fig. 6, pl. 182.) Wimron Aster. Plant somewhat hatiry. Sitem yigr-zage, not hranching, 1 to $2 ! \mathrm{ft}$. high. Leaves broud laner-shaped conspicuomsly slender printed, the borders toothed, the leates often conded near the tope so ats to appear whorlent. Heads several, rays purplish to white. Woods, northern and western New York, and southward. July-Oct.

44. A. salicifolius, Lam. (Fig, 2, pl. 182.) WILLow AsTER. Stem 2 to $4 \mathrm{ft}$. high, much branched, very leafy, leaves lanee linear, 2 to $4 \mathrm{in}$. lome, 1 to $\frac{1}{2} \mathrm{in}$. wide, toothed at margins, the atpex slember pointed, tapering from a ratlier wide base. Ileads about an inch broad, rather numerous; rats violet or purple, rarely white. Seales linear, in 4 or 5 series. Low grounds, most of our area. Aug.-Oet.

45. A. paniculatus, Lam. (Fig. 5, pl. 182.) Tal, White Aster. Stem and latves similar to No. 43, but leaves somewhat longer. Rays 

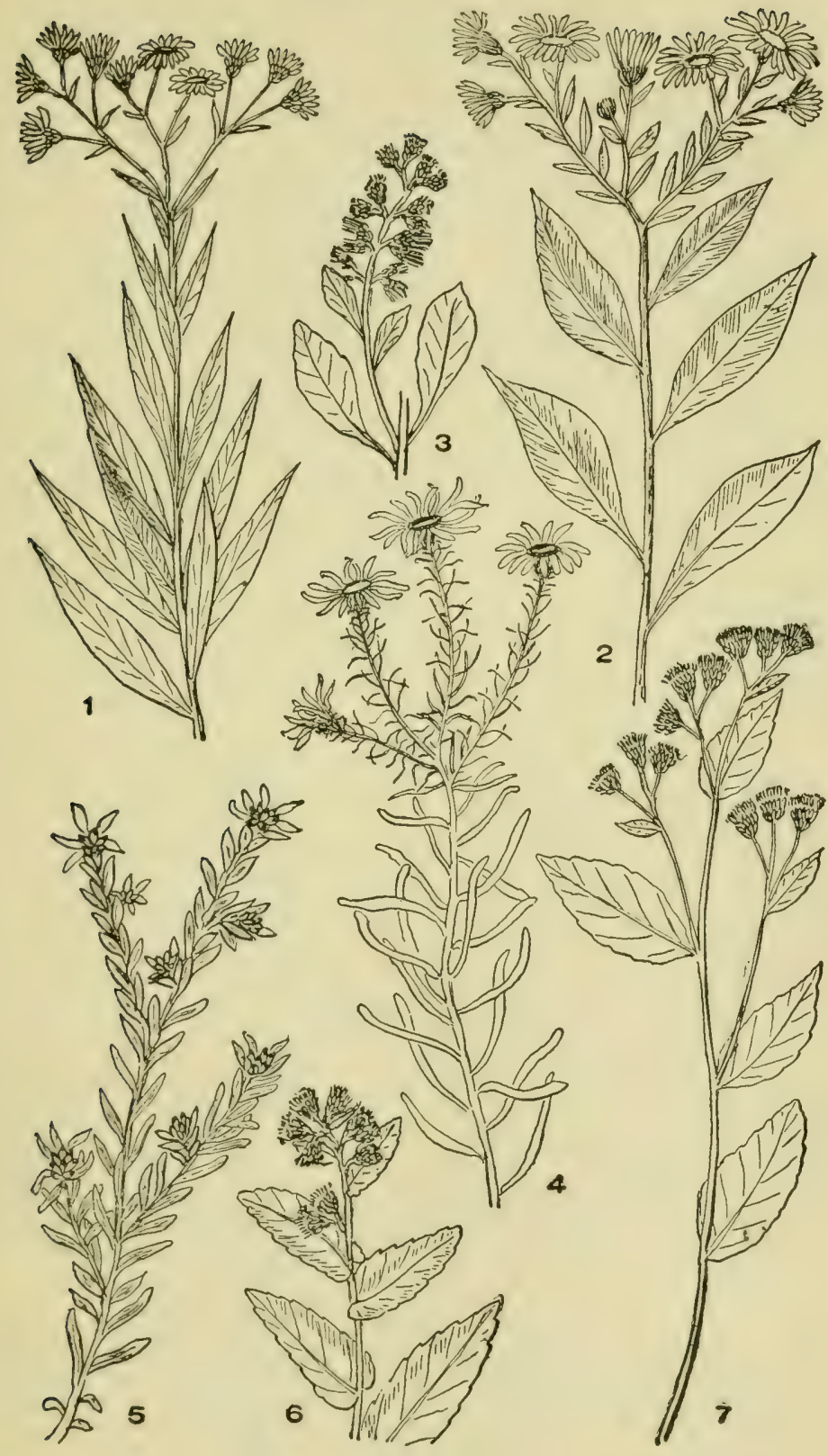

Plate 182

1. Aster spectabilis. 2. A. salicifolius. 3. A. radula. 4. Ionactis linariifolius. 5. Aster paniculatus. 6. A. acuminatus. 
white or tinged with violet. Low grounds, throughout most of our range. Aug.-Oct.

46. A. Tradescanti, L. (Fig. 1. pl. 184.) Micinalums Daisy. Stem branched, 2 to $5 \mathrm{ft}$. high. Leaves linear or narrow lince-shaped, the lower toothed at margins, the upper nearly or quite entire. Heads very numerous; rays white or purplish, short, the head being about 3 in. broad. Scales linear, acute. Ficlds and swamps, throughout our range. Aug.Oct.

47. A. ericoides, L. (Fig. 5, pl. 183.) White Meıti Aster. FrostwEED ASTER. Smooth, stem 1 to $3 \mathrm{ft}$. high, branched above. Upper leaves linear or awl-shaped, firm, rigid, to $3 \mathrm{ill}$. long. Heads very numerous, small, $\frac{1}{2}$ in. broad. Rays white. Dry soil, in all our area. Sept.-Dec.

48. A. Pringlei, (A. Gray) Britton. (Fig. 4, pl. 184.) Pringle's Aster. Stem higher than the last. Basal leaves long lance-shaped to spatula-form. Heads usually smaller than No. 47. Rocky places, Mass., Vermont, and westward. Aug.-Oct. Regarded as variety of A. cricoidcs by Dr. Gray.

49. A. hirsuticaulis, Lindl. (Fig. 5, p!. 184.) IIAiry-stemmed Aster. Stem erect, slender, 13 to $3 \mathrm{ft}$. high, notably downy, branches short. Leaves linear lance-shaped, the lower about 6 in. long by 1 in. wide, the margins toothed, the upper, smaller leaves with entire margins. Heads somewhat but usually not notably one-sided, clustered along the stem; rays white. Woods, New York, Penna., and southward. Aug.-Oct.

\section{Inflorescence largely Unilateral (Secund)}

50. A. lateriflorus, (L.) Britton. (Fig. 4, pl. 183.) Stanved Aster. Nuch branched, more or less downy; stem 1 to $5 \mathrm{ft}$. high. Leaves broad lance-shaped, tapering at each end, the margins toothed, 2 to $5 \mathrm{in.}$ long. Heads numerous, forming short dense cluster's aloug the branches; rays white or purplish; disk flowers purple; seales of the involuere linear, overlapping in 3 or 4 rows. 'Thickets and fields, in all our range. Aug.-Oct.

51. A. vimineus, Lam. (Fig. 3, pl. 1S3.) Small IVirte Aster. Much branching, "2 to $5 \mathrm{ft}$. high, smooth. Leaves linear, the lower somewhat dentate with low teeth. Ileads very numerous, crowded upon the spreading branches, largely unilateral. liays numerous, white; seales linear, acute. Moist soil. Common. Aug.-Sept.

52. A. multiflorus, Ait. (Fig. 1, pl. 183.) White Wre.itir $\Lambda$ strir. Dexse-fooweres Aster stem ereet, hut freely branching, bushy, eovered with a whitish down. Joaves rigid, linear, not toothed, somewhat clasping at base. Ileads densely erowled aloner the spreading, more or less one-sided, branches; rays 10 to 20 , white or bluish. Dry fields, in all our area. Aug.-Nov.

\section{ERIGERON. L.}

Jerlos with alternate or hasal leaves, with 1 to many heads, with disk and raty forets, the latter white or colored, never yellow (rarely the heads are without ray florots). Involuere of nearly equal, narrow bracts nearly in one row; receptace flat or convex, naked. Anthers without tails at the base, obtuse at alfex. Aigrette of a single row of fragile bristles. 

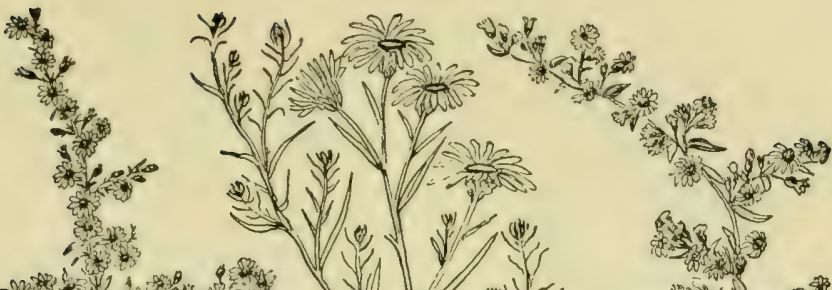

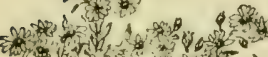

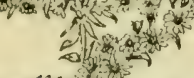

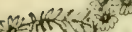
भी

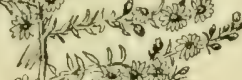
होi. $\mathrm{s}^{\mathrm{a}} \mathrm{s}$

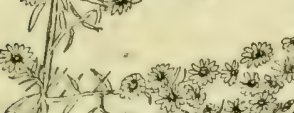
$2+\frac{1}{4}=2$
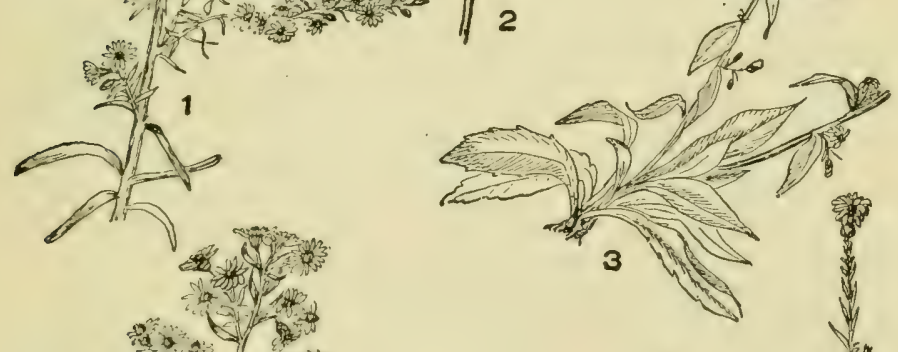

$\rightarrow$ a 100

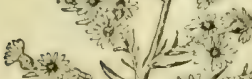

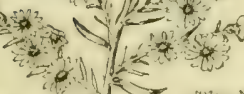
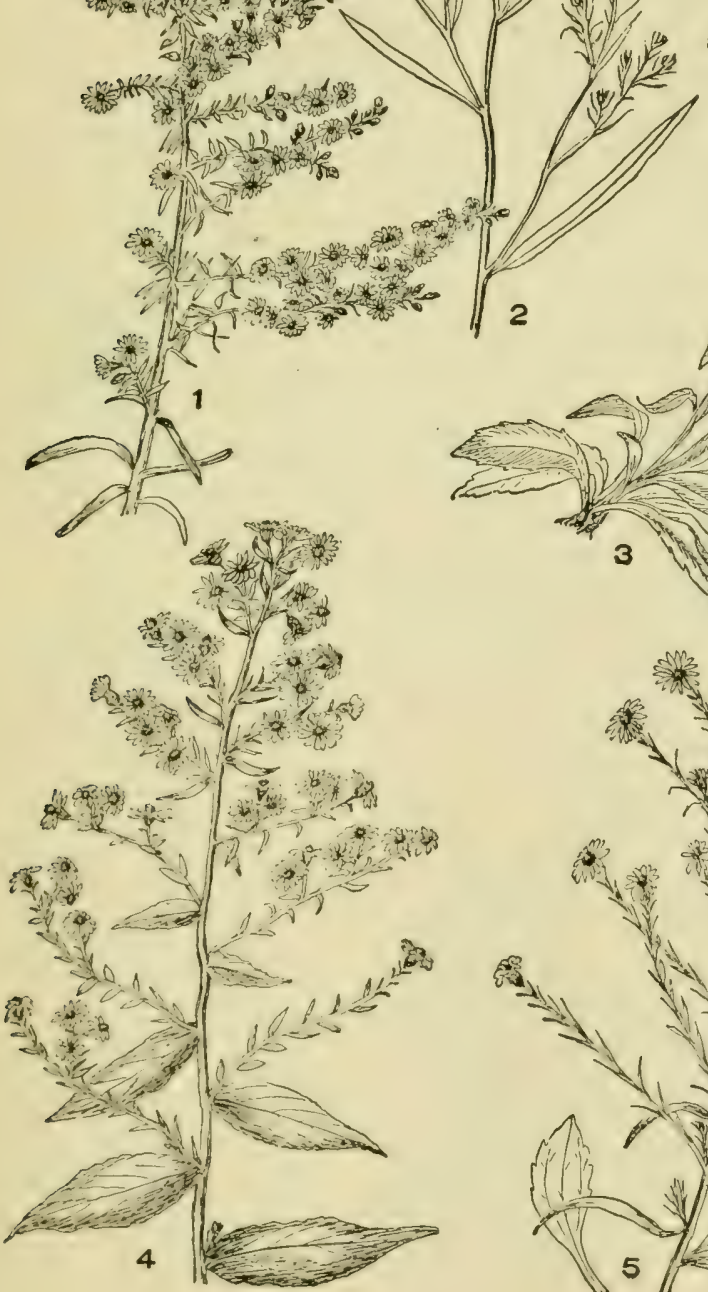
stivis 2.

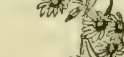
in

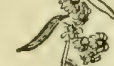
conterses (1) 0

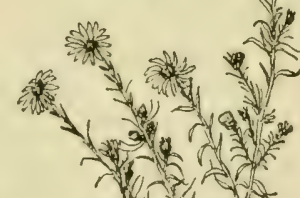

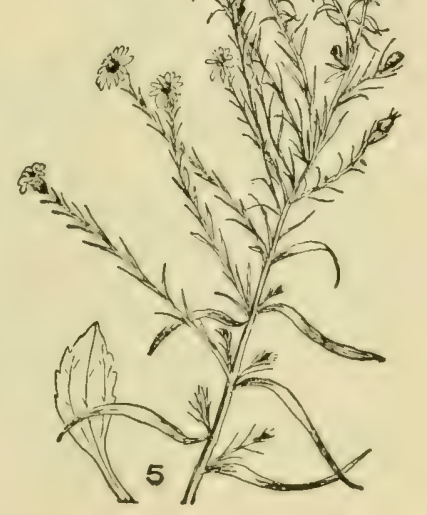

Plate 183

1. Aster multiflorus. 2. A. dumosus. 3. A. vimineus. 4 A. laterifloruz. 5. A. ericoides. 

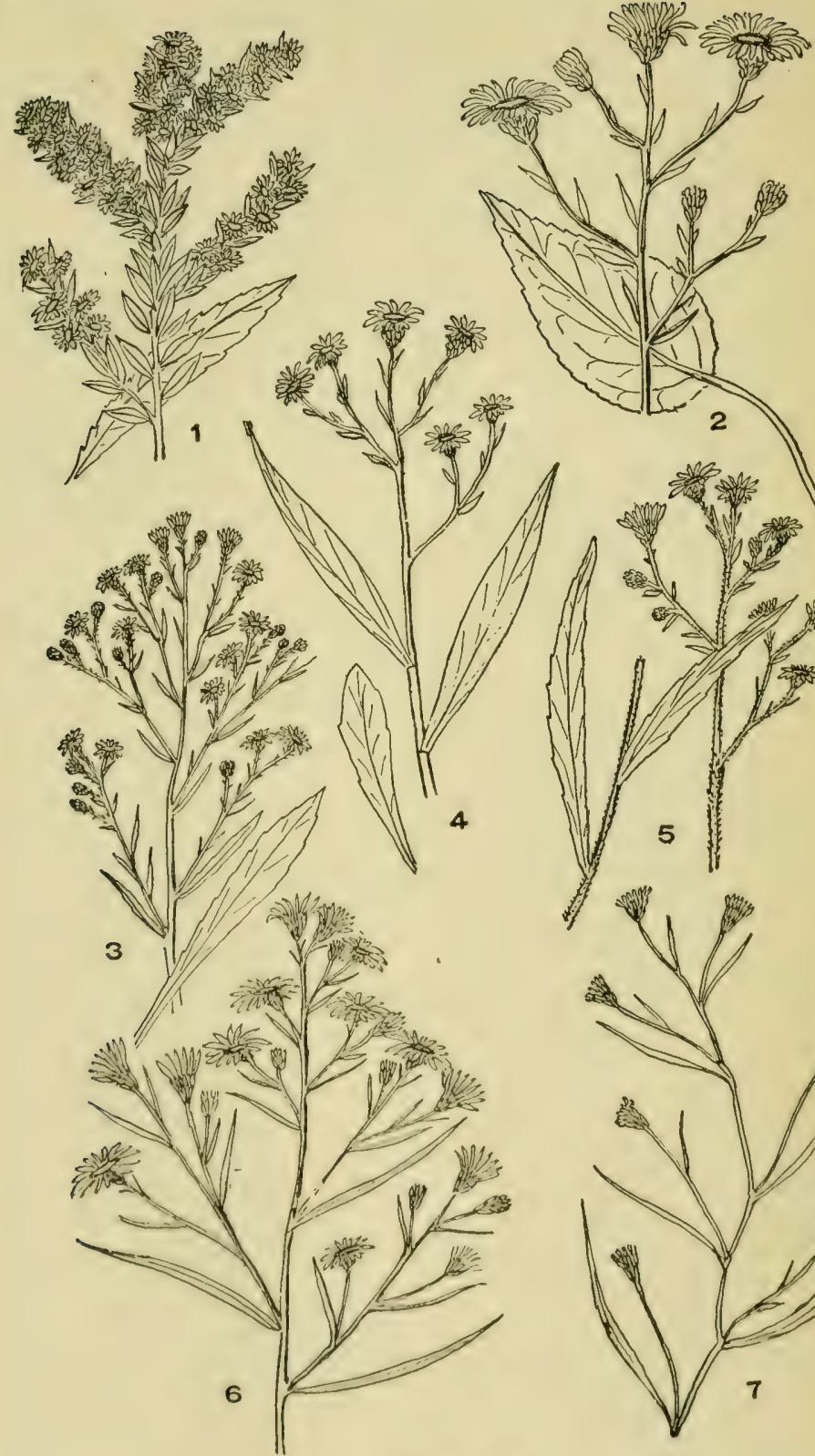




Plate 185

1. Erigeron philadelphicus. 2 E. annuus. 3. E. pulchcllus. 4. E. hyssopifolius. 5. E. ramosus. 6. Leptilon canadense. 


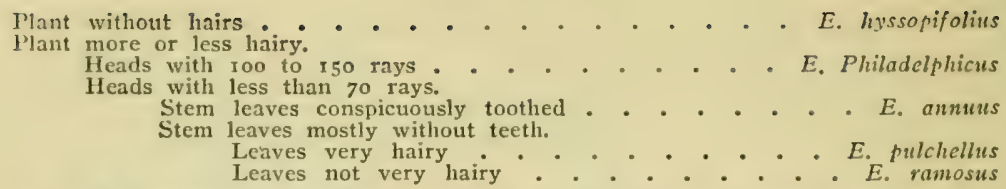

1. E. hyssopifolius, Michx. (Fig. 4, pl. 185.) Hrssop-leaved ErigERoN. Stem slender, 6 to 15 in. high, from slender rootstocks. Leaves -numerous, the upper linear, acute at apex, tapering to base, the lower slightly broader and less acute. Heads solitary or several, usually 1 to a branch, the branch being prolonged to a slender naked flower stem, about $\frac{1}{3}$ to $\frac{2}{3}$ in. broad; rays 20 to 30 , white or purplish. Northern part of New England. July-Aug.

2. E. pulchellus, Michx. (Fig. 3, pl. 185.) Romin's Plantain. (E. bellidifolius, Munhl.) Whole plant very hairy, stem slender, not branching, 1 to $2 \mathrm{ft}$. high, bearing a few remote, small leaves, the lower leaves tufted and larger; the upper without or with a few marginal teeth, the lower with low teeth. Heads 1 to 6 at and near the summit of the stem, on slender flower stems. Rays about 50, light bluish purple. Moist banks and hills, common. April-June.

3. E. philadelphicus, L. (Fig. 1, pl. 185.) Common Fleamane. Stem 1 to $3 \mathrm{ft}$. high; plant hairy but less so than No. 2, especially the leaves. Leaves of the stem partly elasping, rather numerous, thin, with a thick midvein, oblong, the lower coarsely toothed. Ileads rather numerous; rays 100 to 150 , rose purple, very narrow. Fields and woods, common. April-Aug.

4. E. annuus, Pers. (Fig. 2, pl. 185.) Sweet Scabious. DaisY Fledbane. Stem 1 to $4 \mathrm{ft}$. high, bramched above, with few hairs. Leaves all coarsely tonthed, the lower egg-shaped, tapering to a long leaf-stalk, the upper lance-slaped, apex sharp pointed, the base narrow or rather Jroad at its attachment to the stem. Heads in a broad diffuse cluster, rays 40 to 70 , narrow, white or tinged with purple. Fields and roadsides. Common. May-Nov.

5. E. ramosus, (Walt.) BSP. (Fig. 5. pl. 185.) DaISY Fleabane. Stem branching, 1 to $3 \mathrm{ft}$. high. Resembles the last, the upper leaves without teeth or with very few. Rays white or purplish. Fields and roadsides. Common. May-Nov.

\section{I6. LEPTILON, Raf. (Erigeron, L.)}

Annual herb, freely branching, with many flower heads, with ineonspicuous rays which searcely exeeed the bristles of the aigrettes. Involuere seales in 2 or 3 series; ray flowers pistillate. Bristles of the aigrette in a single series.

L. canadense, (L.) Britton. (Fig. 6, pl. 185.) IJonse Werd. CaNADA Fubabane. (Frigeron canalensis, L.) A common weed in dry fields; strm crect, wand-like, $3 \mathrm{in}$. to $6 \mathrm{ft}$. or more high, the whole plant eovered with bristly hairs. Leaves linear, the upper very narrow, the lower be. coming lance-shaped with a few remote teeth, the upper with rough margrins. Heads very numerous, of no beauty, the rays (which are not very noticeable), white. Roadsides, abandoned fields, etc. Aug.-Nov. 

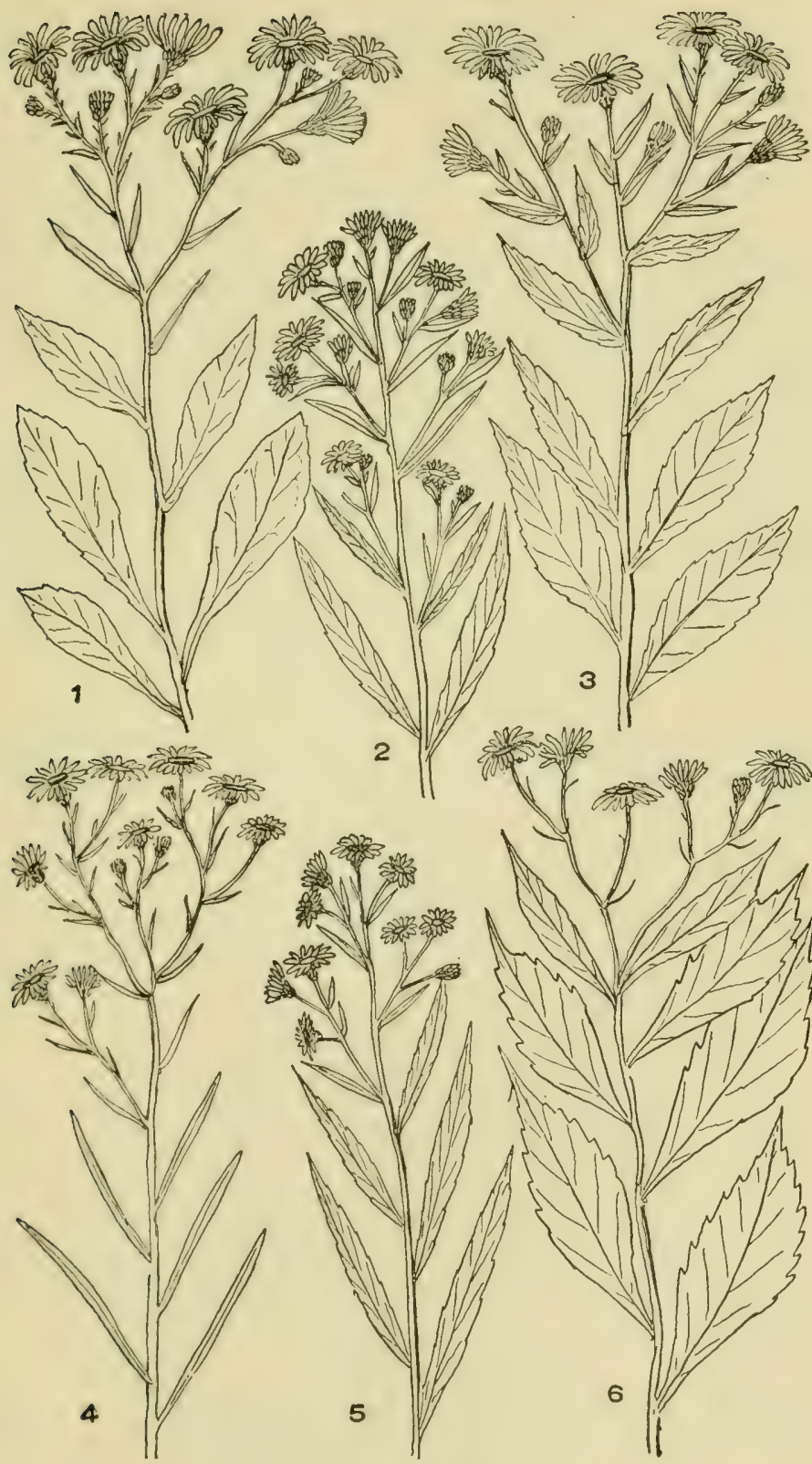

है। हौन
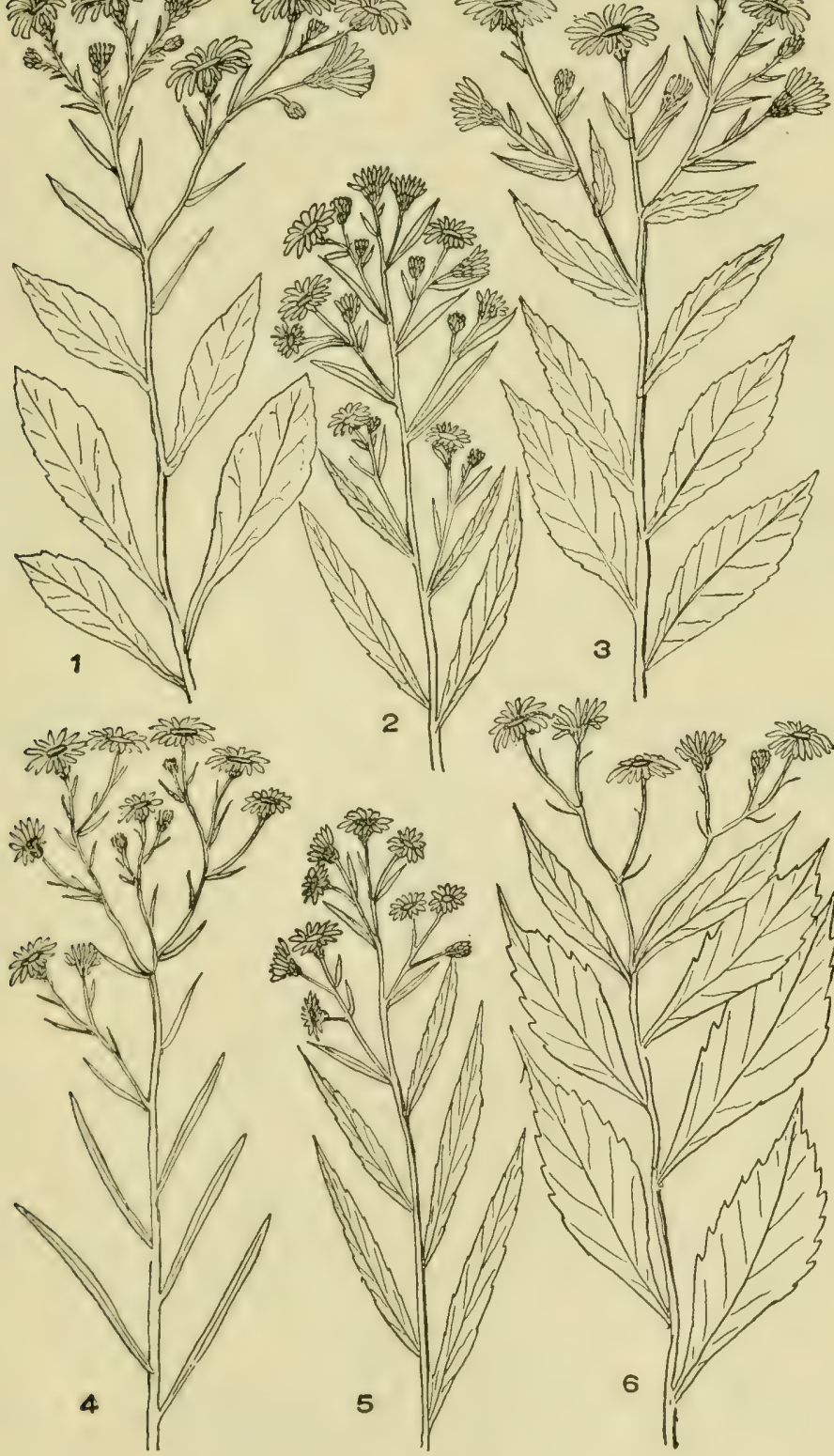

PLATE 186

1. Doellingeria umbellata. 2. D. infirma. 3. Baccharis halimifolia 4. Aster ptarmicoides. 5. Gifola germanica. 6. Pluchea foctida. 7. P. camphorata. 
17. DOELLINGERIA, Nees.

Perennial herbs resembling the Asters. Basal leaves none, and those of lower part of stem reducec to seales. Upper leaves in our species broador narrow-lance-shaped with margins entire. Heads in broad rather flat clusters, conspicuous, with white rays, which are pistillate. Florets of the disk white to greenish, with both stamens and pistils. Involuere cup- or saucer-shaped, of several series of closely laid overlapping bracts. Aigrette of 2 rows of bristles

1. D. umbellata, (Mill.) Nees. (Fig. 1, pl. 186.) Flat-Top Whitf Aster. (Aster umbellatus, Mill.) Stem smooth or somewhat downy at top, 2 to $7 \mathrm{ft}$. high, leafy to the branching summit. Leaves lance-shaped, narrow, taper-pointed, 3 to 6 in. loner. Ileals numerous in a flat cluster. Rays 10 to 15 . Moist thickets. Common. July-Oct.

2. D. humilis, (Willd.) Britton. Broad-Leaved White Aster. (Aster umbcllatus, Var. latifolius, Gray.) Leaves broader than those of the preceding species, egg-shaped to broad lanee-shaped, 1 to $3 \mathrm{in}$. long. Moist thickets, southern New Jersey and Penna. July-Sept.

3. D. infirma, (Michx.) Greene. (Fig. 2, pl. 186.) Cornel-Leaved Aster. (1ster informus, Michx.) Stem often more or less zigrang, 1 to $3 \mathrm{ft}$. high. Leaves inversely cyg-shaped or oblong. IIeads few or several. Open woods, Mass., New York and southward. Aug.-Sept.

\section{IONACTIS, Greene}

Aigrette of fruit not distinctly double; seales of involuere without herbaceous tips. Otherwise mostly resembling the Asters; rays violet, bearing pistils only.

I. linariifolius, (L.) Gireene. (Fig. 4, pl. 182.) StrFF-Leaved AsTER. (Aster linariifolius, L.) Stems tufted, several springing from a common root, 3 to $20 \mathrm{in}$. high. Leaves linear, rigid, about 1 in. long, rough above, passing to stifl seales. IIeads solitary at the ends of the branches, about 1 in. broad. Rays 10 to 15, violet. A handsome plant with rich violet ray flowers. Dry soil, throughout our range. July-Oet.

\section{I9. BACCHARIS, L.}

Shrubs with smooth stems and leaves and with white or yellow flowers, our species found in salt marshes. Flowers dioccious, i. e., with pistillate flowers on one plant and staminate on another. Flowers all tubular.

B. halmifolia, I. (Fig. 3, pl. 186.) Grotndser, Busir. A branehing, smooth shrul), 3 to $10 \mathrm{ft}$. high, foumd in salt maxshes, with thick wedireformed leaves very enarsely toothed or somewhat lobed or less freguently with entire margins. Heads in long, somewhat eompact clusters, those? with pistillate flowers conspicuous later in the season by the long white plumes. Sept.-Nov.

\section{GIFOLA, Cass.}

White, woolly herb, with alternate seale-like leaves and small woolly heads groujed in compact rounded elusters. Involucre small; receptacle clongated, top-shaped or cylindric. Onter florets pistillate, without aigrette; inner flowers crowned with an aigrette of still bristles. 


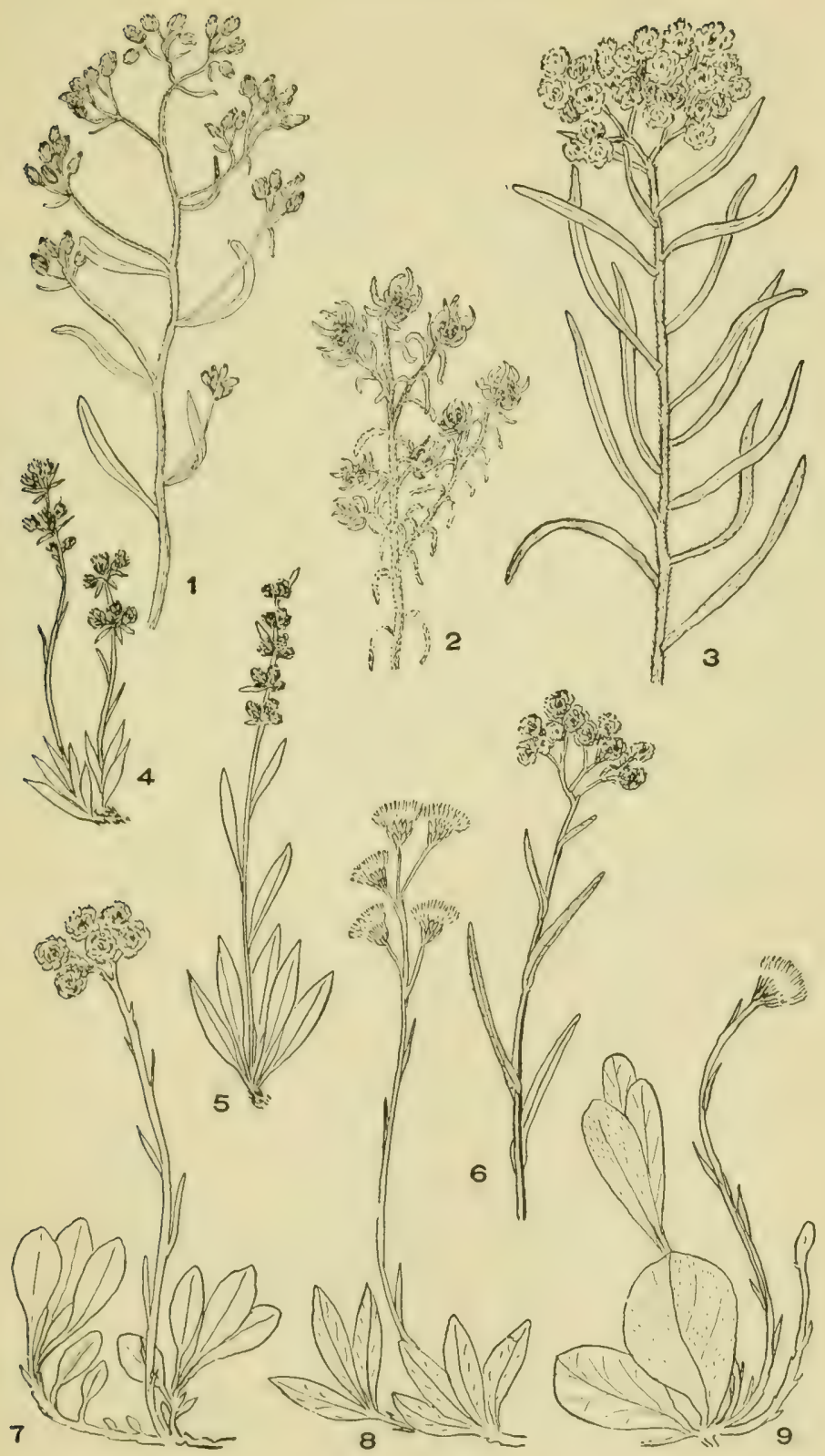

PLATE 187

1. Gnaphalium obtusifolium. 2. (A. uliginosum. 3. Anaphalis margaritacea. 4. (inaphalium supinum. 5. (:. purpureum. 6. G. decurrens. 7. Antennaria neodioiea. 8. A. neglecta. 9 A. plantaginifolia. 
G. germanica, (L.) Dumort. (Fig. 5, il. 386.) CtrdweEd. Stem erect, 4 to $18 \mathrm{in}$. high, very leafy, terminated by a rouncied cluster of woolly heads from which rise one or more branches, each also terminated by a group of heads, 12 to 30 in each cluster. Dry fields, southern New York and Penna. July-Oct.

21. PLUCHEA, Cass.

Our species herbs cmitting an odor of camplor; alternate leavas, coarsely toothed and with heads of purple flowers, all of which are tubular, in terminal clusters. The margin 1 florets are pistillate, those of the center with both stamens and pistils. Style undivided or 2-eleft; receptacle flat, naked; involucre of overlapping scales in several series.

Leaves without leaf-stalks, heart-shaped at base . . . . . . . P. foctida Leaves with short leaf-stalks, not heart-shaped $\cdots^{\circ} \cdot P^{*}$. camphorata

1. P. foetida, (L.) DC. (Fig. 6, pl. 186.) Viscid Mansm FleaBANE. Perennial, 2 to $3 \mathrm{ft}$. high, with ohlong coarsely toothed leaves which are broad, somewhat heart-shaped at base and directly attached to stem. Swamps and low grounds, southern New Jersey and southward. July-Sept.

2. P. camphorata, (T.) DC. (Fig. 7, pl. 186.) Spicr Marsir Fue.BAxe. Annual, 2 to $3 \mathrm{ft}$. high. Leaves egg-shaped on short leaf-stalks margins coarsely toothed. Salt marshes, New Hampshire and southward. Aug.-Oct.

22. ANTENNARIA, Gaertn.

Perennial herbs, white woolly, with alternate and basal leaves and small heads with disk flowers only. Heads many flowered, the pistillate florets on one plant the staminate on another or with the staminate or pistillate flowers there may be those bearing both pistils and stamens. Bracts of the inwoluere overlapping in several series, leathery and dry, the outer scilles usually shorter and woolly. Receptacle flat or convex, not clatfy. Anthers lailed at base. Aigrette of a single row of bristles, in the pistillate or the perfoet flowers these bristles somewhat united at base. All of our species have stolons or suckers, which arise from beneath the ground and spread out horizontally or are more or less ascending.

Basal kaves not more than $1 \frac{7}{2}$ in long.

Bracts of heads bearing pistils lance-shaped, acute.

Basal leaves spatula-formed ......... A. ncodioica Basal leaves inversely egg-shaped ${ }^{\circ} \cdot{ }^{*} \cdot{ }^{\circ} \cdot{ }^{*}$ A. neglecta

Basal leaves 3 to 5 in. long, stem leaves purplish $P$ Parlinii loasal leaves mostly more than $1 \frac{1}{2}$ long and $\frac{1}{2}$ in. wilc, leaves silky white

A. plantaginifolia

1. A. Parlinii, Fermald. Punte Everdastixg. Basal deaves large, broally coreshaped, olutuse, 3-surved. Stem 12 to $20 \mathrm{in.} \mathrm{high,} \mathrm{crowded}$ with spatulatormed leaves. Stem, leaves and stolons purple or purplish with colored hairs. Inwoluce of alonut 3 rows of bracts, $4 / 12$ to $5 / 12 \mathrm{in}$. high. Sityles becoming crimson. Open woods, New England, and westward. Mlay-July.

2. A. neodioica, Greene. (Fig. 7, pl. 187.) Sumritr Catsfoot. Similar to No. 1, but the bracts of the involuere of the pistil bearing heads are lanireshriped and arule. In wools and shady places, Maine to Mass. and New York. April-July.

The form found in our area is, Var. grandis, Fernald. 


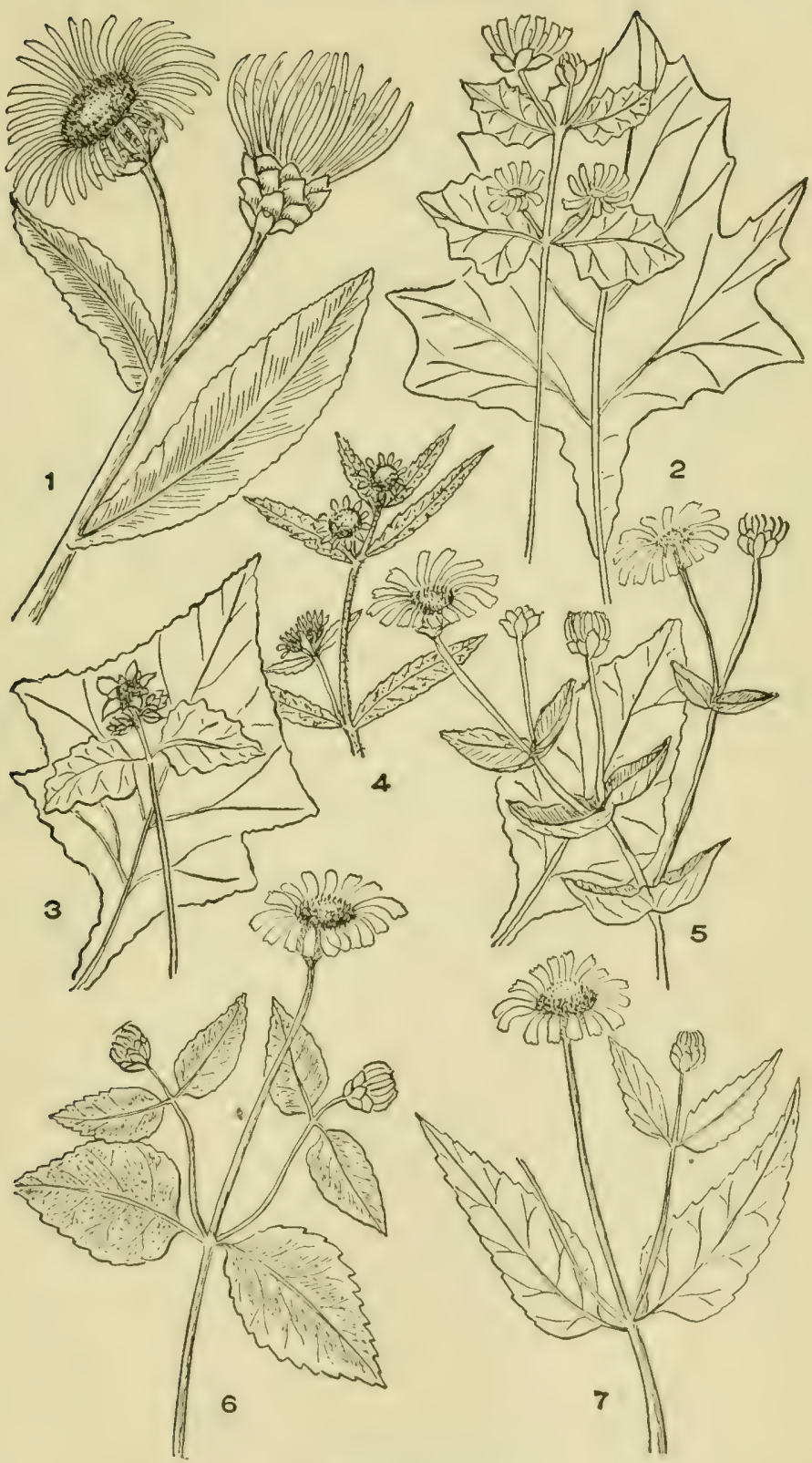

Plate 188

1. Inula Ifelenium. 2. Polymnia uvedalia. 3. P. canadensis. 4. Eelipta alba. 5. Silphium perfoliatum. 6. Ileliopsis scabra. 7. II. helianthoides. 
3. A. neglecta, Greene. (Fig. S, pl. 187.) Fiemp Catsfoot. Similar to No. 2, but basal leaves are inversely egg-shaped. Abundant in old fields and pastures. April-June.

4. A. plantaginifolia, (L.) Richards. (Fig. 9, pl. 187.) PlantainLEAVED Evilisistisg. Larger than either of the preceding forms and leaves much broader. Open woods, in all of our area. April-June.

\section{ANAPHALIS, DC.}

IIas the characters of Antemarin but in the pistillate flowers the bristles of the aigrette are not united and those of the staminate flowers, which are often club-shaped at the top are, in Anophalis, not thickened or only slightly so. There are no stolons (runners).

A. margaritacea, (L.) Benth. and Ilook. (Fig. 3, pl. 187.) IaAngeFlowren Evirl.stivg. Plant usually rather more than a foot high, but sometimes reaches a height of $3 \mathrm{ft}$., the stem white woolly, branching at top into a broad rather flat cluster of rounded white heals. Leaves alternite, linear lance-shaped, light green but downy and woolly beneath. IIeads many, about $\frac{3}{4}$ in. broad, round, the scales of the involuere pearly white. Dry lilly fields. Common. July-Sept.

\section{GNAPHALIUM, L.}

Wonlly heris with alternate leaves and clusters of many or few heads, branching diffusely or nearly erect. Heads of tubular flowers only, the outer bearing pistils the central all perfect, $i$. $e$., with both stamens and pistils. Scales of the involuere dry, leathery, white or colored; receptacle llat, without chaff. Anthers tailed at bise. Aigrette of a single row of bristles.

Low, tufted mountain herbs with heads in a rounded group or arranged in such groups one above the other, involucre bracts turning brown . . G. supinum Low diffuse herbs with heads in dense leafy rounded groups, bracts turning brown - . . . . . . . G. uliginosum Erect, somewhat tall herbs, with heads in spreading diffuse clusters. Leaves not decurrent on the stem; heads mostly conical or slender egg-shaped ............ G. obtusifolium I.eaves decurrent on the stem, heads bell-shaped $:{ }^{*}:$ G. decurrens $^{\circ}$ Erect, the heads arranged in a spike or terminal cluster . . . . G. purpurcum

1. G. obtusifolium, I. (Fig. 1, pl. 187.) Swert Evencastrang. $(C$. polyccphalum, Mich.) Stem ercet, 1 to $3 \mathrm{ft}$. high, somewhat woolly. Lealves laner-shatperl to lnear, without leaf stalks, white woolly beneath, usually dark green above. Ileads very numerous in elusters of 1 to 5 which altogether form a large, sprealing difluse compound cluster. The individual heads conical then exw-shaped. Seales white, eger-shaped. Common in fields and woods. Aug.-Sepit.

2. G. decurrens, Ives. (Fig. 6, pl. 187.) Clamm Everiastixg. sirem $2 \mathrm{to}: 3 \mathrm{ft}$. high; plant much orsembling the preceding, hut the laneeshaped leaves are decurrent on the stem. Heads less conical. Open places, most of our area. July-Sept.

3. G. uliginosum, T. (Fig. 2, pl. 187.) Tow Cunwern. Mnstly dif-

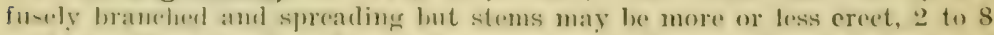
in. high. Plant woolly. Leaves linear or spatula-linear. Heads in rounded 
clusters, terminal to the main stem or to short branches along the stem. Common in low grounds. July-Sept.

4. G. supinum, L. (Fig. 4, pl. 187.) DwarF CudweEd. 'lufted, about $2 \mathrm{in}$. high; leaves mostly basal, linear or linee-shaped, with 1 or 2 along the stem. Whole plant white woolly. Heals 1 or more, when several, a spike-like arrangement. Flowers yellowish. Rare, summits of the White Mountains. July-Aug.

5. G. purpureum, L. ( Fig. 5, pl. 157.) Punple Cudweled. Simple or branched from the base, stem from $2 \mathrm{in.}$ to $2 \mathrm{ft}$. high, woolly or silvery with a silky coat. Leaves narrow, almost linear, or the lower spatulaformed, green above, silky below. Heads attached almost directly to the stem, forming groups at the upper leaf-axils and an intermpted spike above. Involuere bracts brown or purple. Dry sandy soil, throughout our area. May-Sept.

\section{INULA, L.}

Our only species a tall, coarse herb with large, alternate leaves and large yellow ray llowers. P'lant not floceose-woolly, but decidely downy or hairy. Involucre of overlapping scales; receptacle flat or convex, naked; ray flowers bearing pistils, disk flowers bearing both stamens and pistils. Anthers arrow-formed at base; aigrette simple.

I. Helenium, L. (Fig. 1, pl. 188.) ElEcAMPANE. Stems in tufts, 2 to $\mathrm{S} \mathrm{ft}$. high, downy above. Leaves large, the Jower egrg-shaped, those of the stem more or less heart-shaped at base and clasping the stem, woolly beneath. Rays very numerous, narrow, yellow. Head, including rays, 2 to $4 \mathrm{in}$. broad. Along roadsides and in fields. An introduced plant. JulyAug.

\section{POLYMNIA, L.}

Tall clammy herbs with opposite leaves and yellow fowers. Icaves broad, lobed or angled, the lowest sometines alternate. Ileads in terminal clusters; involucre of about 2 rows of bracts, the outer of abont 5 rather broal ones, leaf-like, the immer narrower and more numerons. liay flowers bearing pistils and producing seeds, the disk flowers with both stamens and pistils but producing no fruit. lieceptacle flat, chafly.

1. P. uvedalia, L. (Fig. 2, pl. 188.) YELLOW LEAF-CUP. Stout, rough, 3 to $10 \mathrm{ft}$. high. Leaves broally regreshaped, angled and somewhat Jobed, the lower leaves sometimes a fort long, narrowed to a winged leafstalk. Rays 10 to 15 , yellow, $\frac{1}{2}$ to 1 in. long, apex 3 toothed. Rich woods, southern part of our area, New York, and southward. July-Oct.

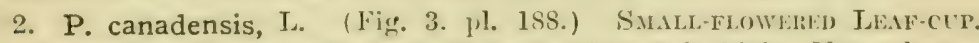
Loss stout than the preceding, viseid downy, 2 to $5 \mathrm{ft}$. hinh. Tpper leaves deeply 3- to 5-lobed with sharp angles, the lower large, the terminal lobe rounded. Heads small; rays 5, small, shorter than the involucre bracts, or minute or wanting, whitish yellow. Moist shaded places, southern part of our area, New York, and southward. June-Sept.

\section{SILPHIUM, L.}

Tall, rough, coarse perennial herbs with resinous juice, with opposite or alternate leaves and with clusters of yellow-flowered heals. II auls with mumerous rays bearing pistils and producing fruit. Disk llowers with stamens and pistels producing no fruit. Seates of the broad involucre over- 
lapping, in several series. Receptacle flat, chaffy, the chaff subtending the ray flowers.

1. S. perfoliatum, L. (Fig. 5, pl. 1SS.) Cup Plant. Stem square, stout, branched above, 4 to $\mathrm{S}$ ft. high. Leaves opposite, the upper united by their bases, the lower contracted to margined leaf-stalks, egg-shaped, coarsely toothed, 6 to $15 \mathrm{in}$. long, 4 to 8 wide. Heads numerous, 2 to 3 in. broad, with 20 to 30 yellow rays. July-Sept.

2. S. trifoliatum, L. WIIORLed Rosin-WEed. Stem 4 to $7 \mathrm{ft}$. high, branched at the top. Leaves lanee-shaped, toward the middle of the stem in whorls of 3 or 4 , usually with quite short leaf-stalks. Heads several, often numerous, $1 \frac{1}{2}$ to $2 \mathrm{in}$. broad. Rays 15 to 20 . Woods, dry plains, Penna., westward and northward. July-Sept.

\section{HELIOPSIS, Pers.}

Perennial herbs with opposite leaves and large showy heads with yellow disk and ray flowers. Leaves on leaf-stalks, 3-ribbed. Heads on rather long flower stems, terminal or axillary; involuere of 2 or 3 series of scales, nearly equal, the outer leaf-like; receptacle convex or conic, chaffy. Ray flowers bearing pistils, and producing fruit, disk flowers with stamens and pistils.

1. H. helianthoides, (L.) BSP. (Fig. 7, pl. 188.) False SunFLower. Stem 2 to $5 \mathrm{ft}$. high, nearly smooth. Leaves opposite or occasionally in 3 s, lance-shaped to egg-shaped on moderately long or on short leaf-stalks, 3 to $6 \mathrm{in}$. long. Heads about $2 \mathrm{in}$. broad, on long flower stems; rays linear, showy. Involucre scales oblong, or linear. Open places, throughout our range. July-Sept.

2. H. scabra, Dunal. (Fig. 6, pl. 188.) Rougin Ox-ExE, Rough, at least above, especially the leaves. Otherwise similar to the precediner. Dry open places, through all but the southern third of our range. JuneSept.

\section{ECLIPTA, L.}

A rough branching herb, annull, with opposite leaves, hairy, with heads of flowers terminal or axillary and with small, nearly white, ray flowers. Leaves without leaf-stallis. lieceptacle flat or eonvex, chaffy; ray flowers bearing pistils and producing fruit; disk flowers bearing both stamens and pistils, also fertile.

E. alba, (L.) Hassk. (Fig. 4, pl. 188.) Echrpts. A rough plant with a procumbent or crect branching stem $\frac{3}{2}$ to $3 \mathrm{ft}$. high, and lanceshaped leaves with low teeth at the margins, 1 to 5 in. long. Ileads on very short flower stems, numerous, about $\frac{1}{2} \mathrm{in.}$ broad, with short white rays. Along streams and in waste places. Naturalized. July-Oct.

\section{RUDBECKIA, L.}

Instly rough herbs with rigid stems and leaves, the latter altermate and showy, torminal heads with comspienous yellow rays. laves, lobed or not, the lower on leaf-stallis, the upper without leaf-stalks. IIeads with many ray flowers; the disk flowers tubular, purple; receptacle conical or in form of a column, chafly. Involuere scales leaf-like in about "2 or more series. liay llowers producing no fruit, disk flowers with stamens and pistils, fruit producing. 


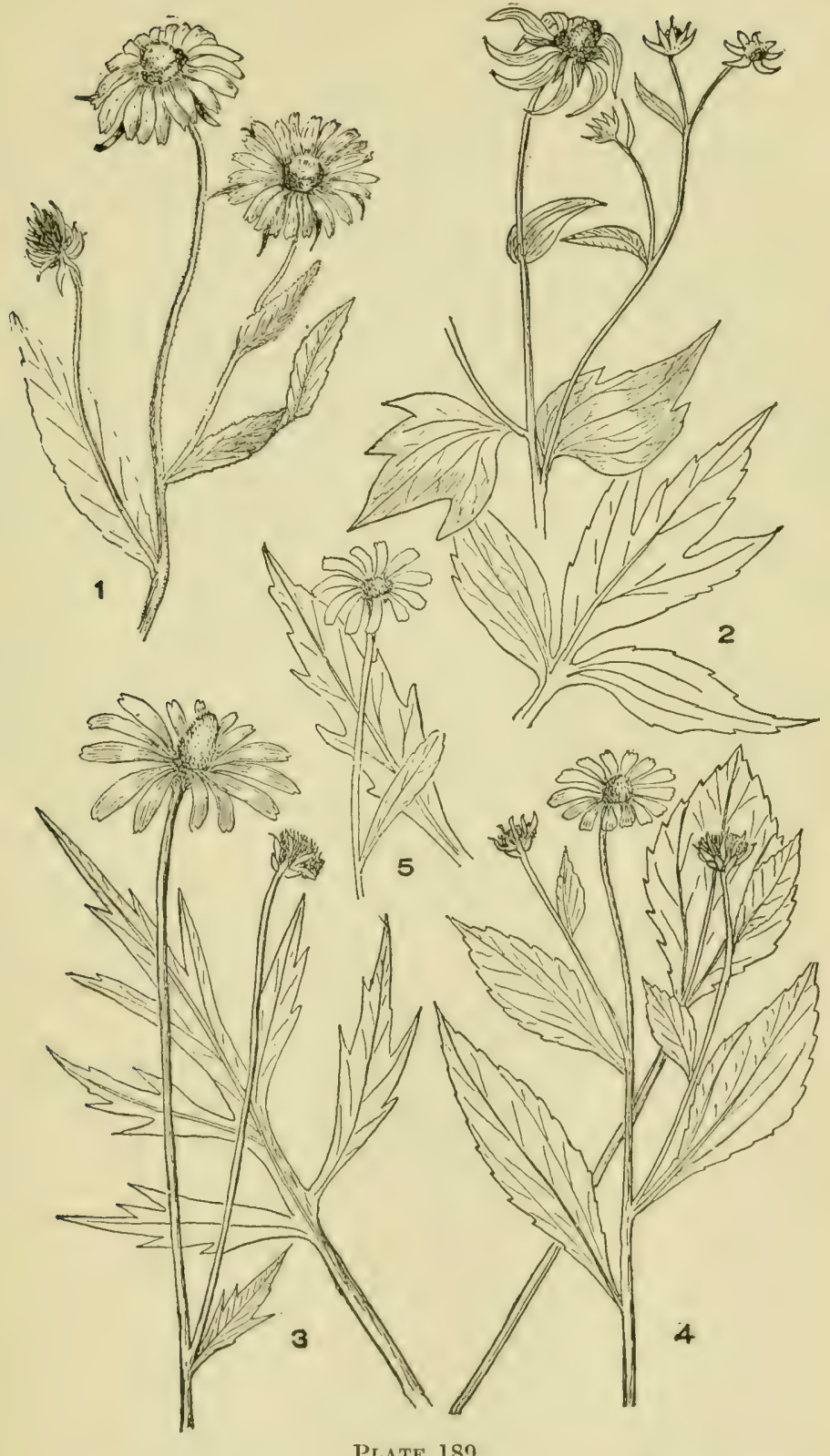

Plate 189

1. Rudbeckia hirta. 2. R. triloba. 3. R. laciniata. 4. R. fulgida. 5. R. speciosa. 
Leaves deeply 3 -lobed . . . . . . . . . R. triloba Lower leaves deeply cut, iorming a serics of opposite lobes (pinnatifid)

Lower leaves moderately cut, forming

- $R_{\text {s specioso }}$ Lower leaves spatula-formed, lance-shaped or egg-shaped with irregular, not very sharp teetl

Leaves all lance-shaped, not deeply toothed or cut . . . . . R. hirta

1. R. triloba, L. (Fig. 2, pl, 189.) THin-Leaved Cone-Flower. Stem ereet, somewhat branched, rather romgh, 2 to $5 \mathrm{ft}$. high. Leaves"thin, rough on both sides, the lower deeply cut into 3 lobes, on leaf-stalks, the upper lance-shaped to egre-shaped, 3-nerved, without leaf-stalls. Heads about 2 in. broad, each on a slender flower stem; rays 8 to 12 , yellow, or at base purple. Involucre bracts linear. Moist soil, New Jersey and south. ward. June-Oct.

2. R. hirta, L. (Fig. 1, pl. 189.) Black-eyed Susan. Yellow DAISY. Usually very hairy throughout. Stem simple or with few branches. Leaves all lanee-shaped with remote low teeth at the margins or entire, 3-nerved, the lower narrowed at base to a leaf-stalk. Heads few, 2 to $4 \mathrm{in}$. broad; the disk glogose or egg-shaped with dark purple or brownish tubular florets; rays 10 ot 20, orange; bracts of the involucre very hairy. Very common in fields and meadows. May-Sept.

3. R. fulgida, Ait. (Fig. 4, pl. 189.) Orange Cone-flower. Stem I to $3 \mathrm{ft}$. high, slender, somewhat branching, rough. Leaves, the upper broad lance-shaped with rather remote, not sharp teeth, mostly tapering to a leaf-stalk at base, or directly attached to the stem; the lower leaves broadly cogg-shaped, spatula-formed, lance- or inversely-lanee-shaped. Heads with rounded disks and dark brown-purple tubular flowers; rays 10 to 15 , deep orange or bright yellow. Southern part of our area. Aug.-Oct.

4. R. speciosa, Wenderoth. (Fig. 5, pl. 189.) Sirowy Cone-Flower. Stem usually simple, 1 to $3 \mathrm{ft}$. high, more or less hairy. Lower leaves somewhat deeply slashed, forming shallow lobes with sharp points or without lobes, but with very sharp and conspicuous teeth; upper leaves lanceshaped with a few low and remote teeth or with none. Heads in a spreading cluster, the disk rounded, high, light brown; the rays nearly or quite an inch long, light yellow. Moist soil. Aug.-Oct.

5. R. laciniata, L. (Fig. 3, pl. 189.) 'TALL Cone-flower. Stem 3 to $12 \mathrm{ft}$. high, branched, smooth or nearly so. Lower leaves 3 to 5 lobed, the lobes themselves deeply eut into 3 to 5 subordinate lobes. Upper leaves

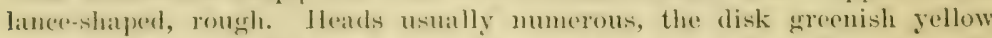
romuled of conical to almost cylindric; rays drooping 6 to 10 , bright yellow. Moist thickets. July-Sept.

\section{I. HELIAN'THUS, L.}

Tall branching horhs with (in all our species) the lower leaves opposite, the nuser altermate; and with larege heads of tubular and radiate flowers, the rays yellow. Ileads with several or many rays which do not produce fruit; disk llowers yellow, brown or purple, producing fruit. In: voluere of several series of overlapping bracts, which are more or léss leaflike. liereptatele llat or comves, chatly. Sigle branches tipped with hairy appendages. 

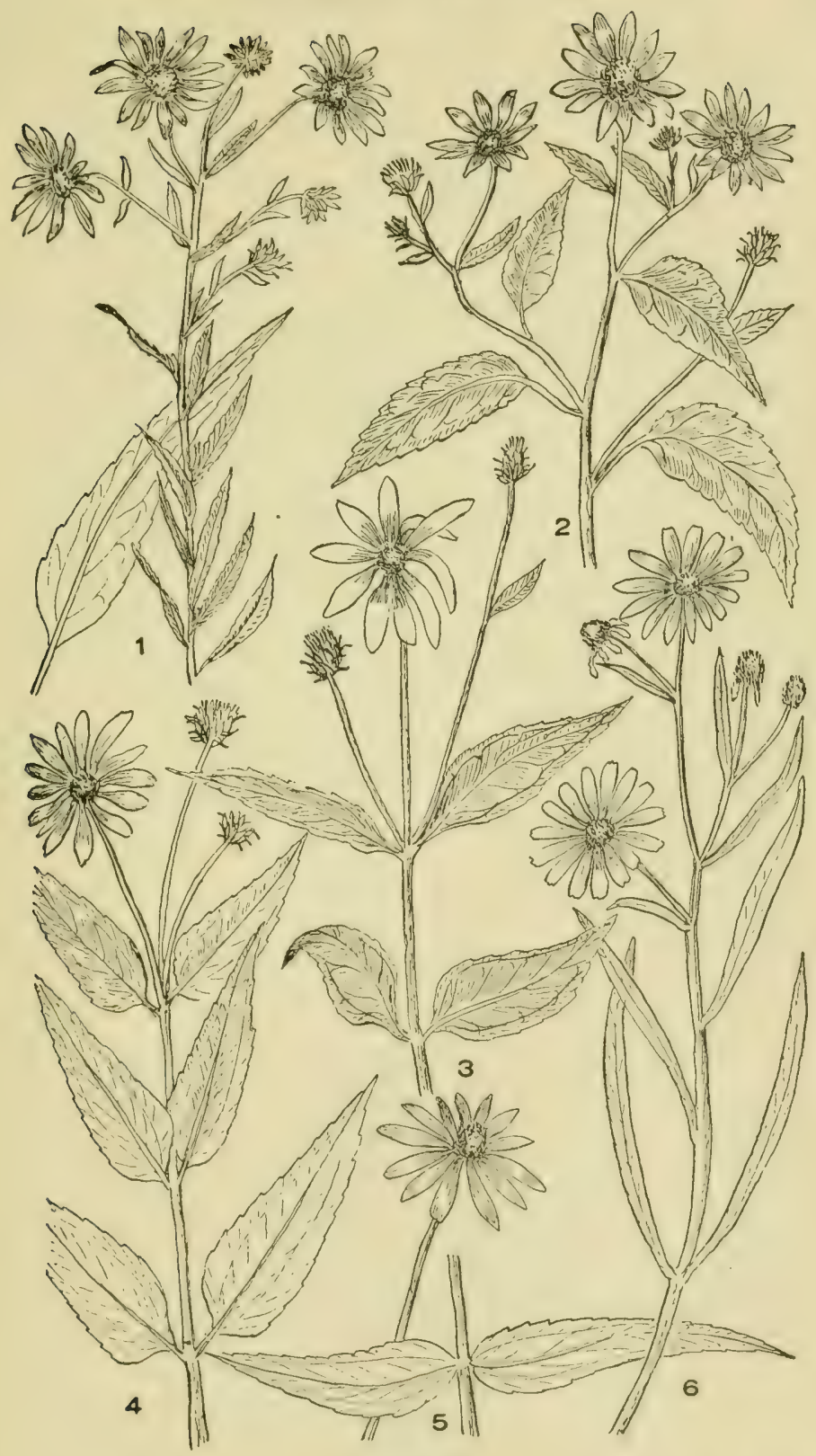

Plate 190

1. Helianthus giganteus. 2. II. tuberosus. 3. H. decapetalus. 4. H. divaricatus. 5. H. strumosus. 6. H. angustifolius. 
Leaves with entire margins

Leaves toothed at margins.

Leaves narrow lance-shaped tapering at base.

Leaves on leai'-stalks . . . . . . H. grosse-serratus

Leaves without leaf-stalks or on very short ones.. . H. giganteus

Leaves egg-shaped . . H. tubcrosus

Leaves rounded or very abrupt at base.

Leaves at nearly right angles with the stem . . H. divaricatus Leaves at an acute angle with stem.

On slender leaf-stalks . . . . . H. decapetalus

Without leaf-stalks or with very short ones - H. strumosus

1. H. angustifolius, L. (Fig. 6, pl. 190.) Swamp Sunflower. Stem slender, 2 to $7 \mathrm{ft}$. high, rough above, hairy below. Leaves linear, without teeth and without leaf-stalk, 2 to $7 \mathrm{in.} \mathrm{long,} \frac{1}{\mathrm{in}}$. wide, upper alternate, lower opposite. Heads few or solitary, 2 to $3 \mathrm{in}$. broad; rays abruptly terminated, 3 -toothed, disk purple; scales sharp pointed. Swamps, southern part of our area. Aug.-Oct.

2. H. giganteus, L. (Fig. 1, pl. 190.) Giant Surflower. Stem rough, hairy, 3 to $12 \mathrm{ft}$. high, branching above, bearing many heads on long flower stems. Leaves lance-shaped, 2 to $6 \mathrm{in}$. long, sharp pointed at apex, tapering to the base which is attached directly or nearly so, to stem. Heads showy, $1 \frac{1}{2}$ to 2 슬 in. broad. Wet meadows, swamps. Aug.-Oct.

3. H. divaricatus, L. (Fig. 4, pl. 190.) Rougir Sunflower. Stem simple or branched above, 1 to $7 \mathrm{ft}$. high. Leaves usually all opposite and extending at right angles with the stem, abruptly terminated, at base attached to stem by a very short leaf-stalk. Heads about 23 in. broad. Dry thickets, common. July-Sept.

4. H. decapetalus, L. (Fig. 3, pl. 190.) Thim-leaved Sunflower. Stem slender, scarcely hairy, 1 to $5 \mathrm{ft}$. high, branching. Leaves smooth or somewhat rough, egr-shiped, slender pointed at apex, base rounded to a marginal leaf-stalk. Rays about 10. Moist woods, borders of streams. Aug.-Sept.

5. H. strumosus, L. (Fig. 5, pl. 190.) Pale-Leaved Wood SunFLower. Stem very smooth, 3 to $7 \mathrm{ft}$. high, branched above, the branches usually downy. Leives lince-shaped, slender pointed, rounded at base, attached to stem without leat-stalk or by a very short one. Heads $2 \frac{1}{2}$ to 4 in. broad. Dry woods. July-Sept.

6. H. tuberosus, L. (Fig. 2, pl. 190.) Jerusalem Anticioke. Plant hairy, 5 to $12 \mathrm{ft}$. high, the root-stocks bearing edible tubers. Leaves egres-shaped to lance-shalped, pointed at each end, the hase marrowed to a molerately loner leaf-stalk. Ratys 12 to 20. Roatsides, borders of old gardens. Moist places. Sept.-Oct.

7. H. grosse-serratus, Martens. SAW-Tootuen Sunfower. Stem 6 to $10 \mathrm{ft}$. high, somewhat hairy on the branches. Le'aves long, narrow lanee-shaped, 4 to $8 \mathrm{in}$. long, fo to $1 \mathrm{in}$. wide, teeth sharp, thomgh the uppermost leaves may be without teeth, downy or with long soft hairs beneath. Heads $\frac{1}{2}$ to $3 \mathrm{in.}$ broad. Involnere hemispherie. Disk yellowish; rays 10 to 20, deep yellow. Long Island, Penna., and southward. Aug.-Oct.

\section{VERBESINA, L. (Actinomeris, Nutt.)}

IIerhs with alternate or opposite leaves and clustered or solitary heads of tuhular and radiato llowers. Involucre seales few, lance-shaped, deflexed. liays not fruitful, disk flowers fertile. 


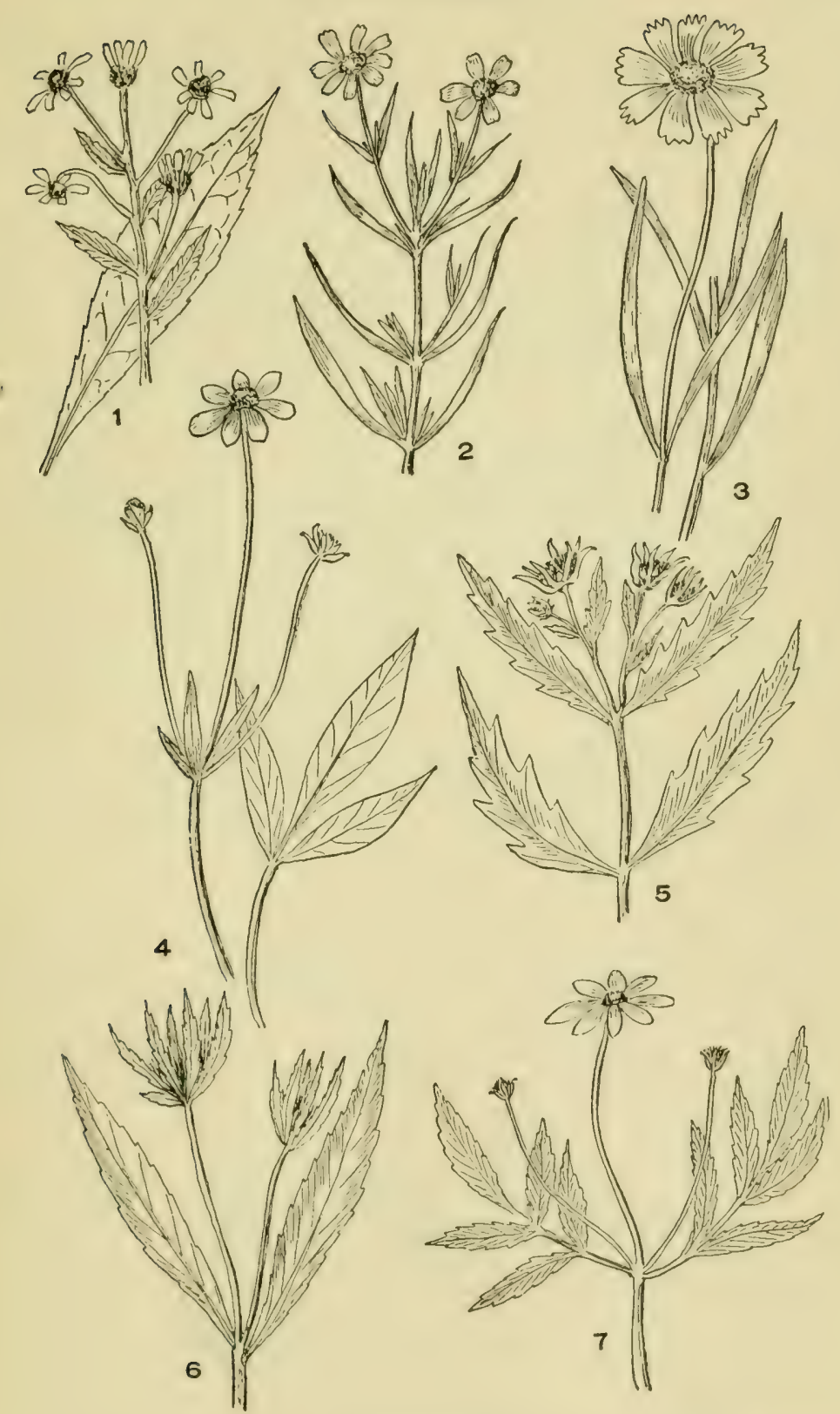

Puate 191

1. Verbesina alternifolia. 2. ('oreopsis rosea. 3. C. lanceolata. 4. C. tripteris. 5. Bidens connata. 6. B. comosa. 7. B. trichosperma. 
V. alternifolia, (L.) DC. (Fig. 1, pl. 191.) Actinomeris. (Actinomeris squarrosa, Nutt.) Stem smooth or somewhat downy, leafy, 4 to $9 \mathrm{ft}$. high. Leaves lance-shaped, sharply toothed, alternate, attached to stem by a narrowed base, 4 to $12 \mathrm{in}$. long. Heads numerous, 1 to $2 \mathrm{in}$. broad. Disk round, yellow; rays 2 io 10, yellow. Southern part of our area. Aug.-Sept.

\section{COREOPSIS, L.}

Herbs, usually with opposite leaves and with large heads on long flower stems, bearing both tubular and ray flowers. Involuere hemispherical, the bracts in 2 rows, each of about 8 scales, the outer rather leafy. Receptale flat or convex with membraneous chafl. Disk flowers fertile; rays not fertile, yellow, brown or pink, usually about 8 .

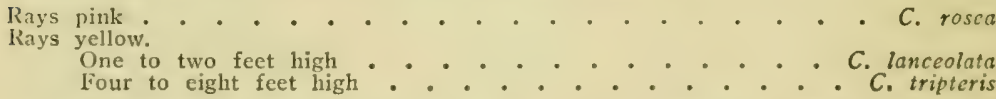

1. C. rosea, Nutt. (Fig. 2, pil. 191.) Smalt Pink Tickseed. Branching, leafy, smooth, slender, 8 to 24 in. high. Leaves opposite, grasslike, without teeth, 1 to $2 \frac{1}{2} \mathrm{in}$. long. Heads on slender stems; rays rose or pink, 3-toothed. Open swamps. July-Aug.

2. C. lanceolata, L. (Fig. 3, pl. 191.) Lance-Leaved Tickseed. slender, smooth or slightly downy at base, 1 to $2 \mathrm{ft}$. high. Leaves opposite, lance-shaped, 2 to 6 in. long, tapering to long leaf-stalks, which partly elasp the stem. Heads on elongated stems, showy; rays 6 to 10 , yellow, 5- to 7-lobed at end. Dry soil. Mlay-Aug.

3. C. tripteris, L. (Fig. 4, pl. 191.) Tall Coreopsis. Perennial plint, 4 to $8 \mathrm{ft}$. high. Upper leaves lance-shaped without leaf-stalks, the Jower on leaf-stallis, eompound, of several lanec-shaped segments. Smooth or rough on the margins. Ileads many : rays 6 to 10 , yellow. Woods and thickets, Penna, and southward. July-Oct.

\section{BIDENS, L.}

Ilerbs, annual or perennial, with opposite leaves and, mostly, yellow raved flower heads, the rays, howerere, in some species absent or rudimentary. Involuere bracts in 2 series, the outer leafy and larger than the inmer; receptacle fiat, chally, but the chall falling with the fruit. Rays, when present, not fertile, in onr speeces always yellow; disk flowers bearing stamens and pistils producing fruit. Fruit with 2 or more rigid awns which are bearded downward.

Rays developed, mostly conspicuous.

Leaves simple, lance-shaped.

Head with moderately rounded disk and conspicuous rays . B. laevis

IIead with disk almost a complete sphere, the 6 to so rays not

very conspicuous . . . . B. cerma

Leaves compound.

IIeads nearly cylindric, the 4 or 5 rays not conspicuous $B$. bipinuata

Ileads spreading, the rays very conspicuoous . . B. trichosperma

Rays absent or rudimentary.

Leaves simplc.

Involucre bracts, outer row somewhat exceeding the inner ones

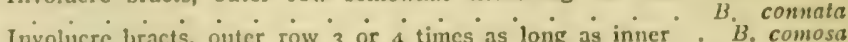
Leaves compound.

Ileads 1 in, high or less 1 . discoidca

Ileads $\frac{1}{2}$ in. high or more ........... B. frondosa 


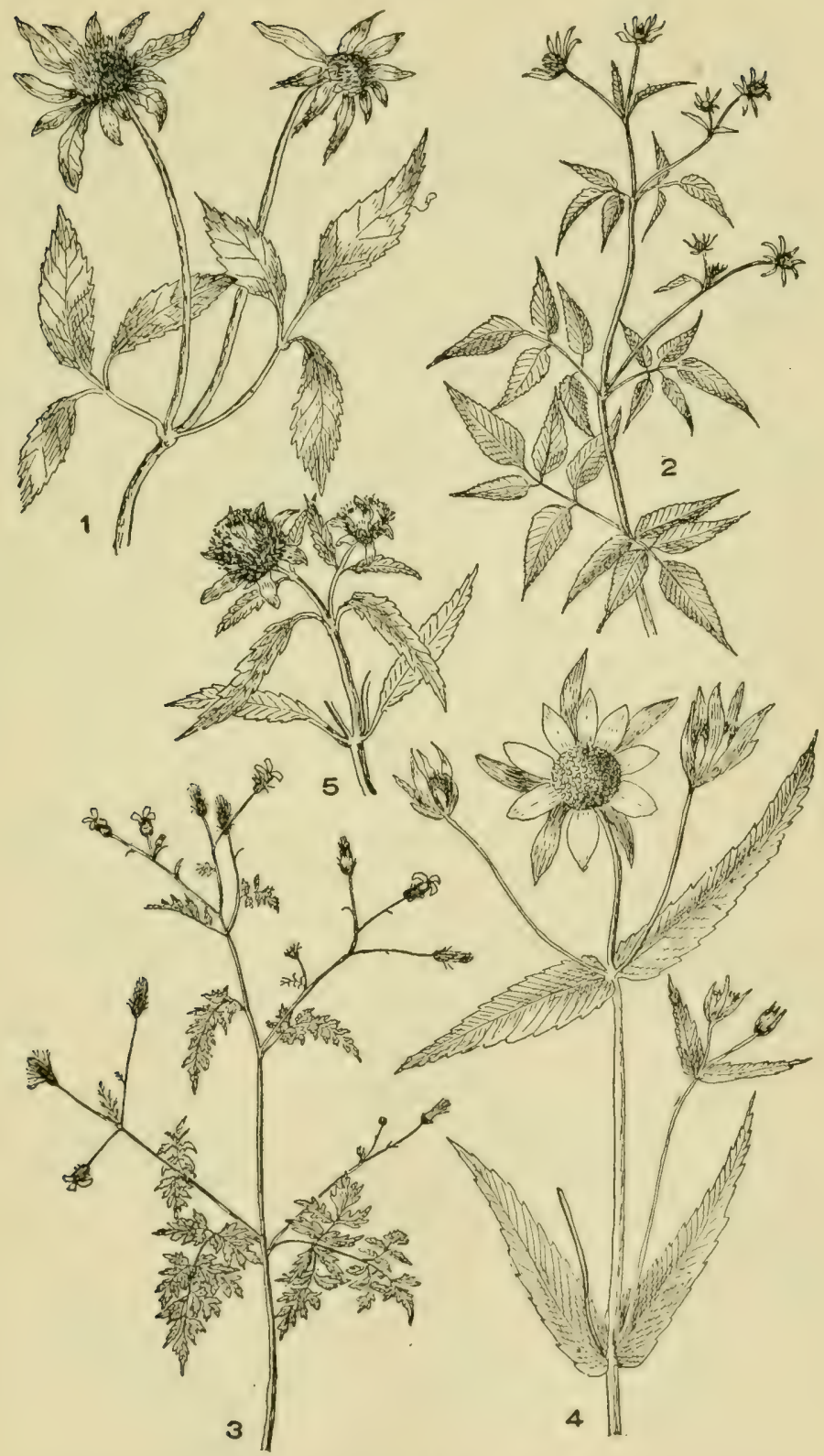

Plate 192

1. Bidens frondosa. 2. B. discoidea. 3. B. bipinnata. 4. B. laevis. 5. B. cernua. 


\section{$\ddagger$ Ray Flowers Conspicuous}

1. B. laevis, (L.) BSP. (Fig. 4, pl. 192.) Larger Bur-Marigold. Brook SUNFLower. Stem branching, more or less erect, or partly reclin. ing, smooth, as is the whole plant, 1 to $2 \mathrm{ft}$. high. Leaves lance-shaped with conspicuous teeth at margins, tapering to a slender point at apex and tapering or more or less abruptly rounded at base, 3 to $2 \mathrm{in}$. long, without leaf-stalks. Heads numerous on slender stems; rays $S$ to 10 , golden rellow, showy; inner bracts of the involuere usually shorter than the rays, the outer bracts often much longer. Fruit wedge-shaped, armed with 2 awl-like erect appendages with fine downward pointing barbs. In swamps, borders of pools and wet meadows. Aug.-Nov.

2. B. cernua, L. (Fig. 5, pl. 192.) Smaller Bur-marigold. Usually erect, nearly smooth, $\frac{1}{2}$ to $3 \mathrm{ft}$. high. Leaves lance-shaped without leafstalk, broad and it is attached to stem, unequally toothed. Heads with or without rays, which, when present are light yellow; outer bracts of involucre exceding the disk, which is glohose, the head on a short stem. Fruit with 2 barbed points. Wet places, our whole range. July-Oct.

3. B. trichosperma, (Michx.) Britton. (Fig. 7, pl. 191.) TALL TICKSEed Sunflower. (Coreopsis trichosperma, Michx.) Plant much branched, smooth, stem obscurely 4 -sided, 2 to $5 \mathrm{ft}$. high. Leaves deeply incised, pinnately divided, the leaflets or lobes (3 to 7$)$, lance-shaped, toothed, the whole leaf 3 to 8 in. long. Upper leaves may be undivided. Ileads numerous, the involuere bracts not extending much beyond the disk; rays, 6 to 19, broad lance-shaped, obtuse at apex, about an in. long, bright yellow. Fruit erowned by 2 triangular sharp upright awl-shaped teeth. Swamps, wet places, Mass., and southward. Aug.-Oct.

\section{赫 Ray Flowers Inconspicuous or Wanting}

4. B. bipinnata, T. (Fig. 3, pl. 192.) Spanisu Needess. Smooth, branched, stem 4-sided, 1 to $5 \mathrm{ft}$. high. Leaves deeply and doubly or tribly incised, the principle lobes lance-shaped, themselves deeply toothed or incisod. Heads numerous, nearly cylindric, on slender stems. Outer involuere scales linear, equalling the short yellow rays, the latter 3 or 4 in number. Fruit 4-angrled, with 3 or 4 awl-like barbed awns. Damp soil, lihode Island and southward. July-Oct.

5. B. connata, Muhl. (Fig. 5, pl. 191.) Purple-stemmed Swamp PFicidr-Tiks. Smonth, erect, branched, $\frac{1}{2}$ to $8 \mathrm{ft}$, high. Leaves laneeshaped derply notelied, on long leaf-stalks, 2 to $5 \mathrm{in}$. long; the lower sometimes 3 eleft. lleads numerous; rays 1 to 5 , inconspicuous or wanting. Outer bracts of the involuere extending somewhat above the head, few, obtuse. Fruit wedge-shaped with 2 barbed awns. Swamps, wet places, common. Aug.Oct.

6. B. comosa, Wiegand. (Fig. 6, pl. 191.) Ifary-eracted Ticksian. Leaves lanee-shaped, tootherl, tapering at each end. Outer bracts of involuere leaf-like, extending very much above the disk, conspiemonsly towthed. Früit with 3 barled awns. Wet places, Mass., southern New York and southward. $\Lambda$ ug.-Oct.

7. B. discoidea, (T. and (.) Britton. (Fig. 2, pl. 192.) SMrarr. Becican-Ticks. Lower leaves divided into 3 lance-shaped segments, 1 to 


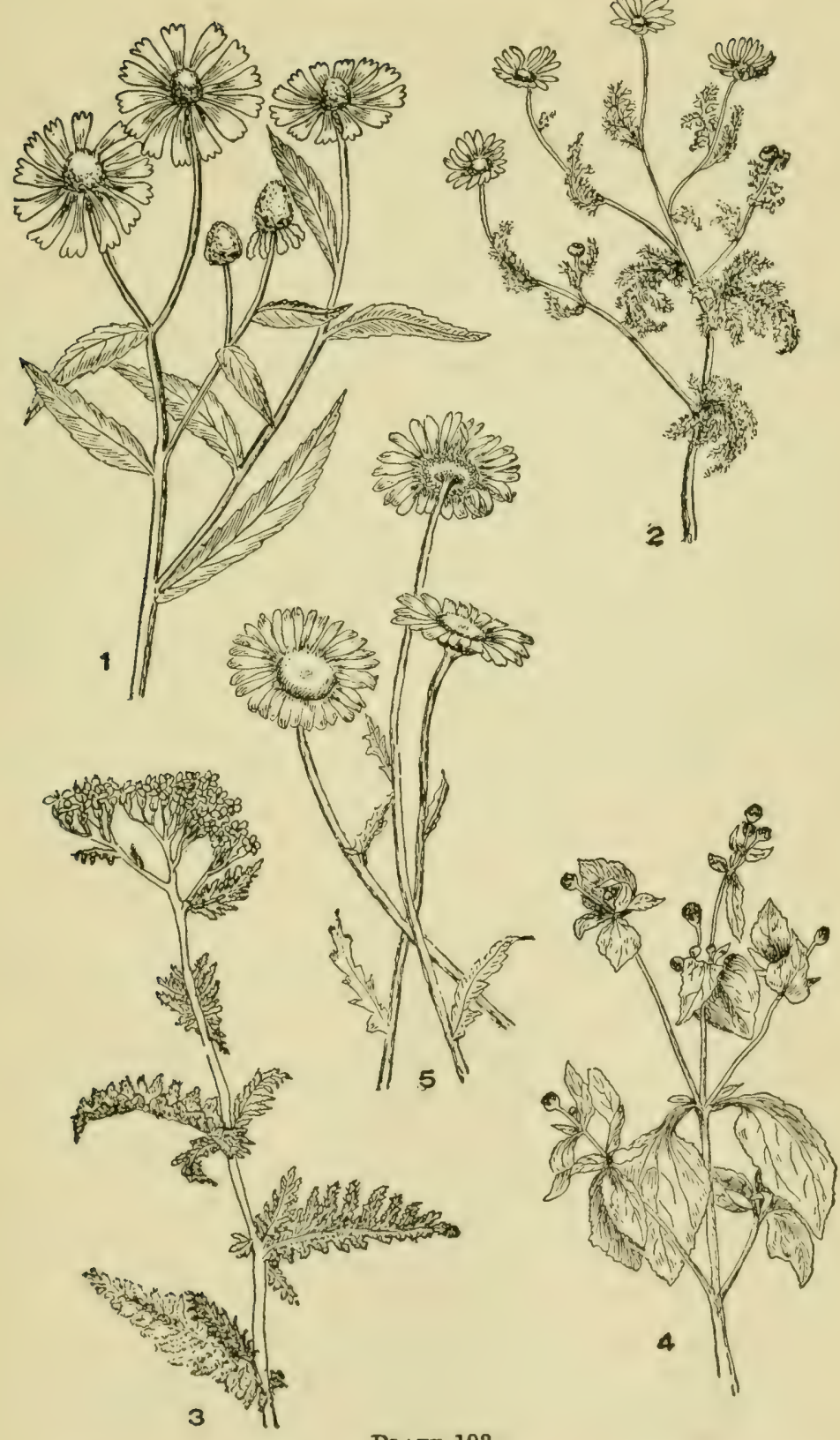

Plate 193

1. Ifelenium antumnale. 2. Anthemis Cotula. 3. Achillea millefolium. 4. Galinsoga parviflora. 5. Chrysanthemum Leucanthemum. 
3 in. long. Upper leaves lance-shaped. Eoothed. Meads small, rays none, bracts 3 or 4 times as high as the heal, linear, scarcely toothed. Fruit 2 awned. Swamps, Connecticut and southward. July-Sept.

S. B. frondosa, L. (Fig. 1, pl. 192.) Beggar-ticks. Smooth, branched, 2 to $6 \mathrm{ft}$. high. Leaves on slender leaf-stalks, 3 - to 7-divided, the segments lance-shaped or often sub-divided. Rays none; bracts 2 or 3 times as high as the head, linear, searcely toothed. Fruit ovate with 2 avins. Moist soil, throughout our range. July-Oet.

35. GALINSOGA, R. \& P.

IIerbs with opposite 3-nerved leaves aind small heads with whitish rays and yellow disk. Heals with several tubular and radiate flowers, the latter 4 to 5, small, roundish, bearing pistils. Involucre of 4 or 5 rows of thin scales. Receptacle conical, chaffy.

G. parviflora, Cavamilles. (Fig. 4, pl. 193.) Galinsoga. Nearly smooth, from 3 or 4 in. to more than a foot high. Leaves deltoid or eggshaped, toothed, 3-nerved, the lower on slender leaf-stalks, the upper sessile. Abundant in newlected eity door yards and other waste places. JuneNov.

\section{HELENIUM, L.}

Erect branching lerb with alternate leaves and numerous heads. Disk globose; rays soveral, fill-shitperl, the apex broad 3 -toothed, reflexed as are the small liracts of the involucre. Fruit top-shaped, ribbed. Aigrette of a few seales with bristle points.

H. autumnale, L. (Fig. 1, pl. 193.) Swamp Sunflower. Stem smooth or slightly downy, rather stout, 1 to $6 \mathrm{ft}$. high. Leaves lance-

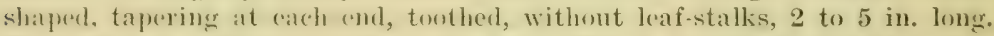
Ilead with a glohular yollow disk, and rellexed, 3-toothed, bright yellow fan-shaped rays. Swamps and wet meadows. Aug.-Oet.

\section{ACHILLEA, L.}

Perennial herbs with flat clusters of small flower heads and with alternate leaves. Heads with numerous florets, tubular and ray, the latter few and producing fruit; involuere seales overlapping, leathery; receptacle flat, chaffy. Fruit oblong, aigrette none.

1. A. millefolium, L. (Fig. 3, pl. 193.) YARrow. Stem simp\%, 1 to $2 \mathrm{ft}$. high. Ifatves in general outline, lance-shaped, very finely dissected into threal-like somments. ('luster of heads flat-topped; heals with 4 or 5) slort white bays and numerous small yellow disk florets. The rays are sometimes pink and eren dark purple, these mostly from old gardens. Common. June-Nov.

2. A. Ptarmica, L. Sxeezewort Yarrow. Leaves linear, sharply toothed; chuster of heads looso; rays 8 to 12 , longer than those of the conmon yarmow, white. Fiare, but found in various parts of oux range. July-Sept.

\section{ANTHEMIS, L.}

Branching herhs some with muleasant sernt, with alternate more or less dissected leaves, heads with tubular and ray florets. Involucre of several overlapping serien, the edeges dry. Liay florets bearing pistils, fer. 
tile or not. Disk flowero with stamens and pistils, fertile. Anthers obtuse, without appendages at base. Aigrette none.

1. A. Cotula, L. (Fig. 2, pl. 193.) Marweed. Stems much branched, erect or semi-prostrate, 1 io $2 \mathrm{ft}$. high, the plant with an unpleasant odor. Leaves finely dissected into thread-like segments. Ileads numerous, about $1 \mathrm{in}$. broad; rays 10 to 18, white, disk light yellow. Common in waste places. June-Nov.

2. A. arvensis, L. Fifld Camomile. Leaves less finely dissected; rays 10 to 18, longer than those of the Mayweed. Introduced, in waste places. May-Aug.

3. A. tinctoria, L. Yellow Camomile. Leaves with feather-form divisions, the segments toothed. Heads 1 to $1 \frac{1}{2} \mathrm{in}$. broad; rays 20 to 30 , yellow. Introduced, waste places. June-Sept.

\section{CHRYSANTHEMUM, L.}

Perennial herbs with more or less divided leaves and with solitary or clustered heads of tubular and ray flowers on long slender stems. Involuere bracts of several series; receptacle flat without chaff. Rays white, tubular florets yellow. Anthers obtuse without appendages.

C. Leucanthemum, L. (Fig. 5, pl. 193.) White Weed. Ox-exe DAIsy. Root perennial. Stem simple or branching, 1 to $3 \mathrm{ft}$. high. Leaves of the upper part of the stem without leaf-stalks, those below with long leaf-stalks, the blades deeply incised or conspicuously toothed. Heads solitary or few, I to $2 \mathrm{in}$. broad. Rays 20 to 30 , white, disk yellow. The too-common daisy of meadows and pastures. May-Nov.

\section{MATRICARIA, L.}

Smooth branching herbs with alternate dissected leaves and heads on long stems with tubular and ray flowers, or rays sometimes wanting. Involucre scales overlapping, with dry borders; receptacle conical, free from chaff; rays white, bearing pistils and producing fruit; disk florets fertile. Anthers without appendages.

1. M. inodora, I. Scextress Camomire. Annual; leaves dissected into almost thread-like segments. Heads large, $\frac{1}{2}$ to $1 \frac{1}{2} \mathrm{in}$. broad; rays 20 to 30 , white. Aigrette a short border. Wild in northern part of our area. June-Sept.

2. M. suaveolens, (Pursh.) 13uchenan. Rayless Camomile. ( $\boldsymbol{H}$. matricarioides, (Lees.) Porter.) Smooth, $\frac{1}{2}$ to $1 \frac{1}{2} \mathrm{ft}$ high. Leaves dissected. Heads numerous; rays wanting; disk conic, yellow. Waste places, introduced from the Pacific Coast. May-Aug.

\section{TANACETUM, L.}

Strongly aromatic herbs with alternate, dissected leaves and many heads of tubular flowers or with, in exerptional casess, not fully developed, a few ray flowers. Involuere of small overlapping scales; rechptacle convex, naked; florets at the margin of the disk bearing pistils only; those 
not marginal with stamens and pistils, fertile. Fruit 5-angled, aigrette none, or a low border.

1. T. vulgare, L. (Fig. 1, pl. 194.) TANSY. Stem simple, 1 to 3 ft. high. Leaves divided pimately, the lobes deeply toothed. Heads numerous, rounded, yellow. A strongly aromatic plant growing in patches. July-Sept.

2. T. huronense, Nutt. LAKE HuRoN TANsr. Plant silky with soft hairs; heads fewer. Otherwise similar to No. 1. Extreme northern part of our area. July-Sept.

\section{ARTEMISIA, L.}

Bitter odorous herbs or shrubs with alternate leaves and commonly with small nodding greenish or yellowish heads without rays, in narrow elongated elusters. Receptacles small, flat, naked. Involucre of overlap. ping dry scales. Marginal florets pistil-bearing or sometimes with pistils and stamens. Central florets perfect. Fruit inversely egg-shaped, without an aigrette.

Plants not white woolly

\section{Receptacle Naled; Disk Flowers Sterile}

1. A. canadensis, Michx. Canada Wormwood. Ileads $\frac{1}{6} \mathrm{in}$. broad, in a narrow interrupted spike-like cluster. Stem downy, straight, simple or branched. Leaves slashed into linear lobes, the lower ones on leaf-stalks. Rncky soil, mostly in the northern part of our area. July-Aug.

2. A. caudata, Michx. (Fig. 6, pl. 194.) WiLn Wormwood. Heads $1 / 12$ in. broad, in a broad rather loose elongated or pyramidal cluster comprising large numbers of heads. Stem slender, smooth, 2 to $6 \mathrm{ft}$. high. Leaves deeply divided into linear segments, the lower on leafstalks. Heads nearly ereet. Sandy soil, especially on sea beaches. JulySept.

\section{Receptacle Naked or Hairy; Disk Flowers Fertile}

3. A. absinthium, L. (Fig. 2. pl. 194.) Ansintir. Common Wormwoop. Leaves deeply divided into fath-like segments, downy. Heads yellow, drooping. Stem angular, branched. Waste places. Naturalized. July-Oct.

4. A. Abrotanum, I. Southerwwood. Shrub. Stems wondy, branched. Jeaves in fine threaly secrments. Flowers numerous, nodding, yellow. Well known as an aromatic garden shrub. Escaped and naturalized in places.

5. A. annua, T. ANNuat Wormwood. Annual herb. An introdued species, smooth, much branched, heads drooping. Leaves thrice divided. A weed in waste places.

\section{Plants woolly white}

6. A. stelleriana, Bess. (Fig. 3, pl. 194.) Beucir Wormwoon. Perennial, densely white-silky. Stem 1 to $2 \mathrm{ft}$. high, bushy. Jeaves ererrshaped or spatula-shaped, deceply lobed, 1 to $4 \mathrm{in.} \mathrm{long.} \mathrm{Ileads} \mathrm{inversely}$ cone-shaped, J in. broad, not drooping. Sandy sea beaches, July-Aug.

7. A. vulgaris, L. (Fier. 4, pl. 194.) ('omson Muswome. Peremial. branches and under side of lcates while woolly. Leaves 1 to $4 \frac{1}{2} \mathrm{in.}$ long, 

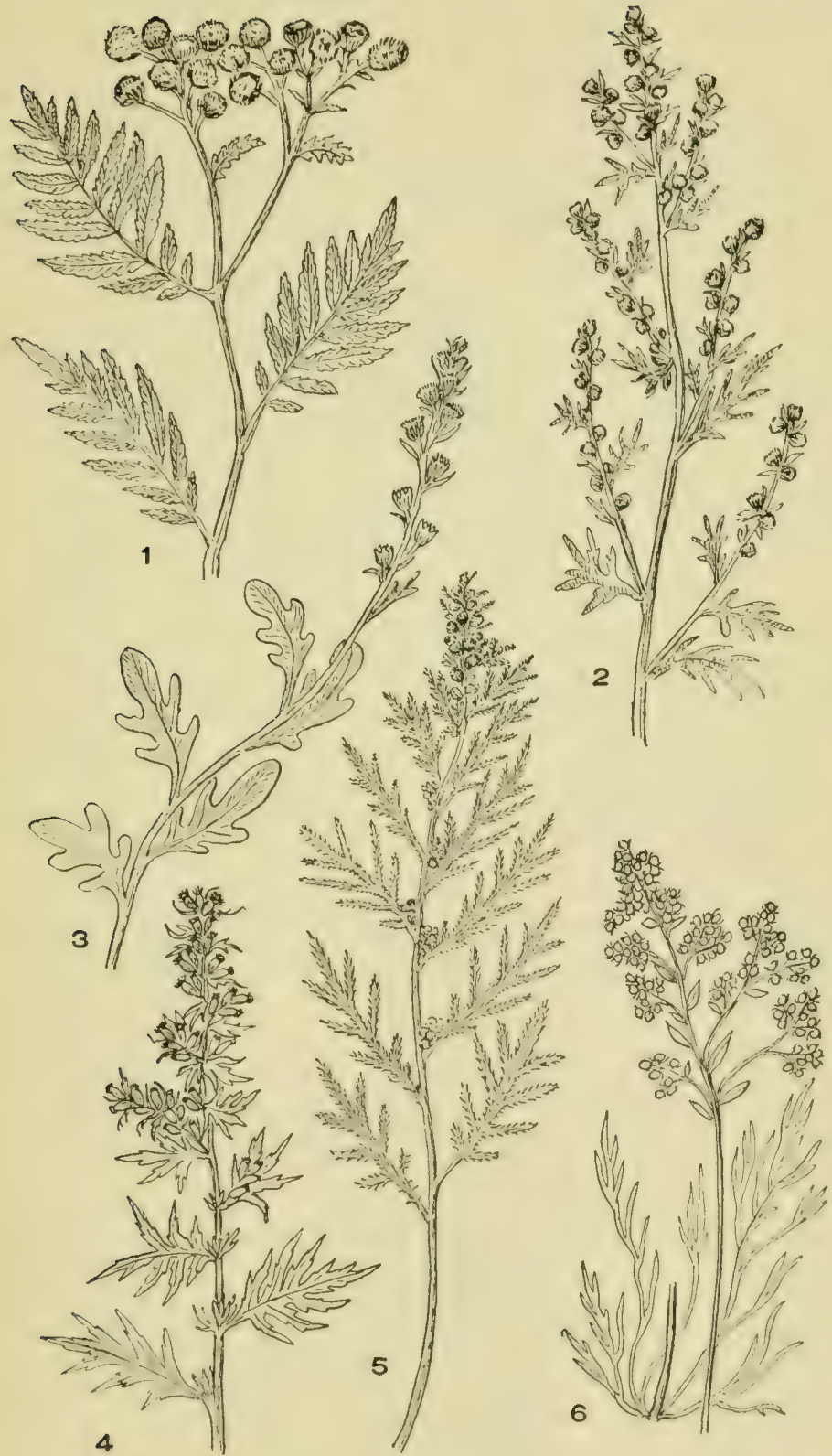

Prate 194

1. Tanacetum vulæare. 2. Artemisia absinthium. 3. A. stelleriana. 4. A. vulgaris. 5. A. biennis. 6. A. caudata. 
deeply lobed. Ileads small in somewhat diffuse elongated clusters. Waste places, introduced. July-Oet.

\section{Plants not woolly}

8. A. biennis, L. (Fig. 5, pl. 194.) Brenniat Wormwood. Smooth, branching, 1 to $4 \mathrm{ft}$. high. Leaves doubly ieather-formed. Heads numerous, in the leaf-axils. Introduced from the Northwest Territory, in Penna., and westward. Aug.-Oct.

\section{TUSSILAGO, L.}

A low herb with perennial root-stock from which, in very early spring, March or April, a seape arises bearing at its summit a flower head including both ray and tubular florets, the stem bearing also alternate seales. Later, broad rounded heart-shaped, angular and toothed leaves which, when young are woolly, appear and replace the flower stem.

T. Farfara, L. (Fig. 1, pl. 195.) CoLtsfoot. Scape 4 to 6 in. high, flowers yellow. Grows in wet places, often on banks of streams. 'The flower and leaves are not generally seen together as the flowers are withered when the leaves appear.

\section{PETASITES, Gaertn.}

Herb from perennial rootstock resembling Tussilago, but heads are in a cluster. Scape bearing scales; leaves deeply lobed. Rays white or purple.

1. P. palmata, (Ait.) A. Gray. (Fig. 2, pl. 195.) Palmate-Leaved Sweet Coltsfoot. Scape 6 to $24 \mathrm{in}$. high. Leaves densely white-silky. Flowers nearly white.

2. P. vulgaris, Hill. (Fig. 3, pl. 195.) Butter-Bur. Seape very stout, the bracts large. Leaves rounded, heart-shaped, with irregular, regular and toothed borders. Flower-heads in a dense cluster, purplish. In parks and, in a few localities, in waste grounds. Naturalized, from Europe. April-May.

\section{ARNICA, L.}

Ereet, stem simple or slightly branched; lenves opposite. IIeads on long stems; rays yellow; involuere bracts of equal lanee-shaped seales in 1 or 2 series; receptacle flat, naked or with a few seattered hairs. Fruit linear, 5- to 10-ribbed. Aigrette of a single series of rigid but rough bristles.

1. A. mollis, IInok. (Fig. 4, pl. 195.) Cindusso's ArNicA. Stem downy with long hairs, simple, 1 to 2 ? $\mathrm{ft}$. high. Joaves downy, becoming less so, 2 to 5 in. long, the upper without leaf-stalks. Heads 1 to 6 at the summit of the stem; involucre hairy; rays 10 to 15 , yellow, 3-toothed. Ifigh places on the Adirondack and White Mountains. June-Aug.

2. A. acaulis, (Walt.) 13SP. (Fig. 5, pl. 195.) Tropand's-Bane. Sitem hairy with fow (1 to 3 pairs) of leaves, 1 to $3 \mathrm{ft}$. hicrh. At summit several heads on rather long flower-stems, Basal leaves in a tuft or rosette, egrg-shajed or oval, hatiry, with about 5 longitudinal nerves. Delaware and Southern Penna. April-May. 

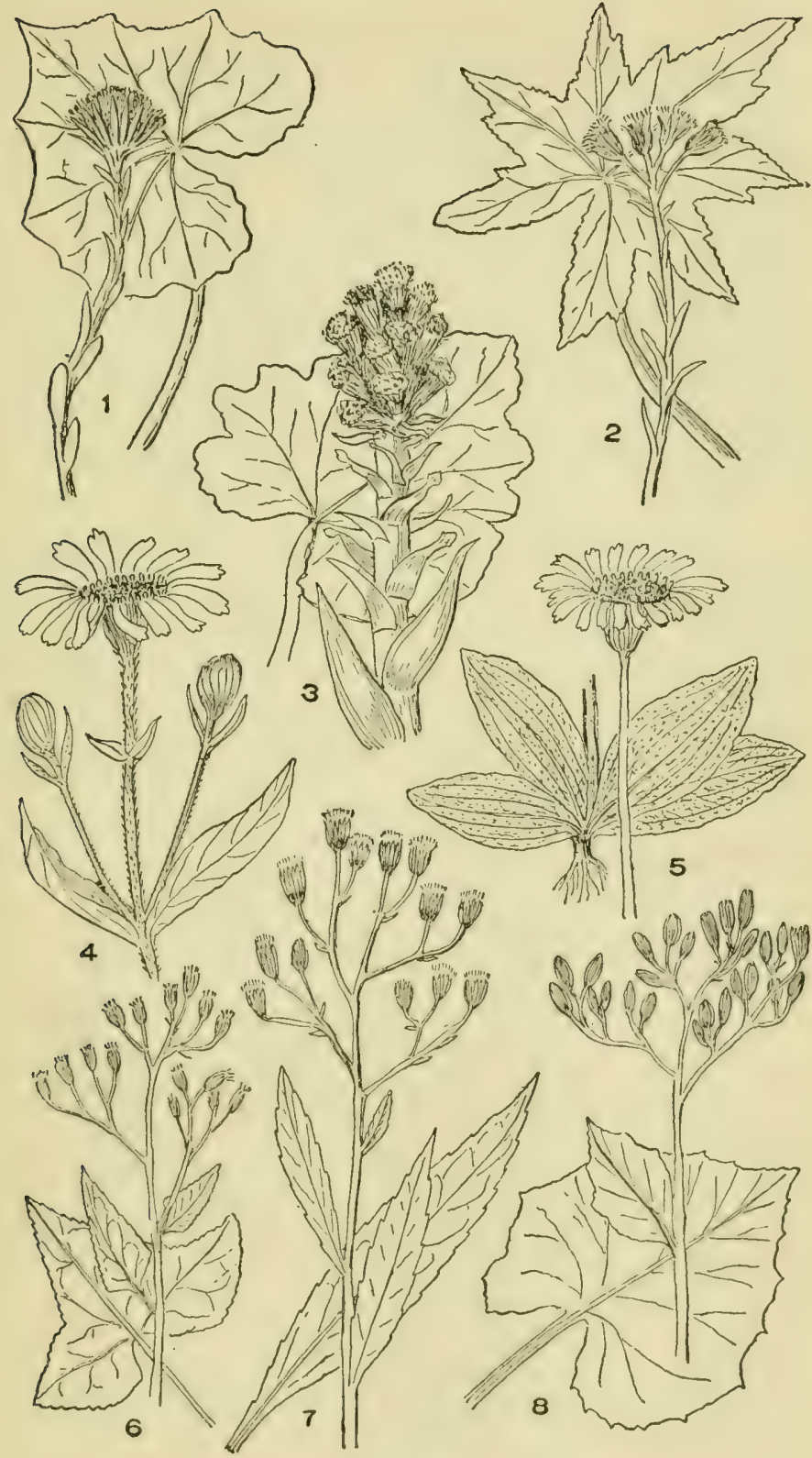

Plate 195

1. Tussilago Farfara. 2. Petasites palmata. 3. P. vulgaris 4. Arnica mollis. 5. A. acaulis. 6. Synosma subveolens. 7. Erechtites hieracifolia. 8. Cacalia reniformis. 


\section{ERECHTITES, Raf.}

Coarse annual herbs with rank smell, with alternate undivided leaves and with many rather large heads of tubular, whitish, flowers. Ifeads many flowered, no rays; the central florets having stamens and pistils, fertile; the marginal florets pistillate but also fertile. Involucre cylindric, of a single row of sharp linear scales and with a few small spreading scales at base. Aigrette of an abundance of soft hairs; fruit oblong, tapering at base.

E. hieracifolia, Raf. (Fig. 7, pl. 195.) Fire Weed. Annual, stem usually branched, striate, I to $8 \mathrm{ft}$. high, sometimes hairy. Leaves alternate, lance-sliaped, 2 to 8 in. long, eoarsely toothed at margins. Heals nearly an inch long, the abundant white hairs of the aigrette showing beyond the involucre. Abundant in spots which have been burned over in fields or in deserted yards and other waste places. July-Sept.

\section{CACALIA, L. (Mesadenia, Raf.)}

Tall, smooth, perennial herbs with alternate leaves on leaf-stalks and with many leads in flattened clusters; with milky sap and with yellowish or pink florets, all of which are tubular and all with stamens and pistil. Involuere eylindric of 5 bracts in a single row. Receptacle flat, naked. Fruit oblong, smooth; aigrette of copious white bristles.

1. C. reniformis, Raf. (Fig. 8, pl. 195.) Great Indian Plantain. Stem smooth, angled and grooved, 4 to $9 \mathrm{ft}$. high. Leaves all green on both silles, on leaf-stalks the lower more or less rounded or kidney-formed in general outline, but several angled, often very large, 1 to $2 \mathrm{ft}$. broad, the upper fan-slaped, coarsely trothed. Heads in flat clusters. Woods, southern part of our area. July-Sept.

2. C. atriplicifolia, Raf. PALE Indan Plantain. Stem smooth, not angled, 3 to $6 \mathrm{ft}$. high; leaves thin, whitish beneath, deeply lobed, in general ontlime triangular or kidney-shaped, on slender leaf-stalks. Rich woods. Aug.-Sept.

\section{SYNOSMA, Raf.}

Coarse perennial lierb resembling Cacalia, with triangular or spearshaped leaves and flat clusters of heads of tubular, pink or white flowers. Florets all with pistil and stamens.

S. suaveolens, (J.) Raf. (Fig. 6, pl. 195.) Swret-scexted Ixpmax Phantain. (Cuculia suavcolens, L.) Smooth, stem 3 to $5 \mathrm{ft}$. high. deaves triangulatr, the lower of 3 angular lobes, 4 to 10 in. long. Woods, Conn., and New Jersey, and southward. Aug.-Oet.

\section{SENECIO, L.}

IIfrlos with alternate and hasal leaves and with lowds of flowers having ray and tubular flowers or tubular only. In our species flowers yellow. Involuere of 1 series of bracts with a few shorter ones at the base. Re("prtale flat or nearly so, naked. Liay flewers, when present, pistillate and fortile. Fruit cylimire, 5- to 10-ribled; ainrette copious, of white hairs. 
THISTLE FAMILY
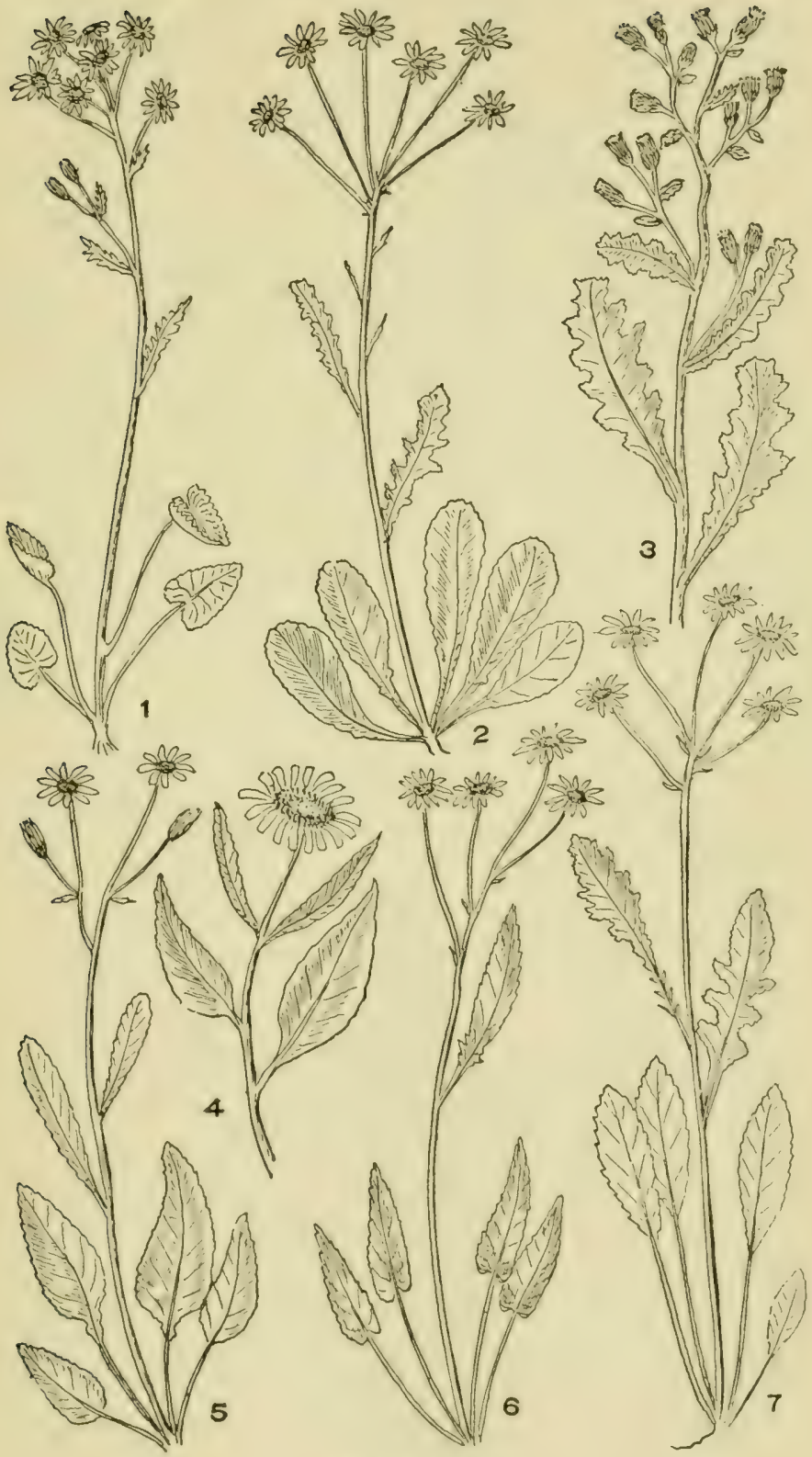

Plate 196

1. Senecio aureus. 2. S. obovatus. 3. S. vulgaris. 4. S. pseudo-arnica. 5. S. tomentosus. 6. S. Robbinsij. 7. S. balsamitae. 
Rays present, yellow,

Flower heads solitary or very few . . . . . . S. psendo-arnica

Flower heads several or numerous.

Basal leaves not heart-shaped.

Plant densely woolly ........ S. tomentosus

Plant not woolly or only at base.

Basal leaves inversely egg-shaped . . S. obovatus

Basal leaves heart-shaped at base.

Basal leaves lance-shaped ...... S. Robbinsii

Rays absent of minute.

Basal leaves broad, rounded ...... S. aureus

Stem not hairy or only slightly so.

Involucre naked or nearly so . . . . . . . . S. sylvaticus

lnvolucre with a row of short bracts at base.... S. zulgaris

Stem viscid downy . . . . . . . . . . . . S. viscosus

1. S. pseudo-arnica, Less. (Fig. 4, pl. 196.) Sea Beacir Senecio. Root perennial, stem 6 to $30 \mathrm{in}$. high, stout; whole plant white woolly, sometimes becoming smooth. Leaves oblong tapering to a narrow base, acute or obtuse at apex, margins sinuate, densely woolly beneath, 4 to 8 in. long. Heads solitary or oceasionally 3 or 4 or even more, 1 to 2 in. in diameter; rays 12 to 15, broad, 3-toothed. Sea-beaches, Maine. JulyAug.

2. S. tomentosus, Michx. (Fig. 5, pl. 196.) Woolly Rugweed. Root perennial; stem 1 to $21 \mathrm{ft}$. high; plant covered with whitish wool. Root leaves oblong not heart-shaped at base, rounded at apex, toothed at margins, on long leaf-stalks, the upper without leaf-stalks, similar in form to the lower or deeply lobed on each side. Heads in a broad flat cluster, each on a long stem, $\frac{3}{4}$ in. broad; rays 10 to 15 . Moist soil, southern part of our area. April-June.

3. S. obovatus, Muhl. (Fig. 2, pl. 196.) Round-LeAf Squaw-Weed. Stem 1 to $2 \mathrm{ft}$. high, smooth or somewhat woolly toward the base. Basal leaves round or inversely egg-shaped, toothed in a circular tuft; stem leaves few and small. Heads several 1 in. broad on slender stems; rays 8 to 12. Wet soil, Maine to Penna., and southward. April-June.

4. S. balsamitae, Muhl. (Fig. 7, pl. 196.) Balsam Groundsel. Stem 10 to $20 \mathrm{in}$. high, somewhat woolly below and at the leaf-axils. Root leaves tufted, oblong or spatula-formed or lince-shaped, deeply lobed on each side of the mid-rib. Heads rather numerous, small; rays 8 to 12. Dry soil, throughout our area. May-July.

5. S. Robbinsii, Oakes. (Fig. 6, pl. 196.) Ronin's Squaw-weed. Simootlı; 1 to $2 ! \mathrm{ft}$. high, stem slender. Lower leaves lanee-shaped, somewhat heart-shaped or simply rounded at base, nente or blunt at apex, toothed, on long leaf-stalks, upper leaves similar but often lobed, especially toward the base. Rays 6 to 12 . Swamps and wet meadows, Maine, Vermont, New Hampshire and New York. June-Sept.

6. S. aureus, L. (Fig. 1, pl. 196.) Golden Ragwort. SquawWEx. Root perennial; stem slenler, 1 to $21 \mathrm{ft}$. high. Jasal leaves round or egreshaped, heart-shaped at base, toothed at margins, on long leafstalks; upper leaves small, lance-shaped, toothed or deeply lobed. Rays 8 to 12 , deep golden yellow. Śwamps; wet meadows, throughout our area. May-July.

Ileads without Ray-flowers or with very minute ones

7. S. vulgaris, L. (Fig. 3, pl. 196.) Common Groundosel. Annual. 


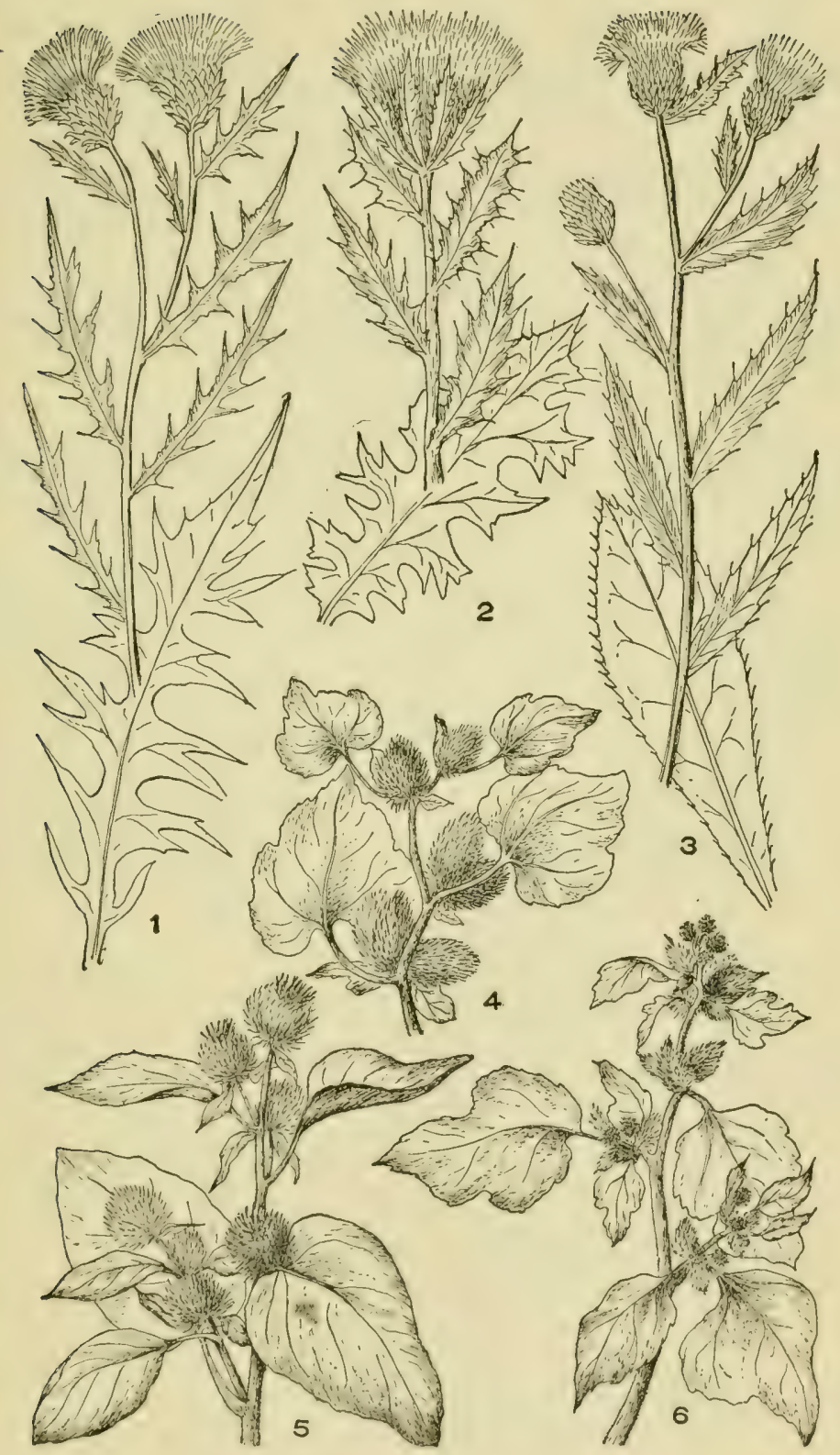

Plate 197

1. Carduus muticus. 2, C. spinosissimus. 3. C. altissimus. 4. Arctium tomentosum. 5. A. Lappa. 6 A. minus. 
Stem hollow, much branched, 6 to $15 \mathrm{in.} \mathrm{high.} \mathrm{Leaves} \mathrm{lance-shaped} \mathrm{but}$ deeply lobed on each side of the mid-rib (pinnatifid), the lobes toothed. Scales of the involucre blackish, almost always a few short ones at the lase of the involucre. A weed in cultivated grounds and waste places. Aprli-Oct.

8. S. sylvaticus, L. Wood Groundsel. Resembles No. 7, but heads are higher and involuere without the short scales at the base. Waste places, introduced. April-Sept.

9. S. viscosus, L. Foetid Groundsel. Resembles No. 7, but heads are much more slender, scales are not black-tipped and the whole plant is covered with a viscid ill-smelling covering of down. Introduced; waste places. July-Sept.

\section{ARCTIUM, L.}

Very coarse biennial weeds with large alternate leaves on leaf-stalks and with elustered heads of purple tubular flowers, the rounded involuere of many overlapping hooked scales, the heads forming a bur. Heads many flowered, all tubular. Receptacle bristly.

1. A. Lappa, L. (Fig. 5, pl. 197.) Bundock. Stout, 1 to $4 \mathrm{ft}$. high or occasionally much exceeding this height. Leaves egg-shaped, 8 to 18 in. long, often heart-shaped at base; margins not toothed. Bur often an in. in diameter, the bracts not cottony. A common large weed in waste places.

Var. A. tomentosum, (Lam.) Schk. (Fig. 4, pl. 197.) CotTony BurDock. Resembles No. 1, but leaves more wavy at margins and the involucre densely cottony.

2. A. minus, Schk. (Fig. 6, pl. 197.) Common Burdock. Similar to No. 1, but generally smaller and leaves firm and somewhat tapering at base, though the lower are heart-shaped. Involuere bracts not cottony. Heads about $\frac{3}{4}$ in. in diameter.

\section{I. CARDUUS, L.}

Erect branching herbs or in some species without stem, mostly biennial, with alternate, usually lance-shaped leaves which are without leaf-stalks, generally deeply lobed and armed with stiff, sharp, prickles. Heads usually large, many-flowered, the flowers all tubular, purple, yellow or rarely white. Involucre ergeshaped of many overlipping bracts, which are in many cases prickle-lipped, but sometimes unamed. Receptacle flat or convex, bristly. Aigrette of several series of plumose hairs.

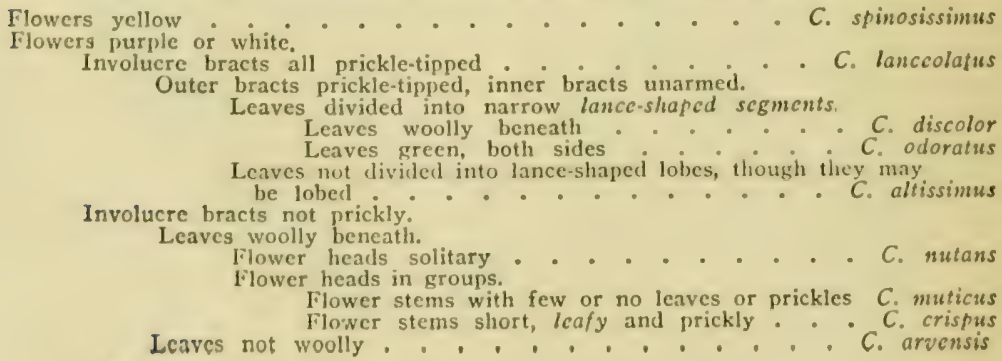



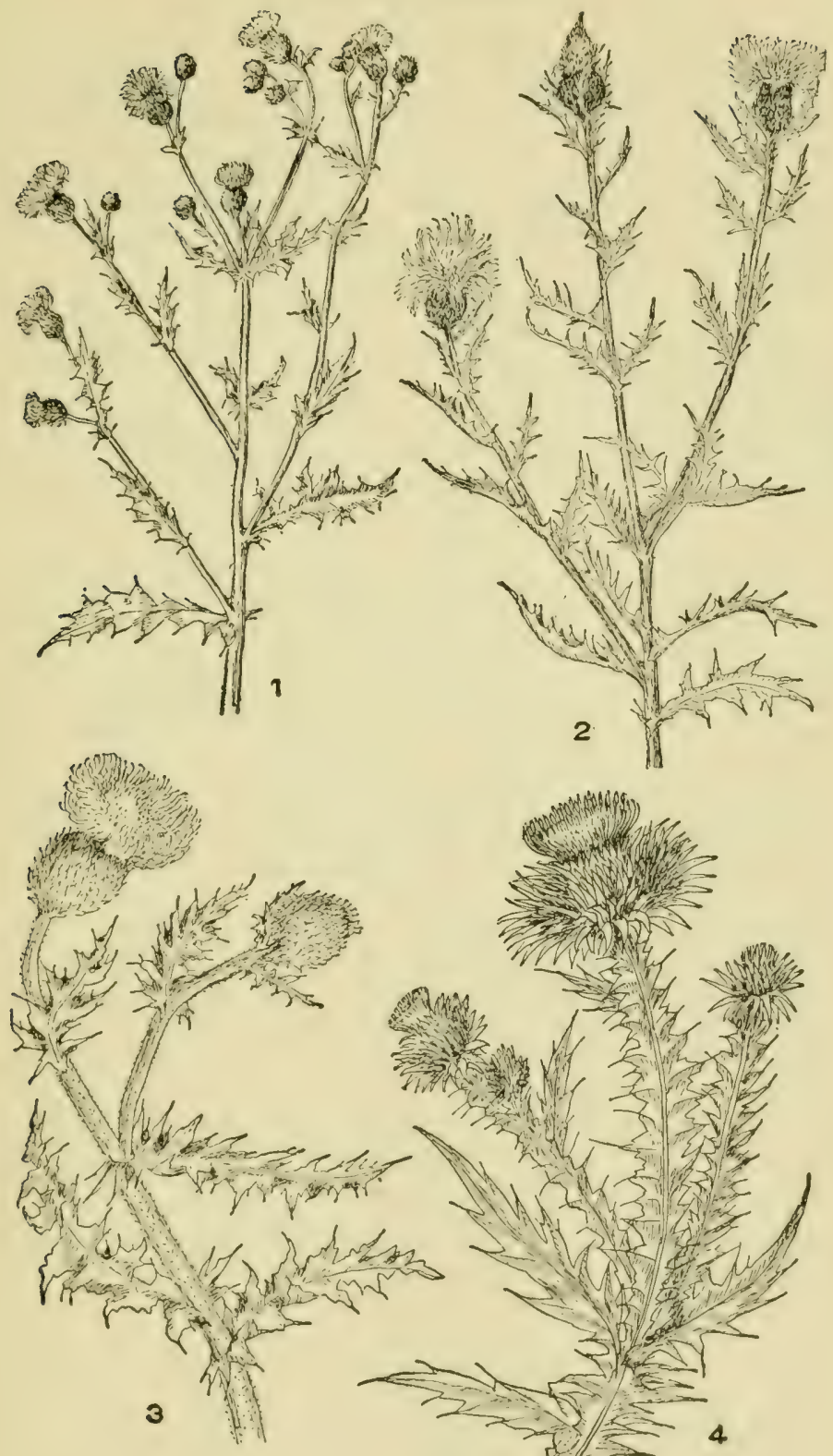


\section{Flowers yellow}

1. C. spinosissimus, Walt. (Fig. 2, pl. 197.) Yeleow THistle. (Cirsium spinosissimum, (Walt.) Scop.) Stem quite stout, 1 to $5 \mathrm{ft}$. high, woolly when young. Leaves in general outline lance-shaped, the upper ones clasping the stem, margins deeply lobed and with strong prickles at angles of the lobes. Heads 2 to $4 \mathrm{in}$. broad, the involucre bracts long, lance-shaped, with prickles at the margins. Flowers yellow. Mostly in moist soil. May-Aug.

\section{Flowers purple, pink or white}

2. C. lanceolatus, L. (Fig. 2, pl. 198.) Common Spenr Thistle. (Cirsium lanccolatum, (L.) Hill.) Stem branclied, 3 to $5 \mathrm{ft}$. high, more or less white woolly but not prïckly or only moderately so. Leaves lanceshaped, divided into triangular lobes each side of mid-vein, the lobes with prickly margins, at base the leaf is decurrent on the stem. All the bracts of the egg-shaped involucre terminate as prickles. Common. Fields and waste places. June-Nov.

3. C. altissimus, L. (Fig. 3, pl. 197.) TALL THIstle. (Cirsium altissimum, (L.) Spreng.) Stem not very stout, somewhat branched, the branches usually ascending, downy or woolly. Leaves lance-shaped, the margins toothed or rather deeply lobed but not divided into narrow segments, prickly at borders. Outer bracts of the involucre terminating as prickles, the inner bracts not prickly. Ficlds, thickets, along fences. Aug.-Sept.

4. C. discolor, (Muhl.) Nutt. Field Tmistle. (Cirsium discolor, (Muhl.) Spreng.) Tall and somewhat slender, 2 to $7 \mathrm{ft}$. high. Hears as in No. 3. Leaves white woolly beneath, deeply divided into lance-shaped segments, the borders of which are prickly. Fields and roadsides. JulyNov.

5. C. odoratus, (Muhl.) Porter. (Fig. 3, pl. 198.) Fragraxt Thistle. Pasture Tinstle. (Cirsium pumilum, (Nutt.) Spreng.) Stem low, stout, 1 to $3 \mathrm{ft}$. high. Leaves green on both sides, lance-shaped, ent into angular lobes with stout prickles. Outer bracts prickly, imer un. armed. This fragrant thistle has much of the time during its season of flowering, a number of butterflies balaneing on the purple flowers.

6. C. muticus, (Michx.) Pers. (Fig. 1, pl. 197.) Swamp Turstus. (Cirsium muticum, Michx.) Stem rather slender, 3 to $8 \mathrm{ft}$. high, angled, branching above. Branches with only a few small leaves and terminated by one or more heads. Leaves lanee-shaped, entire or deeply lobed on (ach side (pinnatifid) and densely white woolly beneath, lower 4 to $8 \mathrm{in}$. long, borders prickly. Meads alwout $1 \frac{1}{2} \mathrm{in.}$ broad. Bracts of the involuere not prickly. Swamps and moist soil. July-Oct.

7. C. arvensis, (L.) Robs. (Fig. 1, pl. 198.) CaNada Tiristle. (Cirsium arvense, (L.) Scop.) Peremial, slender, 1 to $3 \mathrm{ft}$. high. Stem striped, smooth. Jeaves lance-shated, deeply lobed, the margins of the lobes beset with strong prickles; green on both sides, the lower 5 to $\mathrm{s}$ in. long Ileals about 1 in. broal and about as high, flowers rose purple, macts not prickly. Very common in cultivated fields, roadsides, etc. June-Sept. 


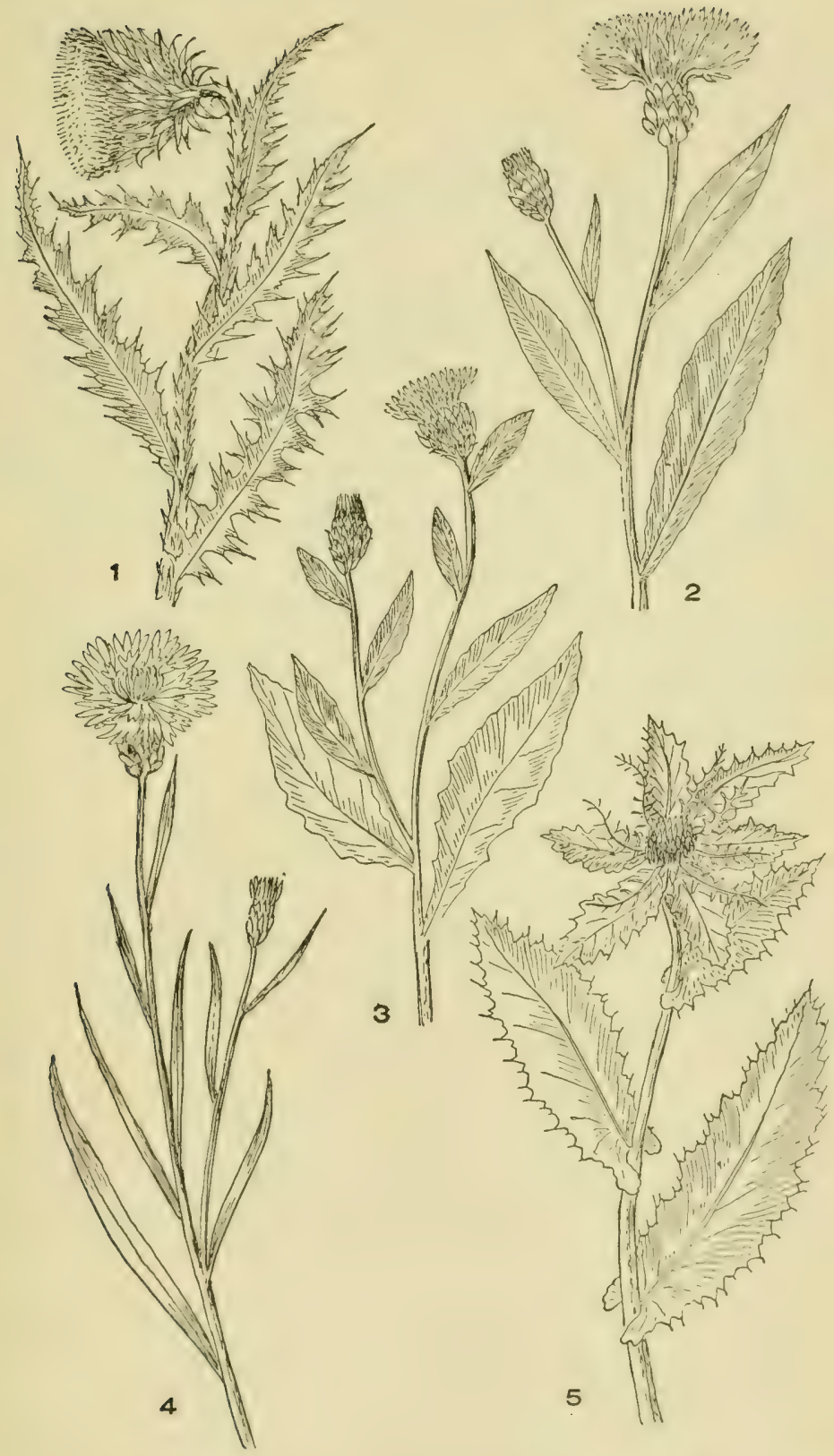

Plate 199

1. Carduus nutans. 2. Centaurea Jacea. 3. C. nigra. 4. C. Cyanus. 5. Cnicus benedictus. 
S. C. nutans, L. (Fig. 1, pl. 199.) Musr Tristle. Biennial. Leaves lance-shaped, broad and often eared at base, extending down the stem. Lobed and very prickly; the stem also armed with strong prickles. Heads solitary, drooping. Occasional in our area, introduced from Europe. July-Oct.

9. C. crispus, L Curled Thistle. Biennial. Plant somewhat woolly; stem densely prickly, 2 to $4 \mathrm{ft}$. high. Leaves with triangular lobes, margins prickly. Heads crowded on very short stems. Introduced. July-Sept.

52. ONOPORDON, L.

A stout thistle similar to Carduus, but the receptacle is honeycombed and not bristly. The hairs of the aigrette or pappus are not plumose.

O. acanthium, L. (Fig. 4, pl. 19S.) Scotcri Tiristle. Stout, 2 to $4 \mathrm{ft}$. high, the stem winged, the wings armed with stout prickles Leaves white-woolly, oblong, lobed, armed with very strong prickles. Heads solitary, the involucre broad at base, constricted above, flowers spreading, light purple. Fields, most of our area. July-Sept.

\section{CENTAUREA, L.}

Herbs with alternate leaves which are entire or more or less cut. Heads usually solitary, terminal, with tubular flowers. Involuere globose, of overlapping bracts. Receptacle flat, bristly. Marginal flowers usually much larger than the central, sterile or fertile. Aigrette of several scales or bristles or absent.

$$
\begin{aligned}
& \text { Leaves linear } \\
& \text { Leaves lance-shaped, spatula-shaped or oblong. - . . . . C. Cyanus } \\
& \text { Leaves not deeply lobed. } \\
& \text { Marginal flower much larger than central . . . . C. Jacea } \\
& \text { Marginal flowers not larger than central . . . C nigra }
\end{aligned}
$$

1. C. Cyanus, L. (Fig. 4, pl. 199.) Corn Flower. An introduced plant from Europe where it is found in grain fields; here cultured in gardens from which it has eseaped. Plant 1 to $2 \frac{1}{2 t}$. high, somewhat woolly, leaves alternate, linear. Heads solitary at end of branches. Involucre rlobular, the scales fringed on the margin. Flowers blue varying to purplish, the marginal ones large thin lobes, assuming a star-like form. Waste places and grain fields. July-Sept.

2. C. nigra, L. (Fig. 3, pl. 199.) KNApweed. Perennial roots. Sitem stiff, branched, 1 to $2 \mathrm{ft}$. high. Leaves lanee- or spatula-shaped, the margins entire or the lower leaves slightly lobed. Ileads about 1 in. broad; seales of the involuere with a black hairy fringe. Marginal and contral flowers of the same size, purple. Naturalized, in waste places. July-Sept.

3. C. Jacea, I. (Fig. 2, pl. 199.) Rayed Knapwled. Like the last, lut margins of leaves are toothed and outer llowers are large and showy. Naturalized to some extent. June-Sept.

4. C. calcitrapa, I. S'TAr THisti.: Leaves decply (pinnately) lobed often with somewhat prickly spines at mareins. Hoads immediately sup)ported by baves which assume somewhat the form of a sub-involucre. 
Outer bracts of the real involuere often in form of spreading spines. Naturalized in some places. June-Oct.

\section{CNICUS, L.}

A thistle-like herb with alternate lanee-shaped, lobed leaves with prickly margins and with large heads of yellow tubular flowers, the heads solitary and without stem. Receptacle flat, bristly. Aigrette of 2 rows of bristles.

C. benedictus, L. (Fig. 5, pl. 199.) Blessed Tinstue. Much branched, stem hairy, $1 \frac{1}{2}$ to $2 \frac{1}{2} \mathrm{ft}$. high. Leaves lobed and with prickly margins, 3 to 6 in. long. Heads 2 in. broad, subtended by an involucrelike cluster of spiny leaves. Flowers yellow. Introduced. May-Aug. 



\section{EXPLANATIONS OF ABBREVIATIONS OF NAMES OF AUTHORITIES}

A. Br........... Braun, Alexander. Adans.................. Adanson, M. A. DC....... De Candolle, Alphonse. Ait.................. All..............Allioni, Carlo. Andr.........Andersson, Nils J. Andrz.........Andrzejowski, A. L. Arn.............Arnott, G. A. W. Aust..........Austin, Coe Finch.

B. \& H..... Bentham, George, and Hooker, Joseph Dalton.

Bab., Babingt..... Babington, C. C. Bart.................... Beauv.... Beauvois, A. M. F. J. P. Benth........... Bentham, George. Bernh...........Bernhardi, J. J. Bess.......... Besser, Wilhelm von. Bigel............ Bigelow, Jacob. BSP.. Britton, Sterns and Pogrenberg.

C. \& S...Chamisso and Schlechtendal.

Carr............ Carrière, Elie Abel. Casp............ Caspary, Robt. Cass... . . . . . . . Cassini, Henri. Celak............ Celakowsky, L. Cham........... Chamisso, A. von. Cham. \& Sch......... Chamisso and Schlechtendal.

Cyrill................ Cyrillo, D.

Darl.......... Darlington, Wm DC........... De Candolle, A. P. Dec............. Decaisne, Joseph Desf... . . . . . . . Desfontaines, R. L. Dietr............. Dietrich, D. N. F. Dougl... . . . . . . . Douglas, David Dryand.......... Dryander, Jonas. Dufr.............. Dufresne, P. Dumort......... Dumortier, B. C.

Ehrh...............Ehrhart, E. Ell.................Elliot, $\mathrm{S}$ Engelm........ Engelmann, George.

Forsk...............Forskal, B. Froel............Froelich, J. A.
Gaertn.............Gaertner, J. Gaud...Gaudichaud-Beaupré, Charles Gmel.............. Gmelin, S. G. Godr..............Godron, D. A. Gren.................Grenier, C. Griseb........ Grisebach, H. R. A.

Haussk........Haussknecht, Carl. Haw... . . . . . . . . Haworth, A. H. HBK..... Humboldt, Bonpland and Kunth.

Hitchc............Hitcheock, A. S. Hoffmg. . . . . . . . Hoffmansegg., J. C. Hook............ Hooker, Wm. J. Huds.............Hudson, Wm.

Jacq............. Jacquin, N. J. Juss..... Jussieu, Antoine Laurent.

Karst............. Karsten, H. Ktze............. Kuntze, Otto.

L...Linnaeus, Carolus, or Carl von Linné.

I. f..... Linné, Carl von (the son). Lag............ Lagasea, Mariano. Lam. . . . . . . . . . . L Lamarck, J. B. Lamb. . . . . . . . . . Lambert, A. B. Ledeb..........Ledebour, C. F. von. Lehm............. Lehmann, J. G. C. L'Her... . . . . . L'Heritier de Brutelle. Lindl... . . . . . . . . Lindley, John. Lodd...............Loddiges, Conrad. Lois.......Loiseleur-Deslongehamps, J. L. A.

Mac M............MacMillan, C. Marsh........ Marshall, Humphrey. Mart...........Martens, Martin. Maxim......... Maximowicz, C. J. Medic............Medicus, F. C. Mert. \& Koch...Mertens and Koch. Michx.............. Michaux, A. Mil..................Miller, B. Moq........... Moquin-Tandon, $\mathbf{A}$. Muench.........Muenchhausen, Otto. Muhl...........Mühlenberg, H. I. Murr..............Murray, J. A. 
Nutt........... Nuttall, Thomas.

Spreng................ Sprengel, K.

Pere. Sudw.............. Sudworth, G. B. Planch..............Planchon, J. E. Poir..............Poiret, J. L. M.

R. \& P....... Ruiz and Pavon. T. \& G........ Torrey and Gray. Thunb.......... Thunberg, C. R. Torr............... Torrey, John. Raf........................ Tournefort, J. Reicheni... Reichenbach, H. G. L. Tratt..........Trattinnick, L. Retz............ Retzius, A. J. Roem............ Roemer, J. J. Roem. \& Scluult........Roemer and Schultes.

Rostk....... Rostkovius, F. W. G. Rottb.............. Rottboell, C. F. Rupp............. Ruppius, H. B. Rupr............ Ruprecht, F. J. Rydb..............Rydberg, P.

Salisb............ Salisbury, R. A. Sarg... . . . . . . Sargent, Charles S. Schleid............Schleiden, M. J. Schreb............ Schreber, J. C. D. Sehult........... Schultes, J. A. Schum.......... Schumacher, C. F. Schwein.......... Schweinitz, L. D. Scop.............. Scopoli, J. A. Sibth............ Sibthorp, John. Trel..............Trelease, Wm. Tuckerm..........Tuckerman, E. Vent........... Ventenat, E. R. Waldst. \& Kit.......Waldstein and Kitalbal.

Wallr........Wallroth, K. F. W. Walp............Walpers, W. G. Walt..............Walter, Th. Wang....... Wangenheim, F. A. J. Wedd............Weddell, H. A. Weinm............. Weinmann. Wetts............Wettstein, R. Wimm...........Wimmer, F. With...........Withering, Wm. Wolfg..............Wolfgang. Wulf...........Wulfen, F. X. 


\section{INDEXES}





\section{INDEX TO LATIN NAMES}

(Classes, Orders, Families and Tribes in small capitals; synonyms and varieties in italics.)

\section{Abama}

Abies

baln $\ldots \ldots \ldots \ldots \ldots$

Abietineae

Abutilon

Abutilon

Theophrasti

Acalypha

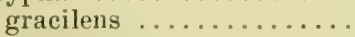

ostryaefolia ...........

virginica ..............

Acaitthaceae ............

Acer

Negundo ...............

nigrum

pennsylvanicum .......

platinoides ............

pseudo-platanus ........

rubrum

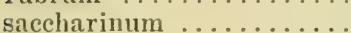

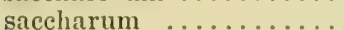

spicatum

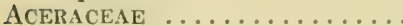

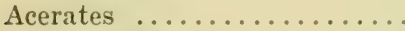
viridiflora

Achillea

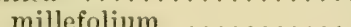

Ptarmica

Achroanthes

Acnida

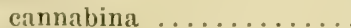

Aconitum

noveboracense

uncinatum

Acorus

Calamus $\ldots \ldots \ldots \ldots \ldots$

Actaea

alba $\ldots \ldots \ldots \ldots \ldots \ldots$

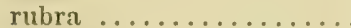

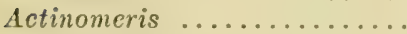

squarrosa ...........

Adicea

Adlumia

fungosa .............

Adopogon
126 Aegopodium ........... 448

88 Podagraria .......... 448

88 Aeschynomene ............ $34 y$

$84 \quad$ virginica ............. 349

400 Aesculus ................ 392

$400 \quad$ glabra .............. 392

400 Hippocastanum ....... 392

370 Aethusa ............... 444

376 cynapium ........... 444

376 Agastache ............. 542

376 nepetoides ......... 542

576 scrophulariaefolia ..... 542

389 Agrimonia $\ldots \ldots \ldots . . .322$

390 Brittoniana ........... 324

$390 \quad$ Eupatoria ............. 324

$390 \quad$ gryposepala .......... 324

390 microcarpa ........... 324

390 mollis .............. 324

389 parviflora ............ 324

389 pumilla .............. 324

$390 \quad$ striata ............... 324

390 Agrostemma ............. 225

389 Githago ........... 225

499 Ailanthus ............... 371

499 glandulosa ........... 371

688 AIZOACEAE ............... 221

688 Ajuga ................. 544

688 reptans $\ldots \ldots \ldots \ldots \ldots \ldots .54$

159 Alchemilla .............. 322

220 vulgaris .............. 322

221 Aletris ................ 134

263 aurea ............... 134

263 farinosa ........... 134

263 Alisma ................ 103

112 Geyeri .............. 104

112 Plantago-aquatica.......... 103

264 tenellum ............. 104

264 AmtsiraceaE ............. 103

264 Alliaria ................. 284

682 Alliaria ............ 284

684 officinalis ........... 284

195 Allioideae ............. 130

272 Allium .................. 130

272 canadense ........... 130

61' cernuum ........... 130 
Schoenoprasum

130

tricoccum

Alnus

130

130

185

Alnobetula

crispa

185

incana

mollis

oveboracensis

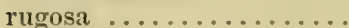

serrulata

Alsine

ArsivoIDEA

Althaea

officinalis

Alyssum

calycinum

AMrA TTHCEAE

Amaranthus

blitoides

crispus

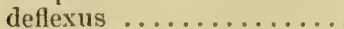

graecizans ...........

hybridus $\ldots \ldots \ldots \ldots \ldots$.

lividus

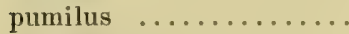

retroflexus

spinosus

AMARYllidaceae ..........

Ambrosia

artemisiaefolia ........

trifida

Ambrosincene ..............

Amelanchier

arguta

Botryanium ............

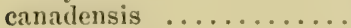

oligocarpa ............

rotundifolia

spicata

AMEXTACEAF

Amianthium

muscaetoxicum

Ammannia

coccinea

Kochnei

Ammodenia

peploides

Amphicitrpat

monoica

Pitcheri

ANACARDIACEAR

Anatrallis

arvensis

Anaphalis margaritaceae ....... 676

Andromeda ............. 469

ligustrina ......... 470

polifolia ........... 46y

Anemone ............ 250

canadensis .......... 252

cylindrica .......... 252

hudsoniana .......... 252

multifida ........... 252

nemorosa ........... 252

quinquefolia ......... $\mathbf{2 5 2}$

riparia ........... 252

trifolia .......... 252

virginiana $\ldots \ldots \ldots \ldots .252$

Anemonella ............. 254

thalictroides ......... 254

Angelica ............. 446

atropurpurea ......... 440

Curtisii ........... 446

villosa ........... 446

Angiosperitae .......... 89

Anonaceae .............. 244

Antennaria ............. 674

grandis ........... 674

neglecta .......... 676

neodioica ...........6 674

Parlinii ........... 674

plantaginifolia ........ 676

Anthemis .............. 688

arvensis ......... $\mathbf{6 8 9}$

Cotula ............ 689

tinctoria ......... 689

Antirrhinum ......... 554

majus .......... 554

Orontium .......... 554

Anychia .............. 239

canadensis ........... 239

dichotoma ........... 239

polygonoides ......... 239

APETALAE .............. 160

1 phyllon .............. 575

Apios ................. 360

tuberosa .......... 362

Apium ................ 446

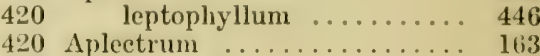

420 hycmale ........... 163

238 spicatum ............ 163

238 AROCYNACEAE ............ 493

390 Apocynum ............ 494

360 androsaemifolium ....... 494

360 eannabinum .......... 494

360 hypericifolium ......... 494

382 Aquilegia ............... 262

478 canadensis ........... 263

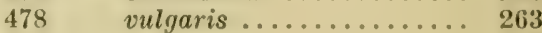

676 Arabis .............. 287 
brachycarpa ......... 287

canadensis ......... 287

dentata ........... 288

glabra ............ 288

hirsuta .......... 287

laevigata ......... 288

lyrati

patens

ARACEAE

Aralia

hispida

nudicaulis

racemosa

spinosa

Araliacene

pusillum

Arctium

Lappa .................

minus

tomentosum ...........

Arctostaphylos

alpina

Uva-Ursi ..............

Arenaria

caroliniana

groenlandica

serpyllifolia

stricta

verna

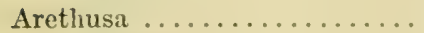

bulbosa ..............

Argemone

mexicana ............

Arisaema

Dracontium

pusillum.

Stewardsonit

triphyllum

Aristolochia

Clematitis.

macrophylla ............

Serpentaria

Aristolochiaceae

Arnica

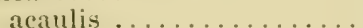

mollis

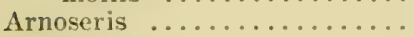

minima

Aronia

arbutifolia

nigra ...............

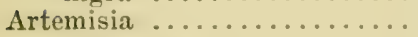

Abrotanum ............

absinthium ...........

ammua ..............

biennis
287

287

109

434

436

436

436

436

434

198

198

698

698

698

698

464

464

464

236

236

236

236

236

236

155

156

269

269

109

110

110

110

110

200

200

200

200

199

692

692

692

612

612

330

330

330

690

690

690

690

692 canadensis

690

caudata ............ 690

Stelleriana ......... 690

vulgaris ........... 690

Aruncus ............. 310

sylvester $\ldots \ldots \ldots \ldots \ldots . \quad 310$

1 rum ................ 109

triphyllum ......... 110

Asarum ............... 199

canadense .......... 199

reflexum ............ 199

Asclepiadacean ......... 494

Asclepias ................ 496

amplexicaulis ......... 498

decumbens .......... 496

exaltata .......... 498

incarnata .......... 49s

lanceolata ......... 496

obtusifolia ......... 498

paupercula .......... 490

phytolaccoides ........ 498

pulchra ............ 498

purpurascens ........ 498

quadrifolia ........... 498

rubra ............. 498

syriaca ........... 499

tuberosa .......... 496

variegata .......... 498

verticillata ......... 499

Ascyrum ............... 402

hypericoides ......... 402

stans ............ 402

Asimina .............. 244

triloba ........... 246

Asparagus ............. 135

oflicinalis ......... 135

Asperula ............... 588

odorata ........... 588

Aster ................. 652

acuminatus ......... 664

amethystinus ........ 658

carmesinus .......... 655

Claytoni .......... 655

concinnus ........... 658

concolor .......... 660

cordifolius ......... 656

corymbosus ......... 655

curvescens ......... 655

divaricatus .......... 655

dumosus ........... 662

ericoides ............ 666

Faxoni ...........6.662

glomeratus ........... 655

gracilis ............ 664

Herveyi ........... 664

hirsuticaulis $\ldots \ldots \ldots \ldots 666$

informus........... 672 
junceus ............ 658

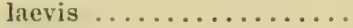

lanthinus

lateriflorus

latifolius

Lindleyanus ...........

lincariifolius ..........

longifolius

Lowrieanus

macropliyllus

multiflorus

multiformis

nemoralis

nobilis

novae-angliae

novi-belgii .............

paniculatus

patens

patulus

phlogifolius

polyphyllus

prenanthoides

prenanthoides.......

Pringlei

ptarmicoides ...........

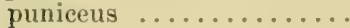

Radula ...............

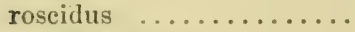

sagittifolius .........

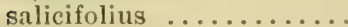

Schreberi ............

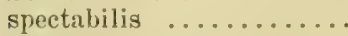

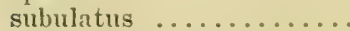

tardiflorus .............

tenebrosus ...........

tenuifolius ...........

Tradescanti ...........

umbellatus

undulatus

vimineus

violaris

Astragalus

alpinus

cantudensis

carolinianus

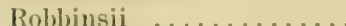

Roblinsii Jesupi........

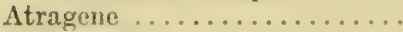

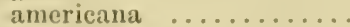

Atriplex

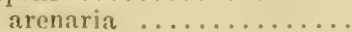

hastata

patula

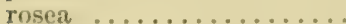

Azalea

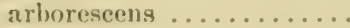

calendulacea ............

canescens
658

656

666

672

6 อั 6

672

660

656

655

660

656

664

656

658

664

664

658

660

658

662

660

666

662

660

664

656

656

664

655

662

662

660

655

662

666

672

658

666

656

348

348

348

348

348

348

250

250

216

216

216

210

210

460

468

468

$46 y$ lutea ........... 468

nudiflora ........... 466

viscosa..$\ldots \ldots \ldots \ldots .46 \mathrm{~s}$

Baccharis ............. 672

halimifolia ......... 672

Bacopa ............. 558

caroliniana ......... 558

Ballota .............. 536

nigra .......... 536

Balsaimnaceae ......... 392

Baptisia .............. 341

australis .......... 341

tinctoria ........... 341

Barbarea ............. 279

Barbarea ........... 279

praecox ............ 279

stricta ............ 279

vulgaris .......... 279

Bartonia ................ 492

iodandra ........... 493

paniculata ......... 493

virginica .......... 492

Batrachium .............. 261

divaricatum .......... 261

longirostris ........ 261

tricophyllum ......... 261

Benzoin ............. 268

aestivale .......... 268

Benzoin ............. 268

BerberidaceAe ........... 264

Berberis ................. 264

vulgaris .......... 264

Berteroa .............. 278

incana ........... 278

Berula ................. 442

erecta ........... 442

Betonica .............. 538

oflicinalis ......... 538

Betula ................ 182

alleghaniensis ........ 184

coerulea ........... 184

glandulosa .......... 185

lenta ............ 184

lutea ............ 184

nigra ............ 184

papyrifera .......... 184

populifolia ......... 184

pumila ............ 185

Betulacear ............. 180

Bicuculla ............... 270

Bidens ................ 684

bipinnata ......... 686

cermua ........... 686

comosa ........... 686

conuata ........... 686

discoiden ........... 686 


\section{frondosa}

laevis

trichosperma

Bigelowia

Bigoniaceae $\ldots . . . \ldots \ldots$.

Jilephilia

ciliata ...............

hirsuta

Blitum

capitatum . . . . . . . . . . . .

Boehmeria cylindrica

Boltonia asteroides

Boraginaceae

Borago officinalis

Bradburya

Brasenia .................... peltata purpurea

Brassica Schreberi

\section{arvensis}

campestris

juncea nimra

Breweria Pickeringii

Broussonetia .............. papyrifera

Buchnera americana

Buda

Bupleurum rotundifolium

Bursa .....................

Cacalia atriplieifolia reniformis suaveolens

Cactaceae

CAESIUPIXICEA

Cakile edentulit

Calamintha Clinopodium

Calla

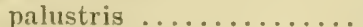

Callitricilaceae

Callitriche Austini

autumnalis

bifirla

deflexa

heterophylla
$6 \mathrm{SS}$

680

686

642

576

532

532

532

216

216

196

196

650

650

508

515

515

360

242

24

242

242

279

280

280

280

279

500

500

194

194

564

564

238

448

450

276

694

694

69

694

417

336

278

$2 \pi 8$

528

528

110

110

379

380

380

380

380

380

380 palustris

380

Calluna ................ 470

vulgaris ............ 470

('alopogon .............. 162

pulchellus .......... 163

Caltha ................ 262

flabellifolia .......... 262

palustris ........... 262

Calypso ................ 160

bulbosa ........... 160

Camelina ................... 278

sativa ............ 278

Campanula ...............605

americana .......... 606

aparinoides .......... 606

glomerata ........... 606

rapunculoides .........6.606

rotundifolia ......... $\mathbf{6 0 6}$

Campanulaceae ..........6.65

Campanulales ...........6 604

Canabis .............. 196

sativa ........... 196

Camoirles ................. 272

CAPPARIDACEAE .......... 288

Caprifoliaceae .......... 590

Capsella .. ........... 276

Bursa-Pastoris ........ 276

Cardimine ............. 284

arenicola ........... 286

bellidifolia .......... 286

bulbosa .............. 286

flexuosa .............. 286

hirsuta ........... 280

parviflora .......... 286

pennsylvanica ......... 286

pratensis ............ 284

purpurea ........... 286

rotundifolia .......... 286

Cardiospermum ........... 392

Halicacabum .......... 392

Carduus ................ 698

altissimus ........... 700

arvensis ........... 700

crispus ............ 702

discolor .......... 700

lanceolatus .......... 700

muticus .............. 700

nutans ............. 702

odoratus ........... 700

spinosissimus ........ 700

Carpinus .............. 182

caroliniana .......... 182

Carum ............... 442

carui ............ 442

Carya ................. 178

alba ............ 180

cordiformis ......... 178 
glabra

Jacinosa $\ldots \ldots \ldots \ldots \ldots \ldots$

microcarpa

ovata

CarrophyLtace

Caryopityllineae ........

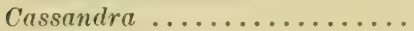

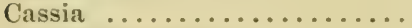

Chamaecrista .........

marylandica ...........

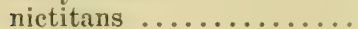

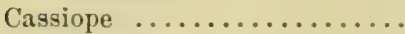

hypnoides ............

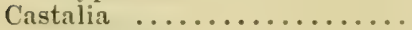

odorata ...............

tuberosa

Castanea

dentata

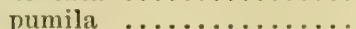

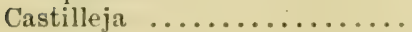

coccinea .............

pallida ...............

septentrionalis ..........

Catalpa

speciosa ..............

Caucalis

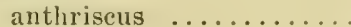

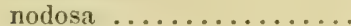

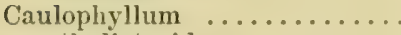

thalictroides ...........

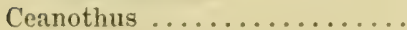

americanus .............

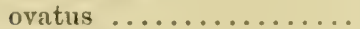

Celastraceae .............

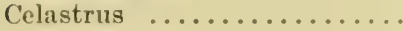
scandens

Celtis

occidentalis

crassifolia

Centaurea ................ calcitrapa ............

Cyanus

Jacea

nigra

Centaurium

umbellatum

spicatum

Centrosema virginianum

Cephalanthus oceidentalis

Cerastium alpinum

longipedunculatum ..... mut:uns oblongifolium
180

180

180

178

225

224

469

338

338

338

338

464

464

243

243

243

186

186

186

566

568

568

568

576

576

444

444

444

264

266

395

395

395

386

388

388

192

192

192

702

702

702

702

702

488

488

488

360

360

$5 \mathrm{~s}$

584

234

235

235

235

235

235 viscosum

234

vulgatum ........... 235

Ceratophyllaceae ....... 243

Ceratophyllum .......... 243

demersum ......... 243

Cercis ................ 338

canadensis .......... 338

Chaerophrllum .......... 448

procumbens $\ldots \ldots \ldots \ldots .448$

Chamaecistus ........... 463

procumbens ......... 463

Chamaecyparis ......... 84

thyoides ........... 84

Chamaedaphne ........... 469

caliculata .......... 469

Chamaelirium ........... 128

luteum ............. 128

obovale ............ 128

Chamaenerium ........... 425

angustifolium $\ldots \ldots \ldots \ldots \quad 425$

Chelidonium ............. 270

majus ........... 270

Chelone ............. 555

glabra ............ 555

Cirevopodiaceae ......... 211

Chenopoditneae ......... 210

Chenopodium ............. 211

album ............ 212

ambrosioides ......... 214

anthelminticum ........ 214

Bonus Henricus........ 214

Boscianum ......... 212

Botrys .......... 214

glaucum ........... 212

hybridum .......... 214

leptophyllum ........ 212

murale............. 214

polyspermum ........ 212

rubrum ........... 214

urbicum .......... 212

vulvaria .......... 212

Chimaphila ............ 460

maculata ......... 440

umbellata .......... 4 ti0

Chiogenes ............. 47t

hispidula .......... 474

Chondrophora .......... 642

nudata .......... 642

Cimoripetalar ............ $166^{\circ}$

Chrosperma ............. ]2s

Chrysanthemum .......... 689

Leveanthemum ....... 6s?

Chrysopsis ............. 642

falcata .......... 612

graminifolia ........ 642

Mariana ........... 642

Chrysosplenium ......... 302 
americanum

Cichoriaceate

Cichorium

Cicuta

$$
\text { Intybus }
$$

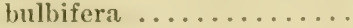

maculata .............

Cimcifuga ..............

americana ............

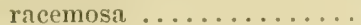

Circaea

alpina

lutetiana

Cirsium

Cissus

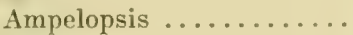

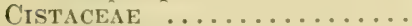

Claytonia

caroliniana ..........

virginica $\ldots \ldots \ldots \ldots . .$.

Clematis

ochroleuca

vertinilliaris ...........

viorna ..............

virginiana

Cleome

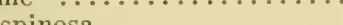

Clethra

$$
\text { alnifolia }
$$

Clethraceae

Clinopodium

Acinos

glabrum

vulgare

Clintonia

borealis umbellulata

Clitoria mariama

Cnicus benelictus

Coelopleurum Gmelini

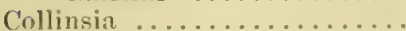
verna ...............

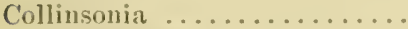
canadensis

Comandra

livida

umbellata

Comarum palustre

Commelina communis

hirtella

nueliflora

virginica
302 Commelinaceae .......... 114

610 Compositá ............ 6.29

611 Comptonia ............. 177

612 perigrina .......... 177

444 Coniferae ............... 81

446 Conioselinum ............. 444

446 chinense ............ 444

263 Conium ................ 442

264 maculatum .......... 444

264 Conopholis ............. 575

430 americana .......... 575

431 Contortae . . . . . . . . . . 484

430 Convallarima . . . . . . . 134

700 Convolvulaceat . . . . . . . 500

396 Convolvulus ............. 502

396 arvensis . . . . . . . 502

$406 \quad$ sepium ............. 502

224 spithamaeus ........ 503

224 Coptis ................. 262

224 trifolia ............. 262

245 Corallorrhiza .......... 160

250 maculata ............ 162

250 multiflora .......... 162

$250 \quad$ odontorhiza ......... 162

$248 \quad$ striata ............ 162

$290 \quad$ trifida . . . . . . . . . 162

290 Wisteriana ........... 162

458 Corema ................ 381

$458 \quad$ Conradii ............ 381

458 Coreopsis ............. 684

528 lanceolata ......... 684

530 rosea ............ 684

$530 \quad$ trichosperma $\ldots \ldots \ldots \ldots 680$

528 tripteris ............ 6.4

135 CORNaCEAE .............. 450

135 Cornus .............. 452

135 alternifolia ......... 452

360 Amomum .......... 452

360 asperifolia . . . . . . . 454

703 canadensis .......... 452

703 candidissima ........ 454

447 circinata ........... 452

447 florida ............ 452

556 paniculata ........ 454

556 serecen ........... 454

542 stolonifer: $\ldots \ldots \ldots \ldots .451$

542 Coronilla .............. 348

199 vitria ............ 348

199 Coronopus ............ 276

199 coronopus .......... 279

318 didymus ........... 278

318 procumbens ........ 278

114 Corsdalis .............. 272

114 aurea ............. 272

116 flavula ............. 272

$11+\quad$ glauca $\ldots \ldots \ldots \ldots \ldots \ldots . \ldots 272$

116 sempervirens ......... 272 
Corylus ................ 182 americana ........... 182 rostrata ........... 182

\section{Cracea}

virginiana $\ldots \ldots \ldots \ldots \ldots$

Crantzia

Crassumaceae ...........

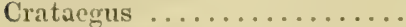
coccinea

Crus-Galli

macracantha

mollis

punctata

rotundifolia

tomentosa

uniflora

Crepis

biennis

capillaris

tectorum

virens

Crotolaria sagittalis

Croton

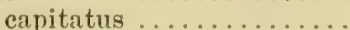

Crotonopsis linearis

Cruciffrate

Cryptotaenia canadensis

Cubelium

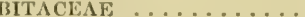

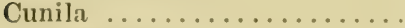
mariana origanoides

Cuphea petiolata

Cupressinear

Cuscuta arvensis cephalanthi

compacta

Coryli

Epilinum

Epithymum

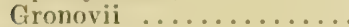

Cuscutaceaf ............

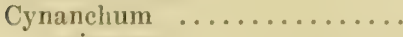

nijrrum

Cynoglossum

oflicinale

virginianum

Cypripedium

acaule

arietinum

candidum
346

346

440

296

331

332

331

332

332

332

332

332

332

332

620

620

620

620

620

341

341

374

376

376

376

272

447

447

416

604

533

533

533

422

422

83

503

504

504

504

50 .

503

503

504

503

499

499

511

511

511

148

148

148

148 hirsutum .......... 148

parviflorum ......... 148

reginae ............ 148

spectabile .........., 148

Cytisus ............. 342

scoparius .......... 342

Dalibarda ............ 312

repens ............ 314

Daphne .............. 418

Mezereum .......... 418

Dasystoma ............ 564

flava .......... 564

laevigata ........... 564

pedicularia ......... 564

virginica .......... 564

Datura ............. 548

Metel ........... 548

Stramonium ........ 548

Tatula ........... 548

Daucus .............. 440

carota ........... 440

Decodon ............. 421

verticillatus ........ 421

Delphinium ........... 263

Ajacis ........... 263

Consolida ........... 263

exaltum .......... 263

tricorne ........... 263

urceolatum .......... 263

Dendrium ............... 463

buxifolium .......... 463

Dentaria .............. 283

diphylla ........... 283

heterophylla ......... 284

incisifolia .......... 284

laciniata .......... 283

maxima ............ 284

Dcringe ............... 447

Desmodium ............ 349

bracteosum ........ 352

canadense .......... 352

canescens ......... 352

Dillenii ............ 352

glabellum .......... 350

grandillorum ......... 350

lievigatum .......... 352

marylandicum ....... 352

nudiflorum .......... 350

obtusum .......... 352

ochroleucum ......... 350

paniculatum ......... 352

pauciflorum ........ 350

rigidum ........... 352

rotundifolium ....... 350

sessilifolium .......... 350

strictum .......... 350 
viridiflorum

Dianthera americana

Dianthus

Armeria

barbatus

deltoides prolifer

Diapensia lapponica

Diapensiaceal

Dicentra canadensis Cucullaria exima

Diervilla Diervilla Lonicera

Diodia teres virginiana

Dioscorea villosa .................

Dioscoreaceae

Diospyrus

Direa virginiana palustris

Discopleura

Disporum languinosum .........

Diplotasis ................. muralis tenuifolial

DIPSACACEAE

Dipsacus lacinatus sylvestris

Doellingeria humilis infirma umbellata

Dondia

Draba caroliniana ............ incana .............. verna

Dracocephalum parviflorum

Drosera

filiformis ..............

intermedia

longifolia

rotundifolia $\ldots . . . . . .$.

Droseraceae

1) RUT'ACEAE:

Dryas
352

578

578

231

231

231

231

231

476

476

476

270

270

270

272

598

598

598

584

584

584

142

142

142

484

484

418

418

440

136

136

282

282

282

602

602

602

602

672

672

672

672

217

286

287

287

287

542

542

292

292

292

292

292

291

332

322 integrifolia

322

Duchesnea .............. 31 .

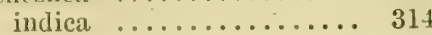

Erevacteae ............ 452

Eibenales ............. 48,

Echinocystia ............ 605

Echinodorus ............. 104

tencllus ........... 104

Echinospermum ......... 511

Echium ................ 515

vulgare .............. 511

Eclipta ..............6.678

alba ............. 678

Elatagnaceae ......... 418

Elatinaceae ............ 406

Elatine .............. 406

americana .......... 406

Elatinoides ............. 552

Elatine ............ 552

spuria ............. 552

Elephantopus .......... 634

carolinianus .........6. 634

nudatus ........... 634

Ellisia .................. 508

Nyctelea .......... 50 s

Elodea .............108, 404

canadensis .......... 108

petiolata........... 404

virginica .......... $40 \pm$

EMPETR.ICE. . . . . . . 381

Empetrum ............. 381

nigrum ............ 381

Epifagus .............. 575

virginiana ......... 575

Epigaea ............. 464

repens ............ 464

Epilobium .............. 425

adenocaulon ......... 426

alpinum ........... 426

coloratum ........... 426

densum ........... 426

hirsutum ........... 426

Hornemanni ......... 426

lactiflorum ......... 426

lineare $\ldots \ldots \ldots \ldots \ldots .426$

molle ............ 426

palustre ........... 426

strictum ........... 426

Epipactis ...........156, 159

decipiens .......... 159

Menziesii ........... 159

pubsicens $\ldots \ldots \ldots \ldots . \quad 15$ ?

repens ............ 159

repens ophioides....... 159

tessclata .......... 159

Erechtites ............. 699

hieracifolia $\ldots \ldots \ldots \ldots$. 69.4 


\begin{tabular}{|c|c|c|c|}
\hline CEAE & 462 & glyptosperma & 378 \\
\hline Ericales $\ldots \ldots \ldots \ldots \ldots$ & 457 & helioscopia ....... & 379 \\
\hline Erigeron ............... & 666 & humistrata ....... & 378 \\
\hline annuus $\ldots . . . \ldots \ldots$ & 670 & Ipecacuanhae ......... & 379 \\
\hline belliclifolius .......... & 670 & Lathyris ............. & 79 \\
\hline canadensis .......... & 670 & $\ldots \ldots \ldots \ldots \ldots$ & 79 \\
\hline hyssopifolius ......... & 670 & $\ldots \ldots \ldots \ldots$ & \\
\hline Philadelphicus ........ & 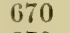 & nicaeensis ............ & \\
\hline pulchellus ........... & 0 & nutans $\quad \ldots \ldots \ldots \ldots \ldots$ & \\
\hline rosus $\ldots \ldots \ldots \ldots \ldots$ & & $\ldots \ldots \ldots \ldots$ & 79 \\
\hline CEAE $\ldots \ldots \ldots \ldots$ & & onifolia $\ldots \ldots \ldots \ldots$ & 18 \\
\hline & 114 & IACEAE .......... & 14 \\
\hline latum...$\ldots \ldots$. & 4 & $a \quad \ldots \ldots \ldots \ldots \ldots$ & 0, \\
\hline essum $\ldots \ldots \ldots \ldots$ & & icana ............ & 68 \\
\hline ulare ........... & & sii $\ldots . . . . . .$. & \\
\hline Parkeri ............. & & $\ldots \ldots \ldots \ldots$ & \\
\hline angulare $\ldots . . . .$. & 4 & $a \ldots \ldots \ldots$ & 50 \\
\hline$\ldots \ldots \ldots \ldots \ldots \ldots$ & & inifolia $\quad . . . \ldots \ldots$ & \\
\hline$n \ldots \ldots \ldots$ & & & \\
\hline$\ldots \ldots \ldots \ldots$ & 439 & FAGACEAE & \\
\hline$\ldots \ldots \ldots \ldots$ & 9 & $\ldots \ldots \ldots \ldots$ & \\
\hline ianum...$\ldots \ldots$ & & $\ldots \ldots \ldots \ldots$ & 02 \\
\hline Erysi & & ntum $\ldots \ldots \ldots \ldots$ & 0 \\
\hline es $\ldots . . .$. & & yrum $\quad . . . .$. & 0 \\
\hline$\ldots \ldots \ldots \ldots$ & 66 & tartaricum $\ldots \ldots \ldots \ldots$ & 04 \\
\hline urium $\ldots \ldots \ldots \ldots$ & 8 & Fagus $\ldots \ldots \ldots \ldots \ldots \ldots$ & 86 \\
\hline $\operatorname{la} \ldots \ldots \ldots \ldots$ & & $\ldots \ldots \ldots \ldots$ & \\
\hline $\sin a \ldots \ldots \ldots$ & & grandifolia ........... & \\
\hline$\ldots \ldots \ldots \ldots$ & 38 & Falcata $\ldots \ldots \ldots \ldots \ldots \ldots$ & 00 \\
\hline$u m \ldots \ldots \ldots \ldots$ & 32 & $\mathrm{~S} \Delta \mathrm{E} \ldots \ldots \ldots \ldots \ldots$ & 12 \\
\hline$m \quad \ldots \ldots \ldots \ldots \ldots$ & & $\ldots \ldots \ldots \ldots$ & 22 \\
\hline tanum ........... & & $\ldots \ldots \ldots \ldots \ldots$ & 22 \\
\hline$\ldots \ldots \ldots \ldots \ldots$ & & $\ldots \ldots \ldots \ldots$ & \\
\hline$\ldots \ldots \ldots \ldots$ & 388 & $: \ldots \ldots \ldots \ldots$ & 82 \\
\hline us $\ldots \ldots \ldots$. & & erpinacoides ....... & 82 \\
\hline$s \ldots \ldots \ldots \ldots \ldots$ & & $\ldots \ldots \ldots \ldots$ & 14 \\
\hline$\ldots \ldots \ldots \ldots \ldots$ & & $\operatorname{sis} \quad \ldots \ldots \ldots \ldots$ & 314 \\
\hline oides ........... & & novae $\ldots \ldots \ldots$. & 14 \\
\hline & & niana $\ldots . . . \ldots$. & 14 \\
\hline mu & & Fraser & 92 \\
\hline $\operatorname{lm} \ldots \ldots \ldots \ldots$ & & isis & \\
\hline$\ldots \ldots \ldots$ & & $\ldots \ldots \ldots \ldots \ldots$ & \\
\hline ium .......... & & 1a $\ldots \ldots \ldots \ldots$ & \\
\hline$\ldots \ldots \ldots \ldots$ & & $\operatorname{ta} \ldots \ldots \ldots \ldots$ & \\
\hline$\ldots \ldots \ldots \ldots \ldots$ & & uxii $\ldots \ldots \ldots \ldots$. & \\
\hline$m \ldots \ldots \ldots \ldots$ & & $\ldots \ldots \ldots \ldots$ & 85 \\
\hline & 8 & sylvanica . & 185 \\
\hline $\mathrm{um}$ & 6 & $\ldots \ldots \ldots \ldots \ldots$ & 72 \\
\hline .... & & oflicinalis ....... & 72 \\
\hline $\operatorname{lium} \ldots \ldots \ldots$ & & FuMARIACEAE $\ldots \ldots \ldots \ldots$ & \\
\hline$\cdots$ & & & \\
\hline $1 \mathrm{~m}$ & & $\mathrm{G}$ & \\
\hline Bo & & ris ... & \\
\hline & 378 & bilis .. & 362 \\
\hline & 379 & Galeop & 34 \\
\hline igtonii .... & 379 & $\operatorname{lum} \ldots .$. & 36 \\
\hline 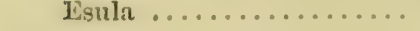 & & $\ldots \ldots \ldots \ldots$ & \\
\hline
\end{tabular}


Galeorchis spectabilis....... 156

Galinsoga ............. 688 parviflora .......... 688

Galium ............. 585

Aparine ............. 585

asprellum .......... 588

boreale ............ 586

cireaezans ......... 580

Claytoni ........... 588

concinnum ......... 588

erectum ........... 585

hispidulum .......... 588

kamtschaticum ........ 586

lanceolatum .......... 586

latifolium .......... 586

Mollugo ............ 585

palustre ........... 588

pilosum ...............

tinctorium .......... 580

tricorne ............. 585

trifidum ............ 586

triflorum $\ldots \ldots \ldots \ldots \ldots \ldots, \quad 586$

verum ........... 585

Gamopetalae ........... 455

Gaultheria ............. 464

procumbens .......... 464

Gaura ................ 430

biennis .............. 430

coccinea ........... 430

Gaylussacia ............... 472

baccata ................

brachycera ...........

dumosa...........

frondosa $\ldots \ldots \ldots \ldots$.

resinosa $\ldots \ldots \ldots \ldots$.

Gemmingia

chinensis

Genista

Gentiana

Andrewsii ..............

erinita ................

dentosa .............

flavida ...............

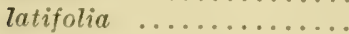

linearis......... .6 .

Porphyrio .............

procera............

quinquefolia ...........

rubricaulis

S:aponaria

villosa $\ldots \ldots \ldots \ldots \ldots$

Gemtianaceae ............

Gemtianales .............

Geraniaceae ..............

Geraniales

Geranium
Bicknellii

carolinianum

columbinum

dissectum

maculatum

(n............... 360

pratense ........... 366

pusillum ........... 366

Robertianum ........ 365

rotundifolium ........ 366

sibiricum .......... 366

Gerardia ............... 564

maritima ......... 566

paupercula .......... 566

purpurea ........... 566

Skinneriana ......... 566

tenuifolia $\ldots \ldots \ldots \ldots \ldots .56$

album ............ 320

canadense ........... 320

ciliatum ........... 320

flavum ........... 320

macrophyllum ........ 320

Peckii ............ 320

radiatum .......... 320

rivale ............ 320

strictum .......... 320

triflorum ........... 320

vernum ........... 320

virginianum ......... 320

Gifola .............. 672

germanica .......... 674

Gillenia ............. 308

stipulata ........... 310

trifoliata $\ldots \ldots \ldots \ldots .310$

Glaux .............. 478

maritima .......... 478

Glecoma .............. 540

hederacea .......... 540

Gleditsia ............. 338

triacanthos .......... 338

490 Glumiflorae ............. 109

490 Gnaphalium ............. 676

491 decurrens .......... 676

491 obtusifolium ........ 676

491 polycephalum ........ 670

491 purpureum ......... 677

490 supinum ........... 677

490 uliginosum ......... 676

491 Gioarlyera ............... 159

491 Gratiola ................ 558

$491 \quad$ aurea $\ldots \ldots \ldots \ldots \ldots . .658$

486 pilosa ............. 558

$484 \quad$ sphaerocarpa ........ 558

364 virginiana ......... 558

364 Grossulariaceae .......... 303

365 Gymnocladus ............. 339 
dioica

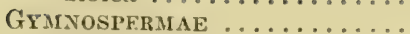

Gypsophila

muralis

Gyrostachys

Gyrotheca

Habenaria

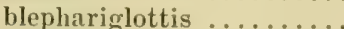

bracteata ...............

ciliaris

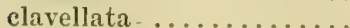

cristata

dilatata

fimbriata

flava

fragrans

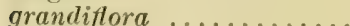

Hookeri ..............

hyperborea

integra

lacera

leucophaea

obtusata

orbiculata

peramoena

psycodes

HAEMODORACEAE ..........

Halenia deflexa

Haloragid

Hamimelidaceae .........

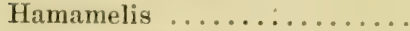

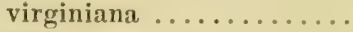

Hedeoma pulegioides

Hedysarum americanum boreale

Helenium autumnale

Helianthemum canadense

corymbosum majus

IIelianthium tenellum......

Helianthus angustifolius

decapetalus

divaricatus

gignutens

grosse-serratus

strumosus

tuberosus

Heliopsis

helianthoides

scabra
339 Heliotropium ........... 510

81 europaeum .......... 511

230 Helobiak .............. 93

230 Helonias .............. 126

156 bullata ............ 126

141 Hepatica ............... 250

acutiloba ............ 250

$150 \quad$ triloba . . . . . . . . . 250

154 Heracleum ............. 447

152 lanatum ........... 447

154 Herpestris ............. $55 \mathrm{~s}$

152 Hesperis ............... 288

154 matronalis ........... 288

152 Heteranthera ............ 116

154 dubia ............ 117

152 reniformis .......... 117

152 Heuchera .............. 300

154 americanus ........... 300

152 pubescens ........... 300

152 Hibiscus ............... 400

152 Moscheutos ........... 400

154 oculiroseus ......... 400

154 Trionum ........... 400

152 Hicoria ............... 17s

152 Hieracium .............. 622

154 aurantiacum ........ 622

154 canadense ........... 624

141 florentinum .......... 624

492 Greenii .............6.624

492 Gronovii ............ 624

431 marianum .......... 624

304 murorum ........... 622

304 paniculatum .......... 624

306 Pilosella ............ 622

533 praealtum ........... 624

533 pratense ........... 624

348 scabrum ........... 624

348 venosum $\ldots \ldots \ldots \ldots \ldots \ldots$

348 vulgatum ............ 622

688 HippocastanaceaE ......... 390

688 Hippuris ................ 431

406 vulgaris ............ 431

408 IIostekia ............... 346

408 Hottonia ................ 477

406 inflata ............. 477

104 Houstonia ............... 58. 58

680 ciliolata ........... 582

682 coerulea ............ 582

$68 \varepsilon$ longifolia ........... 5s2

682 Toxonorum .......... 582

6ş JIulsonia ............. 408

682 ericoides ............ 40 s

68 tomentosa ........... 408

682 IIumulus . . . . . . . . . . . . . 196

678 Lupulus ............ 196

678 IIYACINTIINEAE .......... 134

678 IIybanthus ............ 416 
concolor

Hydrangea .

arborescens

Hydrastis canadensis

IIydrocharis

Hydrocotyle

americana

Canbyi

umbellata

verticillata

HydropityllaceaE

Hydrophyllum

appendiculatum

canadense

virginianum

Hyoscramus

$$
\text { niger }
$$

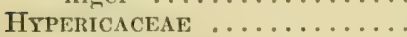

Hypericum

adpressum

Ascyron

Bissellii

boreale

canadense

densiflorum

ellipticum

Kalmianum

maculatum

majus

mutilum

mulicaule

perforatum

prolificum

punctatum

pyramidatum

Hypochaeris radicata

Hypopitys

americana

IIypopitys

Hrpoxis

hirsuta

Hyssopus officinalis

Ilex

bronxensis

glabra

laevigata

monticola

opaca

verticillata ...........

TLtCACEAE . . . . . . . . .

Ilicioides

mueronata

Ilysanthes
416

302

303

254

256

108

439

439

439

439

439

507

507

507

508

507

548

548

402

$40 z$

403

403

403

404

404

403

403

403

404

404

404

404

403

403

404

403

612

612

462

462

462

142

142

525

525

384

386

380

386

386

386

386

384

$38 \boldsymbol{H}$

380

560 attenuata .......... 560

gratioloides ......... 560

Impatiens ............. 392

aurca ............. 394

biflora ............ 392

pallida ............. 394

Inula ................ 677

Helenium ...........6 677

Ionactis ............... 672

linariifolius ......... 672

Ipomoca ............. 500

hederacea .......... 502

lacunosa ............ 502

pandurata ......... 502

purpurea ......... 50\%

IRIDACEAE ............. 142

Iris ................... 143

Hookeri ............ 143

lacustris ............ 143

prismatica .......... 143

pseudacorus .......... 143

setosa ............ 143

verna ........... 143

versicolor .......... 143

Isanthus .............. 544

brachiatus ......... 545

Isnardia .............. 425

palustris .......... 425

Isotria verticillata......... 155

Itea .............. 303

virginica ........... 303

Iva ............... 628

frutescens ......... 628

ovaria ........... 628

Jeffersonia ........... 260

diphylla ............ 260

JUGLANDACEAE ............ 178

Juglans . . . . . . . . . . 17s

Cinerea ............ 178

nigra ............. 178

Julitforales $\ldots \ldots \ldots \ldots \ldots .166$

JUXCACEAE ............. 118

Juncoides ................ 123

Juncus ................. 118

acuminatus ......... 123

articulatus ........ 122

asper ............. 120

balticus . . . . . . 119

bufonius ........... 120

Caesariensis ........... 120

canadensis ........... 122

dichotomus ........... 120

Dudleyi ............. 120

effusus ............ 119

filiformis .......... 119

Gerardi .......... 120 


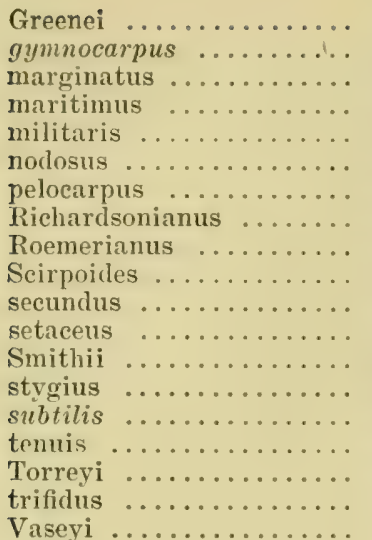

Juniperus

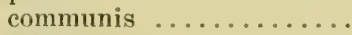

depressa

nana

procumbens

sabina

virginiana

Kalmia

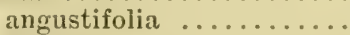

glauca

latifolia

polifolia

Knautia arvensis

Kneiffia

\section{Alleni}

fruticosa

linearis

longipedicellata ........

pratensis pumila

Fochia

Scoparia

Koollia

Kosteletzkya ............. virginica

Krigia

caroliniana

Kuhnia virginica

eupatorioides ...........

LABIATAE

Lachnanthes tinetoria

Lacinaria

Lactuca

\section{8}

468

469

468

469

602

604

428 canadensis ......... 618

floridana ............ 620

hirsuta ............. 61s

integrata ........... 618

Morssii ............. 618

sagittifolia ........... 620

sareola ............6.618

Scariola .......... 618

spicata ............. 620

villosa ................ 620

virosa ............ 618

Lamium ............... 534

album ............ 534

amplexicaule ......... 534

maellatum ......... 534

purpureum .......... 534

Laparquraea ............. 418

Laportea .................. 195

canadensis .......... 195

Lappula ............... 511

echinata .......... 511

Lappula ............ 511

virginiana ......... 511

Lapsana ................. 614

communis ...........6.614

Larix ............... 84

decidua ............ 84

laricina ............ 84

Lathyrus ............. 358

maritimus .......... 358

myrtifolius ........... 358

ochroleucus .......... 358

palustris ............ 358

pratensis ........... 358

venosus ............. 358

Lauraceat .............. 268

Jechen .................. 408

intermedia .......... 409

juniperina ........... 409

Legrettii ............ 409

maritima .......... 409

minor .............. 408

racemulosa ........... 408

stricta ............ 409

tenuifolia .......... 409

villosa ............. 408

Ledum .............. 463

groenlandicum ........ 463

Legousia ............. 606

Lciophyllum buxifolium..... 463

Lemna ................. 94

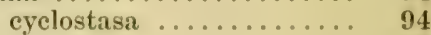

minor ............. 94

perpusilla .........

polyrhiza .......... 94

trisulea ............ 94

LeMNaCEAE …......... 93 
Lentibulariaceae

Leontodon autumnale nudicaule

Leonurus cardiaca

Marrubiastrum sibiricus

Lepidium apetalum campestre Draba ruderale sativum virginicum

Leptamnium

Leptandra virginica

Leptilon canadensis

Leptorchis

Lespedeza angustifolia

Brittonii capitata frutescens hirta Nuttallii ............. procumbens repens

Stuvei violacea virginica

Leucophysalis grandiflora

Lencothoe racemosa

Liatris scariosa spicata

Ligusticum $\ldots \ldots \ldots \ldots \ldots \ldots$ seothicum

Lilaeopsis lineata

LiLiaceae

LIIIIFLORAE

LIIIOIDEAE

Lilium canadense philadelphicum suberbum triginum

LIMNANTHACEAE

Limnanthemum aquaticum lacunosum

Limnobium
571

614

614

614

534

534

534

534

275

276

270

276

276

276

276

575

562

562

670

670

160

352

354

355

354

355

354

354

354

354

355

355

355

546

$5+0$

469

469

640

640

640

440

440

440

440

124

117

130

132

132

132

132

132

382

493

493

493

108 spongia

108

Limnorchis

152

fragrans

152 media

152

Limodorum ................ 162 tuberosum ............ 163

Limonium ............ 482 carolinianum ........ 482

Limosella ............ 560 aquatica .......... 560 tenuifolia ........... 560

Linaceae .............. 368

Linaria .............. 552

canadensis ......... 554

Cymbalaria .......... 554

clatine ............. 552

genistaefolia ......... 554

repens ............ 554

spuria ............ 552

vulgaris .......... 554

Linnaea .............. 594

borealis ........... $\mathbf{5 9 4}$

Linum ............... 368

medium ........... 370

striatum .......... 370

sulcatum ........... 370

usitatissimum ........ 368

virginianum ........ 368

Liparis ............. 160

liliifolia ........... 160

Loeselii ............ 160

Lippia ............. 518

lanceolata .......... 519

Liquidamber ............ 306

Styraciflua ......... 306

Lirodendron ............ 224

Tulipifera .......... 224

Listera .............. 158

auriculata ......... 159

australis .......... 158

convallarioides ......... 158

cordata ........... 158

Smallii ........... 159

Lithospermum .......... 514

arvense ........... 514

canescens .......... 514

Gmelini ............ 514

latifolium ........... 514

officinale ........... 514

Littorella ............ 580

uniflora ........... 580

Lobelia .............. 608

Canbyi ............. 610

cardinalis .......... 608

Dortmanna .......... 608

inflata ............ 608

Kalmii ........... 608 
Nuttallii........... 610

paludosa ............ 610

puberula ........... 608

spicata ........... 608

syphilitica

LOGANIACEAE

Loiscluria

Lonicera

canadensis

caprifolium ..........

ciliata

coerulea

dioica

glaucescens

grata

involucrata

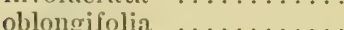

sempervirens ..........

tartarica

Lophanthus

Lophiola americana

Lophotocarpus

calycinus

spathulatus

spongiosus

LORANTIIACEAF

Lotus

corniculatus

Ludwirria

alternifolia $\ldots \ldots \ldots \ldots \ldots$

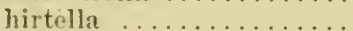

linearis .............

palustris ...........

polycarpa ............

Lupinus

sphaerocarpa

Luzula

perennis

campestris

confusa

hyperborea

parviflora

pilosa

saltuensis

spicata

Lychnis

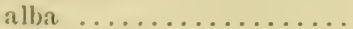

chalcedonica

dirisat

Flos-cueuli

Lyerppis

arvensis

Lyeopus

americanus

europacus
608

485

403

594

598

596

598

596

596

596

596

596

$59 \mathrm{~S}$

596

596

598

542

142

142

104

104

104

104

198

346

346

424

425

425

424

425

424

424

341

341

123

124

123

123

123

123

123

123

228

230

$2: 30$

230

230

515

515

524

525

525 rubellus ........... 525

sessilifolius ......... 525

sinuatus ........... 525

virginicus .......... 524

Lyonia mariana.......... 469

Lysimachia ............. 480

Nummularia ......... 482

punctata ........... 480

quadrifolia ........... 480

stricta ............ 482

terestris .......... 482

vulgaris .......... 480

Jythraceae ............ 420

Lythrum ............... 421

alatum ............ 421

Hyssopifolia ......... 421

lineare ........... 421

Salicaria .......... 421

Mlacrocalyx ............ 508

Magnolia .................. 244

acuminata .......... 244

glauca ............. 244

virginiana .......... 244

Magnolinceae ........... 244

Maianthemum ............ 136

canadense .......... 136

Mairania .............. 464

alpina ........... 464

Malanthium ............ 129

latifolium .......... 129

virginicum ......... 129

Malus ............... 330

angustifolia ......... 330

coronaria ........... 330

Malus ............ 330

sylvestris ........... 330

Malva ............... 399

moschata .......... 399

rotundifolia ......... 399

sylvestris ........... 399

verticillata ......... 399

MLLVACEAE ............ 398

MLALVALES ............ 396

Marubium ............. 540

vulgare ............ 540

Matricaria ............. 689

inodora ............ 689

matricarioides ........ $\mathbf{6 8 9}$

suaveolens .........689

Medeola ................ 138

virginiana .......... 138

Medicago ............... 342

arabica ............. 344

denticulata ......... 342

hispida ........... 342

lupulina $\ldots \ldots \ldots \ldots \ldots, 342$ 
sativa

Mechania cordata

Meibomia

Melampyrum

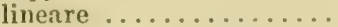

Melanthioideae

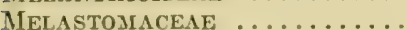

Melilotus alba oflicinalis

Melissa officinalis

Menispermaceae

Menispermum canadense

Mentha alopecuroides ..........

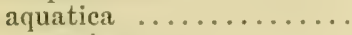
arvensis canadensis cardiaca

citrata

crispa

gentilis

longifolia

piperita

rotundifolia ...........

sativa

spicata

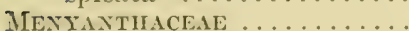

Menyanthes trifoliata

Mertensia virginica

Mesartenia.

Micrampelis lobata

Nicranthemum micranthemoides Nuttallii

Microstylis monopliyllos mifolia

Mikania scandens

Mimulus alatus

guttatus

Jamesii

Langslorbii

moschatus ringens

Mitchella repens

Mitella diphylla
342

540

540

349

571

571

125

422
344

344

$3+4$

530

530

266

266

266

521

522

524

524

524

524

522

524

524

522

522

522

524

522

493

493

493

511,512

512

697

605

605

560

560

560

159

160

160

640

640

556

550

$55 \mathrm{~B}$

558

556

558

550

584

584

300

302 nuda

........... 302

238

lateriflora ........... 238

macrophylla ......... 238

Mollugo .............. 222

verticillata ......... 222

Monarda ............... 530

clinopodia ......... 532

didyma ............ 532

fistulosa ............ 532

media .......... 532

punctata .......... 532

Moneses .............. 459

uniflora ........... 460

Monniera .................. 558

Monopetalae .......... 455

Minotropa ............. 460

uniflora ........... 460

Monotropaceae ......... 460

Montia .............. 223

fontana ........... 223

MoRACEAE . . . . . . . . . . 194

Morus .................. 194

alba ............ 194

rubra ............. 194

Muscari ............. 134

botryoides ........... 134

racemosum .......... 134

Myosotis ............. 512

arvensis ........... 512

laxa ............ 512

palustris .......... 512

scorpioides ......... 512

versicolor ......... 512

virginica .......... 512

Irosurus ............ 256

minimus ........... 256

Mrrica ............. 177

asplenifolia ......... 177

carolinensis ........ 177

Gale ............ 177

MIYRICACEAL . . . . . . . . 177

Myriophyllum ........... 432

alternillorum ........ 432

Farwellii ............ 434

heterophyllum ....... 434

humile ............. 432

pinnatum ........... 434

scabratum ........ 434

spicatum ........... 432

tenellum ............ 432

verticillatum ......... 432

Mrratales ............ 418

Tabalus .............. 624

Naiadaceae ............ 94

Naias .............. 102 
flexilis

102 Opuntiales ............ 417

gracillima .............

102

marina

$10 \%$

Ninthecium $\ldots \ldots \ldots \ldots \ldots \ldots$

120

americanum

126

Naumburgia .............

thyrsiflora

478

Nelumbo

478

lutea ..................

243

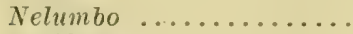

nucifera ..............

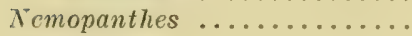

Nepeta

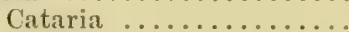

hederacea ............

Neslia

243

243

243

386

540

540

540

paniculata ...........

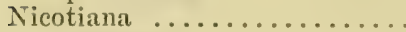

rustica

Nuphar

278

278

548

548

Nymphaea

$24 \mathrm{t}$

242

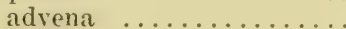

hybrida .............

242

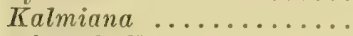

microphylla ...........

odorata

242

243

243

Nтmphaeaceae ...........

Nyssa

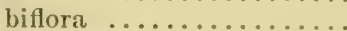

sylvatica

Oaliesia sessilifolia

243

242

454

454

454

Obolaria virginica

Odontites rubra

130

130

492

492

$56 \mathrm{~s}$

570

Oenothera

humifusa

laciniata

Oreaceae

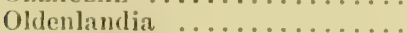
uniflora ............

Onagra

biennis

eruciata

Oakesiana

ONAGRACEAE

Onopordon

Acanthium

Onosmodium

earolinianum

hispidissimum

virginianum

428

428

428

484

582

584

426

428

429

428

422

702

702

514

514

Opulaster opulifolius........

308

OrChidacEAE ........... 146

Orchis ............... 150

rotundifolia ......... 150

spectabilis ............. 150

Origanum ............ 526

vulgare ........... 526

Ornithogalum .......... 132

umbellatum .......... 134

OROBANCHACEAE ........ 574

Orobanche .............. 575 minor ........... 575

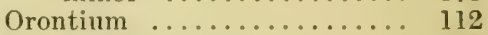
aquaticum .......... 112

Osmorhiza ............. 448

Claytoni ........... 448

longistylis .......... 448

Ostrya ............... 1s2

virginiana $\ldots \ldots \ldots \ldots \ldots \quad 182$

Oxalidaceae ............ 366

Oxalis ................. 308

Acetosella ........... 368

corniculata ......... 368

stricta ............ 368

violacea .......... 368

Oxycoceus .............. 474

macrocarpus ........ 476

Oxycoccus ........... 476

palustris .......... 476

Oxydendrum .......... 470

arboreum ......... 470

Oxygraphis .............. 261

Cymbalaria .......... 261

Oxypolis .............. 447

rigidus ........... 447

Oxvria .............. 210

digyna $\ldots \ldots \ldots \ldots \ldots 210$

Panax ............... 436

quinquefolium ....... 436

trifolium ............ 430

Pandanates .......... 90

Papaver ................ 269

Argemone ............ 269

Rhocas ............ 269

somniferum ......... 269

Papaveraceal ............ 269

Papilionaceae ........... 339

Paranassia ............. 302

caroliniana ......... 302

Parmetales ............ 400

514 Parietaria ............. 196

b15 pennsylvanica ......... 196

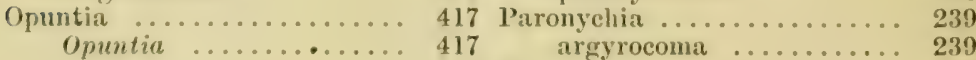

vulgaris .......... 417 l'arsonsia ............ 422 
Parthenocissus quinquefolia.

Passifloria

$$
\text { lutea }
$$

PASSIFLORICEAE

Pastinaca sativa

Paulownia tomentosa

Pedieularis canadensis

Furbishiae lanceolata

Peltandra virginica

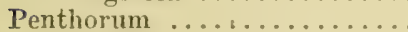
sedoides

Pentstemon

Digitulis

hirsutus

laevigatus

Pentstemon

Peramium

Petasites palmata vulgaris

Phacelia dubia

Purshii

Phaseolus helvolus perennis polystachyus

Philotria

Phlomis

Phlox tuberosa

divaricata maculatit ovilat paniculatar pilosia subulata

Phoradenilron flavescens

Phryma Leptostachya

P'inguachal:

Phyllanthus carolinensis

Phyllodoce coerulea

\section{Physalis} grandiflora lenteropliylla philadelphica pruinosa pubescens
396

417

417

$+16$

4.50

450

5.50

556

57

570

570

570

110

110

297

297

553

555

555

555

555

159

692

692

692

509

$50 \mathrm{~S}$

508

362

362

362

362

108

533

533

504

506

506

506

506

506

506

198

198

578

578

578

374

374

463

464

545

$5+6$

546

540

545

545 virginiana

546

Physocarpus ........... 308

opulifolius .......... 308

Physostegia ............ 533

virginiana $\ldots \ldots \ldots \ldots \ldots 533$

Phytolacea .............. 2.21

decandra ........... 221

Pitytolaccaceal . . . . . . 221

Phytolaccineal .......... 221

Picea .............. 88

canadensis $\ldots \ldots \ldots \ldots .88$

mariana ........... 88

mariana brevifolia ...... $\mathrm{SS}$

rubra ............. 88

Picris ................. 614

echioides ............ 614

hieracioides ......... 614

Pieris .............. 469

mariana .......... 469

Pilea ................. 195

pumila ............ 196

Pimpinella .............. 446

integerrima ........ 446

saxifraga .......... 446

Piaxcean ............ 82

Pinguicula ............ 574

vulgaris $\ldots \ldots \ldots \ldots \ldots .574$

Pinus ............... 84

Banksiana ........... 86

divaricata .......... 86

echinata .......... 86

inops ............. 86

pungens .......... 86

resinosa .......... 86

rigida ........... 86

strobus .......... 88

sylvestris .......... 88

Taeda ............ 86

vircriniana .......... 86

Piperaiks ........... 160

Plantaginalial ........ 579

Plantaginales ......... $57 \mathrm{~S}$

Plantano ............. 579

aristata ........ 579

cordata .......... 579

elongata ........... 580

heterophyllat ........ 580

lanceolatia ......... 579

major .......... 579

maritima ......... 579

media ............ 579

Rugelii .......... 579

virginiea . . . . . . . 580

Piataniceae ........... 306

Platanus ............... 306

occidentalis ........ 306

Plucheal ............. 67.4 
camplorata ......... 674

foetida ........... 674

Plumibiginaceae ......... 482

Pnemmaria ........... 511

maritima ......... 511

Podophyllum ........... 266 peltatum ........... 266

Podostemaceae ......... 295

Podostemon ............. 295

ceratophyllum ........... 295

Pogonia ................ 155 aftinis .......... 15b

divaricata .......... 155

ophioglossoides ....... 155

trianthophora ....... 155

verticillata ......... 155

Polanisia .............. 290

graveolens ........... 290

Polemoniaceae ......... 504

Polemonium ........... 507

coeruleum ......... 507

reptans ........... 507

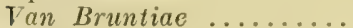

Polygala

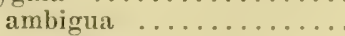

brevifolia ............

cruciata

incarnata ...........

lutea ................

mariana .............

Nuttallii ..............

polygama ............

paucifolia ............

sanguinea $\ldots \ldots \ldots \ldots$.

semeril $\ldots \ldots \ldots \ldots \ldots \ldots$

verticillata ...........

viridescens ............

Polygalanceae .............

PoLYGoNACEAE ...........

Porygonales ........... 200

Polygonatum ............ 136

biflorum ........... 138

commutatum

Polygonella articulata

gonum ..............

acre

amphibium

arifolium

avieulare.........

Chichine............

Careyi $\ldots . . . \ldots \ldots \ldots . . . .$.

convolvulus ......... 208

cristatum .......... 208

Douglasii ........... 208

dumetorum .......... 208

cmersum
507

372

372

371

372

372

372

372

372

372

371

200

00

210

210

204

206

205

210

206

206

208

208

205 erectum ........... 208

exsertum .......... 208

Fowleri ........... 200

Hartwrightii ......... 205

Hydropiper .......... 206

hydropiperoides ....... 206

incarnatum ......... 205

lapathifolium ........ 205

littorale ......... 206

maritimum ......... 206

Muhlenbergii ......... 205

orientale ........... 206

pennsylvanicum ....... 205

persicaria .......... 205

punctatum .......... 206

ramosissimum ........ 208

Rayi ............ 206

sagittatum .......... 210

scandens .......... 208

tenue ............. 208

virginianum ....... 206

viviparum ......... 20,

Polymnia ............ 677

canadensis .........6.677

uvedalia ........... 677

Poltyetalae ........... 2.23

Polypremum ........... 486

procumbens ........ 486

Pomaceae .............. 328

Pontederia ............... 110

cordata ........... 116

Pontederiaceae .......... 116

Populus .............. 176

alba $\ldots \ldots \ldots \ldots \ldots \ldots, 176$

balsamifera $\ldots \ldots \ldots \ldots \quad 176$

" candicans. 176

deltoides ........... 177

grandidentata ....... 176

heterophylla ........ 176

nigra .......... 177

pyramidalis ........ 177

tremuloides ......... 176

Porteranthus ............. 30 .

Portulaca .............. 2.24

grandiflora ......... $2: 4$

oleracea ........... 224

Portulacaceak .......... 2.23

Portulaciveaf ........... 2.23

Potamogeton ............ 95

alpinus ..........

americanus ......... 96

amplifolius $\ldots \ldots \ldots \ldots .96$

angustifolius ........

bupleuroides .......... פs

confervoides ......... 100

crispus .......... 99

dimorphus ......... 9s 
diversifolius

epiphydrus

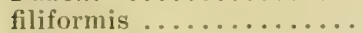

foliosus ............

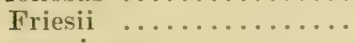

gemmiparus...$\ldots \ldots$.

heterophyllus $\ldots \ldots \ldots \ldots$.

\section{Hillii}

hybridus

interruptus

lanceolatus

lateralis

lonchites

lucens

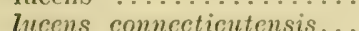

mysticus ...........

natans $\ldots \ldots \ldots \ldots . .$.

Nuttallii ............

Oakesianus ............

obtusifolius ..........

pectinatus .............

perfoliatus

praelongus ...........

pulcher .............

pusillus ..............

Richardsonii .........

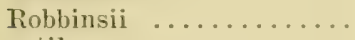

rutilus

spatlulaeformis .......

spirillus

strictifolius

Vaseyi

Zizii .

zosteraefolius

Potentilla

Anserina.........

argentea

arguta

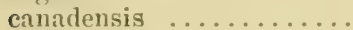

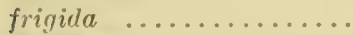

frutiensa

intermedia

littoralis

monspeliensis

norrentere

palustris

paradoxa

pennsylvanica .........

recta $\ldots \ldots \ldots \ldots \ldots \ldots$

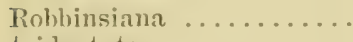

tridentata

Prenanthes

alba

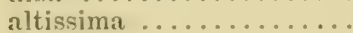

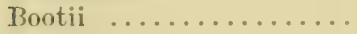

erepidinea
98

96

96

100

99

99

100

99

98

100

98

98

96

99

99

99

95

96

95

99

100

98

99

96

100

98

100

100

96

98

100

98

99

99

314

318

316

316

318

316

316

316

316

316

316

318

316

316

316

316

316

624

626

626

626

628 nana ............ 626

racemosa .......... 628

serpentaria .......... 626

trifoliolata ......... 626

virgata .......... 626

Primula .............. 47'

farinosa .......... 477

mistassinica ......... 477

Primulaceae ........... 477

Primulales ........... 476

Proserpinaca ............ 431

palustris .......... 432

pectinata ......... 432

Prunella ............. 538

vulgaris .......... 538

Prunus .............. 332

alleghaniensis ........ 334

americana .......... 334

angustifolia ......... 334

cuneata ........... 336

Gravesii ............ 334

maritima .......... 334

nigra ............ 334

pennsylvanica ........ 336

pumila ........... 336

serotina ........... 336

spinosa ........... 334

virginiana $\ldots \ldots \ldots \ldots \ldots 336$

Ptelea ................ 370

trifoliata .......... 370

Pterospora .............. 460

andromedea $\ldots \ldots \ldots \ldots .460$

Ptilimnium ............ 440

capillaceum ......... 440

Pulmonaria ............ 511

Pyenanthemum ......... 526

aristatum .......... 528

clinopodioides ........ 528

flexuosum ............ 526

incanum .......... 52s

lanceolatum .......... 526

linifolium ......... 5:0

muticum ......... 5:8

Torryi ............ 520

verticillatum $\ldots \ldots \ldots \ldots \quad 5: 6$

virginianum ......... 526

Pyrola ................ 45s

americana .......... 459

asarifolia ......... 459

chlorantha ......... 459

cllipticat .......... 45!

minor . . . . . . . . 45?

oxypetala .......... 459

rotundifolia ........ 459

secundta ............ 459

uliginosa .......... 459

Prrolaceae ............ 458 
Prrus

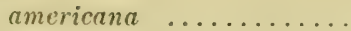

communis ............

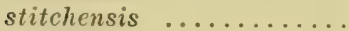

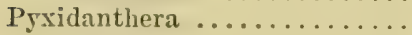

barbulata .............

Quercus

accuminata .............

alba

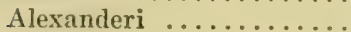

bicolor

borealis

coccinea

digitata

falcata

illicifolia

imbricaria

lyrata

macrocarpa ..........

marylandica ..........

Michauxii

minor

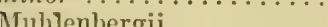

nana

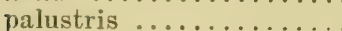

phellos

platanoides .............

prinoides

prinus

rubra

stellata

velutina

R.ixales

Ranunculaceae .........

Ranuneulus

abortivus ...............

acris

alleghaniensis ........

aquatilis ..............

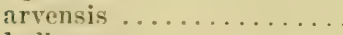

bulbosus

cymbalaria ............

delphinifolius

fasicularis

lispidus

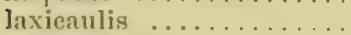

micranthus

obtusiusculus

parvulus

pennsylvanicus

pusillus

recurvatus

repens

reptans

sclerntus ...................

sejetentrionalis
328 Raphanus ............. 28s

328 raphanistrum ........ 282

$330 \quad$ sativus ............ 282

328 Razoumofskya ........... 198

476 Reseda ............... 290

476 alba .............. 291

$186 \quad$ lutea ............. 290

$191 \quad$ Luteola ............. 290

190 Resedacene ..................... 290

191 Riramadeeae ............ 394

190 Rhamnales ............ 394

188 Rhamnus ............. 394

18s alnifolia ............. 395

189 caroliniana .......... 395

188 cathartica .......... 394

188 Frangula ........... 395

190 lanceolata .......... 394

190 Rhexia ............... 422

$190 \quad$ aristosa ............ 422

190 mariana .......... 422

191 virginica $\ldots \ldots \ldots \ldots \ldots .422$

190 Rhinanthus ............ 570

$190 \quad$ Crista-galli ......... 570

188 oblongifolius ........ 570

Is8 Rhododendron .......... 460

190 canadensis ........... 466

190 lapponicum .......... 460

191 maximum .......... 466

191 Rhodora ............. 466

188 canadensis .......... 466

190 RHoEAdales ........... 268

188 Rhus ................... 382

aromatica .............. 384

240 canadensis .......... 384

246 copallina ........... 382

256 glabra ............ 384

258 hirta ............. 384

260 radicans ............ 384

258 toxicodendron ......... 384

261 typhina ............ 384

260 Vernix ............ 384

260 Ribes ................ 303

261 cynobasti .......... 304

258 floridum ............ 304

260 Grossularia ........... 304

$260 \quad$ lacustre ............. 304

258 oxyacanthoides ........ $30 \pm$

258 prostratum ......... 304

258 rotundifolium ........ 304

$260 \quad$ Uva-Crispa $\ldots \ldots \ldots \ldots \ldots .304$

258 vulgare .............. 304

258 Robinia ............... 348

260 P'seudacacia .......... 348

261 Roripa ............... 282

261 americana .......... 283

$258 \quad$ armoracia $\ldots \ldots \ldots \ldots \ldots 283$

$200 \quad$ lispida $\ldots \ldots \ldots \ldots \ldots . . \ldots 283$ 
Nasturtium .......... 283

palustris ........... 283

Rosa

sylvestris $\ldots \ldots \ldots \ldots \ldots .283$

blanda

canina ............... 326

carolina ........... 326

humilis ............ 326

lucida $\ldots \ldots \ldots \ldots \ldots \ldots .326$

nitida ........... 326

rubiginosa ........... 320

virginiana ............ 326

RosACEAE ................ 306

Rosales ............... 292

Rotala ............... 420

ramosior ...............

Roubieva

multifida ............

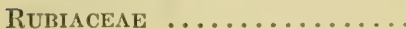

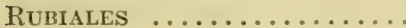

Rubus

alleghaniensis .........

Baileyanus ............

canadensis ..............

Chamamorus .........

cuneifolius ...........

frondosus .............

hispidus

Millspaughii ..........

neglectus ............

nigricans $\ldots \ldots \ldots \ldots$.

occidentalis ..........

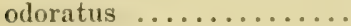

procumbens ..........

setosus ..............

strigosus ................

triflorus ............

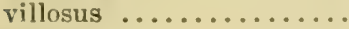

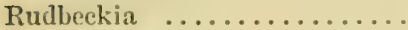

fulgida

hirta

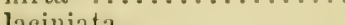

680

speciosa ........... 680

triloba $\ldots \ldots \ldots \ldots \ldots \ldots 680$

Ruellia .............. 576

ciliosa ........... 576

strepens $\ldots \ldots \ldots \ldots \ldots .578$

Rumex

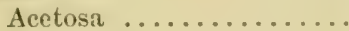

Acetosella .............

altissimus .............

ancricanus .......... 20

britamiea ........ 202

crispus ........... 202

hastatulus ......... 201

obtusifolius ......... 202

Patientia .......... 202 persicarioides ........ 202

salicifolius ........... 201

sanguineus .......... 20\%

verticillatus ......... 202

Ruppia ............... 102

maritima .......... 102

Rutaceae ............ 370

Sabbatia ............. 488

angularis ......... 488

campanulate ......... 490

dodecandra ......... 490

gracilis ............ 488

lanceolata ........... 488

stellaris .......... 488

Sagina ............... 235

apetala ............ 235

decumbens ......... 236

nodosa ........... 236

procumbens .......... 235

Sagittaria ............... 104

arifolia ........... 106

Eatonii ............ 106

Engelmanniana ........ 106

graminea ........... 106

heterophylla ........ 106

latifolia ........... 106

longirostra ........ 106

rigida ............ 106

subulata ........... 10s

teres .............. 10s

variabilis ......... 106

Salicaceae ............ 167

Salicornia ............ 217

ambigua .......... 217

Bigelovii............... 217

curopaca ........... 217

herbacea ............ 217

mucronata .......... 217

Salix .............. 168

adenophylla ......... 174

alba ............. 170

amygdaloides ......... $\mathrm{m} 70$

argyrocarpa ......... 174

babylonica .......... 170

balsamifera ......... 174

Bebbiana .............. 172

candida ........... 174

coactilis .......... 176

cordata ........... 174

discolor ............ 172

eriocephala ......... 172

fluriatilis .......... 170

fragilis ........... 170

glaucophylla ......... 170

herbacea .......... 176

humilis ............ 172 
longifolia

lucida

myrtilloides

nigra

phylicifolia

prinoides

purpurea

rostrata

sericea

serissima

squamata

tristis

Uva-Ursi

viminalis

Wheeler

Salsola

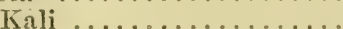

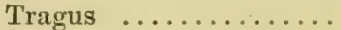

Salvia

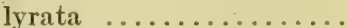

pratensis

Sambucus

canadensis

racemosa

Samolus

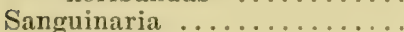

canadensis

Sanguisorba

canadensis

minor

officinalis

Sanguisorba

Sanicula

canadensis

gregaria

marylandica

trifoliata

Santalacear

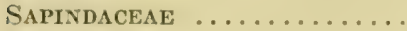

Sapindates ..............

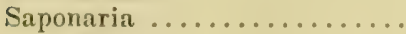

officinalis

Vaccaria

Sarothra gentianoides

Sarracenia

purpurea

Sarracentaceat

SARRACENIALES

Sassafras

variifolium

Satureia

acinos

glabra
170

170

174

168

174

172

172

172

172

170

172

174

176

172

170

218

218

218

530

530

530

590

591

591

478

$47 \mathrm{~S}$

270

270

324

324

324

326

324

440

442

442

440

442

198

196

392

380

230

230

230

404

404

291

291

291

291

268

268

268

528

530

530 hortensis ......... 528

Saururaceae ........... 166

Saururus ............. 167

cernuus .......... 167

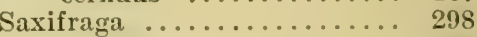

Aizoon ............ 298

azoides ............ 295

comosa ............ 300

micranthidifolia ...... 300

oppositifolia ......... 298

pennsylvanica ....... 300

rivularis .......... 298

stellaris .......... $\mathbf{3 0 0}$

virginiensis $\ldots \ldots \ldots \ldots .298$

Saxifragaceae ......... 297

Scandix ................ 448

Pecten-Veneris ........ 448

Scheuchzeria ............ 103

palustris .......... 103

Schwalbea ........... 568

americana ......... 568

Scleranthus ............ 239

annuus ............ 240

Sclerolepis ............. 636

uniflora ........... 636

Scrophularia .......... 554

leporella ............ 555

marylandica ........ 555

Scropitulariaceat ...... 550

Scutellaria ............ 538

galericulata ......... 538

incana ........... 539

integrifolia ....... 539

lateriflora ......... 539

nervosa .......... 539

parvula .......... 539

pilosa ............ 539

serata ........... 539

Sedum ............... 296

acre ............. 297

purpureum ......... 296

reflexum ........... 297

roseum ............ 296

telephioides ......... 297

telephium ........... 297

ternatum ......... 297

Senecio .............. 694

aureus ............. $\mathbf{6 9 6}$

balsamitate ......... 696

obovatus ............ 696

pseudo-arnica ........ 696

Robbinsii .......... 696

sylvaticus ......... 698

tomentosa .......... 696

viscosus ........... 698

vulgaris .......... 696

Serapias .............. 156 
viridifora

156 Smilax .............. 140

Sericocarpus ............ 650 asteroides $\ldots \ldots \ldots \ldots, 652$

linifolius ......... 650

Sesuvium ............. 222 maritimum ........ 222

Shepherdia ........... 418 canadensis ......... 418

Sherardia ............ 588 arvensis .......... 588

Sibbaldia procumbens

Sicyos ............... 605

Sidnguatus ............ 605

399

Silene spinosa ............. 399

223)

acaulis

alba ............... 226

angelica ............ 228

antirrhina .......... 228

Armeria ............ 228

caroliniana .......... 228

dichotoma .......... 228

gallica ............. 228

latifolia $\ldots \ldots \ldots \ldots \ldots .226$

noctiflora ........... 228

nutans ............. 226

pennsylvanica ........ 228

stellata ........... 226

virginica..$\ldots \ldots \ldots .225$

Silexoideae ............ 225

Silphium ............ 677

perfoliatum ........ 679

trifoliatum ......... 678

Simarubaceae .......... 371

Sinapis .............. 280

alba ............ 280

Sisymbrium …....... 280

altissimum ......... 282

humile ........... 282

officinale .......... 280

Sophia ........... 282

Sisyrinchum .......... 144

angustifolium ........ 144

atlanticum .......... 144

graminoides ......... 144

intermedium ......... 144

Sium mucronatum ........ 144

Carsonii ............ 442

cicutaefolium ......... 442

Smilacina ............. 134

racmosa .......... 130

stellata ............ 136

trifolia ........... 136

SMiracoideate

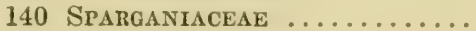

141

140

140

141

141

141

141

140

141

545

546

548

548

546

548

Solea .................. 416

Solidago ...........650, 642

alpestris .......... 645

arguta $\ldots \ldots \ldots \ldots \ldots, 648$

bicolor ............ 645

caesia ............ 644

canadensis ..........6 648

Elliottii ........... 640

erecta ............ 645

fistulosa .......... 646

hispida ............ 645

Houghtonii .......... 650

juncea ............. 649

latifolia ........... 644

macrophylla ........ 645

neglecta ...........6 640

nemoralis ..........648

odora ............ 646

ohioensis .......... 648

patula ............ 640

puberula ............ 645

Purshii ............ 645

rigida ............ 648

rugosa $\ldots \ldots \ldots \ldots \ldots, 646$

sempervirens ........ 646

serotina .......... 648

speciosa ............ 645

squarrosa ........... 644

stricta ............ 645

uliginosa ...........6 645

ulmifolia .......... 646

uniligulata ......... 648

Virgaurea .......... 646

Sonchus ............ 616

arvensis ........... 616

asper ............. 616

oleraceus ........... 616

Sorbus .............. 328

americana .......... 328

sambucifolia ......... 328 
Sparganium ............. 92

americanum .......... 92

androcladum ........ 92

angustifolium ........ 92

eurycarpum ......... 92

fluctuans .......... 92

lucidum $\ldots \ldots \ldots \ldots \ldots .9 \mathrm{gz}$

minimum $\ldots \ldots \ldots \ldots$.

simplex .............

Spatmiflorae $\ldots \ldots \ldots \ldots \ldots$.

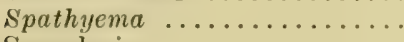

Specularia

perfoliata

Spergula ................ arvensis

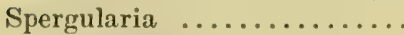
canadensis

marina

rubra

Spigelia

marylandica ...........

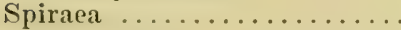

corymbosa ...........

latifolia .............

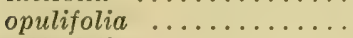

salicifolia ..............

tomentosa ..........

Spiranthes

cernua ..............

gracilis

Tucida

plantaginea

praecox

Romanzofliana ..........

simplex

vernalis

spirodella polyrhiza

Stachys

ambiqua .............

arenicola

arvensis

aspera

lıyssopifolia

palustris . ..........................

tenuifolia ..............

Staphylea

trifolia

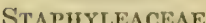

Statice

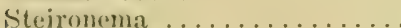

ciliatum

lanceolatum ..........

quadriflorum ..........

Stellaria

aquatica

borealis graminea ........... 234

Holostea ........... 234

humifusa ........... 231

longifolia .......... 234

longipes ........... 234

media ............ 232

pubera ............. 234

uliginosa .......... 232

92 Stenathium ............. 128

109 gramineum .......... 128

$110 \quad$ robustum ........... 128

606 Stenophragma ........... 288

606 Thaliana ............. 288

238 Streptopus .............. 136

238 amplexifolius ......... 130

238 roseus ............. 136

239 Strophostyles ............ 362

239 helvola ............ 362

239 umbellata ........... 362

486 Stylosanthes ............. 349

486 biflora ............. 349

308 Sunerla ................. 217

308 aínericana ......... 217

$308 \quad$ maritima ............ 217

$308 \quad$ Richii ............... 218

30 Subularia ............... 278

308 aquatica ........... 278

156 Succisa ................. 604

158 australis ............ 604

158 Sympetalat ............. 455

156 Symphoricarpos .......... 594

156 orbiculatus .......... 594

158 pauciflorus ............ 594

150 racemosus . . . . . . . . . 594

158 vulgaris ........... $59 t$

158 Symphytum ........... 515

94 officinale ........... 515

94 Symplocarpus ............ 110

530 foetidus ............ 110

536 Syndesmon ............. 254

538 Synosma .............. 694

538 suaveolens .......... 694

538

536 Tanacetum ............. 689

538 huronense ........... 690

$530 \quad$ vulgare ............. 690

389 Taraxncum ............. 616

383 erythrospermum ...... 616

388 oflicinale .......... 616

482 Taraxacum ........... 616

480 Taxacene ............... 82

480 'laxus ................. 82

480 baccata ............ 82

480 canadensis .......... 82

232 Tecoma ............. 576

232 radicans ............ 570

234 Tephrosia ............. 346 
Tetragonanthus

Teucrium (n) occidentale

Thalesia uniflora

Thalictrum

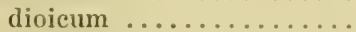
polygamum ........... purpurascens .......... revolutum

Thaspium barbinode

Thlaspi trifoliatum

Thuja occidentalis

Thiymelacene

Thimaleneales

Thymus serpyllum

Tiarella cordifolia

Tiedemannia

Tilia americana

europaea

heterophylla

Michanxii pubescens

Tiliticene

Tillaea

Tissa aquatica

Tipularia discolor unifolia

Tofieldia glutinosa racemosa

Toxicodendron

Tradescantia pilosa virginiana

Tragopogon ............. parvifolius ............

Trapa pratensis natans

Trapaceae

Triadenum

Trichostema dichotomum lineare

Trientilis americana
492

544

544

544

575

575

254

254

254

254

254

450

450

450

276

276

84

84

417

417

525

525

300

300

447

398

398

398

398

398

398

398

296

296

238

162

162

162

126

126

126

382

116

116

116

614

610

610

431

431

431

404

544

544

544

478

478
Trifolium

344

agrarium ........... 344

arvense ........... $\mathbf{3} 10$

dubium ............ 344

hybridum ......... 346

incarnatum ......... $346^{\circ}$

medium .......... 346

pratense ......... 346

procumbens ........ $3 \$ 4$

repens ............ 346

Triglochin ........... 103

maritima .......... 103

palustris . . . . 103

Triglochineat .......... 102

Trillium .................. 138

cermum .......... 138

erectum .......... 138

grandiflorum ........ 135

nivale ............ 140

undulatum .......... 140

Triosteum ............ 592

angustifolium ........ 592

perfoliatum ......... 592

Triphore ............... 155

trianthophora ....... 155

Trollius ............... 262

laxus .......... 262

Tsuga $\ldots \ldots \ldots \ldots \ldots \ldots \ldots . \ldots$

canadensis ......... S8

Tubiflorales ........... 499

Tussilago ................ 602

Farfara .......... 692

Typha ............... 90

angustifolia ........ 90

latifolia ............ 90

Typmacean ........... 90

Tlex ................ 342

europaeus .......... 342

Ulatacene ............. 191

Ulmaria .............. 322

Ulmus ............... 192

americana $\ldots \ldots \ldots \ldots \ldots \quad 192$

fulva .......... 19

racemosa $\ldots \ldots \ldots \ldots \ldots \quad 192$

TTMBdLlales ............ 434

UMBELlifERAF $\ldots \ldots \ldots \ldots \ldots 436$

Unifolium ............ 136

Urtica ............. 195

dioica ........... 195

gracilis ........... 195

Lyallii ............. 195

urens ........... 195

URTicaceae ............ 194

Utrticales ............ 191

Urticastrum ........... Ins

divaricatum ......... 195 
Utricularia $\ldots \ldots \ldots \ldots \ldots$

571 Verbena

billora ............ 574

clandestina ......... 572

cleistogama ........ 572

cornuta ........... 572

fibrosa .............

gibba $\ldots \ldots \ldots \ldots \ldots \ldots$

inflata $\ldots \ldots \ldots \ldots \ldots$

intermedia ............

minor

angustifolia

518

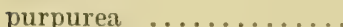

hastata

518

oflicinalis ......... 518

572

urticifolia .......... 518

Verbenaceae .......... 51

$\mathbf{5 7 4}$ Verbenixales $\ldots \ldots \ldots \ldots \ldots 516$

572 Verbesina ............ 682

$574 \quad$ alternifolia $\ldots \ldots \ldots \ldots .684$

574 Vernonia ............... 634

572 altissima $\ldots \ldots \ldots \ldots \ldots \ldots .634$

resupinata ......... $572 \quad$ gigantia $\ldots \ldots \ldots \ldots 634$

subulata ........... 572 glauca ............ 634

Uvularia

Noveboracensis........... 634

Veronica .............. 560

grandiflora ...................... 129 agrestis 562

perfoliata .......... 129

sessilifolia .......... 130

Vaccaria ................. 230

vaccaria ............ 230

VACCINIACEAE .......... 470

Vaccinium ............. 472

atrococcum ......... 474

caespitosum ......... 473

canadense .......... 474

corymbosum ........ 473

nigrum ........... 474

pennsylvanicum ....... 474

simulatum .......... 474

stamineum .......... 473

uliginosum .......... 433

vacillans .......... 474

Vitis-Idaea ......... 473

Tagnera ................ 135

Valeriana .......................... 600

officinalis ........... 600

pauciflora .......... 600

sylvatica .......... 600

uliginosa $\ldots \ldots \ldots \ldots \ldots 600$

VALERIANACEAF ......... 598

VAlerianales .......... 598

Valerianella ............. 600

chenopodifolia ........ 600

Locusta .......... 600

radiata .......... 600

Woodsiana ...........6. 602

Vallisneria ............. 10s

spiralis ........... 108

VALLisneriaceae ......... 108

Veratrum ............. 129

viride ............ 129

Verbascum $\ldots \ldots \ldots \ldots \ldots \ldots \ldots+551$

Blattaria ........ 552

Lychitis . . . . . . . 5..

phllomoides .......... 552

Thapsus

alpina $\ldots \ldots \ldots \ldots \ldots$

americana .......... 561

Anagallis-aquatica ..... 561

arvensis .......... 562

Byzantina ......... 562

Chamaedrys ........ 561

hederaefolia ........ 562

officinalis .......... 561

perigrina ......... 562

scutellata ......... 561

serpyllifolia ........ 562

virginica ........... 562

Viburnum .............. 591

acerifolium ......... 591

alnifolium .......... $59 \mathrm{I}$

cassinoides ........ 592

dentatum .......... 592

lantanoides .......... 591

Lentago ........... 592

nudum .......... 592

Opulus ............ 591

pauciflorum ......... 591

prunifolium ......... 592

pubescens ......... 592

venosum ............ 592

Vicia ............... 355

americana ......... $\$ 56$

angustifolia ......... 356

caroliniana ......... 356

Cracea .......... 356

hirsuta $\ldots \ldots \ldots \ldots \ldots$ 35ti

sativa .......... 356

sepium ............ 356

tetrasperma ......... 350

Vinen .............. 4 .

minor ........... 494

Tincetoxicum ........... 499

Viola ................ 400

arenaria .......... 410

atlantica .......... 412

blanda ............ 414 


\begin{tabular}{|c|c|c|}
\hline canadensis & 416 & ffia \\
\hline$\ldots \ldots \ldots \ldots$ & 410 & brasilionsis ........... \\
\hline cmarginata $\ldots . . . .$. & 412 & columbina $\ldots \ldots \ldots \ldots$ \\
\hline 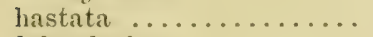 & 416 & punctata ............. \\
\hline labradorica .......... & 416 & \\
\hline lanceolata ............ & 414 & Santlium \\
\hline Miulfordae ........... & 412 & canadense ........... \\
\hline notabilis ............ & 412 & commune $\ldots \ldots \ldots \ldots$. \\
\hline obliqua $\ldots \ldots \ldots \ldots \ldots$ & 410 & spinostum $\ldots \ldots \ldots \ldots$. \\
\hline odorata ............. & 416 & strumarium $\ldots \ldots \ldots \ldots$ \\
\hline$\ldots \ldots \ldots \ldots \ldots$ & $4 I 4$ & Xanthorrhiza $\ldots \ldots \ldots \ldots \ldots$ \\
\hline palmata ........... & 412 & apiifolia $\ldots \ldots \ldots \ldots$ \\
\hline palustris ............... & 412 & Xanthoxylum ........... \\
\hline$\ldots \ldots \ldots \ldots$ & 414 & americanum .......... \\
\hline primulaefolia ......... & 414 & Terophyllum ............ \\
\hline pubescens ........... & 414 & asphodeloides $\ldots \ldots \ldots$ \\
\hline olia .............. & 414 & $\ldots \ldots \ldots \ldots$ \\
\hline ta $\ldots \ldots \ldots \ldots \ldots$ & 416 & ligustrina $\ldots \ldots \ldots \ldots \ldots$ \\
\hline folia .......... & 414 & TYridaceaE $\ldots \ldots \ldots \ldots \ldots$ \\
\hline $\operatorname{ta} \ldots \ldots \ldots \ldots$ & 412 & 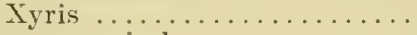 \\
\hline seula ........... & 414 & arenicola $\ldots \ldots \ldots \ldots$ \\
\hline sii $\ldots \ldots \ldots \ldots \ldots$ & 412 & caroliniana $\ldots \ldots \ldots \ldots$ \\
\hline septentrionalis $\ldots \ldots \ldots$. & 410 & Congdoni ............ \\
\hline sororia $\ldots \ldots \ldots \ldots \ldots$ & 410 & fimbriata $\ldots . . . \ldots$ \\
\hline striata $\ldots \ldots \ldots \ldots$ & 416 & flexuosa ............. \\
\hline triculor ............ & 410 & 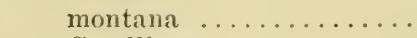 \\
\hline villosa ............. & 410 & Smalliana .......... \\
\hline ACEAE $\ldots \ldots \ldots \ldots \ldots$ & 404 & torta $\ldots \ldots \ldots \ldots \ldots$ \\
\hline$\ldots \ldots \ldots \ldots$ & 395 & \\
\hline . & 396 & Zannichellia $\ldots . . . \ldots \ldots$ \\
\hline$\ldots \ldots \ldots \ldots$ & 396 & palustris $\ldots \ldots \ldots \ldots$ \\
\hline $\operatorname{lor} \ldots \ldots \ldots \ldots \ldots$ & 396 & Zizia $\ldots \ldots \ldots \ldots \ldots \ldots$ \\
\hline ifolia . . & 396 & aurea \\
\hline labrusea ............ & 396 & cordata \\
\hline$\ldots \ldots \ldots \ldots$ & 396 & $\begin{array}{r}\text { Zostera } \ldots \ldots \ldots \ldots \ldots \ldots \ldots \\
\text { marina } \ldots \ldots \ldots \ldots \ldots \ldots\end{array}$ \\
\hline & 318 & $\mathrm{Zy}$ gadenus. \\
\hline des & 318 & chlorantlıus ......... \\
\hline . & 448 & $\ldots \ldots \ldots \ldots$ \\
\hline hbya & 640 & leimanthoides $\ldots \ldots \ldots$. \\
\hline
\end{tabular}





\section{INDEX OF ENGLISH NAMES}

(Classes, Orders, Tribes and Families in sarall Capitals.)

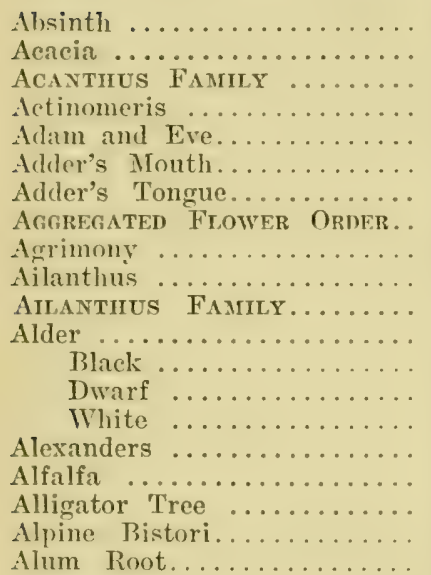

Alyssum .

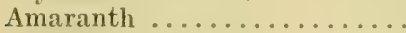

Amarantir Family.........

Amaryeis Family..........

Ammannia

AMevt Bearers

Angrelica

Angelica Tree

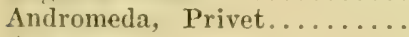

Anemone Rue

Apple Balsam

APRLE FAMLT.

Arlon Vitae

Arbutus, Trailing...........

Arethusa

Arnica

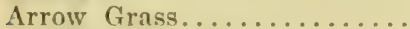

Arrow Grass Famity......

Arrow-head

Arrow-wood

Artichoke

Arum

Arum Famity.

ARUMY ORDER.
690 Ash .................. 485

338 Mountain ........... 328

$576 \quad$ Prickly ............ 370

684 Asparagus ............... 135

163 Aspen ............. 176

160 Asphodel, $\mathrm{B} n g \ldots \ldots \ldots \ldots \ldots .126$

132 Aster ............650-66, 672

604 Golden .............. 642

324 Atriplex .............. 216

371 Avens ................ 320-1

371 Awlwort, Water.......... 27S

185 Azalea ............463, 466-8

386

395 Salloon Vine............ 392

458 Balm ............... $530-2$

450 Balsam Apple............ 605

342 Balsam Fir.............. 88

306 Baneberry ............. 264

205 Barberry .............. 264

300 Barberti Famit......... 264

278-9 Bartonia ............. 492-3

220 Basil, Wild............. 528

218 Basil Balm.............. 530

$1+1$ Basswood ................ 39s

420 Bastard Toad-flax........... 199

167 BAyberRY FAMIIY.......... 177

446-7 Bay, Rose............. 466

436 Bean ............... 362

470 Bean Vine............. 362

252 Pearberry .............. 464

254 Peard-tongue ........... 5.5

330 Bedstraw ............ 585-8

605 Beech ................ 186

328 Blue ............. 182

84 Beech Drops............ 575

464 BEECH FAMILY........... 18h

155 Beectr Tribe.............. 180

692 Begrar-ticks .......... 686-8

103 Bellflower .............. 606

102 BeLL Flower FaMILY...... 605

106 Bellwort ........... 129-30

592 Bergamot ............... 532

682 Bergamot Mint............ 522

110 Bettony ............... 534

109 Wiood ........... 570

109 Billberry ............. 473 
Bindweed .208, 502-3 Buckthorn...........334, 394-5

Birch ............... 184-5 Bucktion Famil........ 394

Birch Famil........... 180 Buckthon Order.......... 394

Birthwort ............ 200 Buckwheat ........... 204

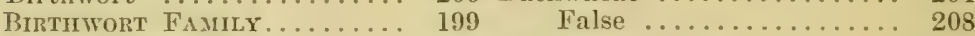

Bishop's Cap............. 302 Buckwheat Family....... 200

Bishop-weed, Mlock........ 440 Buffalo Berry............. 418

Bistori, Alpine........... 20b Bugbane ............. 264

Bitter Cress............ 284-6 Bugle ................ 544

Bitter Nut................ 178 Bugle Weed............... 524

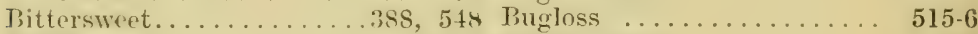

Blackberry .......... 311-2 Jinnch Berry.......... 452

Alpine ............ 464 Bunch-flower .......... 129

Blackberry Lilly............ 144 Buncir-Flower Tribe......... 125

Black-eyed Susan......... 680 Bur Cucumber........... 605

Black Grass.............. 120 Burdock ................. 698

Black Haw............. 592 Bur-marigold ........... 686

Black Jack............. 190 Burnett ............. 32 t

Black Walnut.......... 178 Burnett Saxifrage........ 446

Bladder Nut............. 389 Burning Bush........... 388

Bladder Nut Family...... 388 Bur-reed ............... 92

Bladderwort ........... 572 Bur-ReEd Family......... 92

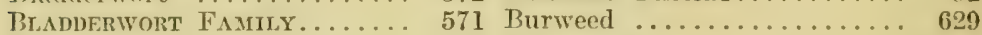

Blazing Star............ 128 Bush-clover ............ 354-5

Jleeding Heart......... 272 Butter and Egrgs......... 554

Blephilia ............ 532 Butter-bur ............ 692

Blinks ............... 223 Buttercup ............ 258-61

Blite, Strawberry.......... 216 Buttercup ORder......... 240

Bloodroot .............. 270 Butterfly Weed........... 496

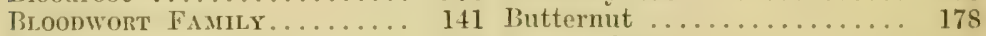

Blue Beech............. 182 Button Bush............. 584

Blue Bells of Scotland...... 606 Button Snake-root........439, 640

Blueberry ........... 473-4 Button-weed ........... 584

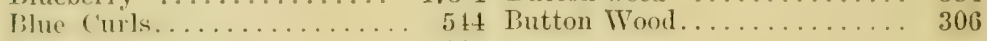

Blue-eyed Grass......... 144 Cabbare, Skumk........ 110

Blue Hearts.............. 564 Cactus Order................ 417

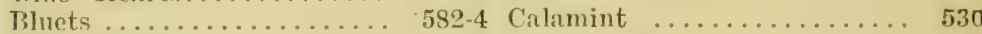

Blue Veed............... 516 Calamus Root........... 112

Bog Aspliodel............ 120 Calopogon ............. 163

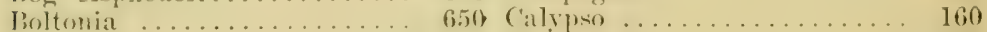

Boneset ............. 63840 Camomile ............... 689

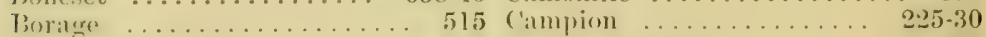

borafie Fanity.......... 508 Caper Famil............ 288

Bouncing Bet............ 230 Caraway .............. 442

Box Elder. .............. 390 Cardinal Flower........... 608

lireweria ............. 500 Carpet, Water.......... 302

Briar ................ 326 Carpet IVeed............ 222

Brook Weed.............. 478 CARpet Weed FaMiLY........ 221

Brooklime ............. 561 Carrion Flower........... 140

Broom .............. 341-2 Carrot Fàily.......... 436

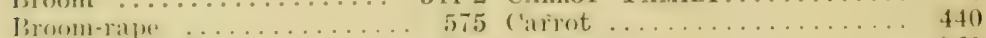

BRonM-RAPE FAMUY....... 574 Catalpa ............ 570

Bucklyan ........... 493 ('atchlly ........... 226.

Buckbeay Famit........ 493 Catkiñ Bearers.......... 167

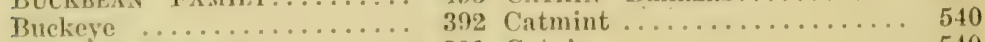

Buckeye Famil........... 391 Catnip ............... 540 
Catsfoot

674-6 Cottonwood ............ 177

Cat 'Tail.

90 Cowbane

446-7

Cat Tail Family.

90 Cow Herb................. 230

Cassandra, Dwarf .

469 Cowslip, Virginia......... 512

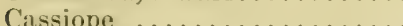

Cedar

Celandine

464 Cow-whent

571

83-4 Crab Apple.............. 330

270 Cranberry .............. 476

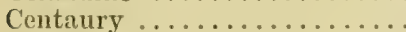

Chaff-seed ................

Checkerberry .............

Cheeses

488

568

High Bush.

591

Cherry

Mountain

473

399 Cranberry-tree ............. 591

336 Crane's-bill ............ 365-6

Ground .......... 545-6 Cress...........276-9, 286-8

Chestnut .............. 186

Horse ............. 392

Chevril .................

Chickweed..........232-5, Indian Rock

282

Water

239

Water

283

Crosswort ............. 480

Chicory

Crotonopsis .............. 370

223 Crowberry ................. 381

Chicory Family...........

612 Crowberry FAMLL........ 381

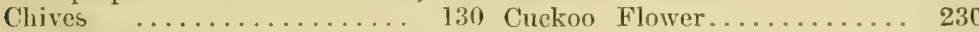

Choke Berry............ 330 Cucumber, Bur........... 605

Cinquefoil ........... 316-8 Cucumber Root, Indian..... 138

Clammy Weed............. 290 Cucumber Tree............. 244

Clearweed

196 Cudweed

674-7

Cleavers

$585-$

Clematis

Culver's Root.

562

250 Cuphea ................ 422

Clintonia

135 Cup Plant.

678

Clotweed

6:9 Currant

311 Indian

304

Cloudberry

$314 \cdot 6$

Clover

225

Custard Apple Family...... 244

Cockle, Corn

$3: 39$

Cohosh

264-6

Colic Root.

134

Cypress Tribe.

Coltsfoot

692

Daisy

$.666,689$

Columbine

263

Columbo

492

Comandra

199

Dalibarda ............ 314

Comfrey

511,515

Dame's Violet

288

Dandelion ............ $612-0$

Dangleberry ............. 472

Cone Benring Trees or

Day Flower

114-6 Silrubs

Dead Nettle.

81 Deerberry .............. 473

Cone-flower

680 Dewberry

312

502 Dew-cup ............... 322

300 Diapensia ............... 476

594 DiaPENSIA FAMILY. . . . . . 476

Coolwort.

476
164

Coral-root

162 Dicotyledons

136

Coreopsis

684 Disporum, Hairy..........

225 Ditch Grass. .

102

Cornel, Dwarf

Ditch Grass
Ditch Moss.

108

Corn Flower.

702 Dittany

533

Corn Salad...

600-2 Dock

201-2

Corn, Squirrel

270 Dodder

503-4

Coronilla

348 DODDER

503

Corydalis

Dogbane 
Dogbañe Fammi.......... 493

Dogwood .............. 452-4

False 278

Dog-twood Family .........

Door Weed...............

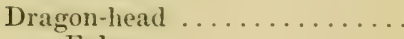
False

Dryas

Duck-weed

DUCK-WEED FAMILY ...........

Dutchman's Breeches.......

Dutchman's Pipe..........

Dyer's Rocket.............

Dyeweed

206 Fleabane...........670, 674

542 Flixweed ............... 282

533 Floating Heart.......... 493

322 Flower-of-an-Hour ........ 400

94 Fly-poison ............. 128

93 Fog Fruit................ 519

270 Forget-me-not .......... 512

200 Foxglove, False........... 564

290 Fringe .............. 27z

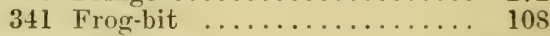

Frostweed .............. 406-8

EBoxy FAMrLY.............

EBony ORder..............

Eclipta ............ 678

Eel Grass.......... 102,

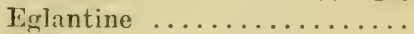

Elder

482 Fumitory .............. 272

482 Furze ................ 342

108 Galinsoga .............. 688

326 Garlic .............. 130

591 Hedge ............ 284

Box ............. 390 Gaura .............. 430

Marsh ........... 628 Gentian ............ 490-2

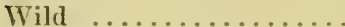

Elecampane...$\ldots \ldots \ldots \ldots$

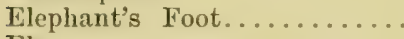

Elm

436

Horse ............ 592

677 Gentian Family......... 486

634 Gentian Order.......... 484

192 Geranium, Feather........ 214

ELM FAMLY.

Enchanter's Nightshade...

191 Geranium Famil........ 364

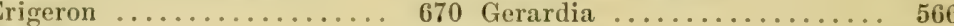

Eryngo ............. 439 Germander ............ 544

Evening Primrose........ 428 Giant-hyssop ........... 542

Evening Primose Family... 422 Gill-over-the-ground ........ 540

Everlasting $\ldots \ldots \ldots \ldots \ldots$ 674-6 Ginger ................... 199

Eyebright ......... $568-70$ Ginseng ............. 436

GINSENG FAMILY.......... 434

False Dragon Ilead.......... 533 Glasswort ................. 217

False Foxglove.......... 564 Globe Flower............. 262

False Gromwell......... 514-5 Grumaceous Flowerei) Prants 109

False Heather........... 408 Goat's Beard.......310,612, 616

False Mermaid........... 382 Goat's Rue.............. 346

Fatse Mermatd Fajily.... 382 Golden Aster............. 642

False Miterwort.......... 300 Golden Club................ 112

False Nettle............ 196 Golden Crest Flower......... 14\%

False Pimpernel.......... 560 Goldenrod ........... 642-50

False Spikenard.......... 136 Golden Seal.............. 256

Featherfoil ........... 477 Gold of Pleasure........... 278

Feather Geranium......... 214 Goldthread .............. 262

Fen Orchis............. 160 Good King Henry.......... 214

ligwort ............555, 592 Gooseberry ............. 304

Figwort Family......... 550 Goosemerri Family........ 303

Fir .............................. 88 Goosefoot .

Fire Weed.............. 694 Goosefoot Fuiniy.......... 211

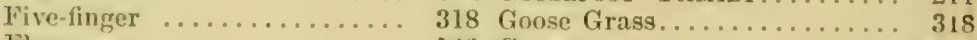

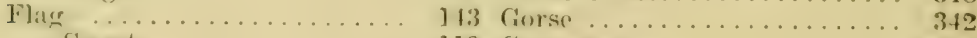

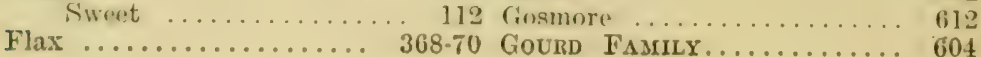


Goutweed

448 Hobble Bush........... 591

Grape

396 Holly

386

Ho.......................

384

120 Hone Wort............... 447

Grass, Black............ 120 Hone Wort................. 302 Honeysuckle ... . . .

Grass-of-Parnassus ........ 302 Honeysuckle ............. 59.50

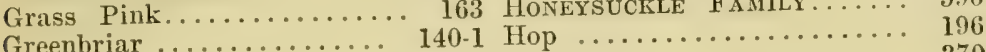

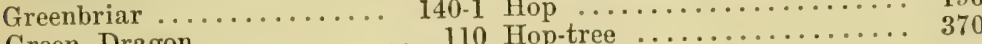

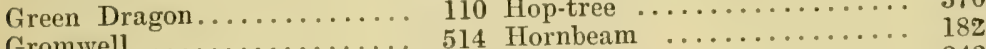

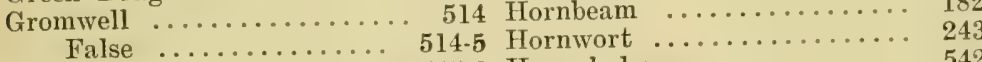

Ground Cherry......... $545-6$ Horse-balm ............... 542

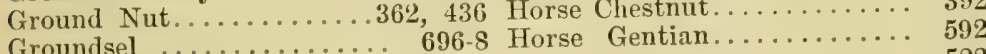

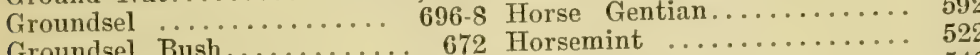

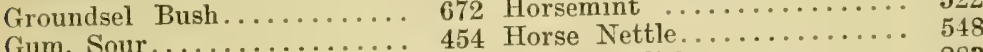

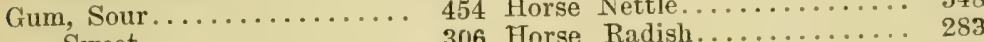

Sweet ............. 306 Horse Radish............. 670

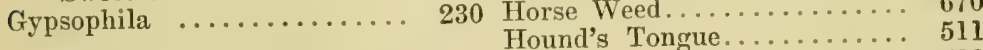

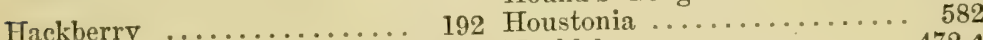

Hardhack ............... 308 Huckleberry .......... $472-4$

Hare Bell ............... 606 HuckLEBERry FaMILY....... 470

Hare's Ear............. 450 Hudsonia .............. 408

Hawkbit ............. 614 Hyacinth ............. 134

Hawksbeard ........... 620 Hracintur Tribe.......... 134

Hawkweed ............ 622-4 Hydrangea ............ 303

Hawthorn ............ 332 Hyssop .............. 525

Hazel Nut............. 182 Hedge ............ 558

Heart Seed............. 392 . . 222

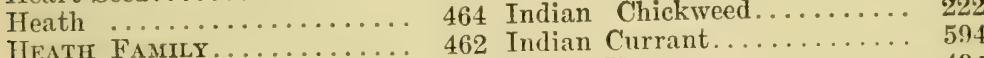

HEATH FAMLY

Heath Order.

Heather

False

Hedge Garlic.

Hedge Hyssop.

Hedge Nettle.

IIedysarum

Teliotrope

457 Indian Hemp.............

494

470 Indian Physic............ 310

408 Indian Pipe............. 460

284 Indian Pipe Family........ 460

558 Indian Plantain.......... 694

536-8 Indian Turnip............ 110

348 Indigo ................ 341

511 Inkberry .............. 386

Hellebore ............. 129 Innocence ........... 556, 582

Helleborine ............ 156 Ipecac .................. 310,379

Hemlock ............. 88 Iris ..................... 143

444 IRIS FAMILY............ 142

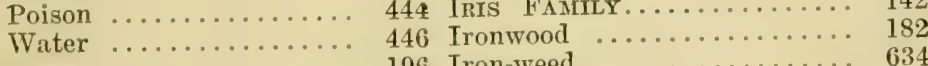

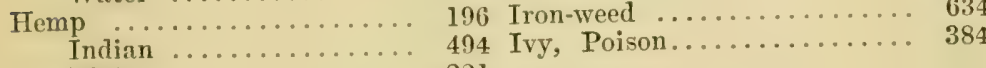

221 Jack-in-the-pulpit .......... 110

TIemp Nettle........... 536 Jack-in-the-pulpit .............. ${ }_{548} 110$

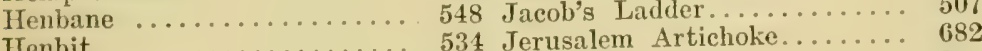

Inenbit .............. 534 Jerusalem Artichoke............. 214

Hepatica .............. 250 Jerusalem Oak..................... 533

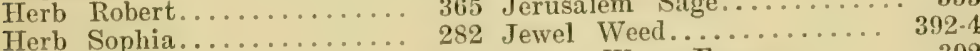

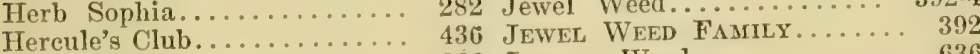

Heron's-bill ............. 366 Joe-pye Weed............ 636

Heuchera ............ 300 Joint Vetch............ 349

Hickory ............. 178-80 Joint Weed............ 210, .431

Hoarhound........525,536,540 Judas Tree............ 338 
June Berry............... Juniper

Kenilworth Ivy...

King Devil.................

King Nut...............

Knnapweed

Knawel

Kinnt-grass

Knotiveed

Kochia

Kosteletzkya ...........

Labrador Tea.............

Lady's Mantle.............

Lady's Slipper.............

Lady's Thumb.

Lady's Tresses.................

Lake Grass................

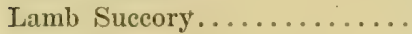

Larch ...................

Larkspur

Laurel

Spurge .

LAURel FaMily.

Lavender, Sea............

Leaf-cup ................

Leather Flower.............

Ieather Leaf. . .

Leatherwood

Leek

Lemon Balm.

Leopard's-bane

letucothee ...................

Lilacopsis

Lily

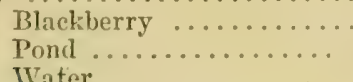

IIILY FAMILYY............

LIISY ORDER...............

LiLY T'RIBE................

Jily of time Valtey Tribe.

Tinden

LINDEN FAMILY............

Linnaea ..................

Linseed ................

Tion's Font...............

Liquorice

Live-For-Ever

Liverwort

lizaral's 'lail

TIZARD TAIL FAMIIX........

Loblia .............. 608-10

Locust . . . . . . . . . 338, 348

LOGANIA FAMLY.......... 485

322
331 Loosestrife.........421, 478.82

83 Loosestrife FaMiLy........ 420

Lophiola ............. 142

554 Lophotocarpus ........... 104

624 Lopseed ............... 578

180 Lopseed Fadily........... 578

702 Lotus .................. 243

240 Lousewort ............ 570

. 240 Lovage .............. 440

206-7 Lucerne ............... 342

217 Lndwigia ........... 424-5

400 Lungwort .............. 511

Lupine .............. 341

463 Lychnis ............... 230

148 Madder $\ldots \ldots \ldots \ldots \ldots \ldots$....... 585-8

205 Madder Family........... 580

156-8 Madder Order........... 580

108 Magnolia ............... 243

612 Magnolia family........ 244

84 Mallow ..............399-400

263 Mallow Family.......... 398

468-9 Mallow ORDER.......... 396

418 Mandrake .............. 260

268 Naple .............. 389-90

482 Maple Fajily............ 389

677 Mare's Tail.............. 431

250 Marigold, Marsh......... 262

46 M Marjoram ............ 520

418 Marsh Marigold ......... 262

130 Marsh Parsley............ 440

530 Marsh Pink............ 485-90

692 Marsh Violet............. 574

626-8 May Apple.............. 266

469 Mavflower .............. 464

440 Nayweed ................689

132 Meadow Beauty........... 422

144 MEAdow Beauty FaMily.... 422

242-3 Meadow Parsnip........... 450

243 Meadow-rue ............ 254

124 Meadow Sweet..........308, 322

117 Medic ............... 342-4

130 Meehania .............. 540

134 Mercury .............. 376

398 Mermaid, False........... 382

398 Mermaid-weed ............ 432

594 Mexican Ter............. 214

368 Michaelmas Daisy......... 666

626 Micranthemum ......... 560

586 Mignonette ............ 290-1

296 Mignonette Famil......... 290

250 Milk Pea.............. 362

167 Villk Veteh............. 348

I66 Milkweed ............ 498-9

Milkwed Family......... 494

Milkwort ........... 371-2

Sea ............. 478 
MILKWORT FAMILY........ 371

Mimulus ............... 558

Mint ............ $522-4$

Horse ........... 532

Mountain .......526-8, 532

Mrnt Family............ 519

Mist Flower............ 640

Mistletoe

Mistlatoe Family.........

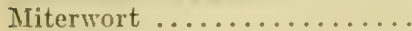

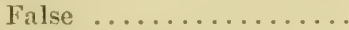

Mocassin Flower...........

Mock Bishop-weed..........

Mocker Nut...............

Modesty

Moneywort

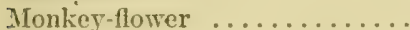

Monkshood ..............

Monocotyledonous Plants.

Moxopetalous Exogexs.....

Monnseed

Moonserd Famit

Moose TVood. 390

Moose Wood FaniLY.......

Morning-glory . . . . . . . . .

Morming-Glont Fanily....

Moss Pink...............

Moss Plant................

Jotherwort

Mountain Ash.

Mountain Fringe

Mountain Heath.

Momitain Mint.

Mountain Sorrel

Mouse Tail.

Mud Plantain.

Tudwort

Mugwort

Mulberry

Mulberry Fainly.

Mullen

Mifusk-flower

Tustarel

Tower

mestard Family

Mrrtle

$$
\text { Sitnd }
$$

MYrTLE ORDER.

Nitias

Naked Flowering Plants

Neslia

Nettle

Dead

False

Hedge

Hemp

300

464
Horse

548

Nettle Alliaxce.......... 191

Nettle Fajill. .......... 194

Nettle Tree............. 192

New Jersey Tea........... 395

Nightshade .......... 546-8

Enchanter's ....... 430-1

198 Ninebark .............. 308

198 Nonesuch .............. 342

30 Nyctelea .............. 508

148 Oak ............... 188-91

$440 \quad$ Jerusalem ............ 214

180 OLEASTER FAMILY......... 418

450 OLIVE FAMILY............... 484

480 Onion ............... 130

556 ONION TRIBE............. 130

263 Orache .............. 216

89 Orange-grass ............ 404

453 Orange Root............ 256

266 ORCHID FAMIL.......... 146

266 Orchis .............. 150-4

$418 \quad$ Crane-fly ............. 162

417 Fen .............. 160

502 Orpine ................ 297

500 ORPINE FAMILY. . . . . . . . 296

506 Osier .............. 454

464 Ox-еуе ............... 678

534 Ox-eye Daisy............. 689

328 Ox-tongue .............. 614

272 Oyster Plant.........511, 616

526-8 Paint Brush............ 622

210 Painted-cup .............. 568

256 P'urietaria ........... 196

117 Parsley ............440, 444-6

560 P.ABSLEY FAMILY......... 430

690 Parsnip...........442, 447, 450

194 Partridge Berry........... 584

194 Partridge Pea............ 338

5.52 Passion Flower........... 41'?

558 PASSION Frower FaMmY... 416

2st) Paulownia ........... 556

288 Pawpaw .............. 246

272 Pea .............. 358-64

4!) P'IA FAMILY............. 339

463 P(i)-nut ............... 360

418 Pear ................. 330

Prickly .......... 417

102 Pearlwort ............ 235-6

90 Pedicularis .............. 570

278 Pencil Flower............ 349

195 Pennyroyal ............. 534

$534 \quad$ False .............. 545

1ng Pennywort ............ 439, 492

536-8 Pepperage .............. 454

536 Peppergrass ........... 276 
Peppermint

522 Pokewced ............... 221

Pepper, Water..............

206 PoKeweed FAMILY.......... 221

Periwinkle

494 Polygala ................ 372

Persicaria ............ 205-6 Polypremum ........... 486

Persimmon .............. 484 Pond Lily ............ 242-3

Phacelia ...............

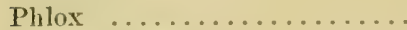

PHLOX FaMILY.............

Phyllanthus

508 Pondweed

$95 \cdot 100$

506 Pondweed Family.......... 94

504. Poor Man's Weather Glass... 478

Physic, Indian. ..............

374 Poplar ............... 176-7

310 Poppy ............... 269

Pieris .................

Pickerel Weed............

Pickerel Wefd Family.....

Pigmy Weed...............

Pig Nut................

Pigweed .............212,

Pig Weed Order.............

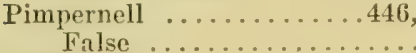

Pine

Prince's ..............

Pine Drops...............

Prne FaniLy................

Pine Tribe...............

Pine Sap..................

Pink

Fire .............

Marsh ............. 488-90

Moss ............. 506

Rose ............ 488

Swamp ...........126, 468

Wild ...............

PINK FiMILY.

Pink-root

Pinkster

Pin-weed

614 PopPY FAMILY........... 269

116 Poppy ORder............. 268

116 Portulaca .............. 224

296 Pотато Family.......... 545

180 Potato Vine............. 504

220 Powder Horn............. 235

210 Prickly Ash............ 370

478 Prickly Pear............. 417

560 Primrose ............. 477

S6-8 Evening ........... 428

460 Primirose Family......... 477

460 Printiose Order........... 476

82 Prince's Feather............. 206

84 Prince's Pine............. 460

462 Privet Andromeda......... 470

231 Puceoon ................ 514

226 Purslane ............... 224

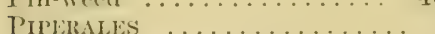

Pipewort .................

PIPliworT FAMILY.

Pitcher Plant..............

pitcher plant family....

Pitcrier Plant Ordeir.

Puane tree family.

Plantain

Indian

MIud

Rattlesnake

Robin's

Water

Puantain family..........

Plantain Order...........

Pleurisy Root.............

Plum

Plumiago famil.

Pogonia

Poison IJemlock...........

Poison Ivy.

228

225

480

466

$408-9$

166

114 Queen-of-the-Prairie ........ 322

113 Quereitron ................ Iss

291

291 Rabbit Foot............. 346

291 Radish ................... 282

306 Ragged Robbin............ 230

579-80 Ragweed ............629, 696

694 Ragweed FaAilx.......... 624

117. Ragwort .............. 690

159 Ram's Head............. 148

670 Raspberry .............. 311

103-4 Rattle Box............ 341, 570

579 Rattlesnake Plantain....... 159

578 Rattlesnake Root........ 626-8

496 Rattlesnake Weed.......... 624

334 Red Bud............... 334

482 Red Root...............141, 395

155 Rlıdora .............. 466

444 Ribwort .................. 579

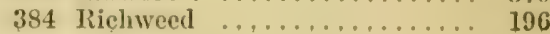


River Weed

River WEed FAMILY

Rock Cress

Rocket. .

Rock Rose Famly

Rose

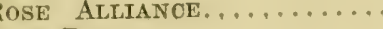

Rose Bay................

ROSE FAMILY.

Rose Mallow.

Rosemary

Rose Pink.................

Rose Twist Foot.

Rosewort

Rosin-weed

Rotala

Rue Anemone.

RUE FAMILY

Rue, Goat's .

Ruellia

Ruppia

Rush

RUSH FAMILY.

Russian Thistle.

Rutland Beauty............

Sabbatia

Sage$$
p^{2}
$$

Jerusalem ............

Wood

Sagittaria

St. Andrew's Cross.

St. John's Wort.

ST. Jomx's WorT FAMILY.

St. Peter's-wort............

Salsify

Soltwort

SANDALWOOD FAMIIXY...........

Sand Bur................ 548

Sandwort ............ 236-8

Sanicle .............440-2, 638

SAPINDALES ORDER........... 38

Sarsaparilla

Sassafras Tree.

Savory, Summer

Saxiframe

Golden

Burnett

Saxifrage Family

Seabious

Scheuchzeria

Sclerolepis

Seorpion Grass.

Sea-Blight

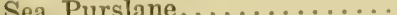

Pustane.

Sea Rocket................

Seed Box.

104-8

412

403-4

402

402

616

218

198
295 Self-heal

538

696

338

336

338

338

331

331

180

448

276

45 ty

580

318

287

399

291

318

282

539

110

334

206

140-1

140

555

588 Snakeroot $\ldots \ldots \ldots \ldots \ldots \ldots \ldots, \quad 640$

$530 \quad$ Black ................... 464

$544 \quad$ Senega .............. 372

Virginia

200

Snapdragon .............. 554

Snowberry .............474, 594

Solpberry FaMily.......... 392

SoApberry Order.......... 380

Soapwort (.............. 230

Soloman's Seal.......... 136-8

Sorrel ................. 201

Nountain ........... 210

Wood 368

SorreLworT ORDER.......... 200

Sour Gum............... 454

470

690

616

686

522

258

561

268

290

110

114

$11 \%$

436

136

308 
Spring

Spruce

Beauty

Spurge

Spurge Family.

Spurge

Spurry

Squaw Root

Squaw-weed

Squirrel Corn..............

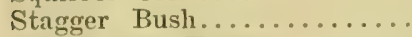

Staff Tree Family.

Star Flower.

Star Grass.

$$
\text { Water }
$$

Star of Bethlehem.

Starwort........232-4, 238,

Steeple Bush.............

Stenanthium ............

Stitchwort

Stickseed

Stonecrop

Stork's-bill

Stramonium

Strawberry...............

Strawberry Blite..........

Strawberry Bush.

Suaeda, Rich's.

Succory Dock-cress

Succory, Lamb.

Sundew

SUNDEW FAMILY

Sundrops

Sunflower False

Sumac

Sumic Famir

Summer Savory.

Swallow-wort

Swamp Pink

Sweet Pay

Sweet-cicely

Sweet Clover

Sweet Fern

Sweet Flag.

Sweet Gale.

Sweet Gum.

Sweet William.......228, 231,

Sweet Woodruff............

Sycamore

Sympetalous Exogens.....

Tamarack

Tansy

Tapk-grass Famiry.........

Tare, Wild.

Tea, Labrador .

Mexican
224 New Jersey

88 Tear Thumb............ 210

378-9 Teasel ............... 602

374 TEASEL FAMILY........... 602

418 Thimbleberry ........... 311

238-9 Thistle ............. 700-3

575 Russian ............ 218

696 Thistle FaMily. . . . . . . . . . 629

270 Thorn .............. 331-2

469 Thorn-apple ............ 548

386 Thoroughwort ......... 636-8

478 Thread Foot............. 295

142 Thrme ................ 525

117 Tickseed ............. 684

134 Tick-trefoil ............ 350-2

380 Toad Flax............. 552-4

$308 \quad$ Bastard .............. 199

128 Tobacco, Indian........... 608

234 Wild .............. 548

511 Tofieldia ............... 126

297 Toothache Tree............ 370

366 Toothwort ............. 283-4

548 Touch-me-not ........... 392

318 Tower Mustard............ 28s

216 Trailing Arbutus........... 464

388 Trefoil .............. 344-6

218 Trillium ............. $138-40$

614 Trumpet Flower.......... 576

612 Trumpet Vine Famli..... 576

292 Trumpet Treed........... 636

291 Tubular Flower Order.... 499

428-30 Tulip Tree.............. 244

$682,686-8$ Tumble Weed............. 220

678 Tupelo ................. 454

382-4 Turkey-beard ............ 126

382 Turnip .............. 280

528 Turtle-head .............. 555

499 Twayblade ............ 158-60

126,468 Twin Flower............. 592

244 Twin Teaf................. 260

448 Twisted Stalk............ 136

344 Twist Foot.............. 130

177

112 Umbelliferous Plants...... 434

177 Uva-Ursi .............. 464

300

506 Valerian .............. 600

588 Greek .............. 507

306 VALERIAN FAMILY.......... 598

455 VALERIAN ORDER............ 598

Velvet Teaf............. 400

84 Vilvet Plant............. 552

690 Venus's Comb............. 448

108 Venus's Looking-glass....... 606

3.56 Vervain ............... 518

463 Vervaty FaMrLY.......... 518

214 Vervary Order............ 516 
Vetch

Joint

Milk

Vetchling

Viburnum

Violet

Dame's

Marsh

Violet FaMily............

VIOLET ORder..............

Virginia Creeper............

Virginia IVillow.

Virgin's Bower

TVake-robin

Walnut, Black.............. 178

WALNUT FAMILY.............

Water Awlwort............

Water Carpet..............

Water Cress................

Water Hemlock.

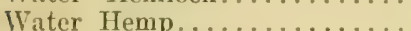

Water Hoarhound

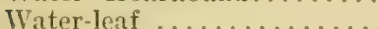

WATER-LEAF FAMILY.........

Water Lily...............

WATER LILY FAMILY........

Vater-milfoil

IVATER MILFoIL FAMULY

Water-nut

II iter-yut Fumily ........

Water Parsnip............

Water Pepper.............

IViter Plantuin.

Water Plantain Faiml....

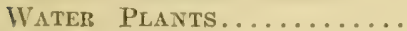

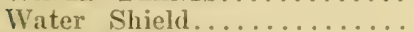

Water Star Griss..........

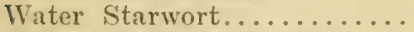

Water Starwort Family....

Water Target..............

Water Willow.............

Water-wort

IVATER-WORT FAMILY........

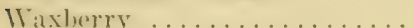

WVax Weed...............

431
356 Whistle Wood............ 390

349 White Alder............. 458

348 White Alder Family........ 458

358 White Weed........... 689

591-2 White Wood............ 244

410-6 Whitlow Grass........... 287

$28 s$ Whitlow-wort ............ 239

574 Wild Ginger............. 199

409 Willow .............. 168-76

$400 \quad$ Virginia .......... 303

$396 \quad$ Water ........... 578

303 WILLOW FAMILY......... 167

248-50 IVillow Herb.........421, 425-6

IVind Flower............. 252

IVinter-berry ............ 386

178 Wintergreen.........459-60, 46

178 Wintergreen FamiLy...... 458

278 Witch Hazel............ 306

302 Witci Hazel Family...... 304

283 Withe-rod ............. 592

446 Woad Waxen............. 341

221 Wolffia ................. 94

525 Woodbine .............. 596

507-S Woodruff, Sweet......... 588

507 Wood Rush........... 123-4

243 Wood-sorrel ............ 368

242. Wormseed............214, 280

432-3 Wormwood ........... 690-2

431 Wortleberry ........... 473

431 Woundwort ........... 538

442 YAM FAMILY............. 142

206 Yam-root .............. 142

103-4 Yarrow ..............6ss

103 Yellow Broom........... 341

93 Yellow-eyed Grass.......... 113

242 YelLow-Eyed Grass FaMily. 112

117 Yellow Flag............ 143

380 Yellow Rocket............ 279

379 Yellow Root........... 262

242 Yellow Weed............ 290

578 Yew .................. 82

406 YEW FAMILY........... 82

406

177 Zannichellia ........... 100

422 Zygadenus ............. 128 






